(n)

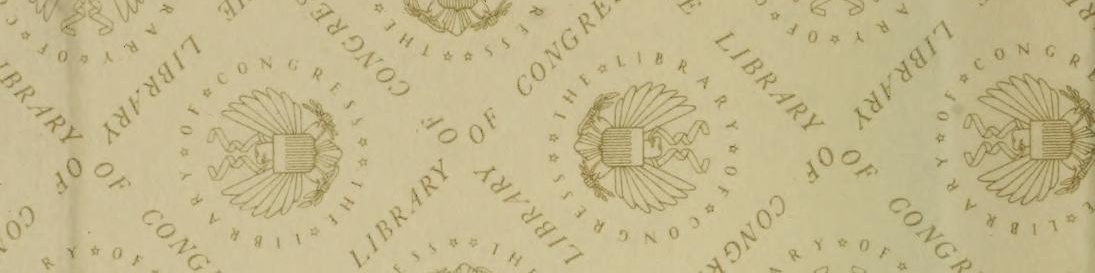
(1) i.

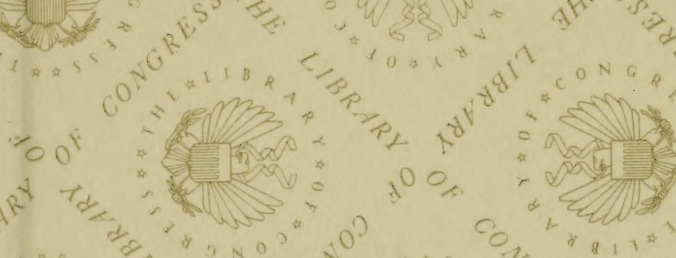

Con - 2$)^{\circ}=0$ $\sin ^{2}, x$

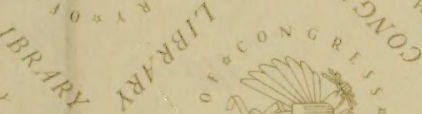

100

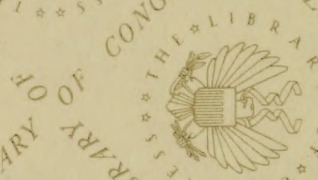

ती

ती है?

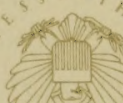

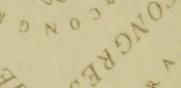
ats स

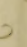

100

o $0^{10}$

$x^{2}+100$

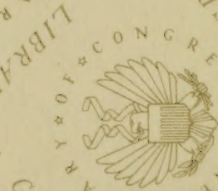

ton (25) (1) 


WHE:

\section{BOTANICAL CLASS-BOOK}

ATD.

\section{FLORA OF PENNSYLVANIA,}

DESIGIXED FOR.

Seminaries of Learning and Private Classes.

\section{IN TWO PARTS.}

PART I. - STRUCTURAL AND PHYSIOLOGICAL BOTANY. PART II.-SYSTEMATIC BOFANY.

COMPRISING A BRIEF SKETCH OF THE LINKAAN AXD FATUEAL EISR TEMS OE BOTAKY; A GLOSSARY OF TFCHXICAL TEABS;

ARALYTICAL TABLES, AND, THE

NATURAL ORDERS,

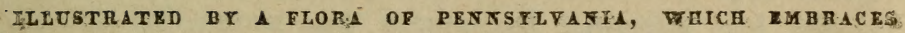
DESCBIPTIONS OF NEARLY NINE-TEXTHS OF THE IXDIGBNOUS,

PLOWEPLAG PLANTS OF THE NORTHERA UNITED STATES.

BY HENRY R. NOLL.

Lewisburg, Pa.:

Q. N. WORDEN, PRINTEB。 :::::

1852 . 

This rolume has been prepared expresely as a Class Booir

Botany for beginners, designed chiefly for students in our eminaries of learning and private classes, as well as a convejient mannsl for those more advanced in the ecience. The first part of the work containg an introduction to Structural and Physiological Botany, in which I have kriefly described the organic elements or tissues of plants, and their compound organs-such as the struoture, growth, theoretical nature and office of the roots, stems, buds, leaves, flowers, fruit and seeds; together with the nature and results of germination, and a short treatise on the food and natrition of plants. The second part of the volume is devoted to. Systematie Botany, and comprises a brief sketch of the Artificial System of Linnæus, together with its classes, orders, \&c. ; and of the Natural System of Jussieu as modified by De Candolle and others, together with its divisions, classes, orders, \&c. ; and a Glossary of Botanic Terms. The whole is accompanied with a Flora of Pennsylvania, in which are described all, or nearly all, the indigenous and naturalized flowering and filicoid plants of our State, together with some of the more commonly cultivated exotics of our gardens; arranged according to the Natural Systern now so generally adopted in works of this kind. But, in order to secure all the advantages of the Linnæan System, and to render analysis as simple as possible to the beginner, I have given a synopsis of the genera, arranged under their respective classes and order, describing the more prominent characteristics of each, with a reference to the page where the genus and speeies are fully described in their respective orders. 
In compiling and preparing that part of the work which relates to Physiological and Structural Botany, I have chiefly relied on the "Botanical Text Book" of Doctor Asa Gray, Wisher Professor of Natural History in Harvard University - an American work of the highest merit. In regard to the names, characteristics and arrangement of the Natural Orders, my principal authorities have been the work above mentioned, and a work by the same author entitled "Botany of the Northern United States."

With few exceptions, I have adopted the nomenclature of the North American Flora of Torrey and Gray, for our native and naturalized plants, (so far as that flora at present extends,) and for our cultivated exotics, the nomenclature of the "Prodromus" of De Candolle, regarding. these, as they truly are, standard works.

In deseribing the genera and species together with their locality, I have consulted Beck's "Botany of the Unitcd States north of Virginia," Doctor Darlington's "Flora Cestrica," Wood's "Class Book of Botany," Gray's "Botany of the Northern United States," and "Barton's Botany and Flora."

Such as my work is, I now submit it to the public. That it will be found free from errors, I hardly expect. I have, however, prepared it with much care and study, having devoted untiringly to the study of botany, for several years, and to the preparation of this work, all the hours of leisure which my occupation as a mechanic permitted me to enjoy. In conclusion, I have only to ask of those who may discover special imperfections in the work, or who may be able to suggest additions important to be made, with descriptions of genera and species indigenous to our State not described in the present work, to communicate their suggestions to me, and should another edition be called for, I shall endeavor to rectify its imperfections to the best of my ability.

LEWISBURG, JANUARY, 1851. 


\section{INTRODUCTION.}

\section{BRIBF SURVEY OF TRE SCIBNCE.}

THR science of Botany has recently attractod considorabls attention in our country, so much so, that it is becoming a popular study in our seminaries of learning. By the labors of De Candolle and Lindley, in Europe, and of Drs. Torrey and Gray, of our own country, it has boen established on the basis of inductive philosophy, and elevated nearly to the rank of an exact science.

It is a science which, though it an not be consichersd as greatly advancing our pecuniary interests, affords more enjoyment than wealth or honor can bestow. It effoctually combines pleasure with improvement, and is caloulated to lead the pious mind to greater reverence for the Deity.

The objects of its investigation are beautiful beyond description; adapted to please the eye, refine the taste and improve the heart; leading to vigorous exercise in the open air, which is conducive to health and cheerfulness. It conducts the student into the ficlds and forests, amid the verdure of spring and the bloom of summer. It leads him to the charming retreats of Nature in her wild luxuriance, slong winding streams; to the borders of craggy rocks; and where she patiently smiles under the improving hand of cultivation. This study imparts a taste for the beautiful in nature, fills the soul with ravishing emotions, and opens before us the enchanted arenues of a world full of wonders.

The study of Botany affords a pleasure which can be equally enjoyed in youth, when the affections are warm and the imagination is vivid; in more advanced life, when sober judgment assumes the reins ; in the sunshine of fortune, and in the obseurity of poverty. The opening buds of spring, the warm, luxuriant blossoms of full blown summer, the yellow bowers of antumn, and the leafless, desolate groves of winter, alike afford amusement and gratilication to the botaniat. 


\section{DEFINITION OF A PLANT.}

Philosephers and Naturalists have distinguished the natural world into three great departments, commonly called the Mineral, Vegetable, and Animal Kingdoms.

Plants are intermediate between minerals and animals. They are distinct from the former by their organization and living principle; and differ from the latter by the absence of instinct and intelligence.

A mineral is an inorganic mass of matter, the result of mere aggregation, and due to external common forces. The separation of the organs of a plant destroys its identity as a species; but a stone may be broken into any number of fragments, each of which will retain the characteristics of the original body.

Plants are organized living bodies, deriving their nourishment from the earth and air, endowed with vitality, (though. not with sensation,) and eomposed of distinct parts, each of which is essential to the completeness of their being.

Animals, like plants, are organized living bodies, endowod. with vitality, and composed of distinct parts, but they are superior to plants by possessing the faculty of perception.

Plants being closely connected to the mineral kingdom are fixed to the earth or other substance on which they grow, and derive their nourishment from it by absorbing into their eysicms mineral food, which is assimilated to their own. substance under the influence of light in organs exposed to. the atmosphere. Animals on the contrary possess the faculty of locomotion and the endowment of sensation; subsist on organized matter and have the power of selecting the food ready prepared for their nourishment which is received into and assimilated by an internal resorvoir or stomach. Thus minerals, by the beautiful cconomy of nature, contribute towards the support of animals through the medium of planta.

Plants, like animals, are destined to perform their funetiens for a limited period only; -some live for one season, othera twice that period; the apple-tree flourishes through a century, and the cedar is supposed to brave the tempests of a thousand years; but the hand of time sooner or later preases upon them all, and without the aid of external injury, their vegetating powers cease; and sharing the fate of all organized beings, they submit to decomposition, and crumble into their primeval elements. 


\section{B O T A N.Y.}

\section{PART I.}

GENERAL DIVISIONS OF THE BCIETCE

1. The English word Botany is derived from the Grok botane, i plant.

2. Botany is that branch of natural history which teachas the knowledge of the vegetable kingdom. It comprehends cvery scientific inquiry that can be made respecting plants, their structure, habits, properties, the laws which govern them, and their office in tha goneral economy of the world; together with their nomonclature and classifcation.

3. Botany, liko its kindred sciences, is resolved into distinet dopurtments, according to the na ur of the subject they treat. That department which investigates the organio strueture of plants, the lind of life which they possess, the organization through which this life is munifested, in other words, thet pass which informs us how plants live and grow, and fulfil the conditions of thoir existence, is called Prysiomomical Botany. It comprises a knowladge, 1st, of the structure of plants, and of the minuts and admirable machinery through which their forces operate; this is the spacial fisld of Vergetable ANATOMY; $2 d$, of the extermal conformations, tho forms and arrangemant of the several organs of which they are composed, the laws of nymmetry which regulate thom, and the various modifications they undergo in tho successive stuges of their development; this branch is called Orannograpir, (i. e. the scienoe of the organs of plunts, ) and nearly corresponds with Comparattve Anatomy in the animal kingdom. It remains only to contemplate this operation in aetion; endowod with lifo, and fulflling the purposes for which it was conatruotod; this the province of Veaetable Physioloay. 
4. A second department of Botany is founded upon the relation which plants sustain to each other; upon their affinities and endless diversities. The vegetable creation is composed of many thousand species, all of which are constructed upon the same general plan, but variously modified according to their relative rank and the circumstances of their position. To describe these belongs to the province of Systematic Botany, or the study of plants, as composing the Vegetable Kingdom; as embracing an immense number of species, differing in some respects, but agreeing in others, and therefore capable of being grouped into kinds or genera, into orders, classes, \&c. This department comprises, 1st, Classification, or the arrangement of "plants in a systematic order, according to their relationship; $2 \mathrm{~d}$, special Descriptive Botany; or, an orderly account of all known plants, designated by names, and distinguished by clear and exact description.

- [Necessarily connected with these departments is TERMrNOLOGY or GLOSSOLOGX, which relates to the application of distinctive names or terms to the several organs of plants, and to their various modifications. The current words of our language being insufficient for the purposes of the botanist, many new terms have been introduced in order to express a curately the great variety of facts which a close examination of the plants acquaints us. Thus Botany possesses a ta hnical language which enables us to describe the subjects o. this study with a precision and brevity not otherwise attainable.]

5. Under a third department, plants may be contemplated with regard to their relations to other parts of the creation. This forms a series of interesting inquiries, which variocisly connect the science of Botany with Chemistry, Geology, Physical Geography, \&c. Among these are inquiries as to what influence vegetation exerts upon the air; what it receives from the soil, and what it imparts to it; what it derives from the atmosphere and what it returns to it; also, what are the relations of the vegetable to the animal kingdom, considered with reference to the sustenance it furnishes the latter; and how plants and animals are mutually subservient in the general economy of the world; these inquiries belong partly to chemistry, and partly to vegetable physiology, and the practical deductions which they afford lay the foundations of scientific Agriculture; \&c. 


\section{PHYSIOLOGICAL BOTANY.}

\section{VEGETABLE ANATOMY.}

\section{SIMPLE OR ELEMENTARY ORGANS.}

6. The principal substance of which plants are composed, is known by the general name of tissue, of which there are three distinct kinds, distinguished as cellular, woody and vascular, which are analagous to the flesh, bones and blood vessels of animals.

\section{CELLULAR TISSUE.}

7. Crulular Tissue is the fleshy or succulent part of plants, of which the pulp of leaves and fruits afford familiar examples. It consists of a great number of cells, or little bladders, of organic membrane, aggregated together and cohering more or less intimately by their contiguous surfaces, constituting the honey-comb-like texture that vegetable matter displays under the microscope.

1.

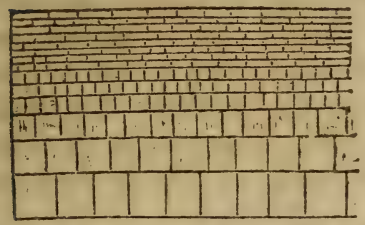

2.

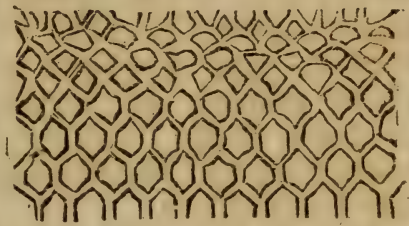

8. Their form is at first globular and egg-shaped, but afterward, being flattened by their mutual pressure, they become cubical, (Fig. 1) or twelve-sided, (Fig. 2) the crosis section being six-sided, each cell assuming a form more or less regular, according to the degrec of pressure exerted upon it by those adjacent.

9. Of this all plants, at their earliest (embryo) state, are entirely composed. Indeed, the plant may be traced back by observation, nearly or quite to a single cell; which cell, endowed with the power of propagation equally with the full developed plant, gives rise to other cells possessed of the same powers, and so forms the whole mass of the vegetable. The delicate walls of the cells, although not visibly perforated, (except sometimes as a secondary result,) are like all organic membrane, permeable to fluids. Through 
them the food of the plant is imbibed, whether direct? from the atmosphere in the form of air or vapor, or in s liquid form by the roots, and transmitted throughout the regetable; hence, plants receive their food in a fluid state only. The cells contain the juices and the products of the plant, whether liquid or solid.

10. The cells vary greatly in size, not only in different plants, but in different parts of the same plant. The largest are found in aquatics, and such plants as the gourd, where some of them are as much as 1-30th of an inch in diameter. Their ordinary diameter is about the 1-400th of an inch. In the common pink, it has been computed that more than 5000 cells are contained in the space of half a cubic line, which is equiralent to almost $3,000,000$ in a cubic inch. Although this tissue is usually soft and spongy, it sometimes acquires considerable hardness by the deposition of solid instead of fluid matter. They are also sometimes drawn out to a considerable length, as in hairs and fibres of cotton, which are long and attenuated cells.

11. Besides the cellular tissue, all Flowering Plants contain more or less of two other kinds of tissue, viz: the woody and the vascular. These begin to be introduced when the plant developes from the seed, and serve to give greater strength and toughness, and to facilitate the transmission of fluids. Both of them arise, however, in all their forms from the transformation of cells, of which they are only modifications.

WOODY TISSUE.

3.

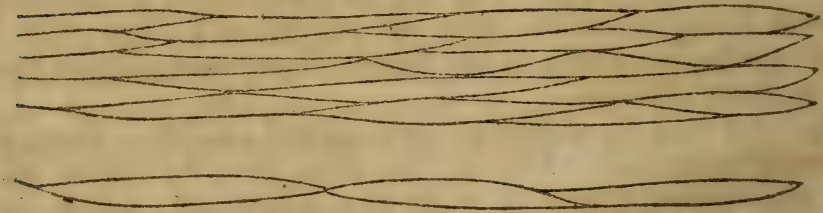

12. Woopy Tissur, (Fig. 3) called also fibre, consists of slender, transparent, membranous tubes, tapering to a point exeh way, and adhering by their sides, the end of one tube extending beyond that of another, so as to form continuous threads. It differs from cellular tissue, in the greater tenuity 
of its membrane. This tissue is not confined to the wood alone, but abounds in the inner bark, where it is usually more tough and flexible, and therefore well adapted for cloths, cordage, \&c. Thus linen is made of the woody fibres of the bark of flax. It also abounds in leaves, forming the frame-work or fibrous skeleton, which gives the leaf the requisite firmuess.

\section{VASCULAR TISSUE.}

4.

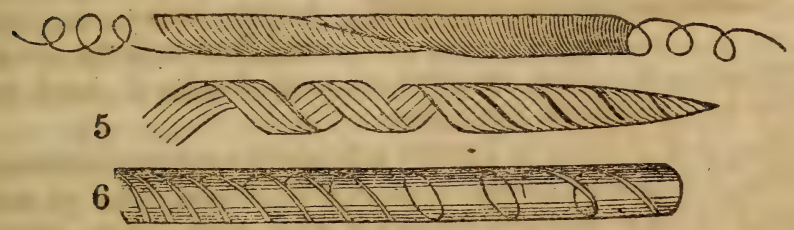

13. Vascular Tissue consists essentially of spiral veg. siLs with their modifications. The true spiral vessel much resembles the woody fibre, consisting of slender tubes, of various lengths, tapering each way, but are thinner and weaker, to the inside of which a spirally-coiled fibre is adherent. The fibre uncoils elastically when the vessel is pulled asunder. In their unrolled state they are readily examined by breaking almost any young shoot or leaf-stalk, and gently separating, when the uncoiled fibres appear to the naked eye like a fine cobweb. In their perfect state they contain air, which they transmit from one to another. The spire is commonly formed of a single fibre, as in Fig. 4; it rarely consists of two fibres; but not uncommonly a considerable number, forming a band, as in Fig. 5. The turns of the coil, although generally in contact, are, sometimes, widely separated. In size spiral ressels are variable, generally their diameter is about 1-1000th of an inch; often not more than 1-3000th.

14. Ducrs differ from spiral ressels in the thread being incapable of uncoiling without breaking, consisting of membranous tubes, with conical or rounded extremities, their sides being marked with transverse bars, rings or coils. In this modification of spiral vessels the tube is much lengthened, and the coil within is either closed, that is, will not unroll, as in the ferns, or it is annular, that is broken into distinct 
rings, as in the garden balsam, Impatiens, (Fig. 6) or it is reticulated, that is, branching, the branches crossing so as to form a net-work. The office of all these ducts is the same, that of conveying fluid.

15. Dotred Ducts, called also Pitted, or VAsiform

7.

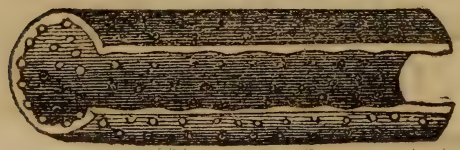

Tissus, consists of large tubes which are formed of cylindrical cells being marked with dots or pits (Fig. 7). They are the largest tubes in plants, and their orifices are conspicuous in the cross sections of most kinds of wood, such as the oak, chestnut, reed, \&c.

16. LACTIFEROU Trasue consists of a series of branching ressels which freely anastomose (pass to and fro), or unite, so as to form a kind of net-work with each other, crossing and re-crossing the other tissues, and spreading from the inner parts, ramify upon the outer surface, and upon the hairs, forming meshes of inconceivable fineness. These vessels serve for the passage of the nutritious sap or proper juice of the plant. Their sides are very delicate, and their average diameter is about $1-1400$ th of an inch. They are remarkable for their irregular contractions and expansions.

\section{THE EPIDERMIS AND ITS APPENDAGER.}

17. EPIdermis. The whole surface of the plant exposed to the air (except the stigma of the flower and some parts of the root) is covered with a cuticle or skin, called epidermis, which consists of layers of cellular tissue in which the cells are much flattened and in close contact with each other. Their form is various, sometimes they are oblong and regular, whilst at others they are very dissimilax, and appear to interlock with each other.-

18. Usually there is but one layer of cells, but sometimes there are two or three, especially in tropical plante. Its office in the economy of the plant is to check the evaporation of moisture.

19. Sтомато. The epidermis is provided with small apertures usually of an oval form, and bounded by two or more reniform (kidney-shaped) cells placed side by side, by the contraction of which the opening is increased or dimin- 
ished. These apertures are called sтомAто, and appear to subserve the functions of respiration and evaporation. They are found in the soft green tissue of leaves and young shoots, but may also be detected in the flowers.

20. GLands are organs designed to elaborate peculiar secretions from the vegetable fluids, such as the fragrant. volatile oil of the sweet briar, and the acrid, colorless fluid of the nettle. They are found in all parts of plants, and are of various forms and composition. Some being composed. merely of cellular tissue, while others contain, in addition, a number of vessels of different kinds.

21. Harrs are minute expansions of the epidermis, consisting of single elongated cells, or a row of cells, placed end to end, simple or branched, containing air.

22. Prickles are larger expansions of the epidermis, composed of indurated cellular tissuc. They have no connection with the wood, being appended to the euticle alone, and are stripped off with it. Example, rose, raspberry, \&c.

23. Receptacles of Secretroy are analagous to glands, being cavities formed in the cellular tissue. They abound in the rind of the lemon and orange, containing minute drops of a fragrant volatile oil.

\section{ORGANOGRAPHY.}

\section{COMPOUND ORGANS OF PLANTE.}

24. A plant, in its early rudimentary state, is an embryo contained in the seed. The form of this initial plantict varies greatly in different species. It is ofiten an oblong or cylindrical body simple at one extremity and notched or lobed at another. Upon this so simple and often minu'e body, all the laws of vegetable life are improssed, and its first effort when it germinates, is to give expression to the most universal of these laws. The two extremities of the embryo are differently affected by the same external agents, and exhibit exactly opposite tendencies. The one end is absolutely stem, the other root:

25. The plant, therefore, possesses a kind of polarity, somposed of two counterpart systems, namely, an ascending 
axis, to produce and continue the stem, and a descending axis, to form the root. The former is gencrally arial, the latter subterranean. Both the stem and roo branch; but these branches are only repetitions of the axis from which they spring, and obey its laws. The branches of the former ascend, those of the latter descend. The branches of the stem are produced at definite points, and with a predetermined arrangement, while thase of the roots are given off without any particular order. The cxtrcmity of the embryo which gives birth to the stem consists of several rudimentary organs, which develope as it devclopes. It is from the first a bud, or growing point containing the undeveloped rudiments - of leaves. As the bud cxpands, and tho sicm lengthons, the leares are sueccssively developed in regulur order. The first leaf, or the pair of lcaves are tormod colyteclons, or sead leaves.

26. The root, stem and leaves pro-cristing in the cmbryo, in a more or less rudimentary condition, and boing the organs concorned in growth, by which the phus tukes in nourishmont from the carth and air, on which it lives, and claborates them into the matcrials of its orm organized substunce are, thorofore, properly tomed the TUNDAMmNal oraANs of plonts, or the organs or viguratron.

27. Flunts of tho highest organization, such as trees, sluubs, \&e, aro hore assumod as cxhibiting tho typical plan of vogotation. Bat this plan is grea!ly molified, and in most respects simplified, as we descond towards the confines of the regetablo kingdom. Bcin: tha tribo of forns is reached, proper flowers disappor, and esnssquently seeds containing a ready-fomod cmbryo-plant aro no longer found. Tho mosscs, and all bolow them in tho suric?, aro composed of simple collular tissue. In soms hoputica nosses, lichens, funci and alcas or searcols tho distinction between stem and leaves are cntirely lost, and even the distinction botween siom and root evontually disapparz, as in those lichens thich prescnt a flat, expanded cmist, and adhore to rocks or the trunizs of trees by tho whole lower surface which answers to a roct, whilo the upper suriace prasented to the light fulflls the office of leaf. Thus, the type of vegctation, obscurely shadowed forth in its most redveed form by the fungi, lichoss, and sea-weeds, but more plinly sketched in the mossez and ferns, is completely realized in the higner or Flowering Plants. 


\section{ORGANS OF VEGETATION.}

28. The organs of vegetation are the Root, Stem, and Leaves.

TIE ROOT.

29. The root is the decending axis, which, aroiding the . light grows downward, fixing the plant to the soil and absorbing nourishment from it. The different parts of roots consist of the caudex (main root) and filrils, (the tiner branches which are sent off from the main stock.)

The so called spongioles or spongelets which were formerly supposed to be tho proper growing points, and the organs through which alsorbtion takes place, according to Prof. Gray bave no existence.*

30. The form of the root is much divensifed in different plants, but the following are the principal rarieties which have received distinctive names:

31. Ramose (branching) Fig. 8. Divided into numerous ramifications, sent off from the main body like the limbs of a tree, but in no determined order. This is the most common form of the roots of trees and shrubs.

8.

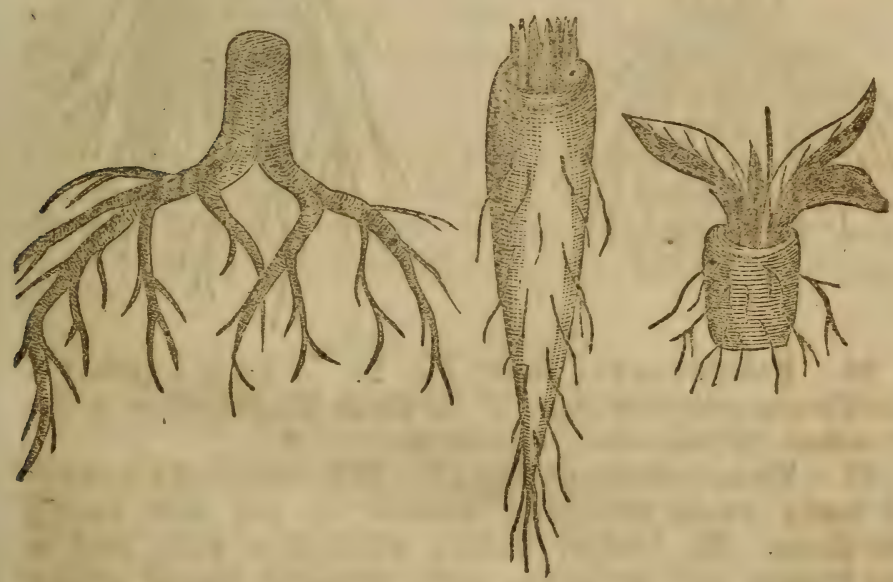

32. Fusiform (Spindle-shaped) Fig. O. This root consists of a thick feshy stalk (caudex) tapcring down wards,

* Aray's Botaniaal Toxt Book; Mird Edition, page 82. 
and also for a short space upwards. It sends off from the sides and extremity, thread-like fibrils, which are its true roots. Example Parsnip, Carrot and Radish.

33. NAPIFORM (Turnip-shaped.) This is a variety of the fusiform, where the upper portion swells out, so that the diameter is greater than the length. Ex. Turnip.

34. Premorse (form promorsis bitten) Fig. 10. This root terminates as though it had been bitten off under the ground. This is due to the fact that the lower extremities perish after the first year. Ex. Viala pedata, Scabiosa, succisa and Primrose.

35. Fibrous Root, Fig. 11. This consists of numerous small fibres, sent off directly from the base, sometimes so close together as to form tufts of a downy resemblance. Such are the roots of most grasses, which multiply their fibres exceedingly in a light sandy soil.

11.

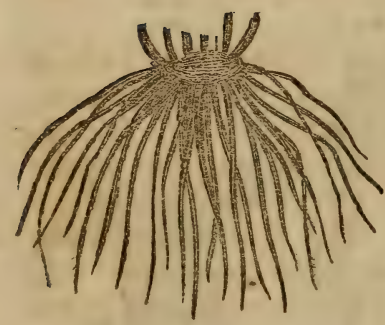

12.

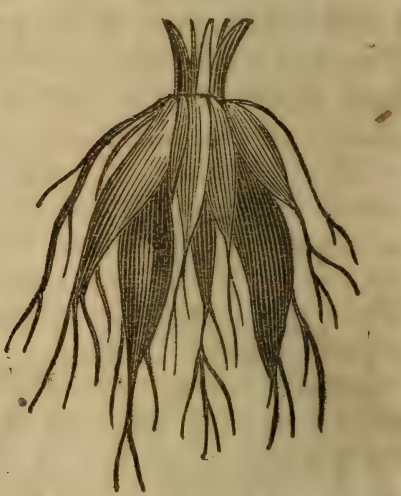

36. Fasciculated Root, Fig. 12. This is a variety of the fibrous root with some of its fibres thickened, as in the Crowfoot (Ranunculus,) Peonia, \&c.

37. Tuberous Root, Fig. 13. This consists of a number of fleshy knobs or tubers, situated at the base among the fibres. Ex. Orchis. Tubers which bear buds, such as the Potatoe and Artichoke, were-formerly classed among tuberous roots, but are now classed among stems.

38. Granulated Root, Fig. 14. This is a variety of the tuberous root, consisting of small tubers or knots growing 
in olusters, connected by fibres. This variety is sometimes oalled moniliform from monile a necklace. Ex. Wood sorrel, and some of the Grasses.

13.

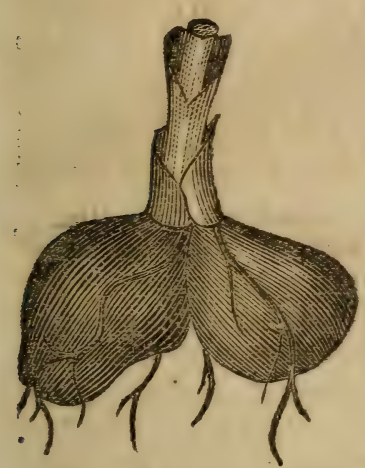

14.

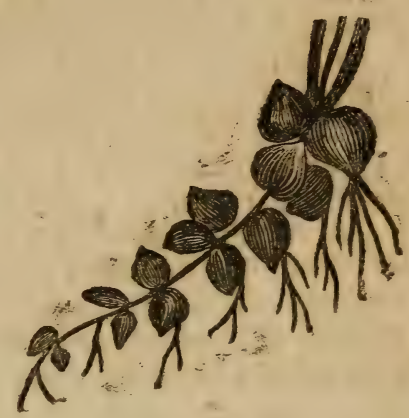

39. Palmate Root, (Hand-Shaped.) This root is akso a variety of the tuberous, where the knob is seperated below into oblong tubers, somewhat resembling the hand. Ex. Dahlia and several species of the Orchis.

40. Flonting Roots. This root is peeuliar to plants which float loosely upon the water. The Lemna (Duckmeat) is an example, it consists of little flat oval green scales, floating on the surface of the water of ditches and stagnant ponds. From the under sides of these proceed the roots hanging like threads of several inches in length. The Calitriche (Water starwort) is another example, it floats upon the surface only until flowering, after which it sinks to the bottom, and ripens its seed.

\section{AERIAL ROOTS.}

41. Thus far, the primitive root, that which originated in germination, has alone been considered. But roots often spring from different parts of growing stems of plants, and when formed, they follow the ordinary course, avoiding the light and seek to bury themselves in the soil. Of these roots several varieties are remarkable. 1st. Those which are sent forth from the joints of creeping or climbing plants. The ground Ivy, (Nepeta glechoma,) and Twin flower (Iinnoca) aro examples of the former, and the Ivy (Hedera helix,) 
Poison Iry (Thus toxicodondron,) and Bignonia or Trumpet creeper, are good cxamples of the latter. Stich plants dorive their nourishment from their croinaly rcots imbedded in the soil, their copicus aral rectlets mcicy scrving for mcchanical support. '2nd. The rcots of ecrtain cicet plants of the cnclegenous structure, originating frem high rp thestem in the cpen air, descond to the ground and stall lish the meclves in the soil. This may be seen en a smaliscale on the stem cf Indian corn, where the lower joints ofien preduce.rcots ef ecveral inches in longth bofore thay reach tho snil. The Pandantis cr Serewpine, a native of the tropical regiens (cften cultivated in our consorvatnies, aficicis a wcil hncwn inctascc. The strong wrial roots cuntted from the lower parts of the irunk are often several foet in longth before rciching the grownd, giving the tree the appemrance of being parially raiscd cut of the ground. The fumous Bunyan-tree affords astill mre striking example. Hers tho, wial roots strike frem the horizontal hriclics of the troo, of son at a great height, and swiag in the air, like pendent cords, but they fnally reach and ceivish themsclves in the ground; where they incicase in cismetex, foming numerols accosory irtuls, which lotp to sur pert the wicsplesd caropy of branches and foliage.

12. Anther class of wrial roo's is peeuliar to the epiployte.s or Air-plants; whicre the roots nots cnly strike in tho free air, but throughout heir existence have no conncetion with the soil. They generally grow upon the trunks and branches of trecs; their roots mercly whering to the bark sufficient to fix the plant in its position, $c r$ else hang loose in the air, from which such plunts traw all their nourishment. Of this class are a large portion of the gergenus Orchidacecus plan's of very warm and huwil clines, which in their flowers and goneral aspest, exhibit such fustastic and infinitely varied forms. Some of tha flowax rasonbl, baterflies or strange insects, in shape as well as gaudy coloring:

43. Purasie; or Paresitic Plunt not ouly strike root upon other vegetables, bui live at their expense, which Epiphytes do not. The Missietoo is a good example, its roots are at no period connected with tha earth, kut the seed germinates upon the trunk or branches of the tree where it happens to fall, and the root penetiates the bark and young wood, just as the roots of ordinary plants peirtrate the soil ; and thus draws the crude sap which the tree has absorbed from the soil, and 
digests it in its own fuliage. Such piants ts the Beach-drops (Orobancha) and Dodder (Cnsents, which draw their food from other plants have to cccitia for lifs,ive crgans of their own, and are thorofore, alwy dostine of green foliage. They may bo redacol to is stalk with as sing? flower or cluster

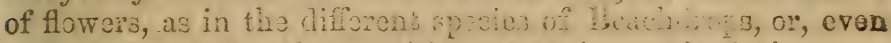

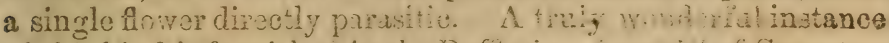

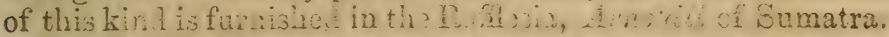
This migratic flomer which crandiutes tha who plint, when

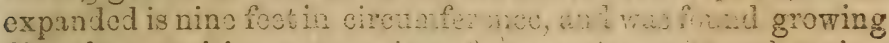
directly parasitic on a specics of fapa ine. Ho colour is a light owange, mottlei with yolowisi wht.

\section{FUNCTIONS OT TUE. TCOTS.}

44. Tho functions of tho ronts are alontion, and the

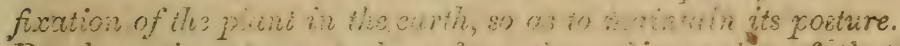

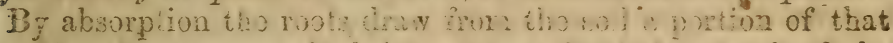

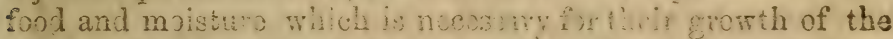

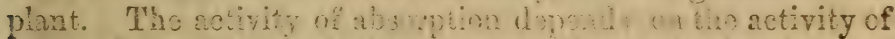

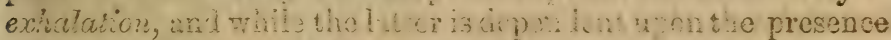

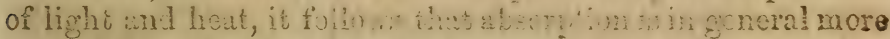
powerfal by day than i.y night.

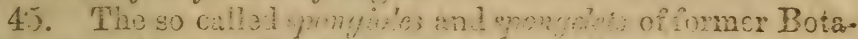

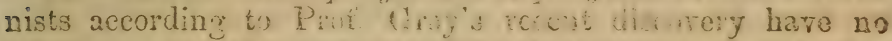

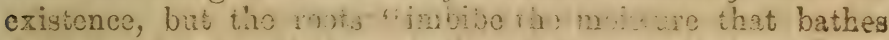

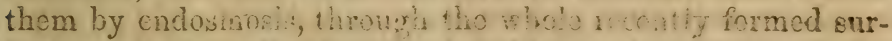
face, and esnecially by the inic-lik plantions of the

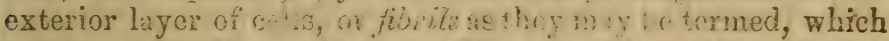

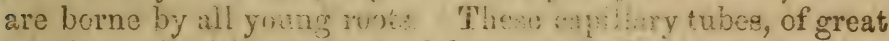
tenuity and with eztrenicly delicats wire, insensly increase

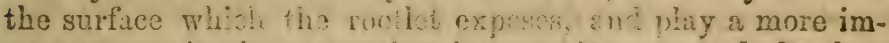
portant part in aivory tion then is goner.tis uposed, for they appear to have attruted little attention."

46. The us wis absomtion $L_{y}$ the roos is not merely to

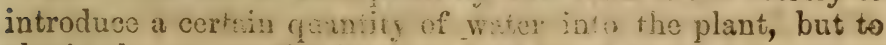
obtain those minoral snbstances held in solution by the water, which constitutes en important part of his ford.

\section{THW ASENDTNG AXIS OR STEM.}

47. The stem is tart porion of the plant which grows in an opposite direction from the roct, sosking the light and air, 
and supports the leaves and organs of reproduction. All flowering plants have stems, but in some cases they are so short and ooncealed under the ground as to appear stemless (acaulescent.) Although stems generally take an ascending direction at first, they do not always retain it but sometimes trail along the ground, or burrow beneath it, sending up branches, leaves, and flowers into the air. In regard to duration, the stem like the root is called annual when it lives but one season, and perennial when it lives an indefinite number of years.

48. From the size and duration of stems plants are divided into herbs, shrubs and trees.

49. Herss are plants producing stems, which do not be. conme woody or hard, but die down to the ground at the end of the growing season, or after fructification; as the Grasses, Corn and Cucumber.

50. Shrubs are plants with woody perennial stems, dividing into branches at or near the ground; and not exceeding thirty feet in height. Ex. Alder, Sumach and Lilac. Shrubs of a diminutive size are called UNDERSHRUBS, such as the Whortleberry, Currant, Gooseberry, \&c.

51. Trees are plants with woody, perennial stems or trunks, which do not divide into branches at or near the ground, and attain to a much greater age and size than shrubs. Ex. Oalk, Elm, Pine, \&c.

52. Stems that are too weak to stand erect, are termed decumbent, or if trailing procumbent, prostrate or running, and if they strike root at certain intervals, they arc called creeping.

53. Climbing Stems, are such as cling to surrounding objects for support, whether by tendrils, as the Vine and Passion flower; by the leafstalks, as the Virgins Bower, or by rrial rootlets, as the Poison-oak.

54. Twining or Voluble Stems, are such as elevato themselves by coiling spirally around stems or other objects, as the Morning Glory, Cypress vine, and Hop.

55. A Storon is a branch which descends from an elevated part of the stem to the ground, there takes root, sends up new shoots and at length becomes a new plant, drawing nourishment directly from the soil. Plants which multiply in this way are called stoloniferous. Ex. Currant, Gooseberry, Raspberry, \&c.

56. A SUCKER is a branch proceeding from a subterranean stem or root, producing leaves, flowers, \&c., and throwing 
out roots from its own base, at length becoming an independent plant. The Rose and Mint afford familiar illustations.

57. A Runner is a prostrate, slender branch sent off from the base of the parcnt stem, extending itself along the surface of the ground, and throwing out roots and leaves at its extremity, which become an independent plant, capable of putting forth new runners in its turn. Ex. Strawberry.

58. An OFFSET is a short lateral branch, with a tuft of leaves at the end, capable of taking root when separated from the parent plant; as the Houseleck.

59. A SPrive or Thorn is a short and imperfectly developed branch of a woody plant, contracted into a sharp, rigid point, either simple, as in the Thorn, or compound, as in the Honey Locust. In some species of the Thorn (Cræetagus,) and Crab Apple (Pyrus coronaria,) they often bear leaves; and in cultivated trees frequently disappear; as in the Apple, and Pear.

60. A TENDRIL is commonly a leafless thread-like branch capable of coiling itself around contiguous objects, so as to afford support to the stem; a fine example of this beautiful appendage is seen in the Grape Vine and Gourd. But sometimes tendrils belong to the leaves, being a continuation of the midrib of the leaf, as in the Pea Family.

\section{SUBTERRANEAN STEMS.}

61. The form of stems when subterranean, is nearly as various as when ærial, but they may all be reduced to a few principal types. They may be distinguished from roots by having regular buds, by scars indicating the insertion of former leaves, or by scales which are the rudiments of those organs. All the scaly roots of the older Botanists are therefore forms of the stem or branches, with which they agree in every essential respect : growing likewise, in the opposite direction from roots. The principal modifications are the bulb, corm, tuber, rhizoma and creeper.

62. A BuLb, Fig. 15, is a thickened subterranean bud, generally of a globular form, and mostly furnished with fleshy scales which are the bases of former leaves; producing roots from its base and a flower stem its centre. The scales are sometimes separate, thick, and arranged in several distinct rows overlaying each other, as in the scaly bulb of the lily, sometimes they are broad and thin, or even in the outer mem. 
branaceous, and investing cach other, in concentric layers, at in the tunicated. bulb of the Onion.

63. BuhBLETs are small arial bulbs borne in the axils of the leavcs, which fall to to ground and produce new plante. The Tiger lily (Lilium bulbiferum) and soveral species of tho Onion are good cxanples. Such plants are called bulbi. terous.

15.

16.
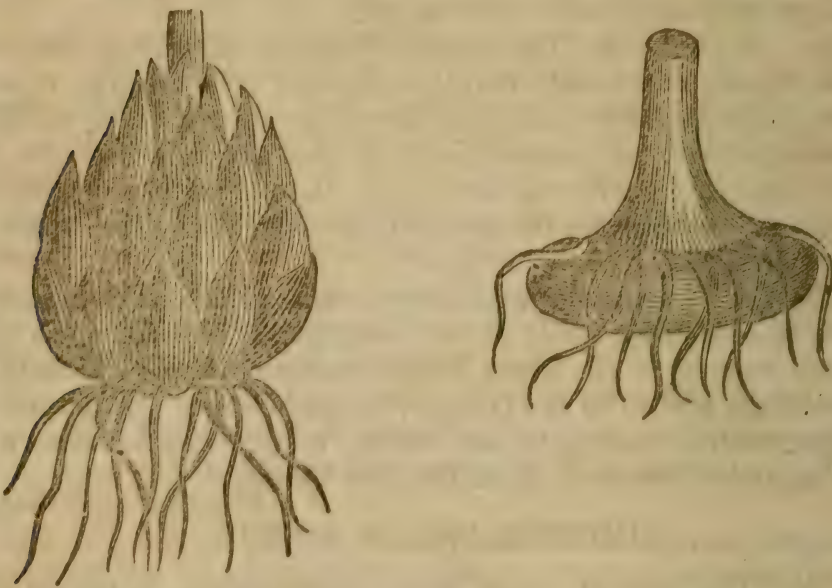

64. $\Lambda$ Co:M, Fig. 16, is a solid fleshy subteranoan stom composed of a simple comnact miss, resembling the bulb in form, but without distinction of layers and scales, as in the Indian Tumip; (Arum triphyllum,) Cyclamen Crocus, \&o.

17.

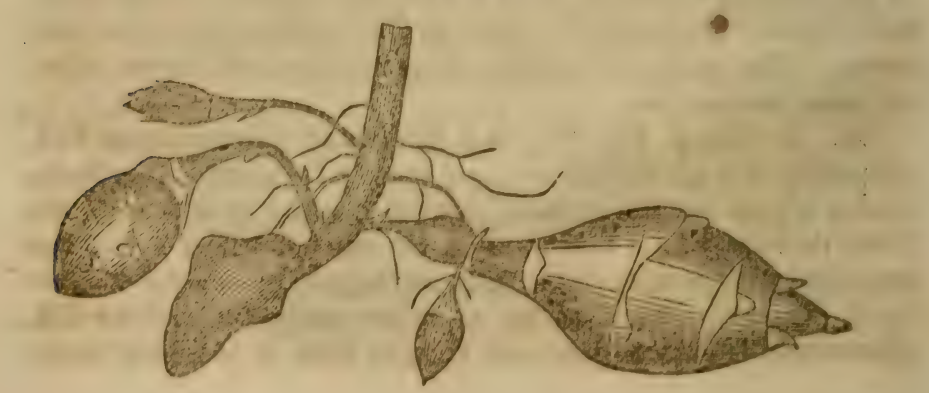


65. A Turer, Fig. 17, is a part of o subtorerean gtem which is much thickened by tha depositin of nutritive matter, provided with latent buds (ejes) hom isbich net planta snring. The commen potato and the Jcmistem Artichoke aford familiar examples.

18.

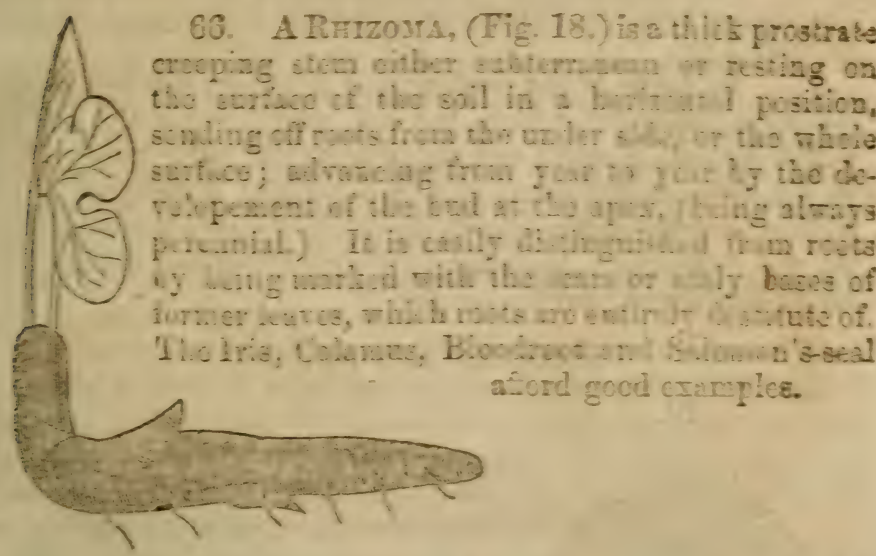

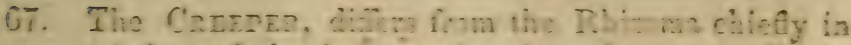

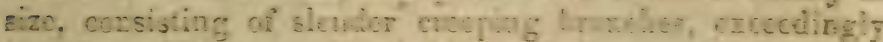

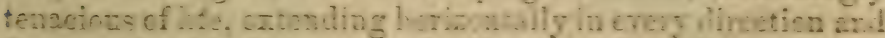

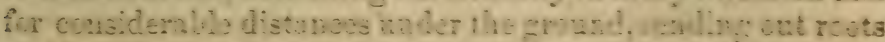

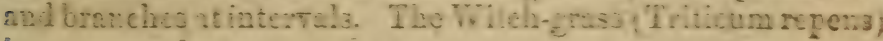
is sn exemple.

\section{PHYSIOLOGICAL BTRUCTUTE OP STEMS.}

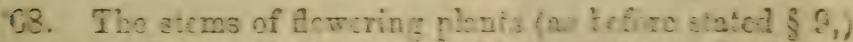
are compred of a cellular syste w, which remstitutes the frame. work of yculy shoots of trices, as woll as cf munale, stech as

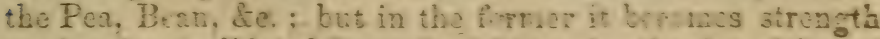
ened and consolidated in course of time by the cleporition of woody fibres and ressels.

69. Plante difier materially in rospcet to tho amangemeat of thece fibres and ressels, and in the mode of th oir increase; but theso dicersities are reducille to try gencral plants, whioh lay the foundation of the frst grand distinction-of Flowering plants into Erocrsa and Ey dogmss. 
70. The difference between the two, as to the structure of their stems, is briefly this. Those of Exogenous plants increase in diameter by the annual formation of a new layer - of wood, which is deposited between the preceding layer and the bark; in other words the wood increases by annual additions to the outside. Flowering plants whose stems grow in this way are called Exogenous Plants or Exogens (outside growers.)

71. In stems of the Endogenous structure the new woody matter is deposited within the oid, and towards the centre, which becoming more and more occupied with woody filores as the stem grows older, causes a gradual distention of the whole, thereby increasing its diameter, the new wood pushing the old outward. Accordingly the plants of this division are called Endogens (inside srowers.)

\section{EXOGENOUS STEMS.}

19.
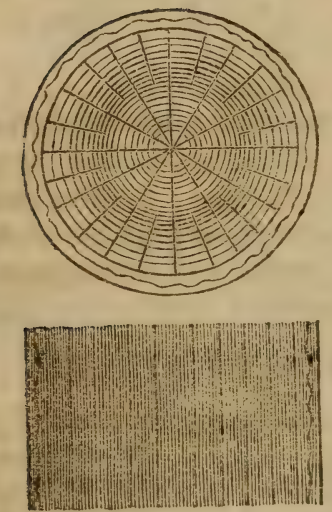

20.
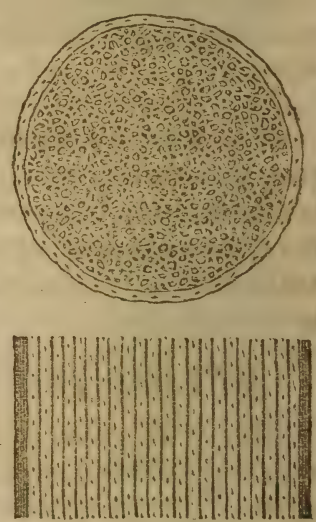

72. The stem of an Exogen, Fig. 19, is composed of three separate parts, the pith, wood, and bark. The pith (medulla,) occupies the centre of the plant, consisting of spongy cellular tissue, at first abounding with nutritive matter for the nour-

- ishment of the terminating buds, but as the plant advances in age it becomes dry and much reduced in volume. It is surrounded by a narrow zone of vascular tissue, called the 
SIEDULLIRY SIEATHINe, which is composed of woody fibre and spiral vessels and is the only part of the stem in which these latter occur.

73. The Woud consists of ligneous fibre, rasiform tissue and ducts, arranged in concentric rows or layers, pervaded by thin, firm, plates of condensed cellular tissue passing from the pith through the modullary sheath to the bark, denominated MEDULLARY RAYs, Fig. 19, which are quite conspicuous in vertical sections of the oak, or the maple, where they are sometimes called Silver grain. The number of zones or layers in a stem is in proportion to its age; the first or inner layer of wood, together with the pith and medullary sheath, is the product of the first year; after which one new layer is formed each successive year during the life of the plant, hence the exact age of a tree can be correctly ascertained by counting the layers at the base of a stem.

In the spring when trees are about to recommence their growth, a kind of mucilage appears between the then readily separable bark and wood, which is called the cambium, and is supposed to be the nourishment of the forming wood, which becomes organized into cells, and forms a new layer upon the wood and likewise to the inside of the liber.

74. The woody portion is also divided into two parts, the Arburnum (sap wood,) and Duramen (heart wood.) The first is exterior, new, colorless, and permeable to the circulating fluids; it is usually of a soft structure, and lighter color than the heart wood, and through the ressels of its layers alone the sap ascends. The other is central, denser, impermeable to the fluids, and usually of a darker color, and is by far the most uscful in the arts.

75. The BarK is the external covering of the stem, and at first consists of simple cellular tissuc, or parenchyma undistinguishable from the pith, except that it assumes a green color when exposed to the light, from the production of chlorophyll in its cells. As the stem increases by external accretions, analogous layers are diposited on the inside of the bark, in the form of tough woody fibre which constitutes the inner fibrous barl, or liber. This rests directly on the wood. The next cellular portion which covers the liber, occupying the space between it and the epidermis or outside skin, is called the cellular integument, and is distinguished into two parts. 1st. The green layer or cellular envelope, which is the 
cisiy part of the bark that assumes a grecn color. 2nd. The cony everope, which lics next to the cpidemin, and is generwily of a brownish ur ash color. It is sometimes rery thick as in the Cork-onk (Quercus suber) forming that useful substenes cullid Cork. The epridermis or outsice cuticle, though smow in and entire at first, at length becomes shagey and rough, With ingyitudinal ridges, which arc scmetimes cut of ino Eomock, Wainut, Hicknry, \&c. Sometimes however, tho sifer layers are extended in horizontal grains, or fibres, creircing the stem, as in the White Birch (Betuia papyracca.)

70. The peculiar virtues or medical propertics of treas reside in the bark rather than in the wood, and is therefore the part chiefly uscd for dying, tanning, medicine, \&re.

\section{ENDOGENOUS STEMS.}

77. The stem of an endogenous plant, (Fig. 20,) presents no distinct separation into pith, wond and bark; nor does a cross-section exhibit any concentric arrangement of layers. The wujy portion consists of cellular tissue, existing equally in sil pirts of the stem, in which is imbedded woody fibre, apir... ressels, and ducts, in the form of threads or bundles. "Liesa 3 by rus bundes arise frem the leaves and pass downward tor and the contre of the stem, and gradualiy force outwards t a. wheh were fist formed. In this way the cxterual . I.... of the stein becomos extremely dense and hard, even so c.. Nu resist tho stroke of an axe, is in tho Palms. Accordi. , oontrary to the exogenous stem the newast and softest Wind formut towards the centre, whilo the oldest and hardest oncippios the circumference. The age of most ondogenous trow, such as the Palms, are therefire limited by this peculiar mola of growih, the stem incrasing in diameier as long as ti. a rind is cupable of distention, further increase being impossilit:

78. Palms, \&e, generally grow from the terminal bud More, and porish it this bud be destroyed; the foliage is also lowe at the sumbit of the trunk; which consequently forms a simple eylinárical column.

70. Whe Gracn-briar affords a grood illustration of a wondy stem of the calogenons structure, and is tha only one indige-

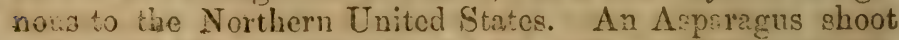
arủ a sizlk of IndianCoru fumish fine herbaceous illustration: 
80. The hollow stcms (cuim of grasses are oringinaty snlid and of the ordinary endogenotis strueture; but then become hollow liy the surface growing fuster that the conte? except at the closed nodes, where the woody threacis ars complicately cntangled so as to form a solid joint.

\section{BUDS.}

81. Buds are undereloped branches or terminaticns $\varepsilon^{\circ}$ stems, enveloped in dry closcly packed scales, being the ruelimentary leares of the jreceding year, formed late in tho season, and arrested in their growth by the frosts and ccont nutriment, which in this form serves for protection from the effects of moisture and sudiden changes of temporature diring. their dormant stutc.**

8.. IBuls arc of tro kinds, namely, the leaf-hut, contin:

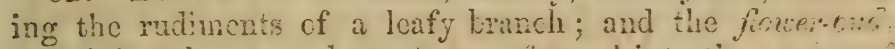
containing the sume clencuts trinsformed into the crevers of a flower for the purpose of reprodiction.

\section{ALI DUDS ARE ETTHER TERMTHAL CR}

\section{AXILLARY.}

83. Termuna Beds aro these which appear at the apez: the stem when it has completed its grow th for the season. "inty often exhibit in miniature the whole plan and amount es thu next yoar's growth ; the rulus and even the leares they licar being alrealy formod, and only requiring the elongation if the internodes for their full cxpanion. As the stem is from a bud, so, at the close of the scason, it is again terminac.: with a similar one, which repeats the same process.

84. The Lateral or AXILIARy Buds are now axis of growth ; when they grow, they give rise to lranches; wi: are repetitions, as it were from the main stem, growing as liat did from the seed. The branches thus produced are in turt? provided with similar buc's in the axils of their leares cat

* That the bud sales are of the natura of leavas w:Il a?ynar verv evidont one who attentively observes the expanding buds of the If irar Cliztnut, Lilac. Buds are only formshed with scales in wintry clmatc. ntise

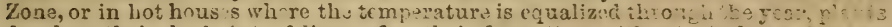

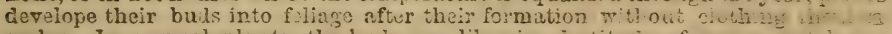

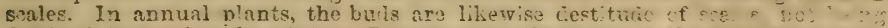

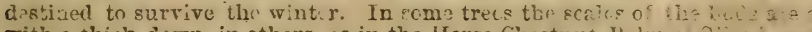

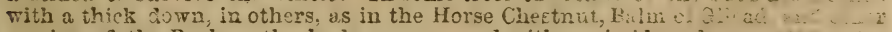
species of the Popiar, the buis are covered with a viscid and azonalio raein, reaembling a coat of varnish. 
occupy the same relation to the primary branch, that they do to the main stem, and are capable of developing into branches of a third order, and so on indefinitely, producing the whole ramification of the plant. The whole is merely a series of repetitions, from new starting points, of what took place in the evolution of the first axis, prexistant in the seed.

85. The arrangement of axillary buds depends upon that of the leaves, which, in all young plants are arranged with great symmetry and order. When the leaves are opposite, the buds in their axils are consequently opposite, as in the Horse Chestnut. When the leaves are alternate, the branches will be alternate, as in the Oak, Poplar, \&c.

86. It is a fixed law in the arrangement of the leaves, and all other sppendages, that they are disposed SPIRALLY, that is in a line which winds around the axis. This spiral line is formed by the union of two motions, the circular and the longitudinal, caured by the advancement in length and increase in diameter of the axis while in a growing state. When a single leaf arises at a node the arrangement is more obviously spiral, and is said to be alteinate. When two arise at each node they are placed opposite to each other, and at right angles to the adjacent pair. When more than two arise at each node, they are said to be rerticellate or whorled. So likcwise the arrangement of the branches (when not interfered with by some disturbing causes) is found to be SFIRAL; that is, alternate in most plants, opposite in the Ash, Dogwood, \&c. or verticellate in the Pine, \&c.

87. Buds may be removed and attached to the trunk of another individual of the same, or even of a different, but nearly related species, where they will grow equally well. This is directly accomplished in budding and in grafing, in the latter however a portion of the shoot on which it grows is transferred with it. Buds may even be made to strike root, by plunging them into the soil, frow which they immediately draw their nourishment, instead of the parent plant. In this way Horticulturists propagate plants, with all their varieties and individual peculiarities, many of which would doubtless bo lost in raising from the seed.

\section{VERNATION.}

88. The peculiar manner in whioh the young leaves are folded in the bad, is called vernarron, which varies, consid- 
erably in different specios and is exhibited in a most interesting manner by making a cross section of a bud with a sharp instrument while in a swollen state, before expansion.

Some of the principal forms of vernation are the following:

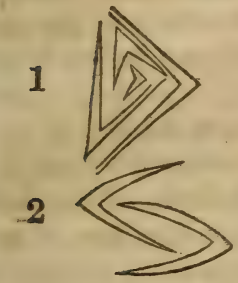
-1. EQuTTANT, overlapping each other in the form of angles, the folds of each side being parallel with each other, as in the leaves of the Iris.

2. OBvolute, (embracing each other) where one of the margins of each leaf is interior and the other exterior to the margin of the opposite leaf, as in the Vallerian \&c.

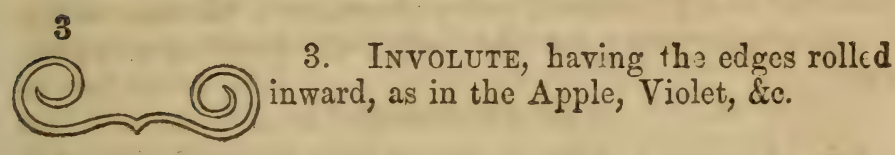

$\sqrt{2}$

4

4. Revolute, having the margins (2olled outward's or backwards, as in the () Willow, Rosemary, \&c.

5

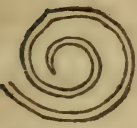

6
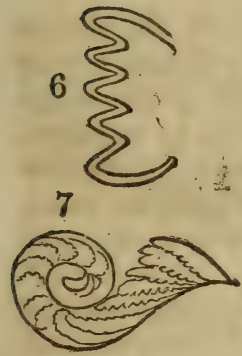

5. Convolute, when the leaf is wholly rolled up from one of its sides, as in the Cherry, and most of the grasses.

6. Platted, where each leaf is folded like a fan. Ex., Vine, Birch, and Palmtree.

7. Circinate, when rolled downwards from the apex. Ex., Sundew, Ferns, \&c.

\section{LEAVES.}

89. Leaves are by far the most conspicuous portion o? plants, and are of the highest importance to the vegetable fabric; being the organs of respiration and assimilation. They 
generally consist of thin membraneous expansions of various forms, growing from the stem or "branches situated immedi* atcly below the bud. "They may be considered as an expan. sion of the skin or cuticle of the plant, supported by a network of fibres and vessels derived from the medullary sheath presenting the largest possible surface to the action of the air and light, which is indispensable to the life and increase of the plant.

90. Leaves are almost universally green, which of all colors is the most agreeable to the eye, the intensity of which raries by an infinite variety of shades, which form a beautiful contrast with the more delicate tints of the flowers. The coloring matter of the leaves consists of innumerable rounded globules of a waxy nature, called chlorophyll, adhering to the insile of the cells upon which the light has its peculiar action.

\section{ARRANGFMENT.}

91. The point of attachment of leares, (or other organs) with the stem is termed their insertion; simply the point of adhesion.

92. In regard to the position on the stem, leares are said to be radical, when they are inserted into the stem at or beIcw the surface of the ground as in in the Cowslip, Primrose, and some of the Violets. Those that arise along the main stem are termed cauline, and those that belong to the branches are called rameal.

93. As to their situation with respect to each other, they are said to be

1. Ariternate, when they arise one above anotlier at regular distances around the stern. They are seldom placed one above the other on exactly opposite points of the stem, lnt the sccond leaf will be found to arise a little to the right or left of the opposite point, and the third a little on one side of the perpendicular of the first, and it is only when we reach the sixth leaf, that we find one placed exactly over the first. Ex. Apple, Peartice, \&c.

2. OprostTe, when placed in pairs on opposite sides of the stem. Ex. Ash.

3. Verticlilate, or Wronled, when more than two arise from the sane nodes forming a whorl or verticel, around

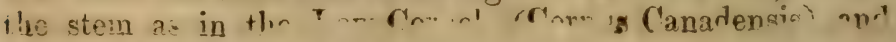
ararlowr $r$ 
4. Fasciculate, or tufted, when in several erowded whorls forming a spire (fasciele). Ex. Calitriche.

\section{CONFORMATION OF LEAVES.}

94. The various forms which leaves assume in different species are almost infinite; affording some of the readiest as well as the most certain marks for distinguishing one species from another.

95. Leaves consist of an expanded surface ealled the LAMina, Limb, or Blade, and an unexpanded part, or stalk called the Petrole. But when the leaves expand immediately on leaving the stem, the petiole of course is wanting, they are then said to be sessile.

96. Leaves are clasping (amplixicaul,) when the base embraces or nearly encircles the sten; perfoliate, when the encircling base unites around on the opposite side so as to appear as if perforated by the stem, as in Uvalaria perfoliatum; connate when the bases of two opposite leaves are united, as in Bonesett; sheathing when the lower part enwraps the stem, as in the Grasses, and decurrent when a portion of the blade of a sessile leaf appears to run down along the stem below the point of insertion.

97. A leaf is simple when it consists of a single pieee; hawever incised, eut or divided; and compound when composed of twa or more separate portions or small blades, in other words, when the petiole is branched. In a truly compound leaf the separate biades or leaflets are generally articulated, (jointed) with the main petiole, and fall off separately just as the petiole separates from the stem, as in the Walnut, while the divisions of a simple leaf, howerer deep they may be, never fall off separately.

\section{VENATION.}

98. The projecting lines on the under surface of a leaf are termed veins, and their distribution Venation. The veins are distributed through the blade in two principal modes, called the parallel-veined, and the reticulated or net-veined. In parallel-veined leaves (Fig. 21.) the veins divide at once where they enter the blade and run parallel with each other to the apex, connected only by simple transverse reinlets; or the petiole is continued into the blade in the form of one or more principal or coarser veins, which send off smaller veins on both 
sides, running parallel with each other, connected by simple transverse veinlets, (Fig. 22.)

21.

22.

23.

24.
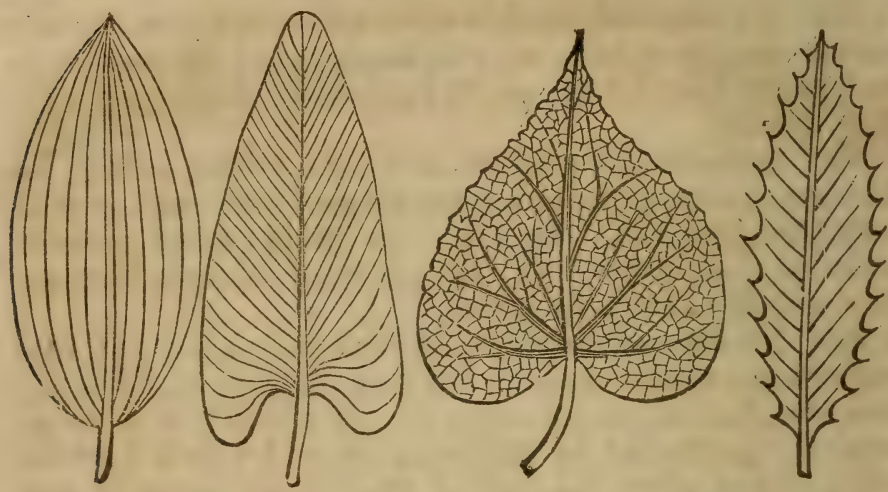

99. Parallel-veined or nerved leaves are characteristic of Endogenous Plants; while reticulated leaves are almost universal in Exogenous Plants.

In reticulated leaves the petiole is prolonged into the leaf in the form of the midvein or several primary branches, dividing and subdividing into branchlets, which unite again, and, by their frequent inosculations, form a kind of network, as in Fig. 23.

100. There are two varieties of reticulated leaves that deserve particular attention, the feather-veined and radiateveined. In the feather-veined leaf, (Fig. 24) a single strong rib forming a continuation of the petiole runs directly through the middle of the blade to the apex, giving off at intervals lateral veinlets, as in the Beech, Chestnut, \&c. In radiateveined leaves (Fig. 23) the ressels divide at the apex of the petiole into three or more portions or ribs of nearly equal size, which are usually divergent, each giving off veins and veinlets like the single rib of a feather-veined leaf. Ex. Maple.

\section{FORM OF LEAVES.}

101. The form of leaves may be considered to depend upon the distribution of the veins, and the quantity of parenchyma. Since it is through the veins alone that the outriment is conveyed for the development and extension of 
the leaf, it follows that there will be the greatest extension of outline where the veins are largest and most numerous.

\section{FEATHER-VEINED LEAVES.}

102. If the principal vein of a feather-veined leaf are not greatly prolonged, and are somewhat equal in length, the blade will have a more or less elongated form.

Middle veinlets longest.

25.

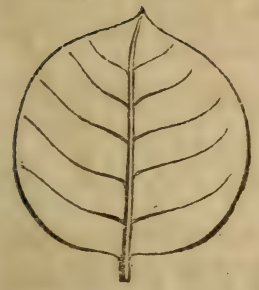

26.

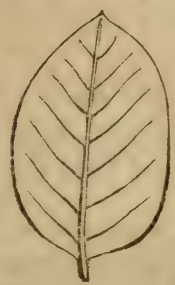

27.

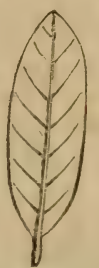

28.

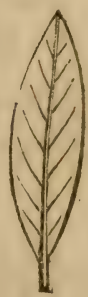

1. Orbicular (roundish, Fig. 25) having the longitudinal and cross diameters nearly equal. It is very rare, if ever, that precise examples of this leaf occur in nature. Pyrola rotundifolia and Anagalis (Pimpernel) afford tolerable examples.

2. Eurpticat (oval, Fig. 26) having the length greater than the breadth, with the curvature equal at both ends. Ex. Lespedeza prostrata.

3. Oblong (narrow oval, Fig. 27) having the length several times more than the breadth, with the curvature nearly equal at both ends. Ex. Solomon's seal, Side-flowering sandwort.

4. Lanceolate (lance-shaped, Fig. 28) haring the length three or four times longer than the width, tapering towards both extremities, and ending in a sharp point. Ex. Peach.

\section{Veins next the base longest.}

1. Ovate (egg-shaped, Fig. 29) having the form of an egg divided lengthwise. - The length is no more than the width, and the base is broader than the apex. Ex. Chequerberry (Mitchella repens,) Pear. 


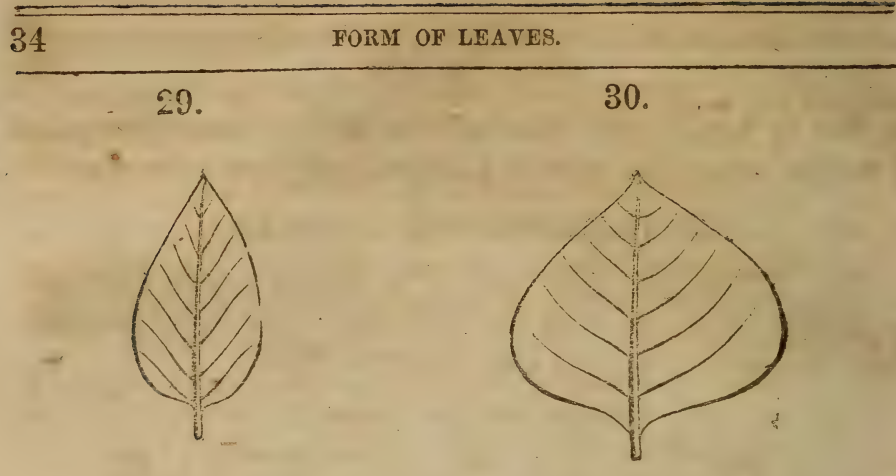

2. Rhombord or Detrord (Fig. 30) triangular in outline w.th the two lateral angles rotinded. Ex. Trillium, Black poplar.

Veins developed beyond the middle of the blade.

1. Овоуате (inverseiy egg-shaped, Fig. 31). Daisy.

2. Spathulate (shaped like a spatula, Fig. 32). Es.

3. Cungate (wedge-shaped).

4. Pasduriform (fildlo-shaped, Fig. 33) rather lnng, broad at the two extremities, and narrow towards the middlc. Ex. B.ndweed (Convolvulus panduratus).

31. $32 . \quad 33 . \quad 34$.

35.
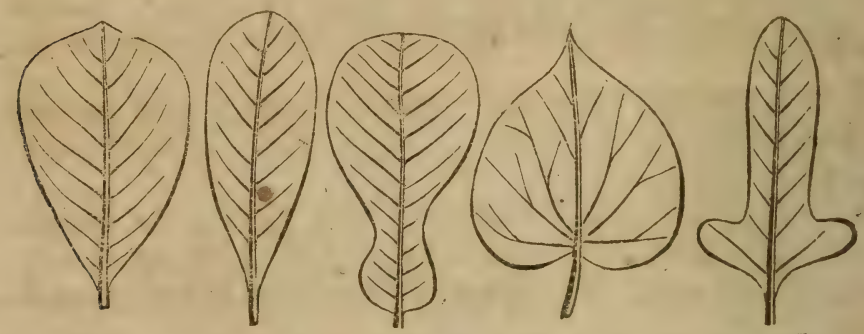

Lowest vein?ets longest sending off veinlets backwards.

1. Condate (heart shaped, Fig.34) where the length is greater than the width, with an oviate form, and hollowed at the base. Ex. Morning Glory, Lilac.

2. Auriculate (Fig. 30) where the form is oblong with two opposite lobss at th baso. Ex. Sage.

3. Hastate (halbert-shaped, Fig. 36) when the form is triangular the base spreading and ending in two opposite points, with the sides a little hollowed. Ex. Bittersweet. 
4. SAGITrate (arrow-shaped, Fig. 37) where the leaf is triangular in nutima with ponted descending lokes at the base. Ex. Scraich-grass (iolyganum cagittatum,) Arowhead.

5. Renifori (kidncy-shapod, Fig. 88). A broad leaf rounded at the apex, and hollowed out at the base. Ex. Cultsfoot (Asarum), Gill-over-the-ground (Glechoma). 36.

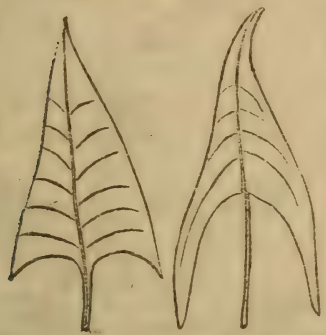

38.

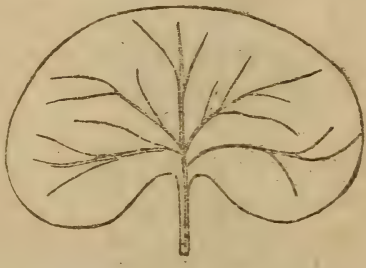

Veinlets nearly of an equal length, with an imperfect developement of the tissues between them.

1. Runcrnate (lion-tonthed, Fig. 39) having the margins cut into transverse acute segments, which turn kackwards. Ex. Dandelion.

2. Lyrate (lyre-shaped, Fig. 40) when the sides are cut into sereral lobes or segments of which those next the petiole are the smallest. Ex. Lyro-leared Sage, White mustard (Sinapis alba).

39.

40.

41.
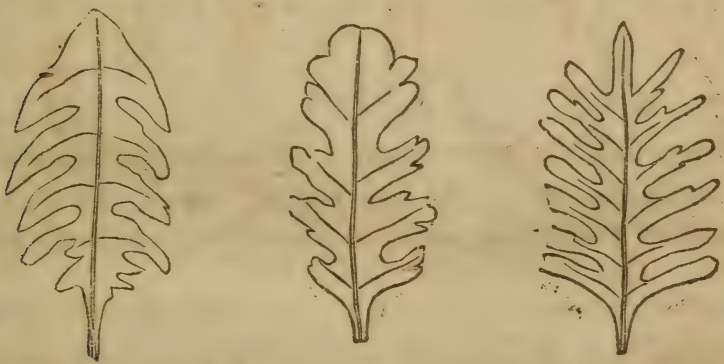

3. Sinuame, cut inte rounded lobeg, or wide open rings betwe the veinlets, with the margin bending in and out. Ex. Black and White oak. 
4. Pinnatifid, (feather cleft, Fig. 41) where cach margin of the leaf is rariously divided into oblong parallel seg* ments. Ex. Cardamine hirsuta.

\section{RADIATE VEINED LEAVES.}

103. Radiate or palmate veined leaves assume various forms, which depend upon the number of the veins, their direction, and the quantity of intervening tissue.

1. Laciniate (gashed, Fig. 42) cut into numerous, irregular portions or lobes, which are again subdivided. Ex. Crowfoot, Cranesbill.

42.

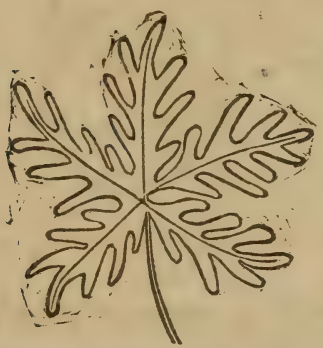

43.

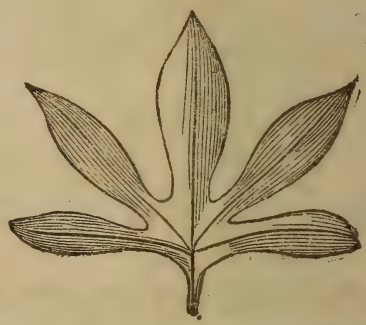

2. Palmate (palm-shaped, Fig. 43) divided nearly to the insertion of the petiole into five oblong lobes of similar sizes, so as to resemble the palm of the hand with the fingers. Ex. Passion flower (Passi-flora corulia,) Castor oil plant.

3. Digitate (finger-shaped, Fig. 44) divided into deeper and narrower segments than the palmate. Ex. Horse chestnut, Hemp.

44.

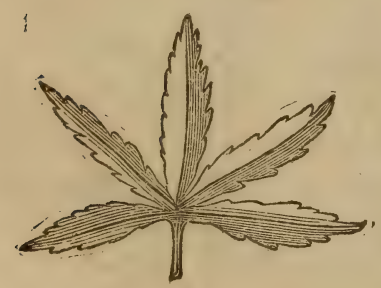

45.

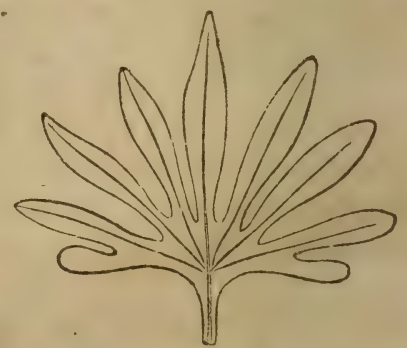

4. Pedate (foot-shaped, Fig. 45) similar to the palmate except that the two lateral lobes are again divided. Ex. Viola pedata. 
5. Pextate (shield-shaped, Fig. 46) where the petiole is inserted near the middle of the leaf, and the veins radiate from it in every direction, connected by intervening tissue. 'This form is generally orbicular in outline. Ex. Nasturtion (Tropeilum), Podophyllim.

46.

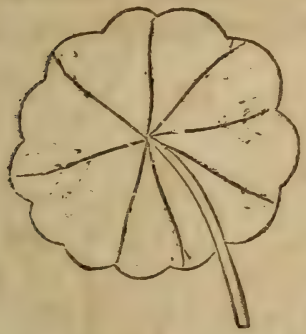

47.

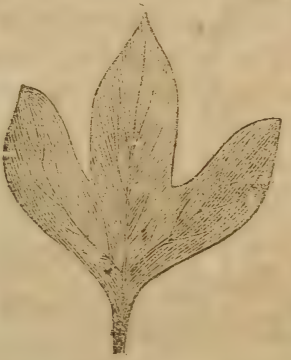

6. LoBED (Fig. 47) divided into segments, the margins of which are rounded. Ex. Liverleaf, (Hepatica).

104. PARALLEL VEINED OR NERVED LEAVES.

Veins parallel from the base to the apex.

1. LINEAR, straight, and narrow, when the edges are parallel, as in the Grasses. This form also ocurs in featherveined leaves by an equal developement of all the veinlets as in Linaria vulgaris (Toad Flax.)

2. ENSIFOR M (sword-shaped) as in the Flag (Iris versicoler.)

3. Acerose, (needle-shaped) as in the Pines.

105. When the veins diverge from the middle, the leat becomes Lanceolate as in the Orehis. Oblong as in the Cyprpedium.

\section{Curvinerval Leares.}

106. When the simple parallel veins or nerves arise from a prolongation of the petiole in the form of a thickened inicrib, they are called curvinerved, as in the Pontederia an! Ethiopian Lily (Calla).

\section{COMPOUND LEAVES.}

107. $\Lambda$ compound leaf consists of several leaves or lerffes attached to the common petiole by articulation, distinct from cach other and falling away separately.

Feather-veined Compound leaves.

108. When a feather-Feined leaf keomes compount, a D 
pinnate (winged) leaf (Fig. 48) is produced. The petiole bearing a row of leaflets on each side, generally equal in number and opposite.

1. UNEQUALLY PINNATE, (Fig. 48) when a pinnate leaf is terminated by an odd leaflet. Ex. Rose, Ash, Walnut. When it is terminated by a tendril it is called cirrhose as in the Pea.

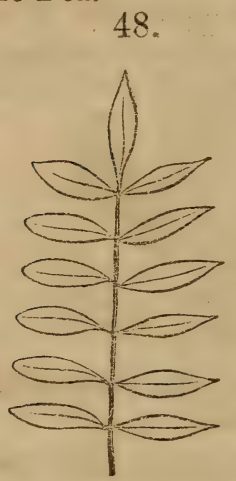

49.
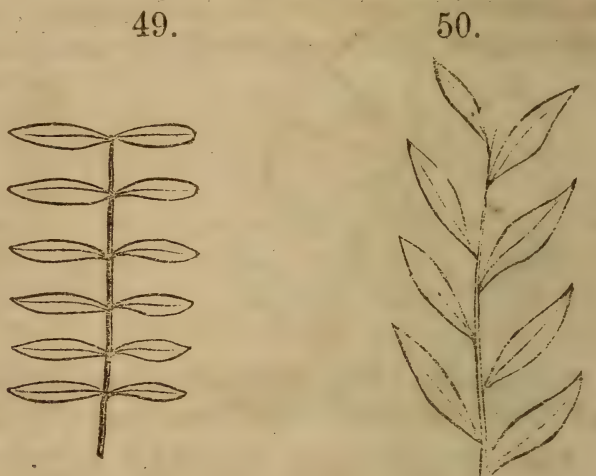

2. Abruptiy pinnate, (Fig. 49) when the petiole of a pinnate leaf ends without an odd leaflet or tendril. Ex. Senna, (Cassia Marilandica.)

3. Alternately pinnate, (Fig. 50) when the leaflets alternate with each other on opposite sides of the petiole. Examples rare, Wood Vetch.

4. Internuptediy pinnate, (Fig. 51) when the leaffets are alternately large and small. Ex. Agrimony, Arens.
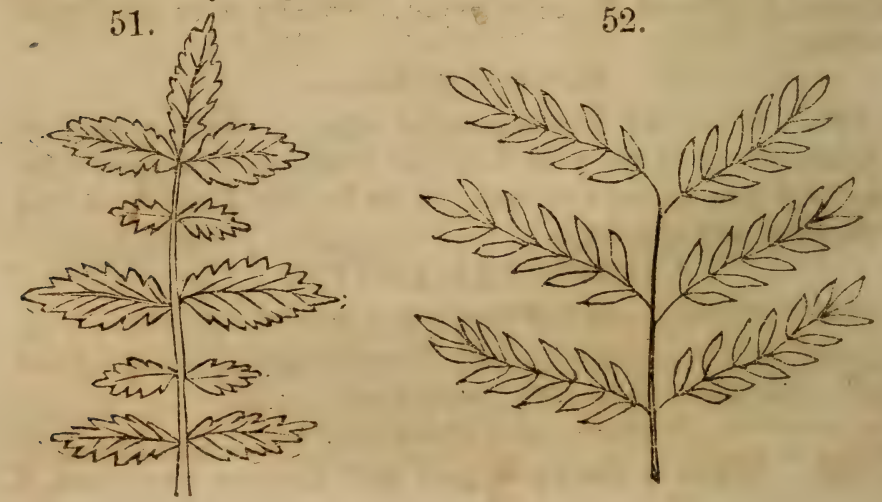
A pinnate leaf sometimes consists of as many as twenty or eren fifty leaflets, as in the Acacia.

5. Bipinnate, (doubly pinnate, Fig. 52) when a common petiole bears pinnate leaves on both of its sides. Ex. : Wild Elder (Aralia hispida.)

6. Tripinnate, (triply pinnate, Fig. 53, ) when the common petiole bears bipinnate leaves on each side. Ex.: Angelica tree, (Aralia spinosa).

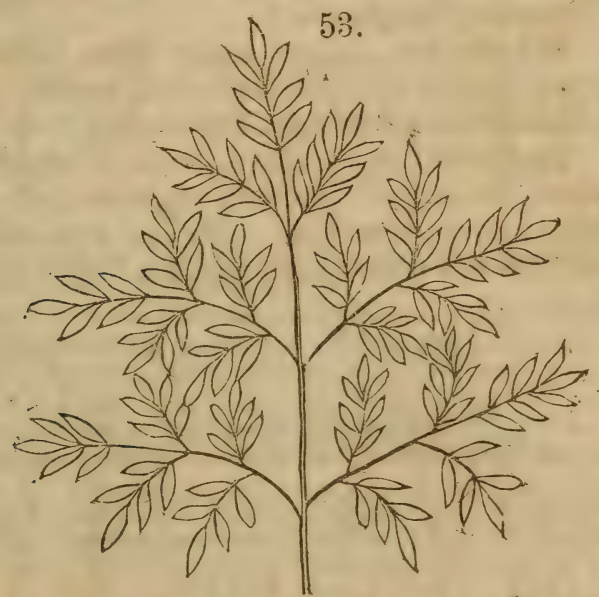

109. Sometimes the number of leaflets is but three, and the leaf becomes pinnately trifoliate, (Fig. 54,) and is readily distinguished by haring the two lateral leaflets attached to the petiole at some distance below its apex, as in the common Garden Bean. Such a leaf may even be reduced to a single leaflet, as in the Orange.
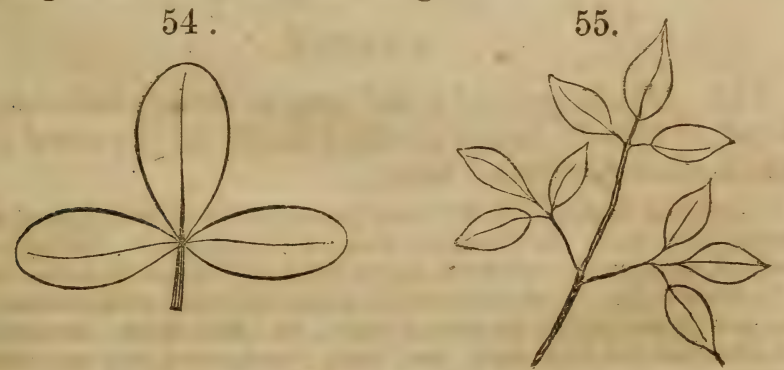


\section{Radiate veined Compound leaves.}

110. When a radiate veined leaf becomes compound, the loaflets are necessarily all attached to the apex of the common petiole, forming a ternate or palmately trifoliate leaf, as in Clover, (Fig. 54,) or a digitate leaf; as in the Horse chestnut, (Fig. 44).

1. Bitzrnate, (twice ternate, Fig. 55,) when the leaflets of a ternate leaf become themselves ternate. Ex.: Squirrel corn (Dicentra Canadensis.)

2. Tritennate, (three times three ternate, Fig. 56,) when the leaflets of a biternate leaf become again ternate. \$x. : Columbine (Aquilegia Canadensis.)

3. Digitate leaves, of five, seven, or any definite number of leaflets, are termed Quinate, Septinate, \&c. ; or digitately five foliate, seven foliate, \&c. By this nomendature, the distinction between pinnate and digitate leaves is readily understood.
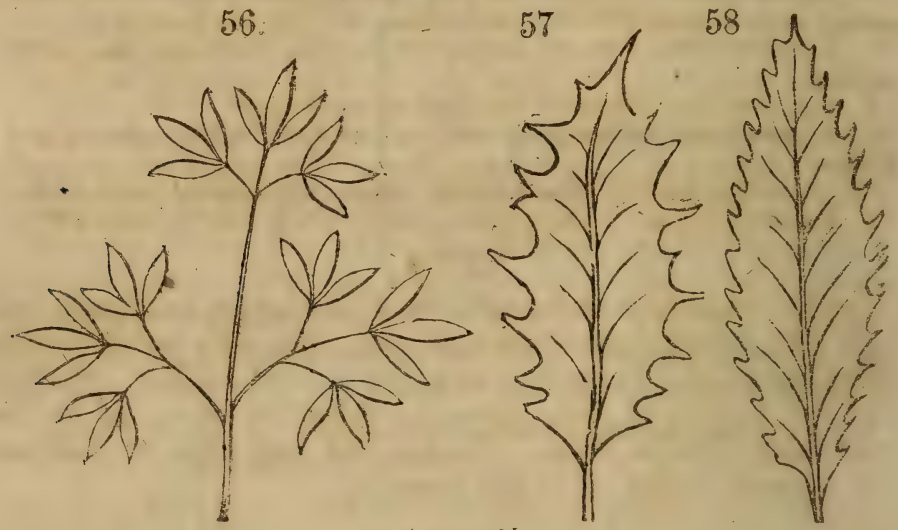

MARGIN.

111. The margin of a leaf may be entire, indented, bor. dered, or rolled; and is modified chiefly by the same causes which effect the form; being,

1. DENTATE, (toothed, IFig. 57 , when the margin is beset with prajecting, hort contal, distant toeth. Fix.: Certaury, Enchanter'a Nightshade. Dienticilate, wien the toeth are very fine; and doubly dentats, when the teeth are themselves toothed

2. SRRRATE, (Fig. 58,) when the margin is beset with sharp teeth, pointing toward - the apex of the leaf, like the teeth of a saw. Ex.: Rose, Beach. Serrilate, when the aerratures are very smill; and doubly serrate when they are theinselves serrato. 
1. ENTIRE, (even edged, Fig. 57 ,) when the line of the margin is uninterrupted. Inx.: Lily, Lilac.

2. CRENate, (Fig. 58,) when the indentations are blunt and rounded, and do not incline to either extremity of the leaf. Ex.: Ground Ivy, (Glechoma.) CвasoLATx, when such notches are rery small, as in the Sage.

59.

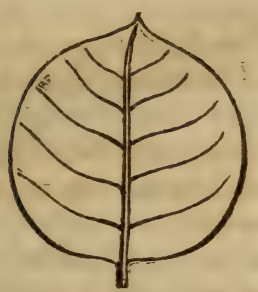

60.

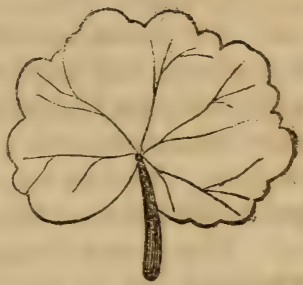

5. EROSE (gnawed, when the margin has the appearance of being bitten by in sects, though not so in reality. Ex.: Fireweed.

6. SPINOSE (armed,) when the marginal denticulations, whatever form they sssume, are terminated with sharp, rigid spines. Ex.: Thistle, Argemone.

7. Undulate (wavy, when the margin rises and falls like waves. Ex.: Amsranthus.

8. Laciniate (torn,) divided by deep and irregular gashes.

9. CRISPED, when the margin is variously curled and twisted. Ex.: Crisped Mallows.

10. Revoute, when the margin is rolled bsckward, or upon the under surface. Ex. : Rosemary, Thyme. Involute, when rolled forward, or upon the upper side.

\section{APEX.}

112. The apex of a leaf is that part which is opposite to the base or footstalk. It varies considerably in shape in different leaves. It is said to be-

1. ACOTE, when it terminates with an acute angle.

2. Acumnate, (Fig. 61, ) when it ends with a long tapering point.

61.

62.

63.

64.

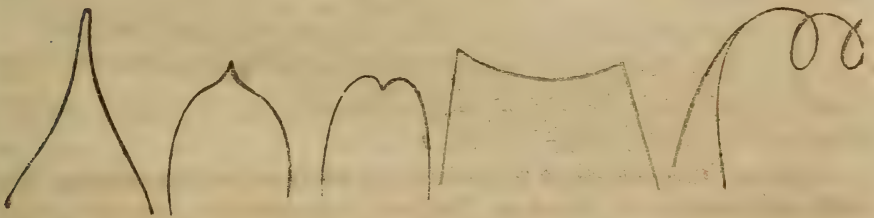

3. Cosproate, when it runs out gradually into a small, awi shaped, rigid spine

4. Mucronate (Fig. 62, when it ends abruptly in a sho-t, kard, crusty point.

5. Emarginate (Fig. 63 , having a small notch in the cnd. 
6. ReTUss, terminating with a round end, having the centre depressed.

7. OBTUSE, when it is rounded.

8. Trundate (Fig. 64,) whon it appears as if eut across in nearly straight lines, as in the Tulip, Poplar.

9. CrRRнose (Fig. 65,) when it is terminated by a kind of tendril.

\section{SURFACE.}

113. The surface of a leaf comprehends both the upper and the under side. The upper surface is generally the smoothest, although the veins can be triced in the form of white or colored lines; yet they very rarely produce those elevated ridges which are generally so prominent on the under surface. In treating of the different characters that distinguish the surfaces of leaves, the upper disk only is alluded to. The greater number of the following terms are equally applicable to the surfuce of the stem as to that of the leaf, when the contrary is not expressed.

114. The different forms which are exhibited by the transverse sections of leaves are said to be-

1. Chanasted, whrn an oblong or linear leaf is longitudinally hollowed, and a transverse section of it is a semi circle.

2. Carrante (kecled, whon a transverse section is angular, and the midrib on the under surface resembles the keel of a boat.

3. StL TE (furrow $d$,) when instead of one longitudinal hollow there are sereral linear deprosions.

4. $\mathrm{S} ? \mathrm{RI} \cdot \mathrm{TE}$ (str aked,) when the depressions are superficial, very narrow, and in parcllcl lines.

5. PLIC:T (fold-d, when the surface rises and falls alternately, in straight angular furrows, like the folds of a fan.

6. FUG $15 E$ (wrink'od) when the tissue between the reticulated veins rises upwards in a conv $x$ form, as in the Sage, Cowslip.

7. Prтma, when on the contrary the fulness between the rcins produces depres\&ion.

115. The different protuberances with which some leaves are covered, are said to be-

1. $\mathcal{C}^{\wedge} \mathrm{B}$. US. When they are snall, bard tubercles, more easily distinguished by the fin $\mathrm{n}$ the the eye.

2. $V E$ $\mathrm{EC}$ (w\&rty, when the tubercles are much larger and more solid.

3. I $\wedge$ PIL ( with \&q 19008 fluid, 28 in the Ice plant.

4. - Ho: 0.T whon th s sirfuce is studded with short, herbaceous spines, or point

116. W an leaves are coverad with hairs, or down, they are sain to

1. Hrзp $D$, if : s with short, Btirit he ire

2. SETO $z$, wh th y star singly, and resemble bristles.

2. S RIG $18 \%$ if they are firm, and upon small prominenecs.

4. Hraci when the hairs are longer and less:i id. 
5. PLLOSE, when the hairs are soft, distinct, and soms what long and bent.

6. Vruose (velvety, when they are soft, nearly erect, and parallel.

7. Pubescent, covered with soft hairs or down.

8. HosRY, white, with very short dense hairs. (Gnaphalium.)

9. Tourvtose, when they are very soft and matted togother, so that tho individual hairs are not distinguishable.

10. Woorux, when they are also matted togother, but yet indiridually distinguishable. (Mullein.)

\section{GLANDS.}

117. When the surface of a leaf is furnished with risible glands, they are said to be-

1. GLANDULSE, when they are elevated or on pedicels.

2. Punctate (dotted,) when a leaf is covered with pellucil grots which cither penetrate the substance, or are merly superficial.

3. VISCID, when a leaf is corered with a moist, tenacious, glandular secretion, is in the Cuphea viscosissima.

4. FARryose, when it is corered with a rery fine, dry, mealy powder, deroid of gloss, and easily wiped off.

\section{PETIOLE.}

118. The form of the patiole is rarely round, but is usually half eylindrical, and channeled on the upper side. It is said to be-

1. CoMPREssed, when it is strongly flattened in a rertical direction, as in tho Aspen Poplar, in which the leares are put in motion by the slightest breeze.

2. Wryard, when it is expanded into a border, as in the Orange; which not unfrequently extends along the stem, as in the Sweet Pea.

3. S.ACATE, when the base is dilated into a broad, membranaceous, inflated sheath, as in many of the Umbeliferae.

4. Sheathed, embracing the stem, as in many of the Grasscs. In the true Grasses, it is furnished at the summ:t with a membrancous appendage called the ligule.

119. The apex of the petiole sometimes terminates in a tendril; as in the Pea tribe. In the Lathyrus Aphaca, the whole petiole becomes a tendril, the office of the sleaf be:n's fulfilled by a pair of large stipules.

120. In some plants, the lamina of the leaf is abortive, and the petiole is dilated, into a kind of nerved leaf, called phyllodium, which is readily distinguished from a true lamina by being entire and parallel veined, while the true leares of the genera in which phyllodia occur are usually compound and net-veined. They generally present the margins instead of their surfaces to the carth and sky; as in the Australian Acacia, in which they sometimes bear a true compound leaf at the apex. 


\section{CAULINER AND FOLIAR APPENDAGES.}

\section{ASCIDTA.}

121. The most remarkable of all cauliner and foliar appendages, are those which are hollowed out into the form of pitchers or ascidic,

122. The Side-Saddle FlowzR (Sarrecenia purpuria, Fig. 6ิ,) a North American plant, found growing in peat bogs, bears pitchers which are evidently formed by the very deep channelling of the petiole, and the union of the involute edges of its winged margin, so as to form a complete vase, with a broad expansien at the tip, which may be regarded as the true leaf. These pitchers are alwayg full of water, making an ocean in which many aquatic insects take up their abode. These are often visited by flies and other insects, who would gladly retreat from their prison, but are prevented by the deflexed hairg at the mouth.

66.

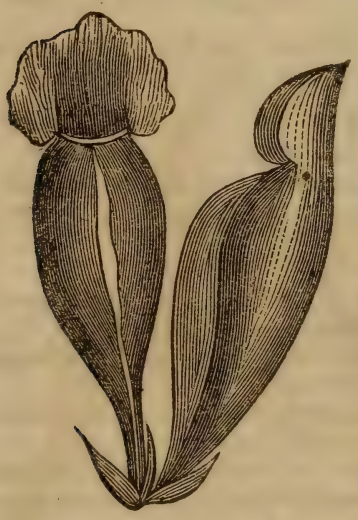

67.

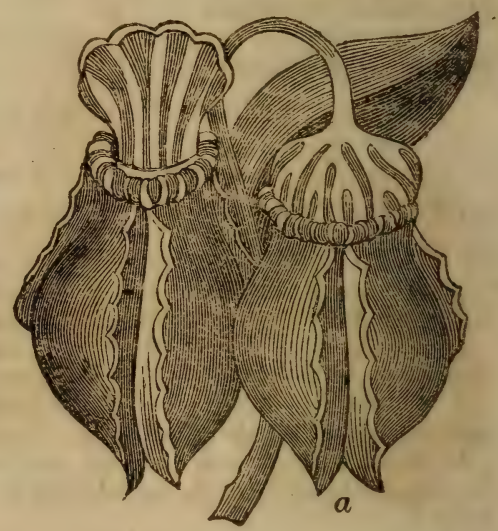

\section{CAULINIR ASCTDIOM.}

123. The Cepralotus Folurcularis, an Australasian plant, besrs pitchere, which grow entangle with the leaves of the plant, forming a circle around the base of each footstalk. It hangs on a curved, projecting petiole; but supported in such a manner that its cavity is upright. The pitcher itself (Fig. 67 ,) is nearly egg-shaped, an inch in length, and furnished with a lid. The outside is crnamented with three coulle costre (a) proceeding from a crested lip. These costæ are projecting, with reute pilose margins, and extend downwards below the bottom of the pitcher. The mouth congists of a ring which gives origin to a number of parallel rib-like processes, which are curved inwards over it by their vppex extremities. The greater part of the inside is shining, and of a besulfful dark purple color. The lid, which is produced from the petiole, and attached to the edge of the piteher by a broad base, is slightly pubescent on the outside, smooth within, and of a green color, printed with broad, branching, dark purple reing. "The pitcherg are generally half filled with a watery fluid, in which great ñmbere of a masl ppecice of axts are frequently 
found drowned. This fiuid, whil has a slightly sweetish taste, may possibly bo in part a secretion of the pitcher itself, but more probably consists of rain water receired and preserved in it. The li 3 , in its full grown state, is found aceurately closed, or standing erect, therefore; leaving it entirely open. It is not unlikely that the position of the lid is determined by the state of the atmosphere, or even by other external causes."

124. The Discardia, a twining plant, native of tho foresis of India, bears cauliner ascidia, presenting at the sam 3 time one of the most wonderful provisions in the vegetable lingdom. It is destitude of leares except near its top, which elimbs to the summit of the tallest trees, 100 feet or more in height from its roots. The pitelers (Fig. 68,) are formed of a leaf with its edges rolled toward each other, and adherent; its mouth or upper end is open to receive whatever water may fall into it, of which they always contain a considerable quantity. But the most singular vart is its absorbent fibres, resembling perial roots, which are sent out from the ncarest parts of the stem next the pitchers-entwining them, and spreading thetis s? through the carity, thus supplying the stem with moisture,

68.

69.

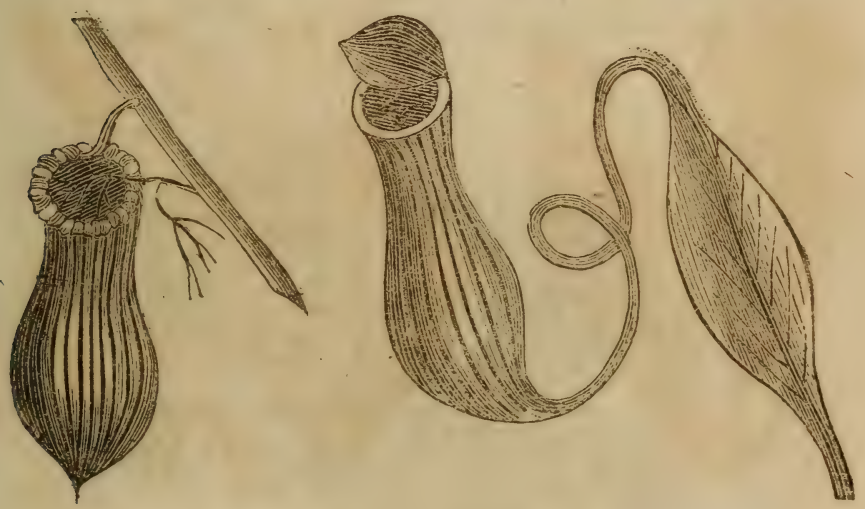

TOLIAR ASCIDIA.

125. The foliar ascidia is peculiar to the genus Nepenthea. In the Neprivrars Distillutoria (Fig. 69, a native of the East Indias, the petiole is first dilated into a kind of lamina, then contracted into a tendril, and fually dilated into a pitcher, furnished with a leafy lid, connceted to it by a ligament wlitil expands and contracts according to the state of the atmosphere, being open in damip weather, and closed when the weather is dry. The pitcher, in the early stage of its growth, is of the same color as the leaf; but, as it advances in age, it becomes beautifully colored with dark, purplish-red streaks and blotches. They vary greatly in size, and in some species the pitchers are capable of holding more than a pint of fluid, with which they are generally filled.

126. One of the most extraordinary productions of the regetable kingdom, is found in the VERUS FLY-TRAP (Dionsea muscipula,) a native of South Carolina. The leares of this plant (Fig. 70,) are radical, sessile, and nearly spatulite in form ; the inidrib, however, is produced beyond the apex of the leaf, and supports an appenditge which has some resemblanice to si steel trap. It consists of two lobels, bonderid 
with bristly spiues resembling tecth. The superior disk of each lobe is studded with minute glands, and furnished with three erect little spincs, placed so as to form an equilateral triangle with the apex, pointing toward the midrib which unites the lobes. This appendage is endowed with so much irritability, that as soon as a fly or other insect touches any of the glands, the lobes immediately close upon it, and the spines either impale it, or the tecth on the edges of the lobes, crossing cach other, prevent its escape.

70.

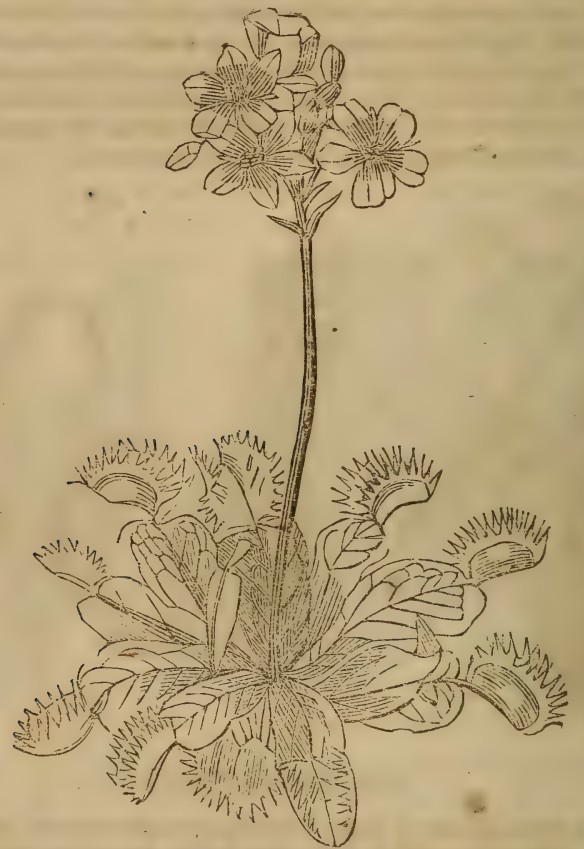

127. Stripules (Fig. 71,) are foliaccous appendages which in some instances accompany the proper leaves, yet are distinct from them ; and in others, they are attached to the base of the petiole. They are not universal, but their presence or absence is commonly uniform throughout each Natural Order. They usually have the texture and color of leaves, are subject to the same laws of venation, and perform the same functions. Like leaves, they are sometimes membranaceous, leathery, or spiny. When they are adherent to the petiole, one on each side, they are said to be adnate, as in 
the Rose, Strawberry, and Clover. Sometimes they are free from the petiole, but adhere by their outer margins, so as to form an apparently single stipule opposite the leaf, as in the Platanus or Button-wood. In other cases, both margins unite, forming a sheath around the stem (called Ochrea,) as in the Polygonacee or Buckwheat family.

128. In some instances, they are fugacious, accompanying the leares in the bud, and falling away when they expand, as in the Magnolia and Oak families; in others, decictious, falling with the leaves, which is the most common occurrence; and in others, again, they are persistent, remaining after the fall of the leaves, as in the Cocoloba pubescens.

129. Leares that are furnished with stipules, are said to be stipulate; and when destitute of them, they are exstipulat. $W$ hen the leaflets of compound leaves are provided with small stipules, they are said to be stipellate, as in the Bcan.

71.

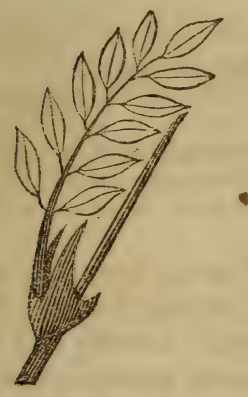

个2.

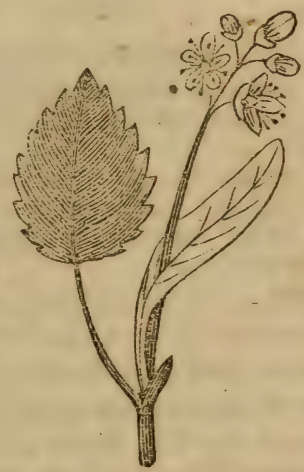

130. Bracts (Fig. 72, )are foliaceous appendages, intermediate between leares and the floral organs; they appear in the vicinity of the flower, distinct from the perianth, and in some instances exactly resembling leaves, but in others differing from them, both in form and color. In some instances, the gradation from the proper leaves to bracts is scarcely perceptible, as in the Purple-topped Clarry (Salvia Hominum.) Painted Cup (Castilleja coceinnia,) \&c. ; but the bract may be truly foliaceous, and yet differ considerable in figure from the leaves of the plant to which it belongs. In the Linden (Tilia Americana,) the leares are heart-shaped, while the 
bracts are linear-oblong, attached to the base of the peduncle, and of a yellowish color.

131. When bracts are arranged in a whorl, surrounding several flowers, they constitute an involucre, which is generally green, as in the Phlox, but sometimes is colored, as in the Cornus Florida, and Canadense. When it is situated at the base of a compound umbel, (Fig. 81,) it is called a general involucre, and at the base of a partial umbel, a partial involucre or involucel, both of which are scen in the Umbeliferæ,

132. In compound flowers, the involucre consists of imbricated bracts, often in several whorls surrounding the base of the heads, as the calyz surrounds a simple flower. In the Grass family (embracing Wheat, Rye, Oats, \&c.,) the bracts are called hushs, or chaif, to which is attached the awn, or beard. The bracts situated at the base of a spikelet of flowcrs, are called the glume, corresponding to the involucre.

\section{DURATION OF LEAVES.}

133. In view of their duration, leares are said to be-

1. FUGACIOTS, when they fill of soon aftur their first appearance.

2. Decintous, when they last for a single season, and fall in autumn, as the Oak, Maple.

3. PrRsistent, or Evengreen, when they remain through the cold season, and until after the appearance of new leaves, so that the sicm is ncrer leafless, as the Pine, Laurel. Accordingly with the last two d:stifictions, lenyes are eaid to the Deciduous or Eiergreen.

134. Defoliation, or the fall of leaves, is owing to the formation of an articulation, or joint between the base of the netiole, and the stem on which it rests. During the latter part of the summer, the tissue of the leaves become gradually hoked by the deposition of eartly matter, which obstructs the exhalation, and finally unfits them for the performance of their functions, consequently they lose their vitality, ory un, and are finally cast off.

\section{PHYSIOLOGICAL STRUCTURE OF LEAVES.}

135.- The organs of leaves are in general composed of three distinct parts: one part firm, and apparently ligneous, constituting the frame work or skeleton of the leaf, another, succulent and pulpy, fills up the intermediate spaces, or mesh-

- es, of this frame work; and a third, a thin, cuticular expansion, inclosing the other two, forming the epidermis, or covering for both surfaces of the leaf. 
136. The FRAME WORK or vascular portion of the leaf (Fig. 24,) is composed of vascular tissue and spiral vessels, which fulfil the same office in the leaf as in the stem, not only giving firmness and support to the delicate cellular apparatus, but also serving for the conveyance and distribution of the sap. These veins divide and subdivide far beyond the limits of unassisted vision, until the threads of woody tissue are reduced to separate fibres ramified throughout the green pulp, so as to supply every portion with the sap they contain, which, having reached the utmost limits of the edge of the leaf, double back upon themelves, pervade the lower surface, and are again collected into the petiole, through which they are finally returned into the bark, constituting the vessels of the latex.

73.

74.

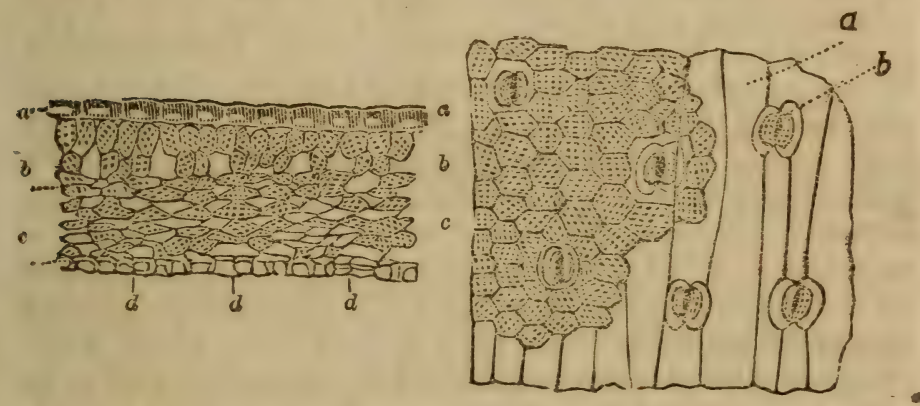

137. The celiular portion, or parenchyma, exists in two layers, arranged upon a regular plan, which varies in different parts of the leaf, according to the different conditions in which it is placed. In all those leaves which expand horizontally, one surface being turned upwards and the other downwards, these two layers are dissimilar in structure; but in those leaves where the lamina is vertical, as in the Iris, they do not materially differ. The upper stratum is composed of one or more compact layers of oblong cells, placed in such a position that their long diameter is perpendicular to the upper surface, (Fig. $73, b . b$.) while the lower stratum is composed of oblong cells arranged longitudinally, and so loosely compacted as to leave numerous vacant spaces between the cells $(c . c$.$) , which communicate with the air by means of the$ stomato or breathing pores, (Fig. 74, a. b.). 
138. The EPIDERMIS of the upper surface, consists of flattened cells, arranged in a single layer (Fig: $73 ; a . a$. ); except in plauts of hot and arid regions, in which case it is often double, and very compact; and in the Oleander, a native of Barbary, it consists of thrce layers of very thick sided cells. The cells of the epidermis of the lower surface, are also arranged in a single layer, provided with stomato (Fig. $73, d . d . d$.$) , opening into air chambers.$

139. Within all the vescicles of the parenchyma, are seen adhering to the walls, the green globules called chlorophyll (green leaf,) which give color to the parenchyma, dark green above, where it is more compact, but pale berreath, where tho cells are more loose and separate.

140. The sтomato (Tig. 74, a. b.), are generally found on the lower surface, except in leaves that liave their lower side in contact with the surface of the water, as in the Nymphaæ (White Pond Lily,) in which case they are found upon the upper surface; and in those leaves whose position is naturally vertical instead of horizontal, they are found equally on both sides. Through the stomato, exhalation principally takes place; they are situated so as to open directly into the hollow chambers, or air cavities, which pervade the parenchys ma, so as to afford free communication between the external air and the whole interior of the leaf. The orifice is guarded by two oblong cells, firmly fixed at their ends, which, when the air is moist becom? turgid, and in elongating, diverge or curve outwardly in the middle, so as to allow a free cornmunication between the outer air and the interior of the leaf. When the atmosphere is dry, they incline to shorten and straighten, so as to bring the sides into contact, and close the orifice completely. The action and use of this machinery will be readily understood. So long as the leaf is supplied with a sufficiency of moisture, the cells that guard the orifice are expanded, and allow the free escape of moisture by evaporation. But when the supply fails, and the parenchyma begins to be exhausted, the guardian cells quickly collapse, and by closing those thousands of apertures check the drain the moment it becomes injurious to the plant.

141. The number of stomato varies in different leaves, from 800 to about 17,000 on the square inch. The leaf of the Apple is said to contain about 24,000 to the square inch, so that each leaf would present about 100,000 of these orifices, 
From their great number, they are doubtless adequate to the office that is attributed to them, notwithstanding their minute size.

\section{FUNCTIONS OF IEAVES.}

142. The functions of leaves are absorption, exhalation, respiration, and assimilation. By the combincd action of these functions, crude sap, absorbed from the soil by the roots, is prepared for the nourishment of the plant ; carbonis acid-absorbed from the atrasphere and from the soil-is decomposed; solid carbon becomes fixed in the substance of the plant, and oxygen gas is evolved.

143. ABsorptron is primarily the office of the root, but is carried on to some extent by the leaves. A plant or a part of a plant, exposed in a humid atmosphere, will absorb moisture, and increase its weight, until it dics. In like manner, plants, parched by the droughts of summer, are revived by the showers which moistcn their leaves, but do not reach their roots. This is further evinecd by the fact that plants having thick and succulent leaves (as the Aloes and Cactus, natives of hot climates, and growing in dry, arid soils, ) perapire very little, while they absorb powcrfully by the whole surface of their leaves.

144. Exhalation in plants, in some respects is analogous to insensible perspiration in animals. In this process, the sap becomes concentrated, giving off its superabundant water to the atmosphere, and containing in consequence a greater proportion of solid matter.

Exhalation eridently takes place through the stomato alone; and sinoe these ara opened $b_{y}$ the influence of the light and closed in the absence, it follows that exhn lation can procecd only in the presence of the light.

During actire vegetation leaves exhale much water; the quantity rarics, however, with the degree of warmth and exposure to the light. A plate of gliss, held near the under surface of an active leaf of the Hydrangen, when the atmosphere is still, is presently covered with moisture, but it rcmains dry if the glass be held over the upper surface. When light is suddenly excluded from a plant in a state of active growth, it immaliat: ly cesses to exhale, whatever may bo the temperature of the atmosphore surrounding it. The stomato will then, on examination, be found alosod.

145. Respiration in plants consists, essentially, in the absorption of carbonic aeid gas from tho air, and the crolution of oxygen. It is, liowever, only by a metaphor that this function of leaves can be calted respiration, for the evolution of oxygen is a necessary rantt of assimilation, or the formase 


\section{tion of organic matter, while the respiration of animals is} part of the process of decomposition of organic matter.*

The absorption of carbonic acid from the atmosphere, is as necessary to the existence of plants, as is respiration to the support of animal life. Formerly, respiration in plants was considered analogous to respiration in animals, and that plants in respiring, absorb and retain oxygen and evolve earbonic acid, or like them vitiate the atmosphere by their respiration, while they purify it bv their digestion. Recent experiments and observations, however, prove this theory to be unfounded." This error arose from the circumstance that plants can only decompose carbonic acid under the influence of light; oxygen is therefore not exhaled during the night, but on the contrary a small quantity of carbonic acid may escape, and oxygen be absorbed, but this process is very different from the respiration of animals; that of plants is mechanical, while that of animals is chemical, both totally unconnceted with the assimilation of food. When the soil abounds in carbonic acid and moisture, the roots must continue constantly absorbing that moisture, mixed with the earbonic acid; and this aeid, rising into the leaves, may eseape in its original state, when light is not present to decompose it. The absorption of oxygen is a cheraieal process, which appears to go on when the process of assimilation has ceased operating, in dead plants as well as in living ones.

\section{Assimimation or Digestion in plants consists,} properly, in rendering the crude sap fit for the purpose of nutrition, the decomposition of carbonic acid by the green tissue of the leaves under the stimulus of light, and the fixation of solid carbor.

147. The sap in its crude state, as imbibed by the roots, is more or less changed in its ascent, by dissolving the soluble, organized matter, with which it comes in contact; thus becoming sweet in the May Apple, and acquiring different sensible properties in different species. By this change, the sap becomes elaborated, and fitted to be consumed in regetable growth. Sap in a crude state is mere unorganized mineral substance, and thus incapable of composing a part of the living. structure.

148. The crude sap is, however, soon converted into an organized substance by the solar light, under whose wonderful influence the vegetable fabric is constructed, and the chlorophyll, or green matter of plants, is developed. Plants growing where the light is insufficient, do not derelope ehlorophyll, as may be seen in the shoots of Potatoes growing in cellars. It will be seen, therefore, that light exerts an important influence on vegetable digestion.

149. Light has also an agency in the essential process of vegetable digestion, by its action upon the sap concentrated in the leaf, and upon the air abserbed in respiration. This agency is exercised, Ist, in the chemical decomposition of one or more of the substances contained in the sap which contain oxygen gas, as well as of the carbonic acid in the air; and by the liberation of the oxygen contained in

\footnotetext{
* There is a characteristic difference between vegetab!es and animals: "The tissue of the latter continues to live and act during the life-time of the animal, and therefore require constant interstitial renewal by nutrition, new particles replacing the old, which are removed and restored to the mineral world by respiration; while in plants there is nosuch renewal, but the fabric once completed, remains unchanged, ceases to be nourished, and consequently snon loses its vitality; while new parts are continually found further on to take their places, to be in turn aurain abandoned." Plants, therefore, having no decomposition and recomposition of any com. pleted fabric, can not have a function of respiration like that of animals,
} 
the sap and in the air, at the ordinary temperature of the atmosphere. This agrney Is exercised, $2 \mathrm{nd}$, by the fixation of this carbonic acid in the form of solid carbor, and by the transformation of this inorganic matter into the organized living subatence of plants.

150. Carbonic acid gas, which is prejudicial to animal life, is indispensab?e to the nourishmest anl growth of plants. Hence, while plants are alsorbing their own peculiar nutriment from the atmosphere, they are at the same time purifying: It, and fitting it for the support of animal life. This they accomplish both by pre- venting a constant increase of carbonic acid gas ire the atmosphere, ari-ing from tho decomposition of regetable and animal substance, and from combustion, as well a: by restoring to the atmosphere oxygen gas, an element indispensable to anims life. Thus by a beautiful arrangement of Providence, the two organic kingdoms o? nature materially sustain each other, being so adaptcd, the one to the other, that cach remores from the atmosphene shat were noxious to the other, and each yiclds to it what is essential to the otleer's continued existence. 'This is but one of a thousand instances in nature of reciprocal adaptations of means and endis, affording us the clearest proof of wisdom and design.

\section{ORGANS OF REPRODUCTION.}

151. The organs of reproduction are those designed for the continuation of the species. Every plant in its natral state posesses some means of reproducing its kind, but these differ very much in the various tribes, from the simple evolution of new cells in the Cryptogamia, to the more complicated apparatus in the Phænogamia. They consist of the FLower, and the parts developed from it, namely the Fruit and the Seed.

152. Flowers, like branches, are evolved from buis. Flower-buds are formed in the same situation as leaf-bude, at the apex of the stem or branch(s, and in the axils of the leaves.

\section{INFLORESCENCE.}

153. The term inflorescence is used to designate the ar. rangement of flowers upon the stem or branches.

154. The simplest kind of infloreseence is that of a solitary flower, either terminating the stem, as in the Tulip and Erythronium, or when it arises from the axil of a leaf representing an axillary bud, as in the Brassenia and leafy-stemmed Violet. These two simple cases exhibit the two types, to the one or the other of which all the forms of infloreseence belong.

155. If the flower is supported by a naked stalk, it is ealled peduncled, but when it rests directly in the axil of the leaf, or is not raised on a proper stalk, it is said to be sessice. 156. The PkDuncLi may be either simple, or branched, 
when it is divided into branches, each of which bears a single flower, these branches are called pedicels.

157. A ScAPE is a flower-stalk which springs directly from the root, or a subterranean stem, as in the Dandelion, sarrecenia, and Hyacinth. Like the peduncle, it is leafless; or with bracts only, and may be either simple or branched.

158. The RACHIS is that part of the general peduncle along which the flowers are generally borne, sometimes called the axis of inflorescence.

159. In centripetal inflorescence, the blossoming or expansion of the flowers commences with those of the base, and proceeds towards the summit, or from the circumference to the centre, as in the Cruciferæ and Umbelliferæ families. It will be readily understood that the circumference of a flattened or depressed inflorescence corresponds to the base of an oblongated one; the centre of the former answering to the summit of the latter.

160. In centrifugal inflorescence, the blossoming commences with the terminal and central flowers, and proceeds towards the outside, or those of the circumference, as in the Hydrangea and Elder. This mode of inflorescence is generally indicated by the presence of a solitary flower, situated in the axils of the forked branches, as in the Pink tribe.

161. "These two modes of inflorescence are sometimes combined in the same plant, the general axis developing in the one way. Thus the heads of all the Compositæ are centripetal, the flowers expanding regularly from the margin or circumference to the centre; while the branches that bear the heads are developed in the centrifugal mode, the terminal or central heads first coming into flower. This is exactly reversed in all the Labiatr (plants of the mint tribe,) where the stem developes in the centripetal mode, and the axillary clusters of the flowers being produced in the form of a general raceme or spite, which blossoms from below upwards; while the flowers from each cluster form a cyme, and expand in the centrifugal manner."-Gray.

162. The following are the principal rarieties of contripetal inflorescence-the spike, raceme, corymb, umbel, head, spadix, ament, panicle, and thyrse.

163. Sprke (Fig. 75,) is an inflorescence, where the sessile flowers in the axils of the bracts are arranged along an 
elongated commom peduncle, as in the Plantain, Vervein, Mullein.

75.

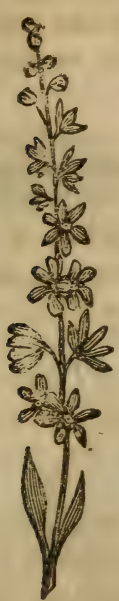

76.

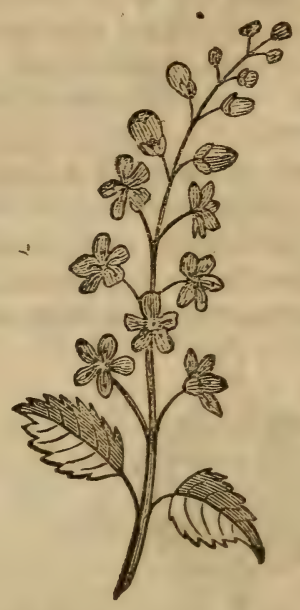

164. The RACEME (Fig. 76,) is the same as the spike, except that the flowers are raised on pedicels; as in the Wild Cherry, Hyacinth, Pyrola.

165. The Corymb (Fig. 77,) is the same as the raecme with the lower pedicels elongated, so as to elerate all the flowers to nearly or quite the same level, as in the Hawthorn, Crab-Apple.

77.

78.

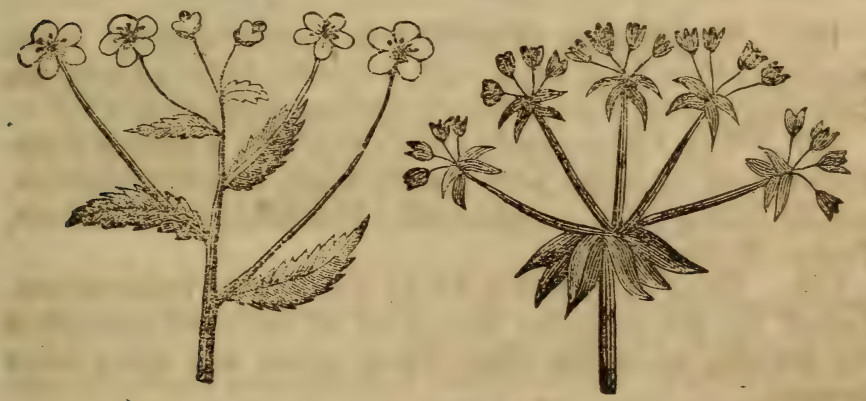

166. The Umbel (Fig. 78,) only differs from a corymb 
in having all the pedicels arising from the same point, and are mostly equal in length, as in the Asclepias, Cowslip, Primrose, and the Umbelliferæ generally.

167. A HEAD (or Capitulum, Fig. 79, is the same as an ambel with the pedicels all shortened, so as to bring the flowers all into a close rounded head, as in the Clover, Buttonbush, Teasel.

The axis or rachis of a head is called the receptacle. Frequently, instead of being at all prolongated, it is flat and dilated longitudinally, so as to allow a large number of flowers to stand on its level surface, as in the Sunflower, and the Gompositæ (compound flowers) generally.
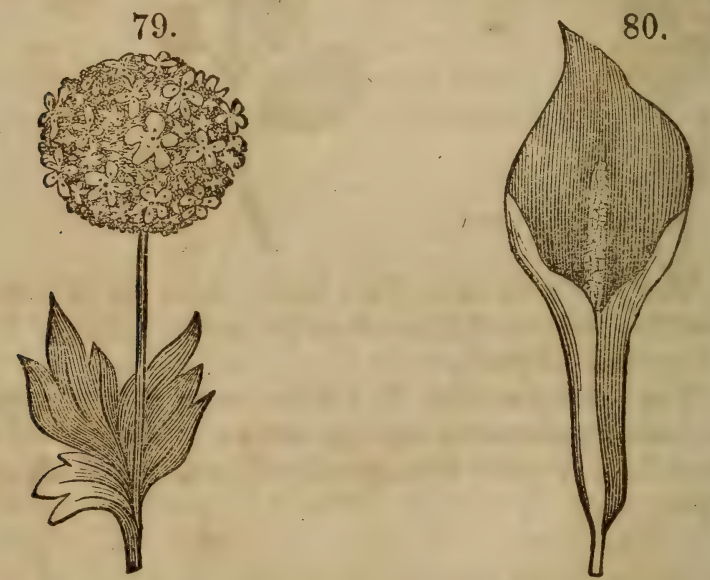

168. The Spadrx (Fig. 80,) is mercly a fleshy spike, onveloped by a large bract, called Spathe, as is seen in the Ethiopean Calla, Indian Turnip (Arum triphyllum.)

169. The Ament or CatKin (Fig. 81, ) is merely a particular kind of spike with a scaly bract, crowded together, asually falling off in one piece after flowering, as in the Birch, Poplar, Willow, Alder.

170. The Panicle (Fig. 82,) is a compound inflorescence, formed by the irregular branching of the lower pedicels of the raceme, as in the Oats, Spear grass, and many other Grasses.

171. The Tryrse (Fig. 83, is the same as the panicle, arring the lower branches shorter than those in the middle, 
and all of them very compact, as in the Lilac, Horse Chestnut.
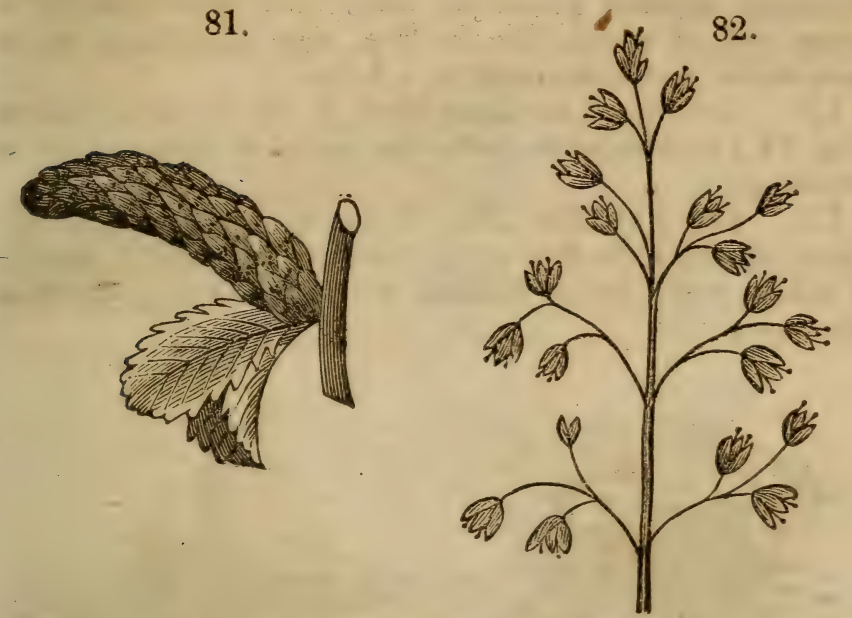

172. Of the Centrifugal inflorescence, the following are the principal varieties: the cyme, fascicle, and vertical.

83.
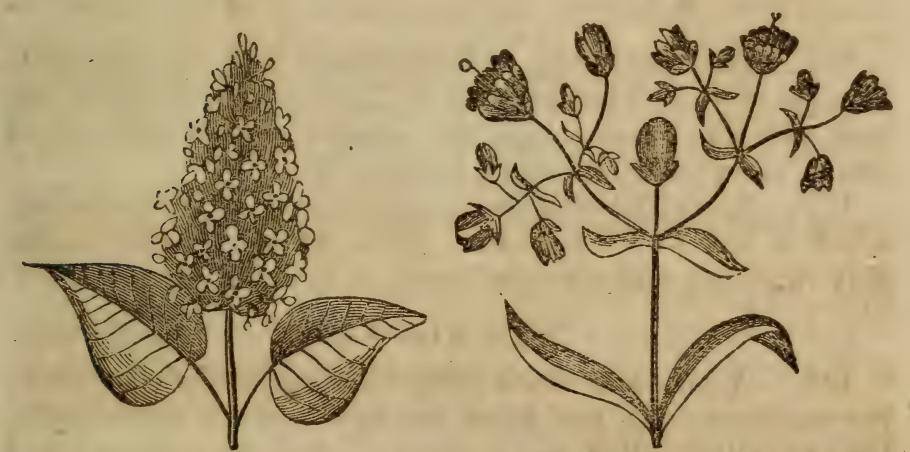

173. The Cyмe (Fig. 84, ) has the general appearance of the Corymb, but is remarkably distinguished by its centrifugal evolution, and by its branches being repeatedly 2 or 3 forked, as in the Hydrangea, Viburnum. This mode of inflorescence is only found in plants with opposite leaves, and is developed in the following manner: 
The terminal flower, which expands first, is borne upon a peduncle of two or more nodes; from these nodes, pairs of econdary opposite peduncles arise, each terminated by a flower, each of which, like the first, may again have two or more nodes, and terminated by a flower,

174. The Cyme as exemplified in the Arenaria stricta (Fig. 84, ) enables us to study this mode of inflorescence to advantage.

175. The FAscrche (Fig. 85, is a modification of the Cyme, in which the flowers are crowded, and nearly sessile, as is seen in the Sweet William, and Wild Pink, (Dianthus armerius.)

85.

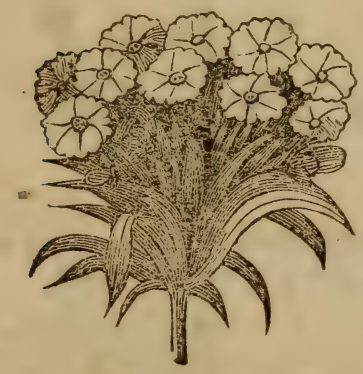

86.

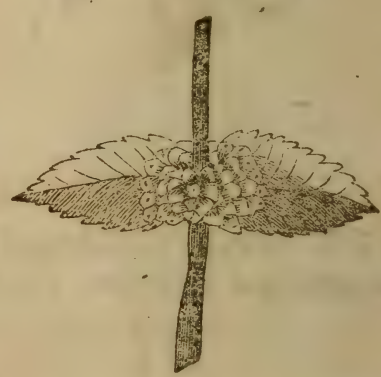

176. The VerTICAL, or Verticillaster (Fig. 86,) is a modification of the Cyme, peculiar to Labiate plants, where two much reduced Cymes occupy the opposite axils of cach pair of leaves, as in the Horehound, Catnip, Mint.

177. Verticillate flowers are sometimes said to be whorled, which is not really the case. True whorled flowers occur only in plants with whorled leaves, as in the Hippurus.

\section{THE FLOWER.}

178. A complete flower (Fig. 87,) consists of the follow. ing members: 1st, the floral cnvelopes, called, collectively, the PERIANTII. 2nd, the staMeNs. 3rd, the PISTILS; and 4 th, the RECEPTACLI, or TORUS.

179. The floral envelopes consist of one or more circles $\mathrm{cr}$ whorls of leaves surrounding the essentiol organs, namely, the stamens and pistils. The outer envelope is called the ealyx, and its leaves are termed sepals. The inner is called corolla, and its leares petals. 


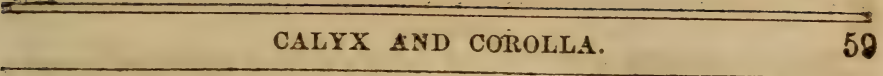

87:

88.
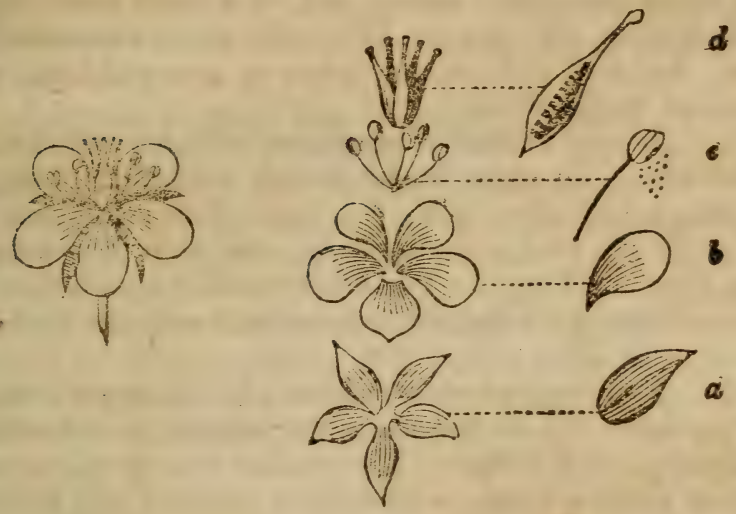

(E:g. 85,) idaal plan of a flower like that shown in (Fig. 87); the different sets of of gans separate d to some distance from each other, to thow the relative situation of the parts; one of each, namely, a. a sıpal, b. a petal, c. a stamen, and d. a pistil.

\section{CALIX.}

180: The Calyx (from the Greek kalix, a cup,) consists of a whorl of loarcs with their edges distinct, or united, generally green, but sometimes highly colored. When the sepals are united so as to form a more or less perfect tube; it is said to be monosepalons or ganosepalous. The lower part is called a tube. When the sepals are separate and distinct, it is polysepalous. When it adheres to the ovary, and invests it, it is said to be superior, and when no such combination takes place, it is said to be inferior.

181. In respect to duration, it is caducuous when it falls off as soon as the flower is expanded; deciduous, when it falls off as the flower decays; and persistent, when it remains after the corolla has fallen.

182. The calyx is sometimes reduced to a whorl of mere hair-like processes, called pappus, or down. This kind of calyx is peculiar to the Compositæ (compound flowers.) If the pappus consists of simple hairs, it is said to be pilose; if the hairs are feathery, plumose; if bristly, setose; and if chaffy, foliacuous.

COROLLA.

183. The Conolua, (Lat. corolla, diminutive of corona 
a crown,) the interior envelope of the flower, consists of one or more circles of leaves, either distinct or united, usually of some other color than green, and of a much more delicate structure than the calyx. When the petals are united into a tube, it is said to be monopetalous or yamopctalous; when not united, polypetalous.

184. A petal consists of two parts ; the claw and the lamina or limb. The claw is the narrow part at the base, corresponding with the stalk of a leaf. It is sometimes very long, as in the Pink and Saponaria, and often is wanting, as in the Rose and Poppy. The lamina is the expanded portion, supported by the cliw, and corresponds with the blade of a leaf.

185. A monopetalous corolla may be regular or irregular. It is regular when all the parts correspond to each other in shape, size, and cohesion. The regular monopetalous corolla assumes various forms, which have received the following names:

1. Companulate (bell-shaped, Fig. 89, when the tube of the corolla is wide and swelling abrubtly at the base, as in the Canterberry bell, and Harebell.

2. Infundibulifori (funnel-form, Fig. 90,) when tubulor at the base, but gradually enlarging towards the border, as in the Morning Glory and Four-o' clock.

89.

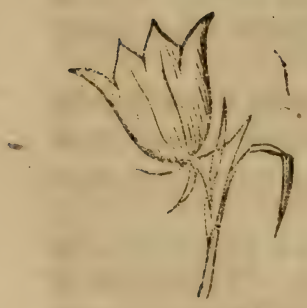

90.

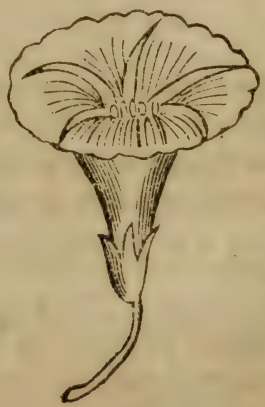

91.

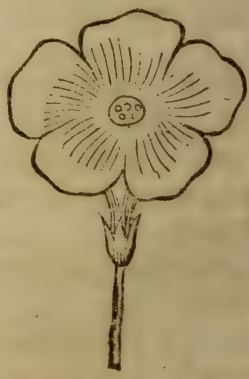

3. Hypercrateriform (salver form, Fig. 91,) when the tube ends abruptly in a border spreading horizontally, as in the Phlox and Primrose. 
4. Rotate (wheel-form, Fig. 92,) when the limb is regular, or nearly so, spreading with a very short tube, as in the Mullein and Lysimachia.

186. It is irregular when the incisions are not uniform, and the opposite sides are not arranged on the same axis. The irregular corolla is-

1. Labrate (lipped, Fig. 93,) when the limb is deeply cleft into two irregular segments, called the upper and lower lips. When the lips are widely separated, and the throat open, it is called ringent or gaping, as in the Monkey flower. When there is an appendage between the lips like a palate, so as to hide the interior, it is called personate from persona a mask, as in the Snap-dragon and Toad-flax. If the upper is arched, it is termed the galea or helmet, as in the Sage, Lavender, and Catmint. This form of the corolla is characteristic of plants of the Labiatæ, (Mint Family.)
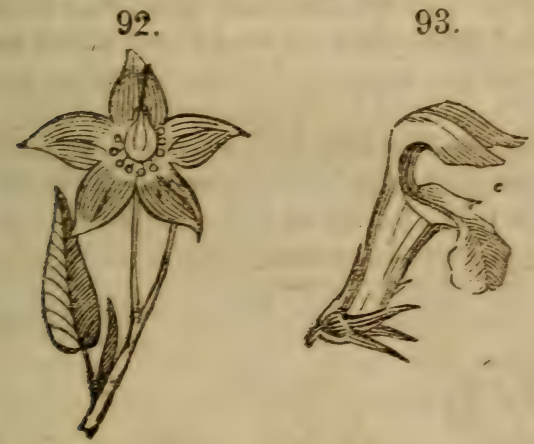

93.

94.

187. A polypetalous corolla also may be regular or irreg ular. The lower part of the petal is called the claw, and when this is well marked, they are said to be unguiculate; the upper and spreading portion is termed the lamina or border.

Regular polypetalous corollas have receired the following names :

1. Cruciform, (Fig. 94,) when there are four petals spreading at right angles to each other in the form of a cross, as in the Mustard, Radish, Turnip. Plants with this corolla constitute the Natural Order Cruciferæ, corresponding to the elass Tetradynamia in the Linnean arrangement.

2. Rosaceour (like the rose, Fig. 95, when the corolla W 
is regular, consisting of five or more petals, attached to the receptacle with little or no claws, as in the Rose, Apple, and Cherry.

95.

96.
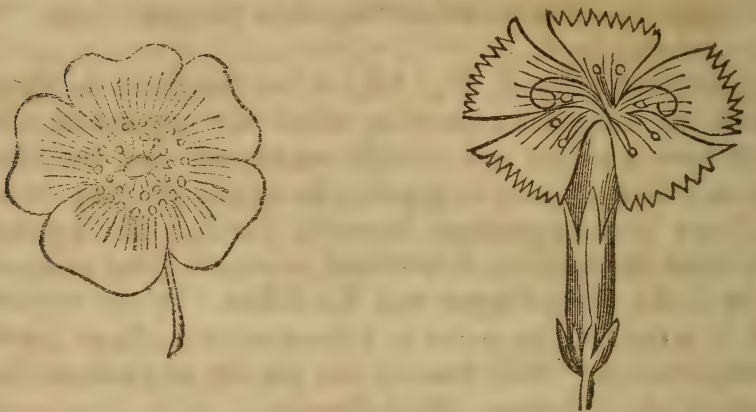

3. Caryophyluaceous, (like the pink, Tig. 96,) when the corolla eonsists of five petals, having long claws which are inserted into a tubular calyx, as in the Pink, Catchfly, and Rose eampion.

4. Lirmaceous, (like the lily, Fig. 97,) when the perianth consists of six parts, each of which curve outwards in the form of a bell, as in the Lily, Tulip, and Erythronium.

188. The irregular polypetalous corolla is-

97.

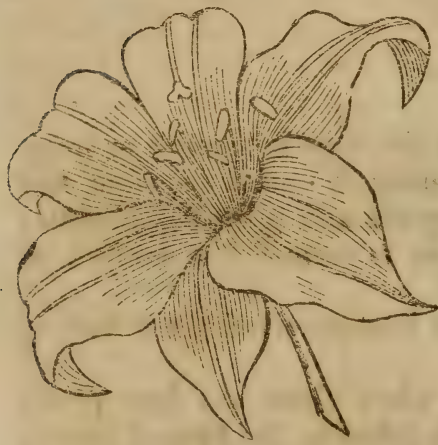

98.

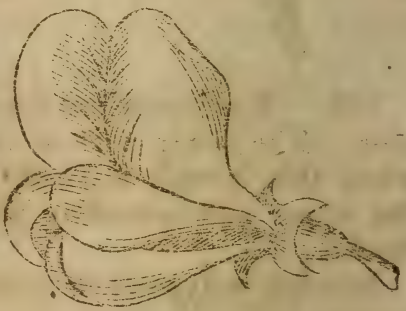

1. Papilionaceous (butterfly-shaped, Fig. 98, when it eonsists of five dissimilar petals, the upper end is called the Janner (vexillum); the two middle and lateral ones beneath the banner, the wings (alæ); and two lower ones, also parallel 
and cohering by their margins, the 7eel (carina); as in tho Locust, Pea, and Bean.

189. Petals are sometimes furnished with appendages on their inner sürface, such as the crown and the scale. The crown is situated generally at the summit of the claws, as in the Silene, Saponaria, and Lychnis. The scale is generally found on monopetalous corollas, as in the Comfrey, Myosotis.

190. "The bodies termed nectaries by the older Botanists, are either petals of unusual form, such as the spur of the Columbine, or petals passing into stamens, such as the fringe of the Passion-flower and of Parnassia, or else abortive and transformed stamens, as in Canna.

The so called nectary of Orchidaccous plants is merely on of the petals, which, being constantly of a different shape from the others, is termed the labellum or lip." - Gray.

\section{STAMENS.}

191. The StAmens, (Fig. 99,) are those slender organs, (b.) situated next within the floral, envelopes and around the pistils $(c$.$) . They vary in number from one to fifty, or$ one hundred. Their office is the fertilization of the seed. They are collectively called the ANDRFCIUM (from andres the plural of aner a man, stamen, and oilios a house). They eonsist of two parts, the filament and anther.
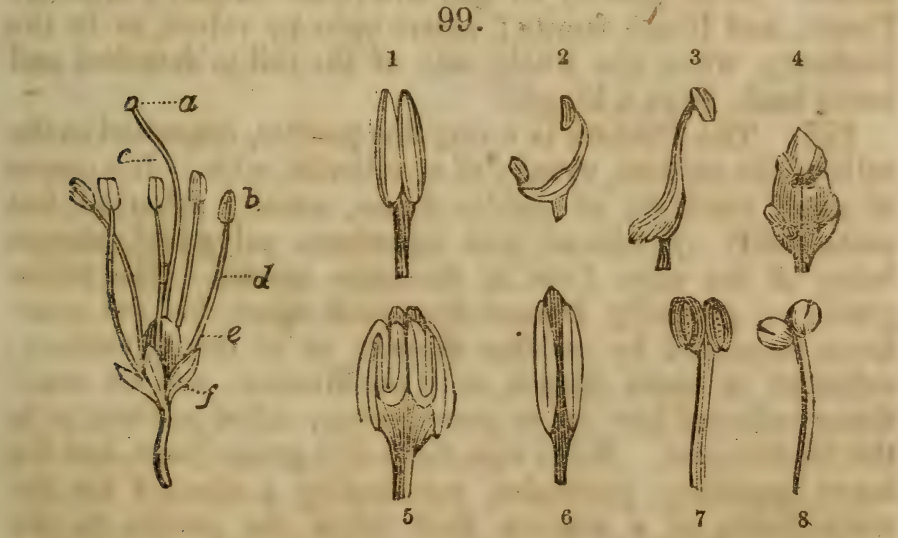

Stamens, pistils, \&c., $-a$, stigma; $b$, anthers; $e$, style; $d$, flament; $e$, orary ; $f$, calyx aud receptacle. Form of anthers-1, Lily; 2, Ginger; 3, Sage; 4, Berberร. ; 5, Cucumber ; 6, Magnolia; 7, Palygonum; 8, Lemaa. 
192. The Frlament, (Lat. filum, a thread, Fig. 99, d.,) is a long slender body which supports the anther, containing numerous spiral vessels. It is called prominent when it projects beyond the anther, petaloid when it is broad and thin; when it is wanting the anther is said to be sessile.

193. The ANTHER, (Fig. 99, b.) is generally situated at the summit of the filament; it is the essential part of the stamen, and contains the pollen. It usually consists of two lobes or cells, connected to each other and to the filament by the connectile.

It is attached to the filament in three principal ways; and is said to be-Adnate, when attached by its back, so as to appear lateral, as in the Nymphrea, and Anemone. Innate, when it is attached by its base, as in the Menispermum. Versatile, when it is attached by a single point, from which they hang loosely, as in the White Lily, and most of the Grasses.

When the filament is on the outside of the anther, so that the latter faces the pistil, it is called introrse, as in the Violet; when, on the contrary, the filament is attached to the inside of the anther so that it faces the pistils, it is said to be extrorse, as in the Larkspur.

194. The cells of the anthers usually open by a longitudinal fissure, called the dehiscence; but they also open by other modes. Some open by an aperture in the summit, as in the Potato, and Heath family; others open by valves, as in the Berberry, when the whole side of the cell is detached and turns back, as on a hinge.

195. The PoLLen is a very fine powder, contained in the cells of the anthers, usually of a yellowish color. It consists of small vescicles, of various forms, usually spherical, but occasionally cylindrical, and sometimes polygonal, always being of the same form in the same species. The pollen grains are generally distinct from each other, but are sometimes connected by cellular threads, as in the OEnothera; coherent in small masses, as in the Mimosa; and are sometimes collected into one or more groups, called pollinia, as in the Orchidaceæ. When ripe, the pollen grains burst, and the inner membrane protrudes, constituting a channel for the transmission of a mucous fluid called the fovilla, to the ovule.

- 196. The Foviula consists of minute particles of mole. 
cules of a spherical or oblong form, suspended in a fluid possessed of tremulous motion.

197. The Drsk is a ring, either entire or lobed, or a row of fleshy bodies, situated between the bases of the stamens and pistils: It is said to be hypogynous, when it surrounds the base of the ovary, as in the Peony; when it adheres to and lines tho tube of the calyx, perigynous, as in Rosaceous plants; and when it appears at the top of the ovary, where the calyx is superior, it is cpigynous, as in the Cornus, Aralia ; in this case, when confluent with the base of the style, it is called the stylopodium.

\section{PISTIL.}

198. The Pistius (Fig. 100,c.) occupy the centre of the flower, sometimes numerous, but often only one; collectively, they are called Graceum, (guna, a woman, pistil, and oikos, a house).

A pistil is composed of three parts-the stigma, the style, and the ovary.

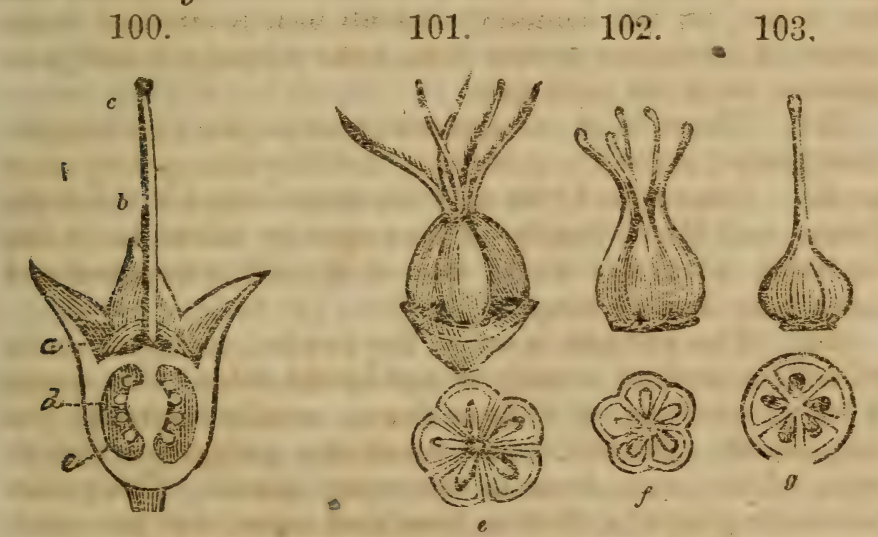

Fig. 100. Pistl of a Whoriluberry; $c$, the stima; $b$, the siyle; $a$, the epigynous disk: $e$, p.rpondicular section of the orary, combined with the sdherent (iuperio:) ealyx; $d$, th placente with the orules. Fig. 101, the gynaeium of a flower with 5 pistils showing the carpe:s and atylegitistinct; e, cross scction of the same; Fig. 10:, the carpols units.1 and the atyles distinct; $f$, cross section of the same; Fig. 10;, both carpeis and styles united; $g$, cross section of the samc.

199. The Stigma (Fig. 100, c.), is the upper portion, ar extremity of the style, usually globular, but varies considerable in different species. It is of a glandular nature, usually eovered with a viseid tluid, and is destitude of a euticle; being $\mathrm{F}^{*}$ 
sn esisential organ in reproduction, and it exercises a peculiar astion on the fecundatory pollen. It is called sessile when tho style is. wanting, in which case it rests immediately on the ovary.

200. The STrue (Fig. 100, b.) is the long cylindrical columm arising from the ovary, and is terminated by the stigma. The number of styles, always equals the number of the carnels, but where the carpels are closely united, the styles may be united, also, into a single compound column.

Whe number of distinct styles (or of stigmas, where the atyle is absent) constitutes the basis of the Linnoean artificial orders, into which the first thirteen classes are divided. - [See Classification.]

201. The Ovary (Lat. ovarium, a depository, Fig. 100,e.) is the hollow portion of the pistil, situated at its base, containing the ovules, or young seeds, within its cavities.

202. The orary is either simple or compound. When simple, it consists of a single sac or cell called the CARPET, (karpos, fruit). When compound, it consists of two or more auch carpels, united together more or less closely. Sometimes the eivision (dissepiments) formed by their contiguous sides are very crident, (Fig. 101,) being but slightly connec\{3a, while in othor cases all external marks of them disappear, (1ig. 103.)

203. In a whorl of simple ovaries, the line which represents the united margins wit the carpels is on the inner side, o: next tho axis. This line is called the inner or ventral aure (seam). A similar line down the back or out side, is callod tho dorsat suture.

204. The line or ridge formed by the union of the margin: ci the carpols, to which the ovules are attached, often projecting more or less into the cavity of the ovary, is called the placenta. Wach placentse necessarily consists of two parts, Jis belonging to each of the confluent margins of the carpels.

205. Whe placenta is central, when the carpels are developed around a central axis ; and parietal, when the dessepimenta are contracted so as to bring the ovules near or on the walls of the compound ovary.

206. When the bases of the stamens are inserted into the toj of the recoptacle, and the ovary forms no adliesion to the wider of the calyx, it is said to be superior, and the stamens ath calyz are inferior or hypogyneus; but when the ovary 
adheres to the side of the calyx, and the stamens and corolla are inserted into it or into a disk above the ovary, it is said to be inferior, and the stamens and corolla superior or epigynous.

207. The Ovules (Fig. 100, d.), are the rudiments of the future seed; they are of a globular form, attached to the placentæe either immediately, or by a short stalk; they vary in number. When there is one, it is said to be solitary; where their number is uniform and not numerous, definite; and where they are very numerous, indefinite. They also vary as to situation and direction, with respect to the cavity on which they are contained; they are said to be ascending, when fixed to the placentre above the base and directed upwards; horizontal, when they project from the side of the cell; pendulous, when their direction is downwards, and susperded, when they are affixed to the top of the ovary, and hang perpendicularly.

208. The ovules are almost always enclosed in the ovary. In the Mignionette, they are partially naked, and in the Coniferæ (Pine fumily) they are entirely so, the carpels being open or wanting, as is scen in the cones of the pines.

209. The ovule consists of a nuclers enclosed within two sacs called the primine and secunctine. Each of these sacs have open mouths; that of the primine is termed exostome, and that of the secundine, endostome; they are at first large and separate, but contract as the ovule becomes a seed, and are brought into contact; when the small aperture, or a scar indicating its position is still perceptible, it is called the foramen or micropyle. The eoats of the ovules are distinet and unconnected, ezcept at the base or point of attachment, to the funiculus (the stalk by which the ovary is attached to the placentæ,) where they are all perfectly confluent. This point of union is called the chalcua. Through the funiculus and chalaza, the orule derives its nourishment from the pla. centre.

\section{FERTILIZATION.}

210. In flowering plants, fertilization or fecundation takes place by the action of the pollen of the anthers on the pistils. This appears to be affected in the following manner : when the anthers discharge the pollen contained in their carities, through their dehiscence, into the air, the pollen grains come in contact with the stigma of the pistil, adbere 
to it by the glutinous secretion it exudes, and in a short time affects a remarkable change; the outer coat of the pollen-cell opening and allowing the inner coat to protrude in the form of a tube of extreme tenuity, filled with the fovilla; this passes between the cells of the stigma, and the loose texture of the style, until it reaches the ovary; in the meantime, a cavity, or sac, called the sac of the amnios, filled with fluid, makes its appearance in the nucleus of the ovule; and the foramen being brought into contact with the placenta, or in orthotropous ovules carried up to the summit of the cell, a pollen-tube enters the orifice, and the granules thus reach the nucleus. What further takes place is not known, but it is known that in a short time the embryo appears in the amniotic sac.

\section{RECEPTACLE.}

211. The ReCEPTACLe or TORUs is the summit of the flower-staik, out of which the floral organs grow, or cn which they are inserted, (in botanical language,) upon which they stand arranged in concentric whorls; the calyz at its very base, the petals just within or above the calyx; the stamens (androcium) next within the petals, and the pistils (gynacium) within or above the stamens, occupying the contre.

212. The receptacle varies considerably in cifferent plants. In the Nelumbo it is dilated into a large, top-shaped body nearly enclosing the pistils in scparate carities. In the Rose, it forms a lining to the urn-shaped tube of tho cillyx, and bears the numerous pistils on its concave surface. Sometimes the receptacle which elevates the ovary is prolonged more or less above them, and coheres with their styles, as in the Geranium and many allied plants. Sometimes two internodes are conspicuously developed, one between the petals and the stamens, the other between the latter and the pistils; so that the stamens appear to grow out of a long stalk which supports the ovary, as in the Spiderwort (Gynandropsis.)

\section{SYMMETRY OF THE FLORAL ORGANS.}

213. A perfect symmetrical flower is composed of four sets of organs, arranged in coneentric whorls. The number of sepals, petals, stamens, and pistils being the same, or multipliss of the same, throughout, and the size and form of the members of each set being likewise uniform; so that, if the 
sepals-be 5 , there should be 5 petals, 5 or 10 stamens, and as many pistils. The Flax and Crassula, afford good examples of a perfectly symmetrical flower. In this case, we have a calyx of 5 sepals, a corolla of 5 petals, an andræcium of 5 stamens, and a gynæcium of 5 pistils, and all the parts are regular and symmetrical, and in the former, also, distinet and free from each other.

214. But this plan is very much disguised and complicacated in different plants. The principal causes which probably interfere with and more or less disguise the typical plan of the flowers are-

1. The production of one or more additional whorls or sets of some of the floral organs.

2. The union of the parts of the same set by the cohesion of the contiguous margins.

3. The cohesion of the adjacent parts of different sets.

4. The non-production (suppression) of some of the sets altogether.

5. The non-production or abortion of some of the parts of one or more sets of organs.

6. The unequal developement, or unequal union, of different parts.

7. The deviations or changes in the form of the receptacle or axis of tho flower.

215. Several of these deviations from the typical state of the flower, do not interfere with its symmetry, a flower being termed symmetrical, when there are an equal number of parts in each series.-Gray.

216. In the typical or normal symmetrical plan, the organs of each set successively alternate with each other, that is, the sepals alternate with the petals, the petals with the stamens, and the stamens with the pistils. This regular alternation is taken for granted in botanical descriptions, unless otherwise expressed. When any exceptions to this plan occur, they almost universally run uniformly through the family; as in Rhamnaceæ, where the stamens stand opposite the petals, and in Primulaceæ, where they are opposite the lobes of the corolla.

217. The number of component parts of the whole flower, or of any set, is designated by the terms binary (in twos); trinary (in threes), as in most Endogenous plants; quater. nary (in fours ; quinary (in fives), the most prevalent mode in plants of the Exogenous atructure. Sometimes they are designated by the following: bimerous in 2, trimerous in 3, tetramerous in 4, pentamerous in 5, and hexamerous in 6 . 


\section{AESTIVATION.}

218. Aestivation (cestivus, the summer state, ) is the term used to denote the manner in which the several parts of the flower, especially the calyx and corolla, are arranged and envelope each other, while yet in the bud. By some authors, it is also called perfloration. The plan of perforation is best seen in a transverse section of a flower bud, made by cutting it in a horizontal direction.

219. There are two principal plans of restivation, the imbricated, or spiral, and the valvate.

220. The TMBRICATED is by fir the most common, and its variecies have received the following names:

- 104.

105.

106.

107.
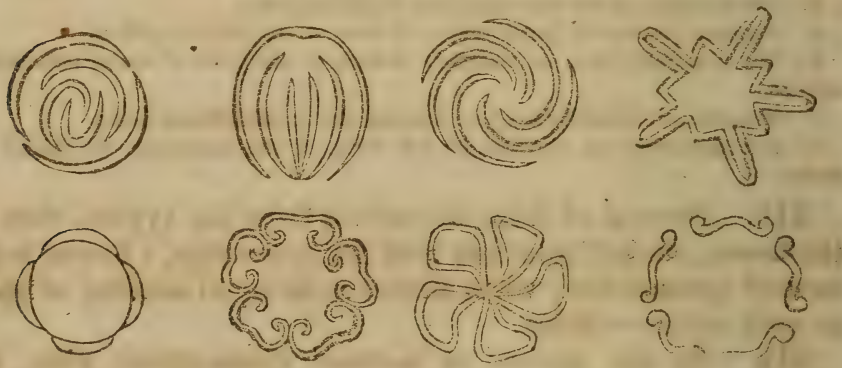

108.

109.

110.

111.

1. Quincunical (Fig. 104,) when the petals or sepals are five in number, two of which are exterior, two interior, and the remaining fifth envelopiug one of the inner by one margin, and has its other margin covered by the exterior, as in the Rose.

2. VBxildary (Fig. 105) when one part, called the rexillum, is wrapped around the other petals, they being arranged face to face, as in the Papilionaceous flowers.

3. Convolute, also ealled contorted or twisted, (Fig. 106,) where each piece is as it were slightly twisted on its axie, so as to have one margin interior and the other exterior, successively orerlapping, each othar, as in the petals of the Wall-flower, the lobss of the corolla of the Phiox, and the petals of Hypericum.

4. Plicate or plaited, (Fig. 107,) where a monopetalous corolis is thrown into plaits and folds, as in the Stramonia, and the Companuis. In the supervolute, the plaits are tristed, as in the Morning Glcry.

221. In the VALVUIAR mode of restivation, the sepals and petals are disposed in a true circle, and their edges are consequently brought into contact in the bud without overlapping; its several varieties have receired the following names: 
1. Valvate (Fig. 108, as in the Mallow tribe and Umbeliferæ.

2. INDEPLCATE (Fig. 1C9, this is a modification of the valvate, when the margins ars bent abruptiy inwards, and the external face of these applied without any twisting, as in the sepals of Clematis.

3. INvoLUTe (Fig. 110, when the margins are rolled inwards until they meet, as in the petals of Lysamachia.

4. REDUPLICATB (Fig. 111, when the edges are turned outwards instead of inwarde, as in the Potato.

222. The æstivation of the two sets of floral envelopes, frequently varies in the same plant. Thus in Malvaceæ, the rstivation of the calyx is valvate, that of the corolla contorted. In the Morning Glory and the Wallfiower, the calyx is imbricated, the corolla contorted. In the Cistacese, the calyx and corolla are both twisted, but in opposite directions.

\section{THE FRUIT.}

223. The fruit is composed of the ovary and its contents, arrived at maturity, and is the provision made by nature for the reproduction of the species, so that it may be justly styled " the termination of the old plant, and the beginning of the new." The fruit is therefore the most important part of the plant, its perfection being the ultimate object and ain of the whole vegetable organization. Although it does not possess the beauty of form and various tints of color of the flower; yet, besides its peculiar office of perpetuating regetable life, it affords one of the principal means of subsistence to the animal kingdom.

224. Sometimes it is dry and membranaceous, crustaceous, and even woody, or clse gradually changing to fleshy, pulpy, or juicy masses, but these are sometimes made up of the other organs, such as an adherent calyx, which, in the Apple and Pear, bocoming greatly thickened and flesliy, forms the principal bulk of the fruit. Sometimes the mass is made up of other organs, as in the Strawberry, in which the pulp is an enveloped and fleshy receptacle, bearing the numerous seeds upon its surface. The Pinc-apple is composed of a whole head or spike of flowers, with their bracts and receptacle all eonsolidated into a solid mass. The Fig lears its seed in a very singular manner, enclosed in a fleshy receptacle which is hollow and nearly closed at the top, resembling a curved cone in form.

225. The fruit consists of two parts, the corcring called the pericarp (peri around, larpos fruit,) or veed vessel, and the seeds. 


\section{PERICARP.}

226. The pericarp consists of three different parts, the epicarp, the outer integument or skin; the endocarp, or shell, and the sarcocarp, the intermediate fleshy or pulpy mass. Thus, in the Peach, Plumb, and Cherry, the outer skin is the epicarp, the hard shell which contains the seed is the endocarp, and the pulpy, fleshy mass between the two, the sarcocarp.

227. The fruit, when mature, often remains closed, as in the Acorn, Apple, Grape, \&c., when it is said to be indehiscent. In other cases it seperates wholly or partially into several pieces, and discharges the seed, when it is said to be dehiscent.

228. Regular dehiscence always takes place in a vertical direction, by the opening of one or both sutures, or by the disunion of confluent parts. The pieces into which a distinct pericarp separates, are called its valves. The several varieties of dehiscence have received the following names:

112.

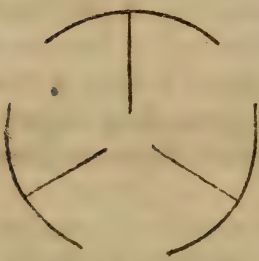

113.

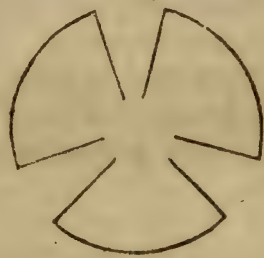

114.

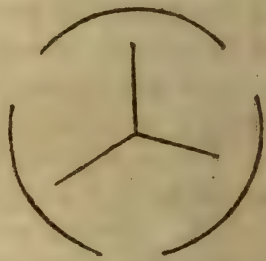

1. Locturcidal (Fig. 112, when the pericarp bursts vertically, the dorsal suture opening direetly into the cell, the parietal plscentæ in this case being borne direet ly in the middle of esch valve, as in the Lily and Rockrose (Helianthamum).

2. SEPTicid $A$ L (Fig. 113,) when the pericarp opens longitudinally through the dissepiments, the placentac occupying the margins of the valves, as in the Mallows.

3. Septrpragal (Iig. 114,) when the dessepiments remain coherent to the axis, and separate from the valves, as in the Morning Glory.

4. The pericarp may also open at one or both sutures of a single carpel, when it is called sutural, as in the Pea; or it may be porous at the apex, as in the Chickweed, Tobacco, and Primrose; and occasionally by mere points or pores, 2.8 in the Poppy.

229. An irregular dehiscence, called circumscissile, occurs in such fruits where the pericarp divides transversely, so that the upper part falls off like a lid, as in the Verbena, Plantain, and Purslane.

230. The pericarp is of various forms, which have been 
studied by Botanists with great attention, and minutely classified. The principal varieties are the following:

1. Capsule (Casket, Figs. 115, 116, 117,) is a general term for all dry and dehiscent fruits resulting from a compound ovary, opening at the sides, or top, by valves, as in the Hypericum, or bursting irregularly, as in Lobelia, or shedding the seeds through chinks or pores, as in the Poppy.

It may be 1-celled, as in the Hippuris (Fig. 115) ; 2-celled, as in the Tobacco (Fig. 116); 4-celled, as in the Polomonium and Phlox; 3-celled, as in the Epilobium; 5-celled, as in the Flax; and 6-celled, as in the Wild Ginger, (Asarum Canadense).

115.

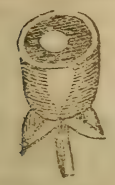

116.

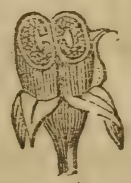

117.

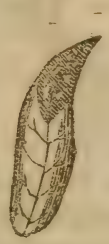

2. A Foliche (Fig. 117,) is a fruit formed of a single carpel, with one valve and one cell, opening by a sutural dehiscence on the inner side, and leaving the seeds at the base or along the suture, as in the Larkspur, Columbine, and Peony.

3. Leaume or PoD (Fig. 118, ) is a fruit formed of a single carpel and dehiscent by both the dorsal and ventral suture, so as to separate into two valres, having its sceds attached to the margin of each valve alternately, as in the Pea, Locust, and Plants of the Natural Order Leguminosa, generally.

4. LoMENT or LOMENTACEOUS LEGUME, where the logume is divided into two or more one-sided joints, and falling to pieces at maturity, as in the Desmodium.

5. SIlique (pod, Fig. 119,) is a long, narrow poricarp of two valves, divided into two cells by a false dissepinent, formed by the extended placentre, to the edges of which the seeds are attachod, alternately, with its opposite sides, as in the Mustard, Wallflower, and Cabbage. This constitutes the 2 nd Order, called Sitiquosa, of the Linnaen class 'Tetradynamia. 
6. Silicle (a little pod,) differs from the Silique in being shorter, and nearly oval, as in the Pepper Grass, and Shepherd's purse (Capsella). On this distinction is founded the first order Siliculosa, of the Linnaen class Tetradynamia.

118.

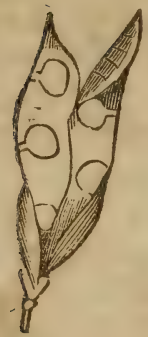

119.

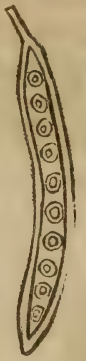

120.

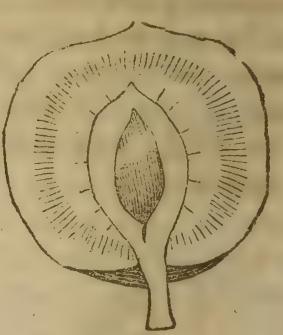

7. A DRupe or stone fruit (Fig. 120,) is a onc-celled, one or two-seeded simple fruit, indehiscent, with a hard and long endocarp, covered with the fleshy sarcocarp, which is also covered with the epicarp, as in the Peach, Plum, and Cherry. This name, though strictly applicable only to fruits of this kind, is extended to all fruits of similar texture resulting from a compound ovary, as in the Walnut, and even to those of several bony cells enclosed in putp, as in the Buck-thorn; the latter, however, are generally called drupaceous.

8. A NuT is a hard, indehiscent fruit, produced from an ovary of two or more cells, with one or more ovules in each, all but a single ovule and cell having disappeared during its

- growth. It differs from the drupe in being seated in a kind of persistent involucre called a cupule, as in the Chestnut, Oak, Hazle, and Beach.

9. An Achenium (Fig. 121,) is a small, dry, indehiscent, - one-seeded pericarp, as in the Ranunculus. It is sometimes terminated by a plumose and persistent style, in the form of a feathery tail, as in the Anemone and Clematis. In the Rose, the achenium are seated on the hollow expansion of the receptacle, while in the Strawberry they are seated on the surface of the pulpy receptacle. In the Blackberry and Raspberry, the achenium are changed to little drupes. The name achenium is also applied to all similar one-seeded fruits rosulting from a one-celled ovary, formed of more than one 
carpel, and invested by the calyx-tube, as in the Compositæ or Syngenesious plants.

10. A CREMOCARP (Fig. 122, ) consists of a pair of achenia placed face to face, and invested by the calyx-tube, which when ripe separate from each other, or from a central axis, called the carpophore, as in the Umbellifera to which the name is restricted. Each separate or half fruit, or earpel is called a hemicarp or mericarp, and its inner face the commissure.

121.

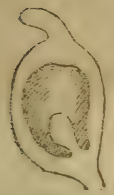

122.

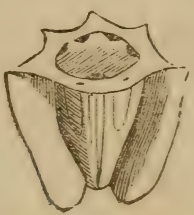

123.

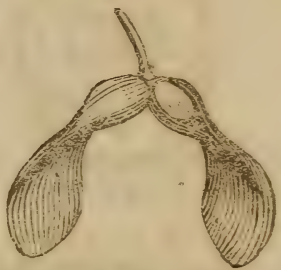

11. A CaRyopsis is a thin, membranaceous, one-celled pericarp, inseparable from the seed which it encloses, as in Wheat, Indian Corn, and most Grasses.

12. A UTRICLE is a caryopsis which does not adhere to the seed, as in the Chenopodium.

13. A SAMARA (Fig. 123,) is a nut or achenium with a winged apex or margin, as in the Birch, Elm, and Maple.

14. A Pyxidiun or Pyxis (box), is a capsule which de hisces transversely, so as to appear like a little cup with a lid. as in the Plantain, Purslane, and Bartonia.

15. A BERRY is an indehiscent, fleshy or pulpy fruit, containing the seeds loosely within, as in the Grape, Gooseberry, and Currant. A Thesperidium or Orange is merely a berry with a leathery rind.

16. A Pone (Apple, Fig. 124,) is a fruit composed of two or mors cartaleginous or long carpels, which enclose the seeds more or less enreloped in the pulpy expansion of the receptacle or disk, and the whole invested by the succulent tube of the calyx, as in the Apple, Pear, and Quince.

17. A Pepo (gourd, ) is an indehiscent, fleshy, or internally pulpy fruit, usually composed of three carpels, invested by the calyx, and a firm rind, as in the Cucumber, Melon, and Gourd. 


\section{6}

SEED.

18. A StrobILE or Cone (Fig. 125, is an aggregated fruit, consisting of scale-like carpels spread open, each bearing one or more naked seeds, as in the Fir tribe (Coniferæ). The cones of the Tulip, Poplar (Liriodendron,) are, however, entirely different, consisting of numerous aggregated carpels of a single flower, attenuated at the apex into a scale, crowded on the elongated receptacle.

124.

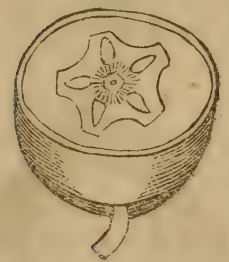

125.

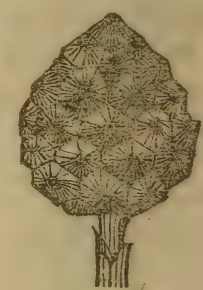

231. Antho-CARPous fruits, are those multiplex or collective fruits which result from the combination of several flowers into an aggregated body or mass, as in the Pine Apple and Mulberry. The Fig results from a multitude of flowers concealed in a hollow receptacle or flower-stalk, which becomes pulpy and edible. Thus the fruit seems to grow directly from the branch without being preceded by a flower. In the Mitchella, and some species of Lonicera, the ovaries of two flowers are uniformly united, so as to form a double berry.

\section{SEED.}

232. The seed is the matured ovule, containing the rudiments of a new plant, similar in every respect to the original It consists of a nucleus usually enclosed within two integuments.

233. The Integuments or external coverings, consist of several membranes, to which appropriate names have been applied. The first or outer membrane is called the testa, or episperm. It varies greatly in texture; sometimes it is membranaceous (papery,) coriaceous (leathery,) bony, fleshy, or woody. Its surface is generally smooth, sometimes beautifully polished, as in the Indian Shot (Canna) or Columbine, and often highly colored, as in varieties of the Bean, \&c. It is 
sometimes expanded into wings, as in the Catalpa and Trumpet flower, which renders the seeds buoyant, and facilitates their dispersion by the wind. The testa is sometimes provided with a tuft of hairs at one end ealled the coma, as in the Epilobium, Asclepias, and Apocynum. In the seeds of the Cotton plant the whole testa is covered with wool.

The inner integument, corresponding to or rosulting from the socundine of the orule, is called the tergmen. Although of ten very obvious, it is sometimes undistinguishable, or entirely wanting.

234. Seeds are somelimes furnished with a complete or partial covering, exterior to the proper integuments, arising from an expanzion of the apsx to the seed-stalk or FUNICUnUs, (or from tha placenta itself when the funiculus is wanting), called the aril. It forms a complete pulpy envelope in Euonymus and Celastrus, or a mere scale on the one side of the secd in Fumaria, and a tough gashed covering: called mace in the Nutmeg.

235. The hilum or scar is that point or mark lefi on the coats of the seed, by its separation from the funiculus. It is cornmonly called the eye, as is seen in the Pea, Bean, \&c.

236. The Nuclevs, or liernel, consists of the albumen (when it is present in the seed,) and the cmbryo.

237. The Albu Me. consists chiefy of starch. It constitutes the chief bulk of some seeds, is Com, Whoat, Rye, \&e., and serves to nourish the embryo in its latent state. It is furinacesus or mea?y in all the grasses, especially in the grains used for food. Cornaceous, or bony, in Leontice, Coffee, \&..; oily in the Poppy and Flax; and fleshy in the greater nuiner of sceds. The albumen not boing an cssential part is sometimss entirely wanting, as in the Pea, Bean, \&e.

238. The Eurryo is the initial plant or new individual, and is the most important part of the seed; to its growth and protection all the other parts are made subservient.

239. The embryo possesses in a rudimentary or undeveloped state, all the essential organs of regetation, such as rotot, stem, and leaves. In some seeds these several parts are distinctly visible, as in the Linden, Bean, and Convolvulus. The embryo is divided into three parts, the Radicle, Plumule, and Cotylectons.

240. The Radiche (Fig. 126, a.) is the lower part, or descending portion, destined to form the root: 
241. The Plumule (Fig. 126, b.) is the terminal bud, or ascending part of the embryo.

242. The Cotruedons (Fig. 126, c.) are the two lobes, or rudiments of the first pair of leaves, usually called seed leaves. They are very conspicuous in some plants, such as the Bean, Squash, Cucumber, \&c.

243. The number of cotyledons is variable; and in this difference is founded one of the most importaut distinctions of the first Grand Division of the Vegetable Kingdom called Phænagamia or Flowering Plants.

126.

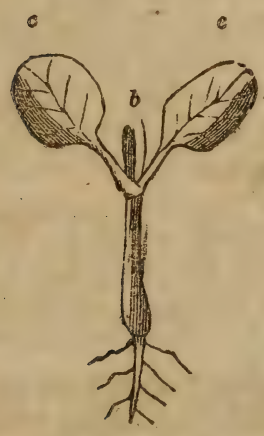

*
127.

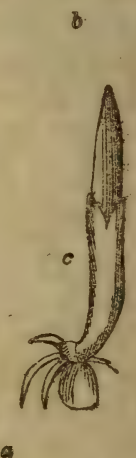

244. Drcotyledong (Fig. 126, ) are those plants which bear seeds with two or more Cotyledons. They are also called Exogens, (outside growers,) because the stem increases by external accretions, and beas s reticulate-veined leaves.

245. Dicotyledonous Plants constitute the first class of the Natural System, which embraces all the forest trees, and a greater part of the herbaceous plants of the Northern United States.

246. Monocotrledons (Fig. 127,) are those plants whose seeds have but one cotyledon. They are likewise called. Endogens (inside growers,) because their stems increase by. internal accretions; and bear parallel-veined leaves, as the Lily, Indian Corn, Pains and Grasses. Monocotyledonous Plants compose the second class of the Natural System.

247. In rome very rare cases the embryo is destitute of cotyledons; such plants are called acotyledonous, as in the Cuscuta. 


\section{GERMIN ATION.}

248. Germination is the developement of the embryo from the seed, and its establishment as an independent individual plant.

249. The conditions requisite to germination are heat, moisture, darkness, and a free communication with the air. Hext is an essential agent in all vital action, whether it be in the sprouting of a seed, or the hatching of an egg. The degree of heat necessary to excite the latent vitality is nearly uniform in the same species, but widely different in different plants, while some seeds germinate at a very low temperature, such as the common Chickweed, the seeds of many tropical plants require a heat of 90 to 100 degrees, and those of temperate climates from 50 to 80 degrees Fahrenheit.

250. Darkness is favorable to germination, from the circumstance that during its process a destruction of a portion of organized matter takes place, and carbonic acid is evolved. The reason why light on the contrary impedes germination, becomes evident when we remember that it incites the decomposition of carbonic acid, and the fixation of carbon by the plant; which would, therefore, tend to increase the quantity of carbon rather than to diminish it.

251. Air is necessary in germination, because the oxygen contained in it, together with the water absorbed from the soil, produce a chemical change in the starch cortained in the albumen, or cotyledons, dissolving it, a portion of which is decomposed and converted into carbonic acid and water with the evolution of heat, while the remainder is generally brought into the more soluble form of dextrine sugar, \&c., for the nourishment of the young plant.

252. When seeds are planted at too great a depth they remain torpid, from not receiving the stimulus of air; and when they have not a proper covering of earth, they do not germinate, from not obtaining an equal and sufficient degree of moisture.

253. Water is also necessary to soften the different parts. of the seed, bring them into a fit state to be absorbed by the embryo, and oonvey in solution nutritive particles from other sources. It also by its decomposition affords two of the most important ingredients of vegetuble bodies. The water which is slowly absorbed swells the cotyledons, the inclosing embryo bursts its envelopes, the radicle protrudes, and taking a 
downward direction, fixes itself in the soil; while the budding end elongates in the opposite direction to elevate the plumule above the surface, when the leaves expand in the air and light. Its establishment as an independent individual plant, completes the cycle of vegetable life, and brings us round to the point where we commenced its account.

\section{LONGEVITY OF SEEDS.}

254. Seeds retain their vitality for periods ranging much in different species of plants, if placed in circumstances which will neither causc them to germinate nor decay, such as a moderate temperature, with the absence of moisture. While some seeds lose their vitality in a few months, others retain it for centuries. Thus the seeds of Corn have been known to grow when thirty years old, Rye forty, Kidney-Boans one hundred, and grains of Wheat taken from ancient mummies under cireumstances of their high anticuity hare been made to germinate; but in such cases there is a possibility of boing deceived. The following remarkable case, related by Dr. Lindley, leaves but little room to doubt. "I have bcfore me," says he "three plants of Raspberries yaised in the garden of the Horticultural Society, from sceds taken from the stomach of a man whose skeleton was found thirty fcet below the surface of the earth, at the bottom of a barrow which was opened near Dorchester. He had been huried with some coins of the Emperor Hadrian; and it is therefore proliclile that the seeds were sixteen or seventeen hurdied year's old."

\section{DISSEMINATION OF SEEDS.}

255. The dissemmination of seeds is a subjort highly interesting to the student of nature, and at the same time illustrates the wisdom and design of the great Author of Nature. The air, winds, rivers, seas, and animals all assist more or less in the dispersion of seeds.

Many s eds of gres: and grains are proviried wilh a stiff; hairy-like awn or bes $\mathbf{r}$. ghis is so much affeted by moisture that it lengthens in damp and shortens again in dry weather. The under side is thickly ect with short prickles inclining towards the point of the long beard, like the teeth of a sarr. When the sced is ripe it drops from the ear and lies thickly strewed upon the ground arouni the bottom of the stom. Were they all to take root in this situstion they would choke each other, and very few if any could come to perfection. The first damp that falla, however, lengthens the awn, the next morning sun shortens it only in one direction, and by this expanding and drying, its place is changed, and soon the seed is dragged away from the foot of its parent stalk. 
256. Seeds are also furnished with wings, as in the Maple, pappus, as in the Thistle, and coma, as in the Epilobium, by means of which they are wafted by winds to great distances across rivers, mountains, and eren the ocean itself. Others are provided with hooks, by which they lay hold of men and animals, and are thus scattered far and wide. Some seeds are thrown to considerable distances by the bursting of the elastic pericarp, as in the Impatiens and Oxalis.

257. Some seeds have been known to perform long royages without injury. Thus the seeds of the Mahogany tree, a native of the southern shores, have been found on the coasts of Norway. The Cocoa nut when it falls into the water does not sink, but is floated to some distant shore, germinates, and becomes a lofty tree. A remarkable provision for the dissemination of its seeds is found in the Rose of Jericho, (Anastatica hierochuntina,) of Arabia and Palestine. It is generally found growing on sandy wastes, about three or four inches high, with very small white flowers. When the flowers decay they are succeded by a little pod, divided into two celis each containing one or two seeds. When the seeds are ripe the leares fall off, the branches curl up, and all unite together forming a rounded ball, about the size of \& mau's fist, which is torn from the earth and rolled by winds over the sandy plains, until it reaches some moist spot, where it opens and parts with its seeds.

258. The most remarkable case is found in the Mangrove tree, (Rhizophora Mangle) which inhabits the deep muddy shore of the vast rivers and seas of tropical regions, and is even occasionally met with on the coasts of Florida and Louisiana. Created thus to stand on a surface of mud in order to prevent its sinking, or the winds from overthrowing it in an instant. The base of its stem is divided into a number of arching branches, or ærial rcots, which spread out in all directions and dive into the mud at a considerable distance from the tree so as to secure it in its place, like the moorings or fastenings of a ship. Above this arch of rerial roots, the trunk of the tree rises to the height of fifteen feet or more.

But how is the seed of the Mangrove to reach the solid bottom of the swamp, that other trees may be produced? If it falls only on the surface of the mud, it will be floated away by the current and borme to the ocean. If not swept away it will rot on the stagnant surface of the mud. But means have been provided to prevent both these evils. The embryo begins to germinate while the pod is yet at tached to the parent branch; the radicle or root end of the embryo elongates into a club-like mass of wood about fourteen inches long, pointed at the end and almost as heary as iron. This continues to grow suspended from the lower side of the branch until the stalk of the seed vessel can no longer bear its weight; then by a singular contrivance the stalk separates from the branch without injury to the embryo. The club thus loosened with its point downwards, and the embryo at the top, falls with the swiftness of an arrow; it pierees through the mud until it reaches the solid bottom. Here it becomes fixed and the new plant in due time rises sbore the surface of the mud to astablish itself by degrees like its parent tree.

\section{CRYPTOGAMOUS OR FLOWERLESS PLANTS,}

259. Having traced the physiological structure of the $\mathrm{Ph}$ nogamia or Flowering Plants through the successive stages from their first developement from the seed, until we have arrived at that point in the cycle of vegetable existence where we commenced, and having assumed them as the exponents of 
the general plan of vegetables, we shall now briefly consider the series of simplifications of the plan assumed, which occur in the Cryptogamia. In framing our brief account in accordance with this view, we shall commence with the highest grade, and trace the progress of simplification downwards. The lower orders of Flowering Plants exhibit the greatest simplification compatible with the existence of proper flowers, as we approach the confines of the Phænogamia. In the Coniferæ and Cycadaceous plants the staminate flowers are often reduced to a single anther, and the pistilate are uniformly reduced to one or more ovules, borne on an open carpellary leaf, which answers to the pistils, and therefore receiving the influence of the pollen in the most direct manner. These are accordingly placed at the very close of the Exogens.

260. The next step in the descending series, brings us to an order of plants of comparatively recent discovery, which in all probability forms the connecting link between the Flowering and Flowerless plants, containing a part of the characteristics of each. They possess a cellular structure, developing flowers immediately trom the root while the ovary is filled with spores instead of seeds, hence they are called Sporogens or Rhizanths. The Rafflesia Arnoldii is an example.

261. The Cryptogamia are divided into three great Classes, called Acrogens, Anophytes and Thallophytes.

\section{ACROGENS.}

262. Acrogens (from aliros the summit or point,) have a regular stem or axis which grows by the extension of the point or apex only without increasing at all in diameter, generally furnished with leaves and composed of woody and vascular tissue. They cmbrace the following regular descending series of orders, called EQUISETACEA, FELICES, (with three suborders Polypodinece, Osmundinea and Ophyoglossene, LycoPODIACE a, and HYDropteizides (with two sub-orders, Marsilece and Salvinece).

263. The Order EQuisetace (Horsetail Family, has been placed at the head of the series on account of the resemblance which the organs of regetation and the spikes of fructification bear to many Coniferæ. Equisetum, (Fig. 128,) exhibits hollow jointed stems, either simple or bearing whorled branches, and having the joints furnished with a toothed sheath instead of leaves. The fructification is a cone or aniks, 
consisting of peltate scales which are attached around the axis, (Fig. 128, a.) each with several thecæ attached to its lower surface, longitudinally dehiscent. Spores numerous, with four elastic club-shaped bodies (of unknown use, called elators) wrapped around them.

128.

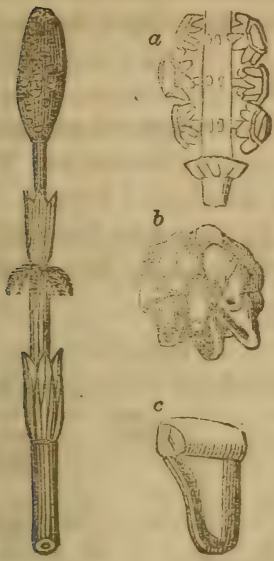

129.

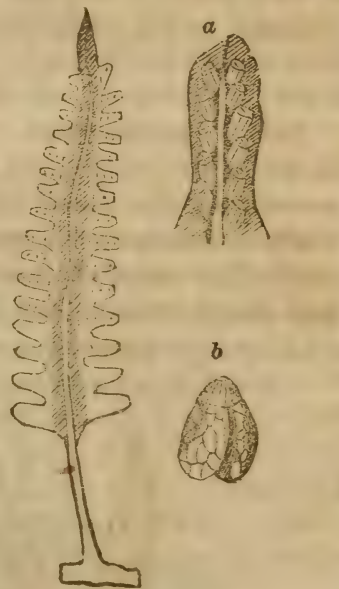

Fig. 128. Summit of the stem of Equisetum sylvaticum; $\alpha$, part of the axis of the cone of fructification; $b$, some of the frt it bearing organs, magnified; $c$, a eparate theca, more magnified.

Fig. 12:. P y olimin vulgarc; $a$, a dirision (pinna) of Schizra pusilla, showing the sussile sporangia cosupying its lower surface; 0 , one vi the sporangia more magnifed.

264. The large Order Filices (Ferns, Fig. 129,) is remarkable for bearing the fructification upon the leaves, or as they are technically termed rRONDS. The fronds usually rise from subterranean root-stalks, separately rolled up, or circinate in thesbud in a spiral form, and bearing the SPorangra upon the brick or lower surface of the fronds, in the form of dots, which open in various ways and discharge the numerous minute spores.

265. The Order Lycopodiace (Club-moss Family, consists of plants such as the Club-moss and Ground Pine, (Fig. 130,) with creeping or leafy stems, mostly branching. The fruit consists of sessile theco in the axils of the leaves, sometimes all collected at the summit under leaves which are changed 
into bracts, and crowded into a kind of ament, 1 to 3 celled, dehiscent, containing either minute grains, appearing like fine powder, or a few rather large sporules; both kinds being often found in the same plant.

266. The Order HYDROPTERIDEs consists of aquatic cryptogamous plants of diverse habits, with the fructification borne at the bases of the leaves, or on submerged branches, consisting of two kinds of organs, of dubious nature, contained in inde- hiscent, or irregularly bursting involueres, (sporocarps).

\section{ANOPHYTES.}

267. Anophrtes. Vegetables composed of parenchyma alone, with acrogenous growth, usually with distinct foliage, sometimes the stem and foliage is confluent inta a frond. They embrace the following orders: MUSCI and Hepatice (with four sub-orders Ricciacece, Anthocerotece, Merchantiacere and Jungermanniacea.)

130.

131.
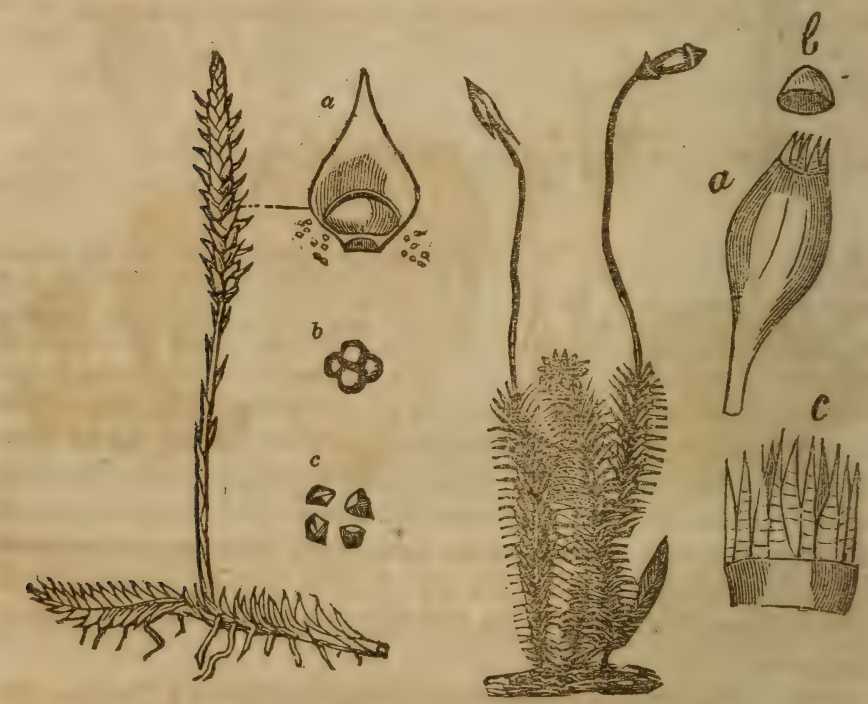

Fig. 130. Lycopodium, nearly of the natural size; $\alpha$, a leaf from the spike of fructification, with the sporecases in its axils, and spores falling out; $b$, a group of four spores magnified; $-c$, the same separated.

Fig. 131. A Moss (Polytrichium) of the natural size; $a$, a magnified theca, from which the lid or operculem, $b$, has been removed, showing the peristome; $c$, a for thon of the outer and inner peristome highly magnified. 
268. The Order Muscr (Mosses, Fig 131,) consists of low tufted plants, always with a stem and distinct (sessile) leaves, producing sporecases which mostly open by a terminal lid, and contain simple spores alone.

269. The Order HeParic (Liverworts, Fig. 132,) consists of frondose or Moss-like plants, of a loose cellular texture, usually procumbent, and emitting rootlets from beneath; the calyptra not separating from the base, but usually rupturing at the apex; the capsule not opening by a lid, containing spores, usually mixed with elaters which consist of thin threadlike cells, containing one or two spiral fibres, uncoiling elastically at maturity.

\section{THALLOPHYTFS.}

270. Vegetables composed of parenchyma alone, or of con. geries of cells or even of separate cells, often vaguely combined in a thallus, never exhibiting a marked distinction into root, stem, and foliage, or into axis and leaves. Fructification of the most simple kinds consisting of sporules or sporidia.

\section{2.}

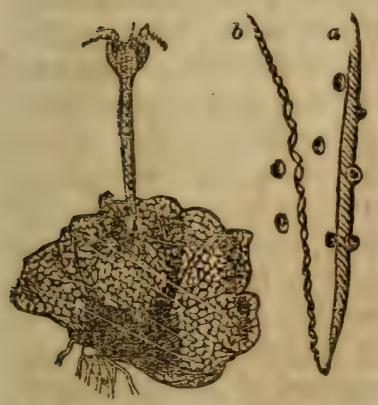

133.

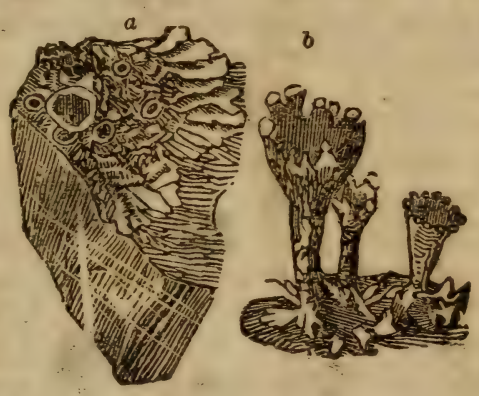

Fig. 13'. Fruit-stalk, with a fortion of the foliage of Jungermannia, magnified to show its entire cellu'ar etructure; $a$, one of the tubular spirally-marked c lls from the fruit; $b$, the sp: ral threads which result from t $t$ d sruption.

Fig. 13?. a. a stone upon which a $L$ chen (P.rmellib con' $p$ 'reg) is growing; $b$. Cladon:a roccinnea, bcaring its fructification in rounded red masses on the edges of a raised cup.

271. The Order Lichenes (Lichens, Fig. 133,) form the highest grade of this lower series. They consist of flat expansions, which are rather crustaceous than fuliaceous, growing on the bark of trees, on the surface of rocks, and on the ground, to which they cling by their lower surface.- The 
fructification is in cups, or shields (APOTHECIA) resting on the surface of the thallus, or more or less immersed in its substance, or else in powdery spots scattered over the surface.

\section{4.}

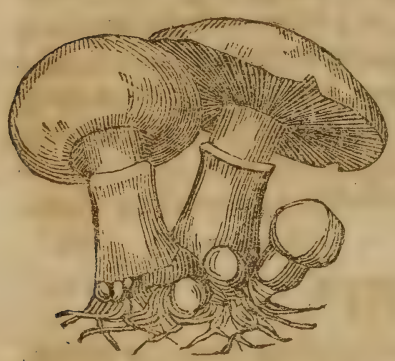

135.

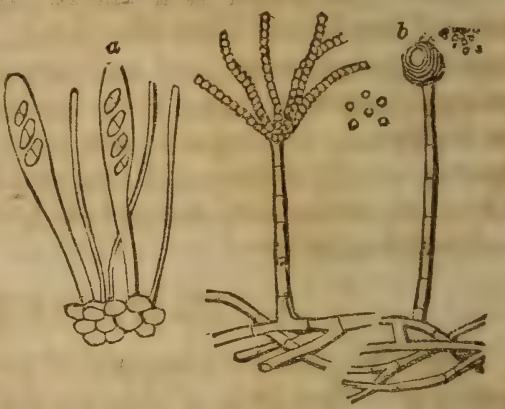

Fig. 134. Agaricus campestres, Edible Mushroom in its various stages; $a$, Asel, from the interior of Sphrria roselia, containing sporules highly magnified. Fig. 135. A Mould (Pennicillum glaucum); b, Bread-mould (Mucor), both highly magnified.

272. The Order Fungr (Mushrooms, Moulds \&c., Fig. 133,134 ,) consists of parasitic flowerless plants, either living upon and drawing their nourishment from living, though moro commonly from languishing, plants and animals, or else appropriate the organized matter of dead and decaying animal and vegetable bodies. Rust, Smut and Mildew, (Fig. 135,) are examples of the former, and Mushroons, Puff balls, \&c., of the latter. Fun $i$ (Fig. 134,) are entirely destitute of foliage and green matter, (chlorophyll,) which appears to be essential to the formation of organic out of inorganic matter.

273. The Order CHARACE (Chara Family,) consists of a few aquatic plants, which have all the simplicity of the lower Algæ, in cellular structure, being composed of simple tubular cells, placed end to end, and often with a set of smaller tubes applied to the surface of the main one. Their fructification consists of two kinds of bodies (shown in Fig. 136,) of which the smaller is problably a mass of antherider, of curious structure, while the upper and larger is a sporocarp formed of a budding cluster of leaves, wrapped around a nucleus which is a spore or sporangium.

274. The next vast Order or rather class, AtG E, consists mostly of aquatic plants. Although they rise to forms moro simultating the higher grades of vegetation, and therefore 
should have been placed before the Fungi, yet, as they descend to the very lowest points of the scale, they have been placed the last in the series.

136.

137.
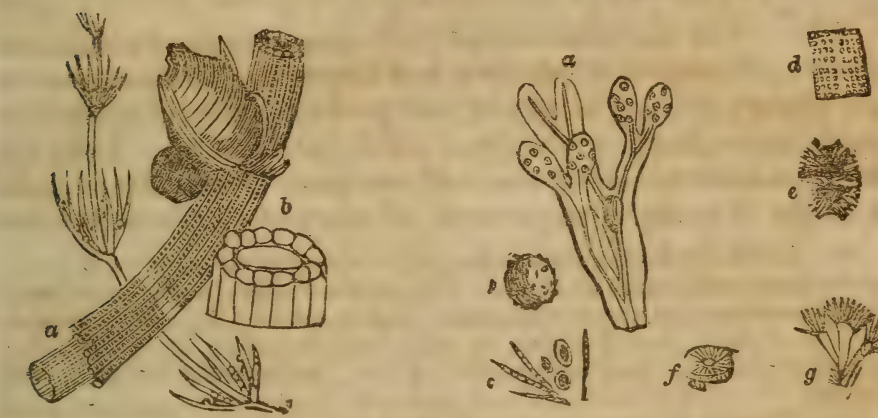

Fig. 136. Branch of the common Chara, nearly the natural size; $\alpha$, a portion magraified, showing the lateral tubes inclosing a central one; also a spore, invested by a set of tubes twisted spirally around it, and with an antheridium borne at its base; $b$, a portion of the lateral tubes more highly magnified.

Fig. 137. $a$, summit of the frond of Fucus resiculosus; $b$, one of the contained globulcs; $c$, sfores and jointed filaments of which the globules are composed; $d$, Gonium glaucum, of Ehrenberg, who thinks it a congeries of animalcules, while it is described as an Alga by Meyen; $e$, Euastrum Crux-Melitensis; $f$, Meridion cireulare; $g$, Echinella tlabellata, perhaps a group of animalcules.

275. The highest forms of the Alga are the proper Seaweeds, "some of which have stems of enormous lengths, and fronds that rival in expansion the leaves of the Palm." "Others again are so minute as to be invisible, except in masses, to the naked eye." From those we descend by successive gradations to simple or branching cells placed end to end, such as the green Confervus of our ponds, and many marine forms, in which the organs of vegetation and fructification become at length perfectly identical, both reduced to mere cells, and finally as the lowest term of possible vegetation we have the plant reduced to a single cell, containing granular matter which gives rise to new ones, each of which at the destruction of its mother cell becomes an independent minium plant, and repeats in turn the same process."

276. "The lowest group of the Algæ, called DiATo MACA, presents peculiarities of the most striking resemblance to those of animals, so that they are claimed at the same time by the Zoologist as well as the Botanist. We see not how they are to be separated from the vegetuble kingdom, espo. 
cially if they evolve oxygen gas as they are said to do. But, werever the line be drawn, in reaching the borders of the vegetable kingdom, we make the closest possible approach to the lowest confines of the animal creation!"

\section{FOOD AND NUTRITION OF PLANTS.}

277. The essential and ultimate constituents of plants are Carbon, Nitrogen, Hydrogen, and Oxygen. These elements are always present in plants, and produce by their union the various proximate principles of which they consist. They are indispensable to vegetation, and compose at least from eighty-eight to ninety-nine per cent. of every vegetable substance.

278. $C$ trion (famili riy known a 3 charcoal ) "s an elemontary substance en low $3 d$ with a considerable range of affinity. W.th oxygen it unites in two proportions, forming carbonic acid and carbonic oxide. Carton enters so largely into the composition of plants, that it retains the exact form and texture of the vood, after the other ingredients have been expelled by heat. Its proportion is from 40 to 60 percent.

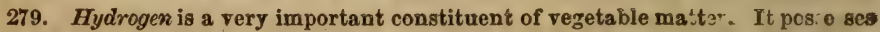
a special affinity for oxygen, with which it unites and forms water. Th: whole phenomena of the decay of organized matter depends upon the exerc se of this affinity, and many of the processes engaged in the nutrition of plants originato in the attempt to grat:fy it. Water is the most common combination in which it is presented; and it may $b_{3}$ separatcd by various processes from the oxygin, with which it is united in this body.

290. Nitrogen is quite opposed in its chemical characteristics to the bodics just described. Its principal characteristic is an inđifference to all other substances. and an apparent reluctance to enter into combination with them. When forced by peculiar circumstances to do so, it seems to remain in the combination by a vis inertia; and very slight forees effect the disunion of these fceble compounds.

Yet nitrogen is an invariable constituent of plants, and during their life is subject to the control of the vital powers, But when the mysterious principle of lifo has ceased to exercise its influence, this element resumes its chemical character, and materially assists the decay of vegetable matter by escaping from the compounds of which it formed a constituent,

281. Oxygen, the only remaining constituent of organic matter, is the most generally diffused substance on the surface of the earth; for, besides constituting the principal part of the atmosphere which surrounds us, it is a component of almost all the earths and minerals found on its surface. It is slightly soluble in water, and hence it is usually found dissoived in rain and snow, as well as in the Fater of running streame.

282. Such are the principal characters of the elements which compose organic matter. Besides these four universal elements, many other substances; earthy and mineral, are found in quantitie greater or less in different species. Thus, forest trees and most inland plants yield potassa ; marine plants, soda, iodine, \&c.; the Grasses, silex and phosphate of lime; Rhubarb and Sorrel, oxalate of lime; Leguminous plante, carbonate of lime. These substances form the ashes which are left on burning a leaf or a piece of wood.

283. These four elements carbon, hydrogen, nitrogen 
and oxygen, must be furnished by the food upon which the vegetable lives, and must be obtained from sources without. These sources are obviously air, earth and water.

284. The composition of the atmosphere has been carefully examined by many chemists, and the result of their researches has shown, that its principal constituants are always present in the same proportion. One hundred parts by weight, of atmospheric air, contain 23.1 parts of oxygen, and 76.9 parts of nitrogen; or 100 volumes of air contain nearly 21 volumcs of oxygen gas.

285. Although oxygen and nitrogen are the principal constituants of the atmosphere, they are not the only substances found in it. Watery vapor, carbonic acid, and ammonia, materially modify its properties. The former of these falls upon the earth as rain, and brings with it whatever soluble matter it meets in its passage through the atmosphere. Carbonic acid is eontained by the atmosphere in the proportion of 1 to 1000 , diffused throughout the whole extent; and as this gas is the principal food of plants, (for it contains 27 per cent. of carbon), it may ke demonstrated that the whole atmosphere contains at least 3306 billion pounds, besides the vast quantity derived from other sourecs, such as the combustion and decay of organic matter. It is likewise discharged in immonse quantities from the active volcanoes of South America, and mincral springs which abound in various parts of Europe-affording an amount fuliy adequate to the vast and ceaseless drain made upon it by the vegetable kingdom.

286. Ammonia - which is generated in the atmosphere, during thunder stormg, by the flashes of the electric fluid, and likewise arises from the decomrosition of organic matter-is composed of 100 volumes of nitromen united with 300 volumes of hydrogen. In its gaseous form it is capable of entering into combination with carbonic acid and forming a volatile salt. Ammonia in all its rolatile compounds as well as its gaseous form, is of extreme solubility in water. It can not, therefore, long remain in the atmosphere, as every shower of rain must condense it, and convey it to the surface of the earth. Hence rain-water must at all times contain more or less ammonia. The rain of a thunder storm, aftcr a long-protracted drought, ought for this reason to contain the greatsst quantity which is conveyed to the earth at one time, which accounts for the luxuriant growth of plants immediately after a thunder shower.

287. S $i$ consists of two classes of materials; namely, mincral and organic. The former, called earth, consists of disintegrated and dccomposed rocks, containing potassa, soda, silica, lime, \&c., all of which are more or less soluble in water, and ent $r$ into the composition of plants. The organic materials consist of the remains of former tribes of animals and vegetables, mingled with the carth, which, after having access to the air are decomposed, evolving carbonic acid and ammonia both to the air and the water.

288. Virgin soil in the form of vegetable mould or hasmus, appears to play such an important part in the phenomena of regetation, that regetable physiologists have bren induced to ascribe the fertility of every soil to its presence. It being the product of the decay of vegetable matter, must, therefore, contain many of the constituents whieh are found in plants during their life.

289. Witer The remaining sourcs of vegetable food, is composed of oxygen and hydrogen, nearly in the proportion of 8 to 1 ; or, 100 parts of pure water consists of 88.9 parts of oxygen and 11.1 of hydrogen. Water, besides supplying these two essential elements, serves another important office, that of conveying to the rcots the requisite supply of nitrogen, either separately or in the form of ammonia, and of carbon in the form of carbonic acid, as well as various mineral substances which it holds in colution after percolating through the soll. 
290. While most plants are dependent on water, earth, and air, for their nourishment, absorbed by the roots and leaves, yet, the essential elements, the whole proper food of plants, may be absorbed by the leaves directly from the air, as in the state of gas or vapor. A vigorous branch of the common Live-for-ever (Sedum telphinem,) or of many such plants, will live and grow for a whole summer when pinned to a dry, bare wall; and the Epiphytes, or Air-plants must derive their whole sustenance immediately from the air; for they have no communication with the ground. Although leaves in some cases absorb nourishment directly from the air, as a general thing, their peculiar office is something quito different.

291. The aqueous vapor, condensed into rain or dew, and bringigg with it to the ground a portion of carlanic acid, and witrogen or ammonia dc., supplies the appropriate food of the plant to the rootlets. Imbibed by these, it is conreyed through the stem and into the leares, where the now superfluous water is restored to the atmosphere by exhalation, while the residue is conrerted into the proper nourishment and substance of the vegetable.

292. After all these materials hare bcen supplicd to the plant, still two other agents are requisite, without which the great work of regetation cen not proceed. These life-giving principles are light and heat, both of wbich cmenate in floods from the sun. Under their influence the raw material is received into the rcssels of the plant, and assimilated to ito own substance.

293. Under the influence of light, the leares imbibe carbonic acid, decompose it, retain tle carbon and return pure oxygen to the air. Next, chlorophyll is develnped, clothing the plant in living green. Neunwhile lignen is produced, the peculiar principle of tissue, whetlier cellular, vascular, or woody, consisting of carbon with the exact elcuents of water.

294. A portion of the plant's food instead of being immediately cosverted into new cells, new branches, \&c., is accumulated in an claborated state for future use, in the form of gum, mucilage, or dextrine, and is usually stored up in the form of starch, either in the root, or in the subterranean portion of the stem, or in the wood \&c., as in the root of the bect, tuber of the potato, and in the fruit of almost all plauta. 


\section{SYSTEMATIC BOTANY.}

PART II.

295. Systematic Botany is the "science of arranging plants in such a manner that their names may be ascertained, their affinities determined, their true place in the natural system fixed, their sensible properties judged of, and their whole history clucidated with certainty and accuracy." All botanists, whatever may be their views as to the mode and order in which the mer bers of the vegetable kingdom are to be arranged, agree in dividing into Species, Genera, Orders, and Classes.

296. A Species, or particular sort, embraces all thoso individuals, which, although they may differ slightly in size and color or such unimportant respects, are identical in their real characteristies, resembling each other more nearly than they resemble any other plant, and produce from their seeda other plants wholly resembling the parent. Individuals from the same parent often bear flowers differing in color, or fruit differing in flavor, or leaves differing in form, such as the different varieties of apples, which all belong to the genus $P^{\prime} y$ rus, species malus; such differences are called varieties. They are uever permanent, but exhibit a constant tendency to revert to their own original type.

297. A GENUS is an assemblage of nearly related species, agreeing with cach other in general structure and appearanoe more closely than they accord with any different species. Thus, the White Oak, Black Oak, Scarlet Oak, and others, constitute the genus Quereus; the rarious species of Rose compose the genus Rosa; so the different Poplars, Willows, Pines, \&c., form so many separate genera. These 
genera are arranged into still higher, therefore fewer groups. In the natural system these groups are formed by the union of related genera, just as genera are formed by the union of related species and are called FAMILIES or ORDERs. Thas the Rose, Raspberry and Strawberry, with the Apple, Thorn, Plum, Cherry, \&c., all agreeing in their general plan of structure are brought together into one order, or family, and called Rosaces, that is, rose-like plants. When certain minor groups exist they are termed Suborders or Tribes. Thus the Plum, Cherry, Peach, \&c., form one suborder of Rosacex ; the Raspberry, Strawberry, Cinquefoil, Rose, \&c., constitute another suborder; and the Apple, Quince, Thorn, \&c., a third.

298. CuAsses are groups of orders having certain marked characters in common, but in a higher point of view. These in like manner with the other divisions are separated in SU BCIASSES.

299. An enumeration of the points of difference, or marks of distinction of any one of these groups, whether of higher or lower order, is denominated its character. Thus the character of a class describes only those important points of structure on which it is founded; that of orders notices the general structure of the plants embraced in it, especially of the fruits and flowers; the generic character, the particular modification of the ordinal character in a given genus; and lastly, the spccific character gives those of less importance, of form, color, \&c., which mark it as distinct from its kindred.

300 . There are two independent and widely different systems of classifying the genera, which have been followed; one the Artificial founded by Linnæus, and at one time almost universally followed by botanists; the other, the Natural, originally sketched out by Jussieu. The former has for its basis those characters which are derived from the organs of fructification, leaving all the affinities out of view. Its arrangement is truly ingenious and beautiful, and furnishes perhaps the readiest mode of determining the names of plants which has ever been devised, but this must be regarded as its principal use. The latter on the contrary is founded upon all those natural affinities and resemblances of plants hy which the God of Nature has distinguished them into groups and families. In acquiring a thorough knowledge of the vegetable kingdom, the Natural System is not only the best, but 
most accurate method which can be relied upon for the purpose. By the labors of De Candolle and Lindley in Europe, and Drs. Torrey and Gray of our own country, the misconceptions and obscurity that formerly embarrassed the science have been so far removed, that it is now brought within the scope of the ordinary mind, and is shown to be founded in true Philosophy.

301. Yet the difficulty attending analysis by the Natural System is too great to be successfully encountered by the young student in the science. On this account I have thought it best to arrange the genera under the Linnæan classes and orders, describe the most prominent characters of each, and refer to the page where, and in what Natural Order, his specimen is to be found.

\section{LINN EAN SYSTEM.}

302. By the Linnæan System the Vegetable Kingdom is divided into twenty-four CLASSES, (twenty-one of which, are now in general use). These are distinguished from each other by the number, situation, connection, proportion, presence or absence of the stamens, so that the arrangement is founded entirely on the flower of the plant.

303. The Classes are divided into Orders; these are founded either on the number of styles or pistils, (in some instances on the number of stamens, ) situation of the fruit, the kind of pericarps, or on some other circumstance which will be explained in its proper place. The names of the classes and orders are derived from the Greek, designating their modifications and expressing their characters as follows:

CLASS 1. MoNandra, (monos, one, and andria, from aner, which is used meta phorically for stamens, ) includes all such plants with one stamen to the flower.

“ 2. Diandria, those with two stamens.

"3. TrIandia, those with three stamens.

"4. Tetrandria, those with four stamens.

"5. Pentrandria, those with five stamens.

"6. HEXANDRIA, those with six stamens.

“7. Heptandria, those with seven stamens.

" 8. OCTANDRIA, those with eight stamens.

" 9. ENNEANDRIA, those with nine stamens.

"10. DRCANDRIA, those with ten stamens.

is 11. DODRCANDRIA, those with twelve to nineteen stamens.

"12. IcosaNDRIA, those with more than ten atamons inserted on the ealyx (perigynous).

¿. 13. POLYANDRIA, those with more than twenty stamens situated on the receptacle (hypogynous), 
14. Didynams, those with two long and two short stamens.?

"6 15. Tetradynami, those with four long and two short stamens.

"6 16. Monodelphis, (a single fraternity) with the filaments united into a single set, tube, or column.

“ 17. Diadelphia, (two fraternities, with the filaments united into two sets or parcels.

16 18. Polydelphia, (many fraternities, with the filaments united in more than two sets or parcels.

is 19. SyngenksIA, (to grow together) with the anthers united into a ring or tube.

"20. GINANDRIs, (union of stamens and styles) with the stamens and styles consolidated.

“ 21. Moncecta, (one house-hold) includes plants, where the stamens and pistils are in separate flowers on the same plant.

“ 22. Diacia, (two house-holds) where they occupy separate flowers on different individuals.

"6 23. Polyg.Ami, (many marriages) where the stamens and pistils are separate in some flowers and united in others, either on the same or two or three different plants.

"24. Cryptegamia, (concealed stamens and pistils,) includes those genera of plants where the stamens and pistils are wanting, or at least invisible, and embraces the Ferns, Mosses, Lichens, \&c., which are now called Cryptogamous, or Flowerless plants.

304. The Orders in the first thirteen classes of the Linnæan artificial system, depend on the number of styles, or of the stigmas in the absence of styles; and are likewise named by having Greek numerals prefixed to the word gynia, used metaphorically for pistils, as follows.

ORDER 1. MoNoGivis, embraces all plants of any of the first thirtecn classes, with one style to the flower.

"2. Digria, those with two stylez.

“ 3. Trigrnia, those with three styles.

* 4. TETRAGYNin, those with four styles.

i6 5. Pentagria, those with five styles.

"6. HeXAGYNia, those with six styles.

“7. Heptagrni, those with seven styles.

" 8. OCtagria, those with eight styles.

"9. EnNeagria, those with nine styles.

"10. DeCAGris, those with ten styles.

"11. Dodecagris, thoge with eleven or twelve styles,

“ 12. Polyernia, those with more than twelve styles.

305. The Orders of the remaining classes are founded upon characters not depending upon the number of styles, as follows: The Orders of Class 14, Didynamia, are only two, namely :

1. Grmoosprasu, (seeds naked) the achenia-like fruits appear like naked zeeds.

2. Avolosprami, with the ceeds evidently in a geed resoel, 
The 15th Class is likewise divided into two orders which are distinguished by the form of the pod:

1. Stuiculosa, bearing seeds in a silicle or short pod.

2. Siliquosa, fruit a silique or long pod.

The orders of the 16th Class Monodelphia, 17th Diadelphia, 18th Polydelphia, 20th Gynandria, 21st Monœcia, and $22 \mathrm{~d}$ Dioecia, depend merely on the number of stamens; that is on the character of the first thirteen classes, whose names they likewise bear; thus-

ORDER 1. MONANDRIA,

"2. DIANDRIA, and so on.

The orders of the 19th Class, Syngenesia, are six, namely:

1. Polyglmia Aezuinz, where the flowers are in heads (compound,) and all perfect.

2. Polygamia Scperflua, the same as the last, except that the rays or marginal flowers of the head are pistillate only.

3. Polygamia Frtstrines, those with the marginal neutral, the others perfect.

4. POLYGAMIA NECBSzIRIA, where the marginal flowers are pistillate, and fortile, and the central staminate and sterile.

5. Polygami Stgregata, where each flower of the head has its own proper in rolucre.

6. Monogami, when solitary flowers (not united into a head) have united anthers, as in Lobelia. This order was abolished by succedin botanists, but upon insufficient grounds.

The 23rd Class Polygamia, has three orders, founded on the characters of the two preceding classes, namely:

1. Moxem, when both separate, and perfect flowers are found in the same individual.

2. DrGCiA, when the different flowers occupy different individuals.

3. TRIECLA, where one individual has the perfect, another the staminate, and a third the pistillate flowers.

The orders of the 24th Class, Cryptogamia, are natural, and therefore indefinable by a single character. They are,

1. Filiers, the Ferns.

2. Muscl, the Mosser.

3. Alas, which as left by Linnæeus, comprised the Hepaticx, Lichens, \&c., as well as Seaweeds.

4. Fungl, Mushrooms, \&c.

\section{THE NATURAL SYSTEM.}

306. The great object of the Natural System is to arrange and bring together into groups such plants which most noarly resemble each other, in all essential particulars, and 
to combine the subordinate groups into larger natural assem. blages, and these into still more comprehensive divisions so as to embrace the whole vegetable kingdom within the limits of a systematic arrangement.

307. Numerous systems have been devised, and proposed by different authors, founded on the peculiar views of the devisers. Some writers, as Jussieu, \&c., commence their exposition with the lowest order, and gradually ascend to the highest; whilst others, as De Candolle, Torrey and Gray, \&c., begin with the highest and most perfect organization, and descend to the lowest or least organized. This system has been adopted in the following pages, being the most generally known and followed.

\section{PRIMARY DIVISIONS OF TIE VEGETABLE KINGDOM.}

308. The Vegetable Kingdom taken as a whole is primarily divided into two great natural divisions, namely: Phanogamia or flowering plants, and Cryptogamia, or Flow erless plants.

309. The Phenogamia,

1. Cnsist of a rejular axis of growth with leafy appendages.

2. They possess a wody and vascular struciure.

3. They produce flowere, essentially with stamens and pistils, and-

4. They produce seeds.

310. The Cryptogania,

1. Are destitute of a regular axis of growth and of true leaves.

2. They generally possess a cellular struciure only.

3. They do not develope flowers, and-

4. They produce spores insiead of seeds.

311. The Phænngamia are again naturally divided into two sub-divisions, depending upon their manner of growth, termed ExoGENs and ENDogENs, whose leading distinctions are as follows :

Cuass I. Exogens-

1. Stems increasing by extcrnal accretions.

2. Leaves uswally articulated with the branches, and having riticulate l vein".

3. Emsryo with two cr more cotyledons, or dycotyledonous. 
PRIMARY DIVISIONS OF THE VEGETABLE KINGDOM.

Class II. Endogens-

1. Stems increasing by internal accretions.

2. Leaves seldom articulated, usually sheathed at the base, with simple parallel veins.

3. Embryo with one cotyledon, or monocotyledonous.

312. The two groups or classes above mentioned, embracing all the Phænogamia, are again divided into subclasses. The first are formed from the sub-division Exogens, and are founded upon the presence or absence of the pericarp, namely:

Sub-Class I. ANGIOSPERMS-

1. Oviles, produced in a closed ovary.

2. Feritized by the action of the pollen through the stigma.

3. Embryo with two opposite cotyledons.

Sub-Class II. Grinosperms-

1. Ovules produced beneath a scale-tihe carpet.

2. Fertitized by the direct action of the pollen witiout the stigma, becoming seeds destitute of a pericarp.

3. Embryo generally with several whorled cotyledons.

313. The next two sub-classes are formed from the subdivisions of Endogens, and depend upon the presence and absence of glumes or husks, namely:

Sub-Class III. AgluMace $\mathbb{E}$, or AqLuMAceodsEndogens-

Plants of the endogenous structure, with flowers constructed on the usual plan; p: rianth verticellat', censisting of on 6 or more whorls of petaloid organs, or wantirg.

Sub-Class IV. Glumace 2 , or Glumaceous Lndogens-

Plants of the exidozenous strurtire, with the flowers investsd in an imbricuted perianth of glumes instead of a calyx.

314. The third Class forms the connecting link between the Flowering and Flowerless plants, combining a part of the characters of each. They possess a cellular struchure, devetope flowers immediately from the roots, and the pericarp contains spores iststect of seeds; hence thes are called Rhizantis or Sforogris. Ex. : Rufflesia. As we have no representative of this class in our country, I shall take no further notice of it in the regular series of classes.

315. The Cryptogamia are separated into three great classes, ealled Acrogens, Anophytes, and Thallophy'tes. 
Class III. Acrogens-

Plants with a distinct stem or axis, groving by the exten. sion of the point, or apex only, containing woody flore and vessels, and usually with distinct foliage.

Class IV. Anophytes-

Acrogenous plants, growing upwards by an axis or stem, usually furnished with distinct leaves (sometimes the stem and foliage confluent into a frond,) composed of celtular tissue alone.

Class V. Thallophytes-

Consisting of cellutar tissue, with a tendency to grow into a flat expansion, called thallus, but having no distinction of root, stem, leaves, or flowers.

316. The general plan may be analytically expressed by the diagram on the following page.

317. Divisions. The classes and sub-classes are next to be broken up into smaller divisions, groups, and alliances, for convenience of analysis. For this purpose, the great class of Exogenous plants is usually broken up into three very convenient divisions, founded on the presence, absence, or union of the petals, namely:

1. Portpetale, the Polypetalous Exogens; where the calyx and corolis are both present, and the latter composed of distinct petals.

2. Monopetal s, the Monopetalous Exogens; flowers with united petals

3. APETALA, the Apetalous Erogens; flowers with no floral enveloges, ar with a calyx only.

318. These divisions, as well as the other classes, are variously subdivided by different authors, which is not necessary to specify, since it is only the classes and the orders that are considered to be founded on a firm basis.

319. Orders or FAMrlies, are the most important of all the natural associations. On the accuracy and distinetness of their characters, botanists have bestowed the highest degree of attention. The orders differ very widely in regard to their extent; while some consist of a single genus, as Sarreceniaceæ, others embrace hundreds of genera, as Compositæ. For the sake of convenience, the larger orders are divided into sub-orders or tribes,

\section{NOMENCLATURE.}

320. The names of orDers are always plural, and sometimes are founded on some characteristic feature of the group; 


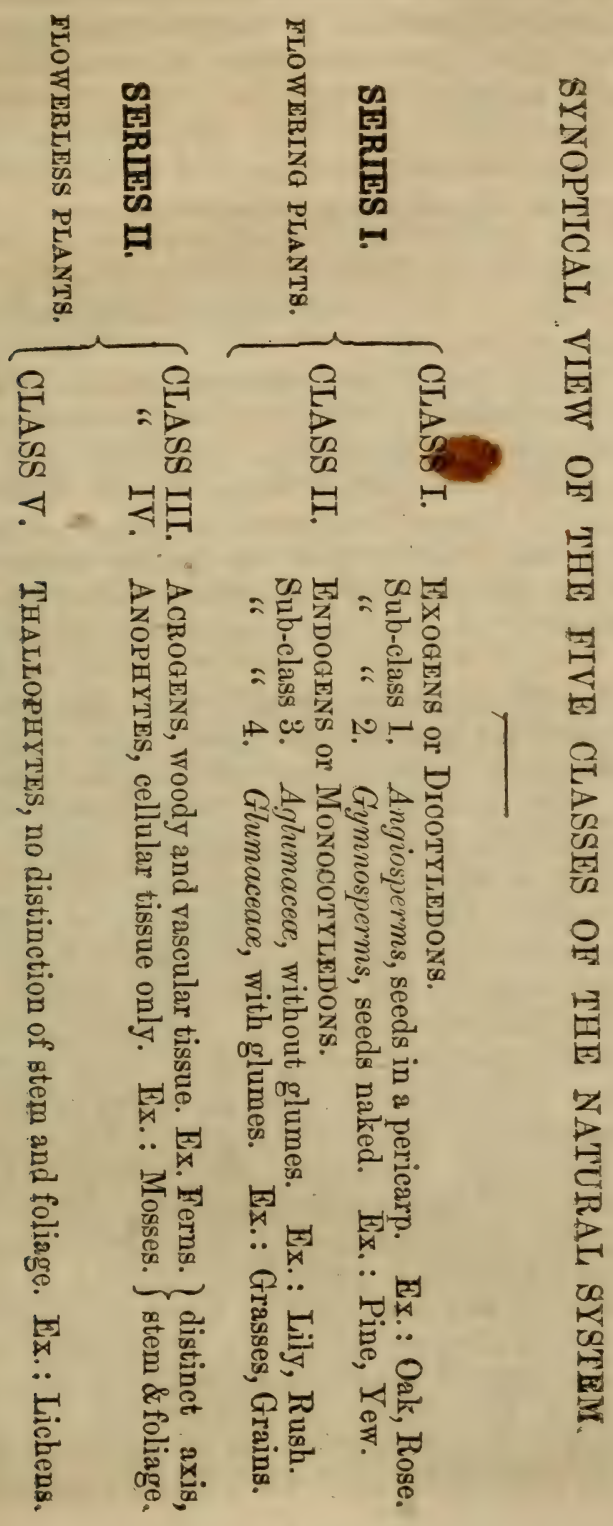


as, for instance Leguminosce, or the Leguminous plants, such as the Pea, Bean, \&c.; Cruciferce, plants which have the four petals somewhat in the form of a cross, such as the Radish, Turnip, \&c. But more frequently, as a general rule, the name is formed from that of a leading genus, which is prolonged in the adjective termination, acece. Thus the plants of the oruer which comprises the rose (Rosa), are called Rosacer, that is Plantre Rosacer, or Rosaceous plants; those of which the Lily is the representative, are Liliacere, or Liliaceous plants, \&e.

321. Generic names are Latin substantives, in the singalar number, and mostly of Greek or Latin derivation. Those which were know the ancients, generally preserve their Classical appellations. (Ex. : Fagus, Prunus, Myrtus, Viola, \&c.) Some are formed from some medicinal virtue, either supposed or real; others from the native country of the plants, or from the name of some distinguished Botanist, or patron of botany, to whom the genus is thus said to be dedieated.

322. Specific names, as a general rule, are Latin adjectives, written after those of the genera, and established on similar principles; as Magnotia grandiflora, the large flowered Magnolia; M. macrophylla, the large leaved Magnolia. Specific names sometimes distinguish the country which a plant inhabits, or where first discovered, as Viola Canadense, \&c. ; or the place where it naturally grows, as Viola palustris, which grows in swamps, \&c. ; arvensis, in fields, \&c. ; or they express some obvious character of the species, as Viola ratundifolia, with round leaves, \&c. Frequently, the species is named after some other genus, which in some respect it resembles, as Viola primulafolia, Primrose-leaved Violet. Gercurtia quercifotia, Oak-leaved Gerardia, \&c.

323. Species, like genera, are also sometimes named in commemoration of distinguished persons. When it bears the name of the discoverer or describer, it takes the genitive form, as Lobetia Kalmii; Viola Muhlenbergii; V. Nuttallii, \&c. When such names are merely given in compliment to persons to whom they are dedicated, unconnected with the history or discovery of the plant, the adjective form is adopted; as Carex Torreyana; C. Hoolieriana, \&c. Specific names are sometimes substantives, as Hypericum, Sorothra, Ranunculus, Flammula, \&c.; when they do not necessarily 
accord with the genus in gender. These, as well as all specific names derived from those of persons or countries, should always be written with a capital initial letter. The generic sud specific names, taken together, constitute the proper cientific appellation of the plant.

\section{BOTANICAL ANALYSIS.}

324. "The application of the rules of Systematic Botany to the natural plant, in order to ascertain its affinities, place, name, \&c., is called botanical analysis.

325 . In order to be in a proper state for this kind of examination, plants should be in full blossom, and fresh, that is, not withered or decayed. A good lens is requisite for the examination of the minute parts of the structure, or of the flower.

326. The analysis of plants is a constant object of pursuit with the practical botanist. Without this exercise, the study of authors will be of little avail. A more accurate and useful knowledge of a plant can be acquired in a few minutes, by a careful examination of the living specimen, or eren of the dried, than by committing to memory the most elaborate descriptions found in books. During the flowering month, the learner will often in his walks meet with plants in blossom, with whicl he is yet unaequainted. And he who is duly interested in his pursuit, will by no means fail to seize and analyze each specimen while the short hour of its bloom may last, and to store his memory with the knowledge of its names, habits, and uses. Thus, in a few seasons, or even in one, he will have grown familiar with nearly, or quite, every species of plants in his ricinity.

327. Let us now suppose the pupil in possession of a epecimen of an unknown plant in full blossom. In order to otudy it by the aid of authors, a point immediately requisite is its name. Now, laving learned by examination the organic and physiological structure of the flower, leaves, stems, \&c., the experienced botanist, who has at his command the characters of all the Natural Families, will at once determine to which of them the plant belongs."

328. But this is not to be expected of the pupil who is supposed to be yet, in a measure, unacquainted with the characters of the orders. He must be guided to the place which bis specimen holds in the classification, by a longer course 
of inquiry and comparison. For the assistane of the learner, therefore, and for the convenience of all, I have added a full series of Analytical Tables, in which the genera described in this work are arranged under the Classes and Orders of the Linnæan Artificial System.

\section{OF COLLECTING AND PRESERVING PLANTS.}

329. Students in botany should give an early and persevering attention to the collection and preservation of as many species of plants as they can procure. The advantages to be derived from such collections are great, and will afford an abundant compensation for all the labor required, either in refreshing the memory by reviewing them, or in institating a more thorough examination at one's leisure.

330. Such a collection of specimens of plants, preserved by drying under pressure between folds of paper, is termed a Herbarium, or by the more significant title Hortus Siccus. (dry garden).

331. A complete specimen consists of one or more shoots, bearing the leaves, flowers, and fruit, and in some eases, as in herbaceous plants, a portion of the root should also be preserved.

332. Specimens intended for the herbarium, should bo gathered, if possible, in a dry day, and carried either in a close tin box, about 20 inches long and 3 or 4 in diameter, or in a strong portfolio, containing a quire or more of firm paper, with a few sheets of blotting paper to receive the delicate plants. They must be dried under a strong pressure, but not so as to crush the parts, between dryers composed of 6 to 10 thicknesses of paper, that will absorb moisture, which should be changed once or twice a day, until all the moisture is extracted from the plants-a period which varies from 3 to 10 days. All delicate specimens should be laid in folded sheets of thin and smooth bibulous paper, and placed between the dryers, and so transfered entire, from time to time without being disturbed, until perfectly dry.

333. Many plants prepared by the above method, will in most instances retain their colors almost as perfect as when first gathered, yet some plants, especially those of the endogenous structure, such as the Narcissus, Iris, \&c., aro very hard to dry so as to retain their coloring. I have found the following method to answer a very good purpose: 
treat the specimens as above directed, and leave them in tho papers for 1 or 2 days, then place them between sevoral thicknesses of dry blotting paper, and pass orer them with a hot iron, at intervals from 1 to 5 minutes, until dry, taking care to shift them into dry paper as soon as the paper around them becomes moist.

334. The dried specimens are next to be arranged in their respective genera, orders, and classes, properly labelled with the names, locality, \&c., and laid either in separate double sheets, or each species fastened with glue, or otherwise on a half sheet of good white paper.* These can bo eollected in folios sufficiently large to contain each naturad order, or artificial class, and labelled accordingly on the out side, received into the compartment of a cabinet, with close doors, and kept in a sufficiently dry place.

- I have found the following mixture to answer a very good purpose for fastening plants. Take of Gum 1 rabic 1 ounce, Izinglass 1 ounce, dissolve them in 1/2 pint of water by boiling over a gentle heat, after which add 1 ounce Tinctaro of Camphor, incorporating them well by sbaking; then spread some of it on plate of glass large enough to receive the specimen intended to be fastened, lar it on the glass, pressing it down so as to receive a coating all over the under face, then transfer it to the paper where it is to be fastened, cover witb 1 or 2 thicknesses of dry paper and pass over it with a hot iron until dry.

\section{PRINCIPAL ABBREVIATIONS OF THE NAMES OF AUTHORS.}

Adans. Adanson.

Agh. Agardh.

Ait. Aiton.

Arn. Arnott.

Bart. Barton.

Benth. Bentham.

Berl. Berlandier.

Bernh. Bernhardi.

Brongn. Brongniart.

Bigl. or $\mathrm{Bw}$. Bigelow.

Boehm. Boehmer.

Bong. Bongard.

Br. Brown.

Cass. Cassini.

Cav. Cavanilles.

Chav. Chaviennes.

Darl. Darlington.

DC. De Candolle.

Desf. Desfontaines.

Desv. Desvaux.

Dew. Dewey.

Dill. Dillenius.

Duh. Duhamel.

Endl. Endlicher.

Ehrh. Ehrhart.

ka1. Elliot.

Engel. Engelman.

Porsk. Forskahl.

Froel. Froelich.
Gært. Grertner.

Ging. Gingins.

Gmel. Gmelin.

Good. Goodenough.

Grev. Grerille.

Grise. Grizebach.

Gron. Gronovious.

Hedw. Hedwig.

Hoff $m$. Hoff man.

Hook. Hooker.

Huds. Hudson.

Jacq. Jacquin.

Juss. Jussien.

Lam. Lamarck.

Lamb. Lambert.

Lec. Le Conte.

Lindl. Lindley.

L'Her. L'Heritier.

Linn. Linnæus.

Lk. Link.

Lehm. Lebman.

Mart. Martius.

Mentz. Mentzel.

Michx. Michaux.

Mill. Miller.

Mirb. Mirbel.

Mitch. Mitchell.

Moench. Monchanzen.

Muhl Muhlenberg.
Neer. Nees von Beanteck.

Nutt. Nuttall.

Pall. Pallas.

Pav. Pavon.

Pers. Persoon.

Poir. Poiret.

Ph. Pursh.

Rrom. Rxmer.

Raf. Rafinesqua

Rich. Richard.

R. Br. Robert Browa.

Salisb. Salisbury.

Schw. Sehwenits.

Schk. Schkuhr.

Scop. Scopoli.

Ser. Seringe.

Sm. Smith.

Spr. Sprengel.

Sulliv. Sullivant.

Sw. Swartz.

Tayl. Taylor.

T. \& G. Torrey \& Gray.

Torr. Torrey.

Tourn. Tournefort

Traut. Trautrettes.

Vaill. Vaillent.

Wahl. Wahlenbers.

Walt. Walter.

Will. Yilldenow. 


\title{
GLOSSARY OF BOTANICAL TERMS,
}

\author{
COMBINED WITH AN
}

\section{IND丽 X}

TO THE FIRST PART OF THE WORK.

(The numbers refer to the paragraphs in the preceding part.)

A, and ana, in composition; destitute of; as Apetalous, without petals.

Abnormal; different from the customary structure.

Angulate; having angles or corners. Annual; living or enduring but one year.

Annular; having the form of a ring.

Abortion; an imperfoct developement of Anomolous; not according to rule or sys. any organ.

Abortive; not arriving at perfection.

Abrupt; terminating suddenly.

Abruptly-pinnate. Fig. 49.

Acaulescent; stemless, apparently without a stem.

Accessary; additional, or supernumerary.

Accumbent; lying against any thing; applied to the radicle when it lies arainst the edge of the cotyledons.

Acerose; needle-shaped.

Achenium: a small dry indehiscent periearp. Fig. 121. tem.

Anophytes; vegetables composed of parenchyma alone, 267.

Anterior; same as inferior; applicd to so pals, petals, or other organs which is axillary flomers lie next the bract, or outward.

Anther; the knob-like kody, mostly borne on the flament, 193.

Antheridia; applied to minute cylindrian sacs or sterilo flowers, of cryptogamous plants.

Apetalous; destitute of petals.

Achlamydeous; without culyz and corolla. Apex; the summit end, or point.

Acicular; bristle-shaped. Aphyllous; without leaves.

Acice, (Acinus); each separate grain of a Apocarpous; having the earpels distinct. collective fruit, like the raspberry.

Acotyledonous; destitute of cotyledons.

Acrogens; growing by the extension of Appressed; lying flat against. . the point; 262.

Aculeate; prickly.

Approximate; growing, or gituated near each other.

Acuminate; ending in a curved, tapering Aquatic; growing naturally in water, or point. Fig. 61.

Acute; sharp, not rounded.

Adelphia; a fraternity. wet places.

Arachnoid; resembling a Epider's web.

Arborescent; tree-like.

Adherent; sticking fast, or growing fast Arcuate; curved or bent like a bow. to, as adnate.

Albumen; 230.

Alburnum; sap-wood; 74.

Areolæ; little spaces, circumscribed by meshes.

Alternate; not opposite.

Arid; dry or parched.

Alveolate; having cells like a honey-comb.

Ament; Fig. 81.

Amentaceous; having aments.

Amorphous; having no definite form.

Amplexicaul; clasping the stem.

Aril, or Arillus; a loose coating of nome kinds of seed, as the mace of the nut meg.

Aristate; having amas.

Armed; having thorns or pricklee.

Arrow-shaped; Fig. 37.

Anastomose; applied to branching vessels Articulated; jointed. which inosculate, or unite again like Ascending; rising from the ground obnet-work.

Anatropous; inverted.

Ancipial; 2-edged. liquely.

Assimilation; 146.

Androcium ; 191.

Assurgent; rising in a curve from a dclined base.

Androgynous; having staminate and pis- Attenuate; tapering gradually antil it tillate flowers distinct.

Androus; refers to stamens.

sagio spermous; tho seeds in a pod. becomes slender.

Auriculate; having rounded apfendages at base, like ears. Fig. 35. 
Awn; a slender bristle-like process, com- Carpophore; the central axis supporting mon on the chaff of grasses.

the fruit in the umbellifer:e.

Axil; the angle between a branch and a Cartalaginous; hard and tough.

stem or leaf \& branch, on the upper side. Caruncle; a protubarance or appendage

Axis; a central stem, or any centre around which parts are arranged.

Baccate; berry-like.
Banner; the vexillum or upper petal in Catkin; sce Ament, Fig. 81. at the hilum of a seed.

Caryophylaceous; a flower like the pink, Fig. 96. a papilionaceous fiower.

Barbs; stiff hooked hairs.

Caudate; having a tail-like appendage.

Barbs; stiff hooked hairs.
Bark; the external covering of the Caudescent; having a sten. stem, 75 .

Beaked; tipped with a terminal process, Cell; a hollow cavity. The cavity of an like a bird's bill.

Bearded; beset with bristly hairs.

Bell-shaped; companulate, Fig. 89. ovary or pericarp.

Cellular tissue; a tissue composed of small bladders or vesicles, 7 .

Berry; a pulpy valveless fruit, in -which Centrifugal Inflorescence; the flowering the seeds are imbedded.

$\mathrm{Bi}$; in composition, twice, as-

Bicarinate; 2 keeled.

Biennials; 2 yearly.

Bifid ; 2 cleft.

Bifarious; 2 ranked-

Bifurcate; 2 forked:

Bilabiate; 2 lipped.

Binate; in twos, twin.

Bladdery; thin and inflated. of a cyme, 160 .

Centripetal Inflorescence; the flowering of a corymb, 159.

Cephalous; headed, or head-bearing.

Cernuous; drooping or bending dewn.

Chaff; the thin covering of the seeds of grasses, \&c., or the flower bracts in compound ffowers. Bladdery; thin and inflated.
Blade; the expanded surface of a leaf. Channelled; hollowred out like a gutter.

Bloom; a fine powdery coating on certain Chartaceous; with the texture of wrifruits, \&c., as the plum.

Brachiate, pairs of branches, spreading Chlorophyll; the colored parenchyma of nearly at right angles.

Bracts; floral leaves, 130, Fig. 72.

Bracted, or Bracteate; having bracts.

Branchlets; small branches or subdivi. sions of branches.

Breathing pores; stomato, 140.

Bristles; stiff hairs, straight or hooked.

Bulb; a subterranean bud, 62 .

Bulbous; bulb-bearing, or bulb-like.

Bullate; as if blistered.

Caducous; falling off very early.

Cæespitose; growing in turf or tuft.

Calcarate; spurred.

Calyciform; cup-like.

Calyculate; with an accessary outer ealyx.

Chalaza; the points of union of the coats

Calyptra ; the cap or hood of the sporan- Climbing; ascending by means of tengia in mosses.

Calyx; the outer floral envelope, 180.

Cambium; the soft layer between the bark and the wood.

Campanulate; bell-shaped, Fig. 89.

Campylotropous; a curved ovule.

Chlorophyll; the colored paren
leaves.
Cilia; hair-shaped appendages.

Ciliate; fringed with hairs on the mar-

Cinereus; ash-gray.

Circinate; coiled or rolled up into a ring.

Circumeissile; cut round, opening trans. versely.

Circumspection; the general outline.

Cirrhous; having tendrils, 60, Fig. 65.

Clasping; where the base of a leaf partly surrounds a stem.

Class; the highest division of plants in a system.

Clavate; elub-shaped, larger at one end.

Claw; the lower narrow end of a petal, by which it is affixed.

drils, leaves or aerial roots.

Coadunate; having united bases.

Coarctate; pressed together.

Coccus; a separable carpel of a compound carpel.

Canescent; becoming white or hoary.

Capillary or Capillaceous; shaped like a slender thread or strong hair.

Capitate; in heads.

Capitulum; a head, Fig. 79 ..

Capsule; a dry and indehiscent pericarp, usually opening by ralves.

Carina; a keol.

Carinate; keeled.

Carpel; a little fruit, usually a partial pistil, or element of a compound pistil.

Cochleate; coiled spirally, like a snail-

Collateral; side by side. [shell.

Colored; any hue but green.

Columella; a solid axis of a pod.

Column; the stamens or stamens and pistils combined.

Coma ; a full tuft of hairs.

Commissure; the face by which 2 car. pels cohere.

complete flower; having both floral en velopes.

Complieate; folded up upon itsels. 
Compound; a whole formed of similar Depressed; flattened from above. parts.

Compressed; flattened lengthwise. Dextrine; a soluble form of starch.

Di, in composition; two, asthe sides are applied face to face.

Cone; a collective fruit. See Strobile, Diandrous; having two stamens. Fig. 125.

Confluent; running together.

C.n rlomerate; clustered into a mass.

Conjugate; in pairs.

Connate; united at base.

Connectile; the prolonga'ion of a fi'ament supporting the lobes of an anther.

Connivent; converging together.

Contorted; twisted.

Convolute; rolled up into a cylinder.

Cordate; heart-shaped, Fig. 34 .

Coriaceous; leathery or parchment-]

Cormophytes; stem growing plants.

Corm; a solid bulb, 64 .

Corneous; horn-like in texture.

Corniculate; bearing a small horn.

Cornate; horned.

Corolla; the inner floral envelope.

Coronate; crowned.

Corrugated; wrinklod.

Cortex; the bark, 17.

Cortical; having bark or arising from Distichous; in two opposite rồs

Corymb; an umbel-shaped raceme.

Costate; ribbed.

Cotyledons; seed-leaves.

Dichlamydeus; having both ealyx and

Dichotomous; 2-forked. [corolla.

Diclinous; when the stamens and pistils are in separate flowers.

Dicotyledonous; having two cotyledons. Fig. 126.

Didymous; double or twinned.

Didynamous; 2 long and 2 short stamens. Diff use; spreading widely and loosely.

Digitate; finger-shaped. Fig. 44.

Digynous; having 2 pistils.

Creeping; running along the surface, or Divided; severed in two or more parts. just under the surface of the ground. Dodocandrous; with 12 stamens.

Cremocarp; the seed-like double fruit of Dorsal; borne on the back. Umbelliferæ, Fig. 122.

Crenate; having round notches or teeth.

Cranulate; finely erenate.

Dorsal suture; outer seam of a carpel.

[Fig. 59.
Crested or Cristate; having an appendage like the comb of a cock.

Crown; the pappus or coma on seeds.

Cruciform, in the shape of a cross.

Cryptogamia; flowerless plants, 259.

Cuccullate; hooded.

Cucurbitaceous; gourd or melon-like.

Culm; the stem of the grasses.

Cuneate or Cuneaform; wedge-shaped.

Cupule; the cup of an acorn.

Diøecious; having the stamens on ons plant, and the pistils on another.

Dipetalous; of 2 petals.

Diphyllous; of 2 leaves.

Discoid; resembling a disk.

Disk; the whole surface of a leaf, or cen tre of a compound flower.

Dissected; deeply gashed.

Curvinerved; leaf-nerves arising from a Eared; having lobe-like appendages. prolongation of the petiole, instead of Echinate; beset with rigid rrickles. the base, 98 .

Cuspidate; with a sharp rigid point.

Cyathiform; cup-shaped, top-shaped and Elliptical; longer than wide, rounded at Cymbiform; bnat-shaped. [hollow.

Cyme; an umbel-like centrifugal inflorescence.

Decandrous; with ten stamens.

Deciduaus; falling off.

Declinate; turned to one side.

Decompound; several times divided.

Decumbent; lying on the ground.

Decurrent; prolonged below the insertion.

Decussate; crossed, in pairs alternately

Deflected; bent back.

[crossing. Endostome; orifice of the outer coat of

Dehiscence; natural opening of capsules.

Doltoid; having a triangular outline.

Dentate; toothed. Fig. 57.

Dontliculate; with small tooth.

[Fig. 30. Ensiform; sword-shaped.

rupe; a pericarp, with a hard stone covered by a sarcocarp, as the Plum, Cherry, \&c. Fig. 120.

Drupaceous; bearing drupes.

Ducts; membraneous vessels or tubes, which do not unroll spirally, 14.

Duplicate; doubly.

Duramen; heart-wood.

E, Ex, in composition; destitute of, as-

Ebracteate; destitute of bracts.

Echinate; beset with rigid rrickles.
Elators; spiral threads in the thecre of Liverworts, 269

each end. Fig. 26.

Elongated; longer than usual.

Emarginate; with a notch at the apex. Fig. 63 .

Embryo; the future plant, contained in the seed, 238.

Emersed; rising out of the water.

Endocarp; the inner coat of a fruit.

Endogen, Endogenous; inside growerz, increasing by internal accretions, 77 . Fig. 20.

Endostome; orifice of the outer cont
the nucleus.

Enneandrous; having nino stamens.

Entire; even-edged. 
Ephemeral; lasting but a day.

Epicarp; the outer skin of a fruit.

Epidermis; cuticle, outer skin, 17.

Epigynous; growing on the apex ovary.

Epipetalous; growing on petals.

Epiphytes; plants growing on other plants. Air plants, 42 .

Episperm; Testa, outer coat of seed.

Equitant; opposite leaves infolding each other, so as to alternately overlap each other's edges, 88 .

Erose; unequally sinuate, as if gnawed.

Etiolated; blanched.

Exalbuminous; seed without albumen.

Exogens; outside growers, increasing by external accretions, 12. Fig. 19.

Exostome; orifice of the inner coat of the nucleus.

Exotic; plants belonging to a foreign country.

Exserted; projecting out beyond the ori- Geniculate; bent at a very obtuse angle fice.

Exstipulate; destitute of stipules.

Extrorse; turned outwards.

Falcate; shared like a scythe or sickle.

Farinaceous; mealy.

Fascicle; a contracted cyme. Fig. 85.

Fasciculated; in bundles or fascicles.

Fastigiate; flat-topped, applied to a clus-

Favose; honey-combed.

Feather; the plumose crown of seeds.

Feather-reined; with the-veins like feather, 99.

Fertile; applied to pistillate flowers.

Fibre; any thread-like part.

Filament; that part of a stawen that supports the anther.

Filiform; thread-like.

Fimbriate; fringed.

Fissure; a cleft, or split.

Fistulous; hollow like a reed.

Hlabelliform; fan-shaped.

riaceid; lax, or limber.

Flagelliform; whip-like.

Bleshy; thick, and containing a firm Gynaphore; a special stalk of the orary. pulp.

Flexuous; bent or curved right and left alternately.

Floccese; covered with loose cottony tufts.

Floral; relating to a flower.

Wlorets; the separate small flowers of a cluster or head.

Floriferous; bearing flowers. Flower; the stamens and pistils, and Heart-shaped; cordate. Fig. 34. their envelopes, 187 . Fig. 87.

Foliaceous; leaf-like in texture.

Foliate; with leaves.

Follicle; a one-valved pericarp, dehiscing longitudinally. Fig. 117.

Foramen; the small aperture in the coats of a seed.

Foveolate; pitted.

Yovilla; the fine dust in the pollen grains. Herbaceous ; not woody.

Free; not adherent to any other organ. Herbarium; a collection of dried plants.

Prond; stem and leaf confluent together, Hesperidium; an orange, or similar frut peculiar to cryptogamous plants, 264.
Fruit; the seed with its enclosing pericarp.

Frutescent; woody, or becoming woody.

Funiculus; foot-stalk of the ovary or seed.

and a gradually expanding limb.

Furcate; forked.

wed marked with longitudinal

ish, 32 .

Galea; a helmet, the upper lip of a labs ate corolla.

Gamopetalous; having one petal.

Gamosepalous; having one sepal.

eminate; in pairs.

Germ; the growing point of a bud.

Germination; the swelling of a seed and the evolution of its emloryo.

Gibbous; swollen or enlarged at one side.

Glabrous; smooth.

Gland; a small collection of tissue prode. cing a secretion, 20.

Glandular; furnished with glands.

Glaucous; covered with a whitish, fine powder, or bleom that rubs off.

Globose; globular, round like a ball.

omerate; densely clustered.

Glomerule; small heads forming a glumo.

Glume; the scales or bracts surrounding the stamens and pistils in the grases.

Gluten; a tenaceous principle found in some seeds.

Granulate; in the form of grains.

mnospermous; naked-seeded planta

Gymnospermia; an order of Didy namis. Gynxecium; the pistillate eystem of $\mathbf{a}$ flower, 198.

Gynandrous; when stamens aro seated on the pistil.

Habitat; the situation where a plant na turally grows.

Hairs ; hair-like appendages to plants, 21

Hastate; shaped like a halbert.

Head; Howers collected in a rounded

Heart-wood; duramun, tho inner layea of a stem.

Helmet; the upper lip of a labiate flower.

Hemicarp; half a cremocarp.

Heptandrous; having geten stamens.

Heptagynous; having seven styles.

Herb; any plant not having a woody stem.

Heterogamous; a compound fiower, wilh
Halbert-shaped, hastate. Hig. 36. 
the disk flowers perfect, and the rays Jointed; separating across by an articaligulate and pistillate, or neutral.

Neterotropous; seo anaphitropous.

Hexamerous; a whorl of six parts.

Hexandrous; having six stamens.

Hexagynous; having six styles.

Hilum; the scar or mark on a seed, left Keeled; furnished with a projecting ridge by the detachment of the funiculus.

Hirsute; clothed with soft hairs.

Hispid; bristly, beset with stiff hairs.

Hoary; whitish from a scaly mealiness.

Homogamous; all the flowers of a head alike.

Homotropous; having the same airection as the body to which it is attached.

Hooded; curved suddenly at the point.

Hybrids; crosses between allied species.

Hypocrateriform; salver-shaped. Fig. 90.

Hypogynous; stamens arising from below the ovary.

Icosandrous; having more than ten stamens inserted on the calyx.

Imbricated; lying over each other with regularity, so as to break joints.

Imperfect; wanting stamen or pistil.

Incised; irregularly and sharply cut.

Incumbent; leaning upon, the radicle Latex; the proper juices of plants. resting against the back of one cotyle- Lactiferous tissue; the series of vessels dion.

Incurved; bent inwards. lation.

Jrga; pairs.

Keel; the lower petal of a papilionaceons corolla. along the under side, like the keel of a boat.

Kidney-shaped; reniform, much hollowed at one side, and rounded at the ends. Fig. 38.

Knot; a node or swelling joint.

Labellum; the lip-formed petal in orch dous flowers.

Labiate; having lips. Fig. 93.

Lacerated; torn, cut into irregular segments.

Laciniate; slashed, deeply and irregro lariy cut.

Iactescent; milky.

Lamella; a thin plate.

Lamina; a broad plate or expansion.

Lanate, Lanaginous; woolly.

Lanceolate; shaped like the head of a srear. Fig. 24.

carrying the latex, 16.

Lateral; at the side.

Indefinite; too numerous to be counted.' Teaflet; one of the small live : of a com-

Indehiscent; not opening naturally.

Indigenous; being a native.

Induplicate; having the elges bent or rolled inwards.

Indusium; a thin membraneous covering, applicd to the scale on the thecre in ferns.

Inferior; towards the base or roct.

Inflated; enlarged, as if dilated by air.

Inflexed; incurred.

Leafstalk; petiole. LFound lear.

Legume; a pod, a two-valved periearp. Kig. 118.

Lenticular; resembling a double convex lens.

Liber; the innermost layer of bark.

Lignin; a vegetable principle found in woody fibre.

Infor scenee; the mode in which flowers Liliaceous; having a corolla like a lily. are arranged on a branch.

Infracted; bent at so acute an angle as Limb; the spreading part of a petal of $s$ to appear broken.

Infundibuliform; funnel-shaped. Fig. 90. Line; the twelfih part of an inch.

Innate; when an anther is firmly at Lincar; narrow and long. tached to the apex of a filament. Lineate; marked with lines.

Inscrtion; the point of attachment or Lirs; the pieces of a 2-labiate (2-lipred) union.

Interfoliaceous; betwcen the insertion of Lobes, Lobed; rounded dirisions. leaves.

Interncde; the space between nodes or joints.

Loculic:dal; the deli cence of the component carpels of a compound fruit, by the dorsal suture. Fig. 112.

Interrupted; when organs of a different Lomént; a jointed legume. size are interposed in a series. Lunate; crescent-shaped.

Interval; the channel on a cremocarp Lurid; of a duil, deathly hue. bctwcen the ridges.

Introdueed; not originally a native.

Introrse ; turned outward.

Inverted; when a part is in an opposite Mammilar; conical, with a rounded apex. direction to other similar parts.

Involucel; a partial involucre.

Lyrate; pinnatifi, having the upper regments largest. Fig. 40 .

Involucre; a whorl of bracts to an umbel Mealy; coverce with a white powder. or head.

Isomerous; equal in the number of parts.

Medullary rays; the silver-grain of wocd.

Membranous, or Membranaceous; tho texture or thinriess of membrane. 
Merizarp; half a cremocarp, a fruit of Nucules; little nuts, or nut-like fruits. an umbelliferous plant.

Micropyle; foraman or scar of an ovule.

Midrib; the main rib of a leaf, extending from the base to the apex.

Mitriform; having two terminal divisions, like a mitre.

Monadelphous; stamens united in ono set.

Monandrous; having one stamen.

Moniliform; necklace-shaped.

Nut; a one-celled, and one-seeded fruit, arising from a two or more celled and seeded ovule.

Nutant; nodding, partially drooping.

Monocarpous; bearing but one fruit, or bearing but once.

Monochlamydeous; when the calyx only is present.

Monoclinous; having the stamens and pistils in the same flower.

Ob; a particle, which, when prefixed to any other term, denotes the inversion of the usual position.

Obconic; conic, with the apex downward.

Obcordate; reversed heart-shaped.

Oblonceolate; with the widest part above the middle, and tapering gradually to the base.

Oblique; not symmetrical, one side as it were cut off obliquely.

Oblong; much longer than broad.

Monocotyledonous; having but one coty- Obovate; ovate, with the narromest porledon. tion at base.

Monoecious; having stamens and pistils Obovoid; inversely ovoid. in different flowers, but on the same Obsolete; when a part is obscure, and as plant.

Monogynous; having but one style.

Monopetalous; where the corolla is of Obsolute; where one margin of a leaf in one piece.

Monophyllous; one-leafed.

Monosepalous; calyx in one piece.

Monospermous; one-seeded.

Mucronate; having a rounded end.

Multifid; many-cleft.

Multipartite; many-parted.

Multiple; a number containing another number several times without a remainder; as 9 is a multiple of 3 .

Muricate; havingshort rigid excrescences.

Muticous or Mutic; pointless, awnless.

Mutilated; not produced in a perfect Operculum; the lid or covering of the form.

Naked; wanting a covering analogous to that of other species.

Napiform; turnip-shaped.

Nitant; swimming, floating.

Navicular; boat-shaped.

Neck; the crown of a root; the upper part of the tube of the corolla.

Necteriferous; bearing honey.

if worn away.

the bud is exterior, the other interior.

Ochrea; a cylindrieal stipule.

Ochroleucous ; whitish-yellow, creamcolor.

Octandrous; having eight stamens.

Octogynous; having eight styles.

Offset; a lateral branch, terminated by a cluster of leaves, and capable of taking root.

Oleaginous; oily, affording oil.

Opercular; opening by a lid fixed at ore side.

theca in mossef.

Opposite; standing directly against each other on opposite sides of the stem.

Orbjeular; having a circular outline,

Orthotropous; where an ovule is turned from its original direction.

Oval; longer than broad, the sides eurving regularly from end to end.

Ovary; the germ or base of the pistil; the young state of a pericarp.

Nectary; the part of a flower secreting Ovate; egg-shaped. honey.

Ovoid; having the outline of an entire

Needle-shaped; linear, rigid, tapering to Ovule; the incipient furm of a seed, con. a point. tained in an ovary.

Nerved; having rib-like fibres.

Nerves; parallel veins or rib-like fibres Palate; a large obtuse projection which extending from above the base to the apex.

Netted; having reticulated fibres.

Neuter or Neutral; having neither sta- Palleaceous; chaffy.

mens nor pistits.

Node; a knot or joint, the projection from

which leaves arise.
Nodding; inclining to one side, partly Panicle; an irregularly-branched raceme. drooping.

Nodi; nodes, knots, joints.

Nodose; having many nodi or joints.

Normal; regular in structure.

Nucamentaceous; producing nuts.

Nucleus; kernel, the substance of a seed or ovule.

closes the throat of a personate flower.

Paler; a chaffy bract to a floret in some compound flowers.

Palmate; divided so as to resemble tho hand and fingers.

Panduriform; fiddle-shaped.

Panicled or Pariculate; arranged in the form of a panicle.

Papillionaceous; butterfly-shaped; a form of an irregular polypetalous corolla.

Papillose; pimpled, having fleshy protuberances.

Pappus; the seed down in compoan! 
Porasitic; drawing support from another Pinnatifid; cut-winged, where the lamina plant.

on each side of a petiole is deeply cleft.

Parenchyma; nommon cellular tissue in Pinnules; the leaflets or subdivisions of a soft state.

a bi.tri or multi-pinnate leaf.

Parietal; arising from the inner wall of Pisiform; formed like a pear. an orgen.

Parted; divided almost to the base.

Partial; particular, not general.

Partition; a dissepiment.

Pectinate; divided like the teeth of a comb.

Pistil; the central organ of flowers composed of style, stigma and ovary.

Pistillate; having pistils only.

Pith; the central spongy substance in

a bird.

lular tissue.

a bird. ovules are attached.

Pedicel; a partial or sccondary flower- Plaited; folded in regular layers. stalk. Plane; flat.

Podicillate or pedicelled; baving or being Plicate; folded like a fan. supported on a pedieel.

Peduncle; a flower-stalk. [duncle. with hairs.

Peduncled or pedunculate; having a pe- Plumule; the incipient ascending axis.

Pellicle: a very thin stratum or coat. Poculirorm; cup-shaped.

l'ellucid; transparent, pervious to light. Pod; a pericarp of two valves; it may bo

Pellucid-punctate; having puncturesadmitting the passage of light.

Peltate; sbield-like, having a stalk or suppert in the water.

Pencilled or pencillate; ending alike a painters pencil or brush.

Pendulous; hanging down.

a Legume or Silique.

[ovary.

Podośperm; funiculus, footstalk of an

Pollen; the granules or dust contained in anthers.

Pentagonal; having five corners or angles. Polydelphous; having stamens united

Pentagynous; having five styles.

Ycntandrous; having five stamens.

Pentsmerous; a whorl of five parts.

Pepo; an indebiscent fleshy, or internal- Polygamo-diocious; having perfect and ly pulpy fruit, formed of three united carpels.

Perennial; issting from year to year.

Perfoliate; where a ctem rerforates a leaf. Tolygynous; having many etyles.

Parforate; having holes and dots, as if Polymorphous; changeable, assuming a rrickad.

Perianth; inr.l envelopes.

Pericarp; the fruit seed case.

Peridium: a spore-case.

Ferigoniem; a perianth.

Polysepalous; having many serals.

Perigynone; infertad around the ovary. Pone; a pulpy or juicy fruit, formod ce

Perisperm; the aibumen.

Peristome; the fringed border of the theca in morges. a juicy or fleshy calyx; enclosing the carpels.

P.rmanent, persistent; remaining for a Profoliation; vernation, the arrargelong ttme. ment of a leaf in a bud.

Personate; masked; a form for a laliate Profioration; restivation, the arrangeHower.

Petal; the colorid leaf of a flower.

Petaloid; resfubling a petal.

Petio'e: the font stalk of a leaf. ment of the floral envelopes in a bud.

Proemorse; as if bitten off.

Prickle; a sharp appendage of the bark, not connected with the wood.

Pitioled or petiolate; with a petiole, not Primine; outer coat of ovule. sr ssile.

Petiolule; the foot-stalk of a leaflet.

Phanognmous or phanerognmous; hav- Process; a protuberance or projectiog ing visible stamens aud pistils. retio?e.

Pilose ; hairy, having s'ender hairs.

Pinnal : the leatlets or divisions of a pinnate les f.

Prismatic; having several parallel fiat sides.

part.

Pinnate; a lenfis tinnatewhen the lenf-Pruinose; covered with a frost-like lets are nrranged in two rows on the meal. side of a common petiole; winged.

Pseudapinnate; falsely or imperfoctly pin- 
nate, not resolving at any time into Replum; a pirsistent placentre, or marseperate leaflets, as the Pea, Vetch.

Puberulent; covered with a minute pubescence.

Pubescence; a general term for the bairy Retroflex; lending in various directions. envering of plants.

gin in eertain seeds.

Resupinate; inverted.

lieticulate; nett: d.

Retrorse or Retrorsely; turned back wards

Pubescent; huiry, having hairs of any Retuse; when an apex is slightly inden. kiud.

Pulp; the soft juicy cellular substance, Reversed; bent back towards the base. found in berries and similar fruits. Revolute; relled backwards.

Pulverulent; powdery.

Pulvinate; cushion-like.

Punctate; dotted.

Puncticulate; haring minute dots.

Pungent; sharp-pointed, or prickly at Rhomboid; when the midrib of a leaf the apex, acrid.

Putamen; a nut-shell.

Pyramidal; tapering upwards.

Pyriform : pear-shaped.

Pyridium; a capsule with a transverse dehiscence.

Quadrangular; four-cornered.

Quadififarious ; in four rows or dircctions, pointing or facing four ways.

Quadrifid; four-cleft.

Quaternate; four together.

Quinate; arranged in fires.

Rhoizoma; a horizontal subterranean stem.

Rhomboidal; oval, but somewhat angular at the middle. sends o:f marked lateral ones.

Ribs; parallel ridues or nerves extending from near the base to the apex.

Ririd; stiff, inflexible.

Rimose; full of chinks or clefts.

Ringent; grinning; applied to a form of labiate flowers.

Root; the descending axis of a plant.

Rooting; sending out lateral roots.

Rootlet; a secondary root or fibre.

Rosaceous; having a corolla like a rose.

Rostrate; beaked.

Rostellate, with a small beak.

Iiosulate; arrangud in the form of a ro-

Raceme; an inflorescence having the Rotate; wheel shaped.

[sette. flowers supported on pedicels ilong a Ruggeu, or Rough; covered with small rachis.

Racemose; flowering in racemes.

Lachis; the axis of inflorescence, or the general potiole in pinnate leaves.

Radiant, or Radiate; divergiug from a commou centre furnished with rays.

Radical; proceeding directly from the root.

Radicle; secondary rnots, rootlets.

Radicating; sending out roots at the noles or joints of the stem.

Rameal; belonging to the branches.

Ramenta; the scales or persistent remains of leaves or other parts of the plant.

Ramentaccous; covered with ramenta.

Ramose; branched, branching.

Rilphe; the ridge or part connecting the hilum and chaíaza. asperities.

Rudiment; a term applied to an organ that is imperfuctly developed.

Rufesecnt; becoming redalish-orange or rusty.

Rutous; reddish-brown or rust-colored.

lugose; wrinkled, having small folds or elevations.

Rugolose; finely wrinkled.

Ruminated; when the albumen has a wriukled or folded appearance.

Runcinate; pinnatifid, with the divisions pointing backwards.

Runuer; a shoot producing leaves and roots at the end.

Saccate; having or resembling a small Sagittate : arrow.headed. [sac.

Raphides; minute crystals in the cellu- Sulver-shared; a monopetalous corolli, lar tissue.

$\mathrm{R} \iota \mathrm{y}$; the outer florets of a compound flower.

receptacle; the base on which the parts of fructification are seated.

Reclined, or Recinate; inclined down- Sapwood; albumen, the outer layer.

Recurved; bent downwards. [wards. Sarcocarp; the fleshy or pulpy coat of a

Redul licate; with the edges folded or periearp, between the epicarp and exaturned outwards.

Rotlexed; bent backwards.

Regular; having the parts equal and uniform; as the dirisions of the calyx or corolla.

Reniote; distant.

Renifurm; kiuney-shaped.

Repand; spread, having a curved o sinuous margin.

Beplicato; bent back on itself. carp.

Sarmentose; a running shoot, rooting at its joints.

Scabrous; rougb.

Scales; thin membraneous processes at tached to the cuticle, \&c.

Scandant; climbing usually by tendrile.

Scape; a radical peduncle, or flower stem.

Scarious; dry and membraneous. 
Scattered; irregularly and thinly arranged.

Scions; lateral shoots or offsets from the root.

Scorpoid; an unilateral racem $\theta$, which is revolute before expansion.

Serobiculate; pitted.

Scutellate; shøped like a target or shield.

Secund; turned to one side, one-sided.

Secundine; the second coat of the ovule.

Seed ; the matured result of fecundation, and designed to reproduce the species.

Segments; the parts into which a corolla, calyx, \&c, are divided.

Semi; half.

Semi-biralved; half divided into two ralves.

Sepaloid; like sepals, not petal-like.

Sepals; the leaves of a calyx.

Septicidal; when a pericarp opens by the opening of the ventral sutures, and a division of the dissepiments.

Septiferous; bearing a septum.

Septifragal; when the disseppiments re. main attached to the axis, separated from the valves, as in the loculicidal dehiscence.

Septum; a partition.

Sericeous; silky, covered with soft short hairs.

Serrate; having teeth like those of a saw.

Serrulate; when serrate teeth are again serrated, it also means finely serrate.

Sessile; where any organ-is destitute of a stalk or support.

Seta; a bristle.

Eeraccous; bristle-like.

Setiform; formed like a bristle.

Setose; hristly, having bristles or stiff hairs.

Sheaths; the prolongation of a leaf, bract, \&c., down a stem, so as to enclose it.

Sheathed; cmlraced by a sheath.

Sheathing; surrounding by a convolute base.

Shield-shaped; shaped like an anciént shield.

Shining; glossy, smooth and polished.

Shrub; a cmall plant with a woody stem.

Sickle-formed; much curred, with sharp edges.

Sillcle; the rod of a plant of the order siliculosa.

Siliculoea; an order of Tetradynamia, having pods almost as broad as long.

Silique; the pod of a plant of the order siliquosa.

Siliquosa; an order of Tetradynamia; having the pods much longer than brond.

Silky ; cluthed with soft and shining appressed hairs.

Single; undivided.

[gions.

Sinuate; having rounded shallow inci-

Sinus; a rounded incision in the margin.

Smooth; having an even surface.

Solitary; single.
Sorus; a cluster or sporangia in ferns.

Spadix; an elongated spike, covered by a spathe or modified bract.

Span (measures); 9 inches.

Sparse; scattered.

Spathe; a kind of sheathing bract, a spadix or single flower.

Spatulate; shaped like a spatula.

Species; the lowest division of plants.

Spermoderm; testa, outer coat of seed.

Spike; flowers arranged in an elongated: rachis, with very short or no pedicels.

Spikelet; a division of a spike.

Spindle-shaped; fusiform.

Spine; a thorn, connected with the roods

Spinose; bearing spines.

Spiral vessels ; membraneous tubes, having internally a spiral fibre or fibres.

Spongioles; the extremeties of root fibres.

Sporangium; the case containing spores.

Spores; sporules; the organs serving as seeds in Cryptogamous plants.

Sporidia; membraneous cases containing. spores in the Fungi.

Sporogens; parasitic plants, having flow-

ers, but propagated by spores.

Spur; a process from the calyx or corolla resembling a cock's spur.

Squamose; scaly.
[scales. Squamellate; bearing small narrow. Squarrose ; ragged scales or leaves standing out from a common axis.

Stamens; the fecundating organ of plants.

Staminate; having stamens only.

Standard; banner, the upper petal of a papillionaceous flower.

Stellate; star-like, spreading out in 2 radiate manner.

Stem; the ascending axis of a plant.

Stemless; unprovided with a stem.

Sterile; a staminate flower.

Stigma; the terminating organ on a pistil.

Stipe; the stalk of a fern, fungus, or of

Stipellate; haring stipelles. [a pod.
[ation.

Stipelles; a stipule of a leaflet.

Stipitate; having a stipe.

Stipulate; furnished with stipules.

Stipule; a leafy appendage or leaflet, at or near the insertion of the petiole.

Stolon; a rooting brauch or shoct.

Stomato; pores in the epidermis.

Striate; streaked with longitudinal lines.

Strigose; clothed with short, rigid, appressed hairs.

Strobile; a cone, a kind of ament with woody seales, each of which is an open carpel.

Strophiole; an appendage at the hilum of some seeds.

Struma; a cushion-like swelling, a pro. tuberance at the base of the carpel of some Mosses.

Style; that part of a pistil between the orary and stigma ; it is often absent.

Stylopodium; the thickened base of some styles. 
Suberose; cork-like.

Sub-; a qualifying prefix, signifying somewhat; as

Sub-cordate; somewhat heart-shaped; sub-rotund, somewhat rounded.

Sukmersed; under water.

Subterraneus; growing beneath the earth.

Subulate; awl-shaped, tapering to a

Succulent; juicy, puipy. [sharp point.

Sucker; a shoot.

Suffruticose; slightly shrubby, gmalfer than a shrub.

Sulcate; grooved, $m$ irked with deep lines.

Superior; a calyx or corolla is superior when it, is inserted on the upper part of an ovary.

Supi $w$-axillary; appearing abore an axil.

Surculose; producing suckers.

Suspenđed; an- orute hanging directly downwards.

Sutural; lielonging to a carpel.

Sutural; lielonging to a carpel.
Suture; a seom at the meeting of two Tuberculate; warty.
parts, the line of dehiscence of a carpel. Tunicated; coated.

Symmetrical; when parts are in their Turbinate; top-shaped. normal proportions.

Syncarpous; sureral carpels uniting in one ovary.

Syngenesious; anthers united in a tube.

Synonymes; names of the same meaning.

Tail; a filiform process affixed to a seed.

Tap-root; a conical root.

Tegnum; the inner corering of a seed.

Tendril; an apperdage by which a climbing plant supports itself.

Terete; cylindrical or tapering, but round.

Terminal; proceeding from the apex.

Ternate; in threes, three-fold.

Testa: the outer coat of a seed.

Tetradynamous; having 6 stamens, 4 of which are longer than the others.

Tetragynous; having 4 styles.

Tetramerous; in fours.

Tetrandria; having 4 stamens.

Thalamous; a name for the receptacle of the flowers.

Thallophytes; stemless, leafless, flowerless plants.

Thallus; the frond of Hepatier.

Thecæ; a spore-case.

Thorn; a spine or short process from the woody part of a plant.

Throat; the orifice of a ealyx-tube.

Thyrsus; a condensed panicle.

Tomentose; woolly with short dense hairs.

Toothed; having salient points not directed towards the apex of the leaf.

Top-shaped; inversely comical.

Tortuous; irregularly bent or twisted.

Torus; a receptacle.

Transverse; erosswise.

Tree; a large wocdy plant.

Triadelphous; having stamens in three sets.

Triandrous; having 3 stamens.

Tribracteate; with 3 bracts.

Tribhotomous; 3 -forked.
Tridentate; 3-toothed.

rifid; 3-cleft.

Trifoliate; 3 leaves together.

Trifoliolate; 3 leaflets together:

rigonous; 3-angled, 3-sided.

Trimerous; a whorl of 3 parts.

Iriquitrous; sharply 3-angled, the 8 sides concare.

Tripinnate; 3 times pinnate.

Triternate; 3 times ternate.

Trophosperm; a synonyme for the placentre.

Trumpet-shaped; tubular, dilated at tho apex.

Truncate; as if eut off tranrersely.

ube; the united part of a calyx or $\mathrm{co}^{-}$ rolla.

Tuber; a thick and fleshy subterranean stem of no regular form.

Tubereles; small knobs or tubers.

Turgid; swollen, thick.

Twinirfg; ascending spirally.

Two-ranked; rows on opposite slues.

Umbel; an infiorescence where the fiow er-stalks diverge from the same poine in a radiated manner.

Umbellate; bearing umbels.

Umbellets; secondary or partial umbels.

Embilicate; depressed in the centre.

Umbilicus; the hilum of a seed.

Unarmed; destitute of spines, prickles, \&c.

Uncinate; hooked.

Under-shrubs; small plants with woody

Undulate; wavy. [stems

Unguiculate; claw-like; having a claw.

Unguis; the claw of a petul.

Unilatoral; one-sided.

Urceolate; urn-shaped.

Urticle; a small bag or sac, a caryopsis. which does not adbere to the seed.

Vagina ; a sheath.

Vaginate; sheathed.

Valvate; having valves.

Valves; the pieces of a pericarp which seperate naturally on riveving.

Kariety; a plant differing from the type of the species in minor particulars.

Fascular plants; plants with epiral ves. sels.

[sels.

Vascular tissue; consisting of spirai ves-

Vaulted; arched as the upper lip in some labiate flowers.

Feins; the ribs of leaves

Felutinous; velrety, clothed with a close, soft, and dense pubescence.

Velvety; as velutinous.

Venation; distribution of veins in a lea $\mathrm{f}$ Venose; veiny.

Ventral suture; the suture opening to the axis of a flower.

Ventricose; icfated, swelling out. 


\section{4}

GLOSSARY.

Veraation; the arrangement of leaves Voluble; twining. in the bud.

Verveose; warty.

Versatile; lying horizontaliy.

Tertical; at right angles with the earth.

Verticel; a whorl.

Verticellaster; a whorled cyme.

Verticeliate; in whorls, bearing whorls.

Vescicular; bladdery, having bladderlike cavities.

Vexillum; the standard of a papillinaceous corolla.

Wand; a small twig, a long reed.

Wedge-shaped; obovato, with straitish sides.

Wheel-shaped; when a corolla has a. spreading limb and a very short tube.

Whorl; flowers or leaves surrounding the stem in numbers.

Wings; lateral appendages to leaves, \&c., also the $t w o$ side petals in a papillionaceous flower.

Villous, or Villose; clothed with long Wood; the solid part of plants, composed and soft shaggy hairs.

Virgate; wand like.

Viscid; clammy, glutinous.

Vitre; oil-tubes, longitudinal canals in the substance of the fruit of Urnbel- slender tubes.
lifirous plants, containing aromatic oil. Woolly; clotbed. with long matted hairsof cellular tissue, woody fibre, spiral vessels, \&c.

Woody tissue; cells with firm and thickish walls, drawn out into tapering or slender tubes.

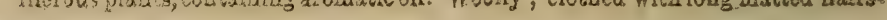




\section{ANALYTICAL TABLES.}

- BEING A

\section{Synopsis of the Genera deseribed in this work, according: to the Linnæn Artificial System.}

WITI REFERENCES TO THE NATURAL ORDERS AND PAGE.

\section{CLASS I. IIONANDRIA.-I Stamen.}

\section{Order I. MONOGYNIA-1 Pistit.}

* Flovers not glumaceous.

Hipptris.-Perianth adherent to the ovary, the border entire. Stamens inserted on the edge of the calyx.-Aquatics, with entire leaves in whorls, and minute fower sessile in the axils.

Caxxa.-Perianth unequal, scarcely lip-shaped. Stamens petaloid, only one with half an anther on its edge.-Herbaceous tropical plants, with transverse parallel-veined leaves and showy flowers.

* Flovers glumaceous (Sedges).

HIEMTCarpha,-Perianth none. Style 2-cleft.-Low tufted annuals, with bristlelike leaves at the base, and many-flowered spikes.

Spceies of Cxperda, Eriophorus, and Fimbristylis, in CYPERACE

Order II. DIGYNIA.-2 Styles or sessile Stigmas, * Flowers not glumaceous.

Callmriche. - Filaments slender. Stiyles 2, awl-shaped. Fruit 4-lobed, 4. celied, naked.-Aquatic small annuals. Leaves opposile, entire.

B:srow-Caly 3 to 5-parted, becoming juicy and berry-like in fruit.-Leaves triangular or halbert-shaped, sinuate-toothed.

* Flowers glumaccous (Grasses).

Cirrs.-Spikelets 1-flowered, in a large compound terminal panicle. Stamens opposite the 1-nerved upper palæ.

Urnoza - Spikelets several-flowered, very flat, eoriacoous.-Tufled, from creep. ing rootstocks.

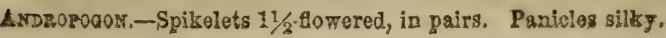




\section{CLASS Il. DIANDRIA,-2 Stamens.}

\section{Order I. MONOGYNIA.-1 Siyle or Stigma.}

\section{* Flowers with only a calyx; not glumaceous.}

ZauzIxus.-Calyx small, 4-cleft. Fruit a samara or key. Leaves pinnate.

* * Flowers with a calyx and corolla.

t. Corolla polypetalous (of seperate petals).

Canonanthes.-Petals 4, long and linear. Stamens very short. Style very short, with a notehed stigma.-Shrubs with white flowers in druoping racemes or panicles.

Curcas.-Petals 2, inversely heart-shaped. Stamens slendex.-Herbs. Ieares opposite- Plowers whitish in racemes.

$\ddagger$ Corolla monopetalous (one-petalled), regular.

Irgustrum.-Calyx 4-toothed. Corolla 4-lobed, funnel-form. Stamens on the tube of the corolla. Style very short, with 2-cleft stamens.-Shrubs with simple entire leaves and small white flowers in thyrsoid panicles.

ธิรат์ GA.-Corolla salver-form, with the limb cleft into 4 deep obtuse spreading segments. Stamens short, included within the tube. Capsule 2-celled.Oriental shrubs with simple entire leares, and white lilac or purplish fragrant flowers.

JAEMINUM.-Calyx tulular, 5 to 10-eleft. Corolla salver-form, with a long tube and a flat 5 to 10-cleft limb.-Beshy or climbing shr ubs, with opposite ccmpound leaves, and white or yellow flowers.

$\ddagger \ddagger$ Corolla 1-petalled, 2-lipped or irregular.

* Stamens irsserted on the twbe of the corolla.

Vzronica.-Calyx 4-parted. Corolla wheel-shaped, with a 4-eleft spresding border, the 2 lower segments mostly narrow. Capsule obcordate or obtuse.-Herbs, with blue, flesh-color, or white flowers.

Lasprandra.-Calyx 5-parted. Corolla tubular bell-shaped, with a 4-lobed border. Stamens and pistils at length much exserted.-Herbs, with mostly whorled leaves and white flowers in terminal racemes.

GratrouA.-Calyx 5-parted. Stamens included. Style dilated or 2-lipped at the apex.-Low herbs, with opposite sessile leaves and axillary 1-flowered peduncles.

Inzanthus.-Calyx 4-parted. Upper lip of the corolla short, 2-lobed. Sterile stamens 2 , inserted on the throat and protruded.- Sinall smooth herbs.

Heminthus.-Calyx 4-toothed, equal. Corolla 2-lipped, the upper lip very short. Style short. Capsule globulaz, 1-celled:-A small annual, with crowded opposite leaves and minute flowers in their axils.

Drasrurra.-Calyx 5-parted. Corolla deeply 2-lipped. Anthers 2-celled, the cells placed one lower down than the other.-Herbs, growing in water, with narrow entire leaves and parplish flowers:

* - Stamens inserted on the corolla or at its base.

Catalpa.-Calyx deeply 2-lipped. Corolla bell-shaped, swelling, with an irregular 5 cleft border. Sterile filaments 2 or 3.-Trees with large heartshaped leaves, and white flowers in terminal panicles.

Trzicularia.-Calyx 2-parted. Corolla personate, the palate on the lower lip projecting. Stigmas bilabiate. Capsule globular, 1-celled.-Immersed aqatics, witin dissected lcares and erect scapes, bearing ycllow or purplish fowers. 
$\$+\$$ Corolla more or less 2-lipped. Stamens in. serted on the tube of the corolla. Style 2-1obed at the apex. Fruit 4 little seed-like nutlets, surrounding the style in the bottom of the calyx. See Class 14 . DIDYNAMIA.

*** Flowers glumaceous (Sedges).

CFPERACE 玉. Species of CYPERUs, Fimbristylus, RHyxcospora, and SClrRiA. 395

Order II. DIGYNIA.-2 Styles or sessile Stigmas.

* Flowers not glumaceous.

Burum.-Petals none. Calyx berry-like or fleshy.

A мүсні A.-Petals none. Calyx of 4 sepals. Secd 1.

ILATive. Petals and sepals 2 or 3 . Seeds sereral.

** Flowers glumaceous (Grasses).

Aмтнохамтним.-Lateral flowers each of 1-awned palex, neutral; the perfect one 2-androus.-Panicle contracted or spike-like.

GRAMINE E. Species of LEersia, Brachyelytrum, and GlycrRia.

Order III. TRIGYNIA.-3 Styles or sessile Stigmas.

Spergularia.-Sepals 5. Petals 5, entire. Capsule 1-celled, many-seededLeaves fleshy. Flower:s small, reddish.

\section{CLASS III. TRIANDRIA, -3 Stamens.}

\section{Order I. MiONOGYNIA. - 1 Style or sessite Stigma.}

* Corolla 5-lobed or parted. Leaves reticulate-veined.

耳EDIA - - Border of the calyx 3 to 6-toothed and persistent or obsolete. Corolla tubular, 5-lobed, regular.-Stems forking. Leaves opposite. Flowers small, whitish.

* * Perianth 6-parted. Leaves parallel-veined.

$\ddagger$ Flowers issuing from a spathe.

Isrs.-Divisions of the perianth alternately reflexed. Stamens under the 3 large petal-like stigmas.-Flowers large, blue, white, and yellow.

Sistrrvenicar.-Divisions of the perianth equal, spreading. Stamens monodelphous. Style short, with 3 stigmas.-Leaves grassy. Flowcrs mostly blue. 369

FARDAntuUs, - Perianth regular, 6-parted. Filaments thread-like. Stigma straight or incurved.-Flowers yellowish, spotied with red.

Crocus.-Spathe radical. Perianth funnel-form. Stigma 3-cleft, conrolute, crested.-Bulbous exotics; with white, llue, and purplish flowers.

Tiarada.-Perianth-lobes oblong, upright-spreading, the alternate ones the broadest. Stamens monodelphous. Filaments united into a long tube. Style filiform.-Bulbous exotics, with yellow and red spotted flowers.

Imsrawthara.-Perianth salver-form, with a slender tube. Stamens dissimilar.-Creeping or floating herbs, with kidney-shaped leaves, and blue or white towers, 
ECEOLLERA.-Perianth salver-form. Stamens similar, with arrow-shared anthers.-A water plant with linear leaves and yellow flower's.

PAGE. ** Perianth in 2 rows, with 3 petals.

$\ddagger$ Flowers not issuing from a spathe.

Commenyna.-Calyx and corolla seperate, irregular. Stamens sometimes 6. Stigma single.-Flcwers blue or white.

XrRIS.-Calyx and corolla seperate, irregular. Stigmas 3.-F'lowers yellow, in a terminal dense head.

Juxcus-Perianth 6-parted, entirely glumaceous, regular.

\section{A. NATURAL ORDER CYPERACE \&.-Proper} perianth none, or bristle-like; the 3 stamens and single style inrested in an imbricated perianth of glumes instead of - a calyx. Fruit 1-seeded.Leaves parallel-veined.

\section{Order II. DIGYNIA. - 2 Pistils.}

AxrCHA.-Calyx 5-parted, greenish. Styles very short. Urticle 1-seeded.Flowers small, white, in the forks of the stem.

A. NATURAL ORDER GRAMINEAE.-Grasses with usually hollow stems, closed at the joints, and alternate 2-ranked parallel-veined leaves. - Stigmas feathery or hairy. Flowers green, in small spilielets. 408

Order III. TRIGYNIA. - 3 Pistils.

Stmllaria.-Calyx 5-parted. Petals 5, 2-parted. Capsule 1-celled.-Herbs.

Molnugo.-Calyx 6-parted. Petals none. Capsule 3 celled, 3-valved, manysceded.-Low anmuals, with verticellate leaves and white tiovers.

Lecina.-Calyx 3-sepalled, with 2 outer bracts or sepals. Petals 3, inconspicuous. Styles scarcely any. Stigmas 3.-F lowers ineonspicuous, greenish or purplish.

Proserpinaca-Calyx-tube i-sided, with a 3-parted limb. Fruit long, 3 angled, 3-celled, 3-sceded, nut-like.-Aquatic licrbs.

CLASS IV. TETRANDRIA, 4 Stamens, equal in length.

\section{Order I. MONOGYNIA.-1 Pistit.}

* Corolla 4-petalled. Leaves reticulate-veined.

Conxos.-Calyx-limb minute, 4 -toothed, adherent to the orary. Petals oblong spreading. Drupo 2-celled, 2 seeded.-Shrubs or hcrbs, with white flowers. 144

Lodwigia.-Calyx 4-lobed. Petals 4, equal, obeordate, often small or wanting. Capsule 4-celled, many-seeded.-F lower s often ycllow or apetalous.

* Corolla 1-petalled; 4-parted or lobed. Leaves reticulate.

* Ca'yx free from the ovary.

Bdironda-Calyx 4-parted. Corolla deeply 4 cleft, not gland-bearing. Stamena 
short. Carsule 1-celied, many-seeded.-Leaves scale-like. Flowers smail yellowish-white.

Oborasra-Calyx of 2 spreading leaflike sepals. Corolla tubular-bell-shaped, 4-cleft. Stigma 2-lipped-Plant purplish-green. Flowers whitish or purplish, solitary or in clusters of 3.

Puarago-Calyx 4-(rarely 3)-parted. Corolla tubular 4-cleft, with a reflexed border. Stamens mostly very lonr. Capsule 2-celled, opening transversely.-Leaves radical, ribbed. F lowers whitish, in a bracted spike.

BRrraret.-Calyx 4 or 5-parted. Corolla funnel-form, with a slender tube and 4 or 5-parted limb.-Leaves opposite. Fiowers rose-purple or reddish, cymose.

* Calyx adherent to the ovary or its base.

Hвртоттs-Calyz 4-lobed, persistent. Cornlla funnel-form. salver-form, or wheel-ghaped, the limb 4-parted. Stigmas 2.-Flower s blue or purplish, single or clustered.

Mrтcrzila-Flowers united in pnirs. Calyx 4-toothed. Corolla funnel-form, 4-parted, spreading, bearded inside. Oraries united.-Thailing herbs. Flowers rose-colored or white. Berries red, edible.

Czpratanthus.-Calyz smail, 4-cleft. Corolla tubular, s?ender, 4-toothed. Style much exscrted; stimma capitate.-Shrubs, with opposite leares, and white flowers in a dense globoso head.

Drpsacus.-Corolla tubular, 4-cleft, nearly regu'ar. Stamens inserted on the corolla. Fruit 1-geded, crowned with the calyx.-Coarse herbs, with opposite connate leares, and bluish or whitish fowers in large oblong heads.

* * Coroll 24 or 5-parted or none. Calyx 4 or 5-parted.

Scabrosa - Intoluere many-leaved. Calyx 5 -parted, with long bristly divisions. Cornlla tubular. Filaments much exserted-Leaves onposite. Flowers dark purple pink, or whitish, in heads.

Lrxarea.-Calyx 5-cleft. Corolla narrow, beil shaped, nearly equally 5-lobed. Stamens unequal. $-A$ traiting evergreen, with rose-colored towers in pairs.

SATgurgorea, - Calyz constricted at the throat, 4-lobed, with 2 or 3 geales or bracts at the hase externally. Petals none.-Leaves unequally pinnate. Flowers small, in close spiked heads.

IrcieM - Corolla tubular, the throat closed with the beards of the filamenta. Stamens often 5. Berry 2-celled.-Shrubs, somewhat climbing, with greenish-purple flowers.

Forrymos. - Sepa!s 4 or 5, united at the base. Petals 4 or 5 , rounded. spreading. Stamens very short, inserted on the upper face of a flat 4 or 5-angleil disk.-Shrubs, with 4 sided branches, and greenish or purplish flowers.

**** Floral envelope consisting of a single petal-lite perianth. Leaves often parallel-veined.

Syrcactsa. Sec. Malaytuenum.-Perianth spreading. Stamens 4. Berry 2 celled-F lowers racemed, white, fragrant.

Orontiva.-Flowers on a cylindical spadix. Perianth 4 to 6-sepalled. Stamens 4 to 6.-Flowers yellow, at the summit of the scape. Spathe radical. 347

STMPLOCARPC8.-Spathe honded, shell-form, pointed. Spadir roundish, corered with fiowers. Perianth deeply 4-parted. Style 4-angled.-Fhetid herb8, with large veiny leaves, and nearly sessile spathes.

\section{Order II. DIGYNIA.-2 Pistils.}

\section{* Corolla polypetalous.}


II tale, fertile. Capsula nut-like, 2-ceiled.-Shrwbs or small trces, with yellow flower's.

* Corolla monopetalous.

G.lium.-Calyx minute, 4-toothed. Corolla 4-partor, rotate. Stamens short. Fruit 2-lobed, 2-seeded.-slender herbs, with 4-angled stems, and small llowers.

Cusceta.-Corulla vell-shared, 4 or 5-eleft. Stamens 4 or 5. Capsule 2-colled, 2 to 4 -seeded.-Leafless, yellowish on redelish herls.

Giantiana.-Corolla funnel-form, 4 or 5-eleft, mostly with plaited folde. Calyx 4 or 5-parted. Stamens 1 or 5. Capsule many-secded-IIerbs, wilh opposite leaves.

Order IV. TETRAGYNIA.-1 Pistil or sessile Stigma.

* Pistils separate, free from the calyx.

Puromoraton.-Calyx 4 -sepalled. Stamens nearly sessile. Fruit 4 nutletg.Aqualic sulinursed herbs, with small greenish flowers on a spike, rising above the water.

TsLis. 1.-Sepals, petuls, stamens, and pistils 3 or 4. Carpels 3 or 4.-Small triftcd herbs, with opposite leaves.

* Pistils combined into one, fiee from the calyx.

SAaINA.-Sepals, petals, and pistils 4 or 5 . Capsule 1 -celled, several-seeded.Sinall matled herbs, with thread-like or awl-shaped leaves.

ILex.-Calyx and corolla 4 or 5-parted. Stnmens and sub-sessile stigmas 4 or 5 . Trees or shrabs, with spinose-dentate leaves.

\section{CIASS V. PENTANDRIA. -5 Stamens.}

\section{Order I. monOgYNIA. - 1 Pistil.}

* Corolla 1-petalled, regular.

A. BOR $\Lambda \mathrm{GIN} \Lambda \mathrm{CE}$ AE.-Merbs, chiefy rough-hairy, with alternate entire leaves, and symmetrical flowers with a 5-parted calyx, a reglular 5-parted corolla, the stamens inserted on its tube, and a deeply 4-lobed ovary, forming in fruit 4 seed-like nutlets. 266

1. Nemum-Corolla obliquely irrogular, naked in the throat. Stamens unequal exserted.-F'lowers cyunic.

2. Lxcursis.-Corolla regular, funnel-form, with a curved tube, and with 5 obtuse hairy seales in the throat.-F Flover's blue.

3. Sумргттим.-Corolla eylindrieal-bell-shaped, 6-toothed; the throat closed with awl-shaped scales.-Flowers white and pinte.

4. Onosmonum.-Corolla oblong or ovate-tubular, with erect or converging lobes, and a naked throat.-F'lower's yellowish-while, in spiked racemes.

5. Lituospermum.-Corolla funnel.form, open. Stamens included.-Flowers while or yellow, in leafy-bracted spities or racemes.

6. Mrosotis.-Corolla salver-form, s'sort, the throat half closed with obtuse Beales. Stamens included ou short flaments, - Flowers small, Ulue or white, in naked racemes. 
7. Mertingsia.-Corolla tubular-bell-form, elongated with a wide spreading border; scales none. - Sinooth herbs, with showy purplish-blue or white flowers, in terminal racemes or clusters.

Eerinosprexum,-Corella salyer-form. Nutlets prickly-margined.-Rough hairy and grayish herbs, with small blue flowers and bracted racemes. 268

9. Cynoctossum.-Corolla funnel-form, the throat closed with 5 ohtuse seales. Nutlets prickly all over-C'oarse herbs, with white or purplish flowers, mostly in panicled racemes.

10. Boraco.-Corolla wheel-form, with acute segments, the throat closed with 5 rays.-Rough herís, with blue flowers, in 1-sided clusters.

11. ANCEUSA-Corolla funnel-form, vaulted; tube straight, orifice closed with 5 prominent scales. Stirma emarginate.-Exotic herbs, with cyaric flowers.

12. Polmonaria.-Calyx prismatic, 5-angied. Corolla fundel-form, with a cylindric tube ; orifice hairy, in 5 lines, alternating with the stamens.Esotic herbs, with mostly blue flowers.

B. HYDROPHYLLACE - Herbs, commonly hairy, with mostly alternate and cut-lobed or compound leaves, regular 5-parted and 5-andious, blue or white flowers, in onc-sided cymes or racemes which are coiled from the apex when young.-Style 2-cleft. 271

1. Hronopayudu.-Corolia boll-skaped, the tube with 5 lnngitudinal appendares. Stamens exserted. Ovary bristle-hairy.-Kerbs, with petioled pinnately or palmately veined leaves, and cymose clustered flowers.

2. Priogria.-Corolla open-bell-shaped. Capsule 4.seeded, the 2 placentre linear-Mairy herus, with divided leaves and usually pale-blue flowers in furked racemes.

3. Cosmanthus.-Corolla broadly-bell-shaped, without scales. Orary 1-celled, bairy above.-F Flowers white or pale blue, in long uractless rucemes.

4. Eutoca.-Corolla broadly-bell-shaped. Capsule 1-celled, 2-valved, manyBeeded.-Flowern: blue or white.

б. Nrmopmun.-Caly x 10-parted, the alternate lobes reflexed. Corolla fiat-bellshaped. Stamens shorter than the corolla. Capsule 4-seeded.-Flowers Uluse or white.

C. POLEMONIACE AE.-Herbs, with alternate or opposite leaves, regular 5-parted flowers, a 3-celled ovary, and 4-lobed style. Stamens often unequal or unequally inserted on the tube of the corolla. 274

1. Pnux.-Calyx somewhat prismatis, the segments erect. Corolla salverform, with a curved slender tube; the stamens uzuqually inserted in its tube.-F loivers pinte, purple or white.

2. PoLrmoniom -Calyx bell-shaped, 5-cleft. Corolla bell-shaped-rotate, with \& short tubo.-Leaves pinnate. Flowers blue or whits, in nearly bractless cory mbs.

3. Guld.-Corolla sornewhat furnel-shaped. Stamens inserted on the inner side of the corolla-tube-Leaves alternate, pinnatifid. Flowers blue, several-flowered, in capitate clusters or panicles.

4. Ipomopsis.-Calyx tubular and membranaceous. Corolla funnel-shaped, the tube much exserted. Stamens inserted in the tube of the corolla. - Leaves finely pinnatifid. Flowers orange, scarlet, or reddish, in clus- 
D. CONVOLVULACE A.-Twining or traitingherbs, with alternate entire or lobed leaves and regular 5androus flowers. Flowers usually large and showy; opening but for one day. Stamens inserted into the base of the corolla.

PAGE.

1. Catystrgia-Ca!yx 5-parted, enclosed in two large foliaceous braets. Co. rolla bell-shaped-funnel-form, 5 -folded, the border obscurely 5 -lobed or cnfire. Stiumas 3.-Leaves heart-shaped or arrow-shaped. Flowers white or light-rose-color, on axillary solitary peduncles.

2. Corvorverus.-Culyx naked. Corolla bell-shaped or funnel-form, with a spreading nearly entire border. Stamens mostly included.-Flowers white, pink, blue, and purple.

3. Quimocir.-Spals 5, mostly mucronate. Corolla tubular-cylindrical. Stamens. exserted.-Leaves often pinnatifid. Flowers white, yellow, orange, and scarlet, delicate.

4. Orscuts.-Plant yellow or redaish, with thread-like-naked stems and small scales in place of leaves.

E. SOLANACE.ZE-Herbaceous or rarely shrubly plants, with alternate leaves, regular 5-parted flowers on bractless pedicels, and the fruit a 2-celied (rarely 3 to 5-celled) capsular berry. Corolla plaited or infolded. Stamens mostly equally inserted on the corolia. Style and stigma simple.

1. Nicomiara-Calyx tubular-bell-shaped, 5-eleft. Corolla funnel-firm or salver-form, mostly with a long tube. Capsule 2-celled.-Acrid herbs, with white flowers, tinged with green or purple.

2. Datura-Calyx prismatic, 5-toothed. Corolla funnol-form, with a large and spreading 5-toothed plaited border.-Runlc herbs, with large and showy flowers.

8. Hyoscramus.-Calyx bell-shaped or urn shaned, 5-lobed. Corolla somewhat irregular, with a 5-lobed plaited border. Capsule 2-celled, opening by a lid.-Rank herbs, with lurid flowers.

1. NiCAXDR1.-Ca'yx 5-parted, 5 angled, at length bladlery and inclosing the 3 to 5 -celled dry berry. - Smooth herbs.

5. Prirsaris - Calyx 5-cleft, at length enlarged and bladdery, and inclosing the 2-colled bexry. Corolla spreading bell-shaped.-F'lowers grenishyellow.

6. Socaxum.-Calyx 5 to 10 -rarted, spreading in fruit. Corolla mostly wheelshaped, with a very short tube. Stamens exserted, converging around the style.-Herbs or shr ubs.

7. Arrops-Calyx persi-tent, 5-cieft. Corolla bell-shaped. Berry glohose, 2 celled, situated on the calyx,-Exotics, $w$ th pale blue flower's.

8. Lroivm.-Calyx 2 to 5-cleft, short. Corolla tubular, with a mostly 5-lobed spreading limb, the orifire closed with the beard of the filaments. Stamens $t$ or 5, exserted.-Shrubs, somewhat climbing.

9. CApsicum.-Corolla wheel-form, with a very short tube. Fruit a juiceless berry, 2 to 4-celled, many-seeded.-Herbaceous shrubby plants, pervaded by a hot pungent principle.

10. Parunta.-Calyx-tube short, with a 5-cleft leafy limb. Corolla funnel-form, with a cyliudric tube, the limb in 5 unequal plaited lobes. - Exotic herbs, w wh showy flowers. 
F. PRIMULACEA, in part-Herbs, usually Tow, with perfect regular flowers, the stamens inserted opposite the lobes of the corolla on its tube, and a 1 celled ovary, bearing several or many seecks.

PAGH.

1. Primula-Calyx tubular, angled, 5-cleft. Corolla funnel-form or salversbaped. Stamens inciaded.-St 6 mless her $b s$, with the leaves in a cluster from the root.

2. Donocatheon.-Calyx deeply 5-cleft, the divisions reflexed. Corolla 5-parted, refiexed. Stamens exserted, united. Style exserted.-Smooth herbs, with clustered radical leaves, and delicate white or purplish flowers in a terminal umbel.

3. Lreimachia-Calyx 5-parted. Corolla with a very short tube, and 5-parted limb. Filaments often united into a ring at base.-Herts, with axillary or racemed yellow flowens.

4. Axtgalis.-Calyx 5-parted. Corolla wheel-shaped, with scarcely any tube, 5-parted. Fiłaments hairy. Capsule globose, the top falling off like a lid, many-seeded.-Small spreading procumbent herbs. Leaves opposite or whorled.

5. SANOLUS.-Calyx 5rcleft, the tube adherent to the base of the ovary. Corolla bell-shaped, 5-cleft, with the sterile filaments in the sinuses.Snooth herbs, with small white flowers in racemes.

8. Hоттолта.-Calyx 5-parted, with linear divisions. Corolla salrer-shaped, with a short tube.-Aquatic hierbs, with pectinate immersed leaves, and white Howers.

G. CAMPANULACE E-Herbs, with a mithy juice, alternate leaves, and scattered flowers; the regular 5-lobed corolla bell-shaped. Stamens free from the corolła, distinct. Stigmas 2 or more.

I. Campanula--Corolla nell-shaped, or rarely nearly rotate. Stamens 3 to 5 : Capsule 3 to 5-celled, opening by lateral valves.-Flowers spicute or axillary, Zlue or white.

2. Speculiria.-Corolla wheel stapcd, 5-lobed. Filaments hairy. Stigmas

3. Capsule prismatic, 3-celled.-Low herbs, with blue or white flowers. * *orolla 1-petalled, regular or irregular.

H. CAPRIFOLIACE $\mathbb{E}$, in part.-Shrubs or rarely. herbs, often twining with opposite leaves, no stipules, the calyx-tube coherent with the 2 to 5 -celled: orary. Stigmas 1 to:4. Fruit a berry, drupe, or capsule.

1. LONicerd.-Calyx 5-toothed. Corolla tubular or funnel-form, often swelled at the base, irregularly or aearly reguiarly 5-lobed. Stigma capitate: Berry several-seeded.-Climbing or erect shrubs. Leaves often connate: 145

2. Diervilia.-Corolla funnel-form, 5-lobed, nearly regular. Capsule oblong, 2-celled, 2tralved:-Low upright shrubs; with yellowish flowers.

3. Triosteum.-Calyx-lobes 5, leaf-like, persistent. Corolla tubular, swelled at the base, scarcely lunger than the calyx. Stigma capitate, lobed.Coarse hairy herbs, with the leaves comnate around the stem:

4. SYMPHORICARPUS.-Calyx 4 or 5-cleft. Corolla bell-shaped, nearly regularly. 4 or 5-lobed. Stamens 4 or 5 , inserted into the throat of the corolia. Berry 4-celled, 2-seeded.-Skrubs, with small whitish flowers in short. spires or clusters. 


\section{Herbs or rarely shrubs, with opposite entire leaves.}

VINCA.-Corolla salver-form, contorted; border 5-cleft, the tube ablique; oriflee 5-angled-Upright or trailing shrubs.

Mrsabiuss. - Perianth funnel-form, with a contracted tube, free from the ovary ; limb plaited, entire, deciduous. Stigma globose.-Showy exotics, with opposite leaves, and white, red, yellow, and variegated flowers.

Mexrantups. - Calyx 5-parted. Corolla short funnel-form, with a spreading equally 5-lobed limb, hairy within. Stigma 1 or 2-lobed. Capsule 1. celled. $-L$ caves 3 at the summit. Flowers reddish, racemed.

Eertnrax.-Calyx 4 ar 5-parted. Corolla funnel-form, with a slender tube, and 4 or 5-parted limb. Anthers after flowering spirally twisted. Capsule linear, 1 or 2-celled.-Low herbs, with rose, purple, or reddish cymose flowers.

Sabiatia.-Calyx 5 to 12-parted. Corolla rotate, 5 to 12-parted. Stamens 5 to 12. Anthers at length revolute. Stigmas 2, spirul. Copsule 1-celled.Herbs, with slender stems and handsome flowers.

Gentrana.-Calyx 4 or 5-cleft. Corolla 4 or 5-lobed, regular, with folds in the sinuses, or fringed on the throat or margins. Styie short or none. Stigmas 2.-Flowers solitary or cymose, showy.

Srigmis.-Calyx 5-parted, persistent, with slender lobes. Corolla tubularfunnel-form, 5-cleft at the summit. Style slender, hairy above. Capsule short, twin.-Herbs, with showy flowers in spikes or 1-sided cymes.

J. Herbs or rarely shrubs, with alternate entire leaves.

VERASCUM-Calyx 5-parted. Corolla 5-lobed, open or concave, rotate, the lobes nearly equal. Stamens often lairy, the anterior longer. Capsule globose, many-seeded.-Flowers in spikes or racemes.

AzALzA.-Calyx 5-parted, often minute. Corolla funnel-form, 5-lobed, slightly irregular. Filaments long, exserted, and usually declined, as well as the long style.-Upright shrubs, with showy flowers in umbelled clusters. 216

Loresia.-Caly x 5-cleft. Corolla irregular, cleft on the upper side, 2-lipned; lower lip 3-cleft; upper lip of 2 rather erect lobes. Anthers cohering and somewhat curved. Stigma 2-lobad. Capsule 2-celled, many-seeded. - Flowers blue, white, or red.

Cumponia.-Calyx, corolla, and stamena nearly as in Lobelia. Capsule siliqueform.-Procumbent herbs, with minute leaves and axillary solitary flowers.

* * Flowers 5-petalled, regular.

Curronia.-Calyx 2-leaved or 2-parted. Petals emarginate or obtuse. Stamens inserted in the claws of the petals. Style 2-cleft.-Small fleshy herbs, with a pair of opposite leaves and a loose raceme of white or recldish flowers.

Cutasrius.-Calyx minute. Petals sessile. Stamens on the margin of a cupshaped disk. Piatil on the disk. Seeds 1 or 2 in each cell, erect, enclosed by a pulpy searlet aril.-Climbing or twining shrubs, with alternate leaves and greenish flowers.

Mus.-Sepals 4 or 5 , united at the base. Petals 4 or 5 , rounded, spread. ing. Stamens very short. Style short or none.-Shrubs, with 4-sided branches, and green or dark purple flowers.

Ceanothos.-Calyx 5-lobed. Petals hood-form, on slender claws. Filaments elongated. Fruit 3-lobed, dry and splitting into its 3 carpels when ripe. -Shrubby plants, with white flowers in little umbel-like clusters.

Irza.-Calyx bell-shaped, 5-cleft, free from the ovary. Petals lanceolate, much longer than the calyx and stamens. Styles 2, united. $-A$ shrul, with white flowers in simple spicate racemes.

**** Flowers 4 or 5-petalled, regular. Fruit a drupe or berry. 
Firis.-Calyx 4 or 5-toothed. Petals 4 or 5, cohering at tise apex, déiduous. Stigma simple, sessile. Berry 2-rell ril, 1 to 4 -sceded.-Shrubs, elimbing by tendrils, with fragrant greenish flowers.

A Mrezopsis.-Calyx nearly entire. Petals 5, concave, spreading. Stigmas capitate.-Shrubby creepers, with digitate or cordate leave3, and cymose clusters of flowers.

Rramnus.-Calyx urn-shaped, 4 or 5-cleft. Petals 4 or 5, shorter than the sepals, sometimes very minute or wanting. Stamens 4 or 5 . Style 2 to 4-cleft.-Small trees or shrubs, with minute flowers.

FIBES.-Calyx bell-shaped or tubular, 4 or 5-parted. Petals 4 or 5, small, inserted into the thront of the cilyx. Stamens 5, very short. Styles 2 , distinct or united.-Shrubs, ef su with prickly branches. Fruit mostly edible.

IIEDERA.-Calgx 5-toothed. Petals 5, dilated at the base. Berry 5-seeded, surrounded by the permanent calyx.-Exotic shrubby, climbing or erect plants; with simple evergreen leaves, and greenish flowers.

***** Flowers 2, 4 or 5-petalled, irregular. Seeds in a capsule.

Vrold.-Sepals 5, auricled at their base. Petals 5, uncqual, the larger one spurred at the base, the 2 lateral equal. Stameus afprrximate, filaments distinct. Anthers connate. Capsule 1-celled 2-valved.-Low herbs, with pretty flowers on angular solitary peduncles.

SoLea.-Sepals not auricled. Petals unequal, the lowest one 2-lohed and somewhat gibbous at the base. Capsule somewhat 3-seeded.-Flowers greenish, in the axils of the leaves.

IMPATIENS.-Sepals 5, the lower one spurred, the 2 upper united so as to appear like one. Petals 2, unequal-sided and 2-lobud. Stamens short. Stigmas 5, united. Capsule bursting elasticaliy.-Herbs, with smooth succulent stems, with tumid joints.

****** Flowers with a single corolla-lite perianth.

Comandra.-Perianth bell-shaped or urn-shaped, the limb 5-ueft. persistent. Anthers adhering to the lobes of the perianth by a tuft of thread. Herbs, with alternate oblong and sessile leaves, and greenish-white flowers in terminal or axillary cymes.

Cosphrexa.-Bracts 5, colored, the 3 out r ones keeled. Sepals 5, villous. Disk cylindric, 5-toothed. Utricle 1-seeded.-Flower's in globose heads.

Celosia.-Sepals 3 to 5, colored. Stamens united at base by a plaited disk. Style 2 or 3-cleft.-Ornamental exotics.

Order II. DIGYNIA. - 2 Pistils or sessile Stigmas.

\section{* Corolla 1.petalled.}

Gentuna.-Calyx 4 or 5-cleft. Corolla 4 of 5-cleft, usually with intermediate plaited folds, appendaged at the sinuses. Style short or none; stigmas 2, persistent.-Bilter herbs, with'solitary or cymose showy flowers.

Cuscera.-Whole plant yellow or recidish; with filiform or naked stems, and small scales instead of leaves.

Apocrxor.-Calyx 5-parted. Corolla bell-shaped, 5-eleft, the base furnished with 5 triangular scales, alternating with the lobes. Anthers arrowshaped, adhering to the stigma-Plants, with milky acrid juice, opposite entire leaves, and small pale flowers.-APOCYNACEA.

A. ASCLEPIADACE AE.-Plants with millsy juice and opposite or whorled entire leaves, regular 5-ann. K* 
drous flowers, with a singular connection of the anthers with the stigma, and cohesion of the pollenmasses into wax-like masses.

1. Asctrpias.-Calyx and corolla reflexed, deeply 5-parted. Crown of 5. hooded lobes, with or without an incurved horn rising from the base of each. 290

2. Govorobus.-Corolla rotate, 5-parted. Crown a small wavy-lobed ring. Pollen-masses 5 pairs.-Twining, shrubby, or herbaceous plants, with greenish or purplish flowers.

* Corolla 5-peialted.

Becchera.-Calyx bell-shaped, coherent with the otary below, 5-cleft. Petais 5. small, entire. Capsule with 2 beaks, 1-celled.-Herbs, with round heart-shaped radical leaves, and greenish-white or purplish flowers.

Parax. - Polygamous. Calyx-teeth obsolete. Styles 2 or 3, short. Fruit a 2 or 3-celled and 2 or 4-seeded drupe, often fleshy-Leares palmately compound. Flowers white, in a single simple umbel on a long peduncle.

B. UMBELLIFER Æ.-Herbaceous plants, with hollow stems, alternate, mostty compound leaves, with their. petioles expanded or sheathing at the base. Flowers in umbels. Fruit consisting of 2 coherent carpels.

+ Inner face of the seed flat or nearly so.

1. Iydrocorrue.-Flowers small, white, in simple umbels or clusters. Fruit orbicular, flattened.-Leaves roundish or kidney-form.

2. Crantzia.-Flowers fer, in simple involucre umbels, white. Fruit globs: lar, with red vitæ.-Leaves linear, fleshy.

3. SAMTCUL - - Flowers in irregular or compound umbels, greenish or yellowish. Fruit clothed with hooked prickles.-Leaves palmately lobed or parted.

4. Daucus.-Flowers in concave umbels, white. Fruit smooth, the carpels strongly winged on the bacik and on the edge.-Ledres finely 2 or 3-pinnate or pinnatifid.

5. HerachedM.-Flowers white, the marginal somewhat radiant, in large flat. umbels. Fruit broadly wing-margined.-Leaves 1 or 2, ternately compound.

6. PaStrYACA-Fiэwers yellow, in large flat umbels. Fruit wing-margined.-Leaves pinnately compound.

7. Archatgelica.-Flowers greenish or white, in perfect umbels, with a many-leaved involucel. Capsule 3-ridged on the back-Leaves $I$ or 2 pinnately compound.

8. THAsprcu.-Flowers yellow or dark purple. Fruit elliptical or ovoid; capsule 5-winged.-Leaves 1 to 4-ternately compound.

9. Zrrn.-Flowers yellow, in perfect umbels. Fruit oval or somewhat twin, 5-ribbed.-Leaves dissected.

10. Crcota-Flowers white, in perfect umbels. Fruit sub-globose, twin.Leaves pinnately or ternately compound.

11. Siur.-Flowers white, in perfect umbels. Fruit ovate-globose-Leaves simply pinnate, with serrate leaflets.

12. Crтptotenia - Flowers white, in compound umbels, with very uncquairays, Fruit oblong--Leaves 3-parted. 
13. Archemora.-Flowers white. Fruit broadly winged.-Leaves of 3 to 9 linear or lanceolate leaflets.

PAGE.

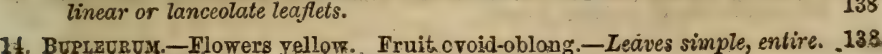

\section{CULTIVATED EXOTICS.}

15. CARUM.-Flowers white, in perfect-unabels, with various involucres. Fruit oval, laterally compressod.-Leaves dissected.

18. ApruM.-Flowers white, in perfect umbels. Fruit roundish, laterally compressed.-Leaves pinnately dissected.

17. Prypinelia -Flowers white, in compound umbels, without inwolucres. Fruit orato, ribbed, with convex intervals.-Leaves pinnately manyparted.

18. Fonicuricm.-Flowers yellow, in perfect umbels, no infolucre. Fruit elliptic-oblong.-Leaves biternately dissected.

t+ Inner face of the seed hollowed out lengthwise, or. the margins involute.

10. Chжrophylum.-Flowers mostly white, in diffuse few-flonered umbels Fruit linear-obloag.-Leaves bi or tri-ternate, with incisely cleft or toothed segments.

20. OsmormizA.-Flowers white. Inrolucre and involucels few-leaved. Fruit linear oblong, angled.-Leaves targe, 2 or 3-ternately dirided.

21. Conivm.-Flowers white. Involucre 3 to 5-leared. Fruit orate, flattened at the sides.-Leaves large, obcompound.

t + Seeds incurred at base and apex.

22. Frigenia.-Flowers white, in a leafy-bracted compound umbel. Fruit twin; carpels nearly kidney-form.-Leaves 2 or 3-ternately divided.

23. Coriandrom,-Flowers white, unilateral. Fruit globose,-Leaves bipinnate. 142 *** Flowers with a single corolla-litie perianth.

Agrvopodrcm.-Perianth 5-parted, Fartially enveloping the fruit. Utriele thin, membranaceous.-Leaves petioled, triangular or rhomboid. Flow. ers sessile, in small clusters.'

Eumos.-Perianth bell-shaped. Fruit flat, winged, 1-seeled.-Tres, with rough leares, and purplish or yeliowish flowers in lateral clusters preceding the leaves.

Gastis.-Polygamous. Ferianth 5 to 6-parted, persistent. Fruit a gloivikar drupe, with thin flesh.-Trees or large shrubs, with pointed leaves, and greenish axillary flowers.

\$chirantrus.-Dicle in the calyx-tube; stamens on its throat.-Homely little weeds, with obscure greenish clustered Howers.

PoLrGonum.-Stamens 4 to 9. Styies or stigmas 2 or 3. Achenium lenticular.-Herbs, with jointed stems.

BET4.-Perianth 5-parted. Styles very short, erect, with acute stigmas. Seed reniform, embedded in the fleshy perianth.-Stems furrowed. Flower's green in spikes or paniculate racemes.

\section{Order HI. TRIGINIA, -3 Styles or sessile Stigmas. * Corolla 5-petalled.}

Ruus.-Caiyx small 5-parted. Petals 5; ovate, spreading. Drupe dry, hairy, 1-celled, 1-seeded.-Shrubs, sometimes climbing by rooting tendrils.

Srdprixua - Sepals 5, obiong. Petals 5, with short claws. Capsule inflated, 3-celled, ferv-seeded.-Shrubs, with opposite pinnate leares. 
SPERG ULARIA.-Capsule 1-celled, many-seeded.-Low herbs, with fleshy opposite leaves and small reddish flowers.

HrPERTCUM.-Capsule 1-celled, membranaceous.-Herbs, with entire dotted leaves and yellow flowers.

* * Corolla 1-petalled, 5-paried.

Viburnum.-Calyx 5-toothed, persistent. Corolla rotate, spreading. Fruit a 1-celled, 1-seeded drupe.-Shrubs or small trees, with simple leaves and white flowers in flat cymes.

\$A seeds.-Shrubby plants, with pinnate leaves and numerous white flow. ers in cymes.

\section{Order IV. TETRAGYNIA.-4 Styles or sessile Stigmas.}

Pardassia.-Calyx deeply 5-cleft. Petals 5. Sterile stamens clustered at the base of the fertile. Stigmas 4, sessile.-Flower's solitary, terminating the long naked scapes.

Drosera.-Calyx deeply 5-cleft. Petals 5.: Styles 3 to 5, each 2-parted.-Low aquatic herbs, with the leaves clothed with reddish gland-bearing bristles.

\section{Order V. PENTAGYNIA. - 5 Pistils.}

Aralid.-Calyx with the margin very short, 5-toothed. Petals 5, spreading. Berry 5-celled.-Low trees, shrubs, or herbs, with 2 or 3-ternately or pinnately compound leaves.

Iiscu.-Capsale sub-globose, 10-valved, 10.celled-Herbs, with simple and sessile leaves, and blue or yellowish flowers.

STATICE.-Calyx funnel-form, 5-toothed. Petals 5, united at base.-Salt-marsh plants, with thick radieal leaves, and small flowers, in a compound corymb.

ARMeria.-Calyx tubular bell-shaped, 5-angled. Petals 5, nearly distinct-Leaves mostly linear, radical. Flewers rose-colored, on a simple seape. 225

Zuxтновiza.--Sepals and petals hypogynous, distinct. Follicles membranaceous, compressed, 1-seeded.-Leaves pinnately divided. Flowers dull purple.

\section{CLASS VI. HEXANDRIA.-6 equal Stamens.}

\section{Order I. MONOGYNIA:-1 Pistit.}

* Flowers with both calyx and corolla. Leaves reticu. late-veined.

BERBERIS.--Sepals 6 , mostly with 2 bracteoles at the base. Petals 6 , with 2 glands upon their claws. Berry 2 or. 3-seeded.-Shrubs, with yellow wood, and pale yellow flowers.

LEoxTice.--Sepals 6, naked without. Petals 6, with a seale at base within. Style short. Seeds naked on their thick seed-stalk, resembling drupes. - Herbs, with 2 and 3 ternate leaves and greenish flowers.

Fuorria - Sepals 3, longer than the 3 petals. Style 2-cleft. Ovaries 3 , tuberculate. $-A$ small aquatic, with pinnately divided leaves.

Prsvos.-Flowers mostly dioecious or polygamous. Calyx minute, 4 to 6 toothed. Corolla somewhat rotate, mostly 6-parted. Fruit a drupe, with 4 to 6 seeds. - Shrubs, with alternate leaves. 
Gyxamdropsis.--Sepals 4, spreading. Petals 4, unequal. Pod linear-oblong, raised on a loug stipe-Leaves digitute. Flowers racemed.

Crromz.-Petals 4, minute or roundish. Stamens 4 to 6. Pod sessile or stipitate. =Leaves simple ar digitate. Flowers purplish.

* Perianth in 2 rows. Leaves parallel-veined.

Fradiscanma.-Calyx s-leaved. Petals 3. Filaments bearded. Capsule 2 or 3-celled.-Leaves keeled. Flowers purple, rose-color, or white.

Commelyna.-Flowers irregular. Stamens unequal. 3 of them fertile, one of wbich is bent in ward: 3 of them sterile and with smaller filaraents, naked. Stems branching.

* * * Flowers with a single corolla-like perianth. Leaves parallel-veined.

4. LILIACE E.-Herbs, with parallel-nerved, sessite, or sheathing leaves, regular perfect flowers, with a petallike 6-merous perianth, free from the 2 or 3-celled ovary. Anthers attached by a point. Style single: stigma simple or 3-lobed.

\section{Not Bullious.}

I Fruit a few-seeded berry, 2 or 3-celled.

1. Asparagus.-Perianth 6-panted.-Stems much branching. Leaves threadlike or bristle-form.

2. Pozrgonatum.--Perianth tubular, 6-cleft, bearing the stamens above the middle.-F lowers axillary, greenish.

3. Sminacina.--Perianth 4 to 6-parted, spreading, the stamens borne on the base.-Flowers white, in a terminal raceme.

4. Cunton1A.-Perianth 6-narted, bell-shaped, the stamens at the base of the segments.-F' $F^{\prime}$ wers greenish, umbelled.

5. Convallaria.--Perianth 6-parted, round bell-shaped. Stamens divergent. Flowers white, fragrant, in a single rank.

+ Fruit a few to many-seeded capsule, 3-celled.

6. Hemorocalurs.--Perianth funnel-form, lily-like. Stamens declined. Seeds globular, black.-Leaves linear, keeled. Flowers yellow or reddish.

7. Fuxmia.-Perianth funnel-bell-shaper, 6-parted. Stamens declined: Seeds very numerons, flat.-Leaces more or less heart-shaped. Flowers white or bluish, on bracted scapes.

8. Asphodelus.-Perianth 6-parted, spreading, with 6 valves covering the ovary. Capsule globular, many-seeded.-Exoties.

\section{Root Bulbous.}

9. Orntrhogaldu.-Style 8-sided.-Leaves linear, radica!. Fiower s corymbed, white.

10. Aluum.-Flowers umbelled, from a spathe.-Strong-scented herbs, with mostly radical leaves and the flowers in a simple umbel.

11. Hyacrnzthus.-Perianth sub-globose or bell-shaped.-Exotics. Flowers mostly very fragrant.

12. Poltanthus.--Perianth funnel-form, incurved. Filaments inserted into the throat. Stigmas 3-cleft,-Exotics. Flowers fragrant, white. 


\section{$\ddagger \ddagger$ Fruit a many-seeded 3-celled loculicidal capsule.}

PAGB.

13. Lilium.-Perianth funnel-form or bell-shaped, colored.-Stcm leafy. Flowers large and showy.

11. Erxthroniom.-Capsule ohovate triangular.-Leaves 2, smooth, sheathing the base of the i-flowered scape.

15. Frittilaria.-Perianth bell-shaped; with a broad base and necteriferous cavity above the claw of each segment.-Flowers showy, but ill-scented.

16. Tulipa,-Perianth bell-shaped. Stigma thick,-Leaves radical. Flowers showy, solitary, on a scape.

*** Not Bulbous. Leaves threact-margined.

17. YUCCA.-Perianth globular or bell shaped. Style none. Seeds fiat-Erergreen herbs, with thread-margined leaves and numerous white flowers in a terminal panicle.

B. AMARYLLIDACE ZI.CRiefy bulöous and'scapebeariny herbs, with linear fat radical leaves, and regular: 6-androus flowers, mostly issuing from a spathe.

1. Amarylits.-Perianth 6-parted, petaloid. Stamens inserted on the throat of the perianth,-Flowers solitary, issuing from a 1 or 2-leaved spathe.

2. AGavE.-Perianth tubular-funnel-form, 6-parted.-Leaves mostly thick and tleshy, whorled around the base of the scape.

3. Frpoxis.-Spathe 2-leaved, rery small.-Leaves grassy, linear. Flowers yellow, on slender scapes.

\section{Cultivated Exoticsi}

4. Galanthus.-Sepals 3, concave. Crown of 3 small emarginate, petal-like segments. $-F$ lowers white, appearing in early spring.

5. Narcissus.-Perianth with 6 regular spreading segments. Crown monophyllus, bell-form, salver-form, or with the tube funnel-form. Stigma 3-parted.-Flowers yellow, straw-color or white, issuing from a withering spathe.

6. Ledcosum.-Perianth regular, 6-parted, with equal spreading segments.Flowers numerous, white, issuing from a terminal spathe.

C. Flowers whitish, yellou, or sometimes rose-color and purplish.

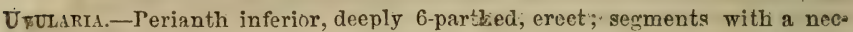
teriferous cavity at base. Filaments very short, growing to the linear anthers. Capsule 3-angled, or 3-lobed,-F lowers pale yellow, mostly. solitary.

Prosartes.-Perianth 6-leaved, bell-shapedispreading. Stigmas short, rocurved. Berry ovoid, pointed, 3 to 6 -seeded, red.-Flowers greenishyellow, terminal, drooping.

Straptopus.-Perianth 6-leaved, bell-shaped at the base, the 3 inner-sepals keeled. Anthess arrow-shaped, 1 or 2-pointed, longer than the filament. Flowers small, axillary, on thread-like peduncles.

Atgrris.-Perianth cylindrical, tubular-bell-shaped, rough-wrinkled on the outside, 6-cleft at the summit. Style awl-shaped, 3-cleft at the apex.Leaves spreading clustered. Flower's whitish, in as slender spiked raceme. 367, 
Pontederia.-Perianth inferior, 6-cleft, 2-lipped, the fleshy persistent base inclosing the 1-seeded fruit. Anthers oval, blue.-Aquatic herbs, with violet-blue flowers.

\section{+ Flowers on a spadix.}

Orontrem.-Spadix cylindrical, covered with flowers. Perianth of 4 to 6 truncate concave sepals. Utricle 1-seeded.-Aquatic herbs, with a yellow spadix.

Aconus.-Spathe leaflike. Spadix cylindric, covered with flowers. Sepals 6, distinct, coneave. Utricle 1 to few-seeded.-Pungent aromatic herbs.

**** Perianth single, glumaceous. Grass-like herbs.

Juncus.-Perianth 6-leaved. Stamens 6, sometimes 3. Stigmas 3. Capsule 3celled, many-seeded.-Stems pithy. Flowers greenish or brownish.

Luzcld-Perianth 6-1 linear, equitant. Flowers in a simple raceme.

Order II. DIGYNIA.-2 Sty?ez or sessile Stigmas.

Porroovum.-Sepals 5. Fruit lenticular.-Stens jinted. Flowers small.

Order III. TRIGYNIA.-2 Styles or sessile Stigmas.

* Perianth 5 or 6-parted, petal-like. Leaves netted-veined.

Polraonom.-Sepals 5. Achenium triangular.-Stems jointed. Flowers small. 303

RuMEx.-Perianth 6-leaved, the 3 inner semewhat colored. Achenium triangular.-Coarse herbs, with greenish flowers.

Smitax.-Perianth duciduous.-Cimbing skrubs or rarely herbs, often priclely. $\quad 372$ * Periunth 6-parted. Leaves parallel-veined.

A. MELANTHEE.-Herbs, with acrid and poisonous properties. Stems simple or rarcly panicled. Perianth mostly persistent or withering away, the divisions mostly distinct.

† Flowers polygamous. Anthers heart-shaped or kidney-shaped.

4. Mecantircus.-Perianth-sogments somewhat heart-shaped, with 2 glands at the base, and the stamens on the long claws.-Flowers cream-color, racernose.

5. Vekatrum,-Perianth free from the ovary, the divisions obovate or oblowg, longer than the stamens. - Leuves plaited, 3-ranked. Flowers racemcpanicled.

I Flowers perfect, racemed or spiked.

6. Amianmemex.- Perianth free from the ovary, the divisions separate and contracted at the base. Anthers heart-shaped. Styles filiform. $-F$ luneers handsome.

7. Heronias.-Perianth of 6 spatulate-oblong sepals. Anthers roundish-oval, blue. Styles revolute.-Leaves lanceolate. Flower's palte-purple, in a short dense raceme, on a naked scape. 
B. TRILLTACE E.-Herbs, with simple stems, whorled net-veined leaves, and rather large terminal mostly solitary trimerous flowers.

1. Trinlrum.-Sepals 3, lanceolate, spreading. Petals 3, Jarger. Perry s-sided, 3-eelled. - Low herbs, with a simple stem bearing at the top a whorl of 3 broadly ovate leaves, and a terminal large flower.

2. Msdrom.-Perianth revolute, of 3 sepals and 3-petals.-Stem simple, with a whorl of 5 to 10 leaves near the middle and another of 3 smaller ones near the top.

C. JUNCAGINER-Marsh-herbs, with petiole-like leaves, without a blade, and the greenish perianth consisting of 3 petals and 3 sepals.

1. Trigrochin. - Sepals and netals nearly alike, ovate, concive. Anthers oval, on short filazents.-F lowers small, greenish, in a spilced raceme.

2. Schzuchzeri.-Sepals and petals oblong, spreading. Anthers linear.Leaves grass-like, sheathing the simple stem. Flowers fow, in a loose raceme, with sheathing bracts.

*** Flowers with neither calyx nor corolla. Leaves net-veined.

Saununes-Fiowers white, in a solitary spike. Scales 1-flowered--Aquatic. Leares hoart-shaped.

\section{Order XiII. Polygynia.-Many Pistils.}

Aursus.-Sopais 3, green. Petals 3. Aq eaticherls, with radical ribbed leavcs, and small white or reddish flowers in a branched panicle.

\section{CLASS VII. BEPTAIDDRA, -7 Stamens.}

Trienarys.-Calyx deeply 6 to 8 parted. Coroila deeply 6 to 8 (mostly 7)-parted, spreading. - Leaves whorled at the summit. Flowers few, white, on solitary peduncles.

ZRsculis.-Calyx beli-shaped, 5 -toothed. Petals 4 rarely 5 , more or less unequal, with claws.-Thees or shrubs, with 5 to 7 -foliate leaves.

Order II-IV. Dr-Tetragynia. - Styles or stigmas 2 to 4. Pourgonun.- Sepals colored, mostly 5. Orary 1-celled-Dtems jointed. $\quad 303$ ULmos.-Filaments long and slender. Styles 2, short. Fruit a 1-celled 1-seeded samara, winged all around.- Trees.

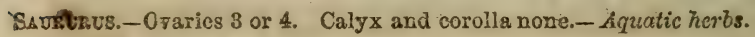

\section{CLASS VIII. OCTANDRIA-8 Siamens.}

\section{ORder I. MONOGYNia.}

* Corolla polypetalous, free.

J Emergomi.-Sepaie 4. Petals 8. Stigma peltate.-Seape sitnple, 1-flowered. I7 arropiry.-Sepale 4 or 5, colored. Petals 4 or 5, fleshy.-Parastic tawny white herbs. 
* * Corolla of 4 petals.

\section{+ Petals on the summit of the adherent calyz-tube.}

RHвXIA-Calyx-tube urn-shaped, narrow at the apex, with a 4 cleft limi. Petals obovate. Anthers Iong, curred.-Leaves 3 to 5-nerved. Flowers cymose, purplish.

Iprosicu.-Calyx-tube 4-sided, the limb 4-parted. Anthers short, fixed by the middle. Stigma often with 4-spreading lobes. Seeds crowned with a tuft of hairs.-Herbs, with nearly sessile leaves.

Exorefr. -Calyz-lobes 4, refiexed. Anthers mostly linear. Stigma 4-lobed or capitate.-Herbs, with mostly yellow flowers.

G.stR -Calyx-tube much prolonged beyond the crars, with a 4-cleft refiezcal limb. Petals somewhat unequal, - F lower's rose-color or white.

++ Petals unequal.

Cardiospenmex.-Sepals 4, the 2 outer smallest. Petals 4, each with an emarcinate scale at the base. Stanens unequal. Style trifid.-Climbing herbs, with biternate leaves.

*** Corolla monopetalous.

- Flowers with a corolla-like perianth.

1. THYMELACEA.-Shrubs, with acrid and very iough bark, entire leaves and perfect flowers.

1. Drncs-Perianth colored, tubular-funnel-shaped, the border wavy or obseurely 4 -toothed. Stamens long and slender. Drupe oval.-Flowers light yellow, preceding the leaves.

2. DApHre.-Perianth 4-cleft, marescent; limb spreading. Drupe 1-seeded.Exotic shrubs, with the leaves from terminal buds and the flowers from lateral.

I Flowers with both calys and corolla.

Ozrcocces.-Calyx superior, 4 cleft. Corolla 4 -parted, with lone revolute divisions. Anthers tubular, 2-parted.-Slender trailiny shrubs, with evergreen leares.

Mrxzresi. -Calyx bell-shaped, deeply 4-cleft. Corolla 4-cleft, globose. Capsule 4-celled, 4-valved.-Heath-like shrubs, with evergreen leaves.

7.Ccrvicx-Caiyx adherent to the ovary, 4 or 5 -toothed. Corolla ovoid, bellshaped, urn-shaped or eylindrical.-Shrubs.

Trop zoldr.-Calyx 4 or 5-cleft, colored, spurred. Petals 4 or 5, unequal. Fruit 3 indehescent 1-seeded nuts.-Straggling or twining herbs, with a pungent juice.

ACsR-Polygamous, Capsule a doubie samara-Leaves opposite.

\section{Order II. DIGYNIA.-2 Pistils or sessile Stigmas.}

Acen.-Calyx 5-lobed or 5-parted. Petals 5 or more. Stamens 6 to 8 . Sama. ra 2-winged, united at base, 1-seeded.-Trees, with simple palmatelylobed leaves, and mostly polygamous flowers.

Tiurs._Capsule a single 1-celled samara.-Trees, with alternate leares.

Order III. TrIGYNIA.-3 Pistits.

CARISOspienicy.-Calyx 4 or 5-cleft, colored. Capsule interseiy heart-shaped: many-seeded. - Low herbv, with fleshy leaves and small towers. Li] 
PcLrgondr.-Perianth mostly 5-parted, Frtalnid. Achenium triangular or lenticular.-Herbs, with jointed stcres and small flowers.

PAGE.

\section{CLASS IX. FNNTAIUDRIA,-9 Stamens.}

\section{ORDER I. MONOGYNIA.}

A. LAURACE BE.-Aromatic trees or shruls, with alternate simple leaves and ciustered flower's. $\quad 307$

Order III. TrigYNIA.-3 Pistils.

Tievur-Perianth colored, C-petalled, persistent. Stigmas multipid, refiexed. Achenia 3-angled.-F lowers fasciculate, in racemose pauicles.

\section{CLASS X. DECANDRIA, - 10 Stamens.}

\section{ORDER I. MONOGYNIA. - I Style.}

* Flowers polypetalous.

\$ Flowers irregular (mostly papillionaccous.)

Baptisi..- Petals 5, nearly equal. Legume stalked in the rersistent calyr.Herbs, with palmately 3 -foliate leaves, and racemed yellow or blue tlowers.

Cercrs.-Petals with claws. Stamens unegual-Trees, with simple round heart-shaped leaves and rose-colored flowers.

Cassia.-Petals 5, unequal. Stamens unequel, 3 lower ones longest.-ITcrbs, with abrupt pinuate leaves and yellow towers.

$+\ddagger$ Flowers regular or nearly so.

Deconix.-Petals and stamens on the tube of the calyx; 5 stamers very long, the alternate ouns shorter.-Herbs, with crposite or whorled leaves and axiilary clustered flowers.

Ceetrra.-Corolla of 5 distinct petals. Style sleriler. Stigmas 3. Capsule 3-celled, 3-valved.-Shrubs, with alternate leaves and white fowcrs.

LEDUr.-Stamens 5 to 10, exserted. Capsule E-celled, 3-valvert.-Low evergreen shrubs, with white flowers.

Irroua.-Petals converging. Filaments awl-shr.ped. Style long, mostly declined. Stigmas 5.-Low smooth evergreen herbs. Leaves roundish. Flowers in a raceme.

Crmarmu,-Petals widely spreadiug. Filaments dilated and hairy in the middle. Style very short and top-shaped, covered by a broad 5-crenate stigma.-Evergreen herbs, with fragrant white or purplish flowers, corymbed or umbelled. 
* Corolla monopetalous.

Facciverai.-Ca!yx acherent to the orury, \& or 5-toothed. Corolla oroid, bellEhaped, urn-shaped or cylindrical, 4 or 5-eleft. Style erect, longer than the stamens. Berry globose.- Shrubs or undershrubs, with white or reulish fiowers.

Gitztriaria.-Corolla opoil-tubular, the limb with 5 small rerolute lobes. Berry globular, rec.- - Spicy evergreen low herbs, with white flowers. 212

Érgea.-Corolla salver-form, with a 5-parted border and a long tube, villous within.-Irailing evergreen leer's, with pale rose-colored fragrant flowers. 213

AxDroxed.-Corolla oroid-cylindrical. Capsule 5-celled,5-valved, many-seeded.-Shrubs, with racemed or clustered flowers.

RenodonA.-Corolla irregular aud 2-lipped; the upper lip 3-lobed or 3-cleft, the lower 2-parted. Stamens declined.-A shrub, with pale purple flowers. 215

RuODoDnNDRox.-Carolla mostly bell-shaped. Stamens and style mostly declined.-Shrubs, with glossy evergreen leaves, and large showy Lotrers, in terminal corymbs or clusters.

FALMA-Corolla between wheel-shaped and boll-shaped, 5-jobed, with io depressions which hold the anthers. Style struight.-Evergrcen shrubs, with showy flowers in umbel-like corywbs.

Preropora.-A lenfiess purplish-broñ herb, destitute of green. Coroila orate-urn-shaped, 5-toothed.-Flowers in a raceme.

OrDER II. DIGYNIA.-2 Styles or sessile Stigmaz.

IIIDRIFGE1.-Mirinal fowens, often sterile and radiant. Petalsovate, segsile. Stamens 8 to 10, slender. Capsule 2-celled, many-seeded, opening by a hole between the 2 persistent styles.-Shruls, with opposite petioled leaves and numerous flowers in compound cymes.

Sasirrian-Calyx deeply 5-cleft. Petals 5, entire, with short claws. Capruie 2-beaked.- Herbs, with cl ustered roct-leaves and yellow white and greenish flowers.

Mirmel.1.-Petals 5, inserted into the calyx, slender, pinnatifid.-Stonder herì, with round eordato leaves, aud sinull greenish and white Howers.

IJAREILA-Petals 5, with claws, entire, inserted into the ealyx. Stamens long and slender.- Herbs, with racical oordate leares aud white flowers.

Saponaria.-Calyx tubular, 5-toothed. Petals 5, with long elaws. Cansule oblong, 1-celled, 4-toothed at the apex.-Flowers cymose ciustered.

Disxrecs.-Calyx tubular, with scaly bractlets at the base. Petals 5, mith long claws.-Ornumental plants, with very showy aud fragrant flowers.

Scleranthes.--Sepals 5, united bolow in an indurated cup, inclosing tive 1 seeded utriele.-Honely weeds.

\section{Order III. TRIGYNIA.-3 Pistils.}

Sinexe.-Calyx tubular, 5-toothed, naked. Petals 5, with claws, mostly crowned at the orifice; limb bifid. Capsule 3 -celled at base, opening by 6 teeth at the top.-Flowers solitary or in cymes.

Stzliaria.-Calyz 5-sepalled. Petals 5, 2-parted. Cupsule 1-celled, 3 or 4 valved.-Smail grass-like herls, with white tlowers in forked cymes.

Arexana.-Calyx 5-sepulled. Petals 5, entire, Capsule 1-celled, 3-ralved.Flower's white.

\section{Order V. PENTAGYNIA. -5 Pistils.}

Lrenvis.-Calyx tubular, 5-toothed, naked at the base. Petals 5, with claws, limb slightly cleft,-Corolla sometimes crowncd. 
Cenastium.-Calyx 5-sepalled. Petals 5, bifid or emarginate.-Flovers white, in terminal cymes.

SPERguLA.-Calyx 5-parted. Petals 5, entire-Leaves in whorls. Flowers

white, cymose.
MoLLeGo.-Sepals:5, united at base. Styles short.-Homely herbs, with vert:cellate leaves and small white solitary flowers.

Oxalrs.-Sepals 5, free or united at base. Petals 5. Stamens uneqal, more or less monodelphous.-Herbs, with leaves of 3 inversely heart-shaped leafiets.

SEDCM. - Sepals and petals 5, rarely 4. Carpels 5, many-seeded, with a little
scale at the base of each. - Thick-leaved herbs, with cymose flowers.

SEDEM- - Sepals and petals 5, rarely 4. Carpels 5, many-seeded, with a little
scale at the base of each.-Thick-leaved herbs, with cymose flowers.

Pentronum.-Sepals 5, united at base. Petals 5 or nore. Carpels 5, united at the base in to a 5 .beaked, 5-celled capsule.- Tpvight herbe, with yellowisisgreen flowe ss.

- Pontrlacca.-Sepals 2, adherent to the base of the eansule, which opens by a lid.-Fleshy herbs.

\section{Order X. DECAGYNIA. - 10 Pistils.}

ParrosAcca, - Perianth 5-leaved. Berry depressed, 10celled, 10-seeded.

\section{CLASS XI. DODECANDRIA,-12 to 19 Stamens.}

\section{ORDER I. MONOGYNIA.-1 Pistil.}

Po:1sisia.-Sepals 4, distinct, spreading. Petals 4 , unequal, with claws.Strong-scented herbs, with digitate leaves.

+ Petals 5 to 9. (Stamens sometimes 6 to 20.)

PDopHrirur.-Sepals oval, caducous. Petals 6 to 9, obovate concave. Derry large, oroid, 1-celled.-Leaves 2 , 1-sided, palmately lobed.

Hodsomia,-Calyx 5-cleft. Petals 5. Stigma simple.-Bushy heath-tike smali shrubs. F'lowers small, brigit yellow.

LrcuI4.-Calyx 3-sepalled, with 2 outer bracts or sepals. Petals 3. Stamens 3 to 12. Stigmas 3. Capsule becelled, 3-valved,-Flowers very small, greenish or purplish.

Portedacci.-Calyz 2parted. Petals 4 to 6, equal. Stamens 8 to 20. Style inostly 5-cleft.-Fleshy herbs.

rannum,-Sepals 2, ovate. Petals 5. Stamens 10 to 30 , inserted with the petals into the torus. Style filiform, 3-cleft.-Fleshy herbs.

CipHea.-Calyx tubuiar. Petals very unequal, 6 or 7 . Stamens in 2 sets. Stigma 2-1obed.-Herbs, mostly clammy.

$\ddagger \ddagger$ Corolla monopetalous.

SABBATtA.-Calyx 7 to 11-parted. Corolla 7 to 11-parted, wheel-shaped. Style 2-parted. Capsule 1-celled.-Flower's showy.

As.RUM.-Perianth bell-shaped, with a 3-parted limb. Style united, bearing 6 radiating crested stigmas at the apex.-Leaves kidney-shaped.

\section{ORDER II-VI. DI-HEXAGYNIA.-2 to 6 Styles or Stigmas.}

HYPERicum,-Petals 5. Styles 3 to 5. Capsule 1-celled, manj-seeded.-Flow ers yellow. 
ElOdEA.-Sepals 5. Petals 5, oblong. Stamens 9 (rarely 12 to 15) in parcels. Styles 8, distinet.-Flower's purplish.

REsepA - Sepals many. Petals 4 to 7 , unequal, oft turned to one side.-FYowers very small,

\section{CLASS XII. ICOSANDRIA,-Mre than 10 Stumens placed on the calyx.}

A. AMYGD ILEA $\rightarrow$ Culyx entirely free from the solitary ovary, decidunus. Style teminal. Finit a drupe (stone-fruit.) Trees or shrubs, with simpie leaves, the bark exuding gum.

1. Preves.-Drupe oral or oblong, covered with a glaucous bloom, the stone flattish, smooth, 2-edged.-Small trees.

2. Cerasus.-Drupe globular, without a bloom; stone round, smooth.-Tices or shrubs.

8. PER iOA.,Drupe rery floshy. tomontose or smooth; stone somewhat compr ssed, acute, rugosely furrowed and perforated on the surface.-Sincull trees.

4. AMrgDilus.-Stone perforate and furrowed, orate, compressed, one edge acute, the cther broad, obtuse.-Shrubs, with reddish flow: $r$ s.

B. ROSACE $\mathbb{E}$, propor-Calyx free fiom the ovaries, but sometimes enclosing them in the tube. Pistils few to many. Finit achenia or follicular.

+ Pistils mostly 5, forming few-seeded follicles in fruit. Style terminal.

5. Spir.ta.-Calyx 5-cleft. Petals 5, roundi:h, equat. Carpels 3 to 12, distinct.-Shrzbs or herbs, with white or rose coiored flowers.

6. Girtexia.-Calyx tubular, bell-shaped, 5-cleft. Petals 5, lincar-lanceolate. Stamens 10 to 20. Carpels 5, distinet.-Herbs, with 3-foliate incised leaves and whitish flowers.

+ Pistils mostly numerous, forming seed-like achenia

or little drupes in truit.

7. Aarrmovia.-Petals 5. Stamens 12 to 15. Styies 2. Achenia 2, invested by the hardened calyx.-Herbs, with yellow Hlowers,

8. Saredisored-Calyx 4-oleft. Petals none. Stamens 4.-Herbs, with unequally pinnate leares.

9. Poterium.-Flowers monœcious. Calyx-limb 4 -part. d. Stamens 20 to 30. Stylle filiform.-Leaves unequally pinnate.

10. Grou.-Calyx 5-eleft. Petals 5. Stamens numerous. Style long, persistent. Achenía hooked.-Leuves pinnate or lyrate.

11. Watdsterint - Calyx 5-oleft. Putals 5 to 10. Stamens many. Styles 5 or 6. - Low herbs, with 3 to 5-lobed or dirided leaves, and small yellow flowers on bracted scares. 
12. Dalrbarda.-Calyx deeply 5 or 6-parted, 3 of the divisions larger and toothed. Stamens numerous. Styles 5 to 8,-Low herbs, with creeping and tufted stems, roundish heart-shaped leaves and white flowers.

13. RUBUS.-Stamens numerous, inserted into the border of the disk. Style nearly terminal. Fruit composed of many pulpy carpels, aggregated on a spongy receptacle.-Half shrubby plants, ar med with prickles.

13. Rosa.-Calyx-tube urn-shaped, fleshy. Pistils numerous, inserted on the hollow receptacle that lines the ealyx-tube.-Prickly shrubs, with oddpinnate leaves, and showy mostly red and white flowers.

$\ddagger \ddagger \ddagger$ Calyx open and flattish. Stamens and pistils numerous. Fruit of dry achenia or immersed in the juicy receptacle.

Potentilla.-Recptacle fattish, dry. Caigx 10-eleft. Petals 4 or 5.-Herbs or rarely shrubs, with compound leaves and solitary or cymose flowers. 433

Fragaria.-Receptacle enlarged and juicy in fruit, bearing the minute achenia over its surface.-Low herbs, with vunners, radical 3 -foliate leaves, and white flowers.

C. POMEF.-Catyx-tube thick and fleshy in fruit, (forming a pome,) including and cohering with 2 to 5 ovaries. Trees or shrubs, with alternate simple or compound leaves.

15. Crategrs.-Stamens 10 to 15 , or many. Styles 1 to 5 . Carpels long in fruit.-Thorny trees or shrubs. Flowers mostly white, in corymbs.

16. Amalanchisr.-Stamens many. Styles 5. Pome 8 to 5-celled.-Small trees or shrubs, with simple serrate leaves and white flowers in racemes, 109

i7. Prous.-Stamens numerous. Styles 2 to 5. Carpels thin in fruit, 2-seeded. -Trees or shrubs, with simple or pinnate leaves and white or reddish flowers in cymose corymbs.

18. Crdonia.-Stamens many. Styles 5. Pome 5-carpelled.-Shrubs, with simple leaves and mostly solitary flowers.

\section{Order I-V. MONO-PEntagynia.-1 to 5 Pistit.}

OPUNriA.-Stamens numcrous, shorter than the petals. Style with numerous erect stigmas.- Stem composed of many flat and oroad fleshy joints, bearing clusters of bristles or spines.

DECODEN-Calyx short, 10-toothed, 5 teeth longer and spreading-Leaves whorled or clustered. Flowers axillary, purple.

Cuphia.-Petals 6 to 7 , unequal. Stamens 12, in 2 sets.-Leaves opposite, entire.

Casrcanthus.-Calyx-lobes imbricated in many rows, colored, leathery or fleshy.-Shrubs, with dull-purple fragrant flowers.

CLASS XIII. POLYAIVDIA.-Mamy Stamens inserserted on the Receptacle.

Order I. monogynia.-1 Pistit.

Trura.-Fruit leathery, globular, by abortion 1-celled, 1 or 2-seeded-Trees, with cordate leaves and small cymes of flowers. 
Heriavthamox-Sepals 5 , the 2 outer smaller.-Herbs, with yellow fowers, opening only in sunshine.

PAGE.

Acr.zA.-Sepals 4 or 5. Petals 4 to 8 , spatulate. Berry manyaseeded. Stigma depressed.-Leaves ternately divided. Flowers white, racemed.

CimicirdGa.-Petals 3 to 8, spatulate, small, on claws, 2-horned at the apex. Pistils 1 to 8 , forming dry follicular carpels in fruit.-Flowers white, in long sleuder racemes;

SARRACEx1. - Petals and sepals 5. Style umbrella-shaped-Leaves pitchershaped, inflated. Fowers large, 8 litary, on a scape.

NrurpheA.-Sepals 4. Petals numerous. Et'gma surrounded with rays.Aquatics, with showy white or rose-colored fragrant flowers.

NCPHAR.-Sepals 5 or 6, concave, colored within. Petals numerous, small, and stamen-like. Stigma discoid, with permanent rays.-Leaves floating. Flowers yellow.

Peiladelphos.-Calyx 4 or 5-parted. Corolla 4 or 5-petalled. Style 4-cleft. Capsule 4-celled, 4-valved.-Shrubs, with opposite leares, and white flowers.

A. PAPAVARACE EE.-Herbs, with milky or colored juice, alternate, simple, or divided leaves, and regular flowers with fugaceons sepals. Flowers solitary, on long peduncles, never blue. Sepals 2 or 3, falling of when the flower expands. Style short. 20

1. Savguraria. - Sepals 2. Petals $\delta$ to 12, in 2 series. - y low herl, with thick prostrate rootstocks filled with scarlet juice.

2. Meconopsis.-Sepals 2, hairy. Petals 4. Stigmas 4 to 6, radiating.-Herbs, with a yellow juice and pinnatifid leaves.

3. Argemorz.-Sepals 3. Petals 4 to 6 . Stigmas 4 to 6 , radiate-Herbs, with prickly spines and yellow juice.

4. Chelidonivm.-Sepals 2, smooth. Petals 4. Stigma 2-lobed.-Herbs, with brittle stems and yellow juice.

5. Paparer.-Sepals 2, concave. Petals 4. Stigma sessile, united in a flat 4 to 20-rayed crown.-Exotics.

6. Eschscholtzia.-Sepals 2, cohering by their edges. Petals 4 . Stigmas 4 to 7 , sessile.-Giaucous herbs, with 2 to 3 pinnatifid leares, with linear segments and yellow flowers.

See Hudsonia, Podophyllum, Portelacca, Talinum, Hypericum, Reseda and Cuphea in Class Dodocaudria.

\section{Order II-XIII. DI-POLYGYNIA. -2 to many Styles} or Stigmas.

\section{B. RANUNCULACEAE.-Herbaceous plants, occa- sionally climbing, with usually palmately or ternate- ly lobed or divided leaves, with half clasping pe- tioles.}

1. Chematis.-Calyx 4 (rarely 5 to 8)-sepalled, colored, pubescent. Achenia numerous, bearing long plumose tails.-Perennial vines, with mostly compound and opposite leaves. 
2. ANEMove.-Sepals 5 to 15 , petal-like, colored. Achenia mucronate-Herbs, with radical leaves, a 2 or 3-leaved involucre and whitish flowers.

3. Hepafica.-Ivolucre 3-leaved, resembling a ealyx. Petals 5 to 9, disposed in 2 or 3 rows. Carpels many, without awus.-Leares all radical, 3lobed. Flowers blue or whitish, simple.

4. Thalictrom-Sepals 4 or more, pełal-like. Achenia 4 to 15, dry, tipped by the stigma or style.-Herbs, with 2 or 3 ternately conpound leaves and white or greenish flowers.

5. Ranunculus. - Sepals 5, deciduous. Petals 5, or rarely more, with a little scale at the base inside. Carpels numerons, in a glowose or cylindrical head.-Herbs, with mostly radical leaves, and yellow flowers.

6. Hydrastis.-Sepals 3, ovate. Carpels berry-like, numerous, in a globose head.-A low herb, with a single radical leaf, a simple hairy stem, 2leaved near the summit, and a single greenish-white flower.

7. Catma.-Calyx colored, with 5 to 10 roundish sepals. Pistils 5 to 10 Smooth her:bs, with round heart-shaped or kidney-form leaves, and yellow. fiowers.

8. Troluus.-Sepals 5 to 15 , petaloid. Petals 5 to 25 , small, linear Pistils many.-Leaves palmately parted. Flowers lerge, sulitary and terminal.

9. Coptrs.-Sepals 5 to 7 . Petals 5 to 7 , small, hoorled. P istils 3 to 7 , on slender stalks.-Low smooth herbs, with radical leaves, a long yellow rhizozan, and white flowers.

10. Ancilegia.-Petale 5, longer than the 5 deciduous serals, spurred, tubular. Pi-tils 5, with slender styles.- Hzrbs, with 2 or 3-ternately compound leaves, and large showy n'dding flowers.

11. Dezphrstu.-Upper sepals spurred. Petals 4, irreguar, the npper pair terminating in a tubular spur, enclosed in the calyx-spur-Flowers blue, white, red, or purple.

12. Aconitum.-Upper sepals hooded, receiving the tri long-clawed petals.Leaves palmate or digitatr.

13. ACres and 14, Cimififuga, in Order I. Znsthonera, in Class V, Order V.

16. Inlmbonts.-Sepals 5, persistent, mostly greenish. Petals $\&$ to 10 , very short, tubular, 2-lipped. Stigmas 3 to 10 . Follicles 3 to $10 .-F$ lowers large, nodding, greenisk.

\section{Cultivated Exotics.}

17. Pronia.-Sepals 5, unequal. Petals 5. Stamens numrous, mostly changed to petals. Stigmas double. Ovaries 2 to $5,-$ Flowers large and showy, terminal.

18. Adoris.-Sepals 5, appressed. Petals 5 to 15, with naked claws. Achenia in a spike, pointed with the persistent style--Leaves finely divided. Flowers mostly red.

19. NigellA.-Calyx of 5-colored sepals. Petais 5, 3-cieft. Styles 5.-Zeaves in many linear subulate segments.

* Styles 2 to 5.

Hrpericum.-Sepals 5, more or less united. Putals j. Capsule membranaceous.-Leaves opposite, entire, punctate, with pellucid dots. Llowers yellow.

Ascrrom.-Sepals 4, the 2 inner ones much smaller. Petals 4, Low plants, with pale black-dotted leaves aud pale-yellow flowers.

Asimix 1.-Sepals 3, united at the base. Petals 6, in 2 rows, inner ones smallest. Pistils few, forming large oblong pulpy fruit.-Shrubs, with dull-colored axillary and solitary flowers.

Reszra.-Sepals many. Petals 4 to 7 , often cleft, unequal. Stamens turned to on side.-Herbs, with very small flowers. 
* Styles numerous.

Magrolia.-Sepals 3, decidunus. Petals 6 to 12, in concentric series. Stamens distinet, with short filaments and long anthers. - Trees or shrubs, with large fragrant flowers.

Lrriodendrox.-Sepals 8, caducous. Petals 6, in 2 rows, forming a bell-shaped corolla. Carpels imbricated in a cone.-Large trees, with showy flowers.

IRASENIA.-Calyz of 3 or 4 sepais. Petals 3 or 4 . Carpols oblong, acuminate. 1 to 2 seeded.-A Aquatic herus, with floating centrally peltate leaves, and solitary axiilary flowers.

Nerturium,Calyx petaloid, of 4 to 6 sepals. Petals numerous. Carpels nu. merous. Seeds large, round.-Aquatic herbs, with peltate fleshy radical leares, and rery large yellowish-white flowers.

\section{CLASS XIV. DIDUINAIIIA. -4 Stamens, 2 longer than the other 2.}

\section{ORDEI. I. GYMNOSPERMIA. - Seets apparently nalsed.}

\section{A. IABIAT E.-Herós, with square stems, opposite} aromatic or strong-scented leaves, and a more or less 2-lipped corolla.

$\uparrow$ Corolla with the border nearly equally 4 or 5 -cleft.

1. Is.svrius.-Stamens 4, nearly equal. Corolla 5-lobed.-A clanmy her., with pale blue flowers.

2. Mexrma-Ctamens 4, distant. Corolla 4-lobed; lobes spreading.-Aromatic herbs, with small pale-purplish flowers in clase axillary whorls.

3. Lrcopes.-Stamens 2. Corolla 4-Iobed; lobas spreading:-Leaves sharp?y toothed or pirnatifid. F'lowers white, whorled.

4. Origanum,-Stamens 4. Corolla 4 lobed, the upper lobe or lip erect.Flowers purplish, crowded in cylindrical or oblong spilies.

+ + Corolla evidently 2-lipped.

5. Comrnsonra-Calyx 2-lipped. Corolla elongated, the pendent middle lobe of the lower lip much longer than the others, lacerate-fringed. Stamens 2, much exserted.-Flowers yellowish.

6. HEDEัri .-Caly x 2-lipped; the lower lip 2-cleft. Upper lip of the corolla flat, the lower equally 3-lobed. Stamens 2, erect, exserted.-Leaves small. Flowers pale blise.

7. Conita-Calyx equally 5-toothed. Upper corolla-lip flattish, the lower somewhat unequally 3-lobed. Stamens eroet, exserted.-Flowers small, white or purpitish, in corymbed clusters.

8. BLEPHILIA.-Calyx short, 2 lipped, the 3 teeth of the upper lip arned. Corolla dilated at the throat, the lips oblong. Stamens $2 .-$ Flowers pale, bluish-purple, crowded in axillary and terminal globose whorls,

9. Morarda-Calyx tubular, 5-toothed. Corolla-lips linear, the upper involving the filaments. Stamens 2,-Flowers large, shoug, in a few capitate whorls.

19. StLria-Calyx and corolla strongly 2-lipped. Stamens 2,-Flowers usuatly large and showy. 
$\dagger+\dagger$ Stamens 4 , the upper pair longer.

PAGE.

11. Cerdronelid.-Stamens all ascending. Upper lip of the corolla flattish, the throat much enlarged. - Siviet-scented herbs, with pals purplish fowers.

12. NePeTA.-Stamens all ascending. Upper corolla-lip more or less concare or vaulted. Anthers mostly approximate.

13. Dracocepandum.-Stamens all ascending under the upper lip. Opper calyxtooth largest, ovate. Bracts arra-toothed.

14. Lophaxtuts. - Stamens direrging, exserted, the upper pair curved downward, the lower ascending.-Fiowers small, crowded in terminal spikes.

$\dagger+\dagger \dagger$ Stamens 4 , the lower pair longer.

15. Prcranturemum.-Calyz nearly equally 5-toothcd, naked in the throat.Flowers whitish or flesh-colored.

16. Turmus.--Calyx 2-lipped, woolly in the throat. Corolla short, slightly 2 . lipped.-Low mostly diffuse herbs, with small leaves.

$++t+$ Stamens ascending in pairs, under the raulted upper lip.

17. Cuinopodicar-Cals $x$ tubular, 13-nerved, more or less 2-lipped, 5-toothed. Upper corolla lip flattish.-Flowers purplish, in capitate whorls.

18. Meurss.-Calyx naked in the throut, 13-nerred, 5-tootled, more or less 2lipped.-Flowers whitish, in loose one-sided clusters.

12. Prunrita.-Calyx 2-lipped, the upper lip truncate, 3-toothed, flat. Upper corolla-lip arched.-F lowers violet or fiesh colored, in clusters of 6 .

20. SCUtellarisa.-Lips of the vaulted calyz ontire. Upper corolla-lip arched, entire.-Bitter herbs, with axillary spiked racemed flowers, mostly blue. 258

21. Prrsosteara.-Calyx 5-toothed, inflated vell-glaped after flowering. Upper lip of the inflated corolla somewhat spreading.-F'lowers large and showy, flesh colored or purplish, in crowded spikes.

22. LAMIUM.-Calyx 5-nerved, 5-toothed. Throat of the corolla inflated, lateral lobes truncate or with a tooth-like appenciage.-Decumbent her's, with axillary whorled clusters of purpish fiowers.

23. LEonurus.-Calyx 5-nerved, 5-toothed, the teeth awl-shaped, rigid or spinelike.-Upright herbs, with cut-lobed lcaves.

24. GALEOPSis.-Calyx 5 to 10 -awned, with 5 spiny pointed teeth. Throat of the corolla intlated.-Herbs, with spreading branches.

25. Stachrs.-Calyx 5 to 10 -flowered, 5 -toothed.-Herbs, with 2 to many flowered whorls, approximated in terminal racemes or spikes.

26. Marnubrum.-Caly x tubulnr, mostly 10 -toothed. Stamens in the corollatube.-Whitish woolly bitter herbs, with whitish flowers.

$+\dagger+\dagger+\dagger$ Stamens curved, ascending and much longer than the corolla.

27. TR 1споsтema,-Calyx uncqually 5-cleft. Corolla-limb unequally 5-cleft, lobes declined.-Herbs, somewhat clammy, with blue flowers.

28. Teucrium.-Calyx equally or unequally 5-toothed. Corolla decply cleft between the 2 upper lobes, the stamens exserted from the cleft.--Herbs downy.

Cultivated Exotics.

90. Ocrmor.-Corolla inverted or sub- bilabiate, the 4 upper lobes nearly equal. Exterior filaments with a process at their base. 
30. L.ATENDChA-Calyx tubular, nearly equal. Shrubly oderiferous plants, with narrow rigid leaves and small white fowers.

31. RosEMinnes.-Caly $\mathrm{x}$ orate-bell-shaped--An orcet evergreen shirub, with bright blue flowers, axillary and terminal.

32. SAtereja-Calyx 5-toothed. tubular 10-ribbed--Lecves numerous, small, narrow. F'lowers pink-colored, in axillary cymes.

33. Irssopts-Calyx 5-toothel.-F'inye delicate. Flowers bright blue, in one-sided cymes.

B. VERBENACEA.-Her'us or shruzs, with oppo: site leaves and a more or less 2-lipped regular corolla. Iruit dry or drupaccous, usually splitting when ripe

- into $\mathrm{a} 1$ to 4 -seeded nutlets.

1. Vensen 4,-Calyx 5-toothed, tubular. Corolla tubular, often curved, salrer-form, the border somewhat unequally 5-cleft. Style slender.-Herbs, with mostly alternately snicate bracted flowers, sometimes bracted or corymbed.

2. PnRrya-Calyz and corolla 2-lipred. Style slender. Fruit 1-celled, 1seeded.-Flowers small, purplish or rose-color, opposite.

3. Lippri.-Calyx and corolla 2-lipped. Fruit 2-celled, 2-seeded.-Heads of flowers on axillary peduncles.

\section{OrDER II. ANGIOSPERMIA.-Seeds in a distinct capsule.}

A. SCROPHULARIACE E-Chiefly herbs with the stamens inserted on the tube of the 2-lipped or more or less irregular corolla. Fruit a 2-celled and usually many-seeded capsule or pod. Style single. 235

2. IINARIA-Caly x 5-parted. Corolla tubular, with a palate, and a spur at the base on the lower side. Capsule opening by 2 chinks.-Herbs.

3. A Avminindy-Calyx 5-scpalled. Corolla gibbous (not spurred) at base, the throat closed by the prominent palate. Capsule openiug by 3 pores.Flowers showy, in leafy terminal racemes.

\section{filament.}

+ Stamens 4, with a 5 th rudimentary scale or sterile

4. Scroprularis.-Corolla inflated, globular, or oblong, with a short border. Flowers greenish-purple, in loose cymes, forming a terminal panicle.

5. Collivsia.-Corolla deeply 2-lipped, gibbous on the upper side, the middle lobe of the lower lip keeled-sac-shaped, inclosing the stamens.

6. Chelone.-Corolla tubular, inflated above, the mouth a little open. Anthers woclly. - Leaves opposite, serrate. Flowers white or purplish.

7. Pentstenon.-Corolla tubular, often enlarging above. Sterile filament long, bearded or naked.-F lowers showy, in thyrsoid panicles.

$\ddagger \ddagger$ Stamens 4 , without a rudimentary fifth.

3. Pacloxra.-Corolla-tube long declinate, enlarged above.-An ornamental tree, with very large leaves, and purplish flowers.

Digrtalis.-Corolla bell-shaped, ventricose, in 5 subequal lobes.-Flowers large, in showy racemes. 
10. Misreues.-Calyx prismatic, 5-angled, 5-toothed. Corolla tubular, the upper lip erect or reflexed-syreading, the lower spreadiug, 3-lobed.-Her.bs, with square stems and handsome flowers on solitary axillary peduncles. 239

11. IIERPrstis.-Calyx 5-parted, unequal, the upper divisicns broadest and often longest. Corolla short.-Prostrate or creeping.

: Lojes of the coirolla flat and open.

15. Lrsoszics-Corolla open bell-shaped, 5-cleft.-Small and creeping fleshy herbs, with single fiowers.

18. Bucruer. -Calyx 5-toothed. Corolla salver-form, with a straight or curved tube.-Flowers blue, in terminal bracted spikes.

19. GenArdi.-Calyx 5 tootbed or cleft. Corolla enlarged above.-Flowers showy, purple or yellow, often in racemes or spikes.

** Tipper lip of the tubular corolla erect, a'rched, including the \pm stamens.

20. CAstizirs. - Calyx cleft down the lower, and often also on tho upper side. Lower corolla-lip very small. - Leaves entire or cut-lobed, the floral ones colored red or yellow.

21. SCHTALEA-Calyx 5-toothed, very oblique, the upper tooth smallest. Flowers dull yellow, in a loose spike.

22. Prdictlaris - Pod ovote or sword-shaped.-Zeaves pinnatifid. Flowers in terminal spikes, yellowish or purplish.

23. MrLdmerrex-Calyx 4-eleft. Corolla ringent or personate.-F lowers yellowish, remote, one-sided, axillary.

B. Trees, shrubs, or herbs, often twiving or climbing.

TECOMA-Calyx bell-shaped, 5-toothed. Corolla funnel-form, 5-lobed, slightly irregular. Capsule long and narrow.-Trees or shrubs often climbing, with digitate or pinnate leaves.

Marrvia.-Calyx 5-cleft. Corolla gikbous, bell-shaped. Capsule at length with 2 long hooked horns:-Leaves subcordate. F lowers large, racemed. 233

Dipter.icastmes.-Corolla funnel-form, the spreading limb nearly regularly and equally 5 cleft. Anthers arrow-shaped.-Flower's blue or purple, clustered.

ThoxbrRgra-Calyx doukle, 5-cleft, with 2 bracts. Corolla bell-shaped, with an inflated tube, and 5-lobed limb.-Exotic climbing herbs, with showy axillary flowers.

C. Herbs destitute of green foliage.

EPIPNEGUs.- Upper fiowers sterile, with a tubular corolla; the lower fertile, with the corolla minute and not expanding.

Conopron.1s.-Flowers in a dense spike, scaly throughout. Corolla ventricose, 2-lipped. Stamens protruded.

Apgyt.Lox-Florvers solitary on naked peduncles or scapes. Corolla tubular. Stamens included.

\section{CLASS XV. TETRADYNAMIA, - 6 Siamens, 4 long and 2 short.}

\section{ORDER 1. SILICULOS $\mathbb{E}$.-Pod short and broad.}

2. Telaspi--Petals equal. Silicle short, fiat, emarginate at the apex, manyseeded.-Leaves undivided. Flowers white or purplisb.

3. CApseil.1.-Calyx equal at base. Silicle trianguiar, wedge-form, obcordate, compressed laterally. - Flowers white. 
3. Exropril.1.-Petals 2-parted. Silicle oval or oblong.-Flowers small, white.

4. LepIDruM.-Petals ovate, entire. Silicles laterally compressed, orbisularovate, or oval.-Flowers white.

5. Cimelixa.-Petals equal. Silicle obovoid or subglobose, obtuse, entire,
mucronate with the persistent style.-Flowers small, yellow.

5. Cimelixa.-Petals equal. Silicle obovoid or subglobose, obtuse, entire,
mucronate with the persistent style.-Flowers small, yellow.

6. Cochle.rea.-Petals entire. Silicle oblong or oroid-globose, with inflated valves. $-F$ lowers white.

\section{Cultivated Exotics}

7. ALY3SUM.-Petals entire. Silicle orbicular or oval, with valves, flat or convex in the centre.-Flowers white or yellow.

8. Luvari, - Petals nearly entire. Silicle pedicullate, elliptical or lanceolate. Flowers light purple.

9. IBERIS.-Petals, the 2 outside larmor than the 2 innor. Silicle compressed, truncate, emarginate.-Oinamental garden anmuals, with white or purple flowers.

10. Isatrs.-Silicle elliptical, flat, 1-celled, 1-ssede l, with boat-shaped $\nabla$ alves.Flower's large, yellow, in long terminal racemes.

\section{ORDER I. SILIQUOSAE.-Pod mostiy long and narron.}

11. Dextaria.-Silique narrow-lanceolate, with the long stgle.-Stem with a few divided leaves, and. white-purple lowers.

12. BARBAREA.-Pod 4-angled, and somewhat 2ed ged.-Leares lyrately pinnatifid. Flower's yellow.

13. Nastuntrum.-Pod nearly terete, linear-oblong, and eurved upwards like a silicle. Seeds small, irregularly 2 rinted in eaeh cell, margialess.Aquatic or mursh plants, with yellow or white flowers izd pinnate or pinuatifid leaves.

14. An ibis.-Pod linear, plane; seeds in a single row in esch cell.-Flowers white.

15. Ioduxthus.-Pod linear, elongated, terete. Style tinick.-Flowers violetpurple, in panicled racemes.

16. CArdume - Pcd linear, flattened, tusually opening elastically.-Flowers
white or purple.

16. Cardimes - Pcd linear, flattened, úsually opening elastically.-Flowers
white or purple.

17. Sxsmibriom.-Pod terete or rather 4 to 6 sided.-Flowers smill, white or yellow.

18. Erystyum--Pods columner, 4-sided.-Flowers yellow.

10. SixApIS.-Pods nearly terete, with a short buak.-Leaves lyrate, pinnatifid or incised. Flowers yellotis.

20. Raphancs.-Pod elongated, transversely many-celled.-Flowers yellow or purplish.

21. Ceminanthus.-Pod tereto or compressed. Stigma 2-lobed or capitateFlowey's fragrant, showy, pale-purple or orange-yellow.

\section{Cultivated Exotics.}

22. Hвspzris.-Pod 4-sided, 2-edged or sub torete. Stigmas forked.-Fiowers purple.

23. Mitraiola.-Pod terete-Herbaceous or shrubby plants, clothel with a heary pubescence.

24. BaAssics.-Pod sub-compresed.-Flowers yellow. 
CLASS XVI. IPONOD足PHIA.-Filaments combined

PkER: in one set.

\section{ORDER III-V. TRI-PENTANDRIA. - 3 to 5 Stamens in one set.}

26radu.-Spathe 2-leared, keeled, 1-ilowered. Perianth 5-parted, with oblong segments. Stamens 3 ; filaments united into a long tube.-Flowers large, very evanescent, yellow and red.

Passurlora.-Calyx 5-parted, colored, the throat crowned with a double or tripie fringe. Petals 5 or none. Stamens 5 , their filaments situated on the stipe of the ovary. Stigmas 3,-Climbing herbs or shrubs, with palmately lobed leaves.

Lixcx.-Sepals, petals, and styles 5. Capsule 5 to 10-celled.

\section{Order X. DECANDRIA.-I0 Stamens in one set.}

Qtararux.-Sepals and petals 5, regular. Stamens all fertile, the alternate unes longer, and with scales at the base.-Peduncles 1, 2, or 3-flowered.

Ox.1.is.-Sepals and petals 5. Styles 5.-Leaves mostly 3-foliate:

gxtogaxtiua, page 88 . Tephrosia and Avorpin, p. 90. Lupinos, p. 93.

\section{Order XIIT, POLYANDRIA. - Many Stamens in one set.}

A. MALVACEA-Herls or shrubs, with alternate stipulate leaves and regular flowers, with numerous stamens, monodelphous in a column. Pistils several. 57

1. MalvA.-Calyx with a 3-leaved involucel at the base.-Flowers perfech. $\quad 57$

2. Altera-Caly $x$ surrounded by a 6 to 9 -cleft involucel.

3. Irbisces.-Calyx surrounded by a many-eleft involucel. Pistils 6 at the summit of the column.-F'lowers usually large and showy.

4. Abtruor-Calyx without an involucel. Ityles 6 to I5.-Flowers in the

asils of the heart-shaped, lobed, or incised leaves.
b. Sida-Calyx 5-cleft, without an involucel. Styles 5 or more. Carpels 1 seeded.-F'lowers white or yellow.

CLASS XVII. DIAD四LPHIA.-Filaments in 2 sets.

\section{Order VI. HEXANDRIA.-6 Stamens.}

A. FUMARIACE Æ.-Delicate smooth herbs, with compound disected leaves and regular flowers, with 4 somewhat united petals.

1. Diosmtra, - Sepals 2, small. Corolla heart-shaped or 2-spurred.-Low slemless perennials, with simple scapes.

2. Corrdilis.-Corolla 1-spurred at the base, deciduous. Style persistent. Yruit a many-sooded pod.-Flowers in racentes. 
3. A purut -Corolla beart-shaped, persistent, 4 -lobed at the apex,-A climb. ing vine.

PAGB,

4. Foxazis.-Corolla 1-spurred. Fruit small, globular.

Order VIII. OCTANDRIA.-8 Stamens in 2 sets.

Porraala.-Sepals 5, persistent, 2 of them urn-shaped and colored. Petals 8 to 5 , united to the stamens, the lower one keel-form.

\section{ORDER X. DECANDRIA.-10 Stamens in 2 sets (mostly 9 and 1).}

B. LEGUMINOSÆ.-Herbaceous plants, shruls or trees, with alternate mostly compound leaves and papillionaceous flowers. Pistil single. Fruit a legume. 77

$\ddagger \ddagger$ Herbs, with abruptly pinnate leaves, the common leaf-stalk produced into a tendril or bristle. Peduncles axillary.

1. Vicia.-Style bearded round the apex or down the anterior side.

2. L.sthrrus.-Style bearded on the posterior side, flattened.

3. Pisuri-Legume oblong, tumid, many-seeded.

4. ChORR,-Legume turgil, 2-seeded.-Flower's white.

5. F $\triangle$ BA.-Legume large, coriaceous, somewhat tumid.-Herbs, without tendrits.

$\ddagger$ Twining or trailing plants, with odd pinnate leares, of 2 to several leaflets, destitute of tendrils.

6. Praseoles.-Keel spiral.-Leaves 3-foliate, stipellate.

7. Apros.-Keel incurred, at length twisted.-Leaves 5 to T-fo'iate.

8. GaLACrLA.-Calyx 1-cleft,-Leaves pinnately tri-foliate,

9. Cratrosema.-Calyx ehort, 5.cleft, with 2 bracteoles. Poduncles fer-flowered.-Leaves pinnately tri-foliate.

10. Axphicarpa.-Calyx 4 or 5-toothed. Peduncles many-flowered.-Leaves pinnately tri-foliate.

11. Wistaria.-Calyx bilabiate. Wings and keel sickle-shaped.-Twining shrubby plants, with pinnate leaces and blue flowers in racemes.

ft Legume separating into 2 to several 1 -seeded joints. Leaves 3 to many-pinnate.

12. Eschyмомгкs-Stamens equally diadelphous (5 and 5). Legume sereraljointed.-Leaflets numerous.

13. HeDYBARUM.-Legume with many joints.-Leaves odd-pinnate.

14. Dzśmodum.-Stamens mostly diadelphous (9 and 1). Legume severaljointed.-Liaftets 3, Mlowers purple or purplish.

15. Lespredeza.-Anthers uniform. Legume of a single 1-seeded joint, oval or roundish.-Leaflets 2 .

16. Struosavtrus,-Stamens monodelphous; anthers of 2 forms. Legumo 1 or 2-jointed,-Zleaflets 3 . 
+++ Herbs, shrubs, or trees, not twining, climbing or tendril-bearing.

17. Astragatus.-Legume partly or quite 2-celled.-Herbaceous or shrubby. Leaves odd-pinnate.

18. Toвinia.-Style bearded.-Trees or stirubs, with prickly spines, pinnate leaves, and showy racemose flowers.

19. Tephrosia. - Stamens monodelphous or scarcely diadelphous.-Silky-hoary heibs, with odd-pinnate leaves and white and purplish flowers.

20. AMorpha. - Stamens monodelphous merely at the base. Petals 1.-Shrubs, with odd-pinnate leaves.

21. Trirolrum.-Flowers in dense heads.-Zeaves tri-foliate.

22. Meirlotus.-Flowers in spiked racemes.-Leaves pinnately tri-foliate.

23. MEDicago.-Flowers racemed or spiked. Legume more or less spiral.-. Leaves tri-foliate.

24. Crotalaria.-Legume infiated, oblong.-Leaves simple. Flowers yellow.

25. Lupinus.-Stamens monodelphous.-Leaves palinately. 5 to 15 -foliate.

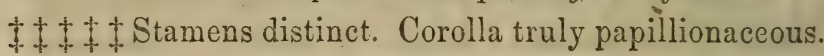

26. Baptrsia.-Legume stalked in the persistent calyx, inflated.-Leaves 3foliale.

27. Cercis.-Trees, with simple rounded heart-shaped leares.-Flowers rosecolored.

\section{CLASS XVIII. SUNGENESIA.-5 Anthers united in a tube.}

OBS. The plants of this class, with a few exceptions, have 5 anthers united into a single tube. The flowers are in heads, inserted upon a common recoptacle, which is surrounded by an involucre: being usually known as Compound Flowers. They form the Natural Order Compositæ.

A. TUBULIFLOR $\mathbb{E}$ - Corolla of the perfect or disk flowers, tubular, regular, the limb 5-cleft or lobed; the ligulate or ray-llowers when present, either pistillate only or neutral (with neither stamens or pistils), and occupying the border.

* Heads discoid (without ray-flowers); the flowers all alike, perfect, tubular; branches of the style slender, thread-form or bristle-form.

\section{$\ddagger$ Flowers violet or purple.}

* Leaves alternate.

Tennonis.-Heads many-fiowered. Pappus dou'ble.-Leaves atternate.

Eiephantopus.-Ifeads 3 to 5-flowered, in dense clusters.-Leaves subsessile.

** Heads discoid or radiate; branches of the style much elongated, obtuse or club-shaped.-Leaves mostly, opposite. 
$\ddagger$ Heads without ray-flowerg. Flowers all alike, tubular, blue, purple or whitisb, not yellow.

Liatris.-IIeads few to many-flowered. Corolla 5-cleft.-Root tuberous. Ledies narrow, rigid.

EuIria.-Hearls 10 to 25-flowered. Corollá 5-toothed.-Leaves laneiolate, resinous-dotted.

- Leaves opposite.

MILAsis.-Ifeads s-floweređ.-Cimbers.

Cosocisnulr.-Heals many flowered. Corolla 5-toothed-Zeaves pstioled.

LetratoriuM.-Heads 3 to many-flowered. Reeeptacle flat.

158

159

+ t Heads radiate (with ray-flowers); flowers dissimilar or dioecious, purplish-yellow.

FARDosma.-Ifeads manj-flowered, somewhat dicecious,-Leares radical.

161

Tussinag0-Ilead (single) with many rows of narrow rays and few disk flowers. 101

*** Heads radiate, rarely discoid; branclies of the style more or less fiattened and linear.-Leaves mostly alternate.

$\ddagger$ Heads radiate; rays white, reddish, blue or purple, very rarely yellow.

Aзтqk.-Ileads many-flowered. Disk yellow, often changing to purple.

Gauatella. - Inrolucre imbricated. Rayв 3 to 12. Disk-corollas deeply cleft.Leaves narron, rigid, entire.

ZRIGRon,-Rays very numerous.-Leaves alternate.

Dirloparpos.-Rays 8 to 12 -Leaves alterzate, entire.

Bontoxis.-Ifeads manj-flowered.-Leaves lancrofate, entire.

Bzricocarpos.-Rays about 5.-Leaves sessise, alternute.

Callisternu6.-Ray-Howers pistillate, numerous.-Exotics.

DAHLIA.-Involuere double. Reeptacle chaffy.--S7sowy exotics.

++ Hcads radiate; rays jellow, rarely whitish. Bolid.ac_- Hends few or many-flowered, small, - Flowers expanding in the
autumnal months.

Inut. - Heads many-flowered, large.-Leaves large.

ILoupTs.-IIeads many-flowered, small, with minute flowers.

$\neq \neq f$ Heads discoid; flowers purplish.

Prcuв.-Heads many flowered, in corymbo.

**** Heads radiate or discoid; branches of the style linear, hairy or hisped at the apex, which is either truncated or produeed in a conical or elongated appendage.

$\ddagger$ Heads radiate ; flowers yellowish or greenish, sometimes monocious.

Poiraxi,-Ieaves opposite, largo. 
SiLPHIUM.-Ifeads large, with yellow flowers.

Ambrosid.-Heads monoecious, the fertile at the base and the sterile at the top of the spikes.-Coarse weeds, with lobed or dissected leaves and inconspicuous flowers.

XaNтнium.-Fertile and sterile flowers occupying different heads on the same plants; the fertile clustered below ; the sterile in short spikes or racemes above.-Coarse plañts.

***** Heads radiate or rarely discoid; the diskflowers always perfect and fertile; receptacle chaffy; anthers blackish, without tails at the base.-Leaves mostly. opposite.

† Rays conspicuous, mostly large.

IILLIopsis - IIeads many-flowered. Achenia 4-angular-Leaves opposite, petioled.

Rudeckit.-Rays long and drooping. Achenia 4-angled.

Jepicirs.-IIeads many-flowered. Tays fer, long and drooping,-Leaves pinnate.

IIExhytrus.-Feads wany-flowered. Rays strap-shaped, neutral-_Cuarse stout herbs.

+ Rays yellow or orange-colored, rarely red, white or purple or sometimes wanting.

Coreopist.-IIeads many-fiowered. Rays about 8 , nextral in a single series.Leaves mostly opposite.

Zrixin.-Heads many-fowered. Rays 5 or 6, entire, pistillate.-Leaves opposite, enitive.

Tiustus.-Heads heterogamons. Ray-flowers 5.-Leaves pinnately divided. 184

Acrironeris.- Heads many-fiowored. Rays neutral, few, or rarely wanting.Leaves serrate, father-veined.

Bidexs.-IIeads many-forvered. Rays 3 to 8, neutral, often wanting.

VERBESINA,-Achenium much fiat tered latera:ly.

* Tappus composed of several distenct cliafy scales.

IIEIEXIUM.--Leaves docuricnt on the angled stcms.-- Iteads terminating the Uranches.

$+t+$ Rays white. Leaves much äissceted.

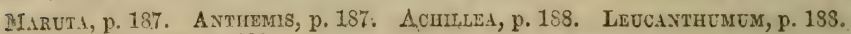
PYRETHRUM, p. 189.

$\dagger+\uparrow+$ Ornamental exotics, with white, ycllow, red, and purple rays. Lcares lobed.

Durysanthemem.

$\uparrow \dagger+\dagger \uparrow$ Heads mostly discoid, fertile or hetcrogamous; flowers yellow or whitish.

* Leaces bi-pinnate or finely dissected.

Tanacescis, p. 189. artemisia, p. 190.

*: Leaves entire, white, woolly.

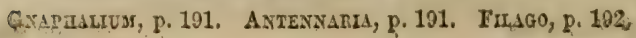


$\dagger \dagger \dagger \dagger \dagger \dagger$ Heads mostly discoid. Pappus soft and axillary. Leaves mostly alternate. Flowers whitish or yellow, rarely scarlet.

Erechthytes, p. 192. Cacalia, p. 193. Senicio, p. 194. Arnica, F. 195.

******Heads ovoid, discoid, rarely radiate, homo gamous (rarely diœcious), heterogamous, with the mar ginal flowers in a single series.

$\dagger$ Flowers mostly purple, blue or whitish, rarely yellowish. Leaves often covered with sharp prickles.

Centaurea, p. 195. Cirsidi, p. 196." Oxopordon, p. 198. Lappa, p. 198. Carces, p. 199.

$\dagger \dagger$ Exotics, with yellow, orange, or rarely white or purplish flowers.

Calendula, p. 199. Carthanus, p. 199. Xeraythemum, p. 200.

B. LIGULIFLORE E.-Flowers all perfect, with ligu-

late (strap-shaped) corolla throughoui.

* Branches of the style slender, obtuse, uniformly hairy.-Herbs, with a milliy juice and alternate leaves.

$\dagger$ Flowers blue or purplish.

Crohoricm, p. 200. Mulgedium, p. 204. Tragopogon, 205. Catanarche, 206.

$\dagger \dagger$ Flowers yellow. Leaves radical, lyrate, toothed or pinnatifid.

Krigi., p. 201. Cynphia, p. 201. Leongodon, p. 201. Tarazicum, p. 203.

$\dagger+\dagger$ Flowers yellow, or rarely whitish or purplish.

Stem leafy, more or less.

Exnthia, p. 201. Hierachu, p. 202. Nabules, p. 202. Lactuca, p. 20t. Son. CHUS, p. 20D. TRAGOPOGON, p. 205.

ORDER I. MONOGYNIA.-Flowers seperate, not compound.

Pioldoes.-Flowers polypetalous, irregular. Style club-shaped.

InPatiens.-Flowers polypetalous, very irregular. Stigma sessile.

LOBELIA.-Corolla monopetalous, irregular. Style 1.

APocrnum.-Corolla monopetalous, regular. Stigma 1.

CLASS XIX. GYNANDRIA.-Stamens situated upon the style or column above the germ. 
A. ORCHIDACEA-Perennial, often stemless herls, with simple parallel-veined entire leaves, and irregular 6-merous flowers.

\section{Anther single.}

* Pollen cohering in definite (4) waxy masses, without any connecting tissue or tail-like prolongation.

† Plants green, and with leaves. Sepals spreading; lip flat.

1. Microstruts.-Lîp arrow or heart-shaped. Columin minute, rouñ d.

8. Liparis.-Lip entire, dilated, Column elongated, margined at the apex: $\$ 56$ + †lants tawny or purplish, nearly leafless.

8. Cordr.lormra.- - Lip with a spur or projection at the base, adherent to the ovary. Anther terminal.

4. Aplectrow.-Lip spurless, frec, raised on a claw. Anther rather lateral. 357 ** Pollen cohering in definite ( 2 to 4 ) waxy masses, furnished with an elastic prolongation. Plants green.

6. Tipularia,-Lip long-spurred underneath.-Flowerg racemed.

*** Pollen cohering in very numerous grains, which are collected on a cobweb-like tissue into 2 large masses and affixed to the glands of the stigma.

6. Orcris.-Anther-cells contiguous and parallel. Giands of the stigma continued in a little pouch formed of a fold or hood of the stigma.

7. Gruradenia.-Anther-cells contiguous and parallel; glands naked.

8. Pratanthrna.-Anther-cells widely scparated at the base; glands naked. 350 * * *ollen powdery, in numerous minute and angled loosely cohering grains (forming 2 to 4 masses). Anther terminal, forming a lid orer the stigma.

\section{+ Pollen-masses 4, angled.}

9. Areturda.-Lip bearded, united at the base to the linear column. $+\uparrow$ Pollen-masses 2.

10. Pogonta.-Lip more or less crested, free. Column club-shaped.

11. Calopogon-Lip bearded, stalked posterior. Column ineurred.

$+\dagger+$ Anthers more or less parallel, with the stigma or column erect.

12. Spirasthes.-Lip nearly entire, channelled, pointless, ascending.

19. Goodrara.-Lip entire, inflated, sac-like below, strap-pointed.

14. Luskris.-Lip fiat, spreading or pendulous, 2-lobed.

\section{Anthers 2.}

15. Crraupadox.-Lip inflated, slipper-form. 
ORDER V. PENTANDRIA.-5 Stamens situated upon the Style.

ASCLEPIADACEx,-Calyx and corolla regular, hypogynous.

\section{Order VI-XII. HEX-POLFANDRIA.}

ArIStolochucex.-Calyx epigynous; corolla none. Fruit 7-celled.

CLASS XX. HONCEIA.-Stamens and Pistils in separate flowers on the same Plant.

\section{Order I. MONANDRIA.-1 Stamen.}

LEMra.-Flowers bursting from the side of a floating frond.

Zaryicirelta.-Flowers axillary, sessile; the fortile of 2 to 5 pistils.-Submersed aquatics.

Euphorbia.-Flowers in a cup-shaped involucre. Fertile flower solitary, central, on a long peduncle. Styles 3 , usually 2-cleft. Ovary 3-celled. 3.5

Orden II-III. DI-TRIANDRIA. - 2 or 3 Stamens.

PODOSTEMCM.-Stamens afixixed to a common pedicel. Stigmas sessile, recurved. $31 \notin$

† Stamens aggregated in a common spike or head.

TrPHA.-Flowers all in a spike, intermixed with down.

SPARGANOM.-Flowers in heads, naked, the fertile bracted.

$\dagger+$ Stamens in the axils of bracts.

Carex.-Achenium lenticular or triangular, inclosed in a sac.

Sclerra.- - dehenium globular, crustaceous or bony, naked.

TRIPSACUM.-Grain inclosed in cartilaginous glumes suuk in the joints of the spike.

$+\dagger+$ Staminate flowers in aments.

Comptonia.-Nutlets 1 under each bract of the burr-like catkin.-Low shrubs. Leaves pinnatifid.

$\dagger \dagger \dagger \dagger$ Staminate flowers in remote spikes or panicles. Leaves parallel-veined.

ZEA.-Styles very long, filiform, pendulous.

Coiz.-Staminate flowers in remote spikes. Style 2-parted.

ORDER IV. TETRANDRIA. - 4 or sometimes 8 Stamens.

* Trees or shrubs. Fertile flowers in aments or spilkes.

BETuLA.-Stigma 2, thread like, becoming a broadly winged and scale-like nutlet or small samara.

ALFus.-Sterile aments long and drooping. Scales of the ament thick and Foody in fruit, coherent below. and persistent. 
Morvo.-Style 2. Achenium orate, compressed, covered by the succulent berry-like calyx.

PAGP.

Broussonertia.- Pistillate aments globose. Oraries becoming fleshy, club-
shaped. Style lateral.

Broussonertia.- Pistillate aments globose. Oraries becoming fleshy, club-
shaped. Style lateral.

MACLURA-Ovaries numerous, forming a compound globose fruit, composed of 1-seeded, compressed, wedge-form carpels. Style 1, filiform.

Buxus.-Sterile flowers; calyx 3-leaved. Petals 2. Fertile flowers; calyx 4. sepailed. Petals 3. Styles 3.-Evergreen shrubs.

+ Herbs.

Urmons.-Herbs (often stinging), with watery juice, and flowers in spikes, heads or panicles. Style single or none.

Amarantius.-Calyx dry and scarious. Styles 2 or 3, filiform. Utricle oponing all round, 1-secded.-Flowers spilie-clustered.

†† Aquatic herbs.

MrRIOPHYILUM.-Flowers spiked. Stamens 4 to 8. Sepals and petals adherent to the 4-celled nutlet-Aquatic herbs.

Erjocadlon.-Sepals and petals free. Capsule 2-celled, 2-seeded. Stigmas 2.Leaves lincar.

\section{Order V. PENTANDRIA.-5 Stamens.}

A HaBANTHEs.-Calyx äry and scarious.-Coarse weedy herbs, with minute spiksclustered flowers,

\section{ORDtR VI. HEXANDRIA. -6 Stamens.}

GazA NIA.-Staminate and pistillate flowers in 1-flowered spikelets in the same panicle.-Large and often reed-like water-grasses.

\section{Order VII, POLYANDRIA.-Many Stamens.}

Irzcidambr.-Styles 2. Capsule 2-beaked, 2-celled, several-sceded.-Trees. Leares deeply 5 to 7 rlobed.

Pratavus.-Style 1. Nutlets club-shaped, 1-celled, 1-seeded.-Trees. Leaves palmately-lobed,

* *taminate flowers mostly in aments. Trees or shrubs.

A. CUPULIFERE.-Trees or shrubs, with alternate straight-veined leaves, deciduous stipules, the sterile flowers in aments or clusters, and the fertile solitary or clustered, furnished with an involucre which forms a cup or covering to the 1-celled, 1-seeded nut.

$\uparrow$ Fertile flowers scattered or few in a cluster.

1. Qunces.-Involuere 1-flowered, of many imbricated small seales, forming a. cup around the base of the acorn.

2. Castana - Intolucre 2 or 8-flowered, forming a prickly burr, inciosing 1 to 3 leathery nuts, opening by 4 valves, 
3. Facus.-Involucre 2-fiowered, somewhat prickly, 4-ralred, inclosing sharply 3-angled nuts.

4. Corylug.-Involucre 1 or 2-fiowered, formed of 2 or 3 confluent scales, which becomo leafy, much enlarged and cut-torn at the apex, inclosing a bony nut.

$\dagger \dagger$ Fertile flowers clustered in a kind of ament.

5. Carpincs:-Involucre a separate open leaf:

6. Ostris.-Involucre a bladdery bag, 1-flowered.

B. JUGLANDACE A.-Trees with alternate unequally pinnate leaves. Fruit a kind of dry drupe with a bony endocarp (nut-shell), containing a large 4-lobed seed.

* Stamens 12 to many.-Herbs.

Ceratophyllum.-Calyx herbaceous. Achenium horned.-Aquatic herbs, with whorled finely dissected leaves.

asartiaria.-Sepals and petals 3, free-Leaves mostly sagittate. Flowers whitish.

C. ARACEAE-Plants, with acrid or pungent juice, simple or compound leaves, and with the fower's crowded on a spadix, usually surrounded by a spathe. Berry 1-celled.

+ Spadix surrounded by a spathe.

1. ARUM.-Flower's naked, covering the base only of the spadix.

2. Prutaxdra.-Flowers naked, covering the whole spadix; spathe long and convolute.

3. Calla.- Flowers mostly perfect, naked, covering the spadiz; spathe open aud spreading,-Leaves heurt, shuped, long-petioled.

Order VIII. MONODELPHIA.-Stamens uniled by their filaments.

Parliantats.-Stamens 3, much united. Stigmas 6. Capsule 3-lobed, 3-celled, 3 -seeded.

ACALxpHA.-Stamens 8 to 16 , united at the base. Styles 3 , cut-fringed.

Podostrmum.-Stamens 2, rarely 3. Styles or stigmas 2.-Aquatics, growing on stems.

RIcixus.-Stamens numerous. Styles 3, 2-parted.-Herbs, with peltate palmate leaves.

* Flowers naked in the axils of scales, forming aments.

A. CONIFER AE.-Trees or shrubs, with resinous juice, and mostly with evergreen subulate or needle-shaped leaves.

1. Privus.-Leaves in clusters, of 2 to 5 in $\mathrm{s}$ sheath, persistent. 839

1. AnIs,-Leaves all scattered, persistent. 
3. LARTX.-Leares mary in a cluster, deciduous.

† Fruit consisting of a colored strobile or drupe.

4. This.-Fruit of a few imbriated oblong scales.-Leaver sculz-like, closely imbricated on the flattened branches.

5. Cupresss.-Fruic of several shiela-form thickened seales united in a woody cone.-Leuves scale-like or awl-shaped, appressed.

6. TAxodrum.-Fruit as in Cupressus.-Leaves linear, 2-ranked, deciduous. 343

7. Taxus-Ovule erect, encircled at the base by an annular disk, which forms a berry-like cup around the seed.-Leaves 2 -ranked, persistent.

ORDER IX. SYNGENESIA. - Stamens connected by their Anthers.

\section{* Fruit an Acheninm.}

XАхтнт. - Staminate and fertile flowers in separate involucres, the latter a 2-celled burr.

A MRROSIA. - Staminate and fertile flowers in separate involucres, the latter nutlike 1-celled.

* * Fruit a fleshy carpel (Pepo).

Cccrnitace.s.--Herbaceous, mostly succulent vines with tencirils, and alternately palinately-veined leaves. Fruit a yepo, more or less succulent. 121

1. Sictós. 2. Echivostrudus. 3. Melotmria.

8. Momordica. 5. Cuctmis.

6. Lagenaria. 7. Cucurbita.

CLASS XXI. DIGCIA,-Stamens anci Pistits in separate flowers and on different plants.

Order I-V. MONO-PENTANDRIA. - Stamens 1 to 5. + Stamens 1.

Nisis.-Flowers axillary, sessile, without a perianth.-Sutmersed aquatics. 350 $\dagger+$ Stamens 2, sometimes 1 to 6 .

salix.-Sturile and fertile flowers both in aments, naked. Stamens 1 to 6.Trees or shrubs.

Fraxives.-Calyx small, 4-cleft. Style single. Fruit a 1 to 2 -seeded samara.-
Trees, with pinnate leaves.

$\dagger \dagger+$ Stamens 3 or 4.

Talussmria.-Capsule cylindrical, 1-celled, many-sceded. Stamens mostly 3.-

submersed aquatics, with long grass-like leaves.

CAREXX.-Achenium in a sac.

Visccr.-Anthers sessile on the calyx-lobes. Berry 1-celled, 1-seeded.-A yetlowish green parasitic plant.

$\dagger+\dagger \dagger$ Stamens mostly 5 (sometimes 4 ).

Hagvid - Fruit a double samara.-Shrubs. Leaves compound: 
MrricA.-Fruit a dry drupe. Flowers in short aments. Filaments 2 to 8 , somewhat united.-Shrubs.

PAGE。

UnTICA.-Fruit an achenium. Flowers spiked or panicled.-Herbs.

Pyrularia.-Style 1. Fruit pear-like, 1-celled, 1-seeded.-A low straggling shrub.

337

NrSSA.-Fruit an cral or oblong berry-like drupe, with a grooved endocarp.Trees, with smooth and shining leaves.

Cannabinez-Calyx of 1 sepal, folding rourd the achenium,-Erect or twining hes-bs, with a watery juice.

ACsida.-Calyx 3 to 5-sepalled. Achenium 3 to 5-angled, crustaceous.-Herbs.

Leaves lanceolate, acuminate.
Xanrnoxruer.-Sepals 5, petal-like. Pistils 3 to 5. Carpels thickish, 2-valved. Seeds black and shining.-Fragrant shrubs.

Prelea. Petals 3 te 5. Stamens 3 to 5. Stigmas 2. Fruit a 2-celled samara, winged all around.-Shrubs, with 3 to 5 -foliate leaves.

\section{Order VI. heXANDRIA.-6 Siamens.}

REMEX.-Achenium 3-angular, covered by the inner sepals.-Sour herbs.

† Climbing or twining.

SmILAx.-Perianth of 6 equal spreading semments. Stirmas 3, thick. Berry

1 to 3 -seeded.- Shrubs varely herbs, climbing by tendrils on the petioles. 372

Drosconfa.-Carsule 3-celled, 3-winged, 3-seeded.-Climbing herbs, with moro or less heart-shaped leaves.

$\$+$ Herbs, with parallel-veined radical leaves.

Ceam.zirrium.-Perianth of 6 persistent sepals. Styles 3, linear-club-shaped. Anthers yellow.-Flowers yellowish-white, in a long' slender racene.

OrDER VIII. OCT-POLYANDRIA.-8 to many stamens. * Flowers with ealyx and corolla.

Mrispramum.-Sepals and petals 4 to 8 , distinct. Drupes 1 to $4 .-$ Twining or climbing shrubs. Leaves palmate or peltate.

* * Calyx regular : petals none.

A. LAURACEAE.-Aromatic trees or shrubs, with alternate leaves. Calys petal-like, 6:parted. Stamens 9. Drupe free.

1. SAssafras.-Drupe ovoid, supported on a floshy club-shaped pedicel.Trees.

2. Benzorn.-Drupe obozoid, the stalk not thickened.-Shrubs.

*** Calyx and corolla none.

Populus.-Flowers in aments. Stamens 8 to 40 . Capsule 1-celled.-Trees,

with more er less heart-shaped leaves.

**** Flowers with a 6-parted perianth. EDora.-Spathe bifid, 1-fiowered. Stamens 9, 4, of them inferior.-Submerged
aquatics. 


\section{Order X. MONODELPHIA. Stamens united by their filaments.}

* Flowers in a kind of short ament: ovules nalied on the scales. Evergreen trees or shrubs.

TAxus.-Scales empty at the base of the naked cup-shaped berry: PAGR.

JUNipraus.-Scales of the fertile aments 3 to 6 , forming a sort of drupe.

\section{CLASS XXII. POLYGAMIA.}

\section{\$Stamens I to 3. Flowers glumaceous.}

Graminez.-Nos. 45 ANDrorogon. 42 PanicuM. 46 Sorghom.

+ Stamens 2. Flowers with a calyx or naked.

Frasivus.-Fruit a 1 to 2-seeded samara.-Trees. Leaves pinnate. 295

Calitriene.-Fruit nut-like, 4-lobed, 4-celled, 4-seeded: 314

$\$ \ddagger \ddagger$ Stamens 3 to 8 .

CHENOPODIACE E.-Calyx herbaceous, inclosing the acbenium. .

ULwus.-Samara rounded, broadly winged. Calyx 4 to 9-cleft.-Trees.

Centrs.-Drupe free from the 5 to 6-parted calyx. Styles 2.-Trees or large shrubs.

NxSSA.-Drupe coherent with the calyx-tube. Style 1.-Trees, with smooth and shining leaves.

Broussonetra.-Style lateral. Oparies becoming fleshy, club-shaped, prominent.-An ornamental exotic tree, with downy, entire or lobed leaves.

GLeditscma.-Sepals, petals and stamens 3 to 5.-Trees, with twice pinnate leares.

Paxax.-Petals and stamens 5. Styles 2 or 3 . Fruit \& 2 to 3 -seeded drupe.Herbs, with palnately compound leaves.

Vitrs.-Berry 2-eelled, 4-seeded. Stamens 4 to 5, opposite the petals.-Shrubs, climbing by tendrils.

Priros.-Stamens mostly 6 . Corolla rotate, usually 6 parted. Fruit a drupe with 6 smooth nutlets.-Shrubs

Nemopanseres.-Valyx a minute ring. Petals 5 , oblong linear. Stamens 5. Stigmas 3 or 4, sessile. Fruit a globose red berry.-Shrubs.

ITELEA.-Samara winged all round, orbicular, 2-celled.-Shrubs.

Mrianthium.-Stamens 6 , on the claws of the 6-parted perianth. Styles 3,Leaves parallel-veined.

Teratrox.-Stamens 6. Styles 3.-Flowers dull colorcd. . " 387

$\neq \neq \neq+$ Stamens 8 to many.

Drosprrus.-Berry 4 to 8-celled, 4 to 8.sceded. Stamens 8 and 16. -Shrubs or trees.

Udona-Ovary 1-celled. Stamens 9. Spathe 2-cleft, axillary, 1-flowered.Șubmerged aquatics. 


\section{FLORA, OF PENNSYLVANIA.}

\section{SERIES I.}

\section{PHANOGAMIA, OR FLOWERING PLANTS.}

Plants composed of cellular tissue, woody fibre, ducts, and spiral vessels, bearing proper flowers, with stamens and pistils, and producing seeds which contain an embryo, radicle and cotyledons.

\section{Class 1.-EXOGENS OR DICOTYLEDONS.}

STEMs composed of distinct bark and pith with an intervening layer of woody fibre and vessels, increasing in diameter by the annual deposition of new laycrs between the old wood and the bark, which are arranged in concentric zones and traversed by medullary rays. LEAves mostly with reticulated veins, and falling off by an articulation. Sfrals and PETALS in fives and fours, and very rarely in threes. Embryo with two or more cotyledons.

\section{Sub-class 1.-Angiospermous Exogens.}

Ovules, produced in a closed ovary, and fertilized by the action of pollen through the medium of a stigma. EMBRyo with two eotyledons.

\section{Division 1.-Pómpetalous Exogens.}

Floral envelopes consisting of distinct petals and sepals.

\section{Order 1. RANUUTCULACERs-Crowfoot Family.}

Herbxceous plants, ocsxsimally climbing-rarely shrubs, with an acrid colorles: jusice, and usually palmately or termately lobed or divided leaves, without stipsites, alier. nate, with half-clasping petioles. 
Calyx of 3 to 15, (usually 5) distinct, mostly deciduous, sepals. Cororla, Petals 3 to $\mathbf{1 5}$ (sometimes irregular or absent,) hypogynous. Sramens indefinite in number, distinct, rarely few, hypogynous. PIstus numerous. Froit, either dry pods, or seedlike achenia, or berries, 1 to several seeded. Saens solitary or several, anatropous, with a minute embryo and fleshy albumen.

\section{Clematis. Linn. Virgin's Bower.}

- Gr. klama, a tondril ; climbing by tendrils, or twining petioles.

Caliy 4 (rarely 5 to 8) sepaled, colored, pubescent. PETALS none, or shorter than the sepals. Frlaments numerous. Anthers linear. Achenia numerous, in a head, bearing the persistent styles in the form of long plumose tails.-Perennial vines climbing by the leafstalk; stems somewhat woody; leaves mostly compound and opposite.

\section{C. Virginiana, L. Common Virgin's Bower.}

Stem climbing; leaves ternate; leaflets cordate, ovate, acute, coarsely toothed or lobed; flowers often dioecious, paniculate.

A common hardy climber in hedges and thickets, flowering in July and August. Flowers white, numerous, borne in panicles on axillary peduncles. Sepals 4, oval, oblong, obtuse. Fruit furnished with long plumose feathery tails.

\section{C. Vionna, L. Leather Flower.}

Stem climbing; leaves pinnately divided; segments entire, or 3-lobed, ovate, acute ; floral ones entire. Calyx companulate; sepals very thick and leathery, acuminate, connivent, reflexed at the apex.

Woods; June, July. Stem 10 to 15 feet in length, cylindrical, pubescent, purple, finally shrubby. Leaves opposite, pinnately decompound, consisting of $9-12$ leafiets. Flowers axillary, purple, nodding, on peduncles 3-6 inches long, with a pair of small, simple, entire leaves near the middle. Fruit with very plumose tails, from 1-2 inches long.

Amragene, DC., Involucre none: Sepals 4 : petals several, minute.

3. C. VertidiLlaris, DC. Whorl-leaved Virgin's Bower.

Stem climbing by the leaf-stalks; Leaves in fours, ternate; Leaflets stalked, ovate, pointed, entire or a little toothed, sometimes slightly heart-shaped; Peduncles I-flowered; Sepals very large, acute.

A handsome climber in highlaud woods and rocky hills, rare, sometimes cultivated. May, June. Stem ascending trces $10-15$ feet by means of its twisting petioies. From each of the opposite buts in spring there arise two ternate leares with long, stalked Leaflets, and a peluncle which bears a bluish-purple flower. Sepals thick 1 inch or more long and nearly $1 / 2$ wide. Filaments about 24, outer ones (1)etals) dilated, spatulate, tipped with imperfect anthers.

\section{ANEMONE. Linn. WIND FLOTER.}

Gr. anemos, wind; because the flowers are supposed to open when the wind blows.

Sepals 5 to 15 , petal-like, colored. Petals none. StaMENS numerous, much shorter than the sepals. Ovaries many, free, collected into a roundish or oval head. InvoLUCRE remote from the flower, of 3 divided leaves. AcHE. 


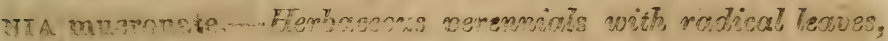

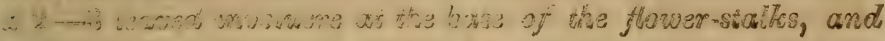
conitish fowores.

\section{A. nemorosa, L. Wood Anemone.}

Stem low, simpie, smooth, 1-flowered. Leaves ternate; leaflets undivided, or with the middle-one 3-cleft, and lateral ones 3-parted, incisely dentate, those of the involucre similar, petiolate. Sepats oval or elliptical.

Tar. quinquifolia D C. Lateral leaves of the involucre 2-parted to the base.

Margin of woods. April and May. A delicate vernal species. Stem or scape 4-8 inches high. Flowers 1 inch in diameter. Sepals 4-7, white or purplish. Carpels 15-20, oblong, with a hooked beak.

2. A. Pennsyuvanica, $I$.

Stem dichotomous; leares 3 to 5 parted; segments 3-cleft, lobes oblong, incisely toothed, acuminate; involucre 3-leaved; involucels 2-leaved, sessile ; sepals 5, obrate; carpels hairy, in a globose head.

Shores and rocky places. June, August. Stem 12 to 18 inches high. Flowers 1 to $1 \frac{1}{2}$ inch in diameter, borne on naked peduncles. Sepals white and membranaceous.

\section{A. Virginiana, L. Thimble Weed.}

Leaves ternate; segments oval-lanceolate, 3-cleft, acuminate, cut serrate, the lateral 2-parted, those of the involucre similar; sepals 5, acute; peduncles elongated; carpels densely wooly, in an ovoid oblong head.

Woods and meaclows; common. June, August. Stem 20 to 30 inches high ; the upright peduncles 6 to 12 inches long. Flovers $3 / 4$ of an inch in diameter. Sepals greenish-white, siiky beneath, 2 narrowor than the others.Fruit woolly, in heads one inch long.

\section{HePATICA. Willd. LiverLeaf.}

Gr. hepar, the liver; from a fancied resemblance of its leaves.

Involucre 3 leaved, simple, resembling a calyx, 1-flowered. Sepals petaloid 5-9, disposed in 2 or 3 rows. OvaRIES many. CARPELS without awns. - Leaves all radical, heart-shaped and 3-lobed, thickish and persistent through the year; the new unes appearing later than the flowers. Flowers single, on hairy scapes.

\section{H. TRILOBA, Willd. Liverwort, Liverleaf.}

Leaves cordate, 3 to 5 lobed; lobes entire.

var. 1. Obtusa, Pursh. Leaves 3-lobed; roundish, obtuse.

Tar. 2. Acuta, Pursh. Leaves 3 to 5 lobed; lobes spreading, aeute.

Woods and rocky places; common. This neat little plant is one of the earljest harbingers of Spring. April and May. Perennial. The root consists of numerous fibres. Flowers generally blue, but frequently purplish and white: becoming double by cultivation.

\section{THaliCtrum. L. Meadow Rue.}

Sepals 4 or more, petaloid, greenish, caducous. Petals none, Achenia 4-15 dry tipped by the stigma or short 
style, grooved or ribbed, or inflated. SeEDs suspended. Perennials with 2-3-ternately compound leaves; the divisions and the leaflets stalked. Flowers in corymbs or panicles; often polygamous.

* Stem-leaves forming an involucre at the summit like Anemone: root tuberous; stamens shorter than the petaloid calyx.

\section{T. Anemonoides, Michx. Rue Anemone.}

Root tuberous; radicalleaves biternate; leaflets subcordate, 3 toothed; floral leaves petioled, resembling an involucre; flowers few, in a simple umbel; petaloid caly $x$ to 10 leaved. Anemone thalictroides, $\mathbf{L}$.

Woods. April and May; common. A pretty plant; the flowers resembling those of Anemone, but the fruit that of Thatictrum. Stems or scapes 4 to 8 inehes high: often several frem one root. Flowers white or purplish, 1 inoh in diameter. Sepals twice as long as the stamens.

** Stem-leaves scattered, 3 to 4 times compound; root fibrous: stamens longer than the sepals.

\section{T. Connutr, L. Meadow Rue.}

Stem-leaves without general petioles, decompound; leaflets roundish-obovate or oblong, 3-lobed at the apex, the lobes acutish; glaucous beneath, with the nerves: scarcely prcminent; peduncle longer than the leaves. Flowsers in very compound. large panicles; diocious or polygamous; carpeis searly sessile, acute at each end; strongly ribbed, twice as long as the style.

Wet ground. June and July. Stem 3 to 5 feet high, branching. Leaves very variable in form, deep green above, paler glaucous smooth or pubescent beneath. Filaments slightly elub-shaped; anthers oblong.

\section{T. prorcum, L. Early Meadow Rue.}

Leaves all with general petioles; decompound, very smooth; leaflets rounded, and obtusely lobed, glaucous beneath; flowers in compound panicles, dioceious of polygamous; peduncles as long as the leaves; carpels oblong, sessile, strongly ribbed.

Banks of streams. April and May. Stem 1 to 2 feet high. Flowers white or purplish. Filaments much longer than the sepals. Anthers yellowish.

\section{T. Rugosum, Ait. Rugose-leaved Meadow Rue.}

Zeaves superdecompound; leaflets prominently veined beneath, cuneate-obovate and ovate-oblong, 3-lobed at apex, the lateral ones often entire; flowers mostly dioecious, rather crowded; filaments filiform.

Along shaded swampy rivulets; common. June and July. Stem 3 to 5 feet high, branching, striate smooth. Leares pinnately decompound. Flowers in rather crowded panicles. Sepals white, elliptic oblong, small. Carpels obovoid-oblong, acute at each end, beaked with the persistent style.

Obs. This may prove to be only a variety of T. Cornuta, to which it bears much general resemblance. Prof. Hookra considers them not specifically distinct.

\section{RANUNCULUS. Linn. Crowfoot. Buttercur.}

Lat. rana a frog; the aquatic species growing where frogs abound.

Sepals 5, deciduous. Petals 5 (rarely 10), with a little scale or nectary at the base inside. Stamens and ovaries aumerous. CARPELS ovate, somewhat compressed, pointed, 
arranged in a globose or cylindrieal head.-Herbaceous annual or perennial plants. Leaves mostly radical, though cauline at the base. Flowers solitary or somewhat corymbed, yellow, ravely white.

\section{* Petals white, claws yellow ; carpels transrersely mugose-striate.}

\section{R. AQUatrus, L. White Water Croufoot.}

Stem floating, filiform; leaves all submerscd, divided into capillary diverging segmouts; petals obovate, longer than the calyx.

Ponds and flowing water. Junc-August. Father rare. Stem 1 to 2 feet high, slender, woak, round, smooth, jointed. Leures dichotomovisly dirided into numerous hair-like segments, roundish in outline, and $1 / 2$ to 1 inch in diameter. Flowers \&mall, white or yellowish.

** Flowers yellow: leaves undivided: carpels smooth, ovate, collected into a roundish head : perennial.

\section{R. Flammula, L. Spearwort.}

Stem declinate; leaves smooth, linear-lanccolate or ovate-lanccoiate, subentire, lower ones petiolate, upper ones nearly sussile; peduncles opposite to the leares.

Dituhes and swanps. July-Sept. Stem 1 to 2 fect long; more or lese decumbent, zooting at the lower joints. Leaves 3 to 6 inches in length: $2 / 2$ to 1 inch wide, eatire or with a fer teeth, thickened at the acute summit. Flswers solitary, of a golde $\mathrm{a}$ yellow colcr, on peduncles 2 to 3 inches long. Whole plant yelluwish greeu.

\section{R. Reptans, L. Creeping Crowfoot.}

Siem creping, slender, jointed; joints 1-flowered. Leaves linear or lanceolate, entire, lower ones tapering into petioleg.

Gravelly or mudidy banks of rivers and ponds; common. Jine-August. A flinder, delichte species. Shm $\ddot{b}$ to 12 inches lcrig, rcund, rocting at the joints. Jeaves 1eshy $3 / 2$ to 1 inch long, mo:tly narrow axd acute at one end. Flowers yellow, small, burne on axillary peduncles. Fruit very smooth.

\section{R. pusillus, Poir. Priny Crovfoot.}

sitcm slender, erect, or decumbent; leares petioled; lowrer ones ovate, rondieh, or subcordate, entire and sparingly toothed; upper ones linear-lanceolate, obscureIy toothed, scarcely petioled; pedicels opposite to the leaves, solitary 1-flcwered; carpels smooth, with a minute, blunt point.

Wet grounds. Junc-August. Strms 6 to 12 inches high, branclied. Flrwers emall, pale-ycliow, on long peduncles. Fetais 1 to 5, often 3, scarcely longer thun the calyx. Siamens 5 to 10 .

*** Lcates divided.

\section{R. abontious, L. Small-fluered Craufoot,}

Smocth; stem simple or branching; radical leaves, pet:olate, cordato-orbiculate, crenate, somctimes 3-parted; stem-leaves ternate, 3 to 5 cleit, with lincar-oblong nearly extire segments; upper ones sessile; scpals longer than the fetals, refexed; carpels in a globular head, tipped with a very short recurred beak.

Wocls and wet grounds. May and June. Per. Sten a foot high, simple or tranching, snoctb. Iecives raricusly dissected, meetly smooth, $1 / 2$ to $11 / 2$ in. : 2 diameter, on petioles 3 to 5 inches long; lower ones pedate. Fluvers small, yellow.

\section{6. - R. scereratus, L. Celery-leaved C'roufoot.}

Snooth; stem branched; touer keaves 3-parted, segments loked, petioled; stem. 
leaves 3-lobed, lobes oblong, linear, entire or crenately incised; sepals reflexed; carpels small, numerous, in cylindrical heads.

Wet ditches. May-August. Per. Stem a foothigh, thick and hollow. Flowers small, numerous, pale yellow. Head sometimes an inch in length. Juice very acrid.

\section{R. REPENS, L. Creeping Crowfoot.}

Stem branching from the base; leaves ternate ; leaflets wedge-form, 3-lobed incisely dentate; central one petiolate; peduncles furrowed; calyx pilose, spreading; potals oborate, larger than the spreading calyx; carpels with a straight point strongly margined.

Hoist or shady places. May-August. Per. Very rariable in size, commencing to flower by upright stems 1 to 2 feet high, increasing by long runners. Flower's snidale size, bright yellow. Petals often emarginate. Leares hairy on the reins, dark green. Petioles long, hairy.

\section{R. Pennsylvanicus, L. Pennsytvanian Crowfoot,}

Stem erect, and with the petioles corered with stiff spreading hairs; leaves ternate, villous, segments sulupetiolate, acutely 3-lobed, incisely serrate; calyx reflexed, rather longer thau the small petals; carpels pointed, with a short straight beak, collected into an oblong head.

Wet places: common. July and August. Per. Stem 1 to 3 fcet high, usually much branched. Flowers small, pale yellow. Carpeis viscid, nearly allied to the next species, but distinguishcd by its oblong heads of carpels, shorter style, and much smaller flowers.

\section{R. Hrspinds, Mich. Hairy Crowfoot.}

Stem erect, branched, and with the pitioles corered with stiff spreading hairs; lexces ternate or 3-yarted; leafets or segments acu'cely lobed; pubescence of the pedicels appressod; colyx hairy, at length reflexed ; carpels.in a globose head, mar. gincd, compresscd, smooth; style short and straight.

Wet grounds. June-A ugust. Per. Stem 18 inches high, very hairy. Lover leares on long petioles; uppir oncs nearly sessile; leafiets nearly all petiolicd, 3-cle st or 3-parted, alternate at base. Flowers numerous, large, bright, yellow.

\section{R. Recurvatus, Poir. Wood Crovifoot.}

stem erect and with the petioles clothed with speading bairs; leaces 3-parted, bairy; secments oval, subinciscd, the Iateral ones 2-lobed; calyx reflexed; petals lanceolate; carpels crowned with a sharp, hookcd style.

Shady woods and damp places. May-July. Per. Stem 12 to 15 inches higin, sparingly branched, often dichotcmous at the summit. Lower leavcs somewhat orate at base, on pet:oles 2 to 6 inches long which are sheathing at base; rixper ones sulisessile and 3-parted quite to the base. Flowers small, pale yellow, on short peduncles. Whole plart pale grcen.

\section{R. Fasctcularis, Muhl. Early Croufoot.}

Stem erect, brarchcd, clcthed with appreseed hairs; leaves on long petioles, pu-besecnt, pinnately divided, the lobes obiong, obovate, pinnatified; catyx villous, spreading, shorter than the petals; carpels orbicular, crowned with a slender subulate style, collected into a subglobose head.

Woods and hills. A pril and May. Per. Roct a fasicle of fleshy fibres: Stem 6 to 12 inches high. Radical leaves on petioles 3 to 8 inches long, so divided as to appear almost pinnate; "xper omes 3-parted, nearly sessile. Floncers large: petals yellow, cuneate-oborate, with a scale at the kase as broad as the transparent claw.

\section{R. Bulbosus. L. Bulbous Croufoot:}

Stem erect, hairy, bulbous at the base; leaves ternate, or quinate-pinnate; leaflets $\therefore$ to 5 parted; segments trifid or incised; peduncles sulcate; calyx reflexed, hairy; carpels tipped with a very ehort beak; collected into a very globoze bead. 
Meadows and pastures. Introduced from Europe. May-August. Per. Stem 9 to 15 inches high, hollow, thickened at the base into a sort of bulb. Leaves appearing as if pinnate. Petals deep yellow and shining, 5 to 7 cuneate-oborate, sometimes obcordate. Flowers more than an inch broad.

\section{R; ACRIS, L. Buttercups Crowfoot:}

Hairy; stem erect; leaves 3 to 5 parted; the divisions all sessile and 3-cleft or parted; their segments cut into linear or lanceolate crowded lobes; peduncles terete, not furrowed; calyx spreading, hairy; petals oborate, not longer than the spreading calyx; carpels roundishi; smooth, compressed, terminated by a short, recurved beak.

Meadows and pastures; common. Introduced from Europe. June-Aug. Per. Stem 1 to 2 feet high, round, hollow, mostly hairy. Leares 1 to 3 inches in diameter. Flowers large, golden yellow, shining; bccoming double by cultivation. Gasden Buttercups.

\section{HYDRASTIS. Linn. Yellow Root.}

Gr. hudor, water; from its growing in moist places.

Sepals 3, ovate, petaloid, caducous. Petals none. Stamens and ovaries numerous. Carpels berry-like, numerous, aggregated in a globose head, terminated by the style, 1-2 seeded.-A low perennial herb, sending up in early spring, from a thick and knotted yellow root-stalk, a single radical leaf, and a simple hairy stem which is 2-leaved. near the summit, and terminated by a single greenish-white flower:

1. H. Canadevsis, L. Yellow Puccoon, Golden-seal.

Lieaves rounded, 2 to 6 inches wide, palmately 3 to 5 lobed; loles acute, doubly serrate.

Rocks, woods, northern sides of hills; rare. May. Chester Co., Dar?. Lancaster Co. Abundant along the Alleghenies. Flcwer solitary, on a peduncle about 1 inch long. Sepals fleshy, pale rose color. Fruit fleshy purplish, about the size of a large raspberry. The root affords a juice of a fine yellow color, used by the Indians for staining skins and clothing.

\section{Calthit Linn. Marsh Marigold.}

Gr. kalathos, a basket; in allusion to the form of the flower.

Calyx colored, with 5-10 reundish sepals, resembling petals. Petals none. Stamens numerous, shorter than the sepals. Pistics 5-10 with no style. Folutcles compressed, spreading, many seeded.-Smooth perennials with round and heart-shaped, or kidney-form, large leaves, and showy yellow flowers.

1 C. Palustris, L. Marsh Marigold, Golden Covstip.

Stem hollow, furrowed; leaves cordate, round, or kidney-shaped; crenate; flowers large, pedunculate; sepals broad oval.

Swamps and wet meadows; cemmon. April snd May. A beautiful plant with 
large flowers of a golden yellow in all their parts. Stem 6 to 10 inches high, erect, aomewhat succulent, dichotomously branched above. Leaves large and shining. Used as a potherb in Spring.

2. C. Flabeluifolia, Pur. Fan-leaved Marsh Marigold.

Stem procumbent, many-flowered; leaves dilated-reniform; lobes widely spreading, coarsely and acutely toothed; peduncles, axillary, solitary-flowered; sepals obovate; capsules uncinate.

Sand spring on Pokono mountain. Pursk. July and August. Stem a foot high, Flowers yellow, middle sized. Allied to C. natans found in Canada and in Siberia.

\section{TROLLIUS. Linn. GLOBE Flower.}

Germ. trol or trollen, globular; alluding to the form of the flower.

Sepals colored 5-10-15, deciduous, petaloid. Petals 5-25, small, linear, tubular at base. STAMens numerous, much shorter than the sepals. Pistils many. Fordicles numerous, sub-cylindric, sessile, many-seeded.-Smooth perennials with palmately parted leaves, and large solitary terminal flowers.

1. T. I $\Lambda$ XUs, Salisb. American Globe-flower.

Leaves palmate, deeply cleft, cut dentate; sepals 5, oblong, spreading; petals 15 to 25 , shorter than the stamens, inconspicuous.

Deep swamps and wet grounds; rare. May-July. Siem a foot or more high. Flowers terminal, large, yellowish, or orange colored. Follicles about 10, crowned with the persistent style.

This is the only American speciee. Probably often mistakcn for a species of Ranunculus.

\section{COPTIS. Salisb. Gold Thread.}

Gr. kopto, to eut; in allusion to the numerous divisions of the lerves.

Sepals 5-7, colored, petaloid, dcciduous. Petals 5-7 small, cucculate. Stamens numerous 20-25. Pistils 37 , on slender stalks. Follicles $3-7$, membranous, $4-8$ seeded.-Low smooth perennial herbs with radical leaves, ard a long, slender, creeping rhizoma.

1. C. trifoura, Salisb. Gold thread.

Leaves. 3-foliate; leaflets wedge-shaped, oborate, obtuse, toothed or obscurely 3 lobed; scape 1-flowered; petals much smaller than the sepals.

Swamps and boggy places: common. May-July. Stem subterranean, extersiro$2 y$ creeping, golden yellow, bitter and ton; c. Lecices evergrecn; scure 4 to 6 inchca high, slender, bearing a single white, starlike flower.

\section{AQUILEgIA. Linn. Columine.}

Lat. aquila, an eagle; the spurs or nectaries rescmbling the claws of that bird.

Serals 5, regular, colored like the petals. Petals 5, with a short spreading lip, produced backwards into long, 
tubular spurs, much longer than the calyx. STamens $30-$ 40. Prstils 5, with slender styles. Fuluicles 5, erect, many seeded.-Perennials, with 2-3-ternately compound leaves, the leaflets lobed, Flowers large and showy, terminating the branches, nodding.

\section{A. Canadensis, L. Wild Columbine.}

Smooth; divisions of the leaves 3-parted, rather obtuse, ineisely dentate; sepals somewhat acute, a little longer than the petals; spurs straight; longer than the limb. Styles and stamens exserted.

A beautiful plant growing in rocky places; common. April-June. Stem 1 to 2 feet high, branched above. Flowers terminal, nodding, searlet without and yellow within, 1 to 2 inches long. Fruit upright. More delicate and graceful than the cultivated. A. vulgaris of Europe.

\section{A. vUlgaris. Common Garden Columbine.}

Stem 1 to 2 feet high, leafy, many flowered; leaves nearly smooth, glaucous, biter: nate; spurs incurved. Flowers purple; becoming double by cultivation, and vary* ing in color, through all shades from purple to white. June.

\section{DELPHINUM. Linn. LARKSPUR.}

Gr. detphin, a dolphin; from the shape of the upper sepal.

Sepals 5, irregular, colored; the upper one produced into a spur at the base. Pexals 4, irregular, the upper pair terminating behind in a tubular, necteriferous spur, enclosed in the spur of the calyx, the lower pair with short claws. STAmens numerous. Pistrus $1-5$, mostly 3 , forming many seeded follicles in fruit.-Showy herbs with palmately cut or divided leaves. Flowers in terminal racemes, blue, red, or purple: never yellow.

1. D. Azureum, Mich. Azure Larkspur.

Pubescent or nearly smooth. Stem erect; leaves 3 to 5 parted, many cleft, lobes linear; racemes erect; petals shorter than the sepals, densely bearded at the apex; flowers on short pedicels; spur ascending.

Woods and uplands; rare. May. Per. Stem 1 to 2 feet high, slender, sometimes softly pubescent. F'lowers large, blue and whitish.

2. D. exaltatum, Ait. Tall Larkspur.

- Stem erect; leaves flat, 3 to 5 cleft beyond tbe middle; lobes wedgeform, 3-cleft at the apex acuminate; lateral ones often 2-lobed; raceme erect; spur straight, as long as the calyx; capsules 3 .

Rich soil: Western parts of the State. June and July. Per. Stem 2 to 3 fet high. Lower leaves 4 to 5 inches broad. Flowers of a brilliant purplish blue, borne on panicled wand-like racemes; many-flowered.

\section{D. TRICORNE, Mich. Three-horned Larkspur.}

Leaves deeply 5-parted, divisions 3 to 5 cleft; segments linear, acutish : petals shorter than the sepals, lower ones 2 cleft, densely bearded inside; spur ascending, straight, as long as the calyx; carpels 3 , spreading in fruit. 
Uplands. W. Penn. April and May. Per. Stem 6 to 18 inches high. Leaves roundish in outline, on long petioles. Racemes loose, 6 to 12 flowered. Flowers bright blue.

\section{D. CONSOLIda, L. Common Larkspur.}

Stem erect, smoothish, divaricately branched; flowers few, in loose racemes; pedicels longer than the bracts; carpels smooth. Anuual. Native of Europe. July. Flowers blue.

5. D. GRANDIFLORUM. Large-flowered Larkspur.

Leaves palmate, many parted; lobes linear, distant; pedicels louger than the bracts; petals shorter than the calyx. A superb perennial species from Siberia. F'lowers double, or kingle, in racemes ; dark brilliant blue, tinged with purple.

6. D. elatum. Bee Larlispur.

Leaves downy, 5-lobed; lobes cuneate at base, trifid, cut dentate; spur inflexed.

Native of Siberia. Stem 5 to 6 feet high. Flowers blue, and at a distance resembling a bee in form.

\section{ACONITUM. Linn. WoLFsBane.}

Gr. akone, a cliff or rock; in allusion to its place of growth.

Sepals 5, very irregular, colored, upper one vaulted, larger than the others. Petals 5, the 3 lower ones minute, often converted into a sac or short spur at the summit. STrues. 3-5; Forlicles 3-5, many seeded.-Perennials with patmate or digitate leaves, and showy flowers in terminal spikes.

1. A. uncinatum, Linn." American Monkshead.

Stem slender, weak, climbing, with diverging branches. Leaves palmate or 3 to 5 lobed, with ovai-lanceolate, cutdentate divisions; helmet obtusely conical, rostrate; spur inclined, somewhat spiral.

Mountains and rich shady soils along streams; rare. August. Stem 5 to 6 feet long, supporting itself upon adjacent bushes. Leaves leathery, dark green, 4 to 5 inches wide. Flowers large, purple, 3 or 4 near the summit of each branch.

\section{A. Reclinatum. Gray.}

A white flowered species; is doubtless to be found in our mountains.

\section{ACTAEA. Linn. BANE-BERRY.}

Gr. alite, the elder; on account of its resemblance to that plant.

Sepals $4-5$, deciduous. Petals $4-8$, spatulate, unguiculate. Stramens numerous, dilated above; antuers 2 -lobed. P'rstrus single; stigma sessile, depressed, 2-lobed. Frurt a many-seeded berry. SEeDs smooth, flattened, and packed horizontally in 2 rows.-Perennials with ternately divided leaves, and thick terminal racemes of white flowers.

1. A. Rubra. Willd. Red Baneberry.

Leaves twice and thrice ternate; raceme hemispherical; petals acute, shorter than the stamens; pedicels of the fruit shorter than the peduncle. Berries ovoid, oblong; 'Blining red, many-sceded. 
Rocky woods. May. Stem about 2 feet high. Leares very large when full grown. Flowers white. Berries red in racemes 3 to 4 inches long; pedicels slender, 1 inch long.

2. A. ALBA. Big. White Baneberry. Cohosh.

Leares twice and thrice ternate; raceme oblong; petals equal to the stamens, truncate at the apex; pedicels of the fruit as large as the peduncles. Berries ferseeded.

Woods. May. Plants 1 to 2 feet high, bearing 2 compound leaves, and a cluster of white flowers. Leaflets 1 to 2 inches long, half as wide. Raceme 1 to 3 inches long, $1 \frac{1}{2}$ thick, at length purple. Berries milk white tipped with red, smaller than in A. rubra.

\section{CIMICIFUga. Linn. Bugbane.}

Lat. cimex, a bug, and fugo, to drive away.

Sepals 4-5, falling off soon after the flowers expand. Petals 3-8, spatulate, small, on claws, 2-horned at the apex. Stanens numerous. Pistils $1-8$, forming dry follicular carpels in fruit; carpels $1-8$, many seeded. Style, short. -Perennials with ternately divided leaves, and white fitid flowers in long slender racemes.

\section{C. Racemosa. Ell. Black Snalicroot.}

Learcs ternately decompound; leafets ovate-oblong, incirely toothed; raceires rery long; petals 2 , forked,slender; style 1 ; capsule follicular, dry, dehiscent, orate.

Rich woods: abundant. July and August. Stems 3 to $\mathrm{S}$ feet high, terminated with long, panicled racemes of white monogynous flowers. Petals 4 to 6 , smali. Stamens about 100. Raceme plume-like, 6 to 12 inches long. Root knotted, medicinal.

2. C. Americana. Michx. American Bugbane.

Smooth. Lecres triternate, segments ovate, terminal one wedge-form at the base; 3-parted, or 3-cleft and incised; pctals concare, sessile, 2-lobed, necteriferous at base; pistils 3 to 8 ; seeds flat, scaly.

High mountains. A ugust. Stem 3 to 6 feet high. Flowers smaller than in C. racemosa; in a long panicle of racemes. Follicles mostly 5, abruptly beaked, 6 to 8 seeded.

\section{ZANTHORIZA. Linn. Yellow Root.}

Gr. zanthos, yellow, and riza, a root.

Calyx deeiduous, 5-sepaled. Petals 5, of 2 roundish lobes, raised on a pedicel. Stamens 5-10. Ovaries 515, beaked with the styles, 2-3 ovuled. Follicles membranaceous, compressed, 1 seeded.-A low plant with shrubby shoots: stem and bark yellow and bitter. Leaves pinnately divided. Flowers polygamous, dull purple, in compound drooping axillary racemes.

\section{Z. APIIFolia. L'Her.}

Leares preudo-pinnate or ternate; leaflets 5 , ressile, incisely lobed and dentate, 
Banks of shady streams in mountainous districts. April and May. Per. Stems clustered 1 to 3 feet high. Racemes many flowered. Flowers purple. Follicles spreading $1 / 4$ inch long.

\section{HELLEBORUS. Adans. HejLebore.}

Gr. helien, to cause death; and bora, food; on account of its poisonous properties.

Sepals 5, persistent, mostly greenish. Petals 8 to 10 , very short, tubular, 2-lipped. STtamens numerous. Strigmas 3 to 10 , orbieular. Follicles 3 to 10 , slightly cohering at the base, many seeded. Seevs elliptical.-Perennials, with coriacious, divided leaves, and large, nodding flowers.

\section{H. viridis. L. Green Hellebore.}

Smooth; radical leaves pedately divided. Stem leaves few, palmately parted nearly sessile; peduncles often in pairs; sepals roundish, ovate, acute. A European plant, naturalized. Stem about 1 foot high. Flowers large, pale green, appearing in early spring. March and April.

\section{CULTIVATED EXOTICS.}

\section{P ȦONIA. Peony.}

Sepals 5, unequal, leafy, persistent. Petals 5. Stamens numerous, mostly changed to petals by cultivation. Ovaries 2 to 5. Style none. Srigmas double, persistent. Foldicles many seeded.-Perennials with fasciculate roots; biternate leaves; and large, showy, terminal, solitary flowers.

1. P. officranalis. Common Pcony

Stem erect, herbaccous; lower leaves bi-pinnately dividcd; leaflets ovatc-lanceolate, variously incised. Fruit downy, nearly straight. Native of Switzcrland. May and June. This splendid flower has long been cultivatcd in every part of Europe, and in this country. The doulle red variety is the most common. The white is truly beautiful.

2. P. Albiflona. White-flowered Peony.

Leaflets elliptic-lanceolatc, acute, entire, smooth. Follicles recurved, smooth. Native of Tartary. Whole plant dark-shining-green, and smooth. Flcuers white, fragrant, smaller than the last. Calyx brown, with 3 green sessile bracts at base. Varieties numerous, with single and double white and rose-colored flowers.

\section{P. Moutan. Chincse Tree Peony.}

Stem shrubby; leaflets oblong-ovate, glaucous, and somewhat hairy beneath; terminal-one 3 -lobed; cvaries 5 , distinct, surrounded by a very large disk. Native of China. Stem 3 to 4 feet high. Leaves large, on long stalks. F'lowers verg large, fragrant, and always doubled in cultivation. Disk very large.

18. ADONIS. Linn.

Sxpals 5, appressed. Petals 5-15, with naked claws. 
Acrenta in a spike, ovate, and pointed with the bardened, persistent style.

\section{A. Autumanis. Pheasant's Eye.}

stem branching; leaves pinnately parted, with numerous linear gegments. erg crimson, 5 to 8 petaled. Carpels crowned with a very short style, and eolloeted into an orate or sub-cylindrical head. Antmuah

\section{NIGELLA. Lint.}

Calyx of 5 sepals, colored. Perals 5, 3-cleft. Strues 5. Carsithes 5, follicular, convex.-Annual European herbs, with leaves in many linear and subulate segments.

1. N. Damascexa. Fennel Flower.

Leaves twice and thrice pinnatifid, as finely cut as those of the fennel. Flcwers in a leafy involucre, terminal, solitary encompassed and overtopped by a circle of leaves divided like the rest, white or pale blue, sometimes double; anthers obture; Carpels 5, smooth, 2-celled, united as far as the ends into an orold-globose capsulo. A hardy annual of the gardens. June-August.

2. N. sativa. Nutmeg Flower.

Stem slightly furrowed, erect, branched. Leaves divided the in the last, with the divisions much more linear. Flowers naked, terminal on the summits of the branches. Anthers obtuse. Capsule with hard short points. From Esypt. Juns -September.

\section{ORDER 2. MAGNOHIACYSTR.}

Trees or shrubs toith the leaflids sheathed by mimlraneous stipules; athernite coriaceous, entire leaver, marked with minute transparent dots, and solitary, harce, perfect, sliowy, often fragrant flowers.

SÉpxts 3 to 6 , deciduous, eclored. Fetars 3 to 27 in sereral rows, hypogynous, imbricate in restivation. STAMENs indefinite, distinct, hypogynous, in several rows at the base of the receptacle. Ovaries numerous; style short; stigma simple. Frura either dry or succulent, consisting of numerous carpels, arranged upon an elongated axis. SEEDS solitary or several, attached to the inner suture of the cargols. BARI aromatic and bitter.

\section{MAGNOLIA. Linn.}

In honor of Prof. Magnol, a French botaxist.

Sepals 3, deciduous. Petals 6-12, in concentric series. Stamens indefinite, distinct, with short filaments and long anthers, opening inwards. Pistils aggregated and cohering: in a mass, together forming a fleshy and rather woody conelike fruit; each carpel opening on the back at maturity, from which the seeds are suspended, when mature, by a long slender funiculus.-A magnificent genus, consisting mostly of large trees, with thxuriant foliage, and large frayrant flowers. 


\section{M. gladda, L. Swamp Laurel. Sweet Bay.}

Leaves oval, glaucous beneath, petiolate; flowers 9 to 12-petaled; petals obovato, tapering to the base ; cone of fruit amall, oblong.

Swampy places: southern parts of the State. July and A ugust. A shrub or tree 10 to 20 feet high, with a smooth whitish bark. Flowers terminal, on thick pedun cles, white, 2 to 3 inches broad, very fragrant. Leaves very pale benoath.
2. M. a cuminata, L. Cucumber Tree.

Leares deciduous, oval, acuminate, pubescent beneath; petals 6 to 9 , oblons somewhat obtuse; cone of fruit small, cylindrical.

Rich damp woods. June and July. A noble forest tree 60 to 90 feet high, per fectly straight. Leaves thin, 5 to 10 inches long. Flowers 5 to 6 inches in diametor, bluish, or yellowish-white, glaucous externally. Cones of fruit 2 to 3 inches long when green resembling a young cucumber.

3. M. Umbrella, Lam. Umbrella Tree.

Leaves deciduous, cuneate-lanceolate, acute, silky when young; sepals 3 , reflexed; petals 9 , oval-lanceolate, acute, the outer ones reflected; cone of fruit large, conical, oblong.

Mountain woods; rare. May and June. A small tree with irregular branches. Leaves 16 to 20 by 6 to 8 inches; often appearing whorled at the apex of the flower ing branches, in the form of an umbrella. Flowers terminal, white, 7 to 8 iache in diameter. Fruit 4 to 5 inches long, of a fine rose color when ripe.

\section{M. Frazerir, Walt. Frazer's Magnolia.}

Leaves deciduous, spatulate-obovate, auriculate at the base; sepals 3 spreading: petals 9 , oblong attenuate at the base.

Allegheny mountains, head waters of the Susquehanna, (Pursh); rare. Aprit and May. A fine tree 30 to 40 feet high. Leaves 8 to 12 inches long, mostly green and smooth on both sides, or slightly glaucous beneath, somewhat rhomboid; aurfcle narrow, rounded. Flowers about 4 inches in diameter, pale greenish-whita Fruit oval-oblong, rose-colored. Torr. \& Gray.

\section{LIRIODENDRON, Linn. Tulip Tree.}

Gr. leirion, a lily; dendron a tree.

Sepals 3, caducous. Petals 6, in 2 rows, making a bell-shaped corolla. CARPELS imbricated in a cone, 1 to 2 seeded; seeds attenuated at apex in a scale.-Large trees with showy and fragrant flowers.

\section{L. Tulipifera, L. Tulip Poplar.}

Leaves alternate, 3 lobed, (the middle lobe truncate); flowers large, solitary, with 2 large caducous bracts at the base; sepals obovate-oblong, spreading, and at length falling off; petals lance-obovate.

Woods throughout the State. June and July. One of the largest trees of our forests; 50 to 100 feet high, from 2 to 3 feet in diameter. Leaves dark green, smooth, on long petioles. Flowers 4 to 6 inches in diameter, greenish yellow, stained with reddish orange below the middle. There are two varieties: one called Fellow Poplar, which is highly valued for cabinet use; Hickory Poplar, which is distiv. guished from the other by its less furrowed bark and tougher, whitish wood.

\section{ORDER 3. ANONACEFE.}

Trees or shrubs with nalied buds and no stipules; alternate, entire, simple-fiather veined leaves, large, solitary, axilkary, green or brown fiowers, and an acrid aromatio fetid bark. 
Sepals 3 to 4, persistent, usually partly cohering. Petals 6, in 2 rows, valvate, hypogynous coriaceous. Stamens indefinite, densely crowded, covering a large bypogynous disk; filaments short; anthers adnate. Ovaries numerous, elosely packed; styles short; stigma simple. FrurT dry or succulent, consisting of a number of carpels in a mass, sometimes fleshy or pulpy. Sreds anatropous.

\section{ASIMINA, Adans. PAPAW.}

Name from Asiminier, of the French colonists.

Sepals 3, united at the base. Petals 6, in 2 rows, spreading, ovate-oblong; inner ones smallest. STAmens numerous in a globular mass. Pistrus few, forming large and oblong pulpy several-seeded fruits.-Shrubs or small trees, with alternate entire leaves emitting an unpleasant odor when bruised, and dull colored axillary and solitary flowers.

\section{A. triloba. Torr \& Gr. Papaw. Custard Apple.}

Leares oblong, crenate, acuminate, and with the branches smoothish; flowers on short peduncles; outer pelals roundish-ovate, 3 or 4 , as long as the calyx.

Banks of streams. Along the Susquehanna. April and May. A small tree, 10 co 20 feet high. Flowers solitary, lateral, appearing in advance of the leares, dark brownish purple, 1 to 2 inches wide. Fruit about 1 inch thick, and 3 inches long, oroid-oblong, 8-seeded, yellowish, fragrant, eatable, ripe in October.

\section{ORDER 4. MENISPERITACEF,}

Shrubs twining or climbing, with palmate or peltate, alternate, entire, simple leaves; alaving small, usually polygamndicecious flowers in panicles or racemes; sepals and pctals confounded in one or several rows, each of which is composed of 3 or 4 parts; deciduous.

STAMENS distinct or monodelphous, equal to the number of the petals and oppo eite to them; or 3 or 4 times as many. AN'rHERs adnate. OVARIES urually volitary, sometimes 2 to 4 each with one style, distinct, or rarely united. Frurr a drupe, globose-reniform. Steps bent into a creseent or ring; embryo curved like the reed; albumen sparing.

\section{MENISPERMUM. Linn. MoONSEED.}

Ar. mene, the moon; sperma, seed; from the crescent form of the seed.

Sepals and petals arranged in fours, 2 or 3 rowed. Sterile Fl. stamens 12 to 20 . Frrtile Fu. pistils 2 to 4. DRupe berried, roundish, reniform, with a single lunate nut or seed.-Sterile and fertile flowers often dissimilar.

\section{M. Canadense, L. Moonseed.}

Stem climbing; leaves peltate, the petioles inserted near the base, roundish corcate, obtusely angled, mucronate; panicles axillary; petals 4 to 8 small.

Banks of streams. July. Root Per. Stem round, 8 to 12 feet long. Leaves 4 to 5 inches in diameter, generally 5 angled, smooth, pula beneath, on petioles 3 to 5 Inches long. Flowers in axillary clusters, mall, yellow, tinged with purple.

Berries black, resembling grapes.

Yar. L'Jatum, has the leares lobed. 


\section{ORDER 5. BERBERDACEF.}

Herbs or shrubs with alternate leaves, exstipulate, simple or eompound; with solitary, racemose, or panicled flowers. SEpals 3 to 6 , imbricated in 2 rows. Conolla hypogynous. PEtals 1 to 3 times as many as the sepals, and opposite to them. STAMENS as many or twice as many as the petals, and opposite to them. OVARY solitary, 1-celled, wimple; style rather lateral; stigma orbicular. FruTt a berry or capsule. SEEDs one or few, attached to the bottom of the cell, or many attached to a lateral placentæ.

\section{BERBERIS, Linn. BARBERRY.}

Arabic Berberis; name of the fruit.

Sepals 6 , mostly with bracteoles at the base. Petals 6 with 2 -glands upon their elaws. Stamens 6 ; filaments flattened; anthers 2-Iobed; lobes on opposite edges of the connectile style. Stigma circular, depressed. Fruit a 1 to 3 seeded berry. SEeDs erect, with a crustaceous integument. - Fine hardy shrubs, with yellow wood and inner bark.

1. B. Canadensis, Pursh. American Barberry:

Branches verrucose-dotted, with short triple spines; leaves spatulate-oblong, remotely serrate with somewhat bristly teeth; racemes sub-corymbose, four-flowered; petals emarginate; berries sub-globose or oval.

Allegheny mountains. May. Leaves alternate at base but nearly sessile, margin serrulate with 6 to 8 distant mucronate teeth. Racemes 5 to 8 fowered, nodding. F'lower's and fruit as well as the leaves smaller than in B. vulgaris.

\section{B. VULGARIS, L. Common Barberry.}

Leaves scattered on the young shoots of the season, mostly small, and with sharp. lobed margins, or reduced to sharp triple spines; simple, elosely serrate, with bristly teeth; racemes many-flowered, pendulous; petals entire; berries oblong.

Roadsides and fields. Native of Europe, naturalized. April and May. A shrub 4 to 6 feet high. Leaves alternate, $11 / 2$ to 2 inches long, $1 / 3$ as wide.. Flowers in pendulous racemes, pale yellow. Stamens irritable, springing violently against the stigma when touched. Berries red, very acid. The bark of the root dyes yellow.

\section{PODOPHYLLUM. Linn. MAY APPle.}

Gr.pous, a foot; and phullon a leaf; tho leaf resembling a web-foot.

Sepals 3, oval, obtuse, caducous. Petals 6 to 9, obovate, concave. Stamens 9 to 18 , with linear anthers. Stigma large, sub-sessile, peltate, persistent. Berry large, ovoid, 1-celled, somewhat fleshy, not dehiscent. SEeDs numerous. - Low perennial plants, with ereeping rootstalks, and thick fibrous roots.

1. P. pellatum, L. May Apple. Wild Mandrake.

Flowering stem erect, 2-parted, bearing 2 1-sided leares, with the stalk fixed near the inner edge, palmately lobed; flowerless stems terminated by a large, round, 7 to 9 lobed leaf, peltate in the middle like an umbrella; flower solitary, in the fork of the petiole, pendulous.

Woods : common. May. Stem a foot high. Flower white, 2 inches in diameter. Pruif oroid, 1 to 2 inches long; ripe in July; yellow, with the flavor of the strawberr. 


\section{JEFFERSONIA. Bart. TWIN-LEAF.}

In honor of Thomas Jefferson.

Sepals 4, colored, deciduous. Petals 8, spreading, incurred. Stamens 8 , with linear anthers. Stigma peltate. Capsules obovate, stipitate, semicircularly dehiscent. Seeds many, arillate at the base.-Perennial smooth plants with matted fibrous roots, and simple nalied, 1-flowered scapes.

\section{J. Diphyla , Barton. Twin-leaf.}

scape 8 to 14 inches high; leaf binate, petioled; flower terminal, solitary; capsule large, coriaceous; secds shining, oblong.

A singular plant, flowering in May: not common. Rhizoma horizontal. Petioles radical, bearing at the top a pair of binate leaves, placed base to base, and broader than they are long, ending in an obtuse point; glaucus beneath. Scupe as long as the petioles. Flonvers large, white. Capsule opening, half roum, with a persistent lid.

\section{LEONTICE. Linn. Lion's Foot.}

Gr. leon, a lion; the leaf resembling in outline a lion's foot.

Sepals 6 , naked without. Petals 6 , bearing a scale at the base within. Stamens 6 , opposite the petals. Pistils gibbous. Style short. Stigna minute. Ovary bursting at an early stage by the pressure of the 2-erect enlarging seeds, soon withering away; the spherical secds naked on their thick seedstalh, looking like drul $e_{3}$; the flieshy integument blue, the solid albumen horny.

1. L. thalictroides, L. Pappoose-root. Blue Cohosh.

Smooth; lower leaf triternate; upper one kiternate; leuficts oblong ovate, and euneate-obovate, mostiy 3-loked at the apex; flocers paniculate; peduncle from tho base of the upper petioles.

focky woole. Ray. Per. St $m$ to 2 fect high, round 2-parted, one of whieh

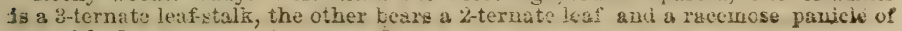
greenish fiowurs.

\section{ORDER 6. CABOPHOBACETI}

Aquatic plants with flating, entire, centrally peltate leaces; ard solitary, axillary gonvers. SEPals 3 to 4, colored inside. PeTals 3 to 4, alternate with the sepals. STAMrns definite or indefuite; ANrrers innate. Pistils 4 to 18 , forming littio elub-shaped indehiscent pods, tipped with the indurated style; sTrums eimple. Sexps globular pendulous.

- BRASENIA. Schreber. Water Shieldos.

Calyx of 3 to 4 sepals. Petals 3 to 4 . Stameks 18 to 36 . Carpels oblong, acuminate, 1 to 2 seeded. Pereñmial herbs. 
1. B. Peltata, Pursh. Water Shield. Water Target.

Leaves alternate, long petioled, centrally peltate, oval, floating on the water, smooth and shining above; flowers on long, slender, axillary peduncles, floating on, the surface.

Lakes and ponds. Often in company with the white water-lily. Juni and July. Whole plant covered with a viscid jelly. Flowers purple, one inch in diameter.

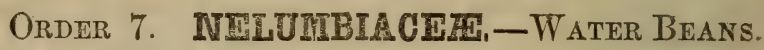

Aquatic herbs with pettate, fleshy radical leaves, arising from a prostrate rhizonna. Frowers large, solitary, on long erect scapes. Sepals 4 to 5. Petals numerous, oblong, in many rows. STAMENS numerous, arising from within the petals, in eereral rows; FILAMENTS petaloid; ANTHERS adnate. PISTILS distinct, numerous, forming acorn-shaped nuts, and separately imbelded in cavities of the enlarged topshaped receptacle. SEEDS solitary, filled with the large, highly developed cmbryo.

\section{NELUMBIUM. Juss. SACRed Bean.}

From the Ceylonese name, Nelumbo.

Calyz petaloid, of 4 to 6 sepals. Petals numerous. Carpels numerous. Seeds large, round, solitary.-Perennials.

\section{N. LUteum, Willd. Water Chinquipin.}

Leaves orbicular, alternate, centrally peltate, very entire; anthers with a linear appendage.

Rivers and stagnant waters: abundant in the ditches of meadows bordering the Delaware, helow lhiladelphia. June. Leaves a foot, or more, in diametcr. I Ieduseles very lons, more or less seabrous. Flonvers 5 to 10 inches in diameter, Jellowishwhite. Seeds eatable.

\section{ORDER 8. WYMPHMACEM,-Water Irities.}

Aquatic herls, with round or peltate floating leares, and solilary showy flou'er fron a prostrate root-stalli. SEPALS and PETALS numerous, imbricated, gradually passing into eachother. Serals persistent. Petals inserted upon the disk surrounding the piatil. Staness numerous, inserted above the petals into the disk; FHAMrNTs petaloid; ANTHERS adnate. Disk large, fleshy, surrounding the orary more or loss. OrARx with radiating stigmas. FRUT many-celled, indehiscent: sEEDS numerous, attached to the spongy placentre and enveloped in a geIatinous aril.

\section{NYMPHAA. Iinn. WATER LILY.}

Dedicated by the Greeks to the Water Nymph.

Sepals 4, at the base of the disk. Petals numerons, inserted on the torus at its base. STAMENs numerous, gradually transformed into petals. STIGMA surrounded with rays. Pericarp many celled, many seeded, depressed, globular, covered with the bases of the decayed petals.-Perennials with showy white, rose-colored, or blue flowers. 
1. N. odorata, Ait. White Pond-Lily.

Leaves floating, orbicular-cordate, rery entire; nerres and reins prominent; sigma 16 to 30 rayed; rays incurred.

Ponds and sluggish streams. Susquehanna. June, July. One of the lovliest of flowers; possessing beauty, delicacy and fragrance in the highest degree. Rlizomac thick, in mud where the water is from 1 to 5 feet in depth, sending up lesres and flowers to the surface. Leaves 4 to 6 imches in diameter, dark shining green above, cleft at the base quite to the insertion of the petiole. Sepals colored within. Petsls very delicate, 1 to 2 inches long, white tinged with purple. . Filaments yellow. $\forall$ lowers 3 to 4 inches in diameter, very fragrant.

\section{NUPHAR. Smith. Yellow WATER LiLy.}

Separs 5 or 6 , oblong, concare, colored within. Petals numerous, small and stamen-like; compactly inserted with the stamens into an enlargement of the receptacle at the base of the ovary. StigMa discoid, with prominent rays. PerICARP many-celled, many-seeded.-Perennials, with yellow flowers, and floating leaves.

1. N. Advena, Ait. Yellow Pond-Lity. Spatter Dock.

Leaves erect or floating, on half cylindrical petioles, heart-shaped at the base, oblong, or rounded; sepals 6 ; petals numerous; small; stigma 15 to 20 raved; froth frorrowed.

Pouds and ditches; mostly in shallow water: common. June-August. Lecres large dark green, shining abore. Flowers rather large and globular in form, erect, on a thick rigid stalk. Three outer serrals, yellow inside; three inner, entirnly yellow, as well as the petals and stamens.

2. N. LuteA, Sinith. Small flowered Yellow Water-Lily.

Leaves floating, cordate, oval; hobs approximate; peticles 3-sided, aeuto angled; siigma 16 to 20 rayed.

Ponds: common. June. Sepals very ohtuse. Petals much smaller, trangate. Canfounded by some of our botanists with the next species.

\section{Kalmiana, Ait. Kalmes Water-Lity.}

Lesves cordate, sulmersed, with approximate lobes; petioles terete; ealyes 5 leaved; stigmas ineised, 8 to 12 rayed.

In Water. July, Aug. Leaves and fowers small; upper leares 2 to 3 inches long, $11 / 2$ to $3 \frac{1}{2}$ inches wide: lower leares 3 to 4 inches in diameter. Dr. Robbins. Beok. Gras considers it a variety of $N$. Lutca; to which it is certainly closely allied.

\section{ORDER 9. SARRACENIACE:-Pitcher Plants.}

Herbaceons plants growing in boggy places, with hollow pitcher form, or trumgesshoped radical heuves; with the petiole and hamina articulated at the summit. Cbaracsoristics, those of the typical genus.

\section{SARRACENIA, Toum.}

In honor of Dr. Sarrazin, of Quebec.

Calyx of 5 sepals, with 3 small bractlets at the base; olored, persistent. Petals 5, oblong or obovate, ineurred, 
deciduous. Stamens numerous, hypogynous. Stiama very large, peltate, persistent, covering the ovary and stamens, in the form of an umbrella, petal-like, 5 angled, 5 rayed; the 5 delicate rays terminating under the angles in as many hooks. CAPsule 5-celled, 5-valved, many seeded.-Perenials, yellowish, green and purplish. Flowers large, solitary on scapes.

1. S. purpurea, L. Side-saddle Flower. Huntsman's Cup.

Leaves (ascidia) pitcher-shaped, inflated, contracted at the mouth, curved, ascending, broadly winged on the inner, (or upper) side; hood erect, open, round, heart-shapod.

Sphagnous swamps. Bear Meadows, Centre Co. Blackhole Valley, Lycoming Co. June, July. A singular plant bearing curious pitcher-shaped leaves, from 6 to 9 inches long, hollow, swelling in the middle, with a wing-like appendage extending the whole length inside, $1 / 2$ to 1 inch wide, and extendcd on the outside of the mouth into a kind of a blade, covered above with reversed hairs; usually half filled with water and drowned insects. Scape 14 to 20 inches bigh, terete, smooth, supporting a single, large, purple, nodding flower, which is almost as eurious in its structure as the leaves.

\section{ORDER 10. PAPAVERACEF, '}

Herbs with milky or colored juice, aiternate, simple or divided leares, withou stipules; and regular flowers with fugacious sepals; polyandrous, hypogynous; having a 1-celled pod with 2 or more pariclal placentx. Flowins solitary, on long peduncles, never blue. Sepals 2, rarcly 3, falling off when the flower expands. Petals 4 to 12, spreading, imbricate in the bud, deciduous. Stamens numerous, $\mathbf{2 6}$ or more, distinct, rarely polydelphous. OrARY solitary; style short; sligmas 2 , or if more, stellate upon the flat apex of the ovary. Frorr either pod-shaped or exsular.

\section{SANGUINARIA. Linn. Bloodroot.}

Lat. sanguis, blood: in allusion to the color of its jwice.

Sepals 2, caducous. Petals 8 to 12, in 2 series, spatulate-oblong, the inner narrower. Stamens about 24. STrLB short; stigma 2-lobed or connate. CA Psule pod-like, oblong, 1-celled, 2-valved, ventricose; valves deciduous: SeEvs numerous, with a large crest.-A low perenial with thich prostrate rootstocks filled with a red-orange acrid juice.

1. S. Canadensis, L. Blood-root. Red Puccoon.

leaves radical, reniform or cordate, with roundish lobes, separated by roundish sinuses.

Open woods and rocky places: common. April, May. A smooth pretty plant sending up in early spring a scape about 6 inches high, with a single white flower appearing in advance of the single large glaucous leaf. Flowers quadrangulax in outline, scentless, and of short duration.

\section{MECONOPSIS, DC.}

Gr. mekon; s poppy; and opsis, appearance: resembling tho poppt: 
Sepals 2, hairy. Petals 4. Stamens many. Strle short, distinct; stigmas 4 to 6 , radiating, convex, free. Capsules obovate, 1-celled, opening by 4 valves at the apex.-Perennial herbs with a yellow juice and pinnatified or pinnately divided leaves.

\section{Diphylum, DC. Celendine Poppy.}

Leaves pinnately divided, glaucous beneath; segments 5 to 7 , orate-oblong, sinuate; stem leaves 2, opposite, petiolate; pedicels aggregated, terminal; capsule 4-valved, echinate.

Woods. Alleghany mountains. May. Stem a foot high. Leaves large, 8 by 6 mches, on petioles about the same length. Pedunctes about 3 inches long, 1-flowered. Flowers deep yellow, 2 inches broad.

\section{ARGEMONE. Linn.}

Gr. argsma, a disease of the eye, which this plant was supposed to cure.

Sepals 3, roundish, acuminate. Petals 4 to 6 . Stameng many. STYLe scarcely any: stigmas 3 to 6 , radiate; CapsuLE ob-ovoid, opening at the top by valves.-Herbs with prickly bristles and yellow juice. Annual or biennial.

\section{A. Mexicana, L. Horn Poppy.}

Leaves repand-sinuate or pinnatifid, with spiny teeth; flowers solitary, ereet, axillary; calyx prickly; capsules prickly, 6-valved.

Banks of streams. June, July. Stem 1 to 3 feet high, branching, armed with prickly spines. Leaves sessile, 5 to 8 inches long. Flowers yellow, about 2 inches in diameter. Probably introduced.

\section{Chelidonium. Linn. Cerendine.}

Gr. chetidon a swallow: flowering about the time when swallows appear.

Sepals 2, glabrous. Petals 4, suborbicular, contracted at the base: STAMENS numerous 24 to 32 , shorter than the petals. Stigma 2-lobed. Capsule silique-form, slender, smooth, 2-valved, the valves opening from the bottom: Seeds several, crested.-Perennial herbs, with brittle stems, and acrid yellow juice.

\section{Majus, L. Common Celendine.}

Ieaves pseudo-pinnate, glaucous; segments ovate, crenate lobed; pedicels somowhat umbellate; petals elliptic, entire, flowers in umbels.

A pale green juicy plant growing in waste places. Introduced from Europe. Naturalized. May-Aug. Stem 1 to 2 feet high, branched. Flowers yellow, very fugacious, borne in thin axillary, pedunculate umbels.

\section{PAPAVER. Linn. Poppy.}

Celtic papa, pap; being added to the food of children to induce sleep.

Sepals 2, concave, caducous. Petals 4. Stamens many. 
Strgmas sessile, united in a flat, 4 to 20 , radiated crown, resting on the summit of the ovary and capsule. Capsule obovoid, 1-celled, opening by minute valves under the margin of the stigma.-Exotic herbs, mostly biennial, with a white juice abounding with opium.

\section{P. Dubium, L. Field or Corn Poppy.}

Leaves pseudo-pinnate; segments lance-obleng, pinnatifidly incised, sessile, decurrent; Stem hispid with spreading hairs; peduncles with appressed bristly Kairs; epals hairy; capsule obovoid-oblong, smooth.

Sparingly naturalized in cultivated grounds. June and July. Stem about 2 teet high. Flowers light red or scarlet. Native of Europe.

\section{P. somniferum, L. Common Poppy.}

Smooth and glaucous; leaves clasping, incised, and dentate, wavy; sepals mooth; capsule globose. Native of Persia. Common in cultivation. Scarcely maturalized. Stem 1 to 3 feet high; Leaves 4 to 8 by 2 to 3 inches, with rather obtuse dentures. Flowers large brilliant white, red and purple: sometimes very double.

\section{P. Rheas. Common Red Poppy.}

Stem many-fiowered, hairy; leaves incisely pinnatifid; capsules smooth, nearly globose. Distinguished from the last species ehiefly by its more finely divided leaves and globular capsules. Flowers very large and showy, of a deep scarlet rød, sometimes variable. Cultirated.

\section{ESCHSCHOLTZIA.}

In honor of Eschscholtz, a German botanist, known by his researches in Californis

Sepals 2, cohering by their edge, eaducous. Petals 4. Stamens many, adhering to the claws of the petals. StiGMAS 4 to 7 , sessile, 2 to 3 of them abortive. CAPSules pod-shaped, cylindric 10-striate, many seeded.-Annual, glaucous herbs with a calorless juice, 2 to 3 pinnatifid leaves with linear segments, and showy yellow flowers on solitary peduncles.

\section{E. Douglasir, Hook. California Poppy.}

stem branching, leafy; torus obconic; calyx ovoid, with a very short abrupt scumination. Petals bright yellow, with an orange spot at the base. 2 inchas broad. Native of California and Oregon. Common in cultivation.

2. E. Californica, Hook.

Stem branching, leafy; torus funnel-form with a much dilat dimb; caly. obconic, with a long acumination; flowers orange-yellow. From California. Calti. vated.

\section{ORDER 11. FUMARIACE㞑.}

Delicate smooth herbs, with watery jwice, compound dissected leaves, and irregular fowers. Flowlars irregular, purple, white, or yellow. Sepals 2, deciduous. Patals 4, cruciate, hypogynous, very irregular. STAMENs 6 , in two set 3 of $3 \mathrm{each}$, placed opposite the larger petals, hypogynous, their filaments more or less united; the 
middle anther of each 1-celled; the lateral ones 2-celled. OVARY superior, 1-celled; ETYLE filiform; sTIGMA with 2 or more points.

\section{DICENTRA. Bork. Wrongly Diclytra or Dielytra.}

Gr. dis, twice; and kentron, a spur: in allusion to the two spurs.

Sepalis 2, small. Petals 4; the two outer equally spurred, or gibbous at the base. Stamens united in 2 sets of 3 in each. Stigma 2-crested or 2 horned. Filaments slightly united. PoD 2-valved, 10 to 20 seeded.-Low stemless perennials; with ternately compound leaves, and simplo scupes, bearing racemose nodding flowers.

1. D. Cuccularia, DC. Dutchman's Breeches.

Root bulbiferous; scape naked; raceme simple, 1-sided, 4 to 10 flowered; wing of the inner petals short; spurs divergent, elongated, acute, straight; pedicels 2-bracted.

Rich woods, shady ravines and hills. April and May. A smooth handsome plant. Bulbs consisting of clusters of little grainlike tubers inclosed in a sheath. Leaves radical, multifid, somewhat triternate, smooth, with oblong linear segments. scape slender, 6 to 10 inches high. Flowers scentless, nodding, white, tinged with yellow and purple.

\section{D. Canadense, DC. Squirrel Corn.}

Scape naked; raceme simple, 4 to 6 flowered; spurs short, rounded; wing of the inner petals projecting beyond the summit.

Rich woods. May. Rhizoma bearing a number of roundish tubers, about the size of peas, and of a bright yellow color. Leaves having the segments longer and narrower than in the preceding species. Flowers white, tinged with purple, very fragrant, 3 to 4 on a scape 6 to 8 inches high.

\section{D. eximia, DC. Choice Dicentra.}

Divisions and lobes of the leaves broadly oblong; scape naked; raceme compound, clustered; corolla oblong, 2-gibbous at the base, erest of the inner petals project ing beyond the summit.

Rocks, along the Alleghanies. April-July. A larger plant than the others blossoming all summer. Leaves 10 to 15 inches high, with 4 to 8 cymee, each with 7 to 10 reddish-purple, nodding flowers. Often cultivated.

\section{CORYDALIS, DC.}

From korudalis; the Greek name of Fumitory.

Sepals 2, small. Petals 4, one of which is spurred at the base, deciduous. Stamens 6, diadelphous: filaments in 2 equal sets by their broad bases which sheath the ovary. PoD 2-valved, many-seeded. SEeDs crested.-Flowers in racemes. Biennials.

1. C. aurea, Willd. Golden Corydalis.

Stem branched, diffuse; leaves glaucous, doubly pinnate, lobes oblong-lineas, acute; bracts lanceolate or ovate, acuminate, toothed, opposite the leaves, terminal; spur incurved, pods terete, pendant: seeds with a scolloped crest. 
Shady rocks. April-August. Stem 8 to 12 inches high, with finely divided leaves. Flowers bright yellow and showy. Pods 1-inch long.

2. C. GLauca, Pursh. Pale Corydalis.

stem erect, branched; leaves glaucous, decompound; segments cuneate, trifid; bracts oblong, acute, shorter than the pedicals; spur short and rounded; pods. erect, slender, elongated; seeds with a small entire crest.

Rocky woods: common. May-July. Stem 1 to 2 feet high. Leares 1 to 8 inches long; the lower ones on long petioles. Flowers whitish, tinged with jellow, ard flesh color.

\section{ADLUmia. Raf. Climbing Fumitory.}

In honor of $M r$. John Adlum, a distinguished cultivator of the vine.

Sepals 2, minute. Petals 4, united in a spongy monopetalous corolla, persistent, and with 2 protuberances at the base; 4-lobed at the apex. Pod 2-valved, few seeded.A climbing biennial vine, with 2-pinnate leaves, cut-lobed delicate leaflets, and numerous panicles of drooping flowers.

A. CIRrhosa, Raf. Alleghany Vine. Mountain Fringe.

Woods and rocky hills. Jüly-Sept. A slender climber 8 to 15 feet long. Leaves pinnately divided; the midrib twining like a tendril. Flowers in compound oxillary racemes, pale violet or nearly white.

\section{FÚMARIA. Linn. Fumitory.}

Lat. fumus, smoke: from its disagreeable smell.

Sepals 2, caducous. Petals 4, unequal, one of them spurred at the base. Filanents in 2 sets, each with 3 anthers. Fruit small, indehiscent, globular, 1-seeded.Branched annuals, with finely dissected compound leaves, and close racemes or spities.

\section{F. officianalis, L. Common Fumitory.}

Leaves bi-pinnate, leaflets lanceolate, cut into linear segments; raceme loom: sepals ovate-lanceolate, acute, shorter than the corolla.

Near cultivated grounds. May-July. Stem 10 to 15 inches high. Flovores rosocolored. Introduced from Europe.

\section{ORDER 12. CRUCIFERI}

Herbs with a pungent watery juice, often accompanied by an etheridi ont; and orsoiform tetradynamous flowers: leaves alternate: Iruit a silique or siliele. FLowers yellow or white, rarely purple or red: without bracts, generally in racemes. SkPals 4, deciduous. Petals 4, regular, their claws inserted into the receptacle, placed opposite each other in pairs, their spreading limbs forming cross. STAMENs 6, of which 2 on opposite sides are shorter, solitary, and opposita the lateral sepals. Ovary, superior, 1-celled: stigmas 2. PoD usually 2-celled, 2-valved, 1 or many-seeded, indehiscent, or opening by the valves. SEeDS atteched in a single row, by a cord to each of the placentre, generally pendulous, without abumen. Exarro with the 2 cotyledons variously folded on the radiele. 


\section{SeCtion I. SILICULOSA. Pod short and broad.}

\section{THLasPI. Linn. Penny Cress.}

Gr. thlao; to compress or flatten: on account of the flattened silicles.

Calyx equal at the base. Petals equal. Silicle short, flat, emarginate at the apex, many-seeded ; valves, bract-form, winged on the back; cells 2, many seeded. Cotyledons accumbent.-Annual herbs with undivided leaves and white or purplish flowers.

\section{T. arvense, L. Penny Cress.}

Leaves oblong-sagitate, coarsely toothed, smooth; silicle (pouch) roundish-obovate, shorter than the pedicel, its wings dilated longitudinally: stigma subsessile.

Cultivated stony fields. June. Stem a foot high, erect, and somewhat branched. Leaves 1 to 2 inches long, $1 / 4$ as wide. Flowers small, white in terminal racemes. The plant has a disagreeable flavor of garlic.

2. T. тuberosum, Nutt. Tuberous Penny Cress.

Leaves rhomboid-ovate, obscurely dentate, smooth and sessile; radical ones petiolate; siticle suborbicular. April and May. Stem 4 to 5 inches high. Flower's rather large, rose-colored.

\section{CAPSELLA. DC. Shepherd's Purse.}

I iminutive of capsa, a ehest or box: in allusion to the fruit,

Calyx equal at base. Silicles triangular, wedge-form, obcordate, compressed laterally ; valves carinate, not winged ${ }^{\circ}$ on the back. Style short. SeEDS many. Annual. Floviers white.

C. Bursa-Pastoris, DC. Shepherel's Purse.

Radical leaves pinnatifid, hairy; cauline ones oblong, more or less toothod, sagitate at base.

Cultivated grounds. April-0ct. A troublesome weed. Stem 6 to 12 inches high. Flowers small, in racemes, which are finally 3 to 12 inches long. Intro duced from Europe.

\section{ERIOPHILA. DC.}

Gr. er, eros, spring; and phiteo, to love : in allusion to its early flowering.

Calyx equal. Petalas 2-parted. Staniens without teeth. SiLICLE oval or oblong; valves flat. SEeds many, not margined.-Annual. Flowers small.

E. vUlgaris, DC. Whitlow Grass.

Leaves oblong-lanceolate, acute subserrate, hairy: scape naked: petals bifi: stigma sessile: silicle flat, oval, shorter than the pedicel.

Fields. March-May. Scape 2 to 6 inches high. F'lowers minute, white. Pouch on long pedicels. 


\section{LEPIDIUM. Linn. PePper-Grass.}

Gr. lepis, a scale; in allusion to the form of the pouch.

Calyx equal at the base. Petals entire, ovate. FiraMents without teeth. Siliches laterally compressed, orbicular-ovate, or oval; septum very narrow, crossing the greater diameter; valves carinate, dehiscent: cells 1 -seeded. SEEDs somewhat 3 -angled. Cotyledons incumbent, rarely aceumbent.-Annual or biennial herbs, with white flowers.

\section{L. Virginicum, L. Wild Pepper-grass.}

Stem branched; radical leaves pinnatifid; stem leaves linear lanceolate, serrate smooth; stamens 2 to 4 ; silicles orbicular, emarginate, shorter than the pedicel.

Dry fields and roadsides. May-Sept. Stem a foot high, branched abore. Flowers small, white. Pouch about 2 lines long.

2. L. Sativum, L. Pepper-grass. Tongue-grass.

Leaves variously divided and cut; branches without spines; silicles orbicular winged. A pleasant anti-scorbutic cress: often cultivated for the table. Stems I to 3 feet high, very branching. Siticles 2 to 3 lines broad, very numorous. Nabive of the East.

\section{CAMElina. Crants. False Flax.}

Gr. kamai, dwarf, and linon, flax: on account of its resemblance to flax

Calyx equal at the base. Petals equal. Filaments without teeth. SILICLE ob-ovoid or sub-globose, obtuse, entire, mucronate with the persistent style. SEeDs numerous, oblong, not margined.-Annual. Flowers yellow.

C. sativa, DC.

Leaves lanceolate, saggitate, sessile, roughish; siticle inflated, margined; cotyledons incumbent.

Cultivated grounds: common in flas fields. May, June. Stem 2 to 3 feet high, panicled above. Flowers numerous, in corymbose panicles, small, yellow. Pouches large, on long slender pedicels. Introduced from Europe. It ha been fancied by some to be a sort of degenerate flax.

\section{COCHLEARIA. Linn.}

Lat. cochlear, a spoon : in reference to its concave leaves.

Calix equal at the base, spreading. Petals entire. Stamens without teeth. Silicle oblong or ovoid-globose, with ventricose valves. SEEDS numerous, not margined.Flowers-white. Perennial.

C. Armoracea, L. Horse-radish.

Radical leaves on long petioles, oblong, crenate: cauline long-lanceolate, serrato or entire, sessile; silicle elliptic.

Wast grounds. Naturalized. June. Roct large, fleshy, very pungent to the teaste. Stem 2 to 3 feet high. Flowers white in elongated racemes. Native Europe. Extensively cultivated. 
CULTIVATED EXOTICS.

\section{ALYSSUM. Linn.}

Gr. a, privative; lussa, rage: supposed by the ancients to allay rage.

Calyx equal at the base. Petals extire; some of the stamens with teeth. SILICLE orbieular or oval, with valves, flat or convex in the centre. Seeds 1 to 4 in each cell. Perennial.

\section{A. saxatile. Rock Alyssum. Madwort.}

Stem suffruticose at the base, subcorymbose: leaves lanceolate, entire, downy; silicle ovate-orbicular, 2-seeded; seeds margined. An early flowering garden annual. Native of Candia. Stem 1 foot high. Flowers numerous, yellow, in close corymbose elusters.

\section{A. малтимом, Lam. Sweet Alyssum.}

Stem somewhat shrubly and procumbent at the base: leaves linear-lanceolate, acute, somewhat hoary: pods oval, smooth. A swcet-scented garden plant, with fno leaves and small white flowers. June-0ct. St:m 1 foot high.

\section{LUNARIA. Linn, HoNestr.}

Lat, luna, the moon: from the broad round siticles.

Sepals somewhat bi-saccate at the base. Petals nearly entire. Stamens not toothed. Silicle pedicellate, elliptical or lanceolate, with flat valves; funiculus adhering to the dissepiments.

\section{L. BIENris, DC. Honesty,}

Stem erect; leaves cordate, with obtuse teeth; si'icles oral, obtuse at both ends, A biennial plant. Native of Germany. Stoms 3 to 4 feet high. Flowers liliocolored. Naturalized near Philadelphia. Nutt.

2. I. Reniviva. Satin Flower.

Stem erect, branching: leaves orate, cordate, petiolate, mucronately serrate: silicles lanceolate, narrowed at each end. A pretty perennial from Germany. Stem 2 to 3 feet high. Flowers light purple.

\section{IBERIS. Linn, Candy-turt.}

Petals, the two outside larger than the two inner. SiliCLES compressed, truncate, emarginate; the cells 1 -seeded.Ornamental garden annuals.

\section{I. umbeliata. Purple Candy-tuft.}

Herbaceous, smooth; leaves linear-lanceolate, acuminate; lower ones serrate; upper ones entire. Silieles umbellate, acutely 2-lobed. A pretty border flower. Native of South Europe. June, July. Stem 1 foot high. Flowers in simplo terminal umbels. This species as well as the rest is remarkable for having the 2 puter petals larger than the 2 inner ones. 
1. saxatrus, Rock Candy-tuft.

Shrubby: leaves linear, entire, somewhat fleshy, rather acute, smooth or ciliato. Flowers white, in corymbs. Stems nearly 1 foot high. April-June. Native of South Europe.

\section{ISATIS. Linn:}

Siltcle elliptical, flat, 1-celled, 1-seeded; with boat-shaped valves, which are scarcely dehiscent.

1. I, TiNCTonia, L. Woad.

Siticles wedge-form, acuminate at the base, somewhat spatulate at the end, very obtuse, 3 times as long as broad. Native of England; cultivated for the Eake of its leaves, which yield a dye that is substituted for indigo. May-July. Stem 4 feet high. Leaves large, broad, clasping the stem. Flowers yellow, large, in terminal racemes.

\section{SECTION 2. SILIQUOSAE. Pod mostly long and narrow.}

\section{DENTARIA. Linn. Tоотн-Wort.}

Lat. dens, a tooth; on account of the tooth-like seales of the root.

SePAls converging. Silique (pod) narrow-lanceolate, with a long tapering style: valves flat, nerveless, revolute, opening elastically: placentæ not winged. SEeDs in a single row, not margined: funiculus slender.-Herbaceous plants - with perennial roots, divided leaves, and white or purplish flowers.

\section{D. Laciniata, Muhl. Common Toothwort.}

Stem leaves 3, verticillate, on short petioles, ternate; leaflets 3-parted segments linear, entire, coarsely toothed or pinnatifid; lateral ones lobed; root moniliform.

Woods and rocky places near streams. April and May. Stem 6 to 12 inches high, simple. Leaves usually in a whorl about half-way up. Flowers in loose terminal racemes, pale, rose-colored, or white. Petals cuneate-obovate, attenuated below. Pod about 1 inch long. Root consisting of a chain of 3 or 4 nearly toothless-oblong tubers, of a pungent taste.

\section{D. DIPHYLla, Mich. Pepper Root.}

Stem leaves mostly 2 , on short petioles, ternate: leaflets ovate oblong, nnequally and coarsely toothed or laciniate.

Woods and wet meadows. May. Stem 6 to 12 inches high. Leaves large, opposite or nearly so, above the middle of the stem. Flowers racemed, large white, the petals much larger than the calyx. Root-stock large, beset with teeth, with a pungent, aromatic taste. Pod about an inch long.

3. D. MAxima, Nutt. Great Toothwort:

Ieaves 2 to 7 , alternate, on long petioles, ternate; leaflets ovate, obtuse, coarsely toothed'and incised, often 2 to 3 cleft; lateral ones lobed; axils naked; racemes lateral and terminal.

n. Woods; rare. June. Stem often nearly 2 feet high. Flowers in racemes, pale purple. Root-stock a string of strongly toothed tubers. 


\section{D. Heterophylla, Nutt. Dwarf Toothwort.}

Radical leaves on long petioles, deeply and obtusely lobed, lobes crenately dentate, with abruptly mucronate teeth; stem leaves 2 , rarely 3 , alternate, petiolate, ternately divided; segments linear-lanceolate, entire or rarely toothed, roughedged:

Woods. June. Ront-stock moniliform, obscurely toothed. Stem 8 to 12 inehes high. Corymbs with about 9 pale purple flowers.

\section{BARBAREA. R. Brown. Winier Cress.}

Anciently called the Herb of Saint Barbarea.

Sepals erect, sub-equal at base. PoD 4-angled and somewhat 2 -edged; valves concave-carinate, awnless at the apex. SEEDS in a single row in each cell, marginless.-Perennials or biennials with yellow flowers, and lyrately-pinnatifid leaves.

B. vUlaARIs. R. Br. Winter Cress.

Snooth; louser lears lyrate, the terminal division round; upper leaves obovate; eut toothe 1 , or pinnatifid at the base; pol t-siled, tapering into a slender style.

Moist places and roadides. Common. May-Aug. Por. Stem 1 to 2 feet high, smooth, branched above. Flowers in dense rasemes, smail yellow. Probably introuluced.

\section{NASTURTIUM. R. Brown, Cress.}

Lat. masus tortus, from the effect of these acrimonious plants upon the nose.

SEP ALs erect, sub-equal at base. PoD 4-angled and somewhat 2 -edged; valves concave-carinate, awnless at the apex. SEeDs in a single row in each cell, marginless.-Perennials or biennials with yellow flowers, and lyraiely-pinnatiful leaves.

\section{N. Palustre; DC. Marsh Water Cress.}

Lower leaves lyrately pinnatifid; upper ones pinnetely lobed, amplexicaul, lobas onfluent, dentate, smooth; petals as long as the calyx; porls oroil-oblong varjing to ovoid, obtuse, turgid, tipped with a very short style.

Wet places, along streams. July. Stem 18 inches high, mostly erect, branchel, obtusely 2 -angled, and striate above. Leaces 2 to 3 inches long, more or less jinnistifil, smoutin, except a fow cillie at tho baje. Flowsis rasomose, ininute, yellcw. Pxlshort, turyid.

\section{N." Hispidum, DC. Hisped Water Cress.}

Stem upright, rough-hairy; leaves pinnatifály lobed, or runcinate-pinnatifid; bojes rathar obtusely toothed; pod ovoid, tumid, pointed with the distinct style, searcely more than half as long as the ealyx; petuls scarcely as long as the calyx.

Banks of stroams. July, August. Stem angular, 2 to 4 feet high, much branched, with many paniculate racemes above. Lecries 3 to 6 inches bons. F'lowers minute, yellow. Siticles 1 line long on pedicels twice their length.

3. N. sylvestre, Br. Creeping Water Cress.

Leaves pinnately divided; serments lanceolate, incisely serrate, the upper ones ontire; petals lonfer than the calyx; pod's oblong, slightly uneven; stybe vers short.

Banks of the Delaware near Philadelphia. July. Koot crosping. Stem a feot $N^{*}$ 
high, angular, branched. Flowers larger than in the preceding. Introduced from Europe.

\section{ARABIS. Linn. Wall Cress.}

Said to have derived its name from Arabia, its native country.

Sepals erect. Petals unguiculate, entire. Pod linear, plane; valves flat, 1-nerved in the middle. SeEDs in a single row in each cell, usually margined or winged.-Annual and biennial plants with white flowers.

\section{A. Canadensis, L. Sickle Pod.}

Stem leaves sessile; oblong-lanceolate, acuminate; the lower, tcothed; pedicels 3-times as long as the calyx, pubescent, reflexed in fruit; petals twice the length of the calyx, oblong-linear; pods pendulous, subfalcate, veined: seeds winged.

Rocky situations. May-Aug. Stem 2 to 3 feet high, slender, round, smooth. Leaves 1 to 3 inches long, $1 / 4$ as wide, sessile and clasping. Flowers in long terminal raccmes, small, white. Pods long, drooping, resembling a sickle blade.

2. A. LyRata, L. American Rock Cress.

Stem diffusely branched, low; stem leaves linear or spatulate, entire, smooth and glaucous; radical leaves lyrately pinnatifid, often pilose: pedicels somewhat spreading; petals twice the length of the calyx; pods erect, spreading, with a short, straight style; seeds marginless.

Rocky hills. April-June. Stem 8 to 12 inches high, often many united at the base. Root-leaves numerous, rosulate, 1 to 3 inches long, $1 / 1$ as wide, petiolate. Flowers middle size, white or rarely pale purple.

\section{A. revigata, DC. Smooth Wall Cress.}

Erect, smooth and glaucous; radical leaves obovate and oblong, tapering to s petiole, sinuate-dentate; stem-leaves linear-lanceolate, amplexicaul, sparingly cuttoothed or entire: petals scarcely larger than the calyx; pods long and narrow, re-curved, spreading and pendulous.

Rocky places. May. Stem 1 to 2 feet high, round, smooth, simple, or branehed a.bove. lioot-leares often purplish, $3 / 4$ to $11 / 2$ inch long, half as wide, with acute teeth. Flowers white, few, small, in corymbed racemes. $P^{\prime} d 2$ inches long, rery narrow.

\section{A. hinsuta, DC. Hairy Waill Cress.}

Frect, branching; leaves dentate, pulescent, or scabrous; radical ones orateoblong, tapering to a petiole; stem leaves ovate, lanceolate, sagittate; pedicels as long as the ealyx; pod straight, erect.

Low, rocky grounds. Not common. May, June. Stem 6 to 12 inches high ; 2 or more from the same root; round, hairy at the base, dividing into slender parallel lranches. Jeares searcely dentate, sessile, with heart-shaped or sagittate bascs. Flowers small, greenish white. Pod 1 to 2 inches long.

\section{IODANTHES. Torr. \& Gray. FALse RockeT.}

Gr. iodes, violet coIored; and anthos, flower.

POD linear, elongated, terete. SEEDs in a single row in each cell, margined. Strue thick. Stigma capitate. Craws of the violet-purple petals longer than the ealyx. $-A$ smooth perennial, with showy flowers in panicled racemes. 
I. HESPERIDOIDES, T. \& G.

Leaves ovate oblong, toothed, pointed; the lower sometimes lyrate-pinnatifid.

Banks of rivers. Western Pa. May, June. Stem 1 to 3 feet high. Petabs $1 / 2$ inch long, spatulate. Pods 1 to 2 inches long, slightly curved upwards, longen than the spreading pedicels, knotty, rather fleshy.

\section{CARDAMINE. Linn.}

Kardamon, an ancient Greek name of Cress.

CALYX a little spreading. PoD linear, fiattened usually opening elastically; valves nerveless. SxeDS in single rows in each cell, ovate, not margined.-Mostly perennial plants with white or purple flowers.

\section{C. Hirsuta, L. Hairy Cardamine.}

Mostly smooth. Leaves pinnate, with 5 to 13 leaflets, or lyrately pinnatifa; leaflets of the radical ones petioled, mostly rounded; those of the stem orate linear, toothed or entires petals twice as long as the calyx, oblong-cuneate; stigma minute, subsessile.

A variable biennial, eommon in ret places. May-July. Stcm 6 to 10 inches high. Leares hairy or smooth, $1 / 2$ to 1 inch long. Flowers small, white. Iod about 1 inch long, 12 to 18 -seeded.

\section{C. Rhomboidea, DC. Spring Cress.}

Root tuberous; stem-leares orate-rhomboid, somewhat petioled; roct-leares rond or cordate, all somewhat angled or sparingly tcothed; pocls linear-lanceolate, pointed with a slender style, tipped with a conspicuous stigma; sccds round oval.

Wet maadows and springs. Per. April-June. Stem 9 to 12 inches high, erect mooth, simple. Flowers in terminal racemes, large, white or reddish. Fods $1 / 2$ to 2 inch long.

3. C. rotundifolia, Mich. Round.leaved Spring Crese

Rool fibrous; stem weak, procumbent; leaves sub-orbicular, sub dentate, smooth, petioled; $p$ x spreading, slender, with a long style.

Wet grounds near springs. Per. July. Stem 6 to 15 inches high, decumbent Flowers in terminal racemes, white or yellowish, half the size of the preceding. Pod $1 / 2$ to $3 / 4$ inch long.

\section{Sisymbrium. Linn. Hedge Mustard.}

An ancient Greek name of some plant of this family.

Caliyx mostly spreading, cqual at the base. Petals nnguiculate, entire. Pon terrete, or rather 4 to 6 sided, sessile upon the disk, the valres 1 to 3 nerred. SeEDs in a single row in each cell, oblong, marginless.-Annual herbs woith small white or yellow flowers.

\section{S. officinale, Scop. Hedge Mustard.}

Leaves runcinate and with the stem hairy. Flowers in a long raceme; pod subo late, closely pressed to the stem.

Waste places. Introduced, May-Sept. An unsightly branched weod, I to 3 
feet high. Flowers yellow, very small, terminating the raceme which becomes 1 to 2 feet long, environed by the appressed sessile pods.

2. S. Thalianum, Hook. Monse-ear Hedige Mustard.

Radical leaves obovate or oblong, entire or barely toothed; siem lecres lanceolate, sessile; pods aseending, rather longer than the pedicels.

Rocks and sandy ficlds. April and May. Stem 6 to 15 inches high, elender, torete, with slender erect branches. Leaves mostly in a radical cluster, 1 to 2 inches long; those of the stem $1 / 2$ to 1 inch long, deuticulate, ciliate. Flowers small, white. Probably introduced.

3. S. CANgscens, Nutt. Foary Tledge Mustard.

Laves 2-pinnatifia, the divisions small and toothed; petals scarcely exceeding the calyx; pods in long racemes, oblong or rather clavate, not longer than the spreading pedicels.

Banks of streams. Rather rare. May. Stem slender, 1 to 2 feet high. Flovers. very small, pale yellow. Pedicels spreading with the pod, often erect. A very variable specios, orten hoary pubescent.

18. ERYSTMUM. Linn. Treacle Mugmard.

Gr. eruo, to diraw blisters.

CAtiyx erect, closed. PODS columnar, 4-sided; stigma eapitate. Sands in a single row in each cell, oblong, marginless; colylecions often obliquely incumbent.-Chiefly biennicals with ycliow fiowers.

\section{E. CHERIANTHOIDIS, L. Wormseed Ifustard.}

Isxices lanceolute, somewhat too'hed, minutely roughish; pods orect, spreading, twice as long as the pedicels; stigna small, nearly sessile.

Along streams: rare. Introducen. July-Sont. Stem 1 to 2 feet high, ereet, branched, roughish. Flowers yollor, in long terminal racemes. Ied about 1 inch long, pointed with a short style.

\section{E. Arranganum, Nute. Western Wall-flower.}

- Binutely roughish hairy; stem simple; leavis lanceolate, somenthat toothed; bwer ones runcinato-toothed; $A$ nwers racemoge corymbed at gammit.

A fine plant rith showy flowers resembiag the Wall-fower. Notive of the Westerm States, cultirated in gardens. Jume and July. Biennial. Stem 1 to 3 feet high, slender. Leaves 2 to 3 inches long, $1 / 4$ to $1 / 2$ inch wide. Sepats straw-color. Pola's large bright orange-yollow. Siliques 3 inclies long, 4-anglech, sub-ercet.

\section{SINAPIS. Linn. Mustard.}

Gr. sinapi, which is said to come from the Celtic nap, a turnip.

Sapals equal at the base, spreading. PETAls ovate, with straight claws. PoDs nearly terete, with" a short beak; valves bearing nerves. SeEDs globose, 1-rowed.-Annual or liennial European plants, with yellow flowers, and lyrate, pinnatifid, or incised leaves.

\section{S. nigra, L. Black Mustard.}

Iorocr leavés lyrate or lobed; upper linear-lanceolate, entire, smooth; pods smooth " and even, somowhat 4-sided, appressed to the stem, tipped with a slender style. 
Fields and waste places: partly naturalized. June and July. Stem 2 to 6 fer high. Flowers yellow. Pods very numerous, nearly 1 inch long. Seeds numerous, nearly black, used as a condiment.

\section{S. ALBA, L. White Mustard.}

Leaves pinnatifid, or lyrate, the terminal lobes large, nearly smooth; pods mostly hispid, spreading, scarcely as long as the sword-form beak.

Cultivated; sometimes spontaneous in old fields: June and July: Stem 2 to 3 feet high. Flowers corymbose, yellow, rather large. Seeds large, pale yellow:

Used as a condiment, and much esteemed in medicine:

\section{RAPHANUS. Linn. RADISH.}

Gr. ra, quickly; and phaino, to appear; from its rapid growth.

Calyx erect. Petals obovate, unguiculate. Pods trans. versely many-celled or dividing into several joints, the lower often seedless and stalk-like; the upper necklace-form, with no proper partition.-Annuals or Biennials.

1. R. Raphanistrum, L. Wild Radish. Charlock

Leaves simply lyrate; pod terete, jointed, smooth, becoming in matury 1-celled, longer than the style; seeds 3 to 8.

Fields and waste places. Introduced. July. Stem 1 to 2 feet high, hispid. Flowers yellow, about as large as the common radish.

2. R. SAtrva, L. Garden Radish.

Lower leaves lyrate, petiolate; pod torose, terete, acuminate, scarcely longer than the pedicels. A well known cultivated salad root from China. Stem 2 to 4 feet high, very branching. Flowsrs white, tinged with purple.

\section{CHEIRANTHUS. R. Brown. Wall-Flower.}

Arabic 7cheyry; and anthos, a flower.

Calyx elosed, 2 of the sepals gibbous at the base. PE: TALs dilated. PoD terete or compressed. STIGMA 2-lobed or capitate. SEEDS in a single series, ovate compressed.Showy perennials, with lanceolate or ovate slightly toothed leaves, and handsome fragrant flowers in panicled clusters or racemes.

\section{C. HESPERIDOIDES, T. \&. G. Rocket Wall-Flower.}

Smooth; lower leaves lyrate-pinnatifid; upper ovate-lanceolate, unequally and sharply serrate; pedicels as long as the calyx ; limb of the petals obovate, entire.

Banks of streams. Western Pa. May-July. Stem 1 to 3 feet high, simple cr branched. Leaves thin, 3 to 5 inches long, $1 / 4$ as wide, those of the stem scarcely petiolate. Flowers in terminal axillary racemes, pale purple, small. Pods 11/2 inches long. Per.

2. C. CHEIRI. Wall Flower.

stem somewhat shrubby at the base; leaves entire or slightly dentate, lanceolate, acute, smooth; branches angular; petals obovate; pods erect, acuminate. A popuLar garden flower from South Europe, admired for its agreeable odor, and its hand some corymbase clusters of orange or yellow flowers. Per. 


\section{HESPERIS. Łinn. Roскет.}

Gr. hesperis, evening; when the flower is most fragrant.

Calyx closed, furrowed at the base, shorter than the elaws of the petals. PETALs bent obliquely, linear or obovate. PoD 4-sided, 2-edged or sub-terete. SEEDs not margined. STIGMas forked, with the points converging.-Perennials.

1. H. Matroxalis. Rocket. Sky Rocket.

Stem simple, erect; leaves lanceolate, ovate, denticulate; petals emarginate moeronate; pedicels as long as the calyx. A îne garden perennial. Stem 3 to 4 foet high. Flowns purple, sometimes donble and white. Said to be found native about Lake Huron.

2. H. АpRIca. Siberian Rocket.

Stem a foot high, erect, simple, pubescent; leaves oblong obtuse, entire, cilliatehispid; pedicels as long as the calyx. Flowers purple. May and June. From siberia.

\section{MATTHIOLA, R. Brown,}

In honur of $P . A$. Matthiola, physician to Ferdinand of Austria.

Calyx closed, 2 of the sepals gibbous at the base. PETazs dilated. Pons terete. Stigmas connivent, thickened or connate at the back.-Herbaceous or shrubly oriental plants, clothed with a hoary stellate pubescence.

1. M. Anvurs. Ten Week Stock.

Stem herbaceous, erect, branched, 2 feet ligh; leaves hoary canescent, lanceclate, obtuse, subdentate; pod sub-cylindrical, without glands. $\Lambda$ fine garíen flower from South Europe. Flowers variegated.

2. M. Incanos. Purple July Flower.

Stem shrubby at the base, erect, branched, 1 to 2 feet high. Leaves lanceolate, entire, hoary-canescent. Pods sub-cylindrical, truncate and compressed at the apex, without glands. Flowers purple and crimson. A popular garden flower, na tive of England.

\section{BRASSICA. Linn,}

Celtic bresic; the cabbage:

Sepals equal at the base, (mostly) erect. Petals obovate. Filaments without teeth. PoD sub-compressed; valves concave, with a central vein. STYLE short, subterate, obtuse. SEeDS globose in a single (sometimes double) row. -Flowers yellow. 


\section{B. campestris. Cale.}

Leaves somewhat fleshy and glaucous; the upper one cordate-amplexicanl, acu minate. Stem $1 \frac{1}{2}$ to 3 feet high, round, smooth above, with a few scattered reversed hairs below. Racemes 1 to 2 feet long. Corolla yellow, nearly $1 / 2$ inch in diametex.

b. Rutabaga. Suedish Turnip.

Root tumid, napiform, sub-globose, yellowish; growing to an enormous sim Cultivated for cattle. Native of Sweden.

\section{ORDER 13. CAPPARIDACER.}

Herbaceous plants or stirubs, without a true stipule, but sometimes with spines in their place. Leaves alternate, petioled, undivided or palmate. Flowers cruciform, solitary or racemose. Sepals 4. Petals 4, or even 8, imbricated or none, crueiate, asually unguiculate and unequal. Stamens 6 to 12, or some multiple of 4. Drse hemispherical or elongated. OVAnX stipitate, of 2 united carpels. STYurs united Into one. Srigma discoid. Frur either pod-shaped and dehiscont, or fleshy and indehiscent. SExDs many, kidney-shaped, without albumen.

\section{GYNANDROPSIS. DC.}

Gz. Gynchatria, a Linnean class; opsis, appearance.

Caliyx of 4 sepals, spreading. Petals 4, unequal. STAMEns 6 ; filaments adnate below to the linear, elongated torus, its whole length. PoD linear-oblong, raised on a long stipe which rises from the top of the torus. - Leaves digitate. Flowers racemed.

\section{G. PEntaphylla, DC. Five-leaved Gynandropsis.}

Middle leaves petiolate, 5-foliate; floral and lower ones 3-îliate; leaflets oboratos ontire or denticulate.

Cultivated grounds. July. Annual. Stem 2 feet high, viscid, simple. Floweene of a very irregular strueture, white in long terminal racemes. Fetals obovate with very long capillary claws. Pod 2 inches long, linear, on a long foot-ktalk.

\section{POLANISIA. Raf.}

Gr. poius, many or much, and anisos, unequal.

Sepals 4, distinct, spreading. Petals 4, unequal, with claws. Stamens 8 to 32 , unequal. Receptacle not elongated. PoD stalkless or nearly so, above the stamens, linear or oblong, veiny, turgid, many-seeded.-Strong scented an nuals with glandular or clammy hairs, and digitate leaves.

P. Graveolens, Raf. Strong scented Polanisia.

Viscid, pubescent; leaves ternate; leaflets elliptie-oblong; flowers axillarg, solitary; stamens 8 to 12 ; capsule oblong lanceolate, alternate at the base.

Gravelly banks of streams. June-Aug. Stem 1 foot high, branching, stristo. Flowers in a corymbose raceme, yellowish-white and purple. Whole plant moore or less viscid and fetid. 


\section{CLEOME. Linn.}

Sepals sometimes united at the base. Pexals 4, minute or roundish. STAmens 4 to 6 . PoD subsessile or stipitate.-Herbs or shrubs with simple on digitate leaves, and racemed or solitary flowers.

\section{Pungens. Spiderwort.}

Glandular pubescent. Stem simple, and with the petioles covered with priekles; leaves 5 to 9 foliate, on long petioles; leaflets elliptic, lanceolate acute at each end, obscurely denticulate; braets simple; flowers racemed; sepals distinct; petals on filiform claws; stamens 6 , twice as long as the petals. A common garden plant with curious purple flowers. July and August.

\section{ORDER 14. RESEDACE庶,一Mignionettes.}

Herbs with unsymmetrical spiked, racemose, small flowers, and alternate leaves. CaLYX not closed in the bud; sEPals somewhat united at the base, unequal, green. Patals lacerated, unequal. Stamens 8 to 20 on the disk. Torus hypogynous. Pod 3 to 6 lobed, 3 to 6 horned, 1-celled with 3 to 6 pointed placentr, opening at the top long before the seeds are full grown.

\section{RESEDA. Linn.}

Lat. resedo, to calm; the plants are said to relieve pain.

Sepals many. Petals 4 to 7 , often cleft, unequal. Stamens 10 to 40, turned to one side.-Annual herbs with very small flowers.

\section{R. Luteola. Dyer's Weed.}

Leaves lanceolate, entire with a tooth on each side at the base; caly $x$ 4-cleft; petals 4 ; the upper one 3 to 5 cleft; the two lateral 3-cleft; the lower one linear and entire; pods depressed. Scarcely naturalized; flowering through the season, Stsm 2 feet high. Flowers greenish yellow, arranged in a long spike. Used for dying yellow.

2. R. odorata. Mignionette.

Leaves entire, 3-lobed; sepals shorter than the petals. A well known and universal favorite of the garden; native of Egypt. Stem procumbent. Flowers very fragrant.

\section{ORDER 15. VIOLACEF.}

Herbs with simple leaves usually alternate, sometimes opposite, stipulate, and axillary nodding flowers with a somewhat irregular, 1-spurred corolla of 5-petals, 5 hypogynous stamens pointed by their anthers, and a 1-celled 3-valved pod with 3 parietal placenta. Sepals 5, persistent, slightly united, elongated at the base, the two lateral interior. Petals twisted, imbricate in the bud. STAMENs with short and broad flaments, prolonged beyond the anther cells, and more or less coherent over the stigma; two of the stamens with spurs or appendages which are received into the 
epur of the corolla. STYLE club-shaped; stigma 1-sided, cucculate. FruIt a 3-valved eapsule. SEeds numerous; ALBUMEN fleshy.

\section{VIOLA. Linn. VIOLETS.}

The ancient Latin name of the genus.

Sepals 5, auriculed at their base. Petals 5, unequal, the larger one spurred at the base ; the 2 lateral equal, opposite. Stamens 5, approximate; filaments distinet; anthers connate, the lobes diverging at the base. CAPSUte 1-celled, 3-valved; seeds attached to the valves.-Low herbaceous perennial plants, acaulescent or caulescent. Pecluncles angular, solitary, 1-flowered recurved at the summit in an inverted position. (Often producing concealed apetalous flowers during the whole summer.)

* Stemless : leaves and scapes from subterranean root-stocks : perennials.

1. Flowers blue: leaves undivided.

\section{V. cuccullata, Ait. Hood-leaved Violet.}

"Smoothish; leaves cordate, cuccullate at the base, toothed, veined; stipules small, linear, fringed; lateral petals bearded : spur short, obtuse.

Low grounds, meadows, \&c.; common. April-June. Leares on long petioles, strongly heart-shaped or triangularly kidney-shaped, rolled at the base, into a hooded form. Flower's light blue or purple, with somewhat 4-sided seapes. Petals twisted. Whole plant variable.

\section{V. sagittata, Ait. Arrow-leaved Violet.}

Smoothish or hairy; leaves oblong-lanceolate, sagittate-cordate, sub-acute, often hastate at the base, serrate or crenate-dentate : petals oblong, ovate, all except the lower one, bearded; spur short, very thick and sac-like.

Gravelly fields: common. April and May. Letres rarying from oblong-sagittats to triangular-hastate on margined petioles, acute or not. Flowers middie sized, purple, on seapes 3 to 5 inches long. Tax. emriginata Nutt. Lecues almost triangular, lacerately toothed at the base; petals emarginate or bidentate.

3. V. ovata, Nutt. Ovate-leaved Violet.

Leaves ovate, crenate, ciliate, abruptly decurrent on the short petiole, mostly roughish, pubeseent; lateral petals bearded; stigma a little beaked.

Dry hills. April and May. Leaves numerous, mostly hairy on both sides, sometimes nearly smooth, $3 / 4$ as wide as long, acute or not, upner cues lacinute-centate. Sepals ciliate, olslong-orate, deeply emarginate behind. Petuls entire, reiny, obovate, the lateral ones with derise white beards. Spur broad,

\section{V. SORORIA, Willd. Becirded or Findred Violet.}

Leaves orbicular, or roundish-cordate with the sinus often closed, crenate-serrate, mostly pilose, thickish, purple beneath, flat lying on the ground; latercl peta's densely bearded, lower one somewhat bearded, upper one naked; siigma depressed, with a deflexed beak.

Dry hills, open woodlands. April and Mrry. Leares 1 to 2 inches long, mostly orbicular or sub-reniform. Scapes few, about as long as the leaves, smooth, with small subulate opposite bracts below the midule. Sepals lance-oblong, rather obtuse. Corolla reddish blue; petals obovate, entire. Capsule smooth, (Darling" ton's F.C.) 


\section{V. ELLIPTICA. Elliptic-leaved Violet.}

Zeaves elliptical-oblong, crenately toothed or entire, somewhat pilose; flowers on slender scapes.

Gravelly hillsides; rare. May and June. Leaves $1 / 2$ to $11 / 2$ inches long, $1 / 2$ as wide, on slender petioles 2 to 4 inches long. Scapes few, slender, 4 to 6 inches long with 2 small opposite subulate bracts above the middle. Flowers smaller than in the preceding species, pale blue. Lateral and lower petats densely bearded, and profusely marked with white lines.

\section{Leaves divided.}

\section{V. PEDATA, L. Bird's-foot Violet.}

I Leaves pedate, nearly smooth, from 5 to 7 parted; segments linear-lanceolate, obtuse or acute, 1 or 2-toothed, or somewhat 3-lobed at the apex, tapering downwards; stipules radical, pectinately lacerated; petals beardless; spur very short; stigma large, obliquely truncate; beak obscure.

Dry hills or sandy woods. May and June. Root premorse. Scapes 2 to 5 inches high, several from the same root. Flowers large, pale blue, sometimes almost white; petals rounded at the extremities. This handsome species presents several varieties-one with variegated flowers, the 2 upper petals intensely velvety purple, and fully as handsome as the finest Pansy.

\section{V. palmata, L. Palmate Violet.}

Pubescent; leaves reniform-cordate, palmate or hastate-lobed, variable; the intermediate one always larger; stipules lanceolate, subciliate; lateral petals densely bearded; spur short; stigma capitate, recurved.

Moist woodlands and low grounds; common. May. Scapes several, 4 to 6 inches high, often pilose with 2 small lanceolate bracts below the middle. Rootstock scaly. The early leaves are ovate, entire; the later and perfect are often purple beneath, variously lobed and cleft. Petals purple or bright blue, entire, veiny, white at the base; upper ones smaller; lateral ones densely bearded and marked with blue strix.

3. Leaves undivided. Flowers white, the lower petals veined with purple.

\section{V. LANCEOLATA, L. Lance-leaved Violet.}

Leaves very smooth, narrow, lanceolate, attenuated at each end, sub-serrate; sepals lanceolate, acute, smooth; petals beardless, nearly equal.

Swamps and wet meadows. April and May. Rhizoma creeping. Lcaves narrow, and with the stalk 3 to 5 inches long. Petioles half round. Flowers small, white, inodorous. Upper and lateral petals marked with violet lines.

\section{V. Primulefolia, L. Primrose-leaved Violet.}

Leaves oblong-ovate, mostly acute, sub-cordate and somewhat unequal at the base, decurrent on the petiole, crenate-serrate, smooth above; sepals lanceolate; petals obtuse, lateral ones sometimes sparingly bearded and striate; stigma capitate and rostrate.

Wet grounds; rare. May. Intermediate between $\nabla$. lanceolata and V. blanda. $\boldsymbol{L}$ eaves 2 to 5 inches long, and an inch or more wide, about as long as the scape. Flowers white, odorous, on sub- 4 -sided stalks.

\section{V. BLANDA, Willd. White Sweet Violet.}

Leaves broad-cordate, remotely serrate or crenate, minutely púbescent, sinus rounded; petals ovate, obtuse, nearly beardless; stigma depressed, acutely margined.

Wet meadows; common. April and May. Leaves close to the earth, nearly round, $1 / 2$ to $11 / 2$ inches in diameter, flat and thin. Flowers small, white streaked with purple, very fragrant.

\section{Flowers yellow:}




\section{V. Rotundifolia, Mich. Round-leaved Violet.}

Leaves round-ovate, heart-shaped, slightly crenate, appressed to the ground; lateral petals bearded and marked with browp lines, lower ones smaller; spur very short.

Rocky woods. May. Scape 1 to 3 inches high. Leaves 1 inch broad at flowering, increasing to 3 or 4 inches in summer. Flowers pale yellow, middle sized.

** Perennials with stems.

5. Leaves undivided: flowers yellow or yellowish white.

\section{V. pubescans, Ait. Downy Yellow Violet.}

Softly pubescent; stem elongated, erect; leaves very broadly heart-shaped, dentate, more or less acuminate; stipules large, ovate, somewhat toothed; spur extremely short; lower petals veined with purple. Var. 1., eriocarpa, is large, villous pubescent; capsule densely villous. Var. 2., scabriuscula, is smaller, slightly pubescent, and brighter green; stems decumbent; pods smooth or woolly.

Rich woods; common. May. Stem 6 to 12 inches high, generally solitary, somewhat angular. Peduncles rather shorter than the leaves, axillary, solitary, with 2 subulate bracts. F'lowers middle sized, yellow; lateral petals slightly bearded, and with the lower ones striped with dark purple.

13. V. Hastata, Mich. Halbert-leaved Yellow Violet.

Nearly smooth; stem erect, simple, leafy above; leaves on long petioles, cordatelanceolate or hastate, acuminate; lobes obtuse, dentate; stipules minute, ovate; spur very short; lower petal dilated, sub-3-lobed; lateral ones slightly bearded.

Mountains and pine woods. May. Stem 6 to 10 inches high. Peduncles shorter than the leaves. Flowers yellow.

\section{V. striata, Ait. Striped Violet.}

Stem assurgent, angular, smooth; leaves alternate, heart-shaped, finely serrate, often acuminate; stipules large, oblong-lanceolate, strongly fringe-toothed; spur thickish, much shorter than the petals; stigma recurved, sub-pubescent.

Wet grounds. May. Stem 6 to 12 inches high, half round. Leares 1 to $11 / 2$ inches wide, on petioles 1 to 2 inches long. Peduncles axillary. Flowers large, yellowishwhite; lateral petals densely bearded; lower one striped with dark purple.

6. Flowers pale blue, or purplish.

15. V. rostrata, Muhl. Long Spurred Violet.

Stem diffuse, erect; leaves smooth, roundish-heart-shaped, serrate; the upper acute; stipules large, lanceolate, serrate-cilliate; petals obovate, beardless; spur longer than the corolla.

Shaded hillsides. June. Stem 4 to 8 inches high, smooth. Flowers large, pale blue, with a very long spur similar to that of the larkspur, by which this species is readily recognized.

\section{V. Muhlenberam, Torr. Spreading Violet.}

Stems aseending, at length with creeping branches, smooth; leaves round, heartshaped, or the lowest kidney-shaped, crenate; the uppermost slightly acuminate; stipules large, lanceolate, fringe-toothed; spu; tapering, about half the length of the petals; petals obovate, obtuse, the lateral ones bearded; stigma rostrate.

Shaded wet places. May and June. Stem 6 to 8 inches high. Flowers middlesized, pale purplish.

\section{V. Canadensis, L. Canadian Violet.}

Upright; leaves heart-shaped, pointed, serrate, lower ones on long petioles; stipules ovate-lanceolate, entire; sepals subulate-lanceolate; spur very short; stigma short, pubescent. 
Shady woods. May-Aug. Stem 9 to 18 inches high, usually simple. Flovers large, blue without, paler within; upper petals marked with blue lines; lateral ones bearded. Flowering all summer.

18. V. tricolor, L. Pansy-Heartsease.

Stem angular, diffuse; leaves oblong-ovate; lower ones oblong cordate, deeply crenate; stipules runcinately pinnatifid or lyrate, the terminal segments as large as the leaves; spur short and thick.

Gardens, where its pretty flowers are earliest in spring and latest in autumn. Flowers variable in size; the 2 upper petals purple; the 2 lateral white; and with the lower striate at base; all yellow at base.

V. odorata. Sweet Violet.

Native of Europe. Flowers dark purple, very fragrant; double by cultivation.

\section{SOLEA. Gingens, DC. Green VIolet.}

In honor of Wm. Sole, author of an Essay on Mentha.

SEpals scarcely equal, carinate, not auricled at the base, decurrent into a pedicel, at length reflexed. Petals unequal, the lowest one 2-lobed and somewhat gibbous at the base. STAMENS cohering, the lower 2 bearing a gland above the middle. Capsule somewhat 3-sided. Seend 6 to 8, very large.-A homely perennial with greenish-white flowers in the axils of the leaves on short pedicels.

1. S. CONCOLER, DC. Green Violet.

Stem simple, erect; leaves crenate-lanceolate, sessile, irregularly toothed above; peduncles short, 2 to 3 flowered; flowers small, greenish; caly $x$ nearly as long as the petals: spur none.

Shady woods; rare. April and May. Delaware and Franklin counties, and vestern parts of the State. Stem 2 to 4 feet high.

\section{ORDER 16. CISTACER.}

Herbs or low shrubs, with regular flowers, distinct hypogynous stamens, and a 1-celled 3 to 5 valved pod. Leares entire, opposite or alternate, usually featherveined. Flowtrs white, yellow, or red; very fugaceous, in 1-sided racemes. SEPALs 5 , persistent, unequal; the 2 external small-like bracts, sometimes wanting. $\mathrm{PE}-$ TALS 3 to 5, usually fugacious, convolute in the opposite direction from the calyx.

"STAMress indefinite, hypogynous, distinct; ANTHER innate. STrue single or none, in the bud. Ovules few or many, on slender stalks, with the orifice at the apex. FruTt capsular 1-celled, 3 to 5 valved, with as many parietal placentre borne on the middle of the valves.

\section{HELIANTHEMUM. Tourn, Rock-ROSE。}

Gr. helios, the sun; anthos, a flower.

Sepals 5 , the 2 outer smaller, twisted in æstivation. Petals 5, or rarely 3 , sometimes abortive, crumpled in the 
bud, fugacious. Stamens many. Style short or none; stigma 3-lobed, scarcely distinct. CAPSULE strictly 1-celled, triangular, 3-ralved, opening at the top; seeds angular. FLOWERs frequently of 2 sorts ; the primary or earliest ones, with large petals, numerous stamens, and many-seeded pods; seconctary or later ones much smaller, and few-seeded pods.Herbs with perennial roots, and yellow flower's, witich open in sunstine, and cast their petals by the next day.

1. H. Canadensé, Michx. Rock Rose. Frost Weed.

stom at first simple, ercct, or ascending; tearcs oblong or somerthat lanceolate, acute, hairy, alternate, without stipules.

Sandy or grevelly dry coil. Jume-Aug. Stem about 1 foot high. Iecies $3 / 4$ to I inch lone, is as wide, entire, sth-sersile. Primary or terminal flowers large, 1ew or solitary, on peduncles as long as the fowers: petcls large bright yollow: seconcary flowers axillery, rery small, nearly sessile, solitary or somert hat chestered, on short leafy branches; the petals very small or none; the outer sepals usually wanting. Late in autumu, chrystals of ies shoot from the cracked wark: hence the sommon name,

\section{LECHEA. Linn. PINWEED.}

In honor of Jolun Lecke, a Swedish botanist.

CALYX 3-sepalled, with 2 outer bracts or sepals, persistent. Petals 3, inconspicuous, lanceolate. Stamens 3 tó 12. Strue searecly any. Strgulas 3, searcely distinct. CAPSULE 3-cellod, 3-valred; placentce nearly as the valves, roundish, each 1 to 2 -seeded.-Inconspicuous perennicl brancing plants, with very small greenith or purplish fiovers.

\section{1. „L. 'M}

Hairy; stem crect, simple, producing slencer prostrate bianclies from the lase reaves oblong-lanceolate, mucronate, pilose, alternate and opposite, or sometimes whorled; panicle short, leafy; flowers lensely crowcled in panicled clusters; ped "cels ohorter than the globose depressed (very small) pods.

Dry woods ant fichis. July. Stem 1 to 2 feet ligh, erect. Flowers small, brom, in racemose clusters.

2. L. MINor, Lam. Smaller Pinweed.

Stem slender, upright or diffusely branched, nearly smooth; leaves linear-lanco.late, acute; leafy shoots denscly tufted at the base; panicle leary, its Iranches elongated; flowers loosely racemed; pedicels mostly longer than the globose pods.

Dry hills. July-Sept. Stem 8 to 12 inches high, often decumbent at the lase. Stem-leaves $1 / 2$ by $1 / 4$ inch alternate, sparingly ciliate and rerolute at tbe markin;
those of the long slender branches minute. Flowers larger than in L. major. P, tals brownish-purple, cohering at the apex. Capsules also larger than in the
precoding.

\section{HUDSONIA. Linn.}

In honor of Wm. Hudson, author of "Flora Anglica."

Caryx 5-parted, segments unequal, the two outer ones 
minute. Petals 5. Stamens 9 to 30. Strle straight, filiform. StTigma simple. CAPSUle oblong enclosed in the calyx, 1-celled, 3-valved, 1 to 6-seeded.-Bushy heath-like lititle shrubs with verg numerous branches, and minute.awlshaped or scale-like persistent leaves, and numerous, small, showy, bright-yellow flowers.

\section{H. erIOCOIDES, Ix. Heath-7ike Hudsonia.}

Downy but greenish; stem sub-erect; branches elongated; leaves filiform, awlshaped, loose; flowers on slender naked stalks; sepats aeutish.

Dry sandy woods; rare, May and June. Stem 4 to 6 inches high, much branched. $\boldsymbol{L}$ caves small persistent. Flowers small, yellow, with about 15 stamens.

\section{H. tomentosa, Nutt. Downy Hudsonia.}

Hoary and downy; leaves oval or oblong, close pressed and imbricated; flowers aggregated, sessile; caly $x$ sub-cylindrical, with obtuse segments.

Sandy soil; rare.. June. Stem ascending: much branched. Flowers yellow, smaller than the preceding. Stamens 9 to 18. Whole plant silvery-gray and tomentose.

\section{ORDER 17. DROSSPRACERA}

Bog herds moslty stemless, often covered with glandular hairs; alternate leaves, or clustered at the base of a scape, tapering into a petiole, rolled up from the apex to the base in vernation. Sepals 5, persistent, equal. Corolla of 5 nearly equal petals. STAMENS 5 to 15; ANTHERs turned outwards. STrLes 3 to 5, either wholly distinct, or slightly connected at the base, bifid or branched. FruIT a capsule 1 to 3 celled, 3 to 5 valved, usually many-seeded, sometimes ariled.

\section{DROSERA. Linn. SUNDEW.}

Gr. drosos, dew; the glands exuding a dew-like secretion.

Calyx deeply 5-cleft. Petals 5. Stamens 5. Strues 3 to 5, each 2-parted. CAPSULE superior, globose or ovoid, 1 to 3 celled, 3 to 5 valved, the valves bearing the numerous seeds on the middle, for their whole length.-Low perennial aquatic herbs, with the leaves clothed with reddish gland. bearing bristles.

\section{D. RotundfFolia, L. Round-leaved Sundew.}

Leaves all radical, orbicular, abruptly narrowed into the spreading hairy petioles, fringed with purple cilia, pilose above; scape erect, bearing a terminal and mostly simple 1-sided raceme, nodding at the apex, so that the fresh blown flower is always the highest.

Sphagnous Swamps. July and August, A singular plant at once distinguished by the reddish glandular hairs with which the leaves are beset. Scape 4 to 8 inches high. F'lowers small whitish.

\section{D. Longtfolia, L. Long-leaved Sundew.}

Leaves spatulate-oblong, erect, spreading, tapering into the long rather oreot naked petioles; scape declined at the base; seeds oblong, not arillate. 
Swamps; rare. July and August. Scape 3 to 6 inches long, usually curred to one side at the base:- Flowers yellowish white 5 to 9 in a raceme, twice as large as in the preceding.

\section{D. FILIFormis, Raf. Thread-leaved Sundew.}

Leaves very long and filiform, nearly erect, with no distinction between the blade and the stalk, glandular the whole length; scape longer than the leaves, many. flowered, simple or bifid.

Sandy Swamps. Aug. and Sept. Scape 8 to 12 inches high. Leaves 6 to 10 inches long. Flowers purple, few, in a 1-sided raceme.

\section{SUB-ORDER. PARNASSIE $A$.}

Smooth herbs with slightly perigynous stamens, an outer series of them sterile and in clusters, imbricated petals and 4 sessile stigmas opposite the parietal placentæ. Leaves alternate, not coiled in the bud.-Consists of the following genus of doubtful affinity.

\section{PARNASSIA. Linn.}

From Mount Parnassus; on account of the beauty of this plant.

Calyx deeply 5 eleft. Petals 5, veiny, spreading, rather persistent, with a cluster of somewhat united sterile filaments at the base of each. Stamens 5, alternate with the petals. Stigmas 4, sessile. Capsule 4-valved, 1-celled. Seeds very numerous, arillate.-Perennial herbs with chiefly entire radical leaves; and solitary flowers terminating the long naked scapes.

\section{P. Carouintana, Michx. Grass of Parnassits.}

Radical leaves cordate, orbicular-ovate on long petioles; stem leaf sessile, claspIng; sterile filaments in 5 clusters, 3 in each, distinct to near the base, surmounted with little yellow spherical tips; petals more than twice as long as the ealyx, marked with many greenish transparent veins.

Wet banks: Limestone, Montour Co. Not common. Aug. and Sept. Scape 12 to 18 inches high. Leaves about 7 -veined, usually but one on the stalk low down and clasping. Flowers solitary, large, yellowish-white. An elegant and interesting plant.

\section{ORDER 18. HYPERICACEE.}

Herbs or shrubs with opposite entire dotted leaves and no stipules, regular hypogynous flowers, with many or few stamens collected in three or more clusters, or bundles. FLOWERS perfect, mostly yellow, with cymose inflorescence. SEPALS 4 to 5 persistent, imbricated in the bud. PETALS 4 to 5 mostly deciduous with a twisted æastivation and oblique veins. STAMENS usually numerous and cohering at base in three or more parcels. CAPSULE 2 to 5 (rarely 6 to 7 ,) lobed, with as many persistent styles which are at first sometimes united, 1-celled with 2 to 5 parietal placnetæ. SxwD very numerous, small, without albumen; EMBRY0 straight. 


\section{HYPERICUM. Linn. St. John's Wort.}

Sepals 5, more or less united at the base, mostly equal, leaf-like. Petals 5, oblique and ofton without equal sides. Stanens numerous or few united or clustercd in 3 to 5 parcels without interposed glands. Strues 3 to 5, distinct, or united at base, persistent. CaPsule membranaceous, 1 or 3 to 5-celled.-Herbs or shmbs with opposite entive leares, punctate with pellucid dots, and yellow flowcrs; solitary, or in cymose panicles.

- Stamenzs 20 to 100. Styies 3 to 5. Flowers mostly terminat, Zarye, yeliow: Therbaceous peremials.

\section{H. pyramidatum, Ait. Giant St. Jolin's Wort.}

Stem square, branching above; leaves oblong-Innceolate, sescile, somewhat clrsplng, acute, smooth, pollucid-punctate; sepals orate-linceolate; styles free, as long os the stamens; seeds numerous:

River banks and bills. July, Aug. A large flowering perennial species, 3 to $\mathbf{5}$ peet high, senirecly angular, fncoth, vigid and herhareovs. Flowers $11 / 2$ incles in diameter, shotry, few or colitary at the ends of the branches. Saments cepiliary 100 or more. Capsules 1 inch long, tipped with the 5 styles uvoid-conical.

2. H. corymbosum, Muhl., Spotted. St. John's Tiort.

Stem orect, punctate; leaves clasping, ollong-aral, obtuse, corered with black atots; sepals ovate, acute; petals oblong.

Shady woods and wet meadows. June, July. Stem 11/2 to 2 feet high, black punctate. Leares $]$ to 2 inches long. Flover's finall, numerous, pale yellow, in a compact paricle or corymle. Ietclis nearly 3 times as long as the sepals, with oblong black dots. Stylcs 3 , longer than the stamens. Stigmas oronge red.

\section{H. extiptioum, Hook. Eltiptic St. John's Jínt.}

Stcms square, simple, cymose at summit; leares clliptical, cbluse, clorely sesile, scarcely punetate; cymes nearly lonfless, fow-flowered, deprosecd; sepals rery unequal, spreading; styles 3, winited nearly to the top; capsules oroid-globose.

Moist grounds. July. Siem 10 to 20 inches high, colored at base. Leaves 1 inch long, somewhat erect. Flower's orange-yellow. Petals acutish. Stigmas minute. Pods purplish.

\section{H. Perforatum, I. Common St. John's Hort.}

slem 2-edged, ?ranched, and corymbed; leares elliptical-oral, obtuse, and with the cepals pellncid-punctate; flower's panicled; sepats lanceolate $1 / 2$ as long as the petals; styles 3 , diverging.

June-August. A pernicious plant introduced from Europe, but thoroughly naturalized, growing in pasture fields, much to the annoyance of farmers. Stemis 1 to 2 feet high, with opposito spreading branches, erect, round, with 2 oprosite, elevated lines extending between the nodes. Flowers numerous, deep-yellow, and in terminal panicles.

** Stamens 20 to 100. Styles more or less united. Strubby perennials.

5. H. ADpressum, Barton. Winged St. John's Wort.

stem 2-winged above, shrubby at base; teaves linear-lanceolate or linear-oblong, sessile with pellucid punctures; cyme 10 to 20 -flowercd, nakcd; sepals very unoqual, $1 / 2$ as long as the oblong-obovate petals, siyles united; capsules 3-celled.

Swamps. July, Aug. Stem 2 feet high. Flowers in compound cymes about $1 / 2$ nab in diameter, with very numerous stamens. 
6. H. nudiflorum, Michx. Naked St. John's Wort.

Stem shrubby at base, 4-angled, winged above; leaves ovate-oblong or lance-oval obtuse, sessile; cymes compound leafless; sepals linear-oblong, shorter than the ovate petals; styles united.

Wet grounds, rare. Aug. Stems 1 to 2 feet high, with numerous 4 -sided branches. Leaves thin, about 2 inches long, with minute reddish dots. Flowers small, and rather loose in the cyme.

7. H. PRolificum, L. Shrubly St. John's Wort.

Stem shrubby, smooth, branching; branches 2-angled; teares oblong-lanceolate, mostly obtuse, narrowed at base, revolute on the margin pellucid-punctate; flowers numerous in simple or compound clusters.

Banks of streams. July. A highly ornamented shrub 2 to 4 feet high, with much compressed branches. Leaves 2 inches long, $1 / 2$ inch wide. Flowers large, orange-yellow; peduneles generally 3 -flowered, the intermediate one nearly sessile.

*** Stamens 5 to 20 rarely 30. Styles short, distinet. Low and stender annuats.

\section{H. мutilum, I. Small St. John's Wort.}

Stem erect, much branched, smooth, square; leaves ovatc-oblong, obtuse, heartshaped, clasping, 5-nerved; cymes leafy ; petals shorter than the lanceolate sepals; capsules ovate, conical.

Damp sandy soils. June-Aug. Stem 6 to 12 inches hish, leafy to the top. flowers very small pale-yellow, solitary in the divisions of the stem.

9. H. Canadense, L. Canadian St. John's Wort.

Stem square, erect, branched; leaves linear, or narrowly-lanceolate, attenuate to the base, rather obtuse; panicle elongated, forked; sepals lanceolate, very acute, longer than the petals.

Low grounds, common. June-Aug. Stems 6 to 12 inches high. Leaves pellucid, and dotted with black. F'lowers small, yellow. Capsule longer than the calys and of a reddish color.

10. H. Sarothra, Michx. Orangengrass.

Stem and branches filiform, square; leaves minute, awl-shaped, scales appressed; flowers mostly sessile and scattered along the erect branches; pods slender, very acute, 1-celled.

Sandy fields and hills. June-Aug. Stem 4 to 8 inches high, much branched. Zeaves very small. Flowers very small, yellow. Stamens 5 to 10. Capsule brown.

\section{ASCYRUM. Linn. St. Peter's Wort.}

Gr. a.privative, and sturos, roughness; the plant being smooth to the touch.

Calyx 4-sepalled, 2 outer ones smaller. Petals 4 caducous. Stamens many, scarcely united at base: Strues 2 to 4, mostly distinct. CAPSULE strictly 1-celled, 2 to 3 (rarely 4) valved.-Low, rather shrubby plants with pale black-dotted leaves and nearly pale-yellow flowers.

\section{Crux Andrex, L. St. Andrew's Cross.}

stems much branched at base and decumbent; leaves narrowly obovate-oblong. contracted at the base ; flowers solitary or cymulose, on short pedicels; outer sepals ovate, inner ones very minute; petals linear-oblong; styles 2 , at length distinct.

Sandy fields. July. Stems 8 to 24 inches high, 2-edged above, thickly clothed 
with leaves, which are variable in width. Flowers pale yellow on very short pedicels. Petals scarcely exceeding the outer sepals, approaching each other in pairs over them, in the form of St. Andrew's cross.

\section{ELODEA. Adans.}

Gr. Elodes, growing in marshy places.

Sepals 5, equal, somewhat united at base. Petals 5 deciduous, equal-sided, oblong. STAMens. 9 (rarely 12 to $15)$, in 3 parcels which alternate with 3 orange colored hypogynous glands. STrues 3 distinct. CApsule 3-celled oblong.-Perennial herbs, growing in marshy places, with pellucid punctate leaves, and small close clusters of purplish flowers in the axils of the leaves and at the summit.

\section{E. Virginica, Nutt. Virginian Elodea.}

Leaves oblong, closely sessile or clasping by a broad base, very obtuse; filaments united below the middle, with 3 in each set.

Marshy places, common. July-Sept. Stem 10 to 18 inches high, erect, branching, of a purplish hue. Leaves 1 to 2 inches long, $1 / 2$ as wide, upper ones lancalate, lower nblong ovate, all very obtuse, pale beneath. Flowers few, reddishyellow. Petals about twice as long as the calyx. Glands ovoid, orange-colored. Capsule ovoid-oblong, acutish.

\section{ORDER 19. TLATINACE正.}

Small marsh annuals, with opposite leaves, membraneous stipules, and axillary flower's. SEPals 2 to 5 distinet, or slightly. coherent at base, persistent. Petals hypogynous, alternate with the sepals. STAMENs as many or twice as many as the petals. Strues 2 to 5, very short or none; stigmas capitate. CApsules 2 to 5 -selled. Seeds numerous, without albumen.

\section{ELATINE. L. WATER WORT.}

Gr. elate, for ; its minute leaves resembling those of the fir tree.

Sepals 2 to 4 , persistent. Petals 2 to 4 , hypogynous. Stamens 2 to 8 . STrue or sessile capitate stigmas, 2 to 4 . PoD 2 to 4-celled, several-many-seeded, margins of the valves not introflexed.- Small marshy plants with minute axillary flowers like Chickweed, but the seeds as in St. John's wort.

\section{E. Americana, Arnott. American.Waterwort.}

Dwarf tufted; leaves cuneate-obovate, obtuse ; flowers sessile, sepals, petals, stamens and sessile stigmas 2, sometimes 3. Seeds 6 to 8 .

Edges of ponds and streams. July-Sept, Stems rooting and creeping in the mud, forming patches. Leaves $1 / 4$ inch long, entire, Flowers solitary, very minute, white. 


\section{ORDER 20. CARYOPHYLLACTE-The Pink Family.}

Herbaceous plants with opposite entire leaves, stems with swelled joints, and symmetrical 4 to 5-merous flowers. SEPALS 4 to 5 either distinct or cohering in a tube, persistent. Petals 4 to 5 unguiculate, inserted upon the pedicel of the ovary, or without claws inserted on the outside of a fleshy disk, sometimes none. STxLEs 2 to 5. Seeds attached to the base or central column of the 1-celled, or 2 to 5-celled capsule, numerous, rarely five, the embryo coiled round mealy albumen.

\section{Sub-order I. SILENE The The prop Pink Family.}

- Sepals united in a tubular calyx. Petals with long claws. Stamens 10, and with the petals borne on the stalk of the many-seeded capsule. Stipules none.-Flowers mostly showy.

\section{SILENE. Iinn.}

Gr. siatan, saliva; in allusion to the viccid secretion on the stems and calyx of many species.

Calyx tubular, 5-toothed, naked at the base. Petals 5 unguiculate, mostly crowned at the orifice; limb bifid. STAmens 10. Strues 3. Capsule 3-celled at base, opening by 6 teeth at the top. Embryo coiled.-Flowers solitary or in clustered eymes.

\section{* Calyx inflated; flowers panicled, white. Perennial.}

\section{S. stellata, Ait. Starry Campion.}

Stem erect, branching, pubescent; leares in whoris of 4 , ovate-lanceolate taperpointed, smooth; flowers in panicles; caly $x$ bladder-like, pubescent, bell-shaped.

Shaded banks and woods. July, August. Stem 2 to 4 feet high, slender somewhat 4 -sided. Leares 2 to 3 inches long, $1 / 3$ as wide, tapering to a long point sessile. Calyx pale-green with more deeply colorcd veins. Flowers white, borne on a large open pyrimidal panicle. Petals cut into a fringe at the apex, crownless.

2. S. nivea, Muhl. White Catchfly. Snowy Campion.

Stem divaricate and dichotomous above; leaves opposite, lanceolate or oblong, acuminate, minutely puberulent; caly $x$ obtuse, bell-shaped, inflated, reticulated, subpilose; petals 2-cleft with a small bifid crown, reflexed; claws exserted beyond the calyx, nearly naked; capsules stiped.

"Islands in the Susquehanna, near Columbia; Muhl." June, July. Stem 1 to 2 feet high, smooth and slender. Leaves opposite, 2 inches long, and $1 / 2$ an inch wide. Flowers white, remote, solitary, dichotomal and terminal.

* Calyx not inflated, elongated or club-shaped. Petals crowned, red or rose-colored: perennials.

3. S. Pennsyluanica, Michx. Pennsylvania Catchfy.

Viscidly-pubescent; stems numerous; radical leaves somewhat cuneate; those of the stem long linear; petioles hairy; flowers in somewhat 3 -forked panicles; calyx long, tubular; petals slightly emarginate, subcrenate.

Gravelly hillsides. May, June. Per. Stems numerous, tufted, 6 to 10 inches high. Caly $x$ club-shaped. Petals wedge-form, bright purple or nearly white. 


\section{S. Viranica, Linn. Virginia Catchly.}

Viscid-pubescent; stem mostly erect, branching; leaves lanceolate; lower ones on long petioles, with long ciliæe at base; flowers in panicles, petals with long claws, broad bifid crowned.

Open Woods. May, June. Stem 1 to 2 feet high, single. Filowers few and loosely cymose, large and showy. Calyx oblong-cylindrical, soon obconical. Petals large, red, oblong, 2-cleft. Stamens and pistils exserted.

\section{S. Catesbait, Walt. Catesby's Catchfy.}

Branching; leaves broad-lanceolate; flowers in panicles; calyx clavate, colored; petals with long claws; limb bifid with two lateral teeth; lobes acute.

Southern part of the State, not common. June. Stem a foot high. Flowers erimson, showy. Considered by some botanists as a variety of S. Virginica. Both De Candolle ara Hooker consider it distinct. Beck.

*** Calyx not inflated; petals crowned: annuals.

\section{S. Anterrhina, L. Snap-dragon Catchfly.}

Nearly smooth; stem erect; leaves lanceolate, acute, subciliate, upper ones linear; flowers small panicled; calyx ovoid, smooth; petals small, obcordate, slightly crowned.

Dry hills. June, July. Stem 1 to 2 feet high, nearly smooth with some of the upper intervals viscid, simple or branching above, somewhat leafy. Flowers small white or pale purple, only expanding towards evening.

\section{S. nocturna, L. Nocturnal Catchfy.}

Stem branched, pilose below; leaves pubescent, long ciliate at base; lower ones spatulate; upper, lance-linear; flowers appressed to the stem in a dense 1-sided spike; calyx eylindrical, nearly smoeth, reticulated between the veins; petals narrow 2-parted.

Introduced and sparingly naturalized. July. Flowers white greenish beneath, small.

8. S. NOCTIFLora, L. Night-flowering Catchfly.

Viscid pubescent; stem erect, branching; tower leares large and spatulate; upper ones lincar-lanceolate, acuminate; calyx cylindrical ventricose with long sub-appressed teeth.

Cultivated grounds. Introduced and naturalized. July. Stem tall, 1 to 3 feet high. Flowers rather large, white or purplish, cxpanding only in the evening and in cloudy weather, solitary in the forks, peduncled; calyx round, inflated, the alternate veins veinleted. Petals rather large 2-parted.

9. S. Armeria, I. Sweet-William Catchfly.

Smooth, glaucous: stem branching glutinous below each joint; leaves oratelanceolate; flowers in corymbose cymes; petals ob-cordate, crowned with the awlshaped scales.

Escaped from gardens. Native of Europe. July-Sept. A popular garden flower. Stem 1 to $11 / 2$ feet high. Flowers numerous crimson and purple. Culyx elongated lub-shaped.

\section{2. 'SAPONARIA. Linn. SOAPWORT.}

Lat. sapo, soap ; the mucilaginous juice has been used as a substitute for soap.

Calyx tubular, 2 to 5, toothed, naked at base. Petals unguiculate, claws equalling the calyx. Stamens 10. STrue\& 2. Capsule oblong, 1-celled, 4-toothed at the apex.Flowers cymose clustered. Petals sometimes crowned. 


\section{S. officinalis, L. Common Soapwort.}

Leaves ovate-lanceolate, ribbrd, acute or obtuse; flowers large, in a fasciculated paniele; calyx cylindrical, slightly dowuy; peta!s crowned.

Naturalized in waste places. July-Sert. A stout plant, 1 to 2 feet high, with large flesh-color, purple or pink flowers; moztly double. Native of Europe.

\section{S. Vaccaria, L. Cow-herb. Fly-trap.}

Stem 1 to 2 fect high. Lexves smocti, orat-lanczolate, partly clasping. Filowers in paniculate cymes. Calyx pyramidal, 5-angled, smooth. Petals not crowned, palered. Capsule 4-toothed. Scels giobore, black. Introduced from Europe.

CULTIVLTED EXOTICS,

\section{DiAnthUS. Linn. Pink.}

Gr. Dios anthos, the forrer of Jove; alluding to its pre-cminent baauty and fragrance.

Calyx tubular, 5-toothed, with 2 to 4 opposite imbricate scales at base. Petals 5, with long claws. Stamens 10. STYLEs 2, tapering, with taporing revolute stigmas. CAPsule cylindrical, 1-celled, 4-valved at the apex. Seeds horizontal. EnBRyo barely curved.-Ornamental planis, of well. known beauty and value in cullivation, with very showy and fragrant flowers.

\section{D. Bannatus. Sweet William.}

Leares Ianceolate; flowers argrezate fiscicled; scales of the caly $x$ ovate-subulate, as long as the tube. An ornamental garien flower of the easiest culture. Stem 10 to 15 inches high. Lexves 3 to 5 inch:s :ones, $1 / 2$ to 1 inch wile, narrowed to the clasping base. Fiowers in fastigiate cymes, red or whitish, often variegated. May -July. Pereninial.

\section{D. Chrvexsis. China Pink.}

Stem branched; lexies linca:-lanceolate; fowers solitary; scates linear-leafy, spreading as long as the tube. Natire of China. A baaut:ful species, easily distinguished by its leafy, spreading scales, and its large toothcd or crenats petals. Tho ground color of the f'owers vary from whits to deep red, but the manner in which these are comkined is most monderful, rar:egated and striped, sometimes with black or deep velvety crimson, almost exceeds any attempts at imitation.-Bienrial.

\section{D. plumaries. Pheasant's-Eye. Single Pink.}

Glaucous; siem 2 to 3 flowered; flowcrs solitary; calyx-teeth obtuse; scales ovate, very acute; leares linear, rough at the elge; petals many-cleft, hairy at the throat. Native of Europe. Perennial. From this speccics, probably, originated those beautiful pinks called "Phensant's-Eye," of which there are over 200 varieties in cultiration in Europe. Flewers white and purple. June-Aug.

4. D. superbes. Superb Pink.

Leaves linear-subulate; flower's fastigiate; scales short, ovate, mucronate; petils gashed in a pinnate manner. Native of Europe. Perennial. A singularly beantiful and highly fragrant species. Stem 1 to $\angle$ feet high, branching and spreading, with many flowers. Petals white, and gashed beyond the middle, and hairy at the mouth. July-Sept. 


\section{D. conyophylios. Carnation Pink.}

Zeaves linear-subulate channeled, glaucous; flowers solitary; scales very short, ovate; petals very broad, beardless, crenate. Stem 1 to $2 \frac{1}{2}$ feet high, branched. Flowers white and crimson. This species is supposed to be the parent of all the splendid varieties of the carnation, known as the Bizarres, Picotees, Flakes, \&c., over 400 are now enumerated by florists. July-Aug. Per.

\section{LYCHNIS. Tourn.}

Gr. Iuknos, a lamp; some cottony species, having been used as lampwicks.

Calyx tubular, naked at the base, 5-toothed. Petals 5 unguiculate, limb slightly cleft. Stamens 10 . Pistils 5. CAPsule 1-celled or half 5-celled, scarcely stalked, opening at the top by 5 or 10 teeth. Embryo coiled in a ring.Corolla sometimes crowned.

\section{L. Girhago, Lam. Corn Cockle.}

Hairy; stem dichotomous; pedicels elongated; leaves linear; caly $x$ longer than the corolla; petals entire not crowned.

Grain fields. Introduced. June and July. Annual. A well known pale-green, handsome weed. Stem 18 to 30 inches high. Leaves 3 to 5 inches long, $1 / 4$ to $1 / 3$ inch wide. Flowers large, dull purple, on long naked stalks. Seeds roundisb angular, purplish-black.

\section{L. Chatcedonica, Scarlet Lychnis.}

Smoothish ; flowers fasciculated; calyx cylindrical, clavate, ribbed; petals 2 -lobed. Per. A fine garden flower, native of Russia. Stem 1 to 2 feet high, with darkgreen, ovate-lanceolate leaves, and large dense, terminal, convex faseicles of deep scarlet flowers. There are some varieties with white flowers, and double. Jun and July.

3. L. conovarta, DC. Mullein Pink. Rose Campion.

Villose; stem dichotomous; peduncles long, 1-flowered; caly $x$ companulate, veined. A popular perennial garden flower, native of Italy. Whole plant covered with dense wool. Stem 1 to 2 feet high. Flowers large, purple. There are varieties with white, red, and double flowers.

\section{L. Floscucura, Ragged Robbin.}

Stem ascending, dichotomous at summit; flowers fascicled; calyx companulate, 10-ribbed; petals in 4 deep linear segments. Native of Europe. A handsome perennial. Stem 1 to 2 feet high, rough angled, viscid, above. Leaves lanceolate, smooth. Flowers pink, very beautiful, generally very double, with a brown angular smooth calyx. June-Aug.

\section{Sub-order II. ALSINE E. The Chick weed-Family.}

Sepals distinct or nearly so. Petals without claws inserted at the base of the sessile ovary; stamens inserted on the margin of the disk, which often coheres with the calyx ; opposite the sepals when not more numerous than they.Low herbs without stipules. 


\section{STELLARIA. Linn. Stitchweed.}

Lat. stella, a star; from the stellate or star-like flowers.

Calyx of 5 sepals, connected at base. Petals 5, 2-parted. Stamens 10 , or by abortion 3 to 8 . Strues 3 , sometimes 4. Capsule superior 1-celled, 3 to 4 ralved; valves 2-parted, membranaceous. SEEDs usually numerous.-Small grass-like herbs, in moist, shady places. Flowers white, in forked cymes.

\section{S. Medra, Smith. Common Chickweed.}

Stem procumbent, spreading, with an alternate, lateral, hairy line; leaces very Emooth, ovate or lanceolate, the lower on hairy petioles; petals 2-parted, shorter than the calyx; stamens 3 to 10 . Annual or biennial.

Roadsides, fields, and around dwellings. March-November. Stems prostrate, branched, brittle, round jointed, and leafy. Peduncles axillary and terminal, hairy deflexed in fruit. Flowers small, white. Introduced.

\section{S. pubera, Michx. Oval-leaved Stitchwort.}

Pubescent; stem decumbent, spreading, marked with 2 opposite hairy lines; leaves all sessile, ovate-obleng, acute, ciliate; pedicels filiform, forked; petals deeply 2 cleft, longer than the calyx. Per.

Shaded rocky places; rare. April and May. Stem 6 to 12 inches high, diffuse and forked. Leaves 1 to 2 inches long, $1 / 3$ as wide. Flowers large, axillary and terminal, on thread-like pedicels with 10 stamens, and 3 styles, deeply bifid.

\section{S. Longiforia, Muhl. Long-leaved Stitchwort.}

Smooth; stem erect, branching above, weak, square; leares linear, acutish at woth ends, spreading; cymes naked and at length lateral, peduncled, many-flowered, the slender pedicels spreading; ptals 2-parted, becoming longer than the calyx; calyx 3-norved.

Grassy places; common. June. Per. Stem S to 15 inches high, often with rough angles. Flowers white. Stamens 8 to 10.

\section{S. boREalis, Bigl. Northern Stitchwort.}

Stem spreading, angular, 2-forked; leaves oval-lanccolate, acute, 1-nerved; petals shorter than the calyx, or sometimes wanting; styles generally 4, capsule ovateoblong, much longer than the calyx; seeds smooth.

Shaded swamps. June-Aug. Annual. A spreading flaccid plant with stems 4 to 15 inches long. Cymes diffuse, both terminal and axillary. Leaves slightly connate. Fetals white, deeply cleft.

\section{S. AQuatica, Pollich. Water Stitchwort.}

Neariy smooth; stem decumbent; leaves oblong acute, veined; sepuls lanceolate, rery acute, 3 -veined: petals 2 -cleft, as long as the calyx; styles 3 ; capsule ovoid as long as the calyx. Per.

Swampy springs. Ifry. Stom 6 to 12 inches long, weak, decumbent, prolonged, bearing the naked few-floreied sessile cymes lateral. Flowers frite, inconspicuous.

\section{CERASTIUM. Linn. CHICKWEED.}

Gr. keras, a horn; in allusion to the form of the capsule.

Calyx 5 (rarely 4) sepalled. Petals 5, bifid or emar- 
ginate. Stamens 10 , sometimes 4 or 6 , the alternate ones short. Strues 5. Capsule superior, cylindrical or oblong, opening at the apex by 10 teeth, many-seeded.-Flowers white in terminal cymes.

* Petals about as long as the calyx; pods tong and curved.

\section{C. vulgatum, L. Mouse-ear Chickweed.}

Hairy, pale green, seldom clammy, in tufts; leares ovate or obovate, obtuse; flowers in sub-capitate clusters; sepals lanceolate, acute, in fruit as long as tho peduncles; petals oblong, emarginate, scarcely longer than the calyx. Annual.

Waste places, fields and hills. May-Aug. Stem 6 to 10 inches high, sub-erect. Flowers white, the petals appearing in 10 segments. Capsule oblong, tapering, twice as long as the calyx, Introduced from Europe.

\section{C. viscosum, L. Clammy Mouse-ear Chickweed.}

Hairy viscid, spreading, deep green; stems numerous, erect; leaves lanceolate oblong, rather acute; flowers in loose cymes; sepals oblong-ovate, obtuse, in point shorter than the peduncles; petals oblong, emarginate, scarcely larger than the calyx. Biennial.

Fields and waste grounds. May-Aug. Stem 6 to 12 inches high. Leaves $1 / 2$ to $3 / 4$ inches long, $1 / 3$ as broad; root leaves somewhat spatulate. Flowers white. Probably introduced.

$$
\text { * * Petals much longer than the calyx. }
$$

\section{C. nutans, Raf. Nodding Chickweed.}

Viscid and pubescent; stem erect, slender grooved, difiusely branched; leares lance-linear, elongated, distant; panicle much clongated, divaricate, many-flowered, with long filiform pedicels; petals oblong, bifid, at the tip, twice as long as the calyx; capsule nodding on the stalks, curved upwards, 3 times as long as the calyx.

Moist places. June. Annual. Stem 8 to 20 inches high, branched from the base. Leaves 1 to 2 inches long $1 / 4$ as wide. Flowers white, terminal, in a loose dichotomous panicle. Whole plant pale-green.

\section{C. oblongifolium, Tourn. Oblong-leaved Chickweed.}

stem ascending, villous, many-flowered; leares oblong-lanceolate and orate, mostly obtuse; peduncles elammy-hairy; petals obovate, 2-cleft, twice as long as the oblong obtuse sepals; capsule twice as long as the calyx.

Rocky places. May, June. Per. Stem 6 to 10 inches high, stout. Leaves $3 / 4$ to 1 inch long, $1 / 3$ as wide, tapering from base to an acute or obtuse apex. Flowers larger than either of the foregoing, white, 7 to 15 in a 2 or 3-forked cyme.

\section{C. ARvense, L. Field Chickweed.}

Stem ascending or erect, tufted, downy, slender, naked and few-flowered; teaves linear-lanceolate, obtuse, the lowest spatulate, more or less hairy; peduncles elongated; petals more than twice the length of the calyx; capsule oblong; scarcely longer than the calyx.

Dry or rocky placeg, May, June. Perennial. Stem 4 to 8 inches high. Leaves $3 / 4$ to $1 \frac{1}{4}$ inches long, very narrow. Flowers white, rather large, 2 to 3 on terminal pedicels. Petals deeply cleft.

\section{ARENARIA. Linn. SAND Wort.}

Lat. arena, sand; in which the species mostly grow.

Sepals 5, rarely 4. Petals 5, entire. Stamens 10 , 
or fewer by abortion. STrues 3, opposite the outer sepals. CAPSULE 3-valved, 1-celled, many-seeded, dividing from above.-Flowers terminal, solitary or cymose, perfect, white.

\section{A. stricta, Michx. Upright Sandwort.}

Erect, or spreading from a small root, smnoth; leaves subulate-linear, with many others clustered in the axils; cyme diffuse, naked, many-flowered; sepals orato, very acute, 3 -ribbed, $1 / 2$ as long as the petals; capsule ovate.

Rocks and dry banks. May, June. Stems 8 to 10 inches high. Leaves $1 / 2$ to $3 / 4$ 3nches long, very narrow and acute. Flowers white. Per.

\section{A. SERPYLlifolia, L. Thyme-leaved Sandwort.}

Roughish, diffusely branched; leaves orate, acute, sessile, subcilliate; sepals hairy, lanceolate, pointed, 3 to 5-nerved, longer than the oval petals; capsule ovate, G-toothed equalling the calyx.

Sandy fields. May-Aug. Annuw Stems numerous, downy, with reflexed hairs, 3 to 8 inches high. Flowers white, on terminal and axillary peduncles. Introduced.
3.
A. LATERIFlora, L.
Side-flowering Sandwort.

Erect, sparingly branched, minutely pubescent; leaves oval or oblong, obtuse; petals twice as long as the sepals.

Shady gravelly banks and woods; not common. June. Per. A slender upright species. Stem 5 to 10 inches high. Leares $1 / 2$ to 1 inch long, $1 / 2$ as wide, on very ohort peteoles. Peduncles terminal and lateral, 2 (rarely 3 to 4 ) flowered, one of the pedicels with 2 bractioles, near the middle. Flowers white, $1 / 2$ inch broad. Caspsule ovoid, obtuse; valves 2-cleft. Mehringia of Beck and Torrey.

\section{SAGINA. Linn. Pearlwort.}

Lat. sagina, food or nourishment, which fattens.

Sepals 4 to 5 , united at base. Petals 4 to 5 , undivided often indistinct or none. StaMens 4 to 10 . Styles 4 to 5 , alternate with the sepals. CAPSULE 4 to 5-valved, 1-celled, many-seeded.-Small matted herbs, with thread-like or awlshaped leaves and minute solitary flowers.

1. S. procumbens, L. Procumbent Pearlwort.

stem procumbent, smooth, branched; leaves linear-mucronste; petals mueh whorter than the calyx.

Borders of springs and streams. May-July. Perennial. Stems 2 to 4 inches ligh, diffuse and rooting at the lower joints. Leaves thread-form narrowly linear: kower ones connate. Peduncles solitary, longer than the leaves. Flowers вmall, white and greenish. Stamens 4 to 5. Petals shorter than the calyx.

2. S. apetala, L. Annual Pearlwort.

stems erect, or procumbent only at base, slightiy pubescent; leares sul ulate; sowers alternate.

Sandy fields. May, June. Annual. Stems numerous, filiform, 2 to 4 inches high. Leaves almost bristle-form. Pedicels elongated, aseending. Sepals wad tamens 4. Petals 4, very minute or none.

9. MOLlugo. Linn. Indian Chrokweed. Sepals 5, united at base. Petals none. Stamens 3 to 
5, sometimes 10. Strues 3, short. Capsule 3-valved, 3-celled, the partitions breaking away from the many-seeded axis,-Low homely annuals, with apparently verticillate leaves, and small white solitary flowers.

M. verticillata, I. Carpet-weed.

Stems prostrate, dichotomous; leaves cuneaform or spatulate; pedicels 1 -flowered, subumbellate.

Cultivated giounds, pavements, \&c.; common. June-Sept. A small prostrate, annual. Sicms 4 to 12 inches long, spreading in all directions. At every joint stands a whorl of wedge-shaped or spatulate leaves of unequal size, usually 5 in number. Flower's few, solitary, on short slender stalks, small, white.

\section{Sub-order III. ILLECEBREAE. KNot-Wort FAmily.}

Small weeds differing from Msineæ only in having scabrous stipules, flowers with inconspicuous petals, the uppermost leaves rarely alternate, and the 1 -celled pods sometimes 1-seeded.

\section{ANYCHIA. Michx.}

Gr. onux, the finger naits; a supposed remedy for the whitlow.

Sepals 5, scarcely concave, indistinctly mucronate on the back, greenish. Petals none. Stamens 2 to 3 , rarely 5. Stryles 2, very short. UTricle 1-seeded, enclosed in the sepals.-Small annual herbs, with many times forked branches, stipulate leaves, and minute white flowers.

\section{A. ріснотома, Michx. Forked Chickweed.}

Stem erect or spreading, dichotomously branched; leaves varying from lanceolate to elliptical, somewhat petioled; flowers solitary, terminal and axillary.

Dry soils. July, Aug. Süem 6 to 12 inches high, round, slender, pubescent above with forked filiform branches. Leaves small, those of the stcm opposite, the branches alternate. Flowers very minute, in the forks of the stem greenish. A 7ariable plant.

\section{SPERGULA. Linn. SpURReY.}

Lat. spergo, to scatter; from the dispersion of the seeds.

Sepals 5, nearly distinct. Petals 5, large, entire. Stamens 5 to 10 . Styles 5 . Capsules ovate, 5-celled, 5-valved, the valves opposite the sepals.-Annual herbs, with narrow stipulate leaves in whorls, and cymose white flowers.

\section{S. ARvensis, I. Corn Spurrey.}

Leaves awl-shaped-linear, numerous in the whorls, with minute interposed stfpules, often clustered in the axils; fcwers in a compound cyme, slender, stalked.

Grain-fields, and sandy places. June-Aug. Introduced. Stem 8 to 12 inehes pigh, swelling at the joints. Leaves narrcw. Cyme forked, the terminal (central) 
peduncles bending down as the fruit ripens. Petals white, longer than the calyx. Capsule twice as long. Seeds numerous with a narrow margin.

\section{SPERGULARIA. Persoon.}

Sepals 5. Petals 5, entire. Stamens 2 to 10 . Striles and valves of the many-seeded capsule 3 , or if 5 the valves alternate with the sepals.-Low herbs, with fleshy opposite leaves, scaly membranous stiputes, and small red or rose colored flowers.

S. RUbra, Pers. 'Common Sandwort.

Stem prostrate, pilose much branched; leaves narrow, linear, or filiform, soma what fleshy, shorter than the interncdes; sepals lanceolate, somewhat obtuse, scarious on the margin; seeds compressed, roughish, not margined.

Sandy fields, near brackish water. June-Sept. Annual. Stems 3 to 10 inches long, at first erect at length diffuse, smooth or pubescent. Leaves variable in length and form. Flowers small, red, axillary and solitary, in terminal leafy cymes or racemes. A very variable plant. Arenaria rubra of Lian,

\section{SUB-ORDER IV. SCLERANTHE FE.}

Small diffusely branched plants, with opposite leaves, without stipules and small flowers. Sepals united into an indurated tube surrounding the utricle; the stamens inserted at the throat.

\section{SCLERANTHUS. Linn. KNAWEL.}

Gr. shlero\&, hard, and anthos, flower, from the hardencd calyx tube.

SePats 5 united below in an indurated cup, inclosing the 1 -seeded utricle. Petals none. Stamens 5 or 10 . Strles 2 distinct.-Homely and inconspicuous little weeds, with obscure greenish clustered flowers.

\section{S. Annuds, L. Annual Knawel.}

Depressed tufted. Stems spreading, slightly pubescent; leaves awl-khaped, somewhat united at the base; flowers nearly sessile; stamens 10 ; calyx of the fruit spreading, acute.

Waste places and sandy fields, introduced. July. Annual. Stems numerons, much branched in a dichotomous manner, forming tufts, 3 to 6 inches in diameter. Thowers very small, green in axillary leafy elusters.

\section{ORDER 21. PORTULACACE职.}

Swccutent or fleshy herbs, with alternate or opposite entire leaves, destitute of proper stipules, and usually ephemeral flowers. CALYX mostly of 2 sepals. Corouta of 5 petals. Stamens 8 to 20. StrLes 3 to 6 united below, stigmatic along the inner adde. CADSOLR 1-celled. SERDS attached to a central placenta; albumen mealy. 


\section{PORTulaca. Tourn. Purslane.}

Sepals united to the ovary below, 2-parted. Stamens 8 to 20. Style mostly 5 5 cleft. Capsule globular, manyseeded, opening transversely, the upper part (with the upper part of the calyx) separating like a lid.-Low herbaceous fleshy annuals, with scattered leaves, and some species with showy brilliant flowers expanding only in sunshine.

\section{P. oleracea, L. Common Purslane.}

Leaves wedge-form, obtuse, fleshy, smooth; axils geniculated, naked; foucre sessile; stamens 10 to 12 .

Gardens, and cultivated grounds; common. May-Aug. Stcm fleshy, much branched and spreading, smosth. Leaves and stems of a reddish-green color.

Flowers in clusters, axillary and terminal, small, pale-yellow. Introduced.

\section{P. PILOSA, Scarlet-flowered Purstane.}

Stems ascending, much branched; branches sub-ercet, enlarged upwards; leaves linear, obtuse, the axils villose with long woolly hairs; fiowers terminal, Eessile, 1 or few together, surrounded by an irregular circle of leares and dense tufts of wool; petals obovate; stamens about 15 . A rery delicate popular garden plant with showy crimson and scarlet flowers, $1 \frac{1}{2}$ inches in diameter. Native of $\mathrm{S}$. Africa.

\section{Claytonia. L. Spring-beautr.}

In honor of John Clayton, a botanist of Virginia.

Sepals 2, ovate or roundish, persistent. Petals 5 emarginate or obtuse. Stamens 5, inserted on the claws of the petals. Style 3-cleft. Capsule 1-celled, 3-valved, 2 to 5-seeded.-Our species are small, feshy, delicate perennials, sending up simple stems, in early spring, with a pair of opposite leaves, and a loose raceme of pretty flowers.

\section{C. Virginica, L. Virginian Spring-beauty.}

Leaves mostly 2, linear, or lance-linear, elongated and attenuated into a petiole bolow; raceme simple, loose, at length elongated; peduncle slender, nodding; petale obovate, mostly emarginate or retuse.

Low moist grounds. March-May. Tubercle as large as a hazle-nut, deep in the ground. Scape 6 to 8 inches long, weak with a pair of opposite narrow leaves, 3 to Lnches long. Flowers 6 to 10 rose-colored, with deeper colored veins.

\section{C. Carouniana, Michx. Spring-beauty.}

Leaves ovate-lanceolate or oval, somewhat spatulate, or abruptly decurrent into - petiole; peduncles slender, nodding; sepals and petals very obtuse.

Woods and rocky hills; common. April, May. Root a compressed brown tuber. le, buried at a depth into the ground, equal to the height of the plant. Roof leaves very few, if any, spatulate. Stem weak, 4 to 8 inches high, with a pair of opposite leaves half-way up. Flowers in a terminal cluster, white with a olight tinge of rod and beautifully pencilled with purple lines. 


\section{TALINUM. Adans.}

Sepals 2, orate, concave, deciduous. Petals 5, sessile. Stamens 10 to 30 , inserted with the petals into the torus. Style filiform, 3-cleft at the apex. CAPSUle sub-globose, 3 -celled at the base, when young, 3-valved, many-seeded.Fleshy perennials.

\section{R. teretifólium, Pursh. Cylindrical-leaved Talinum.}

Stem simple or branched, short and thick; leaves subulate; crowded at the summit of the stem, on short branches; peduncles long and naked; flcwers in a dichoto mous cyme.

Rocks, Chester county. Dr. Darlington! June-Aug. Rcots a few coarse fibres from the base of a short thick firm but somewhat fleshy perennial stem. Branches 1 to 3 inches long. Leaves 1 to 2 inches long, incurved, cylindrical, fleshy. Bracts orate-lanceolate, small. Peduncles 5 to 8 inches high. Flowers small, bright purple, expanding only for a day.

\section{ORdER 22. MALVACRE,-Mallow Famity.}

Herls or shrubs, with alternate stipulate leaves, and regular flowers, with numerous stamene, monodelphous in a column. Flomers axillary, showy, oftcn with an involucel at the base. SEpals generally 5 , more or less united at the base, persistent. Petals 5, cohering by their short claws with the tube of filaments. Stamexs indefinite, monodelphous : anthers 1-celled bursting transversely. PIstiLs several, with the oraries united into a ring, or forming a several-celled capsule. SEEDs with little albumen. Emlryo curved.

\section{MaLVA. Linn. Mallow.}

Gr. malate, soft; on account of the soft mucilaginous properties.

Caryx 5-cleft, with a 3-leaved involucel at the base, like an outer culyx. CARPELS many, 1-celled, 1-seeded arranged circularly.-Flowers perfect.

1. M. Avericana, Muhl. American Mallow.

Leaves ovate, crenate; stipules oblong-linear; peduncles axillary, 1-flowered.

Southern part of the State. Annual. Stem 12 to 18 inches high, sparingly branched, elothed with white hairs above. Leaves hairy on the veins beneath, nearly smooth abore. Tetioles 1 inch long. Eracteole bristly. Carpels hispid, in a depressed, globular head. Petals jellow, twice as long as the calyx. T. \& G.

\section{M. Rotundifolta, L. Low Mallow.}

Stem prostrate; leaves roundish-cordate, obtusely 5 to 7 -lobed, crenate, long petioled; flowers axillary; corrola twice the length of the calyx, notched at the end.

Cultivated grounds; common. June-Oct. Per. Root fusiform. Stems numerous, a foot or more long. Peduncles axillary, aggregate. Petals pale pink with darker veins, deeply notched at the end. Fruit depressed, composed of the numer ous carpels arranged circularly. Extensively naturalized.

\section{A sylvestris, L. High Mallow.}

Stem erect, branched, hairy; leaves large roundish, with 5 to 7 somewhat acute lobes; flowers axillary, 3 to 4 together; peduncles and petioles hairy ; petals ob-cos date, 3 times as long as the calyx. 
Waste places, escaped from gardens, sparingly naturalized. June-Oct. Per. Stem 2 to 3 feet high. Flowers reddish purple, with veins of a darker hue. Whole plant emollient and mucilaginous. Native of Europe.

\section{M. CRIsPa, L. Curled or Crisped-leaved Mallow.}

Stem erect; leaves angular-lobed, dentate, crisped, smooth; flowers axillary, ses* sile. A tall, straight, simple, erect plant from Syria. Gardens, almost naturalized. Stem 5 to 6 feet high. Leaves large, roundish, margin abundantly crisped and curled. Flowers small, inconspicuous, white. June, August.

\section{M. моschata, L. Musk Mallow.}

Stem erect; radical leaves reniform, incised; stem leares many-parted, the seg. ments linear; peduncles and calyx hairy. Native of Britain. Stems $\mathbf{2}$ feet high, branched. F'lowers large and handsome, rose-colored and white. The whole plant emits a musk-like odor in favorable yreather. July. Perennial.

\section{ALTHEA. Linn. HoLLYHоск.}

Gr. althea, to cure.

Calyx 5-cleft surrounded at base by a 6 to 9 cleft involucre. Carpels many, 1-seeded, indehiscent, arranged circularly around the axis.

\section{A. offictnatis, L. Marsh Hollyhock.}

Stem erect; leaves ovate, or slightly heart-shaped, toothed, sometimes 3-lowed, clothed with velvety down; peduncles axillary, many-flowered, much shorter than the leaves.

A European plant, cultivated in gardens and in some places naturalized. Aug.Sept. Per. Stem 2 to 3 feet high, erect, firm, very downy. Leaves alternate. Flowerś large, axillary and terminal, pale purple. Medicinal.

2. A. Rosea, Cra. Hollyhock.

Siem erect, hairy; leaves cordate, 5 to 7 angled, rugose; flower's axillary, sessile. Native of China. Annual and biennial. Flowers large, with numerous varieties of single, double and semi-double flowers of various shades of coloring, as white, crimson, dark red, purple, brownish-black, yellow, straw-color, \&c. Cultivated in gardenș.

\section{A. Ficifouia, Cav. Fig-leaved Hollyhock.}

Stems ercet, hairy; leaves palmate, 7-lobed beyond the midale, lobes oblong, obtuse, angularly toothed. Native of the Lrevant. Cultivated for ornament. Flowers large, orange-colored.

\section{HIBISCUS. Linn.}

Carrx 5-cleft; or 5-toothed, surrounded by a many-leaved involucel. Antuer-bearing column prolonged, the apex generally divided into 5 slender styles bearing the 5 globular stigmas. CAPSUlE 5-celled, 5 or many-seeded, opening into 5 valves which bear the partition on their middle. - Herbs or shrubs, usually with large and showy flowers. 


\section{H. Moscheutos; L. Marsh Hibiscus.}

Herbaceous, simple, erect; leaves ovate, pointed, toothed, the lower 3-lobed, whitish-tomentose beneath, somewhat scabrous-pubescent above; peduncles and petioles often united; caly $x$ tomentose.

Borders of marshes, near Harrisburg, Aug. Per. Stem 3 to 6 feet high, stout. Leaves 4 to 6 by 3 to 4 inches, often with 2 lateral lobes. Flowers large, 5 inches in diameter, pale rose-purple, or white with a crimson centre. Showy.

\section{H. miltiaris, Willd. Halbert-leaved Hibiscus.}

Smooth; lower leaves orate-heart-shaped, toothed, 3-lobed; upper leaves halbertform, the short lateral lobes approaching at the base, the middle one prolonged and acuminate; peduncles slender; fruiting caly $x$ inflated; seeds hairy.

River banks. Aug. Per. Stem 3 to 4 feet high. Flower's pale rose-colored, with a purplish centre 3 to 4 inehes in diameter.

\section{Cultivated for ornament.}

\section{H. Syriacus. Syrian Hibiscus.}

Leaves cuneaform, ovate, $2-l o b e d$, dentate; pedicels scarcely longer than the peti. oles; involucel about 8-leaved. A beautiful, hardy, free-flowering shrub from Syria, 5 to 10 feet high. Flowers in the different varieties purple, red, white and striped, both single and double. July. Sometimes erroneously called "Rose of Sharon."

\section{H. TRIONUM. Flower of an hour.}

Somewhat hairy; upper leaves deeply 3-parted, with lanceolate divisions, the mid. dle one much the longest; lower leaves undivided, dentate; calyx inflated, membra. naceous, with bristly ribs, 5-winged at the summit; seeds rough. Annual. Native of Italy. Stem 1 to 2 feet high. Flowers numerous but soon withering. Petals of a rich chlorine yellow, the base deep brown, one variety has flowers 2 inches in diameter, continuing expanded nearly all day.

\section{H. coccineus, Walt. Scarlet Hibiscus.}

Very smooth; leares palmate, 5-parted; lobes lanceolate, acuminate, remotely serrate alone; corolla expanding; capsule ovoid, smooth. A splendid flower, native of Georgia, sometimes cultivated in our gardens. Root perennial. Stem berìaceous, 5 to 9 feet high. Flower's of a bright carmine red. Petals slender at the base, 4 to 5 inches long. Column still longer, slender and terete. July-0ct.

\section{H. Малінот, L. Hand-leaved Hibiscus.}

Leaves palmately divided into 5 to 7 broad-linear, acuminate, scarcely dentate lobes; peduncles and involucel hispid; involucel bracts 5 to 7 , ovate or lanceolate, acutish, persistent, entire; calyx split on one side; carsule densely hirsute, acuminate. Native of the Western States. A beautiful perennial plant, 3 to 5 feet high. Leaves cordate, the lobes 5 to 10 inches long, $1 / 2$ to $11 / 2$ wide, separated to near the base, about as long as the petioles; teeth largest near the summit. Flowers sulpheryellow, purple in the centre. Petals 2 to 4 inches long. July, Aug. Per.

\section{4. abUtilon. Tourn. Indian Mallow.}

CaLyx 5-cleft, without an involucel, often angular. Strues 5 to 15 . CARPels 5 to 15 arranged circularly, coherent, spreading at the summit, where each splits open along the inner edge. SEEDs about 3 in each carpel.-Flowers in the axils of the heart-shaped leaves. 
1. A. Avidenn $\pi$, Gærtn. Indian Mallow. Velvet Leaf.

Leaves roundish-heart-shaped, acuminate, dentate, velvety-tomentose; pedunetes shorter than the leaf-stalks, solitary; carpels about 15, 3-sscded, beaked, the beaks splitting in two.

Waste grounds. Introduced from India; naturalized. Annual. July, August. Stem 3 to 5 feet high, with spreading branches. F'lowers in the axils of the leaves, or ange-yellow, near 1 inch in diameter.

\section{SIDA. Linn.}

Calyx 5-cleft, without an involucel. Strues 5 or more, the ripe fruit separating into as many 1 -seeded carpels, cach splitting open at the top, arranged circularly.

1. Flowers parfect. Stigmas torminal, minutely capitate.

1. S. spinosa, L. Prickly Sida.

Stem rigid, branched from the base, minutely pubscont; 7exves orate-lanceolats, toothed, with the tubercles at the base spiny; pedice's axillary, solitary, shorter than the stipules and petioles; fruit separating into five 2-beaked ca:pels, opening between the beaks.

Waste places, roadsides; common. July and August. Annual. Plant bushy, 1 to 2 feet high. Leaves 1 inch long and $1 / 2$ as wide, mostly obtus at cach ond. Petuls obovate, yellow, of short duration.

\section{S. Napea, Willd. Smooth Sicta.}

Stem slender, smooth; leaves palmately 5-lobed, smooth; lobes oblong-lincar, acuminate, coarsely toothed; carpels 10 , acuminate, awnless.

Shaded rocky planes; rare. July. Per.- Stems angular, 3 to 5 festhigh. Lzares on short petioles, cordat3; lobes. 2 to 4 inches long, $1 / 2$ to $3 / 1$ wide. Fl oral lexves much smaller. Peduncles axillary and terminal, long and slender, somowhat leafy, the divisions som what 4-flowered. Flow rs nearly $1 / 2$ inch in diameter. Petals white, twice as long as the calyx.

2. Napza. Clayton. Flowers diocious: styles stigmatic along the inside.

\section{S. DIoICA, Willd. Diocions Sida.}

Leaves palmately 7 to 9 lobed; lo'jes lanceolate, incisely toothed; peiuncles manyflowered, bracteate, sub-corymbed; staminatc flowers entirely destitute of pistils; the fertile with a short column of filaments but no anthers; carpels 8 to 10, pointless in a roundish depressed head.

Stony grounds; not common. July-Sept. Per. A tall and roughish herb, 4 to 5 feet high, with very large 7 to 9-parted lower leaves, with tho pointed lobas pinnatifid cut and toothed, and small white flowers in panicled clustered corymbs.

\section{Order 23. TILIACE正-Linden Family.}

Trees or shrubs, with simple, stipulate, alternate leaves and axillary flowers, usually perfect. Sepals 4 to 5, deciduous, valvate. Petals 4 to 5 , entire, hypogynous, rarely wanting, imbricated in the bud. STAMENs numorous, usually polydelphous; ANTHERs 2 celled. Disk often with 4 to 5 glands at the base of the petals. OVARY of 2 to 10 united carpels; STYLES 1; STIGMAS as many as the carpels. Frctr capsulax, 2 to 5 celled; seeDs solitary or numerous, with fleshy albumen. 


\section{TILIA. Linn. LINDEN.}

Sepals 5. Petals 5, spatulate-oblong. Stamens numerous; filaments cohering in 5 clusters with each other, or free. PISTIL with a 5-celled ovary, and 2 half-anatropous ovules in each, a single style, and a 5-toothed stigma. Fruit a sort of woody globular nut, becoming 1-celled and 1 to 2 seeded.-Fine trees with heart-shaped leaves and small cymes of flowers, hanging on an axillary peduncle which is united to a leaf-like bract.

\section{T. Americana, I. Basswood.}

Leaves deeply cordate, abruptly acuminate, acutely serrate, coriaceous, smooth; flowers in cymes; petals truncate at the apex, crenate; style as long as the petals; fruit ovate, somewhat ribbed.

Rich woods. June. A fine tree from 60 to 70 feet high, the trunk straight and naked more than half this height, and 2 to 3 feet in diameter. Leaves 4 to 5 by 3 to 4 inches; those of the young shoots often more than twice this dimension. Bracts yellowish, linear-oblong. Flowers yellowish-white, honey-bearing, fragrant. The wood is white and soft, and much used by cabinet and eoach makers.

\section{T. LAXIFLoRa, Michx. Loose-flowered Linden.}

Leaves cordate, graduaily acuminate, serrate, membranaceous, smooth; flowers in loose panicles; petals emarginate; styles longer than the petals; fruit globose.

Near the sea coast. May. Shrubby or arboreous. A very distinet species, though generally confounded with the former. Pursh. Becl.

\section{T. ALBA, Michx. White Linden.}

Lexves ebliquely-cordate, abruptly acuminate, whitish and thinly pubercent beneath, with reins of the same hue, smooth and bright green abore, acuminately serrate; petals emarginate; scales spatulate; styles nearly smooth.

Woods and mountains. June. Trunk $30-40$ feet high, 1 to $11 / 2$ feet in diameter; branches with a smooth silvery bark. Leaves 3 to 5 often 8 inches in diameter, slightly oblique, and with reddish hairs in the axils of the veins beneath. Flowers larger and whiter than in the other species.

\section{T. Europea, L. European Linden.}

A common ornamental tree, which is planted along the streets of our cities, is easily distinguished from our native species by the absence of the petal-like scales among the stamens.

\section{ORDER 24. LINACRTER.}

Herbs with regular hypogynous flowers, tetramerous and pentamerous throughout, strongly imbricated caly $x$ and convolute petals. Sepals 3 to 5, persistent. Petals a many as the sepals, unguiculate. STAMENS as many as the petals, and alternate with them at the base into a hypogynous ring, which is often toothed. OVARY of as many cells as sepals and styles; STIGMA crpitate. SEEDS solitary in each cell, compressed, suspended.

\section{LINUM. Linn. Flax.}


united carpels and only 5 celled, with 2 seeds hanging from the summit of each; but each cell is incompletely or completely divided into two by a false partition which projects from the back of the carpels, thus becorning 10-celled. SEEDS ovate compressed, mucilaginous. - Herbs with a fibrous bark, simple and sessile entire leaves, alternate or often opposite, without stipules, and terminal corymbose or panicled fowers.

\section{L. Virginianum, L. Wild Flax.}

Radical leaves ovate and spatulate; those of the stem linear-lanceolate, alternate; fowers small, scattered on the corymlcose or panicled branehes, on very short poduncles, tnrned to one side; sepals ovate, pointed, smooth.

Woods and fielde. June, Aur. Biennial or per. Stem 1 to 2 feet high, slender. smooth, leafy, tercte. Leaves $3 / 4$ inch long, $1 / 8$ wide, with 1 diatinct vein. Flowers 4 to 6 lines in diameter, yollorr, on short pedicels. Sepals 1-veined.

Variety diffusum. Woo's. Stcm angular, diffusoly branched; brancies and Ian. coolate leaves spreading; fiowsrs very small, yellow. Wet places, along dítches. Quite different in habit.

\section{L. usitatissimum, L. Common Flax.}

Stem branching above; leaves alternate, linear-lanceolate, acute; panisle corgmbose; sepals ovate, acute, 3-veined at the base; peials crenate; capsule roundish, acuminate.

Cultivated and somewhat naturalized about folds. June, July. Annual. Stem 1 to 2 feet high. Leaves distinct 3-veined. Flowars large, purplish-blue. A useful plant, from the strong fibres of the bark linen is manufactured, and the seeds yield hinsced oil, so extensively used in mixing paint, printer's ink, \&c.

\section{ORDER 25. GERAMIACFB-Crane's-bill Family.}

Piants with mostly regular, lyp gynous, pentamsrous flowers, imbricated sepals, and convolu'e petals. Leavis opposita (at lcat the low( $\mathbf{r}$ ones), mostly stipulate, petiolate, paimately-veined. Flowens on peduncles, terminal or opposite the leaves, sometimas axilia:y. SEPALS 5, persistent, veined, one cometimes saccate or spurred at base. Pexals 5, unguisulate, hypozynous or perigynous. Stamens usually monodelphous, hyposynous, 2 or 3 times as many as the petale. FruIT formed of carpals cohering around tho axis, having a mombranaczous pericarp and terminated by an indurated style, which finally curves upwazd carrying the pericarp with it. SEEDs solitary, without albumen.

\section{GeraniUm. Linn. Crane's-BiLl.}

Gr. gexanos, a cranc; tho bakad fruit rosambling a crane's bilt.

Sepals and petas 5, regular. Stamens 10, all fertile, the alternate ones longer, and with nectariferots scales at the base. Carpels with long awns, at length seperating elastically from the summit to the base; awns smooth internally.-Herbaccous plants, rarely shrubby at base. Peduncles 1, 2 or 3 flowered. 
1. G. maculatum, L. Spotted Geranium. Crane's bill.

Stem somewhat angular, erect, dichotomous, setosely pubescent; leaves 3 to 5-parted; lobes wedge-shaped and entire at base, incisely serrate above; radical leaves on long petioles, upper opposite, on short petioles; sepals mucronately awned; petals entire.

Open woods; common. May, June. Per. Stem 10 to 20 inches high. Leaves 2 to 3 inches in diameter, cleft $3 / 4$ way down, 2 at each fork. Flowers mostly in pairs on unequal pedicels, large, purple. . Root powerfully astringent. Mcdicinal.

2. G. Pusillum, L. Small-flowered Geranium.

Stems procunibent, slender, minutely pubescent; leaves rounded, kidney-form, 5 to 7-parted, the divisions mostly 3-cleft; peduncles skort, 2-flowered; sepals awnless, about as long as the emarginate calyx.

Sandy soils. May-July. Stems 1 foot lon $;$, much branching, covercd with skort deflected hairs. Leares op posite, divided almost to the base. Peduncles axillary, forked, bearing 2 purplish-2ed flowers, much smaller than the preceding. Intro duced. Annual.
3.
G. Carolinianum, L.
Carolina Crane's bill.

stem diffusely branchcd; leaves deeply 5-parted; lobes incisely toothed 3 to 5 -cleft; peduncles crowded towards the top; petals notched, as long as the calyx; carpels bairy.

Fields and hills. May-July. Stems pubescent, diffuse, 8 to 15 inches long, swelling at the joints. Leaves $3 / 4$ to $1 \frac{1}{2}$ inches in dinmeter, hairy. Flowers $\leqslant$ mall, rose-colored or nearly white, in pairs and somewhat fasciculate. Biennial.

4. G. Robertianum, L. Herb Robert.

Stem diffuse, hairy; leaves 3 to 5 -parted to the base; leaflets somemhat pinnatifid, segments somewhat mucronate; peduncles long, 2-flowered; sepals awned, shortor than the entire petals.

Rocky places and shaded ravines. June-Oct. Annual. Stem reddish, with long diffuse weak branches. Leaces on long petioles somewhat hairy, $1 \frac{1}{2}$ to 3 inches in diameter, with pinnatifid segments. Fiower's small, pale purple, beautifully lined with darker shades. Capsule small, rugose, kcelcd. Secds smooth. The whole plant is very petid.

The genus Pelargcnium embracing more than 300 species of shrubby and herbar ceous plants, with innumerable varieties of magnificent fiowers, nearly all natirea of the Cape of Grod Hope, are embraced in this order. Many of whieh are culti rated in our green houses and conservatories.

\section{ORDER 26. OXAUDACRE, - The Wood Sorrel Famity.}

Plan's with sour juice, componind lexves, and regular flowers. SEPALS 5, persisient, equal. Petals 5, equal, unguiculate, with a twisted astivation. Stamins 10, usually more or less monodelphous, those opposite the petals longest. Struzs $\mathbf{5}$, filiform; stigmas capitate. Fruit capsular, membraneous, with 5 cells, and from $\mathbf{s}$ to 10 valres. Sceds few, with a flesly integument, which bursts elastically.

\section{OXALIS. Linn. Wood Sorrex.}

Gr. oxus, sour; from the acid tasto of most species.

Sepals 5, free or united at base. Petals 5. Stamens 10 , usually more or less monodelphous, alternately shorter. CAPSULE deeply 5-lobed, 5-celled, each cell opening on the back. SEEDS few in each cell, pendulous from the axis.- 
Herbs, with alternate or radical stipulate leaves, mostly of 3 inversely heart-shaped leaflets, which close and droop at nightfall.

* Stemless; leaves and scapes from a root-stock or bulb.

\section{O. acetocella, L. Common Wood Sorret.}

Stalk creeping and scaly-toothad; scape 1-flowered, longer than the leaves; leaflets broad-obcordate, with rounded lobes; petals oval, obtuse; styles as long as the inner stamens.

Deep shady woods, on northern sides of mountains. June. Scape 3 to 5 inches high with 2 small bracts above the middle. Flowers large, white, with red veins, drooping. The whole plant has an agreeable acid taste. This is the shamrock of the Irish.

\section{O. VIOLACEA, L. Violet Wood Sorrel.}

Bull scaly; scapes several-flowered in an umbel, longer than the leaves; leaves ternate; leaflets obcordate, smooth; styles shorter than the outer stamens.

Woods and shady places; common. May, June. Scape nearly twice as high as the leaves 4 to 6 inches. Flowers violet, large, from 3 to 9 on umbels, drooping. Petals obovate, and sometimes slightly emarginate.

* Stems leafy: peduncles axillary.

3. O. corniculata, L. Decumbent Wood Sorrel.

Pubescent; stem rooting; decumbent, branched; peduncles 2-flowered, shorter than the leaves; leaves ternate; leaflets obcordate, pubescent; petals wedge-shaped, erose at the apex; style as long as the inner stamens:

Cultirated grounds and banks of streams. May-Aug. Stems prostrate, leafy, from 4 to 12 inches long. Sepals pubescent, $1 / 2$ as long as the emarginate deepyellow petals. Capsules densely pubescent.

\section{O. STRICTA, L. Upright Wood Sorret.}

Stem branching, erect; peduncles umbelliferous, longer than the petioles, 2 to 6-flowered; leaves ternate; leaflets obcordate; petals obovate, entire; styles as long as the inner stamens.

Sandy fields and bordcrs of woods. May-Aug. Stem 6 to 12 inches high. leafy, round, smooth, succulent. Leaves numerous, scattered on long stalks, Plowers small, pale-yellow.

\section{ORDER 27. BALSAMINACE正.}

Annual herbs, with succulent stems filled with a bland watery juice, very-irregular flowers, and simple leaves without stipules. SEPALS 5, irregular, deciduous; the two upper commonly united into one, the lower spurred. Petals 4, hypogynous, united in pairs, so that apparently there are only 2 petals. STAMENs 5 ; filaments subulate. Ovarx 5-celled; stigma sessile, more or less, 5 lobed. Fruit capsular, with 5 elastic valves and 5 cells. SEEDS solitary or numerous, without albumen.

\section{IMPATIENS. Linn. Batsàm.}

Name from the sudden bursting of the pod when touched.

SEPALS 5, the lower one spurred, the 2 upper united so as to appear like one. Petals 2, unequal-sided and 2-lobed. Stamens 5, short; anthers opening on the inner face. Stig- 
yas 5, united. Capsules prismatic-terete, clongated, 5valved, the valves coiling elastically and projecting the seeds in bursting.-Annual herbs with tender, smooth, suculent stems, tumid joints, and capsules lurtsing elastically uhen touched.

\section{I. Paltida, Nutt. Snap-rceed. Touch-me-not.}

Ieaves oblong-orate, coarsely and obtuscly scrrate, teeth mucronate, on silort petioles; peduncles 2 to 5-fiowered, solitary, elongated: lower sepal dilated-conicai. storter than the petals, with a rery short recurved spur.

Damp shady places: common. Aug. Stem 3 to 5 feet high, much branched. Leaves 2 to 5 inches long, $11 / 4$ to 2 inches wide, with large obtrs treth on petioles $2 / 2$ inch long, upper ones sessile. Flowers large, mostly in pairs. Tiro onter sepals pale-grcen, hard-pointed, the rest pale-yellow. Pctils pale-yellow, słightly spotted.

2. I. Fulya, Nutt. Jewel-weed. Balsam-weed.

Stem much branched; teaves rhombic-orate, somewhat obtuse, coarcely and obtusely serrate; teeth mucronate lower sepals acutcly conic, with a long round spur.

Damp shady ravines; common. Aug. Stem 2 to 4 feet high. Leaves 1 to 3 inches Jong, $1 / 2$ as wide, sonewhat glaucous, on petioles 1 to 2 inches long. Flneers deep orange with rodush-brown spots, smaller and less uumerous than in the furmer species.

\section{I. BaLsamma, Garien Balsamine. Ladies' Stipper.}

Leaves lanceolate, serrate, upper ones altcrnate; pecluncles clustererl; spur ehorter than the fower. Native of the East Indics. A leautiful garden annual. The prevailing color of the flowers are red and white, but the former varies in svery possible shade of crimison, Ecarlet, purple, pink inl tesh-color, often doubie and semi-double.

\section{ORDER 28. TROPWOLAOFIT.}

straggling or twining 7ierbs, with a pungent waiery juice, petiate or palvale leaves, and irregular flowers. Catrx of 5 colorid, united sepals, the intrer one spurret. Petals 5 ; two upper arising from the throat of the calyx remote from the 3 which are stalked. Stameng 8, unequal, distinct. OraRT of 3 united carrels; style 1; digmas 3. Froir separating 3 indehiseent, 1-seeded nats. Neds large. Ailumen none. *i

\section{TROP AEOLUM. - Linn.}

Lat. tropoum, a trophy; the leaf rescmbles a shield, the flower an empty heimct.

Generic character essentially the same as the order.

\section{T. MAJUs. Nasturtion. Indian Cress.}

Leaves peltate, roundish repand on the margin, with the long petiole inserted an little one side of the centre; petals obtuse, the 2 upper distant from the 3 lower which are fimbriate at base and contracted into long claws. A common garden onnual. Native of Peru. Stem at length climbing by means of its long petioles several feet. Leaves 2 inches in diameter. Flowers large and showy, oranger solored, with blotches of a deeper shade, The fruit is used for pickling. 


\section{ORDER 29. LMINANTHACT妮。}

Low annual herbs, with pinnated alternate leaves without stipules. FLowers regular, trimerous or pentamerous. SEPals 3 to 5 united at base persistent, valvate in sestivation. Petals 3 to 5, withering on the plant, inserted upon àn hypoygnous disk. Stamems 6 to 10, inserted with the petals; filaments opposite the sepals. STrues united; stigma simple: ovary of 2 to 5 distinct carpels. Frurt 2 to 5 achenia rather fleshy. Seeds solitary.

\section{FLGRKIA. Willd.}

Named in honor of Frloerke, a German botanist.

Sepals 3 , longer than the 3 petals. Stamens 6 . Ovaries 3, tuberculate. STYLE 2-cleft.-A small anpual aquatic, with pinnately divided leaves and minute solitary flowers on axillary peduncles.

F. proserpinacoides, Lindl. False Mermaid.

Stems deeumbent, weak, and slender; leaves alternate, upper ones, or thow above the water, pinnately 5-parted; lower or submersed ones mostly 3-partcd, all on slender petioles.

Marshes and shores of rivers and lakes. April, May. Stem 4 to 10 inches long. Flowers small, $1 / 4$ inch in diameter, white. Petats about half as long as the sepals Whole plant slightly pungent to the taste.

\section{ORDER 30. ZANTHOXYIACTIP.}

Trees or shrubs, pungent and aromatic bitter, with alternate or opposite leaves, vithout stipules, with pellucid dots and small regular diceicus or polygamous flowers. Flowers regular diclinous, gray, green, or pink. Separs 3 to 5, small, cohering at the base. Pexals longer than the sepals, as many, rarely wanting, convolute. Stamens as many or twice as many as the petals. Prsirus 2 to 5 , distinct or united, 1 to 2 seeded, (ovules 2, collateral). Frur baccate, membraneous or drupaceous, or 2-valved capsules. SEEDS solitary or in pairs.

\section{ZANThOXYluM. Linn. Prickly Ash.}

Gr. xanthos, yellow, and xuton, wood.

Frowers diocious. Sepals 5, petal-like when the petals are absent. Stamens 5 . Pistils 3 to 5 , raised on a short base or stalk, distinct, the styles connivent. CARPEIS thickish, 2-valved. SEeDs black and shining.-Fragrant aromatic shrubs, with pellucid punctate, pinnately 3 to 5 foliate leaves, and greenish-yellow flowers.

\section{Americanum, Mill. Prickly Ash.}

Stem and branches prickly; leaves pinnate; leaflets in 4 to 5 pairs and an odd one, ovate-oblong, downy when young; petioles round, unarmed; prickles stipular; fowers in short axillary sessile umbels. 
Rocky woods; not common. April. Shrub, 4 to 10 feet high, cororcd with sharp gtrong prickles. Leaves and flowers axillary. Flowers small greenish appearing before the leaves. Baric and pods very pungent to the taste, Medicinal.

\section{PTElea. Linn. Shrubby Treforr.}

Flowers polygama-dioecious. Sepals 3 to 5, small. Petals 3 to 5, much longer than the sepals. Stamens 3 to 5 , longer than the petals, and alternate with them. Ovary 2-celled; style short; stigmas 2. Fruit a 2-celled samara, winged all round, nearly orbicular. Shrubs, with 3 to 5 -foliate leaves and greenish-white small flowers in compound terminal cymes.

\section{P. TRIFoliata, L. Shrubby Trefoit.}

Leaves on loug petioles; ternate; leaflets ovate, puinted, downy when young, atd one much attenuated at base; flowers polygamous, mostly with 4 stamens.

Moist woods and rocky piaces; rare. Juno. An ornamental shrub 6 to 8 foet high. Flowers white, odorous, ncarly $1 / 2$ inch in diameter. Samera nearly 1 inch in diameter.

The Ailantrus glandilosus, or Tree of IIeaven, is a cultivated tree of this family, common in and around our villages, whose flowers are redolent of anything bat "airs from heaven."

\section{ORDER 31. ANACARDIAOEBE.}

Trees or shrubs, with a resinous gummy, caustic or milly juice, dotless, alternate, simpie, ternate or pinnate leaves, and small ofien polygamois, rigillar penianilrous flowers. Flowers terminal or axillary, with bracte, commonly dixcions. SEPalg 3 to 5, united at base, persistent. Pet.lus 3 to 5, sometimes none, imbrieate. Orar 1-celled, 1-ovuled. Strues 3, or none. Sticmas 3. Frum intehiscent, usually drupaceous. SEEDS without albumen.

\section{RHUS. . Linn. Sumagh.}

Calyy of 5 sepals, united at base. Petals 5. Stameng 5, equal, inserted on the disk. Strues 3. short. Stigmas - capitate. Fruit a small-seeded sub-globose, dry drupe.-Small trees or shrubs, sometimes climbing by rooting tendrils, alternate, mostly compound leaves, and greenish-white flowers.

- Not poisonous; friti clothed with (acid) crimson hairs: panicle compound, densea terminal; leaves odd pinnate.

\section{R. GLABRA, L. Smooth Sumach.}

Stem and branches smooth; leaftets 6 to 15 pairs, sessile, lanceolate, acuminates smooth, whitish glaucous beneath; flowers all perfect.

old fields and thickets; common. July. Shrub 6 to 15 feet high, consisting of many straggling branches, smooth except its point. Leafic's about 3 inches long, $3 / 4$ inches wide. Flowers greenish-yellow. Fruit crimson, covered with ebort hairs, acid, used for dyeing red. The bark is used for tanning morocco. 


\section{R. Copaluina, L. Dwarf Sumach.}

Branches and stalks downy; leaflets 4 to 7-pairs, oval-lanceolate, or oblong, very entire, shining on the upper surface, pubescent beneath, unequal at base; common petiole winged, appearing as if jointed.

Rocky hills and dry fields. July, August. Shrub 2 to 7 feet high with running roots. Common petiole about 6 inches long expanding into a leafy margin, between each pair of leaflets. Leaflets 1 to 3 inches long, near $1 / 2$ as wide, dark green and glossy on the upper surface. Flowers dioecious, yellowish-green. Fruit red, small, compressed, hairy, acid, and bitter.

\section{R. TYPHINA, L. Stag-horn Sumach.}

Branches and petioles densely villous; leaflets 6 to 15 pairs, oblong-lanceolate, acuminate, acutely serrate, whitish beneath.

$\approx$ Hillsides or low barren places. June. A large shrub, or a spreading tree, 15 to 30 feet high with orange-colored aromatic wood and copious milky resinous juice. Flowers greenish-yellow, diocious. Fruit in clusters, covered with a relvety purple down, acrid.

* Poisonous to the touch: fruit smooth: panicles axillary.

\section{R. Venenata, DC. Poison Sumach.}

Smooth ; leaves odd-pinnate, 3 to 6 pairs, oval abruptly acuminate, very entire; panicles loose, pedunculate.

Margins of swamps. June, July. A shrub or small tree of fine appearanee, 10 to 15 feet high. Petioles 6 to 10 inches long, red. Leaflets about 3 inches long, nearly $1 / 2$ as wide, sessile, except the odd one. Flowers very small, greenish, divecious. Fruit about as large as a pea. The whole plant is very poisonous, tainting the air to some distance around with its pernicious effluvium.

\section{R. Toxicodendron. L. Poison Oak.}

Frect or decumbent; leaves ternate; leaflets broad-oval or rhomboid, entire, sinuate or lobed, somewhat pubescent; flowers in racemose axillary sub-sessilo panicles.

Moist woods and thickets. June. A small shrub, 1 to 3 feet high, nearly smooth in all its parts. Leaflets 2 to 6 inches long $2 / 3$ as wide, petiolate, the common petiole 4 to 5 inches leng. Flowers small, dioecious, greenish-yellow. Fruit smocth, roundish, pale-brown. Poisonous.

Var. b. radrcans. Torr. (R. radicans. Linn, DeCandolle and Beck.) Poison Iry.

Stem elimbing; leaves ternate; leaflets petiolate, ovate, acuminate, smooth, gen. erally entire; flowers in axillary racemestowards the top of the stem, diceious.

Woods and hedges. June. Stem climbing by myriads of rooting tendrils 10, 20 or 50 feet. Flowers yellowish-green. Fruit sub-globose, brown.

* * Leaves ternate; flowers dicecious, not poisonous, aromatic.

\section{R. aromatica, Ait. Fragrant Sumach.}

Branches slender, nearly smooth; leaves ternate; leaflets rhombic-ovate, sessile, the middle one wedge-shaped at the base, unequally cut-toothed, pubescent when soung.

Dry locky soil; rare. April, May. A small aromatic shrub 2 to 6 feet high Leaflets 1 to 2 inches long, $1 / 2$ as wide, the common petioles 1 to 2 inches long. Flowers yellowish, in clustered scaly-bracted spikes like catkins, preceding the leaves. Fruit red, acrid, more or less hisped.

\section{R. сотіnus. Venitian Sumäch.}

$\Lambda$ emall shrub, cultivated: native of Arkansas, according to Nuttall, remarkablo chiefly for the singular and ornamental appearance of its long, diffuse feathery fruit-s alkg, showing in the distance as if the plant were enveloped in soloud of moke. 


\section{ORDER 32. ACERACEF.}

Trees with opposite palmately loled, rarely pinnate leares, without stipules, and flowers often polygamous, sometimes apetalous, small, in axillary racemes, corymbs or fuscicles. SEPals 5 , rarely 4 to 9 , more or less united, colored, imbricate in æsti. vation. Petals 5, rarely 4 to 9, alternate with the sepals, hypoygnous. STAMens usually 8 , sometimes 9 to 12, distinct. Struls 2. Stigmas 2. Orary 2-lobed, 2-celled. Frut of 2 indehiscent winged samara, each 1-celled, 1 to 2-seeded. SEcDS with little or no albumen.

\section{ACER. Linn. Maple.}

Lat. acer, sharp; the wood was anciently manufactured into weapons of war.

Calyx 5-lobed, sometimes 5-parted. Petals 5, or more. Stamens 6 to 8, rarely 5. Samara 2-winged, united at base by abortion, 1-seeded.-Trees with simple, palmately lobed leaves, often heart-shaped at the base, and mostly polygamous flowers.

* Flowers in corymb or fascicles. Trees.

\section{A. Rubrum, L. Red Maple. Swamp Maple.}

Leaves 3 to 5 lobed, heart-shaped at the base, irregularly serrate and notched, acute, the middle one usually the longest, glaucous, underneath; flowers on rery short pedicels; petals linear oblong.

Moist woods. March, April. A common tree from 20 to 40 feet high, with reddish twigs. Trunti covered with a smooth bark, marked with large, whit spots, becoming dark with age. Letves raviuble in size, pubescent when young. Flows's appearing in early spring: before the leaves, searlet, o: yellowish, about 3 in each fascicle. Fruit on pedicels 2 to 3 inches long, smotr.

2. A. Dasycarpun, Ehrh. White Maple. Silver Maple.

Leaves deeply 5-lobed, with the sinuses rather acute, unequally and incisely toothed; whitish glaucous underneath; flowers aggregated on short petioles; petals none; fruit woolly when young, nearly smooth when grown, with large dilated. wings.

Banks of streams; not common. April, May. A fine ornamental tree, 30 to 50 feet high, affording a sweet sap. Leaves on long petioles, nearly smooth when old. Flowers greenish-yellow or purplish, usually about 5 together. Pedicels of the fruit about an inch long.

\section{A. saccharinum, L. Sugar Maple. Rock Maple.}

Leaves 3 to 5 lobed, with rounded sinuses and pointed lobes, sparingly sinuate toothed, subcordate at base, glaucous beneath; flowers from terminal leaf-bearing and lateral leafless buds, drooping; pedicels slender, hairy; caly $x$ hairy at the apex; petals none.

Woods and mountain valleys. April. A fine tree 50 to 80 feet high, with a trunk 2 to 3 feet in diameter. Bark of a light-gray color, rough and sealy. Branches numerous and finely ramified in open situations. Foliage very luxurient, deep green and smooth above. Flowers yellowish, on long thread-like peduncles. Peti oles smooth. This is one of the most useful trees of the forest; the sugar obtained frow its sap is perhaps the most delicious of all sweets. The wood is very strong and compact, often presenting that beautiful arrangement of fibre, called bird's-eye maple, which is so highly esteemed in cabinet work. It is oxtensively cultirated as an ornamental shade tree. 
4. A. Pennsylvanicum, L. Striped Maple.

Leaves with 3 acuminate lobes, rounded at base, finely and sharply double serrate; racemes drooping, loose; petals obovate; fruit with large diverging wings.

Rich woods and shady rocks. May. A shrub or small tree 10 to 15 feet high. Trunk beautifully striped lengthwise with green and black. Leaves rarely undivided. Flowers large, yellowish-green, 10 to 12 in a raceme. Fruit clustered, with pale-green wings.

5. A. spicatum, Lam. Mountain Maple.

Leares small, 3 to 5 lobed, acute, dentate, pubescent beneath; racemes erect, dense, somewhat compound; petals linear; fruit smooth; wings somewhat diverging.

Rocky hills and mountains. May, June. A shrub 8 to 12 feet high growing in clumps. The bark is of a light gray color. Leaves somewhat pointed, with large sharp teeth, more or less cordate at base. F'lowers greenish, numerous and small, in round, oblong, close-branched clusters 2 to 3 inches long, becoming pendulous with the winged fruit.

\section{NEGUNDA. Moench.}

Calyx minute, 5-cleft. Petals none. Stamens mostly 5.- Small trees with compound pinnately 3 to 5-foliate leaves, and dioceious flowers, from lateral buds; the sterile in clusters on capillary pedicels; the fertile in drooping racemes.

N. ACERoIdes, Monch. Ash-leaved Maple. Box Elder.

Leaves ternate, or pinnate by fives; leaflets ovate, acuminate, remotely and unequally dontate; pistillate racemes long and pendulous; barren flowers corym. bose; fruit oblong, with large wings dilated upwards.

River banks, low wet grounds and along mountain streams. April. A small but handsome tree 10 to 20 feet high, with light-green twigs, and smooth yellowishgreen bark. Flowers yellowish-green, very delicate, in drooping clusters, rather preceding the leaves. Fruit pubescent, oblong, the wings about an inch long.

\section{ORDER 33. SAPINDACR西.}

Trees, shrubs, or cimbers furnishet $u i$, tendrils, rarely herbe, with alternate and mostly compand leaves, and small, unsymmetrical, usually irregular and polygamous flowers. CaLyX of 4 or 5 sepals. Petals irregular and often one fewer than the sepals, sometimes wanting. STAunens 8 to 10 . OVARY 2 to 3-celled, the styles or tigmas more or less united. SEeDs usually with an aril, destitute of albumen.

\section{CARDIOSPERMUM. Linn.}

Cr. kardia, heart, sporma, seed; the globose seeds marked with a large cordals hilum.

Sepals 4, the 2 outer smallest. Petals 4, each with an emarginate scale above the base, the 2 lower remote from the stamens; their scales crested; glands of the disk 2, opposite the lower petals. Stramens 8, unequal. Strue trifid. CAPSULE membraneous. - Climbing herbs, with biternate 
leaves, the lower pedicels changed to tendrils, and small whitish flowers.

C. Haliacabum, L. Heart-seed. Balloon-vine.

Plant nearly smonth; leaflets crate-lanceolate, incisely lobed and dentate; flowers small, axillary, solitary; fruit pyriform-globose, large, bladder-like. Native along the Missouri river. Tcrr. \& Gr. July. A curious vine 4 to 6 feet long, with remarkably large inflated membraneous capsules.

\section{SUE-JRDER. HIPPOCASTANACE \#.}

Trees or shrubs, with opposite digitate leaves, without stiputes. Fruit roundish, coriaceous, dehiscent, with 1 to 3 very large seeds, resembling chestnuts. EMBRYo very large and fleshy, showing a 2-leaved plumule. COTYLEDons united.

\section{AESCULES. Linn. Horse-CHestnut.}

Calyx regular, 5-lobel, companulate. Petals 4, sometimes 5 , more or less unequal, with claws. Stamens 7 (rarely 6 or 8); filaments long and slender, often unequal. STYLE 1, filiform, acute; ovary 3-celled, with 2 ovules in each, only one of which, or one in each cell, ripens into a seed.-Trees and shru's with 5 to 7-foliate leaves, and flowers in thyrse-like panicles.

1. A. GLaBRA, Wills. Olio Buckeye.

Lexfe's 5, oval or oblong, acuminate, sarrats cr serrulate, rery smooth; corolla 4pctalled, spreading, with the claws as long as the calyx; stxmens longer than the corolla; fruit echinate.

Banks of streams: Western par of the State. May. A small ill-scented tree. Leafiets 3 to 6 inches long, 1 to 2 inches wide, sub-scssile, or abruptly contracted at base to a short stalk. Fiower; ye' lowish-white, small, slightly irregular, in terminal racomoso ranicles. Fruit alout $3 / 4$ icch in ciameter, prickly.

2. F. Pavia, L. Small Buckeye.

Leaflet; 5, oblong-lanceolate, cuncate at kase, abruptly and shortly acuminate, finoly serrat3; flwwers very irrezula: in a loose thyrsuid racome; petxls 4, erect, as long as the stamens.

A beautiful shrub, 6 to 10 feat high, cultivated for ornament : natire of the Southern States; probably indigenous in the South-western part of our State. April, May. Flowers larg?, red, smooth.

3. AE. Hippocastanum, I. Common Horse-chestnut.

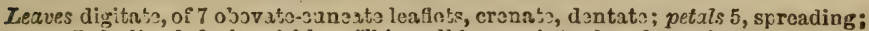
stamens 7 declined, fruit prickly. 'This well lnown introduced trez is mearly naturalized. Native of Asia. In Juns it puts forth numorous pyram:dal racemes or thyrses of pink and white flowers, finly contrasting with the dark-green of its meassy foliage.

\section{ORDER 34. CELASTRACP正。}

Shru's or small trees, with spp isite cr altrrnate leaves, small, regular and symmetrical flowars. S3pals 4 to 5, unital at base, imbricated. Parals 4 to 5, inseried 
by a broad base under the margin of a flat expanded disk which surrounds the ovary. STAMENs 4 to 5, alternate with the petals, inserted on the margin of the disk. OVARY superior, immersed in, and adhering to the disk. FRUIT a capsule or berry. SEEDS solitary or fow.

\section{TRIBE 1、 STAPHYLEA. \\ Leaves pinnate, opposite. Seeds long, not arited. Ovary many-ovuled, free from the cup-shaped disk.}

\section{STAPHYLEA. Linn. Bladder-nut.}

Gr. staphu'e, a cluster; in allusion to its mode of flowering.

Sepals 5, oblong, erect, colored, persistent. Peĩals 5, with short claws. Stamens 5. PIstils 3, united in the axis, their long styles cohering, but separating as the ovary enlarges into the membranaceous inflated 3-lobed, 3-celled capsules.-Upright shrubs, with opposite pinnate leaves and white flowers in raceme-lite clusters, terminating the Granchlets.

1. S. tRIFolia, L. Blardder-nut.

Leaves ternate, on long petioles; leaflets ovate, acuminate, serrulate, pubescent, the terminal one petioled; styles smooth.

Moist thickets and roky places. May. A handrome shrub 6 to 10 feet high, w:th strai, ht and smooth slender branches. Flowers white, with sput of orange, in pendulous clusters.

\section{TRIBE 2. EUONYME AE.}

Leaves simple; styie 1 ; stigmas 3-lobed; cvaries 2 in each cell; seeds with pu'py arits; disic adhering to the lottom of the calyx.

\section{CELAs'trus. Linn. Shrubby Bitter-sweet.}

FLowers sometimes polygamous. Sepals 5, united at base. Petalis 5 sessile. Stamens on the margin of a cup-shaped disk. Pistils on the disk. Capsule globose, or 3-angled, 3-celled. SEeDs 1 to 2 in each cell, erect, enclosed by a pulpy scarlet aril.-Climbing or twining shrubs, with alternate leaves, minute deciduous stipules and small greenish flowers in raceme-like clusters terminating the branches.

C. scandens, L. Climbing Bitter-sweet. Wax-worl.

Stem climbing and twining, unarmed; leaves oblong, acuminate, serrate, petioled, stipules minute; racemes terminal; flowers diocious.

Woods and thickets. May, June. A handsome climbing shrub, the stems twining about trees and each other, ascending to a great height. Leaves smooth. Flowers in small racemes, greenish-white. Seeds covered with a searlet aril, contained in an orange-colored 3-valved capsule. 


\section{EUONYMUS. Tourn. SPINDLE-TREE.}

Sépals 4 or 5 , united at the base, forming a short and flat calyx. Petals 4 to 5, rounded, spreading. Stamens very short, inserted on the upper face of a broad and flat 4 to 5-angled disk. Style short or nơne. Capsule with 3 to 5 angles, 3 to 5 cells and as many valves. SeEds 1 to 2 in each cell, inclosed in a red fleshy aril. - Shruls with 5-sided branchlets, opposite serrate leaves, and loose cymes of small green or darle purple flowers on axillary peduncles.

\section{E. Atropurpureus, Jacq. Burning Bush.}

Stem with sinooth, opposite, square branches; leaves petioled, oval-oblong, pointed, serrate, pubescent beneath; flowers mostly in fours; fruit smooth, deeply lobed.

Hedges and banks of streams; sometimes cultivated. June. A handsome ornamental shrub 4 to 8 feet high. Flowers dark purple. Fruit very showy at the close of autumn, drooping on long peduncles. Capsule crimson, smooth. Arit enclosing the seed, scarlet.

\section{E. Americanus, L. Strawberry Tree. Burning Bush.}

Branches opposite, smooth, square; leaves opposite, sessile, oblong-lanceolate, rarying to oval, acute, serrate; peduncles 1 to 3 -flowered, rounded; caly $x$ small, with acute segments; flowers in fives, fruit rough, warty, depressed,

Wet places and moist woods. June. Shrub 4 to 6 feet high, Flowers greenishycllow with a tinge of purple. Fruit not as copious as the above, crimson when ripe, the aril scarlet:

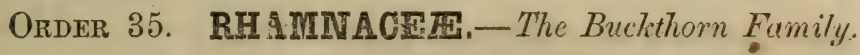

Shrubs or small trees, with simple leaves, minute stipules, and small regular exillary or terminal flowers (sometimes apetalous). Branches often thorny. SEPALS 4 or 5, united at base, valvate in æstivation. Perals 4 or 5 , distinct, cuccullate or concave, inserted along with the stamens into the edge of a fleshy disk which lines the Bhort tube of the calyx. STAMens 4 to 5 opposite the petals. Orary superior or half superior, 2 to 5-celled. Stigmas 2 to 5 . Frux fleshy and indehisecnt, or dry and separating in 3 parts. SEeDs erect, mostly with fleshy albumen.

\section{RHAMNUS. Linn. BUCK'THORx.}

Gr. Ramnos, the ancient name; from the numerous branchlets.

Calyx 4 to 5-cleft. Petals 4 to 5, shorter than the sepals, alternate with the lobes of the calyx, sometimes very minute or wanting. Stamens 4 to 5, inserted above the petals. Strue 2 to 4 -cleft. Fruit a berry-like drupe, containing 2 to 4 cartilaginous nuts. - Small trees or shrubs, with mostly alternate leaves, and minute flowers in short axillary clusters, often polygamous or dioecious. 


\section{R. ALNIFOLIUs, L'Herit. Alder-leaved Buckthorn.}

Shrub erect with unarmed branches; leaves alternate, ovate, acuminate, serrate, pubescent on the veins beneath; peduncles aggregate, 1-flowered; flowers mostly pentandrous; calyx acute, styles 3 , united, very short; fruit top-shaped.

Sphagnous swamps. May, June. A spreading shrub 2 to 4 feet high. Leaves 1 to 3 inches long, $1 / 2$ as wide, acute at base. Flowers small, greenish, mostly apetalous. Berries about as large as small peas, black.

\section{R. Lanceolatus, Pursh. Lance-leaved Buckthorn.}

Leaves oblong-lanceolate, acuminate; floral ones obtuse, mostly ovate or round. ish), closely serrulate, minutely downy underneath; petals 4, deeply obeordate, sbout as long as the short stamens; seeds 2.

Hills and river banks: Mercersburg, Franklin Co. Prof. Traill Green. May. A tall shrub, not thorny. Later leaves long, often oblong-ovate. Flowers yellowishgreen, diøecious-polygamous; the pedicels usually single in the more fertile plant, which has the 2-eleft style exserted, and produces abundant globular drupes about the size of a pepper-enrn. The less fertile plant bears rather larger flowers, on clustered pedicels, with a very short and included style. Drupes large top-shaped, distinctly pointed with the short style. Seeds obovate, deeply groored.

\section{ORDer 36. VITACERA-The Vine Family.}

shrubs, climbing by tendrils, with simple or compound leaves, and small, regular, - flen polygamous or diocious flowers with a minute truncate nearly entire calyx. Prats 4 to 5, very deciduous, inserted on the outśide of the disk. STamens 4 to 5 opposite the petals, inserted on the disi, sometimes sterile, by abortion. Prstrus with a short style, or none, and a slightly 2-lobed stigma. OvARY 2-celled, with 2 erect anatropous orules from the base of each. Frvir a globose pulpy berry, with luxd albumen.

\section{- 1. VITIS. Linn. VINE.}

CalyX somewhat 4 to 5-toothed. Petals 4 to 5, cohering st their apex, usually falling off without expanding. STAMENS 5. STYLe none. Base of the ovary surrounded with a 4 or 5 -lobed ring, or 4 to 5 glands alternate with the stamens. BERry 2 -celled, 1 to 4 -seeded; cells and seeds often abortive.-Flowers fragrant in a compound thyrse. -Peduncles often changed into tendrils.

\section{V. Labr Usca, L. Northern Fox Grape.}

Leaves very large, broad-cordate, angular-lobed, acutely toothed, smooth abov, very woolly beneath, racemes small, panicled; berries large.

Moist thickets and wools; common. June. Stem climbing to a great height. Leaves and young branches very woolly. Flowers small, green. Fruit large, purple, often green or red, ripe in Sept. The Isabella, Catazbba, Blands and other morts known in cultivation, are varieties of this species.

2. V. Astivalis, Michx. Frost Grape. Winter Grape.

Young leaves downy with loose ferruginous hairs beneath, smoothish when old, sroen above, broadly cordate, 3 to 5-lobed or psimate-sinuate, coarsely dentato: forkile ravme long, panicled, opposito tho leaves; berries small. 
Hills, woods and river banks. June. Stem very long, slender, climbing. Leaves ₹ory large, clothed beneath when young with cobreb-like, rust-colored pubescence. Tendrits from the peduncles, with an opposite leaf. Berries deep blue, with a bloom well flavored, but small, ripe in sept.

3. V. CoRdifolia, Michx. Frost Grape. Winter Grape.

Eeaves cordate, acuminate, somewhat equally but coarsely toothed, smooth on both sides; raceme loose, many-flowered; berries small.

Thickets by river banks; common. June. Slem ascending, shrubs and trees to the height of 10 to 20 feet. Leaves large, membraneous, often 3-lobed, with pubeswnt veins when young, and a few mucronate teeth. Berries nearly black, small, late, acid, but well flarored after being frosted.

\section{V. vinifera. Common Wine Grape.}

Leaves cordate, sinuately 5-lobed, Emooth; flowers all perfect. Naturalized in nearly all temperate climates. Varieties without end may bo raised from the seed. which will bear fruit the 4 th or 5 th year.

\section{AMPELOPSIS. Michx.}

Gr. ampelos, the vine, and opsis, appearance; resembling the rine.

Calyx slightly 5-stalked. Petals concave, spreading deciduous after expansion. Strgmas capitate. Ovary without a 5-lobed ring, 2 to 4 -seeded.-Fine shrubby creepers with digittate or cordate leaves and cymose clusters of flowers: supported by radiating tendrils.

\section{A. Quinquefolia, Michx. Virginian Creeper.}

Leaves quinate, digitate; leaflets oblong, acuminate, petiolate, dentate, smooth, racemes somewhat dichotomously cymose.

Woods and thickets. June, July. A vigorous climber, cultivated as a covering for palls, trellises, \&c. Flowers inconspicuous, greenish, in forked clusters. Berries dark blue, smaller than peas.

\section{E. condata, Michx. Heart-leaved Creeper.}

Stem climbing, with slender branches; leaves cordate, acuminate, toothed and angular; nerves beneath, pubescent; racemes dichtomous, few-flowered.

Banks of streams. June, July. Panicles opposite the leaves, Berries pale-zed, Beste.

\section{ORDER 37. POLYGATACERS.}

Plants, shrubby or herbaceous, with simple, entive, alternate or rarely opposite, leaves destitute of stipules, and irregular papitionaccous flowers, with 4 to 8 diadesphous stamens. Sarals 5, very irregular, distinct, 3 exterior, of which 1 is superior and 2 inferior, 2 inner ones called the wings much larger, and colored like the petals. Putals 3 , hypogymous the anterior (keel) larger than the rest, and usually erested. STAMEN 6 or 8 , with their filaments combined in a tube which is aplit on the upper side, cohering more or less with the petals, free above. ANTHERs 1-celled, opening by s terminal pore. OVARY superior, 2-celled. STrue and stigma simple. TrUs usually a capsule generally rounded or notched at the aper, SERDos with an abue lant albumen. 


\section{POLYGALA. Tourn. Minkwort.}

Gr. potus, much, and gala, milky; supposed to favor the lacteal secretions.

Sepals 5 persistent, 2 of them wing-shaped and colored. Petals 3 to 5, united to the stamens, the lower one keelform. CAPSULe obcordate, 2-celled, 2-valved, 2-seeded. Seeds smooth with a caruncle.-Low bitter herbs, with simple entire leaves, often dotted, and no stipules, sometimes bearing conceated fertile flowers also next the ground.

* Annual: flowers purple to white; spites ovate globose or oblong, dense.

1. P. incarnata, L. Flesh-colored Milliwort.

Stem erect, slender, simple or sparingly branched; leaves small, linear-subulate, few; spikes oblong or cylindrical, without glands; corolla with a long tube.

Dry soils. June, July. Stem. 1 to 2 feet high. Leaves $1 / 2$ inch long, remote. Spikes 1 to $11 / 2$ inches long. Flowers pale rose-color or flesh-color; wings, much shorter than the conspicuously crested corolla; claws of the petals united into 2 very long and slender-cleft tube.

\section{P. PURPURea, Nutt. Purple Mitlewort.}

Stem branching at top; leaves linear, alternate; flowers beardless, imbricated in obtuse, cylindrical spikes; wings of the calyx cordate-ovate, erect, twice as long as the capsule.

Meadows and wet grounds. July-Sept. A handsome erect plant 6 to 10 inches high, easily recognized by its short purplish, cylindrical spike of flowers. Stcm angular with fastigiate branches, cach ending with a spike smaller than the main stem, but rising above it in height.

* * Spikes elongated or racemose; flowers white or greenish.

3. P. Ambigua, Nutt. Ambiguous Milkwort.

Stem erect, very slender, loosely branched; lowest stem leaves in whorls of four; the rest scattered, narrowly linear; spikes Iong peduncled, very slender; flowers crested; bracts deciduous.

Dry woods. Aug., Sept. Stem 6 to 12 inches high, somewhat angular. Leaves sessile, tapering to the base, $1 / 2$ to 1 inch long, narrow. Racemes spicate, acute, about 1 inch long, 20 to 30 -flotrered, on peduncles 1 to 3 inches long. Flowers small, greenish-white, tinged with purple. Wings of the calyx round and veined.

4. P. verticellata, L. Whorl-leaved Milkwort.

Stem erect, branched; leaves whorled, linear and lance-linear; raceme spiked, dense, acute, on rather short peduncles; bracts falling with the flowers; wings round, clawed.

Dry hills; common. July-Oct. Stem very slender, square, 6 to 10 inches high. Leaves in whorls of 4 or $5,1 / 2$ to 1 inch long, alternate on the branches. Flowers small, greenish-white, sometimes tinged with purple; crest rather large in proportion.

\section{P. senega, L. Seneca Snake-root.}

Stems several form a thick and hard knotty root, simple; leaves alternate, lanceolate, tapering at each end, rough on the margin, spikes cylindrical, rather dense, somewhat acute; flowers on extremely short pedicels; wings of the calyx orbicular; capsule elliptic, emarginate.

Woods and meadows. June, July. Perennial. Stem a foot high, with ovato scale-like leaves at the base. Leaves smooth, finely serrulate, 1 to 3 inches long, $1 / 3$ as wide, numerous, scattered. F'lowers white in a filiform spike 1 to 3 inchas long. 
Sepals obtuse, larger than the petals. Root medicinal. A valuable stimulating expectorant.

** Perennials: flowers pusple, showy, Larger than the former; bearing whitish fortile one on subterranean branches.

6. P, polygama, Wält. Bitter Milkwort.

Stems numerous, simple, erect and procumbent; leaves linear-lanceolate, of obovate, altarnate, attenuate downwards; racemes filiform, terminal and lateral, elongated; flowers sersile, the broadly obovate wings longer than the crested corolla.

Field and pastures. June, July. Stems crowded, many from the same root, angular, smooth. Leares smooth, lower oborate, upper linear-lanceolate, obtuse, assile. Flowers purple, $1 / 4$ inch in diameter, very handseme, 8 -ardrous. Sulteror nean flowers on procumbent racemes, without petals, sessile. Bitter and tonic.

7. Padcifolia, Willd. Fringed Polygala.

stem simple, erect, naked below, rising from long and slender prostrate or subteranean shoots, which bear concealed fertile flowcrs; leaves orate, acute, smooth; terminal flowers mostly in threes, large cristate, sometimes axillary ; wings obovate, rather shorter than the conspicuously fringe-crested keel.

Woods along mountains in light soil. May. A delicate plant with large showy purple flowers, $3 / 4$ inch long. Siem 3 to 4 inches high. Lower leaves small and sesttered, scale-like. The radical flowers are eitber close to the ground or subter zean, smaller, greenish.

\section{ORDER 38. LEGUMINOSH,-Leguminous Plants:}

Herbaceous plants, s7irubs or trees, with alternate mostly compound leaves with stipwhe, and papitionaceous flowers, 10-monodelphous, diadelphous, or rarely aistinct ctamens, and a single, simple pistit, producing a legume in fruit. CALYX of 5 sepals more or less united. PrTals 5, papitionaceous or rarely regularly spreading. Stamans definite or indefinite, inserted with the corolla. Orary simple, superior: Faur a legume. SEEDs sttached to the upper suture, without albumen.

\section{Sub-order I. PAPILIONACE AL.}

PETALs truly papilionaceous, imbricate in æstivation, the apper one extended. Stamens 10 , mostly diadelphous, 9 united by their filaments into a sheath split on the upper vide when the 10 th is free.

\section{Tribe 1. VICIEA. The Vetch or Pea Tribe.}

rarbs with abruptly pinsate leaves, the common petiole produced into a tendril or lorts: tle; peduncles axillary.

\section{VICIA. Tour. VFTCH.}

CalpX tubular, 5-cleft or 5-toothed, the 2 upper tecth often shorter. Stamens diadelphous. Strue filiform, bent at a right angle with the orary, hairy down the entire side. ILGU ME oblong, many-seeded.-Herbaceous mostly climbing plants, with abruptly pinnate leaves of several pairs of leaflets. and a branching tendrit. Peduncles axillary. 


\section{V. Caroliniana, Walt. Carolina Vetch.}

Nearly smooth; leaflets 8 to 10, elliptical-lanceolate, obtuso, scarcly mucronato; peduncles loosely flowered, as long or longer than the leaves; flowers distant; calyx teeth very short.

Borders of woods and along fences. May, June. Per. Stem 2 to 4 feet long, elimbing. Leaflets $3 / 4$ inch long, $1 / 8$ to $1 / 4$ wide. Flowers small, white or paloblue. Standard black at the tip. Legume oblong.

\section{V. Americana, Muhl. American Vetch.}

Smooth; leaflets 10 to 14, elliptical or ovate-oblong, very obtuse, many-veined; stipules semi-sagittate, deeply-toothed; peduncles 4 to 8-flowered, shorter than tho leaves.

Moist thickets and woods. June. Per. Stem 1 to 3 feet long, slender, some what 4 -angled. Leaflets 1 inch long, nearly $1 / 2$ as wide. F'lowers purplish-blue, $3 / 4$ inch long. Style very hairy at the summit. Legumes oblong-linear, compressed, reticulated.

\section{V. Cracca, L. Tufted Vetch.}

Downy-pubescent; stem branching; leaflets 10 to 20 , oblong-lanceolate, strongly mucronate; stipules semi-sagittate, linear, nearly entire; peduncles densely manyflowered; calyx teeth shorter than the tube; style hairy at the top.

Border of fields, woods and meadows. June, July. Per. Stem 2 to 3 feet long, Blender, square. Leaflets $1 / 2$ to $3 / 4$ inch long, $1 / 4$ inch wide. Flowers 10 to 20 in a long, dense, one-sided raceme pale-purple. Legume oblong, compressed, coriaceons, smooth.

* Annual. Naturalized.

\section{V. tetrasperma, L. Slender Vetch.}

Smooth; leaflets 8 to 12, linear-oblong, obtuse; stipules lanceolate, semi-eagittato; peduncles mostly 2-flowered; calyx teeth unequal; legume oblong, smooth, mostly 4reeded.

Fields and banks of streams; introduced. May, June. Stems almost fliform 1 to 2 feet long. Leaflets $1 / 2$ inch long, 1 line wide, acute or obtuse. Flower's very small, white, or bluish-white, sometimes 3 or 4 together.
5. V. sativa, L. Common Vetch or Tare.

Somewhat pubescent; stem simple; leaflets 10 to 14, ovate-oblong or linear-oblong, notched and mucronate at the apex; calyx-teeth equal; legume linear, severaseeded.

Cultivated fields and waste places; introduced. June. Stem 1 to 2 feet high, erect or decumbent. Leaflets $3 / 4$ to 1 inch long, $1 / 4$ wide. Flowers $1 / 2$ inch long, pale-purple. Iegume 1 to 2 inches long, erect, roundish, reticulated, smooth.
6. V. Hinsuta, Koch. Hairy Vetch.

Leaflets 8 to 20, linear, or linear-oblong, truncate, mucronate; stipules semi-6agittate, narrow; peduncles 3 to 6 -flowered, shorter than the leaves; legumes oblang, hairy, 2-seeded.

A ereeping weed in cultivated fields; introduced. May, June. Stem 2 to 3 feet long, much branched and diffused. Leaflets about $1 / 2$ inch long, very narrow. Flowers very small, bluish-white. Legumes short, with roundish comprassed brown seeds.

\section{LATHYRUS. Linn. Vetchling.}

Gr. Lathuros, a legaminous plant of Theophrastus.

Calyx 5-cleft, the upper teeth shorter papilionaceous. Stamens diadelphous. STyLE flattish, not grooved above, 
hairy along the inner side. LEGUMES oblong, several-seeded, 2-valved, 1-celled.-Herbaceous mostly climbing plants with abruptly pinnate leaves, and petioles produced into branching tendrils.

\section{L. venosus, Muhl. Veiny Vetchling.}

Stem climbing, square, naked; leaflets 5 to 7 pairs ovate-oblong, obtuse, subopposite, mucronate, veined, often downy beneath; stipules very small, semi-sagit tate; peduncles many-flowered.

Shady banks and low meadows. July, Aug. Per. Stem 2 to 3 feet long, climbing, mostly smooth. Leaflets $11 / 2$ to 2 inches long, variable in width. Peduncles manylowered, about the length of the leaves. Corolla purple. Legumes flat and narrow.

\section{L. Palustrus, L. Marsh Vetchling.}

Stem slender, often wing-margined; leaflets 3 to 4 pairs, lanceolate, linear, or narrow-oblong, mucronate; stipules semi-sagittate, acute; peduncles 3 to 5 -flowered.

Low grounds, wet meadows and thickets. June, July. Per. Stem 2 to 3 feet long, square, broadly-winged at the angles, supported by the tendrils. Leaflets variable in width, somewhat coriaceous. Flowers drooping, rather large, variegated with blue and purple.

\section{L. myrtifolius, Muhl. Myrtle-leaved Vetchling.}

Stem slender, weak, square; leaflets 2 to 3 pairs, oblong-lanceolate, acute, mucro nate; stipules semi-sagittate, lanceolate, acuminate; peduneles 3 to 6 -flowered, longer than the leaves.

River banks and marshy places. July, Aug. Per. Stem about 3 feet long. Leaflets 1 to 2 inches long, $1 / 2$ as wide. Flowers pale-purple, somewhat resembling L palustris, but has a more slender stem, and broader leaflets and stipules.

\section{L. ochroleucus, Hook. Pale Vetchling.}

Stem slender; leaflets in 3 to 4 pairs, ovate, obtuse, mucronate, reticulate beneath: atipules large, half-cordate; peduncles 4 to 10 -flowered, shorter than the leaves.

Hillsides and banks of streams. June, July. Per. Whole plant smooth, pale and somewhat glaucous. Stem 1 to 2 feet long, often erect. Leaflets 1 to $11 / 2$ inches long, $3 / 4$ as wide, larger than the stipules. Peduncles axillary. Flower 8 large, pale jeliow. Legume compressed, smooth.

\section{CULTIVATED EXOTTCS}

\section{L. xatrouros, Everlasting Pea.}

Leaflets 2, lanceolate; joints membraneous, winged; peduncles many-flowered. A very showy perennial plant; native of England. Stem 6 feet long, climbing, winged between the joints. F'lowers large, pink, clustered on a peduncle 6 to 10 tnches long.

6. L. odonatus, Sweet Pea. -

Ieaflets 2, ovate-oblong; peduncles 2-flowered; legume hirsute. A well known garden annual, native of Sicily. The flowers appear in June, are large weet conted, varigated with red, purple and white.

7. L. sАTivum, Chick Pea.

Ieaflets 2 to 4 ; peduncles 1-flowered; legume orate, compressed, with 2 wraged magins at the back. A common annual; native of $\mathrm{S}$. Wurope where it bee been nomotimes enlivated for food; but has proved to be aslow poison. 


\section{PISUM. Linn. PeA.}

Lat. pisum, pea.

CALXY segments leafy, the 2 upper shortest. BANNER large, reflexed. Stamens 9 and 1-diadelphous. Style compressed, carinate, villous on the upper side. Legume oblong, tumid, many-seeded. SEEDs globose, with an orbicular hilum.--Herbaceous climbing plants, with abruptly pinnate leaves, ending with branching tendrils.

\section{P. satifum, L. Common Garden Pea.}

Leaflets ovate, entire, usually 4 ; stipules ovate, semi-cordate at base, crenate; peduncles several-flowered. A valuable annual garden plant, cultivated from time immemorial, so that its native country is unknown. Whole plant smooth and claucous. Stem 2 to 5 feet long climbing by tendrils. Leaflets 2 to 3 inches long. $2 / 3$ as wide, obtuse, mucronate. Flowers 2 or more, on axillary peduncles, large, white.

\section{CICER. Tourn. Chick Pea.}

The Latin name for a species of vetch; applied to this genus.

Calyx 5-parted, the 4 upper segments incumbent on the rexillum; tube more or less gibbons at base on the upper side. LEgUme turgid, 2-seeded. SEeds gibbous, mucronate.-A cultivated annual, with odd-pinnate leaves, and white solitary or axillary flower's.

\section{C. Ametixum, I. Coffee Pea. Chick Pea.}

Leaves odd-pinnate; leaflets cuneate-oborate, serrate; stipules lanceolate, $\mathrm{kub}$ \&enticulate; calyx slightly gibbous. Cultivated in gardens; the seeds are said to afford a tolerable substitute for coffee. Stem 9 to 18 inches high, branching. Leaftets in 4 to 6 pairs, $1 / 2$ inch long, $1 / 4$ wide, with a terminal odd one. Flowers white. Legume nerly 1 inch long. Seeds gibbous, in form much resembling ram' hesd.

\section{FABA. Tourn. WINDSOR BeAn.}

The Latin name for a bean; appropriated to this genus.

Calyx tubular, 5-cleft, 2 upper segments shorter. Styla bent at a right angle with the ovary. Stigma villose. LE. GUME large, coriaceous, somewhat tumid. SEeDs oblong with a terminal hilum. - Herbaceous plants, apparently without tendrils, and simple, erect, axillary racemes of fiowers.

1. F. Volganis, Monch. Horse Bean.

Ieaflets 2 to 4, oval, mucronate; stipules semi-sagittate, obliquely orate. Native of Esypt. Cultivated in gardens. Stem rigidly erect, with axillary, many-flowered noemes, 1 to 2 feet high. Flowers whito, with a large black spot on eaeh wing logume torulose. 
Tribe 2. PHASEOLEA. The Bean Tribe.

Twining or trailing plants, with odd-pinnate leaves of 3-several leaflets, mottly stipellate, destitute of tendrils; flowers often in racemes.

6. PHASEOLUS. Linn. KIDNEY BEAN.

CALYX companulate, 5-cleft or 5-toothed, the 2 upper teeth more or less united. KEEL of the COROLLA with the included stamens and style spirally coiled or incurred. LEGUME linear or falcate more or less compressed, many-seeded, tipped with the hardened base of the style-Herbaceous twining or trailing plants, with stipellate pinnately trifoliate leaves, and 7notty or compressed racemes of flowers.

\section{P. Perennis, Walt. Wild Bean-vine.}

stem twining, pubescent; leoflets ovate, short-acuminate, 3-nerved; racemes olitary or somewhat clustered, simple or-in pairs, axillary, longer than the leares; legume pendulous.

Dry woods; common. July. Per. Stem 4 to 10 feet long, scmemhat branching. Leaflets $1 \frac{1}{2}$ to $3 \frac{1}{2}$ inches long, $2 / 3$ as wide, terminal one often sub-cordate. Raceme 6 to 12 inches long, loosa. "Filcwers numerous, purple and riolet, handsome. Legume abont 2 inches long, $1 / 2$ inches wide scythe-shaped, broad, mucronato. Seeds dark-purple.

\section{P. Diversifolius, Pers. Lobed Bean-vine.}

Leaflets broad-orate, angular, 2 to 3-lobed, some of them oblong-ovate and entire; peduncles angled, longer than the leares; flowers in heads; legume broadly linear, rouud.

Sandy fields and woods. Aug. Annual. Stem 2 to 6 feet long: Leaflets 1 to 2 inches long, $3 / 4$ as wide, with scattered hairs beneath, sonetimcs more or less 3-lobed. Peduncles 4 to 6 inches long, 2 to 3-flowercd. Flowers purple. Legume 5 to 7 -seeded, black when ripe.

3. P. Helvolus, L. Long-stalked Bean-vine.

Stem slender, hairy, twining, diffuse, or prostrate; leaflets ovate or oblong, entire; stipules lanceolate; petuncles 3 to 6 times the length of the beans; flowcrs few, in heads; legume narrow-linear, cylindric, $\delta$ to 10 -secded, slightly pubescent.

Sandy fields. July-Sept. Fer. Stem 3 to 5 feet long. Laaflets 1 to 2 inches long, $1 / 4$ to 1 inch wide. Yeduneles 4 to 8 inches long, 4 to 7 -flowered. Calyx with 2 lance-oblong nerved bracts at base. Corclla purplish; rexillum large, roundish. Legumes 2 to 3 inches long, very narrow, subfalcate. seeds woolly.

\section{OULTIVATED EXOTIC SPECTES.}

\section{P, volgaris, L. Pole Bean. Kidney Bean.}

Stem twining; leaflets ovate acuminate; raceme solitary, shorter than the leares: pedicels in pairs; calyx as short as its 2 bracts at base; legume pendulous. Seeds reniform. Annual. Natire of the East Indies. Universally cultivated in gardcrs for table use. Flowers mostly white.

\section{P. nunatus, L. Lima Bean.}

Stem twining; leaflcts ovate, deltoid, acute; raceme shorter than the leave: peduncles in pairs; caly $x$ longer than its 2 bracts at base; legume short, skordBhapcd or lunate; seeds large, much compressed, purplish-white. Annual. Native of the East Indies. Stem 6 to 8 feet long. Flowers small, white. Valued in. eultivation. 
6. P. multiflonus, I. Scarlet Pole Bcan.

Stem twining; leaflets ovate, acute; raceme solitary, as long as the leaves; caly longer than the 2 appressed bracts at base; legume pendulous; seeds kidney-shaped. Annual. Naive of S. America. Flowers scarlet, numerous, and very brilliant.

7. P. Nanus, L. Bush Bean.

Stem smcoth, very branching, erect; leaflets broad-ovate, acute; caly $x$ shorter than its 2 bracts at base; legume pendulous, compressed, rugose. Annual. Native of India. Stem 1 foot high. Flowers white. Seeds white, small. Much cultivated.

\section{APIOS. Borh. GROUnd-Nut.}

Gr. apios, a pear; in allusion to the form of its tuberous roots.

CaLyx companulate, obscurely 2-lipped; the upper lip of 2 short rounded teeth. STANDARD very broad, with a longitudinal fold in the centre, reflexed. KeEL long, falcate, and with the stamens and style at length spirally twisted. LEGUME straight or slightly curved, rounded, many-seeded.A perennial twining herb, with pleasant tasted tubers on underground shcots, pinnately 5 to 7 foliate leaves and dense, short, often branching racemes of flowers on knotty peduncles.

\section{A. Tuberosa, Mœnch. Ground-nut.}

Stem twining; leaflets 5 to 7 , ovate-lanceolate; raceme shorter than the leaves.

Low ground, thickets and shady woods. July, August. Root producing oval tubers about $1 / 2$ inch in diameter, very nutritious. Flowers in short oval racemes, purple and briwn, fragrant.

\section{Gallactia. P. Brown. Milk Pea.}

Gr. gala, milk; in allusion to the juice of some of the species.

CaLyx 4-cleft, equal, the upper lobe broadest. KeEr scarcely incurved. Standard incumbent, broad. Legumes compressed, linear, many-seeded.-Low mostly prostrate or twining perennials, with pinnately trifoliate stipellate leaves, and axillary racemes of flowers.

\section{G. Glabella, Michx. Smooth Mitk Pea.}

Stem nearly smooth, prostrate, somewhat twining; leaflets elliptical or ovate oblong, obtuse or notched, sometimes slightly hairy beneath; racemes axillary, simple, few-flcwered, on peduncles as long as the leaves; calyx smooth; legume pubescent.

Sandy woods. July, Aug. Root fusiform. Stem 2 to 4 feet long. Leaflets 1 to $1 \frac{1}{2}$ inches long by $1 / 2$ to 1 inch wide, varying in form from elliptic through oblong to ovate. Flcwers rather large, reddish-purple, greenish externally.

\section{G. Moluis, Michx. Soft Milk Pea.}

Stem twining, softly villous; leaflets ovate-oblong, obtuse, nearly smooth abovo, coftly villose and whitish beneath; racemes longer than the leaves, pedunculate; ealy $x$ acuminate villous, legume compressed, villous. 
Dry soils, pine barrens, \&c.; Southern part of the State. July, Aug. Steme prostrate or climbing. Leaflets about 1 inch long, $2 / 3$ as wide. Flowe:"s about half as long as in the last.

\section{CENTROSEMA. DC.}

Gr. kentron, a spur, and sema, the standard.

Calyx tubular, 5-toothed; the teeth much shorter than the tube. STANDARD very large, with a spur-shape 1 projection on the back, notched at the top. KEEL small, shorter than the wings, incurved, acute, on long claws. Style dilated at the apex, longitudinally bearded. LEGUME linearoblong, flat, pointed with the awl-shaped style, manyseeded.-Twining perennials, with pinnately 3 to 5-foliate leaves, and large showy flowers.

\section{C. Virginiana, Benth. Spurred Butterfy Pia.}

Rather roughish with minute hairs; stem twining; leaflets varying fiom oblong* ovate to linear, very veiny, shining; peduncles 1 to 4 -flowered; caly $x$ a'out as long os the lenceolate bracts, teeth linear-awl-shaped; legume linear, compressed.

Sandy dry soils. July. Stipules, bracts, and bractlets striate, the latter longer than the calyx. Flowers large, purple, 1 to 2 inches long. Pods straicht and narrow, 4 to 5 inches long, thickened at the edges, the valves marked with a lino on each side next the margin.

\section{AMPHICARPA. Ell.}

Gr. amphi, around, karpos, fruit; in reference to the ovary at base, sheathed.

CaLYX tubular, companulate, 4 (rarely 5) tooth $2 d$ with nearly equal segments, with no bractlets. KeeL and wingpetals similar, nearly straight, the standard partly folded round them. STIGMa capitate. Ovary on a sheath ${ }^{2}$ stipe. LEGUME of the upper flowers flat, 2 to 4-seedel.-Low slender twining perennials, with pinnately trifolia'e leaves, and 2 kinds of flowers, the upper ones perfect bus seldom ripening fruit; lower ones apetalous and fruitful.

\section{A. MonorcA. Nutt. Hog Pea-nut.}

Stem hairy; leaflets ovate, acute, smooth; raceme of the stem with nodding, pendulous petaliferous (generafly barren) flowers; bracts shorter than the pedicels; alyx teeth short and broad.

Rich woodlands. July-Sept. A delicate slender herb, with pale-purplish of whitish flowers. Legume of the stem smootish, with 3 to 4 dark-pu:plo seeds. Radisal legumes hairy, often very numerous, obovate or pear-shapsd, fleshy, repining usually but one large seed.

\section{WISTARIA. Nutt.}

In memory of Casper Wistar, M. D., President of Am. Philo. Soc.

CalyX bilabiate, upper lip emarginate, the lower one with 
sub-equal teeth. VexiluUm with 2 hard bunches ascending the claw and separating above. WINGS and KEEL sickle-shaped, the former adhering at top. LEGUME uneven or swelling. SEEDs numerous, kidney-shaped.-Twining shrubby plants, with pinnate leaves, and large racemes of blue-colored flowers with large colored bracts.

1. W. Frutescens, DC. American Wistaria.

Stem pubescent, when young, at length smooth; leaflets 9 to 13, orate or ellipt1eal-lanceolato, acute, slightly pubescent; wings with 2 auricles at base; ovaries smooth.

Rich alluvial soils: Western parts of the State. April, May. An ornamental vigorous vine, 6 to $10^{\prime}$ fect long, climbing over bushes, \&c. Leaflets 1 to 2 inches long, $1 / 2$ to 1 inch wide. Flowers numerous, on racemes 4 to 8 inches long, lilac. Bracts very conspicuous, sheathing the racemes. Seeds spotted.

2. W. consequana, Benth. Chinese Wistarta.

Stem of rapid growth, 12 to 15 feet long. Leaflets 0 to 13, orate-lanceolate, silkypubsscent. Flowers numerous, loose, in long terminal nodding racemes, clustered. $\triangle$ snlendid flowering rine from China. May, June.

\section{TrIbe 3. HEDYSAREZE. The Saintfoin Tribe.}

Stamens monodelphous or diadelphous. Legume (a loment) separating transversely into 2-sevcral 1-seeded indehiscent joints, or rarely reduced to 1 such joint.

12. ReSCHYNOMENE. Linn. Sensitive Joint Vetch.

Gr. aischunomene, to be modest or ashamed; alluding to its sensitive properties.

CaLyx 2-lipped, the upper lip 2-cleft, the lower 3-cleft. VEXILLUM roundish. KEEL PETALS boat-shaped, distinct at base. Stamens diadelphous, in 2 sets, 5 in each set. LeGUME exserted, flattened, composed of several square easily seperable 1 -seeded joints. - Lueaves odd pinnate, sametimes sensitive, as if shrinking from the touch.

IE. HIspIDA, Willd. Sensiiive Eschynomene.

Rough, bristly ; stem erect; leafets very smooth and numerous, 20 to 25 pairs, lin ear, obtuse; stip. ovate, acuminate; racemes 3 to 5 -flowered; arillary loment $\mathrm{ccm}$ pressed, 6 to 10 jointed.

Along rivers and in marshas. Aug. Stem 2 to 3 feet high. Leaflets about $3 / 4$-inch long. Racemes usually bearing a leaf. Flowers ycllow, tinged with red externally. Legume 2 inches long, stalked, 6 to 10 -jointed.

\section{HEDYSARUM. DC.}

CALYX 5-cleft, segments- linear-subulate, nearly equal. Standard large. Keel obliquely truncate. Wings much shorter than the keel. Stamens diadelphous (9 and 1). LEGUME with many joints; joints compressed, roundish 1 seeded.-Mostly herbaceous plants with odd pinnate leaves, not stipellate. 


\section{H. BOREALE, Nutt. Northern Hedysarum.}

Ieaves nearly sessile; leaflets 8 to 12 pairs, oblong smoothish; stiputes sheathing, subulate; racemes on long peduncles; legumes with smooth roundish joints.

Mountains. June, July. Per. Stem 10 to 20 inches high, rather stout, very leafy. Leaflets $1 / 2$ to $3 / 4$ inehes long, $1 / 4$ to $1 / 3$ wide, obtuse, mucronate. Racemes 2 to 4 inches long, on rigid peduncles 3 to 5 inches long. Flowers large and handsome, violet-purple, numerous.

\section{DESMODIUM. DC.}

Gr. demos, a ehain; from the appearance of the jointed pods.

Caryx mostly 2-lipped, upper lip 2-parted, lower one 3-parted. STANDARD roundish. KEEL obtuse, not truncate, shorter than the wings. Stamens diadelphous (9 and 1), or monadelphous, below the middle. LEGUME flattened, composed of several square easily separable joints.-Herbaceous perennial plants, with pinnately-trifoliate leaves, stipellate; and flowers in axillary or terminal racemes, often panicled, purple, or purplish, often turning green in drying; loments mostly hoary with minute-toothed hairs by which they adhere to the fleece of animals or to clothing.

s Stem ereet or ascending; Stamens all connected: calyx toothed or entire: raceme terminal panicled, or the pedicels of ten clustered: legumes long-stallced.

1. D. Nudiflonum, DC. Naked-flowered Tick-Trefoit.

Leaftets roundish-ovate, acuminate; scape radical, smooih, panicled; joint of the legume, obtusely triangular.

Dry open woods; common. Aug. Stem 8 to 10 inches high, remarkably distinguished by having its leaves and flowers on separate stalks, often distart fiom each other. Lenflets ternate, 3 to 4 inches long, 1 to 2 or 3 inches wille, whitish. Scape 1 to 3 feet long, slender, smooth, leafless. Flowers purple.

2. D. acuminatum, DC. Pointed-leaved Desmodium.

Ieaves all crowded at the summit of the stem, on very long petioles; leafrets round-ovate, acuminate; paniele tcrminal, on a very long peduncle; joints of the legume 2 to 3 , semi-oval, pubescent.

Shady woods. July, Aug. Whole plant slightly hairy. Stem about 1 foot high, ending in a slender panicle 1 to 2 feet long. Leaflets 3 inches in dirmeter, terminal one orbicular, ovate, 4 to 5 inches long. Flowers pale-purple or flesh-color.

3. D. Paudiflorum, DC. Few-flowered Desmodium.

Ieaves scattered along the low ascending stems; lateral leaflets obliquely-ovate, the terminal one dilated, rhomboid-ovate, all sub-acuminate and pubescent-ciliate; raceme few flowered, terminal; legume stipitate.

Woods; rare. Aug. Stem 6 to 9 inches high, decumbent or sub-erect. Petioles 2 to 3 inches long. Leaflets 1 to 3 inches long, 3/4 as wide. Flowers 2 to 6 , white or reddish white, in a loose slender raceme. Legume with 2 to 3 semi-oval pubés. cent joints slightly connected.

- Stems prostrate; legumes short stalked, of 3 to 5 joints.

4. D. HUMifusum, Beck. Running Desmodium.

Smooth; stem procumbent; leaflets ovate or ovai; stipules ovate-lanceolate; pacemes axillary and terminal, elongated; joints of the legume suthwhmhnif. 
Woods, rare. Aug. Stem 2 to 3 feet long. Leaflets sub-acute. Flowers rurplo: Resembles the next.

\section{D. Rotundifolium, DC. Round-leaved Desmodium.}

HIairy all over; leaflets orbicular; stipules broad-oval, acuminate, reflexed; racemes axillary and terminal; legume with 3 to 5 rhomboid-oval hisped joints.

Dry rocky woods. Aug. Stem extensively träiling, ussually very hairy, 2 to fect long. Leaflets pale beneath, 1 to 2 inches in diameter, on hairy stalks. F lcwers fow; purple.

** * Stems (tall) erect; legumes of 4 to 7 inequitateral joints which are longer than broad; flowers large.

6. D. Canadense, DC. Canadian Desmodium.

Stem hairy, striate; leaflets oblong-lanceolate, much longer than the petioles; nearly smooth above; stipules lanceolate, acuminate, large; racemes dense, erect, in a terminal panicle; joints of the legume 3 to 4, ovate, triangular, hisped.

Dry woods. July. Stem 3 to 6 feet high, often branched. Petioles very short, $1 / 4$ to $1 / 2$ inch long. Leaflets 2 to 3 inches long, broadest at base, pointed, nearly Bmooth. Flowers pale violet or blue. Racemes with conspicuous bracts.

\section{D. canescens, DC. Hoary Desmodium.}

Stem branching, striate, hairy and scabrous; leaflets ovate, bluntish, about tho length of the petioleg, scabrous, pubescent on both sides; stipules large, broadlyovate, persistent; flower's in a loose terminal panicle; legume with 4 or 5 unequally rhomboidal reticulated strongly hisped joints.

Moist grounds. Aug. An upright branching plant 3 to 5 feet high with very long panicles of flowers, greenish externally, purple within. Leafiets 2 to 4 inches long. Branches clothed with minute and hooked glutinous hairs, and the fine partly hooked pubescence of the leaves eause them to adhere to cloth.

8. D. cuspidatum, T. \& Gr. Sharp-pointed Desmodium.

Very smooth; stem erect; leaflets ovate or lance-ovate, very acute, or acuminate; sipules obliquely lanceolate; bracts large, lance-ovate, acuminate; panicle terminal, "elengated, rather slender; joints of the legume rhomboid-oblong.

Along streams, thickets and shady places; common. July, Aug. Stem rather timple, 3 to 5 feet high. Leaflets 2 to 5 inches long, widest at base, smooth, entire, green on both sides. Bracts and stipules $3 / 4$ inch long. Flower's large, purple. Legumes about 6-jointed.

**: * Stem erect; racemes panicled; stipules and bracts small and inconspicuous.

9. D. Vinidiflorum, Beck. Green-flowered Desmodium.

Stem very downy, rough at the summit; leaflets broadly-ovate, obtuse, scabrous on the upper surface, villous and very soft beneath; panicle terminal, very long; naked; Tegume with 3 to 4 roundish triangular hisped joints.

Wools and thickets; frequent. Aug. Stem 3 to 4 feet high, rigid, branched, very scabrous towards the summit. Leaftets 2 to 3 inches long, 1 to $21 / 2$ inches wide. Flowers purplish, turning blue-green in withering. Legume 1 to 2 inches long.

10. D. Drulenir, Darl. Dillenius' Desmodium.

Stem pubcscent, branching; leaflets oblong or ovate-oblong, pale beneath, softly and finely pubescent; stipules subulate; racemes slender, forming a loose terminal panicle; legume with 3 to 4 rhomboid reticulated hisped joints.

Open woodlands; common. Aug. A variable species 2 to 3 feet high. Zeaflets 2 to 3 inches long, obtuse, sometimes acute. Flowers purple, changing to bluishgreen.

11. D. Paniculatum, DC. Panicled Desmodium.

Necrly smooth; stcm slender, ercet; leafiets oblong-lanceolate, rather obtuge, 
smoothish; stipules subulate; panicle terminal; legumes with 3 to 4 rhomboidal joints.

Woods; common. July, Aug. Stem 2 to 3 feet high, slender, often branching. Zeaflets 3 to 5 inches long, 2 to $31 / 2$ wide. Flowers purple, numerous, in a paniculate raceme. Legumes large; joints pubescent.

\section{D. RIGIDUM, DC, Rigid Desmodium.}

Stem branching, somewhat hoarg; leaftets ovate-oblong, rather obtuse; terminal onc s the longest, reticulated-reiny, rather rough above, hairy beneath; racemes paniculate, erect, very long; legumes with 2 to 3 half-round or oval hisped joints.

Dry woods and hillsides. Aug. Stem 2 to 3 feet high, often with numerous, long, erect, rigid branches. Leaflets 1 to 3 inches long, $1 / 2$ as wide, rather leathery reticulately veined. Flowers small, purple.

\section{D. CIllare, DC. Fringed Desmodium.}

Sten slender, haịry, or rough pubescent; leaves crowded on very short hairy petioles; leaflets small, round-orate or oval, obtuse, thickish, more or less hairy on the margins and underneath; stipules subulate-lincar; racenaes paniculate, terminal.

Dry hills and sandy fields; common. Aug. Stem about 2 feet high. Leaflets $1 / 2$ to 1 inch long, $1 / 4$ to $3 / 4$ wide. Flowers violet-purple. Legumes of 2 to 3 sem:orbicular bispid joints.

\section{D. Mariluandioun, Booth. Smooth-leaved Des'm.}

Nearly smooth throughout; siem erect, simple, slender; leaflets orate or roundish, rery obtuse, often sub-cordate, thin; petiole as long as the lateral leaflets, smooth; panicle elongated; legume with 2 to 3 hisped semi-orbicular joints.

Fields and woods; common. July, Aug. Stem 2 to 3 feet high, nearly smooth. Ieaflets about $3 / \frac{1}{1}$ inch long. Flowers small, violet-purple, in a terminal crect panicle.

\section{LESPEDZA. MicLx,}

In honor of Lespedez, a Spanish Governor of Florida.

CALYX 5-cleft, segments nearly equal, slender. STAMENS diadelphous (9 and 1 ); anthers all alike. LeGUnE of a single 1-seeded joint, oval or roundisis, flat, reticulate, not opening, 1-seeded.-Perennials with pinnately trifoliate leaves, minute stipules and bracts, and often polygamous flowers.

* Flowers of 2 kinds, perfect, and apetalous, thie latter chiefly bear'ing the forwit; corolla violet or purple, much longer than the calyx.

\section{I. Procumbens, Michx, Procumbent Lespedeza.}

Stems procumbent, slender, with the branches assurgent, all oxer pubescent; leaves on long petioles; leaflets oval or elliptical, obtuse, mucronate peduncles slender, mostly simple, few flowered; legume orbicular orate, pubescent.

Sandy soil. Aug., Sept. Stems several from the same root, 2 to 3 feet long. Teares consisting of 3 oblong or roundish leaflets on hairy stalks. Flowers purple, in short raceme-like heads, axillary; the lower ones apetalous, on short poduncles, the upper ones on long filiform peduncles.

2. L. violaces, Pers. Violet-flowered Lespedeza.

Stems upright or spreading, somewhat pubescent; leaves on long petioles; leaflest elliptic or oval-oblong, obtuse or emarginate, somewhat hairy; racemes sub-umbel late, axillary, about as long as the leares, lower ones with apetalous flowers; 
flowers in pairs, distinctly pedicellate; legume rhomboidal, retieulate and smooth, much longer than the calyx.

Dry woods. July. Stems clustered, slender, 8 to 14 inches long. Apetalous flowers few, perfect ones seldom producing fruit. Leaflets $1 / 2$ to 1 inch long, $1 / 3$ to $2 / 3$ inch wide. Petioles $3 / 4$ to $11 / 2$ inches long. Flowers violet-colored, small.

Var. b. divergens, (L. divergens of Pursh). Pedicels filiform, divergent, much longer than the leaves; flowers in loose panicles mostly unfruitful; legume reticulate; leaflets oval or oblong.

Var. c. sessitiflora. (L. sessitiflora of Nutt.) Leaves on short petioles; fascicles of flowers subsessile, on peduncle much shorter than the leaves.

Var. A. ungustifolio. (L. ungustifolio, Raf. L. reticulata. Pers.) Leaves crowded; teaflets narrowly oblong or linear, often silky; flowers clustered on straight branches. I have followed Torrey and Gray in giving the above only as varieties of $\mathrm{L}$. violacere.

* Stems upright; Flowers all alike and perfect, in spikes or heads.

3. L. capitata, Michx. Shrubby or Capitate Lespedeza.

Stem erect, sub-simple, villose; leaflets elliptic-ovate, pubescent beneath; common petioles very short; spikes eapitate, ovoid, on short axillary peduncles; legumos elliptic ovate, pubescent much shorter than the calyx.

Dry sandy soil. July, Aug. Stem 2 to 4 feet high, rigid, straight, woolly. Leaves numerous, on short petioles. Leaflets 1 to $11 / 2$ by $1 / 4$ to $1 / 2$ inches, nearly smooth above. Flowers in oblong or sub-globose heads, white or very pale yellow.-Vв. angustifolia slender; leaflets linear; peduncles sometimes elongated.

\section{L. HIRTA, Ell. Hairy Lespedeza.}

Stem branched, very villose; leavbs on very short slender petioles; leaflets round, oval, obtuse, hairy; spites oblong-cylindric; peduncles longer than the leaves, axillary.

Dry hilly woodlands; frequent. Aug., Sept. Stem 2 to 4 feet high, very hairy. Leaflets $2 / 3$ to $1 \frac{1}{2}$ inches long, $1 / 2$ to 1 inch wide. Legume compressed, elliptic-0vate, very hairy, nearly as long as the calyx segments.

\section{L. NuttaliII, Darl. Nuttall's Lespedeza.}

Stem hairy, somewhat branched; leaflets ovate and obovate, villose beneath; racemes somewhat spiked, pedunculate, longer than the Ieaves; legrome lance-ovate, acuminate, very pubescent, rather longer than the calyz.

Dry hills; frequent. Aug., Sept. Stem 2 to 3 feet high, striate. Leaflets $1 / 2$ to $11 / 4$ inches long, $1 / 3$ inch wide. Flowers rather crowded in somewhat spiked peduncled racemes, mostly longer than the leares, purple with tinges of violet.

\section{STYLOSANTHES. Swarts.}

Gr. stulos, a column, and anthos, a flower; the flowers appearing stipitate.

Tube of the CALYx very long, slender; limb 2-lipped, upper 2, the lower 3-cleft. ConoLla inserted in the throat of the ealyx. Stamens monodelphous; 5 of the anthers linear, the 5 alternate ones ovate. FerTILE FLOWERS with a hooked style. LEGUMe reticulated with 1 to 2 joints, the lower joint when pressed empty and stalk-like, the upper ovate, 1-(2)-seeded.-Low perennials, with pinnately 3-foliate leaves; the stipules united with the petioles, and 2 linds of flowers intermixed in the clusters; one kind complets but unfruitful, the other fertile and consisting only of a pistil between 2 bractlets. 


\section{S. ELATion, Swarts. Pencil Flower.}

Stem erect, herbaceous, somewhat branched above, often several frem the root; beaflets lanceolate, strongly straight-veined, smooth, acute; upper stipules sheathin:; spikes few flowered.

Sandy woods and pine barrens. July-Sept. Stems 6 to 12 inches long, wiry, often bristly. Leaflets $3 / 4$ to $11 / 4$ inches long, $1 / 8$ to $1 / 3$ wide. Bracts lanceolate, hisped ciliate. Floucers yellow, in terminal compact heads. Legume 2 -jointed, the lower joint sterile and stipitate, 1-seeded, hooked at the summit.

\section{Tribe 4. I.OTE E. The Melilot Tribe.}

Stamens monodsiphous or diadelphous (9 and 1); Legume continous 1-celled, or 2-celled? lengthwise. Not twining, climbing, nor bearing tendrils.

17. Astragalus. Linn. Milk Veteh.

Calyx 5-toothed or cleft. Conolla with the keel obtuse: Stamens diadelphous. Legume 2-celled by the introflection of the lower suture.-Herbaceons or suffinticose plants, with odd-pinnate leaves, and spiked or racemed flowers.

\section{A. Canadensis, L. Canadian Mitle Vetch.}

Tall and erect; stem downy; leaflets 10 to 14 pairs with odd one elliptic-oblone, rather obtuse, smoothish; stiputes broad-lanceolate, acuminate; peduncies about as long as the leaves; flowers in oblong spikes; legume ovate-oblong, erect, smooth, 2-celled, many-seeded.

Banks of streams. June-Aug. Per. Stem 1 to 3 fcet high, buchy, very leafy. Ieaflets usuaily smooth above, slightly pubescent beneath. Flowcrs palc-yellow, in spikes 1 to 4 inches long. Legume $1 / 2$ inch long, leathery.

\section{ROBINIA. Linn. Locust.}

In honor of John apd Vespasian Robin, French botanists.

Calyx short, 5-toothed, teeth lanceolate, 2 upper ones approximate. Vexiluum large. Keel obtuse. Stranexs diadelphous (9 and 1). Style bearded. Legume compressed, elongated, margined on the seed-bearing edge.Trees or shruls with stipular prickly spines, unequally pinnate Leaves, and showy axillary racemes of flowers.

\section{R. Pseudacacia. Locust Tree.}

Leafiets 8 to 12 pairs ovate and oblong; siipules prickly; racemes pendulous, Joose, slender; legumes smooth.

A handsome tree, native in our mountainous regions, much cultivated for its invaluable timber. May. Flowers white, fragrant, in racemes 3 to 6 inches long.

\section{3. viscosa, Vent. Clammy Locust.}

Branchlets, \&c., clammy; leaflets ovate; stipular spines very short.

A handsome tree cultivated like the last; native of the Southern Alleghenieg where it attains the height of 40 feet. Flowers numerous, crowded, rose-colored in erect, crowded axillary racemes.

3. R. HISPIDA, L. Rose Acacia.

Slarab reostly hispid; stipular spines scarcely any; racemes boose, sub-ewect. A 
beautiful shrub 4 to 8 feet high, native of the Southern States, cultivated in gasdens. F'lowers deep rose color or red.

\section{TEPHROSIA. Pers.}

Gr. tephros, ash-colored or hoary, in allusion to the color of the foliage.

CaLYX about equally 5-cleft. Standard large, roundish, pubescent, reflexed-spreading, scarcely longer than the coherent wings and keel. Stamens monodelphous or nearly diadelphous. LEGUMEs linear, flat, several-seeded.-Silky Toary perennial herbs (except in the tropics), with odd-pin. nate leaves, and white or purplish racemed flowers.

\section{T. Virginiana, Pers. Goat's Rue. Hoary Pea.}

Stem erect; leaflets 7 to 14 pairs, oval or linear-oblong, mucronate, white, villous Weneath; raceme terminal ; legume falcate, villous. '

Sandy soils and gravelly hills; common. June, July. Ront long and tough. Stems simple, usually several or many from one root. Leaftets 1 inch long, 1 ; wide, odd one obcordate. Stipules subulate, $1 / 3$ inch long, persistent. Bracteoles deciduous. Calyx very villous. Flowers large, in a dense terminal raceme. Bar-. ner white, with a tinge of yellow on the upper side. Keel rose-colored. Wings red.

\section{AMORPHA. Linn. FALSE Indigo.}

Gr. $a$, privative, morpha, shape; alluding to the deficiencies of the corolla.

CalyX inversely conical, 5-toothed, persistent. Stan-. DARD concave, erect; the other petals entirely wanting! STAMEN 10, exserted, monodelphous at base, otherwise distinet. STYLE filiform, straight, smooth. LEGUMES oblong, longer than the calyx, somewhat curved at the point, 1 to 2-seeded.-Shrubs, with odd-pinnate punctate leaves, and bluish or violet-colored flowers, crowded in clustered terminal. spikes.

\section{A. Fruticosa, L. Common False Indigo.}

Rather pubescent; stem shrubby or arborescent; leaflets 8 to 12 pairs, oval, scattered, the lower pair remote from the stem; calyx-teeth obtuse, 4 of them. acuminate, pubescent; legume few-seeded.

Southern part of the State. July. A tall shrub 6 to 16 feet high. Leares 3 to 5 inches long. Leaflets about 1 inch, by $1 / 2$, rather remote from each other. Racemes spicate, terminal, solitary or fascicled, 3 to 4 inches long. Standard purple, emar. ginate.

\section{TRIFOLIUM. Linn. Clover-Treforl.}

Lat. tres, three; and folium, a leaf.

CaLyX persistent, tubular, 5-cleft, the teeth bristle-form. Petals more or less united below. Standard longer than the wings, which are mostly longer than the keel. STAMENs. 
diadelphous (9 to 1). ILEGUME small, scarcely dehiscent, often ovate, 1 to 6 -seeded, covered by and scarcely longer than theacalyx. SEEDs roundish.-Tufted or diffuse herbs, with palmately trifoliate leaves, with straight, scarcely reticulated veins, and flowers chiefly in dense heads or spilies.

* Flowers sessile in compact heads; corolla purple or purplish, deciduous or with. ering.

\section{T. Pratzinse, L. Red Clover.}

Stems sub-erect, branched; leaves on long petioles, oral, entire, often notched at the end, and marked with a pale spot; heads of flowers ovate, dense, nearly sessile; teeth of the calyx setaceous, the lowest longer than the rest.

Meadows and fields; largely cultirated, and naturalized. May-Oct. Per. Nems 1 to 2 feet high. Flmeers united into a tube at base, rose-colored, fragrant. Seeda yollowish. Native of Europe.

\section{T. Pennsyluanicum, Willd.}

Stcm ascending, much branched, flexuous, leaflets ovate.clliptic, obtuse, rery entire; stipules awned; heads of fowers ovate-cylindric, solitary, dense; lower teetb. of the calyx shorter than the corolla.

Wools. June-Sept. Por. Flowers fine red. Resembles T. medium of Lin. næus. Introduced. Beck's Bot. I suspect this to be merely a variety of T. prutense.

\section{T. ARVense, L. Rablit-foot Clover. Stone Clover.}

Stem branching; leaflets oborate-linear or narrowly wedge-form, minutely 3-toothed at the apex; stipules oval acuminate; spities oblong-cylindric, very villous; calyx-teeth longer than the corolla plumose, voolly.

Old fields and roadsides; common; naturalized. May-Sept. Annual. Stem 6 to 12 inches high, much branched round, hairy. Leaves hairy, in short petioles. Leaflets narrow, $1 / 2$ to 1 inch long. Heads $1 / 2$ to $1 \frac{1}{2}$ inches long becoming greyish and very softly woolly. Flowers minute white or pink.

* Corolla white or yellow; flowers in umbel-like round heads on a naked peduncle.

4. T. RePens, L. White Clover.

Smooth, the slender stem spreading and creeping; leaflets inversely heart-shaped, somewhat retuse, serrulate, mucronate; stipules scale-like narrow; petioles and especially the peduncles, rery long: heads small and loose; flowers fedicelled.

Pastures, waste places, and roodlands; common. May-Oct. Per. Stem 6 to 10 inches high, rooting at the joints several from the same root. Peduncles angular much longer than the leares. Flowers white, rarely purplish. Legumb 4-seeded.

\section{T. PROCUMBens, L. Hop Clover.}

Stems mostly procumbent, spreading, pubescent; leaflets wedge-ovate, notohed at the end, denticulate, the lower pair at a small distance from the other; stipules lance-orate, ciliate, shorter than the petioles; peduncles equal to or longer than the leares; heads axillary, oval.

Dry fields; maturalized. May-Aug. Annual. Stems 3 to 6 inches long, many from the same root. Leaves on short petioles. Heals about 2-flowercd, small on clender peduncles $1 / 2$ to $1 \frac{1}{2}$ inches long. Flovers yellow. Legume 1-seeded.

\section{T. agrarium, L. Golden Clover. Hop Trefoil.}

Stem ascending, with erect branches; leaves nearly sessile; leaflets oblong-ovato or wedge-shaped, dentieulate, all from the same point nearly scssile; stipules narrow, cohering with the petiole for more than half its length; heads on rather long peduncles. 
Sandy fields; naturalized. June-Aug. Annual. Stem 6 to 15 inches long, branched, minutely pukescent. Common petiole $1 / 4$ to 1 inch long. Leaflets $1 / 2$ to 1 inch long, narrow. Heads of Flowers twice as large as in the last, on peduncles $1 / 3$ to $1 \frac{1}{2}$ inches long. Flowers small, pale yellow, brown when old.

\section{MELILOTUS. Tourn. MeLilot.}

Gr. meti, honey, and lotus, the genus, so called.

Fuowers much as in clover, but in spiked racemes, small. Corolla deciduous. Legume coriaceous, ovoid, wrinkled, longer than the calyx, 1 or few-celled.-Herbs fragrant in drying, with pinnately trifoliate leaves and racemose flowers.

1. M orficinauis, Willd. Yellow Melilot. Sweet Clover.

Upright; leaflets obovate, obtuse, remotely serrate; spities axillary, paniculate; regume 2-seedec', rugose; style filiform, as long as the legume.

Fields and waste places; introduced. Aug. Annual. Plant 2 to 4 fect high, branched. Flcwers yellow, in long racemes. Native of Europe.

\section{M. Leucanthe, Koch. White Melilot.}

Upright, branched; leaflets ovate-oblong, truncate, mucronate at the apex, ro motely serrate; standard longer than the keel and wings; legume 1 to 2-seeded, ovate, green.

Scarcely naturalized; common in cultivation. July, Aug. Stem 3 to 5 feet high. Flowers white, on longer and less crowded racemes than the last.

\section{MEDICAGO. Linn.}

('r. medika; because it was introduced into Greece by the Medes.

FLowers nearly as in Melilotus. LeGume many-seeded, varying in form, always falcate or twisted into a spiral.Herbs with palmately trifoliate leaves and more or less spiral legumes, often resembling snail shells.

1. M. Lupulina, L. None-such. Black Medick.

stem procumbent; leaflets wedge-ovate, toothed at the apex; stipules lanceolate, cute, somewhat entire; flowers in capitate spikes; legume reniform, 1-seecied.

Haste places; naturalized. June-Aug. Stem 6 to 12 inches high. Flowers small, yellow, crowded. Legume black when ripe, short, compressed, curved or kidney-shaped, 1-celled, 1-seeded.

2. M. SATIVA, L. Lucerne.

Frect, smooth; leaflets ovate-oblong, toothed above, mucronate flowers in oblong racemes; legume spirally twisted.

Fields and waste places, scarcely naturalized. Sometimes cultivated for green fodder. June, July. Per. Stem 1 to 2 feet high. F'lowers purple.

\section{M. scutellata, L. Snail.}

Pedicels 2-flowered. Legume unarmed, cochleate, orbicular, convex at the base, fat above with concentric folds. Native of South Europe. Cultivated for the ceriosity of its pods, which much resemble snail shells. July. Annual.

M. INTERTEXTA a native of Europe, naturalized in some parts of the U. S. with yellow flowers and spirally legumes like the last is sometimes cultivated in ous gardẹn. 


\section{CROTALARIA. Linn. Rattle-Box.}

Gr. crotalon, a rattle; the seeds becoming loose in the ripe pods.

CALYX 5-cleft, somewhat 2-lipped. STandaRd large, cordate. Keel falcate, acuminate. Frlaments all united with the sheath often cleft above. LEGUME inflated, oblong, many-seeded.-Herbs or shrubs, with often simple leaves, ard racemed yellow flowers.

C. Sagitalis, L. Arrow-leaved Rattle-box.

Hairy ; stem erect, branched; leaves simple, oblong-lanceolate, searcely petioled; stiputes united and decurrent on the stem, inversely arrow-shaped; peduncles fortflowered; corolla as long as the calyx.

Sandy soils. July, August. Ann. Stem 4 to 10 inches high, with spreading branches. Leaves alternate, hairy on both sides, rounded at the base. Flowcr: yellow. Seeds few, rattling in the turgid pods.

\section{LUPINUS. Tourn. LUPiNE.}

Iat. lupus, a wolf, because these plants were thought to devour the fertility of the soil.

CaLYX deeply 2-lipped. Sides of the standard reflexed: KEEL scythe-shaped, pointed. SHEATH of the MONADELPHOU: STAMENS entire; anthers alternately oblong and globose. LEGUMES coriaceous, oblong, flattened, often torulose.Herbs with palmately 5-15-foliate leaves and showy flowers in terminal racemes or spikes.

\section{L. Perennis. L. Wild Lupine.}

Somewhat hairy; stem erect; leaflets 7-11, narrowly obovate-oblong, mucronato; fiowers alternate, in a long and loose terminal racerne; calyx without appendage apper lip emarginate, lower entire; legume linear-oblong, very hairy.

Sandy woods and hills; common. May, June. Per. A beautiful plant, soms times cultivated in gardens. Stem a foot high, soft, smoothish. Leaves soft, downy, on long stalks. Flowers purplish blue, varying to white. It is often called Sun-dial, from the circumstance of its leaves turning to face the sun from morning till night.

Several handsome species are sometimes cultivate 1 in gardens, among. which is L. polyphyllus, from Oregon, a splendid plant 3-5 feet high, with racemes of white purple or yellow flowers more than a foot long. L. Foothatensis, from Nootka Sound, a handsome species 2-3 feet high, flowers purple. L. arboreus, a magnifir cent exotic shrub, 6 feet high, with large yellow flowers.

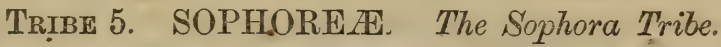

Stamens distinct : Corolla truly papitionaceous.

26. BAPTISIA. Vent. FAlse Indigo.

Gr. bapto, to dye; in allusion to the coloring properties of some of the species

Calyx 4 to 5-toothed bilabiate. Petals 5, nearly equal. Standard with the sides reflexed. Wings oblong. KeEL slightly incurved. Stamens deeiduous. LEGUME stalked 
in the persistent calyx, roundish or oblong, inflated, pointed, several seeded.-Perennial herbs, with palmately 3-foliate (rarely simple) leaves, which generally blacken in drying, and racemed flowers,

\section{B. tinctoria, R. Brown. Wild Indigo.}

Smooth; stem branching; leares palmately 3 -foliate, almost sessile; leaflets rounded wedge-obovate, acute at base, very obtuse, sometimes margined at apex; stipules setaceous; racemes few-flowered terminating the numerous branches.

Sandy woods and gravelly hills ; common. Aug. Piant 2 to 3 feet high, bushy, slender. Leaves bluish-green. Flowers yellow, 6 to 12 or more on each raceme. Corolla $1 / 2$ inch long. Legume about as large as a pea, on a long stipe, mostly 1-seeded.

2. B. australits, Brown. Blue-flowered False Indigo.

Smooth, tall and stout; leaves ternate on short petioles, the upper ones nearly Eessile; leaflets oblong-wedge-form, obtuse; stipules lance-linear as long the petioles, zather persistent; raceme elongated, many-flowered, erect.

Banks of streams. Near Easton, Pa. Becl. Sometimes cultivated. June, July, Siem 2 to 3 feet high, branched. Leaflets $13 / 4$ to 3 inches long, $3 / 4$ to 1 inch wide, sometimes acute. Stipules $1 / 2$ to 1 inch long. Racemes 2 to 3 inches long, oraloblong, on a stipe about as long as the calyx.

\section{CERCIS. Linn. RED-Bud. JudAs-TREe.}

Gr. Tcerkis, a weaver's shuttle; alluding to the form of the legume,

Calyx 5-toothed, gibbous at base. Petals 5, with claws aub-papilionaceous, all distinct. WINGs larger than the standard. Stamens 10, distinct, rather unequal. Legume oblong, flat, many-seeded, the upper suture with a winged margin.-Trees with simmple rounded heart-shaped leaves, deciduous stipules, and rose-colored flowers in little umbel-litie clusters along the branches, appearing before the leaves.

\section{C. Canadensis, L. Red-lud.}

Leaves roundish-cordate, asuminate, villous in the axils of the nerves; legume on short foot-stalks.

Banks of streams, Southern part of the State. March-May. A handsome treo 20 to 30 feet high, often cultivated. Leares 3 to 4 inches by 4 to 5 entire smooth 7 -veined, on petioles 1 to 2 inches long. Flowers appearing before the leaves, asually in abundance, in small lateral clusters. Corolla bright purple. Legume about 3 inches long, acute at each end.

\section{SUB-ORDER II. CAESALPINE $\not E$.}

\section{TrIBE 6. CASSIEA. The Senna Tribe.}

stamens distinct, some of t7.em often imperfect: corolla open, irregular or almost regular.

28. CASSIA. Linn. Senna.

Sepals 5, scarcely united. Petalis 5, unequal. Sta. 
MENs 5 to 10, free, unequal, spreading, 3 lower ones longest; 4 middle ones short and straight; 3 upper ones usually abortive. Anthers opening at the apes. Legume terete or compressed, many-seeded.- Trees, shrubs or herbs (herbs in the United States) with simply abrupt-pinnate leaves and mostly yellow flowers.

\section{- 1. C. Marilandica, L. Wild Senña.}

Stem crect; lcafe's 6 to 9 pairs, ovate-oblong, mucronate, equal; petioie with a club-shaped gland near the base; stipules deciduous; flowers crowded in short axillary racemes, panicled at the summit of the branches.

Alluvial soils, along streams; common. July, Aur. Per. Stem 3 to 4 feet high, smooth or slightly pubescent. Leafleis 1 to 2 inches long, $1 / 3$ to $3 / 4$ wide. liacemes in the upper axils, forming a leafy panicle. Peials brirht-yollow, 3 erect and 2 declined. Legume compressed, linear, hisped, at length smooth. Medicinal.

\section{C. Chдmacrista, L. Partridge Pea.}

stem erect or decumbent; leaftets in 10 to 15 pairs, linear-oblong, oblique at base, obtuse, mucronate; gland on the petiole cup-shaped; flowers on slender redicels, fascicled above the axils of the leaves.

Sandy places. June-Aug. Annual. Stem a font or more high, spreading, round, pubescent. Leaflets crowded, $1 / 3$ to $2 / 3$ inch long, smooth, sub-sessile. Flowers large, 2, 3 or 4 in cach fascicle. Petrils bright-yellow, the 2 upper ones with a purple spot. Stamens 10 , elongated, unequal, 4 of them yellow, the others purple.

\section{C. nictitans, L. Wild Sensitive Plant.}

Stem erect or decumbent, branched; laffets 10 to 20 pairs, oblong-linear, obtuse, mucronate; gland on the petiole cup-shaped, on a slender foot-stalk; racemes lateral above the axils of the leaves, short, few-flowered; stamens 5, nearly equal; style very short; legume pubescent.

Sandy banks of streams. June-Aug. Ann. Stem 8 to 12 inches high, slender, a little branching. Lraflets crowded, $1 / 3$ to $1 / 2$ inch long. Flowers very small, paleyellow, on short pedicels. The leares are somewhat sensitive like the Mimosa, closing by night and when touched.

\section{GLEDITSCHIA. Linn. Honey Locust.}

In honor of Gleditsch, a German botanist of the last century.

Flowers polygamous. CaLYX of $3-5$ spreading sepals, united at the base. Petals as many as the sepals, and equaling them, the 2 lower somewhat united. STAMens $4-5$, distinct, inserted with the petals on the base of the calyx. Legume flat 1-many-seeded. Seeds oval, flat.-Trees, with supra-axillary branched spines abruptly once on twice-pinnate leaves and inconspicuous green flowers.

\section{G. triacanthes. L. Honey Locust.}

Thorns stout, usually triple or compound; leaflets lanceolate-oblong or linearbblong, somewhat serrate; legume much elongated, compressed flat, often twisted, many-seeded.

Rich woods; cultivated. July. A handsome tree $30-50$ feet high, with spines on its branches $2-3$ inches long. Foliage bright and elegant. Leaflets about 18, 
1-11\% inches long, $1 / 3$ as wide, geveral of them usually transformed partly or wholly into smaller leaflets. Flowers small, white, succeeded by flat, crooked, hanging pods, 12-18 inches long, which appear in autumn like large apple-parings pendant from the branches.

The Granocladus Canadensis, Kentucley Coffee-tree, is occasionally met with in caltivation, but is probably not native in our State.

\section{ORDER 39. ROSAGTM, The Rose Family.}

Trees, shrubs or herbs with alternate leaves with stipu'es; regular flowers with numo rous (rarely few) distinct stamens, inserted on the calyx, and 1-many pistits. SHPALS 5, (rarely 3-1-8) united at the base, often appearing double by a row of bractlets outside. Petals 5, regular, rarely wanting, inserted with the stamens on the edge of a disk that lines the calyx tube. OVARiEs superior, 1 or several, distinct, 1-celled often cohering to the sides of the calyx and each other. STrues distinct or united. Fresit a drupe, pome, acheuia, or follicle. This important family comprises three prinoipal sub-orders.

\section{SUb-ORDER I. AMYGDALEAE. ALmond FAMILY.}

CALYX entirely free from the solitary ovary, deciduous. STYLE terminal. Fruit a drupe (stone fruit.) - Trees or shrubs, with simple leaves, the bark exuding gum, and the bark, leaves and kernels yielding the peculiar flavor of prussic acid.

\section{PRUNUS. Tourn. Plum.}

Carty 5-cleft, regular, deciduous. Petals 5 spreading. Stamens 15--30. Ovary with 2 pendulous ovules. Drupe oval or oblong, fleshy, smooth, usually covered with a glaucous bloom; the stone smooth, sharp-edged and pointed, and the margins mostly grooved.- Small trees or shrubs with serrate leaves, rolled up in the bud, and white flowers, usually preceding the leaves from lateral buds, the pedicels in simple umbel-like clusters.

1. P. Americana. Marsh. Wild Yellow Plum. Red Plum.

Leaves ovate or obovate, acuminate, sharply and often doubly serrate, very veiny, smooth when mature; wbels $2-5$ flowered, drupe roundish-oval, nearly destitute of bloom.

River banks, and along hedges; common. Florvers in May. Fruit in Aug. A small tree 10-15 feet high, much branched and thorny. Leaves $2-3$ inches long, $2 / 3$ as wide. Petioles $1 / 4-1 / 2$ inch long, mostly with 2 glands near the summit. Flowers white, preceding the leaves. Fruit $3 / 4-1$ inch in diameter, yellow or orange often tinged with red, with a yellow pulp and thick, tough skin, pleasant tasted.

2. P. spinosa, L. Sloe. Black Thorn.

Branches thorny; leaves obovate-elliptical, downy beneath, sharply doubly-toothed; geduncles solitary; calys companulate; drupe globose.

Hedgerows and cultivated grounds. Introduced. A thorny shrub 12 to 15 feet Bigh, native of Europe. Sparingly naturalized. 


\section{P. Domestica, L. Common Garden Plum.}

Branches unarmed; leaves oval-lanceolate, acute; pedicels nearly solitary; drupe globose, oval, ovoid and obovoid. This long cultivated tree or shrub is said to be a native of Italy. It rarely exceeds 15 feet in height. Fruit black, varying through many colors to white, covered with a rich glauoous bloom, ripe in Aug. Varietiez very numerous.

\section{P. Chicasa, Michx, Chickasaw Plum.}

Branches spinose; leaves oblong-lanceolate, glandular serrulate, acute, nearly smooth; umbels 2 to 3 -flowered; pedicels short, smooth; drupe globose. A fine fruit-shrub, native of Arkansas, often cultivated. Height 8 to 12 feet. Leaves 1 to 2 inches long, $1 / 2$ as wide. Flowers small, white, expanding with the leaves. Fruit red or yellowish-red, tender and succulent, ripe in July.

\section{ARMENIACA, a genus very closely resembling Prunus.}

A. vulasris. Common Apricot. A tree 10 to 15 feet high, from Armenia. Flowers white, preceding the leaves. Fruit 1 to 2 inches in diameter, purplish-yellow. Cultivated.

A. DASCYCARPA. Black Apricot. A tree about the size of the last, from Siberia. Flowers white, preceding the leaves. Fruit dark-purple, when mature.

\section{CERASUS. Tourn., Juss. Cherry.}

Cerasus, a town in Pontus from where the garden cherry was first brought.

Flowers, \&c., as in Prunus. Drupe globular, without a bloom; the stone almost globular, smooth.-Trees or shrubs with the leaves folded in the bud, and white flowers in umbels or racemes.

* Flowers in racemes at the end of leafy branches.

1. C. Virginiana, DC. Choke Cherry. Wild Cherry.

Leaves broad, oval or obovate, abruptly acuminate, often sub-cordate, sharply (often doubly) serrate with slender teeth, thin, smoothish; peitoles with 2 to 4 glands; racemes short and close, erect or spreading; petals obovate; fruit subglobose.

River banks and woods; common. F!. May. Fr. Aug. A tall overhanging shrub or small tree, with greyish bark. Leaves 2 to 3 inches long, $1 / 2$ as wide, with a short abrupt acumination. Flowers white. Fruit (cherries) abundant, of a dark red color, very austere and astringent to the taste.

\section{C. serotina, DC. Wild Black Cherry.}

Leaves oval-oblong or lance-oblong, acuminate, smcoth and shining above, finely serrate, bearded along the midrib beneath; petiole mostly with 2 or more glands; racemes elongated; petals obovate; drupe globose.

Woods; common. Fl. May, June. Fr. Aug., Sept. A fine large tree, 50 to 80 feet high of uniform size and undivided to the height of 20 to 30 feet, 2 to 4 feet in diameter. Bark of the trunk black and rough, that of the branches reddishbrown. Leaves 3 to 5 inches long, $1 / 2$ as wide, with 1 to 2 pairs of reddish glands at base. Flowers white, in long racemes or clusters, which are at length pendulous. Fruit nearly black when mature, slightly bitter. The wood is close-grained and very valuable for cabinet work.

* Flowers sub-umbellate or solitary.

\section{C. Pennsyluanica, DC. Bird Cherry.}

Leaves oval or oblong-lanceolate, acuminate, finely and sharply serrate, shining, green and smooth on both sides, mostly with 2 glands at the base; flowers mang in a cluster, on long pedicels; fruit globose. 
Rocky woods and thickets، Fl. May. Fr. Aug. A small tree 20 to 30 feet high, with light red-brown bark. Leaves 2 to 5 inches long, $1 / 2$ as wide. Flowers white, on slender pedicels $2 \frac{1}{2}$ inches long, collected into a sort of umbel. Fruit small, red, thin, and sour flesh.

\section{C. PUnula, Michz. Dwarf Cherry. Sand Cherry.}

Smcoth, depressed and trailing; leaves obovate-lanceolate, acute or obtuse, serralate, smooth, glaucous beneath; umbels sessile, few-flowereu; drupe ovoid.

Gravelly soils. May. A small trailing shrub, with ascending branches 1 to 2 feet high. Flowers white, 3 to 5 in each umbel; pedicels smooth, 1 inch long. Fruit small, dark-red, acid, agreeable to the taste.

\section{OULTIVATED EXOTIC SPECIES.}

\section{C. vulgakis, Mill. Red or Sour Cherry.}

Eranches spreading; leaves ovate, lanceolate or obovate, acute at apex, mostly narrowed at base, smoothish; umbels sub-sessile; fowers rather preceding the leares; fruit globose; pedicels rather short. A tree 12 to 20 feet high, with a roundish compact head. Flowers white, 2 to 3 from each bud appearing in April. Fruit large, various shades of red and brown, acid or sub-acid $1 / 2$ to $2 / 3$ inch in diametcr. There are about 50 varieties of this species cultirated in the United States.

6. C. Avium, Moench. English Cherry. Black Cherry. Sweet Cherry. Bleeding-heart. Ox-heart. Duke Cherry.

Branckes erect or ascending; leaves oblong or obovate, acuminate, doubly and rather coarsely serrate-dentate, smooth above, pilose beneath; umbets sessile; jloner's searcely preceding the leaves; fruit roundish-ovoid, or sub-cordate at base; pediceis drooping. A common cultivated tree 20 to 50 feet high with an oblong or ryramidal head. Leaves 3 to 6 inches long, $1 / 2$ as wide, on petioles 1 to 2 inches long, cften with 2 glands. Flowers white. Fruit various shades of red, black or mottled, firm and fleshy, generally sweet. Varieties numerous.

\section{Persica. Tourn. Peach. Nectarine.}

Named from Persia its native country.

Calyx 5-cleft, tubular, deciduous. Petals 5. Drupe fleshy, tomentose or smooth. STONE somewhat compressed, orate, acute, rugosely furrowed and perforated on the surface.-Small trees. Leaves conduplicate in æestivation.

\section{P. vulgaris, Mill. Common Peach.}

Leaves lanceolate, serrate, with all the serratures acute; flowers solitary, subsessile, preceding the leaves; drupe tomentose. A common cultivated tree or shrub $S$ to 15 feet high. Leaves 3 to 5 inches long, $1 / 3$ as wide, smooth; petioles s.hort with 1 or 2 glanis. Flowers rose-color. Fruit large, 1 to $2 \frac{1}{2}$ inches in diameter, yellowish, tinged with purple, densely tomentose. Numerous varietien of this delicious fruit are now cultivated in the United States.

\section{P. LAWIS. Nectarine.}

A trec closely resembling the peach in form, foliage and flowers. The fruit it 2 to 3inches in diameter, smooth, yellow, purple, red, de. Native of Persia. 


\section{AMYGDALUS. Willd. ALmond.}

Specific character as in Persica, except the fruit, which is not fleshy; compressed. Stone perforate and furrowed, ovate, compressed, one edge acute, the other broad, obtuse.

\section{A. communis, Willd. Common Almond.}

Leaves lanceolate, serrate, with the lower scrratures glandular; flovers in pairs, sessile, appearing before the leaves. Native of Barbary. Scarcely cultivated in this country, 10 to 20 feet high.

\section{A. PUMILA, Dwarf double-floweriny Almond.}

Leaves lanceolate, doubly-serrate; flowers in pedicels. A low branching shrub, 2 to 3 feet high. Native of China. Highly ornamental, common in cultivation. Flowers very double, pale rose-color, very numerous, clothing the whole shrub in their roseate hue while the leaves are yet small. May, June.

\section{SUB-ORDER II. ROSACEA PROPER.}

Calyx free from the ovaries, but sometimes enclosing them in its tube. Pistrus few to many, (sometimes single); fruit achenia or follicular:

\section{TrIBe 1. SPIRAEAE. The Meadow-sweet Tive.}

\section{SPIRAA. Linn. MEADOW-SWEET.}

Calyx 5-cleft, persistent. Petals 5, roundish, equal. Stamens 10 to 50 exserted. Carpels 3 to 12, distinct, rarely united at base, follicular, sessile, rarely stiped. SEeps 2 to 15.-Unarmed perennial simmbs or herbs, with alternate leaves and branches, and white or rose-colored flowers; rarely dicecious; never yellow.

* Shrubby; leaves lobed and tooticed.

1. S. opulifolta, L. Nine-bark.

Nearly smooth; leaves roundish, somewhat 3-lobed and cordate, doubly-toothed and crenate, petioled; corymb umbel-like; pedicols filiform; carpels 3 to 5 , at length spreading.

Rocky river banks and along streams; common. June. A shrub 4 to 10 feet high, much branched. Leaves 1 to $2 \frac{1}{2}$ inghes long, nearly as wide, sometimer eordate at base with 3 obtuse lobes above. Corymbs resembling simple-umbels, hemispherical, 1 to 2 inches in diameter. Flowers white, often tinged with purilo. Follicles diverging smooth, purplish, 2-seeded.

* Shrubby; leaves entire or toothed. SPIREA PROPER.

2. S. Corymbosa, Raf. Meadow-sweet.

Nearly smooth; leaves oval or ovate, on short petioles, whitish beneath, ineisely serrate towards the apex; corymbs large and flat, sereral times compound, termi-
nsl; carpels 3 to 5-seeded. 
Alleghenies; rare. June. Stem 1 to 2 feet high, slightly pubescent, reddish. Teaves 2 to 3 inches long, $3 / 4$ to $11 / 4$ wide, nearly smooth above, entire towards the base. Flowers very numerous, white or rose-colored, in a corymb 4 to 6 inches broad.

3. S. SALICIFolio, L. Meadow-sweet.

Nearly smooth; leaves wedge-lanceolate, simply or doubly serrate; racemes in dense terminal-compound panicles; carpels 5, distinct, smooth.

Meadows along streams; common. June, July. A small bushy shrub 2 to 5 feet high, with purple and brittle branches. Leaves varying in form, mostly acute, but sometimes obtuse, $1 \frac{1}{2}$ to 3 inches long, $1 / 3$ to $1 / 2$ inch wide. Flowers numerous, white, often tinged with red, small, with conspicuous stamens.

4. S. tomentosa, I. Hard-hack Steeple-bush.

Stem and peduncles reddish-tomentose; leaves ovate-lanceolate, unequally serrate, densely tomentose beneath; racemes terminal, compound, crowded; carpels 5, woolly.

Low grounds and meadows; common. July, Aug. A small shrub 2 to 3 feet high. Stems very hard, 3rittle. Leaves $11 / 2$ to 2 inches long, $1 / 2$ as wide, dark green above, rusty white beneath. Flowers very numerous, small, light-purple, with eonspicuous stamens forming handsome pyramidal clusters.

* * Herbaceous perennials.

5. S. Lobata, Murr. Queen of the Prairie.

Zeaves interruptedly pinnate, the terminal leaflets very large 7 to 9-parted, the lobes incised and toothed; lateral leaflets 3-lobed, the lobes all serrate, mostly incised or toothed; flowers in a compound clustered panicle; sepals reflexed.

Moist grounds. June, July. A beautiful herb 4 to 8 feet high. Stem angled. Flowers large, deep rose-color, numerous, and very delicate, in panicled compound clusters, on a long naked peduncle. Carpels 6 to 8, smooth.

\section{CULTIVATED EXOTIC SPECIES.}

\section{S. Ulmaria. Double Meadow-sweet.}

Zeaves 3 to 7 -foliate, with minute leaflets interposed; lateral leaflets ovate-lanceolate; terminal ones much larger, palmately 5 to 7 -lobed, all doubly serrate, and whitish tomentose beneath; stipules reniform, serrate; paniole corymbose, longpedunculate. Native of Europe; cultivated in gardens. Flowers numerous, white, mostly very double, appearing in July.

\section{S. Filapendula. Pride of the West.}

Zeaves int erruptedly pinnate; leaflets 9 to 12, pinnatifidly serrate, with many minute ones interposed; stipules large, semi-cordate, serrate; corymb on a long terminal peduncle. Native of Europe. A handsome delicate herb 1 to 3 feet high with white flowers $1 / 3$ to $1 / 2$ inch in diameter. Cultivated in gardens.

\section{GILLENIA. Mœnch.}

CALYX tubular, bell-shaped, constricted at the throat, 5cleft; TEETH erect. Petals 5, linear-lanceolate, somewhat unequal, elongated in the throat of the calyx. Stameng 10 to 20, mostly included. STYLES 5, filiform, terminal. Carpels 5, distinct, 2-valved, 2 to 4-seeded, included in the calyx.-Perennial herbs with almast sessile 3-foliate leaves, daubly serrate and incised, and pale rose-colored or white flowers in paniculate corymbs. 


\section{G. Trifontata, Monch. Indian Physic.}

Zeares ternate; reafets lanceolate or ovate-oblong, pointed irregularly cut-sersate; ctipules small, awl-shaped, entire.

Rich shady woods; common. June. A handsome plant 2 to 3 feet high, slender and nearly smooth. Lower leaves petiolate; lsaflets 2 to 4 inches long, $1 / 3$ as wide, pubescent beneath, sub-sessile. F'lovers axillary and terminal, few, neariy white. Medieinal.

\section{Stipulacea, Nutt. American Ipecac.}

Radical leaves pinratifid; those of the stem alternate; leaflets rerrate, deeply incised; stipules large and leaflike, doubly incised and clasping.

Testern part of the State. June. Stem 2 to 3 feet high, branching. Readily distinguished from the former by the large clasping stipules. Slowers fer, sose: colored. Medicinal.

\section{TRIBE 2. DRYADEA. The Bramble Tribe.}

Pistile mostly numerous, forming seed-like achenia or little drupes in frurt.

\section{AGRIMONIA. Tourn. Agrimony.}

Carra 5-cleft; tube top-shaped, contracted at the throat, armed with hooked bristles above, indurated and enclosing the fruit; limb 5-cleft, closed after flowering. Petaxs 5. Stamens 12 to 15 , inserted with the petals upon the calyz. Achonia 2, invested by the hardened calyz. STrues terminal.-Perennial herbs, with interruptedly pinnate leaves and yellow flowers in slender-spiked racemes; bracts 3-cleft.

\section{A. Eupatoria, L. Common Agrimony.}

Stem and stalks hairy; leaflets oblong-ovate, crenate dentate, the terminal one petioled; spike long and slender, terminal, many-10wered; petals twice the length of the ealyx; fruit distant, top-shaped, hisped, smooth at base.

Bonders of woods and hedges; common. July - Sept. Stem 1 to 3 feet high, braxching, leafy. Leaflets $3-5-7$, with small ones interposed, nearly smooth. racemes 6 to 12 inches long, spicate. Flowers yellow, about $1 / 3$ inch in diameter on very short pedicels. Calyn tube fluted with 10 ribs, and surroundad with red. dish hookod bristles.

\section{A. PARVIFLora, Ait. Small-flovered Agrimony.}

Stem and stalks bristly with brownish spreading hairs. Leaflets numerous; linesr-lanceolate, invisely serrate, crowded, 11 to 19, with smaller ones intermixed; spikeslong and slender; petals small.

Woods and dry meadows. July, Aug, Stem 3 to 4 feet high. Ieaflets 2 to 3 inches by $1 / 4$ to $2 / 2$. Flowers pale yellow, numerous, in long slender racemes. Fruit roundish divaxicstely hispid.

\section{SaNGUisorba. Lind. Griat Bernet.}

Iat. sanguis, blood, sorbso, to absorb, the plants having been esteemed as vulnerarles.

Flowers perfect or rarely polygamous. CaLyX 4-cleft with 2 to 3 scales or bracts at base externally. Prexaxs aone. Stamens 4 , the filaments usually enlarged upwards T* 
opposite the cals segments. AcBENIUM dry, included in the hardened 4-wingod calyx-tube.-Pereninial (rarely annusl) herbs, with unequally pinnate leaves and small fowere in close spiked heads.

\section{S. Canadensis, L. Burnet Saxifiage.}

Swooth; leaves pinate; leqfets orato-oblong, sub-condato, serrate; spiles eglin. Arie, long; stamens longer then the corolla.

Wot meadows. Aug., Sept. Stew 2 to $\$$ feet bigh, smonth, atriate, enaringly branched. Stipules leafy, sorrate. Fhowers white, in crowded spikus, which are from 2 to 5 inches loug, torminating the long naked brascheo. Clsiyz greenisho white, rosombling a corolls.

\section{POTERIUM. Linn.}

Lat. poteriom, a drinking ressel.

Flowers monocious. CalyX-rUbe contracted at the mouth, 3-bracteate, limb 4-parted. Petals none. StaMEns 20 to 30. OVARIEs 2; style filiform. Achenta dry, included in the calys. - Herbs with unequally pinnate leaver.

\section{P. sanauisorba, L. Bumet.}

Smooth; stem unarmed, sngular; layfets 7 to 11, orate or soundish, deeply sor rate; spake or heads sub-globnse, the lower flowers stamiante. Per. Cerasioanlly eulisated, and at one timo held in high roputo for its supposed medieinal propurties.

\section{GEUM. Linn. AVENs.}

Gr. gevo, to give an agreesble odor; some of the roots being aromatie.

CaLYX bell-shaped or concave, deeply 5-cleft, usually with 5 small bractlets alternating with the segments. PeTals 5. Stamens numerous, inserted with the disk that lines the base of the calyx. ACHenra numerous, hooked on a conjeal or cylindric dry receptacle, the long persistent styles forming hairy or jointed tails.-Perennial herbs, with pinnate or lyrate leaves.

1. G. Viramianur, L. White Avens.

Stem rather hairy below; radical leaves pinnste, lyrate, or rarely simple and counded; those of the stem 3 to 5-lobed or divided, sll unequally and incisely dontsto, softly pubescent; stipules obovate, entire or ineised; petals wedgr-oborate soarcely as long as the calys.

Woods and mesdows; common. June, July. Stem simple or branched. Leates very rariable in form; lower oncs often 3-foliate, with appendaged petiolos 6 to 8 inchos long. Epper leaves sinple, acute, sessile. Flotoers rather small, white or pale yellow on peduncles 1 to 3 inches long terminating the branches, at first somewhat nodding at lepgth erect.

2. G. rivale, L. Water Avens. Purple Avens.

Pubescent; stem sub-simple; radieal kaves lyrate and interroptedy pinnate, 


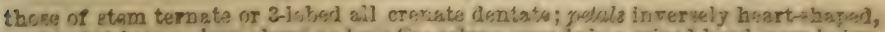

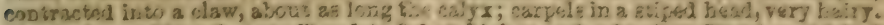

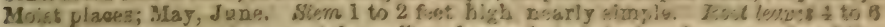

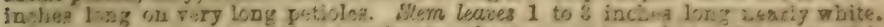

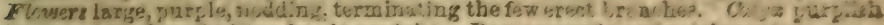

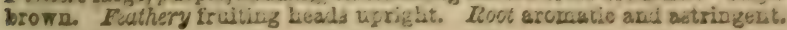

\section{WALDSTEINIA. Willd.}

In bonor of Francia von Wivistein, a derman botanict.

CaryX-tube inversely conical; the limb 5-cleft, with 5 alternate often minute and dociluous lractlets. Petals 5 to 10. Stamess many, incerted into the throat of the calyz. Strues 5 to 8, long, dociduous. Achrevia 2 to 6 , minutely hairy. SExD erect.-Lovs perensial herls, vith s to 5-lobed or divided, leaves and small yellowo forvers on Zracted scapes.

\section{W. FRAGABtordes, Traut. Dry Stravberry.}

Low; leafets 3 , broadly wedgroform, cruast ly cot, tcothed, ciliatc; acupes eeveral. comered iracted; petals lor ger than the caigz; cerpe?ts kaisy.

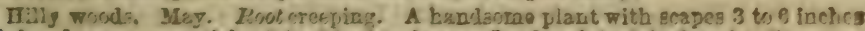

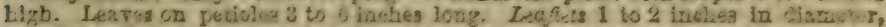

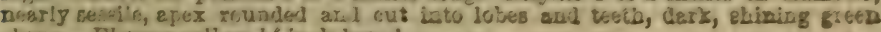
alove. Flowers yellow $1 / 3$ inch broad.

\section{DALIBARDA, Linn.}

In honor of Dalizard, a French botaniet of the last een'tury.

Caryx inferior deeply 5 to 6 parted, 3 of the divisions larger and toothed. Petals 5, sessile, deciduons. Stamers numerous. Struss 5 to 8, long deciduous. Acrienia fire, dry, adhering to the calyz. - Low perennials, with creeping and tufted stems, roundish heart-shapied leaves on slender petioles and 1 to 2 white flowers on scrape-lites peduncles.

\section{REPENs, L. False Violet.}

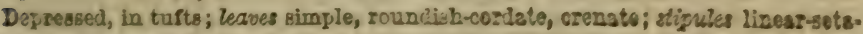
coous; calyz spreading in flowor, erect in fruit.

Biciat slachy places. Junc-Alag. Slem herbacenus, creqjing and roottng, 2 to 12

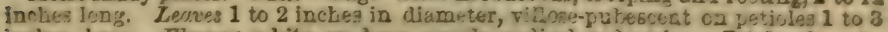
inchas long. Fleners white on long neariy ralical peduncies. Petals oborsto, louger than the sepala.

\section{RUBUS. Linn. Bramble.}

Coltic rub, red, the color of the fruit of some species.

Calyx 5-parted, spreading. Petals 5, deciduous. ETa. MENs numerous, inserted into the border of the stick. STYLE bearly terminal. Frerrm momnnaer of mann nnlne 
carpels aggregated on a spongy receptacle, persistent or deciduous. - Perennial half shrubby plants, with usually biennial stems armed with prickles, white (rarely reddish) flowers, and edible fruit.

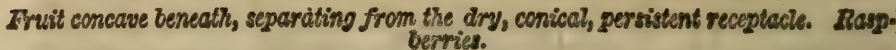

- Leaves simple ; flowers large reddish; priclites nome.

\section{R. ODORATUS, L. Rose-flowering Raspberry.}

Hisped with glandular hairs; stem erect, branehed; leaves Iarge 3 to 5 lowed, the lobes acute or acuminate, unequally serrate; peduneles many-Lowered, compound; calyx-lobes tipped with a narrow appendage as long as themselves; petals rounded.

Rocky places; common. June-Aug. Stem 4 feot high with the stalks, bran. ches and caly $x$ bristly with giandular clammy hairs. Zeaves 4 to 8 inches long, nearly as wide, cordate at base. Flowers large, purple, resembling s rose. Stamens vory numeroub, 1 to 200 , whitioh. Fruit broad snd flat, bright rod, swoot whop ripe.

- Leaves 3 to 7 -foliate.

2. R. TRIFLORUs, Rich. Droanf Raspberry.

Frems ascending or trailing; leaves ternate or pedato-guinate, on elender petioles; leaflets rhombic-ovate or lance-ovate, scute at both ends, coarsely doubly serrate, terminal ore petiolate, thin; peduncie torminal 1 to 3 flowered; sepals lancoolato.

Moist woods and hills. June. Stem flexuous, smooth, reddish. Ieafets 1 to 8 inches long, $1 / 2$ to 1 wide. Petioles 1 to 2 inches long. Petals white, rsther longer than the rellexed sepals. Frunit small, dark red, usually sour, ripe in August.

\section{R. STRIGosus, Michx. Wild Red Raspberry.}

Siem erect, shrubby, strongly hisped; leaves tesnate or quinste; leaflets oblong. orate, pointed, cut-serrate white tomentose benesth, the terminal one of ten mbcordate; peduncles 4 to 6 flowered.

Rocky places, common in mountsinous regions. May. Item reddish-brown, 2 to 3 feet high, covered with strong bristles. Leaflets $11 / 2$ to 2 inches long, $1 / 2$ to $\% / 389$ wide, terminal one distinctly petiolate. Nlovers white. Sepate spreading, nesrly ss lorg as the petals. Corolla cup-shspod. Fruit beraispherical, light red, rich flarored, ripe in June-Aug.

\section{R. OOCIDENTALIS, L. Black Raspberry.}

Shrubby, glaucous, srmed with recurved priskles; teaves pinnstely 3-soliste: leaflets ovate, pointed, coarsely doubly sorsate, whitened downy undorneath; flowere asillary and terminal.

Thickets and fields along fonces; common. May. Stem 4 to 8 feet long, sparing ly branched. Ledfiets 2 to 3 inches long, $1 / 2$ to $1 / 3$ as wide, on long round potioles: Irowers whito, 1 to 3 on axillaxy peduncles, in terminal leafy racomes. Druit coundish, nearly black, sweet, and well flavored, ripe in July.

\section{R. IDXUs, L. Garden Raspberry.}

Hisped or armed with recurved prickles; leaves pinnately 3 to 5 soliate; leafots broad-ovate or rhomboidal, pointed, unequally and ineisely serrate, hoary tomen. tose beneath, sessile; flowers in panicled corymbs. Stem shrubby, 3 to 5 feet high. Leaflets smoothish above, 2 to 4 inches long, $2 / 8$ as wide. Petals white, entire, shorter than the hoary tomentose calys. Frruit rod, amber color or white, ripe in Jume and July. Many varieties of this plant are cultivated for the delicious fruit.

BusozBnarims. Fruit inseparable from the juicy, deciduous recuptacle.

6. R. villosus, Ait. High Blackberry.

Prickly; stcm angular, and with the branches, peduncles and lower eusface of the 1. Tha *n 
ted, unequelly serrate, the terminal one somewhat cordate, conspicuously stalked : flowers in elongated terminal racemes; sepals acuminate, mouen shorter than the obovate spreading petals.

Var. frondosus, Torr. : smoother and mueh Iess glandular; flowers lower corymbose with leafy bracts.

Fields and borders of thickets; common. May, June. Stem erect or declined, 4 to 8 feet high. Flowers white, numerous. Fruit ovoid-oblong, $1 / 2$ to 1 inch long, purple or nearly black when ripe, sweet and well flavored. Aug., Sept.

\section{R. Canadensis, L. Low Blackberry. Dewberry.}

Stem procumbent or trailing, somewhat prickly; leaves ternate or pedately 5 to 7-parted; leaflets oval or lance-oval, mostly pointed, thin, nearly smooth, sharply and unequally cut serrate, the terminal on petioles and sub-cordate; flowers in racemes, with leaf-like bracts.

Sandy and gravelly fields; common. May, June. Stems ascending at base, trailing several yards on the ground. Flowers white, on slender pedicels. Petals twice as long as the calyx, obovate. Fruit $1 / 2$ to 1 inch in diameter, black, sweet and juicy, ripe July and Aug.

\section{R. HISPIDUs, L. Running Swamp Blackberry.}

Stems long, slender, somewhat shrubby, prostrate, beset with small prickles turned backwards; leaves ternate or pedate, 5-foliate; leaflets somewhat coriaceous, obovate, obtuse, coarsely serrate, entire towards the base, smoothish; flowers in corymbs or racemes, without bracts; sepals spreading, half as long as the petals.

Swamps and wet woods; common. May, June. Stem profusely trailing with Bhort erect branches. Leaflets 1 to 2 inches long, $1 / 2$ as wide, nearly sessile, persistent through the winter on the common petiole 1 to 3 inches long. Flowers white. Fruit composed of a few large blackish grains, red or purple.

\section{R. cunetrolius, Pursh. Sand Blackberry.}

Low shrubby armed with stout recurred prickles; leaves ternate and pedateiy s-foliate; leaflets wedge-form, obovate, thiekish, serrate towards the apex, pubescent tomentose beneath; peduncles 2 to 4 -flowered.

Sandy fields and woods. May, June. Stem 1 to 3 feet high. Petioles often prickly. Flowers white or roseate. Petals 3 times as long as the tomentose oblong mucronate sepals. Fruit black, juicy, well-flavored, ripe in July, Aug.

\section{R. TRIVIAlis, Mich. Low Bush Blackberry.}

Procumbent with many leafy and nearly erect branches, armed with numerous recurved prickles; leaves mostly ternate; leaflets ovate or oval, unequally serrate, more or less pilose; peduncles 1 to 3 -flowered.

Dry woods or rocky negleeted flelds. A pril, May. Stem 4 to 8 feet long, slender, often several from the same root running in different directions, smoothish, purple, and giving out numerous leafy flowering branches 2 to 6 inches long, nearly erect. Flowers terminal, white, rather large. Petals obovate, twice as long as the calyx. Fruit oblong or roundish, $1 / 2$ to 1 inch in diameter, very succulent and sweet, black when ripe. July.

\section{ROSA. Tourn. Rose.}

Celtic rhos, red; Gr. rodon,; Lat. rosa.

CALYX-TUBE urn-shaped, fleshy, contracted at the orifice; limb 5-parted, the segments often with a leafy appendage. Petals 5, inserted with the numerous stamens into the edge of the calyx-tube. Pistims numerous, nearly included, inserted over the whole inner surfuce of the disk. Ovaries 
many becoming bony achenia in fruit included in and fixed to the fleshy tube of the calyx.-Prickly shruls with oddpinnate leaves, stipules cohering with the petiole, and showy, mostly red and white fragrant flowers.

\section{NATIVE SPECIES.}

\section{R. Carolina, L. Swamp Rose.}

Pricles recurred, often wanting; leaflets 5 to 9 , elliptical, often acute, sharply Berrate, glaucous beneath, dull-green above; fiowers in corymbs, rarely solitary; bobes of the calyx very long, appendaged, spreading, with the panicles glandularbristly; fruit depressed-globose, somewhat bristly.

Swamps and low grounds; common. July-Sept. A handsome specics 3 to 8 feet high, erect and bushy, with retdish branches sometimes unarmed. Leuflets 1 to 2 inches long, $1 / 2$ as wiule, somewhat variable in form. Flowers 5 to 7 in terminal corymbs. Petuts large, crimson, inversely heart-shaped.

\section{R. LUCIDA, Ehr. Low Wild Rose.}

Armed with scattered unequal bristly prickles, mostly deciduous, the stouter persistent prickles nearly straight, slender; leaflets 5 to 9 , lance-elliptical shining above, sharply serrate; stipules dilated, long, smooth; peduncles somewhat hisped, 1 to 3-flowered; segments of the calyx entire appendaged, spreading but not reflexed; fruit globose-depressed, hispid or smooth.

Dry soil or borders of swamps; common. June, July. Shrub 1 to 3 feet high, slender, with greenish branches. Leaflets 1 to $11 / \%$ inches long, half as wide, acute or obtuse, odd one petiolate. Flower's rather large, pale red. Feials inversely boart-shaped. Fruit small, red, mostly smooth when mature.

3. R. BLANDA, Ait. Early Wild Rose.

Prickles few, straight, slender, deciduous; leaflets 5 to 7 , oval or oblong, obtuse, eerrate, pale and mostly pubescent beneath; stipules large; flower's 1 to 3 on short mooth peduncles.

Dry hills and rccks; common. May, June. Stems 2 to 3 feet hich with reddish bark, prickly near the base. Bracts large, downy. Flewers rather large, rosecolor. Petals olcorlate, longer than the sopals. Fruit globose, rud, crowned with tho persistent erect and connivent calyx lobes.

\section{NATURALIZED SPECIES.}

4. R. Rubiginosa, Ait. Sweet Brier. Eglantine.

Stem smooth, armed with numerous very strong recurved prickles; leaflets 5 to 7, ovate or somewhat rounded with rusty glands beneath; doubly serrate; flowers mostly solitary; fruit ovoid or obovate, and with the peduncles hisped.

Hedges and roafsides; common. June, July. A stout prickly shrub 4 to 10 feet high. Leaflets $1 / \mathrm{s}$ to 1 inch long, $2 / 3$ as wide, acute. bright green above, rusty beneath, and when i ubbed over, fragrant. Flowers solitary or 2 or 3 together. F ale red, fragrant. Fruit orange-red, crowned with the persistent calyx lobes. Faristies in cultivation about 25 , single and double.

\section{OULTIFATED EXOTIC SPECIES.}

\section{R. Gallica, L. Common French Rose.}

This is the common red rose of gardens. Stem and petioles armed with numerous ine scattered prickles. Leaflets mostly 5, elliptical or broad oval, thick flowers erect, large; sepals ovate. Fruit ovoid, and with the peduncles bisped. Numerons 
varieties are known in cultivation, among which are the velvet, carmine, carnation, \&c.
6.
R. PIMPinelififolia, Ser.
Scotch or Burnet Rose.

A shrub 2 to 3 feet high with the stems densely covered with straight needle shaped prickles. Leaflets 5 to 9 , small, roundish, obtuse, smooth, simple serrate. F'lowers small, numerous, globular, usually roseate, but changing in the numerous varieties to white, red or yellow. Native of Scotland.

7. R. Eglanteria, S. Austratian Eglantine. Yellow Rose.

A bushy shrub about 3 feet high, with ash-colored stems and red branches, both armed with straight, slender, scattered prickles. Leaflets 5 to 7 , small, broagd, oval or obovate, smooth, shining above, sharply serrate. Flowers numerous, golden yellow, of very short duration. Tarieties numerous, both single and double, - variegated with red.

\section{R. Damasoena, L. Damask Ros?}

A fine species 3 to 4 feet high, branching, bushy stems, armed with unequal sp:n:s, mostly stipular or hooked. Leaflets large, broadly elliptical, white downy beneath. Sepals reflexed. Flowers rather numerous, of a delicate pale roseate hue, usually with numerous petals and a delicious fragrance. Among its numerous varieties is the common monthly rose. Native of the Levant.

\section{R. Centifolia. Hundred-leaved Rose. Provens Rose.}

A shrub 2 to 4 feet high. Stems covered with numerous neariy straight pricklea. Leaflets 5 to 7, ovate glandular ciliate on the margin, sub-pilose beneath. Sepals spreading in flawer. Flowers usually of a pink color, but varying in hue, form and size in the numerous varieties. Native of S. Europe.

10. R. ALBA. White Garden Rose.

A fine shrub 5 to 8 feet high, with slightly glaucous stems, armed with slender recurved prickles, sometimes none. Leaflets roundish ovate, shortly pointed. Sepals pinnatifid. Petals spreading. Flovoers large corymbose, sweetsscented, generally pure white, sometimes tinged with blush. Native of Germany.

11. R. MUltiflora. Japan Rose.

A free growing shrub with long shoots easily trained to the height of 15 to 20 feet armed with slender] scattered prickles. Leaflets 5 to 7 , ovate-lanceolate, soft and slightly rugose. Flowers corymbose, often numerous. Sepals short. Styles exserted. Petals white, varying through roseate to purple. Native of Japan.

\section{R. Indica. Chinese Monthly or Bengal Rose.}

An erect or climbing shrub, with purplish stems, armed with strong, remoto prickles. Leaflets 3 to 5, acuminate, 'thickish, shining, smooth, serrulate. Flowers solitary or paniculate, in the numereus varieties every hue from pure white to crimson, blooming from April to November.

13. R. setigera, Michx. Michigan Rose. Prairie Rose.

Branches long, ascending, smooth, spines few, strong, stipular; leaflets large, 3 to 5 , ovate, serrate, pubescent beneath; stipules narrow, pointed; flowers corymbose, calyx glandular, segments sub-entire; styles united; frut globose.

This splendid species is a native of Michigan and other Western States. Stems hardy and of rapid growth, capable of being trained 12 to 20 feet. F'lou'ers in very large clusters, changeable in hue, nearly scentless, and of short duration. About 20 varieties are cultivated. 


\section{Sub-order III. POME $\nexists$. The Apple Family.}

Trees or shrubs with alternate simple or compound leaves.

\section{CRATAEGUS. Linn. HAwTHORNS.}

Gr. kratos, strength; in allusion to the hardness of the wood.

Calyx-tube urn-shaped, limb 5-cleft. Petals 5, roundish. Stamens many or only 10 to 15 . Strues 1 to 5 , smooth. FruIT a pome, containing 1 to 5 bony 1 -seeded carpels.-Thorny trees or shrubs, with simple mostly lobed beaves, subulate deciduous bracts, and showy white (rarely rosecolor) flowers in corymbs.

* Leaves serrate sub-entire, not lobed.

1. C. Crus-galli, Ait. Cockspur Thorn.

Smooth; leqves wedge-obovate, thickish, shining, serrate, entire near the base; spines very long; corymbs smooth; styles 1 to 3 .

Borders of woods and thickets; rare. May, June. A thorny shrub or amall tree 10 to 20 feet high, much branched. Thorns 2 to 3 inches long. Leaves nearly sessile 1 to $21 / 2$ inches long, $1 / 2$ to $2 / 3$ as wide. Flowers white, fragrant on corymbs, on very short lateral bractlets. Sepals lanceolate, smooth, sub-serrate. Style often solitary. Fruit red, pear-shaped or ovoid-oblong.

\section{C. PUnCtata, Jacq. Common Thorn.}

Leaves wedge-obovate, cut-serrate, smooth, narrowed at base into a margined petiole, furrowed by the impressed straight veins; corymbs compound, and with the calyx pubescent when young.

Thickets, hedges and swamps; common. May. A small tree 12 to 25 feet high with rugged branches, usually armed with stout sharp thorns 1 to 2 inches long, cometimes nearly unarmed. Bark ash-colored. Leaves light green, mostly hairy. Flowers white, numerous. Styles 1 to 3. Fruit large, red or yellowish, globose, dotted.

3. C. parvifolia, Ait. Dwaif Thorn.

Leaves wedge-obovate or cuneate, nearly sessile, rounded at the apex, cuneate, serrate, rarely somewhat incised, pubescent; flowers subsolitary; calyx lobes foliaceous, incised as long as the petals; styles 5 ; fruit roundish, pyriform.

Sandy woods and banks of stream; not common. April, May. A much branched fhrub 4 to 7 feet high, armed with a few long and sharp thorns. Flowers white, mostly solitary and terminal. Fruit $1 / 3$ to $1 / 2$ inch in diameter, red or yellow, eatoble when ripe.

* Leaves incised, more or less lobed.

4. C. tomentosa, L. Black Thorn.

Leaves ovate-elliptic or oval-wedge-form, and narrowed at base into a short margined netiole, incisely serrate and sub-lobed towards the apex, smooth and furrowed above, tomentose beneath when young; styles 3 to 5 ; fruit pyriform.

Borders of woods and thickets; common. May, June. A large shrub 12 to 15 feet high, branching, armed with sharp thorns 1 to 2 inches long. Leaves 3 to 5 inches long, $1 / 2$ to $2 / 3$ as wide, acute at apex, on petioles $1 / 2$ to 1 inch long. Flowers large, white, fragrant, in a large leafy compound corymb. Fruit large, orangered, eatable, ripe in Sept.

\section{C. Coccinea, I. White Thorn.}

Leaves roundish-ovate, thin, sharply cut and toothed, 5 to 9-lobed, somewhat eordate at base, on long slender petioles, nearly smooth; styles 3 to 5 ; fruit globoes: 
Thiokets on borders of streams. May, June. A thorny shrub or small tree 12 to 20 feet high, with crooked end spreading branches. Branchlets white. Thorns stout, rigid, a little recurved, white, $11 / 2$ inches long. Flowers white in corymbs terminating the young branches. Fruit large, bright red or purple, eatable, ripe in Sept. Very variable.

\section{C. Cordata, Ait. Washington Thorn.}

Smooth; leaves broadly-ovate and sub-corclate, on long and slender petioles acuminate, incised and serrate, mostly 3-lobed noar the base; styles 5; fruit small, globose-depressed.

Banks of streams. June. A shrub 15 to 20 feet high, cultivated in the Middle States for hedge-rows, branching; the branches dark purple and armed with rery Eharp and slender thorns 2 to 3 inches long. Leaves often deeply 3 to 5-lobed, about 2 by $1 \frac{1}{2}$ inches. Flowers white, numerous, in corymbs terminating the branches. Fruit small, bright purple or red, numerous.

\section{C. Oxycantha, L. Hauthorn. English Thom.}

Smooth; leaves broadly ovate, cuneate, 3 to 5 -lobed, incised and serrate; segments of the calyx acute or acuminate; styles 1 to 3 ; fruit oroid.

Roadzides, heitse, \&c., sparingly naturalized. June. A rery branching shrub 4 to 10 feet high; the branches armed with sharp, short, tapering thorns $1 / 2$ inch long. Leaves rariously lobed, pale heneath. Petioles 1/2 to 1 inch long, with 2 leafy stipules at base. Flowers white, in corymbs. Fruit small, purple when mature. Introduced from Europe.

\section{AMALANChIER. DC. June Berry.}

\section{Calyx 5-cleft. Petalis 5, oblong-obovate or ob-lanceo-} late. Stauens many, rather shorter than the calyx. Styles 5, somewhat united at base. Pove when mature 3 to 5celled. - Small trees or shrubs with simple serrate leaves and white flowers in racemes.

\section{A. Botriapium, DC. June Berry. Shad Berry.}

Learcs cordatc-oval, conspicuously acuminate, puhescent when young, smooth when mature; flowers in looze racemes, appearing before the leaves: petals linearIanceolate, four times as long as the calyx.

Rich moist woodlands and hills; frequent. April. A handsome tree 10 to 20 feet hish, with rather slender distant branches forming an open top. Teetrers 2 to $31 / 2$ inclies lnug, 1 to 2 wide, acutely serrate, on petioles $1 / 2$ inch long. Flowers large white in loose racem 2 inches long, terminating the branches; somewhat pendulous. Fruit dark purple, pleasant tasted, ripe in June, July.

\section{A. ovalis, DC. Medler-bush,}

$\boldsymbol{L}$ laves roundish elliptic, or oblong-oval, acute or acuminate, serrate, smooth when mature; flowers in compact racemes; petals obovate, oblong.

Fence-rows and woodlands; rare. A pril, May. A slender branching shrub 2 to 5 fuct high. Leaves 1 to 2 inches long, and $3 / 4$ to 1 wide. Flowers white, in erect villose racemes. Fi uit dark-purple or nearly black, pleasant tasted, ripe iu July. Supposed by some botanists to be a variety of the preceding, but considered dis. tinet by Beek, Darlington and others.

\section{PYRUs. Linn. Pear. Apple.}

Calyx-tube urn-shaped, the limb 5-cleft. Petals round. ish. Stamers numerous. Strues 2 to 5 . Pome fleshy 
or berry-like, the 2 to 5 carpels of a cartilaginous texture, each 2-seeded.-Trees or shrubs with simple or pinnate leaves, and handsome white or flesh-colored flowers, in cymoes corymbs.

* Sonbus, Tourn. Petals spreading. Stybes 2 to 5 . Leaves xinnate.

\section{P. Americana, DC. Mountain Ash.}

I-aflets 13 toi15, oblong-lanceolate, pointed, sharply serrate with pointed teeth, common petiole smooth when full grown; flowers in large compound eymes; frust globose.

Swainps and mountain woods. May. A large shrub or low tree, 15 to 20 feet high, with the younger branches pubescent. Leaves 10 to 15 inches long. Leaflets 2 to 4 inches long, $1 / 2$ to 1 wide, sub-opposite, often acute. Flovers small, white, rery numerous. Fluit scarlet, very showy, remaining through the winter, somowhat acid. A low, smaller fruited variety is found on the Alleghenies.

* Adevorachis, DC. Petals spreading, with claws. Styles 2 to 5 . Leaves sim gle, the midrib beset with glands along the upper side. Fruit berry-tike.

\section{P. ARbutifolio, L. Choke Berry.}

Leaves obovate, oblong or lanceolate, acute or acuminate, crenate-serrate, smooth atore, reiny beneath, with 2 rows of glands along the midrib; flowers in corymb ; fruit nearly globose.

1. Var. MELANOCARPA is nearly smooth, with purplish-black fruit.

Damp thickets; common. May. A slender branching shrub 2 to 5 feet high. Leares 1 to 2 inches long, $1 / 2$ to 1 wide, the under surface usually very tomentose. Elowers numerous, nearly black, sweetish and astringent, ripe in Aug., Sept.

* * MaLus, Tourn. Petals spreading, flat. Styles 5, nearly united. Legres simplo worthout glands.

3. P. coronaria, L. Sweet-scentéd Crab Apple.

zeavcs broad ovate, rounded at base, eut serrate or lobed, smoothish; corymbs terminal, few-flowered, on long peduncles; styles woolly and united at base; frmit globose, depressed.

Borders of woods; common. May. A small tree 10 to 20 feet high, with spreading hranches. Flowers large, fragrant, pale rose-color, in loose corymbs of 3 to 10 . Fruit $1 \frac{1}{2}$ inches in diameter, pale-greenish-yellow, firm and hard, very aeid, translucent and fragrant when ripe. Sept.

\section{P. angustifolia, Ait. Narrow-leaved Crab Apple.}

Icaves oblong, or lanccolate, often acute at the base, crenate-dentate or almost entire, smooth, shiny alove; flowers in corymbs; styles smooth and distinct; pedicels smooth.

Woods. April-May. A tree 15 to 20 feet high resembling the last, but with smaller loaves and fruit.

\section{P. Malus, L. Common Apple Tree.}

Leares ovate, or oblong-ovate, serrate, acute or short acuminate, pubcreent above, tomentose beneath, petiolate, corymbs sub-umbeilate; pedicels and calys rilloso-tomentose; petals with short claws; styles 5 , united and villose at base; rome globose. Native of Europe, and almost naturalized with us. Probably nearly 1000 varieties are cultivated in the United States.

\section{P. communis, I. Pear Tree.}

Leaves ovate-lanceolate, sub-serrate, smooth above, pubescent beneath, acute of acuminate ; corymbs racemose; calyx and pedicels pubescent; styles 5 , distinct and villose at base; pome pyriform. Native of Euroje. Flowers white. Numerom varieties are cultivated in the United States. 


\section{CYDONIA. Tourn.}

Named from Cydonia, a town in Crete, from whence it was brought.

Calyx urn-shaped, limb 5-cleft. Petals 5. Sitameng many. Styues 5. Pome 5-carpelled; carpets cartilaginous, many-seeded. SEeds covered with mucilaginous pulp.Trees or shrubs, with simple leaves, and mostly solitary flowers.

\section{C. vulgaris, Pers. Quince.}

zeares oblong-orate, obtuse at base, acute at apex, rery entire. smooth abore, tomentose beneath; peduncles solitary, and with the calyx woolly; pome tomentose, obovoid. Shrubs about 8 to 12 feet high, with crooked straggling branchea. Flowers white, with a tinge of purple, large, terminal. Fruit clothed with a sof dorn, yellow when ripe, highly esteemed for jellies and preserves.

C. JAPoxrcA, or Scurlet Pyrus, a low straggling ehrub with beautiful scarles ahowy flowers, is occasionally met with in cultivation.

\section{ORDER 41. CALECAMFHACER.}

Shru's with square stems exthibiting 4 axis of growth surrounding the central an, with opposite, entire, simple leaves, without stipules, and axillary solitary fiowers. 8zPals and petals confounded, indefinite, imbricate, combined in a fleshy tube. Orabigs several, simple. Achenia hard, enclosed in the calyx-tube.

\section{CALYCANTHUS. Linn.}

Gr. kalux, a calyx and anthos, a flower; the calys resembling a corolla.

LOBES of the CALYX imbrivated in many rows, lanceolate, colored, all more or less leathery or flezliy: Stamens about 12, unequal, deciduous, the outer ones fertile. Anthers extrorse.-Shrubs with lurid purple, fragrant flowers, and with the barte and leaves exhaling the odor of camphor.

C. Floridus, L. var. Teevigatus, Torr. \& Gr. Sucea Scented Shrub. Carolina Allspice.

Lsaves oblong or oval, gradually acuminate, somewhat rugose, smooth and groen *n both sides; branches straight, erect; lobes of the calyx lanceolate.

Mountains and fertile soils along streams; rare. May, Junc. A handame hrub, cultivated in gardens, 4 to 6 feet high. Flowers large, golitary, terminai. ablyx brownigh-purple, very fragrant.

\section{ORDER 41. IMEASTOMACERS,}

Herbs, shrubs or trees, with opposite mostly entire ribbed leaves, and isminal Dlitary or cymose flowers. Anthers opening by pores at the apex; atherseise math es in Onogracras. (Evening Primrose Family.)

\section{Rhexia. Linn. Meadow Beautr.}

CALXX-TUBE urn-shaped, narrowed at the apox, the limb 
4-cleft. Petals 4, obovate, inserted with the 8 stamens on the summit of the calyx-tube. Anthens 8, long, curved, attached to the filaments behind, naked at base. Strue 1 . Stigma 1. Capsule free in the calyx, with 4 many-seeded placentæ projecting from the central axis. SEEDs coiled like a snail shell, without albumen:-Low perennial herbs, often bristly, with sessile 3 to 5-nerved, and bristle-edged leaves, and showy cymose purplish flowers.

\section{R. Virginica, L. Deer Grass. Meadow Beauty.}

Stem square, with wing-like angles; leaves oval-lanceolate, acute, sessile, ciliate, serrate, sprinkled with hairs on both sides; calyx hisped.

Wet meadows and sandy swamps. July, Aug. Stem a foot high, often dichoto mously branched above. Leaves with 3 (rarely 5 or 7 ) prominent nerves, 1 to 3 inches long, half as wide. Flowers large, in corymbose cymes. Petals reddish-purple, obovate, hisped beneath, caducous. Anthers long and prominent, crooked, golden yellow above with a purple line beneath. Style long, a little declined.

\section{R. Mariana, I. Maryland Deer Grass.}

Stem nearly round, covered with bristly hairs; leaves lanceolate, or linear-oblong, acute at each end, sparingly hisped on both sides, ciliate-serulate; caly $x$ hisped.

Wet grounds. July, Aug. Stem 1 to 2 feet high, slender, with opposite branches. Flowers situated in the forks and terminatians of the branches. Petals obovats, hairy on the outer surface, flesh-eolored or white dilated with rose-red. Anthers yellow. Style larger than the stamens.

\section{ORDER 42. LYTHRACER.}

Herbs rarely shrubs, with usually 4-sided branches, mostly opposite entire leaves, without stipules, and rarely irregular flowers, axillary or whorled, sometimes in racemes or spikes. CALYX tubular, the limb 4 to 7 -lobed, sometimes with as many intermediate teeth. Pexals inserted between the teeth of the calyx, sometimes wanting. STAuexs as many, or 2 to 4 times as many as the petals, inserted into the tube of the calyx. Strue 1; stigma capitate, or rarely 2-lobed. Ovary superior, 1 to E-celled. CAPSULE membraneous, covered by the calyx, dehiscent. SEEDS numerous, small.

\section{DECODON. Gmel.}

Gr. deka, ten, and odous, a tooth, from the ten-toothed calyx.

CALYX short, broadly bell-shaped, with 5 erect teeth and 5 longer and. spreading horn-like processes. Petals 5, wedge-lanceolate. Stamens 15,5 very long, the alternate ones shorter. Strues filiform. CAPsule covered with the calyx, globose 3 to 4-celled, many-seeded.-Perennial herbs, with opposite or whorled lanceolate almost sessile leaves, and clustered pedicelled flowers in their axils.

\section{D. Verticellatum, Ell. Swamp Willow Herb.}

Swamps and wet places. Aug. Stems 2 to 6 feet long, sometimes prostrate and rootivg, 4 to 6-angled, smooth or pubescent. Leaves opposite or in whorls of 3,3 to 
5 inches long, gradually acuminate or acute at apex, on short petioles. Flower in axillary sub-sessile umbels, apparently whorled, constituting a long, leafy, terminal and showy panicle. Petals 5 to 6 , large, and of a fine purple.

\section{CUPHEA. Jacq.}

Gr. kuphos, curved; in reference to the form of the calyx.

Calyx tubular, 12-ribbed, somewhat inflated below, gibbous or spurred at the base, on the opposite side, 6 -toothed at the apex, with usually as many little intermediate processes. Petals 6 to 7 , unequal. Stamens mostly 12, approximate in 2 sets, included, unequal. STrLe filiform. Stigma 2-lobed. Capsule membranaceous, 1 to 2-celled, few-seeded.-Herbaceous or half shrubly plants, with opposite entire leaves, and axillary and terminal flowers.

\section{C. viscosissima, Jacq. Clammy Cuphea.}

Viscid-pubescent; leaves oryosite, orate-lanccolate, long-stalked, rough; flwers - lateral, and solitary, on short peduncles; petals ovate, short-clawed.

Fieids and roadsides. July, Aug. Annual. Sten 10 to 15 inches high, erect, branching. Lcaves 1 to 2 inches long, $1 / 3$ as wide, on petioles $1 / 4$ to $1 / 2$ inch long. Caly $x$ often purple, ventricase. Petals violet-colored. Stcimens included. Cinsubs bursting lengthwise before the secds are ripe.

\section{CRDER 43. OUAGRAOTRP.}

Herbaceous plants or shrubs, with simple alternate or opposite leaves, and axillary serminal flowers of varinus colors. Petals 4, (sometimes 2 or 3). STAMENS 1-25-9 inserted with the petals into the throat of the calyx. OVARY 2 to 4 -celled, cohering with the calyx-tube; PLACrinta in the axis. Fruit baccate or capsular, 2 to Acelled, many-seeded. 'There are two sub-orders,

\section{SUB-ORDER I. ONOGRACEA PROPER.}

CalyX-Tube often prolonged beyond the ovary, the petals and stamens inserted on its summit. Stamens 2-4-8. Strues single, slender. Stigma 2 to 4-lobed, or capitate, Ovary 4-celled. Seeds without albumen.

\section{EPILOBIUM. Linn. WILLOW-HERB.}

Gr. epi, upon, lobou, a pod, ion, a violet, viz: a violet on a pod.

CALYX-TUBE not prolonged beyond the ovary, 4-sided; limb 4-parted, deciduous, Petals 4 . Stamens 8. An. THERs short, fixed by the middle. Stigma often with 4 spreading lobes, OVARY and CAPSULE linear, 4-cornered, 4-celled, 4-valved. SEEDs numerous, crowned with a tuft of U* 
hairs.-Herbaceous perennials, with nearly sessile leaves, and violet, purple or white flowers.

\section{E. Angustifolium, L. Willow Herb. Rose-bay.}

Stem simple, erect; leaves scattered, lanceolate, sparingly denticulate with a marginal vein; flowers large, pedicellcd, in a terminal spike; petals clawed; stamens unequal, declined; style at length deflexed.

Newly cleared land, and waste places. July. Stem 4 to 6 feet high, often bravched abore. Leaves sessile, smooth, 2 to 5 inches long, $1 / 4$ as wide, acuminato with pellucid veins. Flowers numerous and showy, colored in all their parts, deep-lilac-purple, in a raceme often a foot long.

\section{E. coloratum, Muhl. Colored Epilobium.}

Stem subterate, erect, very branching, pubercent; leares mostly opposite, lanceolate, sefulate, acute, somewhat petiolcd, smooth; peicls small, 2-cleft at the apex; stigma club-shaped.

Ditches and wet shady grounds; common. July, Aug. Stem 1 to 3 feet high, much branched, often purplish. Leares 2 to 4 irches long, $1 / 4$ as wide, with minute white dots, upper ones alternate and sessile. lower on shcrt petioles. Flowers small purplish facling to white, axillary near the extrem.ty of the branches.

3. E. Palustris, L. Marsh Willow Herb.

Minutely hoary; stem slender, roundish, at length much branched; leaves nearly 8ossile, lanceolate or linear, acutish at both ends, slightly toothed or entire; putals 8mall, obcordate, twice as long as the calyx; style includcd; sticma undivided, clarate.

Swamps and marshy places. Aug., Sept. S'em 1 to 2 fcet high, rery branching. Ieaves mostly alternate, 1 to 3 inches long, $1 / 3$ as wide. Flcwers numcrous, axillary, rose-color. Capsule 1 to 2 inches long, pubesecnt.

\section{E. Molle, L. Soft Willow Herb.}

Soft downy all over; stem round, straight, crcet, tranching above; leaves crowded, lanceolate or linear-oblong, alternate or opposite, mortly entire.

Swamps; rare. Aug., Sept. Stcm 1 to 2 feet high. Leares numeroue, $3 / 4$ to $11 / 4$ inches long, $1 / 4$ as wide. Flivers rose-color, axillary in the uprer rert of the etem. Petals deeply notched, twice as long as the calyx. Stigmu large ard thick. Capsule 3 izches long on a short pedicel.

\section{anothera. Linn. Evening Primrose.}

Gr. binos, wine; and thera, a chase : application uncertain.

CALYX-TUBe prolonged beyond the ovary, deciduous; the lobes 4 , reflexed. Petalls 4. Stamens 8. Anthers mostly linear. Stigma 4-lobed or capitate. Capsule 4-valved, many-seeded. SEEDS naked.-Herbaceous plants, with alternate leaves, and mostly yellow flowers.

\section{G. BIEnnis, L. Common Evening Primrose.}

Stem erect, mostly hairy; leaves oval-lanceolate, acute, obscurely toothed, pubescent; lower ones on short petioles; flowers in a ter minal rather leafy fpike; petals obcordate; capsule sessile, obtusely 4-angled, somewhat swelled. Var. 1. Murrcata Gs, muricata, Ph.) Stem muricate or strigosely hirsute, red; petals scarcely langer than the stamens. Var. 2. Grandiplona (\&, grancifflora, Ait.) Putals much longer than the stamens, deeply obcordate. Stem branched. Biennial. 
Fields and waste places; common. June, Aug. Stem 2 to 5 feet high, simplo or 3ranching from the base. Leaves 3 to 6 inches long, $1 / 2$ to $11 / 2$ wide, roughly pubescent: radical ones tapering into a petiole. Flowers numerous, light-yellow, fragrant, opening after sunset and closing next day, in a spike 3 to 12 inches long.

2. E. Fruticosa, L. Sundrops. Per. Eve'g Primrose.

Stem erect, simple or nearly branched, pubescent or hirsute; leaces oblong or Ianceolate, slightly toothed; pe'als broadly obcordate, longer than the calyx-lobes and stamens; capsule oblong-club-shaped, 4-winged, longer than the pedicels.

Open places; common. June-Aug. Per. Stem hard, rigid, 1 to 3 feet high, branched, purple. Leaves variable in pubescence, form and size. Flowers large, $13 / 2$ inches in diameter, bright jellow, in a peduncled corymb.

\section{E. pumila, L. Dwarf Evening Primrose.}

Low, pubescent; stem ascending; leaves lanceolate or oblanceolate, mostly obtuse, sttenuate at base, entire; flowers in a loose and prolonged leafy raceme; petals obcordate, scarcely longer than the stamens.

Dry fields. July, Aug. Biennial. A small half-erect plant, 6 to 10 inches long, with a round, slender simple sten. Leaves 1 to $11 / 2$ inches long, $1 / 4$ to $1 / 2$ inch wide; radical ones spatulate, petiolate. Flowers yellow, $1 / 2$ inch broad, opening in succession, 1 or 2 at a time. Copsule oblong-club-shaped, nearly sessile, 8-angled.

\section{GAURA. Linn.}

Gr. gauros, superb; on account of the showy flowcrs of somę specice.

CALYX-TUBE much prolonged beyond the ovary, deciduous; limb 4-eleft, reflexed. Petals 4, clawed, somewhat unequal, inserted into the tube. Stamens 8, declinate. Strle long. Stigia 4-lobed. Fruit 4-angled, dry and indehiscent, by abortion mostly 1 -celled, 1 to 4 -seedcd. SEEDs naked.Herbaceous or shrubly plants, with alternate leaves and rosecolor or white changing to red flowers, in wand-like spikes or racemes.

\section{G. Binnns, L. Biennial Gaura.}

Whole plant softly hairy or downy; leaves lanceolate, remotely dentate, alternat, sessile; flowers numerous, sessile, in terminal spikes; fruit sub-seseile, 8-ribbed, pubescent.

Banks of streams. July, Aug. A handsome biennial 3 to 5 feet high. Leaves pale-green, acute at each end. Caly $x$ reddish. Corolla rose-color, changing to doe red. Fruit rarely with more than one mature seed.

\section{LUDWIGIA. Linn.}

In honor of C. D. Ludwig, Prof. of Botany at Leipsic, about 1750.

CaLYX-TUBE not prolonged beyong the ovary; limb 4-lobed, usually persistent. Petals 4, equal, obcordate, often small or wanting. Stamens 4, opposite the apex. Strue short. Capsule short, 4-celled, 4-valved, many-seeded and crowned with the persistent calyx lobes. -- Perennial herbs, with entire mostly alternate leaves and axillary flowers, often yellow ar apetalous. 


\section{I. ALternifolta, L. Seed-box.}

Nearly smooth; stem erect, branched; leaves alternate, lanceolate, acute or pointed at both ends, sessile, pale beneath; peduncles axillary, 1-flowered, 2-bracted above the middle; petals scarcely as long as the spreading acuminate sepals; capsule large, with 4 winged angles, crowned with the colored calyx.

Shady swamps. July. Stem 1 to 3 feet high, round with a strong bark, and severad branches. Leaves 2 to 3 inches long, $1 / 2$ to 1 wide, with marginal veins. sepals large, reddish. Petals large, ovate, yellow, soon falling off.

- Petals very minute or none. IsNaRdis.

\section{L. SPH AROCARPA, Ell. Round-fruited Ludwigia.}

Nearly smooth; stem erect, much branched; leaves lanceolate, acute, tapering at the base, alternate; flowers solitary, axilliary, or clustered towards the summit of the branches; petals mostly none; capsule globular, obscurely 4-sided, rery small.

In water and swampy places; rare. July, Aug. Stem 2 to 3 feet high, angular seddish. Margin of the leaves rough. Flowers greenish, inconspicuous.

\section{L. Palustris, L. Water Purslane.}

Smcoth, low; stem procumbent at base, rooting or floating; leaves opposite ovate-lanceolate, tapering into a slender petiole; flowers axillary, solitary, sessile; capsule sub-ovate, slightly angled.

Floating in water, or creeping in muddy places; common. Junc-Oet. Stem succulent, purplish, 10 to 20 inches long. Leaves and slender petioles $1 \frac{1}{2}$ by $1 / 2$ inches, ovate-spatulate. Flowers very small. Calyx-lobes and style very short. Ietals when present, flesh-color.

\section{CIRCAEA. Tourn. Enchanter's Nightshade.}

Named from Oirce, the enchantress.

CaLYx slightly produced above the ovary, deciduous; limb 2-parted. Petals 2, inversely heart-shaped. Stamens 2 , alternating with the petals. CAPSULE reflexed, obovate, 2-celled, 2-seeded, bristly with hooked hairs.-Low inconspicuous perennials, with opposite leaves on slender petioles, and small whitish flowers in racemes.

1. C. Lutetiana, L. Common Enchanter's Nightshade.

Slem erect, mostly pubescent; leaves ovate, sub-cordate, acuminate, toothed, longer than the petiole; bracts none; fruit reflexed, bristly.

Moist woodlands; common. July. Stem 1 to 2 feet high, sparingly branched, sumid at the nodes. Leaves dark-green, 2 to 4 inches long, $1 / 2$ as wide. Flowers mall, reddish-white, in a long terminal raceme.

\section{C. Alpina, L. Alpine Enchanter's Nightshade.}

Iow, smooth and weak; leaves cordate, shining, coarsely toothed, the lower ones long as the petiole; bracts minute.

Cold, moist, shady places. July. A small delicate plant 3 to 8 inches high. stem transparent, juicy. Leaves 1 to 2 inches long, $2 / 3$ as wide. Flowers whito, minute, in terminal racemes.

Sub-order II. HALORAGEA. Morsh or water plants, with very small axillary sessile 
Alowers, often monoecious or dicecious. CALYX-TUBE not at all prolonged, the lobes obsolete or none. Petals 3 to 4, often none. Stamens 1 to 8. Ovary inferior, 1 to 4 -celled. Fruir dry, indehiscent, 1 to 4 -celled. Seeds pendulous, 1 in each cell.

\section{ProserpinaCA. Linn. Mermaid-weed.}

Lat. proserpo, to creep; the stems creeping and rooting at the base.

Caliyx-tube 3-sided, limb 3-parted. Petals none. Stamens 3. Stigmas 3. Fruit-long, 3-angled, 3-celled, 3-seeded, nut-like.-Low perennial aquatic herbs, with the stems creeping at the base, alternate leaves, and small fertile flowers sessile in the axils, solitary or 3 or 4 together.

\section{P. Palustris, L. Common Mermaid-weed.}

Upper leaves linear-lanceolate, scrrate; lower ones often pinnatifid; fruit sharply 3-angled.

Wet sivamps; rare. July, Aug. Stem 12 to 18 inches long, roundish. Leaves about 1 inch long, $1 / 4$ wide, acute at each end, lower ones on short petioles, if submerged pinnatifid with linear segments like the teeth of a comb. Flovers greenish, Bessile, 1 to 3 together. Stigmas purple, cylindrical.

2. P. pectinacea, Lam. Cut-leaved Mermaid-weed.

Leares all pectinate, the divisions linear-awl-shaped; fruit rather obtusely 3-angled.

Sandy swamps; rare. Aur. Stems 5 to 15 inches high, ascending at base from long creeping roots. Leaves all regularly and finely divided into very narrow oegments like the teeth of a comb. Styles none. Stigmas attenuate above.

\section{MYRIOPHYLLUM. Vaill. Water Milfoil.}

Gr. murios, a myriad, phullon, a leaf; from the numerous divisions of the leaf.

Flowers monocious or polygamous. CaLYX of the sterile flowers 4-parted, of the fertile 4-toothed. Perats 4, or none. Stramens 4 to 8 . Fruit nut-like, 4-celled, deeply 4-lobed. Stigmas 4, recurved.-Submersed aquatic perennial herbs, with crowded often whorled leaves, those im. mersed pinnately parted into capillary divisions, and sessite flowers in the axils of the upper leaves: upper ones staminate.

- Stamins 8; petals deciduous; leaves whorled in threes.

\section{M. spicatuin, L. Spiked Water Milfoil.}

Leaves all pinnately parted and capillary; floral ones or bracts shorter than the flowers, ovate entire; lower ones sub-serrate and larger; petals broadly-ovatc; stamens 8 .

In water. Aug., Sept. Stem slender, branched, varying in length with the depth of the water, the flowers only rising above the surface. Leaves composed of innumerable, hair-like segments. Flower's grcenish sessile. Carpels smooth. 


\section{M. verticillatum, L. Whorled Water Milfoil.}

Leaves verticellate pinnately divided into capillary or sctaceous segments; floral leaves pectinate pinnatifid, usually longer than the flowers; petals oblong-obovate; oarpels smooth and even.

In water. July-Sept. Stem long and stouter than in the preceding, only the upper part cmerging. Flowers small, greon, in a terminal spike with conspicuous Boral learcs.

3. M. heterophyludu, Michx. Various-leaved Water Milfoil.

St: $m$ rether stout; floral leaves ovate and lanceolate, thick, crowded, sharply Nerrate; lower leares pinnatifid; petals oblong; fruit obscurely roughened.

In sluggish water. July. Stem thick and branching. Leaves very various, lowest firely divided. Flowers purple, whorled in the axils of the upper lesves. Sepals minute. Petals somewhat persistent. Stamens sometimes only 4 to 6.

* Stamens 4; leaves whorled in fours and fives, the lower fincly divided.

\section{M. Ambigudm, Ambiguous Water Milfoil.}

Sublmcrsed leaves cut into capillary segments; the emersed ones pectinate; floral ones linear, tapering into a short petiole, toothed or entire; flowers mostly perfect; petals oblong; carpels smooth and even.

Ponds ant citches. July, Aug. Stems 2 to 6 inches long and crecping in the mud, or when floating in water, long and slender. Leaves variously dirided, when the stems are procumbent and rooting the leaves are all linear, rigid, and often entire, but when submersed they are finely divided like the teeth of a comb. Plowers small purplish.

\section{HiPPURIS. Linn. MARE's-TAIL.}

Gr. hippus, a horse, and oura, a tail.

Calyx entire. Petals none. Stamen 1, inserted on the cdge of the calyx. Strute single, thread-shaped, stigmatic down one side, received in the groove between the lobes of the anther. Fruir nut-like, 1-celled, 1-seeded.-Perennial aquatics with simple entive leaves in whorls, and minute flowers sessile in the axils, perfect or polygamous.

\section{H. vUlGaris, L. Common Mare's-tail.}

Leaves in whorls of 8 to 12, linear, acute, smooth, entire.

Borders of ponds and springs; rare. Stem 12 to 18 inches high, simple, erect.

Flovers at the base of the upper whorls, one to each leaf, small.

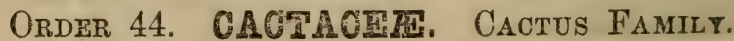

Fleshy and thickened leafless plants of peculiar aspect, globular or columnar and many-angled or flattened and jointed, usually with pricicles. Flowers solitary, sessile; the sepals and petals numerous, imbricatcd in several rows. Staмsis numerous, with long and slender filaments, inserted on the inside of the tube or cup formod by the union of the sepals and petals. StrLe 1. Stigus eumerons. Fruxz a 1-colled succulent berry, many-seeded. 


\section{OPUNTIA. Tourn. Prickly Pear.}

8EPALs and PETALs not prolonged into a tube, spreading, the inner roundish. STamens numerous, shorter than the petals. STYLE with numerous erect stigmas.- Stem composed of flat and usually broad joints, bearing clusters of bristles often with spines intermixed, arranged in a special order.

\section{O. vulgaris, Mill. Indian Fig. Cow's-tongue.}

Stems low, prostrate-spreading, of obovate joints, armed with short barbed brte tles, rarely with a few spines; flowers sessile, on the margin of the joints.

Dry rocks and sandy soils; rare. June, July. Flowers large, sulphur-yellow. Fruit obovate, umbillicate, nearly smooth, eatable. Seeds numervis, immersed in the crimson pulp. Cultivated.

\section{ORDER 45. GROSSULAC}

Low shrubs, sometimes priclily, with alternate palmately lobed leaves, a 5-bobed alyx coliering with the 1-celled orary, and bearing 5 small petuls and 5 stamens Frcir a 1-celled berry, with 2-parietal placentæ crowned with a minute embryo the base of hard albumen.

\section{RIBES. Linn.}

CalyX companulate or tubular, 5-parted, sometimes colored. Petals small, inserted alternately with the stamen in the throat of the calyz. Stamens 5, very short. STrues 2 , distinct or united. BERRY crowned with the shrivelled remain of the flowers, 1-celled, pulpy, many-seaded.-Leaves often clustered in the axils, with the flowers from the sams clusters or from separate buds.

* Stem unarmed; flowers in racemes: berries never prickly. CuRraxis.

1. R. FLORIDUm, L'Her. Wild Black Currant.

Leaves sub-cordate, 3 to 5-lobed, sprinkled on both sides with ycllowish resino dots, doubly serrate, on long petioles; racemes drooping, many-fowercd, downy; bracts longer than the pedicels; calyx tubular, bell-shaped; fricit obovoid.

Woods and hedges; common. May. A handsome shrub 3 to 4 feet high. Leaves 1 to 2 inches long $1 \frac{1}{2}$ to $2 \frac{1}{2}$ wide, on petioles 1 to 2 inches long. Flcurre somewhat bell-ghaped, greenish yellow. Fruit black, smooth. incipid.

The $\mathrm{R}$. nigrum or llacle currant of the gardens. Native of Europe, is probats not distinct from this species.

2. R. prostratum, L'Her. Mountaii Currant.

Stem reclining or prostrate; leaves deeply cordate, 5 to 7 -lobed, smcoth; the lob ovate, acute, doubly serrate; racemes erect, slender; caly $x$ rotate, segments obovate; petals spatulate, small; fruit glandular-hisped.

Mountains and rocky hills. May, June. A small procu mbent shrub with creet branches 1 to 3 feet high. Racemes erect, about 8-flowerad, at length pendulous Bracts very short. Flowers marked with purple. Berrizs red, ill-scented. Tho wholo plant has a disagreeable odor. 


\section{R. RUBRuM, L. Red Currant.}

Stems straggling or reclined; leaves somewhat heart-shaped, obtusely 3 to 5-lobed, serrate, downy beneath; racemes nearly smooth, drooping from lateral buds, ditinet from the leaves; caly $x$ flat; frut globose, smooth. This is the common red eurrant of the gardens, so universally cultivated. Indigenous in swamps and mountains from New York to Wisconsin, and may probably be found in Western Pennsylvania.

\section{R. Aureum, Pursh. Missouri, or Golden Currant.}

Plant smcoth; leaves 3-lobed, lobes spreading entire or with a few large teeth: octioles longer than the leaves; bracts linear; racemes loose, many-flowered; caly 5 tubular; segments oblong, obtuse; petals linear; fruit smooth, oblong or globose; A beautiful shrub, 6 to 10 fuet high, with numerous yellow, very fragrant flowers, appearing from April to May. Fruit yellow, finally brown. Native of Missouri and Oregon. Common in cultivation.

* * Stem usually armed with sub-axillary spines, often priclily: berries pricily or emonth. GOOSEBERRIRS.

\section{R. Cynosbati, L. Prickly Gooseberry.}

Stem unarmed or prickly; sub-axillary spines 1 to 3; leaves cordate, roundish, pubescent, with 3 to 5 incisely toothed lobes; peduncles slender, 2 to 3 -flowered; stamens and style not longer than the broad companulate calyx-tube; petals obovate shorter than the calyx segments.

Shocky woods and mountains. May, June. A handsome shrub 2 to 4 feet high, branching, the lower part of the stem often prickly. Flowers greenish-white, in pendulous racemes. Berries usually with long prickles, brownish purple.

\section{R. hirtellum, Michx. Rough Wild Gooseberry.}

Siem unarmed, rarely prickly; lcaves roundish, cordate, 3 to 5-lobed, toothed, pulescent beneath; peduncles very short, defiexed, 1 to 2 -flowered, smootin; calyxtube bell-shaped, the segments twice as long as the petals; styles hairy, 2-cleft; fruit smooth.

Rocky places. May, June. Stem 2 to 3 feet long. Leares $3 / 4$ to $11 / 2$ inehes in diameter, generally cleft half to the maiddle. Flowers nodding, greenish. Fruit bluish-purple, pleasant-tasted.

\section{R. rotundifolium, Michx. Wild Gooseberry.}

Stem without prickles; sub-axillary spines mostly solitary, short; leaves roundish, searly smooth, 3 to 5 -lobed, incisely dentate; peduncles slender, 1 to 2-1lowcred; stamens and 2-parted style slender, longer than the narrow cylindrical calyx; fruit fmooth.

Mountain woods; common. May, June. Stem 3 to 4 feet high, with a whitish rark. Leaves 1 to 2 inches in diameter, mostly truncate at base, shining alove, om ciliate petioles 1 to 3 inches long. Flowers whitish, with a tinge of purple. Fruif purple when ripe, well flavored, resembling the garden gooseberry.

\section{R. Lacustres, Poir. Swamp Gooseberry.}

Young stems olothed with bristly prickles, and with several weak thorns; leaves deeply 3 to 5 -lobed, cordate at base, lobes deeply incised; raceme 5 to 9-fiowered, pilose; calyx broad and flat; stamens and style not longer than the petals; fruit bristly.

Mountain swamps; rare. May, June. Siem 3 to 4 feet high, reddish from the numerous prickles, which differ from the spines only in size. Learcs shining above, $11 / 3$ to $21 / 2$ inches in diameter, on ciliate hisped petioles longer than the leares Filowers small, greenish-yellow. Fruit bristly, dark-purple, unpleasant to the taste. 


\section{R. Uva-CRISPA, Garden Gooseberry.}

Stem prickly; leaves roundish, 3 to 5-lobed, hairy beneath, on short hairy petioles; peduncles hairy, 1-flowered; caly $x$ bell-shaped; style hairy; fruit smooth or hairy, globose. Native of England. Common in eultivation. Varieties numerous, witk red, green and amber fruit very large.

\section{ORDER 46. PASSIFLORACE开.}

Herbaceous or shrubby plants, usually climbing by tendrits, alternate, often glarditar leaves, foliaceous stipules, and axillary and terminal flowers often with a 3-leaved involucre. SEpals 5, combined in a tube, the throat crowned with a double or triple fringe. Petals 5, arising from the throat of the calyx, sometimes wanting. STANExs 5, monodelphous, rarely indefinite, surrounding the stipe of the orary. Strles 3. OVARY superior, on a large stipe, 1-celled. FrUTt many-seeded, placentro, sometimes 3-valved.

\section{PASSIFLORA. Linn. PASsION-FLOWER.}

Iat. passio, passion, and fos, a flower; the several parts of the flowers, were compared to the instruments of the Saviour's passion.

CALYX colored, deeply 5-parted, the throat crowned with a double or triple fringe. Petals 5, inserted into the calyx, or none. Stamens 5; their filaments situated on the stipe of the ovary, separate and spreading. ANTHERs large, fixed by the middle. STIGMas 3, club-shaped, capitate. Fruit a pulpy berry, many-seeded.-Perennial climbing herbs or shrubs, with palmately lobed leaves, generally with stipules, and showy flowers on axillary peduncles.

1. P. Lutea, L. Yellow Passion-flower.

Smooth, slender; leaves cordate, 3-lobed; petioles without glands; stipules minzte; peduncles mostly in pairs; petals narrow, much longer than the ealyx.

Banks of streams; Southern part of the State. June, July. Stem climbing, slender, 3 to 10 feet long. Leaves yellowlsh-green, nearly as broad as long. Flowers small, greenish-yellow. Crown in 3 rows, the inner row a membraneous disk with a fringed border. Fruit dark-purple.

2. P. incarnata, L. Flesh-colored Passion-flower.

Zeaves smooth, 5-nerved, deeply 3-cleft, lobe oblong, acute, serrate; petioles with 2 glands; involucre 3-leaved, obovate, glandular, serrate; crown triple; ovary smooth. A handsome cultivated species, native of the Southern States. Stem elimbing, 10-20-30 feet. Flower's large and showy, on pedicels. Petals white, oval-oblong. Two outer rows of filaments long, purple with a whitish base, the inner row of short rays, flesh-color. Berry pale-yellow, eatable.

\section{ORDER 47. CUCURBITACEF.}

Herbaceous mostly succulent vines, with tendrils, alternate palmately veined leaves, and axillary monceious or diocious flowers. CALYX 5-toothed, sometimes indistinct. Corolla 5-parted, scarcely distinguishable from the calyx, strongly marked sith reticulated veins. STAMENS 5 , distinct, or cohering in 2 or 3 sets. ANEHERs 
sinuous. OVARY adherent, 1-celled; STYLB short; STIGMA very thick, velvety or fringed. FRUT a pepo more or less succulent, often 1-celled by obliteration. SERDs flat, with no slbumen, often winged.

\section{SICYOS. Linn.}

Gr. sikuos, the ancient name of the cucumber.

Flowers monocious. Petals 5, united below into a bell-shaped or flattish corolla. Stamens 5, monodelphous or at length triadelphous; anthers contorted. STYLES 3, united at the base. Frurt ovate membranaceous, filled by the single seed, covered with barbed prickly bristles which are readily detached.-Climbing annuals, with compound tendrils, and whitish flowers, the sterile and fertile mostly from the same axils, the former corymbed, the latter in a long-peduncled capitate cluster.

\section{S. angulatus, L. Single-seed Cucumber.}

Stem branching, hairy; leaves roundish, heart-shaped, and 5-angled-lobed, the lobes minutely toothed, pointed; pistillate flowers much smaller than the staminate.

Banks of streams. July, Aug. A weak climbing vine with long spiral tendrils. Leaves 3 to 4 inches broad, on long stalks. Flowers whitish, marked with green lines. Fruit $1 / 2$ inch long, ovate, spinous, 8 to 10 together in a crowded cluster.

\section{ECHINOCYSTIS. Torr. \& Gray.}

Gr. exiros, prickly, and Kustis, a bladder; in allusion to the appearance of the fruit

Flowers monocious. Calyx flattish, segments 5, filiform subulate. Petals 6 , united at the base into an open spreading corolla. Stamens 3, diadelphous. Strle 1; stigmas 3, fringed. Ovary 2-celled, with 2 erect ovules in each cell. Fruit globose-ovoid, bristly-echinate, 2-celled, 4-seeded.-A rank tall-climbing annual, with branching tendrits, sharply 5-lobed thin leaves, and very numerous small greenish-white flowers.

\section{E. lobata, Torr. \& Gray. Wild Balsam Apple.}

Leares palmately 5-lobed, cordate at base, lobes acuminate, denticulate; flowers kmall, the barren ones very numerous, in axillary racemes, the fertile ones solitary ar several, situated at the base of the raceme.

Rich river soils. July-Sept. A smoothish running vine. Stem deeply furrowed, with long 3-parted tendrils placed nearly opposite the long petioles. Fruit 1 to \& inches long, at length dry and membranaceous, with 4 large seeds.

\section{MELOTHRIA. Linn.}

FlOwers polygamous or monœcious. STERILE FlOWER, calyx 3 to 5 -toothed; corolla companulate; filaments 5 , in 3 sets. Fertile Flowers, calyx and corolla as in the 
sterile; style 1 ; stigmas 3 , fimbriate. FruIT 3-celled, manyseeded.-A stender climbing annual, with simple tendrils, five lobed leaves, and small yellowish flowers.

\section{M. pendula, L. Snall Creeping Cucumber.}

Ireaves roundish-cordate, 5-lobed or angled, slightly hispid; flowers axillary, the sterile in-small racemes, the fertile solitary, on long peduncles.

Banks of streams. June, July. A slender vine, climbing over other vegetables. Leaves 1 to 2 inches in diameter, on petioles. Tendrils 5 to 6 inches long. Flowers yellowish, small. Fruit small, oval.

\section{CULTIVATED EXOTIOS.}

\section{MOMORDICA. Linn.}

Flowers monœcious. Calyx 5-cleft. Petals 5, united at the base. Stamens 5, triadelphous. STrLe 3-cleft; PEPO fleshy, bursting elastically. SEEDs compressed with a fleshy arillus. - An annual climbing herb, with simple tendrits, palmately lobed leaves, and pale yellow flowers.

\section{Balsamina, L. Common Balsam Apple.}

Leaves palmately 5-lobed, dentate, naked, shining; peduncles solitary, filiform, 1-flowered, with an orbicular-cordate dentate bract above the middle; fruit roundish-ovoid, angular, tuberculate, bursting elastically on one side. Native of the East Indies. Stem slender, climbing by simple tendrils. Flowers pale-yellow. Irruit orange-color, balsamic and eatable.

\section{CUCUMIS. Linn.}

Celtic, cuce, a hollow vessel.

Flowers monocious or perfect. Calyx tubular, bellshaped, with awl-shaped segments; CoroLLA deeply 5-parted. Stamens 5, triadelphous. STYLE short; STIGMAS 3, thick, 2-lobed; PEPO fleshy, indehiscent. SEEDs ovate, flat, acute and not margined at the edge.-Annual herbs, crceping or climbing by tendrits, alternate leaves, and axillary solitary yellow flower's.

\section{C. Sativus, L. Common Cucumber.}

Stem prostrate, rough; tendrits simple; leaves sub-cordate, palmately 5-angled or lobed, lobes sub-entire, acute, terminal one longest; fruit oblong, obtusely prigmatic, prickly on a short peduncle. Native of Tartary and India. Numerous varieties are now cultivated for the table. Gathered and eaten before maturity. June-Sept.

\section{C. Melo, L. Musk Melon.}

stem prostrate, rough; tendrits simple; leaves sub-cordate, roundish, obtuse, palmately 5-angled; lobes rounded, obtuse, obscurely denticulate; flowers pistillate, perfect, and staminate, the perfect on short peduncles; fruit oval or sub-globase, 
Iongitudinally torulose. Native of Asia, cultivated for the juicy, yellowish, delicately flavored flesh of the mature fruit. June, July.

3. C. Anguria, L. Prickly Cucumber.

Stem prostrate, slender, hisped; tendrits simple; leaves palmately and deep sinuate lobed, cordate at base; fruit oval-ovoid or sub-globose, prickly. Native of Jamaica. Fruit about the size of a hen's egg; cultivated and used for pickles.

4. C. Citrulues, Ser. Water Melon.

Stem prostrate, slender, hairy; tendrits branching; leaves palmately 5-1obed, very glaucous beneath; lobes mostly sinuate-pinnatifid, all the segments obtuse; flowers solitary, on hairy peduncles, bracted at base; fruit elliptical, smooth. Native of Africa and India. Cultivated for its large and delicious fruit. June, August.

\section{LAGENARIA.-Ser.}

Gr. lagenos, a flagon or bottle; from the form of the fruit.

Flowers monoecious. CaLyx bell-shaped, 5-toothed, obovate. Stamens 5, triadelphous; anthers very long, twisted. Stigmas 3, thick, 2-lobed, sub-sessile. Pepo woody, 1-celled many-seeded; seeds ariled, obcordate, compressed, margir tumid.-An annual herbaceous plant, climbing by branching tendrits, with axillary solitary, white flowers.

\section{I. vulgaris, Ser. Calabash. Bottle Gourd.}

Softly pubescent; leaves roundish-cordate, abruptly acuminate, denticulate, with 2 glands beneath at base; flowers on peduncles; fruit club-shaped, inflated, at length smooth. Native of the Tropics; cultivated for the rind of the fruit, which is used for dipping water, \&c. Flowers white. July, Aug.

\section{CUCURBITA. Linn.}

A Latin word signifying a vessel.

Flowers monocious. Corolla bell-shaped; petals united and coherent with the calyx. Stam. Fls. Calyx 5-toothed. STAMENS 5, triadelphous; anthers syngenesious, straight, parallel. Pist. Fls. Calyx 5-toothed, upper part deciduous after flowering. Stigmas 3, thick, 2-lobed. Pepo fleshy or woody, 3 to 5-celled. SEEDS numerous, thickened at the margin, obovate, compressed, smooth.-Annual herbs with prostrate running stems, mostly branched tendrils, and yellow solitary axilary flowers.

\section{C. Pepo, L. Pumpkin.}

Hispid and scabrous; leaves (very large) cordate, palmately 5-lobed or angled, finely toothed; flowers axillary; stem fls. on long peduncles; fruit very large, roundish or oblong, smooth, furrowed and torulose. Native of the Levant. Long cultivated as a useful kitchen vegetable, or for cattle. Flowers large, yellow. 
Fruit sometimes 3 feet in diameter, yellow when mature. The Barrel Pumptin and 7-year Pumpkin are varieties of this species. July.

2. C. Melopepo, L. Flat Squash, Sweet Pumpliin.

Hairy; leaves cordate, somewhat palmately 5-Iobed, finely toothed; flowers pedunculate; fruit depressed-orbicular or club-shaped, often elongated and incurved at base, more or less furrowed with the ridges swelling. Native country unknown. A useful and well known kitchen vegetable.

3. C. verrucosa, L. Warted Squash. Club Squash.

Hairy; leaves cordate, palmately and deeply 5-lobed, denticulate, terminal lobes narrowed at base; flowers pedunculate, large; fruit roundish elliptic, or clubshaped, often elongated and curved at base. Probably a native of North America, as Mr. Nutall says it has been lon $r$ cultivated by the Indians West of the Missivsippi. Common in cultivation, with numerous rarieties. July.

\section{ORDER 48. CRASSULACRE,}

Succulent herbs, with simple mostly sessile leaves, and perfectly symmetrical flowers; the petals, pistils and sepals equal (3 to 20), and the stamens the same or doulte their number. Sepals more or less united at base. Petals distinct, rarely cohering. Ovaries as many as the petals and opposite to them. Filaments distinct. Axthers 2-celled, bursting lengthwise. Frur. Follicles as many as the oraries, epening by the rentral suture, many-seeded.

\section{TILLEA. Linn.}

In honor of Tilli, an early Italian botanist.

Sepals, petals, stanens, and pistills, 3 to 4 . Carpels 3 to 4 , distinct, opening by the inner suture, many-seeded.Very small tufted annuals, with opposite entire leaves and axillary flowers.

\section{T. SIMPlex, Nutt.-Pigmy Weed.}

Stem diffusely branching from the base and rooting; leaves linear-oblong, their bases somewhat confiuent; flowers solitary, nearly sessile, caly $x$ half the length of the petals, carpels 8 to 10 -seeded.

Muddy banks of streams; rare. Near Philadelphia. July, Aug. Stems 1 to 3 inches long, Leaves $1 / 8$ to $1 / 4$ inch long, spreading. Flowers very minute, white,

\section{SEDUM. Linn.}

Iat. sedeo, to sit; alluding to the manner in which these plants fix themselves upon rocks and walls.

Sepals and petals 5, rarely 4 . Stamens 10 , or rarely 8. Carpels 5, many-seeded, with a little scale at the base of each.-Mostly herbaceous thick-leaved perennials, with cymose flowers.

1. S. ternatem, Michx. Three leaved Stone-crop.

stems low and spreading; lower leaves whorled in threes, wedge-oborate; wppon $\mathrm{V}^{*}$ 
leaves oblong, scattered; cymes mostly 3-spiked, spreading; terminal flowers decandrous, the rest octandrous; stamens shorter than the linear-lanceolate petale.

Rocky woods; sometimes cultivated. May, June. Stems 3 to 8 inches long, branching and decumbent at base. Leaves from $1 / 2$ to 1 inch long. Flowers white, loosely arranged on the 3-branched spreading cymes.

2. S. TELEPHOIDEs, Michx. American Orpine.

Stems erect, leafy at the top; leaves scattered, lance-ovate or oval, flat, acute at each end, somewhat toōthed, smooth and fleshy; flowers in a terminal capitate cyme, decandrous; petals ovate-lanceolate.

Rocks: Allegheny mountains. July. Stem branching, 10 to 12 inches high. Leaves 1 to 2 inches long, $2 / 3$ as wide. F'lower's pale purple, with leafy bracts interspersed.

- 3. S. теLEpHIUM, L. Common Orpine. Live-forever.

Stems erect, leafy to the top; leaves flat, oval, obtuse, serrate, tapering at the base; cymes dense, compound. Native of Europe, cultivated and nearly naturalized. July. Stems 1 to 2 feet high, simple, leafy, round, smooth, purplish. Leaves sessile, fleshy. F'lowei's white and purple, in dense terminal leafy tufts.

\section{S. Anacampseros, I. Evergreen Stone-crop.}

Root fibrous; stems decumbent; leaves wedge-form, tapering at the base; cymes corymbose, leafy. Native of Europe. July. Stems reddish. Leaves fleshy, bluishgreen. Flowers purple.

5. S. ACRE, L. English Moss. Thall Pepper.

Procumbent, spreading, branching from the base; leaves very small, somewhat ovate, fleshy, crowded, alternate, closely sessile, obtuse; cyme few-fiowered, trifid, leafy. Native of Great Britain. Common in cultivation, spreading very rapidly on walls, borders of flower beds, \&c., densely covering the surface. Flower's yellow.

\section{PENTHORUM. Gron.}

Gr. pente, five, and oras a rule or mode; in allusion to the quinary flowers.

Sepals 5, united at base. Petals 5, or none. Stamens 10. PistiLs 5, united at the base so as to form a 5-angled, 5-horned and 5-celled capsule, which opens transversely on the inner sides of the beaks. SEEDS numerous, minute.Upright perennials, with scattered leaves, and yellowish-green flowers loosely-spiked along the upper side of the naked branches of the scorpoid cyme.

\section{P. SEDOIDES, L. Ditch Stone-erop.}

stem branched, angular above; ledves alternate, lanceolate, acute at both ends unequally serrate.

Ditches and overflowed grounds; common. Aug., Sopt. Stem 12 to 15 inches high. Flowers pale yellowish-green.

\section{ORDER 49. SAXIFRAGACEF,}

Herbaceous or shrubby plants, with alternate leaves, ind simple flower stems (often naked). CALYX free or more or less adherent to the ovary, superior or inferior, 4 to 5-cleft. Pexals 5, rarely none. Stamene 5 to 10, inserted either into the calys or beneath the orary. OTARY 1 or 2-eelled. STrLis nono. SIIGMAs sessile, on the 
tips of the lobes of the ovary. Frort a capsule or berry with numerous small seeds.

\section{SUB-ORDER I. SAXIFRAGE坐.}

Herbs; the petats imbricated (rarely convolute) in the bud; capsule 2-beaked; calyx free or partly adherent; petals 5 (rarely 4 to.6).

\section{SAXIFRAGA. Linn.}

Lat. saxum, a rock, and frago, to break; in allusion to the root penetrating the erevices of rocks and stones.

Calyx deeply 5-cleft. Petals 5, entire, with short claws. Stamens 10. Styles 2. Capsule 2-beaked, 2-celled, many-seeded, opening between the beaks or sometimes 2 almost separate follicles.-Chiefly perennial herbs, with clustered root-leaves, the stem leaves alternate, and yellow white and greenish flowers.

\section{S. Viratniensis, Michx. Virginian Saxifrage.}

Pubescent; leaves obovate or spatulate-obovate, often obtuse, crenate-dentate, tapered at the base into a broad petiole; flowers in a clustered eyme which at length becomes open and loosely panicled; petals oval, twice as long as the calyx; capsules 2 , united at the base, divergent.

Exposed roeks and hilly places; common. April-June. Scape 4 to 12 inches. high. Leaves in a radical spreading tuft. Flower's white, with a tinge of purple, A well known and pretty species, flowering in early spring.

2. S. Pennsytuanica, Linn. Swamp Saxifrage.

Pubescent; leaves oblanceolate or oval, narrowed at the base into a short and broad petiole, obscurely toothed; cymes in a large oblong panicle, at first clustered; flower's pedicellate; petals lance-linear, about the length of the nearly free recurred calyx lobes; filaments awl-shaped.

Wet grounds; common. May, June. A homely species 1 to 3 feet high. Leaves 4 to 8 inehes long, all radical. Flowers small, greenish-yellow. Capsuies at length. divergent.

2. S. erosa, Pursh. Lettuce Saxifrage.

Zeaves all radical oblong or oblanceolate, obtuse, sharply-toothed, tapering into arshort winged petiole; scape slender; paniole elongated, loosely flowered; pedicels slender; calyx reflexed, 3-nerved, free from the ovary nearly as long as the oral obtuse petals; filaments club-shaped.

Cold mountain brooks, near Bethlehem. Mr. Wolle. June. Root fibrous. Stem 12 to 30 inches high. Leaves 8 to 12 inches long. Petals small, white, with gellowish spot near the base.

\section{HEUCHERA. Linn.}

In honor of John Henry Heucher, a German botanist.

Catyx bell-shaped, cohering at the base with the ovary/2 5-cleft. Petals 5, spatulate, small, entire, erect. Stamens 5 , inserted alternately with the petals into the throat of the oalyz. STYLES 2. CAPSULE 1-celled, with 2 parietal many? 
seeded placentæ, 2-beaked, opening between the beaks.Perennial herbs, with round heart-shaped radical leaves, and greenish-white tinged with purple flowers in small clusters disposed in a prolonged mostly loose panicle.

\section{H. Americana, I. Alum Root.}

Hairy-pubescent and somewhat visced; lobes of the leaves short and rounded; panicle loose; stamens at length much exsierted.

Rocky woodlands; common. June, July. Scape 2 to 3 feet high, somewhat clammy hairy. Leaves deeply cordate. Flowers small, in a long simple panicle.

2. H. Pubescens, Pursh. Pubescent Alum Root.

Scax e nake, minutely glandular pubescent, or smooth below, often 2 to 4 -leaved; leaves orbicular-cordate; lobes rounded, sharply-toothed, with broad pointed teeth,

- eiliate with bristly hairs; flowers in a contracted panicle; stamens shorter than the erect lobes of the calyx.

Mountains and hills. May, June. Scape 10 to 15 inches high, slender. Flowers nearly $1 / 2$ inch in length. Calyx-lobes unequal, greenish-white. Petals violet-purple, veiny.

\section{MITELLA. Tourn.}

$\Delta$ diminutive of the Latin mitra, a mitre or cap; in allusion to the form of the capsule.

Calyx short, bell-shaped, coherent with the base of the ovary, 5-cleft. Petals 5, inserted into the calyx, slender, pinnatifid. Stamens 10, included. Styles 2, very short. CAPSUle short, 2-beaked, 1-celled, 2-valved; valves equal. SEeDs numerous.-Low and slender perennial herbs, with round heart-shaped leaves on slender petioles, those of the scape opposite, flowers small, greenish and white, borne in a simple slender raceme or spike.

1. M. Diphylla. L. Two-leaved Bishop's-Cap.

Radical leaves heart-shaped, acute, somewhat 3 to 5-lobed, toothed; scape leaves 2, opposite, mearly sessile; flowers in a terminal raceme; petals toothed-pinnatifid. Hillsides and rich woods. May. Stem 8 to 12 inches high. Radical leares on long petioles. Scape many-flowerod. Flowers small, white, in a raceme 4 to 8 inches long. Plant hairy. Two-leaved Mitre-wort.

2. M. NUDA, L. Heart-leaved Bishop's-Cap.

Stem slender; radical leaves somewhat 3-lobed, deeply and doubly-crenate; scape naked, or with a single leaf, fow-flowered; petals fimbriate-pinnatifid.

Deep moist woods with mosses. May-July. Scape 4 to 8 inches high, occa lonally prostrate with creeping suckers. Root-leaves on long petioles; stem leaves much smaller and sessile. F'towers greenish-white, few, in a terminal spike.

\section{TIARELLA. Linn.}

A diminutive of the Latin tiara, a head dress; in allusion to the form of the capsule.

Calry 5-parted, bell-shaped, nearly free from the orary. 
Petals 5, with claws, enfire, inserted into the calyx. Stamens 10, long and slender. Strules 2, distinct. Capsulies 1-celled, 2-valved; valves unequal. SEeDs few, globular near the base of the eapsule.-Perennial herbs, with radical cordate leaves and white flowers.

\section{T. cordifolia, L. False Mitre-wort.}

Scape naked; leaves arising from the root-stock or runners, heart-shaped, acutely lobed and toothed, slightly hairy above, ewowny beneath.

Rich rocky woods. April, May. Leaves on long petioles. Scape 6 to 12 inches high. Flowers white, in a simple terminal raceme. A handsome plant in flower

\section{CHRYSOSPLENIUM. Tourn.}

Gr. krusos, golden, and splen; in allusion to its supposed medicinal virtues.

CALYX-TUBE coherent with the ovary, the limb 4 to 5-parted, lobes obtuse, yellow within. Petals none. Stamens 8 to 10, very short. Styles 3. Capsule obcordate, 2-beaked, flattened, 1-celled, 2-valved at the top. SEEDS numerous.-Low and smooth herbs growing in wet places, with fleshy leaves, and small solitary or leafy-cymed flowers.

\section{Americanum, Schwein. Amer. Golden Saxifrage.}

Stem decumbent, slender, spreading, forked; leaves opposite, upper ones sometimes alternate, roundish-orate, slightly crenate lobed; flowers distant, inconspicuous, nearly sessile.

Springs and brooks. April, May. An inconspicuous sucoulent creeping plants with small greenish flowers. Stamens mostly 8, hisped; anthers orarge-color. Considered distinct from the European C. oppositifolium.

\section{SUB-ORDER II. ESCALLONIEA}

Shrubs; leaves alternate; petals valvate in the bud.

\section{ITEA. Linn.}

The Greek name of the willow; from a resemblance of foliage.

CALYX companulate, 5-cleft, free from the ovary; seg. ments subulate. Petals 5, lanceolote, much longer than the calyx and stamens. Stamens 5, inserted into the calyx. Styles 2, united. Capsule 2-celled, 2-grooved, 8 to 12 seeded.-A shrub, with alternate simple and minutely serrate leaves, and white flowers in simple spicate terminal racemes.

\section{I. Virginica, I.}

Leaves oval acuminate serrulate, on short petioles; capsules oblong, aeuminate tipped with the 2 united styles.

Margins of swamps. May, June. A shrub about 3 to 8 feet high. 


\section{SUB-ORDER III. HÝDRANGEA.}

Shrubs; leaves opposite; petals valvate in the bud; calyx-tube coherent with the ovary.

\section{HYDRANGEA. Gronov.}

Gr. hudor, water, aggion, a vase; in allusion to the form of the capsule.

Calyz-tube hemispherical, 8 to 10-ribbed, adherent to the ovary; limb 4 to 5-toothed, persistent. Petals ovate, sessile. Stramens 8 to 10 , slender. Styles 2. Capsule 2-celled, many-seeded, crowned with the 2 diverging styles, opening by a hole between the styles. - Shrubs with opposite petioled leaves and numerous flowers in compound cymes. The margined flowers are often sterile and radienit.

1. H. arborescens, L. Wild Hydrangea.

Leares ovate, obtuse, or cordate at base, pointed, serrate, ncarly smcoth; flowers in fastigiate cymes.

A handsome shrub, native along the banks of the Susquehanna, flowering in June. Stem 5 to 6 feet high. Fertile flowers small, white, yellowish or roscate, very numerous. In cultivation, the marginal flowers become radiate.

2. H. Quercifolio, Bartram. Oak-leaved Hydrangea.

Leaves deeply sinuate-lobed, dentate, tomentose beneath. Cymes paniculate, radiant; the sterile fowcrs very large and numerous. Native of Florida. A handsome shrub from 3 to 5 feet high, with very large leares, and showy flowers. at first a dull white becoming reddish.

3. H. HoRtensis, L. Changeable Hydrangea.

Leaves elliptical, crowned at each end, dentate-serrate, strongly veined, fmooth. Cymes radiant. Flowers mostly radiant. Native of China. This beautiful species has long been cultivated for its showy flowers which are at first green but pass successively through straw-color, white, purple and pink. The var. H. Japonica has the central flowers all fertile, bluish-purple, hardy about Philadelphia.

\section{SUB-ORDER IV. PHILADELPHE $Æ$.}

Shrubs: leaves opposite; petals convolute in cstivation; capsule 3 to 4-celled. lcculicidal.

\section{PHILADELPHUS. Linn.}

Name from Philadelphus, King of Egypt.

CALYX 4 to 5-parted, half-superior, persistent. CoroluA 4 to 5-petalled. Strue 4-cleft. Stamens 20 to 40 , shorter than the petals. CAPsule 4-celled, 4-valved, with loculicidal dehiscence. SEEDs many, ariled.-Shrubs, with opposite exstipulate leaves and showy white flowers.

\section{P. GRANDIFLoRus, Willd. Large-flowered Syringa.}

Leaves ovate, acuminate, denticulate, 3-veined, axils of the veins hairy. Stigmas 4, linear. Style undivided. A handsome shrub 4 to 8 feet high, with long slender branches. Native at the South, cultivated for its large showy white flowers, whieh are borne in a terminal uzabel of 2 or 3 together. 
2. P. Coronarius, L. False Syringa.

Leaves orate, sub-dentate, smooth. . Style distinct. Cultivated. Native of South Europe. Stems 4 to 6 feet high with opposite reddish twigs bearing leafy clustera of numerous fragrant showy white flowers.

\section{ORDER 50. HAMAMTELACE正.}

Shrubs with alternate simple leaves, the 4-cleft calyx cohering with the base of the ovary. Petals 4 to 5, linear. Stamens 4 to 24, inserted on the calyx; ovary consisting of 2 pistils united at the base, forming a 2-beaked woody capsule opening at the summit, 2-celled below, with a single pendulous bony seed in each cell.

\section{HAMAMELIS. Linn.}

Origin of the name uncertain.

CALYX 4-leaved or eleft, with 2 or 3 bractlets at its base. Petals 4, long, linear. Stamens 8, very short; the 4 alternate with the petals fertile, the other imperfect and scale-like. Styles 2, short. CAPSUle nut-like, 2-celled, 2-beaked. - Sthrubs or small trees, with short-petioled straightveined leaves, and yellow flowers.

\section{H. Virginica, L. Witch Hazel.}

Leaves obovate or oval, with wary-toothed margins, downy when young, on short petioles; flowers sessile, 3 or 4 together.

Dimp wools; common. A large shrub consisting of sereral crooked branching trunks from the same root, 6 to 12 feet high, flowering in Oct. and Nov. Leaves nearly smooth, obliquely cordate at base. 3 to 5 inches long, 2 to 3 wide, on petioles 1/2 inch long. Culy.x downy. Tetals yellow, curled or twisted. Capsule woody, containing 2 nuts.

\section{ORDER 51. UABBHLIFRREA,-Parsley Family.}

Mer3acenus plants with hollow stems, alternate, mostly compound leaves, petioles expanded or streathing at the base. Flowers in umbels, the calyx entirely adherent to the orary, the 5 petals and 5 stamens inserted on the disk that crowns the ovary and surrounds the base of the 2 styles. Frcir consisting of 2 coherent carpels separating from each other by their faces (eommissure) into 2 halves called merocarps. SEEDS solitary and suspended from the summit of each cell, anatro. pous, with a minute embryo.

\section{SUb-ORDER I. ORTHOSPERM A.}

Inner face of the seed flat or nearly so (not excavated).

\section{Hydrocotyle. Tourn. Marsh Penny-wort.}

Gr. muder, water, and kotile, a broad or flat cup; in allusion to the leaves of somo of the species.

Calyz-teeth obsolete. Petals equal, ovate, spreading, 
entire, apex straight. Stamens 5. STyLes 2, shorter than the stamens. FRUIT laterally flattened, orbicular or shieldshaped, the commissure narrow; corpels 5-ribbed, two of the ribs enlarged, often forming a thickened margin.-Low and smooth aquatic perennials, with slender stems, round peltate or lidney-form leaves, and small white flowers in simple umbets or clusters, single or proliferous.

\section{H. Americana, L. American Marsh Penny-wort.}

Smooth and shining; leaves round, kidney-form, doubly crenate, slightly-lobed; flowcrs in scssile umbels, 3 to 5-flowered; fruit orbicular.

Moist shady places. June, July. Small delicate plants, with filiform, branching stems 2 to 6 inches leng, sending out running suckers. Leaves thin, 1 to 2 inches in diameter on petioles 2 to 3 inches long. Flowers greenish-white, small, in very small axillary umbels.

\section{H. Ranunculoides, L. Lobed Marsh Penny-wort.}

Smooth; leaves round-kidney-form, 3 to 5-nerved, the lobes crenate; umbels-8 to 10-flowered; pedicels very short; fruit roundish, smooth, scarcely ribbed.

In water. June, July. Stems reak, 1 to 2 feet long, crecping or floating. Leaves mostly deeply 3-lobed, the midale lobes smaller than the other, 1 to 2 inches in diameter, on petioles 2 to 3 inches long. Flowers white on peduncles shorter than the petioles.

3. H. INTERRUPTA, Muhl.

Smooth; stem filiform; lcaves peltate, orkicular, crenate, 11-nerved; umbels capitate, subsessile, 5 to 8 -lowered; fruit orbicular.

Wet places; rare. June-Aug. Stem and root creeping. Leaves armost centrally peltate, $1 / 2$ to 1 inch in diameter, on petioles 2 to 3 inches long. Pedruncles about as long as the leaves, bearing clusters of a few sessile fowers, interruptedly along its length. Flowers small, white, on very short pedicels. Fruit notched at the base.

\section{H. umbelilata, L. Umbellate Penny-wort.}

Smooth; stems rooting at the joint; $l$ aves peltate in the middle, orbicular, notched at the base, doubly erenate; umbel many-flowered on an elongated peduncle.

Ponds and boggy places; rare. June-Aug. Stem creeping or floating, 2 to 4 inches long. Leaves on petioles 2 to 4 inches long. $3 / 4$ to 1 inch wide. Umbels 20 to 30 -Howered, the upper pedicel often proliferous with 2 or 3 umbels. Flowers small. Fruit notched at the base and apex.

\section{CRANTZIA. Nutt.}

In honor of Prof. Crantz, an Austrian botanist of the 18th century.

Calyx-teeth indistinct. Petals roundish, entire, obtuse. Fruit roundish; the carpels hollowed on the inner face, 5 -ribbed, 3 of the ribs on the back, narrow, the lateral ones thickened and spongy.-Small perennial creeping plants, with linear or filiform, entire feshy leaves, and few flowers on simple involucrate umbels.

\section{LINEATa, Nutt.}

$L$ caves cuneate-linear, obtuse, with transverse vein,, shorter than the peduncles. 
Muddy banks of streams. July. Stem 1 to 2 inches long, rooting and creeping In the mud. Leaves 1 to 2 inches long, nearly terete. Umbels 4 to 8 -flowered. F'lowers white, pedicelled. Fruit with red vittæ.

\section{SANICULA. Linn.}

Lat. sano, to heal; on account of its supposed medicinal virtues.

CALYX-TUBE beset with prickles, segments acute, leafy, persistent. Petals obovate, erect, converging, deeply notched. Fruir sub-globose, thickly clothed with hooked prickles; carpels without ribs.-Perennial herbs, with palmately-lobed or parted leaves, those of the root long-petioled; umbels irregular or compound, the greenish or yellowish flowers capitate in the umbellets, perfect, with staminate ones intermixed, and involucre of few often cleft leaflets, involucel of several, entire.

\section{S. Marilandica, L. Sanicle.}

Leaves 5 to 7 -parted, mostly radical, segments oblong, incisely serrate; sterite flowers numerous, on slender pedicels, about as long as the fertile ones; styles long and recurred.

Woods and thickets; common. June, July. Stem 1 to 2 fect high, branching at the top. Rurtical lcaves on petioles $1 / 2$ to 1 foot long, 3-parted at the base, with the latcral segmeats deeply 2-parted. Stem leaves few, nearly sessile. Petals white or yellowish, obcordate. Fruit several in each umbellet.

\section{S. Canadensis, L. Cenadian Sanicle.}

Leaves 3 to 5-parted, the segments incisely and sharply serrate; sterile flowers few, on very short pedicels, shorter than the fertile onos; styles shorter than the prickles of the fruit.

Woods. June, July. Plant 1 to 2 fect high. Leares thin, aivisions redge-obaTate or oblong, sharply cut and Ecrrate (the upper ones only 3-parted). Frut about 3 in each umbellet.

\section{DAUCUS. Tourn. Carrot.}

(The ancient Greek name.)

CALyX 5-toothed. Petals obovate, emarginate with an inflexed point. FrUit ovoid or oblong, the carpels with 5 primary, slender, bristly ribs, 2 of which are on the inner face, and 4 sccondary ones, (equal, more or less winged,) each bearing a single row of slender bristly prickles.-Biennials, with finely 2 to 3-pinnate or pinnatifid leaves, pinnatifid involucre, involucels of entive or 3.cleft bracts, white flowers, and concave umbels, dense in fruit.

\section{Carrota, L. Carrot.}

Stem erect, hisped; leaves tri-pinnate; loaflets pinnatifld; sagments linear-lcneesLate, acute. 
Old fields and roadsides; naturalized. July-Sept. Root fusiform. Stem 2 to 8 feet high. Leaves pale-green, numerous. Umbels large and compact, concave in fruit, resembling a bird's nest. F'lowers white or cream-color, central one of owals umlellet ajortive and dark-purple.

\section{HERACLEUM: Linn. Cow Parsnip.}

Dedicated to Her'cules.

Calyx 5-toothed, teeth minute. Petals obovate, emarginate, with the point inflexed. Fruit compressed, flat, with a broad, flat margin, and 3 obtuse dorsal ribs to each carpel; intervals with short club-shaped oil-tubes.-Stout perennials, with large sheathing pelioles, large flat umbels, decriduous involncres, and many-leaved involucels.

\section{II. lanatum, Mich. Cow Parsnip.}

Pubescent; stem groovel; leaves 1 to 2-ternately compound; leaflets petioled, round-cordate, lobed; fruit nearly orbicular.

Moist cultivated grounds. June. A very large coarse looking strong scented plant 4 to 8 feet high. Stems thick, furrowed, branehing. Lcaves large, on broad chanmelled membranaceous petioles. Fr howers white, in very large terminal umbels, sumetimes 1 foot in diameter. Pelals intersely heart-shapod, the outer commonly Jargor and radiant, appearing 2-cleft.

\section{PASTINACA. Tourn. PARSNIP.}

Lat. pustus, food or repast; from the nutritive properties of the root.

CAryx with the margin obsolete or minutely 5-toothed. PuTdus roundish, entire, involute. Fnum oval, flat, with a thin cntire winged margin; the carpels minutcly 5-ribbed, 3 of the ribs equi-distant on the back, the lateral ones distant from and contiguous to the margin.-Chiefy biennial plants, with spindic-shoped reots, pinnatly compound leaves, yelloin jowers with roundish entire petals, none radient, and small or no involucres or involucels.

\section{P. satriva, L. Common Parsnip.}

sten grooved, smooth; leaves pinnate; lcafets sessile, oblong, incised; termisat ones 3-lobed, downy berieath, shining above; umbels large, terminal.

Helds and waste places; naturalized. July. Roct large, sweet-flavored, and matritious in its cultivaled state, but in its wild state kecomes hard, acrid and risunous. Sterin 2 to 3 feot higb, erect, furrowed, branching. Flowers smallo yellow. Frwit large, llat.

\section{ARCHANGELICA: Hoffman.}

So named from its highly esteemed qualities.

CalyX-TeEth short. Petals lanceolate, equal, entire, acuminate, point inflexed. Fruit flattened, the carpels each z-ribbed on the back and winged at the margins, forming a 
double winged border to the point; the seeds separating, and coated all over with the numerous oil-tubes. - Stout and of en very large perennials, with 1 to 2-pinnately compound leaves, and usually large inflated petioles, scarcely any involucre, many-leaved involucels and perfect umbels of greenish or white flowers.

\section{A. atropurpurea, Hoffm. Great Angelica.}

Smooth; leaves 2 to 3-ternately eompound; the leaflets pinnate, 5 to 7 , sharply out serrate, acute, pale beneath; petioles much infiated; involucels $\delta$ to 10 , very short; fruit smooth.

Meadows and fence rows; common. July, Aug. Stem 3 to 6 feet high, stont, hollow, dark-purple, furrowed. Petioles large, infated, channelled on the upper side, with inflated stipules at base. Tinbels 3 , terminal, rounded, 4 to 8 inches in diameter. Flowers greenish white. A popular aromatic herb.

\section{A. Hirsuta, Torrey \& Gray. Hirsute Angelica.}

Stem striate, downy at the top; lcaves twice pinnately or ternately divided: leaflets ovate-oblong, equally serrate, smooth; involucels of 6 to 8 subulate leaves directed to one side; pedunc?es and fruit downy.

Dry open woods. July, Aug. Stem 2 to 5 feet high, simple, erect, straigdi. Leaves on petioles 6 to 10 inches long. Cmbels 3 to 4, on long relrety peduncles. Wlowers numerous, white.

\section{THASPIUM. Nutt. Meadow Parsnip.}

From the Isle of Thaspia, which gave name to the ancient allied genus Thapsia.

CaLYX minutely 5 -toothed. Petar elliptic, with a long inflated point. Frurt elliptical or oroid, not compressed laterally; carpels with 5 winged ribs, interstice with single vittæ. InvoLUCRe none.-Perennials with 1 to 4 ternately compound leaves, and yellow or dark-purple fowers.

1. T. Barbinode, Nutt. Hairy-jointed Thaspium.

Leaves 2 to 3 teruntely compound; leaflets redge-orate, acute, unequally and incisely serrate, entire towards the base; umbels terminal and opposite the leaves.

River banks, Northern part of the State. June. Stem tall and branching, downy on the joints, 2 to 3 feet high. Leaves smooth; upper ones sub-opposite. Flowers deep yellow, numerous.

2. T. Aureum, Nutt. Golden Thaspium.

Stem smooth; lower and middle stem leaves biternately, and the upper onew ternately divided; segments oblong-lancelate, fnely serrate, with cartilaginou teeth, the root-leaves often simple and round heart-shaped; fruit oval.

Banks and moist meadows. June. Stem 1 to 3 feet high, simple. Leaflets rery smooth, thickisk; the larger often heart-shaped, the upper wedge-shaped at the base. Umbels on long peduncles 10 to 12-rayed, with very short involucres. flowers yellow. Fruit oval.

3. T. atropurpureum, Nutt. Purple Alexanders.

Stem smooth or slightly pubescent; root-leaves simple and heart-shaped, some times ternate, serrate; stem leaves tcraste; leafiets heart-ovate and oblong-orato, aronate-serrate. 
Rocky hills and woods. Stem 1 to 2 feet high. Flowers dark purple. Fruse strongly winged, as broad as long.

\section{ZIZIA. Koch. Golden Alexanders.}

In honor of J. B. Zizie, a German botanist.

Calyx minutely 5-toothed. Petals elliptic, apex acuminate, inflexed. Fruit ovate or oval, flattened, didymous; CARPELS 5, ribbed, without wings; ribs narrow; vittce 1 to 3 in each interstice.-Smooth perennials, with divided leaves, no involucre, few-leaved involucels, and perfect umbels of yellow flowers.

\section{Z. CORDATA, Koch.}

Root-leaves simple, cordate, rarely lobed, crenate-serrate; stem-leaves sub-sessile, ternate, segments petiolate, ovate or oblong; serrate.

Meadows; common. May, June. Stem 12 to 18 inches high, smooth. Rootleaves sometimes slightly lobed. Involucels 1 to 2-leaved. Umbels on long naked peduncles. Flowers yellow. Fruit short, oval, black.

\section{Z. AUREA, Koch.}

Lower leaves biternate; upper ones biternate or ternate; segments oblong-lanceolate, acute, sharply serrate and often cut, the end ones attenuate into a wedge-form: base or winged stalk; involucels 3-leaved.

Rocky hills, woods and river sides. June, July. Stem 1 to 2 feet high, branching at the top, rather slender, erect, hollow, smooth. Lower leaves on long petioles. Umbels about 2 inches broad, 10 to 15 rayed. Flowers numerous, orange-yellow. Truit oval, brown, with prominent ribs.

\section{Z. INTEGERRIMA, DC.}

Leaves all 2 to 3-ternately divided; segments ovate or oblong; entire, obtuse; smooth and glaucous; involucels 1-leaved, very short.

Rocky woods; rare. May, June. Stem 1 to 2 feet high, branching above. Leaves. all petiolate, pale beneath. Umbel with elongated filiform rays 1 to 3 inches long, with minute involucels. Flowers yellow. Fruit roundish, compressed laterally, dark brown.

\section{CiCUTA. Linn. Water Hemlock.}

(The ancient Latin name of Hemlock.)

Calyx minutely 5-toothed. Petals obcordate, the points inflected. Fruit roundish, a little contracted at the sides; carpels with 5 flattish strong ribs; the lateral ones margined; interstice with single vittæ. - Smooth marsh perennials, with hollow stems, thrice pinnately or ternately compound leaves, few-leaved involucre, many-leaved involucels, and perfect umbels of white flowers.

1. C. maculata, L. Water Hemlock.

Lower leaves triternate and quinate; upper ones biternate, segments oblonglanceolate, coarsely serrate; umbels terminal and axillary.

Wet meadows; common. July, Aug. Stem 3 to 6 feet high, streaked with purple, smooth, jointed, glaucous, branched above. Petioles dilated at base inta long abrupt clasping stipules. Leaflets 1 to 3 inches long, $1 / 4$ to $3 / 4$ wide, semetimes lobed, pointed. Umbels numerous, 2 to. 4 inches broad. Poisonous 
2. C. Bulbifera, L. Bulbou: Hemlock.

Lexves ternate and biternate; leaflets linear, remotely toothed or cut-lobad; upper axils bearing bulbs; umbe?s terminal and axillary, small.

Wet meadows and swamps; rare. Aug. Stem 2 to 4 feet high, round, smooth and slender, striate, green, brancting. Involuce's of 3 to 5 subulate leares. Tmberlets of small, close, white flowers.

\section{SIUM. Linn. Water Parsnip.}

Celtic siu, water; in allusion to its place of growth.

CALYX with the margin 5-toothed or obsolete. Petars obcordate, with an inflexed point. STYLES divergent, reflexed. Frur ofate or globular, flattish or contracted at the sides; carpels with 5 rather obtuse ribs; interstice with several vittæ.-Marsh or aquatic perennials, with groovedangled stems; simply pinnate leaves, lanceolate serrate leafets (immersed ones cut into capillary divisions); several-leaved. involucres, and perfect umbels of white flowers.

\section{S. Latifolium, L. Water Parsnip.}

Slem angular and sulcate; leaflets broadly lancolate, pointed serrate, seasile mooth, sometimes pinnatifid.

Swamps. July-Sept. A tall plant found in ditches and swamps. Stem 3 to 5 feet high, smooth, hollow, about 7 -angled. Lenfiets 7 to 11,4 to 7 inehes long, 1 to 2 broad, equally serrati. Pelioles clasping the stem. Umbels long, with many. flowered rays. F'owers small, white.

2. S. Lineare, Michx. Narrou-leaved Wuter Parsnip.

Leaflets narrowly lanceolate or linear, fnely and sharply serrate, acute; ealym. teeth obsolete.

Swamps; more common than the last. July, Ang. Siem 2 to 4 fect high, mooth, about 7 -angled. Leaflets 9 to 11,2 to 4 inches long, $1 / 4$ to $1 / 3$ wide. Irrolws. ere of 5 or 6 linear bracts. Umbellets with numerous small white flowers. Frwit very strongly ribbed, crowned with the broad, yellowish stylopodium.

\section{CRYPTOT EANIA. DC. HONEWORT.}

Gr. kruptos, hidden, and tainia, a fillet, from the concealed vittæ.

Calrx with the margin obsolete. Petals obovate, with an inflexed point. FRUIT oblong, contracted at the sides; carpels equally 5-ribbed; vittce very slender, one in each interstice, and one under each rib.-A perennial smooth herb, with thin 3-parted lobed and toothed leaves; no involucre, few-leaved involucels, compound umbels with very unequal rays, and white flowers.

C. Canadense, DC. Canadian Honewort.

Ieaflets rhomboid-ovate, distinct, entire or 2 to 3-lobed, doubly serrabe, Iatora ones obligue at base. 
Rich moist woods. June-Sept. Stem erect, 1 to 2 feet high, branched above. Teaflets 3, 2 to 3 inches long, 1 to 2 wide. Petiotes clasping, 2 to 6 inches long. Umbels numerous, paniculate, the lower ones rising from the axils of the upper leaves. Flowers small, white. Fruit oblong beaked with the persistent style.

\section{ARCHEMORA. DC. COWBane.}

A fanciful name given by DeCandolle in allusion to Archemarus, who is said to have died from eating parsley.

Calix 5-toothed. Petals obcordate, inflexed. Fruit oval, with a broad winged margin; carpels with 5 sub-keeled equi-distant filiform ribs; vittoe one in each interstice, and 4 to 6 on the inner face.-Smooth perennials, with rigid leaves, of 3 to 9 linear or lanceolate leaflets; scarcely any involucre; involucels of numerous small leaflets, and white flowers.

\section{A. RIGIDA, DC. Rigid Cowbane.}

Stem rigid, striate, erect; leaves simpily pinnate; lcaflets 3 to 9, varying from lanceolate to ovate oblong, entire, or remotely toothed, in Var. AMBIGUA, linear, long and narrow.

Swamps; rare. Aug., Sept. Stem 2 to 4 feet high, slender. Leaflets 2 to 4 by $1 / 4$ to $3 / 4$ inches, varying in outline. Umbels 2 to 3 , of many slender rays. Fetals white. Fruit with sub-equal greenish ribs, and large purple vittæ filling the intervals. Poisonous.

\section{BUPLEURUM. Tourn. Thorough Wax.}

Gr. bous, an ox, pleuron, a rib; it is uncertain why so called.

Calyx-teeth obsolete. Petals somewhat orbicular, entire, with a closely inflexed point. FruIT ovate-oblong, laterally flattened, or somewhat terminal; carpels 5-ribbed, with or without vittæ.- Herbaceous or shrubby plants, with simple entire leaves; various involucres, and yellow flowers.

B. Rotundifolium, L. Modesty Thorough Wax.

Leaves roundish-ovate, entire, perfoliate; involucre none; involucels of 5, ovate, mucronate bracts.

In cultivated grounds; escaped from gardens. Annual. July, Aug. Stem 10 to 15 inches high, branching. Leaves 1 to 3 inches long, 3/4 as wide, rounded at base, acute at apex, very smooth. Involucels longer than the umbellets. Lmbels 5 to 9-rayed. Fruit crowned with the wax-like shining base of the styles. Carpets. mostly without vittæ.

CULTIVATED EXOTTCS:

\section{CARUM. Linn. CarawaY.}

From Caria, the native eountry of the plant.
Calyx-margin obsolete.
Petals obovate, emarginate, the point inflexed. STYLES dilated at base, spreading. FruIT 
oval, laterally compressed; carpels 5 -ribbed, lateral ribs margined; intervals with single vitta.-Herbs with dissected leaves, perfect umbels, various invoiucres, and white flowers.

\section{Carvi, L. Caraway.}

stem 1 to 2 feet high, branched, smooth, striate. Leaves somewhat bipinnatifid, with numerous linear segments, lotrer ones las ge, on long petioles, with tumid, clasping sheathe. Tmbels on iong peduncles; involucrate bract when present linear-laneeolate. Native of Europe. Cultivated for its fine aromatic fruit.

\section{APIUM. Linn.}

Celtic apon, water; the plants grow in watery situations.

Calyx-margin obsolete. Petals roundish, with a small or narow inflexed point. FruIT ioundish, laterally compressed; carpels 5-ribbed, the inteivals with single vittæ.European herbs, with pinnately dissected leaves; perfect umbels and white flowers.

\section{A. Graveolens, I. Celery.}

Lower leaves pinnately dissected, on rery long petioles, segments broad redgea shaped, incised; upper leares 3-parted, segments wedge-shaped, lobed and incisely dentate at apex. Stem 2 to 3 feet high, branching: furrawed. Umbels with unequal spreading rays. Native of Britain. The stems $n$ hen blanched are used as a sallad. June, Aug:

2. A. Petroselinum, Willd. Parstey.

Leaves decompound, segments of the lower ones wedge-ovate, terminal ones trifid, all incised; cauline segments lance-linear, sub-ertire; involucels of 3 to 5 subulate bracts. Slem 2 to 4 feet high, branched. Lec res smooth and shining. Juno. Tative of Sardinia and Grcece. Esteemed as a pet herb.

\section{PIMPINELLA. Linn. ANISE.}

Calyz-limb obsolete. Petals obcordate, somewhat unequal. STYLEs capillary as long as fruit. FruIt ovate, ribbed, with convex intervals.-European perennial herbs, with pinnately many-parted leaves, compound umbels without involucres, and white flowers.

P. Anisum, L. Anise.

Radical leaves incisely trifid; those of the st $m$ many-cleft, with narrow-lineassegments, smooth and shining. Tmets large, n any-rayed. Native of Egypt. \& ₹ell, known aromatic carminative of the garden.

\section{FoeniCulem. Adans. Fennei.}

Lat. diminutive of fonum, hay; from the resemblanee of its odor.

Calyz-margin obsolete. Petais revolute, with a broad, 
retuse apex. FruIt elliptic-oblong, laterally sub-compressed; carpels with 5 obtuse ribs, those of the margin a little broader; intervals with single vittæ. - Autumnal herbs, with biternately dissected leaves, no involucre or involucels, perfect nimbels, and yellow flowers.

F. volgare, Gart. (Anethum, Willd.) Fennel.

Leaves biternately dissected, segments linear subulate, elongated; rays of the nmbel numerous, unequal, spreading; carpels turgid, ovate oblong. Nutive of Fingland. Cultivated in gardens. Stem 3 to 5 feet high, round and smooth, branched. Leaves large and smooth, finely cleft into numerous very narrow sents, seeds warmly aromatic.

\section{SUB-ORDER II. CAMPYLOSPERM IE.}

Innes face of the seed hollowed out lengthwise, or the margins invoidte.

19. CHÆROPHYLLUM, Linn.

Qs Laira, to gladden, and pliullon, a leaf; alluding to the agreeable odor of the leaves.

Cazrx-teeth obsolete. Petals ubovate, cmarginate, point inflexed. Fruit laterally compressed, linear or oblong; carpels with 5 obtuse equal ribs, inner face deeply furrowed lengthwise, intervals with single vittæ.-Annual or biennial plants, with bi or tri-ternate leaves, incisely clefi or toothed segments, no involucre, many-leaved involucels, and mostly white flowers.

C. procumbens, Lam. Wild Chervil.

Stems slender, spreading, somewhat hairy; segments of the leares pinnatifi, with obtuse oblong leaflets; umbels diffuse, few-Howered, of ten simple.

Moist shady places; not common. May. Stems 1 to 2 feet long. Tmbels quito tregular, often with leaves in the place of the involucre. F'lowers white.

\section{OSMORHIZA. Raf. Cicily.}

Gr. osma, a scent, and riza, a root; in allusion to the aromatic root.

Calix-teeth obsolete. Petals oblong, nearly entire, the sharp straight point inflexed. FruIT linear-oblong, angled, attenuated at base, contracted at the sides, erowned with the styles; carpels with hisped angles and 5 acute ribs, inner face with a deep bristly channel; vitto none.-Perennials, with thick aromatic roots, large 2 to 3-ternately compound leaves, few-leaved involucre and involucels, and white flowers.

1. O. Longistruis, DC. Sweet Cicily. Sweet Myrrh.

zeaflets sparingly pubescent or smooth when old, short pointed, cut-toothed, somotimes lobed; styles slender, neariy as long as the ovary. 
Rich moist woods; common. May, June. Stem 2 to 3 feet high, branching, purplish, nearly smooth, striate. Leaves mostly bi-ternate, those of the root on long petioles; leaflets oblong ovate. Flowers white, mueh larger than in the next. Fruitblackish, one inch in length, crowned with the persistent styles. Root with the flavor of anise.

2. O. BRevistruits, DC. Short-styled Cicily.

Leaflets pinnatifid cut, acuminate, downy-hairy; styles conical, not longer than the breadth of the ovary; fruit somewhat tapering at the summit.

Moist rocky shady places; commoner than the last. May, June. Stem about 2 feet high, branching, pale-green, at length smooth. Leaves bi-ternate; leaflets incised, often pinnatifid. Fruit similar to the last, but crowned with convergent styles. Root nearly tasteless, said to be poisonous.

\section{CONIUM. Linn. Poison Hemlock.}

Konieon, the Greek name of the Hemlock by which criminals and philosophers were put to death at Athens.

Calyx-teeth obsolete. Petals obcordate, with an acute inflected point. FruiT ovate, flattened at the sides; the car. pels with 5 prominent waving ribs; inner face with a deep narrow groove; vittce none.-Biennial poisonous herbs, with large ob-compound leaves, 3 to 5-leaved involucres and involucels, and white flowers.

\section{Maculatem, L. Poison Hemlock.}

Stem spotted; leaves tri-pinnate; leaflets lanceolate, pinnatifid; involucols shortes than the umbellets; fruit smooth.

Waste places, naturalized along Chillisquaque creek, Montour county. A large branching herb, about 4 feet high, rery smcoth. Stem much branched, round, hollow, with purplish spots. Lower leaves rery large, bright green, on long sheathing foot-stalks. Lmbels terminal, the in volucre with 5 to 8 lanceolate bracts, the involucels with the inner balf wanting. I lowers small, white. Whole plant highly poisonous; fetid when bruised.

\section{SUB-ORDER III. CCELOSPERM Æ.}

Seeds incurved at base and apex.

\section{ERIGENIA. Nutt.}

Greek erigeneia, a name of Aurora, the harbinger of day, or of the spring; or account of its being the first conspicuous flowering plant in the U. S. Nutt.

Caliyx-teeth inconspicuous. Petals obovate or spatulate, flat, entire. Fruit somewhat laterally compressed, reniform or termined with 5 very slender acute bristly ribs.A smooth and slender perennial, with 2 to 3 ternately divided leaves, a somewhat leafy bracted compound umbel, with white flowers.

E. BUlbosa, Nutt. Bulbous Erigenia.

Alluvial soil; Western part of the State. March, April. Root globose, tuberous Stem simple, 4 to 5 inches high, 2-leavcd. Leares 3-parted; divisions sub-pinnate. Tmbels terminal, 3 to 5 -flowered. Flowers white. 


\section{CORIANDRUM.}

Gr. koris, a bug; on account of the smell of the lcaves.

Calyx with 5 conspicuous teeth. Petals obcordate, inflexed at the point; those of the outer flowers radiate, bifid. Fruit globose; carpels cohering, with 5 depressed primary ribs, and 4 secondary, more prominent ones; seeds oncave on the face. - Smooth anmuals with bi-pinnate leaves; involucre one-leaved or none, involucels 3-leaved, unilateral, and white flowers.

\section{C. sativum, I. Coriander.}

Leaflets on the lower leaves broad, wedge-shaped, upper with linear ones; carpels hemispherical. A well known plant, cultivated chicfly for its aromatic seeds. Native of Europe. Stem 2 feet high. Leaves much divided, strong scented. Un: bels with only the partial involucre. Flowers white. July.

\section{ORDER 52. ARALIAOMERE.}

Trees, herbs or shrubs, with the hatit of the Umbelliferce, but with usually 5 to 10 Rat petals, 5 to 10 stamens, 2 to 5 styles, and the fruit 2 to 3 -celled drupes.

\section{ARALIA. Linn. Spikenard.}

CaLyx with the margin very short, 5 -toothed. Petals, ETAMENS and PISTILS 5. FRUIT a berry-like drupe, 3 to 5-celled, 5-seeded, crowned with the remains of the calyx and styles.-Low trees, shrubs or perennial herbs, with large 2 to 3-ternately or pinnaiely compound leaves, and panicled umbels of greenish-white flowers.

1. A. nudicaulis, L. Wild Sarsaparitla.

Herbaceous, smooth; stem very short; leaf solitary, decompound; leafets olion. ovate or oval, pointed, serrate, 5 on each division; scape naked, bearing 3 umbels.

Moist rocky woods; common. May, June. Root large, fleshy and aromatie, running under ground sevcral fect in length, from whick arises a single leaf-stalk and scape, without a proper stem. Scape about 1 feet high, with 3 simple umbels of greenish flowers.

\section{A. RACEMosa, L. Spikenard.}

Herbaceous; stem widely branched, leafy; leares decompound; leaflets heartovate, doubly serrate pointed, slightly downy; umbets small, very numerous.

Rich rocky woods. June, July. Jioots large, spicy, aromatic. Stem 2 to 5 feet high, dark green or reddish. The leaf-stulks are 3-parted, each division of which bears 3 or 5 large leaflets. Flower's greenish-white, in pauicles 4 to 8 inches long.

3. A. HISPIDA, Michx. Bristly Sarsaparilla.

Stem shrubby at base, hispid; leaves twice pinnate; leaflets oblong ovate, acnte, ent-serrate; umbels on long peduncles, axillary and terminal.

Rocky places. Junc-Aur. Stem 1 to 2 feet high, the lower part woody and thiokly boset with sharp stiff bristles, the upper part branching, herbaccous. 
Leaflets numerous, long. Umbels numerous, simple, globose. Flowers greenishwhite. Fruit blackish, nauseous to the taste.

\section{A. Spinosa, L. Angelica Tree.}

Arborescent; stem and petioles prickly; leaves large, 2 to 3-pinnate; leaflets ovate, pointed, serrate, sessile, glaucous beneath; umbels in a branched panicle, nomerous.

Dainp woods, Southern parts of the State. Cultivated. July, Aug. A small tree 8 to 12 feet high, (sometimes 20 to 40 ,) the leares crowded near the summit. Flowers white, in very large terminal panicles. The bark is said to be emetic and eathartic.

\section{PANAX. Linn. Ginseng.}

Gr. $p x n$, and alcos, a medicine, i. e. a panacea, or a universal remedy.

Flowers polygamous. Calyx-teeth obsolete. Petals and stamens 5. Styles 2 to 3. Frutt a 2 to 3-lobed, 2 to 3 -celled, and 2 to 3 -seeded drupe, often fleshy.-Perennial herbs or shrubs, with palmately compound leaves, (in our species 3 stem leaves in a whorl,) and whitish flowers in a single simple umbel on long peduncles.

\section{P. trifolium, L. Dwarf Ginseng. Ground-nut.}

Iont glolular; leaves 3-rerticillate, 3 to 5 -foliate; leaflets lanceolate-oblong, serrate, sub-sessile; styles 3 ; berries 3 -seeded.

Lor lnoist woods; common. May. A neet little plant 4 to 8 inches high with a tubsr dsep in the ground. Siem smonth, slender, simple. Leaves 3 , in a whorl at the sumit, compounl, with a central peluncle terminating in a little umbel of pure white flowers. Barren and fartile flowers on different plants, the latter without stamens succeeded by green berries.

2. P. QUinquefolium, I. Ginseng.

Rnt fusiform; leaves 3, verticillate, 5-foliate; leafets oblong-orate, pointed, serrate, long-petioled, the latoral ones smaller; perluncles sloorter than the petioles; siyles 2 ; fruit flattened; seeds 2.

Rich woods and mountain siles; not common. June, July. Roct spindle shaped, 3 to 6 inches long, often forkel, aromatic. Stem round, smonth, ahout 1 foot high, with a terminal whorl of 3 compound leaves, and a central peduncle bearing a single umbel of yeliowish flowers. Berries light-scarlet. The root is bighly esteered by the Chinese and Tartars for its supposed medical properties

\section{HEDERA. Linn. IVY.}

Celtic hedra, a cord; from the vine-like habit.

Calyx 5-toothed. Petals 5, dilated at the base. Berry 5 -seeded, surrounded by the permanent calyx.-European shrubby, climbing or erect plants, with simple evergreen leaves, and greentsh flowers.

\section{H. HELIX, L. English Ivy.}

Stem and branches long and flexible, attached to the earth trees or walls by its numerous radicating fibres; leaves dark green, smootb, with white veins, petiolate; lower ones 5-lobed, upper ovate, fower's in numerous umbels, forming a corymbi berry blaek, with a mealy pulp. Native of Britain. Cultivated. 


\section{ORDER 53. CORNACER.}

Low trees, shrubs or rarely herbaceous plants, with simple mostly opposite and entire leaves. CALYX SEPALS adherent to the ovary, with the limb minute, 4 or 5-toothed or lobed. Petals 4 or 5 dietinct, alternate with the teeth of the ealyx. STAMENS 4; STYLE single; STIGMA capitate; ovary 1 to 2-celled, with a single anatropous ovule suspended from the apex of each eell, and fruit a gloBose 2-celled and 2-seeded drupe.

\section{CORNUS. Tourn.}

Lat. cornu, a horn; on account of the hardness of the wood.

Calix minutely 4-toothed. Petals 4, oblong, spreading, sessile. Stamens 4. Strue 1. Drupes berry-like, separate.-Trees, shrubs or perennia? herbs, with mostly opposite entire leaves, and white or whitish flowers in cymes, often involucrate. Bark bitter and tonic. red.

* Flowers capitate, surrounded by a petal-litce 4-leaved whitc involucre: firit bright

1. C. Canadensis, I. Dwarf Dogwood.

Herbaceous; stem low and simple; lowsr leaves small, upper ones whorled, veiny, on short petioles, ovate or oval, pointed; leaves of the involuere ovate.

Damp cold woods. May-July. A handsome little plant 5 to 7 inches high, arising from a slender creeping and subterranean rather woody rhizoma, with 1 to 2 pairs of opposite leaves and a whorl of 4 to 6 at the summit, 2 of which are large, placed a little lower and opposite. Flowers greenish, surrounded with a large showy involucre of 4 white leaves, sometimes mistaken for a single flower.

2. C. FLORIDA, L. Flowering Dogwood.

Arborescent; leaves ovate, pointed, lowny beneatin when joung; leaves of the involucre inversely heart-shaped; flowers and fruit in a close head.

Rocky woods; common. Nay, June. A tree 15 to 20 feet high, very showy in nower. Flowers inconspicuous, greenish-yellow. Involucre very large and showy, obovate, veiny, white, ending in a callous point, which is turned up or down se abruptly as to give an emarginate appearance to the leaf. Berries red, very ghowy

** Flowers in cymes: involucre none; shrubs.

3. C. crrcinata, L'Her. Round-leaved Dogwood.

Branches warty-dotted; leaves round-oral, abruptly pointed, winite, downy beneath; cymes crowded, depressed; drupe globose.

Banks of streams. June, July. Shrub 6 to 10 feet high. Stem greyish, upright, with opposite, round, green, spotted or warty branches. Leaves large, 4 to 5 inches in diameter, opposite, somewhat acuminate. Flowers white. Lerrics light-blue, hollowed at base, crowned with the remains of the style.

\section{C. Sericea, L. Red Osier. Silly Dogwood.}

Branches spreading; leaves ovate, acuminate, silk-downy (often rusty) beneath; cymes flat, close; caly $x$-teeth lanceolate; drupe globose.

Wet places, banks of streams; common. June. Shrub 4 to 10 feet high, with purplish bark, and opposite branches and red shoots. Leaves 2 to 4 inches longo $1 / 2$ as wide. Flowers yellowish-white. Fruit pale-blue.

5. C. Paniculata, L'Her. Panilled Dogwood.

Branches erect, fmooth; leaves orate-lanccolate or ora!, ncuminate, acute at bas, phitish beneath; cymes convex, loose, often panicled; fruit depressed-globose. 
Thickets and hillsides. June. Shrub 4 to 8 feet high, very much branched, with a yellowish bark. Leaves small, 1 to 2 inches long, $1 / 2$ to $2 / 3$ as wide. Flowers profuse, pure white, in small conical cymes. Drupes small, white or bluish.

6. C. stolonifera, Michx. Red-Osier Dogwood.

Stem often with running shoots; branches spreading, smooth; leaves ovate rounded at base; abruptly acuminate; cymes small, flat, rather crowded; drupe globose.

Bogs and wet banks of streams. May, June. A small tree 8 to 10 feet high, with smooth, slender, spreading branches, which are mostly red in winter. It multiplies by prostrate running suckers which send up red shoots forming large clumps 3 to \% feet high. Leaves distinctly veined, minutely pubescent, and whitish beneath, petiolate. Flowers white, in small cymes. Drupe small or lead colored.

7. C. alternifolia, L. Alternate-leaved Dogwood.

Leaves alternate, oval, long-pointed, acute at the base, whitish and minutely pubescent underneath; drupes globose.

Hillsides and moist shady woods. June. A small tree or shrub 8 to 20 feet high, with spreading one-sided branches forming a depressed summit. Barke greenish, marked with warty streaks. Flowers in broad open cymes, pale buffcolor. Iruit dark-blue.

\section{DIVISION II.}

\section{MONOPETALOUS EXOGENOUS PLANTS.}

Floral envelopes consisting of both calyx and corolla, the latter composed of petals more or less united (monopetalous.)

\section{ORDER 54. CAPRIFOLIACEF. - Honey-suckle Plants.}

Shrubs or rarely herbs, often twining, with opposite leaves, no stipules, the CALYX TUBE coherent with the 2 to 5-celfed ovary. CoRolla tubular or rotate, regular or irregular. STAMens as many, or one less than as many, as the lobes of the corolla, and inserted on its tube. Strles 1 ; stigma 1 to 4 . FruT a berry, drupe, or cepsule.

\section{TribE 1. LONICERE $Æ$.}

Corolla tubular, often irregularly cleft; style slender; stigma capitate.

\section{LONICERA. Linn.}

In honor of Lonicer, a German botanist of the 16th century.

CALYX 5-toothed; teeth very short. CoRolla tubular or funnel-form, often swelled at the base, irregularly or nearly regularly 5-lobed. Stamens 5. Ovary 2 to 3 -celled. StigMA 'capitate. BERRY several seeded.-Climbing or erect shrubs, with opposite and often connate entire leaves, and often showy, fragrant flowers. * CAPRIFOLIUM. Stem climbing; flowers in sessile whorled clusters from the axile
of the leaves. 


\section{L. Sempervirens, Ait. Trumpet Honey-suckle.}

Leaves oblong evergreen, pale beneath, the lower petioled, the u ppermost pairs anited a ound the stem; flowers in nearly naked spikes or distant whorls.

Borders of swamps; common in cultivation. May-0ct. A beautiful climber blooming all summer. Stem 6 to 20 feet long, woody, twining with the sun. Leaves deciduous at the north. Corolla trumpet-shaped, nearly 2 inches long, dilated at the mouth, with 5 short, nearly regular segments, of a rich scarlet without and yellow within. A variety has pale yellow blossoms. Berries searlet.

\section{L. GRATA, Ait, American Woodbine.}

Leaves obovate, smooth, glaucous beneath, the upper pairs united; flowers in sessile, terminal and axillary whorls; corolla ringent, tube long, slender, not swelled.

Rocky woodlands. May, June. A beautiful elimber with very obtuse leaves, ending in an abrupt point, opposite or in whorls of 3 . Flower's large and very fragrant, 5 or 6 in each whori. Corolle white, within a purple, fading yellowish. Berries red. Cultivated.

\section{L. PARViflora, Lam. Small-flowered Honey-suckle.}

Leaves smooth, elliptical or oblong, shining above, glaucous beneath, tho upper pairs united, all closely sessile; flowers in heads of several approximate whorls; coralla ringent; tube short, swelled at the base; filaments bearded.

Rocky bauks; common. Mav, June. A low branching species. Leaves thickish, wsry and revolute on the maryin, very glaucous beneath. Flowers small, yellow, tinged with dull red. Stamens and styles exserted. Berries orange-colored.

4. I. Pericly menum, Tourn. Woodbine Honey-suckle.

Leaves elliptical, on short petioles, deciduous. Flowers in ovate imbricated terminal heads; corolla ringent, yellow and red, fragrant. Eerries red. MayJuly. A woody elimber, native of Europe. Cultivated.

\section{L. Caprifolium, L. Italian Honey-suckle.}

Lexv s deciluous, the upper pair united. Flowers in a terminal verticel, yellow, rod and white. Much admircd for its beauty and fragrance. Native of Europe. June-A ug. Cultivated.

* * XrLosteur, Juss. Stem erect; leaves distinet; peduncles axillary, single, 2-iracted and 2-flowered at the summit.

\section{L. ciniata, Muhl. Fly Honey-suckle.}

Leaves oblong-ovate, often cordate, distinctly petioled, thin, downy beneath; peduncles shorter than the leaves; bracts minute; corolla funnel-form, swelled at the base.

Rocky woods, Northern parts of the State. May, June. A branching erect shrub 3 to 4 feet high. Flowar's pale straw-yellow, in pairs, at the top of the peduncle, with o,n obtuse spur turned outwards at the base. Berries ovoid, red, in pairs.

7. L. Tartarica, L. Tartartan Honey-suckle.

Stems erect, much branched; leaves ovate, cordate, obtuse, shining and darkgreen above, pale bencath, entire, on short petioles; peduncles axillary, solitary, 2-flowered; segments of the corolla oblong, obtuse, equal. An elegant shrub much admired in cultivation. Native of Riussia and Tartary. Slems 4 to 8 feet high, forming large clumps. Leaves 1 to 2 by $3 / 4$ to $1 \frac{1}{2}$ inches, coriacious. Flowers small, pale-purple, varying to pure white, very fragrant. May-June.

\section{Diervilia, Tourn. Bush Honey-suckle.}

In honor of M. Dierville, who sent this species from Canada to Tournefort. CALYX-TUBE tapering at the sumamit; the lobes slender, 
awl-shaped, persistent. CoRouLA funnel-form, 5-lobed, nearly regular. Stanens 5. CAPSULE oblong, aeute, 2-celled, 2-ralved, septicidal, many-seeded.-Low upright shrubs, with opposite, ovate, serrate pointed leaves, and yellowish flowers in cymosely-several-flowered peduncles.

D. TRIFIDA, Moench. Bush Honey-suclile.

Leaves oblong-ovate, acuminate, petioled; peduncles mostly i-flotrered; capsulo long-beaked.

Rocky woods and banks of streams. May-July. Stcm 1 to 3 feet high, branching. Leaves 2 to 4 by 1 to $1 \frac{1}{2}$ inches, finely serrate, long-pointed. Flower greenish-yellow. Style much exserted. Stigma capitate.

\section{TRIOSTEUM. Linn.}

Gr.treis, three, and osteon, a bone; alluding to thethree bony seeds.

Calyx-Lobes 5, linear-lanceolate, leaf-like, persistent. Corolla tubular, swelled at the base, somewhat equally 5 lobed, scarcely longer than the calyx. STAMENs 5, included. Strigma capitate, lobed. Fruit a drupe, mostly 3-celled, erowned with the calyx, containing 3 angled and ribbed, bony nuts.-Coarse hairy perennial herbs, with the stem leafy to the top, and the ample entire pointed leaves tapering to the base, but connate around the stem.

\section{T. Perfoliatum, I. Feverwort.}

Softly hairy; leaves oval or spatulate-ovate, acuminate, entire, abruptly narrowed at the base, crenate, downy beneath; flowers sessile, 1 to 3 in the axils c 1 the leaves.

Rich woodlands. June. Stem 2 to 4 feet high. Leaves 6 by 3 inches. Fruit a rather dry drupe, orange-colored. The root is large and fleshy, and in some reputo in medicine.

\section{T. Angustifoutum, L. Narrow-leaved Feverwort.}

Bristly hairy; leaves lanceolate, tapering to the base; flower's mostly solitary in the axils, sessile or pedunculate.

Shady places, along fences. May, June. Stem 1 to 2 feet high. Flowers greenish-rean-color, mostly singly clustered in the axils of the leaves.

\section{SYMPHORICARPUS. Dill.}

Gr. symphoreo, to bear together, and carpus, fruit; from the clustered berrie.

CALYX-TUBE 4 to 5-toothed; persistent; teeth small. Co. RoLLA bell-shaped, nearly regularly 4 to 5-lobed. STAMENs 4 to 5 , inserted into the throat of the corolla. Ovary 4-celled, only 2 of the cells with a fertile orule; the berry therefore 4-celled and 2-seeded. SEeDs long.-Low and branching upright shrubs, with oval shortly petioled leaves, and small white flowers tinged with rose-color, in close shork spites or clusters. 


\section{S. vulgaris, Michx. Indian Currant. Coral-berry.}

Leaves round-oval; flowers in small spikes or clusters in the axils of nearly all the leaves; corolla sparingly bearded.

Banks of streams. July. Stem 2 to. 3 feet high, with numerous purplish branches. Corolla greenish-red, companulate, lobes nearly smooth; stamens and bearded style included. Berries small, purplish.

\section{S. Racemosus, Michx. Snow-berry.}

Leaves oval or oblong, the margin often wavy, nearly or quite smooth, paler beneath, on short petioles; flowers in a terminal loose and somewhat leafy interrupted spike.

Cultivated; native from Lake Champlain to Wisconsin. June, Sept. Stem 2 to 4 feet high. Corolla rose-color, the throat filled with hairs. Berries large, round or ovoid, of a snowy white, remaining till winter, very ornamental.

\section{LINNAEA. Gron.}

In honor of tinnoeus, the most profound of naturalists, ancient or modern, with whom this charming little plant was an especial favorite.

Calyx-teeth 5, awl-shaped, deciduous. Corolla narrow, bell-shaped, nearly equally 5-lobed. STAMens 4, 2 of them shorter, inserted near the base of the corolla. OVARY 3-celled, 1-ovuled, (2 cells abortive,) forming a 1-seeded dry berry.-A slender creeping and trailing evergreen, with round-oval leaves and delicate nodding flowers, widely dis-" seminated through the northern temperate zone.

L. BoREalrs, Gron. Twin-flower.

Stem slender, creeping and trailing; leaves round-oval, sparingly crenate, contracted at the base into short petioles; peduncles filiform, forking into 2 pedicels at the top, each bearing one flower.

Moist mossy woods; common northward. June. Stems long, filiform, brownish, rooting and branching their whole length, and covering the ground in large patches. Leaves small, opposite, with obtuse lobes or teeth and scattered hairs. F'lower's nodding, delicate and fragrant, rose-colored.

\section{Tribe 2. SAMBUCE A. The Elder Tribe:}

Corolla regular, rotate; stigmas 3 to 5 , nearly sessile.

\section{SAMBUCUS. Tourn. ELDER.}

Gr: sambuca, an ancient musical instrument, supposed to have been made of Elder-wood.

Catyx small, 5-parted. Corolla urn-shaped, with a broadly spreading 5-cleft limb. Stamens 5. STIGMas 3, obtuse, small, sessile. Frurt a berry-like juicy drupe, containing 3 seeds. - Shrubby plants, with pinnate leaves, serrate pointed leaflets, and numerous small white flowers in compound cymes. 
1. S. Canadensis, L. Common Elder.

Stems scarcely woody; leaflets 7 to 11 , oblorg, smcoth, the lower often 3-parted;: cymes flat, 5-parted.

Thickets and waste grounds; common. May, June. Stem 5 to 10 feet high, filled with a light porous pith, esfecially wlen young. Flowers numerous, in very large (1 foot hroad) level-topped cymes, white, rathicr fra orant. Berries dark purple or biack.

2. S. pubens, Michx. Recl-berried Elder.

Siems woody; leafiets 5 to 7 , oratc-lanceolate, clowny keneath; cymes panicled, convex-pyramidal.

Rocky woods. June, July. Sicm 6 to \&, somet.mes 15 feet higb, warty, often round-topped and tree-like. Leaves s:mple and unequally pinnate. Flowers in a close, ovoid thyrse or panicle. Corolla white. Lerries small, scarlet.

\section{VIBURNUM. Linn.}

CALYX . 5-toothed, persistent. Conolla rotate, spreading; deeply 5-toothed. Stamens 5, equal. Striguas 3, sessile. FRUIT a 1-celled, 1-seeded drupe with thin pulp and a bard flattened stone.-Shrubs or small trees, with petioled leaves, and white flowers in fat compound cymes.

* 1. Lextago, DC. Flowers all alile and perfict; fruit blus or blac.: wihen ripe, glausous.

Icaves serrate or tooticd, entire.

1. V. prunifolium, L. Bicck Haw.

Branckes spreading, smooth; leaves broadly oral, obtuse at both ends, fine'y and fharply serrate, shining above, smooth; petioles raked; cymes sessile; firuit ovoidoblong.

Wcods; common. May. A shrub or small tree 10 to 20 feet himh, with spreading, sometimes stinted branches. Leaves about ' 2 inches long, $11 / 2$ wide, on short, elightly margined petioles. Cymes large, terminal, sessilc. Flower's white. Fruit dark-blue or klackish, swcet and eatable.

2. V. Nudun, L. Withe Rod. Sicamp Haw.

Lcaves thickish, oral, oblong or lanceolate, revolute at the edge, subcrenate; ryme-short peduncled; fruit round=nvoid.

Cold swamps; common. May, June. A handsome shrub 6 to 10 fuet high. Leares 3 to $t$ inches long, punctate-dottel heneath like th short patioles and cymes, with small brownish scales, smooth abore, the margin more or less rolled. Flowers numerous, white. Berries dark blue, coverud with a glaucous bloom, eatable.

\section{V. Lentago, L. Sweet Viburnum.}

Leares ovate, acuminate, acutely and sharply serrate; petio'es with wavy margins; cymes terminal, sessile; fruit oval.

Rocky woods. May, June. A small bandsome tree 10 to, 20 feet high. Leaves kmooth, long-acuminate, 3 inches long, $1 / 2$ as wide, on long wavy mar fined petioles. Petioles midribs and branches of the cyme sprinkled with rusty glands when young. Flowers white, in broad spreading cymos. Berries $1 / 2$ inch long, blueblack when ripe.

\section{V. Dextatum, L. Arrownood.}

Smooth; leaves broadly-ovate, coarsely and sharply-toothed, sub-plieate; petioles slender; cymes peduncled; fruit ovoid-globose. 
Damp grounds, rather common. June. Shrub 8 to 12 feet high, with long, straight, slender branches when young, and ash-colored bark. Leaves on slender petioles, roundish, 2 to 3 inches in diameter, strongly straight-veined, and often with hairy tufts in the axils of the veins beneath. Flowers white, in large expanding cymes. Fruit small, dark-blue.

\section{V. Pubescens, Pursh. Downy Arrow-wood.}

Leaves ovate or oblong-ovate, acute or pointed, rarely toothed, sub-plicate; cymes peduncled; fruit ovoid.

Dry rocky places; rare. June. Shrub about 2 to 6 feet high, somewhat strag. gling. Leaves 2 inches long, strongly straight-veined, each with a pair of short, hairy, stipular appendages at the base of the short petiole. The lower surface and petioles velvety-downy. Cymes small, few-flowered. Flowers white.

\section{Leaves lobed or incised.}

\section{V. ACerifolium, L. Maple-leaved Arrow-wood.}

Leaves 3-lobed, cordate at the base, coarsely and unequally toothed; cymes on long peduncles, many-flowered; fruit oval.

Rocky hillsides. June. A shrub 4 to 8 feet high, with yellowish-grean bark. Leaves broad, heart-shaped, or rounded at the base; lobes acuminate, with sharp Eerratures; veins and stalks hairy; under surface and young stalks downy. F'lowers white, with a slight tinge of red; filaments long. Fruit nearly blac's.

* * Opulus, Tourn. Marginal flowers of the cymes destitute of stamens and with large showy corollas.

\section{V. uantanoides, Michx. Hobble-bush.}

Leares round ovate, abruptly pointed, closely serrate; cymes closely sessile, broad and flat; fruit ovoid.

Rocky woods, near streams. May. A straggling shrub 4 to 8 fcet high, the decumbent branches often taking root. Leaves heart-shaped at the base, manyveined, the veins, veinlets, stalks and branchlets very scurfy with rusty colored tufts of minute down. Flowers white, the sterile ones very large. Fruit red, when ripe, black.

\section{V. Opulus, L. Cranberry-iree.}

Lcares 3-lobed, wedge-shaped or truncate at the base, 3-nerved; lobes spreading, pointed, toothed on the sides, entire in the sinuses; petioles glandular; cymes peduncled, radient; fruit ovoid.

Woods; rare. June. A handsome shrub 8 to 12 fect high, with spreading branches. Leares with large remote teeth, the stalls with 2 or more glands at the base, channelled above. Flowers white, the central fertile, those of the border large, barren. Fruit red, very acid, resembling the common czanberry in flavor, and is sometimes substituted for it.

Var. b. Rosetr, L. Guelder Rose. Snow-ball. Leaves rather acute at base, longer than broad, lobes acuminate, with long pointed teeth; petioles glandular; finuers all sterile in globose cymes. This is a well known European rariety, cultivated for its large, dense spherical clusters of snow-white flowers, which are all barren.

\section{Order 55. RUBIACIID-Madder Family.}

Shrubs or herbs, with opposite entire leaves connected by interposed stipu'es, or rarely whorled without apparent stipules. CALYX usually coherent with the 2 (rarely 3 to 4)-celled ovary, or in one group, free. Stamens as many as the lobes of the regular corolla, and inserted on its tube. OVARY 2-celled. STrLe mostly simple; fTIGMAs 2. FRUIT various. 


\section{Sub-order I. STEllat Fe. The true Madder Family.}

Leaves whorled, with no apparent stiputes; cvary 2-relled, cntirely coherent with the calyx-tule. Herbs.

\section{Galium. Linn. Cleavers.}

Gr. gala, milk, which some spacies are used to curdle.

Calyx minute, 4-toothed. Corolla 4-parted, rotate. Stamens 4, short. Strles 2. Fruit twin, globular, separating when ripe into the 1 seed-like indehiscent, 1 -seeded carpels.-Slender herbs, with 4-angled stems, verticellate leaves, and small cymose flover's.

* Annual: leaves abcut 8 , in a whorl; peduncles few-flowered.

1. G. Aparine, L. Cleavers. Goose-grass.

Siem weak, procumbent, rctror ely rickly, hairy at the joints; leaves in whorls of $\mathrm{Cs}, \mathrm{is}$ or $8 \mathrm{~s}$, lincar-oblanceolate, mucrouate; peduncles axiilary, 1 to 2-forrered; fruit bristly, with hoolkod prickles.

Moist thickets. June. St ms 2 to 6 feet long, leaning on other plants and closely adhering to objets in their way by their hooked prickles. Leaves 1 to 2 inches long, 1/4 wide, rough on the margins and midribs. Flowers numerous, small, white. Fritit rather large, almed with hoolied prickles. The root is sometimes used to dye red. Medicinal.

$*$ Perennilt: leares $t$ to 6 , and sometimes 8 in a whorl; peduncles axillary and terminal, few-flowered; fruit smooth.

\section{G. Aspreludi, Michx. Rongh Bedstraw.}

Stem cliffuse, weak, mich branched, rough backwards; leaves in $6 \mathrm{~s}, 5 \mathrm{~s}$ or $4 \mathrm{~s}$, lancolate, acuminats or cuspiclats; peduncles mans, short, 2 to 3 times forked.

Low thickets; common. July. Stem weak, 2 to 5 fect long, reclining on other plants, and closely acihcring to them by thicin minute retrore priekles. Leares $1 / 2$ to $3 / 4$ inches long, $1 / 2$ as wide. Fluwers numerous, small, white. Fruit minute, smooth.

3. G. trifidum, L. Small Bedstrau. Dyer's Cleavers.

stem decumbent, reny iranching, roughish with retrcrse pricklcs; leaves in whor!s of 4 to 6 , lincar or oblanccolate, obtusc, the margins axd mithibs rough; pecluncles 1 to 3 -fowered; pedicels slender; ccrolla 20 bes and stamens often 3.

Var. 1. TINctoricx; stem stouter with nearly smouth angles, and the parts of the flowers usually in fours.

Var. 2. LATIFOLICM; itcm smooth, widely branched; leaves elliptical or oblong; quite rough on the midribs and margins.

Swamps and low grounds; common and very rariable. June-Aug. Leares $1 / 4$ to $1 / 2$ inch long, $1 / 4$ as wide, often wcdge-shaped at the base. Pcduncles mostly in 3, axillary. Flowers small, white.

\section{G. Triflorum, Michx. Sweet-scented Bedstraw.}

stem weak, often procumbent, bristly on the angles, turned backwards; leaves in $5 \mathrm{~s}$ and $6 \mathrm{~s}$, elliptical-lanceolate, acuminate-cuspidate; peduncles 3 -flowered; flowers all pedicelled; fruit hisped, with hooked hairs.

Rich woodlands; common. July. Stem 1 to 4 feet long, slightly branched. Leaves 1 to 2 inches long. $1 / 4$ as broad, 1 -veined, scarcely ciliate on the margin. Flowers small, greenish-white; lokes of the corolla pointed. Fruit whitish.

*** Peduncle sercral-flowered; petals pointed; fruit densely hoolied, prickly. 


\section{G. PIlosum, Ait. Hairy Bedstraw:}

Stem ascending, somewhat simple, hairy; leares in $4 \mathrm{~s}$, oval, dotted, bairy, indistínctiy 2-veined; peduncles several times forked, each division 2 to 3 -flowered, the fowers all pedicelled.

Dry woods; rare. June-Aug. Stem 1 to 2 feet high acutely 4-angled, with a few short spreading branches. Leaves $3 / 4$ to 1 inch long, $1 / 2$ as wide, very hairy. Filcwers purplish.

6. G. circezans, Michx. Wild Liquorice.

Stem smooth or downy, erect or ascending; leaves in $4 \mathrm{~s}$, oval, mostly obtuse, 3-nerved, ciliate; pelunclés lateral and terminal, diverging, few-flowered.

Var. 1. Lancelatum, Torr. Leaves lanceolate or orate-lanccolate, tapering to the point, slightly ciliate.

Var. 2. montanum, Torr. \& Gr. Dwarf; leaves obovate, nearly smooth.

Rich wocds. July, Aug. Stem al ont $1 \mathrm{fcot}$ high, simple, or with a few short tranches ncar the tor. Leares 1 to 2 inches ]crg, $1 / 3$ as wide. Irdur.cles us ually cnce forked, the kranches e]cncated axd widely diresgirg in fruit, and hearing Eeveral ovate flowers on very shert lateral pecicels. Flourr's purple. Fiuit clcthed with dense white bristles resembling Circxa. 'I he lcares and loct bare.a.sweet taste like the liquorice.

**** Peduncles many-flcwered, in ciose terminal panicler.

7. G. Boreale, L. Northern Galium.

Stem upright, smooth; leaves in 4s, linear-lanceolate, 3-nerved, smooth; fiowers in a terminal, pyramidal panicle; fruit minutely bristly.

Recky shady places, and fence-rows. Jure-Aus. 'tems 12 to 18 jrches high, branched akove. Lcaves 1 to 2 inches long, $1 / 4$ as wide, tarc ring to an chtuse roint. Flowers numerous, small, white, in an elongated fanicle, naking ratler a land some appearance. Fruit small.

\section{Sub-order II. CINCHONE:AE. Time Cinchona Family.}

Ieaves opfosite with stipules tetween them; ovary colierent with the calyx-tube, or the apex rarely free.

\section{CEPHALANTHUS. Linn. Button-Bush.}

Gr. lephale, a head, and anthos, a flower.

CALYX small, angular; inversely pyramidal, 4-c\}eft. CoroLta tubular, slender, 4-tontled. ETYLE fliform, much exserted ; stigma capitate. Frurt dry and liard, 2 to 4 -celled, 2-seeded, mostly 2-parted.-Shrubs with opposite leares, short stipules, and white flowers densely aggregated in glolose hads.

1. C. occidentalis, L. Button-bush. Pond Dogwood.

Mostly smooth; leaves opposite, or in $3 \mathrm{~s}$, petioled, ovatc-oblong, pointed, with. chort intervening stipules; peduncles long.

Borders of ponds and streams, forming thickets; common. Tuly, A ug. Stcm 4 to 6 feet high, l ranchcd. Ieaves sprcading, entire, 3 to 5 inclies Jnng, 2 to 3 wide. Heads of flowers akout 1 inch in diameter. Corolla white, tulular, with. long projecting styles. Flowers insertid on all sides of the rcund rccptacle.

\section{Mitchella. Linn. Partridge-efrry.}

In honor of Dr. John Mfitchell, a botanist of Virginia.

Frowers in pairs, with their ovaries united. Calrx. 
4-toothed. Corolua funnel-form, 4-lobed, the lobes spreading, densely bearded inside. Stamens 4. Strles slender; stigmas 4. FRUIT a berry-like double drupe, crowned with the calyx-teeth of the two flowers, each containing 4 small seed-like bony nutlets.- Smooth and trailing cvergreen herbs, with rose-color flowers, and bright scarlet edible berries remaining over winter.

1. M. RePens, L. Partridge-berry.

Stem creeping; leaves roundish-orate, often slightly cordate, petiolate; peduncles 2-fiowered.

Woods; common. June, July. A handsome trailer. Lcarcs dark-green and shining, usually rariegated with whitish lines. Flowers fragrant. Ferrics remarkable for their double structure, well fiavored, but full of stony seeds.

\section{HEDYOTIS. Linn.}

Gr. hedos, sweet, and ous, otos, an ear, of no obrious application.

Calyx 4.lobed, persistent. Conolla funnel-form, salverform, or wheel-shaped, the limb 4-parted. Stamens 4 . Stigmas 2. Capsule 2-celled, many-secded.-Herbs, rarely shrubs, with opposite leaves and stipules connate with the petiols.

* AvpнIotrs, DC. Corolla funnel-shaped, longer than the calyx-tceth; fiouers in terminal racemes; perennials.

1. H. purpurea, Torr. \& Gray. Purple Hedyotis.

Pubescent; leaves ovate or lanceolate, 3 to 5 -reincd, elosely sessile: caly $x$-lobes longer than the capsule, lance-linear; cymes 3 to 7 -flotrered, often clustered.

Woods and river banks. May-July. stems ascendirg, $S$ to 15 inches high, clustered, branching, tangled. Lcares 1 to 2 incles long, 1,3 as wide. Fiowers 3 to $z$ in a cluster, pink-purple, or nearly white.

2. H. LONGIFOLIA, Hook. Long-leaved Hedyntis.

Smooth; radical leaves oval-elliptic, narromed to each end ; stem leaves linear or lance-linear, 1-reined; flwers in small paniculate cymes; calyr-lobes scarcely as long as the capsule.

Dry hills and shady banks. June. Stems somerthat tufted, 5 to 10 inches high, 4-angled. Leaves 1 to $11 / 2$ inches long, $1 / 1 / 4$ as wide, sessile on the stem. Flowers 2 or 3 together, on rery short pecicels, pale purple, with deeper colorcd lines in the throat.

* * Horsmonta, Linn. Corolla nearly salver-form, with a long tule, limb smooth; peduncles 1-flowered.

3. H. Cerelia, Hook. Innocence. Venus' Pride.

Smooth; stems erect, numerous, dichtcmous; radicallcares ovate-spatulate, petiolate; pedicels filiform, 1 to 2 -flowered.

Moist banks; common. May-Aug. An elegant little plant 3 to 5 inches high, producing in spring a profusion of handsome bright llue tlowers, with a yellow eye. The stem leaves are small, opposite, lance-ovate.

\section{SUB-ORDER III. LOGANEAE.}

Laaves opposite, with stipules botween them, united with the petioles; ovary free from the calyx. 


\section{SPIGELIA. Linn. PiNK-Root.}

In honor of Prof. Spigelius, who wrote on botany at the beginning of the 17 th century.

Calyx 5-parted, persistent; the lobes slender. Coroula tubular-funnel-form, 5-lobed at the summit. Stamens 5. Strue slender, hairy above. Capsule short, twin, 2-celled, separating at maturity into 2 carpels, few-seeded.-Chiefly herbs, with opposite leaves, united by means of stipules, and showy flowers in spitees or 1-sided cymes.

\section{S. Marilandica, L. Pink-root. Worm-grass.}

Erect, simple, nearly smooth; stem square; leaves sessile, oval-lanceolate, acute or pointed, roughish, hairy on the margin and ribs; spike 3 -fiowered.

Rich woods; rare. June. A beautiful herb with dark green foliage and scarlet flowers. Stem 1 foot high. Leaves 3 to 4 inches long, $1 / 2$ as wide, entire. Flowers $\mathbf{1 1} / 2$ to 2 inches long, somewhat clavate, scarlet without, yellow within. Style exserted.

\section{ORDER 56. VALPRIANACRR.}

Herbs with opposite leaves and no stipules; the calyx-tube coherent with the ovary. Corolia tubular or funnel-form 4 to 5-lobed, sometimes spurred at the base. Stamens 1 to 5. Strule slender; stigmas 1 to 3 . Fruit indehiscent with 1 fertile cell and 2 empty ones. SEEDS suspended, anatropous, with a large embryo and no albumen.

\section{FEDIA. Gært. CoRn-SALAD.}

CALYX with the limb 3 to 6 -toothed and persistent or obsolete. Corolda tubular, 5-lobed, regular. Stamens 3. Fruit 3-celled, two of the cells empty and sometimes confluent into one, the other 1-seeded.-Annuals and biennials, with forking stems, opposite sessile leaves, and white or whitish clustered-cymose small flowers.

\section{F. оцitoria, Vahl. Lamb Lettuce.}

Leaves spatulate, obtuse; radical leaves petiolate; fruit compound, oblique at Iength, broader than long, the cross section elliptical, with a corky or spongy mass at the back of the fertile cell.

Fields; naturalized. June. Stem smooth, 4 to 10 inches high, forked. Leaves mostly entire. Flowers in dense corymus, white.

\section{ORDER 57. DIPSACERI,-Teasel Family.}

Herbs with opposite or whorled leaves, no stipules, flowers in dense heads, upon a common receptacle, surrounded with a many-leaved involucre. CALYX adherent, often pappus-like. Conolua tubular, somewhat irregular, the limb $4-5$ parted. StamBNS 4, alternate with the lobes of the corolla. Stxule 1, simple. Fruir dry, indebiscent, with a single suspended seed. 


\section{DIPSACUS. Tourn. TeAsEL.}

Gr. dipsao, to thirst, alluding to the water held in the axils of the leaves.

FLowers in heads. Invoudcre many-leaved, longer than the chaffy, leafy-tipped, pointed bracts among the capitate flowers. CalyX superior. Corolta tubular, 4-cleft, nearly regular. Stamens 4, inserted on the corolla. Fruir 1-seeded, crowned with the calyx.- Stout and coarse biennials, hairy and priclely, with opposite, connate (sometimes distinct) leaves, and bluish or whitish flowers in large oblong heads.

\section{D. sylvestris, Mill. Witd Teasel.}

Leaves lance-oblong, toothed, or the uppermost entire, connate; leaves of the involucre slender, longer than the head of flowers.

Naturalized by hedges and roadsides. Aug. Native of Europe. Stem 3 to 4 feet high, angled and prickly with the opposite and lanceolate leaves united around it. Bracts (chaff) tapering into a long flexible awn with a straight point. Flowers bluish, in a large oval or cylindrical head.

\section{D. Fullonum, L. Fuller's Teasel.}

Lenves connate, entire or serrate; heads of flowers cylindrical; bracts hooked, involucre spreading. A cultivated European plant, used by the clothiers who em. ploy the heads with the hard, hooked scales to raise the nap upon woolen cloth Stem erect, furrowed, prickly, hollow, about 5 feet high. Leaves 2 at each node' united at their bases around in such a way as to hold a quantity of water. Flovoers whitish, in large oval or ovoid heads. July.

\section{SCABIOSA. Linn.}

Lat. scaties, leprosy; said to be useful in cutaneous diseases.

CaLyX 5-parted divisions long, bristly, sometimes partial. ly abortive. INVOLUCRE many-leaved. INVOLUCEL nearly cylindrical with 8 little excavations. - Biennial and perennial mostby European herbs, with opposite leaves and showy flowers in heads.

\section{S. sUCCISA, L. Devils'-bit.}

Root premorse; stem leaves remotely toothed; heads of flowers nearly globose; corolla in 4 equal segments. Cultivated in gardens. Stein 1 foot high. Corolle pale violet. Sept.

2. S. atropurpurea, I. Mourning Bride.

Leaves pinnatifid and incised; heads of flowers radiant; receptacle cylindrical; outer crowon of the seed short, lobed and crenate. A handsome species, 2 to 4 feet bigh, with dense heads of dark purple, pink, and whitish flowers. Sept.

\section{ORDER 58. COMPOSITIE.}

An immense family, chiefly herbs in temperate regions, without stipules with perfect, polygamons, monacious or diacious flowers. Flowers in close heads (the compound 
Hower of the older botanists) upon a common receptacle, surrounded by an involuore. CALYX closely adherent to the ovary, the limb wanting or membranaceous and divided into bristles, hairs, \&c., called pappus. Corotra superior, consisting of 5 anited petals either ligulate (strap-shaped) or tubular. Stamens 5, inserted on the corolla, their anthers united in a tube (syngenesious). STYLE 2-cleft at the apex. Frurt seed-like (aithenium, dry, containing a single, erect anatropous seed, with no albumen.

\section{SUB-ORDER I. TUBULIFLORÆ.}

Corolla of the perfect or dislc flowers tubular, regular, the limbs 5-cleft, or lobed; the ligulate or ray-flowers, when present, either pistillate only or neutral (with neither stamens nor pistils), and occupying the border.

\section{TrIBE I. VERNONIACEAE.}

Heads discoid (without ray flowers); the flowers all alike, perfect, tubular; branches of the style slender and thread-form, or bristle-fcrm, acute, hairy all over, the stigmatic lines only on the lower part, (corolla often slightly irregular).

\section{VERNONIA. Schreb. IRON-WEED.}

In honor of Wm. Vernon, an English botanist who traveled in this country.

Heads 15, many.flowered, in corymbose cymes. Flowers all tubular. INvOLUCRE shorter than the flowers, of many appressed closely imbricated scales. RECEPTACLE naked. Achenia cylindrical, ribbed. Pappus double, the outer chaffy; the interior capillary.-Perennial herbs, with alternate leaves and mostly purple flowers.

\section{Noveboracensis, Willd. Common Iron-weed.}

Stem erect, smoothish; leaves on short petioles, elliptical-lanceolate, pubescent beneath; heads numerous, 20 to 30 -flowered; scales of the involucre tipped with a long bristle-form or awl-shaped spreading appendage, or awn.

Low grounds; common. Aug., Sept. Siem branching at top, reddish, 3 to 6 feet high. Leaves crowded, paler beneath; root-leaves sometimes lobed. Flowers deep purple, in terminal flat-topped compound cymes. Scales purple, ending in long thread-like appendages.

\section{ELEPHANTOPUS. Linn. Elephant's-Foot.}

Gr. elephas, elephant, and pous, foot.

HeADS 3 to 5-flowered, clustered into compound heads. INVOLUCRE narrow and flattened, of 8 oblong dry scales. ACHenia many-ribbed. Pappus of stout bristles, chaffy, dilated at the base.-Perennials, with alternate subsessile teaves and violet-purple flowers.

\section{E. Carouinianus, Willd. Carolinian Elephant's-foot.}

Stem branched, leafy, somewhat hairy; leaves ovate-oblong, thin, obtuse, crerate-serrate; heads terminal and sub-terminal. 
Dry soils. July-Sept. Stem 2 to 3 feet high, divaricately branched. Louver stem leares 5 to 7 inches by 3 to 5 , 'uppex $1 / 2$ as large. Heads composed of Lour clusters, each 4-flowered, witl the involuere o to 10-leaved. Corclla purple.

\section{TRIBE 2. EUPATORIACE ⿷匚.}

Heads discoid or radiate; branches of the style much elongatod, ottuse or chuth shared, minutely pubexcent towards the summit outside; anther's without tails at the base: leares mostly opposite.

SUb-tribe 1. EUpatoriese. Heads discoid. Flowers all alitie,perfect and tubular seciom yellow.

\section{LIATRIS. Shreb. Button Snake-roor.}

Heads several-many-flowered. SCALES of the InvoutCRE imbricated. RICEPTACLE naked. Frowers all tubular. Conolla 5-lobed, the lobes slender. Parpus of 15 to 40 capillary bristles, plumose or barbellate. STrLE with the branches much exserted. Acrenia slender, about 10-ribbed, somervat cylindric.-Perennial herbs, with tuberous roots, chiefly with simple wand-like stems, many narrow rigid alternate entire leaves, and the heads of showy flower's arranged in an elongated spike or raceme.

* Heads 16 to Co-fiowered.

\section{L. sejarrosa, Willd. Blaiing Star.}

Siera simpie, smoo!h or senh-nus-pabescent; icares "inear, clongated; heads few,

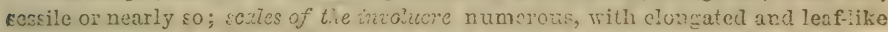
spreading tips; inner cnes pointed, scarcely colored; fiowers numerous; pappus plumose.

Drv coils. Aur, A bandsome plant 1 to 3 fect high, thickly beset with long linear lesves. Feads 5 to 20 , senerally 4 to 5 . Fiows brilliant purple,

\section{L. scariosa, Willd. Gay Feather.}

Scabrour-pubescont; st:m stout; leares lanceolate, lower on long petioles, upper linear or liavar-lanecolate much smaller; hiads few or many, 33 to Go-forered, remctely racemed; icaics of the somewliat splicrical invelucre obovate or spatulate, with dry and scarious often colored tips or margins; paxpus scabrous.

Dry sandy soils; raze. Sept. iten 2 to 5 fect ligh, rather stout. Lpares numerous, entire, lowcr 3 to 9 inches long, upper 1 to 3 inchos long, $1 / 4$ to $1 / 3$ of an incil witle, rougla-eliged. Hexds 4 to 20,1 inch in diameter. Flowers bright purple.

* Heads 5 to 15-forvered.

\section{L. spicata, Willd. Blue Blazing Star.}

Smooth or romerthat hairy; itcm wend-lile, rery leafy; leaves linear or laneelinear, cntire emooth, the lower 3 to E-ncrved; leads censely crowded in a long spike, nearly sessile, 8 to 12 -forrerel; involacre kell sliaped, cy?indrical, with slight

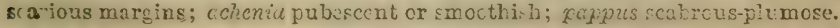

Moist grounds; rare. Aus. A hendsome species, sometimes celtivated, 2 to.5 fect high, mostly stout. Simil.e terminal, 0 to 8 iaches long. Inveliacre Ecxacribat rcsinous. Heads numerous, with briglat purplo fowers. 


\section{KUHNIA. Linn.}

In honor of Dr.Adam Kuthn, of Pennsylvania.

Heads 10 to 25 -flowered. Scales of the involucre loosely imbricated, lanceolate, in 2 or 3 series. Corols a slender, 5-toothed. Receptacle naked. PAPpus in a single series, plumose. Achenia cylindrical, many striate. $-A$ perennial herb, with mostly alternate lanceolate leaves with resinous dots and whitish flowers in panicled corymbs.

K. EUPATORIOIDES, L. Thoroughwort-like Kuhnia.

Leaves varying from linear and entire to broadly lanceolate and toothed; corymbs terminal, few-flowered.

Dry soiis. Aug., Sept. Stem 2 to 3 feet high, slender, somewhat branched, often parple. Flowers whitish or pale-yellow.

\section{MiKania. Willd. Climbing Hemp-Weed.}

In honor of Prof. Mikan, of Prague.

Hrads 4 to 6 -flowered. Frowers all tubular. Involud CRE of 4 scales. RECEPTACLE naked. PAPpUs capillary, simple, scabrous. ANTHERs partly exserted. ACHenia angled. - Climbing perennials, with opposite mostly heartshaped leaves and corymbose-panicled flesh-colored flowers.

\section{M. scandens, Climbing Bonesett.}

Fearly smooth, twining; leaves somewhat triangular heart-shaped or balbertlorm, pointed, toothed at the base; heads in pedunculats axillary corymbs.

Copses along streams, climbing over bushes; rare. July-Sept. Every part smooth. Leaves 2 to inches long, 1 to 2 wide, on petioles 1 to 2 inches long, apex tapering to a long point. Branches short, each bearing a small corymb of whitish or pink-colored flowers.

\section{CONOCliniUM. DC. Mist-Flower.}

Ar. Conon, a cone, and cline, a bed; reforring to the conical receptaste.

Heads many-flowered. Receptacle conical. InvoldCRE bell-shaped. SCALrs linear-awl-shaped, somewhat imbricated. Corolia 5-toothed. Achenia 5-angled. Pappus a single row of slender capillary bristles.-Perennial erect herbs, with opposite petioled leaves, and violet-purple flowers in crowded terminal corymbs.

\section{Coelestinum, DC.}

Somewhat hairy, much branched; leaves triangular-ovato and slightly heark Ahropod, crenato-serrate, veiny ; petioles slender; corymbs numerous, sub-umbellate; seales numerous, setaceous.

Hedges, thickets and roadsides. Sept. Stem 1 to 2 feet high, terete with oppoolte branches, somewhat tufted. Leaves 1 to 2 inches long, $2 / 3$ as wide. Flowers 30 to 50 in s bead, bluish-purplo, fading roduish. 


\section{EUPATORIUM. Tourn. THOROUgHWORT.}

Dedicated to Eupator Mithridates, who is said to have used a species of the genus in medicine.

HEADs 3-many-flowered. InvoluCRe cylindrical or bellshaped. ReCEPTACLE flat, naked. Corolla 5-toothed. Pappus simple, a single row of slender capillary longish bristles. Achenia 5-angled.-Perennial herbs, with opposite or verticillate leaves, corymbose heads, and flowers white, blue, red, \&c., never yellow.

\section{E. purpureum, L. Trumpet-weed.}

Stem tall and stout, simple; leaves 3 to 6 in a whorl, oblong-orate or lanceolate, pointed, very veiny, roughish, fincly glandular serrate; corymts very dense and compound with whorled peduncles.

Low grounds; common. July-Sept. Stem 6 to 12 feet high, smooth glaucous purple, striate or fistular spotted or unspotted. Leares in about 12 whorls of 3 to $6 \mathrm{~s}$, largest in the middle of the stem, 8 inches long, and 2 wide, on petioles 1 inch long. Corymbs often 1 foot in diameter. Flowers purple, showy.

* Heads 5 to 20-flowered; invorucre of 7 to 15, more or less imbricated and unequal scales; flowers white; leares mostly cpposite, sessite or nearly so; heads mostly 5-flowered.

\section{E. Hysopifouium, L. Narrow-leaved Thoroughwort.}

Minutely pubescent; leaves opposite (the upper ones alternate) often whorled, narrow, linear or lanceolate, elongated, obtuse, 1 to 3-nerved, lower ones subserrate, upper ones entire; scales of the involucre obtuse.

Dry fields and sterile soil. Aug., Sept. Siem 1 to 2 feet high, branching, with numerous narrow leaves. Coiyinb spreading at the summit. Heads 5 -flowered. Flowers purplish.

\section{E. ALtissimum, L. Fall Thoroughwort.}

Stem tall and stout, pubescent; leaves lanceolate, tapering at both ends, sul. sessile, acutely serrate above the middle, conspicnously 3-nerred; corymbs numexous, dense; heads 5 -flowered; scales 8 to 12, obtuse, shorter than the flowers.

Wools and sandy soil. Sept., Oct. Stem 3 to 7 feet high. Leares 3 to 4 inches long, $1 / 2$ to $3 / 4$ wide, small ones often fascicled in the axils. Corollas whitish, much longer than the scales.

\section{E. ALBUM, I. White-flowered Thoroughwort.}

Stem pubescent; leaves ovate-larceolate, coarsely toothed, veiny; heads clustered in the corymb, 5-flowered; scales of the involucre closely imbricated, rigid, narrow, pointed, white and scai ius above.

Sandy and barren places. Aug.-Oct. Siem 2 to 3 inches $10 n g, 1 / 2$ to 1 wide, upper ones entire and alternate. Heads very white. Involucre concealing the flowers, sprinkled with resinous dots.

\section{E. TeUCRIfolium, Willd. Vervein-leaved Thoro'wort.}

Roughish-pubescent; leaves opposite, sessile, ovate-oblong and ovate-lanceolate, rough, veiny, coarsely toothed towards the base, upper ones alternate; corymb. compound, somewhat panicled with few branches; heads 5 to 6-flowered; scales of the involucre 10, oblong lanceolate, rather obtuse.

Low grounds. Aug.-Oct. Stem 2 to 3 feet high, erect, rather slender. Leaves sometimes almost incised; the lower broad at base and closely sessile. Heade somewhat clustered, corymbose. Flowers white. Scales scarioun on the margip, vite at the tips. 
6. E. rotundfolium, L. Ronnd-leaved Thoroughwort.

Downy-pubescent; leaves opposite, sessile, roundish-ovate, obtuse, sub-cordate at basc, 3-nerved, veiny, roughish, coarsely serrate; heads about 5-flowered, in largo and dense corymbs; scales of the involucre linenr-lanceolate, slirhtly pointed.

Dry soil. Aug., Sept. A slender species : to 3 feet ligh. Leaves sprinklud with rosinous dots 1 to 2 inches long, $3 / 4$ as wirle, sometimes almost orbicular, mostly obtuse. Flowers white. I'appus longer than the corolla. Styles much exserted.

\section{E. PUBescens, Muhl. Hairy Thoroughwort.}

Pubescent; leaves ovate, opposite, sessile, acutc, obtusely dentate, somowhat 3-nerved, veiny; involucre 7 to 8-flowered, with lanceolate, acuto seales.

Dry grounds. Aug., Sept. A large rough plant, 3 to 4 fect high, with the iower branches opposite. Leaves thin and slightly scahrous, slightly truncato at the base. Involucre of sbout 12 seales, the outer shortest. Flowers white.

8. E. sessiliforium, L. Sessile-leaved Thornughwort.

Stem smooth, branching; leares opposite, sersile, distinct, roundish-orate or lanceolate, somewhat clasping the stems, smooth, serrate; involucre 5 to 12-flowcred, with oval and oblong obtuse scalcs.

Rocky woods and banks. Sept. Slem slender, erect, branching at top. Leaves large, somewhat truncate at base, tapering regularly to a long point, minutely dotted beneath. Flowers white, in a widely spreading terminal corymb.

\section{E. Resinosum, Torr. Resinous Thoroughwort.}

Minutely velvety-downy; lcares linear-lanceolate, elongated, closely sessile or elasping at the base, scrrate, slightly vciny beneath; corymb fastigiate, compound; heads 10 to 15-flowered, with obtuse hoaryetomentose scalcs.

Wot sandy soils. Aug., Sept. St $m s 2$ to 3 fect high, growing in tufts. Leares 4 to 6 inches long, $1 / 1$ to $1 / 2$ inch wile, membranaccous, viscil with resinous globulos. Heads very numorous, rather small.

\section{E. perfoliatum, L. Thoroughwort. Bonesett.}

Slem stout, hairy; leaves lanceolate, connate-perfoliate, tapering to a slender point, serrate, very veiny; corymls compound; heads 8 to 10-1lowe:ed, with lincar lanceolate scales.

Low grouns?s, meaciows; aburiant. Aug. A well known common plant 2 to 4 feet high, hairy or woolly, branched at the top. Lerres.s lirge. unitel at the base around the stem, the two measuring from 8 to 14 inches in leagth. Ileacls in largo elustered corymbs. F'lowers white. Mcdicinal.

* Leaves opposile; flowers white, 8 to 30 in a head.

\section{E. ageratoides, I. Nettle-leaved Thoroughu:ort.}

Smooth, branching; leaves opposito, on long petioles, brcadly ovate, rointed, coarsely and sharply toothed; heads 12 to 2 -flowered, with narrof lanccolate scales; corymbs compound.

Rich woods and rocky hills; common. Aug., Sept. Stem 2 to 3 fiet high, romowhat branched. Leares on retioles 1 to 2 inches long, somet mes sliwhtly cordate, 3 to 6 inchos long, 2 to 4 wide. Heads num rous, in small clusters, forming a compound corymb. Flowers pure white, somewhat fragrant.

\section{E. aromaticuni, L. Aromatic Thoronghuort.}

Smooth or nearly so; stem teret: pubeseent, nearly simple; leares opposite, on short petioles, ovate, rather obtusely tosthad, acuminate, 3-nerved; corymb somewhat panicled; heads about 2 -flowered.

Low woods. Aug., Sept. Stem about 2 foet high. Lcaves 2 to 4 inches long, 1 to 2 wide, on petioles $1 / 2$ to 1 inch long. ITeads of the flowers large. Involucre with 10 to 12 linear, acute, equal scales. Flowers in small corymbs, large, white, and aromatic. 


\section{SUB-TRIBE 2. TUSSILAGINE $A$.}

Head's radiate; flowers dissimilar, or dioccious.

\section{NARDOSMIA. Cass.}

Gr. nardos, spikenard, and osnce, odor.

HEADS many-flowered, somewhat diøecious. STERILE FLOWERS of the ray in a single series, ligulate, pistilate, those of the disk tubular. FERTILE FLowers with many rows of minutely ligulate ray-flowers, and a few tubular perfect ones in the centre. Receptacle flat. ACHenia terete. PAppus of soft capillary bristles, longest and most copious in the fertile flowcrs.-Perennial woolly herbs, with radical leaves, the scape with sheathing scaly bracts, and the heads of purplish fragrant flowers in a corymb.

\section{N. palmata, Hools. Palmate Sweet Colt's-foot.}

Ieaves rounded or kilney-form, palmately 5 to 7 -lobed, the lobes toothed and eut, white, woolly beneath.

Swamps; rare. May. Sipe 1 to 2 feet high, stout, clothed with numerons shentining seales. Lowes large, 6 to 10 inches broad. Heads numerous, in a. eorymbose thyrse.

\section{TUSSILAGO. Tourn. Colt's-Foot.}

Iat. tussis, a cough, for wbich the plant is a reputed remedy.

HeADS many-flowered. RAY FLowers narrowly ligulate; pistillate, fertile, in many rows ; tho tubular disk flowers few, staminate. Soales of the involdcre nearly in a single row. Receptacle flat. Fertile achexia cylindric-oblong. Paprus capiliary, copious, in the fertile flowers.-A low perennial, with horizontal creeping rootstoclis, radical leaves, and simple scaly scapes bearing a single head of yellow flowers.

\section{T. Farfara, I. Common Colt's-foot.}

Leaves rounded-heart-shaped, radical; flowers with very narrow rays.

Wet places, trooksides. A low plant sending up a single scape about 5 inches high in March or April, with a single, terminal, many-rajed head of yellow flowers betore a leaf is to be seen. Leaves arising after the flowers are withered, 4 to 5 inches broad, corcaste angular, toothed, dark-green alove, woolly underneath, on. long petioles.

\section{Tribe 3. ASteroIde FE. The Aster Tribe.}

Feads radiate, rarely discoid; branches of the style more or less flatlened and innear, minutely and equally pubescent above; leaves nostly alternate. 
SEcTion 1. Heads radiate; rays cyanic.

\section{ASTER. Linn. STARwort. Aster.}

Gr. astro, astar; from the appearance of the radiate heads of flowers.

HeADs many-flowered; ray-flowers in a single series, fertile; dist flowers tubular, perfect. Scales of THE INVOLUCRE more or less imbricated, often with leaf-like tips. REeEP. TACLE flat, alveolate (honey comb-like). AcHenIA usually more or less flattened. PAppus simple, of capillary bristles.-Perennial herbs, with alternate leaves, corymbed, panicled or racemose heads of flowers, with white blue or purple rays, and yellow diste, often changing to purple.

1. Brotu, DC. Scales imbricated with appressed greentsh tips ; rays 6 to 15 (white or aearly 80); lower leaves large, heart-shaped, petiolate; heads in open corymbs:

1. A. conymbosus, Ait. Corymbed Aster.

Stem slender; leaves ovate, mostly cordate, coarsely and unequally serrate, nexminate, petioled; heads loosely corymbose; rays 6 to 9 .

I) ry woods; common. July, Aug. Stem 1 to 2 feet high. Leaves thin, large, lower ones heart-khaped, pointed; middle cnes ovate; upper becoming lanceolate: F'lowers in a brosid flat-topped corymb, large, very opeu, with long, narrow, white rays:

\section{A. Macrophymus, L. Large-leaved Aster.}

Stem stout, branched, difiuse; leaves rough, thickish, serrate; lower and radical (n)es on long petioles, cordate; upper on winged petioles or sessile; heads in large wrymbs; rays 12 to 25.

Woods; common. Aug., Sept. Stem 2 to 3 feet high, rigid, the branches rough, downy above. Lower leaves 4 to 10 inches long, and 3 to 6 inches wide on somewhat winged petioles. Heads in a spreading terminal corymb. Scales of the involucre oblong-lanceolate, obtuse. hays white or pale-blue.

2. Cammasmum, T. \& G. Scales imbricated with spreading green tips; rays 12 ta 30 , violet; achenia narrow, smoothish; pappus rigid, of unequal thicliness ; heads full, barge and showy; stem-leaves all sessile; lower ones not cordate.

\section{A. RAduia, Ait. Rough-leaved Aster.}

Wess erect, simple below, angular, smooth; leaves oblong-lanceolate, pointed, simple, sharply serrate, rough on both sides and rugose-veined; involucre bellshaved, with oblong appressed scales, and small spreading green tips; achenia smooth, linear-oblong.

Bogs and low grounds; rare. Aug., Sept. Stem 1 to 3 feet high, very leafy, with a few spreadiug undivided branches at the summit, purplish, each bearing a single lurge head, rarely more. Leaves 2 to 3 inches long; nearly equal throughout. Involvcre acarly 6mooth, except the ciliate margins. Rays light violet-purple.

\section{A. spectabilis, Ait. Showy Aster.}

Stem erect, minutely rough and glandular-pubescent at the summit; leaves ablong-lanceolate, very rough, upper sessile and entire, lower ones scrrate in the middle; branches corymbose; heads hemispherical, with numerous linear-oblong obtuse scrlos, and conspicuous spatulate downy tips; achenia slightly pubescent.

Sandy goil. Aug.-Nov. Stem 2 to 4 feet high, branched above into a nearly simple corg mob of 10 to 15 heads. Rays about 20 in a head, narrowly-lanceolate, pawly 1 incia Long, very deep-violet blue. Probably the handsomest of the genus. 
3. ASTER proper. Scales green or with green tips: rays numerous; pappus bristles soft and nearly uniform; achenia flattened.

\section{A. CONCOLOR, L. Silly Aster.}

Stem nearly simple, wand-like; leaves oblong or lanceolate, crowded, appressed, the upper appearing like small bracts; heads in a simple or compound virgate raceme; involucre obovoid, with closely imbricated, appressed, somewhat rigid, lanceolate, silky scales, in sereral rows; achenia silky.

Dry sandy soll. Aug.-Nov. A handsome plant 1 to 3 feet high, sparingly branched. Leaves 1 inch in length, 1/3. as wide, reduced in size upwards, greyish: silky, and of the same hue on both sides. Heads middle-sized, in a long raceme, showy. Rays bright violet-purple. Pappus rust-colored.

3: * Lower leaves not heart-shaped; the upper all sessite and more or less clasping by a cordate or auricled base; rays large, deep purple or blue.

\section{A. Patans, Ait. Spreading Aster.}

Rough:pubescent; stem simple, paniculate above; leaves oblong-lanceolate or ovate-oblong, generally contracted below the middle; panicle lonse, few-flowered; scales imbricate, lanceolate, loose.

Dry grounds; commion. Aug.-Nov. Stem 2 to 3 feet high, slender, branching into a loose terminal panicle above. Leaves iarge, 3 to 6 inches long below, becoming small and bract-like on the branches, all clasping by a deep auricled-heartshaped base, rough. Heads solitary, on the ends of the leafy branchlets, large, with 20 to $30^{\circ}$ violet-colored rays.

\section{A. IÆvis, L. Smooth Blue Aster.}

Very smooth, glaucous; stem angular; leaves lanceolate or ovate-lanceolate, thickish, mostly entire, shining; involucre closely imbricate, with broadly-linear, thick and rigid seales; achenia smooth.

Rich woodlands and banks; common. Sept.-Nov. A very small and beautiful species, 2 to 3 feet high. Stem polished, green. Leares rather tleshy, the upper more or less clasping by an anricled or heart-shaped base. Heads in a close panicle, large and showy, with numerous rays of a fine bright sky-blue, becoming purple, and triangular green tips.

4. * Lower leaves all heart-shaped and̄ petioted, conspicuousily serrate; rays bright biue, pale or nearly white.

\section{A. CORDIFolius, L. Heart-leaved Aster.}

Stem much branched above, smooth; lower leaves all heart-shaped, on slender petioles; involucre inversely conical, with closely imbricate appressed scales, tipped with short obtuse or acutish points.

Woodlands; very common. Sept., Oct. Stem 2 to 4 feet high, smoothish below, more or less pubescent above. Leaves varying from heart-shaped to narrow-ovate. Lower leaves more or less winged, on hairy petioles. Cpper leaves gradually reduced to small bracts. Heads very numerous, in racemed panicles, rather small, angled on the spreading branches. Rays 10 to 15 , pale-blue varying to white.

\section{A. sagtTifolius, Willd. Arrow-leaved Aster.}

Stem erect, rigid, with racemose ascending branches; leaves ovate-lanceolate, pointed, serrate in the middle; lower ones cordate-sagittate, on slender narrowly. winged petioles; involucre oblong, with closely imbricate linear-subulate scales.

Dry woods. Aug.-Oct. Stem 2 to 4 feet high, with erect branches above, bearing numerous racemose heads, forming a compound panicle of racemes. Heads small, almost sessile, each with about 12 bluish or white rays.

\section{A. undulatus, L. Wave-leaved Aster.}

Pale or somewhat hoary with close pubescence; stem spreading; leaves ovate or lanceolate, with wavy or slightly-toothed margins; heads numerous, in racemo. panieles; involucre oboroid, with closely imbricate scales. 
Dry wocds; common. Sept., Oct. Slem 2 to 3 feet high, spreading, bearing numerous heads in racemose panicles. Lover leaves heart-shapod, on long winged petioles, which are dilated and clasping at the base, or directly sessile by a heartshaped base. Heads middle-sized, with viotet-blue rays and yellow disks, at length becoming purple.

5. *** Lover leaves never heart-shaped; those of the stem sessite or clasping; heads small or middle-sized; rays white or pale bluish-purple.

11. A. ERICOIDEs, L. Heath-leaved Aster.

Smooth or sparingly hairy; lower leares oblong-spatulate, sometimes toothed; the upper ones linear lanceolate or linear awl-shaped, acute at both ends; scales of the involucre imbricate, linear obtuse, somewhat squarrose.

Dry open places. Aug.-Cet. Stcm 1 to 3 feet high, with the simple branchlets or peduncles racemose along the upper side of the wand-like spreading branches. Leaves rery numerous and somewhat rigid, those of the stem 3 inches in length. Heads small, alout 20-rayed. Fays white or pale purple. Diste at length purplish

12. A. mulmiflonus, Ait. Nany-fowered Aster.

Hoary with minute pubescence; leaves crowded, linear, entire, with rough or ciliate margins, somexhat 3-nerved; those of the branchlets spreading and partly olasping at the base; involucre linear or spatulate with loosely imbricate oblong, ciliate, squarrose scales.

Dry gravelly or sandy soil; common. Sept., Oct. Siem about 2 feet high, with numerous spreading racemose branches, usually covered with a dense white pubescence. Leaves 1 to 2 inches long, obtuse, very narrow. Heads small, in crowded terminal racemes, on horizontal branches. Rays white or purplish. Disti at length purplish.

6. *:*:* Leaves none of them heart-shaped; heads small or middle-sized; rays: eohite or pale buish-purpte.

\section{A. Dumosus L. Bushy Aster.}

Nearly smcoth; leaves linear entire or remotely serrate, rough on the margin sessile; those of the kranches smaller and acute; involucre inversely conical or bell-shaped, with closely imbricated, linear-spatulate, obtuse scales.

Thickets in dry or moist soil; common. Aug.-Oct. A variable species 1 to 3 feet high. Stem loosely branched, racemoscly compound, with the scattered heads mostly colitary at the end of the sproading branchists. Leaves decreasing in size: to the branchlets, the upper small. Rays pale-purple or blue.

\section{A. Tradiscanti, I. Tradescant's Aster.}

Smoothish; leaves sessile, smooth, with rough margins; cauline linear-lanceolato pointed; involucre with imbricated, narrowly-linear, acute scales in 3 to 4 rors.

Var. FRAGILIS; leares entire or nearly so, except the lowest; heads more scattered? on the branchlets.

Moist banks, fields, \&e.; very common. Aug.-Oct. Stem 2 to 4 feet high, smooth, bushy, the numerotis heacis closely racemed along the erect spreading or diverging branches. Lowcr stom lcaves about 4 inches long, narrowly lanccolate, remotely kerrate in the middle with fime sharp tceth, gradually reduced in sizo upwards. Heads small, very numercus. Fiays white or pale-purple.

15. A. MISER, L. Starved Aster.

More or less hairy ; stem much branched; leaces lanceolate, pointed or acuminato at each end, sharply serrate in the middle; involucre imbricated with linear, acute or rather obtuse scales in 3 or 4 rows.

Thicketg, fields, \&c.; rery common. Aug.-Oet. A very variable species, varying in height from 8 to 10 inches to 3 to 4 feet, erect or diffuse. Stem very branching or nearly simple, the branches usually diverging, bearing racemose often scattered heads. Lcaves varying from narrow-lanceolate to broad-ovate, 1 to 5 inches in length. Heads usually numerous, with short, inconspicuous pale bluish-purple: ar white rays. 


\section{A. stmplex, Willd. Simple Aster.}

Nearly smooth; stem tall and much branched; leaves lanccolate, rointed, tho lower serrate; involucre loosely imbricate with linear awl shaped scales.

Shady moist banks; common: Aug.-Oct: Another rariable specis from 1 to 5 feet high, the branches and scattered heads somerhst crrymbose at the summib. Leaves sessile, 2 to 4 inches long, $3 / 2$ to 1 inch wid terering to a slender point, those of the branches small in proportion. Ifads nicdic-size, lonsely racemnse or a little crowded on the short branchlets. Rays pale jurple. Listo yeliowish, at. length purple-brown.

\section{A. tenuifolius, L. Slender-leaved Asier.}

Nearly smooth; leare: linear-lanceolate, tarering into a long slender point; lower somewhat serrate in the midule; ir vsucre hemisperical. with closely inbr:cated, numerous, lincar-awl-shaped, acute scales; heads in fanicles or racemes.

Low grounds. Aug.-Nov. Slem 2 to 5 feet hirh, mostly stout, much branched: Stem leares 2 to 6 inches long. smaller in rroportion on the iruxchs and branchIets. Heads small or midale-sized. Fays 20 to 50 , short sud narrow, pale purplo or whitish.

\section{A. CARneus, L. Flesh-colored Aster.}

Smooth, rough or pulescent; :tem much branched; leares lanceolate, pointed; upper short and partly clasping; invoiucre obovate, with closely imbricated. lanceo. late, abruptly acute scales; heads racemose along the ascending leafy branches.

Moist soils; rare. Sept., Cet. A handsome I ushy srecies, rery rarial le, abcut 2 foet high. Stem often purple. Lraves fim in texture, smonth cr $10 u \mathrm{~h}$ aliove those of the stem 3 to 5 inches loas, $1 / 2$ inch widc. the of the liranches much smaller. Hearls nuincrons, midd le-sized, $s$ men hat 1 -sided on the branches. Yays 20 to 30 , rather long, fest-2olored or ncarly white.

c. *\$**** Stcm leare: sessile, the rpper more cr less clasping; heads middle-sized or large; rays blue or purple.

\section{A. Longifolids, Lam. Lony-Zeaved Aster.}

Smooth or nearly so; stem branched; leares lanceolute or linear, entire or spar ringly serrate in the middle, acuminst, slining abore; invelucre imbricate with linear scales in 3 to 5 rows, crowned with acute or awl shaped spreading or recurted green tips; heads in corymbose panicles at the summit.

Mo st places along straams; common. Nor. Stem 3 to 6 fect ligh. Icaves rariable in for $\mathrm{m}$, the low $\mathrm{s}$ metimes orat lanceolate. pale leneath, toth sides smooth, 4 to 6 inches long. Heads numerous, large and showy. with 25 to 30 large bright purpli:h-line rays. 'This rarialle plant inciules several nominal species, including A. laxus, Willd., A. prealtue, Poir., and A. elodes, Torr. \& Gray.

\section{A. puniceus, L.' Rouigh-stemmed Asier. Cocash.}

Slem hispcd, stout; lcares oblong-lanceolate, chasping 1 y an auricled base, coarsely gerrate in the mild!e; involucre scales loose, narrowly linear, acute, equal in about 2. rows; heads in paniclos.

Low thickets and swrmps; ccmmon. Aug.-Oct. Sicm 3 to 6 fect hich, usually purple and $\nabla c r y$ rough with sigid bristly hairs. Iraves sf aringly tcothed in the middle, rough above, nearly smorth bencath. Hecids large and showy. Riays 50. to 80 , lcng and narrow, lilac-purrle or bluish.

\section{A. Prenanthoides, Mulil. Pronanthes-lite Aster.}

Stem low, and with the branches hairy in lines; lecires spatulate-lanceolate or orate-lanccolate, inciscly scrrate in the middle; involucre imbricatcd, with narrowly linear scales, crowncd with recurvcd spreading tips; heads in corymbose panicles.

Moist woods. Seft., Oct. Sfrm 1 to 3 feet high, sparingly branched. Leares conipicuously acuminate, tapcring below into a long contracted cntire portion, wh:ch is ar.ruptly dilated into on auricled-heart-shared clasping base; tranch leares smaller, nearly entire. Heads atout middlc-size, rather few, clustered towards the ends of the branches. Rays violet, lilac or light-blue. 


\section{A. Nove Anglis, L. New England Aster.}

Stem stout, hairy; leaves very numercus, lanceolate, acute, entire, auriculate elasping, roughish pubescent; involucre-scales linear-awl-shaped, loose, equal, nearly in a single row, viscid, as long as the disk; heads in a loose terminal panicle; achenia hairy.

Moist grounds; common. Sept.-Nov. Stem 3 to 6 feet high, almost hisped, with spreading branches. Heads showy, large, crowded in close corymbs. Rays violet purple, sometimes rose-purple, very numerous.

\section{A. oblongifolius, Nutt. Ablong-leaved Aster.}

Stem rigid, much branehed above; leaves narrowly oblong or lanceolate, mucron ately pointed, entire, partly clasping, roughish; involucre imbricated with broadly linear scales appressed at the base, crowned with long and spreading foliaceous: tips; heads in corymbose panicles; achenia canescent.

Banks of the Juniata, Huntingdon Co. Dr. Porter ! in Gray's Flora. Stem 1 to. 2 feet high, with the branchlets, the uppermost leaves and involucre minutely roughish-glandular with resinous dots. Leaves 1 to 2 inches long, $1 / 4$ to $1 / 2$ wide. Heads fower and much smaller than in A. Novæ Angliæ. Rays violet-purple:

4. ****** ORTHoneris, Torr. \& Gray.--Scales imbricated, with membranaceous margins, destitute of green tips; pappus of soft and unequal capillary bristles.

\section{A. acuminatus, Michx. Pointed-leaved Aster.}

Somewhat hairy; stem simple, flexuous, angular; leaves oblong-lanccolate acuminate, serrate; involucre imbricated with linear-lanceolate, pointed, thin scales: heads in corymbose panicles.

Mountains and woods. Aug. Stem about 1 foot high. Leaves conspicuously pointed, coarsely toothed above, wedge-form and entire at the base, 3 to 5 inches long. Panicle eorymbose, terminal, few-flowered, nearly or quite naked. Heads. rather large with 12 to 18 long, white, often tinged with purple rays.

5. ******* OxyтRipoliom, DC.-Pappus soft and capillary; achenia striate: Teaves thickish or succulent.

25. A. Flexuosus, Nutt. Perennial Salt Marsh Aster.

Stem very smooth, flexuous, sparingly branched; leaves linear; lower lance-linear thick and fleshy, pointed, entire; involucre bell-shaped, with ovate-lanceolate imbri-, cated scales in many rows; heads large, terminal on the ends of the branches; rays numerous, shorter than the involucre.

Salt marshes. Sept.-Nov. Stem 1 to 2 feet high, with the whole plant very smooth, usually with a few spreading branches at the summit. Heads large, 1 to 2 on the branchlets. Rays numerous, lange, pale purple. Disi yellow.

\section{A. IINIfolius, L. Annual Salt Marsh Aster.}

Smooth; stem much brarched, erect, spreading; leaves linear-lanceolate, pointed, entire, flat, on the branches awl-shaped; involucre oblong, with linear awl shaped scales in few rows; heads in raeemes or panicles.

Salt marshes. Aug.-Oct. Stem 12 to 18 inches high, thick, smooth, reddish, very branching. Leaves smooth, sessile. Heads small, in a loose terminal panicle. Rays somewhat in two rows, short, not projecting beyond the disk, more numerous than the disk flowers, pale purple or nearly white.

\section{GALATELLA. Cass.}

Heads many-flowered, the rays few, sterile. Involucre shorter than the flowers, the scales closely imbricated in 3 or 4 rows, the outer often 3-nerved. RECEPTACLE alveolate. 
ACHenia oblong, silky-hairy. PAPPUS of copious capillary bristles.-Perennial plants with straight stems, narrow 1 to 3 nerved, rather rigid entire leaves, often dotted, and flowers with purple or pale rays, and a yellow disk.

1. G. Hyssopifolia, Nees. Hyssop-leaved Galatella.

Stem erect, corymbose at the summit; lower leares lanceolate-linear, acute, dotted, entire, rough, 3-nerved ; branch leaves linear-subulate, 1-nerved; involucre scates acutish; rays elongated.

Sandy fields and open woods. Aug.-Oct. Stem 1 to 2 feet high, smooth, with spreading branches, terminated with a single head. Rays 5 to 10, white or palo purple. The $G$. linifolia of Nees is perhaps only a variety of this species.

\section{ERIGERON, Linn. Fleabane.}

Gr. er, the spring, and geron, an old man; because it is hoary early in the season.

Heads many-flowered, mostly hemispherical; the ray flowers numerous, very narrow, pistillate; those of the disk tubular, perfect. Scales OF THE INVLOUCRE narrow, nearly equal and almost in a single row. RECEPTACLE naked, flat. Achenia flattened, usually pubescent and 2-nerved. PAPpus mostly simple.-Herbs with alternate leaves, mostly ses. sile, entire or toothed, and solitary or corymbed flowers with white or purple rays.

* Rays not exceeding the disk.

1. E. Canadense, L. Horse-weed. Butter-weed.

Bristly-hairy; stem erect, wand-like; leares linear or lance-linear, mostly entiro ciliate, lower sometimes serrate; heads small, very numerous, panicled; rays crow ded. scarcely longer than the cylindric involucre.

Fields and waste places, very common. July-Nov. A common annual weed of no beauty, growing everywhere, from 6 inches to 6 feet high, mostly very hairy. Leaves very narrow with rough edges. Flowers small, white, of mean appearance, irregularly racemose upon the branches, and forming a large oblong panicle. The plant varies greatly in size, according to the soil.

* Rays longer than the disk.

\section{E. Bellidifolium, Muhl. Robin's Plantain.}

Hairy; radical leaves oborate and spatulate, sparingly toothed; stem-leaves sessile; distant, lance-oblong, partly clasping, entire; heads few, large, corymbose; rays 50 to 100 , twice as long as the involucre. Perennial.

Shady woods and moist banks, common. May. Stem 1 to 2 feet high, producing offsets from the base, rather naked above, bearing 1 to 9 large heads, on slender peduncles. Leaves 2 to 3 inches by $1 / 2$ to $3 / 4$ mostly widest above the middle. Rays bluish-purple sometimes nearly white.

3. E. Philadelphicum, L. Philadelphia Fleabane.

Hairy; stem leafy; lower leaves wedge-obovate, sometimes obtusely serrate or in. eisely toothed; upper clasping, usually entire; heads few, on elongated peduncles: rays very numerous, 150 to 200 . Perennial.

Woods and fields, common. Aug., Sept. Stem slender, 1 to 3 feet high, loosely corymbed at the summit, bearing several small heads. Leaves 2 to 4 inches long by 3/. to $3 / 2$ wide. Rays reddish-purple or desh-colored, very narrow. 


\section{E. Annum, Pers. Daisy Fleabane.}

Sparsely hairy; stem tail ; lower lexves ovata, obtuss, coarsily toothed, tapering into a margined petiole; upper louves ovate-Ianceolate, acute and entire at both ends; grays very narrow. Annual.

Ficlds and mealows; very common. Junc-0et. Sten 3 to 5 feat himh, stout, angular, more or le:s hirsuta, bearing num rous corymbed hen!s. Rays 100 or mors, white, tinged with purple, scarcely the length of the somewhat hisped involucre.

\section{E. Strigosum, Muhl. Strigose Fleabane.}

Stem slender, hairy; leaves tootlied or entire; lower spatulate-lanceolate, 3-nervad tapering to a long narrow peticle; rupper lancoolats; hecids in panicled corymbs rays narrow-linear.

Fields and meadors; common. June-Augs. Sem 1 to 3 feet himh, ancular, furrowed with short stif hairs, and buaing a larre, loose co:ymb. Ficuss white, twice the length of the minutely hairy involucre. Plant smaller and move simple than the last, but with longer rays.

\section{DIPLOPAPPUS, Cass.}

Gr. diptoos, double, and pappiss, prpmes, the character which distinguishes the genus from Aster.

Heads many-flowered; rail fovoers 8 to 12 in a single series, pistillate; those of the disk tubular, periect. InvouUCRE with imbricated, appressed, laneoclate or awl-shaped scales, 1-norvel or keoled, destitute of horbacsous tips. RECEPTACLE fa', alveolate (honey-comb-like). Acrinia flattish. Paprus double, the outer very short, subulate, the innor long, capillary.-Peiennials viti entive ulternate lenves, and corymbose or simple heads of flowers with cyanic rays and yellow distes.

1. D. urmearifolius, Hook. Violet Diplopeppus.

Stem erect, or somewhat decumbent, roughish; lecie: rigid, spreading, linear, strongly 1 -nerved, smoth, with very rough margins; icuts ieminating the simple siightly hoary branches.

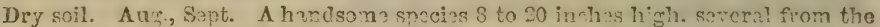

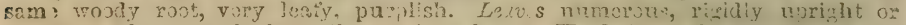
ricurvol, obtuz, pale bonsath, sataiar abova. Had; lavio for the size of the p.at, solitary and terminal on the branchus, with lons showy viot-colozd rays.

2. D. umbeluatus, Torr. \& Gray. Untuelled Diploprppus.

Smooth, lenfy at the top; leares lancolate, clongated. acuminate and tapering at the base; heuds very numorous; scales of the inbolucre closely imbricated, obtusely Ianceolate.

Moist thickets, river banlss. $\Lambda$ um., Sept. Sten 2 to 5 foet high, bushy at the top. Leaves somewhat rough above, smooth beneath, 3 to 6 inches long, narrow, those of the branchos smaller. Hacils aumerous, in a level-topped corjmb. Izujs about 12, white.

3. D. Amygdalinus, T.\& G. Almond-leaved Diplopappus.

Smooth or roughish abovo, leafy; lecuss ovats-lanseo'at, acate, abru; ly na r uved at the base; heads numcrous; sczles of the involucre loosely imbricited, oltusc.

Low grounds. Aug. Rescmuling the last, viually lower, rourb, and with broader and shorter leaves. 
4. D. connifolius, Darl. Cornel-leaved Diplopappus.

Stem slender, low, pubescent and loosely panicled above; leaves elliptical or ovatelancélate, acuminate, ciliate-hirsute on the margin, hairy on the veins beneath.

Woods. July-Sept. Stem 1 to 2 feet high. Leaves conspicuously pointed at both ends, pale beneath on very short stalks. Heads usually few, on rather rigid peduncles. Rays white.

\section{BOLTONIA, L'Her.}

In honor of $J$. Botton, a botanist of the last century.

HEaDS many-flowered, the ray-flowers numerous, pistillate; those of the disle tubular, perfect. INvOLUCRE hemispherical with imbricated appressed scales, somewhat in 2 rows, crowned with narrow membraneous margins. RECEPTACLE conical, punctate. Achenia flat 2 or 3 winged. Pappes of several minute bristles with 2 to 4 longer awns.- Smooth branching perennial herbs, with lanceolate entire, sessile leaves, and loosely corymbose heads of flowers, with white or purplish rays.

1. B. Asteroldes, L'Her. Aster-like Boltonia.

Leares entire or obscurely serrate; pappus of few minute bristles and no awns; achenia broadly oval.

Moist places, along streams. July-Aug. Stem 3 to 6 feet high, with a diffusely branched summit. Leaves 2 to 6 inches long by $1 / 4$ to $1 / 2$ wide, reduced upwards to setace ous bracts 1 to 2 inches in length. Heads terminal on the filiform bractlets. Rays purple, $1 / 2$ inch long.

2. B. glastifolia, L'Her. Glaucous Boltonia.

Leaves lanceolate, somewhat glaucous; pappus of several short bristles, and 2 or 3 more or less prolonged awns; achenia obovate, broadly winged.

Rich moist soil. Sept. Stem 3 to 7 feet high. Stem leaves 2 to 4 inches long by $1 / 4$ t $3 / 4$ wide, those of the branches smaller. Heads in a loose corymb. Rays purplish, $3 / 4$ of an inch long. Dist yellow.

\section{SERICOCARPUS, Nees.}

Gr. seritos, silky, and karpos, fruit.

Heads 12 to 15 -flowered; ray-flowers 4 to 8 pistillate; disk-flowers 6 to 10, perfect. Involuche oblong or clubshaped, closely imbricated with appressed cartilaginous scales in several rows with short and abrupt green tips. RECEPTACLE alveolate-toothed (honey-comb-like). AcHenia short, obconic, very silky. PAPPUS simple, of capillary bristles. Perennial tufted herbs, with sessile alternate leaves, and small clustered heads of flowers with white rays and yellow disks, disposed in a flat corymb.

1. S. solidagineus, Nees. Narrow-leaved Sericocarpus.

Smooth; stem erect, slender; leaves linear, rigid, obtuse, entire, with rough mar gins obscurely 3-nerved, tapering to the base; heads very small, in close clusters, few-fowered; rays slender. 
Woods and low places; rare. Aug., Sept. Stem simple, about 2 feet high, often several from the same root. Leaves smooth, pale green, 1 to 2 inches long, $1 / 4$ to $1 / 2$ inch wide. Heads in a flat-topped corymb. Rays white, longer than the disk. Pappus white.

\section{S. CONYZOIDES, Nees. Broad-leaved Sericocarpus.}

Slightly pubescent; leaves oblong-lanceolate or the lower spatulate, obscurely 3-nerved, smooth beneath, acute at each end, ciliate; lower serrate towards the apex; involucre top-shaped; heads rather loosely corymbed; rays short.

Dry woods; common. July-Sept. Stem 1 to 2 feet high, somewhat 5-angled, sigid, but rather slender. Leaves somewhat fleshy. Heads few in small clusters. Rays longer than the disk, white.

\section{CALLISTEPHUS, Cass.}

Gr. kallos, beautiful, and stephos, a crown.

RAY-TLOWERS pistillate, numerous; disk-flowers perfect. Involdore hemispherical. Receptacles sub-convex. Paprus double, each in one series, outer series short, chaffy, bristly, with the bristles united into a crown; inner series of Iong, thread-like, rough, deciduous bristles. - Exotic annuals with alternate leaves and showy heads of flowers.

\section{C. Chinensis, Nees. China Aster. Qucen Margaret.}

Siem hisped; branches divergent, 1-flowered; leaves ovate, coarsely dentate, petioIate; stem leaves sessile, medge-shaped at the base.-Native of China. Cultivation. Las produced many beautiful varieties, double and semi-double, with white, blue, red, flaked and mettled rays. Stem 15 to 20 inches high, with long branches, each terminated by a single large head. Disk yellow. July-Sept.

\section{DAHLIA, Linn.}

In honor of Andrew Dahl, a Swedish botanist.

INVOLUCRE double, the outer series of many distinet scales, the inner of 8 scales united at base. RECEPTACLE chaffy. Pappus none.-Showy Mexican perennial plants, with opposite pinnate leaves, and showy large heads of fiowers.

\section{D. variabilis, Desf. (D. superfiua. Ait.)}

Siem green; raches of the leaves winged; leaflets ovate, acuminate, serrate, puberellent or nearly smooth; outer involucre refiexed; ray-fowers pistillate, sterile or fertile. - Stem 2 to 4 feot high. Leares coareo and roughish resembling those of the conmon elder. Flowers large and beautiful, sporting into innumerable varietiez, kingle and double, of every concoivable shade of white, scarlet, crimson, purple, red, rarely yellow, blooming from $\mathrm{Aug}$. until arrested by frost.
2.
D. COCCINEA, Cav.
(D. frustranea. Ais.)

Sitem frosty, or hoary, hollow; leaves with the ractis naiked; leafleis roughish be: ncsib; outer involucre spreading; rays neutral.-Stem 3 to 4 foct high. Leares Slaucous. Foys searlet, orange-colored or yellow, never purple on white.

SEcrios 2. Heads radiate; rays yctlow. 


\section{SOLIDAGO, Linn. GOLDEN-ROD.}

Lat. solido, to join, or make whole; in allusion to its reputed rulnary properties.

Heans few, or many-flowered. RaYs 1 to 16 , pistillate. ReCEPTACLe small, alveolate (honey-comb-like). SCALES OE THE OBLONA INYOLUCRE imbricated appressed. ACHENIA many-ribbed, nearly round. PAPPUS simple, of equal capil. lary bristles.-Perennial herbs with stens branching near the top, wand-like; alternate leaves, and small heads of yellow (cne speies whitisit) flowers expanding in the autumnal months.

* Stems mueh branched, corymbose; leaves all linear, entire, sessïe.

\section{S. Lanceodata, Ait. Bushy Golden-iod.}

Stem angular, halry, much branched; leaves lance-linear, 3 to 5 nerrca, rought margineä; fieac's oboroid-cylindrical, in aense corymbed clusters; rays 15 to 20 .

WFods and meadows; common. Sept. Stem 2 to 4 feet high, torminating in s flat-topped corrmb. Leaves numerous, long and narrow, aistinctly 3-reinoc? aentu? if pointed. F'lower's in terminal crowded clusters. Whole plant somewhat frogzant.

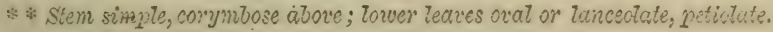

2. S. RIGIdA, I. Rigid Golden-rod.

Fough and somewhat hoary; stem stout, erect, very leafy; lower leaves oral, cre zate-dentate, rigici; upper orate-oblong; sessile, entire, veiny, thick and rigid; fucs abou $\$ 3$ to 4 flowered, large, in compact erect racemes; rays 7 to 10.

Dry felds and rocky woods. Aug., Sept. A tall species, 3 to 5 feet high, rexs pubescent when young. Leares rigid, the radical ones sometimes near a foot lons Heads very large, many-flowered, clustered near the summits of the branches. Rays deep yellow.

*** Head's in glomerate axillary clusters.

3. S. squarnosa, Mulhl. Large spized Golden-rad.

Stem stout, simple, densely pubescent abore; leaves smooth, oblong or the iotrer spatulate-oval, serrate, reiny; scales squarrose with spreading green tips; hewhs many-flowered.

Rocky wooded hills. Sept. Stem 3 to 5 feet high. Lower Icaves large, tapering into a margined petiole. Heads in dense axillary clusters, forming a long lcafy compound spike. Rays 10 to 12, elongated, bright yellow.

\section{S. CдsIA, Ait. Blue-stemmed Golden-rod.}

Smooth; stem terete, ereet; leaves lanceolate or oblong-lanceolate, serrate, pointed, sessile; heads in short axillary clusters or racemes; rays 5 to 7 .

Muist rich woodlands; common. Aug. Stem 2 to 3 feet high, slender, usually dark purple and glaucous, simple or branched. Leaves 2 to 5 inches long, longpointed, scs i glaucous beneath. Heads middle-sized, in numerous axillary racemes. Flowers deep yellow.

\section{S. LAtifolia, I. Broad-leaved Golden-rod.}

Nearly smooth; stem angled, mostly flexuous, smooth; leaves broad, orate or oval, long pointed at each end, coarsely dentate-serrate; heads in rery short axillary clusters or racemes.

Moist woods and shaded banks; common. Augo-Oct. Stem 1 to 3 feet bigh, elender, mostly smooth. Leaves 3 to 5 inches long, 2 to 4 wide, with acute and ofte 1 long serratures. Clusters of heads short, the stem terminating with a long terminal one. Rays 3 to 4. Disli-flower's 6 to 7. 


\section{S. BICOLOR, L. White-rayed Golden-rod.}

IIairy; stem simple ; leaves oblong or elliptical-lanceolate, acuto at each end ; lower ones serrate, short-stalked; racenves short, dense, leafy, erect; scales of the involucre obtuse.

Woods and dry hills; common. Aug.-Oct. Stem 1 to 2 fect high, erect. Lovver leaves tapering into a petiole. Clusters or stiort racemes from the axils of the upper leaves, forming an interrupted spike or crowded panicle. Rays about 8, small, cream-color or nearly white. Var, concolor, Torr. \& Gray. Flowers all yellow.

***: Heads in erect, terminal, simple or compound racemes.

\section{S. Puberula, Nutt. Puberulent Golden-rod.}

Minutely puberulent; stem-leaves lanceolate, acute, tapering to the base; lower Zeaves wedgo-lanceolate, subserrate; heads very numerous, crowded in compact erect-spreading short racemes; scales of the involucre linear-awl-shaped, appressed; rays about 10, elongated.

Low woods in sandy so il. Aug.-Oct. Stem straight, purplish, 1 to 3 feet high. teaves very minutely pubescent, 2 to 3 inches long; the lower ones on dense winged stalks. Ifeculs rather large, bright yellow, in a prolonged and dense narrow or pyramidal panicle.

\section{S. sTRICTA, Ait. Upright Golden-rod.}

Smooth throughout; Stem simple, strict; leaves lanceolate, pointed, the lower ones tapering gradually into winged petioles, somewhat sheathing at the base, minutely sorrate above the appressed tecth; racemes much crowded and approssed in a dense wand-like paniele; scales of the involucre linear-oblong, obtuse; rays 5 to 6 , small.

Wet woous. July, Aug. Siem 2 to 3 feet hich, very smooth. Root leaves 6 to 10 inches lon 3,3 to 1 inch wide. Tinicle terminal, close, compound, of short, dense, appressed racemes. Heads 12 to 18 flowered.

\section{S. speciosa, Nutt. Shovy: Golden-rod.}

Stem smooth, simple; leaves oval or ovate, slightly scrrate, the uppermost oblong* lanceolate, the lower ones contracted into a margined petiole; heads somewhat crowded in numerous erect racemes; peduncles and petioles rough-hairy; involucre cylindrical with oblong, obtuse scales.

Woods; rather common. Aug.-Oet. A very handsome species, sometimes 6 feet high. Leaves thickish, 4 to 6 inches long and 2 to 4 wide in the larger forms. IIeads very numerous with conspicuous, rays of a rich yellow, in a large showy pyramidal panicle. Rays about 5, large.

**** Heads in one-sided racemes; teaves triple-veined.

\section{S. nemoralis, L. Grey Golden-rod. Ficld Aster.}

Minutely greyish, hoary, pubescent; stem simple or corymbed at the summit leaves oblanceolate or spatulate-oblong, the lower somewhat crenate-dentate and tapering into a potiole; heads in numerous paniculate-secund racemes; scales of the involucre linear oblong, appressed; rays 6 to 9 .

Dry, sterile fields; very common. Sept. A common starved looking species, 1 to 2 feet high, with a greyish, dusty aspect. Heads small but with conspicuous yellow rays. Racemes numerous, dense, at length reeurved, forming a crowded compound panicle, which is usually turned to one side.

\section{S. Canadensis, L. Canadian Golden-rod.}

Stem tall and stout, rough, hairy; leaves lanceolate, pointed, sharply serrate, more or less pubescent beneath; heads small; racemes paniculate, one-sided, recurved; rays very short.

Borders of thickets and fields; very common. Aug., Sept. Stem 2 to 5 feet high, furrowed. Leaves sessile, 3 inches long, sometimes nearly entire, rough on the up- 
per side. Heads very numerous, small, with very obscure yellow rays.-Varies greatly in the roughness and hairiness of the stem and leaves, the latter varying to oblong-lanceolate or elongated linear-lanceolate.

12. S. SERotina, Ait. Late-flowering Golden-rod.

Stem very smooth, tall and stout, often glaucous; leaves lanceolate, pointed, serrate, roughish, slender; pubescent; rays numerous, short.

Thickets and-low grounds; common. Sept., Oet. Stem 4 to 8 feet high, terete; sometimes purplísh. Leaves 3 to 7 inches long, $1 / 2$ as wide, lower ones slightly. toothed, upper ones entire. Heads numerous, midale-sized, forming a more or less compact panicle inclined at the summit.

13. S. GIGANTEA, Ait. Gigantic Golden-rod.

Stem smooth, stout and tall; leaves lanceolate, acuminate, very sharply serrate; smooth on both sides, margin rough, ciliate; heads in paniculate racemes; branches pubescent; peduncles and pedicels hairy; rays rather long.

Fields and fence rows; common. Aug.-Oct. Stem 4 to 7 feet high, green sometimes purplish, sometimes much branched above. Leaves 2 to 7 inches long, $1 / 3$ as wide, acuminate at each end. Heads larger than in the two preceding species. Panicle diffuse on spreading, leafy branches.

****** Heads in one-sided racemes; leaves feather-veined, all entire.

14. S. Sempervirens, L. Evergreen or Sät Marsh G.-rod.

Smooth ; stem stout; leaves fleshy, lanceolate, closely sessile or somewhat clasping; the radical leaves oral or lanceolate-oblong, obscurely triple-nerved; heads in erect racemose panicles; rays 8 to 10 , elongated.

Salt marshes and river banks near the water. Sept. Stem 2 to 8 feet high, purplish, somewhat glaucous, with numerous long and narrow leaves. Heads showy, with golden yellow rays.

15. S. ODORA, Sweet-scented Golden-rod.

Smooth; radical and lower stem-leaves elliptical or lance-oval; leaves lincar-lancea late, entire, smooth, pellucid-dotted, scabrous on the margin; racemes paniculate one-sided.

Borders of thickets, sunny hills and fertile woodland. July-Sept. Stem 2 to 3 feet high, yellowish green, with lines of pubescence from the base of the leaves. Leaves 2 to 3 inches long, $1 / 4$ to $1 / 2$ wide. Heads middle-sized, in one-sided racemes, forming a terminal pyramidal panicle. Rays 2 to 4 , oblong, large. The leaves and flowers when dried form an excellent substitute for tea. The leaves are aromatic, and yield by distillation a fragrant volatile oil.

******* Heacis in one-sided racemes; leaves feather-veined; the lower ones toothed.

\section{S. Patula, Muhl. Spreading Golden-rod.}

Stem smooth, strongly angled; leaves ovate, acute, serrate, very smooth and veiny. underneath, upper surface very rough; racemes paniculate, spreading.

Swamps; common. Aug., Sept. Stem 2 to 5 feet high, often purple, branched above. Leaves often 6 to 8 inches long, lead-colored; the lower ones oblong-spatulate, the upper surface remarkably rough. Heads rather large on numerous ran cemes, on the spreading branches. Rays to 7, oblonts.

17. S. NeGLecta, Torr: \& Gray: Neglected Golden-rod.

Smosth; stem stout; leaves thickish, varying from narrow-latceolate to ovatilanceolate, tupering to both ends, feather-veined, entire, the lower ones serrate; $r a_{\text {. }}$ cemes dense,one-sided, at length spreading, on elongated, slender; sub-erect branches.

Swamps. Aug., Sept. Stem 2 to 3 feet high, straight, round, dividing at top into: several nearly erect branches. Lower leaves 5 to 7 inches long. Heads middle-sized, 20 to 20 flowered. Racemes at first erect and scarcely one-sided.

18. S. ARguta, Ait. Sharp-toothed Golden-rod. Smooth; radical and lover stem-leaves eliptical or lance-oval, sharply serrate, whith: $\mathbf{Z}^{*}$ 
spreading teeth, obscurely 3-nerved, pointed, tapering into winged and ciliate petioles; upper leaves lanceolate or oblong, tapering to each end, mostly entire; racemes dense, at length elongated and recurved, forming a crowded and flat corymb-like panicle; rays 8 to 12 , small.

Woods and banks; common. Aug., Sept. Stem 2 to 4 feet high, round, sometimes purple. Heads small, very numerous. Scales of the involucre closely appressed.Well distinguished by its long or drooping racemes. S. juncea of Ait. is a variety with narrow leaves and less dense panicles.

19. S. Muhlenbergir, T. \& G. Muhlenberg's Golden-rod.

Smooth; stem angled; radical leaves ovate, on margined petioles; stem leaves ellip. fical-lanceolate, rery sharply and strongly serrate, pointed at both ends; racemes one-sided, spreading, disposed in an elongated open panicle.

Low grounds. Aug.-Oct. Stem 2 to 3 feet high, mostly simple, bearing a long open paniele. Leaves large and thin, notched with very acute teeth, feather-veined. Heads middle-sized, with 6 to 7 large spatulate-oblong rays.

\section{S. Altissima, L. Tall Rough Golden-rod.}

Iough, hairy; stem erect, hisped, with rough hairs; leaves orate-lanceolate, elliptical or oblong, acute or pointed, coarsely serrate, rough and wrinkled; racemes paniculate, spreading or recurved; rays 6 to 9.

Eorders of fiolds and woods; very common. Aug., Sept. Stem 2 to 7 feet high, much branched at top. Leaves numerous on the stem and branches, variously tootled or serrate. Branches widely spreading, each terminating in a recurrea ponicle with the flowers turning upwards. A very variable species.

\section{S. vimifoura, Muhl. Elm-leaved Golden-rod.}

Siem smooth, the branohes hairy; leaves thin, elliptical-ovate or oblong-lanceolate, pointed, tapering to the base, coarsely serrate; racemes panicled, reeurved-spreading; involucre scales lanceolate-oblong; rays about 4.

Low grounds; common. Aug., Sept. Stem about 3 feet high, rarely with scat terel hairs. Favt-leaves tapering to winged petioles. Heads in racemes which are iftcn slender and usually recurred. Rays deep-yellow. Distinguished from the last by its smooth stem and the larger leavos.

\section{CHRYSOPSIS, Nutt. Golden Aster.}

Gr. chrusos, gold, and opsis, aspect, in allusion to the golden blossoms.

Heads many-flowered. RAX-nLowers numerous, liguIate, pistillate; those of the disk tubular, perfect. INvoluCRE imbricate, with linear scales destitute of herbaceous tips. Peceptacle flat. AcHenIA obovate, flattened, hairy. PAPrus double, the exterior short, interior copious, capillary.-Perennial liairy herbs, with alternate entire leaves, rather large, often corymbose head's of golden yellow flowers terminating. the branches.

\section{C. Martana, Nutt. Maryland Chrysopsis.}

Clothed with long somewhat silky hairs; leaves oblong or elliptical, veiny, nearly entire, the upper closely sessile, the lower spatulate and generally obtuse; corymb nearly simple.

Sandy soil. Aug. Stem 1 to 3 feet high, mostly simple, leafy, and with the leaves nothed with scattered long, silky laairs. Heads rather few, large, 12 to 20 rayed, in a termiual somewhat unibellate corymb. Peduncies viscid, glandulaz. 
SEOTIOX 3. Heads radiate; rays yellow; anthers with tails at the base; receptacte nalied.

19. INUla, Linn. Rlecampane.

The ancient Latin name.

HEADS many-flowered. RAY-FLOWERS in a single series: pistillate, ligulate, rarely tubular; DISK-FLOWERS perfect, tubular. INVOLUCRE imbricated. PAPPUS of capillary bristles. Receptacle flat, or somewhat convex, naked. HEADS solitary or corymbose.-Coarse European perennial herbs with alternate leaves, and large heads of yellow flowers.

\section{Helenium, I. Common Elecampane.}

Stout; root-leces ovate, tapering into a petiole; stem-leaves somewhat clasping, all of them acute, toothed, woolly underneath; outer involwcre scales leaflike; rays narrow, very numerous; achenia prismatic, 4-sided.

A large coarse-looking plant, naturalized by road-sides. Natire of Enrope. Aug. Stem 4 to 6 feet high, furrowed, branching and downy abore. Ractical-leaves 1 to 3 feet long, 6 to 12 inches wide. Flovers large, solitary, terminal, bright yel. low. Rays linear, with 2 or 3 teeth at the end. The root is mucilaginous, and is zighly esteemed as a domestic medicine.

\section{ECLIPTA, Linn:}

Gr. ekleipa, to be deficient, alluding to the absence of pappus.

Heads many-flowered. RaY-FLowers pistillate, in one series, ligulate, very narrow and short; DISIK-FLOWERs perfect, tubular, 4-toothed. Involudre in 2 series; the scales 10 to 12, leaf-like, ovate-lanceolate. Receptacie flat, furnished with linear thread-like chaff. Achenta short, 3 to 4 sided, in the disk 2 sided, sometimes hairy at the summit. Pappus none, or an obscure toothed crown.-Annual or biennial rough herbs, with slender stems, opposite lanceolate or oblong leaves, and whitish flowers, axillary, or solitary and terminal; an. thers brown.

\section{E. Procumbens, Michz. Procumbent Eclipta.}

Rough with close appressed hairs; stem procumbent, ereeping or ascending; isaves oblong lanceolate, acute ot each end, sessile, slightly scrrate; peduncles axil lary or terminal longer than the head. Annual.

Damp sandy soils, Western parts of the State. June-Oct. Stem 1 to 3 feet Iong, often rooting at the base. Leaves $1 / 2$ to 1 inch by $1 / 4$ to $1 / 2$, rough, obscurely triplereined. Feads small, with minute flowers and short rays ou peduncles many times longer than the head.-Var. BaACEYPODA has the peduncles scarcely longer than the bead.

SECTION 3.-Heads discoio.

21. Pluchia, Cass. Marsh Fleabane.

Named in honor of N. Pluche, a French botanist. 
HEADs many-flowered; the flowers all tubular; the central ones perfect or sterile, few, with a five-cleft corolla; the outer inmany series, with thread-shaped truncate corollas, pistillate and fertile. INVoLUCRE imbricated. RECEPTACLE flat, naked. Achenia grooved. PAppus capillary in a single row. - Herbs somewhat glandular, emitting a strong camphoric smell, with alternate entire leaves and corymbs of purple flowers.

P. FETIDA, DC. Faetid Marsh Fleabane.

Nearly smooth; stem erect, very leafy; leaves broadly lanceolate, acute at each end, distinctly petioled, veiny, obtusely serrate; heads numerous, in paniculate corymbs.

Open, hilly grounds and river banks, western parts of the State. Aug. Per. Slem 2 to 4 feet high, sub-simple. Leaves 4 to 7 inches long, $1 \frac{1}{2}$ to 3 wide, sprinkled with minute dots, on petioles $1 / 2$ to 1 inch long.

\section{Tribe IV. SENICIONIDEA. The Groundseu Tribe.}

Heads radiate or discoid; branches of the style linear, hairy or hisped at the apex, which is either truncated or produced into a conical or elongated appendage; leaves opposite or alternate.

\section{SECTION 1.-Heads radiate; flowers yellowish or greenish.}

\section{POLYMNIA, Linn.}

Dedicated to one of the ancient Muses, for no imaginable reason.

HEADS many-flowered. RAY-FLOWERS pistillate, ligulate, in one series; DISK-FLOWERS perfect, tubular, sterile. RECEPTACLE flat, chaffy. InvoLUCRE double; the outer scales about 5 , leaf-like, large and spreading, the inner small and membranaceous, surrounding the round obovoid achenia. PAPPUS none.-Tall, branching, viscid and hairy perennial herbs, with large opposite leaves, the upper lobed with dilated appendages at the base, and light yellow heads of flowers in panicled co. rymbs.

\section{P. Canadensis, I. Leaf-cup:}

Clammy, hairy; lower leaves deeply pinnatifid, or lyrate; the uppermost triangular-obovate or wedge-form, shorter than the involucre.

Moist, shaded ravines. June, July. Stem 2 to 5 feet high, roughly pubescent and somewhat viscid, branching. Leaves opposite or alternate, very thin, mostly 3 to 5 lobed at the apex. Flowers light yellow, with short rays, surrounded by the concave leaflets of the double involucre, so as to form a sort of a cup, hence called leaf-cup. Heads $1 / 2$ inch in diameter.

\section{P. Uvedalia, L. Large Leaf-cup.}

Roughish, hairy, stout; leaves broadly ovate, angled and toothed, nearly sessile, the lower palmately lobed, abruptly narrowed into a winged petiole; outer scales of the involucre very large; rays 10 to 15.

Bich soils. July, Aug. Stem 3 to 6 feet high, round. Lower leaves very. large. 
Fieads of flowers large, few, arranged in loose panicles, the rays much longer than the involucre, bright yellow; disk dull yellow.

\section{SILPHIUM, Linn. RosIn-PLANT.}

Gr: sitphion, the ancient name of a medicinal plant of Africa, transfered to the genus by Linnæus.

HEAds many-flowered. RAY-FLOWERS numerous, ligulate, pistillate and fertile, their broad flat ovaries imbricated in 2 to 3 rows; DISK-FLOwERS perfect but sterile; tube short. RECEPTACLe somewhat convex, chaffy. InvoluCRe bellshaped, with imbricated scales in several rows, the outer with loose leaf-like summits. Achenia broad and flattened, surrounded by a ring which is notched at the top, destitute of pappus, or with 2 teeth confluent with the winged margin; those of the disk abortive, with an obsolete crown-like pappus.-Coarse and tall rough perennial herbs, with a copious resinous juice, and large heads of yellow flowers in corymbose pan icles.

* Stem round or slightly 4 angled, leaffy : leaves undivided.

1. S. trifoliatum, L. Three-leaved Rosin Plant.

Stem tall and rather slender, smooth, often glaucous; stem leaves lanceolate? pointed, entire or scarcely serrate, rough, on very short petioles, in whorls of 3 or 4; upper leaves opposite; leads loosely panicled; involucre smooth; scales broadly ovate, rather obtuse; achenia broadly oval, sharply 2-toothed at the top.

Dry woods and plains. Aug. Siem 5 to 6 feet high, slightly angled, purplish: Leaves thick, 3 to 5 inches long. Heads loosely cymose on rather long peduncles. Rays 12 to 16, expanding about $2 \frac{1}{2}$ inches, bright yellow.

* Stem square; teaves opposite, connate.

2. S. perfoliatum, L. Cup Plant.

Stem stout, square; leaves orate, coarsely toothed, connate-perfoliate, narrowed. towards the base; heads in a trichotomous cyme, the central on a long peduncle.

Rich soil along streams. Aug. Stem 4 to 6 feet high, often branched above: Leaves 6 to 16 inches long, the upper united by their bases and forming a cupshaped disk, the lower narrowed into winged petiolus, which are connate by their bases. Heqds large, with 15 to 25 yellow rays. Achenia winged and variously notched.

\section{AMBROSIA, Tourn. RAG-WEED.}

Gr. ambrosia, the food of the gods, a term strangely applied.

Heads monocious; the fertile at the base and the sterile at the top of the spike. STERILE INVOLUCRE flattish or top-shaped, composed of 7 to 12 scales united into a cup, containing 5 to 20 funnel-form staminate flowers. FERTILE INVOLUCRE oblong or top-shaped, closed, pointed, and usually with 4 to 8 horns near the top in one row inclosing a single pistillate flower. AcHenia ovoid.-Herbaceous chief- 
ly annual coarse weeds, with opposite or alternate lobed or dissecied leaves, and inconspicuous greenish or whitish flowers.

\section{A. TRIFIDA, L. Great Rag-weed.}

Stem tall and stout; leaves 3-lobed serrate, the lobes oval-lanceolate, acuminate; racemes panicled; fruit 6-ribbed, the ribs terminating in as many crested tubercles Var.-INTEGRIFoLIA has all the leaves, or the upper ones, undivided, ovate or oral, pointed.

Low moist grounds, and banks of streams; common. Aug. Stem 4 to 12 feet

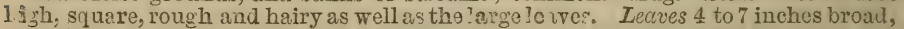
opposite. Flowers obscure and unattractive, in long leafless spikes, axillary and terminal.

2. A. ARteniszalia, I. Roman Wormuood. Hoij. weed. Common Rag-weed.

Stem slender, much branched hairy or roughish-pubescent; leaves opposito, and the upper alternate, twice pinnatifid, smoothish above, paler or hoary beneath; racemes or spities loosely panicled; frut obovoid globular, pointed, armed with about 6 short tecth.-Var. HeTEROPHYLIA, has the stem leaves pinnatifid, those of the branches lanceolate.

Waste places; common everywhere. July-Sept. An extremeiy variable weed, 3 to 3 feet high, with finely cut leaves, embracing several nominal species.

\section{XANTHIUM, Tourn. CockuE-BUrr.}

Gr. xantrus, yellow; in allusion to the color the plants are said to yicid.

FERTILE and STERIIE FLOWERS occupying different heads on the same plant; the fertile clustered below; the sterile in short spikes or racemes above. FERTILE InvouUcre closed, coriacious, ovoid or oblong, clothed with hooked prickles, so as to form a rough burr, 2-celled, 2-flowered, the flowers pistillate, with a slender filiform corolla. STERILE INVOLUCRE sub-globose, many-flowered, with the scales in one series. AcHrNIA oblong, flat.-Low coarse anmucls, with stout branching stems and alternate lobed or toothed petioled leares.

1. X. strumarium, L. Common Coctele-bum. Clot-weod.

Stem unarmed, branching; leaves cordate, lobed, 3-veined, unequally serrate, rough; fertile involucre oval, somewhat pubescent, the beaks straight.

Roadsides and waste places; introduced. July-Sept. Stem bristly, spotted, 2 to 3 feet high. Leaves large, 3 to 6 inches broad, on long stalks, rigid. Fertile flowers in sessile axillary tufts. Sterile flower's few together, terminal, globular, green. Fruit a hard 2-celled burw, near an inch long, corered with stiff hooked prickles.

\section{X. spinosum, I. Thorn Clot-burr.}

Leaves ovate-lanceolate, pointed, wedge-shaped at the base, entire or slightly 3lobed, minutely pubescent above, hoary underneath.

Waste places; introduced. Sept.-Nov. Stem 1 to 3 feet iigh, armed with 3-parted slender spurs. Leaves entire or repand-denticulate. Heads few, axillary, solitary; fertile in the lower and sterite in the upper axils.

\section{Tribe V. HELIANTHEAE. THE SUN-FLOWER TRIBE.}


Feacts radiate or rarely cliscoid; the disti-fowers always perfect and fertile; receptricle chaffy; anther's blechish, without tails at the base; pappus none, or croun-tike, or of one or two chaffy awns, never capillary or of uniform chafty scales; leaves chiefly opposite.

\section{HELIOPSIS, Per's. OX-EYE.}

Gr. hetios, the sun, and opsis, appearance, from the resemblance of the flowerg.

HEADS many-flowered; the RAY-FLOWER 10 or more in one series, ligulate, fertile; DISK-FLOWERS tubular, perfect. INvoLUCRE in 2 or 3 rows; the outer leaflike and somewhat spreading; the inner shorter than the disk. RECEPTACLE conical; CHAfr linear. Achenia smooth, 4-angled. Pappus none, or a mere border.-Perennial herbs, with opposite petioled leaves, and large showy heads of flowers with conspicuous yellow rays.

\section{H. LAvis, Pers. Common Ox-eye.}

Nearily smooth; leaves oval-lanceolate or oblong-ovate, coarsely serrate, petiolate, 3-reined.

A large showy plant in hedges and thickets; common. July, Aug. Stem 2 to 6 feet high, angular, 2 or 3 times forked abore. Leaves 2 to 6 inches long, 1 to 4 wide. Branches thickened at the summit, each terminating with a large, solitary, yeliow head.-Tar. SCASR.1, has roughish foliage, and the involuere somewhat hoary, 6 feet high. Var. GRACILEs is small and slender, with orate-lanceolate leares, acute at the base, 2 feet high.

\section{RUDBECKIA.}

In honor of Olaus Rudbeci, Professor of Botany at Cpsal, in Streden.

HEADS many-flowered; RAY-FLOWERS neutral, in a single series, ligulate; DISK-FLOWERS tubular, perfect. SCALES OF THE INYOLUCRE leaf-like, in about 2 rows, spreading. RECEPTACLE conical or columner, with short concare chaff. ACHENIA 4-angular, smooth, not margined, flat topped. PAPPUS none, or a minute crown-like border- Chiefly peronnial herbs, with alternate leaves and showy large heads of flowers ferminating the stem branches, with long and drooping yellow rays.

* Distl pate green or purplish.

\section{R. indiniata, L. Tall Cone-flower.}

Stem smooth, branching; leaves smocth or roughish, the lower pinnate, with 5 to 7 cut or 3-lobed leaflets; upper leaves irregularly, 3 to 5-parted; the lobes ovateIanceolate, pointed, or entire; chaff truncate and dorny at the tip.

Low thickets: common. July-Sept. A tall, showy plant, 6 to 8 feet high. Leaves gradually less and less dirided from the lowest to the umrormost ones. Ir.uds rather laree, temminal. Foys linear, 1 to 2 inches long, bright yellow, spreading or drooping. Dish greenish yellow.

* Diste broadly conical, dar\% purple or brown.

2. R. triloBa, L. Three-loted Cone-flower.

Iniry; stem much branched, the branches slender and epreadino; upper teaves crat-lanceolate, somewhat claspine, serrate or entire; lcuen leaves 3-lobed, taner ins at the base, coarsely serrate; scales of the involecre linear. 
Dry soil. July-Sept. Stem 2 to 5 feet high, very branching. Leaves 2 to 4 inches long, 3-veined. Heads small, numerous and showy. Rays about 8, deep yellow, $1 / 2$ to 1 inch long, $2 / 3$ as wide.

\section{R. SPECIOSA, Wender. Showy Cone-flower.}

Roughish-hairy, branched; leaves lanceolate or ovate-lanceolate, pointed at both ends, petioled, 3 to 5-nerved, coarsely and unequally toothed or cut; involucre much shorter than the numerous elongated rays; chaff of the disk acutish, smooth.

Dry soil. Aug.-Oct. Stem 1 to 2 feet high, branched, the branches upright, elongated and naked above, terminated by single large heads. Leaves rather thin, those of the root 4 to 5 inches long by 3 to 4 wide, on petioles, 6 to 10 inches long. Rays about 18, oblong-linear, bright yellow.

\section{R. FULGIDA, Ait. Small-flowered Rudbeckio.}

Hairy; stem with slender branches; leaves spatulate-oblong or lanceolate, partly clasping, 3-nerved, the upper entire, mostly obtuse; scales oblong, spreading, as Tong as the spreading rays; chaff linear-oblong, obtuse.

Dry soil. July-Oct. Stem 1 to 3 feet high, branching, the upright branches naked at the summit and bearing single heads. Rays 12 to 14 , scarcely longer than the leafy involucre, deep orange-yellow, 2-cleft at the summit. Disk nearly hemispherical, purple.

\section{R. HiRta, L. Hairy Rudbeckia.}

Very rough and bristly-hairy; stem simple or branched near the base; leaves nearly entire; the upper oblong or lanceolate, sessile; the lower spatulate, 3-nerved, on petioles; scales nearly equalling the rays; chaff hairy at the tip.

Dry soil. July-Sept. A showy plant, 2 to 3 feet high, with the stem simple or branched near the base, naked above, bearing single large heads. Rays 12 to 15 , bright yellow, 1 inch long, surrounding a broadly conical disk of dark purple or brown chaff and flowers.

\section{LEPACHYS, Raf.}

Gr. lepis, a scale, and patus, thick, refering to the thickened tips of the chaff.

HEADS many-flowered; the RAYS few, neutral, in a single series; those of the DISK small, tubular, perfect. SCALES OF THE INVOLUCRE few, small, spreading. RECEPTACLE oblong or columiner; the CHAFF truncate, thickened and bearded at the tip, partly embracing the flattened and margined achenia. PAPPUS none, or 2 teeth.-Perennial herbs, with alternate pinnate leaves, and showy heads of yellow flowers, with long drooping rays; disk grayish.

\section{L. pinnata, Torr. \& Gray. Tall Lepachys.}

Hairy with minute, appressed hairs; leaves pinnate; leaflets 3 to 7 , lanceolate, aeute at both ends, toothed or entire; disi oblong; rays much longer than the disk.

Dry soil. July-Sept. Stem 3 to 4 feet high, grooved, with naked branches above, terminated by single showy heads. Rays yellow, about 2 inches long, slightly toothed at the apex. Disle ovate, exhaling an anisate odor when bruised. Achenia of the ray 3-angled, hairy; that of the disk compressed, smooth or ciliate.

29. HELIANTHUS, Linn. Sunflotwer.

Gr. hetios, the sun, and anthos, a flower.

HEADS many-ftowered; RAY-FLOWERS in one series, ligulate, neutral; those of the DISK, tubular, perfect. INVOL- 
UCRE imbricated. RECEPTACLE flat or convex; the persis: tent chaff embracing the 4-sided and laterally achenia. PAPpus very deciduous, consisting of two thin chaffy-awned scales (sometimes additional smaller ones).-Caarse and stout herbs, mostly perennials, with mostly opposite leaves, generally triple-veined, and solitary or corymbed heads, with yellow rays.

* Disk flowers dark purple.

1. H. atrorubens, L. Dark-red Sunflower.

Stem erect, branched above, hisped with long scattered hairs: leaves mostly opposite, oblong-spatulate or ovate, slightly serrate, 3-nerved, scabrous; involucre scales lanceolate, acuminate, smooth, as long as the disk.

Gravelly soils. Aug., Sept. Per.-Stem 3 to 4 feet high. Lower leaves very large and often slightly cordate. Heads in a loose terminal panicle; rays about 16, yellow; disk dark purple.

\section{H. annuus, L. Common Sunflower.}

Ieaves cordate, 3-nerved, lower ones opposite; peduncles thick; flowers nodding: Native of South America. July, Aug. Stem 7 to 15 feet high. Heads of flowers very large, with broad rays of a brilliant yellow color. A splendid variety occurs with the flowers all radiate.

** Disk flowers yellow; leaves opposite, or the upper sometimes alternate.

3. H. Mollis, Lam. Downy Sunflower.

Stem villous; leaves ovate with a somewhat cordate and clasping base, pointcd nearly entire, hoary above; involucre scules lanceolate, downy.

Low grounds. July-Sept. Per.-Stem clothed with soft white hairs, simple, leafy, 2 to 4 feet high. Leaves hoary above, very scft white-hairy and reticulate underneatb. Heads few, rather large; rays 15 to 25, about one inch long, yellow.

\section{H. strumosus, L. Pale-leaved Sunflower.}

Stem tall, rather simple; leaves ovate-lanceolate, long acuminate, serrate, 3-nerv' ed, rough above, whitish and pubesbent beneath, abruptly contracted into short margined petioles; involucre scales broadly lanceolate with spreading tips, equalling the disk.

River banks and dry woods; common. Aug., Sept. Per. Stem rough above, smooth below, 2 to 4 feet high, slender, simple or sparingly branched. Heads few, on roughly pubescent peduncles; rays about 10 , bright yellow.

\section{H. Divaricatus, L. Cross-leaved Sunflower.}

Siem smooth, simple or forked at the top; leaves sessile ovate-lanceolate, rounded at the base, tapering to the point, opposite and divaricate, s-nerved, serrate, thick i th rough; involucre scales lanceolate, acuminate from a broad base, ciliate, spreading; equalling the disk.

Thickets and barrens; common. Ang., Oct. Per.-Stem 1 to 5 feet high, sometimes purple and glaucous, simple or forked and corymbed above. Leaves 3 to 5 in thes long. Heads small, few, in a terminal panicle; rays 8 to 12 , bright yellow; disk yellow.

6. H. TRACHELIFOLIUS, Willd. Throatwort Sunflower.

Srem tall, hairy, loosely branched above; leaves thin, ovate-lanceolate, or oblong] lanceolate, acuminate, serrate, 3-nerved, smoothish or roughish-pubescent on both sides, contracted into short petioles; involucre scales lance-linear, elongated and very acuminate, loose, outer ones larger and equarrose. 
Dry swamps. Aug.-Oet. Fur. Sicm 3 to 6 fiet high, parplish. Laves $\&$ to 6 inchos long, by $1 / 2$ to 3 inches wide on petioles $1 / 2$ to $1 \frac{1}{2}$ inches long. Hinds niddie sizd, borno at the top of the elender suberect branches; rag's expanding 2 to $\$$ inclies long.

7. H. Granters, $\bar{Z}$. Tall Sunflower.

Whem rough or hairy, branched abore; leaves lanceolate, pointed, serrate, rery rough above, rongh-hairy beneath, narrowed cnl cillate at the base, nenrly secsile; inva'uce scales long, linear-lanccolate, pointed, hairy or strongly ciliate.

Ihickets and swamps; common. Aug., Sept. Ier.-Siem 3 to 10 fect ligh, paniculately branched at the summit, somitimes smoothish bolow. Heal's nunierous, in a loose terminal panicle; rays 12 to 20, pale yellow; disk grconish yellow.

\section{H. DeCAPEThus, L. Thin-leaved Sunflower.}

Stem erect, till and branching, smooth below, rough abore; leares ovate-lancrolata, on eliort margined petioles, acuminate coarsely serrate, \&-nerfol, thin and slight:y scabrous; incolucre scales lance-linear, elongatud, loosely spreading, tho outer longer than the disk.

Copses and low banks of streams; common. Ang.-Oct. Per.-Sitcm 3 to 5 fect ligh, s!ender, somewhat branching at the summit. Outer irvolicral scales somctim is fuliaccous or changing to leaves. Eleads in a fastigiate corymb; rays 8 to I0, zarrow, pale gellow.

9. H. Mrnocephalus, Torr. \& Gr. Small-haded Sunfower.

Fen smooth, with 4 to 6 siender branches abore; leaves opposite, or the urfer cnos alternate, thin ovate-lanceolate, acuminate, fomerhat serrate, reiny, petso10, rough abore, downy or hairy underneath; puluncles slender, rou rh; intolucrs scaics ovate and oratc-lancelate, ciliate, the outer with equarroso tips.

Foods and thickets, western part of the State. Stem 3 to 8 fect high, uscally in tufts. Hcads small, oblong, $1 / 4$ to $1 / 2$ inch broad; roys 5 to 0 , neariy 1 irch long.

* Icaves alternate, somctimes cpposite below.

\section{H. MuLtirlonus, L. Many-rayed Sunflower.}

Stem crect, branching, Ecabrous; leaves alternate, petioled, toothed, \&-nerred ; Jower cordate, upper orate; invlucre ecales linear-linccolate, ciliate, inner cnos Ianccolate.

Mountain moods. July-Sept. Fer. Stcm and peduncies rongh hairy. Ieraes sometimes opposite, rough, Eerrate. Involuere with 40 to $E 0$ scalcs, inilicate, Ict squarrose. Hedds erect; rays numerous, oblong. I'rhaps introciuced.

\section{I. tuberosus I. Jerusctem Artichoke.}

roo bearing tuber:; Stcm stout and tall, branched, rough; leancs alternate, orate, petiolate, 3-nerved, rough, serrate; lozor cordato-ovate; petioles ciliate at base; involucre scalcs lincar lancolate.

Ficlds and eultivated grourids; naturalized, also cultivated. July-Sert. Fer. stenn 1 to 8 fet ligh, branched. Leaqes large Hedge-shared at buse; lewer crico cyposite, rurely temate or loted. Ifeads rather large, tem minal, on angular jutco-

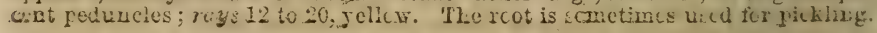

\section{COREOPSIS, Linn. TICKSEED.}

Cr. horis, su we, and of sis, rescmulence; from the form of the fruit.

HEaDs many-fiowered; ray flowers about $\varepsilon$, neutral, in a single series; disle flowers, small, tubular, perfect. INToLLCIE double; cach of ahout 8 scales, the outer somcrilat fo- 
liaceous and sprading; the inner browler and appressed. -

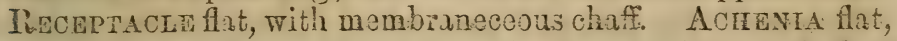
often winged, 2 toothed, 2 arrned, or sometimes naked at tho summit.-Herbs with mostly opposite leaves, and yellow or pari-colored, rarely purple rays.

* Rosys roantiaj.

\section{C. BIDentotdes, Nutt.}

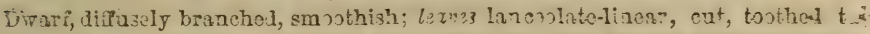
poria into a patiole; avons slender, upwards barbel, rauch longer than the corol1a, or the bristly young achenia.

Near Philadelphia, Nuttall.-Prof. Gray thinks this a Fery obscure and undouhtful plant.

* Rays and dist yellow; leaves opposite, dividei.

2. C. trichosperma, Michx. Tiickseed Sunflower.

Snooth, branched; leaves short petioled, 5 to 7 -divided; Teaflets lanceolate or lin. ear, cut-toothal or the upper leaves only 3 to 5 cleft and nearly sessile; outer invol ucre sciles subspatulate, ciliatc-serrate; heads in corymbose panicles.

Siramps, near tha const. Aug.-0ct. Biennial. Stem 2 to 3 feet high, obtusely 4-angled, much branched, smooth. Branches and leaves mostly opposite. Lewe; thin, sabsessile. Le flets narrow tapering to s lon point with a far a a mote surraturos. Hads largo showy, yellow. Achenia narromly wadge-oblons, bristly eiliats abose, crownal with 2 triangular or awl-shaped stout toeth.

3. C. tripteris, Michx. Three-leaved Tickseed.

Snooth; Sicm simple, tall, corymbose at summit; leaves 3 to 5-diviled; le flet lanceolate, acute, entire, scabrous on the mar.rins; healts smail on short peluneles.

Banks of streams. Aug.- - iet. Por: An elegant spacies, $\frac{1}{x}$ to 6 fest high, slen. der, terete. Divisions of tho lesres 3 to 5 inches long, by $3 / 4$ to $11 / 3$ inehus wids. Hidis rathar smali. in a loose terminal corymb, on short peiuncles; rajls aboat 8 , spreading $1 / 2$ inch long, Jellow. The heads exhale tho odor of anise when bruised.

* * Rays or disk purple.

CLLTIVATED IPEC IES.

\section{C. тinctonia, Nutt. Dyer's Coreopsis. Elegant Coreopsis.}

Leares alternate, those of the root subpinnate; leaflets oval, entire, smooth; ster 3 leares subpinnate; leaflets linear; ackenia naked. A handsome border annual, natire of tho Upper Missouri. Stem 1 to 3 feet high, with light smooth foltage. Freads with yellow rays, beautifully colored with brownish purplo at their base. Ilowering all summer. Partially naturalized in Union Co.

\section{C. DRumandr, T. \& G. Dirumond' \& Coreopsi?.}

Pubeseent; leares pinnately divided, sometimes simple, segments (or leares) oral, entire; inwolucre scales lanceolate-acuminato; rays anequally 5 toothed, trice 1. onger than the involucre; achenia obovate, incurved, scarcely tonthed. $\Delta$ beantiful annual from Texas. Stems 10 to 20 inches high. Eiays large, yellow, with a purple spot at the base:

3. atrosanguinsch, a variety in oultivation, with daris orange flowers.

\section{ZINNIA, Linn.}

Dedieated to John Godfrey Zinn, a German botanist, 1557. HEADS many-flowered; BAYS 5 , persistent, entire, pistila 
late; DISK FLOWERS perfect. RECEPTACLE chaffy, conical. PAPpus of the disk of 2 erect awns. INvolucre scales oval, margined, imbricate. Annual, native at the South, common in cultivation, with opposite entire leaves and showy heads of flowers.

\section{Z. elegans, L. Elegant Zinnia.}

Stems hairy; leaves cordate, sessile-amplexicaul; heads on long peduncles; chaff serrated. July, Aug. Several varieties are known In cultivation with violet, white, purple, scarlet and yellowish flowers.

2. Z. MUltiflora, L. Many-flowered Zinnia. Youth and old age.

Leaves ovate-lanceolate on short petioles; heads on long peduncles with dull scarlet rays. Z: pauciflorum, with bright yellow flowers, is also found in cultivation.

\section{TAGETES, Linn. MARIGOLD.}

Named for Tages, a Tuscan divinity.

HeAds heterogamous; RAY-FLowers 5, persistent. IN* VOLUCRE simple, tubular; of 5 united scales. RECEPTACLE naked. PAPpus of 5 erect awns.-Annual herbs, natives of tropical America, with pinnately divided leaves and showy heads of flowers.

1. T. Patula, L. French Marigold.

Stem erect, with spreading branches; segments of the leaves linear-lanceolate; peduncles elongated, sub-cylindric, one-flowered; involucre smooth. Stem 1 to 2 feet bigh. Flowers yellow-orange, striped and variegated with deep brown.

2. T. ERECTA, L. African Marigold.

Ieaves pinnately divided; segments lanceolate; cilliate-serrate; peduncles 1 -flow. ered, ventricose and thickened at the summit; involucre angular. Stem 2 to 3 feet higb, with large heads of deep yellow and orange colored flowers.

\section{ACTINOMERIS; Nutt.}

Gr. attin, a ray, and meris, a part, alluding to the small number, or irregularity of the rays.

Heads many-flowered; RAY-FLowers neutral, few, elon-. gated or rarely wanting; DISK FLOWERs tubular, perfect. Involuche foliaceous, nearly equal, in 1 to 3 rows. RECEPTACLE convex, chaffy, the outer chaff embracing the outer margin of the flat, obovate, compressed and winged achenia. PAPPUS of 2 smooth persistent awns. - Tall and branching perennial herbs, with serrate feather-viened leaves, and corymbed heads of chiefly yellow flowers.

1. A. squarrosa, Nutt. Tall Achtinomeris.

Silem erect, somewhat hairy and winged above; leaves alternate, or the lower op. pasite, oblong or orate-lanceolate, pointed at both onds; heads in an open corymbed. 
panicle; involucre scales in 2 rows, the outer linear spatulate; achenia broadly: winged.

Mist grounds; common:- Aug., Sept.-Stem 4 to 8 feet high, slender, smooth be: low. Heads small, in a termimal leafly corymbose panicle; rays \pm to 10 irregular; oblanceolate, yellow; disli greenish-yellow. Recegtacle globular.

\section{BIDENS, Linn. Burr Marigold.}

Lat. bidens, having two tecth; in allusion' tö the twe arwis of the achenia.

HEADS many-1lowered, the RAY-FLOWERS 3 to 8 neutral, often wanting; DISK-FLOWERS tubular, perfect. INVOLUCRE double, unequal, the outer series often large and leafy. RECEPTACLE flattish, chiaffy, the chaff deciduous with the fruit. AcIrenia flattened, parallel with the scales of the involucre, or slender and 4 -sided, crowned with 2 or more rigid and persistent awns whish are downwardly barbed.-Annual or perennial herbs, with opposite various leaves, and mostly yellow flowers.

* Rays inconspicrious or none:-

1. B. rrondosa, Li Common Beggar-ticks.

Smooth or somewhat hairy; stem tall and branching; leaves 3 to 5-dirided, thic. isafitis lanceoiate, pointed, coarsely toothed, mostly petioled; onter leafy involucre much longer than the head, ciliate below; rays none; achicia wedge-oborate, 2-awned, somewhat ciliate on the margin.

Moist waste places; common: July-Sept. A very troublesome reed 2 to 4 feet bigh, sending out many spreading branches. Lower leaces pinnate, upper ones ternate, lanceolate, serrate. F'luwer's in clusters at the ends of the branches, without rays, yellow, surrounded by.a large and leafy involucre. Acheniu 2 -awned, and as in the cther species, adluering by their retrorsely barbid awns to the dress, and to the fleece of animals.

\section{B. connata, Muhl. Siwamp Beggar-ticlis.}

Smooth; leaves lanceolate, serrate, connate at the base; lower ones mostly trifid scales of the outer involucre longer than the head, mostly obtuse, scarcely ciliate; rays none; achenia narrowly wedge-form, 3-awned.

Wet grounds; common. Atig. Annual. Stem $1^{7}$ to 2 fiet high, smooth and 4 furiowed, with opposite branches. Leares tapering into margined petioles which as e slightly united at the base; the lower often divided; the lateral divisions united at the base and decurrent on the petiole. Flower's terminal, solitary, without rays, cunsisting only of the tubular yellow florets, surxounded by a leafy involucre.

\section{B. cernuA, Lr Nodding Burr-Marigold.}

Nearly smooth, low; laires all undirided; lancolate, unequally serrate, scarcely connate; heads discoid or radiate, nodding; outer involucre longer than the head achenia wedge-oborate, 4-awned, the margins downwardly barbed.

Swamps and ditches. Annuad. A ug.-Oct. Stem 1 to 2 feet high, purplish, stri-. ate above, branched around the base. Branches opposite. Leares opposite, slightly connate. Fiowers yellowish-green, with or without rays. Rays when present, sibut 8 , smaller than $B$. chrysanticmoides, the leaves irregularly toothed and the outer involucre more leaflike.

\section{B. biprnnata, L. Spanish Needles.}

Smooth, branching; leaves petioled bipinnately parted, the segments lanceolateor cblong orate, mostly wedge-shaned at the base; heads on slender peduncles, with: A. 2 * 
2 to 4 small rays; outer involucre of linear scales as long as the inner; achenia long and slender, 4-grooved and angled, nearly smooth, 3 to 4 aw ned.

Dry soil, waste places. Annual. July-Sept. Stem 2 to 4 feet high, branching, smooth, 4-angled. Leaves 1 to 2 pinmately parted. Leaflets ovate-lanceolate, nearly smooth. Heads of flowers on long peduneles, each with 3 - to 4 (or none) obscure, obovato yellow rays.

* Rays conspicuors

5. B. CERYSANTHEMOIDEs, Michx. Large-flowered BurrMarigold.

Smooth, eroct or reclining at the base; leares laneeclate, tapering at both ends, mors or less connate, acute, serrate; heads croct or nodding, conspicuonsly radiate; outer ineleucre mostly shorter than the long rays; achenia wedgi-shaped, with 2 to 4 awns.

Swamps and ditches; common. Annual. Ang., Sept. A tow plant, with largo yeilow-rayed flowers. Stem 6 to 20 inches high. Leaves smoth, with few remote treth. Heads rather large, solitary at the ends of the branehes, erect or somewhat zooldiag; rays elliptic, 8 to 10, bright yellow, 1 inch long.

\section{VERBESINA, Linn. CrownzeARD.}

"Name altered from Ferbena."

HEADS few and many-flowered, mostly radiate; RAYs pis-milate. SCALEs of the erect involucre few, imbricated in 2 or more rows. RECEPTACLE flat or somewhat convex, the CIIAFr concave and embracing the flowers. ACHENIA flit (compressed laterally), usually winged at the angles, crowned with 2 rigid awns. - American perennial plants, with the toothed or lobed leaves decirrent on the stem, and solitary or corymbose lieads of yellow fowers."

1. V. Sregesbeeria, Michx. Stiegesbectís Crownleard.

Sicm smooth, 4-winged; leaves opposite, ovate, 3-nerved, serrate, pointed at both cads, smooth or pubescent underneath; heads in compound corjmbs; inco'ucre scales obtuse, few; achenia wingless.

Rich soil. Aug., Sept. Stem 4 to 6 feet high, crect, with 4 leafy wings. Leaves 5 to 8 inches wille, thin, tapering to a winged petiole. Heads in corymbs, yollow. Rays 1 to 5 lazceolato, 3 toothed, $3 / 4$ inch long.

2. V VIrainica, Virginian Crownbeard.

Stem narrowly winged, dow ny pubescent abowe; leaves alternate, orate-lanccolate, feitie:-veinel, serrate, acute at eaeh end, the lower decurrent; heads in compouna caryrabs, crowded; rays 3 to 4 oval; achenia narrowly winged.

Dry wools. Aug., Sopt. Stem 3 to 6 feot high. Heids about 20-flowered, in crowded corymls. Rays very short, the tube (and involucre) pubescent, pale yellow, oral, scarcely $1 / 2$ inch long.

SECT10N 2,-Pappus composad of severa! distinct chaffy scales.

86. Helenium, Linn. False Sunflower.

Named after Heien, the wife of Menclaus.

MEADs many-flowered; radiate ; the RAY-FLOWERS in a sing 
gle series, pistillate, ligulate or rarelv tubular, 3 to 5 cleft, DISK-FLOWERs perfect, tubular, very short 4 to 5 toothed. INVOLOCRE small, refiexed, tho scales linear or awl-shaped. RECEPTACLE globose or oblong, naked. ACHzNIA top-shapod, ribbed. Pappus of 5 to 8 thin and 1-nerved chaffy. scales, each extended into a bristle or point.-Erect branch. ing herbs, with alternate leaves decurrent on the angled stem and branches, which are terminated by single or carymbed heads of yellow fowers.

H. AUTUMNaLe, I. $S$ eeze-weed.

Nearly smooth; stem erect, branched; leaves lanceolate, toothed, acuto, decurront; disk globose; rays 3 to 5 cleft, spreading or reflexed.

Alluvial soils, low grounds. Per. A ug.-Oct. Stem 2 to 3 fezt high, winged by tho decurrent leaves. Leaves narrowed at tho base, tho upper nearly entire. lieads showy midule-sized, in a terminal corymb; rays yellow, wedge-siniped; d is $k$ greenish-yellow. Wholo plant intensely bitter.

Secrior 3. Pappus none, or a very short croun. Heads radiate or disccite. Licaves alternate.

37. MARUTA; Cass. MAY-WEed.

HEADS many-flowered; RAY-FLOWERS, ligulate, neutral; DISK-FLOWERS perfect. INVOLUCRE somewhat imbricated shorter than the disk. RECEPTACLE conical, more or less chaffy. Achinna obovoid; ribbed, smooth. Pappus none.-Ansual acrid herbs, with a strong. odor, finely thrice pinnately divi. ded leaves, and single heads with white rays and yellow disk termis nating the branclies.

M. сотU⿻і㇒, DC. Cömmon Máy-weed.

Smoothish; lcaves 2 or 3 times pinnatifd, the segments subulate-linear scales of the inwolucre with whitish margins; receptacle conie.

Roadsides, common. Annual. June-Oct. Sten a foot high, erect, branehed: Leares pale green, more ox less pilose; segments very narrow. Heads on elongated slender peduncles; rays about 12, white; disk convex, yellow. Fecrptucle chaffy only among the upper flowers.. An exotic, every where naturalized...

\section{ANTHEMIS, linn. Cmaנromite.}

Gr. Anthemis, the ancient name, given in allusion to the profusion of the forrers.

HEADS many-flowered; RAY-FLOWFrs inone series ligulate; pistillate; DISK-FLOWERS tubular perfect. INVOLUCRE SCALES imbricate in a fuw series. RECEPTACLE convex oblong or conic. Achenia terete, striate or smooth. Pappus none or a minute crown.-Annual or ferennialherls, with aromatic or strong odor, 1 to 2 pinnately divided leaves, and the branches ter.. minated by single heuds, with white rays and yellow dish. . 


\section{A. arvensis, L. Corn Chamomile.}

Pubescent; leaves pinnately parted; aivisions linear-lanceolate, tonthed, very acute ; branchlets leafless at the summit; involucre scaiés obtuse; chaffl lanecolate, pointed; achenia crowned with a vory short margini.

Fields and cultivated grounds. Introduced from Europe. Junc-Aur. Bienn:al. Stem 9 to 15 inches high, branched. Leavos grayish-pubescent. Heads large; rays broad, white, spreading; disk yellow, convex.

\section{A. NoBILIs, L. Garden Chamomile.}

Stem prostrate, branching from the base, wcolly; leaves decompound-pinnatifid; segments linear-subulate; chaff with a thin membrancous margin, lanceolate, searcely as long as the flowers. Perr. Native of Europe Cuitivated in gardens for its tonic and anodyne properties. The agreealle scent of the chamomile is well known.

\section{ACHILLEA, Linn. YARRow.}

Só named beause its virtues are said to have been discorcrect bj Ac.illles.

Hrads many-flowered; RAY-FLOWERS 4 to 6 pistillate, ligulate, short, or none; DISK-FLOWERs perfect, tubular 5 -toothed. Tieceptacle chaffy, flattish. Aenenia oblong, flatrened, margined.. PA.ppus none.-Perennial herbs, with much divided alternate léaves and small corymbose heads of whitish flowers.

\section{A. Mrmetefolium, L. Common Yurrow. Milfoit.}

Stems mostly simple, erect, somewhat hairy; leaves twicc-pinnately parted; the divisions linear, 3 to 5 cleft, crowded; corymb compound, flat-topped; involucre oblong; receptacle small.

Fields and hills; common. Aug. . Siem 1 to 2 feet high, branched at the top. Leaves 2 to 6 inches lon', cut into very numerous narrow segments. He:uls numerous, in a dense terminal fastigiate corymb; ruys 4 to 5 , short, white or ruse colorcid.

\section{LEUCANTHEMUM. Tourn. OX-eye Dirsy.}

Gr. leutos; white, and anth:mon, a flower.

HEADS many-flowered; RAY-FLOWERS numerous, fertile, or rarely neutral ; DISK-FLOWERS perfect, with a fleshy somewhat 2-winged tube. Involucre broad and flat, imbricated; scales with scarious margins.. RECEPTACLE naked, flat or convex: Acmenia of the disk and ray similar, striate, destitute of pappus.-Peirennial herbs, with toothed or pimnatifid, alternate leaves and large single heads, with white rays and yellow disk terminating the branches.

1. L. Vulgare, Lam. Ox-eye. White Daisy. Whiteereed.

Stem erect, nearly simple, noked above; root-leaves spakulate, petioled, toothed; stem-eaves somewhat clasping, cut or pinnatifid-toothed; involucre scules with os narrow rusty brown margin.

A pernicious weed, extensively naturslized in fields and meadows. June-Aug. Stem 1 to 2 feot bigh, erect or sub-tecumbent at base, smooth:sh.. Leares compara- 
atively few and small. Heads large, solitary on the branches, with 20 to 30 showy white rays, and numerous. yellow disk flowers. (Chrysanthemum Leucanthemum. Linn.)

\section{PYRETHRUM; Linn. Feverfew。}

INVOLUCRE hemispherical, imbricate; sCaLES with membraneous margins. RECEPTACLE naked. PAPPUS a membraneous margin crowning the achenia.-European herbs, chiefly perennials, with alternate leaves, and white flowers.

\section{P. parthenium, L. Feverfew.}

Stem erect; leaves petiolate, flat tripinnate; segments ovate; heads on branching corymbose peduncles; involucre pubescont. Several varieties are common in cultivation, and are in great favor with many florists, on account of their pure. wh ito. double flowerz, borne on a pyramidal corymb.

\section{CHRYSANTHEMUM, Linn.}

Gr. Krusos, gold, anthos, flower; many species bearing golden colored flowers.

HEADS many-flowered; RAY-FLOWERS pistillate, ligulate 12 or more ; DISK-FLOWERS perfect. INVOLUCRE imbricate, hemispherical; SCALES with membraneous margins. RECEPTACLE naked. PAPPUS none.-Annual and perennial, ornamental cultivated plants natives of China and other Eastern countries, with alternate lobed leaves and large showy heads of flow. ers.

1. C. coronarium, L., Showy Aster.

Stem branched; leaves bipinnatifid, broader at the summit, acute. Annual. $\mathrm{Na}$. tire of S. Europe and N. Africa. Aug. Stem about 3 feet high, striate smooth, erect, with alternate clasping leaves. Flowers large, terminal, solitary, of a deep Jellow color, double in cultivation.

2. C. CARINATUM, Willd. Three-colored Chrysanthemum.

Mostly smooth; leaves bipinnate, fleshy; involucre. scules carinate. Native of Barbary. Annual. July-Oct. Heads large and beautiful; disk purple, rays white with a yellow base.

\section{C. sinense, Sabine. Chinese Chrysanthemum.}

Leaves coriaceous, petiolate, serrate-pinnatifid, dentate, glaucous; rays very numerous, long. Native of China, where it has long been cultivated and highly es. teemed for its beauty. Numerous varieties have been produced, with double, semi-double and quilled flowers of every possible shade of color. Blooming in No-. vember, when all other flowers have disappeared, makes them desirable plants for every flower gardep.

\section{TANACETUM, Linn. TANZx.}

Said to be a corruption of athanasia, undying, from its durable flowers.

HEADS many-flowered, nearly discoid, all fertile; the mar.- 
ginal flowers chiefly pistillate and 3 to 5 toothed, forming. a kind of ray. INvoLUCRE hemispherical; SCALES imbricatel, dry. Receptacle convex, naked. Acmenia angled or ribbed, with a large flat top. PAPpus a short orown.-Bitter and acrid strons-scented herls, with alternate 1 to 2 pinnately dissected leaves and carymbed heads of yellow flowers.

\section{T. vUlgare, L. Common Tanzy.}

Siem ereet, smooth; lexves twice-pinnately parted, the leaflets and the margined patiole cut-toothed; corym 3 duse ; rays terete ; pappus 5-lobed.

Cultivatod and naturalized, common. Auz. Per. Stems clus teres 2 to 3 feet high, branched above into a handsome corymb of yellow flowers. Na ire of Europe.

Var. crismum has the leaves moro cut and crisped.

\section{ARTEMISIA, Linn. WORMWOOD,}

Dedicated to the Goduess Artemis.

Heads discoid, few to many-flowered; the flowers all trtbular, those of the disk porfect; marginal ones pistillate, or sometimes all similar and perfect. IN VOLUCRE oroid ; SCALES imbricated, with dry and searious margins. REC ERTACLE small and flattish, naked: AcHenta obovoid, with a small summit and' no pappus.-Bitter herbs or shrubby plants, with alternate leaves and small heads of yellow or purplish flowers in panicled spilies or racemes.

- Reccptale naked. Asrotivou, Tourn.

1. A. vulgaris, L. Common Mugwert.

Eranches and lower surface of the leaves whitish-woolly; stem-leares pinnatifd; seyments lanceolate, rariously cut or entire; heals crect, oroid, subsessile, in open leafly panicles.

Banks of streams, and waste places. Per. Sept., Oct. Siem 2 to 3 feet high, branclaing into a panicle of spicate racemes. Laaces very variable. Heads few, purplish. Introluced from Europe and naturalized.

\section{A. Abrotanum, L. Southernwood.}

Sten erect; lower leaves bipinnate; upper ones capillary, pinnate; intolucre hor:is pherical, downy. A well known shrubby plant, common in cultivation. Stem about 3 feet high. Lexves alternate muels divided into linear sagments. Flowers дumrous, nodding, yellow. Native of South Europs.

*t Receptacie hairy. Fonoers all feritle. ABsintwum, Tourn.

3. A. absintinum, L. Common Wormuood.

SLrubby, crect, silky-can escent; leaves bipinnatifd; segments lanccolate, often incised, obtuse; heals hemispherical, in leafy paniculate racmes, nocding; recep* tale hairy. Common in gardens. Aug. Stem 2 to 4 fuet high, angular, severiblt from one rost. Ifeads numerous. Flowers yellowish. The wholo plant is very bittor, and possessed of valuabie medicinal properties as a tonic, stomachic, \&c.

4. A. Pontica, L. Roman Wormwood.

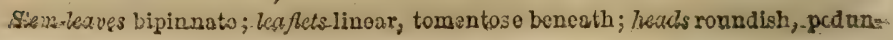


cled, noduing. Cultivated in gardens. Stem 3 to 4 feet high, with simple branches and racemes of yellow flowers. Heads about 21 flowered. From Austria.

\section{GNAPHALIUM, Linn. CUDWEED.}

Gr. gnaphaton, a lock of wool; in allusion to the floccose down of the leaves.

IfEADs many-flowered; the flowers all tubular; the outor pistillate and very slender, the central perfect. InvoLUCRE orate; SCALES imbricated in several rows. ReceptaCLE flat, naked. PAPPUS a single row of capillary rough hristles. - Wonlly herbs, with alternate sessile or decurrent entire leaves, and clustered or corymbed heads of whitish-yellow or purplish flowers.

1. G. Polycephelum, Michx. Fragrant Life-everlasting.

Stem erect, woolly; leates lanceolate, tapering to the base, with wary margins, rint docurrent, smcothish abore, white tomentose beneath; heads oborate, ciusterod at the summit of the panicled-corymboce branches; involucre scales orate and oblong.

Oli fields and roods; common. Annual. July-Sept. Stem 1 to 2 feet high, often much branched at the summit. Lecives sessile, cottony beneath. Flower: $\mathrm{x}$ crowdgd clusters at the erds of the brauches, yellowish-mlite. Whole plant fritErast.

2. G. vligonosum, L. Lowo Cudroced. Irow. Lifecoerlasting.

Stcm simple, or branched, Foclly ell over; learcs lanceolate or linear; heads small in terminal sessile capitate glusters; involucre scules oblong, inner acute.

Wet rrounds, ronlsides; common every where. Annual. July-Sept. Stem 4 to 6 inches high, much branched. Lcates numerous, acute, narrow at the base; involucre scales yellowish-brown, shining. Whole plant clothed with whitish down.

3. G. punpereun, I. Purple Life-everlasting.

Stcm simple or brenched from the base, ascending roolly; kaves oblong-sratulate, mostiy outuse, green above, rery white with close wool underneath; hecids in sessile clusters in the asils of the upper leares, and spiked at the summit of the stem; involucre scales lance-oblong, tawny, the inner citen marked with purple.

Grarcliy soil, sandy fields and pastures; common. Annual. June--ifem S 12 inches bigh, sending out shoots at the base. Heads somewhat spiked at the top of the stcm, with purplish scales and yellow corollas.

\section{ANTENNARIA, Gært. Everlasting.}

Wame in allusion to the bristles of the pappus, which resemble antennx,

HeaDs many-flowered, diccious or nearly so, corolla tubular; PISTILLATE FLowers filiform, 5-toothed. InvoluCRE SCALES dry and scarious, white or colored, imbricated. ReCEPTACLE convex or flat not chaffy. ACHenia nearly terete. PAppus a single row of bristles, in the fertile flowcas capillary, in the staminate club-shaped.-Perennial vchite 
woolly herbs, with entire alternate leaves, and corymbose heads with white scales and yellowish corollas.

1. A. Margaritacea, R. Brown. Pearly Everlasting.

Stem erect; tomentose; leaves linear lanceolate, acuminate, 1-nerved, sessile: fer tile heads often with a few imperfect stiminate flowers in the centre; scales of the pearly white involucre obtuse or roundea.

Dry hills and woods, common. Aug. Stem 1 to 2 feet high, and with the numerous scattered leaves clothed with white and cottony down, corymkose at the summit with many heads. Heads hemispherical, pedicellate. Involucre pearly white. Flowers yellow. Slightly fragrant.

2. A. Plantaginifolia, Hook. Plantain-leaved Everlasting.

Stem simple, with procumbent shoots; Teaves silky-woolly when young, at length green above and hoary beneath; radical leaves oval, petiolate, 3-nerved; stem leaves linear; heads in a small crowded corymb.

Wooded banks and sterile hills. April, May. Stem 3 to 8 inches high, often branched at the base into several from the same root. Root leaves much larger than those of the stem, ovate or oval-spatulate. Stem leaves few, bract-like. Heads clustered, terminal, purplish white. Scales of the mostly white involucre obtuse, in the sterile, and acutish and narrow in the fertile plant.

\section{FILAGO. Tourn. Cotton Rose.}

Iat. filum, a thread; in allusion to the cottony hairs that cover these plants.

Heads many-flowered, heterogamous; the terminal or central flowers numerous, pistillate, perfect or infertile, tubular, 4 to 5-toothed, the outer fowers filiform, pistillate, searcely-toothed. InvoluCRE SCALES few, woolly. RECEPTACLE elongated, filiform, naked at the summit, chaffy towards the margins or base. PAppus of the central flowers filiform, of the outer none or dissimilar.-Low annual branching : woolly herbs with entire, alternate leaves and small heads of whitish or yellowish flowers in capitate clusters.

\section{F. Germanica, I. Herba Impia. German Cud-weed.}

Stem erect, short, dichotomous or proliferously branched; leaves linear-lancealate, acute, tomentose, crowded; heads woolly in capitate clusters, terminal and Iateral; scales of the involucre awned.

Dry fields; introduced from Europe and sparingly nataralized. July-Aug.Stem 4 to 8 inches high, woolly-tomentose, clothed with linear-lanceolate and upright crowded leaves, producing a capitate cluster of woolly heads, from which rise one or more branches, each terminated by a similar head, and continue in the same manner.

\section{SUBTRIBE 6. SENICIONOIDEAT.}

Pappus soft and capillary. Anthers without tails at the base. Receptacle raked, - Beads radiate or discoid. Leaves mostly alternate.

\section{ERECHTHITES. Raf. FIRE-WEED.}

$\Delta$ apcient zame of some epccies of senicio. 
HEaDs many-flowered, discoid, the flowers all tubular and fertile; the marginal pistillate with a slender corolla. INVOLUCRE cylindrical ; SCALES in a single row, linear, acute, with a few small bractlets at the base. ACHENIA oblong, striate. Pappus copious, of very fine and white soft hairs.Erect and coarse annuals. with alternate simple leaves, and panicu. late-corymbed heads of whitish flowers.

\section{E. hieracifolia, Raf. Fire-weed. Whipsizog.}

Stem groored, simple or paniculate above; leaves oblong or lanceslate, acute, cuts toothel, sissile; upper auriculate at base and partly clasping. (Senicio hieracifolia, L.)

Moist woo:ls, and especially recent clearings, where the ground has been burnt orer, hene it is called Fireweed; common. July-Sept. Stem 2 to 5 feet high, stout, suceutent, somewhat hairy, branching. Leaves light green. lar ge, irregular. ly cut into many deep and acute teeth. Fiowers terminal, crowded, destitute of rays, white. Whole plant emitting when bruiced a rank odor. The distilled oil is probably one of the most powerful styptics the vegetable kinglom affords.

\section{CaCalia, Linn. Indian Plantain.}

An ancient name, of uncertain meaning.

Heads 5 to many-flowered, discoied; the flowers all tubular and perfect. IN VoluCRE SCALES in a single row, 5 to 30. Conolla deeply 5-cleft. Receptacle flat. Achenia oblong, smooth. YAPPUS of numerous capillary bristles.Smooth and tall perennial herbs. with alternate iften pelioled leaves, and ruther large heads of mostly white or whitish fiowers, in flat corymbs.

* Involucre 5-leaved and 5-fowered.

1. C. reniformis, Muhl. Great Indian Piantain.

Stem grooved and angled: leaves petioled, smooth above, hairy on the reins bo low; rootleuves broad-corlate, reniform, repand-toothed and angled, palmately veined; stem-leaves oblong, toothed, wedge-form and very entire at the base; corymb darge.

Rich, damp woods. Aug., Sept. Stem 4 to 8 feet high, nearly simple, smooth. Leaves 3 to 12 inches lnng by 5 to 8 inches wide, repand-dentate; lower petioles very long. Involucre whitish. Heads white.

\section{C. Atriplicifolia, L. Pale Indian Plantain.}

Stem erect, smooth, terete; leaves petioled, smooth, glaucous beneath; lower leaves deltoid-cordate, einuate-angled, the upper rhomboid or wedge-form, toothed; involucre ablong.

Moist rich woods. Aug.. Sept. Stem 3 to 5 feet high, leafy, round. Lowerleaver 4 to 6 inches long, and nearly as wide, on long petioles, unequally toothed. Heads numerous, small, in a loose terminal corymb, greenish white.

* * Involucre 25 to 30 -flowered; receptacie flat.

3. C. suavolens, L. Sweet-scented Cacalia.

slem grooved, erect, ₹mooth; leaves triangular-lanceolate, halbert-shaped, pointed, serrate; those of the stem on winged petioles, smooth; scales about ; 3 ; involucts with sereral slender spreading bractlets.

B2 
Rich woods and banks of streams. Sept. Stem 3 to 4 feet high, grooved and an gled, leafy. Leaves smooth and green on both sides. Root-leaves on long petioles. pointed. Stem-leaves on winged petioles. Flowers whitish, in a terminal compound corymb.

4. C. coccrnea, Ourt. Scarlet Cacalia. Tassel Flower.

Radical leaves orate-spatulate; stem-leaves clasping, crenate; involucre ovato - findric; scales linear, at length reflexed; achenia ciliate; pappus in several rows A handsome border flower from the East Indies." Stem 1 foot high. Flowers brigh serset. June-Sept. Annual.

\section{SENECIO, Linn. GROUNDSET.}

Lat. senex, an old man; the pappus resembling a white beard.

Heads many-flowered, discoid, with the flowers all perfect and tubular, or mostly radiate, the rays pistillate. InvoLUCRE'SCALES in a single row, or with a few bractlets at the base. RECEPTACIE flat. PAPPUS of numerous very soft and slender capillary bristles.-A vast genus embracing about 600 species of herbs and shrubs, with alternate leaves and nostly עellow flowers exceeding the involucre in solitary or corymbed heads.

- Rays none; annuat.

\section{S. vulgaris, I. Common Groundsel.}

INearly smooth, or at first woolly; stem erect, often branching; leaves pinnstifa and toothed, clasping, the lowest petioled; heads in a corymb, nodding; pagpre qualling the corolla.

Waste places; common, naturalized. May-Oct. A common weed, growing bout houses, rubbish, \&c., 6 to 18 inches high, leafy, branching, mostly smoos Leaves thin, bright green. Heads terminal, without rays, jellow.

- Rays present; heads corymbed; perennial.

\section{S. Aureus, L. Golden Senicio. Squaw-reed.}

Bmooth or downy-woolly when young; root-leaves simple and rounded, the largot mostly cordate, crenate-toothed, long-petioled; the lower stem-leaves lyre-shapeco per lancedtate, cut pinnatifid, sessile or partly clasping; corymb umbel-like.

A very variable plant, embracing several nominal varieties, of which the follow ing are the most common: Var. 1, obovatus, with the root-leaves round obovate renerally found in dry places. Var. 2, Balsamite, with the root-leaves oblong patulate or lanceolate, sometimes cut toothed, tapering into the petiole. Rocky piaces; common everywhere. May, June. Stem 1 to 2 feet high, branched above eften woolly. Heads midale-sized, numerous, on long pedunclcs which are thich aned near the involucre. Rays 8 to 12 , and with the disk yellow.

3. S. tomentosus, Michx. Downg Graundsel.

Whito-tomentose and woolly; radical leaves oval-oblong, obtuse crenate-toothed *n slender petioles; skm leaves oblong, somewhat divided; corymb flat-topped.

Dry rocks on the Blue Mountains. Pursh. May, June. Stem 1 to 2 feet high, werly leafless abote. Heads yellow, larger than in S. aureus; rays 12 to 15, elod ented.

4. S. elongatus, Pursh. Elongated Groundsel.

mooth; radical heaves spatulate, serrate, attenuated into a petiole; stem leave Minnatiod, toothed, very remote; on olongatod peduncles, erranged to :

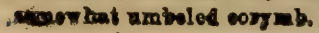


Rocks on banks of streams near Easton. July, Ang, Resembles var. Bakamo. tis, but is destitute of ray-flowers. Beek's Bot.

\section{ARNICA, Linn:}

Name supposed to be a corruption of Plarmica.

HEADS many-flowered; radiate, the rays pistillate; those of the disk tubular, porfect. INvoLUCRE canpanulate; soales in 2 rows, equal, lanceolate. Receptacle flat, fimbrillate. Achenia spindle-shaped. PAppus in a single row, consisting of rather rigid and strongly rough-denticulate bristles.-Perennial herbs, chiefly natives of alpine ro gions, with simple stems, opposite leaves and yellow flowers in sin. gle or corymbed large heads.

A. NudicAULIs, Nutt. Leopard's-bane:

Hirsute; lexves sessile ; the radical leaves clustered elliptic-ovate, nerved, enttro ar slightly toothed; stem leaves 1 to 2 pairs, lance-ovate; heads terminal, on loosely corymbose peduncles:

Meadows. Chester county. Dxrlington; rare. July, Aug. Stem 1 to 2 feet high, with a few peduncle-like branches at the summit, somewhat viscid. Heads large; rays num rous, deep-yellow, 2 to 3 -toothed at the apex; disic greenish-yel10

\section{Tribe V. CYNARE}

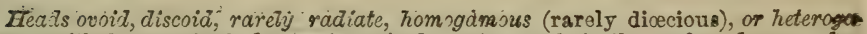
sous, with tine marginal flower's in a single series; style in the perfect fowers ofton tisckened near the su:nmit.

\section{CENTAUREA, Linn.}

Named from the Centaur, Chiron.

HEADS many-flowered; the flowers all tubular; the matginal mostly falsely radiate and larger, sterile: INvoLUCRs imbricated, the sCALES margined or appendaged. RECEPTACLE bristly. Achenia compressed. Pappus of filiform rough bristles in several series, sometimes none.-Herbs, with alternate leaves, and mostly showy flowers in single heads.

\section{C. JACEA, L. Brown Knap-weed.}

Stem erect, branched; leaves linear-lanceolate; lower broader and toothed, pets oled; involucre globular, scales scarious and torn, the outer pinnatifid; heads ragh ate; pappus very whort or none.

Waste places. July, Aug. Per. Stem about 2 feet high, branching. Heads Fith numerous purple flowers. Involucre pale brown, shining. Introdueed from Lurope. Beck's Bot. This is probably only a variety of the next.

2. C. nIGRA, L. Black Knap-weed.

stem erect, branched; leave scabrous, lower angular-Iyrate, potioled; upper tow culate; involuore globular, scales appendaged, and with a stiff black friage; roys canting; pappus very short. 
Meadows and pastures. Aug. Per. Stem 2 to 3 feet high, simple or often divided into elongated branches. Heads terminal solitary. Flowers purple. Involw cre scales almost black, the teeth brown. Native of Europe, naturalized, and becoming in some places a troublesome weed.

\section{CULTIVATED SPECIES.}

\section{C. cyanus, L. Blue-Bottle. Bachelor's Button.}

Cottony-tomentose; stem erect, branched; upper leaves linear, entire; lowermost toothed or pinnatifid at base; involucre globular; scales fringe-margined; rays lon-. ger than the disk; pappus very short:

Common in gardens, and in some places naturalized along roadsides, \&c. July, Aug. Annual. Stem 2 to 3 feet high. Heads in terminal peduncles; rays few, spreading, white, blue and purple; disk flowers smaller, mostly purple. Native of Europe. Justly prized for its handsome flowers which are variable in color.

\section{C. Americana, Nutt. American Centaury.}

Siem erect, sulcate, sparingly branched; lower leaves oblong-ovate, repand-den: tate, upper ones lanceolate, acute, all sessile and glabrous; heads few and solitary, very large; peduncles thickened at summit; involucre depressed-globose, scales with a rectinate-pinnate refexed appendage. Native in Ark. and La. Cultivated in gardens. Aug.-0ct. Stem 2 to 4 feet high, with very showy heads of palepurple flowers. Scales appendaged with a pinnate reflexed margin resembling the teeth of a comb.

Aмвғвв0A, De Candolle. Pappus of oblong or oborate palae, attenuatcd to the base, all similar, rarely small or none.

5. C. моschata; L. Sweet Sultan.

Iéaves lyrate-dentate; involucre subglobose, smooth; scales ovate; ray-flowers acarcely enlarged, not exceeding the disk; pappus none. A handsome border annual from Persia, with white and pale purple, sweet-scented flowers, blooming from July to Oct:

6. C. suavolens, Willd. (Amberboa odorata, DC.) Yellow Sweet Sultan.

Lower leaves brcadly subs patulate, dentate, upper leaves lyrate at base or scarce: Iy pinnatifid; heads globose; ray-flowers enlarged upwards, longer than the disk; pappus chaffy, a little shorter than the fruit. Native of the Levant. Flower yellow.

\section{CIRSIUM, Tourn. ThISTLE.}

Gr. Kirsos, a swelled vein, for which the Thistle was a reported remedy.

HEADS many-flowered; the flowers all tubular, perfect and similar, or rarely diøecious. INvOLUCRE ovoid or spherical; SCALES imbricated in many rows, tipped with a point or prickle. RECEPTACLE clothed with soft bristles or nairs. Achenia oblong, flattish, not ribbed. Pappus of numerous bristles united into a ring at base, plumose to the middle.Herbs with sessile alternate leaves, armed with 'spinose prickles, and large heads of purple or cream colored fliwers terminating the stem with branches.

- Isaves decurrent. 


\section{C. Lanceolatum, Scop. Common Thistle.}

Siom branched, hairy ; leaves decurrent, pinnatifid, hisped above, woolly beneathy ngments divaricate and spinous; scales linear-lanceolate, spinous, outer ones spreat fing.

Pastures and roadsides, common every where, introdaced. July-Sept. Biten nivl. St:m 2 to 4 feet high, winged by the decurrent leaves, which are white with deciduous webby hairs beneath, armed with formidable spines at all points. Hocts sumerous, large, purple.

- Leaves sessile.

2. C. Artissimum, Spreng. Tall Thistle.

shem downy, branching, leafy to the heads; leaves roughish hairy above, whits; With cloze wool beneath; radical leaves petioled, pinnatifid; stem leaves olong-lam ceslate, sinuate toothed; scales ovate-lanceolate, spinous, appressed.

Old fields and open woods, common. Per. Aug., Sept. Stem 3 to 8 feet hize. zeaves 6 to 8 inches long, and 1 to 6 wide, oblong-lanceolate, undulate-pinnatifid, of undivided, the lobes or teeth prickly, those from the base pinnatind; lower hort, oblong or triangular. Heads large. Flowers purple.

\section{C. DISCOLor, Spreng.. Two-colored Thistle.}

stem grooved, hairy, branched, leafy; leaves all deeply pinnatifid, smoothish a bove, whitened with elose wool bencath, the diverging lobes 2 to 3-cleft, linent Iinceolate, prickly-pointed; involucre subglobose; scales ovate spinous.

Keadows and open woods. Aug., Supt. Bienniel. Stem 3 to 6 feet high. Hede orminating the branches 1 inch in diumeter, with reddish-purple flowers.

\section{C. Virgrniandu, Michx. Virginian Thistle.}

Sem woolly, slonder, simple or eparingly branched, branches on long peduneles naked; leaves lanceolate revolute on the margins, green above, white with close Fool beneath, ciliate with prickly bristles; outer involucre scales scarcely prickly.

Woods. July, Sept. Per. Stem 1 to 3 fect high, covered with a white down, er pecially towards the summit. Leives entire or sparingiy sinuate-lobed, the lowes ponstimes deeply sinuate-pinnatifid Heads $1 / 2$ inch in diameter; flowers purple.

\section{C. Muticum, Michx. Swamp Thistle.}

siem tall, angled, smoothish; leaves pinnatifi, acutely cut, somewhat hairy. ebore, whitish with loose webby hairs beneath; when young; divisions lanceolaie, acute, prickly pointed; iuvolucre glutinous and webby, scales closely appressed, gointress or barely mucronate.

Suramps and low places, common. Aug. Per. Stem 3 to 8 fect high, panicled at the sumnit, the branches sparingly leatly and bearing single or few naked head Leaves armed with spines at each angle. Hads midale-sized; flowers deep pus 2.e.

6. C. pumilum, Spreng. Pasture Thistle.

Stem low, hairy, 1 to 3 flowered; leaves lance-oblong, partly clasping, green, som That hairy, pinnatifid; involucre round-orate, spinose, outer scales prickly-pointur, tho inner very slender:

Low or dry fields, common. July, Aug. Biennial. Stem 1 to 3 feet high, low and stout, bearing 1 to 3 very large heads which are somewhat leafly bracted at the base. Leaves pinnatifid, with short, and cut very prickly-margined lobss. Heads $1 \frac{1}{2}$ inches broad; fiowers fragrant 2 inches long, pale purple; pappos suore than one inch long.

\section{C. Horridulum, Michx. Yellow Thistle.}

shem stout, webby-haired when young; leaves lanceolate, partly clasping, pinner end, the short toothed and cut lobes very spiny with yellowish prickles; hends harge, surrounded at the base by a whorl of leaflike and very prickly braets ; inver excesubglobose; scales linear, seuto, scareely upinous. 
Sandy fields and hills. June-Aug. Per. Stem 1 to 4 feet high, short, webby. haired when young, hollow. Leaves somewhat clasping, woolly and hairy, armod with stiff spines. Heads large, axillary and terminal, with 20 to 30 narrow bracts at base, the outer of which haye spines somevhat in pairs. F'lowers dull yellow, rarely purple.

8. C. Arvense, Scop. Canada Thistle. Cursed Thistle.

Low, branched ; roots extensively creeping; leaves oblong or lanceolate, smooth, or slightly woolly beneath, sinuate-pinnatifid, prickly-margined; involucre round or ovate, with minute spines; scales close-pressed, ovate-lanceolate.

Cultivated fields and pastures, naturalized. July, Aug. Per. Stem 3 feet high, with a branching panicle at the top. Leaves alternate, thickly beset with spines. Heads small, numerous, terminal. Flowers purple rarely whitish; the involucro: is nearly thornless, and is the only part that can be safely handled. A most trub. lesome weed, which it is extremely difficult to eradicate.

\section{ONOPORDON, Vaill. CотTon Thistle.}

Heads discoid, homogamous. INvolucre ovate-globose; SCALES coriaceous, tipped with a lanceolate prickly appendage. Rrceptacle deeply alveolate. Achenia 4-angled, transversely wrinkled. PAPPUS in several series; BRIsTLES numerous, slender not plumose, united at the base into a hoary ring.-Coorse branching herbs, with decurrent leaves, and large heads of purple flowers.

\section{O. Acanthium, L. Cotton Thistle. Scotch Thistle.}

Stem and lcaves woolly; leaves orate-oblong, sinuate and spinous, decurrent: involucre scales linear-subulate, the outer spreading and woclly at the base.

Waste grounds, in some places naturalized. Cultirated in Scotland $2 \mathrm{~g}$ the Scotch Thistle. July. Bienniel. A tall cotteny plant 4 to 6 feet high, branched and winged at the summit, wings very spinous. Involucre round, cottony, spinous. Fllowers purple.

\section{LAPPA, Tourn. BURDDCK.}

Lat. lapp $x$ a burr, from Gr. labein, to lay lold of, a characteristic term.

Heads many-flowered, the flowers all perfect and similar.: INVOLUCRE globose ; SCALES imbricated coriaceous and ap.-. pressed at the base, with a long subulate hooked point. $R E$ CEPTACLE bristly. ACHENIA oblong, flattened, wrinkled: transeversely. PAPpUs short, of numerous rough bristles, not. united at the base, deciduous.-Coarse liennial weeds, with large altêrnate heart shaped and petioled leaves, with wavy: margins, and middle sized heads of purple (rarely white) flowers, solitary or in clusters.

\section{1. . L. Major, Gært.' Common Burdock.}

Cpper le aves ovate, lower very large, heart-shaped; involucre moothish ; scaies: subulate.:-

Cultivetel and waste grounds, common, introduced. July-Oct. Stem stout 3 to 4 foet li i h. Root leaves very large, (often 1 to 2 feet long and a foot wide) with: wavy odgca.s The scales of tho involucre all terminate in a minute, firm hooks. 
which seizes hold of every thing that passes by: clustered. Flowers purple.

I. Bardana, a species or variety with pinnatifld leares, has been observed by $\mathrm{D}_{\mathrm{r}}$ Darlington in Cbester county.

\section{CNICUS, Vaill.}

Gr. Iniso, to prick; well applied to these herbs.

HEADS many-flowered; the ray-flowers tubular and sterile;. shorter than the rest, which are all tubular and perfect. IN. VOLUCRE swelled, imbricate with deeply spinous scales. $R E$ CEPTACLE clothed with capillary bristles. ACHenia smooth, striate. PAPpus in 3 series, the outer 10 toothed, the 2 inner each 10 bristled._- Oriental somewhat woolly herbs, with elasping léaves and large bracted heads of yellow flowers.

\section{C. Benedictus, L. Blessed Thistle.}

Leaves scarcely pinnatifid, decurrent, dertate and spiny; involucre doubly spio nous, woolly, bracteate.

Cultivated, scarcely natu:alized along roadsides; native of Persia. June. Stem 1 to 2 fect high, branching. Leaves clasping. Heads large, with yellow flowers. It was at one time in great repute as a medicine, but is now consiacered of no im portance.

\section{E.TOTICS。}

\section{CALENDULA; Linn.}

Iist. calenda, the first day of the month; some species blossom monthly.

Heads radiate. Involucre of many equal leaves, in about 2 series. ReCEPTACLE naked. ACHeNiA if the disk membraneous, curved. Pappus none.-An oriental genus of annual herbs, with alternate leaves and showy. flowers, in termia nal heads.

\section{C. officianalts, I. Fot Marigold.}

Visced-pubescent; stem erect, branched ; leaves oblong, acute, mucronate, sesille, subdentate and scabrous ciliate on the margin; heads terminal, solitary; achenia reeled, muricate incurved. A common showy garden plant, native of South Eu. zope. Flowers single and double, large and brilliant, nostly yellow and orange colored. June-Nor.

58. CARTHAMUS, Linn.

Arabic, quorthom, to paint ; from its coloring property.

HEADS discoid ; FLowers all tubular and perfect. IN. VoLUCRE imbricated, outer bracts foliaceous. ReCEFTACLE with bristly chaff. Achenia 4-angled. Pappus none.Oriental herbs.

1. C. tinctorius, L. Common Safjron.

sien smooth; leaves orste-lanceolate, sessile, scipose-denticalate. Natire or. 
Eypt, common in cultivation. July. Annnal. Stem branching, 1 to 2 feet $\mathbf{B l a g}$ triate. Leaves sub-amplexicaul, smooth and shining, spinose. Heads large, ter minal, with numerous Yong and slender flowers, useful in coloring tinctures.

\section{XERANTHEMUM, Linn.}

Or. xeros, dry, anthos, flower; on account of its dry imperishable flowars.

HEADS discoid. INVOLUCRE hemispherical ; SCALES rađient, opaque, colored, scarious. RECEPTACLE chaffy. PAPpus bristly-chaffy. - Annual herbs, natives of South Europe, with radient involuere scales which retain their beauty a great length of time.

X. Annudm, Willd. Eternal Flower. Straw Flower.

Diem ereet branched; lexves oblong-lancsolate, som 3 hab obtuse, alternate, on *rs; heads large, terminal, solitary; involucre scales obtuse, scarious; inner on of the ray spreading, lanceolate, obtuse. A singularly beautiful plant, cultivated Ror its imperishable flowers which retain their beauty through the winter. 4 to 4 feet high. The radiant involucre scales are of a rich purple, but thero ar cono varictiez with red, white, blus and yellow rays; expanding in sunohino, bat. dosing in rainy wather.

\section{SUBORDER II. LIGULIFLOR FE:}

Flowers all perfect with ligulate corollas throughowt.

\section{SUdTRIBE 6. CICHORACE F.}

Flowers all perfect and ligulate; branches of the style slender, obtuse, uniforre af hairy. Plants with a milly juice; leaves alternate.

\section{CICHORIUM, Tourn. SUCCORY.}

Said to be derived from the Arabic Chikourych.

Feads many-flowered. Involudere double, the outer ries of 5 short spreading scales, the inner of 8 to 10 scales: Achenia striate. Pappus of numerous very small chaffy cales, forming a short crown.-Branching perennials, wiih oothed or pinnatifid radical leaves, and sessile axillary and termial heads of bright blue showy flowers.

\section{C. Intrbus, L. Common Succory or Cichory.}

Radical.leaves runcinate; stem leaves gmall, oblong or lanceolate, partly clasping, Wothed or entire; heads 2 or 3 together.

Cultivated and somewhat naturalized in grass fields, roadsides, \&e. Siem 2 to eet high, round, rough, with few long branches. Heads of flowers 1 to 2 inchen n diameter, sky-blue, somewhat remote on the long branches. Corollas flat, \& wothed. July, Sept. Native of Europe.

2. C. Endivia, L. Endive.

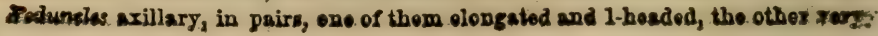


short, about 4-həaded; heads capitste. 1 hardy plant from the East Indien, toemed and cultivated for salad.

61. KRIGIA; Shreber.

In honor of Daniel Krig, an early German botonieal collector in this country.

HEADs 15 to 20 flowered. Involuche in a single series with 8 to 12 scales. Receptace naked. Achenia turbinate, many striate or angled. PAPPUs double; the outer of 5 broad, chaffy, rounded scales; the inner of as many alternate slender bristles. - Small annual or bienniel acaulescent plants, with radical, lyrate or toothed leaves and solitary heads with 20 to 30 yellnw flowers.

\section{K. Virginica; Willd. Duarf Dandetion.}

Ieaves lyrate, smooth; scapes several 1-fiowered; involucie smcoth.

Dry sandy soil. May-July. Scopes 2 to 10 irches Ligh, emcoth. Primary leaves roundish, entire. Heads solitary, small. Flevers decp yellcw. This plent continues in blocm for scme time, during which it varies grcatly in the length of tho scape.

\section{CYNTHIA, Don.}

Probably named after Mount Cynthus.

Heads many-flowered. Involucre nearly simple; BCALES in one or two rows. AcnenIA short striate. YAPPUs double; the cutcr of numerous rery small chafy bristles; the inner of numerous elcngatcd bristles.- Perennial herb: with alternate or all radical leaves and ruther slicu'y single head of 15 to 20 yeillow ficuers, cn sccipes or naked pediuncles.

1. C. Virginica, Don. Virginian Cynthia.

Smooth and glaucous; stem scape-like, of ten 2 or 3 parted, few-leaved; root-leaves petioled, lyrate, sinuate-certate or pinnatifd; stem-leares lanceolate, clasping, nearJy entire; peduncles 3 to 5 .

Moist baxks and low or en woods. June, July. St $m 1$ foct or more high, often 2 or 3 from one root, divicied.into long slex der branches, with a clasping leaf at th.

foŕs.s. Heads solitary, middle sized orange yellow.

\section{LEONTODON, I., Juss. HAwkBIT.}

Gr. leon, lion, and odcns, a tcoth; in allusicn to the toothed margins of the leares.

HEAds many-flowered. Involucre scarcely imbricated; sCALES lanceolate acuminate with several bractlets at thebase. Achenia spindle-shaped, striate, all alike. Pappus persistent, composed of plumose bristles which are enlarged and flattened towards the base.-Low and stemless perennials, with toothed or pinnatifid root-leaves and one or two heads of yellow fowers borne on a scape. 


\section{L. autumnate, L. Autumnal Hawkbit.}

Leaves more or less pinnatifid; scape branched; peduncles several, thickened at Who summit and furnished with small scaly bracts; involucre ovoid-oblong.

A European plant, naturalized in meadows and roadsides. July-Sept. Scapos 16 to 18 inches high spreading, branched into a few peduncles. Leaves all radical, preading, 6 inches long, with deep round sinuses, and covered with remote hairs. Hoads 1 inch in diametor, bright yellow, resembling the Dandelion.

\section{HIERACIUM, Tourn. HaWKWEED.}

Gr. hierak, a hawk, supposed to strengthen the vision of birds of prey.

Heads many-flowered. Involudere more or less imbricated, ovoid; scales linear, obtuse. AcHenia oblong or columner, striate. Pappus a single row of tawny fragile capillary bristles.-Perennial herbs, with entire or toothed alternate leaves, and single or panicled heads of yellow flowers.

\section{H. SCABRUM, Michx. Rough Hawleweed.}

Stem erect, leafy, rough-hairy; leaves obovate or oval, entire or somewhat den. Uiculate, hairy, the lower narrowed, at the base the upper-closely sessile; panicle stiff flexuous, at first racemose, at length rather corymbose.

Woods and dry hills. July-Aug. Stem 1 to 3 feet high, round, striate, rathe? stout. Leares subacute, often purplish as well as the 'stem. Involucre 40 to 50 flowered, densely clothed with glandular bristles. Heads large, with yellow flowers. Achenia obtuse at apex, bright red, with a tawny pappus.

2. H. Grovovir, Li, Gronovius's Hawleweed.

Siem erect, wand-like, mostly simple, leafless and paniculate above, leafy and hairy below; leaves oblong and obovate, nearly entire, hairy; involucre axd peduncles sparingly glandular-bristly.

D:y sterile soil, com non. July-Aug. Stem 1 to 4 feet high, furnished with a fe: $\mathrm{t}$ leaves below, naked above, and forming a long and narrow panicle. Heads zather sma!l, 20 to 30 -flowered. Flowers yellow. Achenia spindle-shaped, with : very tapering summit.

3. H. venosum, L. Veiny, Hawtoweed, Rattlesnatieweed.

Stém scape-like, naked or with a single leaf, smoth and slender, forking above Lato a spreadiag loose corymb; leaves obovate oblong and lanseolate, entire or obseurely donticulate, hairy on the margin and midrib beneath.

Dry soil and pine woods, common. Juns-Aug. Stem 1 to 2 feethigh. Radical Kaves spreading on the ground, colored with purple veins. Heads 20 -flowered on very slender peluncles. Rays rather large for the size of the head, yellow. Beputed as an antidote for the poison of the rattlesnake.

\section{H. paniculatum; L. Panicled Hawkiveed.}

Stem slender, leafy, paniculate, hairy below; leaves lanceolate, acute at botb ends, slightly toothed, smooth; hedds in a loose paniclo on slender spreading poduncles; achenia short, not tapering at the summit. .

Damp woods, common. August. Stem 1 to 3 feet high, diffusely branched. Ieaves thin, 2 to 4 inches long. Heads small, 12 to 20 flowered. Flowers yellow... Achenia ribbed, reddish-brown..

\section{NABULUS, Cass.}


Heads 15 to 30 flowered. Involucre cylindrical. SCALEs b. to 14, linear, in a single row, with a few small bractlets at the base. AcHunia linear-oblong, striate or grooved, truncate at the apex. PAPPUS in many series of yellow brownish, roughish capillary bristles.-Perennial herbs with - pindle-shaped bitter tubers, upright leafy stems, with variable leaves and racemose-panicled, mostly nodding heads, with greenish-white or cream-colored flowers, sometimes tinged with purple.

* Involucre smooth or nearly so, 5. to 12-fowered.

\section{N. Albus, Hook. White Lettuce, Rattlesnake-root.}

Smooth and glaucous; stem tall; leares angular-hastate or angulate, sinuato. toothed, or 3 to 5-cleft; the uppermost oblong and undivided; racemes short, paniculate; involucre with about 8 scales, 8 to 12-flowered. Var. Serpentaria is a form with decply divided leaves, with their margins often rough-ciliats.

Woods and hill sides, in rich soils, common. Aug., Sopt. Stcai 2 to 5 feet high, simple or much branched. Heads numerous, in a loo:e coryubed paricle. Is - olucre purplish. Flowers white. Pappus deep cinnamon-color. Achenia yellow. Roputed as a remedy for the bite of the rattlesnake.

\section{N. Altissimus, Hook. Tall White Letiuce.}

Smooth; stem tall and slender, branched; leaves all peticled, undivided, or tho lower 3 to 5 -cleft or parted; the lokes or leares acuminate, repandly toothed of Genticulate; involucre slender, of 5 scales, 5 to 6 -fotrered; heads in small axiliary and terminal loose clusters, forming a long leafy panicle.

Rich moist woods. Aug., Sept. Stem 3 to 6 feet high, erect. Leaves rery variable, sometimes cordate, deitoid or triangular-hastate, with naked or winged petioles. Heals nodding with yellowish white flowers, Puppus dirty white, ox psle strair color.

\section{N. Fraserir, DC. Lion's-foot. Gall-of-the-earth}

Nearly smooth; stem erect, branched; leaves mostly deltoid, roughish; loroer 2 ;o 7-lobed, on margined petioles; upper nearly sessile and undivided; involueve woothish, of about 8 scales, 8 to 12 -fiowered; heads in corymbose panicles. Tam ntegrifulix has the thickish leaves all undivided and merely toothed.

Dry sandy or sterile soil. Aug.-Oct. Stem 1 to 4 feet high. Leaves very rariat ble. Invoiucre greenish or purplish, sometimes slightiy hristly. Flowers crean solor, sometimes with a tinge of purple. Puppus dull straw-color.

\section{TARAXACUM, Haller. DANDELION.}

Ar. taratetileos, cathartic; on account of its once celebrated medicinal properties HeAD many-flowered. InvoluCRE double, the outer of short scales; the upper of long linear scales, erect in a single row. Achenia oblong ribbed prolonged into a long beak, erowned with the copious, white capillary pappus.-AcauRescent perennial herbs, with radical runcinate leaves and slendes naked hollow scapes, bearing a single le rge head of yellow flowera.

\section{T. Dens-leonis, Desf. Common Dandelion.}

smooth or at frst pubescent; leaves unequally and deeply runcinate; outer to roluere scales reflexed.

Pastures and fields, common orergwhere. Aprti-0ct. After blossoming the th 
a.

ner involucre closes for a time, the slender beak elon rates and raises up the pappue while the fruit is forming, the whole involucrs is then reflex d, exposing to the wind the naked seeds with the pappus displayed in an open globular form. Th. zaves are used in spring as a pot-herb.

\section{LACTUCA, Tourn. Lettuce.}

The ancient name of Lettuce, from lac, milk in allusion to the milky juice.

Heads several-tiowered. Involucre cylindric; Scalzes imbrieated in 2 or more sets of unequal lengths. RECEPTAcle naked. Achenia flat, obcompressed, abruptly produced into a long thread-like beak. PAppus of very soft and white capillary bristles. - Leafy-stemed herbs, with panicled heads of various colored flowers.

\section{L. elongata, Muhl. Wild Lettuce.}

Stem tall and stout; leaves partly clasping, pale beneath; the upper lanceolato and entire; the lowcr runcinate pinnatifid; heals in a long and narrow panicle, varies greatiy. The var. integrifolia is mostly smooth, with the leaves vearly all entire and the flowers yellow or bluish. Var. sanguine. is smaller, mostly hairy, with the leares chiefly runcinate, and the flowers variously colored. $\mathrm{Gr}$.

Rich damp soil, h d pes and thickets, common. July-Sept., Biennial. Stem 2 to 8 feet high, often purple, bearing a leafless, elongated, sometimes corym 3 s - spreading panicie of num rous heads of flowers. Carolies yoliow. A inenia oblong, eompressed, about the len th of the beak.

2. sativa, L. Garden Lettuce. Sallad.

Slem corymbose; leaves suborbicular, thosc of the stem cordate. A well known cultivated exotic, with several varieties. The rar. capitati has the leaves so thick to form heads like the cabbage. Heads numerous, small, with yellowish caroilas. The milky juice contains opium.

68. MULGEDIUM, Cass.

Lat. mulgeo, to milk.

Heads many-flowered. Involucre calyculate-imbricate, the outer scales much shorter than the inner. RECEPTACLE naked, honey-combed. Achenia smooth, compressed, attenuated in a beak at the summit, appearing as if a part of the achenia, and expanded at the apex into a ciliate disk, which bears copious pappus of soft capillary bristles. - Leafystemmed herbs, with panicled or racemed heads of cli.efly blue flowers.

\section{M. ACuminatum, DC. Sharp-leaved Mulgedium.}

Smooth; stem panicled above; stem-eaves ovate and ovate-lanceolate, pointed merely toothed, sometimes bairy on the midrib beneath, contracted at th, base into a winged petiole; the lower ones sometimes runcinate or sinuate; heads in thyrse-like panicle; peduncles somewhat scaly.

Borders of thickets and shady woods. Aug.-Sept., Biennial. Stem 3 to 6 feet high, erect, smooth, simple. Leaves 3 to 6 iuches lop. the lower ones often deltoid. hastate or truncate at the base, narrowed into a winged petiole. Fruds small, not -... Corollat suruerous, in a widely spreading terming past

bive. 
2. M. Floridanum, DC. Gall-of-the-earth.

Nearly smooth; stem erect, paniculate above; leaves all lyrate or runcinate, the aivisions sharply toothed; heads in a loose erect panicle.

Rich soil, woods and road sides. July-Aug., Biennial. Stem 3 to 6 feet high, purplish or somewhat glaucous. Leaves 4 to 8 incher long, variable in form, the upper triangular; lower ones petioled. Heads rather small, in an oblong terminal panicle. Flowers blue. Pappus dirty white. Pursh states that this plant is used as a cure for the bite of the rattlesnake, and is known by the name of Gall-of-theearth.

\section{M. Leucopheum, DC. Tall Mulgedium.}

Nearly smooth; stem tall, very leafy; leaves irregularly pinnatifid, sometimes runcinate, coarsely toothed, the uppermost often undivided; heads in a large and dense compound panicle.

Low grounds, common. July-Sept., Biennial. Stem 3 to 12 feet high. Leaves 5 to 12 inches long, irregularly divided in a runcinate or pinnatifid manner, the cegments repand-toothed, those of the root on long stalks, the upper ones sessile. Heads small, with pale blue or yellowish corollas. Pappus tawny white.

\section{SONCHUS, Linn. Sow-THISTLE.}

The ancient Greek name.

Heads many flowered, dilated at base. INVOLUCRe imbricated. RECEPTACLE naked. ACHENIA flattened laterally, ribbed or striate, not beaked. Pappus of numerous soft and very white, fine capillary bristles. - Leafy-stemmed herbs, chiefly smooth and glaucous, with mostly spinulose leaves and corymbed or umbellate heads of numerous yellow fiowers.

\section{S. oleraceus, L. Common Sow-Thistle.}

Stem-leaves runcinate-pinnatifid, or rarely undivided, slightly toothed, with soft spiny teeth, clasping by a heart-shaped base, the auriele acute; involucre downy when young; achenia striate, wrinkled transversely.

Waste places, naturalized. July-Sept. Stem 2 to 4 feet high, hollow, angular. Zeaves apparently clasping, with large retreating lobes at base, wavy and serrated in a runcinate manner. Heads in a scmewhat umbelled eorymb. Flowers yellow. Fappus very white and silky. Introduced from Europe.
2.
S. ASPER, Vill.
Spiny-leaved Sow-Thistle.

stem-leaves mostly andivided, undulate or slightly runcinate, spinulose-toothed, cordate clasping; lower ones spatulate or owal; heads umbellate-corymbose; achenia margined, 3-nerved on each side, smooth.

Fields and waste places. Aug.-Sept., Annual. Stem about 2 feet high, smooth or slightly hairy. Leaves with numerous short, spiny teeth; the uprer ones clasping so as to appear perfoliate. Heads small, somewhat umbelled. F'lowers yellow. Introduced from Europe.

3. S. ARVensis, L. Corn Sow-Thistle.

Root creeping; stem erect, smooth; leaves runcinate-pinnatifid, spiny-tcothed, cordate clasping, the auricle obtuse ; peduncles and involucre bristly; achenia transversely wrinkled on the ribs.

Near cultivated grounds. Aug.-Sept. Per. Stem angular, about 2 feet high. Heads large with deep yellow flowers. Introduced from Europe and sparingly naturalized.

70. TRAGOPOGON, Linn. Salsify. Gr. fragos, a gost, pogon, a beard; in allusion to the tawny, Bhowy pappus 
INVOLUCRE simple, of many leaves. REOEPTACLE naked. Pappus plumose. Achenia longitudinally striate, contracted into a long, filiform beak.-Bienniel European herbs, with long linear grass-like leaves, and terminal solitary heads.

1. T. porrifolius, L. Salsify. Vegetable Oyster.

Leaves long, linear, undivided, straight; peduncles thickened upwards; involwere mach longer than the corolla. Stem 3 to 4 feet higi. Filowers terminal, golitary, large, bluish purple or sometimes pale straw-color. Native of Europe, cultirated for its long tapering root, which is nutritious, and when properly prepsred has a wild swoetish taste, similar to that of the oystor.

\section{CATANANCHE, Linn.}

Qr. kata, anagke, from necessity; it must recessarily be adrairod.

InvoldCRe imbricated, scarious. RECEPTACLE paleaceous. Pappus paleaceous, 5-leaved; PALE $\mathbb{E}$ awned.-Annual oriontal herbs, with allernate leaves, and solitary heads of showy flown ers.

\section{C. CGRULEA, L. Blue-flowered Catananche.}

Ireaes linear and lanceolate, villous somewhat bipinnatifid at base; involuene scales orate, mucronate. A handsome annual from South Europe, 2 to 3 fot high. Heads solitary, on long peduncles. Flowers blue, ligulate. Coroilas tooth. cd at apax. July-Sopt.

\section{Order 59. LOBELIACER, - Lobelia Family.}

Terbs (often with milky juice) with altermate leaves and scaltered flovors, an regulas momopetalous 5-lobed corolla split down to the base on one side; the 5 stamens free from the coroll $\alpha$, and united into a tube both by their filaments and their anchers.-Calyx-tube adherent to the many-secded capsube. STILI 1; stiaks fringed. Sisos anatropous.

\section{LOBELIA, Linn. CARdinat Flower.}

In honer of Miatthias de Lobel, a Flemish botanist of the close of the 16th century.

Calix 5-cleft, with a short ovoid tube. Coroula irregulax, cleft on the upper side, 2-lipped; lower lip 3-cleft, upper lip of 2 rather erect lobes. Stigna 2-lobed. Capsulk 2-celled, many-seeded, opening at the top-Herbaceous plants, with alternate leaves, and blue, white or red flowers, in ax. illary, or terminal, bracted racemes,

* Flowers deep red.

1. L. Cardinalis, L. Cardinal Flower.

Smoothish; orect, simple, pubescent; leaves oblong-lanoeolate, weuto at both ends, slightly toothed; raceme elongated, rather one sided; pediecls much whort then the leaflike braets; stamens langer than the corrolle 
Low grounds, common. July, Aug. Perennial by offsets. Stem 2 to 3 feet high, often quite smooth. Leaves 2 to 4 inches long, $3 / 4$ to $11 / 4$ inch wide, usualiy denticulate. Flowers few or numerous, in nodding raceme, very showy, and in. tensely red. Corolla $1 \frac{1}{2}$ inch in length:

* Flowers blue, or white.

\section{L. syphilitica, L. Blue Cardinal Flower.}

Siem erect, somewhat hairy and simple; leaves ovate or ovate-lanceolate, acute, slightly toothed, somewhat hirsute; raceme or spike leafy; caly $x$ hispidly-ciliates with the sinuses reflcxed.

Wet meadows and along streams, common. Aug. Per. A handsome plant, 1 to 3 feet high. Leaves broader at base, acute at each end, pilose: Calyx lobes hali the iength of the corolla, the obtuse reflexed auricles shorter than the tube, F'lower: large on short peduncles, each solitary in the axil of an crate-lanceolate bract. Corolla bright blue or purplish, rarely white. I found the white variety growing in company with the deep blue in a meadow near Mooresburg, Montcu: Co.

\section{L. puberula, Michx. Downy Lobelia.}

Minutely downy pubescent; stem erect, simple; leaves ovate or oblong, obtuse, denticulate with glandular teeth; flowers in a one-sided spike, the leafy bracts orate, acute, serrate, as long as the flotrer; calyx hirsute at base the lanceolate ciriate segments as long as the tube of the corolla.

Moist grounds, rare. Aug., Sept. Per. Stem 1 to 2 feet high, scarcely furrow: ed. Leaves 1 to 2 inches long, and half as wide, the lower ones broadest towarcis the end, covered with a short down or silky pubescence. Flowers large on very short pedicels, in a one-sided raceme. Corolla of a bright purplish biue.

\section{L. SPICATA, Lam. Spiked Lobelia.}

Somewhat pubescent; stem slender, and very simple; leaves obtuse, pubescent nearly entire; radical leares spatulate or oblong, those of the stem.oblong-ianceolate; raceine spiked one-sided, elongated; segments of the calyx subulatc, near'y as long as the tube of the corolla.

Open woods and fields, common. July, Aug. Per. Stem 1 to 2 feet high, fow leaved, ending in a long wand-like raceme. Flowers numerous, crowded, each axillary to a short bract, pale-blue.

\section{L. Inflata, L. Indian Tobacco. Eye-bright.}

Hairy; stem low, panicled, branched above; leaves orate-lanceolate, uncqually toothed, the lower obtuse, sessile; rucemes leafy, somen hat paniculate; capsule inflated, oroid.

Fialds and roods, common. July-Sept. Bienniel. Stem 1 to 2 feet high, becoming branched in proportion to the luxurience of its growth. Flowers small, pale biue, on pedicels much shorter than the pointed bracts; lobes of the smooth calyx as long as the corolla. This plant is much used in the Thompsonian practice of medicine, and is an invaluable emetis; as mell as a powerful expectorant, seldom failing to give almost instantaneous relief in attacks of croup, astbma, \&c.

\section{CLINTONIA, Douglass.}

Caryx 5-sepaled, subequal. Corolia 2-lipped, lower lip cuneate, 3-lobed ; upper erect, 2-parted. STAMENS incurveà, united into a tube. CAPSULE silique-form, dry, chartaceous, 1-celled, many-seeded, dehiscent by 3 strap-shaped valves.Procumbent annual herbs, with minute leaves and axillary solitary flowers. 


\section{C. elegans, Doug. Elegant Clintonia.}

Smooth; stem slender, angular, sparingly branched; leaves sessile, ovate, 3-veined; ovary sessile, long acuminate, triangular, contorted, much longer than the leaves. A beautiful garden annual, native of the Rocky Mountains. Flowers of the most intense blue; corolla with a white spot in the middle of the lower lip.

\section{ORder 60. CAMPANULACEF,-Bell-flower Family.}

Herbs with a milky juice; alternate leaves, no stipules, and mostly blue, scattered flowers; the calyx generally 5-cleft, adherent to the ovary; the regular bell-shaped corolla 5-cleft, valvate in aestivation; the 5 stamens inserted with the corolla on the calyx, free, and usually distinct. STrLE 1, beset with collecting hairs above; STL6MAs 2 or more. CAPSULE 2 or more celled, many-seeded.

\section{CAMPANULA, Toura. BeLl-FLOWER:}

Lat. campanula, a little bell; from the form of the corolla.

Calyx 5-cleft. Conoula mostly bell-shaped, 5-lobed. STAMENS 5, seperate, the filaments broad and membranaceous at the base. Stigmas 3 to 5 . CAPsule 3 to 5-celled, opening by lateral valves. - Mostly perennial herbs, with ab. ternate leaves, and terminal spicate, or axillary flowers.

\section{C. rotundifolia, I. Rock Bell-flower. Hair Bell.}

Stem slender, branchingin; root-leaves round heart-shaped, crenate, on long petior oles; stem leaves linear, narrow, entire, smooth; flowers few; nodding; calyx-lobes awl-shaped.

On damp racks and rocky streams, common. June-Oct. An exceedingly delicate species from 6 to 15 inches high, smooth. The root-leaves generally decay on the opening of the flowers, when the specific name appears wholly inappropriate. Stem-leaves 2 inches long and scarcely a line in width.. Flower's terminal, in a loose panicle, bright blue.

\section{C. aparinoides, Pursh. Slender Bëll-flower.}

Stem weak, slender, simple, somewhat 3-angled; leaves linear-lanceolate; pedun. cles divergirg, slender, 1-flowered; calyx-lobes triangular, half the length of the bellshaped corolla.

Bogs and wet meadows, common. July, Aug. Stem 8 to 20 inches high, roughi backwards on the angles, by which it supports itself upright among the grass. Leaves smooth on the upper surface, denticulate, the margin and veins rough backwards. F'lowers small, nearly white, on thread-like, flexuous peduncles at the top of the stem.

\section{C. Americana; I. American Bell-flower.}

Slem tall and wand-like, nearly simple; leaves ovate-lanceolate, accuminate at both ends, serrate, sparingly hairy, thin, the lower somewhat heart-shaped; flowers axillary, sessile; style exserted; lobes of the calyx awl-shaped.

Moist rich soil, common. July, Aug. A tall erect ornamental species, sometimes oultivated, 2 to 3 feet high. Stem nearly smaoth. Leaves ending in a long point, smooth, with fine teeth. Flowers numerous, sessile or on short stalks, one or more in each axil, forming a terminal leafy raceme or spike, sometimes $\mathbf{2}$ feet long. Corolla nearly wheel-shaped, deeply 5-cleft, blue. 


\section{C. pyramidalis, Ls Pyramidal Bell-flower.}

Stem upright, elongated; branched below; leaves ovate-cordate acuminate, po tiolate; uppper ones lanceolate; peduncles about 3-flowered. Native of Franco. July-Sept. A showy perennial cultivated in gardens for its showy bell-shaped flowers, which are borns on pyramidal branches, rising from the border like a Ch:nose pagoda.

5. C. Medrum, I. Canterbury Bell.

Stem simple, erect, hispid; leaves lanceolate, obtusely serrate, sessile, 3-rienod at base; flowers erect. An ornamental biennial from Germany, of the easiest culture. Stem 2 to 3 feet high, branched, rough with bristly hairs. Flowers very large, the base broad, limb reflexed, mostly of a doep blue. Sereral varietiez are cuttivaled with blue, purple and white corollas. Junc-Sept.

\section{C. Persicifolia; Lr. Peach-leaved Bell.flower.}

Stem angular, erect; leaves rigid, obscuroly crenate-serrate, radical oblong oborate, stem-leaves lance-linear; corolla large, broadly-companulate. A beautiful species, native of Europe, ranked among the most ancient ornaments of the Ing lish parterres. Flowers large, blue, varying to white. June-Sept.

\section{C. Carpatica, L. Curpatic Boll-Flower.}

Difuse, spreading; stem trailing, somewhat angled; leaves heart-shaped, coarsely Eerrate, wary on the margin, with a few scattered hairs on the milrib beneath; flowers terminal; ccty $x$-ijbes linear-subutate, epreading; stigma 3 -cleft, the lo ves epreading. A beautiful perennial, native of the Carpatic Mountains. July-Oct. Stems prostrate forming dense patches. Laaves 1 to 2 inches long, $1 / 2$ to 1 inch wide on petioles 2 to 5 inches long. Flowers purplish-blue 1 to $1 \frac{1}{2}$. inch in dianz. otor on peduncles 4 to 8 inchas long.

\section{SPECULARTA, DC.}

Namo from Specutum Tesweris, the ancient name of one of the European species.

CalyX 5- (rarely 3 to 4)-lobed, tube elongated. Corolia. wheel-shaped, 5-lobed. Stamens 5, distinet, half as long as the corolla ; FILAMENTs hairy, shorter than the anthers. STYLE included, hairy; strgmas 3. CAPSUlie clongated, prismatic, 3-celled, openiag by 3 small lateral valves.-Low annual herbs, with sessile, axillary and terminal, erect flowers.

1. S. Perfoliata, DO. Clasping Bell-flower.

Somewhat hairy ; leaves roundish or orate, cordate, amplexicaul, crenate; flow. ors sessile, solitary or three together in the axils of the leares:

Dry hills, or open fields, common. May-Aug. Stem 9 to 15 inches high, mostIy simple. Leaves clasping by the heart-shaped base, distunt, alternate. Floucers small, purple; corolla with spiedading segnents; calyx segments acute, lanceo. Inte.

\section{S. speculum, L. Tenus' Looking-glass.}

Siem difuse, very branching; leaves oblong-crenate; flowers solitary. July, A ug. Native of Europe: A pretty border flower. Stem 6 to 12 inches high, with. epreading branches. Flowers blue, axillary; corolla salver-shaped, resembling . In form, a little round concare mirror. Towards evening the corollas fold up in-. a pentagonal figure, enclosing the parts of fructification, and securing from. the damp air until they are again opened by the morning sun. 


\section{ORDER 61. PRICACER,-Heath Family:}

Shrubs, sometimes herbs, with simple alternate or opposite leaves, of ten evergrean urithout stiputes, and regular flower's or nearly so, the stamens as many or twice as mony as the 4 to 5-lobed corolla, and inserted with $i t$. Arrirns 2-celled, mostly appendaged, opening by chinks or pores. Orary 4 to 10-celled; STYLz 1. FROT erp: sular, baccate, or drupaceous.

\section{SUb-ORDER 1. VACCINE A. WhortLeberhy FAMILT:}

OVARY adherent to the tube of the calyx, becoming a berry or drupe-like fruit, crowned with the calyz-teeth... Shrubs. with scattered leaves.

\section{VACCINIUM, Linn. W WortleberRY.}

Calix adherent to the ovary, 4 to 5-toothed. Corouta ovoid, bell-shaped, urn-shaped or cylindrical, 4 to 5-cleft Stamens 8 to 10. Strue erect, longer than the stamens. Berry globose, 4 to 5-(rarely 10)-celled; cells many-secded.Shrubs or under-shrubs, with scattered leaves, solitary or racemose, white or reddish flowers, and succulent many-secded berries.

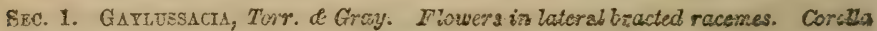
5. deft ; stameñs 10.

* Leaves thick and evergreen, not resinnus dotted.

1. V. BRachycerum, Michx. Box-leaved Fuckleberry.

Low, very sarath; leaves oval, finely crenate-toothed; racemes short and neariy: sossile; pedicels rery șhort; corolla cylindrical-bell-shaped. (Gaylussacia brachy cera, Torr \& Gr.)

Hillsides, rare. May-June. I found this species in the summer of 1850 vary abundant on a small hill near Bloomfield, Perry County. Slem 8 to 12 irchea higb, Fith leaves resembling those of the Box.

** Lexves decicuous, entire; whole plant more or less rezinous dotted.

2. V. Frondosum, Willd... Blue-tangle. High Blue. birry.

Smooth; branches slender and divergent; leaves obovateoblong, obtuse, pale, glaucous boncath; racemes slender, loose, with oblong or lincar bracts; corolle qubular-bell-shaped. (Gaylussacia frondosa, Torr. \& Gis.)

Low sandy woods, common. May-June. Sitrub_3 to 6 feet high, with smooth slonder branches aad grayish bark. Leaves twice as. long as wide. Kacemes latoral, few-flowered. F'lowers small, nearly globose, reddish-white. Berries large, globose, blue, covered with a glaucous bloom when mature, sweet.

3. V. REsInosum, Ait. Black Huckleberry or Whordeberry.

Much branched, rigid, slightly pubascent when young; leaves petiolate, oral, hong-orste or oblong, obtuse, very entire, sprinleled with shining resinous dow: : 
racenes short, clustered, one-sided, bracteate; corolla ovoid-conical or at length. - glindrical, contracted at the mouth, at length open. (Gaylussacia resinosa, Tors:

\&. Gr.)

Woods and swamps, common. May-June. Shrub 1 to 3 feet high, bushy? Leaves 1 to 2 inches long, $1 / 3$ as wide, rarely acute, shining beneath with resinou mpots, on petioles 1 line in length. F'lowers reddish in lateral, dense, corymbose elusters, small drooping. Curclla greenish or yellowish-purple, longer than the stamens, but shorter than the style. Berries black, globose, without bloom, sweet and eatable, ripe in A tigust.

Sac. 2. VAccixivm proper. Flowers in sotitary clusters or racemes, whils ar raddish; stamens 8 to 10.

* Ouary more or less completely 10-celled by false partitions; corolla 5-6obad.

4. V: stamineum, L. Deerberry. Squazo Hucklsberry. White Whortleberry.

Difusely branched, young branches pubescent; leaves ovate or ornl, acute, very entire, glaucous beneath; pedicels Eolitary, axillary, filform, nodiing; corilus boll-shsped, spreading; anthers exserted, with 2 awns on the back.

Dry woods, common. May, June. Shrub 2 to 3 fcet high. Leares 1 to 2 inches long, $1 / 4$ to $1 / 2$ as vide, mostiy rounded at bage and on very short petioles. Fiowers on lorig, slenuer pediculs, arranged in loose, leafy racemes. Coroili $\pi$ hite, siresdants. Stunens conspicuously exsorted, but shorter than the gtyle. L'arites large, gresnish-rhite, bitter.

5. V. Penneyluanicum, Lam. Common Low Sliuring-leaved Blueberry.

Dwarf, smooth; leares cratc-lanceolate or oblong-lanceolats, acute at erch end, xainutely serrulate, thin; corolla short, ovoid-cylindrical.

Thiokets and dry hills, in haril soil, common. May. A low undershrub, 6 to 15 inches high, growing in donse patches. Branches green, angled, with 2 puleseent lines. Leares sub-segsile, cruwcied 1/2 to 1 ineb long: 1/4 to 1/2 wide. Flower's red distwhite, $1 / 4$ inch loug, with mostly color ed braets. berries alunciant, lerge and westo bluish-black, somewhat glaucous, ripening early in July.

\section{V. conymbosum, L.. High Swamp Whortleberry.}

Tall; flowering brancies almost leafiess; leaves oblong-oval, rather acute at ezch od, nearly entire, pubescent when young; racemes s'lort, sessile, bracteate; corobin oroidicylindrical.

Stramps acd marshy places, common. June. A tall shrub, 4 to 8 feet high, with 2 fer etraghing branches, which are green or purplish when young. Leates emcoth on both sides, (when young somewhat downy on the veins). Filwers numous, nodding, generally appearing in advance of the leaves, on short bracted podicels, crowcied near the suminit of the naked branches. Corolla large, $1 / 2$ incls. in diameter, purplish-white, contracted at the mouth. Barries large, sub-ain, covered with a glaucous bloom; ripening in July and August.

7. V. Fuscatum, Aits Black Swamp. Whorteberry.

Tell; leaves oval obovate or oblong, downy beneath, and also usually on the reins above; racemes shorti corolla cylindrical.

Marshes, common. June. Stem 5 to 9 feet high. Leares 2 to 3 inches long when full grown, at length thickish and semewhat shining above, but always sort owny underneath. Berry purplish-black, destitute of bloom, erowned with very conspicuous calyx-teeth. Gray. "Shis may prove to be only a varioty of $V$. ecryanasum.

8. V. vaccillans, Solander. Sugar. Whortleberry.

Low; branches angular, smooth; leaves oval or obovate, acute or rather obt arrulate, smooth on both sides, glaueons boneatb; reemos rery abort, elusterw exells egliadrieal-beil-shapod. 
Dry hills and open woods, common. May. Stem 1 to 2 feet high, with numerous Tullowish-green branches. Leaves pale and dull, fringed with bristly or glandular hairs, which tip the serratures. Flowers greenish white tinged, with red, on short petioles. Berries dark blue, glaucous, very sweet, ripening a little later than those of No. 5 .

9. V. Ligustrinum, Michx. Privet Whortleberry.

Branches angular, erect, slender; leares sub-sessile, erect, thick, lanceolate; mucronate, serrulate, pubescent; fascicles sessile, with short glomerate pedioele; orolla ovoid-oblong.

Dry woods and mountains. May-June. A small khrub, with straight and alender branches. Flowers punplish-red. Berries blaet. Fery yariable in the chape and size of the lcares.

\section{OXYCOCCUS, Pers.}

Gr. oxys, acid, and coccus, a berry.

CaltX superior, 4-cleft. Conolla 4-parted, with elongas ted, revolute divisions. Stamens 8, convergent. Anthers tubular 2-parted, opening by oblique pores. Ovary 4 celled, many-seeded.- Slender trailing shruls, with alternate evergrecn lcaves, with revolate margins, aud red acid berries.

\section{O. macrocarpus, Pers. Common Cranberry.}

stems elongated, creeping, the flowering branches ascending; leares oblong, obtuse, glaucous underneath; peduncles lateral, from the base of the young shoots.

Peat bogs, common. June. Stem creeping, and throwing up short erect branch cs. Leaves about $1 / 2$ ineh long, and nearly $1 / 1 / 1$ wide, rounded at each end, on very short petioles, obscurely serrulate. Flowers tiesh-colored on slender petioles $1 / 2$ to 1 isch long, solitary in the axils of the upper leaves, the 4 segments reficred. Berry large, scarlet or purplish, ripe in October. Highly prized for its fine acid sivit

Sub-order 2. Ericlnez. The Proper Heath Family.

Ovary free from the calyx. SEEd-COAT close and thin, rarely loose and cellular.-Shrubs or small trees.

TRIBE 2. ANDROMEDEEE. Fruit a capsule opening: loculicidally.

- Ouly $x$ becoming berry-like in fruit and enclosing the capsule.

3. GAULTHERIA, Kalm.

Drdicsted by Kaln" to "Dr. Gaulthier," of Quebee" .

CalyX cylindrical-ovoid, 5-toothed. Conolla ovoid-tubulàr, limb with 5 small revolute lobes. Stramens 10 , ineluded. Capsuzi depressed, 5-lobed, 5-celled, 5-valved, many-seeded, inclosed when ripe by the calyx which thickens, Becoming fleshy, so as to appear like a globular red berry.- 
Somewhat shrubby plants, with alternate evergreen leaves, and axillary, nearly white flowers, on pedicels which are 2-bracted.

1. G. Procumbens, L. Creeping Wintergreen. Boxberry. Checkerberry.

Stem somewhat creeping, with ascending flowering branches; leaves obovate or oral, obseurely serrate, shining; flowers mostly single in the axils, drooping.

Cold damp woods and mountain sides, common. May-July. Stems slender, 3 to 5 inches high, extensively creeping on or below the surface, the flowering branches ascending, simple, leafy at the summit. Leaves thick, acute at each end. Corolla white, contracted at the mouth. Fruit having the appearance of a bright scarlet berry. The leaves and fruit have the well-known spicy aromatic flaror of the Sweet Birch.

** Calyx dry and unchanged in fruit.

\section{EPIGEA, Linn. Ground Lauret. \\ Gr. epi, upon, ge, thè earth.}

CaLYX deeply 5 parted, with 3 bracts at the base. Coro: If salver-form, with a long tube, villous within; $\operatorname{limb} 5$ parted spreading. STAMENs 10 , with thread-like flaments: Anthers oblong; awnless; opening lengthwise. Capsule 5-celled, 5-valved, many-seeded.-Trailing scarcely shrubby plants, bristly with rusty hairs, evergreen alternate leaves, and pale rose-colored fragrant flowers in axillary clusters.

1. E. Repens, L. Trailing Arbutis.

Stem prostrate, creeping; leaves roundish-oval and heart-shaped, on slender:" petioles; tube of the corolla hairy inside.

Damp woods and north side of mountains, common. April, May. A small: trailing evergreen, covered with a hairy pubescence in all its parts, 10 to 15 inches long. Leaves 2 inches long, and 1 to $11 / 4$ wide, rounlish at the end, abruptly tipped with a very short point: Flowers very fragrant, white or tinged with va. sious shades of red, in small elusters on short stallis:

\section{ANDROMEDA, Linn.}

Named for Andromeda of ancient fable.

CALYX small, various in form 5-(rarely 4)-parted, persistent. Conouria ovoid-cylindrical, the limb 5-cleft, reflexed. Stamens 10, rarely 8, included. Capsule 5-celled, 5valved, many-seeded.-Shrubs prostrate or erect, with evergreen or deciduous alternate leaves, and mostly racemed or: clustered flowers.

SEc. 1. ANDROMEd proper. Gulyx without bracts. Anthers 2-awned. Leaves evergreen. -

1. A. polifolia, L. Marsh Andromeda. Wild Rosemary. Rosemary Andromeda.

Erect, very smooth; leaves thick, lanceolate or linear, entire, with strongly : re rolute margins, green above, white beneath; flowers on short naked pedunclen: 
rowded in a terminal umbel; corolla globose urn-shaped, much contracted at tho top; filaments bearded.

Sides of ponds, and in swamps. May. A beautiful evergreen shrub 1 to 2 feet high. Leaves very smooth, 2 to 3 inches long, and less than $1 / 2$ ineh wide, on very short petioles. Flowers in pendulous clusters. Calyx white, tipped with red. Corolla rose-colored.

SEC. 2. Lroni., Nutt. Corolla sub-globose; capsule with 5 supernumerary valwes. Shrubs with deciduous leaves.

\section{A. Ligustrina. Muhl. Pivet Andromeda:}

Pibescent; leaves obovate-oblong; pointed nearly entire, finely serrulate; flow ers in racemes, crowded in a somewhat'leafy or naked panicle on terminal branches of the preceding year; calyx without bracts; capsule globular.

Swamps. June. A deeiduous shrub 4 to 8 feet high, minutely downy when young, sometimes rusty. Leaves abruptly acuminate, paler beneath, 2 to 3 inches long, and nearly half as wide, on'short petioles: E' lower's small, nearly globoses: white in dense panicles.

Sec. 3. Cissandra, Don. Calyx with 5 acute sepats and 2 traetlets capsulevalves double. Shrubs with-evergreen leaves.

\section{A. Calyculata, L. Box-leaved Andromeää.}

Erect; leaves oval-oblong, obtuse, sub-revolute, mearly entire; rusty dotted; bracts orate; racemes one-sided, leafy, terminal; corolla cylindrical-oblong, the mouth slightly narrowed and 5-toothed; filaments smooth.

Swamps and marshy places, common. April-Nay. Shrub 1 to 3 feet high. Jeaves corizceous, shining, dotted; about 1 inch long and $1 / 2$ wide, those of the racemes not half as large. Fluwers numerous, 20 to 30 in each raceme, white, each fiom the axil of a small leaf.

Sec. 4. Eubotrys, Nutt. Calyx with 2 bractlets; capsule depressed-globular. Shrubs with deciduous leaves.

\section{A. racemosa, L. Racemed Andromeda.}

Nearly smooth; leaves oval lanceolate or oblong, acute, serruiate; racemes erect or spreading; sepals ovate-laneeolate; corolla cylindrical; anthers 4 awned at the summit.

Swamps and wet woois. June-July. A branehing shrub 3 to 5 feet high. Leaves 1 to 2 inches long, $1 / 3$ as wide, minutely notehed, veiny, thin. Flowers numerous, white, closely set in a simple one sided spiked raseme, 2 to 6 inches long. Bracts awl-shaped. Carolla 4 to 5 times as long as the calyx.

Scc. 5. Marra, DC. Culyx without bractlets; anthers awnless; capsule-vatues simple. Shrubs with deciduous leaves.

5. A. Mariana, L. Maryland Andromeda.

Nearly smooth; leares thickish, oral or oblong, entire, paler beneath; fowering branches neariy naked; calyx leafy; corolla oroid-cylindrical; filaments hairy.

Sandy woods. June. Shrub 2 to 4 feet high, with very smooth leaves on short petioles. Flowers large, aearly $1 / 2$ inch in diameter, white or pale red, arranged in umbel-like clusters crowded on leafless branches, from buds developed in the axils of the deciduous leaves of the preceding year.

Sao. 6. OXYDENDnon, DC. Calyx without bractlets, acuminate; capsule pyramidal, gentangular. Trees with large, acid deciduousleaves.

\section{A. ARBorea. L. Sorrel-tree. Sour-wood.}

Arborescent; leaves oblong-lanceolate, pointed, petiolate, shining above; corolla oblong-ovoid, narrowed at the summit, 5 -toothed; filaments thickened; capsubs 5-angled.

Sich roods, rare. June-July. A fine tree, 20 to 60 feet bigh, trunk 10 to 16 
fnches in diameter, with thick and deeply furrowed bark. Leaves 5 to 6 inches long, and 2 to 3 wide, turning bright scarlet early in autumn. Flowers white arranged in slender, somewhat 1-sided racemes crowded in a large tcrminal pari ale. Bracts minute, deciduous.

\section{Clethita, Linn. Sweet Pepper Bush.}

Klethra, the ancient Greek name of the Alder.

CaryX 5-parted, persistent. Coroli 4 of 5 distinct obo. rate-oblong petals. Stamens 10, exserted. Antuers inrorsely arrow-shaped. Filanents subulate. Strle slender. Stigmas 3. Capsule 3-celled, 3-valved, many-seeded, enclosed by the calyx.- Shrubs, with alternate deciduous leaves, and white flowers in single or panicled racemes.

1. C. Almifolia, L. Sweet Pepper Bush. White Alder.

Leaves wedge-obovate, serrate, entire towards the base, smooth, green on both sides; raceme upright, hoary; bracts as long as the pedicels; filaments smooth.

Wet woods and swamps. July-Aug. Shrub 4 to 12 feet high. Leaves 2 to 3 inches long, $1 / 2$ as wide above, with $a$ long, wedge-shaped base, tapering into a shor petiole, slightly pubescent beneath. Flowers white, fragrant, in racemes, 3 to 5 inehes long; Corolla sprealing, about equaling the stamens and styles.

\section{MENZIESIA, Smith.}

In honor of Archibald Menias, companion of Vancouver in his vorage around the world.

Calyx bell-shaped, deeply 4-cleft. Conolla globose, 4-cleft. Stamens 8, included. Filaments subulate, smooth. Stigma obtuse. Capsule 4-celled, 4-valved.Heath-like shrubs, with evergreen leaves, and mostly solitary flowers.

1. M. globularis, Salisb. Globose Menziesia.

Branches and pedicels somewhat hairy; leavcs oval-lanceolate, ciliate, pubescent except on the veins beneath, with a sharp glandular point.

Mountains. June. Shrub 4 feet high. Leaves very hairy whon young. Flowers yellowish-brown, nodding, and mostly solitary on eaeh terminal pedicel.

TrIBE 3. RHODORAE. Fruit a capsule opening septisidally.

\section{RHODORA, Duhamel.}

Gr. rodon, a rose, from the color of the showy flowers.

Caliyx minute, 5-toothed, persistent. Corolla irregular and 2-lipped; the upper lip 3-lobed or 3-cleft, the lower 2parted or of 2 distinct spreading petals. Stamens 10, deslinate. Fildaments unequal. Capsule 5-celled, 5-valied, 
many-seeded, opening at the top.-A shrub with deciduous alternate leaves, and pale purple flowers.

\section{R. Canadensis, L. Rhodora.}

Leaves alternate, oval, veiny entire, nearly smooth above, downy beneath; flow- ers clustered on short peduncles.

Mountain bogs. April-May. Shrub 2 to 3 feet high, with erect branohes; the - stems clothed with a smooth brown bark, each dividing at top into several erect, flowering branches. Flowers purple, in terminal clusters of 2 to 5 , somewhat preceding the leaves.

\section{AZAIEA, Linn.}

Gr. azaleos, arid, inappropriate as applied to our species, which mostly grow in wet places.

Calyx 5-parted, often minute. Corolua funnel-form, 5lobed, slightly irregular; the lobes spreading. STAMENS 5 , with long exserted filaments, usually declined, as well as the long style. ANTHERs short, opening by terminal pores, pointless. CaPsUle 5-celled, 5-valved, many-seeded.- $U p$ right shrubs, with alternate deciduous leaves, and large and showy flowers, in umbelled clusters, from large scaly-imbri cated buds.

* Flowers appearing after the leaves.

1. A. Arborescens, Linn. Tree Azalea.

Branchlets smooth; leaves obovate, obtuse, very smooth on both sides, shining above, glaucous beneath, the margins ciliate, flowers in leafy corymbs, not viscid, tube longer than the segments; stamens and style very much exserted.

Blue Mountains. June. Shrub 3 to 10 feet high, with thickish leaves. Flowers 'large, rose-colored, fragrant. Scales of the flower-buds large, yellowish-brown with a fringed white border.

2. A. viscosa, I. Clammy Azalea. White Honeysuckle. Clammy Swamp Pink.

Branchlets bristly; leaves obovate and oblong-lanceolate; corolla viscid, hairy; -calyx-lobes minute.

Woods, common. June-July. Shrub 4 to 6 feet high, much branched above, the branches hispid. Leaves 1 to 2 inches long and about $1 / 2$ as wide, Smoothish, hispid, ciliate on the petiole, midvein and margin. Flowers white or tinged with rose-color, fragrant, in large clusters.

* Flowers appearing before or with the leaves.

3. A. Nudiflora, L. Purple Azalea. Pinxter-flower.

Branchlets rather hairy; leaves obovate or oblong, downy: underneath; calyx - hort; tube of the corolla longer than the lobes; stamens and style much exserted.

Woods and mountains, common. Shrub 2 to 6 feet high, much branched above. Leaves crowded at the ends of the branches, 2 to 3 inches long, 1 to $1 \frac{1}{2}$ broad, with ciliate margins. Flowers pale pink or purple, in terminal clusters, appearing a little before the leaves. Stamens purple, declinate, twice as long as the corolla. Style much longer than the stamens. There are numerous varieties, some with 10 - ar more stamens.

4. A. Calendulacea, Michx. Flame-colored Azalea.

Iranchlets somewhat hairy; leaves obovate or oblong, mucronate, pubercent on 
both sides, ciliate on the margin ; fowers large in rather naked corymbs, not visced: calyx-lobes oblong, conspicuous; stamens and style much exserted.

Woods and mountains, southern parts of the State. May. A splendid flowering ehrub 3 to 10 feet hich, covered about the time that the leaves appear with a profusion of large and showy yellow or orange flowers. usuaily turning to fiame-color. C) rolla about $2 \frac{1}{2}$ inches long and 2 wide. Cultivation has produced many varieties, from golden yellow to dark crimson, single and double.

5. A. Hispidum, Torr. Hisped Azalea.

Branches straight, very hisped; leaves lanceolate, acuminate at each end, hisped above, smootil beneath, glaucous on both sides, ciliate on the margin; fowers very viscod, appearing with the leaves; calyx-teeth oblong, rounded; stamens and styles exserted.

Margin of lakes, on high mountains. July, Aug. Shrub of a bluish appearance, 10 to 15 feet high, very upright. Flowers white, with a red border; the tube reduish-white. Stimens often 10. Professor Gray cousiders this scarcely distinct from $A$, viscosaic

\section{RHODODENDRON, Linn. Rosebay.}

Rhododendron, rose-tree; the ancient Greek name.

Catyx 5-parted, mostly small. Corolda somewhat bell. shaped, or partly funnel-form, sometimes slightly irregular, 5-lobed. Stamens 10, vary rarely fewer, commonly declined. Anthers opening by 2 terminal pores. Capsule 5-celled, 5-valved, many-seeded -Shrubs or low trees, with evergreen entire alternate leaves, and large showy fowers in compact terminal corymbs or clusters from large sccly-bracted buds.

\section{R. maximum. L. American Rosebry.}

Leaves elliptical-oblong or lance-oblong, acute, narrowed towards the base, very smooth, paler beneath, thick and evergreen; corolla companulate.

Shaded ravines and water-courses, common. July. Shrub 6 to 20 feet high, with - crooked stems. Leaves when young downy, bccoming very smooth when tull grown, 4 to 10 inches long, thick and leathery, remaining on the stem 2 or 3 years. Crymbs 15 to 20-fiowered. Corolla 1 to 2 inches broad, pale rose-color or nearly white, greenish in the throat on the upper side and spotted with yellow or reddish.

\section{KALMTA, Linn. AMERICAN LAUREL.}

Dedicatcd to Peter Kalm, a pupil of Linræus.

Calyx 5-parted. Corolla between rotate and companulate, 5-lobed, furnished with 10 depressions in which the 10 anthers are severally lodged until they begin to shed their pollen. Filaments elastic, thread-form. Capsule globose, 5-celled, many-seeded.-North American evergreen shrubs, with naked flower-buds, alternate coriucious leaves, bracted pedicels and showy white and red fowers in umbel-like corymbs.

1. K. Latifolia, L. Mountain Laurel. Calico-bush.

Branches tercte; leares mostly alternate, on long petioles, orate-lanceolate or elliptical, tapering at each end, bright-green on both sides; corymbs terminal, many-fiowered, clammy-pubescent. 
IIills and mountains, damp soil, common. June, July. A beautiful shrab 4 to 5 feet high, with irregular branches. Leaves 2 to 3 inches long, thick, smooth and shining. Flowers very showy, in spreading corymbs, profuse light or deep rosecolor. Corolla $3 / 4$ to 1 inch in diameter, with a short tube. Leaves poisonous to some animals.

\section{K. ANGUStifolia, L. Sheep Laurel.}

Branches terete; leaves mostly opposite or in threes, petiolate, narrowly-oblong, obtuse, pale or whitish underneath, light-green above; corymbs lateral, slightly glandular, many-flowered; bracts linear-lanceolate.

Sandy woouls and hillsides, common. June, July. A besutiful shrub 2 to 3 feet figh, upright. Leaves acately and narrowly elliptic, with rounded ends, 1 to 2 inches long and $1 / 3$ as wide, on short petioles. Flowers crimson and purple, in lateral corymbs, forming a kind of whorled faseicle around the stem. Corolla $1 / 2$ to $3 / 4$ inch in diameter.

3. K. GLAUCA, Ait. Swamp Laurel.

Branchlets 2-edged; leaves opposite, nearly sessile, oblong or lanceolate, whiteglaucous underneath, with revolute margins; corymbs terminal, few-flowered, smooth; bracts large. Var. rosmarinifolia, Pursh. Leaves linear, conspicuously sevolute, nearly green beneath.

Cold peat bors and mountains, common- June, July. A delicate straggling shrub, about 1 foot high, the branches distinctly 2 edged. Leaves smooth and shining, about 1 inch long. Flowers pale rose-color, 8 to 10 in each corymb. Corolla $1 / 2$ inch in diameter. Calyx red. Bracts 2, concave, obtuse,

\section{LedUM, Linn. Labrador Tea.}

Iedom, the ancient Greek name of the Cistus, transfered by Linnæus to this genus.

CALYX 5-toothed, very mall. Corolta 5-petaled, spreading. Stamens 5 to 10 , ezserted. AnTwiers opening by 2 terminal pores. CAPsule 5-celled; 5-valved, manyseeded, splitting from the base upwards.-Low evergreen shrubs, with alternate entire leaves clothed with rusty wool underreath, and handsome white flowers in terminal umbel-like clusters from large scaly-bracted buds.

\section{L. Latifolium, Ait. Broad-leaved Labrador Tea.}

Lecues elliptical or oblong, revolute on the margin, ferruginous-tomentose be neath; stamens 5, sometimes 6 or 7., as leng as the corolla; capsule oblong.

Cold bogs and damp mountain woods. June. Shrub 2 to 5 feet high, with ir. regular woolly branches. Leaves 1 to 2 inches long, broad-oblong, obtuse. F lowers in terminal corymbs, white.

2. L. Palustre, I. Narrow-leaved Labrador Tea.

Ieaves linear, revolute on the margin, ferruginous-tomentose beneath; stanker 10, longer than the corolla.

Swamps. June. A shrub smaller than the last and with narrower leares Both species have been used as substitutes for tea, but the latter is considered the test.

\section{Sub-order 3. Ptrolez. The Prrola Family.}

\section{OVARY free from the calys. Petals nearly diatinct}


FRUIT a capsule.-Mostly. herbaceous plants, with evergreen foliage.

\section{Pyrola, Linn. False Wintergreen.}

A diminutive of the Latin pyrus, a pear, from the resemblance of the leares of some species.

Calyx minute, 5-parted, persistent. Petals 5, concave, deciduous. Stamens 10, with awl-shaped, naked filaments. Style long and generally turned to one side. Stigmas 5. CAPSULE depressed-globose, 5 -valved from the base upwards, many-seeded.-Low and smooth perennial herbs, bearing a cluster of rounded and petioled evergreen root-leaves, and a simple raceme of nodding flowers on an upright scaly bracted scape.

\section{P. Rotundifolia, L. Round-leaved Wintergreen.}

Leaves orbicular, thick, entire or crenulate, usually shorter than the dilated petioles; raceme elongated, many-flowered; calyx-lobes lanceolate, acutish; stigma clavate.

Damp or sandy woods, common. July. Scape 6 to 12 inches high, many-bracted: Leaves all radical, $1 \frac{1}{2}$ to 2 inches in diameter, on petioles about the sane length. Flowers $3 / 4$ inch broad, nodding, white, fragrant, 8 to 20 in a raceme.

2. P. elliptica, Nutt. Shin-Leaf.

Ireaves elliptical or obovate-oval, usually longer than the margined petiole; raceme many-flowered, naked or with a subulate bract; calyx-lobes ovate, acute; stigma clavate, 5 -lobed.

Rich woods, common. June, July. Leaves all radical, membranaceous, finely serrate, with an attenuated base much longer than the petiole. Scaje 6 to 10 inches high, slender, bearing 8 to 12 greenish-white fragrant flowers.

\section{P. Chlorantha, Swartz. Smail Pyrola.}

Leares small, roundish, retuse, thick, shorter than the petiole; scape few-flowcred, nearly naked; caly $x$-lobes very short, obtuse; petals elliptical, converging; stigm a with the disk 5-lobed.

Open woods, common. June. Leaves about 1 inch long, varying from orbicular te broad-ovate, crenulate, smooth, leathery, shining. Seape 6 to 8 inches high, 3 to $\delta$-flowered. Flowers nodding, greenish-white, fragrant, on pedicels $1 / 2$ inch long; each in the axil of a very short bract.

\section{P. secunda, L. One-sided Pyrola.}

Leaves ovate, acute, thin, serrate, longer than the narrow petiole; raceme dense, many-flowered, secund; caly $x$-lobes ovate, shorter than the oblong petals; style ex. serted; stigma depresssd, 5-lobed.

Rich woods. common. July. Leaves somewhat raised on a decumbent stem, about 1 inch long, and petioles about the same length. Sape 3 to 6 inches high, with the flowers all turned to one side. Flowers greenish-white.

5. P. Minor, L. Lesser Pyrola.

Leaves roundish, slightly crenulate, mostly longer than the margined petioles: raceme spiked; bracts as long as the pedicels; calyx-lobes rery short; corolla glo. bose; style included; stigma 5-lobed.

Base of mountains, rare. July. Leaves on short petioles, mucronate at the spez. Scape angular, 5 to 10 inches bigh. Flowers small; white of rose-solor. 


\section{Chimaphila, Pursh. Pipsissewa.}

Gr. keima, winter, and phileo, to love.

Calyx 5-parted, Petals 5, spreading, concave. Stamens 19. Filaments dilated in the middle. Style very short, inversely conical, nearly immersed in the depressed summit of the globular ovary. Strama broad and orbicular, the border obtusely 5-toothed. CAPSULE 5-celled, opening from the summit. SEEDS numerous.-Low perennial, nearly herbaceous plants, with running underground shoots, evergreen thick shining opposite or whorled leaves, ana fragrant white or purplish flowers corymbed or umbelled on a terminal pe. duncle.

1. C. umbellata, Nutt. Prince's Pine. Pipsissewa.

Zeaves wedge-lanceolate, sharply serrate, acute at the base, in 4s or $6 \mathrm{~s}$; peduncles 4 to 7 flowered, corymbed; bracts linear-subulate; style immersed in the ovary.

A beautiful evergreen, common, in dry woods. June. Plant 4 to 8 inches high, leafy. Leaves in 2 or more irregular whorls, 2 to 3 inches long, $1 / 2$ tc $3 / 2$ wide, $r e$ motely and distinctly serrate, on short petioles, shining of a unifurm dask green color.- Flowers light purple on nodding petioles.

2. C. Maculata, Pursh. Spotted Wintergreen.

$\boldsymbol{I}$ eaves ovate-lanceolate, rounded at base, remotely toothed, discolored, opposite or in threes; peduncles corymbose, 1 to 5-flowered; filaments wooly.

Dry woods. June, July. A pretty evergrcen 4 to 6 inches high, with leaves 1 to 2 inches long, $1 / 3$ as wide, marked with a whitish line along the midvein and vein lets. Flowers purplish-white, on nodding pedicels.

\section{SUb-order:4. MONOTROPE A. Indian Pipe Family.}

OVAry free from the calyz.-Leafless herbs, destitute of green.

\section{PTEROSPORA, Nutt. PIne-Drops.}

Gr. pteron, a wing, and spora, seed; alluding to the singular wing borne by the
seeds.

Calyx 5-parted. Corolia ovate, urn-shaped, 5-toothed, persistent. Stamens 10 ; AnTHERs 2-celled, peltate. STYLI short; stigma 5-lobed. Capsule globose, depressed, 5lobed; 5-celled, 5-valved. Seeds very numerous, minute, with the apex expanded into a broad reticulated wing. $-A$ stout and simple purplish.brown clammy puiessent perennial plant, with lanceolate scales in place of leaves scattered along the stem, and whitish flowers in a raceme.

1. P. Androneda, Nutt. Tall Bird's Nest.

Hard clayey and limestone soils; rare. July. Plant covered with brownish riscid hoirs. Stem 8 to 24 inches high, straight, simple, grooved, brownish-red or 
purplish, clothed at the base with imbricated scales. Flowers very numerous, 20 . to 60 in a long terminal raceme, rose-red and white:

\section{HYPOPITYS, Dill. PINe-SAP.}

Gr.hypo, under, and pitus, Pine-tree; from the place of its growth.

Sepalis 4 to 5-colored. Petals 4 to 5, fleshy, with a ac-like necteriferous depression at the base. Stamens 8 or 10 ; ANTHERs kidney-shaped; FILAMENTS subulate, persistent. Sryle columner, hollow; stigma disk-like, with a bearded margin. CAPSULE nvoid or globose, 8 to 10 -grooved, 4. to 5-celled, mnny-seeded.-Purasitic tawny white herbs, with scaly ronts, simple stems, scales instead of leaves, and bracted racemes of flowers, at first nodding; but in fruit erect.

1. H. lanuginosa, Nutt. Pine-sap. False Beech-drops.

Plant clothed with a relvet-like pubescence; pedicels much longer than the tlower; capsule globose.

Oak and pine woods. Plant 4 to 6 inehes high in flower, and sometimes 12 inches in froit, tawny-white. Flowers 7 to 12 in a turminal raceme, the terminal. bith 5 patals an 110 stamens, the other with 4 petals and 8 stamens. The whole-

plant turns black in drying.

\section{Monotropa, Gron. Indian Pipe:}

Ar. monos, one, and tropos, turn; the solitary finwer turned to one side.

CALYX represented by 2 to 4 scale-like deciduous bracts. Corolita 4 to 5-petaled, persistent, gibbous at the base GTAMENS 10 ; FILAMENTS persistent, alternating with 10 reflexed appendages of the torus; ANTHERs short. STIGMA 5-crenate. CAPSUle 5-celled, many-seeded.-A singular white fleshy par asitic herb, rising in a cluster from a matted mass of fibrous roots, with scales like the petals instead of leaves. biearing a solitary finwer turned to one side.

\section{M. EnIflora, L. Indian Pipe. Bird's Nest.}

Stem short; scales approximate; flowers nodding; fruit erect; stamens 10.

Diep rich woods; common. June-Aug. A small succulent plant from 4 to 6 : inohes higk; white and smooth, becoming purplish-black in drying.

\section{ORDER 62. AQUIFOLLACE屈,- Holly Family。}

Trees or sirrubs vith alternate or opposite leaves, without stipules, and small axit lary 4 to 6-merous white or greenish flowers. CaLXX 4 to 5-sepaled, imbricate in æativation. Corolla regular, 4 to 6 parted or cleft, hypogynous. STAMENs inserted into the tube of the corolla and alternate with its segments: ANTHERS adnate, epening lengthwise. Stramas 4 to 6 or united into one, nearly sessile. Otary free from the calyx 4 to 6-celled. Fruir a berry-like drupe, with 2 to 6 stones or nus calea : sard suspended, with a minute embryo in fleshy albumen. 


\section{ILEX, Linn. HoLly.}

Caurx 4 to 5-toothed, persistent. Coroula subrotate, 4 to 5-parted. Stamens 4 to 5 . Stigmas 4 to 5 , subsessile, united or distinct. BerRy 4 to 5-seeded.-Shrubs or trees, with alternate spinose dentate leaves, and whitish, nostly perfect flowers.

SEC. 1. AQUTOLIUM, Tourn. Leaves evergreen, spiny-toothed.

\section{I opacA, Ait. American Holly.}

Leaves oval, flat, acute, smooth, margins wavy, armed with seattered spiny teeth; floryers in loose clusters along the base of the young branches and from the axils; calyx-teeth acute.

Moist woodlands, rare. June. An evergreen tree 10 to 15 feet high. Leaves tough and shising, with rigid spines. Flower's small, white, in scattered clusters, the fertile ones succeeded by red berries which remain until late in autumn. The wood is fine grained and compact, and is employed by cabinet makers and turners.

SEC. 2. Privordes.-Leaves membranaceous, deciduous.

2. I. montana, Torr. \& Gr. Mountain Holly.

T2aves oblong-ovate or oval-lanccolate, pointed, sharply serrate, smooth, closely approximated on the ends of the branches; fertile flowers on very short péduncles; calyx-teeth obtuse.

Damp woods, along the Alleghanies. June. Shrub or small tree 6 to 20 feet high, straggling. Leaves 3 to 5 inches long, very thin. Fertile flowers perfect, on short stalks. Sterile flowers, if any, unknown. Nutlets strongly striate-ribbed on the back.

\section{PRTNOS, Linn. WinTERBERrY:}

The Greek name of the Holly.

Frowers mostly dicecious or polygamous. Calyx minute, 4 to 6-toothed. Corolid somewhat rotate, usually 6-parted. Stamens mostly 6. Ovary superior, 4 to 6 . celled. Frutt a drupe, with 6 smooth nutlets. - Shrubs with alternate leaves, and inconspicuous flowers.

* Leaves deciduous; fruit bright red.

1. P. verticellatus, L. Black Alder. Winterberry.

Leaves oval, obovate, or wedge-lanceolate, painted, acute at the base, sharply serrate, downy on the veins beneath; sterile flowers axillary, subumbellate; fertile flowers somewhat clustered or solitary; berry 6-celled, 6-seeded.

Swamps, common. June, July. Slirub 3 to 10 feet high, very variable in foliage, often rugose veiny. Floners numerous, small, white. Frnit globose, bright scarlet, crowded so as to appear in whorls on the branches, and remaining until late in autumn.

\section{P. Lavigatus, Pursh. Smooth Winterberry.}

Leaves lanceolate, pointed at both ends, minutely serrate with appressed hairs, shining above, minutely pubescent on the veins beneath; sterile flowers 2 to 5 in a cluster, or single on slender peduncles; the fertile mostly single, and on short peduncles.

Swamps, along cold streams and mountains. June. STrub 4 to 8 feat high, 
with grayish and warty branches. Leaves 1 to 2 inches long, $1 / 2$ to 1 inch wide, on pstioles $1 / 2$ to 1 inch long. Flnwers mostly solitary, the sterile on pedicels near 1 inch long, the fertile scarcely $1 / 4$ as long. Berries large red.

** Leaves coriaceous, evergreen, shining above; fiuit black.

3. P. GLABER, L. Into-berry. Evergreen Winterberry:

Laves wedge-lanceolate or oblong, somewhat toothed towards the apex, smooth; pedicels axillary, of the fertile 1-flowered, the sterile 3 to 6 -flowered at the summit.

Sandy woods. July. Sirub 3 to 4 feet high, mush branchel. Leaves crorded, about $1 \frac{1}{2}$ inch long, broadest above the midule. F'lower's white mostly 6-parted. Burries globose, black and shining.

\section{NEMOPANTHeS, Raf. Mountain Holly.}

Gr. neinx, a thread, pous, a foot, and anthns, a flower; a flower with a filiform $p 6$ duncle.

Flowers polygamo-dioceious. Caryx a minute ring. Petals 5, oblong-linear, reflexed, distinct. Stamens 5. Ovary hemispherical; stigmas 3 to 4 , sessile. Fruit a 3 to 4-celled globose berry, with 4 to 5 long nutlets. -4 slirub with alternate entire deciduous leaves, on short petioles, and solitary flowers on long and slender axillary peduncles.

\section{N. Canadensis, DC. Canadian Holly.}

Eeaves oval, very entire, smooth, mucronate-pointel ; peduncles nesrly solitary, very long; fruit somewhat 4 -sided.

Damp cold woods. May, June. Siru' 4 to 6 feet high, with smooth ash-gray bark. Leaves about 2 inches long on petioles $1 / 2$ as long. Flowers small, greesisth. white. Berries dry, red.

\section{O,BDER 63, FBENAOER, - The Ebony Family.}

Trees or shrubs, with alternate entire leaves, and polygamous regular flowers which have a calyx free from the ovary, the stamens 2 to 4 times as many as the lobes of the crolla, and the fruit a severat-celled berry. SEeds anatropous, mostly single in each cell, large and fiat, with a smooth coriaceous integument; EMBnro shorter than. the bard albumen.

\section{DIOSPYRUS, Linn. Permimaron:}

Gr. Dios, pyrus the fruit of Jore.

Diœcious. Calyz 4 to 6-cleft. Corolla 4 to 6-lobed. Sramens mostly 16 in the sterile flowers, and 8 in the fertile, in the latter imperfect; FILAMENTS shorter than the anthers. BerRy large ovoid or globular, surrounded at the base by the permanent calyx, 4 to 8 -celled, 4 to 8 -seeded.A large genus of shrubs or trees, mostly tropical, with alternate entire. leaves and axillary flowers, the fertile axillary and solitary, the sterile smaller and often clustered.

1. D. Virginiana, L. Common Persimmon. Zeaces orate-oblong, nearly smooth, entire; peduncles very short; calyx 4-parted; ; 
corolla somewhat bell-shaped; stamens 8; styles 4, 2-lobed at the apex.

Woods and old fields, abundant near Liverpool, along the Suspuehanna. June. A. small tree 20 to 30 feet high. Leaves 2 to 3 inches long, glancous beneath. Flowers obscure, pale, yellowish-green, the fertile ones succeded by a plum-like fruit, 1 inch in diameter, which is exceedingly astringent when green, golden-yel. low when ripe, and sweet and edible after exposure to trost.

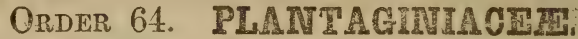

Chiefly stemless herbs, with regular 4-merous spitied flowers, the stamens inserted? on the tube of the dry and memlranaccous veinless monopetalous corolla alterrate. with its lobes;-chiefly represented by the typical genus:

\section{PLantago, Linn. Plantata:}

The Latin name of the Plantair.

F Frowers perfect. CAivX of 4 imbrioated persistent? sepals. Conolua tubular, withering on the capsule, the border 4-parted, reflexed. Stamens 4, mostly with long and weak filaments. CAPSULE 2-eellod, 2-sevoral-seeded, opening transversely so that the top falls off like a lid.Acaulescent herbs, with radical ribbed leaves, and small whitish. jowers in a bracted spike raised on a naked scape.

\section{P. MAJOR, L. Common Plantain.}

Smooth or hairy; leaves oval or ovate, somewhat toothed, 5 to 7 -nerved, abruptly marrowed into a channelled petiole; spike long, cylindrical, densely flowered; stamens and style long.

Rich moist soil, about footpaths near houses. June-Sept. Per. Scape 8 to 12 inches high, pubescent. Leaves sprealing on the ground. coarsely toothed. Spilce 2 to 6 inches long, close. Fiovers whitish. Probably introduced:

2. P. cordata, Lam. Hearl-leaved Plantain.

Smooth; leaves orate and mostly heart-shaped, scarcely toothed, thickish, on iong stout petioles; spike very long, at length rather loose; bracts ovate, obtuse seeds mostly 4.

Banks of streams, rare. June, July. Per. Scapes stont 1 to 2 feet high. Leaves 3 to 8 inches long, the 6 to 8 ribs or veins confluent helow with the thick midrib. F'lowers in a slender elongated spike, with white corollas.

\section{3, P. lancelata; L. Lance-leaved Plantain.}

Hairy or almost smooth; leaves lanceolate, 3 to 5-nerved, entire or nearly 80 ; thpering to each end, on slender petioles, remotely toothed; scape slender, elongated, grooved; spike short, ovoid or oblong-cylindrical, very dense; bracts scale-like, ovate, pointed; seeds 2.

Dry fields among grass, common. May-Aug. Per. Scape 12 to 18 inches high, somewhat hairy. Flowers whitish, with 2 of the sepals commonly united into one. Introduced.

\section{P. Virginica, L. Virginian Plantain.}

Woolly with soft hairs; leaves oblong or lanceolate-ovate, 5-nerved, sparingly toothed, or entire, narrowed into a short margined petiole; spike cylindrical, dense-flowered above and interrupted and scattered below; lobes of the corolla in Grait.inyolute and converging into a sort of beak. 
Sandy fields. April-Sept. Biennial. Scapes 3 to 10 inches high, angular: Deaves 2 to 3 inches long, ottusc. Biacts nearly as long as the calyx. Filowers: yellowish, with the anthers exserted in some specimens, aud included and smail in others. Seeds oval, concave on the inner face.
5.
P. PUsilla, Nutt.
Dwarf Plantain.

Minutely woolly; leaves linear-subulate, flat, entire, acute; scape terete, slender longer than the leaves; spilie loosely-flowered, the lower flowers distant; bracks. ovate, acute; stimens short.

Dry bare soil and rocky hills. April-Aug. Annual. Scape 2 to 3 inches high, slender. Leaves crowded, about 1 inch long. Spilie $1 / 2$ to 2 laches long, the flowers interrupted.

\section{ORder 65. PLUIIBAGIVACPBS.-Leadwort Family.}

Herbaceous plants or undershrubs, with alternate or clustered leaves, somewhat: sheathed at base, and regular 5-mernus flowers, in loose panicles or contracted inio heads. Cansx tubular, plaited, persistent. Corolla monopetalous, or of 5 regular petals. Stavers 5, opposite the separate petals or the lobes of the corolla. Orane. free, 1-celled, rith a sclitary ovule hanging from a long cord which rises from the base of the cell. Fruir an utricle.

\section{STATICE, Tourn. Sea Lavender.}

Gr. statike; to stop, on account of its astringency.

Calyx funnel-form, 5-toothed. Petals 5, united at base. Stamens 5, inserted on the claws of the petals. STyLes 5, separate. FruIt membraneous and indehiscent, 1-seeded, in the bottom of the calyz. - Salt-marsh perennials, with thick and stalked radical leaves, cond small flowers loosely. spiked on the branches of a compound corymb, onc-sided, 2-bracted.

\section{1.. S. Limonium, L. Marsh Rosemary.}

Zeaves obovate-lanceolate or oblong, tippod with a point, 1-ribbed; scape much branched, the flowers rather crowled slong the upper side of the spreading branchlets.

Sall marshes, rare. Aug. Scape about a foot high, with sereral lanceolate, clasping bracts. Culyx pink, hairy along the angles. Corolla pale-blue. Root thick and woody, very astringent. Perhaps not a native of this State.

\section{ARMERIA, Willd. THRIET.}

CALYX tubular, bell-shaped, 5-angled, with 5 shallow lobes, plaited. Petals 5, almost distinet. Stamens 5, inserted on the base of the petals. STrues 5, distinct. Fruit indehiscent, invested by the ealyx.-Perennials, with mostly linear radical leaves, and a simple scape appendaged above, with the showy rose-colored flowers in a dense head.

\section{A. vulgaris, Willd. Thrift.}

Leaves linear, flat, obtuse; outer bracts of the involucre ovate, scute, shortez: than the sheathing appendage at their base; scape terete, smooth. 
Rocky places, rare. July, Aug. Root large, woody. Leaves 3 to 4 inches long, and about $1 / 4$ inch. wide, numerous, crowded. Scape about 1 foot high, bearing a singular sheath at top. Flowers in heads, rose-colored, intermixed with scales. Pursh gives this as a native of this State, while Prof. Gray thinks it is not in: diginous in the United States.

\section{ORDER 66. PRIMULACRZR-Primrose Family.}

Herbaceous annual or perennial plants, with regular perfect flowers, the stamens as many as the lobes of the monopetalous (rarely polypetalous) corolla and inserted opposite them on the tube. CAlyx 4 to 5-cleft, persistent. Stamens 4 to 5, rarely 6 to 8. STYLE 1; strgira capitate; ovary 1-celled. CAPSULE 1-celled, with a central placentia. SEEDS numerous.

\section{TrIBE I. PRIMULEEA. The Primrose Tribe.}

Capsule entirely free from the calyx, opening by valves:

\section{PRIMUla, Linn. Primrose.}

Zat. primus, first; on account of the early appearance of the flowers of some species.

Calyx tubular, angled, 5-eleft. Conolla salver-shaped, enlarging above the insertion of the stamens, 5-lobed; LOBES of ten notched or inversely heart-shaped. STAMENS 5 , included. Capsule many-seeded, splitting at the top into 5 valves or 10 teeth.-Lowo perennial herbs, with the veiny leaves in a tuft at the root, and nostly. simple scapes bearing the flowers in an umbel.

\section{OULTIVATED EXOTIC SPECIES.}

\section{P. vulgaris, Huds. Common Primrose.}

Leaves oborate, oblong, toothed, rugose, villous beneath; umbel radical; flower stallis as long as the leaves; corona flat. Native of Europe. A beatiful garden plant, cultivated and highly esteemed for its early flowering, in the numerous varieties there are some with red, pink, white, orange, and purple flowers, and in some instances the umbels are on a scape. The roots and seeds smell of anise seed. April.

2. P. VERIs, Cam. Cowslip.

Leaves toothed, rugose, hairy beneath; umbels many-fíwered; flowers all nodding; corolla concave. Native of Britain. Flowers yellow. The plant smells Btrongly of anise. Its varieties may be increased by raising from the seeds.
3. P. ELATIOR, Jacq.
Oxlip Primrose. Polyanthus.

Leaves toothed, rugose, hairy on each side; umbel many-flowered, with the outer flowers nodding; corolla flat. Native of Britain. This is the Oxlip from which all the varieties of polyanthuses have been grown. The flowers are on a scape from 3 to. 9 inches high, rarying from yellow to red, purple and white. 


\section{DODECATHEON, Linn. American Cowslip.}

Gr. dodelca, twelve, theoi, gods; alluding to its curious flowers which are about 12.

CALrX deeply 5-cleft; the divisions lanceolate, reflexed. Conolla with a very short tube, and rotate, 5-parted limb, with reflexed long and narrow segments. Stamens 5, inserted into the throat of the corolla; FILAMENTs short, monodelphous at the base, with long and linear approximate anthers. Strue exserted. Capsule oblong-ovoid, 5-ralved, many-seeded.-Perennial smooth herbs, with fibrous roots, radical oblong or spatulate leaves, in clusters, and an erect simple scape bearing a terminal umbel of nodding flowers, purple rose-color or sometimes white.

1. D. Media, L. American Cowslip. Mead's Cowstip.

Leaves oblong or oval, obtuse, tapering into a margined petiole, toothed or entire; umbel many-flowered; involucre bracts ovate or lanceolate; anthers acute, much longer than the short filaments.

Rocky places, along the Susquehanna. May. A beautiful smooth plant, with radical clustered leaves, 5 to 10 inches long, by 1 to 2 inches wide, the margin often wavy. Scape 6 to 12 inches high. Corolla white, rose-colored or purple. Anthers $1 / 4$ to $1 / 2$ inch long, yellow, purple at base.

2. D. integrifolium, Michx. Divarf American Cowslip. Ieaves ovate or lanceolate, subspatulate, obtuse, potiolate; involucre bracts lanceolate or linear, acute; umbel ferv-flowered; fower's erect.

Mountains, rare. June. A much smaller plant than the preeending. Scape 4 to 8 inches high, thick. Leaves 3 to 5 inches long, on naked petioles. Flowers pale-blue, somewhat crowded, on short pedicels. This may prove to be only a var riety of the preceding species.

\section{TRIENTALIS, Linn. STARFLower.}

Lat. triens, the third part of a foot; alluding to the size of the plant.

Calux mostly 7-parted. Corolia mostly 7-parted, spreading, flat without any tube. Stamens 6 to 8 ; FILAMeNTs slender, united into a ring at base. STYLE filiform. CAPsule globose. few-seeded.-Low and smooth perennials, with simple orect stems, a whorl of veiny leaves at the summit, and a fero white flowers on solitary peduneles.

\section{T. Americana, Pursh. Chickweed Wintergreen.}

Leavcs narrow-lancelate, serrulate, acuminate; pctals finely pointed.

Low woods, rare. May. Stem 6 inches high. Leaves 2 to 3 inehes long, 6 or 7 in a terminal whorl, with a fow minute alternate ones below. Flowers white on terminal filiform peduncles.

\section{LYSIMACHIA, Linn. LoosestrifE.}

Gr. lusis, a release, and mache, strife.

CAlyx 5-parted. Conolla with a very short tube: 
limb 5-parted. STAMEns 5; FILAMENTS often united into a ring at base. CAPsure globose, 5 to 10 -valved, few-manyseeded. - Perennials with entire opposite or verticellate leaves, and axillary or rucemed fluwers with yellow corollas.

\section{L. stricta, Ait. Upright Loosestrife.}

Stem erect, smooth; leaves opposite, or rarely aiternate, lanccolate, acute at each end, punctate; raceme terminal, very long, loose; pedicels long, slender.

Low grounds, common. July, Aug. Stem 1 to 2 fuet high, often with bulblets in the axils, at length branched, very leafy. Flowers yellow, on slender pedi cels in a whorled raceme, 5 to 10 inches long, which is leafy at the base.

2. L. QUADRIFolia, I. Whorled Loosestrife.

Somewhat hairy; stem simple; leaves whoried in founs or fives (rarely 3 s or 6s), orate-lanceolate, acuminate, punctate; flowers on capillary peduncles from the axils of the leaves.

Moist or sandy soils, common. June, July. Stem 12 to 15 inches high, with many whorls of 4 to 5 leaves, each bearing a pecluncle about 1 inch long in its axil, with a single flower. Corollo yellow, with purple lines. Anthers puxple.

\section{L. crliata, L. Hairy-stalked Loosestrife.}

Zeaves lanceolate-ovate, tapering to an acute point, rounded or keart-shaped at the base, on long petioles; petioles ciliate; pedunctes mostiy in pairs, 1-flowered; fower's arooping; eorolla longer than the calyx.

Banks of stresms and thickets; common. July. Fiem 2 to 3 fcet high, square, sparingly braneied. Leaves 3 to 6 inches long, on hairy petioles $1 / 2$ to 2 inches long, somewhat cordate at base, the upper ones apparintly in fours. Flowers Jarge, yellow, axillary. Stamens with 5 alternate teeth or rudimentary filaments.

4. I. Lanceolata, Walt. Lance-leaved Loosestrife.

Leaves lanceolate, acute, narrowed at the base into a short and margined petiole fringed with hairs, or the upper nearly sessile and linenr, the lovest oblong and spatulate; peduncles axillary, mostly in pairs, 1 flowered; corrollu longer than the calyx.

Var. 1. hybrida, has the leaves varying from lanceolate to nearly oblong.

Var. 2. heterophyla, with the leaves narrow, linear and acute at each end.

Swamps and moist grounds. July. Siem 12 to 20 iaches high, som tincs branehed at base. Leaves 2 inches or more long, varying from $1 / 2$ to 1 inch wide. Flowers Jellow regembling those of $\mathrm{L}$. ciliata.

\section{Tribr 2. ANAGALLIDEAL-The Pimpernel Tribe.}

Capsule frce from the calyx, opening all round by a transverse line, the top falling off like a lid.

\section{ANAGAlis, Tourn. Pimpernel.}

Gr. anagalao, to laugh; on account of its supposed exhilerating virtues.

CaLYX 5-parted. Corolla wheel-shaped, with scarcely any tube, 5-parted, longer than the calyx. Stramens 5; FILAMENTS hairy. CAYSULE globose, circumscissile, the top falling off like a lid, many-seeded.-Small spreading procumbent herbs, with opposite or whorled entireleaves, and solitary flowers on axillary peduncles. 
1. A. arvensis, L. Common Pimpernel. Poor Man's Weather-glass.

Leaves ovate, sessile, shorter than the peduncles; sepals linear-Ianceolate, about is long as the petals; petals obovate, obtuse, fringed with minute teeth, longer: than the stamens.

Waste sandy fields, introduced from Europe. June-Aug. Stem 6 to 20 inches long, with elongated branches, or simple. Leaves $1 / 2$ inch long. Frlowers opposite, mall but beautiful, with scarlet, sometimes purple, blue or white petals, quickly closing at the approach of rainy weather; whence the common name of "Poor" Mun's Weather-glass."

\section{Tribe 3. SAMOLEA.-The Water Pimpernel Tribe.}

Capsule half adherent to the calyx.

\section{SAMOLUS, Linn. WATER-PIMPERNEL.}

From Samos, the island where the original species was first found,

Calyx 5-cleft, the tube adherent to the base of the ovary. Coroula somerwhat bell-shaped, 5-cleft, with 5 sterile filaments in the sinuses. Stamens 5, included, on the tube of the corolla. Capsule 5-valved at the summit, many-seeded.- Smooth herbs, with alternate entire leaves, and small white flowers in racemes.

\section{S. Valerandi, L. Brooteweed.}

Siem erect, subsimple; leaves ovate, obtuse, radical ones on long petioles, upper sessile; racemes elongated, loose, many-flowered; pedicels with a small bract near the middle.

Wet gravelly places. July-Sept. Stem 8 to 12 inches high, smooth. Leaies 1 inch long, broadly-lancoolate. Flowers small, white.

\section{Trine 4. HOTTONIE \#.-The Featherfoil Tribe.}

Capsule opening by valves; seeds fixed by the base, aratropous.

\section{HotTONIA, Linn. Featherforl.}

Calyx 5-parted, the divisions linear. Corolla salverform, with a short tube; the limb 5-parted. STAmens 5, included. CAPSUle 5-valred, many-seeded. SEeds attached by their base.-Aquatic perennials, with pectinate immersed leaves, and white fowers whorled at the joints in a some what interrupted raceme torne on hollow nearly leafiess peduncles.

1. H. Inflata, Ell. Inflated Featherfoil.

Leaves dissected into thread-like divisions, seattered on the foating stems, or "whorled or crowded at the base of the cluster of peduncles; peduncles inflated between the joints; flowers verticellate, mostly in fours, on short pedicels.

Stagnent water, ditches and pools. Jung, July. Stem immersed, thick, round, 
spcngy. Peduncles 6 to 10 together, arising in a sort of umbel from the top of the siem, 8 to 10 inches long. F'lwers small, white in numerous verticels.

\section{ORDER 67. LENTIBULACER, - Bladderwort Family.}

Small aquatic herbs, with a 2-lipped calyx, and a 2-lipped personate corolla, 2 sta. mens with 1-celled anthers, and a 1-celled ovary with a free central placentre, bearing anatropous seeds.-Corolla deoply 2-lipped, spurred at the base in front; the palute usually bearded. OFARY free. Strue very short or none. Stigma 1 to 2-lipped, the lowor lip longer and revolute over the approximate anthers. CAP3ULs of bursting irregularly. SCAPES 1-few-flowered.

\section{UTRICULARIA, Linn. BLADDERWORT.}

Name from utriculus, a little bladder.

Calyx 2-parted, subequal, the lips entire or nearly so. Corolis personate, the palate on the lower lip projecting, and often closing the throat. Stamens 2. Stigma bilebiate. Capsule globular, 1-celled.-Immersed aquatic herbs, with axillary dissected, leaves. mostly bearing little bladdcrs, which are filled with air and fioat the plant at the time of flowering, and crect scapes bearing yeillow or purplish flowers.

\section{U. inflata, Walt. Inflated Bladderwort.}

Tpar leaves in a whorl, floating; leaf-stalks inflated, each into an oblong bladder; lower leaves capillaceous, dissected; seape 4 to 10 -flowered; spur conical, 3/5 os long as the corolla; style distinct.

Ponds. Aug. Stem very long, branching, suspended in the water by a gingle inregular whorl of 5 or 6 floating, inflated leaves which are oblong, cleft, and pinnatifid at the ead. Flower's large, yellow, on a seape 8 inehes long, peduncled, with sheathing bracts.

2. U. Punpurea, Walt. Purple Bladderwort.

Siem long, floating, branched; leaves whorled along the submersed stoms; potioled, decompound, capillary, bearing many bladders; scape assurgent, 2 to 4 fiowered; spur appressed to the lower lip of the corolla and about $1 / 4$ as long.

Ponds. Aug., Sept. Stem 1 to 3 feet long. Leaves $11 / 2$ inches long. Flowoers riolet-purple, with a greenish spur on axillary, solitary scapes 2 to 4 inches long.

3. U. vulgaris, L. Common Bladderwort.

Foating; stem immersed, 2-forked; leaves many-parted, crowded on the long atems, capillary, bearing many bladders; fowers 5 to 12, on scapes; upper lip of the closed corrolla, scarcely longer than the prominent palate; spur conicul incurved.

Pools and ponds of deep water; common. July, Aug. Per. Root mueh branched. Immersed stems 1 to 3 feet long. Leaves very numerous 1 inch long. Flotcers $1 / 2$ to $3 / 4$ inch broad, yellow, raccmed on scapes 6 to 12 inches long, rising ont of the water.

4. U. Connutr, Michx. Horned Bladderwort.

Sem erect, rigid, 2 to 7 -filowered; pedicels not longer than the calyx; rypper lip of the corolla obovate, entire; lower lip large and helmet-shaped; spur aw l-sbajed, turned downwards.

Pow bogs and sandy swamps. June-4ug. Negpe 8 to:12 inrbes bigh, leaden, 
but furnished with a few small, ristant, orate, pale seales, and bearing at the top 2 to 3 large, deep-yellow" crow ded flowers.

\section{Order 68. OROBAWOEACES.-Broom-rape Fumily.}

Fierls destitute of green fuliage, growing parasitically upon the rosts of othin plunts, with didynumous flowers, a 1-celled ovary with 2 or 4 parictal placentie and many-seeded capsules. Calzs persistent, 4 to 5-toothed or parted. Corolia tubular, more or less 2-lipped, ringent, persistent. . Stamens 4, more or less dydariamous, inserted on the tube of the corolla; Aximers 2-celled. Orany free, oroid, pointed with a long style which is curvicd at the apox; sirgus large.

\section{EPIPHEGUS, Nutt. BEEct-DRors.}

or. epi, upon, pliegus the beech; because it grows on the roots of that tree.

Frewers monoeiously-polygamous, racemose or spiked, seattered on the branches. Calyx 5-toothed. STIGMa capitate, somewhat 2-lobed. CAPSULE 2-valved at the apex, with 2 approsima.e placentre on each. - Low perennials, witit lurid yeilowish or brownish scales instead of leaves, and simple Uranches floriforous their whole length, the upper flowers sterile, with a long tubulur corolla and long filaments and style; the lower fertile, with a very short corolla, which seldom opens, but is forced off from the base by the growth of the copsule.

1. E. Virginiana. Burt. Cancer-root.

Whole plant purp!ish-brown; stem branched, leafiess; finvers remote, sltëriste. Common under the shade of Beech-trees, parasitic on their rosts, 6 to 12 inches high, much branched, slender, with scattered incouspicaous. scales. Curollu of the upper flowers whitish and purple, $1 / 2$ inch long, curved, 1-toothed, the upper $1 \mathrm{ip}$ broadest, notched at the apes, urched. 'Sects yery numerous, shining.

\section{CONOPHOLIS, Wallr. SQuaw-ROot.}

Gr. konos, a fir-cone, and photis, a scale; the lower seales corering each other sini. lar to tinose of the fir-cone.

Fuowers in a thick scaly spike, perfect with 2-bractlets at the base of the irregular calyx. Corolua tubular, swelled at the base, 2-lipped; the upper lip arched, notehed at the summit, the lower short, 3-parted, spreading. STAmexs protruded. Strama depressed. Capsule with 4 placentæ, approximate in pairs on the middle of each valve.

\section{C. Americana, Wallroth. American Broomrape.}

Stem simple, covered with oval-lanceolate imbricated scales; spitie smooth, terminal ; corolla recurved. (Orobanche Americana, L.)

Oat woods, growing in elusters among fallen leaves. May, June. A singular plant chestnut colored or yellowish throughout, 4 to 6 inches high, very emovits. 


\section{APHYLLON, Mitchell. Naked Broomrape.}

Gr. a, privative, and phullon foliage, alluding to the naked stalks.

FLowers perfect, solitary on long naked scapes, without bractlets. Calyx 5-cleft, regular. Corolla-tube long, curved, with a spreading border, somewhat 2-lipped; the upper lip deeply 2-cleft, the lobes similar to the 3 of the Iower lip. Stamens included, Stigma broadly 2-lipped. CAPSule with 4 equidistant placentæ, 2 borne on each valve half way between the midrib and the margin.

1. A. uniflona, Torr. \& Gr. One-flowered Cancer-root.

Stein subterranean or nearly so, very short, scaly, often branched, each branch: sending up 1 to 3 slender 1-flowered scapes; calyx-lobes lance-awl-shaped; corollatobes obovate.

Woods. April, May. Hairy, brownish-yellow: Crrolla 1 inch long, tinged and: edged with purple, with 2 yellow bearded folds in the throat. (Orobanche uniHora, L.)

\section{Order 69. BIGNONIAC焉,-Bignonia Family.}

Woody or sometimes herbaceous plants, with monspetalous didynamous flowers, $a$. mostly 2-celled ovary and the numerous anatropous seeds with a large flat embryo and no albumen.-CaLYX 2-lipped, 5-cleft, or entire. Corolla tubular or bell-shaped, 5-lobed, somewhat irregular and 2-lipped. STamens 5, inserted on the corolla, 1 or s sterile. OTARY free, bearing a long style and a 2-lipped stigma.

\section{Sub-order i. BIGNONIE E. True Bignonia. Family。}

Fruit a 2-valved pod; seeds flai winged. Trees or woody vines.

\section{TECOMA, Juss. Trumpet-Flower.}

Abridged from the Mexican name.

CAryx bell-shaped, 6-toothed. Conoura funnel-form, 5alobed, a little irregular. Stamens 4 , didyna mous. CapSULE long and narrow, 2-celled, 2-valved, the partition contrary to the valves. SEEDS in a single row in each cell. Trees or shrubs, often climbing, with opposite, digitate or unequally pinnate leaves and showy flowers.

\section{T. radicans, Juss. Trumpet Crceper.}

Climbing by radicating tendrils; leaves unequally pinnate; leafets 5 to 11 , ovate, pointed, toothed; flower's in terminal corymbs; corolba-tube thrice longer than the calyx; stamens included.

A splendid climber in woods and thickets, along rivers. June-Aug. Stem 20 to 80 feet in length, ascending trees. Leaves 10 to 15 inches long; leafleis 2 to $3 \mathrm{bz}$. 1 to 2 inches. Flowers $1 \frac{1}{8}$ inch long, orange and scarlet showy. 
2. T. Grandiflora, Delaun. Chinese Trumpet-floweẍ.

Climbing, smooth; leceves unequally pinnate; leaflets 3 to 5 pairs, orate-acum:nate, dentate-serrate; panicle terminal; pedicels nodding, biglandular; corollatwhescarcely lon rer than the 5-cleft calyx. Native of China and Japan. Fiverers of a rich scarlet, shorter and brouder than in T. radicans.

\section{CATALPA, Scop., Walt. Inda n BeAN.}

The aboriginal nams.

CAlyx deeply 2-lipped. Corolua bell-shaped, swellina; the irregular border 5-lobed, spreading, wavy. Starexs 5, but mostly only 2 of them -anther-bearing. POD rery longs and slender, nearly cylindrical, 2-celled, the partitions contrary to the valves. SEEDs in a single row in each celi, broadly winged on each side, the wings cut into a fringe.-Trees with simple opposite or ternctie-verticellute petivlatelecurs, and terminal panicles of white flowers.

\section{C. Bignoniordes, Walt. Cutalpw:}

Leaves heart-shaped, membranaceous, pointed, downy bczestri ; fowers in open ormpound panieles; calyx-lips mucronats.

Xative of the Soath, but naturilized along the Schuylkill nenr Philatelritiat. Jine. A well known ornamental tree growing from $\mathbf{1 5}$ to 30 ftet high, with is

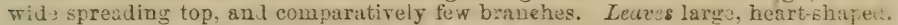
Fluw $r_{3}$ white, slightly tinged with violet and dotted with purphe and yellow in tho throat. Pol remaining on the tree until the following spring, of wen 1 foot long.

Sub-oider it. SESAMEA. The Sesamum Family,

Pul or fieshy and wooly fruit fitsely 1 to 5 celicd; seeils wingitess.

\section{MARTynia, Linn. Uniconn Plany.}

In honor of Prof. John Murtyn of Cambrilge, Eng. $17 \mathrm{CJ}$.

Caryx 5-cleft. Cororra gibbous, bell-shaperl, 5-1úbel, irregular. Stamens 5, one aterile, 4 didynamous. Capsum fleshy, and with the inner part soon becomes woody, terminated by a long beak, which at length splits into 2 hooked horns, the capsule opening at the apex between the beaks, inperfectly 5-celled. SeEDs several, wingless, with a thich and spongy roughened coat. - Low branehing annuals, clamsmy pubescent, exhaling a heavy odor, with opposier, petiolate, sibcordate roundish leaves, and large racemed flouters.

\section{M. proboscidea, Glox: Crowspur.}

Leaies heart-shaped, oblique, or undulate, the unper aiternate; fiowers on lonis, axillary peduncles; bealis much longer than the capsule.

Banks of the Susquehanna, near IFarrisburs. Ju'y-Sept. Stem 1 to 2 feet hif. Guiolla large, ale, dull-yeliow, the limb nearly as hroad as the leares, tinged ob L2* 
apotted with yellow or purple. Stamens bright yellow, exserted. Woody endocary orested on one side, with 2 long claws.

\section{ORDER 70. ACANTHACE础-Acanthus Family.}

Chiefly herbs, with opposite simple leaves, didynamous or diandrous stamens, in. seried on the tube of the mors or less 2-lipped corolla. Frorr an 8-celled and fewseeded eapsule. Calrx 5-cleft. Corolia 5-lobed, subequal. STYLE thread-form. STIGMa simple or 2-cleft. CAPSULE loculicidal; sæiDS anatropous, supported by booked projections of the placentre.

\section{DIANTHERA: Gronov.}

Gr. dis, double, and anthera, anther; the separated cells giving the sppearance of 2 anthers on each filament.

Calyx 5-parted. Corolla deeply 2-lipped; the upper Iip crect, notched; the lower spreading, 3-parted. STAMENs 2; Anthers 2-celled, the cells placed one lower down than. the other. CAPSULE obovate, compressed, attenuated at tho base, 4 to 5-seeded.-Perennial herbs, growing in water, with narrow and encire leaves, and purplish flowers in axil lary peduncled spitces or heads.

\section{D. Americana, L. Water Willow.}

Leaver linear-lanceolate, elongatod; spikes oblong, dense, long-pedunclod. (Justicia pedunculosa, L.)

Borders of streams and ponds; common.- July, Aug. Root creeping. Stem 3 feet high, simple or sparingly branched above. Leaves nearly 6 inches long; smoth, wary, contracted to a short petiole. F'lowers palo-purple.

\section{DIPTERICANTHUS, Nees. (RUEllia, partly, L.)}

As: dipteros, 2-winged, and akanthos, the Acanthus; on account of the 2-leared peduncles.

Caryx deeply 5-cleft: Conolla funnel-form; the spreading limb nearly regularly and equally 5-cleft. Stamiens 4, included, didynamous; ANTHERS arrow-shaped; CELLS parallel, and nearly equal. CAPSULe somewhat compressed, and stalked at the base, 8 to 12 -seeded, SEEDs with a mucilaginous coating.-Perennnial herbs, with ovate or elliptical nearly entire leaves, leáfy bracts, and chistered blue or purple flower.

1. D. Szrepens; Nees... Two-winged Acanthus.

Somew hat smooth; lekves ovate or ovate-oblong, entire; peduncles axillary, very ahort; calyx-lobes lanceolate, acute, ciliate, spreading, shorter than the tube of the corolla. (Ruellia strepens, Is.)

Shady woods. July. Stem 1 to 2 feet high, often simple, clothed with whitobriatly hairs. Leaves $1 \frac{1}{2}$ to $21 / 2$ izehes long $1 / 3$ to $1 / 2$ as wide. Corolla 2 inches lon 6 ; bright blueiab-purple, 1 to $1 \frac{1}{2}$ incis broad, with a long and siendor tubo. 


\section{THUNBERGIA, Linn.}

In honor of Charbes Peter Thunberg, Professor of Botany at the Uuiversity of Upsal.

Calyx double, 5-cleft, with 2 bracts. Corolla bellshaped, with an inflated tube, and 5-lobed limb; lobes equal. Stigma 2-lobed. Capsule globose, beaked, 2-celled.Mostly climbing herbs, with showy axillary fiowers:

1. T. Alata, L. Black-eyed Susan.

Stem twining; loaves triangularly-cordate, sinuately toothed, 5 -nerved; petio'ss winged. July. Native of the East Indies. Flowers 1 to $1 \frac{1}{2}$ inch broad, pale buf or orange, with a deep-purple throat.

\section{ORDER 71. SOROPHULARIACER,-Figwort Family.}

Ohïefly herbs, with didynamous, diandrous, or very rarely 5 stamens inserted or whe tube of the 2-lipped or more or less irregular corolla. CALYX of 5 oro or lees united sepals, persistent. OrARY 2-celled, with a single style. Frurr a 2-colled and : usually many-soeded capsule, with the placentre in the axis.

\section{Seb-order r. ANTIRRHFNIDE I. Tue Snapdragon} FAMILY.

Typer lip of the corolle eovering this lobes of the lower in the bud. Cispsule usually: septicidal.

\section{VERBASCUM, Linn. Mullern.}

The ancient Latin name, altered from Barbascum.

Calyx 5-parted. Corolla 5-lobed, open or concave, ro. tate, the lobes nearly equal rounded. STramens 5, perfect, . often hairy, the anterior longer. STYLE flattened at the apex. Capsule ovoid or globose, many-seeded.-Tall biennial. herbs, usually woolly, with alternate leaves, and ephemeral flowers in terminal spites or racemes.

\section{V. Thapsus, L. Common Mullein.}

Donsely woolly throughout; stem simple tall and stout; leaves ovato-oblong, ds ourrent; flowers in a prolonged dense cylindrical spike; lower stamens usually beardless.

Fields and roadsides; very common. Introduced from Europe. June. Stem 3 to: 6 feet high, angular, winged. Leaves 6 to 12 inches long. Flowers yellow in a long dense eylindrie spike.

2. V. Blattaria, L. Moth Mullein.

Green and nearly smooth; leaves obiong, elasping, crenate-serrate; the radioal anes petioled, oblong, doubly serrate, sometimes lyre-shaped; raceme long and: Hoose; filaments all bearded.

Rosdsides, common; : Introduced from Europe. June, Jüly. Stem 2 feet high, angled. Lines acute, serrate or toothed. Flowars yellow or white, with a gur: 
plish tinge, on pedicols.nearly an inch long. Stamens unequal, parplish; the filaments all hairy.

\section{V. Lychnitrs, L. White Mullein.}

Clothed with a thin powdery woolliness; leaves oblong, wedgo-form, greenish above; flowers in a pyramidal panicle; filainents white-woolly.

Old fields, roadsides, rare. Introduced from Errope. July, Aug. Stem 2 to 5 feet high, angular. Flowers pale-yellow. Calyx small, with lanec-8ubulate segments.

\section{IINARIA, Tourn... TCAD-FLAX.}

Named from Linum, the flax, which the leaves of some species rescmble.

CalyX 5-parted. Corolia personate, with the prominent palate nearly closing the throat, spurred at the base on the lower side. Stamens 4 , didynamous. Capsule ovoid or globose, opening - below the summit by 1 or 2 pores or chinks, the orifice split.into teeth. SEEDS numerous.-Hei?s with the lower leaves opposite or whorled, the upper alternate, and solitary, axillary flowers often forming terminal lenfy racemes.

1. I. canadensis, Spreng. Wild Toad-flax.

Smcoth; stem slender, erect, mostly simple, with scattered linear leares; funocr zacemed, on short pediecls; spur thread-form, curved:

Low grounds. May-Aug. Annual. Stem about 1 foot high, slender, often throwing out suckers at the base, which bear oblong; crowded, mostly opjosite or whorled leaves. Flowers blue, in a slender raceme, variable in size.

2. L. vulgaris, Mill. Common Toad-flax.

Smooth and glatucous; stem erect; leares alternate, crowded, lincar-iancealste; flowers in a dense raceme, on pclicels shorter than the bracts; spur awl-shaped.

Roadsides and waste places; common. June-Oct I'er. Stem 1 to 2 feet his h, metimes somewhat branched. Flowers large and numerous, pale yellow, with a deep orange palate, hairy in the throat id a dense bracteate ractme, rarely with's to 5 spure.

3. L. Elatine, Mill. Sharp-poinied Toacl-fax.

IIairy; branehed from the base; leaves alternate, orate-halbert-form petioled; fowers axillary, on slender peduncles; spur slender.

Fields and tanks, sparingly introduced. July. Ann. Stem procumbent, 1 to 3 feat bigh, with spreading branches. Flowers yellow and purplikh, emall.

\section{ANTIRRHINUM, Linn. SNAP-DRAGON.}

Mr. anit; lke, rin, a nowe; from ithe resemblance of the flowers to the snout of soust auimale.

Calyx 5-sepalled. Coroula gibbous (not spurred) at base, the upper lip 2-parted, lower 3-parted, closed by the prominent palate. CAPSULE without valres, opening by 3 pores,-European herbs, with the lower lcures opposite, the usper alternute, and show'y flowers in lenfy terminal racemes. 


\section{A. MaJus, L. Great Siap-dragon.}

Leaves lanceolate, opposite; flowers in racemes; sepals glandular-hairy, smooth, laneeolate, acute. A showy garden flower, native of England. Stem 1 to 2 feet high. F lowers large, rose-colored, the lower lip white and the mouth yellow, with a gibbous prominence at the base beneath. There are rumerous raricties with scarlet, searlet and white, and white flowers. June, July.

\section{SCROPHULARIA, Tourn. Figtort.}

So called from its supposed virtues in curing scrophula.

Calyx deeply 5-eleft. Corolia subglobose; limb contracted, with 2 short lips; upper lip 2-lobed, frequently witl. a scale or abortive stamen at the summit of the tube. CAP. вULE 2-celled, 2-valved, many-seeded.-Rank herbs, wills mostly opposite, leaves, and small greenish-purple or lurid: flowers, in loose cymes forming a terminal panicle.

\section{S. NODosa, L. Cómmon Figwort.}

Smooth, tall and branching; Stem 4-sided; leares ovate, oblong or the uppere lanceolate, acute, cut-serrate, rounded or heart-shaped at tho base. (S. lanceolata, Pursh, S. nodosa, Benth, in DC.)

Woods and hedges; common. June-Aug. Per. Stem 3 to 5 fest high. Leaves 3 to 7 inches long, thin, often long-acumizate. Flowers oroid $1 / 4$ to $1 / 2$ inch long purple-brown tinged with green.

\section{COLLINSIA, Nutt.}

In honor of $Z$. Collins of Philadelphia, an accurate botanist.

Calyx deeply 5-cleft. Corolla bilabiate, the orifice olosed; upper lip 2-cleft; lower 3-cleft, its middle lobe keeled. and sac-like, infolding the 4 declined stamens and style. Capsule globose, many-seeded.- Slender branching an. nuals, wilh opposite leaves, and handsume flowers in um. bel-like clusters, appearing whorled in the axils of the $u_{1}$ per leaves.

\section{C. Brcosor, Benth. Tiwo-cotored Collinsia:}

Siem upright, somewhat branched; leaves orate-lanceolate, remotely serrate or. nearly entire, sessile with a somewhat heart-shaped base; flowers in axillary racomes. A pretty annual plant from the Rocky Mountains; common in cultivation. Stem 4 to 8 inches high, with opposite leaves and branches. Leaves 1 to 2 inches long, $1 / 4$ to $3 / 4$. inch wide, broadest at the base. Flowers showy, $1 / 2$ to $3 / \frac{1}{4}$ inch long. Corolla white, the lower lip a beatiful violet-purple.

\section{CHELONE, Tourn. SNake-mead.}

Gr. ketome, a tortoise; the corolia much resembling in shape the head of that animal.

CALYX 5-sepaled, imbricated. CoRoLLA inflated-tubular, 
with the mouth a little open; upper lip broad, concave, keeled in the middle, notched at the apex; the lower lip spreading 3-cleft, bearded in the throat. STAMENs 4, didynamous, with a 5 th shorter sterile filament; ANTHERs heartshaped, woolly. Capsule 2-celled, 2-valved, many-seeded; SEEDS wing-margined.-Smooth perennials, with upright branching stems, opposile serrate leaves, and lamge white or purplish flowers, sessile, in spikes or clusters, and closely imbricated with roundish bracts and bractlets.

1. C. GLABRA, L. Turtle-head. Balmony Shell-flowcr.

Ikaves very short-petioled, lanceolate, pointed; flowers in dense spikes.

Wet places; common. Aug.-Oct. Stem 2 to 3 foet high, simple. Leaves thick, and somewhat coriaceous, virying from narrow to tery broad-lanceolate. Flouer's large, white or redalish.

\section{PENTSTELION, Mitchell.}

Gr. pente, five, and sieman, a stamon; in allusion to the 5th large abortive stamer.

G A.tyX 5-parted. Corolda tubular, more or less inflated, mostly 2-lipped; the upper lip 2-lobed, and the lower 3.cleft, STAMENS 4, declined at the base, ascending above; and a fifth sterile filament, mostly as long as the others, either naked or bearded. CAPSule ovoid, 2-celled, 2-valved.Perennial herbs, branches at the base, with opposite leaves, and showy flowers in thyrsoid panicles.

\section{1: P. pubescens, Soland: Beard-tongue.}

Somewhat pubescent; radical leaves petioled, orate or oblong; stem leaves lancoolate from a clasping base, serrate, sometimes entire; flowers looscly panicled; strile filament bearded from the top to below the middle.

Irills aud viver banks; common. Juno-Sept. Stem 12 to 15 inches high, round, smooth below, supperting a loese cppositely branched panicle of bluish-purpio flowers. Corolla 1 inch long, gradually enlarged upwards, flattened and 1-ridged on the upper side. Sometimas quite smooth, whon it is P.latigatus, Solund, sc.

\section{PAULONIA, Sieboldo.}

Calyx deeply 5-cleft, fleshy. Corolla-Tube long, deelinate, enlarged above, limb oblique, with rounded segments. Stamens 4, arehed downwards. CApsule woody, acumdnate; valves septiferous in the middle. SEEDs numerous. A magnificent flowering tree, native of Japan, wilh large leaves, and large terminal panicles of numerous purplish finwers.

\section{P. impertaurs, Siebold. Pautonia.}

Leaves broad-cordate-ovate, entire or somewhat 3-lobed, villous-canescent on both siles, smoothish above when full grown. A splendid tree with tho sabit of 
Catalpa, reently introduced in cultiration in this eountry! Branches crootsed, nearly horizontal. Leaves 7 to 20 , by 15 or 20 inches, opposite, on petioles. Punicles large, terminal, many-flowered. Corolla 2 inches lonot, pale-violet, striped within, somowhat fragrant. (Bignonia tomentosa, Thunb.)

\section{DIGITALIS, Linn. Foxglave.}

Let. digitabulum, a thimble; from the form of the flowers.

- Calyx 5-parted. Corolla bell-shaped, ventricose, in 5 subequal lobes. CAPSULE ovate, 2-celled, 2 -valved, with a double dissepiment.-European and Asiatic herbs or shrubs, rulivated for oriament, wiih large flowers in showy ra. cemes.

\section{D. purpurea, L. Purple Foxglove.}

ueaves oblong, rugose, crenate; calyx segments ovate-oblong; corotia obtuse, upper lip entirs; patuncles as long as the calyx. Native of Europe. A well known biennial showy border flower, 2 to 3 fect high, with large, rough, downy leares. Flowers numerous, in a lon $_{i f}$, simple spike, large crimson or purplish, often white, with beautiful spots within. Medicinal.

\section{D. Grandiflora, Allioni. Great yellow Foxglove.}

Lcaves ovate or oblong-lanceolate, veiny, serrulate, amplexicaul; raceme tom.n. tase, lax; calax segments lanceolate, acute ; corolla rentricose-bell-shaped, segm:nto bronder than long, lowest twice as broad as the lateral. Native of Europe. A perounial plant 2 to 3 feet high. Flowers $11 / 2$ inch long, yellow, varying to brownish onorange.

\section{MiMUluU, Linn. Monkey·rlowir.}

- Gr. mimo, an ape, on account of the gaping corolla.

Calyx prismatic, 5-angled, 5-toothed, the upper tooth largest. Conolis : tubular; the upper lip erect or reflesedspreading, 2-lobed; the loucr spreading, 3-lobed. Stamens 4. Stigma 2-lipped. Capsule 2-celled, many-seeded.Prostrate or erect herbs, with square stems, opposile leaves, and mostly handsome fluwers on solitary axillary pe. duncles.

\section{M. Ringens, L. Purple Monkey-flower.}

Froct, smooth; leaves oblong or lanceolate, pointed, serrate, clasping by a heartolsaped base; peduncles larger than the fiowers. Per.

'Wot places; common. July, Aug. Stem 1 to 3 foet high, somewhat branehed. $F$ lorcers pale-purple, ringent. Culys-teeth acuminate frem a broud base.

\section{M. Alatus, Ait. Wing-stem Monkey-flower.}

Stem somewhat winged at the angles above; leaves oblong-ovate, tapering into a petiole; poduncles shorter than the calyx; calyw-ecth very short, 'abruntly pointod. Per.

Low grounds, rare. Aug. Stem 2 feet wigh with winged angles, somewhat beanchod. Flowers palo-blue, ringent. 


\section{HERPESTIS, Gært.}

Gr. herpestes, a creeper; from the prostrate habit of the plants.

Calyx 5-parted, unequal. Corolia bilaliate; upper lip notched or 2-lobed; the lower 3-lobed. Stamens 4 , didynamous. STYLE concave, dilated or 2-lobed at the apex. SEEDS small, numerous.-Prostrate or creeping herbs, with opposite leuves and inconspicuous solitary or subracemose flowers.

1. H. Monnieria, Humboldt, Wedge-leaved Herpestes.

Smooth, fleshy, prostrate; leaves wedge-obovate, entire or obscurely crenate near the summit; pedicels as long as the leaves, with 2 braeteoles near the calyz; calys segments ovate. Per.

Inundated banks. Aug. Leaves opposite, thick, somewhat clasping, varirble in gize and form. Flowers very small, pale purple, on peduncles about as long as the leares.

2. H. micrantha, Pursh.

Smooth, prostrate; leaves oval, entire, sessile or clasping, obscurely many-reineä; padicels ebracteate, nearly as long as the leaves; corollo scarcely longer than the orlyx.

Border of pools and rivers. Aug. A minute weed, 2 to 4 inches in length. Leaves about $1 / 4$ inch long, 5 to 7 -reined. Flowers very small, blue.

\section{GRATIOLA, Linn. Hedge-Hysur.}

Name from gratia, grace or favor; on account of its supposed excellent medicinal properties.

CALYX 5-parted; the divisions narrow and nearly equal. Conolla tubular subbilabiate; upper lip entire or 2-cleft, the lower 3-cleft. Stamens 4, 2 sterile or wanting. Style dilated or 2-lipped at the apex. CAPSUle orate, 4-valved, many-seeded.-Low mostly branched and diffuse herbs, with opposite sessile leaves, and axillary 1-flowered peduncles, usually with 2 bractlets at the base of the calyx.

\section{G. Virginiana, L. Common Hedge-Hysup.}

Smooth or nearly so; leaves lanceolate,-slightly serrate, narrowed at the base; peduncles longer than the leaves; calyx segments linear-lanceolate, equal; stcrile flaments nearly wanting. Anu,

Wet places; common. July, Aug. Plant 4 to 6 inches high, branched at base. Leaves 1 to 2 inches long, and $1 / 2$ as widn, sessile. Corolla whitish, the tubo palo yellow, often tinged with purple, searcely $3 / 2$ inch long. Caly $x$ with 2 linear-lance olate bracts, which are rather longer than the sepals.

2. G. MEGALOCARPA, Ell. Luarge-pointed IIectge-Hysup.

Leaves lanceolate, serrate, pubescent; peduncles opposite, longer than the leaves; ealyx segments linear, as long as the globose capsule. (G. acuminata of Pursh.) Per.

Ditches and pools. July, Aug. Fkwers pale-yellow, large. Caprule larger than In any other spceies. 


\section{ILYSANTHES, Raf. (Lindernia, Muhl.)}

Gr. ilus, mud, anthos, flower; alluding to their place of growth.

CALYX 5-parted, nearly equal. Upper lip of the corolla short, erect, 2-lobed, the lower larger and spreading, 3-cleft. Stamens 2, fertile and 2 sterile filaments forked, one of the divisions glandular, the other smooth, acute, or rarely with half an anther. Strue 2-lipped at the apex. Capsule ovate ór oblong, many-seeded. - Small smooth herbs, with opposite leaves and small axillary flowers, or the upper racemed.

\section{I. gratioloides, Benth. False Pimpernel.}

In noch branched, diffusely spreading; leaves orate, rounded, or oblong, or the lower obovate, slightly toothed or entire, mostly obtuse, the upper partly closping; capsule ovoid-oblong, a little longer than the calyx. Ann. (Lindern ia dilatata, and L. attenuata of Muhl.)

Low grounds, and along rivulets; common; flowering all summer. Leaves variable in size, $1 / 2$ to $3 / 4$ inch long. Curolla much exserted, nearly $1 / 2$ incl long, bluish-white,

\section{HEMIANTHUS, Nutt.}

Mr. hemi, half, anthos, flower; alluding to the uneqally divided coro!la.

Calyx 4-toothed, equal. Cororria 2-lipped; the upper lip very short, entire; lower 3-lobed, the middle lobe long, spreading. Stamens 2, anterior, with a scale at the base of the filament. Strue short. Capsule globular, 1-cell sd, 2.valved, many-sseded.-A small inconspicuones annucl, with crowded opposite roundish leaves, and minute solitary flowers sessile in the axils of the leaves.

1. H. MiCRANTHemordes, Nutt. Creeping Hemianthus.

Creeping and rooting; stem dichotomously branched; leares roundish-orate, opposite, crowded, sessile, obscurely 3-veined.

Inundated banks of the Delaware below Philadelphia. Aug., Sept. Siem 1 to.2 inches long, branehed.

\section{SUB-ORDER II. RHINANTHIDEE.}

- Inflorescencs entirely centripetal or compound. Lateral lobes of the corolla or one of them outermost in the bud.

\section{LIMOSELLA, Linn. MUDWORT.}

Lat. limus, mud; in allusion to its place of growth.

CALYX bell-shaped, 5-toothed. Corollia shortly comipanulate, 5-cleft, equal. Staniens 4 ; anthers by confluence 1-celled. Strue short, club-shaped. Capsule globular, 2-valved, many-seeded.-Small annuals, growing 
272 mud, crceping by slender muners, with entire fleshy leaves in dinse clusters around the simple 1.flowered peduncle.

\section{L. Tenuifolia, Nutt. Common Mudwort.}

leaves tcrete, awl-shaped or thread-form, scarcely dilated at the apex; scepe 1 . flowered, as long as the leares.

MLuddy Ehores. Aug. Ieares about 1 inch long. Flowers bluish-white, minuto.

\section{VERONICA, Linn. SPEEDWEYL.}

Name of doubtful orig:n.

CAITX 4-parted. COROLLA with a 4-cleft spreading border, louer segments mostly narrow. STANiens 2, ore each side of the upper lobe of the corolla, exserted. S'True entire; stigma single. CApsure flattened, usually obtuse or notched at the apex, 2-celled, few to many-seeded.Chiefly herbs, with various fuliage, and blue, flesh culor or ukite flowers, axillary or racemed.

* Spities or raccmcs ierminal. Ferennials.

1. V. SERPyliforita, L. Thyme-leared Speca'uell.

Bruch brancled, at the base, low; traniches ascending, simple; leaves orate or oblong, obscurely crenate, smorthish; raceme-elongated, many-Howered; capsals inversely heart-shaped, as long as the style.

Rordsides and felds, common; introduced and indigenous. May-July. Mc procumbent, 3 to 8 inches Iong, scmotimes creeping. Leares rather fickby, 3 -veincd, $1 / 3$ to 1 inch long. Corolla scarcely excochirg the calyx, blue and white, beantifully finciled with f urple linca.

* * Pines or racenes axiliary. Percrnicits.

2. V. ECUTeliata, I. Marsh Speeduell.

Smooih, ascending, slender and weak; ledves sersile, linear, acute, somewhat tcothed; racemes very slender, zig-zag; with the fowers few and scattered; capsuls fiat, much broader than long, notched at both ends.

Moist fiacrs, common. June-Aug. Plant 8 to 12 inches high. Leares 2 to 8 inches long, $1 / 4$ tor/2 inch whe. Flewers flesh-colored or bluikh, in simple rarely ompound racunes.

\section{V. Anagaliss, L. Tíater Specơrell.}

Smpoth, creeping and rcoting at the base, erect abore; leaves scsslle, mortly clasping by a hcart-shaped hase, ovate-lanceolate, acute, serrate or entire; pedicels epreading; capsute orbicular, slightly notched.

Brcoks and ditches. Junc-A ug. Ste 1 to 2 fect high, sueculent. Leares 2 to 8 inckes long, $1 / 4$ to $1 / 2$ inch wide. Flcwers numcrous, blue or purplish. Conolita soarked with purple lines.

\section{V. Americana, Shweinitz. American Brooklime.}

Fmcoth, decrnabext at tho kase, then ercet; leares orate or obleng, mostly potioled, acutish, corrate, thickik $h$, ecmewhat cordate at base; copesile rounder, torgit, notehed. (V.Beceabunga. American euthors.)

Brosks and ditclies; ccmmcn. June-Aug. Elcms 8 to 15 inehes higb. Iecres

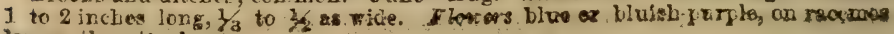
bover than tho leares. 


\section{V. officinalis, L. Common Speedivell.}

Pubescent throughout; siem prostrate, rooting at the base; leaves oborate-elliptical or wedge-oblong, short-petioled, obtuse, serrate; racemes densely many-fowered; capsule triangular-obovate, broadly notehed.

Dry hills and woods; commou. May-July. Plánt trailing, 6 to 12 inches long, mith rscending branches. Leaves mostly elliptical, 1 to $11 / 2$ inch long. Flower's pale blue, in long, erect, pedunculate spikes.

*** Flower's axillary, solitary, scarcely racemed. Annuals.

6. V. perigrina, L. Neck-weed. Purstane Speedwet?.

Nearly smooth, ascending, branched; lower leuves petioled, oval owlong; toother, the othars sessile, oblong, obtugs; the upper oblong-linear and entire; capsule orbicular, slightly notched.

Cultivated grounds; commor, introduced. April-Jnne. Flunt often brancher prone the base, 4 to 10 inehes high. Leaves thiskish. Flovoers rery small, white or pale blue, nearly or quitersessile.

\section{V. ARYensis, L. Corm Speedwell:}

Simple or diffusely branched, hairy; lower leaves orate, crenate, petioled; the nip. pornosí sessile, lanceolate, entire; flowers subsessilc; capsule invercely. hewrtshaped, the lobes roinded.

Cultirated grounds; common, introdnced. Júne. Stem 3 to 8 inches hish. fibonwers on short peduncles, very small, pale blue, besutifully penciled with purplo lines.

\section{V. AGrestis, L. Field Speedwell.}

' Prostrata, hairy; leaves petioled, cordato-orate or round, crenate-toother, cal yosbobes ovate-lanceolati; peduncles as long as the leaves; copsuie nearly orliculur, sharply notched, few-seeded.

Sandy felds, introdueed. May-oet. Stem 3 , to 4 inches long, round; leaify branching nearly at the base. F'lowers small, light blue or white, veined.

\section{a. V. IED}

Prostrate, hairy; leaves petioled, cordate, roundish, 3 to 5 toothed or lobed; $\eta^{\mathrm{e}-}$ dunches searcely longer than the leaves; sepals triangular, sub-cordate, acute, at length erect; capsule turgid and wrinkled, 2-lobed.

Shady rocke and hills; spuringly naturalized. March--May. Stem slenter. 4 to 10 inches long; diffusely branched. Calyx somervat 4 -angled in fruit, Curcile atwaller than the calyx, bluo.

**** Exotics. Perenniatz:

\section{V. sprcata; I. Spited Garden Speeduell.}

Freet, tall; leaves petiolate, ovate-oblong or lanceolate, lowcr ones olture, crenate, riper acute, crenate-serrate. entire at apex; raceme most? solitary; patice's much shorter than the sepals; caly $x$ mostly hoary-pubescent. Cultivated in farciers; tantife of Europe and Asia. Varietics numaerous, with flowers blue, rose-color, \&c.

\section{LEPTANDRA, Nutt.}

Gr. leptos, slender, and aner, andros, a man; in allusion to the stamens.

CALYx 5-parted; segments acuminate. Corolla tubularWell-shaped; border 4-lobed, somewhat ringent, the lower sey-, ments narrower. STAMENS 2, and with the pistil at lengti much exserted. CAPsule oroid, acuminate, 2-celled, many; 
sceded, opening at the summit.-Tall perennials, with mostly whorled leaves and dense spiked terminal racemes of white flowers.

1. L. Virainica, Benth. \& Nutt. Virginia Spiced well.

Siem erect; leaves whorled in $4 \mathrm{~s}$ to $7 \mathrm{~s}$, short petioled, lanceolate, acute or pointed finely serrate; spikes panicled, crowded.

Rich moist places, often cultivated. July. Stem 2 to 4 feet high, angular, simple. Flowers nnmerous, white, nearly sessile in long terminal and verticellate, subterminal spikes. Cupsule many-seeded. The root is medicinal. Culver's Physic.

\section{BUChNERA, Linn. Blue-Héarts.}

In honor of $J$. G. Buchner, an early German botanist.

Calyx tubular, obscurely nerved, 5-parted. Corolta. salver-form, with a straight or curved tube, and a nearly regularly 5-oleft limb. Stamens 4, included, approximate in pairs. STYLE club-shaped and entire at the apex. CAPsule 2-valved, many-seeded.-Perennial rough-hairy herbs, with opposite leaves or the uppermost alternate, and blwe flowers in terminal bracted spikes.

\section{B. Americana, L. Blue-Hearts.}

Rough-hairy; stem mostly simple and wand-like; lower leaves oborate-oblong, obtuse; upper ones oblong and lanceolate, sparingly and coarsely toothed, vein: : flowers in an interrupted spike; caly $x$ longer than the bracts.

Moist places. June-Aug. Siem 1 to 2 feet nigh. Leaves 2 to 3 inches long, very rough, appressed to the stem. Flowers axiliary and sessile, blue or purple. Corolla 1 inch long, hairy. Stamens inserted 2 in the throat of the corolla and 2 in the midale of the tube.

\section{GERARDIA, Linn:}

In honor of John Gerard an English botanist.

CALYX bell-shaped, 5-toothed or 5-cleft. Corolita bell. shaped-funnel-form, swelling above, with 5 more or less un. equal lobes, the 2 upper smaller and usually more or less united. Stamens 4, didynamous, included, hairy. Strue elongated, mostly enlarged and flattened at the apex. CAPsule ovate, pointed, many-seeded._Erect branching herbs, with the stem leaves opposite, or the upper ofien alternate, and showy purple or yeilow flowers often in racemes or spikes.

Sec. 1. Gerardia proper. Leaves linear; flowers purple. Annual.

\section{G. purpurea, L. Purple Gerardia.}

Upright, with long widely spreading rigid branches; leaves linear, acute, roughmargined; flowers nearly sessile; calyx-teeth subulate.

Swamps and low grounds. Aug.-Oct. Stem 1 to 2 feet high, rough on the angles. Leaves $3 / 4$ to 1 inch long, and nearly $1 / 4$ inch wide, coiled up in drying: Flowers large, axillary, often opposite, purple. 
2. G. TENUIFotra, Vabl. Slender Gerardiu.

Mrteh branchod, very slender, diffuse, neariy smooth; lences linear, acuta; pot duencles axillary, thread-form, larger than the flowers; calyx teetic short, aeute.

Dry wood3, common. Jaly-Sopt. Stom 8 to 15 inchos high, 4-angled. Laties variable, about 1 inch long, very narros, entire rough. Crolla $1 / 2$ to $1 / 3$ in is long, pale purple, spotted within, the border much spreading, Emooth and nearly equal.

\section{G. SETACEA, Walt. Setaceous Gerardia.}

Fery slender; branchlets and lecives setaceous, ronghis's; paluncles rery muc't longer than the leaves; calyr-tecth awl-khaped; cupsule orate, larger than the calyz, at length execrtod.

Dry woods, rare. Aug., gept. Plant 8 to 12 inches bigh. Corolla small $1 / 4$ to 1/2 inch long.

SEc. 2-Diststoma, Raf. Leaves rether larrye; flowers yellow. Perenialals.

\section{G, FLAVA, I. Downs Filse Foxgloüe.}

Pubescent with a fine close down; stem tail, mostly simple; leaves orate-laneco-

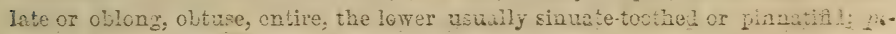
dancles very short; floiverg axillary.

Woods and rosky places, common. Aug. Siem 3 to 4 feet high, reest. Lower

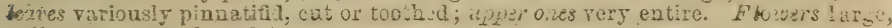
yelloir, trumpet-sianod.

5. G. Quercifozia, Pursh. Giancous Fulse Foxgluze.

Smooth and glaucous, ta!l, mostly branching: lower leaves trice pinnatif a ; the apper oblong-lenceolate, pianatifil or entire: $p$ luncles nearly as lon $q$ s the caiys; buty-lobes linear-ianccolate, acute, as long as the at length inflated tube.

Rich roods; common. Aug. Siem 2 to 5 fuet hioh. Flowers lary and of is brilliant yellow, opposite and axillary, near the top of the stem, formin: a looss spike. Corolla trumpet-shaped, 2 inches long.

\section{G. Pedicularia, I. Bushy Gerardic:}

Smoothish or pubescent, much branehed; leares ovate-kanceolete, finnatifl, the Tores cut and toothad; pedicels longer than the ca!yx; calyx-lojes toothel, as bon: as the hairy tubs.

Dry wouls; cominon. Ang. Slem 2 to 3 feet high, very leafy. Leave 1 to 3 inches long, aud $1 / 2$ to 2 inches wide; segments crenately incised-serrate. Flww yellow, 1 to $1 \frac{1}{2}$ inch long, villose. Sizle longer than the stamens.

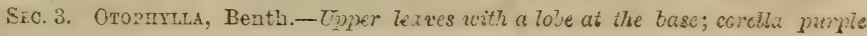
(rarely white), spuringly hairy inside. Annual: :

\section{G. auriculata, Michs. Auriculate Gerarda.}

Rongh-hairy; stem erect, nearly simple ; leceses lanceolate or ovate-lanceolat, tha Thive entire, the others vith an oblong-larceolate-iobe at the lase, cn each sile; fowers nearly 6escile in the axils of the upper leares, forming a prolonged and interrupted leafy spike.

Low grounds, rare. Aug, Sept. Stem 9 to 20 inches high. Lear:3 1 to $12 / 2 \mathrm{by}$ $1 / 3$ th $2 / 3$ of an inch; entire on the margin, eessile. Corolla purple cr rarely white, gubscent, dilated at the mouth, nearly 1 inch long.

\section{CAstillieja, Mutis. Painted-cup.}

In honer of Custiblejo, a Spanish botanist,

CALYX tubular, flattened, ventricose, 2 to 4 -cleft. Coror LA 2-lipped; upper lip long and narrow, arehed, keoled and $\mathrm{F}_{2} *$ 
flattened laterally, inclosing the stamens. STAmens 4. Capsule ovoid-compressed, many-seeded.-Herbs, with alternate entire or cut-lobed lexves, the floral ones dilated, colored and usually more showy than the pale yellow or purplish spiked flowers.

\section{C. coccinea, Spreng. Scarlet Painted-Cup.}

IIairy; strm simple; root-leaves clustered; stem-leaves lanceolate, pinnatifidly incised; floral-leaves trifid or incised, colored at the summit; calyx nearly equally 2 cleft, the lobes dilated at the apex, nearly: entire the length of the corolla. Bien.

Low grounds. May, June. Stem 8 to 16 inches high, simple redaish or purple. Floral-leaves scarlet towards the summit. Stem-leaves alternate, zessile, with about 2, long, linear segments on each side. F'lowers in a crowded spike, greenish-yellow. The variety palens of Pursh, having the floral-leaves dull-yellow is occasionally found.

\section{SCHWALBE Gronov. ChafF-SeEd.}

In honor of Christian Sc?

Calyx declined, very oblique, tubular, 10 to 12 -ribbed, 5 -toothed, the upper rib much smaller, the anterior united much higher than the others. Coroula bilabiate; upper lip arched, oblong, obtuse, entire; the lower shorter, erect, 2plaited, with 3 very short obtuse lobes. Stamess 4, didynamous, included in the upper lip. STrue club-shaped at the apex. CAPSULE ovoid-roundish, 2-celled, 2-valved, manyseeded. SEEDs winged with the chaff-like coat.-Perennial herbs, with alternate, sessile, entire teaves, and leafy simple stems, terminated by a loose spike of rather large dull yellow flowers.

\section{S. Americana, L., American Chaff-seed.}

Minutely pubescent; stem simple, leafy; leaves ovate or oblong, the upper gradually reduced into lanceolate and linear bracts, 3-nerved; pedicels very short, with \& bractlets under the calyx.

Wet sandy soil; rare. May-July. Plant 1 to 2 feet high, somerhat visced: pubescent. Flowers dull purple or jellowish, 1 to $11 / 4$ inch long.

\section{PEDICULARIS, Tourn. LOUSEWORT.}

Lat.pediculus, a louse; of no obvious application.

CaLYX tubular or bell-shaped, unequally 5-toothed or 2 . lipped. Conoula strongly 2-lipped; the upper lip arched, flattened, often beaked at the apex; the lower erect at the base, 2-crested above, 3-lobed, commonly spreading. STAMENS 4, under the upper lip. CAPSUte ovate or lanceolate, mostly oblique, several-seeded.-Perennial herbs, with chiefly alternate pinnatifid leaves, and rather large flowers iu terminal spikes.

1. P. Canadensis, L. Common Lousewort.

IIairy; atoms simple, low, clustered; leares acattered; the lowas pinnatiodhy; 
parted, the others half pinnatifid; spilee short and dense; calyx split in front, otherwise nearly entire, oblique; upper lip of the: corolla hooded, incurved, 2 towthed under the apes:

Pastures and low grounds, common. May-July. Plant 5 to 12 inches high, often several stems from one root. Leaves 3 to 6 inches long, by 1 to 2 wide, chicfly radical. Corolla yellowish and purple, in a short terminal spike. Cupsule com. pressed, somewhat sword-shaped.

2. P. Lanceolata, Michx. Tull Lousewort.

Stem upright, tall, nearly simple, mostly smooth; leaves sub-opposite, oblong:lanceolate, double-cut-toothed; spilios somowhat crowded; calyx bifid, with round ish-ovate segments; upper lip of the corolla truncate at the apex, the lower erect so as to nearly close the throat.

Low grounls. Aug., Sept. Stem 1 to 3 feet high. Flowers large, straw-color. Calyx-lobes leafy, crested. Cipsule ovate, scarely longer than the calyz.

\section{MELAMPYRUM, Tourn. Cow-wheAT.}

Gir. matas, blask, and puros, wheat; from the color of the seede, as they appear mixed with grain.

CALYX tubular, 4-cleft or 4-toothed. Conolla ringent or personate; upper lip arched, compressed, with the marging folded back, the lower lip somewhat longer, biconvex, 3 . lobed at the apex. Stamens $\frac{1}{1}$, under the upper lip. CAP. SULE compressed, ovate, oblique or falcate, 2-celled, 1 to 4 seeded.-Erect branching annuals, with opposite leaves, and solitary axillary, or leafy-spiked fluwers.

M. pratense, L. Var. Americanum. Benth. Corv-wheat.

Lonver leaves lanceolate or linear-lancealate; floral leaves lanceolate, toothed at the base; flowers remote, one-sided, axillary.

Dry woods; common. June, July. Stem 8 to 12 inches high, branched above. Leaves oppose, 1 to $11 / 2$ by $1 / 4$ to $1 / 2$ inch, the upper ones broader, with setaceous teeth at the base. Flowers slender, yellowish, the eorolla twice the length of the ealyx.

\section{ORDER 72. VERBENACE巴E,- Vervain Family.}

Herbs or shrubs, with opposite leaves, more or less 2-lipped or irregular corollas, and didynamous stamens, the 1 to 4 celled fruit, dry or drupaceous usually seperating when ripe into as many 1-seeled indehiscent nutlets. CALYX tubular 4 to 5-toothed, inferior, persistent. COROLLA tubular, irregularly 4 to 5-cleft, deciduous... SEgDS. with little or no albumen.

\section{VERBENA, Linn: Vervain.}

The Latin name for any sacred herb; derivation obseure.

Calyx tubular, 5-toothed, with one of the teeth often shorter than the others. Corolla tubular, often curved, salver-form. the border somewhat unequally 5-cleft. STAMENs 4 (rarely but 2), included, the upper pair sometimes. 
without anthers, STrLe slender; STIGMA capitate. CAPsULE seperating into 4 seed-like nutlets.- Herbs, with opposite leaves, and mosily allernately spicate, bracted flowcrs, rarely sapitate or corymbed.

I. V. hastata, I. Blue Vervain.

Tall; leaves lanceolate or oblong-lanceolate, acuminate, cut serrate, petioled, the lower often lobed and sometimas balbert-form at the base; spilies slender erect, densely flowered, corymbed or panicled. Per.

Iow and waste grounds; common. July-Sept. Stem 3 to 4 fiet high, with paniculate opposite branches above.- Leaves rough, opposite. F lowers small, blue, arranged in loag, close, imbricated spikes, erst and parallel to each other. Seed 3 4. A variety with lance-ovate, or lance-oblong sharply serrate leaves and snaller flowers is occasionally mot with; probably a hybred between this and the next species.

2. V. untrafroli, L. Nettle-leaved Vervain.

Erect, somewhat pubescent; leaves oval or oblong-ovate, aeuto, coarsely serrate, petioled; spilces very sleuder, at length much elongated with the flowers remote, loosely panicled; flowers totrandrons.

old fislds and roadsides; common: introluced. July-Sopt. Par. A roughish, hairy plant with slender sprealing branches, 2 to 3 feet high. Flowers white, very sma!l, remote, on divivergent, sleuder spikes.

3. V. spunia, L. Cut-leaved Vervain.

Stem desumbent, loosely branched, difase; leaves sessile, pinnatifid, the lobos eut-trothed; spilies vory slender, loosely panicled; bracts longer than the ealy apper stamens imperfect. Annual or Biennial.

Sandy fields and roadsides; rare. Aug.-Oct. Stem sqnere, 1 to 2 feet long, at length much branched, half erect. Spilies 3 to 6 inches long, baring very small purplish-blue or rose-colored flower, at length-scattered on the spike.

4. V. Angustifolia, Michx. Narrow-leaved Vervain.

Dwarf, erect, mostiy simple; leaves linear-lanceolate, attenuate at the base, romotely toothcd; spilies solitary, the flowers at first crowded.

Dry hills or sandy fields. July - Sept. A emall hairy epecies 6 to 12 incluos high, with leaves 3 inches long, and $1 / 2$ inch wide. Flowers purplish-blue, largar than in any of the preceding species.

\section{V. Melindrei, Lind. Scarlet Verbena.}

stem and tranches spreading, $\mathrm{h}$ iry; leaves oppusite, obcrate or broad-ianceolate. deeply toothed, rough on the apper side, hairy beneath; flowers in termina: branches; culyx hairy, tubular, half as long as the corrolla. A beautiful perennis: border flower, native of Buenos Ayres, blooming all summer, much eultivated ir houses and conservitories. Flowers of a dazling scarlet, but in the pumerous vir rieties some are white, lilac, purple, pink and flesh color. Curolla with a spreading. limb, the 3 lower segments larger than the 2 upper ones.

\section{2.. PHRYMA, Linn. LOPSEED.}

CALrX cylindrical, 2-lipped; upper lip of 3 bristle-awlshaped teeth; lower shorter, 2-toothed. Conoula 2-lipped; upper lip notched; lower much larger, 3-lobed. STAMENs 4; included. Style slender. Stigma 2-lobed. Fruit oblong, 1-celled, 1-seedad.-A perennial herb, with stender 
branching stemis, coarsely toothed ovate leaves, and small purplish or rose color opposite flowers, in elongated and slevider ierminal spikes.

1. P. Leptostachya, L. Shender-spiked Lopseed.

Laves ovate, acute, coarsely and unequally toothed, petioled; caly $x$ in fruit re. flexed.

Rich sandy woods, common. Jaly. Slem 2 to 3 feet high, with a few spreading branches above. Leaves 3 to 6 inches long, thin, on short stalks. Flowers small, mostly opposite.

\section{LIPPIA, Linn. (Zapania. Juss.)}

In hønor of Lippi, an Italian traveler and naturalist.

Calyx compressed, 2 to 4 parted, 2-lipped. Conolla tubular, strongly 2-lipped; upper lip notched; the lower much longer, 3-lobed. Stamens 4, included. Strie slender; STIGnA obliquely capitate. Fruit 2-celled, 2. seeded. - Shrubs or prostrate herbs, with opposite leaves, and heads of flowers on axillary peduncles.

\section{L. NODIFLORA, Michx. Fog-fruit.}

Procumbent or creeping; leaves wedge-ovate or oblancelate, serrate above; $p c$. duncles axillary, slender, bearing solitary closely bracted heads of flowers. Per.r

Low grounds. July. Stem 6 to 8 inches long, branching. Leavcs with conspicuous veins, 1 to 2 inches long, $1 / 3$ to $1 / 2$ as wide, on petioles $1 / 4$ to $1 / 2$ inch long. Peduncles 2 to 3 inches long, bearing ovoid or roundish heads of bluish-white flowers.

\section{ORder 73. IABIATPE,-Mint Famity.}

Chiefly herbs, with square stems, opposite aromatic leares, more or less 2-lippea corolla, didynamous or diandious stamens, and a derply 4-lobed ovary, wihich forms in fruit 4 little seetl-like nutlets or aehenia surrounding the base of the single style in the persistent calyx, each filled with a single erect seed. Flowens axillary or opposite, without stipules. CALYx tubular, regularly 5-toothed or cleit. CPPER IIP of the corolla 2-lubed or sometimes entire; the LOWER 2-parted. STAmexs inserted on the tube of the corolla. Strue 2-lobed at the apex.

\section{ISanthus, Michx. False Pennyroyel:}

Gr. isos, equal, and anthos, a flower; referring to the nearly regnlar corolla.

CALYX bell-shaped, deeply 5-toothed, equal, 10-nerved. Conolica nearly regular, 5-lobed; the lobes nearly: equal, rounded, spreading. Stamens 4, nearly equal, erect, distant, searcely as long as the corolla. Achenia wrinkled and pitted.-A low branching clammy-pubescent annual, with entire leaves, and small pale blue flowers on short axillary 1 to 3 , flowered peduncles. 


\section{I. Caeruleus, Michx. False Pennyroyel.}

Viseid hairy; leaves oblong-lanceolate, strongly 3-nerved.

A branching leafy horb with the aspect of the pennyroyel. Grarolly banks, common. July, Aug. Plunt about a foot high. Siem round, slender. Levres 1 inch long, and $1 / 4$ as wide. Flowers numerous, blue with included stumens. The whole plant when rubbed, emits a balsamic odor.

\section{MENTHA, Linn. MrNT.}

Mintha or minthe, an ancient Greek term.

CalyX bell-shaped or tubular, 5-toothed, equal or nearly sto. Corolla with a short included tube, the border bellshaped, nearly equally 4-eleft, ihe upper tube broadest, entire or notched at the apex. Stamens 4, equal, erect, distant. AcHeNia smooth.-Aromatic herbs, with opposite leaves, and small pale purple or whitish fiowers moslly in close clusters, form. ing axillary capitate whorls, sometimes approximeted in intcrrupted spiles.

* Nearly smooth; naturabized, Perennials.

\section{M. viridis, L. Spearmint.}

Leares nearly sessile, ovate-lanecolate, unequally serrate; flowers in approzicrate loose panicled spikes; calyx somewhat hairy.

Low crounds; perfectiy naturaized. July, A ug. Stem 1 to 2 feet high, brancked, 4-angled. Spities somewhat panfeled, long. comrosed of distinct cy mes, apparesitly whorled, a little remote from each other. Corolla pale purple. ityle much exserted.

2. M. piperita, Li. Pepzermint.

Leaves smooth, petioled, ovate-oblong, acute, serrate; whorts of flowers crowded in short obtuse spikes, interrupted at the base; calyx-teeth hairy.

Low grounds and along breoks ; common. Aug. Stem 1 to 2 feet high, arising from nnderground running shcots, brancked, cften purplish. Leaces dark green, flisply serxabe, rounded at the base. Flower's pale purple. Nicdicinal. Native of Europe.

3. M. arvinsis, L. Corn Mint.

A.scending, pubescent; lecives petioled, orate or oblong, serrate; fowers in giviono remote whorls; caly $x$ mostly hairy.

Fiolds and hodgerows; common. July. Séem stout oiten crect, about 1 foot minh. Leaies virying to oblong or ovati-lanceolate, cometimas nearly smonth, 1 to 2 inches iong, and $1 / 2$ as wido. Flowers small, numerouz; pale purpte: st tha ens exserted. The plant when bruised emits the odor of decayed chese. Native of Europe.

* * Truly intigenons species. Ferennials.

4. M. Canadensis, L. Wild Mint. Canadian Mint.

Shem low, spreading, whitish-hairy; leares petioled, oblong, lanceolate or orat lanccolate, serrate; flower nuwerous, in globular axillary. Whorls; calyx hairy; stamens exserted.

Moist grounds and shady places; common. July-Sept. Plant grayikh-green, with the odor of Ennyroyel, 1 to 2 feet high, Leaces hairg, espocially beueath, tapering to both ends. Flowers pale-p urple. 


\section{LYCOPUS, Linn. WATER Horehound.}

Gr.hucos, a wolf, and pous, a foot; from some fancied resemblance in the leares.

Caryx oblöng-bell-shaped, 4 to 5-toothed. Corolia bell-shaped, nearly equally 4-lobed, scarcely longer than the calyx. Sramens 2. distant. Achenra 4, smooth, with thickened margins. - Low perennial herbs, with sharply toothed or pinnatifid leoves, and dense axillary whorls of small white fiowers.

\section{L. Virarinicus, L. Bugle-weed.}

Snootli; stem stoloniferous at base, smoothisb, obtuse 1-angled; leares oulong or ovate-lanceolate, toothed, cntire towards the base, short-petioied; calyx-iecth 4, orate blunt.

Shady moist places, common. Aug.' Plunt often purplish. Slem 10 to 15 inches high, often purplish, simple or sparingly branclied. Leaves opposite, Fluwers white in minute capitate clusters.

\section{I. sinuatus, Ell. Wuter Horehound.}

Sicm ercet, sharply 4 angled; lcares oblong-lanceolate, narrowed at both enda, petioled, the lower ones pinnatifid, the others sinuate toothed, or the uppermas linear and nearly entire; calyx-teeth 5 , spiny-pointed.

Lnw graunds, common. July, 1 ug. Smoothish. Stem 1 to 2 fect Ligh. Flowers in dense frhoris, white, larger than the last.

\section{ORIGANUM, Linn. MarJoram.}

Gr.oros, a mountain, and ganos, delight.

CALYX oroid-tubular, 5-toothed. Corolla somewhat 2lipped; upper lip erect, nearly fiat, slightly notched; lower of 3 nearly equal spreading lobes; tube about as long as the calyx. Stamens 4, exserted, somewhat didynamous.-Herls with nearly entire leaves, and purplish flowers crowded in cylindsical ar oblong spilies which are imbricated with colored bracts.

\section{O. vUlgare, L. Wild Marjoram.}

Perenniel, upright, hairy; branched at the summit; leaves round-orate, petiolox", obtuse, nearly entire; bracts ovate, obtuse, longer than the calyx; spities roundish panicled, clustered, smooth.

Rocky fielus and dry banks, sparingiy naturalized. June-Oct. Stem 10 to 14 inches high, purple. Leaves very siightly serrate, opposite. sprinkled with resinons dots. Bracts tinged with purple. Flouers pale-purple, in numerous small spike wich are crowded together so as to form a terminal head.

\section{O. Marjorana, Ph. Sweet Marjoram.}

Leaves oval or obovate, obtase, entire, petiolate; hoary-pubescent; spikes roundish, compact, pednnculate, clustered at the ends of the branches; bracts roundich. Na tive of Porbugal. A perennial plant, cultirated in gardens for its pleasant aromatto thavor, which is employed in various ways as a coanoning. Whole plant sost downs 1 foot high. Flower pink. July, Lü ug. 


\section{COLLINSONIA, Linn. Horse-Balm.}

In honor of Peter Collins, of London, a patron of botiny.

CALYX ovate, about 10-nerved, 2-lipped; apper lip 3toothed, truncate; lower 2-toothed. ConoLla elongated, expanded at the throat, somewhat 2-lipped, with the 4 upper lobes nearly equal, the lower larger and longer, toothed or lacerate-fringed. STAmens mostly 2, much exserted, diverging.- Sirongly-scented perennials, with large ovate leaves, and yellowish fiowers on slender pedicels in loose and panicled terminal racemes.

\section{Canadensis, L. Common Horse-Balm. Stone-root.}

Nearly smooth; leaves broadly ovate, scrrate, pointed, petioled; panicle loose, many-tiowered; stamens 2.

Rich moist woods, common. July-Sept. Stem 1 to 3 feet high, somewhat branched, 4-angled. Leaves thin, 6 to 8 inches long, and 3 to 4 inches wide. Flozoers large, greenish-yellow, exhaling the odor of lemons.

\section{HedeOMa, Persoon. Pennyroyel.}

A Greek name for Mint, alluding to its agreeable odor.

CALYX oroid-tubular, gibbous on the lower side near the base, 2-lipped; upper lip 3-toothed; lower lip 2-cleft. CoROLLA 2-lipped; upper lip erect, flat, notehed at the apex; lower spreading, 3-cleft, the lobes nearly equal. Stamens 2, fertile and ascending, 2 lower, sterile filaments or wanting.Low aromatic plants, with small leaves, and loose axillary clusters of pale blice flowers, somewhat approximated in terminal leufy ra. cemes.

\section{H. pulegioides, Pers. American Pennyroyet.}

Stem erect, branched, pubescent; leaves ovate or elongated, obscurely serrate, narrowed at the base, petioled; wiorls about 6-fiowered; corolla about as long as the calyx.

Open barren woods and dry fields, common. July-Sept. Plant 6 to 10 inches high, branched above. Leaves opposite, with 1 to 2 teeth on each side. Flowcrs small, pale-blue, about 3 in each opposite axil. A popular domestic medicinal herb.

\section{CUNIIA, Linn. Dittany.}

An ancient Latin name of unknown origin.

Caliyx ovoid-tubular, equally 5-toothed, hairy in the throat, about 13-nerved. ConoLlia 2-lipped; upper lip erect, flattish, mostly notched; lower lip 3 -lobed, spreading. Stamens 2, erect, exserted, distant. Style 2-parted at the summit.-Perennial herbs, with small white or purplion Alowers in corymbed cymes or close clusters. 


\section{Mariana, I. Common Dittany.}

Stems tufted, corymbosely branched; leaves orate, serrate, smooth, rounded os beartshaped at the base, nearly sessile; cymes peduncled, loosely eorymbed.

Dry hills and rocks; common. July-Sept. Plant 1 foot high, syrinkled with resinous and pellucid dotg, much branched; branches triangled, purple. Flowers rose-colored. Stimens and style much exserted, of the same hue as the corolle Whole plant delightfully fragrant, often uschis a substitute for tea.

\section{BLEPHILIA, Raf.}

Ar. blepharis, the eye-lash; in reference to the bairy fringed bracts and calyz-teeth CALYX ovoid-tubular, 13-nerved, 2-lipped, naked in the throat. Conolla 2-lipped, inflated in the throat; upper lip -erect, entire; lower lip spreading, 3.eleft, with the lateral lobes ovate and rounded. S'TAMENS 2 , ascending, exserted. Perrennial her bs with entire or toothcd leares. and small pale bluis.s. purple flowers, crowded in axillary and terminal globose cavitate whiorls.

\section{B. ciliata, Raf. Finged Blephilia.}

Somewhat downy; leaves nearly sessile, oblong-cvate, narrowed at the base, whitish downy underneath; outer bracts ovate, acute, ciliate, colored as long as the ealyx.

Dry open places. July. Stem simple, acutely 4-angled, 2 to 3 feet high, rareiy with 1 or 2 spreading branches. Lfaces 1 to $23 / 2$ inehes 1 eng, $1 / 2$ to 1 inch wite Fwwers small, numerous, pale purplish.

\section{B. Hirsuta, Benth. Haixy Blepkilia.}

Whole plant hairy; leaves lonr-petioled, ovate, pointed, rounded or heart-shaynat at the base; bracts colored, linear awl-shaped, shorter than the calyx.

Dump woods; rare. July. Stem 2 to 3 feet high, with spreading branches, wat numerous close whorls. Leaves 1 to 2 inches long, on petioles $1 / 4$ to $2 / 2$ inch loug. Corclla fearcely $1 / 2$ inch long, pale purple, with gpcts of a deeper bzie. Sty.e longes than the stamens and corolla.

\section{MONARDA, Linn. Horsemint.}

In honor of Monardea, an eariy Spanish botanist.

Calyx tubular, elongated, 15-nerved, nearly. equal, 5 toothed. Conolla ringent, with a long cylindric tube, upper lip spreading, 3-lobed at the apex, the middle lobe longex. Stamens 2, exserted from the upper lip of the corolla. Odorous erect herbs, with entire or toothed leaves, and showy large flowers in a few capitate whorls elusely sarrounded with bracts.

\section{M. Didyma, L. Oswego Tea. Burgamot.}

Somewhat hairy; stems acutely 4 angled; leaves broadly orate acuninate, rounded or slightly heart-shaped at the base, short petioled; calyx smocth, incurved, nearly nakid in the throat; corolla kmooth, much elongated. Per.

Moist roods and miadows; cultirated. July. A handscme fragrant plant, 2 so 3 feet high, most'y branched Leares 2 to 5 inches long, very broad at base, sorrate, with scattered hairs above. Flcwers erimson or searlet, in heads, often pro. lifarous with large or ate-lanceolate bracts, tinged with red. Ooralla 2 iacices !org. 


\section{M. Fistulosa, L. Wild Burgamoi.}

Smoothish or downy; leaves ovate-lanceolate, rounded and somewhat cordate at bese, acuminate, coarsely toothed; floral leaves and outer bracts slightly colored; c sly $x$ slightly curved, very hairy in the throat. Per.

Woods and rocky banks; common. July-Sept. A very variable plant 2 to 5 feet high, embracing several nominal species and varieties. Stem quadrangular, with the sides somewhat concare. Leares 2 to 4 inches long on petioles $1 / 2$ to $3 / 4$ inch long. Flowers purplish, rose-color or nearly white.

3. M. PUivстатA, L. Horsemint.

Minutcly downy; leaves lanceolate, narrowed at the base, petioled; bracts lanco olate, obtuse at the base, sessile; caly $x$-teeth short and rigid, awnless; corolla nearly mooth, tho tube scarcoly exceeding the calyx.

Sandy fields and dry banks. Aug., Sept. Stem 2 to 3 feet high, branchrd. Ieaves punctate. Bracts yellowish and purple. Corolla yellowish the upper lip gotted with purple. The whole plant is very odorous and pungent to the tasto.

\section{SALVIA, Linn. Sage.}

Lat. salvo, to sare; in allusion to its reputed healing qualities.

CALYX somewhat bell-shaped, 2-lipped; upper lip mostly 3-toothed, the lower 2-cleft. Conouna deeply 2-lipped, ringent; upper lip erect, straight or falcate and vaulted, entire or barely notched; the loncer lip spreading or pendent, 3 -lobed, the middle lobe longer and sometimes notched. Stamens 2, on short filaments; connectile transversely articulated to the filament, supporting at each end a cell of the dimidiate anther. ACHenIA 4.-A large genus of which but jew are indigenous, with usitally large and showy, spiked, racemed, or panicled whorls of flowers.

1. S. Lyrata, L. Lyre-leaved Sage.

Somewhat hairy; stem nearly simple and naked; root-leaves obovate, "lyre-shaped or sinuate-pinnatifid, sometimes nearly entire; those of the stem mostly a single pair, smaller and narrower, the floral oblong-linear; whorls of flowers loose and distant, forming an interrupted raceme; upper lip of the corolla short, straight and raulted.

Woodlands and meadows. Mry, June. Plant 10 to 12 inches bigh. Flowers im whorls of abaut 6 , distant. Corolla blue, the tube much exserted.

\section{S. urticifolia, L. Nettle-leaved Sage.}

Downy with clanamy hairs, lcafy ; leaves rhombic-ovate, pointed, crenate, rounded at base, short-petioled; whorls remote, many-flowered; upper lip of the corolla erect, much shorter than the lower; style bearded.

Woodlands, Western Counties, rare. Leaves very pubescent. Flovers blue, viscid, in remote whorls. Corolla $1 / 2$ inch long, the lateral labes defexed, the wid. dle notched.

CULTITATED EXOTIC SPLCIES.

3. S. offictanalis, L. Common Sage.

Ieaves orate-lanceolate, crenulate, rugose; whorls 6 to 10 -flowered in 2 opposito 
cots; calyx striate, the divisions pointed; uppar lip of the corolla as long as the lower, somewhat vaulted. A well known garden plant, cultivated for its medicinal properties. Stem 1 to 2 feet high. Lacaves 1 to 3 inches long, of a dull green color, aromatic. Corolla ringent, blue or purplish. Native in the South of Europe.

\section{S: Sclarea, L. Clarry:}

Leaves oblong, heart-shaped, rugose, serrate; bracts colored, concare, longer then the calyx. A strong-scented exotic, native of Italy. Stem 1 to 3 feet high, with leares 5 to 7 ineher long and 3 to 4 wide, viscid. Flowers variagated with palo parple and jellowish-mhite, in whorled spikes. Bracts pale purple or yellowish.

5. S. splendens, Ker. Spendid Sage.

Stem erect, smooth; leaves broad-orate and ovate, petiolate, rounded or acute $2 t$ baze, dentate-serrate, acuminate, smooth on both sides; bracts deciduous; caly $x$ and corolla pubescent; upper lip entire. A beatiful spccies, cultirated in gardese; nstive of Níxico. Plant 2 to 4 feet high, branched. Flowers large, scarlet. Calya carlet, after flowering becoming enlarged and-as showy as the corolla.

\section{CEDRONELla, Monch.}

Gr. kearos, diminutire of Cedar; from the aromatic leaveg of the original apecies; C. trighylla, the Bulm-of.Gilead of Evorlish gardens.

CALYX somewhat obliquely 5 -toothed, many-nerved. Coroura much expanded at the throat, 2-lipped; upper lip flattish or concave, 2-lobed, the lower 3 -cleft, spreading, the middle lobe largest. Stamess 4, as cending, shorter than the upper lip, the lower pair shorter than the other!- Sucetscented perennials, with pale purplish flowers.

\section{C. condata, Benth. Creeping Cédronella.}

Low, creeping by slender runnars, hairy; lexes broally hoart-shaped, crenati, petioled, the floral shorter than the calyx; whorls few-flowered, approximate at tho sumwit of short ascending stams.

Low shaly banks of streans, w sstern part of the Stake, rar3, June. Flowers purjlish. . Curolla hairy inside $1 \frac{1}{2}$ inch long. (Dacocephalum cordatum, Nutt.)

\section{NEPETA; Linn: CAT-Mint..}

Supposed to be from Nepet, a town in Tuscang.

Caryx tubular, often incurved, obliquely 5 -toothed. CoroLLA naked and dilated in the throat, 2-lipped; upper lip erect, notched or 2-cleft, the lower spieading, 3-cleft, the midale lobe largest.. Stamexs 4, ascending under the upper lip, the lower pair shorter.-Perennial herbs.

* Cataria, Benth.-Clusters dense and many-fowered, forming interrapicd squies ar racemes.

1: N: Cataria, L. Catnip.

Dowuy, erect, branched; leaves heart-shaped, oblong, deepiy crenate, petioled, vilitish downy underneath; spilied racemes somerhat panicled.

Wuste and cultirated grounds, a rery, common naturalized reed. July, Aug. Siem 
sruare, pubescont, branching, 2 to 3 feet high. Floxers numorous, whito or perplish, the tower lip dottod with erimson.

* GuECHOMr., L. Axillary clusters loosely few-flowered.

2. N. Grechoma, Benth. Ground Ivy.

Crecping and trailing; lenres petioled, round-kidney-shaped, crenato; corolla about 3 times as long as the calyx.

Waste ground6, in shated plares, perfectly naturalizod. May-Aug. Stems prostrate, from a few inches to 1 to 2 feet Inng. Flowers axillary in 3s. Corolla bluish-purple, with a variegated throat. Anthers with tho colls diverging at a right anglo, cach pair approximate and forming a cross.

\section{DRACOCRPHALUM, Linn. DRAGON HEAD:}

Gr. dration, a dragon, and lephale, head; alluding to tho form of the corolla.

CalyX tubular, 13 to $15 \cdot$ nerved, 5-toothed, the upper toath much largest. Corolna dilated in the throat, 2-lipped; rpper lip slightly arched and notched; the lower spreading, 3-cleft, with the middle lobe much larger, rounded or 2-cleft. Stamens 4, ascending under the upper lip.-Whorls of flowers mostly spiked or capitate, and usually subtended with. large conspiculous bracts.

D. PARviriorum, Nutt. Small-fowered Dragon-head.

Sab-pubascent; stam erect, somewhat branchod, leafy; leaves ovato-lanceolate, eharply cut-ioothed, pitioled; wilmts crowded in a terminal globular or oblong capitate spike; brast leafy, ovate, fringed; biennial.

Rosky places, and gravelly shores, aions the Susquehrnna. May-Aug. Stem 8 to 2 ) inclies high, obtuseiy 4 -angled. Upper calyx-tooth nearly as long the coralIa. Crrolla bluish-purple; the upper lip arched, emar;inate, central lobe of the howor lip crenate.

\section{LOPHANTHUS, Benth. Giant Hyssup.}

Gr. lophos, a crest, and antinos, a flower.

Caryx tubular-bell-shaped, 15-nerved, oblique, 5-toothed; the uppor tooth rather longer than the others. Corolda: S-lipped; upper lip nearly erect, notched; the lower-some. what spreading, 3-cleft, with the middle lobe broader and crenate. Stamens 4, exserted; the upper poir declined; thelower ascending, shortest !-Perennial upright herbs, with petioled serrate louves, and small flowers crowded in terminal spikes.

\section{L. Nepetordes, Benth. Yellow Giant Hyssup:}

Smooth or nearly so; leaves ovat, som?what poipted; calyz-teeth ovate, ratherobtuse, little shorter than the corolla.

Borders of woods. Aug. Stem stout, gmooth, quadrangular; 4 to 6 feet high. beaves 2 to 4 inches long, conrsely cronate-toothed. Flowers small, grecinish-yel4 , in eylindrical apikes 2 to 4 inches long, crowded with ovato pointed bractas. 


\section{L. scrophelarifolius, Benth. Purple Giant Hyssup.}

stem and lower surface of the leaves pubescent; leaves orato, acute, serrate cPenate; calyx-teeth lancsolate, acute, shorter than the corolla.

Borders of rich woods. Auz. Stem 3 to 5 feet high, mostly of a purple anlor, branched. Leaves often cordate at base, 5 inchos long and about 3 inches Fid:, coarsely-8errnte. F'low in crowled, axillary verticels, forming a long; dense; terminal spike. Corcila palo purple. Stimeits asad sigle exserbed.

\section{PyCnanthemum, Michx. Mountain Mrnt.}

Gr. puknos, dense, and antienom, a blossom; fom the crowded or capitate fiowurs.

CAxyx tubular or orate-oblong, striate, 5-toothed. CoRorcA with a short tube and a somowhat 2-lipped border; anper lip entire or slightly notehed, the lower 3-eleft; lobes all orate and obtuse. Spamess 4, distant, the lower pair rather longest.-Perennial aromatic upright herba, corymbore. ly bianched above, ofien whitish floral leaves, and dense many-fowered whorls, crowled with bracts, usually forming terminal heads or cióse cymes, with whitish or ftesh-colorad Alowsrs.

\section{P. Incandm, Michix. Cimmon Mountain Mint.}

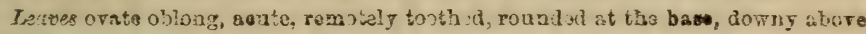
Aut hary with whitish wool undern zeth; cymes pelunded, eompound, open; bruste subulute.

Roek, woods and hills, common. Jily, Ang. Stem 2 t, 4 fost hich, obtuagly

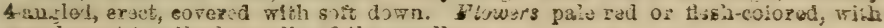
sippls spots on the lower lip of the eorolla.

2. P. nutravm, Pers. Viny-leaved Morniain Mint.

Smooth or somewhat hoary througlout, corymbosely branchod; lecves ovate or.

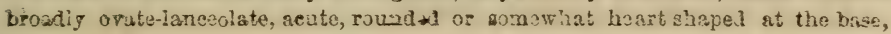
motly sossile, minately toothed, rigil; wrorls dense, mostly in terminal hewie; ouker urbets and orate lannolate cilyz-hieth houry with a fine elose down.

Dey hills; common. Aas. Stem 1 to 2 fuot high w:th widely apreading brants. ce, rusrs. Leines opposite, Iarge, $1 / 3$ as wist as long. Flower's redaish-white with parpla spots, in dease terminal heals which wro sosout $1 / 2$ inch in dameter.

3. P. Layceotatum, Pursh. Lance-leaved Rountain Mint.

Sunothish or minutely down, corymbosely branehed abore, very leary; haws Inavolute or nearly linear, ontire, rigid, obtuse at the basi, sessile, featber-re!ned. unats orate-lanceolate, barely pointcd, dorfry.

Thiekets and dey wools; common. Jilly, $A$ uz. Stem about 2 feet high, oquars with obtuse angles. Laves variable in width. Floncers small, reddish-wite, witb purple dots, in numorous sinall clustered dense beads.

\section{P. Linifourum, Pursh. Flax-leaved Mountain Mint.}

Smosth, or nearly so; leaves narrowly linear, crowdel, 3-veined, entire; brachs wiightly awoed ; calyx-teeth lanee-subulate.

Thickets and moist wools. July, Ang. Stem ereet, 12 to 18 inches high, with fustigiate, trichotomous branches, often purplish. Leaves very narrow, punctats, with fascicles of smaller ones in the sils. F'towers gcall, white, is nonorvias mall, roundish heads, mostly terminal. 


\section{THYMES, Linn. Thyme.}

The ancient Greok name.

CaLYX 2-lipped, hairy in the throat, 13-nerved; upper lip 3-toothed, spreading; lower 2-cleft. Conoun short, slight1. 2-lipped; uppar lip straight and flattish, notched at the apox; lower spreading, equally 3-cleft, or the middle lobe loiggost. STARENS 4, mostly exserted.-- Low moslly prostrace and difiuse porennials, will small ontire veiny leaves, and purplish or whitish furers.

1. T. Snrptulum, L. Garden Tryme.

Sam proena'sen:; lexvas flat, ovate, obtus?, entire, shori-pelioled, more or less eiliste; flusens appraximate at the end of tho branches in an oblong head.

old fislds, esoop d from cultivation and sparingly maturalized. Julg. Stcm

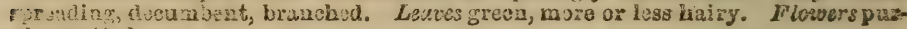
ple, spottad.

\section{CLINOPODIUM, Linn. Baste.}

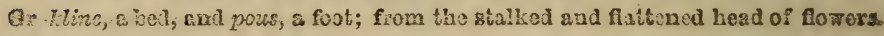

Catyx tubular, 13-nerved, ncarly equal at the base, hairy in the throat, more or less 2-lipped; upper lip 3-clcft, the Tower 2-cleft. Coromin infated in the throat, distinctly 2. lippod; upper lip erect, entire; lower spreading, 3-parted. STAMens 4 , asconding.-Perennials, with many-fowered copitute whorls of purplish flowers, and numerous linearaw-shaned exterior bracts forming co sort of involucre.

\section{C. vuladre, L. Wild Basil.}

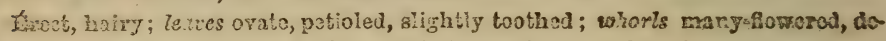
prossed-glolose; ceryx curred; bracts subulate as long 2.3 the calyx.

Hills aud old folds; natrealizol. July. Stan 1 to 2 fothigh, equaro, nimple or sparingiy wrand lod, and, as well as tho whoie plant clothed with a wbitish ๓ะol. F Fowers vale purple.

\section{HELISSA, Linn. BALM:}

Gr. meitssa, a bes; the fowers jielding an abundance of honeg.

CALYX slightly gibbous at the base, 2-lipped; vepper lip 5. toothed; loiver 3 -eleft. Conoura with a recurved-ascending tube, 2-lipped; upper lip ereet, flattish ; lows spreading, 3-lobed; tive middle-lobo: mostly brosder. STAMens 4, ascending, mostly approximate in pairs at the summit.Perennials, with few-flowered, loose, one-sided clusters of white or cream-colored flowers, and few mostly ovate bracte rasembling the leaves. 


\section{M. orficinalis, L. Common Balm.}

Upright, branching; leaves broadiy ovate, crenate-toothod, petioled, moro or lore halry; warls dimidiats or secund, losse, txillary.

Eacuped from gard inq, partisliy naturuliad. Aug. Sem 1 to 2 fest high, morg

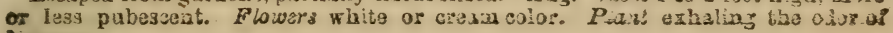
Domans.

\section{PRUNELLA, Linn. SELPERAL.}

CatrX tubular-bell-shapad, 2-lipped; upper lip broad and Alt, truneate, with 3 sho:t teath; lower 2-clest. Corouta 2-lipped; upper lip erzet, arehed, entire; lowar refaxedspreading, 3-cleft; the later.l lobes oblong, the midule ons rounded, coneave, finsly toothed. Sraviss 4, aseending under the uppor lip; filanents 2-tosthed at the apex, tho lower tooth bearing the anther. - Lono perennials, with nenrly

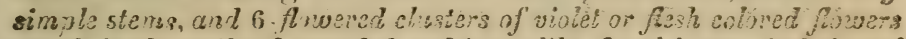
sessile in the arils of roinds d and brast like forut leaves, intricated in a czpitate silics.

\section{P. vuigaris, L. Commen Sslf-heal Thal-all.}

Letves orato-oblong, entire or tosthal, pitioled, hairg or sacothish; corolat nasily twice as long as the calyx.

Woods and fislds, common. Aug. Plent 10 to 15 inches higin, oret or szeand? ng

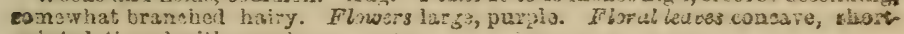
pointed, tinged with purple.

\section{SUUTHLLARIA, Iinn. SkUldga.}

Lat. scutalia, a dish, in allision to the form of the calyx.

Calyx bell-shaped, cibbous, 2lipped; the lipg entire; upper one with a winged appendago on the bick, deciduoua after flowering. Conorsa:2-lippod, with an elongated tubs, dilated at the throat; upper lip arehed, entire or nearly so, lower dilated, convex. STAMENS 4, ascending under tho upper lip; anthers approximate in pairs.-Bitter perennial herbs, with axillery: spited or racemed flowers, the short pedusodas opposite, 1-flowered of ten 1-sided.

* Flowers axillary, solitary.

\section{S. galericulata, I. Common Shullcap.}

Sthoth or somowhat doway, mostly branching; leaves orate-lanceolate, cento, wrrate, roundish and slightly cordate st base; short-petioled; flowera on sisert. podicels.

Wet shady places, common. Aug. Stem squsre, 12 to 18 inches high. Ieane $13 / 2$ inoh long, and $1 / 2$ wide, on very short petioles. Flowers blue, pubescent, $1 / 2$ to 1 inch long.

2. S. nervosa, Pursly. Nerzed Skullcap.

$8 \mathrm{~m}$ oth, simple or branched, slender; lowest leaves roundirh, petioled; matas ches ovsts, toothed, somewhat heart-shaped, exsile; syper for al orete-lanscolate, entire; flowers emall, opposite. 
Moist thickets. June. Stem 10 to 15 inches high, weak, often with a few fliforw branches. Leaves about 1 inch long, $1 / 2$ as wide, with 3 to 5 promlnent vainy underneath, thin. Flowers small, pelo-blue.

\section{S. Parvula, Michz. Small Sleullcap.}

Minutely downy, dwarf; branchod and spronding; bowest leaves round-orato, short-petioled, the others sessile orate or lance-orate, obtuse, all entire or nearly so; flowers small, axillary.

Dry banks and felds. May, June. Stem 3 to 6 inches high, simple or branched from near the base and spreding, mostly purplinh. Leaves $1 / 2$ to $3 / 4$ lnow long, sessile, distinctly veined, purplish beneath. F'onver's $1 / 4$ to $1 / 2$ inch long, blat, heiry

- Flowers in axillary and terminal racemes.

\section{S. Lateriflora, L. Mid-dog Skulicap.}

Smooth; stem upright, much branched; leaves laneo-ovate or ovate-oblong; pointed, coarsely serrate, rounded at the base, petioled, upper floral leawes scorcely longer than the calyx; flowers small, in lateral raom 3 s.

Wet shaded plases, common. Aug. Stem square, 1 to 2 foet high, very branching. Lenves opposite, 2 to 3 inches long, on pettoles 1 inch leng: Ragemes oppoitite, axillary, Eomewhat 1-siled, on long stalks. Fiowers small, blue, $1 / 4$ inol loag; the upper lip scarcoly arched. This plant was in great repute wome yoars ago al a oure for hydyophobia.

\section{S. PILOSA, Michx. Hiiry Slullcap.}

Stem erent, mostly simple, hairy; leaves remoto, rhombieovate, crenste, olture, more or less hairy; the lowest roundad and often heart-shaped; the other wedgosiaped at the base; upper foral spatulate, shorter than the bairy calyx; raceme, terminal, short.

Open dry woods. June, July. Stem 12 to 1 ï inches high, ofton pnrplish. Leares fer 1 to $21 / 3$ incbes lone, $1 / 2$ as vide, on petioles 1 ineh lons. Rareme mostly simpile, f-w-ficwertd, with opposite elliptienl bracts. Corvlı tube nearly white below, bluo st the summit, $1 / 2$ to $3 / 4$ inch long.

\section{S. Canescens, Nutt. Canescent Shullcap.}

Stem tail, branched, pubescent; leares orate or orate-lanceolate, acute, crenate, tho upper nerrowad, but the lows ronded or sllyintly heart shoped st the base, zearly smooth above, white downy benesth; flovers in loose peniculate rzemes.

Dry open woods and mealows. July. Sism 2 to 8 feet high, erect, mosily par ple. Leaves 2 to 3 inches long, 1 to 2 wide, often with a purplo margin and purple fpote. Flowers rather numerous, 3/4 inch long, deep blue, shory, in latoral and terminal racemes.

\section{S. INTEGRIfOLIA, L. Entire-leaved Steullcap.}

Whole plant downy with a minute hoarinoss; stem upright, nearly simple; iecves ob!ong-lanceolate or linear, most!y ontire, obtuse, remole, the upper on very short petioles; racems often branched, leafy; braets lanceolnte.

Koist open grouzids. Juns, July. Stem 1 to 2 feet high, sparingly branched a bive, grayish-green. Leaves 1 to 2 inches long, variable in wilth. Cursula $3 / 4$ to 1 inch long, bright blue at the summit, nearly white at the base.

\section{S. serrata, Andrews. Serrate Skullcap.}

Rather s'f nder, vpright; leaves ovato; serrate, acute or pointed at both ends, sll tapering into the petiole, green and nearly smooth on both sides; the floral laneaolato, the $u$ per shorter than the ijhtly hairy calyx; raceme mostly simple, loce, lesfy at thr Bise; upper lip of the corolla in urved.

Woods, Scuthern parts of the Strate. July. Stem 2 to 3 teot high, mooth Ifares 2 is 3 inches long. F' bowers doep blue, $\% / 3$ inch logg. 
21. Physostegia, Benth. False Dragon-mead.

Gr. phusa, a biadder, and stego, to cover; on account of the inflated caly $\mathrm{x}$ and corolla.

CaLYX nearly equally 5-tootbed, obscurely 10-nerved, after fowering infated-bell-shaped. ConouLa 2-lipped, with a much exserted long tube and infiated throat; upper lip nearly erect, somewhat concare; lmwer lip spreading, 3lobed, the lateral lobes small, the middle broad and rounded. Stamens 4, ascending under the upper lip; antirens ap. proximate-Perennial smooth herls, with upriglit slender stems, sessile leaves, and large showy fiesh colored and purplish flowers, opposite, in simple or panicled terminal leafiess, crowded spikiks.

\section{P. Virginiana, Benth. Lion's-heart. Dragon-head.}

$\boldsymbol{L}$ eaves varying from lance-linear to oratc-lanceolatc, serrate: calyz acutely and elmost equally 5-toothed; bracts shorter than the calyx, ovat, point d.

Hoist place, along rivers. Juiy, Aum. Stem rariable in height, 1 to 4 feet hich Leaves opposite, closely secsile, 4 to 5 inclies lons: $2 / 3$ inch wide, with remote shallow teeth, of a shining dark green. Fiowers in 4-roweu spilses, large psio purple, sbout 1 inch long, spotted inside.

\section{LAMIUM, Linn. DeAD-Netrife:}

Gr. laimos, the throat; in allusion to the ringent corolla.

Calyx tubular-bell-shaped, about 5-nerred, with 5 nearly equal serulate teeth. Corolla dilat d at the throat; upper lip ovate or oblong, arched; narrowed at the base; lower lip with the middle lobe broad, notched at the apex, contracted at base. Stamens 4 , ascending under the upper lip; ANTHERS approximate in pairs, - Lerls, derumbent at base, with the lowest leaves small and limg-petingled. the middie ones cor. date and doubly toothed. the foral nexrly sessile, and axillery whorled olusters of purplish flowers:

\section{L. amplexicaule, L. Common Dead-Nitile. Hen-bit.}

Leaves rounded, deeply crensto-toothd or entire, the upper clisping; lower whorts. remote, the upper crowied; corolla elongrated, the upper lip heardcd, the luwer. apotted; lateral lobes truncate.

Waste and cuitivated grounde, intrcduced. Bicnvicl. Nag-Nop. A smalt sender herb, with abcending stems, several from the fame root, 6 to 10 inches high, with opposite, short, broad hairy lares. Flouers in ciense whcr!s, purple, dorny : corolla-tube much exserted, the lowcr lip spotted with white.

23. LEONURUS, Linn. Motherwort.

Gr. leon, a lion, and oura, a tail, i. e. Lion's-taut.

Calyx top-shaped, 5-nerved, with nearly equal subulate teeth. Corolta 2-lipped; upper lip ohlong, entire, somewhat arched; lower lip spreading, 3-lobed, the middlo lobo 
larger, broad and inversely heart-shaped, the lateral oblong. STAMENS 4, ascending under the upper lip; ANTHERs ap. proximate in pairs.- Cpright herbs, with cut-loted leaves, and close whorls of pale purple flowers in their axils.

\section{Cardiaca, L. Common Motherwort:}

Comewhat hairy, tall; leaves long-petioled; the lower roundod; palmately. lobad; the floral wedge-shaped at the ba se, 3 -cleft, the lobes laneolste; uppor lip of corolla beardea.

Waste places, arnund houses, natur alized. July-Sept. Per. Stem 2 to 3 feet ligh, hranched, villous, Leares pubescent, fale beneath. Flowers in many whorls, white or with a reddish tinge. Corolla hairy. without, varieg ted within.

\section{GALEOPSIS, Linn. HeMp-Nettle.}

Or. gatea, a weasel, and opsis, resemblance; from some resemblance of the corolla: to the head of the weasel.

Caryx tubular-bell-shaped, about 5-nerved, 5-toothed, equal and spiny tipped. Corousa 2-lipped, dilated at tho throat; upper lip ovate, arched, entire; lower lip s-cleft, spreading, the middle lobe ob-cordate, the lateral lobes ovate; the palate with 2 teeth at the sinuses. STAMENS 4 , ascending under the upper lip. - Annuals or bienniels, with spreading branches and several to many.flowered whorls in the axils of the Doral leaves.

\section{G. Tetrairit, L. Common Hemp-Nettle.}

stem swollen below the joints, bristly-hairs; leaves ovate, coarsely serrate; eorof za 2 to 3 or 4 timas the length of the calyx.

Waste places, naturalized, rather common. July. Sicm 1 to a feet high, re storsely hisped, bronched. Flower's numcrous, p.ic-purple, with darker spots, in dense whorle.

\section{STACHYS; Linn. HedGE-NetTle.}

Gr. statias, a spike; in allusion to its mode of flowering.

CAryx tubularblll-shaped, 5 to 10-nerved, equally 5-. toothed, or the upper ones longer. Cororta 2-lipped; upperlip erect or spreading, often arched, entire or nearly so; lower lip usually longer and spreading, 3-lobed, the middle lobe largest. Stanens 4, ascending under the upper lip; ANTMERS approximated in pairs. - Hostiy perennial herbs, with 2 to many-flowered whorls, approxinated in terminal racemes or spilies.

\section{S. Aspera, Michx. Rongh Hedge-Nettle.}

stin ercet, angles hairy backwards; teares orate-oblong or obleng-lanccolate, arute, serrate, rounded at the base, bristly on the midrib aud veins, short-petioled ; ealyx bristly; whorls alout 6-flowered.

Wet bauks and thickets. June-Aug. Per. Plant 2 feet high, sparingly branched. Flcwers in loose whorls of 1 to 8 ; forming a turmiual leafy spike, pale purple. 
2. S. palustris, L. Marsh Hedge-Nettle.

Stem softly pubascent, or smooth below; leares oblong-lanceolate, crenate-toothed, rounded or heart-shaped at the base, rugose, hairy, nearly seasile; whorls 6 to 10 flowered; caly $x$ smooth, the teeth lanceolate, acute and somewhat spiny.

Wet places. July, Aug. Per. Siem 2 to 3 feet high, branched. Flowers purplish, in whorls, forming a long terminal spike.

3. S. HYฐsopIfolia, Michz. Smooth Hedge-Nettle.

Smooth or nearly so; leaves linear-oblong, sessile, obscurely toothed towards tho apex; whorls 4 to 6-flowered; caly $x$ smooth, lanceolate, acute; corolla twice or thrice the length of the calyx.

Wet sandy places. July. Per. Stem slender, ascending, 9 to 12 inches high. Leaves often linear, very finely toothed. Flowers purple, sessile in whorls near the summit of the stem.

\section{MARRUBIUM, Linn. Horehound.}

A name of Pliny, said to be derived from the Hebrew marro3, a bitter juice.

Calyx tubular, 5 to 10 -nerved, nearly equally 5 to 10 toothed; throat hairy. Conolla 2-lipped; upper lip erect, flattish, notched; lower lip spreading; 3-cleft, the middle lobe broadest. Stanens 4, ineluded in the tube of the corolla.-Whitish-woolly bitter perennial herbs, with rugose and crenate or cut leaves, and whitish flowers.

\section{M. vulgare, L. Common Horehound.}

Stems ascending; leaves round-ovate, crenate-toothed, petioled; flowers in distant and dense capitate whorls; calyx with 10 recurved teeth, the alternate ones shorter.

Roadsides and waste places, common, naturalized. July, Aug. Stem 12 to 18 inches high, branched from the base, covered with a white wool. Flowers small, hite, in crowded whorls. An aromatic bitter herb, much used as a clomestic medi: cine. Native of Europe.

\section{Trichostema, Linn. Blue Curls.}

Gr thrix, trikos, a hair, and stema, stamen; in allusion to the hair-like stamens.

CaLyx bell-shaped, oblique, deeply 5-cleft; the 3 upper tceth elongated, the 2 lower short. ConoLLA 5-lobed; the lobes oblong, declined; the 3 lower more or less united. STAMens 4, much exserted beyond the corolla, declined and than turned upwards.-Low somewhat clammy pubescent annuals, with entire leares, and mostly blue flowers on solitary 1 . flowered pedicels terminating the branches.

\section{T. діснотомa, L. Bastard Pennyroyel.}

Stem pubescent; leaves lance-oblong or rhombic-lonceolate, rarely lanco-linear, petiolate, entire; flowers inverted ; stamens very long, exserted.

Sandy fielols : and roadsides, common. July-Sept. Stem 10 to 12 inches high, obtusely 4-angled, bushy. Flover's axillary and terminal, becoming inverted by the twisting of the petiole, purple. Stamens slender, curred from the lower lip of the eorolla to the upper, forming a beautiful arch. 


\section{TEUCRIUM, Linn. Germander.}

\section{Named for Teucer, king of Troy.}

CALYX equally 5-toothed, or the upper tooth larger. Corolla 5-lobed; the 4 upper lobes nearly equal, oblong, declined; the lower one linge. Sramens 4, exserted from the cleft between the two upper lobes of the corolla. Achenia wrinkled. - A herbaceousdowny perennial, with white or purple flowers.

T. Canadense, L. Wild Germanier. Wood Sage.

Iroary-pubescent; leaves ovate-lanceolate, serrate, rounded at the base, shortpetiold the floral scurcely long rs than the calyx; whorls about o-flowered, crovded in a single terminal spike; ctlyx bell-shapod, with the 3 upper teeth broader.

Fields and roadsides, not rars. July. Stem 1 to 3 feet high, simple, erect, equare with coneave s.d.s. Luitres 3 times as lon; as wide, gruea above, hoary ben ath. Biacts longer than th calyx. Croilu puiplo, rarely white, apparint!y vithout the upper lip, instead of which is a fissure throug which the stanone are exo Dested.

\section{CULTIVATED ETOTICS.}

\section{OCYMUM, Linn. BasrL.}

Gr. osa, to smell; on account of the powerful scent of the plants.

CALYX 2-lippel; upper lip orbicular; lower 4-oleft. Corolla inverted or sub-bilabiate; the 4 upper lobes nearly equal, the lower one declinate, undivided, Hat or concave, carinate or saccate. Sramens 4 , declined; exterior filaments with a process at their base.

\section{O. Basinicum, L. Royal Ocymum. Sweet Basil.}

Ieavs smooth, ovate-oblong, subdentate, petiolate; calyx fringed. An exotic annual from Persia, cultivated for its delightful odor. Stem about a foot high branched, rétrorsely pubescent above. Leates smooth and soft, variously cỏlored." Flowers white, in simple terminal racemes.

\section{LAVENDULA, Linn. LAVENDER.}

Lat. lavare, to wash; the distilled water of this plant being used.as a cosmotic.

CaLYX tubular, nearly equal, 13 or rarely 15 ribbed, with 5 short teeth, the upper one often largest. Corolia 2lipped; upper lip z-lobed; lower 3-lobed. STAMENs 4, declined; filaments smooth, distinet, not toothed.-A small genus of oderiferous slirubby plants, with narrow rigid leaves, and small white flowers

L. SPICA, L. Common Lavender.

Leures linear-lancelate, tapering to the base, sessile, revolute at the eige, the 
npper ones linear-lanceolate; sptlies interrupted; bracts awl-shaped. Native in the South of Europe. A perennial aromatic plant, exhaling a delightful fragrance, 12 to 18 inches high, branching from the base. Leaves crowded at the base of the branches, clothed with a whitish down. Corolla pale-lilac, much exserted. July.

\section{ROSEMARINUS, Linn. Rosemary.}

An ancient Latin name; 'ros, dew, and marinus, of the ses.

CALYX ovate-bell-shaped, 2-lipped; upper lip entire, lower 2-parted. Corolla bilabiate; upper lip 2-parted; lower lip reflexed, 3-lubed, the middle lobe largest. Stamens 2, ascending, inferior, exserted; filaments toothed at base. Upper lobe of the style very short; stigmas minute, terminal.An erect evergreen shrub, with opposite leaves, and bright blue axililary and terminal fowers.

\section{R. ofricinalis, L. Rosemary.}

Leaves sessile, linear, smooth, with revolute margins; flowers peduncled. Na tive of South Euiope. Leaves dark green and shiningakove, downy and sometimes whitish beneath. Flowsrs bright blue, having like the ledvez a strong aromatic fragrance lilse camphor.

\section{SATUREJA, Linn. SAVORY.}

Arabic satur, the general nume for ldbiate plants.

Calyx 5-toothed, tubular, 10-ribbed. Corolla bilabiate, with the segments nearly equal. Staniens 2 to 4 diverging, scarcely exserted.-A cultivated perennial, with numerous small narrow leaves, and axillary cymes of pinle-colored flowers.

S. HoRtensis, L. Summer Navory.

Stem branching; leaves linear-oblong, entire, acute at the ends; peduncles axillary, cymose. Nutive of Italy. Cultivated as a culinary aromatic. Stem busiy, 1 to $1 \frac{1}{2}$ fuet high, woody at base, often purple. G'aly $x$ about as long as the corclia Corolla pink-co!ored- July, Aug.

\section{HYSSOPUS, Linn. HYSSOP.}

Hebrew ezob; Arabic azzof; English hyssop.

Calyx 5-toothed. Conolla 2-lipped; upper Tip crect, Alat, emarginate, lower lip 3-parted, the middle segment largest, the tube about as long as the calyz. STAMENS 2 to 4, exserted, diverging.-A showy perennial, with delicate foliage, and bright blue flowers in one sided verticels.

H. officinalis, L. Common Myssop.

Leaves linear-lanczolate, acute, entire, sessile; calyx-tceth erect, midule division of the corolla 2-lobed, entire. Native of South Europe; cultivated for its reput=d medicinal propertics. Plant 2 feet high, tufted. Flower's bright blue, apnearing in July. 


\section{ORDER 75. BORAGINACRE-Borage Family.}

Therts, Ehisfly rough-hoiry, with alternate entire leaves, and symetrical flowers atith a 5-parted calyx, a reguilar 5-lobed corolla, 5 stamens inserted on its tube, and a deeply 4-lobed cvary which forms in fruil 4 seedili.e nutlets surrounding the tase of the single seed. Futrins axillary, or mostly in one-sided racemes or spikes which aro revoluto (circinate) bofore expansion, and often bractless.

\section{ECHIUM, Tourn. VIPER's Bugloss.}

Gr. echio, a viper; from the spotted stem of some specics.

Calyx 5-parted; scgments subulate, erect. Coroum bell-shaped or funnel-form, with an. unequally spreading 5lobed border ; lobes rounded, throat expanded, naked. STAmens 5, mostly exserted, unequal. Strute filiform. Acmenia tuberculate, irrperforate-Herbs or shrubs, with entive leaves and irregular cyanic fiowers, in spicate panicled racemes.

E. vuligare, L. Viper's Bugloss. Blue-reed.

Rough-bristly; stem erect, mostly simple; stem-lerces linear-Ianocoloto, sesilio ; spines lateral, hairy, deflected; corolla-tube shorter than the calyz.

Readsiles and maadows, rare, introduced. June. Bicnnial. Stem 18 to 20 inches hirh. Leares 2 to 6 inehes long; and $1 / 4$ to $1 \mathrm{inch}$ wide, urrer ones clarfing. entire, elull green. Flowers in shortlateral spikes, at frst sprcading, than elect, dirfosed in a long and narrow raceme; corcila reddish-rurple changing to riolet-blue.

\section{LYCOPSIS, Linn. Bugios.}

C.r. lucos, a wolf, and opsis, appearance.

Corouta furnel-form, with a curred tube; the throat closed with 5 convex obtuse kristly scales placed opposite the lobes. Stamens 5, and with the style included. AcheNiA rough-wrinkled, concare (pcrforate) at the base.Annual herbs, with blae fowers, dietinguished from Anclusa only by the curved corolla tule.

\section{L. arvensis, I. Small Bugloss.}

Tery rough-bristly; lauves lano olate, obecurely toothed, the upper partly elaspIng; fowers in leafy racemes; ealyx as long (or nearly as long) as the tube of the corolla.

Iry or sandy fells and roadsiles, sparingly neturalized. June, July. Stem 1 foot hilh, erect, branching, roundish. Leaves 5 or 6 times 28 long as wick. Fiww- ere emall. Curotla sky-blue with white scales within.

\section{SYMPHYTUM, Tourn. COMPREY.}

Or. sumphcin, to grow together; probably in allusion to its reputed heal ing virtues.

Carrx 5-parted. Corolia oblong-tubular, inflated abore, 5-toothed, the throat closed with 5 converging linear-subulate scales. Stamens included; ANruers elongated. Strue 
filiform. Achenia smooth, ovate, fixed by a large perforate base.-Cuarse perennial herbs, with thick mucilaginous roots, and one-sided nodaling racemes, single or in pairs.

S. offictnale, L. Common Comfrey.

Huiry; stem branched, winged above by the decurrent leares, lower orato-lancelate, petiolate, upper and floral lanceolate; sepals lanceolate; corolla limb with resurved teeth.

Moist places, naturalizad, cultivated in gardens. June. Whole plant rough with dense hairz. Stem 2 to 3 feat high, bearing terminal revolute racemes of whita and pink flowers appearing all summor. Roo: modieinal.

\section{ONOSMODIUM, Mich. Fazse Growhell.}

So called from its near resemblance to the genus Onosma.

CALYX deeply 5-parted, with linear segments. Conolia oblong-tubular, with 5 erect lobes, naked in the throat; sey ments converging. Aintners included, nearly sossile, sagittate. Sryla much exserted, smooth. Acrienia ovoid, smooth and shising, fixed by a flat baso.- I'erennicl herbs, with oblong sessile nerved leares; and yellowish-white flowcrs in terminal and one sided ereet, leafy bracted spzked racenies.

\section{O. Viramanum, DC. Virginiun Onosmodium.}

Clothed with harah appressed bristles; leares oblong or oblong-lancealato, tho lower narrowed at the base; calyx lobes lanceolate, balf as long as the corolla, bearded with long bristtes ontside. (Lithospermum Virginianum, L.)

Bunks and hilsides. Jine-Ans. A very rourh crect plant about 18 inehes high. Leaves 1 to $2 \frac{1}{2}$ inches long, $1 / 2$ to $3 / 2$ inch wide, 3 to 5 veined. Flowers greenish-white, in lealy racemes, winich are ricured at fist, at length erect.

\section{O. Carolinanius, DC. Carolina Onosmodium.}

Clothed with long spreading bristly hairs; leares ovatelanceolate or oblongInnceolate, acute; corclla twice as long as the ealyx, with deltoid-orate lobes; axlyz lobes laneeolate; anthers oblong, longer than the narrow fi' aments.

Rirer banks and Rocky hills. June, July. Stem stout; upright, 3 to 4 feet high. zaves 2 to 4 inches long, thiekly clothed with long and shaficy hairs. Corvilus. lojes more or less hairy on the back.

\section{LTTHOSPERMUH, Tourn. Gromyel.}

Gr. Tithos, a stone, and sperma, seed; from the hard or stony sced.

Caltx 5-parted, persistont. Conolia funnel-form, or rarely salver-form, 5-lobed; lobes rounded; throut open, mostly furnished with 5 small folds or gibbous projections Srameis included; ANTIERS oblong, nearly sessili Achexia ovate, smooth or wrinkled, imperforate at base.Herbs, with rough hairy or dowiry mostly sessile leaves, and spiked or racemed leafy-bracted white or yellow flowers. 
* Tiowers white.

\section{L. Arvense, L. Corn Gromuell. Wheat-thief.}

Slender, hoary rith minute appressed hairs; leaves lanccolate or linear-lancea late; calyx norrly equal to the corclla, with spreading segments; racemes few-flowered, the lower fiowers remote.

Grainfelds, and waste grounds. June, July. Annual. Stem 12 to 18 inches With, more or less branched. Leaves 1 to 2 incheslong, brigth green, rough. Flowers small, white, subsessile, solitary in the axils of the upper leares.

\section{I. ompicinale, L. Common. Gromwell.}

Sicm herbaceous, erect, rery branching above; leaves broadly lanceolate, acute, veiny; calyx about as long as the tube of the corolla; achenia very smooth.

Taste grounds, introduced, sparingly naturalized. June, July. Siems much branched, clustared, 12 to 18 inches high. Laves grayish-green, rough on the upper side, hairy beneath 2 to 3 inches long, $1 / 2$ to $3 / 4$. wide. Flowers small, white, axillary, in leafy spilic-like racemes.

** Flowers yetlow. Perennials.

3. L. IIntum, Lehm. Hairy Puccoon.

Horbaceous, hairy above, orect; leaves linear-lancolate, rough-hairy, obtuse; the floral ovatc-Innccolate; corollo-tule alout as long as the calyx, bearded at the base inside, lobes obovate; achenia ovoid, shining.

Dry woods. May, July. Stems 8 to 12 inches high, el ustered. Fr lowors crow ded in somewhat scorpoid racemes. Corolta large, orange yellow:

\section{MIYOSOTIS, Linn. Foraet-ME-NOT.}

Gr. mus, moure, and ous, otos, ear, in allusion to the laares of some species.

Calyx 5-cleft or 5-partet. Conoula salver-form; tube short; limb flat; throwt closed with 5 short arching appendages. STAuress 5, included, on short flaments. AcueNIA smooth compressed.-Low and mostly soft-hairy herbs, wilh cntire leaves, and snall blue or white flowers in naked racemes.

\section{M. Бтигта, Link. Field Scorpion Grass.}

Whole plant somowhat hoary; stom crest, simple or branched; leaves oblong, oltuse; raceme leafy at the base, long; pedicels erect in fruit, rather shorter than the 5-cleft calyx, coroll $x$ - $\left\{u^{7} e\right.$ included. (M. arvensis, Pursin, M. vorna. Nutt.)

Dry hills and sandy woods, rare. May-Jialy. Ann. Whole plant of a grayish hue from its dense pubescence, 4 to 10 inches bigh, at length much branched. Eeares $1 / 2$ to 1 inch loug, sepsile, acutish, the lower ones obtuse. Flowers very small, whits or pale blue, on terminal revolute racemes, short at first but at length 6 to 8 inches long.

\section{M. LAXA, Lchm. Marsh Sctorpion Grass. Forget-me-not.}

Ascending stems roobing along at the baso, terete, branching, sprinklcd with minute appressed hairs; leaves linear-oblong, obtuse; pedicels filiform, longer than the flowers, spreading; calyx 5-cleft; style very short.

Ditches and marshy places, common. June-Sept. Per. Slem 6 to 15 inches Inigh, asconding from long creeping roots. Leaves scattered, scssile, 1 te 3 inches long, $1 / 4$ to $1 / 2$ inch wide, the lower often petioled. Flowers small bright blue with a yellowish eye, on pedicels $1 / 4$ to $1 / 2$ inch long.

\section{M. Palustris, With. True Forget-me-not.} Wholc plant moro or less hairy; stcm angled; leaves oblong-lanceolate, acutich; 
ofy'e nearly as long as the 5-toothed calyx. May-Sept. Per. Native of Europe, probably wrongiy attributed to this country also. Stem creeping, and with the leaves covered with close appressed bairs. Curolla bright bilus, with \& yellow eye, $2 / 8$. to $1 / 4$ inch in diameter.

\section{MERTEnSIA, Roth. Lungwort.}

In honor of Prof. Mertens, an eaply German botanist.

Carry short, 5-cleft or 5-parted. Conorla trumpetshapad, much longer than the calyx, naked or with 5 small folds in the throat; border spreading, blobed. Sramers inserted in the upper part of the trobs, protruding. STYLE long and filiform. Achenia ovoid, smoth or somewhat wrinkled. - Smoolh! perennial herbs, with pale entire ovate leaves, and showy purplish blue (rarely whiie) flowers in terninal raccines.

\section{Viranica, DC. Virginian Cowslip. Lungwort.}

S'em upright; radical leaves ovate oblong, obtase; stem-leavcs narrower: ractmes at first corymbel, elongated in fruit; corolia 4 times as loug as the calyz, zaked in the throat. (Pulmonaria Virginica.)

Allavial banks, often cultivated. May. A showy plant 10 to 20 inches hish, with smooth somemhat glaueous learas, 1 to $\mathrm{S}$ inches long. Flower's large, tricht blue, 1 inch long.

\section{EChINOSPERMUM, Swartz. Strchseed.}

Gr. elinos, a hedgehog, and sperma, seod; from the prickly nutlets.

CalyX 5-parted. Corolda salver-form, short; thruat closed by short scales, the limb with obtuse lobes. STAmens included. Acheria erect, fired to a central column, trianguLar or compressed, the margin armed with prickles, bartod at the apex.-Rougl-hairy and grayish herls, with oulong or linear leaves, and small blue fiswers in bracted racemes.

\section{E. Lappula, Lohm. Common Stickseed. Burrseed.}

Nem erect, branched abore; leaves lanceolate, sessile, tristly-ciliate; corolla longer than the calyx, border erect, spreadiaz; achenia with 2 rows of lockeil prickles on the margin.

Roadsiles, probably introduced. July, Ang: Ann. Stem erect, 10 to 20 irelses bigh. Lewes 1 inch long, $1 / 8$ to $1 / 4$ wide. Flinurs minute, blue, in leafy raccums.

\section{CYNOGLOSSUM, Tourn. Hound's-Tonaue.}

Gr. kum, a dog, and glossa, a tongue; in allusion to the form of the leares.

CaLyX 5-parted. Corolia short, funnel-form, the throat closed with 5 obtuse scales; LOBES rounded. STAMENs included. Achenia depressed or convex, laterally afficed to the base of the style, corered with short hocked prickles.$\mathrm{H} 2 *$ 
Coarse herbs, with mostly panicled racemes of blue, purple or white fowers, naked above butrally bracted at the base.

\section{G. ofrichate, I. Common Hound's-tongue.}

Clothol with silky hairs, leafy, panioled above; lower leaves laneeolato, oblong, st tenuated into a petiole; upper lanoeolate, closely sessilo by a rounded or slightly hisart-shaped base; racemes without bracts; ealyxlobes oblong, obtuse, shorter than the corolla.

Waste grounds, introduced. May, Juno. Bionniel. An erect downy plant of a thll green color, 18 to 20 irches high. Lower leaves 6 to 10 inches lon and 1 to 2 inches wide. Fifow purplish-reh in naked one-siled racemus. Fruit rough, a lhering to the filece of sheep.

\section{C. Virginicum, L. Wila Comfricy.}

Ioumbish with sprealing bristiy hairs; stem simplo, with fow leaves; tower leaves ovsl-oblong, petiolate; upper laneo-oblong,clasping by a deep heart-shaped base; racmes somewhat corymbose, nakou; calyx lo'ves acute, villous, about balf os long asthe tizbe of the eorolla.

Rich shady woods. Miay, June. Per. Stem 2 to 3 feet high, very hairy. Root tomes 5 to 6 inches long and half as wilo. Flowses pale blue or nearly white, in a torminal corymbose panicle.

3. C. Morisont, DC. Begger's Lice.

Stem erest, hairy, broally branched, leafy; leaves oblong-orate, acute, tapering to the base, thin, minutely downy undern ath and roughish above: $r$ acemes pasichat, furking, diverging, hairy. with leafy bracts at the base; pedicels reflexed in fruit:

Bovierg of wools, rather common. Ja'y. Bienniel. Stem 2 to 3 foet high, farIn: ${ }^{2}$, with many slender remote branches. Leaves entire, remote, 3 to 4 inches ioug, taperin to enchend. Flowers very small, whita or pale blue in forked ter. rainal racemes. Isalicels reflexed in fruit. Achenia convex, tho prickles with bar bod points.

CULTYVATED EAOTICS.

\section{Borago, Tourn. Borage.}

Calyx 5-parted. Corouna whecl-form, with acute seg. monts; throat closed with rays. Finaments converging. ACHENIA rounded, imperforate at base, inserted lengthwise into an excavated receptacle. - European herbs, with alternate rough leaves, and moslly blice flowers in one sided clissters revolule before expansion.

\section{B. ofmicinalis, I. Common Borage.}

leaves ovate, alteruate, the lower ones petioled; calyx spreading; peduncle ter. minal, many-fowerea. Annual. The whole plant is rough with short bristly

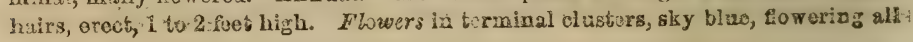
summer.

\section{ANCHUSA, Linn. Bugross.}

CALYX 5-parted. Corolita funnel-form, vaulted; tulo straight; orifice olosed with 5 prominent scales. STAMENss 
included. Stigma emarginate. Achenia perforate at the base, with mostly rugose surfaces. - Showy, mostly. Euro: pean plants with cyanic flowers.

\section{A. offictanalis, I. Bugloss Ox-tongue.}

Lexves lanceolate, clothed with short stiff appressed hairs; spikes one sided, inbricated; calyx as long as the tube of the corolla. A rough garden plant, native of Britain. Slem 2 fect high, rough with brietly hairs. Leaves long, rough. Bracts orato. If lowers purplo, with a long hairy corolla, very atiractire to bees.

\section{PULMONARIA, Linn. LUngwort.}

Catyx prismatic, 5-angled, 5-toothed. Conolia funnele form, with a cylindrical tube; cuffice hairy in 5 lines alternating with the stamens. AcHeNia imperforate- - European perennial herbs, with mostly blue flowers.

P. ofmicianalis, L. Common Lungwoort.

Punt rough; radical leares orate, cordate, seakrons; stem leeves orate, nerih; abyx a loag as the corolla tube. Native of Enrland, but naturalized and cultivated in our gardans. Stem $1 \theta$ to 15 inches bigh, with rough loves. Frowass blue, in termainal elusters.

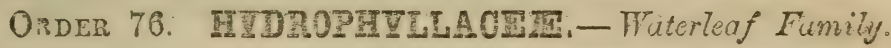

Frbs, cmmmonty hairy, with motly chlernats and cus-lobed leaves, rezular 5-parted

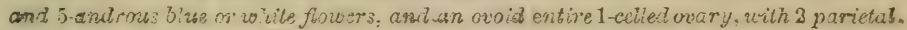

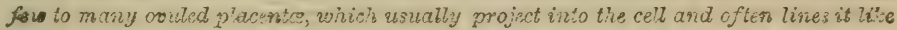
an inierior cxpsise. SrxLs 2 -cleft abore. CApoli globular, 2-ralred few-seoded.

\section{HYDROPIYLLUM, Linn. WATER-LEAP.}

Gr. Audor, water, and phullom, leaf, of no obvious application to the plast:

CALYX. 5-parted, rarely with a small appendage in eaeh sinus. Conortut bell-shaped, 5-cleft, the tube furnished with 5 lougitudiaal appendages opposite the lobe which cohere by their midlle, with their edges folded inwards, forming a noteriferous groore. STameNs 5, czserted; fluments more or less bearded. Ovary bristly-hairy. Capólne globoze, 2-celled, 2 -valved, 4 -sceded, 3 of the seeds mostly abortire. North American perennial herbs, with petioled pinnatcly or palnately veined leases, and sesrpoid braelless clistered cymes of white or pale blue flowers.

* Calyx not appendaged; flamends mush exsertad.

1. H: MACrophyLuU, Nutt. Great Wuterleaf.

Rough hairy; leaves oblong, pinnsto and finnatifid, the divisions orate, obtue,

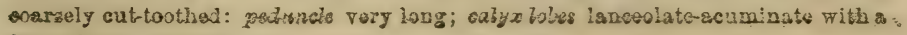
brost baso, verg hairy. 
Allegheny mountains. July. Stem about 1 foot high, almost leafless. RootEaves 1 foot long, with 9 to 13 divisions. Floroer's white in a terminal giobose rme, crowded. Corolla twice longer than the sepals. Filaments $3 / 4$ inch long.

\section{H. Viranicum, L: Virginian Waterleaf.}

Smoothish; leaves pinnately divided, the divisions ovate-lanceolate or oblong; pointed, sharply cut-toothed, the lowest mostly 2-parted, the uppermost confluent; peduncles as long as the potioles; calyx-lobes narrow-linear, bristly-ciliate.

Rich moist woods and fence-rows; common. June. Stem 12 to 16 inches high, often bxanched from the base. Leaves pinnately cut into 5 to 7 sogmentis, on long petioles. Flowers white or blue, in crowded elusters, on forked peduncles.

\section{H. Canadense, L. Canadian Waterleaf.}

Nearly smooth; leaves palmately 5 to 7 -lobed, rounded, hart-shaped at tha base; nnequally toothed; the radical leaves sometimes with 2 or 3 smail and scattored lateral leaflets; pecluncles mostly shorter than the long petioles, forked, the crowded flowers on very short petioles.

Shady woods. June. Siem 12 to 18 inches high, arising from a thickened roototock. Leaves 3 to 5 inches broad; Tobes broad, cut and toothed: Fiuscicles denso; axillary and terminal. Coro? $a$ white or variously tinged with purple, $1 / 2$ to $3 / 1 / 2$ iach broad. Filuments hairy about half way up.

* Corolla appendaged between the scpals at base; stamens scarcely exceeding t'be corolla.

\section{H. Appendeutatum, Michx. Muiry Waterleaf.}

Hairy; stem-leares palmately 5-lobed, rounded, the lobes toothed and pointed the lowest pinnately divided; cymes rather loosely flowerid; sepals lance-subulato. (Nemophila paniculata, Spreng.)

Moist woods, not common. May. Stem 12 to 18 inches himh, branched. Lexres on petioles 1 to 4 inches long, roundish in outline, the broal acute lobes diver sing in a stellate manner. Chly $x$ nearly $1 / 2$ inch long, ap penulages deflexed, 1 inch long: Corblla blue, on long peduncles.

\section{PHACELTA, Juss.}

Gr.piatelos, a fascicle, probabiy in allusion to the clustered or forked racomes.

Caryx 5-parted. Coroula opon bell-shaped, 5-cleft, the scale-like appendages in the tube sometimes obsolete. OVAPY with 2 linear adherent placentæ, each 2-ovuled. CAPSUI: ovoid, 2-valved, 4-seeded.-Iniry herbs, with alternate divided leaves and usually pale blue flowers in forled scorpoid racemes or raceme-like cymes.

\section{P. Bipinnatifida, Michx. Pinnatifid Phacelia.}

Stem somewhat erect, branching, hairy; leaves pinuately divided; the divisions or leaflets orate, acute, incisely lobed or pinuat:fad ; racemes elongated 2 to 4 partd, many-flowered; corolla-loles entire, twice as long as the linear-acuminate caly $x_{\text {. }}$

Shaded banks and damp woods, rare. May, June. Ann. Stem 10 to 20 inches high, often much branched from near the base. Lenves 3 to 6 inches long. inclading the petiole, thin and smoothish, bright blue $1 / 3$ to $1 / 2$ inch in diameter, the groovis. bordered with narrow pubescent margins. Raceme erect in fruit.

\section{P. Purshir, Buckley. Fimbriate Phacelia.}

Whole plant hairy; stem upright or ascending; lonver leaves pinnately divided; petiolate, the segments few and entire; upper deeply pinnatifid, scssile and partiy elasping, the labes lanceolate, acrte or pointod, entire; racame 8 to 10-flowered, sim. 
ple; pedicels olongated; calyx-lobes lanco-linear, acutish; corolle fimbriate. (P. ธิmbriata, Pursh. Cosmantbus fimbriatus, Nolte.)

Muist woods and river bottoms. April-June. Biennial. Plant 8 to 12 inches high, sliader and with slender branches. CHrolla light bluo, $1 / 4$ to $1 / 2$ inch in diamater, strongly laciniate-fringed, nearly destitute of folds and scales inside.

\section{COSMANTHUS, Nolte.}

Gir. Kosmos, elegance, anthos, a flower:

Calyx 5-parted, the sinuses naked. Corolla broadly bell-shaped, 5-cleft, without scales. STamens 5, slender, about as long as the corolla. STrLe bifid; ovary 1-celled, hairy above. CAPSULE 2-valved, septiferous in the middle, 2 to 4, sometimes 8-seeded.-North American annual herbs, with ailernate leaves, and white or pale blue flowers, in long bractless. racemes.

\section{C. parvifuorus, DC. Small-flowered Cosmantius.}

Diffuse, pubescent; leaves pinnatifid and trifid, middle lobe obovate, lateral acute, direrg.ng; lower leaves petiolate, upper sessile; raceme solitary; calyz-lobes larceorate, shorter than the errolla; stamens exserted; filaments hairy at base.

River banks and hillsides, common along the Susquehanna. May. Stcm often branched from the base, 4 to 8 inches in:mh. Corolla smooth, pale wius izelining to violet, greenish white in the contre, the divisions rounded.

\section{EUTOCA.}

Gr. eutoros, fruitful

CalyX 5-parted. Conolla 5-cleft, broadly bell-shaped, caducous, the tube without appendages. STamens 5, as long as the corolla. Strue bifid; ovary hairy. Capsule 1-celled, 2-valved, the valves septiferous in the middle. SEens numerous, rugulose.-Annuals, with alternate leaves and showy blue or white flowers.

\section{E. VESCIDA. Viscid Eutoca.}

Stem ascending, branched, covered with a viscid glandular pubescence; leaves ovate-cordate, crenate-serrate ; corolla broadly bell-sbajed or salver-form. A beautiful garden annual, often cultivated. Stem 1 to 2 feet high, very vised, emitting a very disagreeable odor. Calyx-segments narrow, $2 / 3$ as long as the corolla-lebsg. Corolla depp-blue with a white contre sprinkled with purple in the form of a pentagon, $3 / 4$ to 1 inch in diameter- Filaments hairy.

\section{NEMOPHILA. Grove-LOVE.}

Gr. nemos, a grove, and phileo, to love; so called from its habitat:

Calyx 10-parted, the alternate lobes reflexed. Conolla flat bell-shaped, 5-lobed; the lobes emarginate, with necteriferous cavities at the base. Stamens shorter than the eorolla. Capsule fleshy, 2-valyed, 4-seeded. 


\section{N. Insignis. B're Grove-lore.}

Lasues alternate, pinnatifix, with some of the divisions lobsd; caly $x 1 / 2$ the length of the eorolla, with acute sezments; inbes of the corolla rounlel, slightly emarginate; an iners sagittate; stigle bifil. A beautiful garlen annual 6 to 8 inches high: Sem branched. Leaves 2 to 3 inches long, $1 / 2$ inch wid, the petiole beset with higir along each sids. Pedanstes rery lonig terete; 1 - flowerod. Corolla sky blua, white in the centre. Anthers dark purple. June-Aug.

N. ATOMaRis, has white flowers, spotted with brown or black, sometimes found e ealivation.

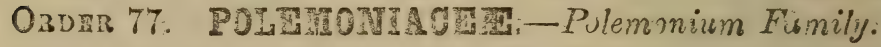

Hirbs, with alternate or opposite lexves, regutar 5 merous ant 5-androus fowors,

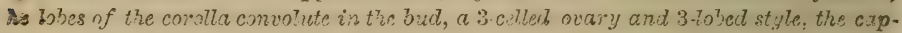

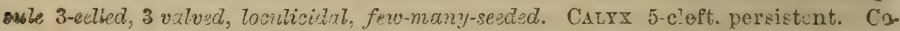
Rout with a 5 -eleft border. STAmess often unequal or unequally inserted on the traba of the corolla.

\section{PHLOX, Linn. Liycimmia.}

Gr. phox, flame, an ancient name of Lychnis, transfered to this genus.

CALYX somewhat prismatic, the segments erect. CoronIA salver-form, the tube s!endor, somewhat curred, the limb flat, 5-lobed. STANens very mequally inserted in the tube of the corolla. Capsute ovoid, with a single seed in each cell.-Chiefly perennial. North American plants, with opposite sessile mostijy entive leaves. and parple pink or white flowers, in open clusters terminal or crowded in the upper axils, cymose, mostly bracted.

* Lojes of the corolla entire. Perenniats.

1. P. paniculata, L. Panicled Phtox:

Tall and stout, smooth; leaves oblong-lanceolate, lanceolato and orato-lanonolate, acuminate, large, tapering at the baso, the upper often heart-shiped at the base; panicü pyramiâal-corymbed, wazy-flowered; calyx-teeth awa-pointed; corolla-lobes obovate.

Rich woodz and modows, cultiratad in mardens. June, July. Sien 2 to 3 fret hirh. Leares 3 to 5 inches lone. 3/4 to $11 / 4$ wide, the lower ones distinctly petioled. Flowers very numerons, pink-purplo varying to whit, in a large oblong trminal panicle. Var. acuninsta. (P. acuminata, Pursh.) has the broad and acumicate leaves downy underncath, like the stom, which is likervise occrsionally sgotted below.

\section{P. maculata, L. Spotted Phlox.}

Bmooth or slightiy roughish; stem erect. simple, spotted with purp!o; Inwer leaves lan,ecolate, the upper ncarly, ovate-laneolate, rounded or somswhat heart-shaned at the base; panic'e oblong, thyreoli or somewhat pyramidal; calyx-teeth triangu Lar-ianceolate, short, scarcely pointed:

Rich woods, moist mearows and river banks, common, often cultivated. JunoJuly. Stem 2 to 3 feet hizb. mostly simple, sometimes spotted with dark furple. I lowers mostly purple or crimson, scmetimes white, when it is $\mathrm{I}^{2}$. suareolons, Aut 
When the lower branches of the panicle ars elongatod so as to form a gyramital puniele, it is P. pyramidalis, Smith.
3. P. Carolina, L.
Carolina Phlox.

Smooth; stem.rather slender, branched at the base, ascending; leaves oblonglancelate or the upper orate-lanceolete, scute, the lower with a slender tapering baze, the upper sessile by a rounded base, marg ns revolute; calyz-teet/ short-aeuminate; corollci-iube awned; segments entire.

Opea woods and barren places, not comana. Jans, Jaly. Stem 1 to 2 feet high

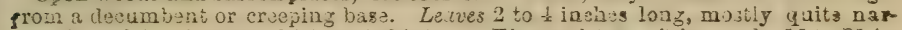

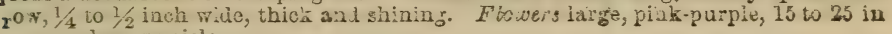
a corymbose paniele.

\section{P. picosa, L. Wairy Phlox.}

Do'my-hairy throughout; stems slender, rather uprlght; leaves lanee-linesr, of nurrowly acute, the uppermost broadest at the base; fowers loosely oorymbed; calyx-teet 2 hairg, very long, asn-like; corollu-lobes oborate, entire.

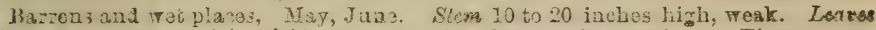
$1 \frac{1}{2}$ to 3 inchas long, $1 / 4$ to $1 / 2$ inah wide, with the mar gins reroluce. Flinoers rowopurple 0: pale, the cocoliariajs a thiru longer thea the long; sisnder tectid of tho a.!yx.

5. P. Reptens, Michz. Creeping Phlox.

Pubescont; stem crect with procumbent suckers at base; lower leaves roandisholorate, thick, those of the stem small, oral or oblong, obtuse; ejme simple, 8 to 8-flowered; calyx-teeth linear-2wl-shaped.

Damp wopils and rocky places, rare. April, May. Runnors creeping and bear

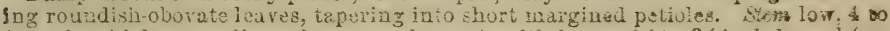
Ii) iabes high, ascending, clammg-puboscent, with leares $1 / 2$ to $2 / 4$ inch lung, $1 / 2$ w $3 / 2$ widu, remote. Flowers lar fe, reduish-parple or crimon.

* Loles of the corolla noteited at the enti. Ferennial.

\section{P. divaricats, I. Eurly-flowering Pllox.}

Minutely downy, loosely branched from ths tas s, the fowering stsms ascending; leaves ora!-Ianceolate or oblon obtuce; cyme corymbose-panicled, loorely floware?; - alyx-teeth linear-a $\mathbf{m}$-8haped; corolla-lo\}es inversely heart-shaped.

Rosky damp woods and fence-rows, common. May. F'bwering-stems 9 to 15 inches high. Upaer lawves nuariy clasping and often alternate. F lowers large, of a pecaliar brilliant grayish-blus color.

\section{P. suburata, L. Moss Pink. Monntain P̈ink.}

Minutely downy; tufted, procumbent, nuch branched; lestes awl-ghaped or narrow-linear, somewhat rigid, crowded and with numerous smaller ones clustered in the axils; corymb iew-lowared; calyz-tecth awl-shaped; corollh-lo'es nedge-shaped, emarginate.

Dry hills and sandy banks, eommon. April, May. A showy plant, forming low matted and prosirate tuifts, often cultivated in garlens. Stem 6 to 12 inches long with numerous assurgeut branehes, 2 to 3 inohes bigh. Leives $1 / 2$ inch loug. Flurvars pink-purple or rosa-color rarely white with a purple centre, 3 to $\delta$ in one oorymb.

* * Lobes of the corolla entire. Anuual.

8. P. Drummonnir, Hook. Drummonds' Phlox.

Eroct, dichotomously branched, glandular-pilose; leswes oblong or lancelata, scabrous; corymb dense-flowered; calyx hairy, segments lancolate, estaceous, elongated, rerolute; corolla-tube pilose, segments obovate entire. July, Aug. A beautiful annual species, native of Texas, common in cultivation. Stom 8 to 12 inches high, and with the leaves rough-glandular. Flowers very showy, all shades from white to dark-purple, with a deeper colored eentre. 


\section{POLEMONIUM, Tourn. GreeK Valerian.}

Wame employed by Dioscorides, from polemos, $\nabla a r$; of doubtful application.

CaLYX bell-shaped, 5-cleft. Corolla bell-shaped-rotate; tube very short, closed by the hairy appendages at the bases of the 5 filaments. CaPsule few, several-seeded.-Low branching heris, with alternate pinnate leaves, and blue or white flowers, in nearly bractless corymbs.

1. P. reptans, L. Greel Valerian. Jacob's Ladder.

Smooth, diffusely branched; leaves 7 to 11-foliate; leaflets ovate-lonceolato or oblong, acute, entire; corymbs few-flowered; flowers noduing.

Moist woods and shady river banks. May. Per. A handsome plant often cultivated, 12 to 18 inches high, with a weak and fleshy stem. Leajlets mostiy 7 , subopposite, smooth, as well as the common petiole. Flowers blue, in small noding corymbs at the end of the branches.

2. P. caruleum, L. Greek Vaterian.

- Srem smooth, simple, erect; leaves pinnately 11 to 17 -foliate; segments acuminate; fowers erect; caly $x$ as long as the tube of the corolla; cells of capsule 6 to 10-seeded. Native of England. Bienniel. Stems clustered, several from the same root, about 2 fuet high, hollow, stout, each dividing at top into a corymbose paniele. Leaves mostly radical, on long grooved petioles. Flowers blue, about $1 / 2$ inch in diameter, terminal, suberect.

\section{CULTIVATED ORNAMEVTAL PLANTS.}

\section{GILIA, Ruiz \& Pavon.}

Calyz 5-cleft, membranaceous, smooth or downy. Corolla somewhat funnel shaped, 5-parted. STAMENS 5, inserted on the inner side of the tube of the corolla. Disk cup-form. Capsule oblong or ovoid, 3-celled few-seeded.Showy annual or bienniel plants, with alternate pinnatifid leaves, and blue or particolored flowers in close capitute clusters or seattered panicles.

\section{G. TRICOLOR, Benth. Tri-colored Gilia.}

Stem erect, nearly smooth; leaves twice or thrice pinnatifid, with narrow linear eegments.; cymes paniculate, 3 to 6 flowered; caly $x$ shorter than the tube of the corolla. downy; corolla tricolored, with a very short tube. An elegant garden plant native of California. July, Aug. Slem 6 to 12 inches high, with bright green shining leaves. Flowers numerous, the limb of the corolla pale lilac-blue, throat purple and tube yellow. Stamens $1 / 2$ as long as the corolla.

\section{G. Achillemfolia, Benth. Millfoil-leaved Gilia.}

Stem ereet, hairy; leaves pinnatifid, somewhat hairy toward the base, neariy mooth at the extremety; flowers corymbed, more dense then in G. tricolor; calym shorter than the tube of the corolla. Native of California. July, $\Delta u g$. Stem 10 to 15 inches high. Flowers bright purple, $1 / 2$ inch in dianaeter. 


\section{IPOMOPSIS, Linn.}

Ipomea, cypress-vine, and opsis, resemblance.

Calyx 5-parted, tubular and membranaceous. Corouta funnel-shaped, the tube much exserted, deciduous. STAmens 5, inserted in the tube of the corolla. Capsule 3celled, many-seeded; seeds angular.-Showy bienniels, with alternate finely pinnatifid leaves, and showy scarlet, orange or reddish flowers in clustered panicles.

I. PICTA, L. Painted Ipomopsis.

Stem erect, tall, hairy; leaves erowded, pinnatifid, with subulate divisions; thyrse elongated, with very short branches; cor olla elongated, with a slender tube, and spreading segments; stamens much exserted. Native of Carolina. Aug. A splendid plant, 2 to 4 feet high, bearing at the top a thyrse of flowers 1 foot long. Corolla $1 \frac{1}{4}$ inch long, orange-red, spotted with carmine, the mouth of the tube nearly white.

\section{ORdER 78. CONVOLVULACE琶-Bindued Family.}

Twining or traiting herbs, with alternate, entire, or lobed leaves, and rcgular 5-androus flowers, with a calyx of 5 imbrieated, persistent sepals, a 5-plaited or 5-lobed corolla, twisted in the bud, and a 2-celled (rarely 3-celled) ovary, with a pair of erect ovules from the base of each cell, the cells often doubled by a fulse partition. FlowERS usually large and showy, opening but for one day. STAmexs 5 , inserted into the base of the corolla. Frurr a globular 2 to 6-seeded capsule.

\section{Sub-order . I. CONVOLVUlacE E. The True Bind- WEED FAMILY.}

Embryo with cotyledons; carpels united. Frutt capsular, dehiscent.-Green and leafy plants.

\section{Calystegia, R. Brown. Bracted Bindweed.}

Gr. kalyx, calyx, and stego, to eover; alluding to the bracts inclosing the calyx.

CALYX 5-parted, enclosed in 2 large foliaceous bracts; sepals equal. Corolla between bell-shaped and funnelform, 5 -folded, the border obscurely 5 -lobed or entire. STAMENS 5, included. Strle 1; stigmas 2; ovary imperfectly 2-celled. Capsule 1-celled, 4-seeded.-Perennials, with heart-shaped or arrow-shaped leaves, and axillary 1-flowered peduncles.

1. C. Sepium, R. Br. Hedge Bindweed.

Smooth; stem twining; leaves arrow-shaped or somewhat halbert-form, pointed, the lobes at base obliquely tru ncate and often toothed; peduncles 4-angled, 1-flow. ered; braets heart-shaped, much longer than the calyx. (Convolvulus sepium, L.) 
A vigorous climber, in hedges and low grounds. June, July; cultivated. Floro. ers 2 bout 2 inches in diameter, white, often tinged with rose-color, opening at dawn and cloudy weather.

\section{C. spitham жa, Pursh. Erect Bindweed.}

Downy; stem low and mostly simple, erect or ascending; leaves oblong-lanceolate, sub-cordate or auricled at base; obtuse or pointed at the apex; peduncles usually longer than the leares, 1-flowered. (Convolvulus stans, Michx.)

Dry fields and hilly pastures. June, July. Stem 6 to 12 inches high, not twining, branching, leafy. Leaves 2 to 3 inches long, $1 / 2$ as wide, with an abrupt cordate hase, on petioles, $1 / 2$ to $3 / 4$ inch long. Flowers 2 inches long, white, on poduncles; 2 to 4 inches long. Bracts concealing the calyx.

\section{CONVOLVULUUS, Linn. Morning=Glony.}

Lat. convolvo, to entwine.

Calyx 5-parted, naked. Conolua bell-shaped or funnelform, with a spreading, nearly entire, or 5 lobed border. Stamers 5, mostly included. Strue 1, often 2-cleft at the apex ; stigmas 2, rarely 3. CAPSule 2 to 3 -celled, 2 to 3 valved.-Chiefly twining or trailing plants, often with milky juice, and axillary peduncles, 1-many-flowered.

Skc. I. Convolvulus proper.-Stigmas 2, linear; capsule 2-celled.

\section{C. ARvensis, L. Small Bindweed.}

Stem procumbent or twining, low, angled, somewhat hairy ; leaves ovate-oblong; arrow-shaped, with acute lobes at the base; peduncles mostly 1-flowered, bibracteate near the base; sepals roundish-ovate.

Fields, common, introduced from Europe; a very troublesome weed. June, July. Stems several feet long. Leaves 1 to 2 inches long, the lower ones obtuse, on short petioles. Flower's 1 inch long, white, of ten with a tinge of red, on peduncles longer than the bracts.

SEC. II. IPomøa, L. Stigmas 2, globular or united into one; capsule 2-elled, 4-seoded.

\section{C. panduratus, I. Wild Potato-vine.}

Stem trailing or sometirzes twining; leaves broad-cordate or panduriform; pes duncles 1 to 5 -flowered, longer than the petioles; calyx smooth, with ovate-oblong sepals; corolla open-funnel-form.

Sandy fields and dry banks common. July, Aug. Stems long and stout, trom a thick root which often weighs 10 to 20 pounds. Leuves 2 to 3 inches iong, and about the same width, acute or obtuse, occasionally some of them are contracted at the side so as to be fiddle-shaped. Flowers 3 inches long, purplish and white, opening in the forenoon. Mun-of-the-earth.

3. C. LAcunosus, Spreng. Morning-Glory.

Rather smooth; stem ereeping and twining, slender; leaves heart-shaped, pointed, angular-lobed or entire, on long petioles; peduncles very short, 1 to 3 -flowered sepals oblong-lanceolate, acute, half as long as the corolla; corolla 5-lobed.

Wonds, dry fields and hills, rare. Aug., Sept. A small prostrate species. 2 to 6 feet long. Leaves 3 inches long, $11 / 2$ wide, deeply heart-shaped, often cleeply 3 -lobed; petioles 1 to 3 inches long. Flowers $1 / 2$ to $2 / 3$ inch in diameter, $3 / 4$ inch long, white, with a purplish rim, the corolla 5-lobed.

Sec. III. Pharbitis, Choisy. Stigmas mostly 3, united, capitate; capsule 3: solled; cells 2-seeded. 


\section{C. NiL, L. Blue Morning-Glory.}

Stem hairy, twining; leaves cordate, 3-lobed. the intermediate lobe dilated at the base, the lateral ones shorter, acute; peduncles short, 1 to 2 -flowered.

A beautiful plant, indigenous in the southern parts of the State, but known as a garden plant. July-Sept. Calyx hairy, the segments long-acuminate, Flowers srge, the tube white and the border of a clear sky blue color.

\section{C. Purpureus, L. Common Morning-Glory.}

Twining, hairy; leaves roundish-heart-shaped, entire, pointed ; peduncles elonga • ted, 3 to 6-flowered; sepals ovate-lanceolate, acute; corolla funnel-form with a spreading entire border.

Fields and about gardens, common in cultivation. June-Sept. Stem climbing 8 to 25 feet. Flnver's large, beautiful, dark-purple, violet-blue, pink, and sometimes nearly white.

Sec. IV. Batatus. Stigma capitate, 2-lobed; ovary 4 or by abortion 3 or 2-celled

\section{C. Batatus, L. Sweet Potato.}

Stem creeping, rarely trining; leaves heart-shaped, hastate, angular, 5-veined, smoothis $\mathbf{h}$; peduncles long; flowers fascicled; sepals lanceolate, acuminate. The sweet potato is found growing wild in both Indies, and is cultivated in all warm countries. The stem is round, hispid, prestrate, sending out scattered oblong tubers which are yellowish or purplish without. Flowers large, purple and white.

\section{QUAMOCLIT, Tourn. Cypress-vine.}

Gr. kuamos, a bean, klitos, dwarf; resembles the climbing bean, but smaller.

Szpals 5, mostly mucronate. Coroula tubular-cy!indrical. Stamens exserted. STYLE 1 ; stigma capitate, 2lobed; ovary 4-celled, cells 1-seeded-Twining herbs, often with pinnatifid divided leaves, and delicate white, yellow, orange and scarlet flowers.

\section{Q. vulgaris, Choisy. Jasmine Bindweed.}

Leaves pinnatifld to the midvein, segments linear, parallel, acute; peduncles 1 to 2-flowered; sepals ovate-lanceolate.

An exceeding delicate vine, common in cultivation. July, Aug. Stem smooth, very slender, twining and climbing to the height of 5 to 10 feet. Flovers $1 / 2$ to $3 / 4$ inch in diameter, scarlet, varying to crimson and rose-color, sometimes white. Curolla-tube slender, limb flat, 5-parted, Cypress-Vine,

2. Q. Cocornea, Monch. Surlet-flowered Morning-Glory.

Leaves heart-shaped, acuminate, entire or angular at base; peduncles elongated, about 5-flowered; calyx awned. Native of the Southern States, cultivated. July, Aug. Annual, Flowers searlet or sometimes tinged with yellow.

Sub-order II. CUSCUTINEA. The Dodder Family.

Eimвкто slender, spirally coiled, entirely destitute of cotyledons.-Parasitic yellowish or reddish plants, with thread-like naked stems and minute scales in place of leaves.

\section{CUSCUTA, Tourn. Dodder.}

Calrx 5-(rarely 4)-cleft. Coroura globose-bell-shaped, 
4 to 5 -cleft. Stamens 4 to 5 , attached to the tube of the corolla, furnished with a scale-like, often fringed appendage at their base. STYLes 2, distinct (or rarely united). Ovary 2-celled, 4-ovuled. Capsule mostly 4-seeded. Embryo thread-shaped, spirally cuiled in the rather fleshy albumen, entirely destitute of cotyledons.-Leafless, chiefly annual, yellowish or reddish herbs, with thread-like stems, bearing a few minute scales in place of leaves; germinating in the soil, at length withering at the root and becoming entirely parasitic on the bark of herbs and shrubs; flowers small cymoseclustered, mostly white.

\section{C. epilinum, Wiche. Flax Dodder.}

Stem very slender; flowers in small and dense scattered heads; corolla globularcylindrical, scarcely exceeding the 5-parted calyx ; leaves small; styles at first upright, not longer than the ovary.

Flax-fields, common; introduced from Europe. June. Stem reddish-orange. Flowers yellowish-white. Calyx thickish. Stamens included. Stigma acute. Capsule depressed-globose, surrounded with the withering corolla.

\section{C. Gronovit, Willd. Common Dodder.}

Stem thickish, branched; scales oblong, fimbriate; flowers peduncled, in close or open cymes; corolla bell-shaped, 5-cleft, with short spreading or reflexed seg. ments, withering at the base of the capsule; calyx-lobes broad ovate, obtuse; style diverging; stigma capitate.

Low grounds very common, chiefly on herbs. Aug., Sept. Stem smooth, slender, 3 to 5 feet long, and with the scales of a light orange-color, wholly destitute of green, always twining from right to left, or hanging in festoons. Galy $x$ and corollh more or less dotted with pellueid glands, yellowish-white.

3. C. compacta, Juss. Compact-flowered Dodder.

Bracts and sepals orbicular, concave, appressed, slightly crenate, much shorter than the slender cylindrical tube of the corolla. Flowers sessile, in dense elusters; stamens shorter than the linear-oblong spreading lobes of the corolla; scules pinnatifid-fringed.

Dry grounds, on shrubs. Southern parts of the State.

\section{ORDER 79. SOLANACER.-Nightshade Family:}

Herbaccous or rarely shrubby plants, with a colorless juice, alternate leaves, regi: lar 5-merous and 5-androus flowers, and the fruit a 2-celled (rarely 3 to 5-celled) many-seeded capsule or berry. CALYx usually persistent. Coroula plaited or infolded; valvate in the bud. Stamens mostly equally inserted on the corolla. Strles and stigma single. Placknta in the axis, projecting far into the cells. SEEDS nearly amphitropous.

\section{NICOTIANA, Linn. Toвacco.}

In honor of John Nicot, of Languedoc, who is supposed to have introduced it into Europe.

Calyx tubular-bell-shaped, 5-cleft. Corolda funnel- 
form or salver-form, usually with a long tube ; border plaited, 5-lobed. Stamens 5. Stigma capitate. Capsule 2celled, 2 to 4 -valved from the apex. SEeds minute-Rank acrid narcotic herbs, mostly claminy-pubescent, with large simple entire leaves and lurid fiowers in racemes or panicles, white, tinged with green or purple.

1. N. rustica, L. Wild Tulacco.

Vircil-pubescent; leaves petioled, ovate; corollu-tube cylindrical, $2 / 3$ longer than the calyx, the lobes rounded.

Sparingly noturalized near dwellings and old fields. Said to have been introduced by the Indians. Aug. Stem 12 to 18 inches high. F'lowers greanish-yellow, in a terminal panicle or racems.

2. N. TABACUM, L. Virginian Tubacco.

Viscid-pubescent; leaves lanceolate, sessile, decurrent; corolla-tube inflated at the throat; lobes acute. Native of Central America. Extensively caltivated in the Middle and Western States, and is exported in vast quantities. Siem 4 to 6 fect high, paniculate above. Leaves 1 to 2 fect long, 6 to 12 inches wide, entire. Flowers rose-color. July. Taken into the stomach this plant is a porrerful nareotic poison.

\section{DATURA, Linn. JAMESTOWN-WEed.}

Altered from the Arabic name, Tatrah.

Calyx prismatic, 5-toothed, seperating transversely above the base in fruit. Corocua funnel-forın, with a large and spreading 5 -toothed petioled border. Stamens 5. Stiama 2-lipped. Capsure globular, prickly 4-valved, 2 celled; cells 2 to 3-parted, many-seelel. -Nircotic-prisonnus ranls wecds, with ovate angulur-tontihed leaves. and large and showy fow. ers on short pedincles in the forks of the branching stems.

D. stramonium, L. Thorn-Apple. Jumestown-Weed.

Leaves ovate, smooth, angular-dentate; calyx-teeth pointed; capsule prickly, erect.

Waste grounds and roadsides, common; introdued. July-Sept. Annual. Plant 2 to 3 feet, often flowering when only 1 foot high. Stem smooth, hollow. Leaves large, situated at the base of the 2 forked branches. Flowers 2 to 3 inches long, solitary; corolla funnel-form, with a long tube sud a plaited 5-toothed border, white with a slight tinge of purple. The whole plant is poisonous.

\section{HYOSCYAMUS, Tourn. Henbane.}

Gr. hus, huss, a hog, kuamos, a bean; the fruit is said to be not poisonous to swine.

Calyx tubular, 5-toothed. Cororga funnel-form, irregular, border 5-lobed, plaited. Stamens 5, declined. Stigma capitate. Capsule ovoid, 2-celled, covered by the persistent calyx, opening transversely all round the apex which falls off like a lid.-Clammy-pubescent rank herbs, with angled or toothed leaves and lurid flowers in their axils. 


\section{H. NIGER, L. Black Henbane.}

Stem branching, erect, very leafy; leaves clas ping, sinuate-toothed and angled; flowers sessile, in one-sided at length recurved leafy spikes.

A tall foetid weed, sparingly naturalized, growing about waste places. July. Annual. Stcm 1 to 2 feet high, round. Flowers large, dull-yellow, with dark purple veins. A powerful narcotic. Introduced from Europe.

\section{NICANDRA, Adans. Apple of Peru.}

Named after the poet Nicander, of Colophon.

CaLyx 5-parted, 5-angled, the divisions arrow-shaped, cnlarged and inflated in fruit, inclosing the 3 to 5-celled globular dry berry. Corolla open-bell-shaped, with the plaited border nearly entire. Stamens 5, converging.-An annual smooth herb, with ovate sinuate-toothed or angled leaves and solitary pale blue flowers on axillary and ter minal peduncle.

\section{Puysaloides, Gært. Apple of Peru.}

Stem herbaccous; leaves smooth, sinuate, angular; flowers solitary, axillary, on short peduncles; calyx closed with the angles very acute.

Cultirated grounds, sparingly naturalized. Natise of Peru. Aug. Stem 2 to 5 feet high, very branching. Leures large, oblong decurrent. Corolla slirhtiy lobed, pale blue, white and with 5 blue spots in the centre.

\section{PHYSAlis, Linn. Ground Cherry.}

Gr. phusa, a bladcer, alluding to the inflated calyx.

CaLYX 5-cleft, persistent, at length much inflated. CoRoLLA spreading-bell-shaped, with a very short tube, marked with 5 concare spots at the. base; border plaited, somewhat 5-lobed. Stanens 5, converging. Fruit a 2-celled globular berry, enclosed within the inflated ealyx.-Herbs, rarely shrubs, with the leaves often unequally in pairs, and axillary or extra-axillary flowers on 1-flowered peduncles.

1. P. viscosa, L. Ground Cherry. Yellow Henbane.

Clammy-pubscent, $1 \mathrm{ow}$, very diffusely branched; leaves ovate or orate-lanccolate, heart-shaped or a cute at base, somewhat angled, tuothed or entire; flowers nodding.

Dry fields and hillsides, common. July, Aug. Per. A very variable plant, and embracing many nominal species. Stem about 1 font hiph, more or less decumbent. Leares 1 to 4 inches long, $1 / 2$ to $2 / 3$ or even as wide, acute, acuminate or often cltuse at the apex. Corclla pale grcenish yellow with 5 brownish spots at lase. Bcrry yellowish, pleasant tasted, wholly inclosed in the much inflated calyx.

2. P. Philadelphica, Lam. Philadelphia Ground Cherry. Smoothish, erect; leaves obliquely ovate, pointed, angled; calyx open in fruit, scarcely inclosing the berry.

Dry river banks. July. Ann. "Flowsrs larger than in the preceeding species, yellow, with brown stripes." 


\section{SOLANUM, Linn. Nightshade.}

Calyx 5 to 10.parted, persistent, spreading. Corolla mostly wheel-shaped; tube very short; limb plaited in the bud 5 to 10-lobed. STAMENs 5, exserted, converging around the style; filaments very short. BERRY usually 2celled.-Herbs or shrubs, unarmed or prickly with pinnatifid or undivided, sometimes geminate leaves, and lateral solitary or extra solitary peduncles.

\section{S. Dulcamara, L. Bittersweet Nightshade.}

Stem somewhat shrubby, climbing, mostly swooth; leares ovate-heart-shaped, the upper ones halbert-shaped, or with 2 ear-like lobcs at the base; flowers in small cymes, which become lateral.

Moist banks and around dwellings, naturalized. June, July. Per. Stem branching, several fect long. Flowers drooping on brauching peduncles from the side of the stem. Corollu of reflexed, segments, purple, with a green spot on each segment. Berries bright red.

2. S. nigrum, L. Black Nightshade.

Low, much branched and often spreading; leaves orate, wavy-toothef; flowers small, in lateral umbel-like clusters, drooping; berries globular.

Waste places. common, introduced. July, Aug. Bienniel. A poisonous plant of no beauty, about a foot high. Leaves mostly erose on the margin as if gnawed by insects. F'lower's very small, white, with yellow anthors. Berries black.

3. S. Carolinense, L. Horse-Nettle.

Ilerbaceous, prickly: leaves orate-oblong, acute, sinuate-toothed or angled, hcary-pubescent, prickly along the midrib ; flowers large, in simple loose racemes; berry globular.

Roadsides, sandy soil, rare. June, July. Per. Stem erect, prickly, branched, about one foot high. Leaves 4 to 6 inches long, 2 to 3 wide, usually in unequal pairs, with a few large repand lobes or teeth. Flowers pale blue or white, 1 to $11 / 4$ inch in diameter, in lateral racemes. Burry globular, orange-yellow.

\section{CULTTVATED SPECTES.}

\section{S. tuberosum, L. Common Potato.}

Root tuberous; stem herbaceous, winged; leaves interruptedly-pinnate, pubescent; flowers sub-corymbed; corolla 5-anglid. This valuable plant is supposed to be a native of South America where it still grows wild. Although it now con. stitutes a large portion of the food of man, it was scarcely known until the 17 th century, and was not extensively cultivated until the micldle of the 18 th. Numerous varieties are raiscd from the setd, which differ in the time of ripening, quality, form, color, size, \&e.

\section{S. melongena, L. Egg Plant.}

Prickly; leaves ovate, sub-sinuate, downy; flowers many-parted. Ann. Stem branching, about 2 feet high. The fruit consists of large egg-shapcd berries, from the size of an egg to that of a water melon, smooth, white or of ' $a$ glossy purple. It is prepared in various ways, and considered delicious.

Sec. II. Lycopensicum, Mill. Berries 3 to 6-eelled, often torose.

6. S. LYCOPERSICUM, L. Tomato.

Hairy; stem herbaceous, weak; leaves unequally pinnatifid, segments cut, glan- 
cous beneath; fruit torulose, furrowed, smooth. A common garden plant, resembling the potato in its general aspect, 2 to 4 feot high. Flowers greenishyellow. Fruit large, minstly with or without acute furrows, at first green, becoming when ripe a beautiful red or golden yeliow. The fruit is prepared in tarious ways, for sauces, steris, \&c.

\section{CULTIVATED EXOTICS.}

\section{ATROPA, Linn. Deadly Nightshade.}

Name of one of the three fates of Grecian mythology, whose office was to cut the thread of human life.

Calyx persistent, 5-cleft. Cororta bell-shaped. Sta* Mens 5, distant. Berry globose, 2-celled, situated on the calys:-Herls, shrubs or trees, natives of the Ohd World.

\section{A. Belladonna, L. Deadly Nightshade.}

Stem herbaceous; leaves ovate, entire, acuminate, at both ends in pairs, on short retioles; flowers solitary, somewhat drooping, on short 1-flowered axillary peduncles; calyx deeply divided into 5 ovate segments; stamens shorter than tho corolla, bearing heart-ihaped 4-lubed anthers. Native of Europe. A powerful harcotic poison, often cultivated. Stem 5 feet high, branching below, and with the leares purplish. Flowers pale purple externally, darker on the upper internal surfaee, and yellowish below. Berries about the size of a small cherry with a transverse furrow, shining, smooth, of a dark violet black color.

\section{LYCIUM, Linn. Fat.se Jessamine.}

From Lycia, the native cbuntry of the original species.

Calyx 2 to 5-cleft, short. Conolla tubular; limb most. 1.y 5-lobed, spreading; orifice closed by the beard of the filaments. Stamens 4 to 5, exserted. Berry 2-celled; seeds several, reniform. - Shrubs, with the branches ending in spinose points, and often with axillary spines. Flowers ax. illary, solitary, or in pairs.

L. Barbarum, Linn. Matrimony Vine.

Stem angular, with long pendulous branches, somewhat spiny; leaves often fasciculate, lanceolate; calyx mostly 3 -cleft. Native of Barbary, cultivated and nearly naturalized. A handsome shrub, growing to the height of 8 to 12 feet; with long slexder trailing or hanging branches, which overspread walls, \&c., with a thick tangled mass. Leaves smooth, 3 times as long as wide. Flowers greenistpurple. Berries orange-red.

\section{CAPsicuil, Tourn. Cayeíne Pepper.}

Gr. kapto, to bite; from the acrility of the fruit.

CALYX erect, 5-cleft, persistent. ConoLla rotate, with a very short tube and plaited 5-lobed limb. Stamens 5, with converging anthers. Fruit a juiceless berry, 2 to 4 -celled, 
many-seeded.-A large genus of herlaceous or shrubby plants, pervaded by a hot and pungent principle, with the leaves ofter in pairs, and axillary solitary peduncles.
C. Annum, $\mathrm{I}$.
Red Pepper.
Cayenne Pepper.

Stem herbaceous, angular, branching above; leaves orate, acuminate, entire, petiolate, smooth; peduncles axillary, smooth; calyx angular, with short, acute lobes; corolla-loles spreading, longer than the stamens; berry oblong or sub-globose. Native of South America. Ann. Cultirated in gardens for its stimulating fruit, which is well known. Stem 1 to 2 feet high. Flowers solitary, on crowded peduncles of a greeni: $h$-white color.

\section{PETUNIA, Juss.}

The Brazilian name is petun, Latinized petunia.

Calyx-Tube short, the limb 5-cleft, leafy. Corolita funnel-form, with a cylindric tube; $\lim 6$ in 5 unequal plaited lobes. Stamens 5, unequal, included, arising from the middle of the corolla-tube. CaPsule 2-valved, manyseeded.-Herbs, with simple leaves, and axillary solitary showy flowers.

\section{P. nyctaginiflora. White Petunia.}

Diffuse; clothed with elammy hairs; lower leaves alternate, ovate, obtuse, hairy; floral leaves scssile, cordate-ovate, opposite; corolla-tube eylindric, 3 or 4 times longer than the spatulate sepals, limb flat, spreading. A handsome border flower, native of Brazil. Stem 1 to 3 feet long. Leaves 2 to 3 inches long.

\section{P. violacea, L. Purple Petunia.}

Stem weak, viscid pilose, prostrate; leaves orate, acute, on short petioles; corolla ventricese, with ovate acute segments. Native of Brazil. A handsome trailing or climbing plant, quite popular in cultivation. Whole plant clothed with clammy hairs. Stems several from the same root, simple or somewhat branched, 2 to 8 feet long. Leaves 1 to 2 inches long, flesby, nearly smooth beneath. Teduncles as long as the learcs. Corolla bright purple, 1 inch or more broad, upper segments smallest. These two species are found to hybridize freely, and the union of the two produces a great number of beautiful varieties, such as violet, white and purple, flesh color, \&c., some of which are highly fragrant.

\section{Order 80. GRNTIANACE正－Gentian Family.}

Smooth herbs, with a colorless bitter juice, mostly opposite sessite entire leaves without stipules, regular flowers with the stamiens as many as the lobes of the corolla, mostly twisted in cestivation, a 1-celled ovary with 2 parietal placento: the fruit a 2-valved many-seeded capsule. CALIX persistent. Corolid mostly withering-persistent, the stamens inserted on its tube.

\section{SabBatia, Adans. American Centadry.} Dedicated to Sabbati, an carly Italian botanist.

Calyx 5 to 12-parted, the divisions slender. Corolid 
5 to 12 -parted, wheel-shaped. STAMens 5 to 12 , with erect at length recurved anthers. STYLE 2-parted, slender, with spiral divisions. Capsule 1-celled, the valves a little introflexed.-Biennicls, with slender stems, and cymose-panicled handsome white or rose-purple flowers.

\section{S. Angularis, Pursh. Common Centuury.}

Stem square and 4 angled, stiff, erect, much branched above; leaves ovate or ovate-heart-shaped, clasping; calyx-lobes lance-linear, neariy $1 / 2$ as long as the corolla ; corolla-labes ovaterelliptical.

Dry neglected fields and river banks. July, Aug. Stem 12 to 20 inches high, with opposite many-flowered branches. Leaves closely erubracing the stem, 1 to 2 inches long, $1 / 2$ to $1 \frac{1}{2}$ wide, obscurely 5 -nerved. Flowers showy, 1 to $1 \frac{1}{4}$ inch in diameter, deep rase-color with a yellowish-green 5-rayod star in the centre,

\section{S. Gracilis, Salisb. Slender Centaury.}

Stem, branches and peduncles very slender, diffuse; leaves linear, the lower rather oblong; calyx-segments linear-bristle-shaped, ahout as long as the corolla; carolla 5-parted, with elliptic-oblong obtuse lobes.

Wet grounds. July, Aug. Stem 10 to 15 inches high, with long diverging branches. Panicle terminal, with spreading few-flowered branches. F'lowers purple, on long peduncles.

3. S. Stellaris, Pursh. Star flowered Centaury.

Stem weak, nearly round; leaves oblong or ovate-lanceolate, the uppermost linear; calyx-lobes linear subulate, about half as long as the obcvate lobes of the corolla.

Brackish meadows. Aur., Sept. Stem 12 to 18 inches high, slightly angular, dichotomously branched; branches elon gated, 1 -flowered. Leaves somewhat fieshy, 1 to 2 inches long, sessile. Flowers bright purple or rose-color, with a yellow star in the centre, edged with crimson.

\section{S. Chlonoides, Pursh. Large-fowered Centaury.}

Stem slender, weak, nearly round; leaves oblong-lanceolate, erect; flowers 7 to 12-parted; sepals linear, shorter than the elliptical-lanceolate lobes of the corolla,

Border of brackish ponds. July -Sept. Stem 2 to 3 feet high, loosely panicled above, with few 1-flowered branches. Le vees 1 to $11 / 2$ inch lang, opposite, entire, smooth, elosely sessile, acute. Carolla $11 / 3$ to 2 inches in diameter, bright purple, with a yellow base, the segments spatulate, rounded at the end.

\section{ERYThR EA, Pers. Centaury,} Gr. eruthros, red; from the color of the flowers,

Calyx 4 to 5-parted, the divisions slender. Corolla funnel-form, with a slender tube and a 4 to 5 -parted limb, which in withering twists on the pod. STAMENS 5, rarely 4 ; anthers after flowering spirally twisted. STYLE slender, single; stigma capitate or 2-lipped.-Low and small branching annuals, with sub angular stems, samewhat ouneale leaves, and rose-purple or reddish cymose flowers.

F. ramosissima, Persoon, var. pulohella, Griseb. Irow; stem simple below, 2 forked, branched above; leaves ovate, oblopg or oral i 
flovers all on short pedicels; corolla-tube thrice as long as the elliptical-oblong lobes.

Wet meadows or shady places; rare; probably introduced. July. Stem 2 to 6 inches high, many times forked above and forming a diffuse cyme. Leares $1 / 2$ to $2 / 3$ inch long, $1 / 4$ inch wide, closely sessile. Corolla bright purple, tube yellowish green, slender, persistent and withering on the capsule.

\section{Bartonia, Muhl. (Centaurella, Michx.)}

Dedicated in the year 1801 to the late Prof. Barton, of Philadelphia.

CALyX 4-parted. Corolla deeply 4-cleft, without glands, fringes or folds. Stamens 4, short. Stigma thick, glandulous and partly bifid. CAPSUle oblong, pointed, 1-celled, 2.valved, many-seeded - Small annual or bienniel erect herbs, with slender stems, awl-shaped greerish scale like leaves, and small yellowish-white peduncled fowers.

B. tenelua, Muhl. Small-flowered Bartonia. Screv-stem.

Stem smooth, branched above; branches mostly opposite, 1 to 3-flowered; leaves awl-shaped, minute; corolla as long as the calyx; style very short.

Open woods and damp grounds. Aug.. Sept. Stem 3 to 10 inches high, square, often twisted. Peduneles opposite or terminal, simple or branched. Flowers small, greenish-white, on the ends of the branches. Stamens inserted in the clefts of the corolla. Centruerella Moser, Grisb., is only a varicty with the seales and peduncles mostly opfosite.

\section{GENTIANA, Linn. Gentian.}

From Gentius, king of Illyria, who discovered the tonic virtues of this genus.

Calyx 4 to 5-cleft. Corolia 4 to 5-lobed, regular, mostly with intermediate plaitcd folds, which bear appendages at the sinuses. Stamens 4 to 5 , inserted upon the tube of the corolla, short. STYLE short or none; STIGMAS 2, persistent. Carsule oblong, 2-valved, many-seeded.-Herls of various habits, with opposite leaves, and solitury or cymose shoury flowers.

* Corolla without crown or plaited folds; annual.

1. G. Quingueflora, Lam. Five-flowered Gentian.

Stem 4-angled, slender, branched; leaves orate-lanceolate, somewhat heart. shaped and clasping at the base, 3 to 7 -nerved, minutely pointed; corolla-lobes triangular-ovate, bristle-pcinted, about $1 / 4$ as long as the slender obconical tube, the tube 4 times as long as the subulate sepals.

IIillsides and pastures. Aug., Sept. Stem about 1 foot high, with the branches racemed or yanieled, about 5 -flowered at the summit. F lowers about 1 inch long, light purplish-blue.

* Corolla with plaited folds; perenniats.

\section{G. SAPONARIa, L. Soapwort Gentian.}

Stem erect or ascending, often roughish above; leaves ovate-lanceolate, oblong ot lance-obovate, with rough margins, narrowed at the base; $c a^{\prime} y x$-lobes linear or spatulute, acute, about $\frac{1}{2}$ as long as the corolla; corolla club-bell-shaped, with 
roundish-ovate, mostly obtuse, erect or converging lobes, which are longer than the 2-eleft minutely-toothed appenciares; anthers united.

Meadows and sides ef streams, common. Sept., Oct. A very variable speciee, embraciug several varieties and nominal species, 12 to 18 inches high, simple, erect, smooth, with opposite smooth leaves. Flowers $1 \frac{1}{2}$ inch long, erect, brightblue, sub-sessile in bunches at the top of the stem, and often solitary in the upper axils.

\section{G. ochroleuca, Froel. Yellowish-White Gentian.}

Stem ascending, mostly smooth; leaves obovate oblong, the lowest broadly obovate, obtuse, the upper ones lanceolate, all nerved at the base; flowers in a dense terminal cluster; caly $x$-lobes linear, unequal, longer than the tube; corolla clubshaped, anex connivent or slightly expanding, lobes ovate, obtuse, the folds entire, acute, short; anthers free.

Dry grounds, rare. Sept., Oet. Stem 9 to 15 inches high, simple, stout. Leaves clasping or sessile, 2 to 4 inches long, $3 / 4$ to $11 / 2$ wide. Flowers 2 inches long, $3 / 4$ iucb thick. Corolla open at top, grecnish-white, painted inside with green veing and lilac-purple stripes.

\section{G. ALBA, Muhl. Whitish Gentian.}

Stems upright, stout, very smooth; leares ovate-lanceolate, from a heart shaped closely clasping base; calyx-lolies ovate, shorter than the top-shaped tube, and much shorter than the tube of the corolla; corolla inflated, club-shaped, at length open, the short and broad ovate lobes nearly twice as long as the toothed appendages; anthers at first united; capsule nearly included.

Glades and low grounds. Aur. Stem 12 to 18 inches high, with the flowers elosely sessile and much crowded in a dense tirminal cluster, and sometimes also clustered in the upper axils. Galyx-lohes reflexed-spreuding. Cor olla white, more or less tinged with greenish or yellowish. This has generally been confounded with G. OCHROLECCA, but Prof. Gray considers it a very distinct species, on whose a uthority I have here inserted it, as indirinous to this State.

*** Corolla 4-cleft, fimbriate on the margins; annual or bienniel.

5. G. CRinita, Froel. Fringed Gentian.

Stem erect, branched above; branches elongated, 1 -flowered; leares lanceolate or orate-lanceolate, with a partly heart-shaped or rounded base; lobes of the 4-cleft ealyx unequal, ovate and lanceolate; corolla-tube bell-shaped, the limb 4-parted with wedge-obovate lobes, strongly fringed around the summit.

Low grounds and hillsides. Sept., Oct. A beautiful specif 8 to 12 inches high, round and smooth, with long branches, slightly curved at the base, becoming erect and straight, each bearing 2 leaves at the middle and a single flower at the top. Lfaves 1 to 2 inches long, $1 / 4$ to $1 / 2$ inch wide, broadest at the base. Flowers 2 inches long, sky-blue, tinely fringed on the margin, expanding in sunshine.

\section{MENYANTHES, Tourn. Buckbean.}

Ar. men, month, and anthos, a flower; because the plant blossoms about that length of time.

Calyx 5-parted. Corolla short funnel-form, 5-parted, deciduous; LIMB spreading, 5-lobed, equal, white, bearded within. Stamens 5. StYle slender, persistent. Stigma 2-lobed. CAPSULE 1-celled, bursting somewhat irregularly, many-seeded. $-A$ perennial herb, with a thickish creeping rootstock, sheathed by the membranaceous bases of the long petioles, which bear 3 oval or oblong leaflets at the summit, and white or slightly reddish flowers, racemed on the naked scape. 
M. trifoliata, L. Mirsh Trefoil. Buclibean.

Ieaves trifoliate; leaflets obovate; perluucles loug naked; scpals cbtuse, $1 / 3$ as long as the corolla ; petals asute, about as long as the stamans.

Bogs, margins of ponts. A fine plant arising from large, black reots, desending desp into the bo ery eartin. Siem 8 to 12 inches high, round. Flowers wlite or flesh-color, beatifully fringed with soft hairs at the base and in the tuke of the corolla.

\section{OBotaria, Linn. Pennywort.}

Gr. abotos, as small coin, with which the leares of this plant are comparea.

CAIXX of 2 spatulate spreading sepals, resemblisg the leavos. Coroula tubular-bell-shaped, withering-persistent, 4-cleft, the lobes oval-oblong, or sometimes spatulate. SraMENS 4 , inserted at the sinuses of the corolla, short. STrLe short persistont: stigna 2-lipped. Capeule oroid, 1-celIed, 2-valved, many-sceded.-A tow and rery smooth purplish green perenniel with opposits wedge obvvate leares, and whitish or purplish terminal and axillary fowers solitary or in clusters of 3 .

\section{O. Virgrnica, L. Virginian Pennzzort.}

Siem simple or with a few opposits branches abore; leares cuncate-oborate or roundish-rhomboilai, sessile and decurrent at base.

Rich wools, rare. A pril, May. Stem 4 to 8 inches high, often in clusters. Cor olla pale-prorplish or whitisb, longer than the stemens.

\section{ORDER 81. APOCINAGR馅-Dogbane Family.}

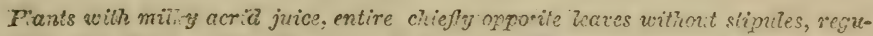
Tar 5-mermis and 5-androus flmors, with the 5 hues of the corrlia convolute ard twista in the bud.-CAirx entirely free from the 2 ovaries, persirt.nt. Filamenes dis linet: pollen granuar, globose or 5-lobed. Freir a pair of follicles, rarely one of them abortive. SeEos numerous, amphitropous. Chiely tropical plants.

\section{APOCYNUM, Tourn. DogBane.}

Gr. apo, away, and kuon, a dog; to which the plent was thought to be poiwonous Calyx 5 parted, with acute lobes. Coromid Eell-shapod, 5-cleft, with 5 triargular appendages in the thront cpposite the lobcs. Stamens 5, inserted on the base of the corrilin: anthers arrow-shaped, longer than the filaments: flaments slightly adherent to the 2 -lowed stigma by their inner fare. FrUIT of 2 long and slender follicles. - Perennial herls, with opposile entire mucroncte loceves, and small pare fowcrs in tsrminal and axillary cymes.

\section{A. androstemifolium, L. Dog'sbane.}

\&mooth, branchra above, the brenches direrging; leares ovate distiretly retio$J 2$ 
Jed; eymes loose, sproading, mostly longer than the leares; corolla open bell-shanod, with revolute lobes, the tube much longer than the calyx.

forders of woods and funcerows, common. June, July. Stem 2 to 3 feet hich, erect reddish. Leaves 2 to 3 inches long aud $2 / 3$ as wide, dark green above, paler benenth, on petioles $1 / 4$ iach long. Corolla $1 / 3$ inch broad, white strired with red, with 5 acute, spreading segmonts.-Varies, also, with the leaves doway undarneath.

\section{A. Cannabinum, L. Indian Hemp.}

Stem and branches upright or ascending; leaves rarying from ablong, oral orata to heart-shaped; cymes clos 2 many-flowered, crect, usually shorter than the leaves; corolle with nearly erect lobes, the tube about as long as the lanecolata lobea of the calyx.

Open woolsan l river ban's, common. Juiy, Aug. Stem 2 to 3 feet high, genera!ly dividing above into long, slendar branch ss. Ls wes $11 / 2$ to 4 inches long, $1 / 4$ to $\frac{1}{2}$ as wile. Var.1. gl eberrimum, DJ. Lewes oblong-lanocolat, on short petio.er, sm roth, obtuse or roundel. Var. 2, pastescens, D. Leares oblong. oral, (r opate, downy und rn ath or ou both sides, as well as ste cymes, Far. 3, hypericifolitm. Le wes inore or less heart shaped at the base, on r.ry short p toles, mos iv sm ioth. (A hyporicifuiinm, A.t.) F'lowers small, with lincoolate acube zepaly. Corolle whitish wiuh straight obtuse serments.

\section{VINCA, Linn. Periwinkle.}

Lat. qirsulum, a band, from the lon twining branches.

Coroula salver-form, contorted, borker 5 .cleft, the lo's oblique, orifice 5-angled; 2 glands at the base of the o:ary. ('AFEULE follicular, erect, fusiform; seeds oblong.-Lipright or trailing shrubs, with everyreen leaves and shony flowers.

\section{V. Mrnon, L. Lesser Periwinkle. False Myrtle.}

Siem procurabent, viaiting; leaves elliptis-lanecolats, smooth on the margine, thick; flowers ped ansulate; sep tls lanceolate. A hands mo crergreen, fiowering in in May. Native of Lurope. Stens suveral feet in length, round, smooth and leafy. Leares opposite, smoth and shining, about an inch long. Flowirs soitiary, ani!lary, alternate, blue, violet and white.

?. V. Majon, I. Greater Periwinlcle.

A beauliful shrub, common in cultivation, native of Europe. stem 1 to 2 to Ii i hi, with numerous, slender, straggling bzanches, rery leaify, forming lizht massce of erergreen foliage. Leaves 1 to 2 inches long, ruunded or somewhat hastshapid at bose. Flower's blue, pink and whit, blossming nearly all scasons.

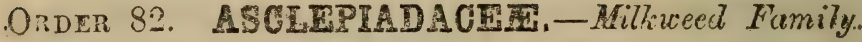

Fiants with mithy juiee and mpoitte or whorted rarely seattered entirs leanes, wegus. 7en 5-nerous, 5-androus fowers, with a valuate corolla, and singular eonnection of

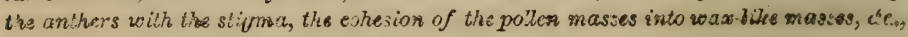
as oxplained under the typieal genus.

1. ASClepias, Jinn. Milkweed. Silkweed. The Greak name of Asculirpirs, to whom this genus is didioated.

CaLyX small, 5-parted, persistent, spreading. Conour. 
deeply 5-parted, the dixisions lanceolate reflexed, deciduouas. Crown of 5 hooded lobes (nectaries) seated on the tube of stamens, each containing a horn-like incurred process. STAMass 5, inserted on the base of the corolla; rILAMrsys united into a tube which incloses the pistil; Axtrers ad- harunt to tho stigm?, with 2 rertical cells oponing lengthwise tippaf with a mombranncous appondage, each cell contining a flattened waxy pollon-mass. STrama depressed, 5 -angled, esvering 2 ovaries. FoLbicies 2, one of them often abortive, inflated, smooth or muricate. SEEDs furnished with a long tuft of silky hirs at the hilum.-Perennial upright herbs, with thick and deep ronts, uswally transersely veined leaves. and terminal or mostly lateral feduncles betwcen the petioles bearing simple many fluwered umbels.

* Lexves opposite.

1. A. Corvutr, Decaisne. Common Mithreed or Silkzeet.

Siem nearly simple, large and stout; leaves ovate-elliptical, with a slight point, Fpreading, petiolats, minutely relrets-downy underneati ; umbel rodding; dirisions of the corolla ovate; hoods of the crown orate, cbtuse, with a lote cr tcoth on exch side of the cláw-liki horn; fullicles murieate.

Rich soil. fields, roadsides, \&e., common. July. A coarse, тery milhy plant, 3 to 4 fest high. Laaves 4 to 8 inches long, 2 to 3 inches wide, tapering at both encle, pale. Uin'uls serura!, donee, globose, each of 20 or more sncet fcentei forer. cmolle pal prople, about $1 / 4$ is long as tho podicoln, rufuxed, learing the crosu quite conspicuenz.

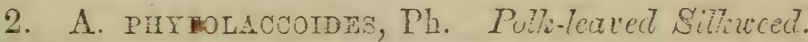

Siem simple; erect, smosth; lexves broaily orate, or the upper oral-lancsolate

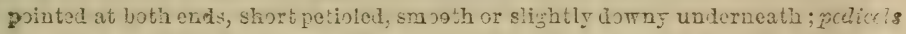
lonso and nodiling, numerous, elongated, slouder; divisions of the corolla orate oblomg, heads of the crown trumeate, the margins 2-toothed at the summit, ine hora with a long projectias poiat; füichs minntely lowny.

Tinw shady grounds, ratuer common. Jume. Stem 3 to 5 feet bigh, abore

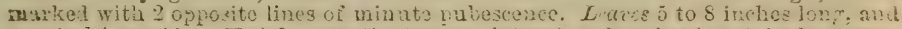

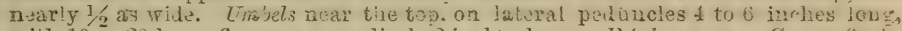
with 10 to 23 large flowerz, on pedicels 2 inches long. I'tuls green. Crown flestcolored.

\section{A. purpurascins, L. Purple Milliweed.}

Shein simple, ercet, with 2 pubescent lines; lexves eliptical or orate-ollong, the lower muronate, thu upper acuminate, minutely relrety dofny undercenih, Empoth above, contractol at base iato a short petiole; pedicels shorter than tio wistly tamianl peduncle; divisions of the corolla lance-orate; loo?s of the erown oblon's; the hoin brondly faleate, with a narrow and broadly inflexed heri

zontal point; follicles smooth.

Border of wools and thickets, not common. July. Stem 2 to 3 fect hich, rather sleuder. Leares pale and domny beneath, the midrein purple. Flowers in term:wal, erect umbels, with a small green calys, and dark purple corolla with refiexid se sments.

\section{A. variegata, L. Variegated Millueed.}

foarly sooth; stom single, erect; leaves orate, oral.or. oborate, somewlat 
wavg, musronate, contracted into a short petiole; pediccls and peduncles short, down; crolla segments ovate; hools of tha crown orbicular, entire, the horn broat-faleate, with a horizontal point; follicle slightly downy.

Dry wosds. July, Aug. Stein 3 to 4 feat high. Lrwves somewhat acuminate, on pubess ast patiolos. Unbis 29 to 43 -flowered, mostly globose. Corollu and crown white, the letter with a bacd of purplo around tho base.

\section{A. Quadrifolia, Jaeq. Four-leaved Millweed.}

Nearly Emooth; sten simple, slonder; leaves ovate or ovate-lanceolate, petioled, mostly aouminate, tho middle ones in vhorls of four; pedicels capillary; corolla segments oblong; hoods of the crown elliptical-orate; horn very short, incurved; folicle linar-lanceolate, smooth.

Dry wools authilis; common. June. Stem 1 to 2 foet high. Leaves thin, 2 to 1 inches long, the uppo: an 1 lower ones opposite. Uinbels 2 to 5 , on slender peduncles 1 to $1 \frac{1}{2}$ inch long. Flowers small, white or purplish, fragrant.

\section{A. obrusiroura, Michx. Wisy-leaved Milkweed.}

Smoth and glaucous; stem simple, erect; leares oblong or ovate-elliptical, very ob.tuse, mucronato. sessile, somewhat clasping by a beart shaped base, the marging wavy; winvels terminal, many-flowered; hoods of the crown truacate and comewhat toothed at tho summit, shorter than the slender subulate horn; folliclo emoothish.

Sandy wools and folds. rather common. July. Stem 2 to 3 feet high, bearing a gingle (rwely 2) lon r iduncied turminal unkel of 30 to 40 -large reddish-rren flowerg. Luve: much waved on the margin, 4 to 5 inches long, $1 / 2$ as wide. Corollo lirbt purple. Crown nearly white, the segments large.

\section{A. RUBRA, I. Red-flowered Millweed.}

Smooth, slenter, eroct; leaves oratz-lanceolate or oblong, acuminate, subcordate or rounded at base, on very short potioles; divisions of the corolla lanceolato,. seste; hoods of the erown oblong, acutish, with an awl-shaped horn.

Low grounds, rare. Ju'y. Stem 1 to 2 feet high, with a pubescent line on one gldo, barring 1 to 3 few-flowored umbels at the nalsed summit of the stem. Leaves 2 to 4 inches long, rough ciliate, in remots pairs. Flowers reddish purple, tinged with orange.

\section{A. incarnata, L. Rose-colored Silkweed:}

Stein erect, branching abjvo; leaves oblong-lanceolate, acute or pointed, obtuse. at tho base, distinctly petioled; umbels many-flowered, erect, mostly terninal, ofton in opposito pairs; divisions of tho corolla ovate; horns awl-shaped, curving inwards.

Wet places, common. July, $\Lambda$ ug. Stem 2 to 3 feet hirh, very leafy, with 2 hairy lines above and oin the branches and peduncles. Leaves 3 to 6 inches long, $1 / 2$ to $11 / 2$ wide, taporiu's to a very acuta point on petioles $1 / 2$ inch long. Cmbels close, a to 1 togethes at the top of the stem or brinches, on a pecluncle 2 inches Iong. Flowero small. Corolla reddish-purple. Crown flesh-color.

\section{A. тuвziosi, L. Butleifly Weed. Pleurisy Root.}

Rouginish-hairy; stems crost or ascending, very leafy, with spreading branches : leaves varying from linear to oblon -lanceolate, sessile or slightly petioled; unbels aumerous, often forming terminal eorymbs; hoods of the crown narowly-oblong, scarcely longer than tho slender awl-shaped horns; follicles hoary.

Dry hills and fields, common. June-Aug. Ront large, tuberous. Plant 1 to 2 feot high, leafy to the summit, usually with numerous corymbed umbols of showy orango flovers ou short pedunclis. Leaves sometimes broad and cordate, at othere linear and somowhat taperiag at baso. Crolla greenish-orange. Croun bright orange- Modicinal. 


\section{A. Ventronlita, I. Whoried Mrikweed.}

Bmothish; stems slevder, simpla or sparingiy branohed, minntely heapyin lines,

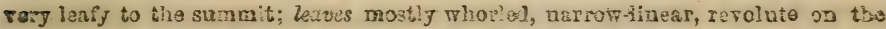
roargin; unbels small lateral and terminsi; hoods of tho croma roundister wh Ealf as long as the hooked cisw-shaped horns.

D:y hills. Jun - Supt. Stem 1 io 3 fest tigh, tery sionder, often a litle kmnatied at tho summit. Leitiex 2 to 3 inches lons, gearcely 1 line wide. 3 to 0 in a 17 burit or the low st aul upporasost nearly opposite. Figuders small, groenish-mbite, it namorous umbels about 1 inely in divmeter.

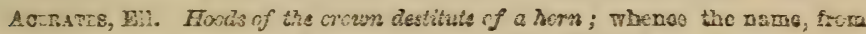
a, privative and kec' $\times s,-a t c s$, a horn.

\section{A. Viridifuora, Raf. Gieen-finwered Milkweed.}

Dorny-honry; stems low and stout, aseending; leaces oral, orate and obcrate ca

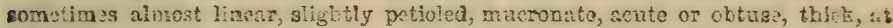
length smoothish; umbels nouriy goć3ile, dencoly monj-fonerta?, glokese, laistal; erown ollong, strictly erect, sessile at the base of the tube of finmente, sheries than the anthers.

Dry hills and sandy filta, common. Jnly-Sopt. Sicm 12 to 13 inches thigh, eom times clusterd. Leare 2 to 3 inchezlong, thick and coriasous, very variatie

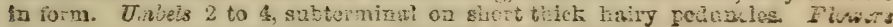
gretuib, when expanded about the lengtli of the pedicol.

\section{GONOLOBUS, Mich.}

Gr. gonos, an angle, snd lobos, a pod, from the ribbed folliciea.

Catrx 5-parted, spreading. Coroura 5-parted, wheolshaped, sometimas reflexed-spreading. Crown a small and fioshy wary-lobed ring in the throat of the corolla. ANTHERs horizontal, partly concealed under the flattened stignai, opening transversely. PoLten-MAsses 5 pairs, horizontal. Foulucers 2, turgid, somewhat ribbed. SEeds comose.Twining herbacen:s or slirubly plants, with opposite heart shaped leaves, urually laciry, and recened or corymbed greenish or purptish flowers, on peduncles rising from between the petioles.

\section{G. Hirsutus, Michx. Hairy Gonolobus.}

Minutiy pubcecent; leaves ovate heart-ihapel, somewhat obtuse or polnted; po din les fow-florcred, shorter than the patioles; pedicels very short; bractkts aw: . shaped; lobes of the corolla oblong minutely so tly-hairy outslie; follicles corered w:th spine-like soft processes.

Rich rirer banks. Western part of the State. June, July. Stem trailing and climbing 3 to 4 feet long, the younger branches very bairy. Lectes slightly aurives. late at base. Embels axillary, 3 to 1 -itarered. Flowers dark purple.

\section{G. macrophyluds, Michx. Large-leaved Gonolobus:}

Stem hirsute with long bairs; leaves broadly orate-heart-shaped, polntcd; peduncles and padicels longer than the petioles; bractlets linear; lobes of the corvils linear or narrowly oblong, downy outsile; follictes ribbed and angled.

Shady banks, near Philadelphia, Burion: Chester Co., Darlington. July. aftem twining several feet long. Leaves 3 to 6 inches wide. Flower' parple and grweelsb, Putid, in loose cymose nubols. 


\section{ORDIR 83. JASTINAOHI:-Jasmine Family.}

Shirus, cfien with twining stems, opposite or altcrnate mostly compond leares and white or ycliow, mostly fragrant flowers in omproite comymbs. CALYx divided or toothel, porsistent. Conolla regular, salver-form, tho limb in 5 to 8 divisions. STAmans 2, arising from the corolla and included within its tubo. Orary free, 2colied, each cell with 1 ereot orule. Strun 1 ; smana 2-loked. Fruif a doublo borry, or a capsule separable into 2,2 -seeded.

\section{JASMINUM, Linn. JASMine.}

Gr. iasme, perfume; from the fragrance of the fowers.

Catrx tubular, 5 to 10-cleft. Conolita salver-form; twle long; limb flat, 5 to 10 -cleft. Fruit a double berry; secds 2, solitary, ariled.-Bushy or climling shrubs, with cipposile conipound leaves on articuluted petioles, and schitc or yellow mostly fragrant fowers in paniculate corymbs.

1. J; rrutionas, I. Yellow Jasmine.

Smcoth, erect; brancles angular; leaves alternote trifoliate, rarely simple;: laafets curved; flowers ferr; subterminal; calyx segments subulate; corclla-tubs twiso longer than the calyx, limb of 5, obtuse lobes. Natirè of South Europs. Stem 3 fet higb, bushy. Flowers yellow, inodorous, the tube about $1 / 2$ inch long.

2. J. ofiricrarte, L. White Jasmine. Common Jasmine.

Smooth, scarcely climbing; branches subangulate; leaflets 3 to 7, lanceolate; acumipate; panicles terminal, few-flowered, corymbose; corolla-tisbe twice longer than the calyx. Native op.Asia. A banutiful and inuch cultivated spesies, several Eqet high; with fragrant white fowers.

\section{ORDER 84. OLPAOPE - Olive Famity.}

Tiees or sirubs, with orpcsite and pinnate or simple leaves, a 4-cleft or sometimes. -35o?ete calyx, a reguin 4 cleft or nearly 4-petalous coroila, sometimes apetalous, 2, or rarely 3 , stanens, and a 2 -celled ovary with 2 suspended ovules isz each cell. HintIx drupaccous; baceate or samarx, usually 1-seeded by abortion. BaED anatropous, with a large straight embryo uswally in hard feehy albumen.

\section{LigUStRUM, Tourn. Privet.}

The classical name.

Caryx minutely 4 -trothed, deciduous. Corours funncl: form, 4-lobed; lobes ovate, obtuse. Stamens 2, on the tube of the corolla, included. STrue very short; stigma 2-cleft. BERriy globose, 2-celled, 2 to 1 -seeded.-Shrubs with sim. ple entive leaves on short petioles, and small white flowers in terminal. thiyrsoid panicles. 
I. velgare, L. Privet. Prim.

Lexves lanceolate and oborato, acute or obtuse, smocth, thickish; panicles dense, torminal.

Introluced from Buropo, nged for low hedres; naturalized. May, June. A wavoth shrub 5 to 10 feet bigh, with wand-like opposice branches, and smooth durie grewn leaves 1 to 2 inches long, $1 / 2$ as wide. Burries black, globose.

\section{CHIONANTHES, Linn. FrRNGE-TREE.}

Ar. etion, snor, and aizthos, blosson; alluling to tho light snow-white clustors of flowers.

CArrx very small, 4-parted, persistent. Corolua of $\frac{1}{4}$ long and linear petals, barely united at the base. STAnens 2 , very short, on the base of the corolla. STYLE rery short; atigma natched. DaUpe fleshy, globular, becoming 1-celled and 1-seeded. - Low trees or shrubs, with entire petioled leaves, and delicale fowers in losse and hooping graceful racemes or panicles.

C. Virginica, I. White Finge-tree.

Lasyes oral, oblong, or objratz-lanozolista, Emoothith or rather domny, reisy; fhowers on sleuder pedicels.

Chester Co. Darl. Union Co. River benks and mountains, rare. June, A smail very oraamental trзe 6 to 12 feet high, with opposite branghas. Flowers white in

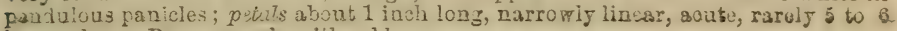
la number. Drup: purplo with a blcom.

\section{SIRINGA, Linn. IILAC.}

Gr. syrinx, a shepherd'spipz; from the us9 onea insle of its branchos.

CAryX smull, with ercet teeth. Corourat salver-form; with the tube several times longer than the calys; limó oleft into 4 deep, obtuso, spreading segments. STAqnexs 2, short, included within the tube. CApsule 2-celled, 2valved.-Oriental, fowering shrubs, wilh simple, entirs leaves, and rootly fragrant thyrsoid flowers.

1. S. vulgaris, L. Common Lilac.

Iasires eordati-ovate, entire, smoth, green on both sides; flowars thyr soid; therb of the corolla sumatriat coacare. Native of Itangary. There ara several varieties. vith purplish-blue, lilac-purple and whito flowers.

2. S. Pensica, L. Persian Lilac.

Iaxves lanceolate, acute, sinooth, green on both sides, rometimes pinnatifid; limb of the corolla flattish. Native of Persia. May. A beautiful flowering shrab, smaller than the first, with wand-like branches in thyrses of whtte or lilac-blas sovera.

\section{PRAXINUS, Tourn. AsH.}

Cm fravis, a separation, from the ficility with which the wood splits.

BLOWERS polygamous or diocious. CALYX small, 4-clefts. 
or obsolete. PeTals 4, slightly cohering in pairs at the base, sometimes only 2 oblong or lincar, often cntirely wanting in our species. STAMens 2, rarely 3 to 4 . STrus single; stigma 2-eleft. FrUIT a 1 to 2-celled samara, fattened, winged at the apex, 1 to 2 -sceded. - Trees, with petioled uncqually pinnate leaves, and small fiowers in erowded panicles or racemes from the axils of the former years growth.

- Culyx present; corolla wunting.

\section{T. AMericana, I. White Ast.}

Teafiets 7 to 8 , stalked, oblong-ovate, pointed, near'y entire, glauesus anderncath, of length snooth; sanara spatulate-linear, obtuse, with a long narrowed base.

Rish roods, common. April, Magy. Tho white ash is exceoded by furs troes. in the bianty and mapnitude of itg proporion. The trunls aris of often to the height of 40 feet withnat a oranch sud then expazis into st regular summ is of

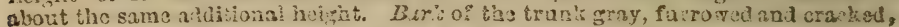
that of the branchlets greenish-gray, smooth. Leuves 1 fuotor more long. Fiow ers in loose panicles.

\section{F. PUBEscens, Walt. Red Ash.}

Lenfet: 7 to 9, lancsolate or ovato-lanccolate, pointed, somerrliat gerrate, velveigdowny undemeath, as well as the petiolez and young branchlets; samara narrorg. Iy lancesinte-spatulate, obinse, usunly vith an obtuse point, tapering at tho base.

Wools a:onr streams, very common. May. The rel ash resemuies the last: Epccios, so as oft n to be confounlol with it. It rises 6$) \mathrm{f}$ ct himh with a straight. trunk, covered with ba:k of a tejp brewn color. Leives at longth reddish under geath. The wood is less valuable thon that of the white ash.

\section{F. Juglandforia, Lam. Swamp Ash.}

Branches smooth; leaflets 7 to 9, ovato, serrate, smoot?, somorvhat downy on tho veins underneath, staiked; samarce wedge-lanceolate, obtuso, scarcely acurainato at the base.

Wotwosds. Mny. 1 smail tree 15 to 25 fuet himh, with greanish branchlsts Jeazes 10 to 15 inches long, green on both sidar, rith a glatusous huo uadoragath Blower's greenish. Fruit much smaller than in the other species.

* Cibjy and corolla bosk wanting.

\section{F. sambuctfolia, Lam. Black Ash. Water $A s h$.}

Leaficts 9 to 11, sossile by an obtuso bass, clliptical-lancanlase, pointer, moro or less hairy on the reing beneath; samara elliptical-oblong, very obtuse at both eada

River banks and swamps. April. A slender tros 40 to 60 feet hirh, with is very tough wosd. Branches ash-color, with dark dots. Leaves 9 to 16 lnchss in leagth, omooth above, and rell-downy on the veins benasth.

\section{DIVISION III.}

\section{APETALOUS EXOGENOUS PLANTS.}

\section{Coroura none; the floral envelopes consisting of a single. series of organs (calyx) only, or sometimes wholly wautiug..}


ORDER 85. ARISTOLOCHIACE丽.-Birthwort Family,

Climbing shatus or herbs, with alternate simple petiolite leave and perfect axillary, olikary, brown or lurix colored flowers, with the calyx coherent below with the 2-celled ovary; which forms a nzany-seeued S-celled capsale or berry in fruit. STAMEN3 6 to 12; moze or less united with the style; anticers adiate, extrorse. Ssina anatropons, with a minute embrjo in flesby albumen

\section{ASARUM, Tourn. Asarabacca.}

An ancient name, thought to be derived from $a$, privative, and seirom; bound; be cause it is rejected from garlauds.

Perianti bell-shaped; limb 3-parted, the tube wholly adherent to the ovary. Stumens 12 ; fllaments awl-shaped, coherent with the apex of the ovary. STYLes united into a Ehort column, bearing 6 radiating erested stigmas at the apcx. Fruit fleshy, globular, erowned with the persistent calyx, many-seeded. Stemless herbs, with aromalicpurgent creeping rootstocks, bearing a nodding fiower close to the ground, between the long petioles of the kidney shaped leaves.

A. Canadense, L. Wild Ginger. Coltsfoot.

Downy; leaves a tarminal pair, broad kidney-shaped; perianth woolly, cleft to. the base, tho gegments reflexed.

Millsides in rieh woocis. Mfay. Lexves 3 to 4 inches wides, on long and hsiry potioles. Flower's brownish purple insido. The root has ail arreeable and aromatic flavor.

\section{ARISTOLOChIA, Tourn. Birtirtort.}

From the Greek; in alluslon to its meảicinal virtues.

Perranth tubular, the tube variously inflated above the ovary, dilated at the apex and ligulate. Antuers 6, subsessile, inserted on the style. Stigan 3 to 6-parted or lobed. Capsule 6-sided, 6-valred, many-seeded. Seeds flat.T'wining, climbing, or sometimes upright perennial herbs or shrubs, with alternate leaves and lateral or axillary greesish. or lurid-purple flowers.

1. A. Serpentaria, I. Virginia Snakernot.

Herbaceous, low, pubesocnt; leave: orate or oblong, from a heart-shaped base, or halbert-form, mostly acute or pointed ; peduncles nearly radical; perianth strongly.

bont and Inflated at the curvature, the border obtusely 3-lobel.

Rich woods; common near the Alleghony Mountains. July. Foot consisting of. numerous coarse fibres, aromatic-stimulent. Etem 8 to 12 inches high, pukescest, geniculate and knotty at the base. Flmers purplish-brown, bent like the letter $\mathbf{8}$,

intlated at the two ends. Stigma :-lobod.

3. A. Sifho, L'Her. Duichman's Pipe.

Wody, twining and climbing, mooth; leaves round beart ehapod, alfghtly eospy 
12. lerneatli; pedunc?es solitary, 1-flowered, with a clasping bract; periamth asceuding curred, contracted at the throat, the border obtusely 3-lobed.

Rich mouutain woods, rare. May. Stem sometimes 2 inches in diameter, allmbing tress. Leivas 8 to 12 inehes brod. Purianth $1 \frac{1}{2}$ inch long, brownish. Stigma slightly 3 -lobed.

\section{ORDER 86. CHMNOPODIACWM, - Goosefoot Fambity.}

Chiefly herbs of horvely aspect, more or less succulent, with mostly alternate leaves qovitious stipules or briats, minute greeinish flowers, wilh the frie cu'yx imbriated in Whe but; the stamens about as many as the lobes and inserted opposite them or on their

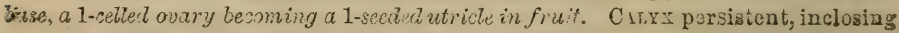
the Afrait. STYLas 2 , raruly 3 to 5. Flowers cominonly perfuet.

\section{CHENOPODIUM, Linn. Goosefoot.}

Or. chen, a goose, and pors, foot, in allusion to tho shape of the Ieaves.

Frowars prefect. Calyx 5-parted, obtusely 5-angled; partially enveloping the deprossed fruit. STAmens 5. Strures 2. UTRICLE membranaceous; sEzDs horizontal, lenticular.Sinooth mostly annual weeds with petiolcd triangulur or rhomboild toothed or entive leaves often covered with a white mealiness and sessile flowers in small clisters.

\section{C. ALBUi, L. Lamb's-quarter.}

Siem upright, somewhat branched; leaves rhcmboil-ovate with a wodge-sl a zed entire baso, coarsely sinuato-toothod; flowers in panicled spikes, nearly lestlozs; seed smooth and shining.

Wibste grounds, common. Julp, Aug. A very common plant about cardens, 2 to 3 feet high, covered with a whitish malines. Uripr leres mostly oblong-linear, and entire. Flnwers numerous small, grcen, in imergular terininal erect racomes. A greener variety is the C. virile of most authors.

\section{C. glaudun, L. Glaucous Goosefont.}

Slems accending or prostrate, much branchod; lesocs ovate-oblong, obtuse, sinwato or toothed, mealy-whitened unlernath; racemes spiked, rather dezo, acconding, leafless; calyx-lobes not keeleủ; seeds smooth and shining.

Hear Philadelphia, rare. Julj. Stem diffuse thick.

\section{C. HYвRIDU⿴, I. Iixple-leavel. Goosefoot.}

Stom erect, wuch branched; leaves ovate-ber rt-shaped at the bass, point d, angied Fith a few larige and distant pointed teeth; racemes loosuly panicled, spreadiug, losfless; ca7yx-lobes keeled in fruit.

Waste places, common. July, Ang. Stem 2 lo 3 feet high, slender, with largo and bright green leaves. Flcwers stevnish, ill-scented, in a loose branching clustor.

\section{C. unbroum, L. Triangular-leaved Goosefoot.}

stom erect, branehing; leaves triangular-acute, coars ly sinuate-toothed, the upparnost lance-lincsu and nearly entire; raccmes spiked-panicled, erect; caly $x$-l bes not keded.-Tar. riombifiliun, Moquin (C. rhombifolium, búubl,), Las ratber rhombic leaves with more prolonged teeth.

Not common. June, July. Whole plant yellowish-green, 1 to 2 foet hatgh,. branched. F lowers swall green, in roundisb dense clustera. 
A 3 miva, Spach. Sz3D either rertical or hozizontal, the embryo not eoiled into a emplete ring; sтrLEs often 3.-Giandutxr and often pituescent herôs, exhating aramutic or bulsamic olor.

5. C. Bотвуs, L. Jerusalem Oak.

Stem ascending; leares oblong, obtuse, sinuate pinnatifid, the upper spatulatelanseolat 3; racimes cymose-pan:clel, diveryent, leafless.

Waste places, common. July-Sept. Whole plant fragrant, 1 to 2 fert high, braucheil. Le ives petioled, wrth deep sinuses, numurous. F'owers green, very num:r us, iu numerous short axillary raccmes.

6. C. Asthelmintica, L. Wormseed.

Nrect; leaies orate-oblong, narrowcd at the base into a periole, coarsely and unequally cat-t jothed or sinuats; racemes clongateland sp:ke-like, slenler, leađese; eaty $x$-Loles not kecled.

Fuadidles and waste plaeng- Per. Ju'y, Aug. Plant 2 feet high, very strongpented. the branches trminating in long spikes of gren, inconspicuous forera. The secds yield the well known rermiftage Wurm-seed oil.

7. C. Ambrosoides, L. Sieet Pigueed. Mexican Tea.

Erect, much branchel; le lves ob.ong, narrowed at the base into a petiols, ro-

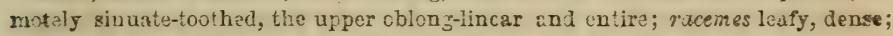
6: $z_{j} x_{2}{ }_{0}$ hes somewhat kieled.

Roulsile: , crmmon. Aug., Sept. Stem 18 inchss high, som?rhat pribereent. Isaves on short patioles, acute at each end. Fluw green in erect spihes.

\section{BLITUM, Tourn. Butte.}

The ancient Grzek an 1 Latin name of some insip:d potherb.

Frowers perfect. Calyx 3 to 5-parted, becoming juicy and berry-like in fruit. Siramens 1 to 2 . Stryles 2 , united. Serds rertical, compressed globular. - Nearly smooth annuals, with petioled tringular or ha!bert-shaped sinuatstoothed leaves, and mostly cupitate-clustered flowers.

1. B. сарitatum, L. Strauberry Blite.

Stem ascending, tranched; leves triangular and somewhat halbert-shaped, sinnat--toothed; c'usters s:mple, interrupt dly spiksd, the upper leafless; ssed smeoth, with a narrow sharp mergin.

Dry rich grounds. Jun". A woedlike plant about a foot in height. The ealyx

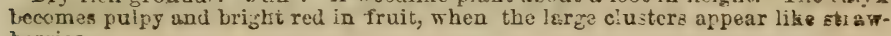
berrics.

2. B. virgatum, L. Slender Strawberry Blite.

skm with spreading branchos; loaves triangular Irastate, sinuab-toothed; heads seatiered, laterab.

Fields and wastes places; introduxd. June. Stem 2 feet in length, eprending or procuinbent. Lecies 2 ti 3 tby 1 to 2 inches, careely toothed on petioles 1 to 2 isishe long. F'lowers always fin axillury ciusters, terminal. Cabyz beoombg fieshy and red in fruit.

\section{ACNIDA, Mitchell. Water Hemp.}

Or a prirative, and kxida, a nettle; for a nettle-like plant which does not sting Flowers diøeious, without bracts. STERILE FLOWERS 
with 5 membranaceous oblong sepals and 5 short stamens. FERTILE FuOWers with 3 acute sepals and a 3 to 5 -angled ovary bearing 3 to 5 linear revolute stigmas. FrurT a 3 to 5-angled coriaceous achenia. SEnos vertical, compressed.Smooth and tall annuals, wilh linceolate and acuminate entire petioled leaves. and clustered sessile ffowers crowded in axillary and ter. minal spikes or panicles.

\section{A. cannabina, L. Common Water Hemp.}

Leaves elongated-lasceolate, tapsring to a long mostly obtuse point; fruil coutoangled, smooth.

Brackish swamps, common. July, Aug. Stem 3 to 6 fect hioh, slightiy angled. Leaves alterate, ribbed, 2 to 5 inchos long. Flows small, groen, in large axiliary asd terminal panicles.

\section{BETA, Linn. BEET.}

Celtic bett, red, the usual color of the beet.

Caryx 5-sepaled. Stamens 5. Styles 2, very short, erect, with acute stigmas. STED reniform, cmbedded in the fleshy calyx-Biennials, with furrowed stems, alternate leaves, and glomerate green flowers in spikes or paniculate racemes.

1. B. vulaaris, L. Common Beet.

Lower leaves ovate: rot fleshy; fows in dense, sessile, urillary clusters. Na. tive of South Burope. Much cultivated for th table. Thore are several varieties, of which the purplo leared is the mast estcem for the kitchen, and the green-leaved for cxtracting sugar.

2. B. Cicla, L. Searcity. Mangel-Wurtzel.

Leares with very thick veins; fowers 3 togethor. Natire of Pertngal. Fook leares stalked, those of the sten sessile. Flonvers green, numerous, in very long spikes. The variaty Scurcity hus very large leaves, with bit a small roo', usecl as

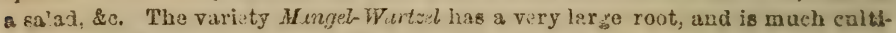
vated as food for cattle, for which purpuse it is highly prized.

\section{Order 87. AMARANTHACEBS-Amaranth Family.}

Fierbe, rarely shrubs, with oppositsm allernate leaves, without sipules and fowere tin liexds or spitces wsually colmed, inbricated with dry and scarious persistent bructs

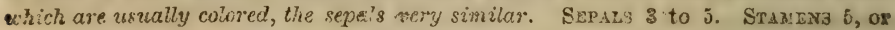
sone multiple of 6 . Orabr 1 , frce, 1 or fow oruled. Strue 1 or nono. Stignas digplo or compound. FRUiT a utriele. SEzDS perduious.

\section{Amarantilus, Linn. Amarantir.}

Gr. $a$, not, maraino, to wither, and anthos, flower.

Flowers monœcious or polygamous, rarcly diccious, 3bracted. Serals 3 to 5 . Stamens 3 to 5 , separate : an- 
Tuers 2-celled. Styles or Stigmas 2 to 3 , sometimes 4 , threadlike. UTRICLE opening transversely all round, or indehiscent, 1-seeded.-Chiefly annual weedy herbs, of coarse aspect, with alternate and entire petioled leaves, and ninute spike. clustered flowers with green or purple bracts and calyx.

-Monacious: stamens 3.

\section{A. Albus, L. White Cock's-comb.}

Smooth; stem upright, angular, with spreading or horizontal branches; leaves obovate or spatulate-oblong, pale-green, obtuse or notehed; clusters axillary; inconspicuous; bracts lance-oval-shaped, with spreading spiny tips longer than the ealyx.

Open waste places and roadsides, common. Aug. A very homely weed, 1 to 3 feet high. Leaves $1 / 2$ to 2 inches long, somewhat wary-margined. F'lowers ineonspicuous, concealed among the greenish bracts, in small cluster.

* Stamens 5 .

2. A. Hybridus, I. Hybred Amaranth.

Roughish-pubescent; stem upright, grooved-angled, sparingly branched, or sirn. ple; leaves ovate and lance-ovate; flowers crowded in dense compound terminal and axillary naked spikes; bracts awl-shaped, nearly bristle-pointed, longer than the flowers.

Waste and cultivated grounds, common. July-0at. Stem 1 to 5 feet high, stout. $\boldsymbol{L}$ eaves 2 to 5 inches long, alternate. Flowers minute, in large green oblong spikes, becoming at length a dull red.

3. A. Retnoflexus, L. Hairy Amaranth.

Rough-hairy; stem upright, stout, often zigzag, the lower branches recurved at the base; leaves ovate, wavy-margined; spilies compact, triply-compound, ercet; bracts awl-shaped, pointed, much longer than the tlowers.

Waste and cultivated grounds, among rublish, common. July-Oct. Plant 2 to 3 feet high, scarcely distinct from $A$. hybridus, being rougher and stouter, with thickerand more crowded spikes and larger flowers.

\section{A. spinosus, L. Spiny Amaranth.}

Smoothish, branching; leaves ovate-lanceolate, spiny at the axils; sterile clusters crowded in compound panicled and naked spikes, the fertile mostly compact and globular in the axils; bracts not longer than the calyx.

Toadsides and cultivated grounds; introduced. June-Sept. Stem 1 to 3 feet high, often purplish. Spines $1 / 4$ to $1 / 2$ inch long. Flowers greenish.

\section{A. Buttum, L. Low Amaranth.}

Smooth, diffusely spreading; leaves ovate or rhomboid, very obtuse or notched; flowers in small and round axillary clusters and in naked terminal spikes; bracts shorter than the calyx.

Gardens and waste grounds; introduced. July-Sept. Stem mostly prostrate and spreading. Leaves as long as the petioles, $1 / 2$ to $2 / 3$ as wide. F'owers numer. rous, greenish. Stamens 3.

*** Flonvers red or purplish.

\section{A. iypochondriacus, L. Prince's Feather.}

Nearly smooth; stem upright, stout; leaves ovate, acute; flowers clustered on upright compound spikes or racemes.

Common around gardens. July-Sept. Whole plant dark red, 8 to 4 feet high. Leaves green with a red pnrple spot or tinged with purple. F fowers bright red. :purple as well as the subulate bracts. 
7. A. malancholicus, L. Love-lies-bleeding.

Lo:ves orate-lanorolate, colorod; racenss axillary, peduncled, roundisk. A leautiful-lant from India, 1 to 2 foet hi ch. Flowers redd ish purple.

\section{CULTIPATED ETOTICS.}

\section{GOMphrena, Linn. Globe Amarantir.}

BRAcrs 5, colored, the 3 outer ones connivent, carinate. Siepals 5, villous. Disk (nectary) eylindric, 5-toothed. UTHICLE circumscissile, 1-seeded.--Annual or perennial herts, with opposite lewves, and globose heads of flowers.

1. A. globosa, L. Annual Globe Amaranth.

Steme erect, hairy; lexves oblong, pubescent ; ficwers in glolose solitary bearls, keols of the bracts winged. A showy flower from India, much acmirel fur its heads of flowers, which retain their beauty for a long time. Slem 12 to 18 inclits bigh, with opposite axillary branches. Flowers purple.

2. A. Perennis, L. Perennial Globe Amaranth.

Ieaves lancoolate; hwid; 2-leaved; fowers with a peculiar calyx. Natire of South Amerioa. Stcm about 3 feet high. Flowers in globose hecis, purple, resculliug treach of elore:. JuIy-0at.

\section{CELOSIA, Iinn. Coor's-COMB.}

Gr. Keteos, burnt; some of the spocios appear a 8 if singed.

Sepalis 3 to 5, colored; stamens united at kase by a pluited disk. STYLE 2 to 3 -eleft. UTRICLE circumscissile.Ornamental exotic herbs, with mostly alternate leaves.

C. cristata, L. Crested Cuck's-comb.

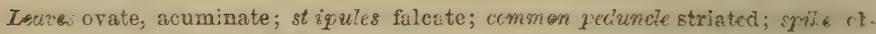
lonz, compressed. Native of Japan, where the fiowers or erests are a fout in dixine. ter, and of an intense purplish-red. Stem 2 foet high. June-Sept.

\section{ORDER 88. NYUTACMMAOED.}

Ferbs or shrubs, with opposite lexces, one of each gair smaller thicn the rthes, and a olored perian the resembling a corolle, with a plaited limb, falling off from the lenver

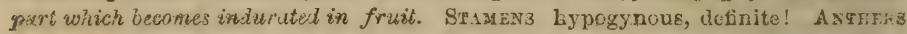
2-oulled. Ovary free, with a single, erect ovule. Sruza 1: smand 1. Pavir a tuin utriols, enelosed within the onlarged inflated bract.

\section{MTRABILIS, Linn. FovR-o'CLOCK.}

Pertanth funnel-form, tube contracted, free from the ovary, limb plaited, entire, deciduous. Stamens 5. Stigin a globose.-A beautiful genus of flowering plants, natives of warm latitudes, with while red yellow and variagatod fiew'rs. 
1. M. Jalafa, L. Rarvel of Peru.

Zoceres smooth, cordate, acuminato; flowers in clusturs, stalked, large. Whiz weil known plant is a native of the West Infles. Stem $2 \mathrm{f}$ et high. Flawers lan's e in sxillary snd terminal clustero, $\nabla$ ith a wide gprealing bouler, ojening at $\frac{1}{x} \cdot 0^{\circ} \mathrm{clock}$, F. Af, bright purple. By cultivation it sports in to meny varieties pith yollow as white, red and white, and rod and yellow flowers. Jung-Sept.

2. M. LONGINLRA, L. Long flowered Fuur-o'clock.

Isares pubescent; flowers crowded; twie of the pcrisngh very long, hary. Thtive of Sexico. Per. Junc-Sept. Stem 2 feet ligh. Floners white.

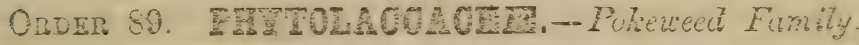

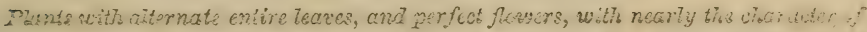

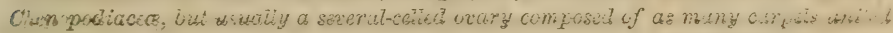

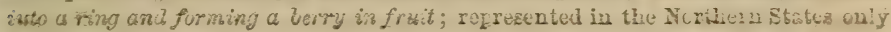
by the typical gezus

\section{PIYTOLACCA, TOMn. POKWERD.}

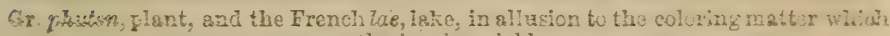
the burries yio!d.

CaLYX of 5 rounded and petal-like sepals. SHALs: 5 to 80 . Orary of 5 to 12 carpels, united into a ring, with as many suort seporate stylcs, in fruit forming a depressedglobose 5 to 12 -celled berry, with a single vertical sect it each coll.-Tull and stout perennial herts, with large petiuber? leaves, and fowers in racemes becoming lateral and upposite by the asillary prolongation of the stem.

P. DECANDra, I. Common Puke or Scule. Garget.

Teaves orate, acute at boti ends; stimens 10 ; styles 10 .

Rorusides and moist grounde, carmon. July-Supt. Root vory larae, poinonoz. Sem 5 to $\&$ feet high, rowad, gmooth, branching, and plien mature of a find dcr.p erimson or purple. Leate 5 inches long, by 2 to 3 wide, smootiz, entire aud "ytioled. Flower greenibh-white. Frait a durk purple borry, fllod vith co crinian juive.

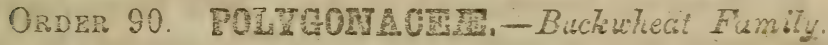

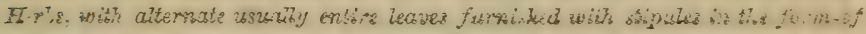

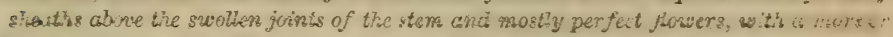

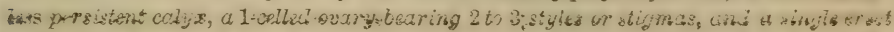

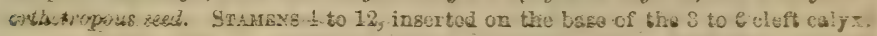

\section{POLYGONUM, Linn. KXOTw.}

Gr. polas, mazy, and gomu, kneo, from the numoroas joist.

CALYX mostly 5-parted, the divisions often potal-1ike, pr-

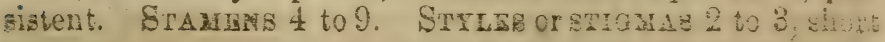


filiform. Achenia triangular or lenticular, usually covered by the persistent calyx.-Herbaceous plants with jointed stems, and small flowers in axillary and terminal fascieles and.spikes, or paniculate racemes.

* Persicaria, Tourn. Flowers in ierminat or axillary spites, witite or rose colored. Mostly annials.

\section{P. Pennsyuvanicum, L. Pennsylvania Knot-Grass.}

Siem smooth, tumid at the joints; leaves laneeolate, petiolate; stipules smooth; swites oblong, crowded; stamens 8; styles 2 or 1.

Margins of ponds and ditches. July-Oct. Stem 2 to 3 feet high. Leaves 3 to 5 inches long, $1 / 3$ as vide, slightly scabrous. Spities dense-flowered, large and somewhat noading. Flower's rose-colored, pedicellate.

2. P. Persicaria, L. Lady's Thumb. Spotied Knotweed.

Stem smooth; leaves lanceolate, pointed, roughish; sheaths fringed; spities ovoidoblong or cylindrical, dense, ereet, on smooth peduncles; stamens mostly 6 ; sty'es 2, united nearly half their length.

Waste and damp places, very common. July, Aug. Stem 12 to 18 inches high, often colored. Leares 2 to 4 inches long, $1 / 4$ as wide, usually marked with a dark heart-shaped spot near the middle. Flowers greanish-purple, in spikes about 1 inch long.

\section{P. lapathifolium, L. Pale Knotweed.}

Stem smooth, geniculate; leaves ovate-lanceolate or oblong-lanceolate, acuminats, smoothish, sometimes hairy beneath; upper sheaths somewhat fringed; spilies eylindrical or oblong, erect or nodding; stamens mostly 6 ; styles 2, distinct and at length divergent.

Swamps and citches, rare. Aug. Stem 2 to 4 feet high. Leaves 3 to 5 inches Jong, $1 / 4$ to $1 / 2$ as wide, on petioles $1 / 4$ to $1 / 2$ inch wide. Flowers small, white, or tinged with red, in numerous panicled spikes.

\section{P. Hydropiper, L. Water-pepper. Smart-iveed.}

Smooth; leaves lanceolate, marked with pellucid dots, wavy-margined; sheaths inflated, fringed; spikes slender and interrupted, drooping; calyx dotted : with glands; stamens 6 to 8 ; styles 2 to 3 , united at base; fruit lenticular or 3-sided. (P. punctatum, Ell.)

Low grounds, very common. Aug., Sept. A well known intensely acrid plant, 12 to 20 inches high, with the stem and leaves sprinkled with glandular dots. Leaves 2 to 3 inches long, 1-5 as wide. Flowers green, tinged with purple and white.

\section{P. Hydropiperoides, Michx. Mild Wäter-Pepper.}

Stem smooth, upright or ascending, often rooting at the joints along the base; leaves lanceolate, roughish, slightly hairy or ciliate; sheaths fringed with long bristles; spikes slender, loosely flowered, weak; stamens 7 to 8 ; styles 3 , united bolow; fruit 3-sided, smooth and shining.

Swamps and along streams. July, Aug. Stem 12 to 15 -inches high. Leaves 2 to 4 inches long, 1-5 as wide, sessile. Spikes several crowded near the summit of the stem, composed of small fascicles of reddish flowers. (P. mite, Pers.)

\section{P. Амрнiвium, L. Water Persicaria.}

Leaves elliptical-lanceolate or oblong, pointed or nearly obtuse, narrowed or somowhat heart-shaped at the base; spikes very dense, ovold or cylindrical; stamens 5 ; styles 2 ; fruit flattened, smoothish.

Marshes or ponds. July, Aug. A very variable species, embracing several distinct varictics. Stem smooth, furrowed, short-jointed, often very long and creeping, 
or loating and rooting. Leaves 5 to 7 inches long, 1 to 2 inches wide, often shising. Sipules large, sheathing, mastly torn. Flowars rose-rid; in spikes 1 to 3 1nches long.

\section{P. Virginianum, L. Virginian Persicaria.}

Fearly smooth; stem angled, upright; leaves ovate or the upper orato-lanceolate, seuminate, rounded at the base, short-petioled, rough-ciliate; sheaths cylindrlerl, truncate, hairy and fringed; flowers loosely disposed in a long and slender nakval spike; stumens 5; sty?es 2, uneqal.

Thickets ix rich soil, common. Aug. Stem 2 to 4 foet high. Leaves 3 to 6 inches long. $1 / 3$ as wide, on petioles $1 / 1$ to $1 / 2$ inch long, Spite 10 to 20 inches long, imple or with one or two branchlets. Flowers small, white.

8. P. onientale, I. Prince's Feather.

Tall, branching, som what hairy; leaves ovate, pointed, petioled; uppor shoatis calver-form; spilces num rrous, nodding; stamens 7 ; styles 2.

Escaped from cultivation, and naturalized about gariens and waste grounds. Auz., Sept. Stem 4 to 6 feet high, erect, paniculately branchod. Leave 8 to 12 inches long, $1 / 2$ as wide. Flowers bright roze colors, open, in num rous lorgo glumz-like terminal spikes.

- Avioularia, Meisn. Flonors greenist -witite, axillary; stamens 5 to 8 ; stigma: 3.

\section{P. arvicularia, L. Knot-grass. Goose-grass.}

Prostrate or spreading; leaves sessile, lanceolate or oblong; flowers eppareat'y. eassile; sleat?/s much shorter than the lower leaves; fruit enclosed in the caliz.

- Roalsides, door-yards and waste places, common. Junc-Not. Siems slencer, 2/2 to $1 \frac{1}{2}$ font lonr, smooth, branching, with sirort white torn stipuleg at the $j$ nintw. Leaves $1 / 2$ to 1 inch lon $3,1 / 4$ as wide. Flnwers greenish- white. Tar. erect am. Roth, (P. erectum, L.) has upright or ascending st ms, largir oral or ellintical learcs and asually 5 stamens.

\section{P. Tenue, Michx. Slenter Tnot-grass:}

Fivm low and slender, upright, sparingly branched, sbarpangled; leaves sessile, narrowly-linea", very acute; sheaths canillary-fringed; flvers acarly susile, uften olitary, greenish-white; fmit nearly smoth, shining.

Dry soil and rocky hills. July-Sept. Plant 6 to 12 inches high. Leaves 1 to 13/2 inch long, $1 / 8$ to $1 / 4$ as wide, sessile, 3 veined. Fiowers greenlsh-white.

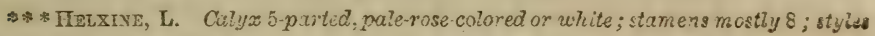
or capitile stigmas 3 ; leaves heart-silaped or arrozo-shaped; aniluals.

\section{I1. P. arifolium, L. Hulbert-leaved Tear-thatmb.}

Slem groove-angled; leares halbst-shaped, acuminate, long-petioled; fiowers Bowewhat rasened, few; peduncles glandalar-bristly ; calyx ofion s-parted, clopod; stimens 6 ; stytes 2 , very short.

Inw mounis. Ang. Stem fnccid, somewhot climbing, by the refexcd prickled which b set its ancles as well as the petiolus. Leares 2 to 5 inchu long nind $1 / 2$ as wide, the divergent lob:s at the base pointer. Clusters racemose, slender, loos, few-flowered at the ends of the branches. Flowers pale rozo colored.

\section{P. sagittatum, L. Scratch-grass.}

Shem 4 angled; leaves arrow-shaped, short-petioled; fivwers espitato; pedursoles Emooth; stumens 8; sty'es 3, slender; fruit sharply 3-angled.

Low grounds, common. Jaly-S spt. A climbing plant often arveral fet in Jugih, smooth except the angli's of the stem and midrib boneath, which are closeIs beset with a line of sharp prickles pointing downwards. Leares acute, 1 to 3 fraches long; $1 / 2$ as wide, on potioles $1 / 4$ to $3 / 4$ inch long, witb smopth stipules. Fin. ers whitish in small terminal beadi. 


\section{P. Convolvulus, L. Black Bindweed.}

Syms twining or procumbent, roughish; leares cordate-hastate, pointod; flowers in small interrupted racomes; calyx segments obtusely keeled; stamens $\mathrm{S}$; styles 3 ; sruit smoothish.

Cultivated and wasto grounds, comnon. July-Sept. A climbing piant 2 ta 6 leot long, with roughish angled stems. Leaves 1 to 2 inches long, $1 / 2$ as wite, with somewhat spreading lobes at base. Flower's whitish.

14. P. crurrode, Michx. Fringe-jointed False Buckwheat.

Minutely downy; sheath fringed at base with reflexed bristles; leares cordate and slightly hastate, acuminate; racemes panicled; stamens 8; styles 3 .

open roods and rocky hills, common. July-Sept. Stems climbing 3 to 8 fuet. Flovers whitish.

\section{P. DUMeTorum, I. Climbing Fatse Buckwheat.}

Smooth; sheaths naked; leaves heart-shaped or slightly hastate, pointed; ro nemes interrupted, leafy; 3 outer calyx-lokes strongly keeled, and in fruit winged; frutit smooth and shining; stamens 8 ; styles 3 .

Mioist thickets, common. Aug. Stem twining 8 to 12 feet over busice. Leaves with distinct round lobes. Flovers in long interrupted racemos, white.

**** FAGOPYREM, Toura. Culyx petal-like, equally 5-parted; stamens 8; styles 3; achenian 3-sided.-Annuals, with triangular-cordate or hastate leaves, and corym bose racemes or panicles of white flowers, often tinged with green or rose-color.

\section{P. Fagopynum, L. 'BuclewTieat.}

Smoothish; leaves cordate-sagittate; raceme panicled; foowers 8 , honey-boarings: glands interposed between the stamens; fruit twice as long as the ealy $\mathrm{x}$, with acuteand entire angles. (Fagopyrum esculentum, Tourn.)

Old fields, escaped from cultivation. June-Sept. A valuable grain, much cul; tivated on poor land. Stems 2 to 4 feet high. Leaves 2 to 4 inches long, $1 / 2$ as wide. Flowers numerous, white, fragrant.

\section{RUMEX, Linn. Dock. Sommer:}

The ancient Latin name of unknown etymology.

CaLYX of 6 sepals, persistent, the 3 outer herbaceous, thia 3 inner large, somewhat colored, valvately. convergent orer the 3-angled achenium. Stamens 6. Styies 3 ; stigmas tufted.-Coarse herts, with small mostly greenish flowers, commonty whorled in paricled racemes.

* Lapathum, Tourn. Flowers perfect, or sometimes polygameus; styles free; in. ner sepals bearing grain-bitic tubercles; bitter herbs, with the petioles sheathing at the base.

1. R. verticiliatus, I. Sioamp. Dock.

Leaves lancolate, acute, flat; racemes nearly leafiess, elongated, the flowers in erowded whorls; sheatis cylindrical; valves broad-cordate, entire, cach bearing a very large gruin.

Wet swamps and ditches, rathor oommon. Juns, Juig. Stem 2 to 4 feet high, hranched above. Leaves long, pale-green, thickish, with coaspicuous sheatha Whorls few-tlowered. Pedicels $1 / 2$ to 1 inch long,

2. R. obtusifolius, L. Broad-leaved Dock.

Stem rougbish; lowest leaves orate-cordate, oltuse, rather dow $n$ on the pelas un- 
unilerncath, elightly wavy-margined, the uppor oblong-lanceolato, acute; whonts loose and distant; valves toothed, one of them bearing grains.

Fields and waste places, common; introduced. July. Stem 2 to 3 feet highi. Purroved, brancling, leaf. Foct-leaves about 1 foot long, 5 to 6 inches ride. $F$ lowers in long, nearly naked racemeg.

3. R. CRIspus, L. Curled Dock. Yellow Dock.

Smooth; leaves lanceclate, with strongly wavy-curled margins, aeute, the lowes truncate or somewhatheart-shaped at the base; whorls crowded in long slezder racemes, leafiess above; valves entire, ovate, one of them besring grains.

Cult:Trted ard raste grounde, rery eommon; introduced. June, Juiy. Stam 3 to $\frac{1}{2}$ fuet high, from a deep epindle-shaped yellow root. Flower numerous, in a large panisie, consisting of numerous racemes of half-whorls. The root is aow medicinally.

4. R. aAnguineus, I. Bloody-veined Dock.

Iacces lanceolate, wavy-marginod, the lowest eordate at the bace; whorls diftant, in long end slenter lesflese interrupted spikes; valess entire, ons of them at lesst berring grains.

Waste and cultivated grounds; sparingly introduced. Jure. Stem 2 to $s$ feet high, redulish, branching, lesfy. Teins of the lesves red, or in the variety riridiz, green.

* Acriosell, Tourn. Flnwers diasious; stgtes acherent to the angles of h. sary; 7erbuge acid.

\section{R. Acetoselta, L. Field Sorrel. Sheep Sorret.}

Inw; leaves lance-halbert-form, the narrow lobes entire; whorls loaflese, in slender panicled racemes; valves otate, without zrains.

A very common weed in sterile soil and worn fields. May. Stema 6 to 12 inoboz high, leafy. Leuves very seid, but pleasant tasted. Flowcrs small, red or rodidish.

\section{RHeUM, Linn. Rhubarb.}

Rha, the riter Yolga, on whose banks the plants are said to be native.

Calyx colored, 6-sepaled, persistent. Stamens 9. Strles 3; stigmas multipid, refezed. Achenia 3-angled, the angles margined.-Perenniuls, with fasciculate flowers in racemose panicles.

\section{R. Rhaponticum, L. Garden Rhubarb. Pie-plant.}

Leaves smooth, coriate-ovate, obtuse; petioles channeled above, rounded at the adges. May. Native of Asia, cultivated in gardens for the juicy acid petioies. Stem stout and fleshy, 3 to 4 feet high, hollow with large sheathing stipules at the joints. Leaves 1 to 2 feet long, $2 / 3$ as wide, on petioles 6 to 18 inches long. Finav. ers greenish-white in a sermixal panicle, at first enclosed in a white mombransous bract.

\section{ORDER 91. IAURACE:-Bay Famity.}

Aromatic trees of shrwbs, with alternate simple leares mostly martied with minuts peltweid dots, and ciustered flewers wizh a regular calyz of 4 to 6 ectured sepals which. are barety united at the bass, imlricated in 2 series in the bud, fres from the carry. STAYaXs definite. STYLE single. FBUP a 1-seeded berry or drupe. 


\section{SASSATRAS, Nees. SAssafras.}

Flowers dioecious, with a 6-parted spreading calyz. Stamens 9, inserted on the base of the calyx in 3 rows, the 3 inner with a pair of stalked glands at the base of each : antuers 4-celled, 4-valvcd. Fertile rlowers with 6 short rudiments of stamens and an oroid ovary. DRUPe oroid, supported on a club-shaped fleshy pedicel-Trees. with spicy aromatic bark, deciduous leaves, and green ish yellow fluro. ers in clustered and peduncled corymbed racemes, cppearing with the beaves.

\section{S. officinale, Nees. Common Sassafras.}

Leaves ovate, entire or some of them 3-lobed and cuneate at base; racemes with linear bracts. (Laurus Sagsafras, L.)

Rich wcods and hillsides, common. April, way A trce 15 to 10 foet high. with yellowish-green twigs. Flowers grectish-yellow, in clustered racemes at the sad of the last years twigs. Fruit a dark blue drupe, torn on a red stalk.

\section{BENZOIN, Nees. SPICE-BUsIr.}

FLowens polygamous-diœcious, with a 6-parted open calyx. The sTERILE FLOWERS with 9 stamens in 3 rows, the inner 1 to 2-lobed and gland-bearing at the base; $\triangle$ NTHERs 2celled, 2-valved. Fentile rlowers with 15 to 18 rudiments of stamens in 2 forms, and a globular ovary. DRUP obovoid, the stalk not thickened.- Shrub with entire decidrous lcaves, and yellow flowers preceding the leaves in nearly sessile umbel like clusters.

B. onontFonum, Nees. Spice-wond. Fever-bushi.

Nearly smooth; leaves cblong-oborate, pale underneath; peüicsls scarcely as long as the flowerg. (Laurus Benzein, L.)

Damp wonds. April, May. A shrub 6 to 10 foet high, pervaded with on aromatio farcr siritar to gem bevzoin. Leares 2 to 4 inclies lone, ard abuut $1 / 2$ as wille. Flcuers ia ciustered umbels, greenisi, appoaring before tho lusies. Lerrice ripo in Eept.

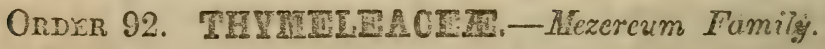

Shrulb, with acrid and very trugh lark, cntire leaves, and perfect flowers with a regular and petal-iike calyx, bearing usually twice as many stumens as its lobes, in. serted into the calyx. Ovanx solitary, with 1 ovule. STylz 1 : strama undirided. BroIr hard, dry, crupacoos.

\section{DIRCA, Linn. LEatmerwood.}

Cr. Dirke, the name of a fountsin ncar Thebe.

Prriantn colored, tubular-funnel-shaped, truncate, the border wavy or okscurcly 4-toothed. STAMENS 8, long and 
slender, inserted on the perianth above the middle, exserted, the alternate ones longer. Strue 1, filiform: stigma capitate. DRUPE oval. - A much branched shrub, with jointed branches. oval obovate alternate leaves, and light yellow flowers, pre. ceeding the leaves.

D. PALUSTRIs, L. Mooserood. Wicopy.

Leaves oval-oborate, alternate, at length smouth, on very short petioles, entirs, obtuse.

Damp rich moods, not common. April. Shrub 2 to 5 fect high, with white soft and very brittle wood, but the fibrous bark is remarkably tough, whence the common name Lcatierivood. Flowers preceeding the leaves, 3 in a cluster on a short thick peduncle. Berry oval, reddish when ripe.

\section{DAPHNE, Linn. Mezereumi}

From the nymph Daphne, who, it is said was changed into a laurel.

Perianti 2-cleft, marescent; limb spreading. Siamers 8 , included in the tube of the perianth. STrue 1. Drurn I-seeded.-Mostly evergreen shrubs, with the leaves generally. from the terminal buds and the flowers from the lateicit.

D. Mezereum, I. Common Mezereum.

Leaves deciduous, lanceo!ate, in terminal tufts, entire, sessile, about 3 from each lateral bud; perianth funnel-form, the segmcnts ovate, spreading; stamens inscrted in 2 rows near the top of the tube; filuments very short; stigma sessile. $A$ beautiful Europcan shrub, 1 to 3 feet high, flowering in March. Flowers piak and white, clothing nearly the whole plant.

\section{ORDER 93. NYSSACF掻,-Tupelo Family.}

Trees, with diocions-polygamous fiowers, consisting only of the genus Nyssa, which has commonly been appended to Santalacere from which it difiers in the sali: ary ovule of the ordinary structure, suspended from the top of the cell.

\section{NYSSA, Linn. TUPeLo.}

STERILE FLOWERs with a 5 -parted calyx, and about 10 stamens on the outside of a convex disk. FerTiLe with the tube of the calyx adherent to the 1-celled ovary, th 3 border 4-parted and deciduous. Stamens 5: style elongated, revolute. FRUIT an oval or oblong berry-like drupe, with a grooved endocarp.-Trees, with alternate deciduous smooth and shining leaves, and axillary peduncles, bearing sterile fowers in capitate clusters or racemes, and the fertile 2 to 4 Logether or sometimes solitary. 
N. Mulmirona, Wang. Pepperidye. Sur Gum.

Zworas cral und olovate, actite or pcinted at teth ezde, entire, tlo foticles snd micrib hairy : fertile forwers mostly in $3 \approx$; drupe ornl.

Wosks, in diy or moist foil, common. Mtry. A midele-rized tree, with dsrli pray

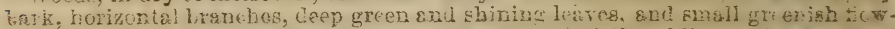

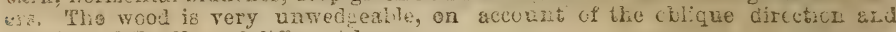
erassing of the fibre of different liyers.

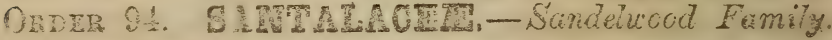

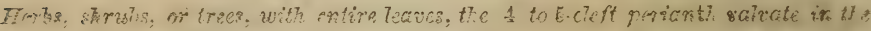

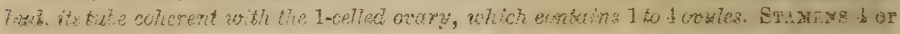

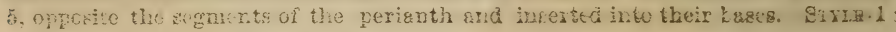
Eastis ofton lowed. Fiurr a nut or drupe.

\section{COMANDRA, Nutt. BAETARD TOAD-TLAR.}

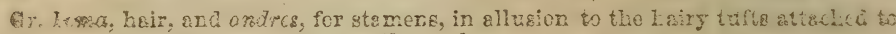
the anthers.

Tromens perfect. Penraxth bell-chaped or urn-chapd, the limb 5-cleft, pursistent. ETAMrNs 5, rarely th the ar. thers achering to the lokes of the perianth ly a tuft of threses. Strue single. Frut dry and rather rut-like, 1-ececed, crowned by the persistent perianth. - Lov and imecth yerennial herbs, with allernate ollctig and sessite lcaves, and greninh-white flowers in terminal or axillary umber-bihe ezmes.

C. uMbeliata, Nutt. Bastard Toad-flix.

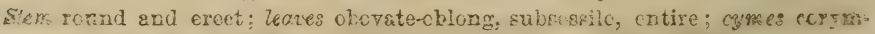
refe-duntered, ceveral-fiowered; feriasth-tule cortinued teyond the crery, foinine a neck to the globular-urn-slaped fruit; style slender, as long as the atamene.

Dry or recky kankg, ecnmon. M8y, June. Sems tronching, \& to 12 iacles Lifh? smerthish. Flowers $u$ hitish, numercub on siort pedicele.

\section{PYRULARIA, Michx. OIL-NCT.}

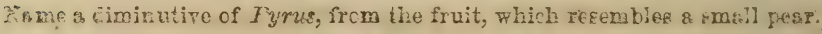

Thowers dicocious. PrRinth 5.cleft, the lokes re. curved. STrRule flowing with 5 stamers en very glert tlaments, alternate with 5 rounded glands. FERTul FLC मेEns with a pear-shaped orary invested by the adherent rorianth; DIEK with 5 glands: STYLE 1, elort ard thick:

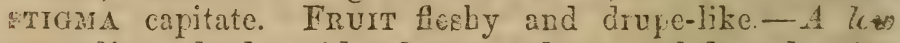
straggling shrwb, with alternate short-petioled and reigry leaves, and small greeniah sessite fiovers in simple terminial epitees. 


\section{P. oleirena, Gray. Bufficio-nut. Oil-nut.}

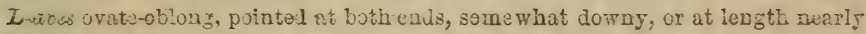
sua soil, somewhat sueetient.

Rieh wooled banks anil mountains. May. Stem 4 to 6 feet high, with a very deep root. Estres 2 to 3 inches long, oily to the taste. Flowers in a terminal gyik grvenizh-y llow. Sy ites ripening bat one frait, which is about 1 inele loag.

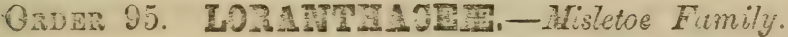

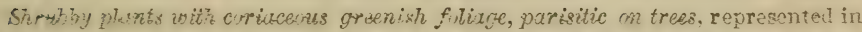
the rozth im tampurate zone chiedy by the Mistletoe, distingaished from the fre-

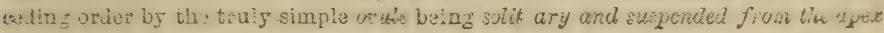
of thas cabl. Pajur a 1-secded berry.

\section{VISCUM; Linn. MisLetoz.}

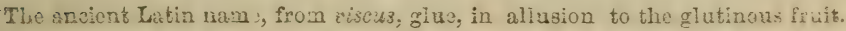

Flowzaz moncosious or diœoioas. Perianti fleshycoriacious; in the sterile fiowers 3 to t-parted, the triangular loges, easin with a sessile anther directly adhering to its inter face, and opening by several pores; in the fertile the tube of the perianti is combined with the ovary, the border obsulete.

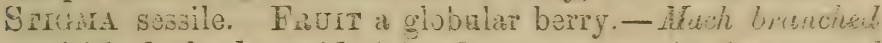
1) xrisitical sirrubs, with jointed stems, opposite besves und sinall flowors in sloort spikes.

T. rudvesdins, Pursh. White Misletoe.

33anches round, spremiag; leases obovate or oval, contriated at the bave inte: a short potiole, 3-aervod; spites axillury, solitary; sterile flowers mōstly-tritid.

Parasitic on the trunks of olu treaz, espesially Eima, Oaks, and Hiekories: April .

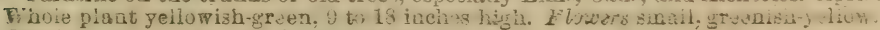
Lorris pzarly-twhite, resoubling white wax.

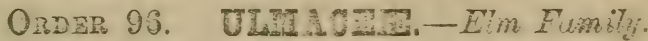

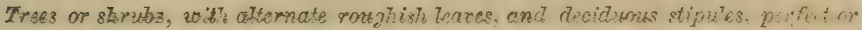

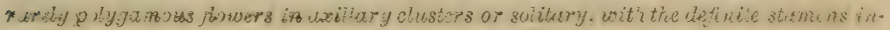

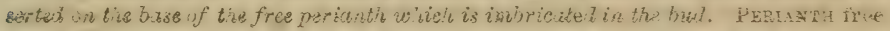

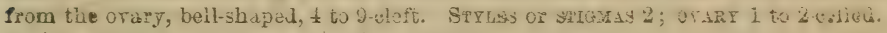
Padit 1-3elled, with s singlo suspendaù sred.

\section{Ulmus, Lina. Elx.}

The olassical Latin name.

Perianti bell-shaped, 4 to 9 -cleft. Stanens 4 to 9 , with long and slender filaments. Srrees 2, short. OVAay flit, 2-celled, with a single anatropous ovule susponded frute the summit of each ceil. Prourr a 1-celled and 1-sascted 
membranaceous samara winged all around.-Trees, rarely shrubs, with rough leaves, and (often polygamous) purplish or yellowish flowers in luteral clusters, preceding the short-petioled leaves.

\section{U. Americana, L. American or White Elm.}

Leaves smooth above, downy underneath, oblong-ovate, pointed, sharply doably Earrate; flowers in umbel-like clusters, on conspicuous pedicels; fruit oval, with woolly-fringed margins.

Moist woods and river banks, common. April. A large tree, 30 to 70 feet high, w: th long spreading pendulous branches, and slender pendulous branchlets. Leaves 4 to 5 inches long, doubly denticuiate. $f^{\prime}$ towers small, purplish. Stamens about 8.

\section{U. Fulva, Michx. Slippery Elm. Red Elm.}

Leaves very rough on the upper sile, roughish downy underneath, ovate oblong doubly serrate; buds rusty-woolly; flowers narly sessile in dense clusters; frwit nearly orbicular, the margins naked.

Woods, in rich, dry or moist soil, common. A pril. A midule-sized or small tree, 20 to 4 ) feet high, and 9 to 20 iachos in dimeter, with stragging branches and rather tough redidish wood, remakable for the tough macilagiaous inner bark. stumens about 7 , short, reddish.

\section{CELTIS, Tourn. NetTle-TREe.}

An ancient ureek name for the Lotus, which this tree is said to resemble.

Flowers polygamous. Periantei 5 to 6 -parted, persistent. Stamens 5 to 6 . Ovary 1 -celled, with a single suspended ovule: stigmas 2 , long and pointed, recurved. Fruit a globular drupe, with thin tiesh.- Trees or large shrubs, with pointed, petioled leaves, and greenish axillary flowers, solitury or in pairs, appearing with the leaves.

\section{C. ocendentalis, L. Silgar-berry. Hick-berry.}

Zeaves roughish, obliqucly-ovate, sharply scrrate, finely acuminate, unequal and ofton beart shaped at the base; flower.small, subsolitary.

Woods and river banks. May. A tree 20 to 30 feet high, with the aspect of ase Flin. Leuves 2 to 5 inches long, with a very long acumination and very unequal at the base. Flowers small, greenish-white. Fruit dull-purple or yellowish-bronn, sweet and edible.

2. C. crassifouta, Lam. Hackberry.

Ieaves lance-ovato, acuminate, s rrate, unequally heart-shaped at base, rough and hairy on both sides; peduncles mostly 2-flowered.

Low grounds. May. A small tree, 20 to 40 feet high, with a straight slender trank, undivided to a considerable height, corered with an unbroken bark. Leaves 3 to 6 inclies long, thick and firm. Flowers small, white, succeeded by a ruund, black drupe about the size of the Whortleberry.

\section{C. pumina, Pursh. Dwarf Hackberry.}

Leaves broadly ovate, acuminate, equally serrate, unequal at the base, Bmooth on both sides, the younger only pubescent; patuncles mostly 3-flowered; fruit Bolitary.

River baris, along the Suaquehanna. A dwarf very straggling shrub, 3 to 10 feet high. Iecives sometimes heart-shapcd, nearly as broud as loag, with a very short acumination. Berries brown ar nearly black. 
SAURURACEIE, CERATOPHYLLACEZE AND CALLITKICEACEAS. 313

ORDER 97. SAURURACEF,-Lizard'stait Family,

Lerbs, with jointed stems, alternate entire leaves with stixuies, and perfect fiowers in spikes, entirely destitute of a perianth, and 3 to 5 more or less united ovaries.cruLE few, orthotropoue. HRIT a capsule or berry, 3 to 5-celled, few seeched

\section{SAURURUS, Linn. LIZARD's-TATI.}

Gr. saura, a lizard, and oura, a tail; in allision to the form of the inforescerce.

Inforescence an ament or spike of 1 -fiored scales. STAMeNs mostly 6 or 7 , hypogynous, wwith long and distinct flaments. Fruit somewhat Aleshy, wrinkled, of 3 or 4 pistils united at the base, with recurred stiguas. SEEDS usually solitary, ascending.-A perennial aquatic herb, witi hecert shaped petioled leaves, and white flowers, each from the axib of a small bract, closeld aggregated in a slencier terminal pistse.

S. CernuUs, L. Lizard's-tail.

stem angular; leaves cordate, acurainate.

Margins of ponds and streans, common. Tuce-Arg. Stem Itwo ri feet hath, wesk. furrowed. Leaves 4 to 6 inches long, $1 / 2$ as wide, emootb ar G glauctous on reticle 1 to 2 inebes lorg. Spilie slender, 3 to 6 inches long, dropide at the tho

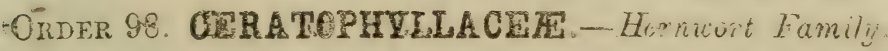

Aquatic herbs, with whoried finely dissected leaves, anả minute osillury ancì stisile menacious flowers without any floral envelopes, but with a many.clejt incolwcre-

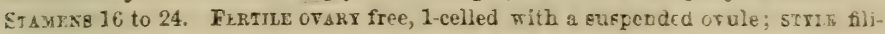

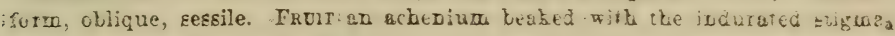
SEEL cortaining 4 cotyledong.

\section{GRRA TOPHELLUM, Kinc. FORYWUT.}

Gr. Feras, w horn, phullon, a lesf, alluding to the bornlike dirjacue of the lestes.

STERILE FLOTERS of 12 to 24 stamene with large sessile anthers. Frurt an ackeniun, beaked with the slender persistent style.- Ferbs, growing under water, in ponds or slow fowing streamsi; the sestite leaves cut into 2 or a forking filitorm rather rigid: divisions.

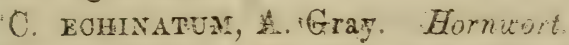

Acherium elliptical, rough-pointed on the sides, with is terkias! aud 2 short iateral spines, the slightly wirged rusgins armed with bluat teetb, which fiadis elongate and equil the ldteral aptaes; dirisions of tee leares minute's aerculare; mostly 2-too thed at the apex.

Cummon. June, July. Flowers mintite.

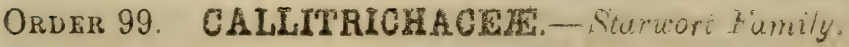

Aquatic small anneats, with opposite entire lesver, anu pulygamoits sulitary flouers. I2 
in their axils, visually between a pair of bracte, without proper floral cnrelopes.IRUI 4-celled, 4-lobed and 4-seeded, consisting cnly of the genus

\section{CALLITRICHE, Linn. WATER-STARWORT.}

Gr. Falos, beautiful, thrix, trichos, hair; alluding to the slender stems.

Stamens 1, rarely 2 : Filaments slender: anthers 1 celled, kidney-form. Strutes 2, awl-shaped, distinct. Frue jedehiscent, nut-like, 4-lobed and 4-eclled, but the styles cnly 2, awl-shaped, distinct. SEED solitary and suspended, filling cach cell, anatropous.-Aquatic small annuals, with ogposite entire leares.

1. C. verna, I. Temal Water-staruort.

Leaves 3-nerved, the foaling ones spatulate or okovate, the immered linear; bracts incurred; styles constantly erect; fruit nuarly sessile; the lobes par allel in $y$ hirs and bluntly kecled on the kack.

Shallow pools and sicw streams, common. May-Sert. Sicm fonting 1 to $2 \mathrm{fict}$ lone, composed of 2 tubes, simple or lranched. Leaves 2 \& $t$ each joint, leceming crowded aborn into a star-like tuft uron the surface of the water. Flescers wite, axillary 1 to 2 toguther.

2. C. FLATYCARPA, Kutzing.

Fruit nearly sessile; the lokes raralle! in paire, slightly winged on the lack; siyles crect in the flowere, refiexcd cicsely orer the fruit. Jracts and foligge much as in the last, the fruit trice as large : growing in similar situaticns.

\section{OnER 100. FODOSTEMAOER,-River-weed Fanily.}

Aquatics, growing on strines in running uater, rescmbling EER-wecde or McEscs, with the minute nulied flowers buriting froin a sputhe as in Liverworts, producing a 3 . colled many-seded capsule; represented in North America by the gents

\section{IODOSTEMUM, Michx. River-nierd.}

Qr. pous, a foot, and sicmon, stamen; the stamen appearing as if on a comraon foot-stalk.

PeniAxti or BRACTs, of 2 to 3 small awl-shaped Ecales. Stamens 2, rarely 3 ; milamints monodejphous belcw. Strues or etignas 2, awl-sbaped. Carecle 2-celled, :ralved, many-ribbed. SEF.DS minute, rery numercus on a thick central placento.-Flowers axillary and solita!y, yedicelied from a tulular spathe.

\section{P. Ceratorhylecm, Michx. Thread-foot.}

Leares rigid, dichotomcusly disfeted; filaments vuitcd to al ore the nifede.

Common in the bottom of ahaliow streams. July. A small olive-green firnt res mbling a Sea-weed, and tenaccously adhering to lcose ftones at the bettrm, eimilar to a Fucus. by flerhy disks or picenses in the place of rects. Leciess ru. Inerous. alternate divided into sereral long lineur-trigtly feguents, 1 io 4 isclas ling. Ilorete ou elurt thick pectuscles. 


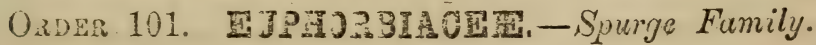

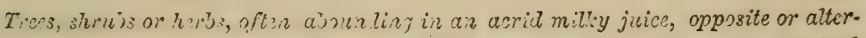
nz:tr, simole, rurely compun l le.tuss, often furizished with stipules, usially terminal or uxilary inmecinus or dixisus fluvirs, and u capsule of 2 to 3 or several 1-seeded on bies united arouize uestrul uxis, separiting when ripe.-CALyx usually valvate in tia ba 1. oe ansisally wanting. Perals somotimes present. Srrasis 2 to 3 or mare, often forked.

\section{EUphorbia, Linn. Siurae.}

Nam ad after Euphorbus, physician to King Juba.

Foowers monæoious, included in a cup-shaped 4 to 5 lobel involuare resembling a calyz or corolla, usually with largy and thic's ghands at itg sinuses. STERILe FLoweres nim rous and lining the base of the involucre, each from the axilis of a littlo brect, and consisting merely of a single set:man jointed on the pedicel like the filament. Fertiris FLOWER solitary in the midlle of the involucre, soon protruded on a lone pedicel, consisting of a 3-lobed, 3-celled ovary withoat a calyz or a mere vestige. SryLes 3, 2-cleft, therefory 6 stigmas. Capsune 3-lobed, 3-celled; cells 1 -

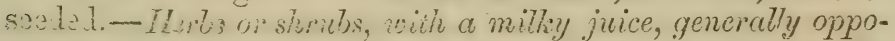
site leaves, the unpernast of fien in whorls or pairs, or sometimes whaling and luteralor termizal pedincles often umbellate clustered.

* Sien leuns arlera ate; fliwurs in invorecrate unbels.

1. E. coromitat, L. Flowering Spurge.

Shems upright, nearly simple; letr?s oblong, obtzse, entire, the floral leares Sil :Il; und divilul into 5 or 6 rays, then 3 or 2 forked; glands oval, each at the base of a potaloil in roluce.

Dor banks a t) 2 festhish, in sty sumcth. Lutw 1 to 2 inches long, often quite linear, vexy entio, snattred on the stem, rerticillate and opposite in the umbel. Corulla-lice in: a'ture larse, whits, showy.

\section{D. Daruingronir, Geav. Dirlington's Spurge.}

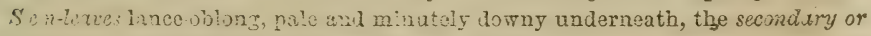

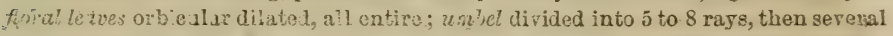
tim ss simply funked; sejments of the floral involucre colored, entire, sub-renifora; ov ling warty.

Mist wo lz, Chastar County, \&a. May, June. Per. Stem 2 to 4 feet high,

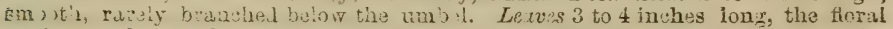
ovil, very obias, th: othor3 rounded and noarly as broad as long. Florul invoiucre purplish-bown wihin. Clipzule at leagth nearly smooth.

\section{E, Hendascopia. L. Sun Spurge.}

Ecest; flurat levess oborate; sten lexves wedge-form, all obovate and nearly rounlel at the end, finsiy surrate; umbel divided into 5 rays, then into $3 \mathrm{~s}$, or at length s.mply forka; glinds orbicular, stalked; fruit smooth and even.

Wast: placis, rare. July-Sept. A An. Stem suncoth, 8 to 16 inches algh, 
branchad from tha root. Laxve acatterca $1 / 2$ to $1 \frac{1}{2}$ inch $10 n g, 2 / 3$ as brosd at th? rounded or fetwse apex. Braneices of the unjel mostly short. Sierile flowers most. mumercus.

\section{E. Peplus, I: Petty Spurge:}

Stem erect or ascending, branched bslow; lexves entiro, very obtuse, the lower oral or oborate, petioled, the floral rouzd-heartshapad; umbel divided into mazy rays, then forking; glands long-horned; fruit roughish and thickened on the baciof each carpel, otherwise smooth.

Waste grounds, introduced. July, Aus. Anz. Plant 5 to 10 inohes high, mooth. Involucels or floral. leaves Large, clasping, broader thay lonz. Flowar: conspicuous

* * Stem leaves opposite. Heads axillary or fusciculate.

5. E. hypericifolia, I. Common Spurge. Ejebright.

Smootbisk; stem branching, neariy erect; le tves orate-oblon; or oval-obloaz. oblique or beart-shapod at the jose, ofien curved, finely serrato, 3 to 5-ribbul uz. derneath; corymbs termizal.

Waste and cultivated plases, common. Julp-Sept. Ann. Stom 1 to to 20 inctus bigh, usually purple, rery smaoth. Lexves $1 / 2$ to 1 inch long, $1 / 4$ as wike, on $v a r y$ short petioles, marked with oblong dots a:1 i Liosehes, ciliats. Corynjs of smas. wite hoods.

\section{E. Maculata, I. Spotted Spurge. Mitk Purslane.}

Iairy or sometimes smoothish; diffusely prostraté, very much branched from the root; leaves oval, minutely sarrulate towards the ead, unequal at the base, sligt: It 3-ribbed; fruit mostly hairy; sesds 4-angied.

Gravelly banks and open places, common everywhere. June-Sept. Ann:s?. Stem 6 to 12 inches in length, spreading flat on the ground. Lexmes opposite, $1 / 4$ io $1 / 2$ inch long, and $1 / 2$ as wide, often purp!:sh, or with a dark purple blotoh oz the upper side. Heads of flowers small, crowdcd near the summit.

7. E. Ipecacuaneze, L. Wild Ipecac. Ipecac Spurge.

Procumbant or suberect, smooth; leaves opposite, varying from obovate or obiong io long and narrowly linear, eatire; peduncles elongated, arillary, 1-fowerud: fruit smootb.

Drg andy soil, rara. May-July. Par. Stems mant frsm a very lañ parper: dicular root, low and diffubely gpraailag, flow sring and gimply furtring from vho - iaser. Zeaves $1 \frac{1}{2}$ to 2 inches long, $1 / 4$ to $1 / 2$ inch wide.

\section{E. Dentata; Michz: Tootied Spurge.}

Opright, hairy; leaves ovato or oblong-ianceolats, coarsely serrate With blin: teeth, narrowed into a slender petiole; flowers crowded at the summit of the stem

Shady hillsiles, in rich soil. Aug. Ann. Plant about 1 foot high, at firgt simpl afterwards with sido branches. Opper leaves apotted. Incolucre lotes sut iriagcd. frust amosth, ahort-stalked.

\section{COLTIPATED EYOTICS.}

9. E. Lataraug, I. Caper Spurge. Hite-tree

Stem erect, stout, smooth; leaves linear.oblonz, entire, the floral obioag.0pa: 3 and heart-shaped, pointed; umbel mostly 1-rayej, rays dichotomous; glands of the iavolucro short-horned; fruit and seeds smooth.

Cultirated grounds and gardens. July-Sept. S'em 2 to 3 fest high. Leaven 2 to 4 inchas long, $1 / 4$ to $3 / 4$ wide, numervas and arrangeil in 1 ropj 00 tho atez. Ombel of 4 perticillate branches with a central. subsessile bead. 
10. E. Punica, L. Scarlet Spurge. Splendid Euphortia.

stem shrubby, flezhy, armed with rigid sharp thorns; leaves orate, tapering to the base, smooth, entire, acute, mucronate; peduncles axillary, 2 to 3 times dichotomous; bracts scarlet. A singular and showy garden plant.

\section{PHYLLANTHUS, Lina}

Or. phullon, ?eaf, anthos, blossom ; the fowers being attached to the leares.

Flowers monceious. Perianti 5 to 6 parted, alike in the sterile and fertile fowers. Stamens 3 : Filaments united in a column, surrounded by 5 to 6 glands or a 5 to 6 lobed glandular disk. Ovary 3-celled, the cells 2-ovuled: STYLES.3, 2-cleft: stigmas 6 . CAPSULE separating into 3 earpels, which split into 2-valres.- Herbs or shrubs, with alternate stipulate leaves, and minute axillary flowers.

\section{P. Carolinensis, Walt. Leaf-blossom.}

Siem erect, herbaceous, with alternate branches; leaves simple, entire, smooth; oval and obovate, short-petioled; fiowers few; subsolitary.

Gravelly banks. July, Aug. Ann. Stem 6 to 10 inches high, slender. Leaves of the stem $3 / 2$ to $3 / 4$ by $1 / 3$ to $1 / 2$ inch, those of the branches $1 / 2$, and those of the branchlets $1 / 4$ as large. Flowers very small, $\pi$ hitish, 1 to 3 in each axil.

\section{ACALYPHA, Linn. Mercury.}

The Grcek name for the nettie, which this plant resembles:

Flowers monoeions. Perianth of the sterile flowers 4-parted, of the fertile 3-parted. Stanens 8 to 16 : FILAMENTs short, united at the base: ANTIER-CLLLs separate, long, hanging from the apex of the flament. Srruss 3, cut-fringed. Carsule separating into 3 globose carpels. which split into 2 valves. - Mostly herbaceous plants, with alternate petioled stipulate leares, and the clusters of vierile fiowers with a minute bract. the fertile surrounded by a large leaf-like cut. lobed persistent bract.

\section{A. Virginica, L. Three-seeded Mercury.}

Leaves ovate or oblong-orate, obtusely serrate, long petioled; sterile spike rather few-flowered; involucre of the fertile fowers beart-shaped, broad-ovate, acuminate, reined and toothed.

Fields and open places, common. Ang. Ann. A homely weed 1 to 2 feet higr, smooth or hairy, often reddish in autumn. Leares 3 -veined, 1 to $21 / 2$ inches long, 1/2 as wide. Pistillate flowers at the base of the peduncle, of the staminate spike.

\section{A. Carouriniana, Walt. Carolinian three-seeded Mercury.}

Zeaves on long petioles, rhombio orate, acuminate, serrate, entire at base; bracts beart-shaped, loked; fertlle flowers at the base of the staminate spike.

Fiolde, rare. July, Aug. Ant. Stem 9 to 18 inches high. A peculiar specieg. 


\section{RICINUS, Linn: Palma Christr.}

Lat. ricinus, an insect, which the fruit of these plants resemble.

Monocious. Sterile flowers: Periantr 5-parted. Sta. TEENS numerous: FILAMENTS united branching. Fertile flowers. Perianth 3-parted. Styles 3, 2-parted. Cap. SULस mostly echinate, 3-celled, 3-seeded.-Herbs and shrubs, with peltate, palmate leaves, and monocious flowers.

R. communis, Le. Castor-oil Bean.

Stem herbaceous, glawcous, teaves peltate-palmate, tobes lanceolate, serrate; cax scie achinate. Aug., Sept. Native of the Last Indies. In our gardeus it is a tall, gmooth plant, of a light bluish green color, but in its native counatry it becomes a tree. Leaves 4 to 12 inches in diameter, on long petioles. Cultivated extensivel 3 in parious parts of the U. S. for the purpose of obtaining oil from tho secd.

\section{BUXUS, Iinn. BOX-WrooD.}

Monoecious. Sterile flowers. Castx 3-leared: PeTals 2. STamens 4, with the rudiment of an ovary. Fertile flowers. CalyX 4-sepaled. Petals 8 . Styles 3. Cap. SULE with 3 beaks and 3 cells: SEEDS 2. - Evergreen sirrubs. with opposite leaves, and inconspicuous flowers.

B. SEMPERVIRENS, I. Box.

Leares ovate; petioles hairy at the edge; anthers oraite, sagitiate. Native of Fu. zope. Var. angustifolix has narrow langeolato leaves. Var. suffruticosa the dwarf box has obovate leaves and a scarcoly woody stem, highiy ormamental for edgings in gardens.

\section{Order 102: JUGLANDACPRE- Watnut Family}

Trees, with alternate unequally pinnate leaves, witionst sipuies, green inconspicuns monosious flowers in aments with an irregular calyz, and a fruit which is a lind of dry drupe with a bony endocarp (nut-shell), containing a large 4-iobed ortiotiopous sect. FCrTLE Fubres solitary or in gmail clusters, with a reguis: 3 to 5 -iobeci calgx adbercent to the incompletely 2 to 4 -celled but only 1 -ovuled ovary.

\section{JUGLANS, Iinn: WALVUT.}

Lat. Jovis glans; i. e. the nut of Jupiter.

STERILE FLOWERS in long and simple lateral aments; the CALYX SCALES unequally 3 to 6 -parted, somewhat bracteate at base. Stamens 8 to 40 : Filaments very short. Fer TILE FLOWERs solitary or geveral ingether on a pedunele at the end of the branches: CALYX 4-toothed, bearing 4 small petals at the sinuseg. STrLES 2, very short: STIGMas 2, somewhat club-shaped and fringed. Frutr drupaceous; 
with a fibrous-fleshy indehiscent epicarp, and a rough irregularly furrowed endocarp or nut-shell. - Large trecs, with strong scented arumatic bark, \&c, odd pinnate leaves of many ser. rate leafists, and sterile flowers in aments, the fertile terminal.

1. J. CINEREA, L. Butternut. White Walnut.

Leaflets numerous (15 to 17), oblong.lanceolate, pointed, rounded st the baso, fowny beneath; potioles and branchlets doway with clamny hairs; fruit oulong, scuminate, clammy, the mut deepiy and irregularly furrowed.

River banhs and rich woods, comman. May; fruit ripe in Sopt. Trec 30 to 50 feat high, with gray bark, and widely spreading branches. Leaves 12 to 20 inches zang. Burren flonors in long aments: fertile in short spikes. The kernel is oily an l pleasant-farored. From the bark is extracted are excellent cationstic.

2. J. nigra, I. Black Walnut.

Leaftets numorous (15 to 21), oraste-lsnceclate, acumingte, serrate, subcordate at base, smoth abore, the loter surfuce snd the petioles minutely down ; fruit gio. bose, with scabrous punctureg.

Rish roods, common. May; fruit ripe in 0ut. A icrge handacme tree 60 to 00 feet high, with a diamoter of 3 to 6 fuet : bark brorn. Tbo rood is very valuabio for cabinet work, purplisk-brown, turning blackish with age.

\section{CARYA, Nutt. Hickory.}

Gr. Karwa, the Walnut.

STERILE FLOFEF, in slender lateral catirins, which aro mostly in threes on a common peduncle : CALYz naked, un. equally 3-parted. STAMEN 3 to 8: FrLAMENTs scarcely. any. FERTIE FLOWERs 2 to 3 together at the ends of the branches, with a 4 -toothed calyz, and no petals. STIGMA. large, 4-lobed. FroIT globular, with a somewhat leathery epicarp, which splits into 4 ralres, and falls away when ripo from the smooth and sligitly 4 to 6 angled nut-shell, which is incompletely 4-celled. Trees, with hard and very tough wood, odd-pinnate lecues of 5 to 9 lexfets, and sterile flowers ir. - branched aments.

* Seed edible and delicions: bark exfoliating in shagary sirips or piates.

1. C. AIBA, Nutt. Shell.bark Hickory.

Leaflets 5, minutely downy underneath, fineig serrate, the 3 upper osovate lanceolate, the lower much gmaller and oblong-lanceoints, sil scuminate; frwit dopressed-globular; nut somewhat fattencd.

Rieh moist wcods, common. April, Nry; fruit in Get. A tali and handpome tree with rough and shaggy bark, conoisting of long gtring adhering ty the middie or one end; the rood is valuable ss timber, and expecialy for fuel. The fruit is covered with a very thick epicarp separaticg into 4 parts, sud contsining-s whitish thin-shelled nut with a lige richly-farcred kernel.

\section{C. sulcata, Nutt. Thick Shell-bark Hickory.}

Lecflets 7 to 8 , obovatolanceolate, downy undernesth, shsmply serrate; fruis oval, 4-ribbud above the middie with intervening furrows; nut 8trongly pointed. slightiy flattened, with a thick jeliowlah sholl. 
Valleys along the Alleghenies; abundant along Chillisquaqus Crenk, Northuarberland Jounty. May; fruit in 0ut. A large tree 50 to 70 feet high. Leav's 10 to 20 inches lons. Sterile aments very long. Nit nearly twice larger than in C. alba, with a thick shell.

* * Seed sweetish but small; nist hard-sholled; barli not shaggy.

3. C. Tomentosa, Nutt. Mrchernut. Bullnut Lickory.

Leaflets 7 to 9 , oblong or obovate-lanceolate, slightly serrate, roughish downy underneath; aments hairy; fruit globular or ovoid, with a thick and hard shell, which splits almost to the base; nut somewhat b-angled, the shell very thick and hard.

Rich woods and hills, common. April, May; friet in Oet. A tall tree 10 to 50 fest high, with resinous seented foliage and whitish cracked bark; the wood is celebrated for axe-handies, fuel, \&c.

\section{C. Microcarpa, Nutt: Small-fruited Iliekory.}

I.eaflets 5 to 7, oblong-lancoolate, serrate, glandular underneath; aments smooth fruit roundis b-orcid, with a thin husk; nut slightly 4-angled, the slell rather thin

Moist woodlands. May; fruit in Oct; A tree 60 to 70 feet high with an even bark. Aments long, slender, smooth. Leaves 4 . to 8 inches long, 2 to 3 inches wide, the under surface tufted in the axils of the veinlets. Fruit $3 / 4$ of an inch in dismeter.

\section{C. gladbra, Torr. Pig-nut. Broom Hickory.}

Leaflets 5 to 7 , ovate-ianceolate, serrate, smooth or nearly so; fruit pear-shaped or roundish obovate, thin, splitting about half way down into 4 coriaccous valves; rut hard and tough with a sweetish or bitterish kernel.

Woodlands; common. May; fruit in Oct. A large tree with a close bark very tough and valuable wood, and exceedingly tough sprouts. Fruit of various furms.

*** Seed intensely bitter; husk thin and sofi; nut-shell thin and fragile.

\section{C. AMARA, Nutt. Bitter-nut. Swanmp Hickory.}

Leaflets 7 to 11 , oblong-lanceolate, serrate, smooth, acuminate : fruit globular, with riaged cr prominent seams opening half way down; nut inversely heartshaped.

Wet woods, common. May ; fruit in Sept. A graceful tree with close bark, and small poirited buds nearly destitute of seales. Futshsll very thin, with an intense-e Iy bitter kernel.

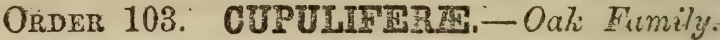

Trees or shrubs, with alternate and simple straight-veined lexves, decidicous stipudes, and moncecious flowers; the sterile in aments or eliusters, the fertile solitary or clustored, furnished with an involucre which forms a cup or covering to the 1-celled 1-seeted nut. STAmens 1 to 3 times as many as the sapals, inserted into their base. Oraer 2 to 7 -celled, with 1 to 2 pendulous anatropous ovules in each cell; all the avules and cells disappearing in fruit. Faur a bony or leathery nut, more or les. onclosed in tho eapsule.

\section{QUERCUS, Linn: OAK:}

The classical Latin name.

STERILE PLOWERS clustered in slender and naked drooping alsents, without btacts; PERIANTH 6 to 8-parted. STA- 
MeNs 6 to 12: ArTrers 2-celled. FerTin fLOTERs seattered or somewhat clustered, consisting of a 3 -celler 6 ovuled ovary with a 3 lobed stigma, inclosed by a sealy budlike involucre which becomes an indurated cup (cupule) around the base of the rounded nut or acorn. - Anotle genu; of trees (rarely shrubs), with greenish or yellowish sterile flower? in axillary.pendulous, filiform aments; the fertile inconspicuins fiowering in A pril and May, and ripening their fruit in. Ootular.

SEC. I. FRUIr annual, podunculate.-LeAves not macronats.

* Leaves siniate-lobed or pinnatifid. Warns OAas.

\section{Q. ALBA, I. White Oalc.}

Lizues smoth, pale or glaucous underueath, cbovate-oblong, obtuss, oblifia anci leeply cut into 3 ts 6 oblong, obtuse mostly entire lowas; cup hemisphuriosi, roughish, naked, mueh shorter than the oroid on oblong acorn.

Rich wonds, cemman. The Witito Oxk is a well known and invalualle tree :? to. 8 f fot high, with a diameter of 4 to 8 feet. Leanes bright green above, th lobes variable in brealth, somatimes very narrow: Nut about 1 inch long, swe j; ish, edible.

2. Q: oztustropa, Michr. Püst Oak: Iron Oxt.

Zluves deepiy cut into 5 to 7 roundish diver gent loves, the upper ones mus ionger and often 1 to 3-notched, grayish-downy underneath, pale and rougd above cup hemispherical, ntked, about $1 / 3$ the length of tha ovoid acorn.

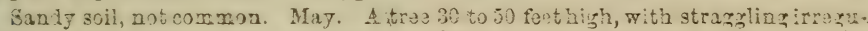
lar branches. Fruit sessile, or 2 to 3 tozather ou a short coman peduncle. The ormber is very durable, and is inuch esteened in ship building.

\section{Q. Macrocinpa, Nichz. Orer-cup White Oals.}

Leaves obovate, deeply and lyrately siauate-icbed, pale or downy undernoath. the lobes obtuse, repand; chip deop, fringed around the margin, more than duit enclosing the ovoid turgid acora.

Wools along rivers, rare, May: A tree 10 to 60 fert high, the branches corere with a corky bark. Leaves dark-green, 10 to 15 inches long. Acorns rerg iass; maxersed $2 / 3$ of thyir length in the cup which is mossy fringed on tho bor ler.

\section{Q. ourvefonms, Michz. Mossy-cup Oat.}

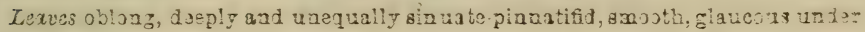
neath; cup Funz duep, mossy-fringed above, inclosing 3/4 of the elliptical-oval aco: I

Swamps and low places, not common. A large and majestic tree to to 80 feat

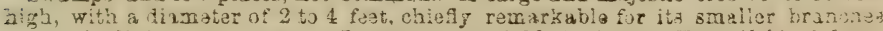
al ways incliniag dowatrara. Leaves very variahlo in form. Frait $11 / 4$ inch ion?

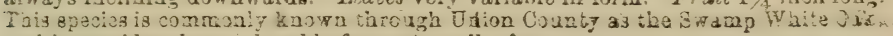
sad is coasilered very durable for posts, raila, \&o.

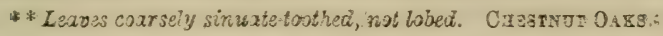

\section{Q. BICoror, Willd. Swamp White Oati}

Leaves on short petioles; oblono-oborate, cuneato at th * base, witish-1onaj ba. neath, coszely and irregularly ginuate-toothed; peduncle elozgated in fruit ; cus

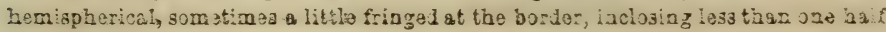
the oblong-oroil acorn.

I. W mo:st wouds, comman. A trea 40 to 60 feet aigh, with tha bark asparatiog into large tlat platsd. Leuves 6 to 7 inches 1003 , witis 3 to 15 soarse tests. Airr ange, in a gall thio and roughis cup 


\section{6: Q. Pirrus, L. Sümp Chestnut Oak.}

Lervos on long petisles, oborate, acute, coarsely s:rrate with nearly uniform round sh teeth; pulesent beneath; cup somowhat top-shaped; acorn orate.

Shady wools arl river barks. A wree 60 to 80 feet high. Leares lirge on petivles 1 inch long. Acom large, sweet. The timbor is valuable in the arts.

\section{Q. Montana, Willd. Rök Chestnut Oał.}

Lerves petioled, bron lly objate, coarsoly and neatiy equally tootliod, whicish downy underneath; pedinstesshort; cipp bemispherical, with rugose and tubercled seales; acom orate

Roiky hills, comanoz. A milule sizel tree, seham more tianz co fet high. Laxes with browl an 10 buse ta:th on a yellow petiole. A m 1 to $11 / 2$ inch long.

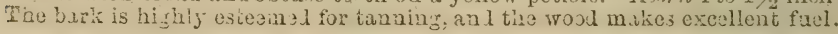

\section{Q. Chstarea, Willd. Yellow Chestrut Oa?.}

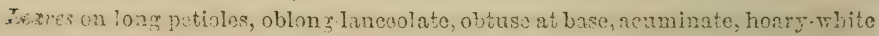

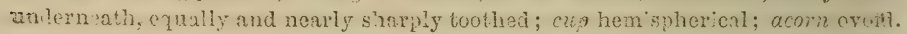

Wich mountain wools nnd valleys. A tree 60 to 70 feet high. Leares narrower th:?n thote of the forase, with aeute toth, whir are cillous at the point. Frut midilp-sizad, sossile or on a short pedunele. The'sa three Chestnut Oaks are vury

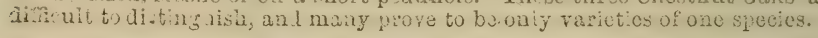

\section{ค. Q Prixordes, Willd: Chinquapin Oak}

Teares on short petioles, obovater anci kuncc-oblong, conrsely wavy-tnothed, downy anderneath; peduncles short or none; caip hemispherical; acom oro:d. (Q. Clinquapip, Pursh.)

Sudy soil. A shwuh s to g fret him. orowine in patrhes intermingled with the

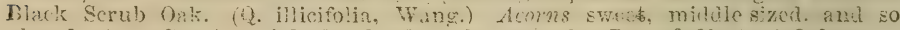
a)undaut as often to weigh the ebrub to the ground. Inorrf Che tnut ouk.

S.c. I. Fruit not maturing until the second ycar, nenriy sessile.

* Lesres cutire, narrow.

\section{Q. mmricarta, Michx. Laurel or S7ingle. Out.}

Jicives lance-oblong, acute at both ends, mucronate, thickisls, s mcoth and clining alove, pubescent beneath; crip) saucer-shaped; ocorn glolular.

Burrens and opeu woollands. A tree 80 to 50 fect high; with numerous iregu-

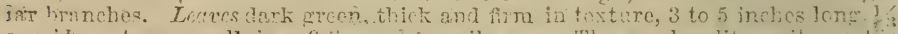

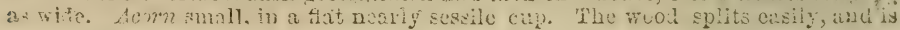
gornetimes used for shingles.

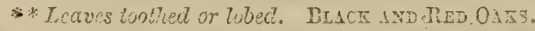

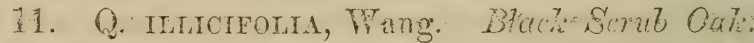

Buarf; leaves on short petioles, oborate, wedse shajed at the base, s to $5 \cdot$ angu-

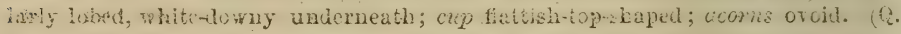
מămnisturi, Michx.)

Sardy kare ns and rocky hills, common. A etraghlingerceked shrus, 3 to 8 foet bigh, nuch brascher. Acorns in numerous dheters ou the branches. ficur cat.

\section{Q. NiGRA, I. Blacti Jicli, or Broun Oati.}

Lfares broadly wedge-shaped, rounded or somowhat heart-shaped at the bese, aliated and slightly 3 , or rarely 5 lobed at the crd, rusty-downy underncath when young; acorm ovoid-gluluiar, half covered by the fery scaly cup.

Dry woods and sandy barrens, ccmmon. A scraggy tree, 15 to 30 fcet high, coired with a thick rough liack bark. Teures lcathery, slining diove, 4 to 8 inches long, with rounced often obecure lober, the frincipal veizs i rojecting in

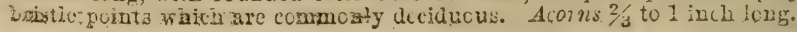


13. Q. Trxctoria, Bartram. Quercitron or Black Oali.

Leares oborate-oblous, slightiy or somotimes deeply siauate-lobed, the lobes soinewhat toothed, more or less rusty puboscent underieath; acorn dipresscdglotiose, in a fiat scaly cup.

Dry woods common. A lar re tros, sometimes attrining the heirht of so to 90 fust, w ith a diameter of $\$ t 0.5$ tect, and a deeply furrowed black or deep twm: bark. The inner tark is vory thick and yeliom, used in dy ing. Leaces 6 to 8 inches long. broadest towads the end, quile variable. Atorias brown, uearly at ssile, aboist half covered with the thick scily cup.

\section{Q. coccrives, Wang. Scurlet Ocil.}

Lrces on long petioles, oral in outline, drepiy sinuate-pinnutifu, with lroad ard open sinuses, the lobs divergent and fparingly cut toothed, 3 to 4 on each side,

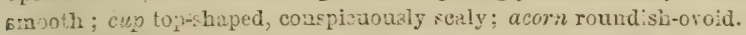

32. oh wools, common. A tree 60 to 80 feet hich, with a diametex of 3 or 4 feet.

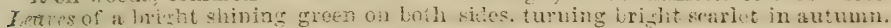

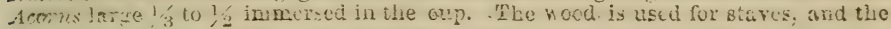
butk fur tinining.

\section{Q, rubra, T. Red OuT.}

Leares on long petinles, cblong, smooth, pale bencath, ơbtusely sinuntrly-lobed; lubes sprealiag, sparingly-t oth d or entire, 4 to 6 ou each side; cup sucer-intped, Eliallow, nearly smoth, much shorter than the ollong oroid acorn.

Forets, common. A true $\% 0$ to $E 0$ fiet high, with a diancter of 3 to 4 feet.

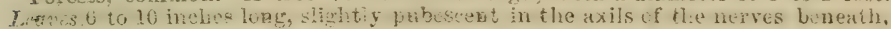
chanring to dall red or yellowidb is atumn. A orms 1 inclu loug, with a fiat base

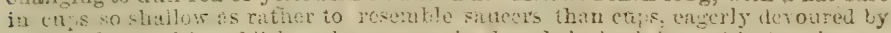

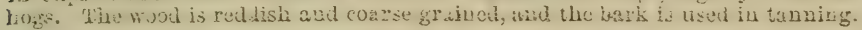

16. Q. Pabustris, Du Rod. Michx. Pin Oak.

I. eures on Icng let:oles, olleng, in outhine emcoth and sl.ining; deeply pinnatifd with broad and rounded sinuses, the lobes cirergent, cut-iob d and toothed, acute; cuc saucur-shapcd, even; acorn nearly glowose.

Swampy wocds, common. A hantrome tre $\triangle 0$ to $C 0$ fet high, with ntmerons fmreaing branches and light eligant foliage. Leares lright green on both ficien. A. orn: unm rous, small, on stort pedurcles, in shalion cujs. It is called trin cak

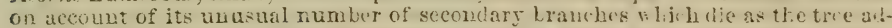
vances, giring the trunk the anpermece of halng pinc or tric nalls driven into it.

Q. hoteron?y?la, Michx., f., ras founded on a cincle tree raised in Bartraus's gar-

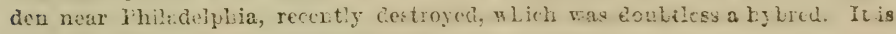
fiqured and deseribed by Michuux in his Syja Americaw.

\section{CASTANEA, Tourn. Cinstatt.}

From Custunea, a city of 'Thessaly, noted for its chestutite.

Polygamons. STERILE TLOWres interuptedly clustored in long cylindrical amonts : PRIANTE decply 5 to 6-parted : STAMENS 8 to 15 . TERTILEFLWERs 2 or 3 together in an ovoid scaly prickly involucte: TRIAXTH ureculate, 5 to 6 cleft, with therudiments of 5 to 12 abortive stamens. Ovany crowned with the periant b, 3 to 7 -celled, 14 to 25 -oruled. Nurs coriaccous, ovoid, 1 to 3 included in the entaiged echinate 1 -lobed involucre.-Trees ant sturbe, with mostly

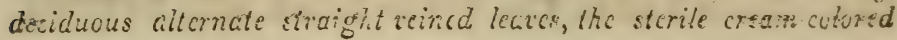


fiowers in cxillary aments near the end of the branches, and the fer. tile flowers at their base.

1. C. vesca, I. Chestnut.

Leares oblong-lanceolate, pointed, mucronate-serrate, smooth and green cn both sides; nuts 2 to 3 in each involucre, flattened on one or both sides.

frocky or hilly woods, common, especially in stony land. June, July. A large tree, with light coarge grained wood. Leaves 6 to 9 inches long, and $1 / 2$ as wide with large uniform teeth. Aments 5 to 8 inches long, very numeroue. Nits about 3 together, of a peculiar brown, enclosed in the enlarged cupule or burr which is keset on all sides with sharp spines.

2. C. pumua, Michx. Chinquapin. Dwarf Chestnut. ztaves oblong, acute, serrate rith pointed teeib, white-downy beneath; nut solitary.

Sandy woode, and sterile places. Jure. A shrub or small tree 6 to 20 feet high, much branched. Leares 3 to 5 inches long, $11 / 2$ to 2 incheg wide, smooth above, on. petioles $1 / 2$ ineh long. Stamenate flowers in anenty 6 to 10 inches long. Nit orvid, fointed, ecarcely haif as large as a common chestis at, very a reet.

\section{FAGUS, Tourn. Bexcr.}

Gr.prago, to eat, in allusion to the esculent nuts.

Honcecious. STERILE fLowers in small heads on drooping peduncles, with deciduous scale-like bracts; PERIANTu bell-shaped, 5 to 6-cleft: stamens 8 to 12. Fertule IIOWERS 2 within a 4 -lobed prickly involucre: PERIANTH with 4 to 5 minute awl-shaped lobes. STrues 3: ovary 3 -celled with 2 ovules in eacb cell. Nuts usually 2, sharpIy 3 -sided, invested by the saft prichly coriaceous involucre, which splits to below the middle into 4 -valves. - Trees with smooth gray bark, undirided straightersined leaves, and yellowish fiowers appeuring with the leaves.

\section{F. Ferruginea, Ait. American Becch.}

Ifaces eblong-orate, acuminate, distinctly and often conreely toolsed, obture a tase; prichles of the fruit recurved or spreading.

Woods along streams, common. Way. A beautiful tree, often 50 or 60 feethigh, covertd with thick amcoth ash-gray bark. Leaves 2 to 5 inckes tong, often a littio heort-shared at base, bright green and shining abore, silky underdenth when young. Nuts $\wedge$ mall, oily, sweet andinutritious. The Red Beech is now cotosidered a only a variety, with the : wCOd sofier sud easier of clearage.

\section{CORYLUS, wourn. HAZEL-Net, FurBerr.}

Gr. lrorus, qhelset or cup, in allusion to the inrolucre.

Monocious. STRme rLowers in drooping cylindrical anents, the concave bracts and the 2-cleft periant combined to form 3.10 bed scales, to the axis of which the 8 sbort filanents irregularly cobere. WERTLE FLcwers screral together in lateral and tenminal scaly buds. STicisa 2, tbreadlike. Ovary 2-oelled witb a orule in each cell. Nirtong, 
roundish-ovoid, obtuse, surrounded by the enlarged coriace. ous and lacerately toothed involucre.-Shrubs, with rounc. ish unequally serrate leaves, the yellowish sterile and red fertile flow. ers appearing in early spring in advance of the leaves.

\section{C. Americana, Walt. Wild Hazle-nut.}

Leaves roundish-heart-shaped, acuminate, coarsely serrate; invaluore roundish. bell-shaped, glandular, with a spreading flattened border about twice the length of the flattened nut.

Thickets and fencerows, common. A shrub 5 to 8 feet high, with the youn 8 twigs, \&c., downy and glandular hairy, Leaves 3 to 6 inches long and $2 / 38$ s wide. Burren fiowers in long pendulous aments flowering in April. Nut fico-fiavored smaller than the European hazel or fitbert.
2.
C. rostrata, Ait.
Beaked Hazle-nuit.

Leaves oblong-ovate, somewhat heart-shaped, acuminate, doubly scrrate; mzon ere bell-shaped-tubular, prolonged above the globular-ovoid nut into a narrow tubular beak, densely elothed with bristles

Banks of streams and along mountain ravines. Mas. $\Lambda$ shrub 2 to 5 teet high with slender smooth branches. Involucre 1 to $1 \frac{1}{2}$ inch long, contracted at the toy into a loug narrow neck, like a bottie, coverod with whort stiff hair:

\section{CARPINUS, Linn. Hornbeam. Iron-Wód.}

The ancient Latin namo.

Monœcious. Sterile flowers in drooping cylindrical aments, consistirg of from 8 to 14 stamens in the axil of 8 simple entire scale-like bract, destitute of a proper calyx : filaments very short. FERTILI ILOWERs several, spiked in an oblong loosely inbricated terminal ament, with small de. eiduous bracts, each with a pair of flowers consisting of a 2celled 2-ovuled ovary teminated by 2 thread-like stigmas. NuT small, oroid, ribbed, acute, ench with a simple, l-seeded, enlarged, open and leaflike involucre.- Trees with a snooth gray bark, with alternate undivided straight.veincd leaves appearing later than the fiowers.

\section{Americana, Michx. American Iilombeam.}

Ieaves ovate-oblong, acuminate, sharply doubly serrate, nearly smooth; twote ore 3-lobed, somewhat halbert-shaped, somerhat cut-toothcl on one side.

Woode along streams, comnon. April, May. A small tree 12 to 20 feet big. with an irregular rigid trunk, and very hard wocd, coverd with a light ush eolor ed or gray bark. Leces 2 to 1 inches long, $1 / 2$ as wire, petiolate. Scaies of the fertile anent z-ported, the middie regutnt nuch the largest, oblique with a lateral tooth.

\section{OSTRYA, Micheli. Hop ITornbean.}

Gr. ostrcon, a shell ; in allusion to the fruit.

Monccious. STERIEE FLowers in cylindrical aments, with orbicular, acumizute, ciliate scales. Sravens 8 to 10 , with somewhat irregularly united filaments. FERTILE rLOWy 
IRs numerous, in a short terminal ament, with small decidaous bracts; each enclosed in a membranaccous sac-like inrolucre which enlarges and forms a bladdery closed bag in fruit, those imbricated to form a sort of strobile, appearing like that of the hop. OVARY 2-celled, 2-ovuled, crowned with the entire and bearded border of the calyz, forming a small anà seed-like smooth nut.- Slender trees with broun. ish finely furrowed bart, enive allernate leaves, and flowers ap. pearing with the leaves.

\section{O. Vingrnica, Willd. American Hop-Hornheam.}

Zeaces oblong ovate, acuminate, sharply doubly serrate, scmewhat downy fertile anceits oblong, rendulous; incolucral sacs bristiy-hairy at the base; thate acute.

Rich mecde. Ayril, Mny. A email tree 20 to 30 feet high. The bark is remnrkalblo for its fine narrow lengitudinal diviciens. I faves on bairy reticlea, si cur awice as long as wide. The fruit is similar in efrcarasce to bors, consisting of membraneous imbricated sacs, containing cach a ficker. Tle wcra is very thit, hald au strong, much used for levers, \&e. Lever-wecd. Iron-wocd.

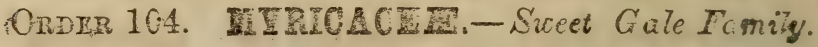

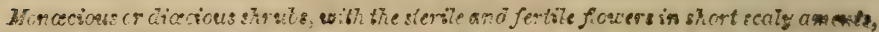
ard resirou doited often frogrant leaves-differing from tho Birch Foraily ehiedy .by the 1-eelled overy with a single erect orthotropous orul

\section{MYRTUA, Linn. BATBERT.}

Gr. murite, the ancient name of the Tamarist.

Diœcious. STERILE Flowers in oblong or cylindrical aments, the rertile in oroid closely imbricated aments, both destitute of calyx and corolla, solitary under a scale-like bract, with a pair of bractlcts. STABINS 2 to 8 with the filaments somewhat united below. OraßY 1, Euperior, with 3 scales at its labe, and 2 thread-like stigmas. Troit a emuil globular nut, studucd with resineus grainz or wax.

1. M. Galm, I. Sweet Gale. Meadow Ferm.

Teares reage-linceolato. ferrato towards the apez, appearing later than the

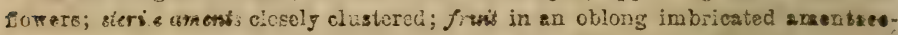
nus head.

Borders of pondi end mountain lakes, rerc. Bay. A hranching clirub 8 to 4

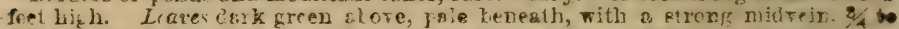
31/2 inch lorg, $1 / 3$ to $1 / 2$ inch wide, critire $1 / 3$ ite lengtb. Fertile ard sierile finors

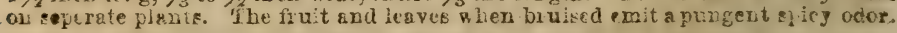

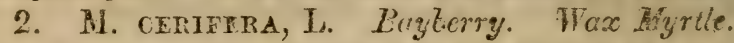

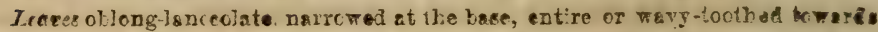

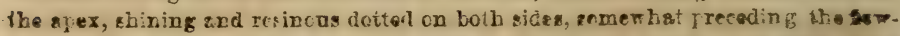

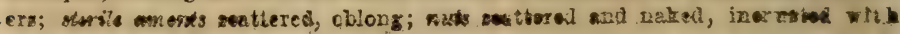
whitonts. 
Sandy soil, rare. Máy. A shrub 2 to 8 feet high, with a very branching top, and grayish bark. Leaves $1 \frac{1}{2}$ to $2 \frac{1}{2}$ inches long by $1 / 2$ to $3 / 4$. Aments gessile along the lagt years branches. The fruit consists of a globular nut or stone enclosing a kernel, and covered with a coating of whitish wax.

\section{COMPTONIA, Solander. Sweet Fenn.}

In honor of Eenry Compton; Bishop of London a contury ago, a patron of botany.

Monorious. SterILE FLOWERS in cylindrical aments with reniform-cordate pointed scale-like bracts, and 3 to 6 stamens. Fertile flowers in globular aments, burr-like; OVARY surrounded by 5 to 6 long linear-awl-shaped seales, persistent around the oroid smooth nut; otherwise as in Myrica.-Low shrubs, with long and narrow pinnatifid-lobed. leaves with small stipules appearing after the flowers.

C. Asplenifolia, Ait. : Sweet Fern.

Laves long linear-ianseolate, alternately sinuate-pinnatifid.

Dry woods and hills, common. May. A woll known, handsomo aromatic shrub, 1.to 2 fuet higl. Leaves nuraerous, on short peduncles, 3 to 4 inches long, $1 / 2$ inch wide, divided nearly to the midvein into numerous ro unded lobes.

\section{ORDER 105: BETULACPB?}

Monscisis trecs or shrubs, with sterile and fertile flowers in scaly aments, 2 or 3 smater each iruct, and no involuere to the nakel 1-cellod and 1 -seeded often winged nut, which rezu'ts fiom a 2-celled and 2-ovule.l ovary. STruss singlo or nono: BTia-

ist. 2.

\section{BETULA, Tourn. Birch.}

The ancient Latin name.

STERILE FLOWERS 3, with 2 bractlets under each scale or bract of the ament, consisting each of a perianth of 1 seale and 4 stamens attached to its base: FILAMENTS short. FER. TILE FLOWERS 3 under each 3 -lobed bract, consisting of a naked ovary with 2 thread-like stigmas, becoming a broadly winged and saale-like nutlet or small samara. SEED suspended, anatropous. - Tieer and shrubs, mostly with the outer bark usually separable in thin horizontal sheets, ovate, serrate alter. nate leaves, and moncecious fiowers, the golden sterile ones expanding in early spring preceding the leaves, the fertile in oblung cylindrical aments appearing with the leaves.

- Trees with the bark of the trunte white externally, separable in thin shest.

1. B. populifolia, Ait. White Bìrch:

Leaves deltoid (triangular), long-acuminate, truncate or slightly cordate at bass, nequally sorrate, smooth and shining on both sides, on smooth petioles; fortile cments on pedundes ; scates with roundish, lateral lobes. 
Poor soils, in rocky mountainous woods, common. May. A small and slender, rery graceful tree, 20 to 40 feet high, with a chalky-white bark. Leaves tapering to a long point as tremulous as an Aspen, on petioles 1 inch or more long. Aments long pendalous. Poplar-leaved Birch.
2:
B. papyracea, Ait.
Paper Birch.
Canoe Birch:

Leaves orate, acuminate, doubly-serrate, the veins hairy bencath, small above; zateral lojes of the fruit-bearing bracts short and rounded.

Hillside woods, common. May, June. A tree 40 to 70 feet high, with fine grained wood, and very tough durable baric, white externally, seperating into paper-like layers. Leares 2 to 3 inches long, $1 / 2$ as wide dark-graen above, pale glandular-dotted underneath. Sterite aments 1 to 2 inches long.

* Trees with reddish-brown or yellowish baric; leaves with short petioles.

\section{B. NIGRA, L. Red Birch. River Birch.}

- Leaves rhombic ovate, acute at each end, doubly serrate, whitish and doxny nnderneath ; fertilc amersts somewhat peduncled, woolly ; bracts with oblong-linesi nearly equal lobes.

Low river banks, common. May. A tree 30 to 50 feet high, with reddish brown bark, which at length becomes very looso and torn, hanging in shreds. Leaves 3 inches long and 2 wide, on petioles $1 / 2$ to $3 / 4$ inch long, dark-green above.

\section{B. Lenta, L. Black Birch. Sweet Birch.}

Laxves cordate-orate, pointed, sharply and finely doubly serrate; hairy on the velns beneath; fertile aments elliptical, thick, erect, somewhat hairy.

Moist rich woods, common. April, May. A beautiful tree 40 to 60 feet high. . with a diameter of 1 to 3 feet, covered with a chestnut-brown dark. Branches glender, spotted with white. Ieaves 3 to 4 inches long, about $1 / 2$ as wide. Tho wood has a close grain and is susceptible of a fine polish, valuable for cabinet work. Tho bark and young twigs are spicy-aromatic.

* * * Shrubs with brownish:bark and rounded crenate toothed leaves.

\section{B. Pumila, L. Low Birch. Dwarf Birch.}

Erect or ascending; leaves obovate or roundish-elliptical, coarsely crenato-toothed, the younger downy and nearly orbicular; fertile catiins cylindrical; scates moro or less unequal 3-lobed; fruit broadly winged.

Mountain bogs, rare. Pursh. May, June. A shrub 2 to 5 feet high, with smooth or sometimas warty branchlets, the young twigs downy. Leaves on short petioles., 1. to $1 \frac{1}{2}$ inch long, pale or whitish underneath:

\section{ALNUS, Tourn. ALDER.}

The ancient Latin namc.

Monœcious. StERILE AMENTs long and drooping, cylindric, with 5 .bractlets and 1 to 3 flowers under each scale; each flower with a 4 -parted calyx and 4 stamens with very short filaments. Fertile aments ovoid or oblong, the fleshy scales each 2 -fiowered, with a calyx of 4 small scales coherent with the seales or bracts of the ament, which become thick and woody in fruit, all coherent bolow and persistent. - Shrubs or small trees, arising from large and strong roots, stalked leaf.buds furnished with a single scale, alternate simple leaves, and the aments produced at the close of summer, and expanding in early spring. 


\section{A. incana, Willd. Black Alder.}

Leaves broadly oval or ovate, rounded at the base, sharp ly serrate, often eoareciy wothed, white and mostly downy uaderneath; stipules oblong-lanceolate; fortits aments oval ; fruit orbicular.

Banks of mountain streams, common. A shrub 8 to 20 feet high, with mooth browa bark. Pertile aments usually 4 to 5 in a paniculate racems.

2. A. serrulata, Ait. Common Alder. Smooth Alder.

Leaves obovate, acute at the base, sharply serrate with acute teoth, thiskish, sm roth and giean on both sides, a little hairy on tho roins beneath; stipulles ovar; fortile aments ovoid oblong; fruit ovate.

Borders of ponds and streamz, ejmmon. A well known shrub 6 to $13 \mathrm{fwet}$ high, growing in clumys. Laves 2 to 4 inches long and $2 / 3$ as wills, strongly relaas. An*ts 2 to 3 inshes long, slendor, peudulous; the fertile oags short, thiek, durk biown, persistent.

\section{ORDBR 106. SALIOACF罢, - Willow Family.}

Diceeious trees or shribs, with alternate undivided leases, the fertile and steribe fmoers in aments, one under each bract; enirely destitute of calyx or exrolla; the frwit a 1-celled and 2-valved capsu?

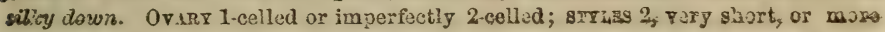
or legs united, each with a.2-lobed stigma.

\section{SALIX, Tourn. WrLlow. OsIrR.}

Celtic, sal, near, and lis, water; alluding to their nsual loeality.

Diceious. Aments cylindric, with entire imbricatod scales. Sterile frowers of 2 to 6 stamons, accompunied with 1 or 2 little glands. FarTILe PLOWERs with a sinall flat gland at the base of the ovary on the inner side; srtaMis short. - Trees or shrubs, generally growing along streams, with round and flexible branches, most'y long and printel leaves, entire or glandularly-tostied, and terminal and lateral ansuts appearing before or with the leaves.

Sac. I. Anents lateral and sassilo, apporing beforo thэ leavos. Shru's or smill tres.

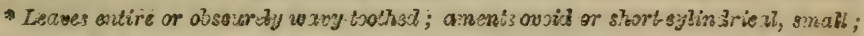
stigmas 2 cleft.

1. S. CANDIDA, Willd. Hary or White-lecued Willow.

Ieaves narrow-lanceolate, asum inate, or the lowest obsass, pubegeent above, whits-tomentose bezeath; stipules sm ull, lanesolsto, trothed; amonts oblon s-ejkinarical, closely ffowered; ovary deneely woolly; sty?e distinct.

Bogs in shaily woods, rare. A pril, May. A shriab 2 to 5 feet high with raddish twigs, smoth and shining at maturly. Leaves 8 to 12 inelod long, 1 to 2 wide. Aments about an inch long, dense on short pedencies.

\section{S. Tristis, Ait. Dwart' G'ray Willow.}

Leaves wedge-lanceolate, almost sessile, pointed, or at the lower obtuce grayts $\mathrm{h}$ woolly on both sides, the upper sido at maturity neariy aznooth; stip sles smill, $\mathrm{MI} 2 *$ 
bairy; aments globular when young, loosely flowered; ovary with a long bairy beak; style short.

Sandy woods. March, April. A small shrub 1 to $11 / 2$ foot high, much branched, with a profusion of nments in spring appearing before the leaves. Leaves at longth numerous, thick, $11 / 2$ inch long, often crowded. Stipules seldom scen, often ro aneed to a mere gland.

\section{S. Humrus, Marshall. Low Bush Willow.}

Leaves on petioles, lanceolate or obovate-lanceolate, acuto or obtuse with an ab. rupt point, slightly downy above; stipules small, semi-ovate and entire, or larger and linear with 2 to 4 teeth, shorter than tho petioles; aments often recurve ; avary hairy; style distinct.

Borders of fields and roadsides, common. A shrub 3 to 8 feet high, varying in slze and appearance. Leaves of the larger forms 3 to 5 inches long, and $3 / 4$ to 1 inch broad. This species, as well as some of the following section of ten bear con Iike excrescences on the ends of the branches, formed of closely imbricated leave

* Leaves more or less serrate, smooth and shining above; antents cylindrical, larga.

\section{S. Dicolor, Muhl. Glaucous Willow.}

Leaves lanceolate or ovate-lanceolate, acute, irregularly toothed on the sides, enthre at the base and apex; stipules semilunar, toothed; anents ereet; scales very hairy, oblanceolate, somewhat acute; ovary densely silky.

Low meadows and river banks, common. A large shrub or small tree 8 to 15 feet high. Leaves when young commonly obtuse and pubescent, at length becoming smooth and whitish-glancous beneath. Young catkins $11 / 2$ inch long, glossy, blaokis w with the canspicuous stipules, elongating in fruit to $21 / 2$ inches.

*** Leaves jinely and eventy servate, silky-gray or glaucous beneath ; ements and or cylindrical; stigma 2-lobed. Shrubs.

\section{S. SERICEA, Marshall. Silly-leaved Willow.}

Leaves lanceolate, pointed, downy above, grayish with short silky bairs ander neath; sterile aments small, the fertile narrowly cylindrical, closely flowered; scales obtuso, round-obovate; stigma nearly sessile.

Sandy river banks. A shrub 4 to 10 feet high, with green or purvle twigs whiek are tough but brittle at base. Fertile antents in fiower $3 / 4$ inch, at length $11 / 6$ ineth long. Anthers at first reddish, then yellow, and finally brown.

\section{S. Petrolaris, Smith. Long-stalked Willoro.}

Zeaves lanceolate, pointed, smooth above, glaucous benoath, silky at base, mostIy unequal; stipules lunate; aments appearing before the leaves, the fertile oroidoylindrical, lcosely flowered; seales very hairy, obovate; style short but distinet.

Sandy river banks and low grounds, common. A shrub 6 to 10 feet high, somo what resembling the last, but the mature leares are smooth beneath, and ary loss black. Fertile aments shorter and broader, the capsule spreating and showing the staiks.

*3*** Filaments seperate; stigmas undivided. Small trees.

7. S. viminalis, L.. Basket Osier. Basket Willow:-

Ieaves linear-lanccolate, very long and acuminate, entire or obscurely crenato; . white-silky beneath; stipules very small; aments. cylindrical-oroid, elothed with * long silky bair; ovary long ard narrow; styles elongated; stigmas linear, mostly entire.

Wet meadows; introduced from Europe. A middle sized tree, with slender and fexible branches. Leaves 3 to 6 inches long of a beautiful lustre beneath. Flat ments yellow. Anthers orange. Considered the best specics for basket making.

SEC. II. Aments lateral, with 4 to 5 leafy brasts at tho baso, appearing with or woiore the leaves:.stam ans 2-Shrubs or smail trees. 


\section{B. oordata, Muhl. Heart-leaved Willow.}

Isaves lanceolate or ovate-lanceolate, sometimes truncate or heart-shaped at Dese, acuminate, sharply toothed, smooth, paler beneath; stipules reaiform or - vate, toothed, often large and conspicuous, or sometimes small and almost entire; enents appearing with the lasves, leafy at base, cylindrieal, the fertite elongating in frait.

Low river banks and low meadows. A shrub 2 to 6 feet or a small tree 6 to 15 thet higb, with leares 4 to 6 inches long. Fertile aments 2 to 3 inches long.

\section{S. Angustata, Pursh. Narrow-leaved Willow.}

Ieaves lanceolate, scute, long and tapering to the base, slightly toothed, smooth and scarcoly glaueous beneath; stipules gemi-cordate; aments large, appearing bo-

Sore the le aves; ovary tapering into a long style.

Brnks of streams. A large shrub or small tree 8 to 16 feet high, with very long and slender twige, and long and narrow leaves.

SIc. II. Aments peluncled (long and loose) leorne on the summait of latersl leafy branches of the season. - Shrubs and trees, with the branches very brittle at the bar.

- Ovary sessile, smooth; stamens 2.

10. S. Alba, L. White Willow. Fellow Willow.

Zaves lanceolate or elliptic-lancelate, pointed, toothed, clothed more or less with white siliky hairs, especially beneath; stiputes lanceolate; stigmas nearly seswile thick and recurved. An introdueed tree of rapid growth, attaining a hoight of 50 to 80 feet, with several varieties. Var. 1, virelirra, has yellow or light red branches; leaves shortef and breader. (8. vitellina, Smith of Borrer. S. Pameachd. ana, Barret.) Var. 2, OERULia has the leaves nearly smooth at maturity.

* Ovary stalked, smooth; stamens 2 io 6.

\section{S. fragilis, L. Brittle Willow. Cracte Willow.}

Leaves lanceolate, acuminate, smooth, glaucous beneath, serrats with inflexed weth; siipules somicorlate, pointed, toothed; stamens mostly 2.

$\Delta$ tall and handsome tree, with smouth and shining branches, introduced frone Terope, and cultivated for basket-work, with several varieties. Var. 1, DECIPILNs, ms dark brow buds, and the lowest leares on the branches broadly oborate, rery - btuse. (S. decipiens, Hofinan.) Var. 2, Rusgelixa, has the leaves long and bright, strongly serrate, the younger ones, and upper branches of the annwal shoota, silky-downy; stipules large and acuminate. (S. Russeliana, Smith.)

12. S. NignA, Marshall. Black Willow.

Leaves narrowly-lanceolate, pointed and tapering at each end, serrate, morkr mooth, green on both sides; stipules small, deciduous; glands of the sterilo flowore 2, large and deeply 2 to 3-eleft; stamens 3 to 6.

Marvins of streams. A tree 15 to 25 feet high, with a rough black bark. Branches very brittle at base, pale yellow: Sterits aments 3 inches long, and ofwere vith but 3 stamens in the upper scales.

\section{S. LUCIDA, Muhl. Shining Willow.}

Zeaves ovate oblong or lanceolate and narrow with a long acumination, smook and shining on both sides, serrate; stipules oblong, toothed; stamens mostly 5.

Overflowed banks of streams. A handsome species, sometimes 12 to 15 feet high, eften flowering at the height of 3 or $\mathbf{4}$ feet. Branches smooth, dark shining groes.: Laves broad and glossy above.

14. S. Babylonica, Tourn. Weeping Willow.

Branches pendulons; leares lanceolate, acuminate smocth, glausous benesth;

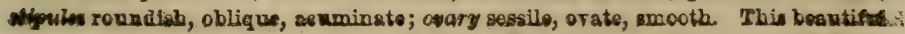


פpecies is a native of the East, and has been cultivated until nearly naturalired. The long slender dreoping branchlets very naturally indicate the common name of the tree. Only the fertile plant is known in the United States.

** Ovary stalked, hairy; stamens 2 .

15. S. Longrfolia, Muhl. Lrong-leaved Willow.

Leaves linear-lanceolate, very long, tapering at each end, nearly sessile, remote Iy denticulate with projecting teeth, clothed with gray hairs when young, at length nearly smooth; stipules small, lanceolate, toothed; scales hairy at the base, often glandular-toothed at the top in the sterile aments; stigma very long, sessile.

River banks. A variable ronting species 2 to 12 fuet high, with brown branohes and white branchlets, often prostrate.

\section{POPUluU, Tourn. Poplar: Aspen.}

Iat. populus, the people, being of ten planted by the public ways.

Diccious. Aments cylindric. Bracts (ocales) of the aments irregularly cut-lobed at the apex. Flowers from a eup-shaped disk, which is obliquely lengthened in front. Stamens 8 to 30 , with distinct filaments. STigmas 4, elongated. CÁpsule superior, 2-celled, 2-valved, manyseeded. Seeds comose.-Trees, with snft wond, usually broad and more $\mathrm{n}$ less heart-shaped or ovate toothed leaves on long petioles, and long drooping aments, appearing before the lea ves.

1. P. Tremuloides, Michx. American Aspen.

Leaves roundish-heart-shaped, with a sharp short point, dentate-serrate, smooth on both sices, with downy marging; scales ent into 3 to 4 deep linear divisions, singed with long hairs.

Wonts and on:n ficlde, common. A pril. A tree 20 tn 50 f et high, with smooth grenikh-white hark. L Laves 2 to $21 / 2$ inches long, $21 / 2$ to 3 wide, on petioles 2 to 3 incher lono. Which are laterally enmreseed. so that they are thrown into a continued agitation by the slightect breeze. White Poplar.

2. P. Grandidentata, Miehx. Large-toothed Aspen.

Ieaves roundich-ovate, with large and irregular sinuate tceth, white-silky-woolly when young, at length smcoth on both sides; scales cut into 5 to 6 unequal small divisions, slightly fringed.

Woods and grores. rath remmon. A tree 40 tn 50 feet high, with a diameter of 1 foot. straight. corered with a smooth, freenish bark. Leaves 3 to 5 inches Jong and nearly as wide, generally at the extremities of the distant, coarse and eroeked branches.

3. P. meteophyla, L. Various-leaved Poplar.

zeaves roundish-ovate or lịeart-shaped, obtuse. sorrate, white-woolly when younc at length nearly smooth, oxcept on the veins beneath:

Sw?mpe. Mry. A tree 40 to 60 fect hich. with round branehes. Leaves largo, nsually quite blunt, the auricled lobes at the base often conceal the insertion of the petiole:

4. P. angulata, Ait. Water Poplar. Cotton- Rood.

Zeaves broadly-deltoid, or heart-orate, smooth, crenate-serrate or cut-serrate, acuminate.

Ranks of streams. March, April. A tree of Iarge dimengions 40 to 80 reat bigh, 
and 1 to 2 feet thick, with acutely anrled or winged branches. Lexves often 7 to 8 inches lono, and about as wide on the young shoots; whilst on full-grown trees they are only 2 to 3 inches long. The buds are covered with resith.

5. P. Balsamifera, L. Batsam Poplar. Tacamatac.

Leaves ovate-acuminate, finely sorrate, smooth on both sides, white and reticulate-veined beneath; scales dilated, slightly hairy; stamens very numerous.

Borders of rivers and swamps, rare. April. $A$ tree 60 to 70 feot high, and 1 to $11 / 2$ feet thick, with round branches. The buds are covered when young with a Dalsamic resin.

\section{CUITTVATED SPECIES.}

\section{P. candrcans, Ait. Balm-of-Gilead.}

Leaves orate-cordate, acuminate, obtusely and unequally serrate, whitish be noath, somewhat 3-reined; petioles hirsute.

Woods, common in cultivation. A pril. A tres 40 to 50 feet high, and 18 to 30 inches in diameter, with smooth and greenish bark, and large dark green foliage. Fertile aments 6 inches long. The buds aro covered with a balsaruic resin, much . used in domestic practice.

7. P. milatata, L. Lombardy Poplar.

Leaves smooth, deltoid, acuminate, serrate, about as wide as long; trunk lobed and sulcate. Native in Italy as its name imports. It has long been cultivated in this country, and is found in the vicinity of all old settlements.

\section{P. alba, I. Abele. Silver Poplar.}

Leaves heart-shaped, broad-orate, lobed and tcothed, acuminate, dark green and smooth above, very white dorny beneath; fertile aments orate; stigmas 4. A highly ornamental tree, native of Europ9. The silvery whiteness of the lower surface of the leaves produce a striking contrast.witb the dark green of the upper.

\section{OrDer 107. BALSAMIFLUR,-Sweet-Gum Famity.}

Frees, with a balsamic colorless juice, alternate palmately lobed leaves, deciduous stipules, and monocious flowers in seperate roundish aments, destitute of calyx or co rolla, the fruit of 2 -beaked and 2-celled several-secded woody capsuies: consists only of tho genus.

\section{LIQUIDAMBAR, Linn. SWEET-GUM:}

Lat. Lirrsidum, flaid, and Arabic ambar, amber, in allusion to the terebinthino juice that flows from the tree.

Sterile flowers in conical clusters, naked. Stamens numerous, intermixed with minute scales : FILAMENTs short. Fertile aments consisting of 2-celled ovaries, subtended by minute scales, all more or less cohering and hardening in fruit, forming a spherical head, the capsule opening between the 2 awl-shaped diverging styles. SEEDs small, often abortive.-Tree, with alternate simple or lobed leaves deciduons stipules and racemed nodding aments, inclosed in the bud by a 4 , haved deciduous involucre. 


\section{Strraciflua, L. Sweet-Gum. Bilsted.}

Leaves rounded, decply 5 to 7 -lobed, smooth and shining, finely glandular-ser$x$ ste, the lobes pointed.

Moist woods. April. A large and handsome tree, with finely grained rood and gray bark, with corky ridges on the branchlcts. The joung twigs are yellowish, putting furth leaves of a rich green, which are fragrant when bruised, turving deep rod or crimson in autumn. Fruit when mature about 1 inch in ditumeter, forming a brownish woody and prickly strobile.

\section{Order 108. PLATANACER,-Plane-tree Family.}

Trees, with alternate palmately-lobed leaves, shealhing stipules and monocious flow. ers in seperate and na7 ed spkerical aments, destitute of ealyx or corollt; the frui: clab-shcped 1-seeded nutiets, furnished with bristly. down along the base: consisting: only, of the genus

\section{PLATANUS, Linn. ButTonwood.}

Gr. platus, broad, in allusion to the ample shade of its foliage.

Sterile Flowers of numerous stamens with clavate small seales intermixed : FILAMENTS very short. Fertile rLOWERS in seperate aments consisting of inversely pyramidal ovaries mixed with little seales : STYLE rather lateral, awl-shaped, or filiform, simple. NuTLETS coriaceous, small, tawny-hairy below, containing a single orthotropous pendulous seed.

1. P. occidentalis, I. American Plane or Sycamore.

Leaves angularly-sinuate-lobed and toothed, the short lobes sharp-pointed; ferHe heads solitary, suspended on a long peduncle.

Banks of streams. A very large aud well-known tree, with a white bark sepersting early in thin brittle plates. Leaves woolly when young, alternate, on long potioles. Aments axillary globose.

2. P. orientalis, L. Oriental Sycamore.

$\Lambda$ handseme shade tree, native of the East, is occasionally met with in cultira tion.

\section{ORDRR 109. URTHCACEE,-Nettle Family.}

Trees, shrubs and herbs, with alternate or opposite leaves, monocious or dicecious flowers, furnished with a regular calyx, free from the mostly 1-celled ovary which forms a 1-seeded utricle or achienium in fruit. Stamens as many as the lotes of the alyx and opposite them. Comprising several very distinct suborders.

\section{Suborder I. MORE 1 . The Mulberry Family.}

shrubs or trees with a milligy juice. Four flesby, composed of the flesby calyz or: seceptacle. 


\section{MORUS, Tourn. MULberRY.}

Gr. Morus, the aneient name.

Frotvers monoeious or diocious ; the two kinds in seperate axillary ament like spikes. CALYX 1 -parted, the sepals ovate. STAMENs 4: TILAMENTs elastically expanding. Ovary 2-colled, one of the cells smaller and disappearing: sTrues filiform, stigmatic down the inside. Acrenium ovate, compressed, covered by the succulent berry-like calyz, the whole fertile spike thus becoming a compressed berry.Trees, with millyy juice, alieriute mosily lobed leaves and inconspicuous flowers.

1. M. RUBRA, L. Red Mulberry.

Lesves hoartovate, serrate, rough above, downy beneaih, pointed, sometizaw Fariously lobed; flowers often diocious; fruit dark purple.

Rich woods, common. Mry; fiwit in July. A sinill sprealing sree, eorered witb a grayish much briten aud furrored lark. Leaces 1 to 6 inch $l o n g, 2 / 3$ a wide, entire or diviled into lobvs, thick, lark green. Berries compounded of a great number of small ones, of an argreable acid fiavor.

2. M. ALBA, L. White Fulberry.

Leares obliquly heart-orate, acute, serrate, sometian lobod, zmooth and shining; fruil whitish.

Nituraize? pear honwas. A small trae, native of Cling. Lenes 2 to 1 incha

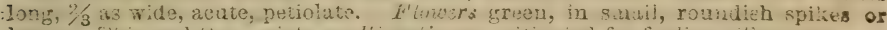

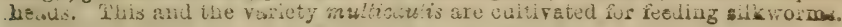

3. M. Nigra, L. Black Mulberry.

Leaves scabrous, corlute, ovste or lobol, ottuse, unequally serrate; fertshe espiun

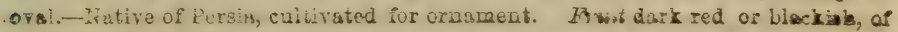
aid aromatic acid flavor.

\section{BROUSSONETIA, L'Her.}

In honor of $P$. N. Broussobet, distiagriehed Yrench nsturalizb.

Thowers polygamous, in eylindrio aments. Calyz 4 . paried. Pistiliate amento globose; RECEPTACua oylindric-club-shaped, compound; CALYX 3 to 1 -toothed, tubular. Ovaries becoming fleshy, club-shaped, prominent. STrua lateral. SaEd 1, corered by the caljx. - Trees, wative of Japan.

\section{B. paptritra, L. Paper Mulbery.}

Leaces of the younger tree, roundish-orate, acuminate, motily undiviled, of the

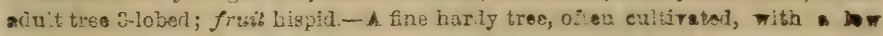

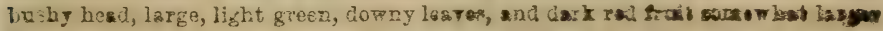
thas pacs, covered with long purplo Laire. 


\section{MACLURA, Nutt.}

Dedicated to William Maciure, Esq., of the U. S., a distinguished geologist.

Flowers polygamous, in aments. Ovaries numerous, coalescing into a compound globose fruit, composed of 1 -seeded, compressed, angular, wedge-form carpels. Strue 1, filiform, villous:-A littescent tree, with alternate entire leaves, without stipules, and axiliary spines.

\section{Aurantiaca, Nutt. Osage Orange. Bow-wood.}

Leaves ovate or ovate-oblonr, obscurely denticulate, somewhat acuminate, coraccous, smooth and shining above, strongly veined beneath. A besutiful tree, no. tive on the banks of the Arkansas. Leaves 4 to 5 inches 1 eng, $11 / 2$ to $21 / 2$ wide, on ehort petioles. Fruit about as large as an orange, golden yollow when ripe, suspeaded by an axillary poduado, which amilst tho dark glosis foliage forms a boattiful contrest.

\section{Suborder. II. CANNABINE Be. Femp Famit.}

Erect or twining herbs, with a waiery jwiee. FLowns diœcieus, the sterile raw mod or panicled. STrues 2. FrRTIL FLOTzRs in a cone-like ament.

\section{IIUMULUS, Linn. Hop.}

Lat. humus, moist earth; the hop fourishes only in rich soll.

Frowers diœcious; the stertue in loose axillary panicles: SEpals and stamens 5. Fertile flowers in short axillary and solitary spiles or aments: BRACTs foliaceous, imbricated, each 2-flowcred: CALYX 1-sepaled, embracing the ovary. Achenia invested with the enlarged scale-like calyx, together forming a membranaceous strobile.-A rough perennia! twining herb, with mostly opposite heart shaped. 3 to 5 lubed leaves and the flowers in axillary panicles and strobile-like-aments.

H. Lunulus, L. Hap.

Leaves-mostly 3-lobcd, decply cordate at base, on long petiolee.

Eatks of streams, truly indigencus. July. Stem twining with the suin. Calyo ecules in fruit covered wirh orange-colored resinous grains, in which the powibor bithrness and aroma of the hop resides.

\section{CANNABIS, Tourn. Hлир.}

The ancient name, of obscure etymology.

Frownrs diøcious; the strrile in axillary compcund raccmes or panicles: Sepals and stamens 5. Trirtile FLOWLRS spiked-clustercd, 1-bracted: CALYX of a single sepal, swollea at the base and folded round the ovary. $-A$ tall roughish annual, wiih digitate 5 to \%-parted leaves, and axillary flowers, the staminate in cymose panicles and the fertile in essile spilkes. 


\section{C. sativa, L. Common Hemp.}

Leaves palmately 5 to 7 -foliate, the leaflets lanceolate, scriate, the mildle one the largest.

Waste places, escaped from cultivation. June. A tall erect plant cultivated for the sake of its fibre, which is the best of all materials for cordage and sail-cloth. El lowers green, small.

\section{SUBorder IH. URTICEA. NETTLE FAMILY proper.}

Therbs (in our country) with watery juice, andflowers in spifies, heads, or parisies. STruts single or none.

\section{URTICA, Tourn. Netrite.}

'Lat. uro, to burn; some of the species are armed with stinging hairs.

FLOwers monoecious or diocious; the sTERILE mostly with 4 sepals, and 4 stamons: the FERTILE with 4 or 2 seperate scpals, and no rudimentary stamens. AcHevium oblong or ovate, flattish.- Herls with stinging hairs, stipulatc Teaves, and greenish fowers in axillary panicles, rucemes, spilses, or heads.

Szc. I. Untica proper. Sierite calyx a.parted; the fortile of 4 rery uneciual so. ipais, the 2 outer small, the inaer follaccous.-Laties opposite.

1. U. GRACILES, Ait.- Slender Nettle.

sparingly bistly, tall and slendix; leares orate-lanceolate, pointed, ferrate, 3 ito 5 -nerred from the roundel $\mathrm{nr}$ scarcely keart-s?aped bass, smotbish, on clougaited lurist'y petioles; flower-elustris in slender and loosely paniclel branched spikes.

Fencerows and moist ground, rather common. July. Per. Plant 2 to 6 feet ihish, with searcely any stiuging hairs except on the petioles and sparingiy on the prinsipal reius, not doway. Fiower's minute, green.

2. U. DrorcA, L. Diesious or Stinging Tetlle.

Tery bristly and stinging; leaves orate, heart-shaned, pointed, rery deeply sorrate, downy underneath as well as the upper part of the stem; flower-clusters in inanicled branched spikes.

Waste places, common; intro iuced. June-Aug. Fer. Stem 2 to 4 feet high, Wranching, obtusely tangled, with opposite short-petioled leaver, 3 tr $\frac{1}{4}$ inches londs, and about $1 / 2$ as wids. Flowers small, wreen. Whole plant copiously besct ritt. stinging bristles.-Like the last mono-dioecious.

3. U. unens, I. Small Stinging. Netlle.

Leaves elliptic or roundish-ovat, somewhat 5-nerved, asutely surrate; with "sprea ling tecth; foxer-cluster's vearly simple, 2 in each axil, shorter than the petLoles.

Cultirated grounas, rare; ;introluced from Europe. Julg. Ann. Stem 10 to 15 inches high, stinging. Leaves 1 to 2 inches long on slendsr petioles.

SEC. 2. Laportea, Gaud. Sterile calyx 5-parted, the fertite of 2 equal sepals :Loaves alternate.

4. U. Canadensis, I. Canadian Nettle.

Leaves ovate, obtus:ly serrate, pointed; flowers in long and loose diraricately. branched panicles, the lower sterile, the upper fertile. 
Moist shady grounds, along streams, common. Aug. Per. Stem 3 to 6 fot high, branching, stout, erect. Leares oftep 6 inches long, strongly fenther-veized. This species has Fery tough and strong-n̂bres, aud was formealy provosed by $\mathbf{M r}$.

Whitiow as a substitute for hemp.

\section{Benmeria, Jacq. False Nettle.}

Named after G. $R$, Bcehmer, a German Botanist.

Flowers monocious or diøecious, minute. Sterru THOWERS with 4 sepals, and 4 stamens. FerTILE with \& tubular or urn-shaped entire or 4-toothed calyx inclosing the ovary. STrue awl-shaped, stigmatic down one side. AcneNIUM clliptical, closely invested by the persistent calyx.Herbs or shruls, (ncarly allied to Urtica) with opposite or aliernate leaves and clustered flowers in axillary spities.

B. cylindrica, Willd. Common False Nettle.

Smathish; stem tall and simple; leaves mostly opposite, oblong-orate or aratelanecolate, pointed, serrate, 3-nerved, on long petilles; flosers dixecious or momstimes intermixed, in clusters.

Moint thickrts, common. June-Aug. Per. Siem 2 to 3 foot high, obtusely Angled. Leares 2 to 4 inches long. T/2 as wide. Fhwars minute creevish. in Flender mestly leafy spizes, the sterile interrupted, the fortlie mostly unintor rupted.

\section{PILEA, Lindl. Srivglesss Netrle.}

Florrens monocious; the two kinds often intermixed in the same panicle, bracted; the sTERILE of 3 to 4 sepals and stamens; the rrRTiLe with 3 more or loss unequal sepals or divisions sxd an incurved scale before each. STIGMA ressile, peneil-tufted. Acirenium minutely warty.-Smonth or hairy herbs, with opposite long pelioled leaver; the fluwers in axiliary clissicrs.

P. pumus, Lindl. Richweed Clearweed.

Tow: stems smonth and shining, translucent; lexvs ovate, coarsely toother, pointed, 3-nezped, Emootbish; flswer-clusters muoh shorter then the potiole; sopals of the furtile thawers larceolate, somewhat unequal.

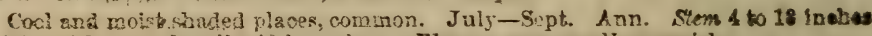
kigh, with rmeotb pe!lucid brasches. Floucrs very small, greenish.

\section{Parietaria, Tourn. Pellitory.}

Iipt parses, o wall; from the place where some of the spocies grom.

TLowers monøcious or polygamous, in clusters surroundof by a many-cleft insolucrate bract, CALYX 4-parted: GPA Hirens 4 , at first incurred, then expanding with an elastio foree. STYLE terminal, short or none: Ersama peneil- 
tufted. - Small herbs, with usually alternate leaves, and green flowers in axillary clusters.

\section{P. Pennsyldanica, Muhl. American Pellitory.}

Eow, simple or sparingly branched, minutely downy; lexvs oblong-lanceolate, vory thin, veing, roughish with opaque dots;: flnvars often perfect, shorter thun the involucral leaves; fertile caly $x$ bell-shaped, 4 -cleft to the midule; stigma sessile.

Shadei rocky banks, rare. June-Aur. Anu. A small hom lly weed 6 to 12 fnches high. Leaves alternate, hairy, $11 / 2$ to 2 inches long, $1 / 2$ inoh. Wide, on potoles. Flowers dense; greenish and reduish-white.

\section{SU'UR-CLASS II. GYMNOSPERMOUS EXOGENS.}

Ovules not enclosed in an ovary, fertilized by the pollen without the intervention of a pistil, and becoming truly naked seeds, the carpel being representcd by a flat open scale or leaf, or entirely wanting. COTYLEDOAs often more than two.

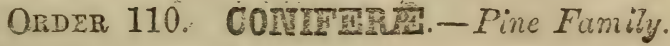

Trees or chrubs, with resinous juice, most'y with su'tu'ate or acerose entira lactes, and moncecious or dicacious flowers in amenis destitude of cutyx or coroula. Orutas ortivetropous. EvBryo in the axis of the albumsa. (Wood destitute of duets, - ruposin chiclly of a homogeneous large woody fibre which is marked with ciscular disks on two sides.) Comprises the three following sub orders.

\section{Sub-order i. ABIETINE 7 . Protrr Pint Family.}

TERTILE FLOWERS in aments, consisting of open imbricated carpels in the form of scales subtended by a bract, in fruit forming a strobile or cone. Ovunes 2, adherent to the base of each carpellary scule, with the orifice turned dotrnward.

\section{PINUS, Tourn. PINE.}

The elassical Latin name.

Flowers monœcious. Strodile large, conical; carFLLLARY SCALES thickened at the summit, becoming strong and woody in fruit. Cotruedons 3 to 12, linear.-Trees, often of the loftiest dimensions, with evergreen, needle-shaped leaves, in fuscicles of 2 to 5 from the same slender buds, sheathed by the scarivus bud-scales at the base. Flowering in May or June; the conss maturing the seeds in the autumn of the second year.

* Icaves 2 or 3 in a sheath, rigid, scules of the cones thictiened at the end, and mostHe tignase with a point or spine; bark rough. 
1. P. Inops, Ait. Jersey or Scrub Pine.

Inaves in pairs, rather short; cones oblong-conical, sometimos curved, the scales tippod with a prominent and stratght a wl-shaped prickle.

Barrens and sterile hill, common. A straggliag tree 15 to 40 foet high, with spreadine or drooping branchlets; young shoots with a purplish glaucous bloom. Leaves $13 / 4$ to $23 / 4$ inches long. Cones 2 to 3 inches long.

2. P. rigida, Miller. Pitch Pine.

Leaves in threes (rarely in fours) from very short sheaths, flattish; cones ovoidconical ; the soales tipped with a short and stout recurved prickle.

Barren sandy or gravelly plains, common. A tree 30 to 70 feet high, with vary rough and dark bark, and hard wood saturated with resin. Leaves rigid, 3 to 5 inclies long, dark green. Cones usually clustered in $3 \mathrm{~s}$ or $4 \mathrm{~s}, 2$ to 3 inches long.

3. P. Resinosa, Ait. Red Pine.

Leaves in pairs, from long sheaths, semicylindrical, elongated; cones oroid-conic21; scaies pointless, dilated in the miadle. (P. rubra, Mich $x$.)

Dry wonds, banks of streams; northern parts of the State, Pine Creek, Lycoming Co., Canisteo, Tioga Co. A tree 50 to 80 seet high, with reddish and rather smooth bark, and compact wood, softer than that of P. rigida. Leares dark green, 5 to 6 inches long. Coises about 3 inches long, sometimes aggregated in large and close clusters.

4. P. Mrris, Michx. Fellow Pine.

Ieaves in pairs (rarely in 3), from long sheaths, channelled, slender; cones oroid or ublong-conical; the soales slightly enlerged at tho end, tipped with a minute and wák prickly point.

Dry gravelly or sandy soil, common. A tree 60 to 80 feet high, is to 36 inches thick, straight, nroducing a very durable, ine-grained, moderately resinous timber, valuable for flooring, \&c. Letres 3 to 5 inches long, softer than in any of the preceding, dark green. Cones 2 to 3 inches long.

\section{P. montana, N. Pome Pine.}

Eeaves in pairs, short, rigid, very acuminate; cones large, growing in clusters, ametimes on the trunk of the tree.

Fiiflin, Centre and Union Counties. This somewhat cioubtful species was first discovered by Mr. F. I. Miller, of Few York, growing on the south slopa of the seven mountains in. Mifflin county from thence to the Natural Bridge west and south to Cumberland Co., Va. Since then I have found it on high sterile land in the western part of Union Co. The trunk is short, rarely exceeding 30 feet in height, with a rough bark and conieal top. Foliage light green, very disagreeablo to the touch. Cones very large, 4 to 6 inches long and 3 to 4 inches in diameter. This may prove to be the Table-mountain Pine of Michx.

* Leaves 5 in a sheath, soft and slender; scales of the cones pointless and not thict; ened at the end: barls smooth.

\section{P. Strobus, L. White Pine.}

reaves in fives, very slender, rather glaucous, with deciduous sheaths; cones napณง, cylindrical, nodding, somewhat curved.

Cool and damp woods, common. The White Pine is one of the most majestio and most useful of forest trers. The trunk is straight, covered with a smoothish bark, and from 80 to 120 feet high, with a diameter of 2 to 4 feet, or more. Leaves about 4 inches long, bluish-green, forming a very soft and delicatc foliage. Cones 1506 inches long; tho scales very slightly thickened upward.

\section{ABIES, Tourn. Sprure. Fir.}

The classical Latin name.

STERTL AMENTS scattered or somewhat clustered towards 
the ends of the branchlets. SCALEs of the strobiles thin and flat, not thickened at the apex, nor with a prickly point. SEEDS with a persistent wing.-Handsome trees or shruls, with evergreen, scattered, short, frequently 2.ranked leaves.

8so. I. Cones lorg, erect, lateral. Bark Emooth, with blisters of baleam.-Leares fiat, becoming 2-ronlied, silerery-whitened urderneath, cbiuse or notched at the apex.

\section{A. Balsamea, Marsh. Balsam Fir. Sitver Fir.}

Isa ves narrcwly linear; cones cylindrical, large, violet-colored; lracts obovate, errulate, tipped with an abrupt slender point, slightly projecting. appresecd.

Cold damp roods and ewamps; Buncy Creek, Lycoming Co. A beantiful erexgreen, wuch cultivated for orn ment. The branchis are nearly horicontel, macnsily bucoming shorter upwards, forming a regular pyramidal head. Lecices $3 / 4$ to 1 inch long, growing upon the sides and top of the tranches, of a bright green aloro and silvery.white beneath. Comes 3 to 4 inches long, 1 inch thick, the seales rery broad and roundid.

2. A. Fadseat, Pursh. Double Balsam Fir. Fraser's Fir.

Lives nar:owly linear, often emarginate, glavcous beneath; cones small, oblorg orate; bracts oblong-cuneate, short-pointed, the upper part much projecting and reflexed. (A. balsamifera, Michx.)

Mountaias, Lewis Lake, Pokona nountain, and Bear meadows, Centre Co. A highly orinamental tree, much resenuling the "Norway Fir" in foliage. Leaves $3 / 2$ to $3 / 1$ inch lun of a yoltowish green color. Cones 1 to 2 inches long when ma-

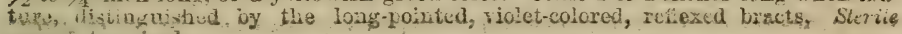
Gatents t r wilinal.

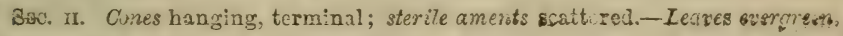

*. Leaves 2-ranked, flat, whitened underneath.

3. A. Canadensis, Michx: Hemloch Spruce.

Lcaves linenr, fat, obtuse; ccnes oral, of few scales, somenthat lorger than the ICarag.

IFilly or rock woods, aud along mountainstreams; common. A well known tree, ro to 80 feet hith. with a li ht spreading spray. and delicate fuliage, byight abcrt, sivery underneath. Cones $3 / 3$ inch-long. The bart is extensively used in tar:ning.

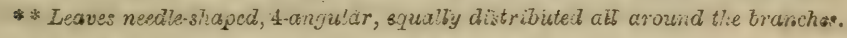

4. A. ALBA, Michx. White Spruce. Single Spruce.

Ieures slender, spreading, of a glauvous or light bluibin-green hue; scules of the oblong eones entire.

Coll staun 7 and moist woods, rare; Bear Meadors, Centre Co. A tree 40 to 60 feet higk, slepdur, with lizht-col red bark slender and often drcoying l.ranchle ts,

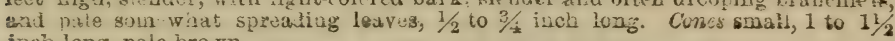
ineỉ long, pale-bro:rn.

5. A. Nigha, Poir. Black or Double Spruce.

Le:wes short, erect, rigil, very dark green; cones orate with tho gosles wary and toothed at the apex.

Swam or m antain woods. A tree 40 to 70 feet bigh, with a straigbt trunk, and iofy pyramilal had. The lewes thickly cover the tranchos, about $1 / 2$ ince lods. Önsi 1 to 2 inchea long, reddista-brown.

\section{LARIX, Tourn. LARCE:}

The aseient name.

AMENTs lateral and weattcred, bad.like. STERLI mort. N2* 
ERS nearly as in Pinus. Cones ovoid, erect, the bracts and scales persistent; otherwise as in Abies. - Trees, with deciduous soft leaves, collected in fuscicles of 20 to 40, (developed in early spring) and crimson or red fertile aments in flower.

I. Ameridana, Michx. American Larch. Tamaract,

Zeaves nearly fliform, without sheaths; cones ovoid, composed of few rounded soalea, inelining upwards; bracts elliptieal, of ten hollowed on tho side.

Swamps, not common. Black-IIole Valley, Liycoming Co. A beautiful tree, 30 to 70 feet high, of en cultivated. Leaves. 1 to : inches long, collected in bunches of 13 to 29 ou the side of the branches. Cones deep purple, $1 / 2$ to 1 inch long.

\section{Sub-order ir. CUPRESSINE 2 . Cypress Family.}

FWRTIE FLOWERs consisting of few carpellary scales, without bracts, bearing 1 to 8 erect ovules on their base, forming a closed strobile or drupe-like fruit.

\section{THUJA, Tourn. ARBon Vrte.}

Gr. Thua, Thuoid, the ancicnt name of some resinsus evergreen,

Frow terminal avoid aments.: ANTHERs 4, sessile. FERTLE AMENTS of few imbricated scales, fixed by the base, each bearing 2 erect ovules, dry and spreading at maturity. CoTruEDONS 2. - Trees or shrubs, with evergreen squamose imbricated leaves.

1. T: occidentalis, I. American Arbor Vitee.

Ieares orate rhombic, with a gland on the back, appreased-imbricated in 4 rowa on the 2-eaged branchlets; scales of the cones pointloss, I-sceded; sects broadly winged.

Stramps and cool rocky banks, rare. A tree 20 to 30 foct high, with very tough and recurved wranches. Cones about $1 / 2$ inch long, yellewish-brown. Tho wood b very light, soft and durable.

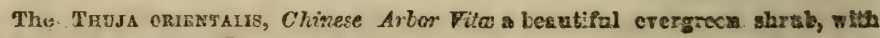
bright green foliage, is comraon ia cultivation

\section{CUPRESSUS, Tourn. Cxprass.}

The classical name.

Wrowers monoecious on different branches, in torminal Emall aments. STERLE AMENTS composed of shield-shaped seale-like flaments, bearing 4 anther-cells under the rargin. Fertile ameats globular, with seales in 4 ranks, bearing neveral creet ovules. Cone globular, firmly closed, but opening at maturity. SEEDs compressed, narrowly winged. COTYLEDONs 2 ar 3.-Strong-scented overgrean treas, with 
very small and scale-like closely appressed-imbricated leaves, and very durable wood.

C. ThYoIdes, L. White Cedar.

Zaxves minute, ovate, with a small gland on the back, closely imbricated in 4 sow 3 on the 2-edged branchlets; cones spherical.

Swamps, rare. Masy. A tree 30 to 70 fest high, with white, fine-grained and very Whbs, soft and durable wood. Cone scarcely larger than a pea, few-seeded.

\section{TAXODIUM, Richard. Bald Crpress.}

Gr. Taxas, the $\mathrm{Yew}$, and oides, regemblance.

Trowers monoecious on the same branches. STERILE aments spike-panicled, of few stamens. Fertile aments ovoid, in small elusters, sealy, with 2 ovules at the base of each scale. CoNE globular, closed, composed of very thick and angular somewhat shield-shaped scales, bearing 2 angled seeds at their base. Cotruedons 6 to 9.-Trecs with linear 2.ranked and deciduous leaves.

\section{T. Distichum, Riehard. American Cypress.}

Lravas linear, strictly 2-rantel and sproading; sometimes awl-shaped and im brioated on tine forering branches; sterile aments paniculate, pendulous, leafleso; cone oblong-globose.

Swamps, along tize Dalaware, rare. A large tree sometimes attaining the height of 100 feut or more. with a wido spread and often depressed head. Foliage light groen and open. Crmes 1 inch in cliameter. The timber is light fino-grained and azable.

\section{JUNIPE RUS, Linn. JUMIPEE.}

The classical name.

Wowers dicocious, or sometimes moncecious, in rery small lateral arents: anthers 4 to 8,1 -celled. Frrtiln AMENTS ovoid, of 3 to 6 fleshy, 1 to-3-ovuled seales; in fruit forming a sort of drupe or berry, scaly-bracted underneath. S ZEDS 1 to 3, long. CorTliedons 2.-Evergreen trees or shrubs, with awl-shaped or scale like rigid leaves.

\section{J. communis, L. Common Juniper.}

Lexvss in thres, linear-awlshapod, pri ckly-pointed, spreading, longer then tho orold ber ry.

Dry wrods an 1 sterile hills. Ma\%. A shrub, witl numero us prostrate spreading branch's, spradin; nearly flat on the ground, rarely ascending. Leaves in whorls of $3,1 / 2$ inch lo.z, bright criven except the glaucous-white comeavo upper ourfoce. Bcrivies dark-purple, as large as a pea.

2. J. Virginiana, L. Red Cedar.

Enaves 4-ran'sed, much crowded, on young plants and rapidly-growiag ghoot a wh. shaped and somewhat spreading in pairs or threes, on older lateral twigs $76 x y$ mall and scale-like, clasely imbricated, triangular-ovate.

Diy rocky hills, common, generally in limestone regions. April. 1 mall tren, vith numerou hoxizontal tranches. Barries small, bluisb, corozed with a while 
powder. Tho wood is fine groined and compact, of a reidish hue, very light and aturabio.

3. J. Susirs, I6 Suvin. A widely spreading or almost prostrato shrub, natim of South gurope, is scmetimes found in cultiration. (J. Virginlace, Yar. bumiles Leok.)

\section{SUB-ORDER III: TAXINEA. YEW FAMILT.}

FIRTILE FLOWERs solitary, consisting of a naked orub, ripening into a drupe-like or nut-like fruit.

\section{TAXUS, Tourn. YET.}

The ciassical name.

Prow MIES 8 to 10 , monodelphous; ANTUER poitate, 6 to 8 eclled. Fentru flowers solitary, scaly-bracted at the base, consisting of a single orule, becoming in fruit a fleshy 1-seedod drupe. Cotyledoxs 2.-Trees or shruts, with wergreen, fat mucronate, rigid, scattered 2.rankel leaves.

T. Canadensis, Willd. American Yew.

Stems diffusely spreading; leavs linear, with slightly revolute margins; simite resptacie globose.

Moint shaded banks and kills, near streams. April. A emall evorgren stragling o prostrate bush, with tlie general aspict of a dwarf hemisek gpruce. Levisa Eearly sn ivch long, groen on beth sid a, arrangel in 20 cyosite rows on the fidas

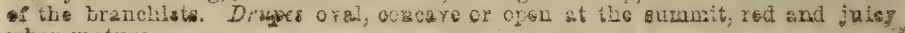
Fhan baturs. 


\section{ENDOGENS OR MONOCOTYLEDONS.}

STEMS with no manifest distinetion into bark, wood, and pith; but the woody fibre and ressels collected into bundles or threads which are irregularly imbedded in the cellular tissue : perennial trunks destitute of annual layers, inercasing by internal accretions. LEAVES mostly parallel-reined (nerved) and sheathing at the base, seldom seperating by an articulation, alternate, entire. FLowers commonly in threes. EMBRYo with a single cotyledons (or if two they are alternate).

\section{SUb-class III. AGLUMACEOUS ENDOGENS.}

Plants of the endogenous structure, with flowers con. tructed on the usual plan; perianth verticillate, consisting of ous or more whorls of petaloid organs, or wanting.

\section{Order 111. ARAOEF,-Arum Famiiy.}

Plarts weth acrid on pungent jeice, sin:p'e cr compoznd often veiny leaves, and monccicus or perfect flswers crowled on a spadix, which is uswilly surrounded bg a spathe. F'Lorat envolopes none, or of 4 to 6 sepals. Fivit usually a berry.

\section{ARUM, Linn. IndAan TURNIP.}

The ancient name, of unknown meaning.

Flowrrs monocious, the upper sterile and the lower fertile, or sometimes polygamous dicecious, on the base of an elongated spadix, surrounded by a hooded spathe, convoluto at base. Perianth none. Anthers crowded and somewhat whorled on the spadiz, nearly sessile. BERRY 1-celled. many.seeded. - Low perennial herbs, with a tuberous rootstoct. or cornu, sending up a simple scape, sheatied with the petioles of the simple or compound veiny leaves.

1. A. triphylum, L. Indian Turnip. Juck-in-the-Pulpit. Leaves nostly 2 , divided into 3 elliptical-ovato pointed leafets; spadix club. shapcd, obtuse, much shorter than the spathe; spithe ovate, acunainate, flat and deflected above.

Rich moist roods, common. May. Corm turnip-shaped, wrinkled, with an in. tensely acrid juice. Leaves 2 to 7 inches long, $1 / 2$ as wile, sinooth. Spathe rvith tho getioles and sheaths green, or frequently varie;ated with dark and whitish stripea or spota. Berries bright scarlet, in a dense head, ripe in sutumn. 
2. A. Dracontium, L. Green Dragon. Dragon-root.

Lenf mostly solitary, pedately divided into 7 to 11 oblong-lanceolate pointed leaflets; spiddix tapering to a long and slender point, beyond the oblong and pointad spathe.

Low grounds, along streams, common. May: Cormsclustered. Leaf' large and sprealing, on a petiole 1 to 2 feet long, extending much beyond the pedulacle. Spathe greenish, rolled in a tube, with a short ereet point. Berries scariet.

\section{PELTANDRA, Raf. Arrow Arum.}

Gr: pelta, a shield ortarget, and andres, stamens; from the sbiold-shaped stamens.

FLOWERS monocoious, thickly covering the long and tapering spadiz throughout; the staminate above, and the pistillate below. SPATHE convolute throughout, elongated. Perianth none. Stamens peltate. Berry 1-celled, 1seeded.-A stemtess perenniat herb; with arrow-shuped lecises ard simple scupes from the rost of thick tufted fibres.

P. Virginica, Raf. Arrow-leaved Arum.

Acaulescent; leares oblong, hastate-cordate, acute at the apex, the lobes obtuse; spathe elong ated, incurved; spadix covered with ffowers ncarly the whole length (Arum Virginicum, L. Lecontia, Turr.)

Swampy borders of ponds and streams, common. June. A smooth dark green plant, with scapes 8 to 15 inches high. Leaves radical, nuratrons, 8 to 12 inches long, $1 / 2$ as wide, on petioles 8 to 12 inches lows. Berries 1 to 3 -zeeded, green when ripe.

\section{CALIA, Linn. Water Arum.}

An ancient nams, of unknown meaning.

Bpatire spreading, ovate, persistent. Spadix oblong, entirely covered with flowers, the lower perfeet, the upper often staminate only; destitute of a perianth. Anruers with slender filaments. Strama sessile. Berries distinct, few-sesded.-Perennial aquatic herbs, with a creeping thich. ishth rootstack, bearing leart shaped lung-petioled leaves, and solitary scapes.

C. palustris, I. Norliern Calla. Common Waler Airum:

Ieaves cordate; spatice ovate, fiat; spadix: covered with ovaries, intermixed with stamens.

Bogs and shallow waters, rare. June. A fine plant. Lexves 2 to 3 inches lon:, $3 / 8$ as wide, on long petioles, with an involute acuminate point. Seupe 6 to 8 inched high, roundish, smooth. Spathe clasping at the base, girenisb-yellow, white and oft within. Spadix 1 inch long.

The C. Rrmoplos, (Nhiopian Calla) A beautiful pisnt from Cape Good Hopo is eton mot with in green houses and parlors.

\section{SYMPLOCARPUS. Salisb. Srunk Cabbaqn:}

Gr. symploko, connection, and karpos, fruit; the berries being united.

SPATHI hooded-shell-form, pointed, fleshy. Spaor ob- 
long, entirely covered with perfect flowers. Periantu deeply 4-parted, persistent. Stamens 4, opposite the perianth lobes, with short filamen'ts. STrLe 4-angled, with a minute stigma. SExps berry-like, imbedded in the enlarged and spongy spadix.-Perenmial herbs, pervaded with a strong odor, with a thick descending rootstock bearing coarse fibrous roots, and a cluster of very large and entire veiny leaves, prectded by the nearly sessile spathes.

\section{S. Fœтidus, Salisb. Common Shunk Caulage.}

Ieaves ovate, heartshaped, short-petioled; spadix globular, much shorter than the spathe. (Ictodes, Bigl.)

Moist grounis, common. Mrarch, April. Leeres 1 to 2 fect long, smooth. Spathe fpotted and striped with purple and yellowish-green, ovate, incurved. Frut ripe in sept. forming a rongh and gicliular mass, 2 to 3 incles in diqmeter, in decos shedding tho kuiblet-like getds. Bedicis.al.

\section{ORONTIUM, Linn. Golden-cleb.}

An ancient name, of obscure origin.

Spatee none. Fucwlis crowdcd all over a cylindrical epadix, perfect; the lower with a 6 parted perianth and 6 ftamens, the topper with 4. Ovatix frce, licellod; stigma bessile, minte. Frut a gren utricie or diy borry.-An requatic perenivial with a detp rootstock. long.prtioical and entire nerved flouting leaves, and the spadix ierninuating the scapes which thicken upwirds, coverca' with yctlow fowers.

\section{Aquaticun, I. Common Golden-club.}

Leares ovate-lanceolate; spize or spatix cylindric on a club-shnfed scape.

Fonds and marshes. Broy. Ieares 6 to 10 inches long, $1 / 2102 / 328$ wide, fmooth of a dep green, reiretike sbore, paler keneath. Sccpe 8 to 15 inches long, exding in a Epadix of a rich jeliaw color, covered with email perfect jeliow fowern.

\section{ACORCS, linn. Calamus.}

r. a, privative, and hore, the fupil of the eje; a suppored remedy for wore eyes.

Spadix latcral,"sessile, emcrging from the side of a ecap which rescmibies the learcs, densely corered with flowers. P'rrianth 6-scpalcd. Stamens 6. Ovary 1, free: stigMa minute, scssile. Fruit at length dry, 1-few-steded-Pungent aromatic plants, especially the thick creeping rootstocke, which send up ensiform leares, and foliaceous scapes bearing the spadix on one edge.

\section{A. Calamus, L. Sweet Flag. Common Calamws.}

scape prolonged and leaf-like far beyond the eylindrical apadix.

Margins of streame and wit medors, not rare. June. Rhizoma horizontal, nromatic. Leares $8 \pi \mathrm{crd}-\mathrm{sl}$ aped. 2 to 3 ffet leng, and $1 / 2$ to $3 / 4$ inch wide. Spantie 8 to 3 inches long, sesile ore the side of the scape, sovered with minute grasulsh slowers. 


\section{ORDER 112. LEIINACER.-Duckweed Family.}

Minute stemless piants, floating free on the water, destivute of distinct stem and folixge, but a flat frond, producing one or two monxcious flowers from a chink at the edge or upper surfuce, and usually hanging roots from underneath. Fructification much as in Aracer, of whicn these plants appear to be minute and greatly reduced forms.

\section{LEMNA, Linn. DUCKWEED.}

The Greek name of uncertain moaning.

TlOwers 2 to 3 , appcaring from the margin of a flat frond, enclosed in a spathe, monceious: the sterile consisting of 1 to 2 stamens with long filaments; the fertile of a 1-celled ovary, a short style and a simple stigma. Fruit a utricle.- Floating annucts, consisting of a stem and leaf confounded (frnnd) sending down from the under surface, roots which hang loosely in the water, and producing the spathaceous flowers from the margins, which are seldom found.

1. L. mINoR, L. Lesser Duckweed.

Fronds roundish-obovate, thickish, often grouped; root solitary; oute solitary; eced horizontal.

Stagnant water, very common; but not yet found in flower in this country. Frontis $1 / 8$ inch long, somewhat fieshy, increasing rapidly by gename (young fronds) EO as of cen completely to cover the surfuce of the water.

2. L. trisulca, L. Star Dickweed.

Frond: oblong-lanccolate, from a stalked base, thin, denticulate at the tip, pro= liferous from the sides near the middle so as to form crosses; fowers very minute; ovule solitary, half anatropous.

Ditches and pouds; rarely in flower. Fronds $1 / 2$ inch or more long.

3. I. Polyrinz, L. Larger Duclueed.

Fronds roundish ovate, thickiah, flsot above, palswately veined. ( $1 / 4$ to $3 / 2$ inch long) often dark purple beneath; root a bundle of 8 to 10 simple fibres in the midule of the frond.

Stagnant Fatere, rare. It is said never to have been seen in flotrer in thi countiy.

\section{Order 113. TyPHACRE,-Cat-tail Famity.}

Mursh herbs, with nerved and linear sessile leaves, aná monœcious flowers on a spa. dix or in heads, destitute of proper florab envelopes. Ovary tapering into a slender style, and usually an elongated tongue-shaped 1-sided stigma. Frurr nut-like when ripe, 1-seeded. SEED suspended, anatropous.

\section{TYPHA, Tourn. Cat-tall Flag.}

Gr. typhos, a marsh; alluding to the plaee of its growth.

Fuowers in long and very dense cylindrical spikes, termi- 
nating the stem; the upper part consisting of stamens, in. termixed with simple hairs ; the lower or fertile part consisting of ovaries, surrounded by club-shaped bristles, which form the copious down of the fruit. Nuthers minute, very long-stalked.-Marsh herbs, with perennial roots, very deciduous spathes or bracts, and narrow leaves sheathing the base of the erect thickish jointless stems.

\section{T. latifolia, L. Common Cat-tail. Reed-mace.}

Leaves linear, nearly flat; sterile and fertile spikes close together or continuous.

Borders of ponds. Jaly. Stem 3 to 5 feet high, round and smooth, leafy below, terminated by the large cylindric spike, which is 6 to 10 inches long, 1 inch thick, brownish at the surface.

\section{T. angustifolia, L. Narrow-leaved Cat-tail.}

Leaves channelled towards the base, narrowly linear; sterile and fertile spikes \& little remote.

Muddy pools and ditches, rare. July. Stems and spilces more slender, änd the leaves narrow $6 \mathrm{r}$ than in the last.

\section{SPARGANIUM, Tourn. BURR-REed.}

Gr. sparganon, a fillet, from the ribbon-like leaves.

Flowers collected in seperate dense globose heads, scattered along the summit of the stem, subtended by leaf-like bracts, the upper ones sterile, consisting merely of stamens with minute seales irregularly interposed; the lower or fertile larger, consisting of numerous sessile pistils, each surrounded by 3 to 6 scales much like a calyx. Frurt nutlike when mature, 1 to 2-celled.-Aquatic herbs, with fibrous perennial roots, simple or branching stems, sheathed by the base of the linear leaves.

\section{S. Ramosum, Hudson. Great Burr-reed.}

Stem erect, branching above; leaves triangular at base, the sides concave; scalles of the fertile flowers thickened and dilated above; stigma linear, longer than the style.

Borders of ponds and ditches, common. July, Aug. Stem 2 feet high, round. Leaces 1 to 2 feet long, $1 / 3$ to $1 / 2$ inch wide, thickish. Heads of flowers 1 : ght green: fertile ones 2 to 5 , the lowest generally somewhat stalked, sterile ones above, more numerous, smaller, sessile. Stigmas often 2.

\section{S. Americana, Nutt. American Burr-reed.}

Stem erect, mostly simple; leaves triangular at the base, the sides flat; stigmo conical, oblong, oblique, about $1 / 2$ as lovg as the slender style.

Small streams and ponds, common. Aug. Stem 1 to 2 feet high, simple or divided at base. Leaves mostly radical, 1 to $21 / 2$ feet long, $1 / 4$ inch wide, keeled at base. Fertile heads sessile, mostly 3 , belor the several barren ones, with the simple styles conspicuous.

3. S. natans, L. Floating Burr-reed.

Stem weak; leaves flat, thin, often floating; heads few, the sterite 1 to 2 stigma oblong, shorter than the style. 
Fonds and strearas, common. Aug. Stem long and slonder, and with the loaves Ilosting. Leaves when flosting, elongated, narrow, and pellucid.

\section{ORDER 114. INAIADACER,-Pondweed Famity.}

Immorsed arratic plants, with jointed stems ard sheathing stipules within the pre. tioles, or sessile sheathing bases, inconspicuous mono-aivecious flowers, which wre naked

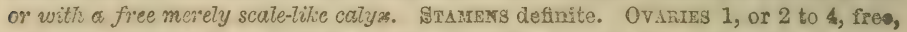
I-ovuled. Srigra simple, often sessilo. Flowbrs usually bursting from a spathe. Fong dry, indehiscent, 1-celled, 1-seedod.

\section{NAIAS, Linn. NAIAD.}

\section{- Gr. Naias, water-nymph; from the habitat.}

Tirowans dicocious, or sometimes moncocious, axillary, olitary and sessile. FERTrLe FLOWERs consisting of a single ovary tapering into a shortstyle; STIGIAS 2 to 4 , awlshaped. Stamens 1, with a slender filament. Farit a little seed-like nuclet, enclosed in a loose epicarp- - Stonder branching lerbs. growing entirely under water, with opposite and whosled crowed linear leaves, sessile and dilated at the base, and very small flowers, solitary, but often clusicred with the branch-leaves in the axils.

1. N. Fuxilis, Rostk. Bending Waver Nympk.

Iecves nombranaceous, spreading, naxrowly linear, very minutely denticulath, opyosite or in 3a, 4s or es at the joints; stigrasususlly 3 to 4 . (N. Canadensis, Mien Caulinia, Fulid.)

Ponds and slow streams, oommon. July- Sept. Stem 6 to 20 inehes long, mang fimes forked. Leaves $1 / 2$ to 1 inoh long, less than 1 line wide. Flowers rery ambul. secils.

\section{N. MINOR, I. Smaller Water Nymph.}

zeaves aiternate or opposite, linear-subulate, recnryed, priekiy-toothed, rigid.

In water, not oommon. Aug. Stem long, submeriod, rather rigid. whall.

\section{ZANNICHELLIA, Mitchell. Horned PONDWED.}

In honor of Zanricholli, \& Venitian botanist.

Frowrrs monceious, sessile, naked, usually both kinds from the same axil; the sterile consisting of a single stamen, with a slender filament; the fertile of 2 to 5 (mostly 4) acssile pistils in a cup-shaped involucre. STIGMA large and poltate. Frut a nutled, on a short stipe, beaked with a short style.-S'ender branching herbs, growing ensirely under" water, with very siender stems opposite or aliernate long and linear thread-form entire teaves, and sheathing membranocus sirpoiles. 
Z. PALUstris, L. Common Horned Pondweed.

Sten fliform, flosting; style ha!f as long as the fruit, which is fiattiah, someivhat incurred, evien, more or less toothed on the back, nearly sessile.

Ponds and slow streang. July, Aug. Stem i to 2 fest long, round, smooth. - eaves grass-like, 2 to 3 inches long, sessile. Flowers issuing frow audilarg bracti, winall, 2 together, a storile and fertile.

\section{POTOMAGETON, Tourn. Pondwed. Er. potomas, a river, and geiton, near.}

Flowers perfoct, spiled. Perianth single, 4-leared. उTARENS 4, nearly seasile, opposite the periantin lobes. JVArIEs 4, pedicellate: stigna sessile or nearly so. FrutT I sescile nutlets or drupes, flattened on one or two sides. SEDs hook-shaped.- Mostly perennial aquatic and submersed serbs, with creeping and rooting stems, two-rankied pellucide leaves, - nited membrancous sheathing stipules, and small greenish flowers ito 10, in a pedunculate spike, rising above the wates.

- Laves of two forms, the upper floating.

\section{P. Natans, S. Broced-leaved Pondweed.}

Leaver all long-petioled, the floating ones coriaceous, orel, ellintieal, or ovate, ijeffy rounded or a little leart-gliaped at the lase, many-nerred; inmarsed oncs - near or lanesolste; spilies rather densa, shorter than the pecluneles; fritit zhortjointed, more or less keeled on the back.

Ponds and slow waters, common in the Susquehanna. July, Aug. Stem slender, i to 3 feet long, branched. Fnilie 1 to 2 inches long, 20 to 40 -nowered. Faries with

2. Pe lower leaves all reduced to petioles.
2. OBLongus, Vir., Fries. "Oblong-leaved Pondruced.

Leaves oblong-elliptical; nutiets small, obtuse and pointless, always rounded at the back.

Pocla and ditches. Floating leavns chlong-elliptical or oblong-lanceolate. Frut rounded, not half as large as in $P$. natans.

3. P. HEterophyluus, Schreb. Tarious-leaved Pona'weed.

Floaing leaves elliptical or oblong; or the lowest lance-spatulate, on long po. Holeg; immersed leaves leuecolate or linear, sometimes elongated and grass-iike, flaccid, obecurcly denticulate or ronghish on the marging, the lower sescile; 24 duncies muth thicker than the stem, elongated; spilie cylindric, many-fowered.

Pools and shallow slow streams, common. Aug. Stems numerous, branched, flliorm. Floxing leaves 1 inch long, very variable. Peduncle 1 to 2 incher long, Kiutiefs roundish, flattened on the sides, obture and rigid on the back.

4. P. hybridus, Michx. Hybrid Pondweed.

Floating leaves oral or lance-oblong, 5 to 7-nerved, on peticles; immersed leans espillary; spitie globular, few-flowered, on a short somewhat club-shaped peduncle.

Shallow pools and streams. Aug. A delicate species, with thread-like branching stoms 1 foot or more in length, and the floating leaves $1 / 2$ to $3 / 4$ inch long, nometimes none. Frait nearly round, flattened on the sides, somewhat keeled and created on the back.

* Leaves all submersed, uniform.
5. P. Luoens, L. Shining Pondweed.

Inawes oral-lanceolate, fiat, large, the short petioles continuing in a thick midrih 
small pointed; peduncles thicken ed upwards; spites cylindrical, many-flowered; nutlets slightly keeled.

Ponds and deep streams. June. Stem long, branched. Leaves Targe, very pellucid, and when dry shining above, beautifully veined, 3 to 5 inclies long, $1 / 2$ to 1 inch wide, acuminate, each with a lanceolate kract above the base. Spitie 2 inches long, of numerous green llowers.

\section{P. Perfolitatus, I. Perfoliate Pondweed.}

Ieaves clasping by a heart-shaped base, ovate or ovate-lanceolate, sometimes round ovate, obtuse; spikes terminal, with a few alternate flowers; nutlets roundeut on the back, short-pointed.

Ponds and rivers, common. July. Stem 2-forked, very leafy, 6 to 10 inches long. Leaves shining, 1 to $11 / 2$ inch long, $1 / 3$ as wide, oltuse, flat, more or les: wavy or crisped. Spite on a peduncle, 1 to 2 inches long.

\section{P. Pauciflorus, Pursh. Grassy Pondweed.}

Stem very slender, and fliform, flattish; leaves narrowly linear, acutish; spites few-flowered, short-peduncled; nutlets obliquely lenticular, distinctly crested on the back.

Ponds and streams, common. July, Aug. Leaves numerous 2 to 4 inches long, scarcely 1 line wide, obscurely 3-nerved, of a bright green color. Flowers 3 to 5 , greenish, on a terminal peduncle an inch long.

\section{P. Pectinatus, I. Fennel-leaved Pondroeed.}

Stems thread-like, many-times forked; leaves bristle-form, 1-nerved; spikes inter rupted, on long peduncles; nutlets rounded-obovate.

Ponds and deep streams. June. Plant much branched and leafy. Leaves 3.to 6 inches long, less than 1 line wide, thickish. Spite in clusters of 3 or 4 seperated in fruit by considerable intervals. Fruit purplish.

s: * Stipules none; leaves all opposite and immersed.

\section{P. DFnsus, L. Dense Pondweed.}

Leaves pellucid, elliptical or lancelate, clasping; spike few-fiowered, shart-peduncled, reflexed in fruit; nutlets beaked and keeled. Bethlehem, Schwenitz.

\section{ORDER 115. ALISIIACER -Water-Plantain Family.}

Marshy herbs, with parallel-veined leaves sheathing at the base, scape-tike flowering: stems, and perfect or monœcious flowers, not on a spadix, furmished with both calys and corolla; sepals and petals each 3 , distinct. Stamens definite or indefinite. OFARIES 3 to-many, distinct or partly so. STILES and STIGMAS as many as the ovaries. FruIT dry, indehiscent, 1 to 2-seeded.

Sub-order I. JUNCAGINE F. Arrow-Grass Family.

CalyX and Corolla colored alike (gxeenish). Seed anatropous, with a straight embryo.-Leaves petiole-like without a blade.

\section{TRIGLOCHIN, Linn. ARrow-GrasS.}

Gr.treis, three, and glochin, a point; in allusion to the points of the capsule. SEPALS and PETALS nearly alike, ovate, concave, deciduous. 
Stamins 6, with oval anthers, on short filaments. Pistils united into a 3 to 6 -celled compound ovary; sTiGMas segsilo: OVULES solitary. CAPSULR splitting when mature into 3 to 6 carpels, which seperate from a central axis.Herbaceous aquatic or marsh plants, with ensiform rush.like leaves, sheathing the base of the slender and jointless scape, and smahl greenish flowers in a spiked raceme, bractless.

\section{T. Maratimum, L. Sea-side Arrow-grass.}

scape and leares feshy, thiekish; fruit ovate, acutirh, of 6 united earpols whish se rounded at the base and slightly grooved on the back.

Salt raarshes, rare. July. Scape 18 inches high, from a horizontal rootstock. Laves linear, smooth, thick, 6 to 12 inehes long; less than a lia wide. Flpusars greenimh, 30 to 40 on the obtuseiy angled seape.

\section{SCHEUCHZERIA, Linn.}

In honor of the two brothers Schersckers, fries botanists.

Sepals and pertals 6 , oblong, acute, porsistent, spreading. Stamene 6, with linear anthers. Ovaries 4, globular, slightly united at base, with flat aessile stigmas, 2 to 8 . oruled, in fruit forming 3 diverging and inflated capsules, 1 to 2 geeded, opening along the sides. -4 low perennial bogherb, with a creeping jointed rootstock, tapering into the ascendinge sirople stem, which is partly slieathed by the grass-like beaves. terminated by a looss racerne of a few flowers with sheathing bracts.

S. PALUSTRIS, L. Marsh Scheuchzeria.

Pat bogs, rare. July. A rash-like plat, 8 to 12 inckes bigh, angular. Iow

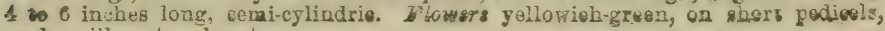
onolh axillary to a braet.

\section{SUB-ORDER II. ALISHER.}

Caryx green and persistent. Conolla white, deciduous. SngD eampylotropous. - Leave commonly furnished with a biade.

\section{ALISMA, Linn. Wampi-Plantain.}

Gr. elysmos, anxiety, from the supposod remedial preportios.

Plowers perfect. Prtals and supals 3. Staming 6. OVARIES and TYLES numerous, in a simple circle on a flattened receptacle, forming coriacious achenia in fruit.-A guatie perennials, with radical several-ribbed leaves, and the seape with whorled panieled branches, bearing small white or pals ress-colored Rowers. 


\section{A. Plantago, L. Common Water-Plantain.}

Leaves ovate, oblong, or laneeolate, narrowed rounded or somewhat cordate at the base, 3 to 9-nerved, on long petioles; panicle louse, compound, many-flowered.

Ditches and marshy places, common. July, Aug. Scape 1 to 2 feet higk. Lieaves 4 to 6 inches loug, $2 / 3$ as wide.

\section{SAGITTARIA, Linn. ARROW-HEAD.}

Iat. sagitta, an arrow; from the peculiar form of the leaf.

Flowers monocious, rarely diceious or perfect. Petats 3. Sepals numerous (about 14). Ovaries many, collected in a spherical head on a globular receptacle, in fruit form-ing membranaceous achenia, covered with the persistent. style.-Marsh or aquatic herbs, with millyy juice and fibrous: roots, radical, mostly sagittate leaves sheathing at the base the scapes. which bear the white or whitish flowers in $3 s$.

SgC. I. Sugirtaria, proper: Ftowers monoeeious, rarely dioecious.

1. S: variabilis, Engolm. MSS. Gray. Common Arrou-head. Variable Arrow-head.

Leaves triangular-arrowshaped, or entire, oblong, lanceolate, linear, and sometimes mere naked petioles; scapes simple.

Ditches, pools, streams, and moist groundis, common. July, Aug. Petals white. 66 This with its Protean varieties of which alnost every pool and stream furnishes a goodly number, embraces many nominal species of authors, and may safely beheld to include all that are found within our limits," Gray. The largest forms bear sagittate leaves 12 inches or more long and 7 wide, others have both the main blade and the lobes linear, many hear entire leaves, or else mere naked petioles; the smallest forms boing only from 3 to 5 inches high.

SEC II. ECHINODCRos, Richard, Engelmann; in Gsay. Flowers perfeet. Star mens 7 to 21 .

2. S. pustura, Nutt. Dwarf Arrow-head.

$\boldsymbol{L}$ eaves linear, obtuse and short, with foliacious summits; scape simple, about as . long as the leaves, rambellately 3 to 8 flowered, some of them becoming proliferous. runners; pedicels elongated, recurved; petals inversely heart-shaped; stamens. about 9 ; styles much shorter than the ovaries.

Muddy margins of ponds and streams. Aug. Scape 2 to 4 inches high. Leaves: rarely ever sutulate 1 to 2 inches long, scarcely a line wide. Flowers 3 to $b_{8}$ each ripening 8 to 15 carpels.

\section{ORDER 116. HYDROCHARIDACRRE, - Frog's-bit Famity ...}

Aquatic herbs, with diccious or potygamous reguiar flowers on scape-like peduncle: from a spathe, and simple or double floral envelopes, which in the fertile flowers arc united into a tube and coherent with the 1 to 6-celled ovary. STAMENs 3 to 12, digtinct, or monadelphous: ANTHERs 2-celled. STLGMas 3 to 6 . Fruir ripening under. water, indehiscent, many-seeded.

\section{ODORA, Nutt. WATER-WEed.}

Gr. udor, water; in allusion to its place of growtb.

Polygamous. Frowers solitary and sessile, from a sessile: 
and tubular 2-cleft axillary spathe. STERILE FLowers minute, with a 6-parted perianth; ANTHERs 9, oval, nearly sessile. FerTiLe flowers with 3 to 6 oblong anthers, and the perianth extended into an extremely long and capillary tube, the small lobes obovate, spreading. STYLE long and filiform: stiguas 3, large and spreading, 2-lobed. OVARY 3-celled, with 3 projecting pointed placentæ, each bearing $x$ few orthotropous ovules. Frum oblong, coriaceous, fewseeded.-A perennial hert, growing under water, with long branching stems, thickly beset with pellucid and veinless, 1-nervecis sessile, whorled or opposite leaves, and very. smuall whitish sessile flowers.

\section{U. Canadensis, Nutt. Ditch Moss. Water-roeed.}

Leaves oblong-ovate or lanceolate, finely serrulate, in $3 \mathrm{~s}$ and $4 \mathrm{~s}$; perianth twbe fliform. (Elodea Canadensis, Michx. Serpicula verticillata, Muhz.)

Ponds and slow streams. July. Stem submersed diffusely 2-forked, fliform. Leaves $1 / 4$ to $1 / 2$ inch loag, less than 1 line wide, thin. Flowers minute, of a dingy white, the slender hair-like tube 2 to 3 inches long. The staminate flowers breat off, and float on the surface, where they expand and shed their pollen to fertilize the stignas, which are raised to the surface by the excessively prolonged calyz. tabe.

\section{VALIISNERIA, Micheli. TAPE-grass.}

In honor of Antonia Fallisneri, an early Italian botanist.

Diœcious. SterILE FLOWERS numerous, crowded in : head on a conical receptacle, inclosed in an ovate at lengtb 3-valved spathe, which is borne on a very short scape : $\mathrm{PE}$ RIANTH 2-parted: sTAMENS mostly 3. FerTILE FLOWERS golitary and sessile in a tubular spathe which is borne on a very long scape: PERIANTH elongated, 6-parted; the alternate segments linear; tube linear, coherent with the 1. eelled ovary: stiguas 3, large, 2-lobed. Ovules very numerous on 3 parietal placentæ. FruIT elongated, cylindric, berry-like, 1-celled, many-seeded. - Stemless plants, with long. and linear grass-lile leaves, growing entirely under water. and spiral scapes.

\section{U. spiralis, L. Eel-grass. Tape-grass.}

Leaves linear, thin, long and ribbon-like, obseurely serrulate, obtuse, somewhak nerved and netted-veined.

Slow watess, common. Aug: Per. Leaves all radical 1 to 2 feet $\operatorname{long}_{3}, 1 / 4$ inch wide, grass-like, smooth and deep-green. Perianth reddish-white. The staminate clusters of tlowers break away from the bottom, as in Udora, and float on the sur: face, where they expand and shed their pollen around the fertile flowers, which: are raised to the surface at this time; fertilization being thus accomplished, the aliforin seapes which are 2 to 4 foet loug, coil spirally and draw the ovary under vater to ripen. 


\section{ORDER 117. ORCHIDACERE, Orchis Family.}

Forennial often acaulescent herbs, with fleshy corms, or tuberous fascioulated roots; armple, parallel-veined entire leaves, and irregutar amerous flowers; the perianth adderent to the 1-celled ovary with 3 parietal rlacentre, gyrandraus stamens, and pollew ohering in waxy or mealy masses. PMRIANTH SEGMENTS in 2 rows, the outer (caly w) mually colored and petaloid like the inner, the lowest one (lip) different from the - thers and often spurred. STAMExs 3 , nnited with the style and thus forming the aharean, on which the 2-celled anther is variously situated.

\section{MiCROSTYLUS, Nutt. AdDen's-Moutr.}

Gr. mizeros, little, and stylos, a ciminitive column or styte.

STPALs spreading. PETALS filiform or linear, spreading. LIP suricled or halbert-shaped at the base, entire or nearly \%. CoLUmn very small, with 2 teeth or wings at the sum. mit. Pou.LEN MAssas 4, collateral, colering by pairs at tho spex.- Small horbs, arising from solid bulbs, producing simyle stems or scapes, which bear 1 or 2 leaves, and a raceme of ninute greenish flowers.

M. ophioglossoides, Nutt. Common Addder's-mouth.

Ieaf solitary near the middle of the stem, ovate, clasping; raceme short and obbuso; pedicels much longer than the flowers; lip obtuagly aurioled at the baso, -toothed at the sammit.

Damp roods, rare. July. Stem 4 to 10 inches high, 5 -angled, with a singlo lest about $21 / 8$ inches long snd 1 inch wide. Flowgrs whitish, ininate, numorons, in s wornal raverae an inch or more in length.

\section{LIPARIS, Richard. TWAYBLAd}

Cr. liparos, fat or ghining; in allusion to the smooth looves.

Sorals and perals nearly equal, linear, or the petals Aliform, spreading. Lip flat, entire often bearing 2 tubercles above the base. Colum elongated, incurved. Polus MAбSES 4, collateral.- Small perennial herbs, arising from - olid bulbe, witts 2 root-leaves and a low scape, bearing a racome of few purplish or greenish flowers.

1. L. LILIIfolia, Richard. Lity-leaved Twayblade.

Iesves 2 , ovate, shorter than the scape; petals filiform, reflezed; lip large, wodgs. bovate, abruptly short-pointed. (Malaxis liliifolia, Willd.)

Moist woodlands. June. Scape 6 to 8 inehes high, triangular. Isaves radical, 2 to 6 inches long, $1 / 2$ to $1 / 2$ as wide, tapering into a sheathing base. Flower ratioer large, 10 to 20 in a terminal raceme; the 3 sepal greenish-whito, 2 uppor potals. yellowish-white, and the large lip white.

2. I. Lasenir, Richard. Smaller Troayblade.

Ieases 2, elliptical-lanceolate or oblong, sharply keelod; soape angeler; is oba Tate or ovate, entire. (Malazi Correana, Burt.)

Poge and w ot mendows, rare. June, July. Scape of to 8 inabes high, 8 to sengled. 
Leaves 2 to 3 inches long, 1 inch wide, sheathing at base. Flawers small, erest, about 4 , appressed to the rachis in a thin raceme, greenish-white.

\section{CORALLORHIZA, Haller. CoRAL-ROот.}

Gr. Forallion, coral, and rhiza, root; the root being coral-like:

Flowers ringent; the SEPALS and PETALS nearly alike, the lateral ascending and the upper arching; LIP recurved, spreading above, 2-ridged below, adherent at the base of the straightish column. ANTHER 2-lipped, terminal: POLLEN MASSES 4.-Brownish or yellowish herbs, desitute of green foliage, with much branched and toothed coral-like root-stacks, and simple scapes furnished with sheaths, bearing dull.colored fowers in spiked raceme.

\section{C. multiflora, Nutt. Large Coral-root.}

scape many-flowered; lip wedge-ovate, 3-lobed, the midale lobe recurved, 3 times as long as the lateral ones; ovary and capsule oblong.

Woods, about the roots of trees; common. Aug., Sept. A brownish or purplish plant 10 to 18 inches high, with a few sheathing bracts instead of leaves, and 10 to 30 rather large brownish-yellow flowers. Lip whitish, spotted with crimson, $1 / 4$ to $1 / 3$ inch long. Spur Jellowish, conspicuous.

\section{C. Wistariana, Conrad. Smaller Coral-root.}

Scape few-flowered; lip oblong, minutely 2-toothed near the base, minutely notched; spur obsolete; ovary elongated.

Woods, near Philadelphia. June, July. Plant about 6 inches high, with 3 to 10 flowers, nearly as large as in C. multiflora.

\section{C. innata, R. Brown. Early Coral-root.}

Scape few flowered; lip oblong, 2-toothed near the base; ovary and capsule oblong or club-shaped; spur obsolete.

Swamps and wet woods. May, June Scape slender, 5 to 8 inches high, yellow. ish-green, with 3 or 4 membraneous sheaths. Flower's 5 to 10, dingy-yellowish; lip white, seldom spotted.

\section{C. odontorhiza, Nutt. Small Late Coral-root.}

Scape several-flowered; lip roundish, entire, thin with a crisped or wavy margin; ovary and capsule globular or roundish oval; spur none.

Rich woods, about the roots of trees. Aug., Sept. Scape 8 to 10 inches bigh, a: little enlarged at the base, with 2 or 3 sheaths. F'lower's 10 to 12 in a terminal pendulous raceme, purplish; lip whitish, spotted with purple, with 2 oval protu. berances on the palate.

\section{APLECTRUM, Nutt. Adam and Eve.}

Gr. $a$, without, and pletitron, a spur; from the total want of the latter.

Flowers ringent. Sepals and petals nearly equal. Lrp with a short claw, free, 3. lobed, with a 3-ridged palate; without a spur. ANTHER situated a little below the summit of the column. Pollen-Masses 4.-A perennial herb, with a simple scape, invested below with 3 greenish sheaths, springing up in May from the side of a thick globular solid 
Zulb or corm, which also produces late in the summer a large oval, many-nerved and plaited petioled green leaf from its apex, lasting through the winter.

A. hymale, Nutt. Puby-root. Adam-and-Eve.

Iich shady woods, rare. May, June. Bu?ts 2 or 3 together, horizontaily connected, often 1 inch in diameter, flled with exccedingly glutinous matter. I lof solitary, 4 to 6 inches long, elliptie acuto at each end, on a potiole 2 to 3 inches 1 ong, inserted on the summit of th $\rightarrow$ bail. Flowers brownish, erect, racemad, cn a scape 1 foot high. Lin whitish and spockled. Capsute lorge, smooth, nocling.

\section{TIPULARIA, Nutt. Crane-TuY Onomis.}

Tivota, the crane-fiy; from the fancied resmiblence of the flowers.

SEPALS and PETALS sproadiag oblong or spatulate. TirP 3-Iobed, prolonged underneath into a filform spur twice as long as the flower. Conjun narrow and winglcas. Armuer lid-like, terminal: poLLEN-IMAsßs. 2, esoh 3-portod.-A perennial herb, with soíd Zullis, connociel horiactelly, prom ducing a single ovaie nerved leaf, and a long and nolied stender scape, bearing a many-glowered racome of grcenish jlowers, tinged with purple.

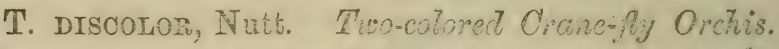

Pine woods, rare. July. Serpe 10 to 18 invies high, with 1 or 3 shaathy at the base. Leaf solitary on a slonder potiole. Flowsers siall, noduling, greenish with a tinge of purple. Spur nearly 1 inch long.

\section{ORCHIS, Inn. Ordis.}

The ancient Greek name.

FLowars ringent. SEPAIE ind paTAts norrly equal, all, or nearly all converging upwards and weoling over the column. LIP turned downwardis, with a spur on tho under side at base. PoLmen-Massis pedicillate, colloctod into 2 large masses borne on a slender stalk, the base of which is attached to the 2 glands of the stigma: GLANDS contained in a common libtle pouch.- Perennial herbs, with showy flowers in a spilee.

\section{O. SPectabilis, I. Showy Orchis.}

Leaves 2, radieal, oblong-obovate, obtuse; seape angular, naked, fer-flowerod, carcely longer than the leaves; braois leaf-like, lanceolate; spur club-shaped, Dhorter than the ovary.

Shady woods. May, June. Scape 4 to 7 inches high, arising from a thick fleshy fibrous root, 5-angled, smooth. Leaves 3 to 5 irches long. Sepals and petals all Toulted, pink-purple; tip orate, undirided, and with the obtuso spar white. 


\section{GYMNADENIA, R. Brown. Naked-gland Oromis.}

Gr. gymnos, naked, and aden, a gland.

Frowers as in Orchis. ANTHer-cerc parallel; the ap. proximate glands naked.

G. TRIDEntata, Lindl. Thres-toothed Gymnadenia.

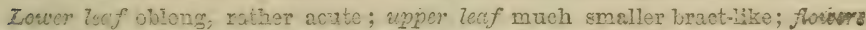
fer, in an ollong teminel spite; lin wolgc-nblong, s-toothed at the apex.

Wet wouls, aul swounjs. July. Slem stenter, 6 to 12 inches high, with a qinele leaf. Sy i. 6 to 12-1lowered, compact. Flowers pale jellowish-green. Four clu shoped, curved upwards, longer than the ovary.

\section{PLATANTHERA, Riolard. Fatsa Oromis.}

Gr.ptatus, wide, and antherc, an anther.

Fuowers as in Orohis, but with the latemal sepals spreading. Antrmen-ondis divorging wo the base; the two naked glands widely separated. LIP with a spur at the base.Perennials, with spicale or racemose fowers, ofien shoncy.

* Scape 2-leavect at the base; spur very long; lip entire.

\section{P, onbroulata, Lindl. Rownd-leaved Orchis.}

Leaves rexy larce, orbicular, spreauling flat on the gronnd; scape bracted, bear-

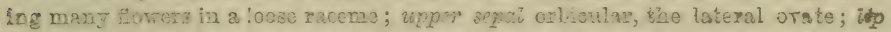
3inest-npetulata, drooling, neariy 3 times as long as tho efpals; spur curred, elender, linear-club-shaped.

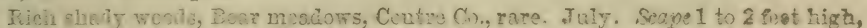

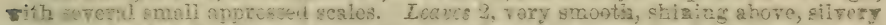

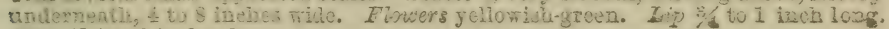
Sour $1 \frac{1}{2}$ to 2 inches long.

- Stem leafy; lip entige aboud the length of the spur.

\section{P. BRAOTEATA, Torr. Bracted Green Orchis.}

Zaver leavcs oborats, the upper oblong, and gzadusily reduced to laneeolsto

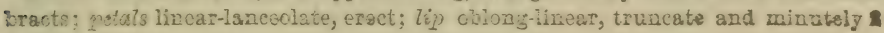
to s-toothed.

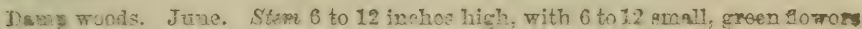
in o locse gike. Lip more than twice the length of the secilke, soraew ho 2-lobed gpur:

\section{P. miAva, Gray. Tellowish Orchis.}

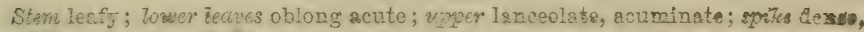
eflinarie: petals orate; lip cliong; oltuke, toothel at the base, and with a small protuluerance on the rialate; spur finorna, ratien shorter than the sessile orcry.

Het places. June-Aug. Stem 10 to 20 inehes high, with small groenich-yellor Eoppcrs, in a long spike at first denas, at length loose. Leswes about 3 , with lone sheaths, 3 to 7 inches long, and $8 / 4$ to 2 inches wide.

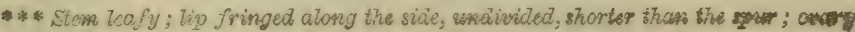
with an acuminate beak.

4. P. crigtara, Lindl. Crosted Orchis.

Zows bays lanceolate, elongatol, the uppor graduslly redwoed to oharp-polatod 
bracts; spike oblong or cylindrical; petals rounded, crenate ; lip ovate, with a torafringed margin; spwr shorter than the ovary.

Swamps, rather common. June, July. Stem 1 to 2 feet high. Flowers strall, yellow, in a crowded terminal spike.

\section{P. oILIARIs, Lindl. Yellow Fringed Orchis.}

Iraves oblong or lanceolate, the upper passing into pointed bracts; spitce oblong, rather closely many-flowered; lateral sepals rounded, reflexed; petals linear fringed at the apex; lip oblong, about $1 / 2$ the length of the spur.

Swamps and wet places, common. July, Aug. Stem 1 to 2 feet high, with a short spike of very showy flowers. Leaves sheathing at base, the lower ones 3 to 5 inches long. Flowers bright orange-yellow. Lip furnished with a very long and copious capillary fringe, $1 / 2$ inch long.

6. P. Blepharioglotris, Lindl. White Fringed Orchis.

Zower leaves lanceolate, channeled; spite oblong; petals oblong, slightiy cut or toothed at the apex; lip oblong or lance-oblong.

Swamps, rare. June, July. Stem 1 to $1 \frac{1}{2}$ foot high, with the lower leaves 6 to 8 inches long, the upper gradually smaller. Flowers pure white, in a dense oblong spike. Lip fringed in the middle.

**** Stem leafy; lip 3-parted shorter than the long spur, narrouved at the base into a claw. Flowers white or greenish.

\section{P. LACERA, Gray. Ragged Green Orchis.}

Zeaves oblong or lanceolate; raceme loosely many-flowered ; pelats oblong, lincar, entire; lip 3-parted, with wedge-shaped segments; spur filiform, club-shaped, as long as the ovary.

Swamps and moist thickets. July. Sicm 1 to 2 feet high, smooth, slender. Leaves few, 3 to 6 inches long, mostly acute. Flowers greenish-yellow, numerous. Lip with narrow divisions, deeply parted into a few long nearly capillary lobes.

***** Flowers purple.

8. P. PYscodes, Gray. Small Purple Fringed Orchis.

Leaves oblong, the upper passing into linear-lanccolate bracts; raceme cylindrical, densely many-flowered; lower sepals round-oval, obtuse; petals wedge-obovate or spatulate, denticulate above; divisions of the $l_{i}$ i broadly wedge-shaped, manycleft into a short fringe.

Moist meadows. July, Aug. Stem 2 feet high, smooth, slender. Flowers bright purple, in a erowded spike 4 to 7 inches long, small, very showy, fragrant. Lip short-stalked, scarcely $1 / 2$ inch broad, its 3 fan-like, spreading segments, as well as the petals beautifully fringed. Spur nearly 1 inch long.

9. P. fimbriata, Lindl. Large Purple Fringed Orchis.

Lower leaves oval or oblong, the few upper ones passing into lanceolate bracts spitic or raceme oblong, loosely-flowered; lower sepals ovate, acute; petals oblong, fringe-toothed down the sides; lip fan-shaped, with pendant, large divisions, manycleft into a capillary fringe. ( 0 . grandifiora, Bigl.)

Wet meadows, rare. June. A superb plant, $11 / 2$ to 2 feet high, with a thick, hollow, stem with a few sheathing bracts at base. Leaves 2 or 3 principal ones 4 to 7 inches long, 1 to 2 inches wide, the upper ones linear, 1 or 2 inches long. F'low. ers very large, showy, lilac-purple, in a terminal raceme 3 to 6 inches long. Lip much dilated, $3 / 4$ to 1 inch broad, with a deep and nearly capillary crowded fringe.

10. P. Peramana, Gray. Fringeless Purple Orchis.

Lower leaves oblong ovate, the upper lanceolate; spitce oblong or cylindrical, densely flowered; lower sepals round-ovate; petals rounded-obovate, raised on a claw; lip large, with broadly wedge-shaped divisions, the middle one 2-lobed. (O. Lissa, Pursh. P. fissa, Lindl.) 
Kioist meadows and banks, rare. Aug. Stem 2 to 4 feet high, slightly winged. Leaves 4 to 6 inches long. Flowers large and very showy, violet-purple. Lip $3 / 4$ lach long, with minutely and variably toothed divisions. Spur $11 / 4$ inch long.

\section{AREThUSA, Grodov. ArethosA.}

Dedicated to the Nymph Arethusa.

Flower ringent, with the lanceolate sepals and PETALS nearly alike, united at the base, ascending and arching over the column. LIP spreading towards the summit, bearded inside. Column adherent to the lip below, dilated at the apex. Pollen-Masses granular, 2 in each cell of the lidlike terminal anther.-A beautiful low herb, with a sheathed scape from a globular solid bulb, bearing a single large purple flow. $e r$, and a solitary, linear, nerved leaf.

\section{A. Bulbosa, L. Bulbous Arethusa.}

Sphagnous swamps, rare. May. Scape 6 to 10 inches high, the lower part beax. ing 3 to 4 loosely sheathing scales, with lanceolate points, from the upper of which there is often a linear-lanceolate leaf. Flowers 1 to 2 inches long, very handsome, bright-purple. Lip yellow and white, bearded in the midale.

\section{POGONIA, Juss. Pogonia.}

Gr. pogon, a baard, from the bearded lip of the original specles.

Flowers irregular, the sEPALS and PETALS separate and somewhat spreading. Lip crested or 2-lobed. CoLUMr free, elongated, club-shaped, wingless. Antrer terminal, stalked, with 2 farinaceous pollen-masses, 1 in each cell.Derennial herbs, with 1 to 5 -leaved stems, and purplish flowsis.

1. P. ophioglossoides, Nutt. Adder's-tongwe Pogonita. Root fibrous; stem bearing an oral or lanceolate, clasping leaf near the miluiesnd a smaller leaf-like bract next the flower; lip spatulate, beard-crested and ringed.

Bogs, common. June, July. Scape 8 to 12 inches high. Flowers mostly soliary (sometimes 2 to 3), handsome, 1 inch long, pale-purple.

2. P. verticillata, Nutt. Whorled Pogonia.

Root of thick fibres; stem bearing a whorl of 5 oval or oblong-ovate painted ses. plie leaves at the summit, 1-flowered; sepals narrowly linear, twice as long as the wiong petals; lip short, 3-lobed, the middle lobe wary and crested.

Bogs, rare, June. Scape about 12 inehes high. Flovers mostly solitary; the copals 2 inches long, brown; petals paler and obtuse.

\section{CALOPOGON, R. Brown. Calopogon,}

Gr. kalos, beautiful, and pogon, beard; from the bearded lip.

SEPALS,and PETALS nearly alike, spreading, distinct. LIP rather spreading, dilated at the summit, strongly bearded along the upper side. CouUns free, winged at the apex. 
ANTHER terminal, sessile; POLLEN-MASses 2 (one in each cell).-Scapes from a soidd bulb, sheathed below by the base of the grass.like leaf, naked above, bcaring several skowy flowers.

C. Pulchellus, R. Br. Grass Pinl.

Leaf linear, 8 to 10 incles loge, sheathing the base of the stem. Scape 12 to 18 inches high, 2 to 6-flowered. Flowers 1 inch broad, pink-purple, fragrant. Sepals and petals orate-lanecolate, acate. Lip benutifully bearded towards the fpreacting summit with white, jellow; ard purple clarate hairs.

\section{SPIRANTHES, Richard. LadIes' Tresses.}

Gr. speira, a coil or curl, and anthos, blossom.

Srrke epiral. Flowers somewhat ringent; the iateral sepals rather oblique at the base and nearly opposite tie lip, the upper one coliering with the petals. LIP oblong, concave and embracing the columin below, with 2 callous procosses at base. COLUMN arching, obtiquely short-stalked, mostly with a 2-cleft beak. AxwuER dorsal: FOLLEN-MASSES 2, club-shaped, affixed to a common gland.-P'erennial herbs, with elustered tuberuns roots sending up mostly natied seapes. bear. ing a spirally twisted spike of small white fowers, bent horizontally.

1. S. aracrus, Bigl. Stencter Exdies' Tresses.

Lexves radieal, orste, caluccus; scaps rery stender, smooth, sheathed; spike Render, with the flowers in a siruight of usually spiral row; bracts ovate, pointed; isp spatulate oblong, etrongly wavy orteped.

Ililly woods a du sandy plains. July. Aus. Srape 8 to 12 inches high, erect, with a few sluesthing scales or leaflets. Leaves 1 to 2 inches long, thin, sometimes full lug off befure the fiowers expand. Flowers white, 1-5 to $1 / 4$ ineh long; the calli at furst oval, at length elongating ond incurved.

2. S. Cennu., Richard. Nodrting Ladies' Tresses.

Zcaves radical, linear-Janccolate, veined, those of the stcm smaller, passing tato atrets; spilie deuse, minutely pubescent; Uracts oxatolanceolate, pointed; lip oblong, furnished rith 2 minute callositice at tise baze.

Wet gramcy plrees, common. Aug-Oot. Seape 6 to 18 inches high; the root

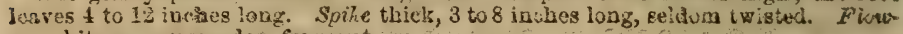
crs white or cream-culor, fragrant.

\section{GOODYera, R. Brown. Ratrlesnake Plantain.} Dedieated to John Goodyer, an eariy English botaniat.

Frowers ringent. CALXX herbaceous, upper sepal vaulted. LIP saceate at the base, sessile, over the 2 lower sapals. Colunn small, straight. Politen-Masses 2, eonsisting of angular grains, loosely colering by a manifest web.- Perennial herbs, with a root of thich filnes from a fleshy somewhat creeping rootstock, bearing a tuft of thickish w: ol oled leaves next the ground, and sasell grecnisht whise flowers in a spike on a siender asape. 
1. G. Pubescens, R. Brown. Rattlesnake Plantain.

Leoves radical, ovate, conspiacusly reticulated and blotched with white; scup sheathed, with numerous florers in a crowded syike; lup inflated with an abrupt orate apex; sigma rounded at the summit.

Rich woods. July, Aug. Scope 8 to 12 inehes high. Leaves 1 to 2 fnches lone, euntracted at base into a winged petiole, searenly half as longr dark green, veined with white. Flowers whitish, in a terminal oblong gnike.

2. G. Repres, R. Brown. Smaller Rattlesnate Plantain.

Small and slender; leares ovato-ianceolate, somewhat reticulated with whitei fowers several iz a loose 1-sided spike; lip influted:with un oblong obtuse apex; stigma distinctly 2 -toothed.

Rich woods, under erergreens, and on mountains. Aug. Seape 6 to 8 inches. ligh. Leaves 1 inch long. Flowers greenish-white.

\section{LISTERIA, R. Broma. Twayblade.}

In honor of Biartin Lister, az eminent British botanist.

SEPALS and PETALS nearly alike, spreading or reflexed. LIP mostly drooping, longer than the sepals, 2-lobed or 2-cleft. Cosurn wingless: strGus with a rounded beak. ANTher dorsal, ovate: POLLEN-MASSEs powdery, in 2 masses, joined to a minute gland.-Perennial herbs, with fibrous roots, the stem bearing a pair of uppnsite sessile leaves in the middle, and' a spike or racene of greenish or brownish purple small fiowers.

\section{L. Australis, Lindl. Twayblade.}

Leaves orate; rascme loose and slender; flowers very small, on pedicels twice the length of the orary; lip linear, slightly sagittate at the base, 3 or 4 times as long as the sepals, 2-parted, with the divisions linear-setaceous.

Damp thickets, rare. June. Flant 4 to 6 inches high. Leares $1 / 2$ inch long. Flowers small, purplish on mixutely gindular-pubescent padicels.

\section{L. CONVALLARIOIDES, Fiook. Large Twayblacie.}

Leaves oral-roundish, sometimes somewhet enzdate at ligs:, often acute; raceme loose, pubescent; flowers on slexdur pedicels; lip wedge-cblong, 2-lobed, at the epreading apex, and 1-toothed on cach side at,the base; sepals narrowly lanceolato, spreading, twice as long as the lip.

Damp mossy moods, rare. Juno. Stem verg slenter, 5 to 10 inches high, sheathed with a few bracts. Leaves nearly 1 ineh lomp. $2 / 3$ as wiale. Elowers dark brown and green, the purplisi lip nearly $1 / 2$ incis long.

\section{CYPRIPEDIUM, Linn. LADY's SLIPPER.}

Gr. Kupros, Venus, and podion, e sock or slipper.

SEPALS spreading; the 2 anteriar distinct, or commonly. nnited into one under the lip. Petars similar but usually narrower, spreading. LIP a large inflated sac, somewhat slipper-shaped. Corumn sknrt, 3.lobed, the middle lobe dilated and petaloid, the lateral bearing a 2-celled antber: 
under each of them. STIGMA terminal-Perennial herbs, with tufted fibrous roots, large many-nerved plaited leaves, sheathing at the base, and solitary or few large and showy flowers.

* Stem leafy, 1 to 3-flowered. Flowers yellow and white.

\section{C. Pubescens, Willd. Large Yellow Lady's Slipper.}

Stem leafy; sepals and linear wary-twisted petals longer than the lip, pointed; lip flattened laterally, very convex and gibbous above; sterile stamen triangular.

Bogs and damp low woods, rare. May, June. Stem 2 feet high, pubescent. Tieaves large, pubescent, 3 to 6 inches long, ovate-lanceolate, plaited, acute. Flovoers 1 to 3, greenish-yellow, spotted with purplish-brown. Lip $11 / 2$ to 2 inches long, much infiated, pale yellow.

\section{C. Parviflorum, Salisb. Small Yellow Lady's Slipper.}

Leaves oval, pointed; sepals ovate or ovate-lanceolate; lip flattish above and bo low; sterile stamen triangwlar, acute.

Rich low woods. May, June. Stem 10 to 15 inches high. Leaves clasping the base, pubescent, 3 to 5 inches wide, strongly veined. Flowers yellowish, fragrant, the perianth more brown-purple than in C. pubescens. Lip bright yellow, $3 / 4$ to 1 inch long.

3. C. CANDIDUm, MuhI. White Lady's Stipper.

Leaves oblong-lanceolate, acute; sepals orate-lanceolato; lip flattish, Iaterally conver abovie; sterile stamen lanccolate.

Low grounds, rare. May. Stem 5 to 10 inches high, slightly pubezcent, 1-flowered. Petals and sepals greenish. Lip white, $3 / 4$ inch long.

* * Scape naked, 2-leaved at the base. Flonvers purplish.

\section{C. ACAULE, Ait. Common Lady's Stipper.}

Downey; scape leafless, 1-flowered; leaves 2, oblong, obtuse; sepals oblonglanceolate, pointed, nearly as long as the linear petals; lip drooping, obovoid, with a fissure in front; sterile stamen rhomboid, pointed. ( $\mathrm{C}$. humila, Salisb.)

Moist woods and sides of mountains, common. May, June. Scape 8 to 12 inches high, with a bract at the top. Leaves 5 to 7 inches long, 2 to 4 inches wide, plaited and downy. Flowers solitary, large purplish or pale pink. Lip nearly 2 inch long, veiny, purple or sometimes nearly white.

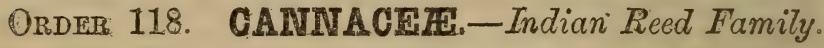

Tropical plants with the nerves of the leaves diverging from a midrib, the isregular perianth with 3 petaloid filaments, only one of which is fertile, with a. 1-celled anthor. IRUYT a 3-celled capsule. SEED round, not winged.

\section{CANNA, Linn. Indial Reed.}

The Hebrew name of the resd.

Periantr unequal, variable in the number of its parte, acarcely lip-shaped. Stamens petaloid, only one with half an anther on its edge. STYLE flat, straight, nearly free. Ovary 3-celled, with many ovules. FruIT membraneous, 3 3-celled, with a deciduous granular surface. SEEDs round, smooth. - An extensive genus of. herbaceous tropical plants. 
with erect stems bearing distant sheathing leaves and handsome flowers in spikes or racemes.

C. IndicA, L. Indian Shot. Indian Reed.

A beautiful plant often found in cultivation, native of the East Indies. Stemleaves 1 to 2 fuet long, and 3 to 6 inches wile. Flowers scarlet and yellow, borte in a spike.

\section{ORDER 119. AIFARYLIDACEב,-Amaryllis Family.}

Chiefly bulbous and scape bearing herbs, with linear flat root-leaves and regular 6-androus flowers, the tille of the 6-parted perianth colierent with the 5-celled wary. Astezng introrse. Stris single. Carsile 3-celled, loculicilal, many.siedid. SnEDS with fleshy albumen.

\section{AMARYLlis, Linn. Amarylits.}

A poctical name.

Periante with 6 petal-like similar divisions. StaMENS 6, inserted in the throat of the perianth: ANTuERS rersatile. CaPsule membranaccous, 3-lobed.-A splendid. genus, with the long linear leaves and scape from a coated bulb, and the showy flowers issuing from a 1 to 2-leuved sputhe.

A. Atamasco, L. Atamisco Lity.

Spathe tubular, 2-cleft, 1-flowered; periunth funnel-form; stamens and style declined.

Sharly woods, rare. June. Leaves a fiot long. linear, concare, smoth. Flower's solitary, white and pink, 3 izekes long, un is sckipe 6 inclies bigh.

A. F тrмozissims, L. Jucobea Lily. A beautiful flower from Mexico, sometimes cultirated. Flower dark red, on a scape 6 to 10 inches high.-

\section{AGaVE, Linn. American Aloz.}

Gr. agavos, wonderful, in allusion to A. Americana, the Ointury-plant.

Perianti tubular-funnel-form, persistent, 6-parted; the divisions narrow, nearly equal. STAMENs 6 , soon exserted : anthers linear. Capsule coriaceous. 3-celled, manyseeded. SeEps flattened.-A splendid American genus, with mostly thick and fleshy radical leaves, often spiny or cartilagi nous teeth, and a large many flowered pyramidal panicle on a scape.

A. Virginica, L. False Alve.

Stemless, herbaceous; leaves linear-lanceoiate, feshy, smocth, with cartilaginous serratures on the margin; scape simple, smooth; the flowers scattered in a locse spike, with leaflike scales.

Rocky banks, southern part of the State. Sept. Scape 3 to 6 feet high, round, loosely spicate above. Flowers greenish-yellow, very fragrant,

A. Azericana, L, American Aloe. Ceniury Plant. A splendid herbaceous plent P. 2 * 
from tropical America, is sometimes found in our conservatories. Leaves radicat;. 3 to 6 feet long, 4 to 12 inches wide, very thick, spinose-toothed. Scape rising to the height of 15 . to 25 fuet, beaxing a pyramicial paniclo of yellow flowers.

\section{HYPOXIS; Jinn: StaR-GRAss,}

Gr. hypos bencath, and oxus, sharp; on account of the pointed base of the fruits

Spathe 2-leaved. Perianth persistent, 6-parted, spreading, the 3 outer divisions somewhat herbaceous. Stamans: 6, with erect anthers. CAPSULIE crowned with the withered or closed perianth, not opening by ralves. Seens-roundish.Acaulescent small herbs, with grassy and hairy linear leaves, and yellow flowers on slender scapes from a solid bulb.

H. ERECTA, L. Star-grass.

Leaves linear, grass-like; scape umbellately 3 to 4-fluwered, mostly shorter than: the leaves.

Meadows and open woods, common. July. Scape 4 to 6 inches high. Isaves alt: radical, 6 to 12 inches long, $1 / 4$ inch wide. Flowers usually 4 , yollow withingereos. beh without.

CULTTVATED EXOTIOS.

\section{GALAMLHUS, Linn. SNOW:DROP:}

Or. gala, milk, anthos, flower; on account of the whiteness of the flowers?

Frowers spathaceous. SERALS 3, conoave; carona formed of 3 small emarginate petal-like segment ; stigma simple.An ornamented bulbonts exotic, sending: up in early spring scape with a single white flower.

G. NTVALIS, I. Sinow-drop:

Leaves linear, radical, kecled, acute; scape 1-flowered. Kative of the Aipe; fow orlng in early wpring. Scape 3 to 6 inches high, arising from a perennial bulbs boaring a bingle, large nodding flower as whito as enow, issuing from a spathe: Grown (petals) atriato with seen.

\section{NARCISSUS, Linn. DAFFodIt. JonquIT.}

Ar. navine, stupor; from the effects produced by the emell of some specics.

Periantir regular, 6-parted. Crow. monophyllous bell-form, salver-form, or with the tube funnel-form. STAMens 6, short: STyLe longer than the stamens: stigma: 3-parted.-Showy bulbous eaotios, with linear or ensiform leaves, and yellow straw-color or white fowers, issuing from a withering compressed spathe, opening on one side.

1. N. Jonquilia, L. Jonguil.

Leaves linear; scape 1 to 3 -tlowered; segments of the perisnth spreading, ellipti. cal or spatulate, acute; cup (corana) bell-6haped, crouate. Nativo of Spaia. A pril, .. 
15ay. Scape 9 to 12 iaches high, roundish, slender; besing a few fragrant flowers, of a rich chlorine yellow, $1 \frac{1}{2}$ to 2 inches in diameter. Cup $1 / 2$ inchilong. Leawes 8 to 10 inches long, with the edges somerhat rolled.

2. N. ecetrcus, L. Poet's Narcissus.

Scape 1-flowered; segments of the perianth, imbricate at baso, 8omewhat reflezed, nearly round; crown short; flat, rotate, crenulate; 3 anthers shorter than the tube. Native of South Europe. June. Scape about 1 foot high, bearing a single whits Lower, $11 / 2$ to 2 inches indiameter; the cup or crown singularty alorned with eireles of crimson, white and yellow.

\section{N. Pseuda-Narcissus, L. Daffodit:}

Scape 2 edged, straighit, striated; segments of the perianth ovatg or spatuisio -vate, sulpher-yellow; crown very long, with.a crenate-serrate orifice. Native of Fingland: A pril, May. Leavs linesr, 9 to 12 inchos long, striate, veined. Scaps 9 to 12 inches high, bearing at the top a single large flower, about 2 inches in dismoter, commonly doubled by cultivation. Cup $11 / 3$ to 2 inches long, orangezellow.

4. I. sulphureus, L. Sulpher-colored Daffodit.

scape 2-edged; leaves linear, flat; spathe 1-fiowered; segments of the perianth elliptic-spatulate; crown somewhat bell-form, crenate. May, June. Flowers atraw-colored, 2 inches in diameter, on a seape 1 foot high. Crown 1/3 lnch lons arange-yellow. Style long.

\section{LEUCOJUM, Linn. SWow-Fiakr.}

Perianish regular, 6iparted : seaments equal, spresding \$tamens 6, equal: Antuers long. Strots olavate, longer. than the stamens. - Exotic bulbous plants, with ensiform leaves and often numerous white flowers issuing: from a terminal spathe.

L. Astivum, L. Summer Snov-F゙lakie.

Ixaies long, ensiform; spathe many-fowered, long; ditirions of the perianthe regular, oval. June. A pretty border tower; native of Austria. Scape 1 to 2 feot high. Leaves 1 to 2 feet long, $1 / 2$ inch wide. Sputhe 2 to 3 inches long, with 3 . to 10 flowers, on peduncles at last $1 \frac{1}{2}$ to $2 \frac{1}{2}$ inches long. Flowers white; tho dh. risions tipped with green.

\section{ORDRE 120: FGEMODORACEE.-Bloodzort Family.}

IIrbceous plants, with flbrous perennial roots, equitint leaves and perfect 3 to 5 : androus regular flower's, which are usually more or less woolly outside; the tube of the 6-lobed perianth coherent with the whole sworfuce, or with merely the loner part, of the 3-celled ovary. STrus single, sometimes 3-partible. Capsuze crowned or inclocel by the persistent perianth, 3-celled, loculioidal, 3-many-secded.

\section{ALETRIS; Linn. Star-Grasg.}

Gr. Aletris, a female slave who grinds corn, in allusion to the apparent mealincsa. of the flowers:

Periantin cylindrical, tubular-bell-shaped; rough-wrinkied 
on the outside, 6-cleft at the summit. Stamens 6, inserted at the base of the lobes, included. STrue awl-shaped, 3cleft at the apex. CAPSULE ovate, inclosed in the roughened perianth, 3-celled, many-seeded, opening at the summit.Perennial and smooth stemless herbs, with very little fibrous roots, spreading clusters of thin flat lanceolate ?eaves, and small white or yellowish flowers, in a slender. spilced raceme.

\section{A. Farinosa, L. Star-grass. Colic Root.}

Ieaves lanceolate, acuminate, smooth ; flowers pedicellate, oblong-tubular; lotes lance-oblong.

Grassy Eandy or gravelly wcods, not common. July, Aug. Scape 2 feet high, with several minute bract-like leares. Flowers white, appearing as if eorered with a rough powder.

\section{ORDER 121. IRIDACE巴,-Iris Family.}

Herbs with equitant 2-rani ed leaves, and regular or irregular perfect flowers, the tule of the 6-cleft petal-lilie periunth coherent with the 3-celled ovary, and 3 distinct or monodclphous stamens with extrcrse anthers. FLowers from a 2-leared epathe, usually showy and ephemeral. Strues single: stigmas 3. Capscus 3-celled, lcculicidal, many-seeded.

\section{IRIS, Linn. Flower-de-Ltce.}

Gr. Iris, the rainbow deified; on account of the bright and various color of the blossoms.

Perianth 6-cleft, the 3 outer divisions spreading or reflexed, the 3 inner smaller and erect. Stamers distinct, placed before the outer divisions of the perianth, and under the 3 petal-like stigmas. Capsule 3 to 6 -angled. Seevs flat.-Perennials, with sword-shaped or grassy leaves and large blue, white and yellow flowers.

1. I. versicolor, L. Blue Flag.

Stem stout angled on one side, more or less flexuous; leares sword-shaped; perianth beardless; cvary obtusely triangular with the sides flat; capsule oblozg, turgid, with rounded angles.

Wet places, common. May, June. Stem 2 to 3 feet high, rarely branched, frcm a large fleshy creeping root. Leaves $3 / 4$ inch wide. Flowers 2 to 6 at the summit of the stem, blue, variegated with green, yellow and white at the base.

\section{I. Virginica, L. Slender Blue Flag.}

Siem slender, round, smooth; leaves narrowly linear; perianth beardless; ovary 3-sided, each side decply 2-grooved; cupsule triangular, acute at both eads.

Wet meadows, rare. June. Root tuberous, creeping. Stem 1 to 2 feet bigh, somewhat flexuous, round. Flowers 3 to 6 at the summit of the stem, blue and yeliow, more delicate than in the preceeding.

\section{I. cristata, Ait. Crested Iris.}

scape mostly 1-fowered, as long as the leares; perianth bearded, the beard crested 
Mountains, southern part of the State. April, May. Scape 10 to 15 inches high, boaring a solitary flowar. F'lowers blue and yellow.

\section{EULTITATED EXOTIC SPZOIES.}

\section{I. pumira, I. Dwarf Iris.}

Scape short, 1-flowered; spathe shorter than the tube; reflexed sepals narrower than the erect petals. April, May. Native of Hungary. A handsome dwarf species, eultivated in the edgings of walks Lcaves numerous, 4 to 6 inches long, broad-sword-shaped, suberect. Flowers large, deep purple, bearded on a rery short scape.

5. I. OCHROLEUCA, L. Yellow Iris.

Beardless; leaves enciform, depressed, striate; scape suib-terete, many-flowered; ovary nearly round, somewhat 6-angled. July. Native of the Levant. Stem 2 to 4 feet high. Leaves $1 \frac{1}{2}$ to 2 feet long. Flowers yellow or sulphur-colored. Capmole 2 inches long, round:

6. I. Germanicd, L. Flower-de-Luce. Fleur-de-Lis.

Siem many-flowered; leaves long-ensiform; aepals reflexed, bearded; petals emarginate, bent in wards at the point. Native of Germany, common in gardens. June Stem 2 to 3 feet high. Lcaves numerous, $1 \frac{1}{2}$ to 2 feet long, $3 / 4$ to 1 inch wilio Flowers 3 to 4 inehes in diameter, purple. Sepals with a beautiful yellow and white beard.

7. I. xipHun, L. Bulbous Fris. Spanish Flag.

Root bulbous; leaves linear, etrongly channelled, the margins confluent torarce the apex; scape few-flowercd. June, July. Tatire of Spain. Leaves 6 to 10 inches high, thick and fleshy, $1 / 4$ inch in diameter, white on the urper or hollow silbe, round towards the point. Flliwsrs rery showy, blue yellow and white, tho outer perianth lobes short, on a scape to to 12 inches bigh.

\section{SistrinchiUM, Linn. Blue-eyed Grass.}

Gr. sus, a hog, and regcios, a snout; from a fancy that hogs are fond of rooting it ap.

Pertanth 6-parted; the divisions equal, spreading. StaMENS 3 , monodelphous. STYLE short: stigMas 3, involute, fliform. Capsule globular-3-angled. SEzDs globular.Low slender perennials, with fibrous roots, grassy or lanceobate leaves, and small mostly blue flowers in umbelled clusters from a 2-leaved spathe.

\section{S. Bermudiana, L. Common Blue.eyed Grass.}

Seaps winged, naked or 1 to 2-leaved; lecives narrow and grass-like; spathe um. Eellately few-flowered; divisions of the perianth obovate, more or less notched at the end, and bristle-pointed from the notch,-Var. $\triangle$ XCEPS (S. anceps, Cur.) has a broadly winged seape, and the outer leaf of the very unequal spathes longer than the Iowers - Var. 2. MUCRoRATUM (S. mucronatum, Michx.) has a slender and narrowly winged scape, very narrow leaves, those of the spathe acute, unequal, one of them usually longer than the flowers.

Moist mesdows, common among grass. Juno-Aug. Seape 6 to 10 incles-Eigh. 
Flowers small, delicate, blue, changing to purplish, 4 to 6 opening in succession. Spathe often purplish. There are various intermediate forms.

\section{CULTTRATED E. SOTFCS.}

\section{Pardanthus, Linn. Blackberry Lity.}

Gr. pardalis, a panther, and anthos, flower; the flowersare spotted like the panther. Spathe oî 2 or 3 ovate short bracts. Perianth regular, 6-parted; the divisions equal. Stamens 3, with threadlike filaments. STIGMA straight or ineurved, fixed by the base, subfiliform.-An ornamental garden plant, with yellowish and reddish spotted flowers.

\section{P. Chinansis, I. Blackberry Lily.}

Stem round, flexuous, leufy; leaves ensiform, pentieal, sheathing; panicle somowhat dichotomous and corymbose; perianth flet, spreading; segments lance-linear. July, Aug. Native of South Africa. Common in cultivation. Stem 2 to 3 feet high. Leaves tapering to in acute point. Flowers yellow, spetted with red, 1 to: $11 / 2$ inch in diameter. Fruit composed of numerous black glossy seeds attached zound the rachis, resembling a blackberry.

\section{CROCUS, Linn. Safrron. Crocus.}

Named from the youth Cnccus, who, according to Greaian mithology, was changed into this tlower:

Periantu funnel-form, the segments united at base into. a slender tube. Stamens 3. Strigma 3-cleft, convolute, crested.-Bullous plants, with a radicul 1 to 2-leaved thin transparent spathe, the long tube of the flowers ncarly or quite sessils upon the bulb.

1. C. Sativa, L. Saffron Crocus:

Leaves linear, revolute on the margins; stigma 3-parted, as long as the corolla; reflexed. Sept. From Asia. Leaves radical, with a longitudinal white furrow abore. Flower nearly sessile on the buib, with a long white tube, and purple elliptical segments. itigmas long; cmangiate, exsert of a deep orange color. The stignias compose the safrou of the shops so much used for medicinal and coloring purposes. There is a variety with yellow perianths.

\section{C. VRrnus, I. Spring Saffion:}

Leaces short, linear; stigmas included within the flower, with 3 short wedgeshaped segments. Native of the Alps. Scane 1 to 2 inches high, 3-sided. Flowers mostly purple, often yellow, pale blue or whitc, very variable; tube very slender, gradtially enlarged upwardz, closed at the mouth with a circle of hairs; limb bell: haped, shorter than the tube. Anthers yellow, sagittate. Mareh, April.

\section{TIGRIDIA, Linn. TIGer Flower.}

Name in reference to the large spotted flowers.

Spatue 2-leaved, carinate, 1-flowered. Periantix 6- 
parted, with oblong segments, upright-spreading; the alternate ones the broadest. STAMENs 3, monodelphous: FILAMENTS united into a long tube: ANTHERS subovate, double. STrye fliform, the length of the tube. CAPSUle oblong, 3 -sided: sEEDS numerous, roundish, covered with a pulp.Showy South American bulbotis plants, with large, vory evanescent yellow and red spotied flowers.

\section{T. Pavonia, L. Tiger Flower.}

Siein simple, flexuous; leaves sword-shaped, veined; segments fiat; petals panduriform. July-Sept. A superb plant, natire of 3 irexico and Peru. Stem 2 to $21 / 2$ rect kigh, ercet, round, leafy, somewhat branched. Leaves erect, 8 to 12 inclsea long, smooth. Flowers 5 to 6 inches broad, yellow, variegated with scarlet, criznson and purple, very eranescent, lasting but a few hours, but a netf one appears duily for several weets.

\section{ORDER 122. DIOSCORFACER, - Yam Family.}

Twining hevis or understirubs, from large tuberous roots or knotied roctstocks, ribied und neited-veined leaves on peticles and small diocious 6-androxs and regu'ar forwers in spilies. Ovari adherent, 3-celled. Struss 3, united balow or distinct Iruix usually a membranaceous 3-angled or wiaged capsule.

\section{DIOSCOREA, Plumier. YAM.}

In honor of the celebrated Gveels naturalist, Disoscoridtes.

Frowers very small, dicocious. STamens 6 at the base of the divisions of the 6-parted porianth : FILAHENTs subulate. Struse distinct nearly to the base. Capsule 3celled, triangular, 3 -winged. Seens 1 or 2 in each cell, Alt, with a membranaceous wing.-Climbing perennials, with alternate of fen heart shaped leares, and inconspicuous greenish fiw. ers in axillary branched racemes or spikes.

\section{D. villosa, L. Wild Yam-root.}

Herbaceous; leaves mostiy alterrate, eometimes ncarly oprofite or in fora, more or les: heart-siaped, frointea, 7 to 11 ribbed.-Var. QUarasaTA, (D. quaternats, Wilt.) has the leaves more acu micate and 7 -nerved, the isteral nerves 2-partch.

Thinkets and old telds, common. July. A s'ender vine twining over burhes, sometim:s 10 or 12 feet lonx. Finwers minute, greenish yellow, the sterile in pob du ous panicies; the ferlile in pelululous simple racemes.

\section{ORDER 123. STILACDIS. - Smilax Famity.}

Tlerbs or shrubs, ofter chmbing, with ribled and conepicsous netkd reiny inoves, regular o-cindrous fiowore whth the 6 parted perianth free from the 3 -xilled oxary.-

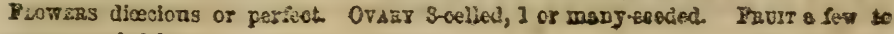
zany-reeded berry. 


\section{SMILAX, Tourn. Greenbrier.}

An ancient Greek name of obscure meaning.

Diøcious or polygamous. Perianth of 6 equal spreading segments, deciduous. Stamens mostly 6 , inserted at the base of the perianth segments: FrLAMENTs short. Stigmas 3, thick, on a very short style. BERRY globular, 1 to 3-celled, 1 to 3-seeded. SEEDS globose, suspended, orthotropous. - Shrubs, or rarely perennial herbs, often evergreen and prickly, climbing by tendrils on the petioles, with greenish tems, cordate or ovate leaves, and small flowers in axillary peduncled umbels.

Sir. I. SMmax proper.-Stems woody, often prickly; covules solitary.

- Leaves broad, thieTish, often persistent.

1. S. Rotundifolia, L. Common Greentrier.

Stem nearly round; branchlets more or less 4-angular; leaves round-ovate, ofler roader than long, slightly cordate, abruptly short-pointed, 5-nerved; peduncles c.arcely longer than the petioles.

Moist thickets, common. June. Stems armed with stout scattered prickles, often climbing 20 to 30 feet. Flowers yellowish-green in small globose axillary umbels. Berries bluish-black.

2. S. QUADRANGULARIs, Willd. Square-stemmed Greenbrier.

Branches and branchlets square, armed with stout scattered prickles; leaves ovate or ovate-lanceolate, acuminate, cordate at base, 3 to 5-norved; peduncles about the length of the petioles.

Dry woods. J une, July. Leaves about 3 inches long, $1 / 2$ as wide, thinnish, sometimes minutely rough-ciliate on the margin. Flowers greenish-yellow. Barries black.

* Leaves, broad, thin, entirely deciduous; pricicles bristle-liki.

3. S. Hisprid, Mahl. Hispid Greenbrier.

Siem round, the lower part very hispid; leaves ovate, mostly heart-shapod, point ed, strongly 5-nerved; peduncles 6 to 10 -fiowered, 2 or 3 times the length of the petioles.

Moist thickets. Jưne. Stem elimbing high, densely beset below with shining brown weak and slender prickles; the flowering branches often naked. Laaves 8 to 5 inches long, minutely rough on the margins, bright green on both sidos. Pr duncles $1 \frac{1}{2}$ to 2 inches long.

SEc. II. Coprosmaxteus, Torr.-Stom herbaceous, not prickly. Leares longs petioled, thin.

\section{S. herbacea, L. Carrion-Flower.}

Stem erect and recurving, or climbing; leaves ovate-oblong or rounded, mostly heart-shaped, 7 to $9-n e r v e d$, mucronate or pointed, smooth; tendrils sometimes none; peduncles very long, compressed.

Moist meadows and river-banks, common. June. Stem 3 to 6 feet long, climbing or leaning on other plants. Leaves very variable, on petioles 1 to 3 inchos long. Flowers numerous, on peduncles 3 to 6 inches lopg, yellowish-green in globose axillary umbels of about an inch in diameter, exhaling the stench of carrion. 


\section{ORDER 124. TRILLIACER,-Trillium Family.}

Herbaceous plants, with simple stems, verticillate, net-veined leaves, and large termimal mostly solitary trimerous flowers. Periaxtr 6-parted. Stayiens 6 to 10. OVAax free, 3 to 5-celled, with as many styles. FBurt succulent, 3 to 5-cellod. Sasps מumerous.

\section{TRILIJUM, Linn. TrILLIUM.}

Lat. trilex, triple; all the parts being in threes.

Flowers perfect. Sepals 3, lanceolate, spreading, herbaceous, persistent. Pertals 3, larger. Stamens 6, with linear adnate anthers, on short filaments. STYLES 3, awl-shaped, distinct or united at base, stigmatic down the inner side. BERRY 3-sided, ovate, 3-celled. SEeds horizontal, several in each cell.-Low perennial herbs, with a stout simple stein rising from a short and abrupt tuberous rooistock, bearing at the summit a whorl of 3 broadly ovate leaves, and a ter. minal large flower.

1. T. Cernoum, L. Nodding Trillium. Wale-Rolin.

Leaves broadly rhomboid, pointed, nearly sessile; petals white, oblong-ovate, pointed, recurved, somewhat wavy.

Moist woods. Miay, Janc. Stem slenter 10 to 15 inches high. Leaves 3 to 5 inches in diameter, nearly round. Flnwer white, pendulous beneath the leaves, con a peluncle 1 to $2 \frac{1}{2}$ inches long. Sepals oblong-lanceolate, graon, 1 inch longe Petals $3 / 4$ to 1 inch long, $1 / 3$ to $1 / 2$ inch wide.

2. T. enectum, L. Purple Trillium. Birth-root.

Leares broaäly rhomboid, aluruptly acuminate; petals dark dull rarple, orate, comewhat pointed, flat, spreading.

Kich woods, common. May. Siem 12 to 15 inches high. Liaves 3-nerved, 3 to $\tau$ inches long. Flower on a peủncle 2 inches long, soon reclining. Retals 1 to 2 ! inch long, greenish autside. Ovary brown-purple. Medicinal.

3. T. GRANDIFLORUM, Salisb. Large-flowered Trillium.

Leaves obovate-rhomboid, pointed, barely sessile; pitals obovate, spreading from an eroct base, longer and much broadcr than the sepals, white, changing to rose color.

Rich woods, rare. June. Slem 10 to 12 inches hlgh. Flower on a slightly ikelined peduncle, which is 2 or 3 inches loug. Petuls 2 to $2 \frac{1}{2}$ inches long, broadest near the apex.

4. T. erythrocarpum, Michx. Painted Tritlium.

Leaves ovate, acuminate, rourded at the base, short petioled; petals ovate or oral-lanceolate, pointed, wavy, wideiy spreading, nearly twice as long as the sepals bhorter than the peduncles.

Cold damp woods. Itray, June. Stem 8 to 12 inches hich. Ieaves long acuminate, 2 -nerved, 3 to 4 inches long, $2 / 3$ \% wide. Putals 1 inch long, white, paintud with purple lines at tho base. Medicinal.

5. T. sessir.e, L. Common Sessile Trillium,

Leares orate or oblong, sessilo or nearly so, acute; petals lapeeolate, erst, much longer than the sepals, dark dull purple. 
Rich woods, rare. April, May. Stem 6 to 8 inches high, smooth. Leares rather thick, $1 \frac{1}{2}$ to $2 \frac{1}{2}$ inches long, 1 to 2 inches wide, smooth and entire. Sepals grean, $3 / 4$ inch long. Petals narrow, 1 inch long.

\section{T. NIVAle, Riddell. Snowy Trillium.}

Small; leares oval or ovate, obtuse; pst ils oval-Innceolate, obtuso somewhat wary, white, as long as the peduncle, longer than the sepals.

Rich shady woods, rare. April. Stem 2 to 4 inches high, from a thick tubarous root. Leaves 1 to 2 inches long, by $1 / 2$ to 1 inch wide. Sepals green, much narrowar than the pitals. Petals $3 / 4$ to 1 inch 1ong. Styles loug and fiiform.

\section{MEDEOLA, Gronov. Indian Cucumber-root.}

Named after the sorcoress Media, from its supposed medicinal virtues.

Penrantil revolute, of 3 sepals and 3 petals. Stamens 6 , inserted at the base of the perianth: FILAMENTs threadlike, longer than the linear-oblong anthers. STrLes 3, filiform, recurved-diverging, deciduous. BERRY spherical, 3colled, few-seeded.-A perennial herb, with a simple slencler stem rising from a horizmtal and tuberous white roolstock, bearing a whorl of 5 to 10 sessile leaves ncar the midale and another of 3 smaller ones at the top, subtending a sessile umbel of small recurved flowers.

\section{BI. Virainica, L. Cucumber Root.}

I.eaves of the lower whorl obovate-lanceolate, pointed; upper ches orate.

Rich damp woods, common. June. Stem 1 to 2 feet high, erect. Flcwers 3 to e, greenish-yellow, reflexed, with long dark red refiexed stigmas.

\section{ORDER 125. CIEHAER-Lity Family.}

Heris, with parallel-nerved sessile or shcathing leaves, regular perfert 6-(rarcly 1)androws flowers with a petal-lilic 6-merous periasih free from the 2 to 3 -celled ovary.STAmeNs 6 inserted into the perianth; AxTHLRS attached by a point. STYLe single;

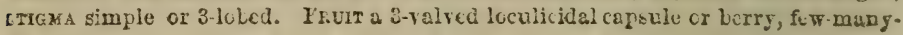
ceeded.

\section{Tribe 1. ASPARAGE瓜. Tine Asparagus Tribe.}

Truit a few-sceded berry, 2 to 3-celled. Rootstocks creeping or tuberous.

\section{ASPARAGUS, Linn.}

The ancient Greek name.

Perianth 6-parted, spreading abore. Stamens 6, with peltate anthers. Style short: stigma 3-lobed. Berry spherical, 3-celled; cells 2-sceded.-Perennials, with muchbranchsd stems from thick and matted rootstocks, narrow leaves in clusters, and small greenish-yellow axillary flowers. 


\section{A. offictanalis, I. Garden Asparagus.}

Siem herbaceous, erect, rounded, mush branched; lecives thread-like, fasciculato and flexible; peduncles jointed in the midlle.

Cultivated in gardens, and naturalized. June. Stem 1 to 3 feet hirlis. Flowers small, solitary, drooping. Berry globose, red.

\section{POLYGONATUM, Tourn. Solomon's SEal.}

ar. poius, many, and gonu, knee, alluding to the many jointed steme and rhizoma.

Periantu tubular, 6-lobed at the summit. STAmens 6, inserted on or above the middle of the parianth-tube, included. Ovary 3-celled: STYLE slonder: STIGMA capitato or triangular. BenRy globular, blue or black, the cells 1 to 2-seeded.-Perennial herbs, with simple erect or curving stenss from thick and knotted crecping rootstoctss, mostly alternate and scssile or half clasping nerved leaves, and axillury nodding grcen. ish flowers.

1. P. Canaliculatum, Pursh. Gieat Solomon's Seat.

Stem stout, ang?ed or channclled; leaves oblong-orate, obtusely pointed, parlly elasping, smonth, nearly equally many-nerrel; pcduncies 2 to 6 -1lorrered, smooth; flamsints smootl, shorter than the anthers, inser ted cu the puiddle of the perianthtube. (Convallaria eanaliculatram, Mutc.)

Rich sandy river banks, eommon. June. Stem 3 to 5 feethigh, curred. Leares green on both sides. Perianth eylindrical-oblong, greenish-white.

\section{P. Pubescens, Pursh. Smaller Sulomon's Seal.}

Stem round, or slightly gromed on one side; leaves ofate-oblong or ellipticallanceslate, minutely dow ay alaucous underneath, with 3 to 5 principal nerves, sersile; peduncles 1 to 2 -ilowered, smooth; filaments minutely glandular puberulent, inserted near the summit of the perianth. (Cenvallaria pubescens, MuTel.)

Wonds and rocky banks, common. May, June. Stern 1 to 2 feet high, slightly eurved. I'rianth $1 / 2$ insh long, cglindrical-oblongy greenish. Ovules often 6 in each cell.

\section{SMILACINA, Desf. False Solonon's Seal.}

Name a diminutive of Smilax, to which this genue, however, has little resemblance,

Periantir 4 to 6-parted, spreading deciduous. Stamens 4 to 6 , inserted at the perianth-lobes: HILALENTS slender: anthers short. Ovary 2 to 3-celled. Styles short and thick: STIGMA obscurely 2 to 3-lobod. Berry globular, 1 and 2-seeded.-Perennial herbs, with simple stems from ereeping or thiclish rootstocks, allernate nerved leaves, and white oflen fragrant flowers in a terminal simple or compound raceme.

SzC I. Smrucna, Desf.-Divisions of the perianth and stimens 6.

1. S. Racemosa, Desf. False Spikenard.

Minutely downy; stem somewhat flexuous; leaves numerous, oblong or orallanceolate, acuminate, ciliate, abruptly short-petioled; racene compound, panicled; axury 3ecllod. 
Moist roods. May, June. Stem zigzag, 2 feet high from a thick and fleshy rootetock. Leaves 4 to 6 inches long, about $1 / 3$ as wide, contracted into a long acumination. Flowers very numerous, small, white, on white pedicels, with white exserted filaments. Berries pale red, speckled with purple, aromatic.

\section{S: stellata, Desf. Star-flowered Solomon's Seal.}

Smooth or nearly so; leaves 7 to 11 , oblong-lanceolate, acute, minutely ciliate; slightly clasping, thickish; raceme simple, few-flowered; ovary 2-celled.

Moist banks. May, June. Stem about 12 inches high, round. Leaves smooth, glaucous beneath, 4 to 6 inches long, $3 / 4$ to 1 inch wide, tapering to the apex. Flow. ers about 8, white, steilate. Berries blackish.

\section{S. trifolia, Desf. Three-leaved Solomon's Seal.}

Smooth, dwarf; leaves 3 , sometimes 2 cr 4, oblong or oval-lanceolate, short-pointed; narrowed into a sheathing base; raceme simple, ovary 2 to 3-celled.

Swamps. May, June. Stem 3 to 6 inches high. Leaves smooth on the margin about 2 inches long, $1 / 3$ as wide. Faceme terminal, erect, consisting of 4 to 6 white Howers. Perianth-lobes spreading. Anthers brownist. Berries red.

SEc. Ir. Marantamum, Desf. Divisions of the perianch and stamens 4.

\section{S. BIfolia, Ker.- Two-leaved Solomon's Seal.}

Smooth or nearly so; stems low, mostly 2-leavod; leaves.heart-shaped, petioled.cs aessile; raceme simple, crowded.

Shady, moist woods, common. May. Stem 3 to 5 inches high, with 2 or somo. times 3 leaves near the summit, and often a larger radical leaf on a long petiolo. Fllowers white, small, fragrant, in an oblong raceme, one inch long. Berries reasdish, speckled.

\section{CLINTONIA, Raf.}

\section{Dedicated to De Witt Clinton.}

Perianti 6-parted, bell-shaped, lily-like, deciduous. Stamens 6, inserted at the base of the segments: FiLAIMENTS long and threadike : ANTHERs finear-oblong. OVARY oroid-oblong, 2-celled ; STYLE long, compressed : sTIGMA depressed. Berry ovoid, blue, few to many-seeded.-Acau lescent perennials, with slender creeping rootstocks, sending up a naked scape, shitathed at the base by 2 to 4 large oblong or oval ciliate leaves, and bearing rather large, umbelled or rarely single, whilc or greenish flowers at the summit.

\section{C. Boreatis, Raf. Northern Clintonia.}

Umbel 2 to 7 -flowered; ovary with 10 to 12 ovules in each cell. (Dracrens borealis, Ait.)

Cold moist mountain:wonda. June: Seape 6 to 8 inches high. Leaves radical, 5 to 8 inches long. Perianth $1 / 2$ to $3 / 2$ inch long, greenish-yellow. Berry blue.

\section{C. umbellata, Torr. Small-finwered Clintonia.}

Unabel. 12 to 30 -flowered; cells of the berry 2-seeded. (Convallaria umbellata; Michx.)

Rich woods, through the Alleghenies. June. Scape many-flowered, 9 to 12 incher. high. Leaves 2 to 5, 6 to 9 inches long. Flovar's 15 to $3 \mathrm{C}$, white, speckled withe gurple $1 / 4$ to $1 / 2$ inch long, odorovg. 


\section{CONVALLARIA, Linn. Lim of the VALLeY.}

Iat: convallis, a valley, the locality of some specice.

- Pertanti bell-shaped, 6 parted. Stamens 6, divergent, arising from the base of the segmont. BERRY giobose, 2 : celled-An eleyant sweet-scented perennial herb, often cultivated in gardens with mostly 2 radical ovate leaves, and a slender soxpe bearing white flowers in a single rant.

\section{C. majalis, L. Lity of the Valloy.}

Scape nak d, smooth, semi cyliadric; leaves nearly radical, orate; reeme simple, one-sided.

Alegheny mantains, common in eultiration. May. Scape 6 inches high: Zerores 4 to 7 inchos long, ovate-elliptical, pointou.

\section{Tribe 2. ASPHODELEß. The Asphodel Trme.}

Fruit a fow to many sented capsule, 3 celled, loculicidal. Seeds anatropous or amphitruyqus.

Szc. r. Not bủbour.

\section{HeMOrOCALLIS, Lina. Day LiLy.}

Gr. kemera, a day, and kallos, beautiful; its flowers lasting but a day.

T'ERIANTI funnel-form, lily-like, the short tube enclosing: the ovary, the spreading limb 6-parted. STAMens 6, insert ed on the throat of the perianth: FILAMENTs long and thread-like, declined: strima simple. Capsule rather Aleshy, 3-angled, 3-ralved, with several hlack round sects in anch cell.- Sthouy perenniul exotics, with fieshy fibrous roots, radical linear, keelen 2:rantied leaves and yeillow or reddisit fowers, (which collapse and decay after expanding for a single day) Zorne on tall scopes.

\section{H. Fulva, L. Common Day Lity.}

Thera divisions of the perianth wary and obtuec, the reins branched.

Damp crounds, escaped from cultiration and naturalized. July. Leares numerous, aluout 2 fect long, and an inch wi le, smooth, acute. Flozers large, tawny. orange or ruduish. Scupe round, thick, smooth, 3 feet higb. Style striate.

2. II. Flava, J. Yellozo Day Lily.

Dirisions of the perianth flat, the reins undiridud. Natire of South Europe. Julg. Leaves 1 to 2 feet lon, $1 / 2$ inch wide, heel + . Sipe 2 feet high, branuhing. Flovers large, yellow, stret seented. Cuit rated.

\section{H. Graminea, L. Grass-leaved Day Lily.}

Icaves grass-like, linenr, keeled; 3 inner perianth lobes larger, waved, the outer emaller. Natire of South Europs. July. Lcaves 6 to 18 inches long, narrome and much Emaller than in either of the preceding species. Scape 9 to 12 inches high, 3 to 6-flowered. Perianth orange-jellow on the inside, reddis on the outsidy. Rare in Cultiration. 


\section{FUNKIA, Gært. JAPAN DAY LILIES.}

Perianti funnel-bell-shaped, 6-parted. Stamens 6. Filaments long, deelined, the upper ones the shortest: ANTHERS oblong, fixed by their sides, turned up at the ends: STYLe long, deolined, superior, furrowed : stigka obtusely 3-angled. CAPSUle 3-sided, 3-celled, 3-valved. Seens rery numerous, flat.-Ornamental perennial herbs, from $f_{a} a$ pan, with somewhat heart-shaped long=petioled leaves, and white or Uluish flowers on bracted scapes.

1. F. ALBA, Grort. White Day Lily.

Zeaves cordate, orate, acuminate; perianth funnel-form; with a long tabe: kug., Sept. Scape 1 to 2 feet high. Leaves smooth, on long radical petioles 3 to s inchos wile. Elowers large, white, very fragrant, 3 to 4 inches long, somewbit orowded, each axillary to a large bract. Anthers yellow.

2. F. canulia, Gært. Blue Day Lily.

Leaves heart shaped, on petioles; perianth tubular-bell-shaped, swelled. July; Aug. Scape 2 to 3 feet high. Bracts yellowish. Flowers bluish-purple, 2 to 3 inches long, the slender tube enclozing the overy; border inflated, round-bell. shaped. Anthers bluo.

3. F: Japonima, Giort. Jupan Day Lity.

Leaves lanceolate or orate-lanceolate; perianth funnel-form, with sorewhat reflexed segments. July, Sept. Leaves 3 to 4 inches long, narrowed into a petiolo of 4 to 5 inches in length. Scape slender, 12 to 19 inches high. Flawers mucist smaller than in the preceding species, pale-purple, 1 to 2 inches long.

\section{ASPHODELUS, Linn. King's Spear.}

Fr. as privative, sphallo, to surpass; a flower not surpassed in beauty.

PERIANTT 6-parted, spreading, with 6 valves, covering. the ovary. STAMENS 6; issuing from the valves, Capsulg. globular, many-seeded-Fine garden plants with showy. flowers.

1. A. nuteus; I. Kiag's Spear. Yellow A'sphodel.

Stem leafy; leaves linear 3-nerved. A showy garden perennial from Sicily, of the easiest culture and rapid increase. June. Stcm 2 to 3 feet high, thickly inrosted with the long linear hollow tapering striped leaves. Flowers yellow, in 2. very long spikio.

2.- A. Ramosus, L. Branching Aephodel.

Stem naked, branched; leaves casiform, boeled, smooth; pcduncie as long as tho bract. Native of Jouth Europe. June. Not so.tall as the preceding, but with. longer white florrers

\footnotetext{
Brc. 1. Tullous:

9. ORNithoGalum, Tourn. Sithr-of-Bethlenem.
}

Gr. ornithos, a birt, and gale, mllix; wh so.called is not obvious.

Permantil deeply 6-parted, spreading abore the middle: 
the divisions several, nerved. Frinaments 6, flattened-awl. shaped. Strues 3 -sided : strama 3 -angled. Capsule roundish-sngular, with a fer roundish seeds in each cell.Perenniad herbs, with ridical leaves and a naked racemose or corymbed scape from a coated bulb.

\section{O. umbellatum, L. White Siar-of-Bethlehem.}

Towers corymbose, 5 to 8 on long epreading pedicels; spals green in the middio outside.

Moist meadows, naturallzed, common in gardens. Natire of England. June. Scape 5 to 8 inches high. Leaves linear and narro: vith a rbite line on the upper viảe. F lowers white, few in a loose corymb. I'o rianth-lobes beautifully marked with a longitudinal green stripe oa the outalis.

\section{0. alliUm, Linn. Orion. Garlic.}

The ancient Latin name of the Gar:?c.

Periarte of 6. entirely colored sepale, which are distinct or united at the rery base, 1-nerred, boconing dry and more or less persistent. Filaments awl-sbaped or dilatcd ab their base. Strle filiform: etrgan simple. Careuta lobed, 3-celled, 3-valved, with a fow black and rough ocecis in each cell.- Strong-scented and pungent acculezcent herbes with the mostly radical leaves and the scape from a cuatal butb, the fowers in a simple umlel, and a 1 to 2 -ralved spathe.

* tombel often densely buidilearing with or withont f.creers.

\section{T. A. vineale, L. Field Garlic.}

Seape slender, clothed with the :heathing tases of the learcs below the midale; beares round, bollow, s'ender, channellud abore; filancrts mack dilated, tho alternate one 3-cleft, the midd!e dirisious snther bearing.

Rinist meadows and lilds, naturaliz d and sume parte pery troublesome. June. Bulb ovioid, Emall. Leaves 6 to 12 inclies long. Earpe 1 to $21 / 2$ fert hizh, begring a spathe of 2 small bracts at the top, and an umbel of rese-culorod ard grcen flowers at the top with which bulbs are eoractimes intermixud.

2. A. Canadersis, Kalm. Wild Meadow Garlie.

Scape leafy only at the base ; lecives narrowly licear, lattish; umiel few forered; fisments simple, dilated below, about as long as the perianth.

Moist fields, common. May, Juve. Leates very long and narrow. Seape 12 to 15 inches bigh, round, smooth, bearing a spathe of 2 orate acute bribts at the top, with a head of bultz and formers. Flowers whitish or fale roso-color, on prediceles the bulbs are sessile, each furniched with a bract beneath.

* Unbeb bearing cnly flowcrs.

3. A. cernudu, Roth. Nodding Garlic. Wild Onion.

Sexpe naked, angular, clongated, often nodding at the apex, bearing a loose or drooping rany-fowered umbel; leavez linear, elongated, skarply kealed; sfrits vilong-ovate, acute, much shorter than the slender filasient: orary f-toothce at the summit, becoming a roundish 3-seeded espsule.

Banks and steep rocks, common. July. Scape 10 to 12 inches bigh, hesring a lause armbel of 20 to 20 eowers. Leares 8 to 12 inches long. Flowers whits of 
rose-color. The variety with white flowers grows abunlantly in steep rouky places along tho Susquehana. The plaut is very strong-seented.

4. A. TRICoccum, Ait. Fild Leel. Lance-leaved Giarlic:

Scape naked, bearing an erect many-flowered unifel; leaves lance-oblong or elliptical, flat; sepals obtuse, oblong; capsule strongly 3-iobed:

Rich shaded sandy woxds, rare. July. Bulbs clustered, pnintail, 2 inches long. Leares 5 to 10 inshes long, 1 to $1 \frac{1}{2}$ inch wid, acute, taperine into a petioje. appeaving in early spring and decaying b fore flowering. Sc zpe 12 to 15 inchis high, bearing a thin 2-leaved deciduous spathe at the top, with an umbel of 10 to $20^{\circ}$ white flowers.

\section{A. TRIFLoRum, Raf. Montain Leck.}

scape naked, terete, shorter than the leares; leaves lanceolite, nervol; umbel few-flowered. Parkh.

Mountains, rare. May; Jưne.

\section{CULTIYATED ETCTIC STECIES.}

\section{A. sativum, L. Commm Garlic:}

$B u l b$ compound; stm lenfy, batbifereus : stamens tricuspidate. Natire of $3 i c \cdot 1 y$. July. Slcm 3 feet high. Fiöters snall, white. Eulbs strong-scented and acria.

7. A. Schonotrasur, I. Chives. Cives.

Surpe as long as the round subulate leaves. Flowers small, rosoeclor. Juner. Common in garilens.

\section{A. Ponrum, L. Leel.}

Siem compressed, leafy; lecwes shathing at bage; stamens tricuspidate. Native of Switzerland. July. Roht hearing a sealy cylindrical bulb. Stem 2 feet high, Dearing long linear alternate sheathing learcs, and at the top a large umbl of: Bmall white flowers.

\section{A. Cepa, I. Common Onion.}

Scape fistulous, swelling towaris tle basc, Ionger than the terete fstulous teaves. Native of Inngary. Cnivereally cultivated for the listchen. Culture has produced numorous varieties:

\section{HYACINTHUS, Linn. Hyacrntir.}

\section{A favulous name.}

Periantir sub-globose or bell-shaped, regular 6-cleft. STAMrns 6, issuing from the midule of the segments. Ovary with 3 necteriferous pores at the summit. Capsures 3-celled, about 2-soeded.-Ornamental bulbous plants, natice of the Levant, with fragrant white, pink blue and purple flowers.

\section{II. orientalis, L. Common Hyacinth.}

Ferianth funncl-form, half 6 -cleft, swelled at the base. May. The hyacinth is a well known garden flower, long prized and cultivated. Leaves thick, linearlanceolate, 3 to 6 inches long. Scape 5 to 10 inches high, thick, bearing a dense sby reoid raceme of different ehedse of blwe, piuk, purple or white fragrant flowers. 


\section{POLYANTHOS, Linn. Tuberose.}

Gr. polus, many, anthos, flower; the plant bearing numerous flowers.

Pertantre funnel-form, incurved. Filaments inserted into the throat. Stigira 3-cleft. Ovary at the bottom of the perianth.-A leautiful bulbous exotic, with white fragrant flowers.

P. TUBEROSA, L. Tuberose.

Leaves linear-lanceolate; flowers alternate, in pairs; perianth-lobes oblong. Na tive of Ceylon. Aug., Sept. Scape scaly, 2 to 3 feet high, with white regular flarers of a delicious fragrance.

\section{Tribe 3. TUlipaCE A2. Tulip or true Lily Tribe:}

Fruit a many-seeded 3-celled loculicidal capsule. Seeds anatropous. Periants. G-leared.-Bulbous.

\section{LIIIUM, Linn. LILY.}

Tho classical Latin name.

Perianth funnel-form or bell-shaped, colored, of 6 distinct sepals, spreading or recurved above, with a necteriferoas furrow at the base, deciduous. STANENS 6, somertat adbering to the bases of the sepals: ANTHERs linear, Tersatile. STYLE elongated, somewhat flub-shaped : sTIGMA 3-lobcl. CAPsule oblong, ê-cellcd, containing numerous fat seeds densely packed in 2 rows in cach coll-Percnnial scaly iulbous herbs, with simple sitms, numercus alternate-scattered. or whorled short and sessile leaves and one to several large and showy flowers.

- Flowers erect, bell-shaped, tho eepats narrowed betow into claws.

\section{L. Philadelpmicum, L. Fild Orange Lity.}

Leaves linear-lanccolate, the upper chieny in whoris of 6 to 8 ; fiowers 1 to 3 or sometimes 5, open-bell-shaped, with lanceolste sepals.

Open $\pi 003 \mathrm{~s}$, hillsiles and fencerors, nct raze. Janc-Aug. Stem 2 to 3 faet high, round, smooth, simple. Leaves 2 ta 3 incles long, $1 / 4$ to $1 / 2$ inch vide, 1 to 3 nerved. Flowers lairge, redaich-orange, the inside si otted with purple near tho base, $2 \frac{1}{2}$ inches long, on a peduacle 1 to 3 inches long.

2. I. Catesbier, Walt. Wild Red Lity. Catesby's Lily.

teaves linear-lanceolate, scsttered; flowsrs solitary, open-bell-shaped, the longciawed sepals wavy on the margin, and recurred at the aumit, the margins of the elawg involute.

Low sandy soil, and meadowg, rare, Montour Co. Ju'y. Stem 12 to 18 inches high, bearing a single large termical scarlet flower, ppotted with dark purple and yellowish inside. Sepals orate or rhombic-orate, with the neld-rein green on the. outside. 
** Elowers nodding, beth-shapect, the sessile sepals revolute.

3. L. Canadinse, L. Wild Meadow Lity.

Lcaves remotely whorled, lanceolate, strongly 3-perved, the margins and nerves rough ; flowers mostly 3 , sometimes 5 or more, long-peduncled, funnel bell-shaped, the sepals recurved-spreading above the midule.

Moist meadows, common. June, July. Stem 2 to 3 feet high. Flovers 1 to 3, mometimes 5 to 20 , pendulous, yellow or orange at the buse, densely spotted vith brown-purple inside and outside above, 2 to 3 inches long.

\section{E. Superben, L. Turte's-cap Lily. Superb Lily.}

Lower leaves whorled, lanceolate, pointed, smooth, 3-nerved, upper ones scattered; flowers often 3 to 40 in a pyramidal raceme, nodding with revolute sepals.

Rich low grounds rather common. July, Aug. A superb plant 3 to 5 feet high, with an erect, round, straight stem. F iowers bright orange, with numerous dark purple spots inside. Sepals 3 inches long, linear-lanceolate, bcautifully and fully sovolute.

\section{CTLTTITED EXOTTC SPECTES.}

\section{L. TIGRINum, L. Tiger-spotted Lity.}

Leaves scattered, sessile, 3-nerred, the upper ones cordate-ovate; sepals revolato, papillose inside. Aug. Native of China, common in cultivation. Sien 4 to 6 feet bigh, woolly, bearing bulbs in the axils of the leaves. Flowers large, dark orange or reddish, spotted with black, in a pyramidal raceme. Sepats 4 to 6 inches long, Deautifully revolute, scabrous on the midvein, inside.

*** Flower's bell-shaped.

6. L. Bulbiferem, I. Orange Lity. Fire Lity.

Leaves scattercd, 3-veined, pubescent when young: flowers bell-shaped, crect zough within. July. Native of Italy. Sicm thick, round, 2 to 4 fet high, bearing small, roundish bulbs in the axils of the leaves. Flowers large, orange-colured, scabrous within. Common in cultivation.

\section{L. Candidex, L. Common White Lity.}

Leaves scattered, lanceolute, narrowed at the base; flowers bell-shaped, smootk on the inside. July. Native of the Levant. A much cuitivated and beautiful gsrden plant, wlth a thick stem, 3 to 4 feet high. Flowcr's large, swow-white, wery frugrant, in a terminal raceme.

\section{ERYTHRONIUM, Linn. DoG's-Tooti Violet:}

Gr. eruthros, red, which is inappropriate as respects our species.

Periantil liliaceous, of 6 distinct lanceolate sepals, recurved or spreading above, deciduous, the 3 inner usually with a callous tooth on each side of the crect base and a groove in the middle. Finaments 6, awl-shaped: ANTHERs oblong-linear. Strue elongated. CAPSUle obovate, contracted at the base, 3-valved. SEeds ovate- - Nearly stemless bullous perennials, with two smooth and shining flat leaves tapering into petioles and sheathing the base of the 1-flovered scape. 
1. E. Americanum, Smith. Yellow Dog's-tooth Violet.

Leaves elliptical-lanceolate, involute at the point, spotted; scape naked; sepals oblong-lanceolate, obtuse, inner ones bilentate near the base; style club shaped; stigmas united.

Meadors in sandy soil, common. April, May. A beautiful little plant. Scape 6 to 9 inches high. Lexves 2 , spotted with purple, and dotted 5 inches long, one of them nearly twiee as wide as the other. Flowcr drooping, yellow, revolute in the Eunshine, spotted near the base.

\section{E. ALBIDUM, Nutt. White Dog's-tooth Violet.}

Leares elliptical-lanceolatc, spotted, not dotted; sepals linear-lanceolate, the inner without lateral teeth; style thread-like azd club-shaped; stigma 3 cleft.

Low thriciets and sandy meadows, often in company with the other species. April, Miy. Leares witlout an acumination, includirg the petiole $t$ to 5 inches long, spotted with purple. Scupe 6 to 7 inches high, bearing a single white flower. Sepals $1 \frac{1}{1}$ inch long.

\section{Frittillaria, Linn. Crown Imperiat.}

Lat. fi itillur, a chess-board; alluding to the checkered flowers.

Periantr bell-shaped, with a broad base and necteriforous cavity above the claw of each segment. STAMEns 6, as long as the sepals. SEEDS flat.-Bullous perennial exotics, with showy, but ill-scented flowers.

\section{F. imieriats, L. Common Crown Imperial.}

Raceme comose, naked below; teaves lanceolate, acute. May, June. Native of Fersia. A showy flower of easy culture, common in cultiration. Stem thick, 1 to 2 foet high, the lorrer part inserted with the long leaves, the upper part is naked, beuring at the top a eluster of several red or yellow nodding flowers beneath a crown formed by the pairs of leares at the base of each pedicel.

\section{F. Maleagris, L. Checkered Crown Imperial.}

Leares alternate, linear, channelled; stem 1-flowercd. May. Native of Britian Stem a foot high, with alternate, long, very narrow leares. F hower usually soll tary, large, nodding, and beautifully checkered with purple pale red or yellow.

\section{TULIPA, Linn. Tulr.}

Persian thouliban, a turban; alluding to the form of these magnificent fowers.

Periantu bell-shaped, with sepals. Stamens 6, short, subulate: anthers 4-angled. Stigma thick. Capsule oblong, triangular. SEEDs flat.-Bulbous exotic perennials, with radical leaves and a showy solitary fiower on a scape.

\section{T. Gesneriana, L. Common Tulip.}

Leaves orate-lanceolate; flswer erect, smooth, with obtuse sepals. May. Native of Parsis. There are more than 500 varieties enumerated in catalogues, with red, searlet, crimson white jellow, brown, purple, striped, blotched and fringed flower

2. T. suaveolens, L. Sweet-scented Early Tulip. Leaves linear-lanceolate; flower erect, smooth with aeute segals, the alternate 
ones lancedate, the athers ovate. Native of Persia. Flowers mostly yellow, fragrant, appearing in April.

\section{TRIBE 4. ALOINE E.}

Fruit 3-celled, 8-valved, with a loculicidal dehiscence, opening at the summtt. seeds numerous.-Not bulbous.

\section{YUCCA, Linn. Abay's Nembl.} Jucca, the Indian name.

Pertanre inferior globular or bell-shaped. Stamens with awl-shaped filaments. STyle none. Capsule oblong, with 3 obtuse angles 3-celled, many-seeded, opening at the summit. SEEDS flat.-Evergreen perennials, with narrow filumentaceous radical leaves, and a scape of numerous white flowers, in a terminal panicled raceme or spilie.

1. Y. ANGUStifolia, I. Narrow-Zeaved Fucca.

Leaves long linear, flamentose on the margins, mucronate. Aug. Fative of the Southern States. Leaves 10 to 15 inches long, $1 / 2$ to $3 / 1$ inch wide, with white threads along the margin. Panicled spike terninal, on a scapo 2 to 3 feet high, many-flowerod. Flower's globular-bell-shaped, white.

2. Y. filanentosa, L. Adam's Neelle. Sill-grass.

Leaves lance-Iinear, filamentose, mucronate; 3 inner sepais broad-lancoolate; eapsule large oblong-obovate. July, Aug. Native of the Southeru States. Lerives 12 to 18 inches long, 1 to 2 inches wide, very filamentose on the margin. Scape 3 to 5 feet high, beaaing a terminal panicle of numerous white fragrant flowers Ferianth globose. Stigmas recurred, spreading.

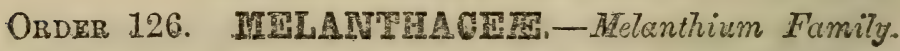

Ierbs, wilh perfect or polygamous and regular 6-merous and G-androns flowers, the petaloid perianth free from the 3 -celled wary, extrorse anthers, and 3 (sometimes unitud) more or less distinct slyles.

Suborder I. UVUlariez. The Bellwort Family.

Periantu soon deciduous, the divisions distinct, petaloid. STYLES united at the base or throughout. Frut a 3.celled few-seeded berry or loculicidal capsule.-Siems from small perennial routstocks and fibrous roots, ovate or lanceolate membranaceous sessile or clasping leaves, and perfect flowers on solitary or 1-jlowered peduncles.

\section{UVULARIA, Linn. Beliwort.}

Name "from the flowers hanging on the uvula, or palate."

Prorante nearly bell-shaped, lily-like, the sepals spatu- 
late-lanceolate, with a necteriferous groove or pit at the base of each. STAmens 6, with short flaments: ANTHERS long and linear, adnate. STrle deeply 3.cleft. CAPSule triangular, 3-celled, 3-valved from the top, with a few obovoid seeds in each cell.-Perennial herbs from creeping rootstocks, alternate sesvile or clasping leaves, and pale yellow nodding, mostly solitary fowers.

- Leaves clasping, perfoliate.

\section{U. Grandiflora, Smith. Large-flowered Bellwort.}

Leaves oblong or elliptical-ovate, pale and very slightly pubescent underneath; sepals smooth within; anthers nearly pointiess; lobes of the capsule with convex sides.

Rich woods, rare. May, June. Stem 12 to 15 inches high, passing through the perfoliate leares near their bases, dividing into 2 branches at the top, one of which bears a large pendulous pale-yellow flower. Perianth $1 \frac{1}{2}$ inch long. dnthers $3 / 4$ juch long.

2. U. perfolitata, I. Perfoliate Bellwort.

Leaves ovate or oblong-lanceolate, smooth, glaucous underneath; sepals grandlar-roughened inside; anthers pointed; capsule-lobes with concave sides.

Moist woods and thickets, common. May, June. Stem 8 to 12 inches high, passing through the perfoliate leaves near the base, 2 -branched at the top. Leaves 2 to 3 inches long, $2 / 3$ to 1 inch wide. Flowers pale-yellow, $3 / 4$ to 1 inch long.

* Leaves sessite.

\section{U, sessiliffolia, I. Sessile-leaved Bellwort.}

Low, smooth; leaves oval or lance-oblong, pale, glaucous underneath; styles united to the middle, longer than the obtuse anthers; cupsule triangular ovate.

Low woods, common. May. Stem 6 to 10 inches high, forked near the summit. Leaves 1 to $11 / 2$ inch long. Flowers 1 to 2 on a slender axillary peduncle, cream. colored, $3 / 4$ inch long.

\section{U. puberula, Michx. Puberulent Bellwort.}

Eeaves shining, orate, green, minutely puberulent, as well as the branches; styles united below, as long as the short-pointed anthars; capsule ovate, sessile.

Mountains, southern parts of the State.

\section{Prosartes, Don. Prosartes.}

Gr.prosartis, to hang from; in allusion to the suspended ovules or flowers.

Perianti bell-form, 6-parted, much as in Uvularia. STAMENs 6, the thread-like filaments inserted at the base of the perianth. Ovari 3-celled, with 2 ovules suspended from the summit of each cell. Strress united into one: STigmas 3 , short, recurved. Berry ovoid, pointed, 3 to 6 seeded, red.-Downy low herls, widely brancherd above, with closely sessile. ovate leaves. and greeinisin-yeliow drooping flowers on slender terminal peduncles, solitary or few in an umbel.

\section{P. Lanuginosa, Don. Pale-flowered Prosartes.}

Lavas orata-oblong, acuminate, roundod or slightly heart-shaped at the base, $\mathrm{R} \cdot 2$ 
closely sessile, downy underneath; flowers solitary or in pairs; sepals lance-linear, acuminate, soon spreading, twice as long as the stamens. (Streptopus, Michx.)

Rich woods, rare. May. Stem 12 to 15 inches high, with 2 to 3 forks near the summit. Flowers greenish-yellow, the sepals $1 / 2$ inch long, marked with conspicuous cross-veinlets like the leaves.

\section{STREPTOPUS, Michx. Twist-Stalk.}

Gr. streptos, twisted, and pous, foot, or stalk.

PERIANTH 6-parted, recurved spreading from a bell-shaped base, the 3 inner sepals keeled. Stamens 6 : Filaments short, flattened: ANTHERs arrow-shaped. OVARY with many ovules in each cell: STYLES and even the stigmas mnited into one! BERRY red, roundish-ovoid, with several seeds in each cell.-Herbs with somewhat stout stems, divergently spreading branches, ovate and acuminate round clusping leaves, and small flowers on slender filiform peduncles.

\section{S. AMplexifolius, DC. Clasping Twist-Stalk.}

Leaves oblong-ovate, closely clasping, very smooth, glaucous beneath; pcduncle abruptly bent or contorted near the middle; anthers acuminate, entire; stigina entire, truncate.

Low cold words, rare. June. Stem 2 to 3 feet high, rough at the base, forked. $F$ owers greenil h-white, on a filifurm peduncle, bent round the clasping base of the 1 vaves, rarely 2 -Howered.

2. S. Roseus, Michx. Rose Tivist-Sialk.

Leaves ovate-oblong, clasping, finely ciliate un the margin, green on both sides; branches:paringly bent with short bristly hairs; anthers 2 -horned; stigme minutely 3-cleft.

Cold damp woods, rare. May, June. Per. Stem 12 to 18 inches high, 2 or 3 . forked at the upper part. Flower's rose colored, 1 to 2 on fliform noduing peduncles.

\section{Sub-order II. MELANTHIE FE. The True Colcmicum FAMILY.}

Pertantir mostly persistent, the sepals distinct or rarely their claws united. Strules 3, seperate. Fruit a 3-celled, 3-parted capsule.-Herbs with acrid poisonous properties, and sometimes polygamous or dicecious flowers.

\section{MELANTHIUM, Gronov., L.}

Or. melas, black, anthos, flower; the flower becoming black after blossoming.

Polygamous. Perianth petaloid, rotate, desply 6-parted; the segments somewhat cordate, raised on slender claws, with 2 glands at the base. Stamens 6 , on the claws of the perianth. STYLEs short, awl-shaped, tipped with simple minute stigmas. Carsule ovoid-conical, 3-lobed, 3-celled, 
many-seeded.-Tall perennials, with simple stems, lancelinear grass-like leaves, and an ample pyramidal panicle of creamcolored racemose fivoers.

\section{M. Virginicum, L. Virginian Melanthium.}

Leaves linear-ianceolate, long; sepats ovate-hastate, at last oblong, flat, the glands distinct; filament cohering with the claws beyond the middle.

Wet meadows, rather common. July. Stem 3 to 4 feet ligh, leafy. Leaves 9 to 15 inches long, somewhat clasping at base. Flower's greenish-white, the perfect and sterile mixed, on short pedicels, in simple alternate racemes, together constituting a pyramidal panicle 10 to 15 inches long.

2. M. hyвRIDum, Walt. Hybred Melanthium.

Leaves long-linear, nearly smooth, clasping the stem; sepals round-rhomboid or breadly ovate, wary, the glands united; filaments involved in the lower part of the involute claws.

Low and high grounds, rare. July - Sept. Stem 2 feet high, leafy. Liecves vary ang from lance-linear to lanccolate. Perianth fery open, yellowish-green.

\section{VERATRUM, Tourn. False Hellebore.}

Eat. vere, truly, atrum, black; in allusion to the color of the flowers or root.

Flowers polygamous. Perianth of 6 spreading and separate sepals, more or less contracted at the base, without glands. Stamens 6 , free from the sepals and shorther than they, recurving. Styles 3, short, awl-shaped. CAPsule ovoid, membranaceous, 3-lobed, the carpels distinct at the summit.-Somewhat pubescent perennials, with simple stems, plaited 3 ranked leaves, and raceme-panicled dull or dark flowers.

\section{VIRIDE, Ait. White Hellebore. Indian Polie.}

Laves broad-orate, plaited; panicle pyramidal, with compound racemes.

Swamps and low grounds, common. June. Stem stout, very leafy to the top, 2 to 4 feet high. Leaves large, sheathing the stem at the base. Flowors yellowishgreen, moderately spreading. Root very poisonous.

\section{AMIANTHEMUM, Gray. Fut-Poison.}

Gr. amiantos, pure, and anthos, flower; alluding to the unspotted giandless perianth.

Flowers perfect. Perianth widely spreading, the dis. tinct petaloid sepals oval or obovate, sessile. FrLaments capillary. Antuers kidney-shaped or heart-shaped. STrres filiform. Capsule ovoid conical, 3-lobed. Seeds nearly wingless, 1 to 4 in each cell.-Perennial herbs, from a bulbous base. with simple scape-like stems, linear.Feeled grass-like leaves, and handsome flowers in a simple or rarely compound.dense raceme.

\section{A. Musc жтохісuм, Gray. Fly-Poison.}

Leaves broadly linear, elongated, obtuse, as long as the scape; raceme simple, oblong or eylindrical; capsule abruptly 3-horned; seeds oblong with a fleshy, red. aat. 
Shady swamps, rare. June. Stem 1 to 2 feet high. Leaves mostly radical, 10 to 15 inches long, $1 / 2$ to 1 inch wide. Raceme 3 to 9 inches long, dense-flowered. Perianth and stamens white.

\section{HELONIAS, Linn. UNICORY.}

Gr. Kelos; a swamp; the place of its growth.

Flowers perfect. Perianth of 6 spatulate-oblong persistent sepals. Sta Mens 6, longer than the sepals: ANTHERs roundish-oval, 2-celled, blue. STruLes 3 , nevolute, stigmatic along the inner side. CAPSULE obcordately ä-lobed, loculicidally 3 -valved, the valves deeply 3-lobed, many-seeded.A smooth perennial, with a hollow naked scape from a tuberous rootstock, numerous leaves, and a simple short dense raceme of pale. purple flowers.

H. Bullata, L. Purpte-flowered Unicorn.

Leaves inversely lanceolate or oblourg-spatulate, flat, nerved; scape leafless. ( $\mathrm{F}$ : Intifolia, Mich $x$.)

Sandy swamps, rare. May. Scape 1 to 2 feet high, thick and fleshy. Leaves 10 . to 18 inches long, 1 to $1 \frac{1}{2}$ inch wide. Flowers purple, with obtuse sepals.

\section{CHAM FLIRIUM, Willd. DeVIL's-BTt:}

Gr. chamai, on the ground, and leirion, a lily; of no obvious application:

Flowers diøeciozs. Pertanth of 6 spatulate-oblong sepals, persistent. Stamens 6, longer than tho sepals: FILAMENTS thread-like: anthers yellow. FertiLe FLow. anS with rudimentary stamens. STYLES 3, linear club. shaped, stigmatic along the inner side. CaPSule ovoid. oblong, not lobed, loculicidally 3-valved from the apex, many-seeded.-A smooth perennial horb, with a s'ender stem from a thick prenoorse tuberous rootstock, clustered spreading. leaves, and a long slender spiked racame of yellowish-white flowers.

\section{LUTEUn, Willd. Enicorn Root. Blazing-star.}

Iieaves flat, lanceolate, the lowest spatulate, tapering into a petiole ; fertile scape very leafy; sterile spilce nodding; stamens exserted. (Helonias dioica, Pursh.)

Low moist grounds, rather common. June. Spike at length 6 to 10 inches long showy. Root-leaves 4 to 8 inches long, $1 / 2$ to 1 inch wide, somewhat whorled at tho base of the scape. Flowers small, very numerous, yellowish-white. The fertila: plants are taller, more erect, but with fewer flowers. Medicinal.

\section{ORDER 127. JUNCACET佂,-Rush Family.}

Grass-like or sedge-itke herbs, with jointed stems and a regular persistent perianth: of 6 similar glumaceous sepals, 6 or rarely 3, stamens with introrse anthers, and a 1 : to 3-celled ovary, forming a 3-valved 3 to many-seeded capsule. STrue single. Sexps: anatropous, with a minute embryo inclosed at the base of the albumen. 


\section{LUZULA, DC. WOOD-RUsir.}

Italian, lucciolx, a glow-worm; from the dew glistening upon its fowers.

Pertanti persistent, 6 parted, spreading. Stauens 6. Srigias 3. Capsule 1-celled, 3-valved, 3 seeded.-Pevennials, with flat and soft ustully hairy leaves and spikederowded or umbelled flowers.

\section{L. pilosa, Willd Pïlose Woodmash.}

Laves lance-linear, hairy; portunoles umbelled; simple, mostly 1-10urered; sepals pointud, shorter than the ontusa capsule; seeds tipped with a curred apperiage.

Wools ard bankz. April. Mas. Stem 6 to 12 inches bi $h$, cresiitose at the bese.

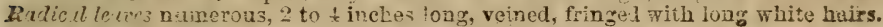
Punicle 8 to 12-flowered, unbelled. Flowers redash-browa.

\section{L. Campestris, DC. Common Wooct-rush.}

Lieaves flit, linear, hairy; spilies 4 to 12 ; sones t umbellod; ovoil, strar color,

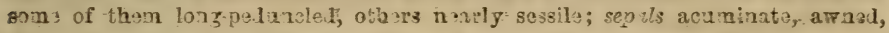
Jonger than the obtuse cansule; sads with a conieal appondage at the base.

Dry filds and woxds. Hiw. Slem 5 to 12 inches high, eans;itose at bage. Leavas gra ss like 2 to b inch long, very haty on the margins. Flowers redish-browu, in oroil or 0 ! ’ng nearly erect spikes.

\section{JUNCUS, Linn. RUsm Bbg:Rusr.}

The classical name, from jung, to join, allu ling to their use fir bands.

Perratir sprenling glumacous, 6-partol. STAMENs 6,

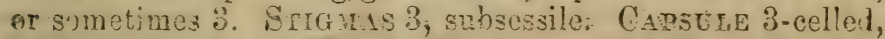
localicild, muy-oolel-Ching perentiats; with pithy stem, antl cymase, paniclul, or clastured smail greenish or brownish flowsrs.

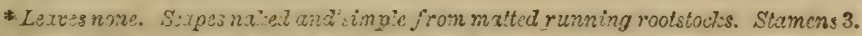

1. J. EFTusas, L. Common or Sift Rush. Bull-rush.

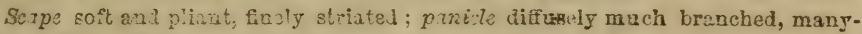
fowered; sepsls green, lanceolate, vary arute, as loag as the obovate very acuts aspsule; stumens 3.

Marshy groual, very abundint. June. Supe 2 to 4 feet high, erect, terminating in a long tappring point. Pinide bursting from a fiscure in the sile of the scspo abue the milill , sussile. Flinus gruezish, with white anthers.

* * Scapes naked, some of the sheuths at tie baselexf-bearing. Stamens 6.

2. J. sETACEus, Rostkow, Bristly, Rush.

sc.xpe slender, filiform; panicle loose, rather simple, few-flowered; sepals lanceolate, very acuts, especially the 3 exterior. longer than the obovate pointed carsule.

Swamps. June, Inly. $\Lambda$ very slend $\mathbf{r}$ spccies, growing in tufts about 2 feet hish. Sapes sheathed at base, tarning light chestnut color. Punicle small, 20 to 30-thowered, bursting from the side of the seape, below the summit.

** Stems leaf-bearing. Leaves round or fluttened laterally linotled, or juinted.

3. J. SCRIPoIDes, Lam. Many-headed Rush.

Ste:n erect, stout, round; leaves round; panicle rather eimple, bearing of to s, $12 \cdot 2 *$ 
pale-green densely many-flowered spherical heads; sepals rigid, awl-shaped, and somewhat awned, especially the outer, as long as the triangular acuminate capsule ; seeds barely pointed at sach end.

Wet borders of streams, rather common. July, Aug. Stem 1 to 3 : feet high, from a thickish creeping nootstoek. Remarkable for its burr-like green heads, usually $1 / 3$ inch in diameter.

\section{J. Paradoxus, E. Meyer, in Gray's Flora.}

Stem stout and round; leaves tere te or Eomewhat flattened; panicle decrmround fieads numerous, globular, 8 to 15-flowered; sepals lanceolate, somewhat awl-point ed, rigid; seeds conspicuously tailed at both ends.

W.et places, common. July, Aug. Stem 1 to $2 \frac{1}{2}$ feet high. Heads less dense, fewer-flowered, and sometimes smaller than the foregoing. "Remarkable for the loose white seed-coat prolonged at both ends into a tail longer than the body of the seed,".

\section{J. acuminatus, Michx. Siharp-frited Rush .}

Stem erect, terete; leaves slender, nearly terete; panicle terminal, with rather slightly spreading branches; heads 3 to 8-flowered, chestnut-colored; sepals linearlanceolate, very acute, shorter than the acutely triangular capsule; seeds taif pointed at both ends.

Peat bogs and borders of ponds. July, Aug. Stem 10 to 15 inches high. Flowerg pale-green or purplish, mostly 3 in a head. Cupsule turning deep chestnut-brown.

**:**: Zeaves joiribléss, flat and opsn. Stamens 3.

6. J. marginatus, Rostkow. Grass-leaved Rush.

Stem leafy, erect, flattened; leaves linear, grass-like, nerved; heads globose, 3 to 8-flowered; sepals oblong, the 3 outer with the bracts slightly awned, the innerobtuse and pointless, as long as the globose capsule; seeds minutely pointed at both ends.

Moist sandy places, common. July. Stem 1 to 3 feet ligh, tuberous at the bare, with numernus root-leaves. Punicle simple or compound. Sepals soft, chestnutpurplish, with a green keel.

***** Leaues channelled or involute, tilread-form or almost setacsous. Stamens 3.

7. J. TENUIS, Willd. Slender Rush.

Stems siender; wiry; simple, leafy only near the base; ieaves setaceous-linear. channelled; cyme shorter than the involucral leaves; flowers solitary one-sided, nearly sessile; scpals lanceolate, very acute, a little longer than the obtuse capsule.

Low grounds and fields, very common. June, July. Stem caspitose, 10 to 13 ; inches high. Flowers green, shining, somewhat racemose or one-sided on the: branchlets.

\section{J. Gerardi, Loisel. Blact Grass.}

Stems simple, flattish, leafy, rigid; leaves linear-bristly, channel:sd; paniuto. terminal, aymose, longer than the involucral leaves, rather crowded; sepals ovato.oblong, obtuse, nearly the length of the obovoid obtuse capsule.

Borders of salt-marshes, common. Aug. Stem 10 to 18 inches Ligh, slender. Eoliage deep-green. Quter sepals deep ohestnnt-brawn, with a deep green keel.

9. J. BUFonius, L. Toad Rush.

Annual; stems diffuse, low and slender, leafy, often branched at the base; panicte forking, spreading, the flowers remote; sepats lanceolate, awl-pointed, mueh. longer than the oblang abtuse capsule.

Low grounds and raadsides, very common. June, Ang. Stem 3 to 9 inches bigh, tufted, divided tow ards the top. Eanicle loose, spreading, fiw-fowered, palo-green.. I'lowers greenish. 
***** Stems leaf bearing; leaves terete, short. Stamens. 6 .

10. J. Nodosus, L. Jointed Rush.

Stem erect, slender, 3 to 5 -leaved; leaves terete, short; he ads I to 2,or several and clustered, globose, 10 to 20-4owered; sepals lanceolate, awl-pointed, nearly as long as the slender 3-angled capsule.

Gravelly borders of streams, \&c., common. Aug. Roststocks slender. Siem 6 to 20 inches high. Heads in a loose panicle, or in a dense cluster. F'lowers brownish or greenish.

\section{ORder 128. PONTEDERIACER,-Pickerel-weed Family.}

A quatic herbs, with perfect more or less irregular flower's from a spathe; the pelo. Doid 6-merous perianth free from the 3-celled ovary, and the 3 or 6 mostly unequal or dissimilar stamens inserted in its throat. Prrianth-lobes colored alike. Strugs 1: miara 3 to 6-cleft. CAPSUle 3rcelled, 3-valved, loculicidal. Szsps pumerous, with omewhat mealy albumen.

\section{PONTEDERTA, Linn. Prokerel-meed.}

Dedicated to Poniedera, Prof. at Padua at the beginning of the last century.

Periantu funnel-form, 6-cleft, 2-lipped; the 3 lower Iobes spreading, and their claws, more or less seperate down to the base. STAMENS 6 , unequally inserted, 3 ncar the base and 3 near the summit of the tube: ANTHERs oral, blue. Ovary 3-celled; 2 of the cells empty, the other containing a single suspended ovule. UTRICLE 1-celled, filled with the single seed. - Stout herbs, growing in shallow water, with thick creeping rootstocks, producing erect longpetioled mostly cordate leaves, and a 1-leaved scape, terminated by a spike of violet-blue ephemeral flowers.

\section{P. condata, L. Common Pickerel-weed:}

Leaves arrow-heart-shaped, llunt; spile very dense, from a spathe-like bractVar. AxGUSTIFomik, Torr., has triangular-elongated and tapering leaves, scarcaly cordate at base.

Ponds, common. July-Sept. Stem 1 to 2 feet high, bearing a single smootha g!ossy lea $\hat{f}, 4$ to 7 inches long and 1:1/3 to 3 inches wide. Flowers aggregated by 28 and $3 \mathrm{~s}$, sessile bright blue, with a pair of small yellow spots on the upper lobe.

\section{Heteranthera, Ruiz \& Paron. IIvd Plantain.}

Gr. heter: $a$ different, and aner, for anther; the anthers being dissimilar.

Spstine several-flowered. Periante salver-form, with a slender tube, the limb somewhat 6-parted. Stamens 3,.2 of the anthers ovate, yellow, the 3d oblong or arrow-shaped, greenish. CAPSULE incompletely 3-celled, many-seeded.Creeping or floating low herbs, with mosity rounded long. 
petioled leaves, and a 1 to few-flowered spathe bursting from: the sheathing side or base of a petiole, with blue or white flowers.

H. Reniformis, Ruiz \& Paron. Muct Piantain.

Ieaves round kidnoy-shaped; spathe oblong-acumizate, 3 to 5 -flowered.

Muddy margins of streams. July, Aug. Sem prostrate and rocting in the mud, partly floating. Leares semicircularly nerred, on petioles 2 to 3 inches long. Elowers white.

\section{SCHOLLERA, Schreber. WATER STAR-GRASS.}

Dedicated to Fredericle A: Secholler, a German botanist.

Pertantri salver-form, with 6 nearly equal lanes-linear apreading segments on a very long filiform tube. STAMens 3 , with similar oblong-arrow-shaped anthers (or rarely an abortive fourth ono): FIEAMENTs nearly cqual, subulate. CAPSULE oblong, invested by the withered perianth, 1-celled, many-seeded. - A grass-like herb, growing wholly under water, only the small pale yellow flowers expanding on the. surface, with slender branching stems, clothed with linean: transtucent sessite leaves and 1-flowered spatie.
S. GRA MiNeA, Willd.
Common Wuter Starwort.

In flowing streams, common in the Susquehanna. July, Ang. Stem. 2 to 3 fert: loug. Leaves 3 to 6 inches lontr, very narrow. Flowers yellow, with a tube $11 / 2$ : inch long and a thick style.

\section{ORDER 129. COMMIPLYNACRB-Spiderwort Funily,}

IIerbaceous plants, with jointed often branclingleafy stems, and inostiy perfect and o-androus flowers, with the perianth free from the 2 to 3-celled ovary. PERIAsin in 2 rows; outer row herbaceous, 3leaved; inn r petal-like, ephemcral. STusers 9, hypogynous. Strlis 1: stigma undivided. Capsule 2 to 3 celled, 2. to 3-ralrod, loculieidal, 3 to sereral-seeded.

\section{Commelyna, Dill. Day-rlower.}

Dedicated to the early Duteh botanists, $J$. $\&$. Commelyn.

Perianth in 2 rows; outer one 3 leaved, ealycine ; inner 3-leavod petal-like. Stamens 6, unequal, 3 of them fertile, one of which is bent inward: 3 of them sterile and smaller, with imperfeet cruciform anthers: FILAMENTS naked. CAPBULE 3-celled, 2 of the cells 2 -seeded, the other 1-seeded of abortive.-Hêrbaceous plants, with brancling stems, lamcelinear leaves contracted: at the base into sheathing petioles, the floral one cordate and clasping, folded together or hooded: 
and forming a kind of spathe inclosing the blue or white ephemeral flowers.

I. C. Angustifomi, Michx. Narrow-leavad Day-flower.

Stem usually reclining and rooting at the joints; leaves lancoolate or linearlanceolate; spathe heartrshaped, folded together; peduncles usually dirided, the smaller branch 1 -flowered or sterile; petals_unequal, the lawer one much smaller; capsule 2-celled.

Damp rich woods and banks; rare. July-Oct. Per: Plant nearly smooth, 12 to 18 inches high. Leuves 3 to 5 inches long, $3 / 4$ to $1 \frac{1}{4}$ inch wide, varying from lance-linear to lanceolate. Spathe veiny, 3 to 5-fowered. Flowers deep blue. stamens 2, perfect.

2. C. Virginica, L. Virginian Day-flower.

Stems upright, smooth; leaves lance-oblong, acuminate, the upper surface and margins rough backwards; sheaths fringed with rusty bristles; spathes crowded and nearly sessile, broadly dilated; peduncle several-flowered; petals nearly equal; capsule 3-celled.

Alluvial shaded river-banks. July, Aug. Per. Stem 1 to 2 feet high, erect. Ieaves 5 to 7 inches long, 2 inches wille. Spathe broadly funnel-shaped. Flowere. blue, clustered at' the top of the stem: Stamens 3.

C. COLLestis, with blue or white flowers is sometimes oultivated:

\section{TRADESCANTIA, Linn. SPIDERTORT.}

Named for Tradescant, yardner to Charles the First.

Flowers regular. Sepals herbaceous. Petals all alike, ovate, sessile. Stamens 6, all fertile: rilamems bearded. CAPSule 2 to 3 -celled, the cells 1 to 2 -sceded.Horbaceous perennials, with keeled linear or lance-limear leaves, and" ephemeral white purplish and rose-colored flowers in axillary and terminal umbelled clusters.

\section{T. Virginica, L. Common Spiderwort.}

Leaves lance-linear, elongated, tapering from the sheathing base to the point, ciliate; umbels terminal, many-flowered; calyx pubescent.

Moist shady woods, common in cultivation. May-Aug. Slems thičk, round, jointed, 12 to 18 inches high. Leares numerous, 12 ta. 18 incheslong, by $1 / 2$ to 1 inch wide. I'lowers blue, in gardens often purpish or white, soon fading.

\section{T. RoSEA, Vent. Rose-colored Spiderwont.}

Small and slender, smooth; leaves linear, long, ciliate at the base; umbel simplo or sometimes a pair; calyx smooth.

Moist woods or sandy fields, cummon. May. Stem 8 to 12 inches high. Leares: grasslike, 6 to 8 inches long, ahout $1 / 1$ inch wide.. Flou:ers rose-colored, mueh: smaller than in the preceding species.

\section{ORDER 130. XYRIDACER.-Tyris Family.}

Rush-like herbs, with equitant leaves sheathing the base by a naked scape, which is: terminated by a head of perfect 3-androus flowers, with extrorse anthers, aglumaceons: oalyx, and a regular corolla. Fruir a 3-valved capsule containing many anstra. yous seeds; - chiefly represented by the genus. 


\section{XYRIS, Linn. YELLOW-EYED GRASS.}

Gr. xyros, sharp, in allusion to the pointed leaves.

Perianth in 2 rows; outer row glumaceous, 2 of the segments boat-shaped or keeled; inner row petal-like, with elaws, more or less coherent. STAMENS 6, 3 fertile with linear anthers, and 3 sterile, plumc-bearing. STrue 3-cleft. Capsule oblong, free, 1-celled, with 3 parietal placentro, 3 ralved.-Rush-litee lwerbs, with narrowly linear rigid radical leaves, sheathing the scape, and yellow flowers in a terminal dense head.

1. X. Caroliniana, Walt. Common Yellow-eyed Grass.

Scape flattish, somewhat 2-edged at the summit, 1-angled below, smooth; leaves linear-ensiform, flat; head globular-ovoid; lateral sepals obscurely torn-fringed: above on the winged keel, rather shorter than the bract.

Wet meadows. rare. July, Aug. Per. Seape 1 to 2 feet high, somewhat bulbons at the base, often spirally twisted. Leaves few flat, 6 to 12 inches long, $1 / 8$ to $1 / 4$ inch wide. Pelals rather large, yellow, the claws turning brownish.

2. X. BRavifolia, Michx. Short-leaved Yellow-eyed Grass.

Icaves subulate, ensiform, short; head glotose; pctuts shorter than the sepals. aightly notched.

Wet meadows, rare. July. Per. Scape 12 to 18 inches high, compressed near the summit. Leaves much twisted. Flowers yellow.

\section{ORDER 131. ERTOOAULONAOWF, - Pipewort Family.}

Aquatic or marsh flants, usucliy acculescrnt, with linear cellular spongy leares natied scapes sheathed at the base, and bearing dense heads of monocious or diacious minute flowers in the axils of minute bracts, with a double perianth, introrse anthers: and a 2 to 3-celled 2 to 3-seeded capsule; principally represented by the genus

\section{ERIOCAULON, Gronov. PIPewont.}

Gr. erion, wool, and kaulos, a stalk; from the woolly scape of many speries.

Frowers chiefly monocious; the central ones of the head sterile, bearing 4 or 6 stamens, the exterior fertile. SEPALS 2 or 3 , the lateral ones boat-shaped. Corolla tubular and 2 to 3 -lobed in the sterile flowers; of 2 or 3 sepals in the fertile, each bearing a black gland. STYLE 2 to 3-parted. Capsule 2 to 3-celled, loeulicidal.-Herbaceous: plants, with smooth often pellucid leaves, simple scapes bearing a single head, the bracts and perianth whitened at the summit with a clothing of dense fine wool and the outer bracts scarious, often empty and forming a kind of involucre.

E. Septangulare, Withering. Jointed Pipewort.

Scape slender, 6 to 7 -angled or furrowed; leaves subulate-cnsiform, conspicuous. Iy cellular, pellucid; outer bracts oborate, rounded; head small, round. 
Ponds and borders of swamps. Aug. Per. Suape 2 inches to 6 feet long, according to the depth of the water, pollucid and collular. Leaves submersed, in a small tuft at the bottom, 1 to 3 inches by 1 to 2 lines, awl-pointed, tapering from \& flattened base. Heud lead-color, $1 / 3$ to $1 / 2$ inch broad. Stamens 4.

\section{SUB-CLASS IV. GLUMACEF, or GLUMACEOUS EN- DOGENS.}

Plants of the endogenous structure, with the flowers inrested in an imbricated perianth of glumes instead of a calyz. Orary with one cell containing a solitary ovule and becoming a 1 -seeded achenium or caryopsis.

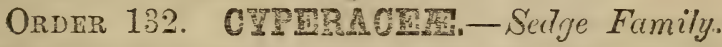

Grass-litie or rashtike herbs, with furous roots and solid stems (culms), closed sheaths, and spitied chiefly 3 -androus flowers, one in the axil of each of the glume-litie imbricated bracts, destitute of any perianth, or with hypogynous bristles or scales in its p'ace, and a 1-celled ovary, with a single erect anatropous ovule, in fruit forming an actenium. STrie 2-cleft, whon the fruit is fiattened or lenticular, or 3-cleft when it is 3-angular.

\section{DULICHIUM, Richard.}

Gr. duo, two, leitien, a scale; alluding to the giumes in two rots.

Spiknists 6 to 10 fowered, linoar, dattened, sessile in 2 ranks on axillary sclitary peduncles emerging from the sheaibs of the leares. EcALzS 2-ranked, lanceulate. PERIANTH of 6 to 9 downwardly barled bistes. STAMENS 3. STrLE 2-cleft abore. Acrivium fattened, liuearoblong, beaked with the long persistent style.-P'erenaiuls, wilh short flat linear 3-ranked leaves, and round simple jointed culnes, leafy to the summit.

D. SPATHACEu, Pers. Spainaceons Dutichium.

Borders of poncls, common. July-Sept. Oulm 1 to 2 f wet high. Leaves flat, sprualing alwost horizontilly in threedirections. Spitelets $\% / 4$ inch long, trowaish, on a fiexuons rachis. Scales rusty-yellow.

\section{CYPERUS, Linn. Gadingale.}

The ancient Greek name.

Spikelews many to few-flowered, disposed in a simple or compound terninal umbel. SCALES 2-ranked, deciduous with age. Stamens 1, 2, or mostly 3. Perianti none. StYle 2 to 3-eleft, deciduous. Achenium lenticular or triangular, naked at the apex.-Mostly perennials, with simple 
mostly triangular culms leafy at the base, 1 to several leaves ut the 8 immit forming an involucre to the umbel, and wnequal peduncles sheathed at the base.

SrC I. Proreds, Beauv.-Style 2-cleft: achenium flattened.

\section{C. muavescens, L. Yellow Sedge.}

Stamens 3; spitce linear, rather obtuse, 14 to 30 -flowered, clustered at the end of the 2 to 4 very short rays; scales obtuse, 1-nerved; achenium shining, orbicular.

Low grounds, rare- Aug. Culms 4 to 10 inches high, Leaves narrow, as long as the culm. Spilielets 5 to 8 inchus long, yellowish. Involucre 3-leaved, very unequal.

\section{C. Diandrus, Torr. Diandrous Galingale.}

Stamens 2 ; spilies lance oblong, rather acute, 14 to 21 -flowered, scattered ar clustered on the 2 to 5 very short or unequal rays; scales oblong, rather obtuse, brownmargined; achenium oblong-ovate.

Low grounds. Aug., Sept. Culms 6 to 12 inches high, o ten weak and somewhat decumbent, clustered. Stamens sometimes 3 in the upper axils. Var. Castaneus, Torr., has oblong-lanceolate, shining close chestnut-brown seales, and scurcely exserted style.

\section{C. Cleaverir, Torr. Delicate Gatingale.}

St tmen 1; culm bristle-form, terminated by a single and similar erect invalucral leaf and a solitary lance-linear 10 to 12 -flowered spike; scales linear-oblong, rather acute, 3-nerved; achenium oblong-obovate.

Near Philadelphia, Dr. Cltaver. Culm 4 to 6 inches high, triangular. Spitie $1 / 2$ Inch long much compressed.

Szc. I. Cypzrus proper-Style 3-cleft. Spikes many-flowered. Aclienium tryangular.

* Stamen 1: umbel contracted or sessile.

\section{C. Inflexus, Muhl. Odorous Galingale.}

Dwarf, in tufts; spilies oblong-linear, about 8-fowered, collected in 2 or 3 ovate heads; scules oblong, tapering into a long recurved point; involucre 3-leaved, verg long.

Sandy shores. Aug. Ann. Culms 2 to 5 inches bigh, densely clustered. Leaves linear, as long as the culin. Umbel often sessile. Spitielets yellowish. Plant stret-secuted dike Me ilot in drying.

* : Stamens 3: culm triangular.

5. C. strigosus, L. Tall Galingale.

Culm mostly stout, tuberous at the base; umbel simple or eompound, many. rayed; rays numeruus, elougated; spiles linear-lanccolate, flat, 8 to 10-flowered, very numerous; seales oblong-lanceolate, strongly nerved, acutish.

Low and cultivated grounds, very common. Aug., Sept. Culm 1 to 3 feet high. Spiles 1 to 2 inches long, consisting of 20 to 80 spikelets. Scales loosely imbricate, yellowish on the sides.

\section{C. Dentatus, Torr. Toothed Galingale.}

Culm slender; umbel to 7 -rayed, compound; spities 3 to 6 on ench partial ray, clustered, oblong or ovatelancelate, flat, 6 to 30 -flowered; scales strongly koeled, with very acute tips; joints of the axis naked; achenium obovate, minute.

Sandy swamps. Aug Fitiroma creoping. Culm 6 to 12 iuches high. Leaves scm what rigid, pale yellowish-yreen. Scules reddich brown on tho sides, green on the back. 
7. C. FILICULMis, Vahl. Slender-stalked Galingale.

Culm slender, wiry, often reclined; spikes numerous and clustered in a denso head, or in 1 to 3 additional looser heads en spreading rays, 6 to 10-flowered; scales ovate, blunt, loose; achenium obovate.

Dry sterile soil. Aug. Culm 1 foot high, clustered, tuberous at base. Leaves linear, dull green. Scales yellowish-green, with a scarious margin.

*** Inner scales herbaceous, free.

\section{C. евтthrohizos, Muhl. Red-rooted Galingale.}

Culm obtusely triangular; umbel compound, many-rayed; involucre 4 to -5-leaved, very long; spikes very numerous, crowded in oblong-cylindrical heads, 10 to 18 flowered; scales lanceolate, mucronate.

Wet alluvial banks. Aug. Culm 2 to 3 feet high, smooth. Leaves shorter thas the culm. Spilies bright chestnut colored. Root fibrous, red.

\section{HEMICARPHA, Nees.}

Gr. hemi, half, and karphos, straw or chaff, in allusion to the single inner sealelet on one side of the flower.

SPIKE many-flowered, ovoid, one or few in a lateral cluster, sessile. Scales imbricated in many ranks, ovate or obovate. INNER SCALE single behind the flower, very thin. Periantir none. Stamen 1. Style 2-cleft.-Low tufted annuals; the naled culms with bristle-like leaves at the base.

H. subsquarrosa, Nees. Dwarf Hemicarpha.

Dwarf; involucre 2-leaved, 1 long as if a continuation of the bristle-like culm, the other a minute leaf; spikes 2 or 3 ; scales tipped with a short-recurved point.

Sandy shores. July. Cuims 1 to 4 inches high, in dense tufts, leafy at baso. zeaves setaceous. Spikes $1 / 4$ inch long, sometimes solitary. Scales very numerous.

\section{ELEOCHARIS, R. Brown. SpIKe-rush.}

Gr. elos, a marsh, and charis, to delight in; being marsh plants.

SPIKE single, terminating the nuked culm, many to several-towered. Scales imbricated on all sides in many, rarely 2 or 3 ranks. Perianth of 3 to 12 (usually 6 ) bristles, often rough or barbed downwards. Stamens 3. STrLe 2 or 3-eleft, bulbous at the base, jointed with the apex of the lenticular or mostly obtusely triangular achenium.-Chiefly perennial leafless herbs, with tufted culms sheathed at the base, sume of them often sterile from matted or creeping rootstocks.

1. E. quadrangulata, R. Brown. Square-stalked Spike-rush.

Culm even, sharply 4-angled, 3 of the sides concsiv, the fourth wider and flat; scales broad-ovate, very obtuse; achenium smooth, crowned with a beaked tuherclo Shallow water. Aug. Culm 2 to 4 feet high, with purple sheaths at base. Spike 1 to $1 \frac{1}{4}$ inch long. Scales with a scarious margin, dotted with purple. 
2. E. овтUSA, Schultes. Obtuse Spike-rush.

Culms nearly terete, tufted; spitice globose-ovoid, many-flowered; seates very numerous ( 80 to 130 ), densely crowded in many ranks; style 3-(rarely 2)-cleft achenium obovate, shining, tumid-margined, about half the length of the 6 bristles, orowned with a broad tubercle.

Muddy places, very common. July. Culms 8 to 15 inches high. Spite thick and obtuse. Scales with a green midrib.

\section{E. Palustris, R. Brown. Common Spike-rush.}

Culms nearly terete, striate, rising from running rootstocks; spikes oblon:lanceolate, pointed, many-flowered; scales ovate-oblong, 1 oosely imbricatcd in several ranks; achenium obovate, somewhat shining, crowned with a flattened tubercle, shorter than usually 4 bristles.

Marshes and low meadows, common. June-Aug. Culm 1 to 2 feet high, stout and tall when growing in the water, or slender and lower when in grassy grounds. A very variable species. Spike $1 / 4$ to $1 / 2$ inch long. Scales reddish-brown, with : broad and translucent whitish margin and green keel.

4. E. intermedia, Schultes. Intermediate Spitie-rush.

Culms capillary, wiry, striata-g rooved, densely tufted from fibrous roots, diffuse Iy spreading or reclining; spitie oblong ovate, acutish, loosely 10 to 18 -flowered; scales oblong, obtuse, green-keeled, the sides purplish-brown; achenium mooth, ohovoid, tubercled, nearly equalling the 6 bristles.

Wet slopes, common. July. Culms very numerous, 6 to 12 inches high. Acher sum light brown.

5. E. Tendis, Schultes. Slender Spilie-rush.

Culms almost capillary, erect, sharply 4 -angular, the sides concave; spite elliptical, acutish, 20 to 30 -flowered; scales ovate, obtuse, chestnut-purple with a broad carious margin and green keel; achenium obovate, roughened; bristles 2 to 3 , half the length of the achenium, or wanting.

Wet meadows and bogs, common. July. Culm 8 to 12 inches high, very sleader, with 1 or 2 purple sheaths at base. Spike $1 / 4$ inch long.

\section{E. actoularis, R. Brown. Capillary Spike-rush.}

Chims finely capillary, 4-angular; spize 3 to 8 -flowered; scales ovate-oblong, rather obtuse, greenish with pxrple sides; achenium obovate-oblong, rather acute st each end, tumid, with 3-ribbed angles, longer than the 3 or 4 very fugaceous tristles.

Muddy placez, and margins of brooks, common. June-Aug. Culm 2 to 8 inches long, clustered, slender.

\section{SCIRPUS, Linn. Bulrusir. Club-rush.}

The ancient Latin name of the Bulrush.

SpIKes many or several-flowered, terete, mostly clustered, often appearing lateral from the extension of the involucral leaf like a continuation of the culm. Scales regularly imbricate on all sides in several ranks. Periantri of 3 to 6 bristles. Stamens 3. STYLe 2 or 3 -cleft, simple at base, deciduous. Achenium lenticular or triangular.-Chefly perennials, with the culms sheathed at the base, sheaths usually leaf. bearing, and solitary conglomerated or corymbose spikes. 
Sic. I. SCrIPUs proper,-Bristles rigid, mostly barbed downwaras.

1. S. Planifolius, Muhl. Flat-leaved Clul-rush.

Culms triangular, loosely tufted, leafy at the base; leaves linear, flat, as long a the culm, rough on the edges and keel; spitce ovate or oblong, 5 to 7 -flowered, rusty color; scales orate, with a strong green keel prolonged into an awned tip; bristies 4 to 6 , uprarally hairy, as long as the blunt achenium.

Dry or moist woods, rare. Juae. Culms 6 to 12 inches long, rough on the edges. Seales yeliowish.

2. S. Pungeng, Vahl. Pungent Cutb-rush.

Culm sharply 3-angled throughout, with concare sides; le:lves 1 to 3 , elongated, keeled and channelled; spities 1 to 6 , capitate, ovoid, long, overtopped by the pointed involucral leaf; scales ovate, sparingly ciliate, 2-cleft at the apex; anthers tipped with a minute fringed appendage; style 2 -cleft; bristles 2 to 6 , shorter than the obovate smooth achenium.

Borders of fiesh ponds and streams. July, Aug. Culm 1 to 4 feet high. Leaves 4 to 10 inches long. This is the species used for rush-bottom chairs.

\section{S. LACUstris, L. Bulrush. Tall Clul-rush.}

Culm large, cylindrical, gradually tapering at the apex; spikes orate-oblong, ntmorous in a compound umbel-like panicle, turned to one side, rusty brown; scales ovate, musronate; bristles 4 to 6 ; achenium oborate, mucronate.

Fresh water ponds and lakes. July. Culm 3 to 8 feet bigh, $1 / 2$ inch thick at the base, tipped with an erect pointed involucral leaf, shorter or longer than the fauicle. Scales brown, minutely pubescent.

\section{S. DEBrLis, Pursh. Weak-stalked Club-rush.}

Culms siend:r, tufted from fibrous roots, leafless, sometimes 1-leaved at the baso spikes ovate, 1 to 8 in a ssssile cluster; scales round-ovate, greenish-yellow; style 2 to 3-cleft; bristles 4 to 6 , longer than the obovate shining achenium.

Low grounds, and banks of streams. Aug. Ann. Culms 6 to 12 inches high. Spikelets apparently bursting from the side of the culm 2 or 3 incles from the top. Bristles retrorsely hispid.

\section{S. Atrovirens, Muhl. Dark-green Club-rush.}

Cuim rigid, oktusely triangular, very leafy; leaves broadly licear, flat, rough margined ; umlel cymose-decompound, irregular, the numercus spikes clustered $1 j$ to 20 together in dense heads; bristles 6 , scarcely exceeding the oboroid con: pressed achenium.

Low grassy ground, common. July. Culm about 2 feet high, leafy nearly to the top, smooth. Spilies ovoid, dark-lead-colored or olive-green, turning brownish. involucre of 3 principal leaves, dark-green.

SEC II. TRICHophorca, Richard.-Bristles 6, capillary, tortuous, Emoothisb. Stem leafy.

6. S. Lineatus, Michx. Loose-flowered Wool-grass.

Culm triangular, leafy; leaves linear, flat, rough on the margins; umbels termlnal and axillary, loosely cymose-panicled, drooping, the terminal with a 1 to 3 -leared involucre; spitces oblong, becoming cylindrical, on filiform pedicels; scales ovate, pointed with a green keel.

Low grounds. July. Culm 1 to 3 feet high. Bristles crisped, scarcely exceeding the scales.

\section{S. Ertophorum, Michx. Woal-grass.}

Culm nearly terete, very leafy; leaves narrowly linear, long, rigid; panicls decumpound, large, loose; spikes orate, clustered on the lateral pedicels, woolly 
at maturity; bristles rusty-colored, much longer than the pointless scales; achenium short-pointed.

Wet meadows, common. July, Aug. A somewhat variable species 2 to 5 feet high, leafy near to the top. Leaves 1 to 2 feet long, flat above, rough on the margin. Scales with the sides brown and the keel green:

\section{ERIOPH ORUM, Linn. Cotton.grass.}

Gr. erion, wool or cotton, and phora, bearing.

Sptike many-flowered. Scales imbricated all round in several ranks. PERIANth woolly, of numerous flat hairs, much longer than the scales, persistent aud forming a silky or cotton-like usually white tuft in fruit. StaMens 3. STru: 3-cleft.-Perennials, with mostly leafy stems, and mostly unibelled spikclets, finally clothed with long. sillky hairs.

1. E. Virginicum, L. Virginian Cotton-grass.

Culm rigid, nearly terete below, obtusely triangular above; leaces narrowly. linear, elongater, flat; witirs crowded in a dense cluster or head; wool rasty-color, 3 times the length of the scale; stamen 1 .

Bogg and low meadows, common. July, Aug. Culm 2 to 4 feet high, leafy. Scciles with pale gides and a green lseel. Hairs very numerous, tawny.

2. E. polystachyon, L. Broad-leaved Cotton-grass.

culm rigid, obscurely triangular; leaves linear fiat, or barely channelled below. triangular at the point; involucre 2 or -leaved; spikes several, on nodding peancles, some of them elongated in fruit.

14. $\mathrm{gs}$ and marshes, common. June, ripe in Aug. A variable srecies. Cilm I to 2 feet high, smooth. Scaies green, at length brown. Hairs very numerous, lowg; white with a reddish tinge, 1 inch long.

\section{FIMBRISTYLIS, Vahl.}

Tat. fimbric, a fringe, and stylus, a style; from the ciliate style.

SpIRes several to many-flowered. Scales regularly im. brieated in several ranks. Bristles none. Stamks 1 to 3. Sxrue 2 or 3-cleft, with a thickened or bulb-like base, deciduous. - Feremials with leafy culms, and cymose-umbelled spikes, as in Scirpus.

SEC. I. IMnnISTYLUS proper.-Style2-cleft, mostly flat and ciliate on the margin.

1. F. LAXA, Vahl.

Culms gronved and flattish, slender; leaves chiefly from the base, narrowly linear, flat, channelled, ciliste-centiculate, glaucous ; umbel simple or compound ; involucre about 3-leared; rites ovate, acute; stamen single; achenium 6 to 8-ridged on each side.

Low clayey soil. aly, Aug. Culm 4 to 12 inches high. Umbel small, some of the rays divided. Syikes $1 / 4$ inch long.

Sec. II. Trichelosryus, Lestib. Style 3-eleft, seperating from the triangular achenium.

2. F. autumiralis, Roem. \& Schultes.

Low, tufted; culms flat, often diffusely spreading; leaves flat, very acuto; in 
volucre 2-leaved; umbel usually decompound; spices oblong, acute, single or 2 or 3 to fether at the end of the rays; stamens 2 or 3 ; achenium obovate-triangular.

Muddy grounds. Aug.-Det. Culm 8 to 12 inches high. Leaves mostly radical. Scales rusty brown with a green keel.

\section{F. Mapillaris, Gray. Capillary Fimbristylis.}

Low, densely tuftel; culms eapillary, much longer than the bristle-form leaves; shraths hairy at the throat; involucre 2 or 3-leaved; wmbel compound or cymoseprnicled; spilies oroid-oblong; stumens 2; achenium very obtuse, tipjed with tho minute bulb.

3indy fledls, common. Aus. Culn 3 to 8 inches high. Leaves mostly radical. Scales rusty-brow a with a green keel.

\section{CERATOSCHGEUS, Neeg. Honved Rusm.}

Gr. keras, a horn, and schoinos, a rush.

SPIKes 2 to 5 -filowered, one perfect, and 1 to 1 staminate. Sudles few and loosely imbricated, the lower empty. PERIANTE of 5 or 6 rigid or cartilaginous bristles. STAMEN3 3. Sryle simple, entirely hardening into a long beak with a narrow base, much exserted, and several times longer than the flat and smooth achenium.-Perennials, with tricugila: Teafy culins and large spires clustered in simple or compound terminsl and crpillury cyines.

\section{C. Corniculata, Necs.}

Cymes decompound, diffuse; bristles awl-shaped, stout, unequal, shorter than t: sohcuiats.

Wut ylaces. Auz. Cidin 3 to 6 fect hi h. triangular. Leaves 12 to 10 iroshes iong, $1 / 2$ incil wile. Fruit $w$.th the beik 1 inch lono.

\section{RHYNCHOSPORA, Vahl. BeAK-RU3E.}

Gr. mugchos, a snout, and spora, a seed; from the beaked acheniuin.

SpIKe orete, few to several-flowered. Scales loosely imbricate, the lower ones amaller and empty. Bristues 6 , rarely more. Stanens mostly 3. Strue 2-cleft. AchenIUu lenticular or globular, crowned with the persistent base of the style.-Perennials, with more or less triaragular leafy culms, and snall spikes in terininal and uxillary clusters, cymes or heads.

1. R. Crmosa, Nutt. Tufted Beak-rush.

Culm triangular; leaves lincar, fiat; cymes corymbose; spizies crowded and elusfered; actienium round-obovate, twice the length of the bristles.

Low grounds, rare. July, Aug. Gulm 12 to 18 inches high, slencer.

2. R. ALBA, Vahl. White Beaki-rush.

Culm triangular above; leaves nearly bristle-form; spites zeveral corymb-ciustered, lanceolate; stamens usually 2 ; acheniwin aroid, nerresed at the base, short: than the 9: to 11 yxisties. 
Bogs and swamps, common. July, Aug. Culm slender, 12 to 20 inches high, smooth. Spikelets about 2-flowered. Scales lanceolate, whitish, when old brownish.

3. R. CAPILlacea, Torr: Capillary Beak-rush.

Culm triangular, slender; leaves bristle-form; spikes 3 to 6 in a terninal oluster, and mostly 1 or 2 on a remote axillary peduncle; achenium oblong-ovoid, stipitate, about holf the length of the 6 stout bristles.

Bogs and rocky river-banks. July. Culm, 6 to 9 inches high. Spizelsts 1 to 3. lowered. Seales light-brown, oblong; mucronate.

4. R. GLomerata, Vahl. Clustered Beak-rush.

Culm obtusely triangular; leaves linear, flat; spikes very numerous in distant. clusters or heads, ovoid-oblong; achenium obovate, margined, narrowed at the base; bristles 6 ; downwardly barbed.

Iow grounds. Aug. Culm 1 to 2 feet bigh, smooth. Leaves tat, shorter thane the culm. Seales lanceolate, brownish.

\section{I0. CLADIUM, P. Browne. TwiG-RUSH.}

Ar. klados, a twig or branch, application uncertain.

SpIKes oroid or oblong. SCALES few, imbricate in a somewhat trifsrious nanver; the lowest empty. BRIstues none. STAMENS 2. STYLE 2 or 3-cleft, deciduous: ACHentur ovoid or globular.-Pèrennials, with leafy stems and terminal and axiliary corymbs or panicles.

C. MARICOIDEs, Torr. Smooth Twig-rush. Bog-mush.

Culm obscurely triangular; cymes small, compound ; spices clustered in heads of 3 to 8 together on 2 to 4 peduncles; style 3 -cleft, with entire lobes.

Bogs and ponds. July. Culm 2 feet high, nearly smooth. Leaves channelled; with long compressed point. Scales about,6, brown;-4.lower ones usually ompty.

\section{SCLERTA, Linn. Nut-RUSH.}

Gr. stleria, hardness; from the bony or crusted fruit:

Flowers monocious: Fertile spikes 1-flowered, usually intermixed with clusters of few-flowered staminate spikes. Scatas loosely imbricated, the lower empty. STAMENs 1. to 3. Strle 3-oleft. Achenium globular, seated in a shallow or saucer-shaped disk.-Perennials, with triangulan leafy cuths; and fascicled or panicled spikes.

9Ec. \$. SEcrorra proper.-Perianth lobod or a ring, often obscure:

1. S. Triglomerata, Michx. Three-cliustered Nut-rush.

Culm broadly-linear leaves roughish; fascicles of spikes few, terminal and axilIarx; in triple clusters, the lower geduncled; stamsns 3 ; aekeniwm ovoid-glubular, alightly pointed:

Low grounds. June, July. Culm 2 to 3 feet high, leafy; Renves 2 to 3 lines. wide, rough on the margin. Scales purplish. Achenium large and white.

2. S. PAUCiflora, Muhl. Few-fiowered Nut-rush. omewhat downy or nearly smooth; leaves narrowly linear; clusters fow-fiowered: 
bracts ciliate; scales smoothish; tubercles of the perianth in 3 pairs at the base of the ehining roughened achenium.

Swamps and hills. July. Culm 9 to 18 inches high, roughish above. Fuscieles 2 or 3 ; the lower lateral ones when present peduncled. Achenium white, zough. with elevated points.

Sвс. II. HYPoporux, Nees. Perianth none: stamens 1 or 2.

3. S. verticillata, Muhl. Whorled Nut-rush.

Smooth; culm simple, slender and with the linear leaves smooth; fuscicle 4 to 6 , alternate, sessile, distant; bracts minute, setacaous; scales smooth; achenium glo. bose, rough-wrinkled, short-pointed.

Swamps. June-Aug. Culm 6 to 10 inches high, very slender, terminated by an interrupted spike or fascicle of 4 to 6 rather distant sessile elusters. Scales. purple.

\section{CAREX, Linn. Sedge.}

A classieal name of cbscure signification.

SpIKEs one or several, androgynous, monœcious or rarely dioecious. Scales of the spikes 1 -flowered, equally im. bricated around the axis. STAMENS 3, rarely 2. STYLE single, included: sTIGMAS 2 or 3 , elongated, exserted. Ovary inslosed in an inflated sac (perigynium). AchenIUM lenticular, plano-convex or triangular, crowned with the lower portion of the style.-Perennial herbs, chicfly. flowering in April or May, often growing in wet places, with triangular culms, grassy leaves usually rough on the margins and keel, and bearing the spikss in the axils of green and leaf-like or scale-like-bracts.

BEC. I. Spikes staminato at the summit.

* Stigmas 3.

1. C. Polytrichoides, Muhl. Bristlè-staltied Sedge.

Culm slender; leaves very narrom, shorter than the culm; spilie very amsll, fe tho. alowered; perigynia erect, alternate, oblong, obtuse, slightly nerved, entire at the. spex, green, twice the length of the ovate scale.

Low grounds and bogs, common. Culm a foot high, very slender. Fertile flow ers 3 to 8.

2. C. Pedenculata, Mubl. Peduncled Sedge.

spikes about 4 , on long peduncles, very remote; sheath with green tips much horter than the stalks; perigynia with a long attenuated base, the orifice minute Iy notched, a little longer than the dark purple scale.

Dry woods and rocky billsides, rare. Culms 4 to 10 inches high, tufted, prostrato. at maturity.

\section{C. tmbellata, Schk. Tmbe?led Sedge.}

Tufted; euslms very short; staminate spitie short, ereet, sometimes with \& fo pistillate flowers; fertile spilies 4 or 5, ovoid, few-flowered, the uppermost clcse to the sterile spike and sessile, the rest on radical peduncles of about an unequal height; perigynia oroid, 3-angled, acuminate.

Rocky hillzides. Culms in dense tufts 2 to 6 inches high. Leaves radical, nar: row, rough, longer then the culm. 


\section{C. Pennsylvanica, Lam. Pennsyluanian Sedye.}

Sterile spiles erect, commouly on a short stalk; fertile spities usually 2 , aprozimate, nearly sessile, ovoid, 4 to 6-flowered; perigynium roundish-ovoid, with $\mathbf{s}$ ehort and abrupt minutely-toothed beak about the length of the orate pointed cliestnut-colored scale.

Dry woods and hillsides, commnn. Curms tufted, 4 to 12 inches. high, slender, rough above. Lexves short, somewhat glaucous.

\section{C. VEstita, Willd. Short Woolly Sedye.}

Sterite spizes 1 or 2 , the uppermost cylindrical, shori-stulk u : fitile spities 1 or 2, approximate, sessile, oroid or oblong: perigynia ovoid, downy, nerved, shortbeaked, a little longer than the ovate pointed seale.

Sandy soils, rare. Culms about 2 feet high, tufted. Leaves fiat, shorter than the culms, rough.

\section{C. tentaculata, Muhl. Eong-pointed Sedye.}

Sterile spities solitary ; fertile syilies 2 or 3 , ovoid, oblong, or cylindrical, densely flowered, approximate and diverging horizontally; ferigynin erowded, ovoid, in. mated, very long-beaked, 2-tcotlied at the arex, longer than the long-3ubulate scale.

Wet meadows, common. Culm 12 to 18 inches high, triangiular, rough on the angles. Leaves bright green, longer than the culm.

\section{C. Intumescens, Rudge. Swollen Sedge:}

Sterile spities oblong, peduncled; fertile spities 1 or 2 , ovoid, loosely 5 to 8-forvered, closely approximated, sessile, or the lower on a vory shortly exierted peduncle; gerigynia oro:d, erect-spreading, thpering into a leng beuk, much longer than tho orate cuspidate scalo.

Wut rrounda, common. C'u'm siender, 15 to 20 inches birh, with 1 to. 3 fertilo spikes closely crowãed together. Leuves broad-linear, rough on the margin.

\section{C. Folliculata, L. Tull Yellow Sedge.}

Sierile spil:e solitary, small, short-stalked, or sessile; fertile spiles 3 cr 4; orrit, very remote, the lower on exserted peduncles; perigynia erect-spreading, tapering to a long point, exceeding the ovate white long-awned scale.

Siramps. Eutm 2 tn 4 fiet high, leafy. Leaves flat, smooth, $1 / 3$ inch wide, yelloryLih. Biucts long, foliaceous.

\section{C. Lupulina, Mubl. Hop-like Sedge.}

Stcrile spities short-peduncled; fertile spities 2 or 3 , oblong-ovoid, erect, the upper approsimate, the lowen on more or less exserted stalks; perigynia erect, inflexed, long-beaked, much longer than the lanceolate awned scale. Var. 1. PEdonculata, Beck. Fertile spities all peduncled, distant; the 3 upper subumbellats.

Swamps and wet meadows, not common. A coarse robust species 2 to 3 feet high, with very thick culms, long bright green leaves, and very thick spikes 2 or 3 inches in lengtli.

\section{C. VESTCARIA, Is}

Staminate spites 2 or 3 ; fertile spikes mostly 2 , oblong, or cylindrical, stout; apIroximate, the upper sessile, the lower on a short rough stalli; perigynia obiongoroid, 1i-nerved at base, 10-nerved above, with a short tapering beak, bread: $\boldsymbol{s}$ than the long pointed scale.

Mrarshes, rare. Chester County, Darlington. A bright green plant about 2 fe: bigh. Culm sharply angled and rough, shorter than the leaves.

11. C. Ecabrata, Schweinitz. Rough Sedge.

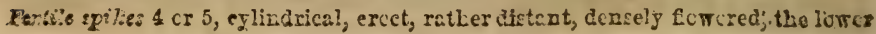


on long stalks; bracts without sleaths; perigynia oroid, contracted at the hase, few-nerred, rough with an oblique notched beak, longer than the ovate brown scale.

Wet meadows and swamps. Culm 18 inches high, and with the dark grcen leares and bracts very rough.

\section{C. DeBilrs, Michx. Weal Sedge.}

Sterile spikes solitary, occasionally fertile at the apex; fertite spities with locse -iteruate flomers, on a somewhat zigz:g rachis; perigynia oblong, tapering at each end trice as long as the orate-lanceolate awned scales.

Moist meadows. June. Culm 1 to 2 feet high, weak and slender, sometimes procumbent, leafy. Leaves narrow.

13. C. orrcocarpa, Schk. Feu-finied Selge.

Sterile spitie solitary, pedunculate; fentile spilies snull. 3 to s-flowered; sty?e rerg. short, thickened towardo the base; porizgizium rouncieh-triangular, with a glightly obique point.

Woods. Outm 6 to 12 inehes high, erect. Leaves longer than the culm, roughi on: the edge, dirk green. Sheatits smooth.

14. O. plantaginea, Lam. Plantain-lize Setho.

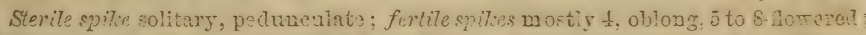

bracts very siont, dark purple or the lowest greenisin at the apez; jeriygnic oblongacute at each end, recurred at the apex.

Shady woods. Gulm 8 to 20 incles bigh, ercet. Icaves ralical, broad, strongly 3-nerved.

15. C. graxularis, Minhl. Pment-fiuted Sutge.

Sterile spine sessile, or short-stalked, occationally lesting a fem frithe flowers; fertile spilies 3 or 4 , eylindrical, densely thowured, remote, the 2 lowest lefuncled; perigynia roundish-ovoid, nerred, minutely pointed; bracts longer than the eulm.

Wet me:durs, coninon. C'ilm 10 to 15 inchts high, erect or somewhat decumber :

16. C. anceps, Willd.. Pule Sulge.

Sterile spilis solitary, triangular; fertile spities. 2 to 4 , slender, looscly florreved; perigynia ovoid, narrowed at each ead. Var. 1. Srratula has the spikes oblong, more densely fiowered, ead the purizynia oboroid with a shorter point. (C. Bianla, Dew.)

Open woorls, common. Cuim 0 to 12 inches hiqh, triangular, leafy near the base. Leares as lowg as the culn, pule-groen and sumewhat giancons.

\section{C. Bullata, Schk. - Iuflated Sedge.}

Sterilc spilies 2 or 3 ; fertile spities 1 or 2 , mostly 1 , approsimated, oblong or cylin = drical, stout, sessile or ou short smooth stalks : perijynia spreading, oroil, longbeaked, trice as lon ris tha lanc on ate seale.

Wet mealows. Culm $1 \frac{1}{2}$ to $2 \frac{1}{2}$ feet hish, triangular, rough above, leaty, Bracts and leaves narrow, about as long as the culm.

\section{C. hystericina, Willd. Porcupine Sedye.}

Sterite spitie solitary; fertile spities 2 to 4 , oblong-cylindrical, densely flowered; the uppermost nearly sessile, the lower on long stalks, at length nodding; perigynia ovoid, inflated, spreading, many-nerved, beaked, twiee as long as the oblong awued scales.

Wet meadows. A pale or yellowish-green plant, 1 to 2 feet high. Leaves lon linear-langeolate. Fertile spilies $3 / 4$ to $1 \frac{1}{2}$ inch long. 
- Stigmas 2. Spikelets mostly sterile at the summit.

19. C. вRомоIDes, Schk. Brome-lilie Sedye.

Spities 4 to 6, alternate, oblong-lanceolate, some of the central ones wholly fertile; porigynia erect, narrow-lanceolate, with a tapering point, longer than the lanceo late scale; style jointed at the bas?.

Swampy grounds common. Culm 12 to 18 inches birb, slender, rough above. Scale light brown. Occasionally diocious.

\section{C. vulpinomea, Michx. Fox Sedge.}

Spite oblong and dense: or more or less interruptid, of 8 to 10 crowded ciusters ; perigynic orate from a broad base, with a more or less abrupt beak, diverging at maturity; scale ovate, cuspidate.

Low grounds, common. Eulm 18 to 21 inches high, obiusely triangular abore, leafy. Spities $1 \frac{1}{2}$ to $2 \frac{1}{2}$ inches long.

21. C. stipata, Muhl. Beaked Sedlye.

Spii:es 10 to 15 aggragated, or the lower ones distinet and sometimes compound; perigynic lancolate, with a long bewk teparing from a truncate base, longer than the sca?e.

Swamps and low grounds, common. Culm 1 to 3 feet high, thick aud succulent. Spitie 2 inches long, straw-eolor.

22. C. Rosea, Schk. Rose Sedge.

Spikes 4 to 6, the uppermost approxinate, the others all distinct and the lowest often remote; perigynia oblong, 8 to 10 in cach spike, narrow at the base, rough on the margin, twice as long as the ovate obtuse scale.

Moist woods and madows, common. CuIm 12 to 15 inches high. Spiries yellowth-green. Varies with weak slender culms, and small 3 to 4 flower.d spikes.

\section{C. Retroflexa, Muhl. Retroflexed Sedye.}

Spit:es 4 or $;$, all approximat ${ }^{2}$, the 1 or 2 lowest distinct but not remote; perigynia about 5 to 7 in each spike, ovate or ovate-lanceolate, smooth on the margin, epreadlag or reflexed, not much exceding the ovate-lanceolate pointed scale.

Moist meadows and pastures. Culm 12 to 15 inches high, slender.

\section{C. cephalophora, Muhl. Oval-heacted Sedye.}

Spines 5 or 6 , small, and densely aggregated into a short ovoid head; perigynia broadly ovate, with 2 or 4 distinct nerves on the outer side, searculy longer then the ovate roughly-pointed scale; achenium roundish ovate; s.yie short tumid at the base.

Woods and fields, common. Culm 1 to 2 fuet hi hh, leafy at base. Whole pIant green.

25. C. caespitosa, L. Smaller Bog Sedye.

Sterile spihes solitary or sometimes 2, cylindrical-oblong; fertile spities mostly $\mathbf{3}$, cylindric, obtuse, distant, the lower on a short exsert peduncle; perigynizm ovoiu or oral, scmewhat acute, smooth, mostly longer than the oblcng obtuse blackish scale.

Mountain bogs. Culm 12 to 18 inches high, slightly round abore. Leaves flat, light green. Beck.

26. C. CRINITA, Lam, Fringed Sedge.

Sterile spities 1 or 2 , often with fertile flowers variously intermixed; fertile spiice 8 to 5 , long-cylindrical, densely flowered, on exserted nodding stalks; bracts longer than the culm; perigynia roundish-obovate, slightly inflated, obscurely nerred, shorter than the oblong light-brown scalo. 
Wet meadows and borders of rills, common. Culm 2 to 4 feet high, sharpiy ongled, w:th pale leaves about $1 / 4$ inch wide. Fertile spiles 2 to 3 inches long.

27. C. STRICTA, Lam.

Sierile spities 1 to 3 ; tho fertile 2 to 4 , cylindrical, slender, usually barren at the simmit, sessile or the lower on a short staik; lower bracts auricled, seldom exceeding the culm; perigynix ovate-acuminate or cllipticul, with a short, entire, or slighty notched point, usually shorter and broader than the reddish-brown scale.

Wet moalows and swamps, common. Culm 2 to $2 \frac{1}{2}$ feet high, slender sharply triangular, rough. Leaves shorter than the culms, narrow, rigid, rough and glaucous. Grows in large thick tufts.

28. C. Alopecoiden, Tuckerman. Fox-tail Sedze.

Lead of 8 to 10 aggregated spikes, oblong; dense; perigynia compressed, obscuro Is nerve1, ovate, some what longer than the scale; achenium pyriform.

Woods not common. C'u'm 2 to 4 feet high, rougla on the angles. Spitie yellow. ish-green.

Bzc. II. Spites pistillate at the sum:nit.

- Stigmas 2.

29. C. Frasert, Sims. Fraser's Sudje.

Spile simple, ovoil; perigynicm oroid-subglubose, entire at the point, striate, longer than the oblong scale.

Mountains. Chlm about a foot high, sheathed at basc. Leaves radical, broad, wavy:- Beck.

\section{C. stellulata, Good. Star-like Sedge.}

Spizes 3 to 5, distinct, obovoid or roundish at msturity; perigynia orate, acumlnate, scabrous on the margin, at leagth spreading horizontally, longer than tho orate aeute scale; achenium oblong or ovate; sly'e s'ightly tumidat the base. (C. ecirpoides, Sciki.)

Swamps and wet moadows, common. Cul 8 to 18 inches high, stiff, leafy bo. low. A rariable plant embrucins sovera! nominal varietics, some of which occar sionally bear divecious spikes.

\section{C. scoparia, Schk. Broom-like Sedige.}

Spikes 5 to 8 , club-shaped, at length ovate, more or less approximate, somelimes forming a dense head; perigynia narrowly lanecolate, tapering into a long slender beak, longer than the lanceolate pointed scale.

Low meadows, common. C'ulm 1 to 2 feet bigh, triangular rough above. Leaves longand narrow. Spilic brownish or straw-colored when ripe.

\section{C. ragOPODIOIDEs, Schk. Hare's-foot Sedije.}

Spize 10 to 15, approximate, alternate and sessile; perigynia ovate-lanceelate, twice as loug as the ovate-lanceolate scale; achenium nariowly oval, on a short Bt:lk. Var. CRISTATA has the spikes closely aggregated, with the perigynia spreading.

Wet feids, common., Cutm 1 to $2 \frac{1}{2}$ feet bigh, furrowed. Spite sub-cylindrio when young.

\section{C. straminea, Schls. Straw-colored Sedye.}

Spikes about 6, roundish-ovoid, approximate; perigynia orbicular-ovate, much ompressed, broally and membranaceously winged, somewhat longer than tho lanceolate scale; achenium sessile, oval.

Wet meadows, borders of wooks and felds. $\triangle$ rariable spocies, including several nomias spocies. 
* * Stigmas 3 .

\section{C. Shortiana, Dew. Short's Sedge.}

Sepikes about 5, cylindrical, erect, more or less distant, and the lowest rather remote, all androgynous and densely flowered; perigynia broadly-obovate, abruptly contracted at the base into a short atalk, but little longer than the short-pointed somewhat obovate scale.

Marshes, Southern parts of the State.

35. C. miliacea, Mul:1. Millet-like Sedge.

Sierile spike solitary, pedunculate; fertile spikes 3 , slender, cylindrical, on filiform nodding peduncles; perigynia ovoid triangular, slightly beaked, entire at the orifice, as long as the ovate-lanceolate scale.

Wet meadows. Culm 1 to 2 feet high, slender, leafy below. Leaves narrow, about as long as the culm, yellowish-green.

36. C. squarrosa, L. Squarrose Sedge.

Fertile spikes ovoid or oblong, obtuse and very thick, rigidly erect on short stalks; perigynia longer than the lanceolate pointed scales, which are ncarly cancealed by the crowded bases of the fruit.

Low meadows. Culm 2 feet high, triangular, rough, leafy. Spike 1 to 2 inches long, $1 / 2$ to $3 / 4$ inch in diameter, densely flowered.

\section{ORdER 133. GRIMINERE-Grass Family.}

Grasses, with usually hollow stems (culms) closed at the joints, alternate 2-ranted leaves, their sheaths split or open on the side opposite the blade; the hypngynous flowers imbricated with 2-ranked glumes or bracts. STAMENs 1 to 6, commonly 3: AfTHERS versatile, 2-celled. Strues mostly 2 or 2-parted: stigmas feathery or hairy. Ovary 1-celled, forming a seed-like grain (caryopsis) in fruit. FlowrRs green, in small spikelets, arranged in a spiked raceme or panicled mannor.

\section{LEERSIA, Solander. White Grass.}

Named in honor of I. D. Leers, a German botanist.

Spikelets 1-flowered, perfect, flat. Glumes none. PALEA (outer perianth) compressed-carinate, awnless, bristly ciliate. Stamens 1 to 6 . Stigmas feathery, the hairs branching.-Perennial marsh-grasses with flat leaves, which with the sheaths are rough upwards.

\section{L. oRysordes, Swartz. Cut.grass. False Rice.}

Panicle diffusely branched, often sheathed at the base; flowers elliptical, with $\mathbf{3}$ stamens; paleo strongly bristly ciliate.

Wet places, common. Aug., Sept. Culm retrorsely scabrous, 3 to 5 feet higb. Leaves lanceolate, acuminate, very rough with hooked priekles. Punicle with zoany widely spreading and flexuous branches.

\section{L. Virginica, Willd. White Grass.}

Panicle simple, the lower branches spreading, the fiowers closely appressed and omewhat imbricated on the slender branches; flowers oblong, with 2 stamens; palece sparingly ciliate, greenish-white. 
Wet woods. Aug. Culm 2 to 4 feet high, sleniler, hranched, erect or decumbent. Leaves linear-linceolate, rough. Puricle terminal, at len th much exsertisd.

\section{ZIZANTA, Gronov. Wild Rice.}

Gr. Zizanion: the ancient name of some wild grass.

Flowers monoecious, the staminate and pistillate in 1. flowered spikelets in the same panicle. GIUnes none, or only rudimentary. PALER 2 , herbacenus, concave, awnless in the sterile. Stamens 6 . Strguas pencil-form.-Lorge and often reet like water-grasses, with the spikelets joinled with the elavate pedicels, very deciduous.

1. Z. Aquatica, L. Indian Rice. Water Oats.

Panicle pyramidal; the lower branches spreading and staminate. the upper ereot = and pistillate; pedicels strongly club-shaped; lover pulece long-awned, rough; styles distinct.

Swampy borders of streams and in shallow water. Ang. Ann. Culm 3 to 9 feet high, stnut terete. smonth. Leaves 2 to 3 feet iong. lineir. lan eelate. Punicle terminal, a font or more long. Grain linear, sluncter, $1 / 2$ inch long; gathered for food by the North-western Indians.

2. Z. Miliacea, Michx. Millet-like Wiater-Rice.

Punicie diffuse, pyramilal; stiminate and pistillute flowers infermixed; awne Bhort; :tyles united; grain ovate.

Swamps; \&c. Aug. Per. Culm ereet, 6 to 10 feet high. Leaves involute, very long, narrow, glaucous. Panicle terminal, large.

\section{ALOPECUTUS, Linn. Fox-tam Grass.}

Gr. alopex, a fox, and oura, tail; in allusion to the form of the spike.

Spikelets 1-flowered. Glunis 2, boat-shaped, and keeled, nearly equal, united at the base, cqualling or exceeding the lower palere, which is awned on the beek below the middle; uppor paleæ none. Stanens 3. Strues mostly united: stigmas long and feathered. - Panicle spiked, cylin dric, terminal.

A. Aristuxatus, Michx. Wild Wuter-Foxiail.

Glaucous; palese rather longer than the obtuse glumes, which are wedge-shaped at the base, and hairy on the back and margin; awns twice as long as the flower; anthers oblong.

Wet meaduws, rare. June, Aug. Per. Culm 12 to 18 inches high, ascending knee-jointed at the base, smooth, terete. Leaves linear-lanceolate, very acute Spike nearly 2 inches long, pale.

\section{PHLEUM, Linn. Trmothy.}

An ancient Greek name.

GLUMes 2, much longer than the palex, distinct, equal, boat-shaped, beaked or mucronate. YALEAE 2, included in T2 
the glumes, awnless, truncate. STYLES distinct. - Spite very dense, cylindric.

P. pratense, L. Timothy. Herd's-Grass.

spicie cylindrical, clongated; glumes ciliate on the back, truncate, tipped with a bristle less than half their length.

Mvadows. \&e., naturalized, and much cultivated. Gulm 2 to 3 fiet high, simple, swooth. Luves flat, snooth and glaucous. Spike grean. Anthers purplish. fiateened very yaluable fur hay.

\section{Villfa, Adans. Rush-Grass.}

SPIKELETS 1-flowered, in a contracted or spiked paniclo. RLumes 1-nerved, carinate; the lower one smaller. PALEA 2 , much alike; the lower one 1-nerved, rather acute, longer than the glumes; the upper 2-keeled. STAMENS mostly 2 . STIG Mas simply feathery. Grain oblong or cylindrical, sleciduous.-Cuims wiry or rigid: leaves involuse, their slieulhs ofien enclusing the lateral panicle. Flower nearly sessile in the glones.

3. V. VAGIN RELOR, A, Torr. Fidden-fowered Rush-Grass.

Culms s'ender, ascending; leaves involute-asl-shaped; panüles simple and spiked, the iateral and often the terminal concealed in the sheaths; gluines equal, about so large as the palese.

Sundy soils. Sept., Oct. Ann. Culms alout a foot birh, tuftrd. Leares with a slesder yoint. Punicle oblong compressed, few-fiowered. Anthers purple.

2. V. aspera, Beauv. Rough-leaved Rush-Grass.

Lowest leaves very long, rigid, rough on the edges, taporing to a long involute aud filform point; the upper ones short, involute; shentis partly inclosing the coutracted panicle; palece much longer than the unequal glumes.

Sandy fields and dry hills. Sept. Culm 2 to $\&$ feet high, simple, terete. Leaveg 1 to 2 feet long. Punicle lateral and terminal. Pulce rough above, smooth oz hairy below, of greatly variable proportions.

\section{SPOROBOlUs, R. Brown. Drop-seed Grass.}

Gr. spora, seed, and bullo, to cast forth.

SPIKELETS 1-(rarely 2)-flowered, in a contracted or open panicle. Fuowers nearly as in Vilfa; the palex longer than the unequal glumes. STAMens 2 or 3 . Grain a globular utricle, containing a loose seed, deciduous.

\section{S. Junceus, Kunth. Rush-like Drop-sced Grass.}

Zeaves involute, narrow, rigil, the lowest elongated; cu? $m$ naked above, bearing - aarrow looso panicle; glumes ovate, rather obtuse, tho lower one kialf as long as the upper one.

Diy soil. Aug. Culm 1 to 2 fect bigh. Spikelets 1 to 2 ines long slining. 


\section{Agrostis, Linn. Bent-Grass.}

Gr. agros, a ficid; the place of growth.

SPIKzizets 1-flowered, in an open panicle. Glumes somewhat unequal, usually longer than the palea, pointlens.

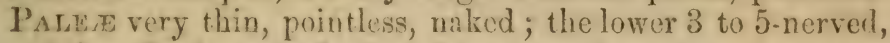
mostly awned on the lack; the upper often minute or wanting. Stamens innstly 3. Grata fico-C'ulmes usually tufied, slender, bearing a diffuse panicle.

Sec. :. Triciodium, Micha-Tpper palea none, or obsolete.

\section{A. soabrom, Muhl. Rozegh Thin-grass.}

Culm senisulate at base, assurgent; leaws flat, linear-laneolate, senhrous on the margin; puacte at length cilluseiy sprealing, jate green, the branches short; glumes unoqual, longor than the awnless palese. (A. perennans, Gray.)

Damp sumied places. Juiy, $\Delta$ urg. Fer. Cuims 1 to 2 fuet bigh. Leaves 4 to 6 lnches long, 1 to 2 lines wide.

2. A. Laxiflonum, Michx. Hair-grass.

Culms very slender, orect; lears short aul narrow, lancolinar, the lower sonn

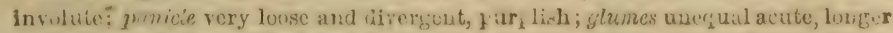
than the awnless or short-awued palea.

Dry fieliz, comaxm. May, June. Jor. Cuim 18 inches high. Lnuer leates 3

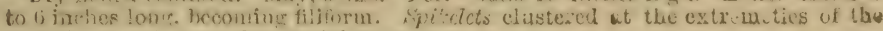
Wranchlets. 1 somewhat variable species.

9rc. II. Aanostus proper.-Upuer palec manifiet.

3. A. velasas, Wiul. Redton. Herd's-grass:

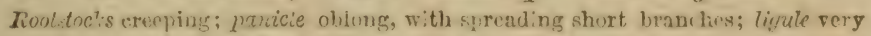

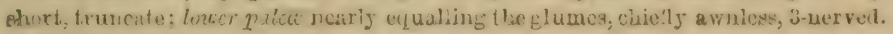
(A. hispida, Willd.)

Low westows, introduced. Cutne 1 to 2 fint ligh mostly upiglit. Leares linear I'unicle furple, 4 to 6 inches long. A valuabie grass.

4. A. ALBA, L. White Bent-Grass. Fiarin-Grass.

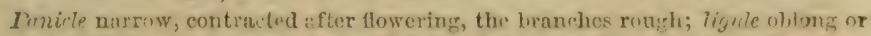

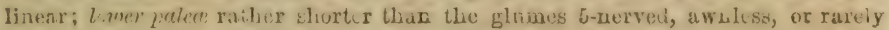
ehort-âwed on tlie back.

Noist mondows aud fields, introduced; native northward. July. Culm 1 to 3

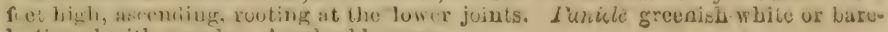
ly. tinged with purplo. A valuable grass.

\section{CINNA; Linn. WOOd RERD-Grass.}

Sirkeriers 1-flowercd, flattened, crowded in an open panicle. GLumes lanceolate, acute, strongly kecled, nearly equal. PALEe 2, nearly equal, compressed, shortly stipitate, naked at the base, the lower one longer than the upper, short-awned near the summit. STAMEN 1, opposite the upper palez. Grain linear-oblong, frec.-Perenniat, rather sweet-scented grasses, with simple upright culms, bearing a lurge sompound teiminal panicle, and lincas -lanccolute flat leares. 
C. ARundinacea, L. Common Wood Reed-Grass.

Punicle spreading. mostly contranted in fruit; lower olume and the upper paleos about $1 / 4$ shorter than the lower paler.

Moist grounds. Aus. Culm simple, smonth, 2 to 5 feet high. Leaves a foot or more in lensth, linear-lanceolate, rough on the margin. Punsicle 8 to 12 inchea long. Flowers green or purplish.

\section{MUHLENBERGIA, Schrebor. Drop-seed Grass.}

Dedicatid to the Rev. Di. Muhlenburg, a distirguished American botanist.

SPIKELETS 1-flowered, in contracted or rarely open panieles. Glumes mostly acute, persistent; the lower rather smaller or minute. linow ver very short-stalked or sessile in the glumes. Parres usually bearded at the base, deciduoug with the inclosed grain, often equal; the lower 3-nerved; mucronate or awned at the apax. STamens 3.-Chiefly perennials, with branched and often diffuse rigid culms and shor: narrow leaves.

1. M. sobotinera, Gray. Shonting Muhtenbergia.

Culms ascending, sparingly branched; panicle contracted, fliform, simple, with appressid alternate branches; glumes barely pointed, almost cqual, $1 / 3$ shorter than the equal palex; lower pa'ece mueronate at the tip.

Onen rocky woods. Aug. Caln 2 feet high, prolucing young shoots from the roots. Leaces pale green, somewhat scibrous. Pinicle with the Howers rather crowded.

2. M. Mexicana, Trin. Méxicxn Muthlenbergia.

Culms ascending, much branched; panides lateral and trminal, ofton included at the base, contracted. dense-flowered; glumes acumiaate awnless, unequal; pulcos about as long as the glumes, equal, awnless.

Moist grounds. Aug. Rnot cr eping. $C_{46}{ }^{7} m s 2$ to 3 fiet high. Lexves broadlinear, flat. Finicles numerous, terminating the brauches, pate green or purplish

3. M. sylvatica, Torr. \& Gr. Wood Muhlenbergia.

Culms ascending, much branched and diffusely spreading; panicle slender, con. tracted, dunsely-many-flowered; gliumes almost equal, bristlo-pointed, nearly as long as the lower long-awned paler.

Low or rocky woods, common. Sept. Roob creeping. Culm 2 to 4 feet high.

4. M. WILLDENowir, Trin.

Culms urright, slender. simple or sparingly branched; panicle contracted, slender, loosely fowered; glumes slightly unequal, short-pointed, half the length of the lower long awned palew. (Agrostis tenuiflora, Wulld.)

Rocky wools. Aug. Koot creeping. Culm 3 f et high, with swelled and puber. scent joints. Leares few, spreading, strongly nerved.

5. M. DIffusa, Schreber. Drop-seed. Nimble Will.

Culms diffusely much branched; panicles coniracted, slender, rather loosely many-flowered, terminal and lateral; glumes very minute, the lower obsolete, the upper truncat; awn about $t$ wice as lon as the paleæ.

Dry hill : and woods. Aug., Sept. Cubm 8 to 18 inches high, compressed. Leares. rough. Bristle purplish. 
10. BRaChreltTrum, Beaur. Short-Husk Grass.

Qr.brachus, short, and elyiron, husk; from the very short glumes.

SPIKELERs 1-flowered, with a filiforn pedicel of an abortive second flower, fow in a simple appressed raceme. Lower GIUMLS obsoleto. PALEA involute, inclosing the linearcblong grain, somewhat equal, the lower 5-nerved, the upper 2-pointed. Sramexs 2; the linear anthers and stiginas very long.-A perennial, grass, with simple culms, rather downy sheaths, brval and fit lunceolate pointed leaves, and large sipikelets.

\section{B. azistatum, Bozuv.}

Culin sreet, from creeping rootutocks; panicle simple, loose.

Rocky woods, common. June. Culm 1 to- 3 fiot high, slender. Iexines 1 to 6 iuches long. Luwer puleve vith a very lug awn. Syikelets $1 / 2$ inch long.

\section{Calayagrostis, Adans. Pued Bent Griss. Gr. calamos; a reed, and agrostis, a griass.}

Spikezers 1-Alowered, in an open, eontractod, or spikel panicle. Grumes 2, keeled or buat-shaped, often acute, nearly equal. PALEA 2, mostly shorter than the gylumes, surrounded with a copious tult of wi ite histly hairs; the luwer one bearing a slender awn on the back or below the tip, rarely amnlege. Stauens 3. Grain free.-Perenuigl, with rinning routotueis, and mostly twll and simple rigid fowers.

\section{T. O. Canadensts, Baziv. Cunatian Reed-Grass.}

Pincle oblous, loose; liwer pilce Le rly a long as the lanceolate acuteglumer,

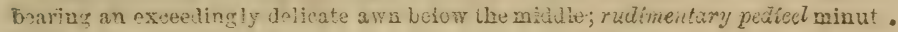
(Arundo Cunadensis, Mich $x$.)

Wet grounda. Julv. Ruther glaxcous. Culm 3 to 5 fcet high. Leavos a font

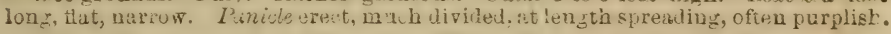

\section{C. Confrnis, Nutt. Close-flowered Reed-Grass.}

Punicle elongated, narrow, the branches appressed after flowering, pale; lower palen nearly equalling the oblong lancelate acute glumes, with a rather stout an 1 slightly exserted awn betwen the mildle and the base; puppus noarly as long as the flower.

Swamps. July. Cuin crect, simple. about 3 feet kigh. Leaves about $1 / 4$ inch wile, smooth. Punicle 5 to 8 inches long.

3. C. coarctata, Torr. Glaucous Reed-Grass.

Panicle contracted, dense; lower prlea shorter than the acuminate tips of tho lanceolate glumes, awned; pappus $2 / 3$ as loug as the flower.

Wet mealows. Ang. Cu'm 3 to 5 feet hich, sinple, som what glaucous. Leaves liwear laceo'ate, scabrods and somewhat hairy. Punicle 5 to 6 inches long.

\section{STIPA, Linn. Feather-Grass.}

Gr. sfypa, tow; in allusion to the flaxen appearance of the feathery awns of some of the species.

Srikelets 1-flowered; the flower stipitate. Lowen PA. T.2* 
GRAMINE西.

LEA coriaceous, cylindric-involute, elosely embracing the smaller upper one and the cylindrical grain, bearing a long and twisted simple awn, jointed with its apex. STAMENs. mostly 3. Stramas plumose.-Perennials, with narrono involute leaves and a loose panicle.

\section{S. AvenaceA, I. Black Oat-Grass.}

Culm slender, leafy at the base; leaves nearly bristle-form; panich spreading: nomewhat one-sided; palece blackish, nearly as long as the pointed glumes; an very long, naked.

Dry or sandy woods. July. Culm 1 to 2 reet high. Leaves mostly radicel, 8 to : 8 inches long. Panicle nodding. Arst 2 to 3 inches long.

\section{ARISTIDA, Linn: Triple-AWNed Grassi}

An ancient Latin name, from arista, a beard or awn.

Flowers stipitate. Glumes uncqual, often bristle pointed. LOTER PALEe tipped with a triple awn; the upper much smaller. Scales 2, entire, smooth.-Annuals or perennials, with branching culnus, narrow, often involute leaves, and: racemed panzeles:

1. As nichotoma, Miohx: Poveriy Grass.

Culms in tufts, much fork-branched; spinelets in short contracted racemes? fover rather shorter than the glumes; lateral awns very short, the middle not longer than the palcr, bent down.

Sterile coils. Aug. Ann. Culm 5 to 15 inchos high. Leaves fiat, very slender, mootuish. Racemes on clubshaped peduxclear.

2. A'. Purpurascexs, Poir Purple Threg-awned Grass:

oulnes mostly simple, filiform, erect; leaves very narrow, flat; panicle spikec, dencely fowered; awns nearly equal, 3 or 4 times the length of the palem, the middle one rather longest.

Sandy fields and woods. Sept. Per. Culm 2 to 3 foot high, clot laed with lons: mopth leaves below. laxicle 1 foot long, purple.

\section{SPARTINA, Schreber. Cond or Marst Grasa.}

Gr. spartina, a cord; on account of its long and tough leaves.

Spikelets imbricate, 1-flowered, much compressed: Grumes and pale ane unual, amnless. Stamens 3. Styleg. long, mostly united below.-Perennials, with simple and rigid reed like culms, long. and tough leaves, very. smooth sheutho, and racemed spikes.

1. S. cynosvrombs, Willd: Fresti-water Cord-Grass...

Leaves very long, filiform at the end, keeled flat, at length convolute; spikes $\$$ to. 10, scattered, spreading; glumes awn-pointed; style 2-cleft at the summit.

Banks of streams and marshes. Aug. Culm 3 to 8 feet bigh, smooth, teretors. Theaves 2 to 4 feet long, narrow. Spilces linear, 2 or 3 inches long, straw color. 
2. S. JUN CEA, Willd. Rush-lile Cord-Grass.

Culms low and slender; lea ves narrow and rush-like, strongly involute; spikes 1 to 5, short-peduncled; glumes acu te, rough-serrulate on the back; palex rathe obtuse; styles distinct nearly to the base.

Salt marshes and river banks. July, $\Lambda u_{c}$. Root creeping, forming thick tufts culm 1 to 2 feet bigh, rigid, Emooth. Leaves 6 to 10 inches long, emcath. Syritese coually 3.

\section{ATHEROPOGON, Muhl.}

Or. ather, a bristle, and pogon, a bard; the beards being bristle-liko.

Brikelets one-sided, nearly sessile, alternate, 2 or 3 : fowered, the terminal flower abortive. Glumes 2, mem. branacecus, uncqual; the lcwer storter. LGWIR TALF E⿸ 3. nerved, 3-toothed at the apex, the upper $3 \cdot$ nerved and 2. toothed. ABortive Flowers pedicellate, neutral. Sta. MENS 3.- Spilies short, arranged in a raceme.

\section{A. Apludordes, Muhl. Bristle-beard Grass.}

Culms erect, in tufts; sheath commonly hairy; leaves narrow, acuminate; spizes linear-oblong, almost sessile, horizontal, numerous or rather remote, furming a trict raceme; rachs tipped with a slender naked point.

3:y rocky banks, rare. Aug. Per. Culm 1 to 3 fect high. Leares lanceolste, nttenuato at tho end. Spites 20 to 40 on short tiat pculuaclig. Antiters urigid red.

\section{CYNODON, Richard. Bermuda Grass.}

\section{Gr. kuon, a dog, and odons, a tooth.}

Gpiketers 1-flowered, with a naked rudiment of a seends flower, imbricate-spiked on one side of a flattis!s rachis. Grumes keeled, pointless, somewhat unequal. Paleze. pointless and awnless, the lower larger, boat-shaped. STAMENS 3.-Low diffusely-branched and creeping perennials, with short. fluitish leaves, und uswally digitate spikes at the naked? sssmmit of the flowering culms.

C. Dactylon, Pers. Dog's-tooth Grass.

Spikes digitate, 3 to 5 ; palece smooth, longer than the blunt rudiment.

Bandy waste places; introduced. July, Aug. Oulm cropeping, a foot of mots: lang, prostrate. Stiginas dark purple.

\section{EleUsine, Gært. Crab-Grass. Yard-Grass.}

Gr. Eleusin, the town where Ceres, the goddess of harrests, was worshipped.

GrIKEI.ETS sessile, 2 to 6 -flowered, with a terminal naked rudiment. Glumes membranaceous, pointless, shorter than: the flowers. PALE membranaceous, awnless and pointless, the lever orate, keeled, larger than tho upper. STauress 2. 
Pericarp free from the oval seed.- Lnow anvuals, with flut leaves, and digitute or clustercd 1-sided spikes.

F. Indica, Gart. Dog's-tail Crass. Wiregrass.

Culms branched at the base, ascending; flattened; spizies 2 to 5 ; spiticiets about 5-flowered.

Yards and cultivated grounls; intro:luect. Tily-Nov. Cu'm 9 to 18 inchas

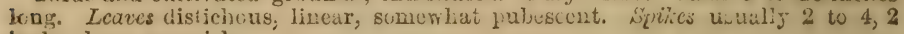
inehes long; greenish.

\section{TRICUSPIS, Beauv.}

Lat. tricuspis, three-pointed; alluling to the lower parice.

Spikelets nearly terete, 3 to 12 -fowered, tho terminal flower abortive. GLuncs shorter than the flowcrs. Inwer PALEIE bifid at the apex, and tricuspidate by the projecting kecl and marginal norwes, the base villous. STAMeNs 3. Stramas dark purple, plumose.-Laves acuminate; sheatlio basded at the throat. I'anicle compound, spreading : the spilselds gurplish, ofien racerred.

T. EESLERIOHDE, Torr. Tall Redtop.

Punicle loose, sirracling; branclies flexuous, smooih; spritelets ovate-lanceolate, 5 to 8 flowcred, nearly tercte, shining.

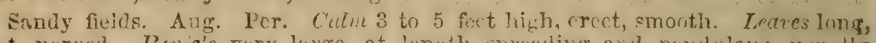

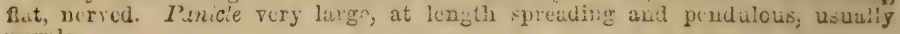
gurple.

\section{DACTYLIS, Linn. Orchand Griss.}

Gr. da?.tylos, a finger; in allusion to the form of the spike.

SpIKelers 2 to 7 -flowered, crowled in one sided clusters, forming a branching dense panicle. GiLumes unequal; the larger keeled, mucronate; the lower 5-nerved, with a fringed keel; upper bifil. Stamens 3. Stramas plumose-- 1 ?'. venniuls, with keeled leaves, and contracted grlomerate panicles.

D. Glomerata, L. Rough Orchard Grass.

Roush and rather glaucous; le:tves broadly lincar; branches of the panicle naked at the base; spilcelets 3 or 4 -flowered.

Fields and meadows; introlueed from Europe. June. Culm 2 to 3 feet bich, eruct. Punicle glaucous. Good for hay.

\section{KGELRIA.}

In honor of M. Kaler, a German botanist:

Sipikelets compressed, 2 to 7 -flowered. Guumes: 2, shorter than the flowers; the lower much narrower, keeled. PALEA membrunaceous, unequal ; the lower acute or obtuse, unawned or with a short awn below the tip; the upper 2- 
keeled. Stamens 3. Strues very short.-Perennials, with simple and tufted culms, often downy sheatlis, and contracted or spike like panicles.

SEC. I. K KeLERIA proper--Spilielets 3 to 7 -flotered, crowded in adenso and narrow spike-like panicle.

1. K. Cristata, Pers. Crested Koeleria.

Punicle narrowly spiked, interrupted at the base; spilielets 2 to 4 -flowered; loner palea acute, often mucronate-pointed.

Dry grounds or hil's. June. Culm 23 to 30 inches high, smooth, leafy to ono ha!f its height. Leuves flat, erect, pubuscent, 2 to 3 inches lung. Sheatlis smooth. or downy.

SEC. Ir. ReEOtLEA, Kunth.-Spirelets usually 2-flowered, and with an atortivo rudiment or pedicel, in a contracted or slender paniele.

2. K. Pennsyluanica, DC. Penmsylumian Koeleria.

Panicle long and slend $r$, rather loose, the racomose branches somewhat elonga. ted; upper glume obovate, barely obtuse; lower pulea rou $\mathrm{h}$.

Moist woods and meadows. Mity, June. Culm about 2 feet high, simple. Leares

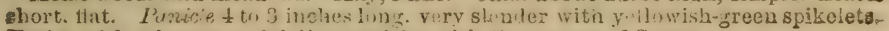

Varies with a larger and fuller panicle, with the aspect of Cinvis.

\section{MELiCA, Linn. Melic-Grass.}

An old name from meti, honey.

Brikelets 2 to 5-flowered, the 1 to 3 upper fowers im. perfect and dissimilar, convolute around each other. GLumes usually liarge, 2 -valved, uncqual, the upper 7 to 9 -nerved. Palem membranacecous, unarmed. STAMens 3. StigMas branched plumose.-Leaves flat and soj $t$. Panicle simple or sparingly branched.

M. speciosa, Muhl. Shony Mflic-Grass.

Smooth: panic'e loase, erect, with a few spikelets on each branch, ench cpikeled contuining 2 perfect flowers and a stalked rudiment composed of 3 abortive oner 8 : glumes and palea very obtuse.

Rich soil. June. Per. Culm 3 to 4 feet high. Spilelets $1 / 2$ inch long.

\section{BRIZA, Linn. Quaking Grass.}

Gr. brizo, to nod or hang down; alluding to the pendulous spikelets.

Spikelets many-flowered, ovate or heart-shaped. Glumes: roundish, unequal, purple. PALEe inflated; lower one cordate at base, embracing the upper, which is nearly round and much shorter. Stamens 3. Stigmas branched plumose. (irarn flattened.-Leaves fat. P'enicle lonse, with. the large and showy spikeléts "ften drooping on delicate splkelets.

B. media, L. Common Quaking Grass.

Punicle erect, the branches spreading; spileelets 5 to 9-flowered, beart-ahaped when old.

Meadowa; naturalized. Juno. Per. Culm 3 to 4 feet higho 


\section{GLYCERIA, R. Brown. Manna-grass.}

Gr. glukeros, sweet; alluding to the sweet-tasted grain.

SprKelets mostly terete, long, linear, many-flowered; Rachis jointed. GLumes 2, membranaceous, nearly equal, pointless. PaLEe somewhat chartaceous, nearly equal, naked, the lower rounded on the back, strongly 7-nerved, the upper 2-keeled. Stamens 3 or 2 . Strigmas decompound. Grain oblong.-Perennial smooth marsh-grasses, witth simple culms from running root-stocks, fiat leaves and nearly entire sheaths; the panicle loose and open.

\section{G. Fluttans, R. Brown. Common Manna grass.}

Panicle 1-sided slightly branched; spikelets 7 to 13-flowered, appresscd; lower palca oblong, obtuse.

Shallow water, common. June, July. Culm thickish, 2 to 15 feet high, from a creeping root. Leaves short and rather broad; very smooth. Panicle 12 : to 15 inches long, slender, partly concealed in the upper sheath.

\section{G. oвtusa, Trin. Obtuse-flowered Manna-grass.}

Punicie dense, narrowly oblong; spizelets ovate, 6 to 7 -flowered; glumes scarious ; lower pa?ece ovate, obtuse, the upper as long when old.

Sramps, rare. Aug., Sept. Culm stout, 1 to 2 feet high, rery leafy. Lieaves linear, long, smooth. Puricle 3 to 4 inches long, many-flowered.

\section{G. mlongata, Trin, Long-panicied Manna-grass:}

Panicle narrowly racemose, elongated, somewhat 1 -sided, recurving; the branthes appressed, bearing tie 3 to 4-flowered spikelets nearly to the base; $l$ wer palece oblong-ovate, obtuse, rather longer than the upper.

Wet woods, common. Jnly. Culm 3 to 4 feet high, simple. Leaves 1 foot or more long, rough. Punicle 1 foot long. Spilielcts pale, with short pedicelled flowerm.

4. G. NeRvata, Trin. Nerved Manna-grass.

Panicle diffuse, loose, the bravches capillary, at length drooping; spitielets rery nunerous, ovate-oblong, 3 to 7 -flowered; palece oval, obtuse, nearly equal in length.

Moist meadows, common. June. Culm erect, 1 to 3 feet high. Leaves rather long, narrow-linear, fat, smocth. Punicle large, broad and oren, often purplish.

\section{POA, Linn. Meadow-grass. Spear-grass.}

An arcient Greek name for grass:

Spikelets ovate or oblong, compressed, few-llowered, in an open panicle. Glumes 2, mostly shorter than the flowcrs. PALEA nearly equal, membranaceous, awaless, often with a villous web at the base; the lower one keeled or concave; upper one 2-keeled. Stamens 2 or 3 . Stramas plumose. Grain oblong,-Grasses, with tufted culms, smooth usually flat and soft leaves, and the spikelets in diffuse or contracted panicles. 


\section{P. AnNuA, L. Low Spear-grass.}

culms spreading or decumbent, flattish; panizle short and broad, often 1-sidea, at length spreading; spilielets crowded, very short-padicelled, 3 to 7-flowered.

Cultirated and wasto groun.ls, very common. April-Oet. Cutms 3 to 8 inches high, very smooth. Leaves lance-linear, short, bright bruwn.

\section{P. Pungens, Nutt. Vernal Spear-grass.}

Culm eompressed; panicle somewhat simple, spreading; spizielets lanceolate, 3 or 4-Howered, crowded at the extremeties of the branches ; flowers rather obtuse.

Rocky places. April, May. Por. Culm sto:oniferous from the base, 1 to 2 feet high. Leaves very short, cuspidate, the radical ones long, linear, those of the culm usually 2 , lanceolate, very short.

\section{P. serotina, Elrh. Rect-top.}

Culm ereet, smooth; panicle difuse, elnngated, at length somewhat nodding at the top, the branches mostly in pairs; spitielets numerous orate-lanceolate, 2 to 4 fowered; glumes lanceclate, sharp-pointed.

Banks of strenms and wet meadows, common. June, July. Per. Culm 2 to 3 feet bigh. Leuves narrow-liuear, flat, smooth. Punicle 6 to 10 inches long, the branchis inostly whorled. Spilicletz green, or often tinged with dull purple.

\section{P. pratensis, L Spar-grass. Malow grass.}

Culms from a creoping base, and with the sheaths smootb; paricle py ramidal, Bunewhat efowded, the brauches commonly in fives, spreauing; spitielets 3 to 5 flowered, oblong ovate; flower's acute.

Fields and meadows, very common in cultivation. May-July. Per. Root creepiug. Chim 2 to 3 feet high. Leaves keeled, linear, abruptly acute, deep green, the lower very long. Highly prized as a pasture grass.

\section{P. compressa, L. Blue-grass. Wire-grass.}

Calm muci flattened, obliquely ascending; ponicle contracted, somewhat 1 . sidcd; spit.elets 4 to 9-flowered, flattined; flowers linear elliptival, rather obtuse, hisiry below on the kel.

Fields and pastures, common; introduced. June, July. Per. Root creeping ext:neively. Culm 12 to 18 inches high. Leaves short, bluish, smooth.

\section{P. conmenta, Ell. Clustered Mealow Grass.}

C.lm erect, geniculate; panicle terminal and azillary, erect; spikelcts about \&. fluw red, compressed; flowers clusterid, smooth.

Meadows, rare. Shweinits. Pur. Culin 2 to 3 feet high. Leaves smooth, surrulitw ou the margin. Punicie 4 to 8 iaches long.

\section{ERATrROSTIS, Beauv.}

An early name, probably from erc, the earth, and Agrostis.

SpIKnnets 2 to 70-10wered, nearly as in Poa, exce pt that the lower palea is but 3-nerved, not webby at the base, and the tipper is persistent on the rachis for some time after the rust of the flower is fallen.-Culms often branching : leaves linear, frequently involute, and the ligule bearded. Paniale various.

1. E. pilosa; Berur. Pilose Eragrestis.

Puncle luose, angle, with ca pillary biancles, all but ihe lower scattered and 
nakcd in the axils, compound; spicielets 5 to 12 flowered, nearly linear, flattish; glowers ovate acutish.

Sandy soil. Aur. Ann. Calms 5 to 12 inches high, tufted. Leaves flat or in. volute, bearded with long hairs at the throat. Spikelets $1 / 4$ to $1 / 2$ inch long, pur: plish.

\section{E. capiluaris, Nees. Capillary Eragrositis.}

Punicle expanding, very compound, delicate; the axils naked; spilkelets oblong 2 to 4 -flowered, on long eapillary pedicels. (Poa capillaris, L.)

Dry sandy p'aces, common. A urust. Ann. Culnis 12 to 18 inches high, tufted. Lecives linear. fiat, the sheaths fringed with Jng hairs. Punicle 8 to 18 inche long, much branched.

\section{E. Spectabilis, Gray. Showy Eragrostis.}

Panicle divergently spreading, the rig:d oranches reflexed with age, and a baardo ed tuft in the principal axils; spikelets oblong or linear 7 to 10 or 15 -flowered; flow ers ovate, minutely ciliate. (P. spectabilis, Pursh.)

Sandy fields. Aur, Sept. Aun. Culm and long leaves rigid, mostly smooth 8 lower sheatiss often dowuy. Punicle 1 to 2 feet long, with purpiish spikelets.

\section{FESTUCA, Linn. FESCUE $\div$ GRASS.}

An ancient Latin name.

Sprneuets oblong, 3 to many-flowered; the flowers not webby at the base. Guumes unequal, mostly keeled. PALEA chartaceous or almost coriaceous, roundish on the back, acute, mucronate or awned at the summit, the upper mostly achering at maturity to the inclosed grain. STanens mostly 3. Stigmas simply p'umose- - F' lowers and leaves rather dry and harsh. Spikelets panicled or racemose.

\section{F. elation, L. Tall Fescue-Gress.}

Punicle branch d. Inose, rathar spreading; spikelets crowded, 4 to 6 flowered; low er palce nearly pointiass; flowers cylindric.

Moist meadows ant pastures. June. Per. Culm 3 to 5 feet hirh. Leaves broad. linear. 9 to 15 inch: s long. Punicle 6 to 10 inches long, mosily noddiug. Spikelets $2 / 2$ inch lons. Introdued.

2. F. pratensis, Hudson. Headow Fescue-Grass.

Punicle simple, or sparingly branched; spizielets 5 to 10-flowered; lower palea barely acute.

Fields aud meadows, common, naturalized. June, July. Per. Caslm 2 to 3 feet high, without a creepin buse. Loives broad-linear, nerved, sneoth, rough on the margin. Punicle 4 to 8 inches long, somewhat one-sided.

\section{F. nutans, Willd. Nidding Fescue-Grass.}

Puncle of several slender and spreading branches, mostly in pairs, drooping when old, naked b:low, bearing near their extremity a few ovate 3 to 5 -flowered opikelets; flower's ovate oblong, rather obtuse, clos: to rether.

Rocky and open woods. Ju!y. Por. Culm 2 to 4 feethigh, naked above. Leaves aroadly-linesr, acuminate, dark green, often rather hairy. Punicle few-flowered.

4. F. rubra, L. Red or Creeping Fescue-Grass.

Plowicle one-sided, erect, spreading; spikelets somswhat terate, 5 or 6 -flowerad; fowers longer than their awns. 
Dry soils. June. Per. Rnot extensively creeping. Culm 12 to 18 inches high, orect. Leaves long pubescent on the upper side. Pinicle contracted. Introduced.

\section{BROMUS, Linn. Brone-grass. Cheat.}

Bromos, a name given by the Greeks to a kind of oats.

Spikelets oblong, 5 to many-flowered, panicled. Glumes nnefual, meinbranaceous, the lower 1 to 5 -nerved, the upper 3 to 9-nerved. LOWER PALEx bifid at the apex, and usually awnec' a little below the tip; upper 2-keeled, at length adhering to the groove of the oblong or linear grain. STAMens 3. Stiguas simply plumose.-Crarse grasses, with large spikelets, at length arcoping, on pedicols thickened at the apex.

\section{B. ciliatús, L. Ciliate Brome-grass.}

$\boldsymbol{P}$ inicle compound, very loose, the elongated branches at length divergent, drooping; spikelets 7 to 12-flowered; lower glume 1-nerved; flowers oblon -lanceolate, tipped with an awn, $1 / 2$ to $3 / 4$ their length; upper pulece bristly-ciliate; the lower silky, with appressed hairs near the mergins. (B. Canad nsis, Michx. B. pubebcens, Muhl. B. purgans, $L$.)

River banks and moist woodlands. July, Aug. Per. Culm 3 to 4 f et bigh. Leaves large, $1 / 4$ to $1 / 2$ inch wide smonth or somewhat hairy; the sheaths oftem hairy o: densely downy near the top. Variable as to its pubescence, \&c.

\section{PB. SeCalinus, L. Cheat. Chess.}

Punicle spreading, the drooping ped uncles but slightly branched; spikelcts oblongo ovate, turgid, smooth, of 8 to 10 flowsrs overlapping each other, mostly longer than the awns; lower glumes 5-nerved; upper 7-nerved.

Cultivated grounds, common in grain-fields. June. Ann. $C u^{7} m 2$ to 3 feet high, with swollen and pulescent jeints. Leaves broal linear, hairy above. Punicle $\$$ to 6 inches long. Introduc d rom Europe. This troublesome grass is very common in wheat fields, especially when the grain is injured by frost; which has given rise to the cemun, but mistaken idea, that wheat is changed into this planto

3. B. Mol.LIs, L. Sift Brome-grass.

Punicle erect, close, compound; spilielets ovate, flattisb, the flowers closely imBricated, downy, as long as the awn.

Fields and pastures, sparingly naturalized. June. Biennial. Culm 1 to 2 feet high. Leaves very seft, pubescent. Zunicle 3 to 4 inches long. Spilielets pearly -erect, 5 to 10-Howered.

\section{B. ARvensis, L. Field Brome-grass.}

Punicle erect, spreading; spikelets lanceolate, compressed, 7 to 8-flowered; flower Imbricate, compressed, smoothish, about as long as the straight awn.

Fizlds and meadows. West Chester. Darlington. June, July. Ann. Culm bout 2 feet high, smooth, with dark-colored rubescent joints. Leaves lancelinear, hairy on both sides. Punicle slender, spreading, at length drouping.

\section{UNIOLA, Linn. SPIKE-GRASS.}

An ancient name of some grass.

\section{SpIRELETs compressed, many-flowered; one or more of the lower flowers sterile, and consisting of a single paleæ. U2}


GLUMES keeled. PALEe of the perfect flowers 2; lower one boat-shaped; upper smaller, doubly keeled. STAMENs mostly 1.-Upright perennixls, in tufts from creeping rootstocks, with broad lewves and large spilkelets in a panicle.

U. LAtifolia, Michx. Broad-leaved Spilee-grass.

Spike'ets on slender podicels, drooping in an ample loose panicle, oblong-ovate, 10 to 15-flowered; flowers nearly appressed, orate-lanceolate and acuminate, somewhat falcate; stamen 1.

Mountains and shaded banks. Aug. Culm 3 to 4 feet higk, somewhat branching. Leares flat, nearly 1 inch wide, Punicle 1 foot long, loose. Spileclets 1 in th long and $1 / 2$ inch wide.

\section{PHRAGMITES, Trin. REED.}

Gr. phragmites, growing in, or forming hedges.

SPIKELETS 3 to 7 -flowered; FLOWERS surrounded by a tnft of hairs, all 3 -androus and perfect, except the lowest, which is either neutral or with a single stamen, and naked. Glumes 2, lanceolate, unequal. PALere very unequal; the lowest one elongated, acuminate; the upper 2-keeled. STYLes long.- Tall and stout perennials, with numerous broad leaves, and a large terminal panicle.

P. communis, Trin. Common Reed Giass.

Punicle loose, diffuse when old ; spikelets 3 to 5 -flowered. (Arundo Phragmites, L.)

Edges of ponds and swamps. Aug., Sept. Culm 9 to 1 - feet high, very leaiy, with numerous joints. Leaves 1 to 2 feet long, linear-lanceolate, flat, glaucous. Funicle very large, loose. The largest grass in the Northern States; resenobling Groom-corn at a distance.

3Q. TRITICUM, Linn. WhEAT.

The classical name.

SPIKELETS 3 to many-filowered, single at each joint, and placed with the side against the rachis. GLUMES transverse, nearly equal and opposite, herbaceous, nerved. PALE lanceolate; the lower one concave, acuminate or awned at the summit; the upper one flattened, bristly-ciliate on the nerves, free or adherent to the grooves of the grain. - STAMENS 3. - Flowers spiked.

8ิв0. I. AGRoprrux, Gært. Perennials. Spikes 2-ranked; glumes acuto pointed.

1. T. REPENS, L. Couch-grass. Quitch-grass.

Rootstocks creeping extensively; spikelets 4 to 8-flowered; glumes 5 to 7-nerved; rachis rough on the angles; awn none, or very short.

zields and muadows, naturalized and troublesome. Juno-Aug. Culm 1 to 2 foet bigh. Lnaves llat, roughish or hairy above, lanoolinear. Spike $\$$ to 6 inchos long. 


\section{T. Caninum, L. Ained Wheat-grass.}

Root fibrous, not creeping; spizelets 4 or 5-flowered; glumes 3-nerred; rachis bristly on the edges; awn longer than the smooth flower.

Woods and banks, introdueed. July. Culm 2 to 3 feet high. Leaves flat, rough. ish on both sides.

SEC. II. Triticum proper. Annuals. Glumes ovate-oblong and rentricose boatshaped.

\section{T. SATIVUM, L. Wheat.}

Culm round, smooth, with the internodes somewhat inflat d; stiputes truncate; spike parallel, somewhat 4 -sided; spilielets crowded, broad-ovate, about 4 -flowered; awns of the upper paleæ gen rally longer than the flowers. Aunual and Biennial. This is the most valuable nlant of the order, and is universally cultivated. Many varieties are known to farmers.

\section{LOLIUM, Linn. DARNEL。}

The ancient Latin name.

SPIKelets many-flowered, solitary, and plaeed edgewise on the continuous rachis. INNER GLUME mostly wanting. LOWER PALEA lanceolate, mucronate or with a short bristle at the tip; upper one 2-beaked.-Spilie simple: rachis not jointed.

\section{L. Perenne, L. Common Darnel. Riye-grass.}

Gilume much shorter than the spikclet; flowers 0 to 9 , awnless, sometimes a wnpointed.

Meadows and fields; notiralized. June. Fer. Cu? $m$ to 2 feet high, smooth. $L$ aves lance linear, smoots, shiving. Spitielets 12 to 20 , alternate, forming a spike about 6 ipches loag. A grood pasture grass.

\section{L. temulentum, L. Bearded Darnel.}

Ginme fully equalling the 5 to 7 -flowers spikelet; awn longer than the flower.

Old ficlds. July. Ann. Culm about 2 feet high, terete. Leaves lance-linear, rough on the margins. Spilielets much compressed. The seeds are said to be poisonous. Introduced from Europe.

\section{ElymUS, Linn. Lyme-grass. Wird Rye:}

Gr. Elymos, a Lull, also an ancient name for some grain.

SpIKELETs 2 to 4 at each joint of the rachis, all fertile, each 2 to 7 -flowered; the uppermost flower imperfect. Glumes nearly side by side in front of the spikelets, rarely wanting. PALE back, usually awned at the apex.-Rye-like grasses, with simple spikes.

\section{E. Virainicus, L. Wild Rye.}

Spize rigidly upright, dense and thick, on a short peduncle usually included in the sheaths; spikelets 2 or 3 together, 2 or 3 flowered, smooth, short-awned; glumos innceolate, sirougly nerred: 
River banks. Aug. Per. Culm 2 to 3 thet high, smnoth, Leaves broadly linear, [at, rough, deep green. Spike 3 to 5 inches long, stifly ereet, thick.

\section{E. Canadensis, I. Canadian Lyme-grass.}

Spike rather loose, curving, on an exserted peduncle; spilielets mostly in pairs of 8 to 5 long-awned rough or rough-hairy flowers; glumes lance awl-shaped, tipped with short awns.

River banks, in rich soil. Aug. Per. Rnot creeping. Cutm 3 to 4 feet high, erect. Leaves broad-linear, flat, sonewhat rough. Spilie 6 to 8 inches long, at length nodding. A variety (E. glaucifolius of Muhl.) is pale or glaucous through out, with spreading awns $1 \frac{1}{2}$ iach long.

\section{E. Hystrix, L. Bottle-brush Grass.}

Spike erect, loose; the spreading spikelets 2 or 3 together, early deciduous from the joints, about 3-flowered; flowers smoothish, or of ten rough-hairy, tipped with an awn thrice their length.

Moist woodlands, commov. July. Per. Crulm 2 to 4 feet high, erect, smooth. Leaves broad-linear flat, and with the sheaths smoothish. Spiks 4 to 6 inches longr at length spreading.

4. E. StRiatus, Willd. Striated Lime-grass.

Spike erect; spitelets in pairs, 2-flowered, awned, hispid ; glumes linear, nervedil. awned, nearly as long as the spikelets.

Shady woods, June, rare. Per. Culm 8 to 12 inches high, erect, striate. Leaves: Tanceolate, acuminate, rourh above; sheaths smooth. Leaves somewhat spreading.

\section{HORDEUM, Linn. BarLeY.}

The ancient Latịn name.

SPIKELETS I-flowered, with an awl-shaped rudiment on the inner side, 3 at each joint of the rachis, the lateral ones usually imperfect. Glumes side by side in front of the spikelets, slender, awn-pointed or subulate. PALE 2 , the lower with a long awn, the upper 2-keeled, obtuse. STAMENS 3.- Spilse dense, simple, the rachis often seperating into joints.

1. H. vulgare, L. Common Barley.

Culm smooth, 2 to 3 feet high; leaves lance-linear, keeled, nearly smooth; sheath : auricled at the throat; spiles thick, about 3 inohes: long; spikelets all fertile, 1 . flowered, with an awn-like rudiment at the apex of the upper paleæ; glumes col lateral; flowers in four rows. Ann. Extensively cultivated. May.

2. H. Distichum, L. Two-rowed Barley.

Culm 2 to 3 feet high; leaves lance-linear, scabrous above; sheaths auricled at the throat; spilse 3 to 4 inches long, linear, compressed; ; lateral spilielets abortive, awnless; fruit arranged in two rows. Ann. more common in cultivatian than the former species.

\section{AIRA, Linn. HAIR-GRASS.}

An ancient Greek name for Darnel.

SPIKelets 2-flowered, in an open diffuse panicle. Glumes 2, unequal, about as long as the flowers. PALEE thin and 
membranaceous, the lower one awned on the back below the middle, 3 to 5-nerved. STAMens 3.

\section{A. Flexuosa, L. Common Hair-grass.}

Panicle loose, spreading, trichotomously branched; branches smoothish, fleznous; flowers scarcely longer than the glumes; lower palece slightly 2 -toothed.

Dry rocky or sandy places, common. June. Per. C'l'm 1 to 2 feat hish, slender, from small tufts of setaceous infolute leaves. Ponicle whilish, the luwer branches somewhat whorled.

\section{A. c.mspitosa, I. Tufted IIair-grass.}

Panicle pyramidel or oblong; lower polce eroded-t-toothed at the truncate apex; awn straight, short.

Wet places. June, July. Per. Cirms 2 to 3 feet higlt, in close tufts. Leaves flat, linear, roughish. Pinicle dull purplish, the branches somotwhat whorled.

\section{A. PR Acox, L. Early Hair-grass.}

Punicle small, ollong, somemhat spiked; lower palece with 2 awl-pointed tips; awn twisted, inserted below the middle, longer than the flowers.

Sanciy fields. June. Culins 3 to $t$ inches high, tufted. Leaves short, smooth, sotaceous. Pinicle few-flowered, greenish.

\section{SECALE, Linn. Rre.}

SPIKELETs solitary on the teeth of the rachis, 2 or 3 . fowered; the 2 lowest flowers fertile, sossile, opposite; tho upper one abortive. GLumes awl-shaped, oppusiiz, shorter than the flowers. INOWER PALEx with a very long awa; upper often biel at the apez. ScALEs abortive, hairy.

\section{S: Cereate, L. Riye.}

Gulm hairy beneath the spike, 4 to 6 feet high; leaves lance-linear, rough edged rough above, glaucous; spitie about 5 inches long, linear, compressed; palec mooth; awns scabrous ciliate, long. Ann. or Biunnial. June. The rye bas long been cultivated and may be considered naturalized.

\section{TRISETUM, Persoon.}

Lat. tris, three, and seta, a bristle.

Spikelets 2 to several-flowered, usually in a contracted panicls. LOWER PALEZ compressed-keeled, awned below. the sharply 2-cleft or 2-pointed apex:-otherwise nearly as in Aira.

\section{T. Palustre, Torr. Meadow Trisetum.}

Smooth; panicle rather long and narrow, loose, the branches capthary; spikelet iat; glumes rather unequal, shorther than the 2 smooth lanceolate flowers; lower palece ending in 2 setose teeth.

Wet meadows, rare. May-July. Per. Culm slender 2 to 8 feet high. Leaves Ant, lanco-linear, about 3 inches long. Spikelets yellowish-white, tinged with green 


\subsection{DANTHONIA, DC. Wild OAT-Grass.}

In honor of $M$. Danthioine; a French botanist.

SPIKELETS 2 to 10 -flowered; the upper flower often imperfect. Guumes nearly equal, mostly longer than the flower. PALEe hairy at the base; lower one 2-toothed at the summit, with a twisted awn between the teeth; upper: one obtuse, entire.-F lowers in a spiked panicle.

\section{D. spicata, Beauv: Wild Oats.}

Punicle simple, raceme-like, rather 1-sided; spilielets few, appressed; 7-flowered; 7ower paleo broadly-ovate, loosely hairy on the back, about $1 / 2$ the length of the awn.

Dry and sterile or rocky soil. July. C'ulms tufted; 1 to 2 teet high, erect: Leaves short somewhat involute-awl-shaped; sheaths bearded at the throat.

\section{AVENA, Linn: OAT:}

The classical Latin name.

SPIKELETS 3 to many-flowered, panicled, commonly large: Flowers rather remote, the upper ones. often imperfect. Glumes loose and membranaceous, nearly equal. Paleze. 2 ; the lower one bifid at the summit, with a long twisted awn on the back below the tip. Stamens 3. Grair. oblong-linear, groored on one side-Panicle compound, toose.

\section{A. SATiva, L. Common Oat:}

Culm 2 to 4 feet high; leaves linear-lanceolate, veined; rough, with loose striato. Aheaths; stipules torn; panicle loose; spitielets pedunculate, pendulous, 2-flowered palece somewhat cartilaginous, closely embracing the grain. Ann. A. highly in partant grain.

2. A. stertuIs, I. Ánimated Oat:

Stem 3 to 4 feet high, and with the leaves smooth, the latter long, acute, flat: spilcelets 5-flowered; outer flowers and awns hairy, inner fiowers awnless. Ann. From Barbary. Cultivated as a curiosity. The awns are 2 inches long, geniculate and twisted more or less according to the state of the atmosphere.

\section{HOLCUS, Linn. SOFT GRASS:}

An ancient name, of obscure application.

SPIKELETS 2 or 3 -flowered in a contracted paniciè, poly gamous. GLUMes herbaeeous, somewhat boat-shaped, mucronate. Lowest flower neutral, small and abortive, or obsolete; the middle one perfect, 3 -androus, awnless; the upper ono staminate only, 3-androus, bristle-awned towardis the tip. 
H. Lanatus, L. Velvet-grass. White Timothy.

Soft-downy, pale; panicle oblong; upper glume mucronate under the apex; awr of the staminate flower recurved.

Moist meadows. Juns. Pur. Root fibrous. Culm 18 inches high Leaves 2 to 5 inches long, flat. Giumes pubescent, whitish or tinged with purple. Introduced srom Europe.

\section{ANTHOXANTHUM, Linn. VERNAL-GRASS.}

Gr. anthos, flower, and zaninos, yellow; from the color of the spikes.

SPIKELETS 3-flowered, the two lower fluwers neutral and each consisting of a single awned palex; the upper flowers perfect, of 2 paleæ, diandrous, nearly equal, short, awnles:Panicle contracted or spike-like.

\section{A. odoratum, L. Sweet-scented Vernal-grass.}

Punicle spiked, the spikelets spreading; one of the neutral flowers with a bent awn near its base, the other short-awned below the tip.

Meadows and woods, completely naturalized. June-Aug. Per. Culm about s foot high, erect. Leaves short. Panicle 1 to 2 inches long, yellow ox brownish when mature. Very fragrant when about half dry.

\section{Phalaris, Linn: Canary-grass. Ribbon-grass.}

Gr.phalos, shining; in allusion to the smooth paleæ.

SPIKExETs 3-flowered; the two lower flowers mere neutral rudiments at the base of the porfect one, which is flattish awnless, of 2 shining palex, shorter than the equal boatshaped glumes. Stamens 3:-Leaves broad, flat. Panicle dense and spike-like.

P. ARUndinacea, L. Reed Canary grass. Ribzon-grass.

Punicle more or less branched, clustered, a little spreading when old; glumes abtusely keeled; palea unequal; abortive flowers hairy:

Swamps. July. Aug. Per. Culm 2 to 5 feet high, erect, a little branching. Leaves deep green, sometimes variegated with white, when it is the "Ribbon gras." of the gardens. Punicle 2 to 4 inehes long.

\section{PANICUM, Linn. PantC-gRasts.}

Anancient Latin name.

Spikntets 2-flowered, naked. Glumes 2, unequal, membranaceous, concave. LowER FLOWER of 1 or 2 paleæ. staminate or neutral, membranaceous. UPPER FLOWER perfect, closed, with 2 paleæ, inclosing the free and grooveless grain. Stamens 3. Stigmas plumose, usually purple.Spikelets panicled, racemed, or sometimes spiked, not ine nolucrate. 
SEC. I. Digrtaria, Scop. Finger Grass. Spitielets crowded, 2 or 3 together in: imple and mostly 1 -sided clustered spikes or spike-like racemes.-Annuals.
1.
P. Sanguinale, L.
Finger-grass.
Crab-grass.

spikes 4 to 15, digitate-clustered; spikelets oblong; downy-margined; upper glume shorter than the flower.

Cultivated grounds, everywhere naturalized: Aug.-Oct. Culm 12 to, 18 inches ligh, spreading from the tufted bace, then upright. Lieaves lin ar-lanceolate, and with the sheaths rather hairy. Spites and of ten the leaves purplish.

\section{P. GLabrum, Gaudin. Smooth Finger-grass.}

Spilies digitate, somewhat alternate, spreading; spitielets ovoid, rather hairy; upper glume nearly equalling the flower.

Sandy fields. Aug., Sept. Culm 6 to 12 inches high, procumbent or spreading. Spilces mostly 3 (2 to 6), about 2 inches long.

3. P. Filiforme, L. Slender Finger-grass.

Spities 2 to 8, alternate and approxizated, throad-like; spitelets all distinctly pedicelled, oblong, acute; lower glume none.

Dry sandy soil. Aur. Culms extremely slender, 1 to 2 feet high. Leaves narrow, 1 to 2 inches long. Spines mostly 3,1 to 2 incles long; rachis rough, flexuous.

SEC. In. Panicum proper. Puxic-Grass. Spilelets seattered, awnluss.-Mlosty. perennials.

4. P. Anceps, Michx. Two-erged Panic-grass.

Panicle contracted, pyramidal; ; i ielets ovate-lanceolate, pointed, a littic surved; upper giume 7-nerved; neatral floivcrs $1 / 3$ longer than the perfect, of 2 palere:

Wet soil. Ang. Culms flat, nuniglt, 2 to 1 feet high. Leaves linear-lanceolate, 1 to 2 feet long, $1 / 3$ to $1 / 2$ inch wide, smoothish.

5. P. Aqrostoides, Spreng. Agrostis-like Panic-grass.

Panicles terminal and often lateral, pyramidal; spitelets racemose, crowded and 1:sided, on the spreading branch : $\mathrm{s}$, ovate-tibjons, acute, purplish; uppor gletme 5 zerved, longer than the neutral flower, with 2 palex.

Wet meadows. Aug. Culm 2 to 3 feet high, flattened, upright. Leaves long : and with the sheatbs smooth, tuftud. Punicle 4 to 8 inches long, mostly dark purple.

6. P. Proliferum, Lam. Protiferous Panic-grass.

Smooth throughout; panicles terminal and lateral, compound, pyramidal; spikelets appressed, lance-oval, acute; lower glume broad, $1 / 3$ to $1 / 4$ the length of the upper; neutral flower little longer than the perfect one, of a single paleæ.

Wet meadows and marshes. Aug., Seipt. Ann. C'ulms thickened, succulent; branched, ascending from a procumbent base. Leaves 8 to 12 inches long; sheath lattened.

\section{P. capillare, L. Hair-stalked Panic-grass.}

Panicle pyramidal, capiliary, compound and very loose, with slender straight oranches, reflexed when old ; spilielets scattered on long pedicels, oblong, pointed; Zonver glume half the length of the single paleæ of the neutral flower.

Sandy soil and cultivated fields, common. Aug., Sipt. Ann. Culm upright; often branched at base and forming a tuft. Leaves flat, broad, and with the lattened sheaths hairy. Punicle often purplish.

\section{P. Latifolium, L. Broad-lecred Panic-grass.}

Panicle terminal, a little exserted, simple, pubescent; spicelets oblong-ovoid, lowny; lower glume ovate, not $1 / 2$ the length of the many-nerved upper.one; sterilo Hower mostly with 3 stamens. 
Moist woods and thickets, common. June, July. Culm 1 to 2 feet high, smooth, the joints and margins of the smooth sheaths bearded with soft woolly hairs. Leaves broadly oblong-lanceolate from a heart-clasping base, often 1 inch wide. Punicle 2 inches long, with downy branches.

\section{P. clandestirom, L. Hidden-flowered Panic-grass.}

Sheaths hispid, enclosing the short lateral panicles; spikelets oroick, pubescent, the lower flower neutral, with 2 paleæ.

Low thickets and river banks. Aug. Culm 1 to 3 feet high, very leafy to the top, at length producing appressed branches. Leaves oblong-lanceolate, from a keart-clasping base, very acuminate. Panicles terminal and lateral, the former wholly concealed in the leaves, exserted, or on a long peduncle. Anthers and stig. mas purple.

10. P. microcarpon, Muhl. Small-pointed Panic grass.

Punicle soon exserted, very many-flowered, narrowly oblong; spikelets long; ovoids smoothish; lowser glume orbicular, very small.

Thickets. July. Culm 1 to 2 feet high, smooth, the joints and the orifice of the throat of the sheaths bearded with soft woolly hairs. Leaves broadly lancea late, rough-margined, bristly-ciliate. Punicle 3 to 7 inches long.

\section{P. PAUCIfloru M, Ell. Small-flowered Panic-grass.}

Panicle open, nearly simple, bearing few tumid-obovate hairy or smoothish apikelets; lower glume $1 / 4$ to $1 / 2$ the length of the upper one.

Wet meadows and copses. June, July. Culm 1 to 2 feet high, at length much branched and reclining, roughish, Lecues lanceolate, 2 to 5 inches long, $1 / 3$ to $1 / 2$ inch wide, fajntly 9-nerved, hairy or smooth, fringed on the margin.

\section{P. піснотопем, L. Variable Panic-grass.}

Punicle small, lateral, nearly simple; spitielets minute, on long peduncles, oboroid, mostly pubescent; lower glume $1 / 3$ the length of the upper; lower flower neutral, the upper paleæ minute.

Moist meadows and woods. July-Sept. Culms 8 to 20 inches high, at first mostly simple, beuring a more ur less exserted compound spreading panicle, 1 to 3 inches long. Leaves lanceolate, Hat, the radical tufted ones, ovate-lanceolate, very short, thickish. Punicle changing its form, often purplish. A very variable species, embracing P. nodiflorum, paboscens, laxiflorum, and nitidum of Lam. P. barbulatum and ramulosum of Michx.

\section{P. depauperatum, Muhl. Few-flowered Panic-grass.}

Panicle simple, contracted, few-flowered, often over-topped by the narrowly linear upper leaves; spikelets oval-obovate, commonly poinied when joung; lower glume ovate, $1 / 3$ the length of the 9 -nerved upper one.

Dry wools and hills, common. June. Gulms simple or branched at the base, forming close tufts, 6 to 12 inches high. Leaves short, becoming longer above, narrow-linear, hairy beneath. Punicle \pm to 7 inches long. Varies with the leaves. often involute.

\section{P. verrucosum, Muhl. Warty Panic-grass.}

Smooth; panicle capillary, widely spreading, few-flowered; spitielets oval, acute, warty-roughened, dark green; lower glume $1 / 4$ the length of the upper one.

Sandy swamps. Aug., Sept. Culm 1 to 2 feet high, branching and spreading. very slender, naked above. Leaves narrow, smooth, spreading.

\section{P. CRUS-GALLI, L. Barnyard-grass.}

Spikes alternate, crowded in a dense panicle; glumes ovate, abruptly pointed; bower palece of the neutral flower bearing a rough awn of variable length.

Wet places, near barn-yards. Aug., Sept. Ann. Culm 2 to 4 feet high, terete, smooth, stout, branching from the base. Leaves lanceolate, $1 / 2$ inch or more wide, sough-margined. Spilkes 1 to 3 inches long. 


\section{SETARIA, Beauv. Bristle-grass.}

Lat. setu, a bristle; in allusion to the bristly spikelets.

SPIKeLETS 2-flowered, invested with an involucre of 2 or more bristles. GLumes 2, unequal, herbaceous. Low Fr FLOWER abortive; PALE 1 or 2 , herbaceous. UTPER FLOWER perfect; PALE eartilaginous.-Annuxls, with linear or linceolate flat leaves, and the inflorescence in a dense spiked panicle or apparently a cylindrical spike.

1. S. verticillata, Beauv. Rough Bristle-grass.

Spize subverticillate, cylindrical, somewhat interrupted; bristles short; palece of the perfect flower roughish-punctate.

Naturalized near dwellings. July. Culm about 2 feet high, smooth. Leaves lanceolate, acuminate, rough on the margin. Spite 2 to 3 inches long, green.

2. S. GLAUCA, Beaur. Bottle-grass:

Spike cylindrical, very dense; bristles 6 to 11 in: a eluster; much longer than tho syikelets; perfect flower transversely, wrinkled,

Very common in stubble. July, Aug. Culm 2 to 3 foet high. Leaves lanceolate, hitiry at base. Spilie 2 to 4 inches long, tawny or orange-yellow. Introduced.

\section{S. viridis, Beauv. Green Foxtail.}

Spike nearly cylindrical, more or less compound; bristles few in a eluster, longer than the spikelets; perfect flower striate lengthwise and dotted.

Cultirated grounds, commron. July, Aug. Culin 2 to 3 feet high, erect. Leaves linear, flat, roughish. Spike 2 to 3 inches long, green.

\section{S. Ittalica, Kunth. Italian Bristle-grass.}

Syike compound, interrupted at the base, thick, nodding; bristles. 2 or 3 in. a eluster, either longer or shortcr than the spikelets.

Wet grounds, sparingly naturalized and sometimes cultivated under the name of Billet or Bengal Giass. Culin 4 feet high. Spilie 6 to 9 inithes long, yellowish or gurplish.

\section{TRIPGACUM, Linn. SESAME-grass.}

Gr. tribo, to rub; perhaps in allusion to the polished fertile spikes.

Monœcious. STERILE sPIKexets above, in pairs on each joint of the rachis, collateral, 2-flowered: FLOW ERS each with 2 paleæ. Fertile spiKecets solitary, as long as the joint, 2 -flowered; the flowers with 2 palea; the outer or lower flower neutral, the inner or upper one fertile. STYLES united: stigMas very long, hairy, purple. Grain ovoid, firee.-Culms stout and tall. Leaves broad and flat. Spikes axillary and terminal, seperating into joints at maturity.

T. dactyloides, L. Sesame-Grass. Gama-Grass.

Spities 2 or 3 together at the summit, and solitary from the upper sheaths.

Mcadows. July, Aug. Per. Culm erect or oblique, 4 to 6 feet high. Leaves liarge, often 3 feet long; linear-lanceolate, smpoth buneath, rough above. Spiistes. 1. to 8 inches long. 


\section{ANDROPOGON, Linn. Beard Grass.}

Gr. aner, a man, and pogon, a beard, in allusion to the hairy flowers.

SpIkelets in pairs upon each joint of the slender rachis, spiked or racemed. LOWER FLOWER staminate or neutral, the glumes and palea very minute or wanting. UPPER FLOWen perfect. Glumes awnless. Palea 2, shorter than the glumes; lower one mostly awned. Stanens 1 to 3. Grain free.-Coarse and rough perennial Grasses, with lateral or terminal spikes cemmonly clustered or digitate, the rachis hairy or plumuse bearded.

1. A. Furcatus, Muhl. Forked Beard-Grass.

Spit:es digitate, mostly in threes or fours; lower flower staminate, awnless; awn of the perfect flower bent.

Sterile soils. common. Sept. Culn 3 to 4 feet high. Zeaves flat, the lowervery lorg. Spities 3 inches long, 3 to 5 at the naked sunimit of the culm.

\section{A. scoparius, Michx. Purple Beard-Grass.}

Spiies simple, latural and terminal, pedunculate, in pairs; lower flower neutral, awned; glumes of the perfect flower smooth; awn twisted.

old fields and roalsides. Aug. Culm 3 to 4 feet high, slender, with many panlculate branches. Leaves flat, hairy. Spikes on a flexuous rachis, often purple.

3. A. Virginicus, L. Virginian Beard-Grass.

Culm flattish below, sparingly short-branched above; sheaths smooth; spites $20 \mathrm{x}$ 3 together in distant appressed clusters.

Sandy soil. Sept. Cu'ms about 3 feet high, somswhat tufted. Lexves a foot oz mure long. Spizies 1 inch long, partly concealed in sheaths.

\section{SORGHUM, Pers. Broom-Corn.}

The Asiatic name of a eultivated species.

SPIKELETS 2 or 3 together on the branches of an open panicle, the lateral ones sterile or often reduced merely to their pedicels; the middle or terminal one only fertile, its glumes coriaceous or indurated, sometimes awnless. PALEAs 3 , the upper one awned. Stamens 3.

1. S. nutans, Gray. Indian Grass. Wond Grass.

Punicle narrowly oblong, rather crowded, the perfect spikelets at length drooplng, clothed near the base with fawn-colored hairs, shorter than the twisted awn sterile spilielets small and very imperfect, or reduced to a mere plumose-hairy pedicel.

Dry soil. Aug. Per, Culm simple, 3 to 5 feet high, terete. Leaves linear-lanceolate, glaucous. Punicle 6 to 12 inches long, the spikelets bright russet brown and shining.

2. S. saccharatum, L. Broom Corn.

Culm 6 to 10 foet high, thick, solid with pith ; leaves lanceolate, acuminate, pabescont at base; panicle large, diffuse, with long yerticillate at length drooping 
branches; glumes of the perfect spikelet hairy, persistent. Ann. From the Eabt Indies. Much cultivated.

3. S. vulgare, J. . Indian Millet.

An annual from the East Indies, is rarely culti vated as a curiosity, or for the seed for food for poultry.

\section{ZEA, L. Indian Corn.}

Gr. Zao, to live; the seeds contributing eminently to the support of life.

Monœcious. StAMinate FLowers in terminal paniculate racemes: SPIKELETS 2-flowered : GLUMES 2, herbaceous, obtuse, subequal: PALEA membranaceous, awnless, obtuse. Pistillate Flowers lateral, axillary, on a spadix enclosed in a spathe of numerous bracts: SPIKELETs 2-flowered, 1 flower abortive : GLUMES 2, very obtuse: PALEA awnless: STYLE 1, filiform, very long, pendulous. SEED compressed.

\section{Z. MAYs, L. Maize. Indian Corn.}

Root fibrous, often with aerial roots; culm erect 5 to 15 feet high, channelled on one side, leafy; lec ves lance-linear, entire, 2 to 3 feetlong. Annual. Native of the warm latitudes of America. Very extensively cultivated throughout the temperate and torrid zones. Varieties numerous.

48. COIX, Linn. Jo's's Tear.

Koix, a palm-leaved tree.

STAMinate Flowers, in remote spikes; GLUMES 2-flowered, awnless. STYLE 2-parted. SEED covered with the bone-like calyx.

C. LAchryma, L. Job's-Tear.

Culm semi-terete above; flowers naked; fruit ovate. June. Ann. A curion grass, often cultivated for its seede, which much resemble beeds. 


\section{ADDITIONS.}

\section{To ORDER 39. ROSACE $\mathbb{E}$, after Dalibarda, page 103, add}

\section{Tribe III. Fragariez.-The Strawberry Tribe.}

\section{POTENTILLA, Linn. Cinque-Forl. Five-Finger.}

Lat. potens, in allusion to its supposed raedical virtues.

Calyx deeply 5-cleft, with 5 bractlets at the sinuses, appearing 10-cleft. Petals 4 or 5, roundish or inversely heart-shaped, deciduous. Stamens numerous. Actienta many, collected in a head on the hairy receptacle.-Herbs, or rarely shrubs, with compound leaves, and solitary or cymose flowers.

* Leaves patmate: leaftets 3 to 5 : flowers yellow.

1. P. Canadensis,L. Common Cinque-foil or Five-finger.

IIairy or pubescent, procumbent and ascending, producing runners; peduncles axillary, elongated, 1 -flowered; leaflets 5, oblong or obovate-wedge-form, cut-toothed towards the apex; petals longer than the calyx.

Dry fields, among grass, very common. April-0ct. Per. Stems at length 12 to 18 inches long. Leaves white villous when young. Flcwers yollow. A very variable species, embracing several varieties. Var. 1. Pumus is a dwarf early flowering state in sterile soil. Var. 2. SnMPLEx is a taller and greener state, with slender ascending stems. (P. simplex, Michx.)

\section{P. argentea, L. Silvery Cinque-foil.}

Low; stems ascending, cymose at the summit, many-flowered, white-roolly; leaflets 5 , wedge-oblong, almost pinnatifid, entire towards the base, with revolute margins, green above, silvery-white-woolly beneath; petals lowger than the calyx.

Dry barren fields. June-Sept. Per. Stems to 10 inches long, somewhat woody at base, at length with slender branches. Leaflets $1 / 2$ to $3 / 4$ inch by $1 / 8$, with 2 or 3 slender spreading teeth on each side; upper ones linear entire. Flowers small, yellow.

3. P. Norwegrca, I. Norway Cinque-foil.

II airy, erect, forked above, many-flowered; leaflets 3 , obovate-oblong, coarsely cut-serrate; caly $x$ longer than the petaIs; achenia wrinkled or ribbed.

old fields and pastures. July-Sept. Ann. or Bien. Stem 1 to 2 feet high, hirsute, at length more or less branched. Lower leaves on petioles 1 to 4 inches long. F'lowers pale yellow, in leafy corymbs at the top, and on long solitary peduncles below.

** Leaves odd-pinnate: flowers yellow.

\section{P. arguta, Pursh. Close-flowered Cinque-foil.}

Stem erect, tall and stout, brownish-hairy, clammy towards the summit; leaves pinnate, the lowest 7 to 9 , the upper to 7 -foliate; leaflets oval or ovate, incised or doubly serrate, downy underneath; flowers cymose-clustered.

Rocky hills and banks. July. Per. Stem mostly simple, 2 to 4 feet high. Radical leaves 1 foot or more long. Leaflets 1 to 2 inohes long; $2 / 3$ as wide, sessile. a lowers $\approx$ bout $3 / 4$ inch in diameter, yellowish-whits. 
5. P. fruticosa, L. Shrulby Cinque-foil.

Stem ercet, very much branched, bushy; leaves pinnate; leaflets 5 to 7 , crowded, oblong-lanceolate, ontire, silky, especially beneath; stipules lanceolate, scale-like ; flower s numerous, terminating the branchlets.

Margins of swamps, rare. June-Sept. A shrub 2 to 4 feet high, with a reddish bark, and numerous branches. Leaces numerous, on short petioles. Flowers numerous, large, yellow. Cultivated.

\section{FRAGARIA, Tourr. Stratwberry.}

Lat. fragrans, fragrant; on account of its perfumed fruit.

CaLyX concave, deeply 5 cleft, with an equal number of alternate exterior segments or bracteoles. PEtals 5, obcordate. Stamens numerous. Strues deeply lateral. RECEPTACLE in fruit much enlarged and conical, becoming pulpy and whitish or scarlet, bearing the minute dry achenia, scattered over its surface.-Low perennials, with runners, radical 3-foliate leaves, aud white cymose flowers on scapes.

\section{F. Virginica, Ehrh. Wild Strawberry.}

Leaftets broad-oval, smoothish above, the lateral oncs distinctly petioled; peduncles mostly shorter than the leaves; achcria imbedded in the deeply pitted ovoid receptacle.

Banks and rocky places. April, May. Fruit in June, July. Fetioles radical, 2 to 6 irches long, with spreading hairs. Leaflets coarsely toothed, 1 to 2 inches long, $3 / 4$ as wide.

2. F. vesca, L. Common Strauberry.

Lcaftets folded, thin; peduncles usually longer than the leaves; achenia superf cial on the conical or hemi plerical receptacle (not sunk in pits).

Fields and meadows, commun. April, May. Fruit June, July. Stolens often crieping several feet. Numerous varieties are cultivated.

\section{To ORDER 35. RHAMNACE $\mathbb{E}$, after Rhamnus, p. 74, add}

\section{CEANOTHUS, Linn. New Jersey Tea.}

An ancient Greek name applied to this genus.

CALYX 5-lobed, the lower part adhering with the ovary, the upper seperating across in fruit. PETALs hood-form, on elender claws. Firaments elongated. Fruit 3 lobed, dry and splitting into its 3 carpels when ripe.-Shrulby plunts, with entire leaves, and small white flowers in little umbet-like clusters, which are crouded in dense panicles or corymls at the summit of naked flower branches.

\section{Americanus, L. New Jersey Tea. Red-root.}

Leaves orate or oblong-ovate, 3-ribbed, serrate, downy beneath, often heart khajed at the base; commion pcduncles elongated, nearly leafless.

Dry woodlands and fcnce-rows, common. July. An undershrub 1 to 3 feet lik b frum a dark red roct, with down trunches and numcrcas small llowers, in fretty u bite clusters. 


\section{ER A T A.}

Generic dascription of Nasturtium on page 29 should real-Pod nearly terete, \&c., see Class 14, Tetradynamia, Order 2, Siliquosæ, in Analytical Tables.

On page 16, for Podophyllum pellatum, read peltatum.

On page 36, 3d line, after Cleome for on, read or.

Page 73, 6th line, from Euonymus for 5-sided, read 4-sided.

Page 87, for Lespedza, read Lespedeza.

Page 103, 2nd line from bottom, for stick, read disk.

On page 110, for $P$. arbutifolio, read arbutifolia.

Page 112, 4th line after Decoden, for stamens 15, read stamens 10.

Page 220, 4th line after Chimaphila, for stamens 19, read stamens 10.

Page 232, 2nd line after Tecoma, for 6 -toothed, read 5-toothed.

On page 272 , 6th line from bottom, after "smoothish," read Corolla,

Page 281, 4th line after Datura, for petioled, read plaited. 



\section{INDEX}

\section{P0 \\ BOTANICAL NAMES.}

The name of the Orders and Sub-orders are in Surall CAPITALs, the Genera and Sub-genera in Roman, and the. Synonymes in Italic.

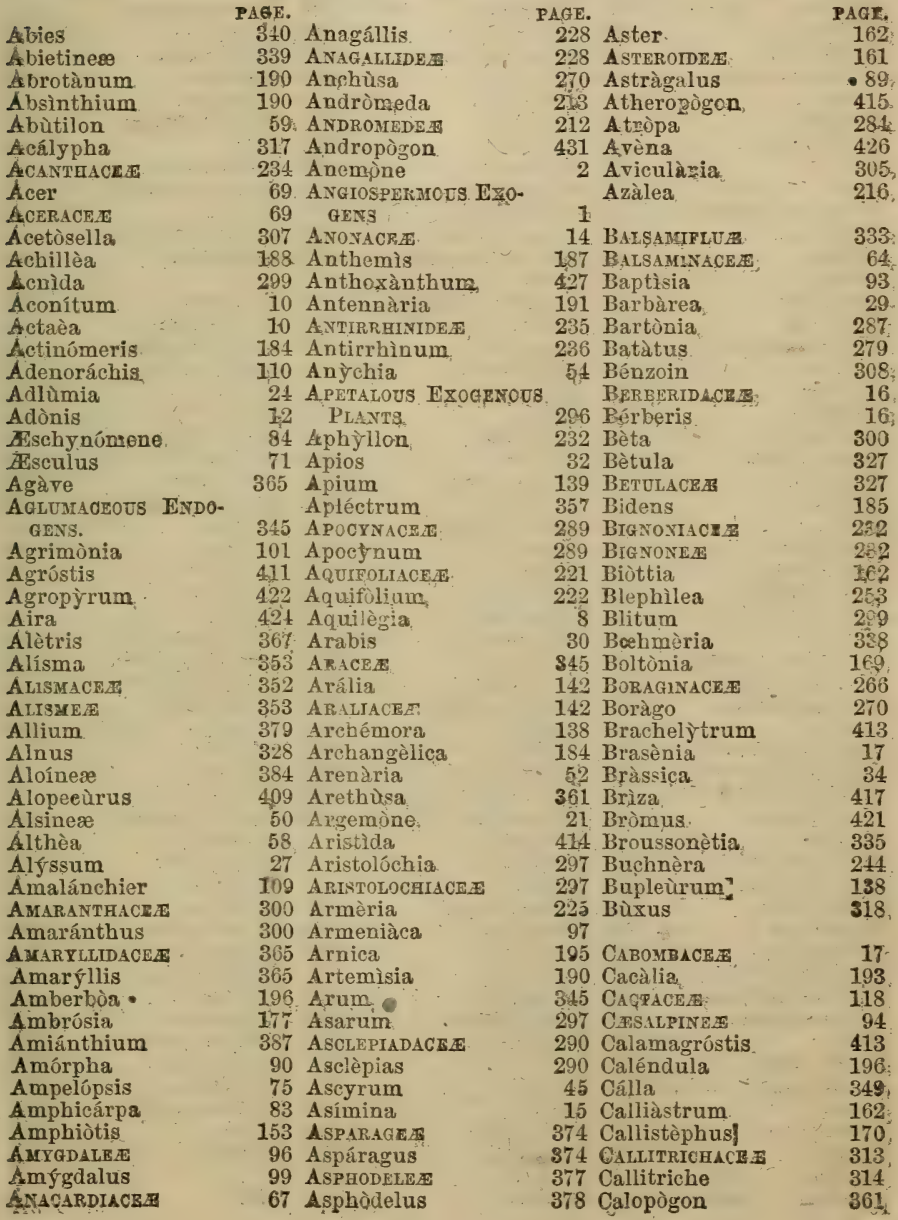


Cáltha

Calycasthacez

Calyeánthus

Calystègria

Camelina

Campanuna

Campanulagese

CAMPX LOSBLEMIS

Cánua

C'́nnabis

Canvabiaze

CANATACBa

Capparidacie

Caprifólium

Capsélla

Cápsioum

Cardìmine

Cardiospérmnm

Carex

Carpinus

Cárthamus

Carum

Càrya

C.Aryophyllaces

Cassindra

Cássia

Cassie

Custinea

Castillèja

Catanáncho

Catálpa

Catária

Caulinia

Cedronélla

Celistrace,

Celástrus

Celúsia

Céltis

Centaurea

Centrùsema

Cophalánthus

Cerístium

Ceràssu

Ceratophymaces

Ceratophyllum

Ceratòschiezus

Cérois

Chorophyllum

Chameilirium

Cheiránthus

Chelidònium.

Chelòne

CHEXOPODIACEx

Chenopodium

Chimàphila

CrNCHONEE

Chioninthes

Chrysópsis

Chrysánthemum

Chrysosplénium

Cicer

Cichorace $\mathrm{B}$

Cichorium

Cieuta

Cimieìfuga

Cinna

Circea

Crisium
PAGE.

7 Cistace $B$

111 Cládium

111 Claytonia

275 Clematis

26 Cleòme

$20 S$ Clèthra

203 Clintonia

140 Clinopołium

S6t Cnìeus

336 Cochledria

336 Colosperma

364 Còix

35 Collinsia

14.5 Collinsonia

25 Comàndra

284 Commellỳna

31 CeMmeliY NACBA

70 Comptònia

403 Composite

325 CONIFERA

199 Cànium

138-Conoclìnum

319 Conophùtis

47 Convallaria

214 Convólvulus

$2+$ Canvolvulace

at Cóptis

323 Coprosminthus

245 Corallorbiza

2,6 Coreópsis

2:33 Coriándrum

255 CORFACHA

350 Córnus

255 Corydalis

71 Corylus

72 Cjsmánthus

302 Crúntzia

312 CrassLLICEx

195 Cratærus

83 Cròcus

152. Crotaiària

51 Crucifara

97 Cryptotæuia

313 Cucumis

313 Cucurbita

401 CtCurbitacs.

94 Cùnila

140 Cuphèa

388 CUPRESSINEA

33 Cupréssus

21 Cupulifer

237 Cuscutinea

298 Cuscetta

298 Cydonia

2:20 Cynoglóssum

152 Cynares

295 Cynthia

174 Cyuolon

189 CXPERACEA

129 Cypripedium

80 Cyperus

200

200 Dúctylis

1,26 Dahlia

11 Dalibárộa

411 Danthonia

116 Dáphne

196 Davicus
IAGE.

40 Datùra

402 Discoden

56 Delphinum

2 Dentriria

36 Desmùdium

215 Diánthus

376, 20\% Dianthòra

258 Dicéntra

199 Dicotrlindors

26 Diclytra

141 Dielytra

4:3:2 Diervilla

2:37 Diritilis

25:2 Diuscòrea

310 DlosCORLACHA

¿92 Diospyrus

392 Diplopáppus

327 DiPSACEA

155 Dipsacus

339 Diptericánthus

$1 \$ 1$ Direa

158 Dodecitheon

2:31 Dracocéphalum

377 Drùsera

278 DROSERACER

277 Dalichium

8

372 Findace

357 Echinocystis $\quad 122$

182 Echinospermum 269

$1+2$ Lichinúdorus 35

144 Echium $266^{\circ}$

$1 \pm 4$ Kelipta $\mathbf{1 7 5}$

2:3 HLATINACE.E 46

324 Klatina 46

273 Hleocharis $\quad 397$

132 Flephàntopus ] $\quad 146$

$1: 5$ Eileusive 415

108 Elymus $4: 3$

373 Elúdea 46

93 ENDOGEYS $3 \pm 5$

2t. Epigèa 213

137 Epilóbium 113

1.23 Epiphègus 231

121. Eragrústis 418

121 Erechthites, $1: 2$

252 ERICACEE 210

113. Erigènia 141

$3+2$ Wrigeron 167

312 Eriocaúlon 394

320 HiriocauloxaCE

279 Eriòphola 25

279 Eriòphorum 400

11 Erỳsimum 32

269 Erythrìea 286

195 Erythrònium $38 \%$

201 FSCALOAIEAl 129

415 Eschschòttzia

395 EUONYMEAE

363 kuònymus

395 EUPATORIACEB

Eupotoriam

416 Euphúrbia 31.5

170 EUPHORBI $\triangle$ CE $X \mathbb{8}$

103 Eutùca 273

4:26 lixogers

309

133 Eaba 80 
INDEX TO BOTANICAL-NAMES.

\begin{tabular}{|c|c|c|c|c|c|c|}
\hline Fàgus & & 324 & Heràclium & 181 & Lapòrtea & 337 \\
\hline Fèdia & & 154 & IIerpèstis & 210 & Larix & $3 \div 1$ \\
\hline F'estùca & & 420 & Hésperis & 34 & Lathyrus & 78 \\
\hline Filàgo & & 192 & Heteránthera & 391 & LACRACEA & 307 \\
\hline Fintristylis & & 400 & Heuchèra & $1: 27$ & Laurus & $3 \cup 8$ \\
\hline Flnerkia & & 66 & Hibiscus & 58 & Lavèndula & $2 i 4$ \\
\hline Foeniculum & & 139 & Hieràceum & 202 & Lèchea & 41 \\
\hline Fráxinus & & 295 & Hippùris & 118 & Lèdum & 218 \\
\hline Fragària & & 434 & HđMODORACEA & 367 & Leèrsia & 408 \\
\hline Frittillaria & & 383 & Hólleus & 426 & LEGLMIXOS.尹 & 77 \\
\hline Fumària & & 24 & Hórdeum & $4: 24$ & Lémna & 318 \\
\hline FUMAFIACE & & 22 & IIottonia & $=229$ & LEMNACEX & 343 \\
\hline Funkia & & 878 & HoTTOXIF AS & 229 & Lèntago & 143 \\
\hline & & & Houstrinia & 153 & LFNTIBCLACEA & 230 \\
\hline Galsctia & & 82 & Hudsònia & 41 & Leúntice & 17 \\
\hline Galánthus & & 366 & Humuius & 336 & Léuntodon & 201 \\
\hline Galatélla & & 166 & Mya 1uthus & 380 & Leomùrus & 261 \\
\hline Galeúpsis & & 22 & Hycrángea & 130 & Lèpachy 3 & 180 \\
\hline Gàlium & & 151 & IITDRANGEZ & 130 & Lepidium & 26 \\
\hline Gaùra & & 115 & Hydrástis & 7 & Leptandra & $2+3$ \\
\hline Guulthèria & & 212 & Hydrocòtyle & 131 & Lespedéza & 87 \\
\hline Gaylu:sicia & & 210 & HYDROCHAKIDACER & $85 t$ & Leucánthemum & 183 \\
\hline Guntiàna & & 287 & IIYDROPHYLLACE.Z & 271 & Leveòjum & 37 \\
\hline GENTIANACEAB & & 285 & Iydropl ýllum & 271 & Liatris & $1 \div 7$ \\
\hline Giraniceas & & 62 & IIyoseýamus & 281 & LIGCLIFLOR $\mathbb{R}$ & $2(i 0$ \\
\hline Gerànium & & 62 & HIPERICACE & 43 & Ligústrum & $29 \frac{1}{2}$ \\
\hline Geràrdia & & 244 & Hypèricum & 44 & LIIIACER & $3: 4$ \\
\hline Gèum & & 102 & Hypòphorum & 403 & Lilium & $3: 1$ \\
\hline Gillia & & $2^{7} 6$ & Hypoxis & 366 & LIDINANTHACE巴 & 66 \\
\hline Gillènia & & 100 & Hys & 265 & bimosélla & 241 \\
\hline Qlechùna & & 256 & & & LIXACF⿻ & (i) \\
\hline Gleditschia & & 95 & Iberis & $2 i$ & Linaria & 235 \\
\hline GLLMACE & & 395 & Ilex & $2: 2$ & Lindernia & 241 \\
\hline Giumaceous Exi & DOGENS & 395 & Ilysanthus & 241 & Linnaèa & 148 \\
\hline Glycêria & & 418 & Impàtiens & 64 & Liruuin & 61 \\
\hline Gnaphalium & & 191 & Inula & 175 & Lìparis & $3: 6$ \\
\hline Gomphrèna & & 302 & Iodanthes & $\therefore 0$ & L̀ppia & $2 \pm 2$ \\
\hline Gonòlobus & & 293 & Ipomea & 278 & Liçuidsmber & $3: 3$ \\
\hline Goodyèra & & 362 & Iromópsis & $27 \pi$ & Liriodénciron & 14 \\
\hline GRAMIN=LE & & 408 & IFIDACE $B$ & 858 & Listèria & 363 \\
\hline Gratiòa & & 240 & Iris & 318 & Lithospérmum & 267 \\
\hline GROSSLLACP.B & & 119 & Isácthus & 249 & Lobelia & 26 \\
\hline Gymnadènia & & 359 & Isatis & 28 & LOBELIACER & 205 \\
\hline GYMNOSPARMOUS & 思：- & & Isnaria & 116 & LCG $\triangle N E D$ & 153 \\
\hline GENS & & 339 & Itea & 129 & Lòlium & $4: 3$ \\
\hline Gynandrònsís & & 85 & & & Lonìcera & 143 \\
\hline & & & JLSMINACF & 294 & L.ONICLRF.A3 & 145 \\
\hline IIALORAGEAR & & 116 & Jasminum & 294 & Lophanthus & $2: 8$ \\
\hline HAMAMEIACLAB & & $1: 1$ & Jeffersònia & 17 & LORANTH $\triangle C E D$ & 311 \\
\hline Hamàmelis & & 181 & JLGLANIACT $\$$ & 318 & LOTKE & $\{9$ \\
\hline Hecec̀ma & & 252 & Jiglans & 3 is & Ludwigia & -.. 115 \\
\hline Hèdera & & 143 & JUNCACFE & $3 \& 8$ & Luñaria & 27 \\
\hline Hedỳotis & & 163 & JUNCAGINEAB & $8: 3$ & Lupinus & 93 \\
\hline MEDYABAREA & & 84 & Juncus & 389 & Luzula & $38:$ \\
\hline Hedýsarum & & 84 & Junìperuฐ & 343 & Lỳ-hnis & 50 \\
\hline HELIANTHE $\not$ Z & : & 384 & Justicia & 284 & Lỳcium & $2 \varepsilon 4$ \\
\hline Helènium & & 186 & i & & Lycopèrsicum & 283 \\
\hline HLLIANтнE. & & 178 & Ka!mia & 217 & Lycópsis & 266 \\
\hline Heliánthemum & . & 40 & Koelèria & 416 & Lycòtus & 25 \\
\hline Hélianthus & & 180 & Ktigia & 201 & Lyònia & 21 \\
\hline Heliopsis & & 179 & Kuhnia & 158 & Lysimáclia & 227 \\
\hline Hellèborus & & 12 & & & LYTHF $\triangle$ CE $\mathbb{B}$ & 112 \\
\hline Helòvias & & 388 & LABIATIZB & 249 & & \\
\hline Helxine & & 305 & Lactica & 204 & Maclura & 326 \\
\hline Hemiánthus & & 241 & Lagenària & 124 & Magnolia & 13 \\
\hline Hemicár pha & & $3 \subseteq 7$ & Làmium & 26.1 & M $_{\triangle G N O I M C E B}$ & 13 \\
\hline Hcmorocállis & & 377 & Lapla & 198 & Maianthemum & 376 \\
\hline
\end{tabular}


Màlus

Mílva

M $\triangle$ LVACEA

Malaxis

Mària

Narrùbium

Martýnia

Marìta

Matthiola

Meconòpsis

Medèola

Medicàgo

Metaniming

Melànthium

Melampyrum

Melastum $A$ CEX

Mélica

Melilotus

Melíssa

Melothria

MinNisperMACEAB

Menispérmum

Méntha

Menyánthus

Menzièsia

Mertènsia

Mikània

Micróstylus

Mimulus

Nirabilis

Mitehélla

Mitélla

Moliúgo

Momúrdica

Monárda

Monocotrledons

MoropeTaLOUS EXOGENS

Monotropa

MONOTFOPEZ

MOR品

Morus

Muhlenbérgia

Mulgèdium

Myosòtis

Uyrica

MYRICACEA

Myriophỳlum

Nàbulus

NAIADACE

Nàias

Narcíssus

Nardósmie

Nasturtium

Negúnda

NELUMBIACE

Nelúmbium

Nemopánthes

Nemòphila

Nèpeta

Nicàndra

Nicotiana

Nigélla

NyCtagináde

Nymphæa

NYMPH $\triangle A C E A B$

Nuphar

Nysa
PAGE.

110 NYSSACEA

$5 \%$

57 Obolària

356 Oeymum

214 बisnothèra

363 OLHACEA

233' ONOGRACEA

187 Onopúrdon

34 Onosmòdium

20 Opulus

374 Opúntia

92 ORCHIDACE

386 Orchis

386 Origantim

247 Ornithògalum

111 OROBANCHACEA

417 Orobanclie

92 Oróntium

258 Orthomeris

122 ORTHOSPERME

15 Osmorhiza

15 Ostrya

250 OXALID ACEA

288 Oxalis

215 Oxydendron

269 Oxycoccus

158 Oxytripolium 356

239 Pæònia

302 Pànax

152 Pànicum

128 Pàpaver

53 PAPAVERACEA

123 Papuronace

253 Pardanthus

345 Parietária

145 Parnàssia

221 PARNASSIEA

220 Passifiòra

334 PASSTFLORACE

335 Pastinsca

412 Paulònia

204 Pediculàris

208 Peltándra

326 Penthòrum

326 Pentstémon

117 Pérsiea

Pèrsiciria

202 Petúnia

350 Phacèlia

350 PHANOGAMTA

366 Phàlaris

161 Pharbitis

20 PHASEOLE

70 Phaséolus

18 PHILADELPHE

18 Philadelphus

223 Phlèum

273 Phlóx

255 Phragmites

282 Phryma

280 Phyllánthus

13 Phỳsalis

302 Physostégia

18 Phytolícea

18 PhytolacCaCF

19 Pilea

309 Pimpinélla
PAGE.

309 Pinus PAGE

Pìsum 80

289 PLANTÁNiNACE 224

264 Plàntàgo 224

114 PlamanaceE

294 Platanthèra $\quad 359$

113 Plàtanus - 334

198 Plùchia 175

267. Plumbagrnace As? 225

150 Pòa 418

119. Podophýllum 16

356. PODOSTEMACE

358 Podostémum $\quad 314$

251 Pogònia 361

378 Polanỳsia 35

231 Polemoniacr 274

231. Polèmònum 276

347 Polyánthus 381

166 POLIGONACE 8 S 303

131 Polýgala 76

140 POLYGALACE

325 Polygonatum . 375

63 Polygonum : $\quad 803$

63 Polýmia. . $\quad 176$

214 Poutretalous Dxogens 1

212 POMEA 108

166. Pontedèria 391

PONTEDERIACE

12 Pòpulus 332

143 Pórtulàca 56

427 Portulacace

21 Potentílla 433

20 Putèrium 102

77 Primula 226

370 PRIMULACE

338 PRIMULEA 226

43 Prinoides 222

43 Prives 222

121 Prosártes 385

121 Proserpinàca 117

134 Prunélla 259

238 Prìus 96

246 Ptèlea 67

346 Pteróspora 220

126 Pulmonària 271

238 Pyenánthemum 257

98 Pirceus. 396

304 Pyrèthrum 189

285 Pyròla 219

272 Pyrolla $\quad 218$

1. Pyrularia $\quad 310$

427 Pỳus $\quad 109$

278

81 Quamoclit 279

81 Quèrcus 320

130

130 RANUNCULACEA

409 Ranúnculus

274 Ràphanus 33

422 Reboúlea 417

248 Resèda 36

317 RHAMNACEAS 73

282 Rhámnus 73

261 Rhèum 307

\$03 Rhéxia 111

303 RHINANTHIDEA . $\$ 41$

338 Rhododèndron $\$ 17$

139 Rhodòra 215 
INDEX TO BOTANICAL NAMES.

441

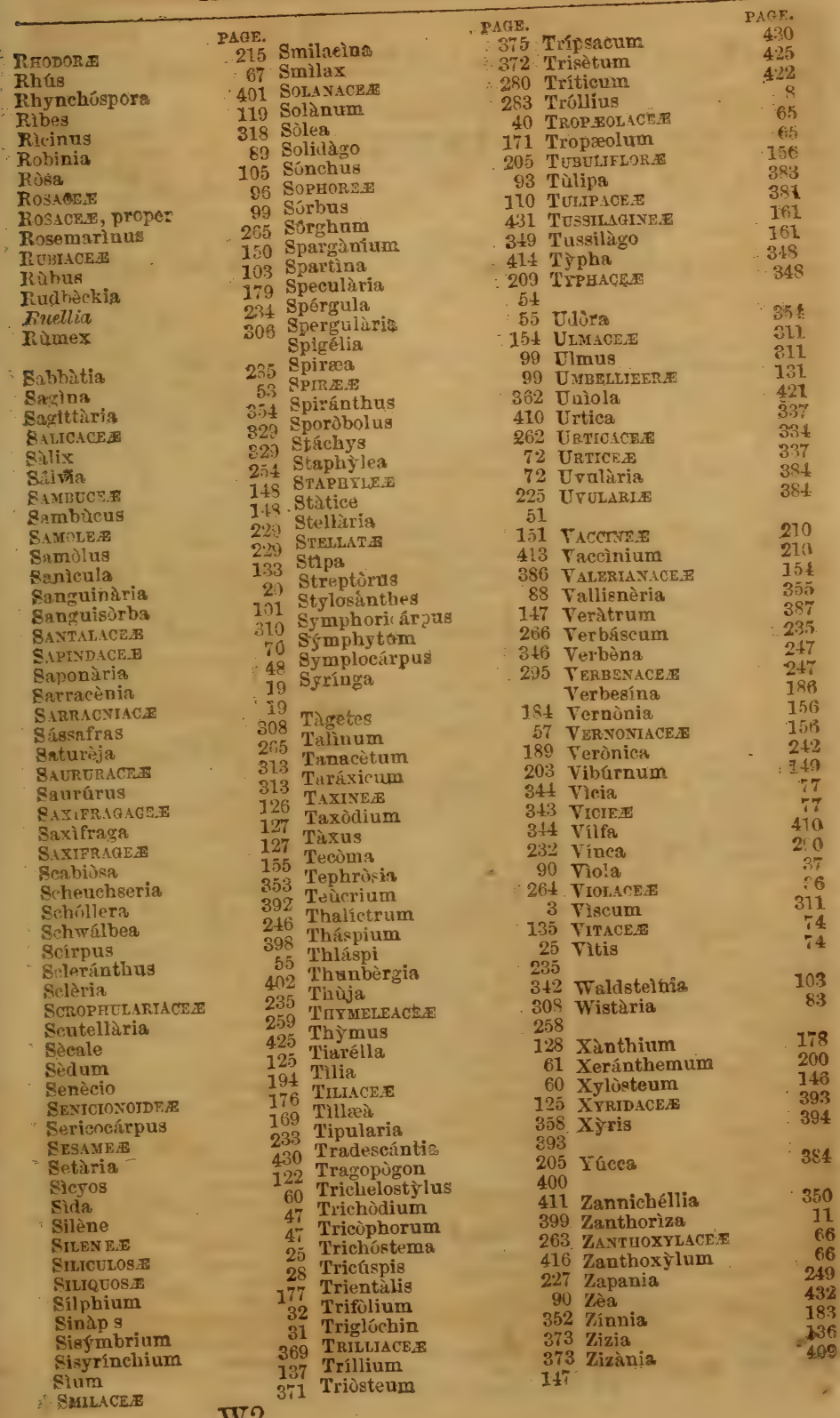




\section{IN DE X}

TO

\section{COIIION NAMES.}

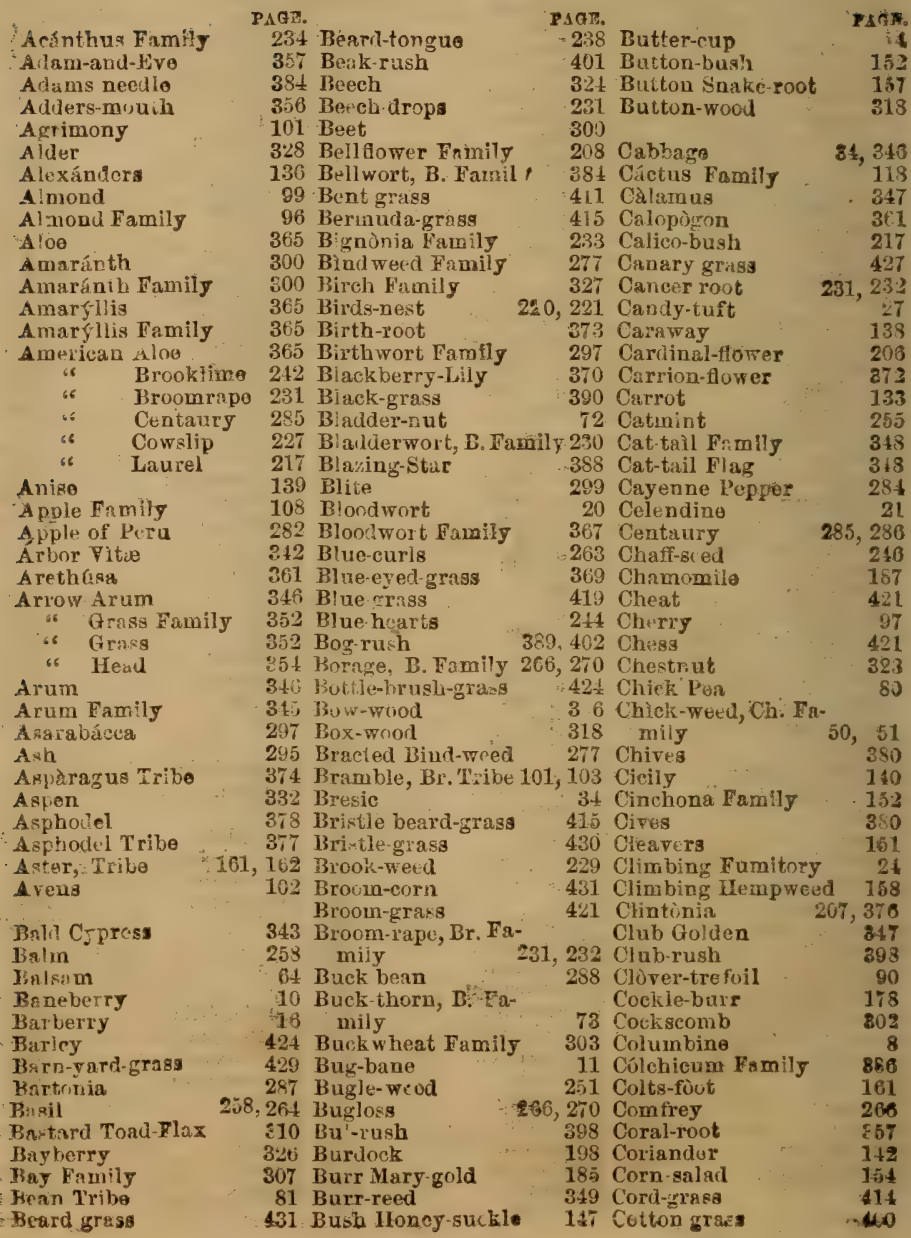




Cotton-rose
Cotton-thistlo
Cowbane
Cow-parsnip
Cowslips
Cow-wheat
Crab-grass
Crane-bill, Cr. Family
Crane-fly Orclis
Cress
Crocus
Crow-foot, Or. Fa-
mily
Crown-beard
Crowspur
Crown Imperial
Cucumber-root
Cud-wecd
Cut-grass
Cypress, C. Fumily
Cypress Vine
Daffodil
Daisy
Dardelion
Disuel
Day-fiower
Da

Day-fiower

Day-lijy

Deadly Night-shado

Dead Nettlo

Devils-bit

Diely tra

Dielytra

Dittany

Dock.

Doduer, D. Family

Dog-bane, D. Fanuily

Doys tooth-grass

Do 5 -touth-violet

Dragon-head

Dregon-root

Drop-seed-grass $\quad 410,412$ Giobe Amaranth

Duck-wèect, D. Family 348 Globe-flower

Dutchman's Pipe 207 Golden Alexanders

Dutchman's Bretches 23 " Aster

Ebony Family

Eel-grass

Elcier, E. Tribe

Hlecampane

Eilephant's-fi ot

Elm, E. Tamily

Enchanters Nightshade

Evening Prim-rose

Everlasting

Eye-bright

False Dragon-head

"5 Hlax

is Gromwell

" Helletore

" Indigo

"Jessemine

" Nettle

" Orchis

- se Pennyroyal

"s. Pimperuel

358 Fennel

29 Fern

370 Feseue-gmes

Fever-few

186 Hilbert.

233 Finger-grass

$37 \pm$ Fireweed

191 Flax

408 Fluabano

342 Flower de-Luce

2"9 Flowering Plants Fly Yoison

366 Fog fruit

188 For get-me-not

203 Four o'clock

423 Fox-glove

392 Fox-tail

Fox-tail-grass

261 Krog's-bit Family

388 Fumitory

23

23 Gale Family

252 Galingale

306 Gall-of-the-earth

279 Gama-grass

289 Garlic

382 Germanuer

241. Hazelnut
PAGF.

408 Heal-all

198 66 Rocket 30 Heath Family 210,213

138 -6 Solomon's Seal 375 Hedge Bind weed 277

134 " Sun-flower 186 "6 hysup

247. Fearinterge 219 " * mustard

:411 " nettle

229 Hellebore

413 Hemicarplas

139. Hewlock

- 326, 327 . Hemlock spruce

428 Hemp

189 Hemp Family

383 lir

416 Gentian, G. Family 285

237 Hemp-nettlo

324 Hemp-weed

428 Henbane

841) Herdsgrass

192 llickory

61 Holly,

167, 175 Holly , Hamily

368 IInewort Iut

1 Hokesty 27

387 Honey-iocust $\quad .95$

249 Honey-suckle $\quad 1 \frac{1}{2} 0$

268 Hop 328

302 Hop-hornbeam 3:25

239, $2: 5$ Horeliound 261, 263

409, 430 Horubeam 325

409 Horned Pondweed 250

295 Horned Rush 401

354 Hornwort, H. Family 313

24 Horse-balm $: 53$

" nettle 283

326 " 6 chestnut 71

395 " mint 253

205 Houndstongue 269

430 Hyacinth 380

379 Hyssup -265, 208

287

$20 \pm$ Indian bean 233

256 " chickweed 53

143 " cucumber-root161,974

302 " 6 corn 121,432

8 " fig 119

136 " griss 4.1

$17 \pm$ " 6 hemp 290

347 " mallow 58

171 " millet 432

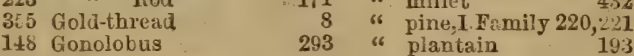

175 Gooseberry $\quad \mathbf{1 2 0}$ " reed, I. Family 3et

156. Goose-foot, G. Family 298 " rice 4 "7

311 Grass Family - 408 " turipip 345

Great Burnet - 101 Iris Family 368

116 Greek Valerian $\quad$ 2:6 Iron weed $\quad 158$

114. Green Violet 40 Iron wood $\quad 325$

191 Grien-łrier $\quad 37 \%$ Ivy $\quad 143$

207 Gromwell $\quad 267$

282 Jamestown reed 281

201 Ground Cherry $\quad 213$ Japan day lilies $\quad 378$

26 " Love 273 Jasmine, J. Family 294

267 is -nut $\quad 82$ Jessamine $\$ 84$

387 Groundsel,G. Tribe176, 194 Job's tear 433

90, 93 Jonquil 368

284 Hairgrass 411, 424 Judas Troe

338 Hawkbit 201 Juniper 161,313

359 Hawkweed 202 June berry 108

249 Hawthorns 108

324

$-81$ 


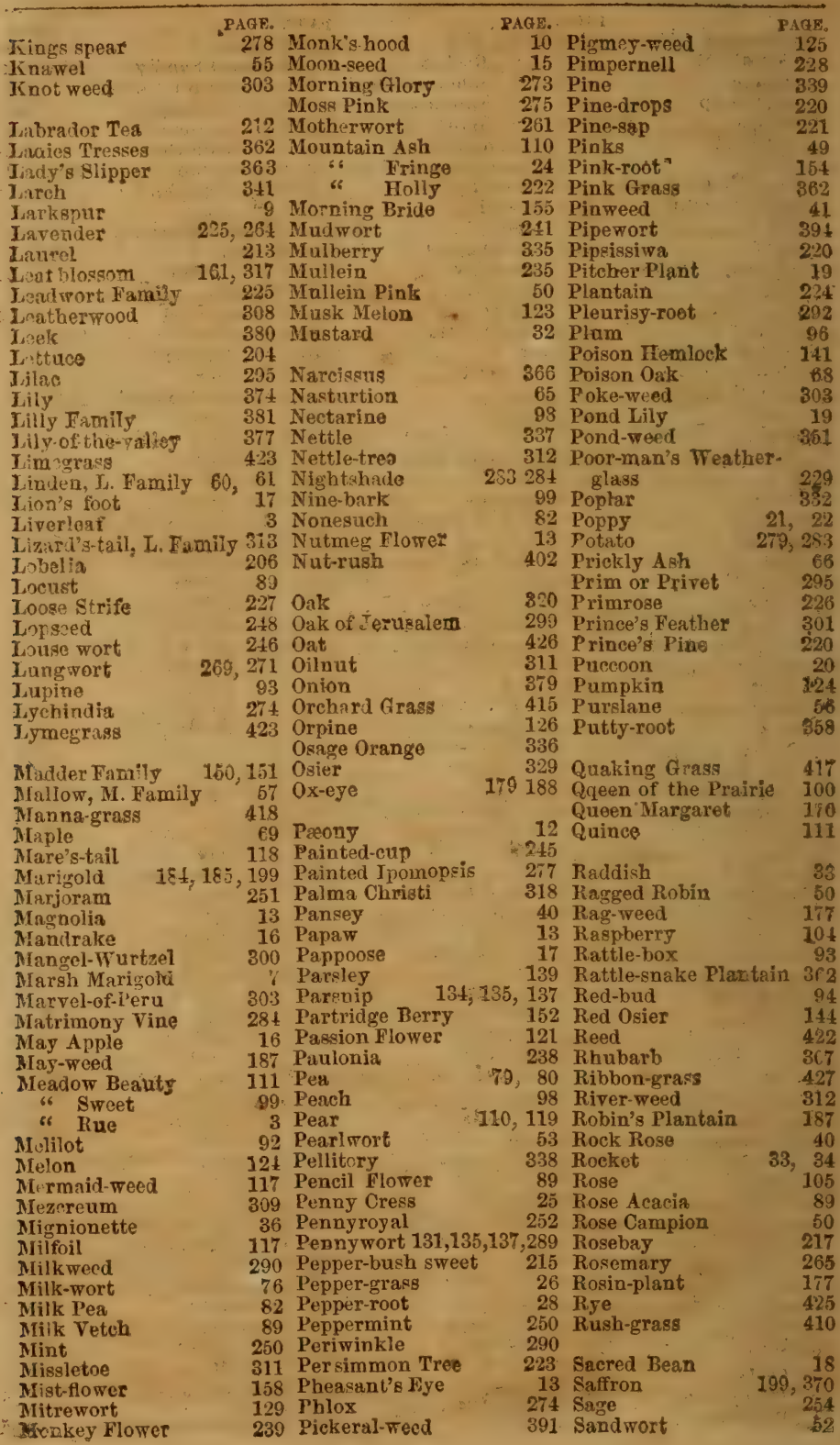


Salsify

Sanicle

Sarsaparille

Sassafras

Saxifrage

Savory

Scorpion Grase

Scratch Grass

Sedge

Seed-lox

Self-heal

Seneca Snake-roct

Senna

Sesame-Grass

Shad berry

Shepherd's Purse

Shinleaf

Ficklepod

Sida

Side-sadale Floner

Silk-w eed

Skull-cap

Skunk Cabbage

Snail

Snake-head

Snake-root

Snap-dragon

Sneeze-weed

Snow-ball

$\begin{array}{ll}\text { " berry } \\ \text { " } & \text { drop } \\ \text { "Flake }\end{array}$

Snowy Campion

Soapwort

Solomon's Seal

Sorrel

Sorrel Tree

Sow Thistle

Spanish Needles

Spear Grass

Spearmint

Speedwell

Spicewood

spiderwort

Spikenard

Spike-grass

Spike-rush

Spindle-tree

Spring Beauty

${ } 6$ Cress

Spruce

Spurge

Spurrey

Squash

Squaw-root

Equirrel-corn

Star-flower

Star-grass

Starry Campion

Star-of-Bethlehem

Starwort

St. John's-Wort

St. Peter's-Wort

St. Andrew'-Cross

Steeple-bush

Stick-seed

Stickwort

Stone-crop

Strawberry
PAGE.

205 Strawberry Blite

133 Straw Flower

142 Succory

308 Sumach

127 Sundew

265 Sundrops

268 Sunflower

305 Susan Black-3yed

d03 Sweet Alyssum

116 65 Brier

259 "s Cicily

76 " Fern

94 " Flag

430 "Gale Family

109 "Gum, S. Family

25 " Pepper baikb

219 "s -Scented.Shrub 1

30 " S Sultan 196

:60 \$ William

20 Sycamore

290 Syringa

259

346 Tamarack

92 Tanzy

237 Tape-grass

297 Teasel, T. Family 15\&, 155

236 Thin-grass

187 Thistle, Th. Tribe 195, 194
150 Thorn

:148 Thorough-wax

366 Thorough-wort

367 Thread-foot

47 Thrift

48 Thyme

375 Tickseed

:63, 306 Tiger-flower

214 Timothy

205 Toad-flax

185 Tobacco

418 Toothwort

250 Treacle DIustard

242, 244 Trefoil

308 Trefuil Shrubby

35, 393 Trillium Famil ,

142 Triple-awned-Grass

421 Trisetum

397 True Lily Tribe

108
138

159,160

314

225

258

is 09,427

236,310

280

73 True Colchicum Family 38

56 Trumpet Creeper

31 65 Flower

810 :Tuberose

315 Tulip-tree

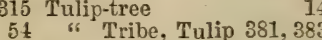

125 Tupelo, T. Famä?

231 Turtle-head

23 Turnip

227 Tway-blade

367 ,Twig Rush

47 Twin-leat

378 "F Flower

162 Twist-stalk

$y 35$
232
232
381
14
383
309

350. 363

44 Two-winged Acanthus 234. Yam Roct

45

$45 \cdot$ Unieorn

100 i6 Root

269 6 Plant

51

126 Valerian

Willow
182

370

.32

.90

67

373

411

425

381

238

345

402

${ }_{148}^{17}$ Xyris

PAGE.

4.

247

77

71

37,383

$2+1$

266

573

Wake Robin

Wall Cress

Walnut

6. Fox-tail

" Ilemlock $136^{\circ}$

"Ilemp 299

"Hore-hound 251

is Leaf, W. Family 271

6) Lily

"c Milfoil

" Oats

6: Pimpernel, W. Tribe

"Plantain W. Fa. mily 352, 35:

"R Rice

"s Shield

"S Star-gre

"Starwort

"Weed

"Willow

is Wort

Wheat

White Grass

Whortle-berry

ild Oats

6 Rice

66 Irerb

Wind Flower

Windsor Bear

17

$39 \%$

814, $39 \%$

354

234

46
138

425

408

212

426

409

423

329

113

80

2.2

29

(6) Cress

Wire-grass

416

10

$4+1$

431

411

" Rush Sorrel, W. Hemils 63

399

393

371

Yard Grass $\quad 415$

388 Yarrow 188

388 Yellow-eyed Grass $\quad 394$

233 " Root i, 15

276 Yew, Y. Family

206 Yuece $38 t$

99

29





\section{FLORAL DICTIONARY.}

A: represented by the Apple leaf. Acrcia; Platonic or Chaste Inve: Acaria (Yelliw); Concraled Luve. Aehilea Millefolia: War.

African Marygold: Vulgar Minds. A yrimonv: 'Thankfuln sq.

Aimond Tree: Indiccretion-IfeedlessAlmond-Laurel: Perfily.

Aloe; Misplaced Derotion.

Althea Frutex: Persuasion.

Alyssum (Sweet): Worth beyond beauty. A warenth : Immortality.

Amaryilis: Haughtin!ss-Pride.

Ambrosia: Love returned.

Ameriean Cowslip; You are iny Divinity.

American Flm; Patriotism.

American Linden: Motrimony.

American Starwort: We crme to a stran-

A nemone: Your Frown I defy.

Anemone (Field): rickners.

Anemone (frarden): Forsaken.

Anemone (Wood): Forsake me not.

Anvelica; Inspiration.

A pocyrum; Faisehond.

Apple-Blossom : Preference-Fame speaks him ereat and gend.

Arhor Vita: While I Live.

Arrow-Huad: Caim rennse.

Arum, or Wake-Rohin: Ardor.

A Roseleaf: I will cot trouhle rnu.

Asclepias; Cure for the Heartache.

Ash ; Grandeur.

Ash-lenved Trumpet-Flnwer; seperation.

Aspon-Tree; Lamentation.

A spen-Tree; Lamentation.
Asphodel; My regrets follow you to the Butterfly-Weed; Let me go.

Auricula: Painting. (Grave.

Azales; Your blush has won me.

\section{B ; Bearh Lraf.}

Bachelor's Button ; I with the Morning's

Love have of $t$ made sport.

Balloon Vine: You are puffed un.

Balm of Gilead Fir ; Healing - Curé.

Balm (Gentle); Pleasantry.

Balsam: Impatience.

Balsam Fir; Alwayg smiling.

Barberry: harpness-sourness.

Basil : Hatred.

Bayberry: Instruction.

Bay-Leaf; I change hut in dying.

Bny-Wreath; Reward of Merit.

Beech: Prosperity.

Bellflower (Blue); Constancy.

Bellflower (Carpatic); I Love my Moun-

tain Home.
Belvidere: I declare against you.

Bellwort: Gracefuluess.

Bee-Ophrys; Frror.

Betony ; surprise.

Bilherry: Treachery.

Birch: Gracefulneca.

Bindweed: Humility.

Bird-Cherry: Hone

Bird'e-Font Trefoil: Ricrenge.

Black Poplar; Courage.

Black Thorn ; Difficulty.

B!adderaut-Tree: Frivolour amusements.

Blond-Rnot; Flattery's smile.

Blue-bottle Centaury: Delicacy.

Blue-flowered Greek Valerian: Ruptara.

Blue Canterhurv Bell: Constauey.

Blur-eved Grass : moekness.

[ger. Blue Lnhelia: Purity of hoart.

Bonus Ifenricus: Goniness.

Borage: Bluntness or Roughuese of Man-

Box: stoicism.

Bramible: Envy.

Branch of Currants: You pleace all.

[nero.

Rranch of Thorns; severity-Riger.

Broken Straw ; Dissension-Rupture.

Broom: Mirth-Neatness.

Brrony: Prosperity:

Bucloss: Falsehood.

Bud of a White Pose: A heart ignorant

Burdock: Importunity. [of Lnve.

Bundle of Reeds with their Panicles; Mr.

Butter-cups: Ingratitude. [sio.

C; chorry reaf.

Cabbage; Profit.

Calla ( Fithionica); Feminine Modeaty.

Calveanthus; benevolence.

Camellia Japonica; beauty and Rlegaños.

Camomile; Energy in Aăversity.

Campanula; Gratitude.

Candy-Tuft; Indifference.

Canterbury Bell (Blue); Constaney.

Cardamine: Paternal Error.

Catesby's Starwort; Afterthought.

Cardinal's Flower; Distinction.

Catalpa-Tree; beware of the Coguets.

Catchfiy; snare.

Cedar of Lebanon; Incorruption.

Cedar-Tree; strength.

Checkered Fritillary; Perfecution.

Cherry-Tree; Good Education.

Cherry-Blosem; spiritual beatuly. 
Chestnut-Tree; Do me Justice.

China-Aster; Variety.

China or Indian Pink; Aversion.

China or Monthly Rose; beauty evernew.

Chinese Chrysanthemum; Cheerfulness under Aüversity.

Cinquefoil ; Parental Lore.

Cistus, or Rock-Rose; Popular favor.

Circrea; fascination.

Clematis; fillial Love.

Clove-Gillyflower; Dignity.

Coboea; Gossip.

Cock's-Comb ; singularity.

Doltsfoot; Justice shall be dove jou.

Columbine; Folly.

Ccmmon Cactus, or Indian Fig; I-burn.

Common Fumitory; spleen.

C. mmon Reed; Complaisance.

Convolvulus Major; Exting uished Lopes:

Convoivulus Minor; Night.

Corcborus ; Impatience of Absence.

C rn: Richis:

Cornelian Cherry-Tree; Durability.

Coreopsis; Love at first sight:

Coriander; Concealed Merit.

Coronilla; success erown your Wishes.

Cowslip; Pensivenesẽ.

Cow:lip American; You are my Divinit

Cowslip American White: $\Delta$ ngelic Pu-

Cranberry ; Hardiness.

Cranesbill Geranium;

Creeping Cereus; Hurror.

Crocus; smiles-Cheerfulness:

Cioss of Jerusalem; Devotion.

Ciowfout-Bulbous; showy but not welcome.

(C) own Imperikl; Majesty and Powor.

C ickoo-Pink; Ardor.

C clamen: Diffidence.

Orpress ; Mourning.

Cypress and Niarygold; Despair:

C) press-'Tree; Death and Eternal sorrow.

Cypress- Vine; My affections eling to you.

D: Dardelion Leaf.

Diffidil; Deceitiul Hope:

Dablia; Heartless leauty-Instability.

Daisy; Innocen e.

Dai:y (Gardun); I partake your sentimerts.

Daisy (W Kite); I will think of it.

Dawa: $\mathrm{k}$ l.ose; Freshness of Complexion.

Dandeiion; Oracle.

Daphue Oc ora; sweets to the sweet.

Darnel, or Ray Grass; Vioe.

Dew-Plant ; : A serenade.

Dead Leaves: sadnes.

Dittavy; Birth:

Dodder: Baseness:

Dog's tr oth Violet; Youthful Areotion.

Dragon Plant; snare.

Dried F ax; Utility.

Dutchnan's Breeches; Domestic Happi-

Dntchman's Pipe: singularity.

E: Ipigea Lear:

Elony; Hypocrisy.

Filder:; Zealousness:

E.:m; Dignity.
Ninchanter's Night 3 hade; fasciuationWitcheraft.

Endive; frugality.

Eupatorium; Delay.

Evergreen; Poverty.

Evergreen-Thorn ; solace in Adversity.

Everlasting; Never-ceasing Remembrunc $\theta$

Everlasting Pea; Lasting Plcasure.

F ; Fir Leaf.

Fennel; strength.

Fern; sinccrity.

Reru (Flowering); Re: axy.

Fig: Argument.

Fig-Tree ; Prolific.

Filbert; Reconciliation.

Fir ; Time:

Fir-Tree; Elevation.

Flax; I feel your Kindness.

Flax-leaved Goldly-locks; Tardiness.

Flora's Bull ; You are without Pretensior: Flower of an Hour; Delicate beauty.

Hlowering Reed; Confidence in Heaven.

Forget me-net; 'True Love.

Hox glote; I am not changed-they wrong me.

Frankineense; The Incense of a faithful

Freuch Honey suckle; Rustic beauty.

French Marygold; Jealousy.

Fringed Geutian; A late but welcome Guest.

Fringe-Treo; beauty in smil

Frog-Ophrys; Disgust.

Eull-blown Eglantine: simplicity.

Eullers' Teasel; Austerity.

; Grass:

Ga:den Chervil ; sincerity.

Garden Marygold ; Uneawinefs.

Garden Rapunculus; You are rich in Attractions:

Garden Sage; Eateem.

Garland of Roses; Reward of Firtue:

Gentiana Fritillaria; Virgin Pride.

Geranium (Sorrowful); Melancholy spi-

Gilly-Flower; Lasting beauty. [rit.

Glory-Flower; Gloxious beauty.

Goat's Rue; Reason.

Golden Cowsilp; Days of Childhood.

Golden Rod; Precaution.

Goosefoot: Goodness.

Grape (Wild); Reckless Mirth.

Grass; Utility.

Arass Pink (Callopogon); smile on the still.

Great Bindweed : Dangerous Insinuation.

Guelder Rose; Wiuter or Age.

H; Hazel branch.

Harebell; Delicate and lonely as this: Flower:

Lawkweed; Quicksigtedness.

[ness. Hawthorn; Hope.

Hazel; Reconciliation.

Heath; solitude.

Helenia; Tears.

Heliotrope; Devotion?

Zillebore; Calunny. 
Hemlock; You will cause my Death.

Hemlock-Spruce; Honor.

Henbane; Imperfection.

Hepatica; Confidence.

Hibiscus; Delicate beaitry.

Hickory ; Glory.

Hoarhound; frozen Kindaess.

Holly; Am I forgotten?

Hollyhock : fecundity.

Honesty ; Honesty.

Iloneysuckle; bond of Lote.

IIoneysuckle (Chinese); Lore unzonght.

II up; Injustice.

Hornbeam ; Ornament.

Horee-Chestnut; Luxuı y.

Hortensia; You are cold.

Houstonia; Content.

Hundred-leaved Rase; Graces:

Ifyacinth; Grief.

IIydrangea; boaster.

I: Iry Leaf.

Icelaud Moss; Health.

Ice-Plant; Your Looks freeze me:

Indian Cress; Resignation.

Indian Jasminu; - I attach myself to you.

Innocence; Innocence.

Iyomopsis Painted; A gay belie.

$J$ : Jessanaine Leaf.

Jacob's Lacider: Come down to me.

Japan Rose; beauty is your only Attrac. tion.

Jessamine or Jasmine; Amiability.

Jessamine (Virginian); soul of my soul.

Jonquil ; Desire.

Judas-Tree; Unbelief.

Juniper; Protection.

Justicia; The Perfection of simale Loveliness.

\section{K : King's Pear.}

Kennedia; Mentid beauty.

King-Cup; I wish I was ricL.

\section{Locust Leaf.}

Laburnum; Pensive beauty.

Lady's Siipper; Win me and wear the.

Larch ; Boldness.

Larkspur; Levity.

Laurel ; Glory.

Lavruatinus; I die if neglected:

Lavenđer; Distrust.

Lead Plant; tranquility.

Leather-flower; Fiexibility.

Lettuce ; Coldhearted.

Lichen; solitude.

Lilac; first Emotion of Love.

Lilac (White); Youth.

Lily of the Villey; Return of Finppiness. Lime or Linden-Tree; Conjugal Love.

Live Oak; Liberty:

Lobelia (Red) ; splendor.

Locust; Vicissitude.

London-Pride; Frivolity.

Loose Stríe; a kjn.

Lotus-Flower; silence.

Love in a Mist; Perplexity.

Jovo in a Ruzzlc; Enobarrassmont.
Love lies a-Blecding; Hopeless, not Heart-

Lueerne; Life.

[less.

Lungwort B.ue; Ileavenly Aspiration.

Lupine; Voraciousness.

Lupine Wild; Oh leave me not to die alonc.

Lychnis; Religious Enthusiasm.

Lythrum; Protecticz.

M ; Mint Leaf.

Madder ; Calumnt.

Madwort (Rock); Tranquility.

Maiden-Hair; Discretion-secrery.

Maizc; Plenty.

Mingolia: Péerless and Proud.

Mallow; Mild or sweet Dispositfon.

Manchincel-Tree; Falsehood.

Manurike; Rarit 5 .

Miple; Reserve.

Marj:ram; blu: bi s.

Murshmallow ; Humanity.

Marvel of Peru; Timidity.

Maryold; Inquietude.

Matrimony Vine; Connubial Ties.

May Rose; Precocity.

Meaków Beauty; beauty in Romance.

Neadow-Rue; A ba!m for a broken hear

Mradow-Saffron; My best days are pust.

Meadow Swreet; Uselessness.

Murcury; Üoodness.

Mesembryanthemum ; Idleness.

Mizereon: Love in a snow-wreath.

Michaelmas Daisy; Farewell.

Mignionette; Your Qualities surpass your Charms.

Milk Vetch; Yuur presence softens my

Mimo:a; Sen itiveness.

Mint: Virtue.

Mistietoe; I surmount all Difficultiv3,

Mock Orange ; Counterfeit.

Moneywort; Transient Friendship.

Mionk's Ilood; Knight:Errautry.

Miconwort; Forgetfulness.

Moschatel; Weak but winnin:

Moss (Tuft of); Maternal Love.

Moss Piuk; Fraternal Love.

Muss-liose: Pieasure without Alloy.

Mos:y-Saxifrage; Mutermal Lovo.

Motherwort; secret Love.

Mountain-Ash; Prudence.

Mountain-Fringe; You are my supporte:-

Mountain Lanrel ; my country's glory.

Hudse-Ear Chickweed; Ingenious sim-

Moving Plant; Agitation.

Mulberry-Tree (White); Wisdom.

Muiberry-Treo (Black); I will zot survive you:

Mushrooln ; suspicion.

Musk-Crowfoot; Weakness.

Musk-Rose; Capricious beauty.

Myosotis, or Mouze-Ear; Forget-me not. Myrtle; Love.

N; Nightshade Blach-Flower.

Narcissus (False); Delusive Hopes.

Narcissus (Poet's); Egoti॰m.

Nasturtium; Patriotism.

Nettle; Cruelty.

Night-klooming Jessamine ; Lora's Vigi? 
Night-blooming Cereus; Transient beauty R; Rose leaf.

Nightshade (bitter-sweet); truth.

Nosegay; gallantry.

0 ; Oak leaf.

Oak; hospitality.

Oats; the witching soul of music-hers.

Oleander; beware.

Olive; peace.

Or his; a belle.

Orchis Pink; seclusion.

Orchis Yellow; your aspirations are high.

Orange Flowers; chastity.

Orange-Tree; generosity.

Osier; frankness.

Ox-Fye; Obstacle.

P : Peach leaf.

Painted Cup; you are proud.

Palm; victory.

Pancey, or Heart's-Ease; think of me.

Parsley: entertainment-feasting.

Passion-Flower; religious faith.

Patience Dock; patienre.

Pasque-Flower; you are without preten-

Paulonia : a foreigner.

Pea; an appoint d meeting.

Pagch-Blosson; I am your captive.

Pennyroyal: flee away.

Peony ; bashful shame.

Pepper-Plant; satire.

Puriwinkle: sweet remembrance.

Yersimon; bury me amid nature's beau-

Persicaria; r storation.

Peruvian Heliotrope; I trust in thee.

Pheasant's-Eve. or Flos Adonis; sorrow-

ful remembrance.

Phlox; unarimity.

Pimpernel; assignation.

Pine; pity.

Pino-Apple; you are perfect.

Piuk: lovely ana pure affection.

Plane-Tree (Wild); independenee:

Polemonium; a declaration of war.

Bolyanthus; confidence.

Pomegranate; foolishness.

Pond Lily White; eloquence-the fairest of the fair.

Pond Lily Yellow (Nuphar); much inferior.

Popry; consolation of sleep.

Potato; beneficence.

Prairie Rose; beauty without exsellence.

Prickly Pear; satire.

Pride of China; discussion.

Primrose; early youth.

Primrose (Evening); inconstancy.

Princes' Pine; my affections are fixed.

Privet; prohibition.

Pulmonaria Blue; heavenly aspiration.

Parple Clover; provident.

Pyramidal Bell-Flower; gratitude.

Pyrus Japonica; fairies fire.

Q; Quince blossom.

Quamoclit; busybody.

Queen's Rocket; you are Quben of eoquettes.
Ragged Robin; wit.

Ranunculus; you are radiant with

Red Bay ; love's memory.

Red Mulberry; wisdom.

Red Shanks; patience.

Rest-Harrow; obstacle.

Rhododendron; danger.

Rocket; rivalrv.

Rock Rose; fading and transitory.

Rose; be uty.

Rose (Wild); simplicity.

Rose (Acacia); elegance.

Rosehud; youthful charms.

Roces (A Garland of); reward of virture:

Rosebay; disnity in misfortune.

Rosebay Willow Herb; celibacy.

Rose Campion; you are without pretension.

Rose (White); I am worthy of you.

Roscmary; remembrunce.

Rose scented Geranium; preference.

Rudbeckia; justice.

Rue: grace or purification.

Bush; docility.

S: Sage Teaf.

Saffron-Flower; excess is dangerous.

Safron-Crocus; mirth.

Sage; esteem.

Sardony; Irony.

Scabius : unfortunate attachment.

Scarlet Fuchsia: taste.

Scarlet Ipomcea. or Indian Jasmine; $\mathbb{Z}$ attach myself to you.

Scotch Fir: elevation.

Sensitive Plant; timijity.

Serpentine Cactus: horror.

Service-Tree; nrudence.

Shaking Saintfoin; acitation.

Siberian Crab-Tree-Blossom : deeply in teresting.

Side-saddle Flower Purple); eccentricity.

Sidesaddle Flower : will you pledge me?

Silver Fir ; elevation.

Skull. cap ; madness.

Small Bindweed; obstinacr.

Srall White Violet; candor and innocence.

Snapdragon; You are dazzling, but dangerous.

Snowhall; thoughts of heaven.

Snowdrop : consolation.

Solomon's Seal (Small); mystery.

Solomon's Seal (Large); let my name be en graven on your heart.

Sorrel : wit ill-timed.

Southern-Wond; jest or bantering.

Spanish Jasmine: sensuality.

Speedwell : fidelity.

Spider-Ophrys ; skill-adroitness.

Spiderwort ; transient happiness.

Spindle-Tree; your image is engraver on $\mathrm{mv}$ heart.

Spiked Speedwell; resemblance.

Spiræ Hpdericum Frutex; uselesenese.

Spring Beauty; can you love.

Squirting Cocumber; critic.

8t. John's-wort; superstitious sanetit. 
Star of Bethlehem; the light of our Violet, pedate; I cannot forget. Faith-follow me.

Stock, or Gillyflower; lasting beauty.

St)necrop; perseverance.

Stramonium (Cammon); disguise.

Strawberry; perfict excellence.

Striped Pink; refusal.

Sumach; splendor.

Sunflower; smile on me still.

Swallow wort; medicine.

S. Namp P.nk; the blush of modesty.

S seet-Brier, or Elangtine; poetry.

S weet Flay; fitness.

Sw et Pea; delicate pleasure.

Sweet Sultan; felicity.

Sweet-scented Tussilage; you shall have justice.

Sweet Violet; modesty.

Siveet-Wiliam; crafiness,

sycamore; woodland beauty.

Syringa ; memory.

T; Tanzy leaf.

Timar:sk; crime.

Tansy; resistance.

Teasel; misunthropy.

1'n-Week's-stock; promptitude.

Thistle; austerity.

Thorn-Apple; deceitful charms.

$I$ irrift; sympathy.

Throutwurt; neglected beauty.

Thyme; activity.

Trailing Arbutis; you have won my af fections.

Ti emella Nostoc; resolve the riddle.

Irillium; solitary musings.

Truftle; surprise.

Tirgin's Bower; artifice.

Virginia Spiderwort; momentary happiness.

Lpy.

Yulkamenica Japonica; may you be bap-

HF; Willow leaf.

W all-Elower; fidelity in adversity.

Wall-Speedwell ; fldelity.

W. tter-Lily; eloquence.

Wainut; int lice:t.

Walking-Lèaf; how came you here?

W iter Lily (White); eloquence-the fitirest of the fair.

Wiatermelon; bulkiness.

Water-Star; beauty combined with piety.

Wix-Plant; susceptibility.

Wax-Myrtle; I will enlighten you.

Weping-Willow; melancholy.

Wheat; riches.

White Lily; purity and mode.ty.

White Mullein; good nature.

White Ork; ind pendence.

White Pink; talent.

White Poplar; time.

White Poppy; sleep of the heart.

Wisite Rose; silence.

White Rose (Driel); death preferuble to loss of inuocence.

Wiuice Rosebud; the heart that knows not love.

Wuite Violet; cand̉or.

Wild or Dog Rose; simplicity.

Wi:d Indigo: highly oulored.

Willow; f rsaken.

Willow Herb; pretension.

Wintergrcen; send me an answer.

Tizer-F ower; for once may pride b friend Winter-Cherry ; deception.

Tree of Life; old Age.

I'uft of Moss; Maternal Love.

Tulip; decleration of leve.

Turuip; charity.

Twin-Fiower (Mitchella); we are united.

F; Tiolet leaf.

[me. Witch-Hazel; a spell.

Wooubine; fraterual love.

Wood-Sorrel; joy.

Wurm-wood; Absence.

Y ; Yarrow leaf.

Yàrrow; war.

Talerian (Red); accommodating disposi- Yellow Carnation; disdain.

s arious-colored Lantana; rigor. [tion. Yellow-Day-Lily : coquetry.

Verbena; sensibility.

Vernal Grass; poor, but happz.

Vervain; enchantment.

Venus's Car; fly with me.
Venus's Flytrap; have I caught you at Ycw; infidelity. last.

Venus's Looking-Glass; flattery.

Tine; intoxication.

violet; molesty.
Z; Zizia flower.

Yellow Gentian; ingratitude.

Yellow Iris; fiame.

Yellow Rose; iufidelity.

Zıuia; Absence.
Y.llow PLlox (Erysimum); false-hear 69 a

\section{SENT I MENTS.}

$$
\text { Rose.-Ivy.-Myrtle. }
$$

To Beauty Friendship, and Love.

\section{Jismine-DStrawber ry.-Tulip.}

Four amiability, and the excollence of your charact $r$, have compelled we to de. clare my love. 


\section{Primrose-Honeysuckle.-Marygold.}

Be not too early entangled in the chains of Love, or yours will be a life of inquictude.

Forget-me-not.-Cypress.-Pimpernel.

Forget me not, for, alas! we may never meet again.

Scarlet Geranium.-Scarlet Ipomoea.-Laurustinus.

In preference, I attach myself to you, but shall die if neglecter.

Bulsam.-White Daisy.

Be not impatient, I will think of it.

Myrtle.-Sweetbrier.-Lucern.

Love is the poetry of life.

Blue Violet.-Daisy.-Apple-Blossom.

Your modesty and innocence seoure you the preference.

Crown Imperial and Tur $k^{\prime}$ ' Cup Lilies.-Lity of the Valley.

You have the power to restore me to happiness.

Pansies.-Broom.

My heart would be at ease, if my solitude were blest with your society.

Mignionette.-Heliotr ope.-Pink.

Jour qualities surpass your charms; I love you with a pure and devoted luve.

Purple and Yellow Iris.-Hawthorn.

I send you a message of love on the wings of hope. 




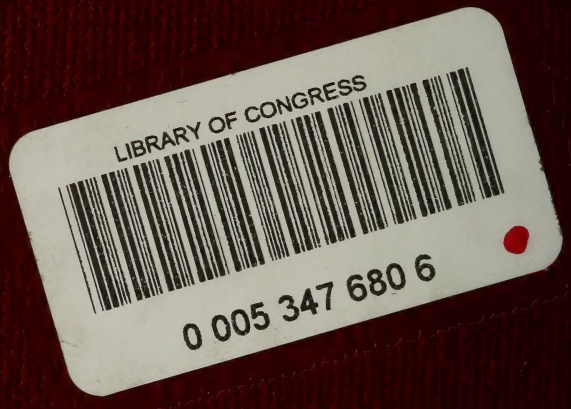

